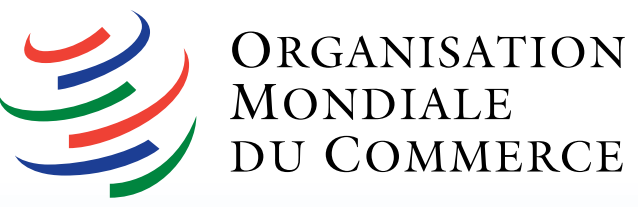

\title{
Q) OCDE
}

PANORAMA DE L'AIDE

POUR LE COMMERCE

2019

DIVERSIFICATION ET

AUTONOMISATION ÉCONOMIQUES

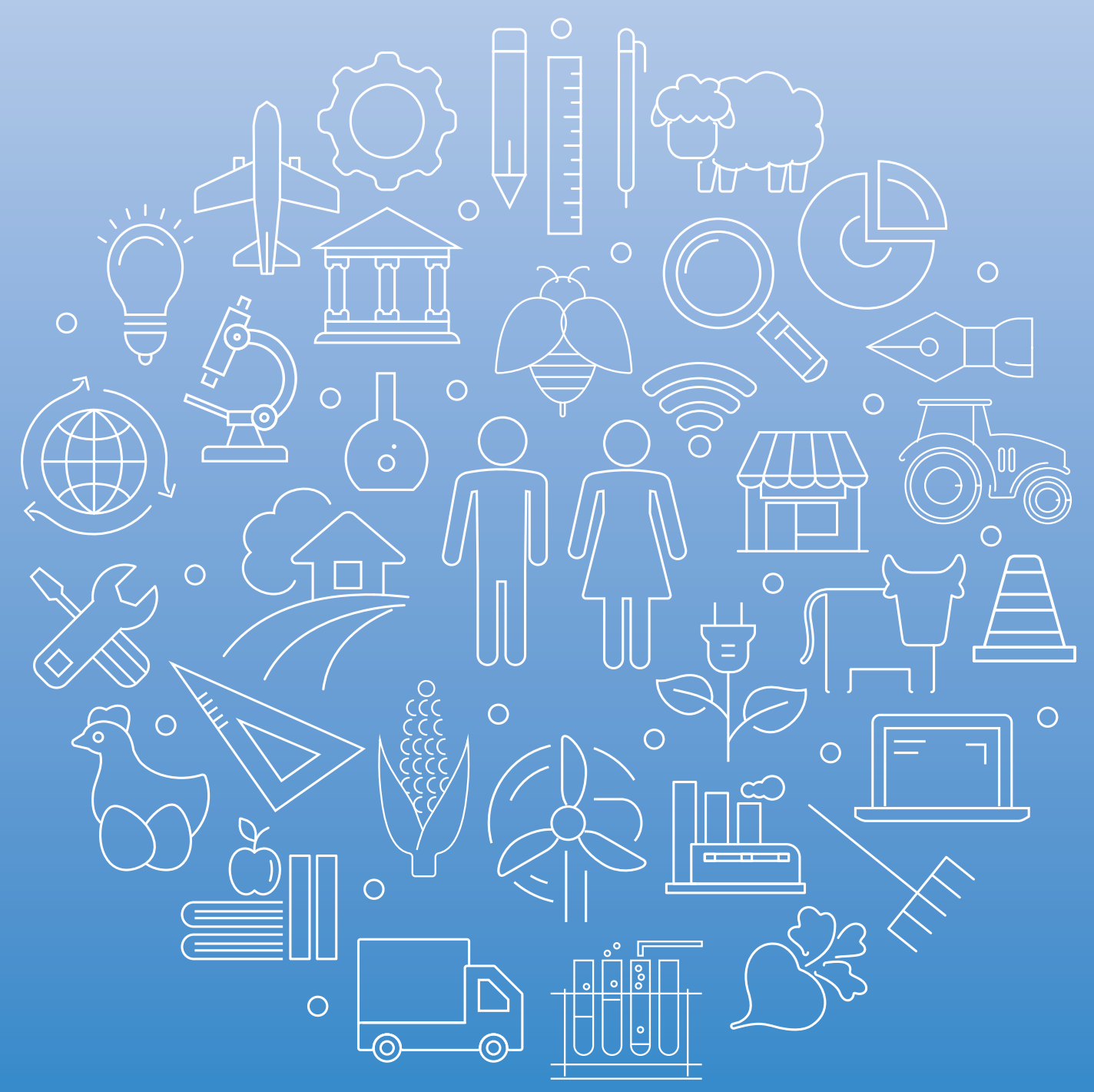





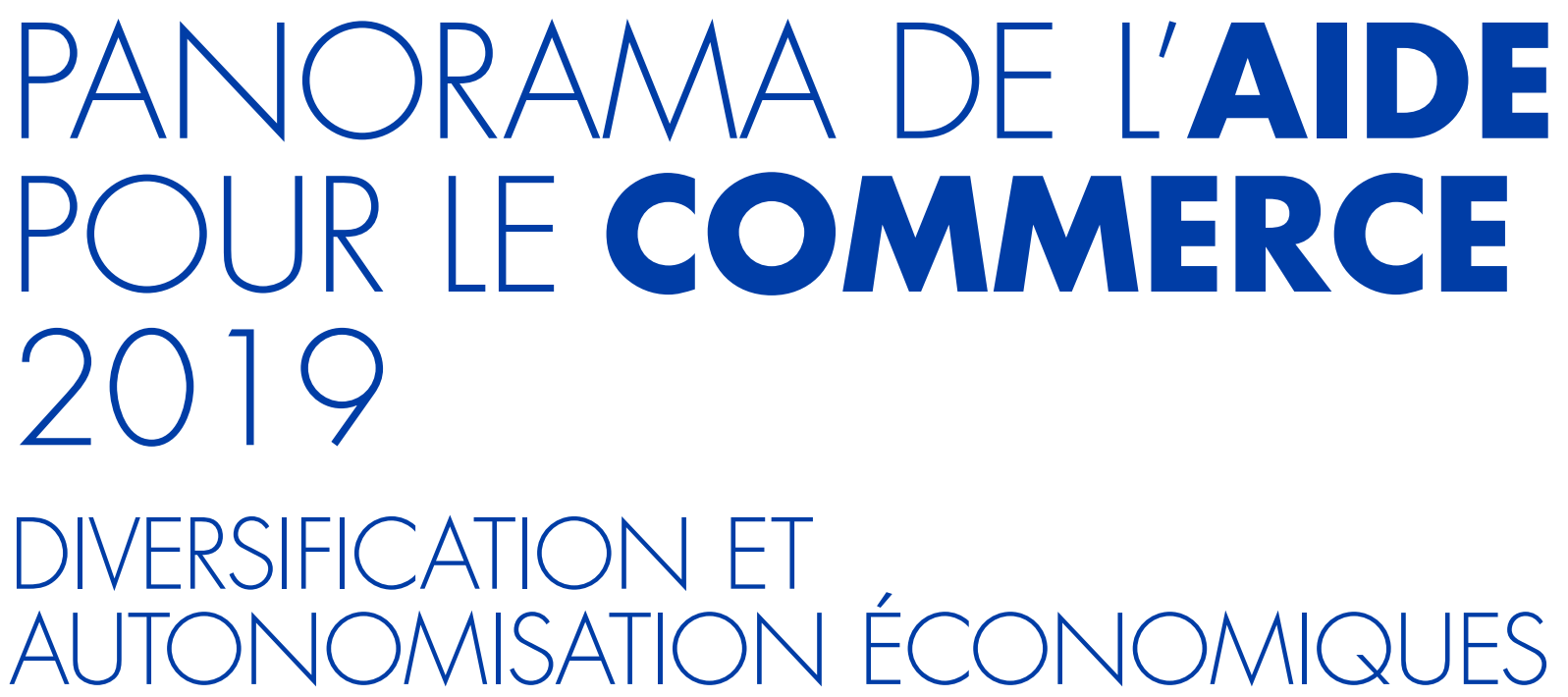

ORGANISATION
MONDIALE
DU COMMERCE

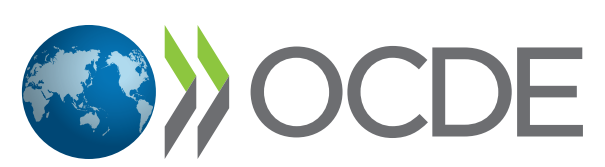


Les opinions et les arguments exprimés ici ne reflètent pas nécessairement les vues officielles des pays membres de I'OCDE ni celles de l'Organisation mondiale du Commerce ou de ses membres.

Ce document, ainsi que les données et cartes qu'il peut comprendre, sont sans préjudice du statut de tout territoire, de la souveraineté s'exerçant sur ce dernier, du tracé des frontières et limites internationales, et du nom de tout territoire, ville ou région.

Les données statistiques concernant Israël sont fournies par et sous la responsabilité des autorités israéliennes compétentes. L'utilisation de ces données par l'OCDE est sans préjudice du statut des hauteurs du Golan, de Jérusalem-Est et des colonies de peuplement israéliennes en Cisjordanie aux termes du droit international.

Merci de citer cet ouvrage comme suit :

OCDE/OMC (2021), Panorama de l'aide pour le commerce 2019 : Diversification et autonomisation économiques, Éditions OCDE, Paris, https://doi.org/10.1787/cc697a19-fr.

ISBN 978-92-64-74574-2 (imprimé)

ISBN 978-92-64-68022-7 (pdf)

Panorama de l'aide pour le commerce

ISSN 2304-5752 (imprimé)

ISSN 2304-5760 (en ligne)

OMC:

ISBN 978-92-870-4987-2 (imprimé)

ISBN 978-92-870-4990-2 (livre électronique/pdf) 


\section{AVANT-PROPOS}

La diversification et l'autonomisation économiques sont essentielles à la réalisation des Objectifs de développement durable. Ces deux objectifs sont aussi la raison d'être de l'Initiative Aide pour le commerce. La diversification économique ouvre la voie à l'autonomisation, laquelle permet à son tour aux femmes, aux jeunes et aux micro, petites et moyennes entreprises de participer au commerce. La croissance des secteurs agricole, manufacturier et des services offre des possibilités entrepreneuriales et crée des emplois productifs. Cette diversification économique contribue ainsi à la hausse des revenus et au développement humain d'une manière plus générale. On observe des tendances analogues en matière de progrès dans de nombreux pays en développement, ce qui entraîne des réductions substantielles de l'extrême pauvreté.

Toutefois, la diversification économique progresse à un rythme irrégulier et les tendances évoluent, tandis que certaines économies sont confrontées à des difficultés intrinsèques. Cela est particulièrement vrai pour les petits pays, les pays insulaires, les pays sans littoral ou les pays tributaires des ressources naturelles, ainsi que pour les pays fragiles ou en conflit. Dans le même temps, le progrès technologique rapide menace de perturber les modèles de développement économique établis, mais il offre aussi de nouvelles possibilités de croissance et de développement. Les risques environnementaux élevés exigent de nouvelles approches de la diversification économique.

Le commerce international peut aider. Un système commercial ouvert et fondé sur des règles contribue au bien-être mondial. II aide à diffuser les marchandises et les services, ainsi que la technologie et les connaissances nécessaires pour gérer les défis environnementaux. Cependant, si nous voulons transformer les possibilités commerciales en flux commerciaux, nous devons redoubler d'efforts pour remédier aux nombreuses contraintes du côté de l'offre auxquelles se heurtent encore bon nombre de pays en développement, en particulier les pays les moins avancés.

Ce processus est déjà bien engagé. Depuis le lancement de I'Initiative Aide pour le commerce en 2006, 409 milliards d'USD d'aide publique au développement et 346 milliards d'USD au titre de prêts accordés à des conditions libérales ont été décaissés pour aider les pays en développement à renforcer leurs capacités commerciales. Un montant additionnel de près de 100 milliards d'USD pour ces deux types d'aide a été engagé en 2017. En outre, les fournisseurs Sud-Sud et les organismes de bienfaisance ont apporté des contributions respectives de 9 milliards et 100 millions d'USD.

Le Panorama de l'Aide pour le commerce fournit de nombreux exemples de la manière dont ce soutien aide les pays en développement à améliorer leur compétitivité, à développer et à diversifier leurs échanges, à attirer l'investissement étranger direct et à créer des emplois pour les hommes et les femmes. Les améliorations observées en matière de facilitation des échanges en sont une bonne illustration. Elles montrent qu'un soutien aligné sur les priorités nationales est plus efficace et contribue à créer un environnement dans lequel les entreprises peuvent prospérer, en particulier les micro, petites et moyennes entreprises, qui constituent l'épine dorsale de la plupart des économies en développement. Le présent rapport met également en évidence l'ampleur du défi qui nous attend.

Nous devons apprendre de ces exemples pour renforcer la cohérence entre l'aide et le commerce, une cohérence indispensable pour surmonter les difficultés et exploiter les possibilités créées par la diversification et l'autonomisation économiques. Nous devons surtout avoir à l'esprit que l'autonomisation économique des jeunes et des femmes n'est pas le résultat du processus de diversification économique, mais souvent son point de départ.

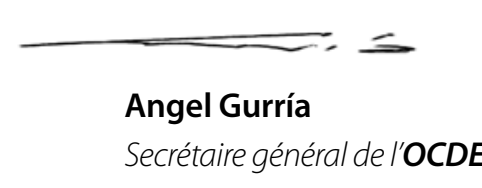

Pobeels Azueids

\section{Roberto Azevêdo}

Directeur général de I'OMC 


\section{AIDE POUR LE COMMERCE: FAITS ET CHIFFRES}

\section{FLUX DE FINANCEMENT}

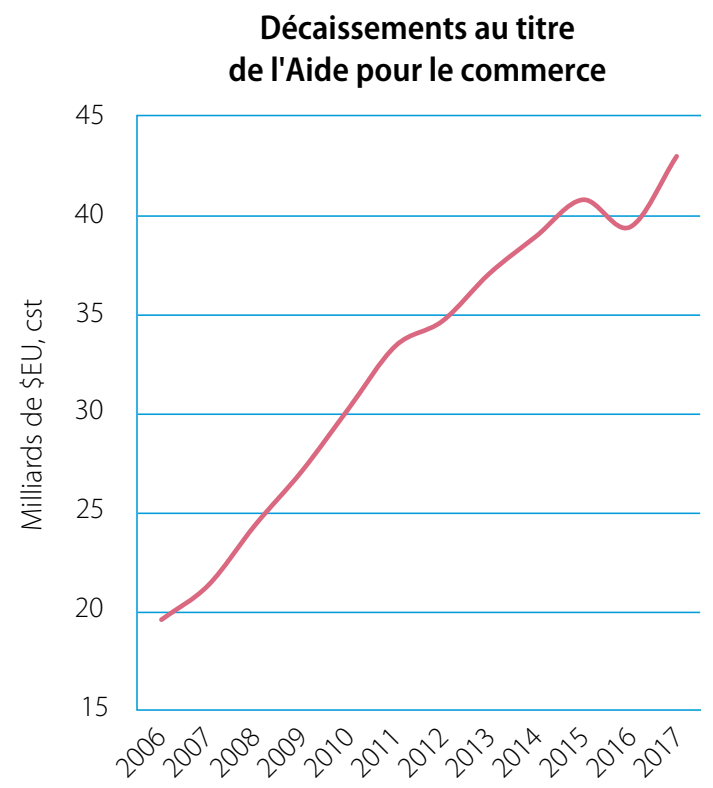

410 milliards de \$EU

décaissés de 2006 à 2017

154,9 milliards de \$EU pour l'Asie

146,2 milliards de \$EU pour l'Afrique

12,2 \$EU par habitant dans les pays les moins avancés (PMA) en 2017

4,7 \$EU par habitant dans les pays qui ne sont pas des PMA en 2017

Source : Système de notification des pays créanciers de l'OCDE

\section{PROJETS ET PROGRAMMES}

Projets de l'Aide pour le commerce depuis 2006

Au total, 178141 projets de l'Aide pour le commerce ont été financés depuis 2006.

Le coût médian des projets est de 98400 \$EU.

Le coût moyen des projets est de $\mathbf{2 , 2 5}$ millions de \$EU

Nombre de projets par région

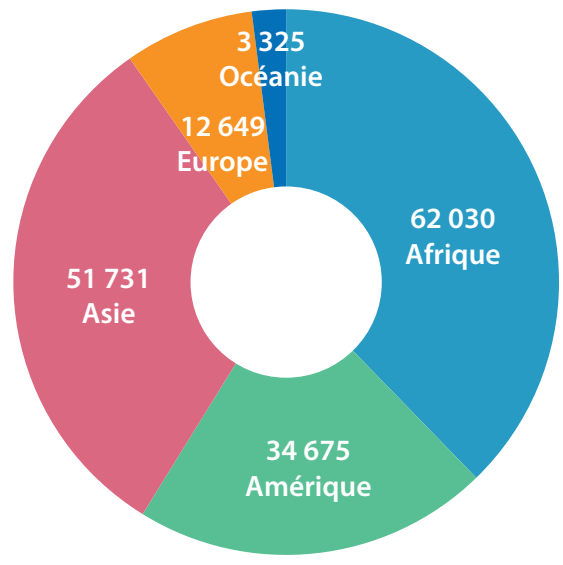

Décaissements au titre de l'Aide pour le commerce, par type

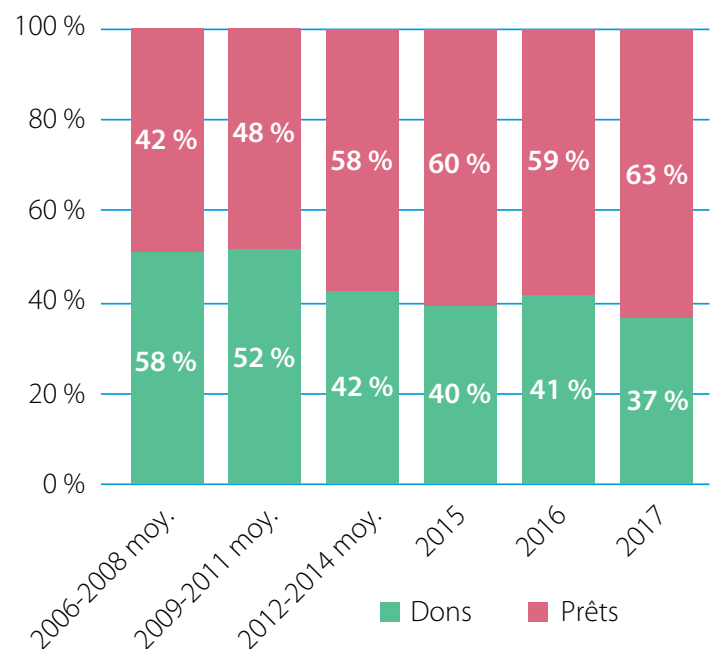

Source : Système de notification des pays créanciers de l'OCDE. 


\section{RÉSULTATS DU COMMERCE}

\section{Diversification des exportations}

\section{Agriculture}

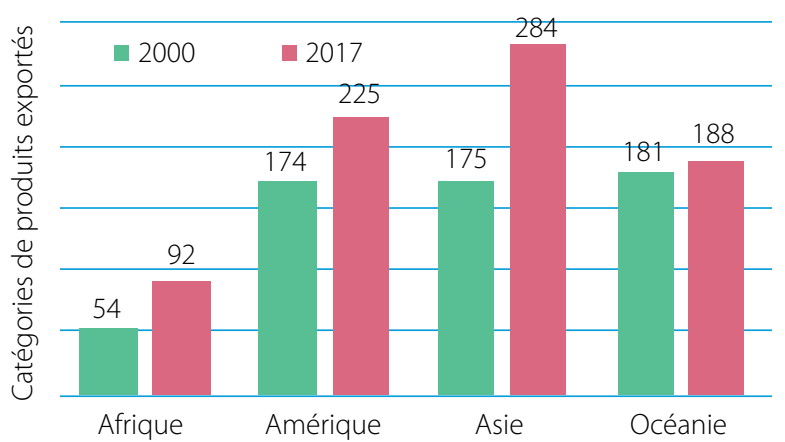

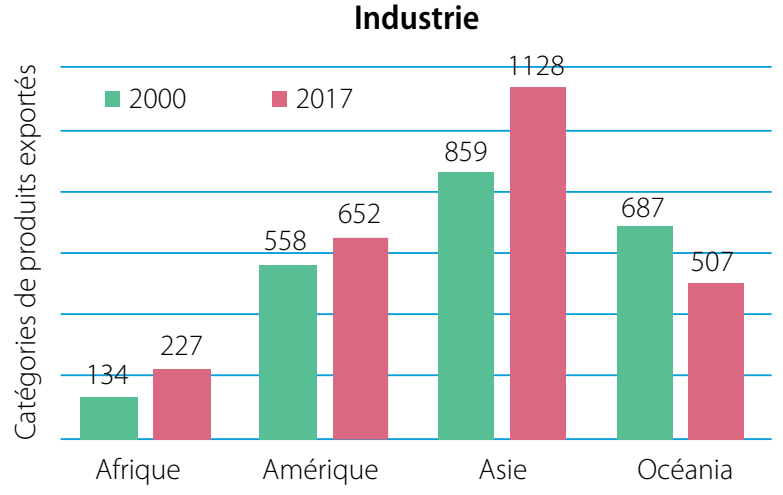

Source : Base de données de l'OMC.

Les progrès accomplis dans la diversification économique et la diversification des exportations ne sont ni uniformes ni universels. D'après l'exercice OCDE-OMC de suivi et d'évaluation 2019, 53\% des pays en développement ont fait état de progrès dans la diversification économique depuis le lancement de l'Initiative de l'Aide pour le commerce en 2006 - 66\% pour les PMA. Le secteur de l'agriculture est celui qui a enregistré le plus de progrès, juste avant le secteur des services, d'après les indications de 33\% des pays en développement.

\section{Secteurs dans lesquels le plus de progrès ont été observés}

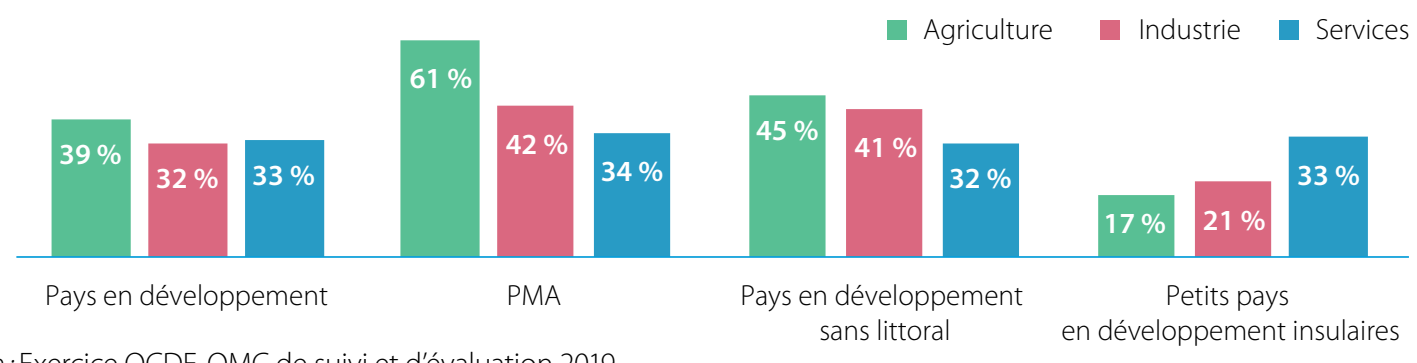

Source : Exercice OCDE-OMC de suivi et d'évaluation 2019.

\section{EFFETS}

90\% des pays en développement qui ont répondu ont reconnu l'autonomisation économique comme une priorité dans leur stratégie de développement nationale ou régionale - 95\% pour les PMA et les pays en développement sans littoral.

PIB par habitant, PPA

(\$ internationaux constants 2011)

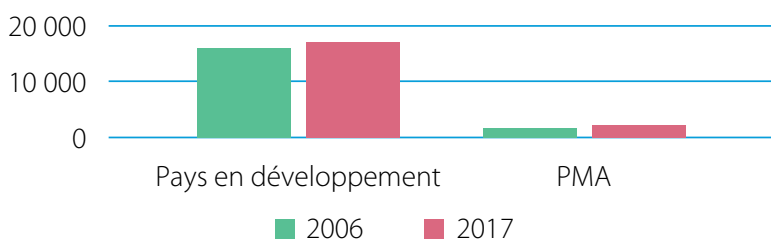

Indice de développement humain

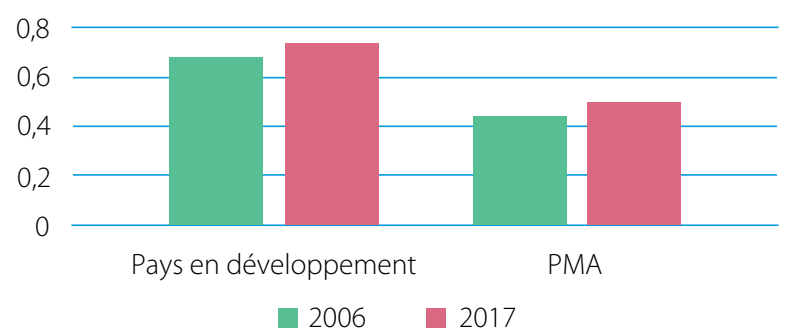

Source: Banque mondiale - Indicateurs du développement mondial, Programme des Nations Unies pour le développement Indicateurs internationaux du développement humain 



\section{REMERCIEMENTS}

Le présent rapport, intitulé "Panorama de l'Aide pour le commerce: diversification et autonomisation économiques", a été établi sous l'égide du Comité d'aide au développement et du Comité des échanges de l'OCDE, en collaboration avec le Comité du commerce et du développement de l'OMC. Les Secrétariats de l'OCDE et de l'OMC tiennent à exprimer leur gratitude à l'ensemble des gouvernements, des organisations intergouvernementales et des organisations non gouvernementales qui ont participé à l'exercice 2019 de suivi et d'évaluation de l'Aide pour le commerce.

Le rapport a été rédigé sous la direction de Frans Lammersen (OCDE) et de Michael Roberts (OMC). Un soutien managérial a été assuré par Jorge Moreira da Silva, Ken Ash (OCDE) et Shishir Priyadarshi (OMC).

Le chapitre 1 a été écrit par Justine Lan, Michael Roberts et Dayong Yu (OMC); le chapitre 2 par Frans Lammersen (OCDE); le chapitre 3 par Nobuya Haraguchi (ONUDI); le chapitre 4 par Luisa Bernal (PNUD) et Daria Shatskova (CIR); le chapitre 5 par Paul Brenton, lan Gillson et Pierre Sauvé (Groupe de la Banque mondiale); le chapitre 6 par William John Gain, Brian O'Shea et Heidi Stensland (Groupe de la Banque mondiale), Evdokia Moïsé (OCDE) et Pamela Ugaz (CNUCED); le chapitre 7 par Miho Shirotori et Cecilia Heuser (CNUCED); le chapitre 8 par Sarah Mohan et Valentina Rollo (ITC); et le chapitre 9 par Kaori Miyamoto et Marianne Musumeci (OCDE). Les profils de pays ont été établis par Rainer Lanz (OMC).

L'exercice de suivi et d'évaluation de l'Aide pour le commerce a été conduit par Théo Mbise et Justine Lan. Aussama Bejraoui (OCDE) a fourni un soutien statistique. La maquette du rapport a été conçue par Peggy King Cointepas. L'équipe a bénéficié du concours de Najat Lachal (OCDE).

Nous adressons aussi nos remerciements aux personnes suivantes: Néstor Pelechà Aigües, Mark Baldock, Juan Casado Asensio, Freerk Boedeltje, Stacey Bradbury, Ana Fernandes, Tomas Hos, James Kim, Anne-Lise Prigent, Jan-Anno Schuur, Annelise Thim, Thierry Vebr (tous de I'OCDE); David Cordobés, Eleonora de Falcis, Jennifer Freedman, Marion Jansen, Evelyn Seltier, Jasmeer Virdee, Matthew Wilson (tous de I'TC); Ratnakar Adhikari (CIR); Riad Meddeb (PNUD); Pamela Coke Hamilton, Poul Hansen, Jan Hoffmann, Brook Kidane, Samuel Munyaneza, Alessandro Nicita, Bonapas Onguglo, Ralf Peters, Mesut Saygili (tous de la CNUCED); Thomas Zörner, Frank Van Rompaey, Ani Gabrielyan (tous de l'ONUDI); et Barbara Marcetich (OMC).

Nous remercions vivement le gouvernement des Pays-Bas pour le soutien financier généreux qu'il a apporté à ces travaux et le gouvernement suédois pour le soutien financier généreux qu'il a apporté à l'analyse sur laquelle s'appuie le chapitre 9. 



\section{TABLE DES MATIĖRES}

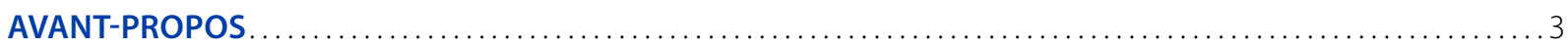

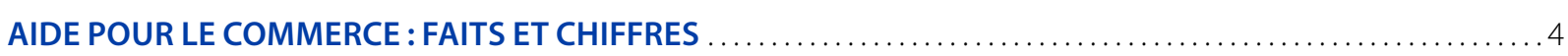

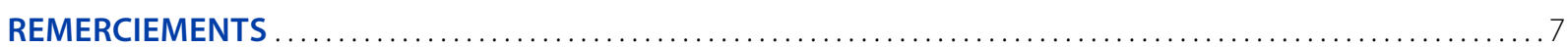

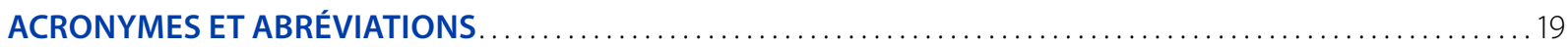

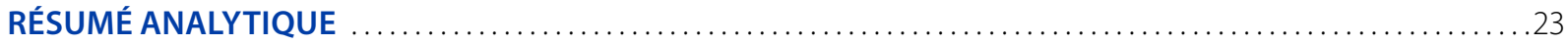

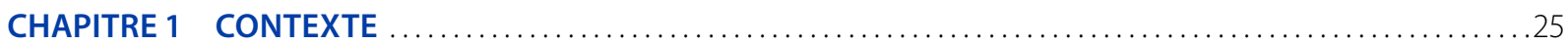

Contribution de l'Organisation mondiale du commerce

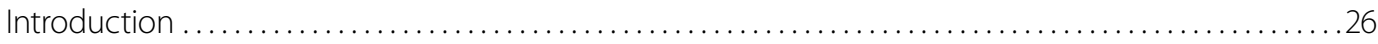

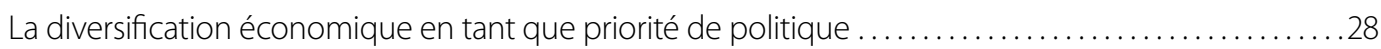

Diversification des exportations: progrès et difficultés ................................ 32

Autonomisation économique ................................................ 41

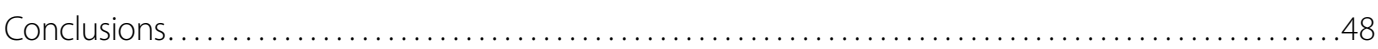

CHAPITRE 2 AIDE POUR LE COMMERCE, DIVERSIFICATION ET AUTONOMISATION ÉCONOMIQUES .....51

Contribution de l'Organisation pour la coopération et le développement économiques

Aperçu ...................................................................... 52

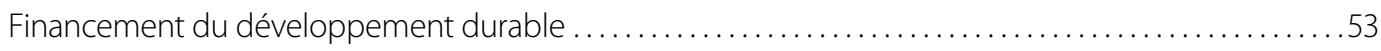

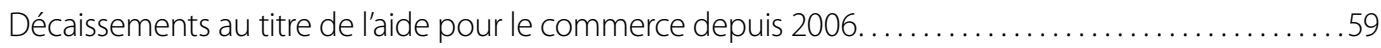

L'Aide pour le commerce est-elle efficace? .......................................61

L'autonomisation grâce à la diversification économique .................................64

Renforcement de l'infrastructure liée au commerce. .................................... 72

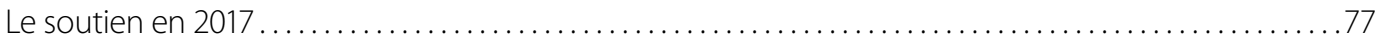

CHAPITRE 3 PROMOUVOIR LA DIVERSIFICATION ÉCONOMIQUE ET LA TRANSFORMATION

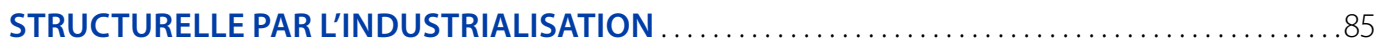

Contribution de l'Organisation des Nations Unies pour le développement industriel

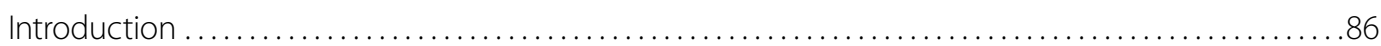

Industrialisation en faveur de la diversification économique et de la transformation structurelle . . ...87

Nature changeante de l'industrialisation et des processus de production ..................... 105

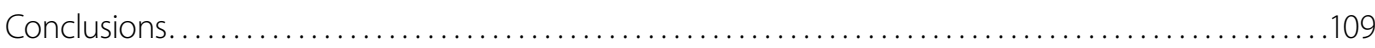

CHAPITRE $4 \quad$ L'AIDE POUR LE COMMERCE DANS LES CONTEXTES DIFFICILES $\ldots \ldots \ldots \ldots \ldots \ldots \ldots \ldots \ldots$

Contribution du Cadre intégré renforcé (CIR) et du Programme des Nations Unies

pour le développement (PNUD)

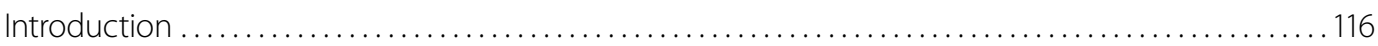

La nécessité de diversifier l'économie dans les PMA .................................. 117

L'Aide pour le commerce destinée à soutenir la diversification de l'économie dans les PMA.........126

Conclusions............................................................ 133

Annexe .................................................................... 139 
CHAPITRE 5 DIVERSIFICATION ÉCONOMIQUE: ENSEIGNEMENTS TIRÉS DE LA PRATIQUE .143

Contribution du Groupe de la Banque mondiale

Importance de la diversification économique. ...

Quel cadre politique et institutionnel pour la diversification? ............................ 151

Réduire impérativement les coûts du commerce .......................................... 159

Politiques d'aide à l'ajustement ........................................................... 165

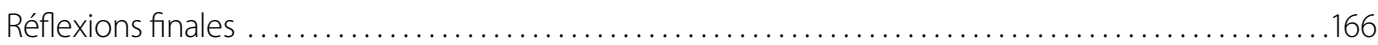

CHAPITRE 6 LE RÔLE ESSENTIEL DE LA FACILITATION DES ÉCHANGES DANS LA PROMOTION DE LA DIVERSIFICATION ÉCONOMIQUE ET DES RÉFORMES STRUCTURELLES.

Contribution de la Banque mondiale, de la Conférence des Nations Unies sur le commerce

et le développement et de l'Organisation de coopération et de développement économiques

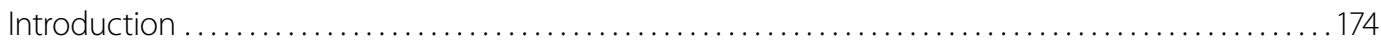

Soutien en matière d'assistance technique et de renforcement des capacités et impacts produits. . . 174

Facilitation du commerce électronique .............................................. 195

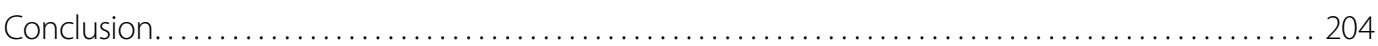

CHAPITRE 7 LA DIVERSIFICATION DES EXPORTATIONS À L'HEURE DE LA "MONDIALISATION LENTE"

Contribution de la Conférence des Nations Unies sur le commerce et le développement

Les stratégies de diversification des exportations - hier et aujourd'hui . ......................212

Commerce des services et commerce interrégional Sud-Sud ............................. 215

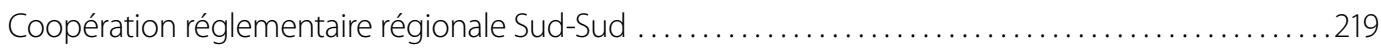

Le rôle de l'Aide pour le commerce ................................................ 223

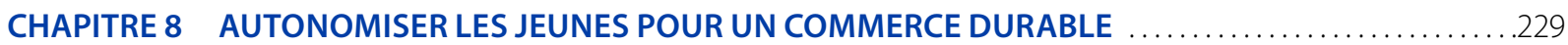

Contribution du Centre du commerce international

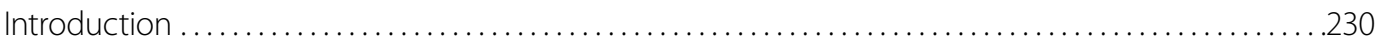

Donner aux entreprises les moyens d'exporter grâce aux compétences des jeunes. ..............231

Promouvoir le travail indépendant et l'entrepreneuriat..................................237

Les gouvernements peuvent favoriser l'autonomisation des jeunes . . . . . . . . . . . . . . . . . . 246

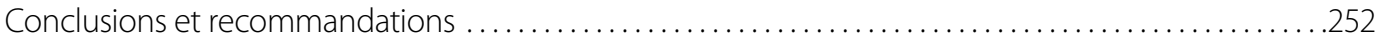

CHAPITRE 9 ENSEIGNEMENTS À TIRER DE L'AIDE POUR LE COMMERCE EN FAVEUR DE L'AUTONOMISATION ÉCONOMIOUE DES FEMMES

Contribution de l'Organisation de coopération et de développement économiques

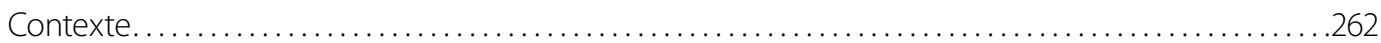

Évaluation de l'intégration des perspectives de genre dans l'aide pour le commerce ..............265

Stratégies et lignes directrices pour l'intégration des perspectives de genre

dans l'aide pour le commerce. ........................................................ 275

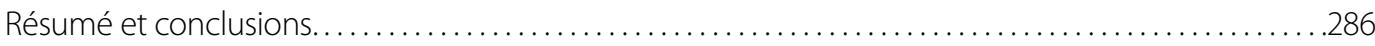


PROFILS DE PAYS

Les profils de pays établis dans le cadre de l'aide pour le commerce sont disponibles en ligne en version anglaise: https://www.wto.org/english/res_e/booksp_e/aid4trade19_profiles_e.pdf

Notes explicatives 299

\section{ANNEXES}

Notes statistiques 307

ANNEXE A PRINCIPALES DONNÉES SUR L'AIDE POUR LE COMMERCE 311

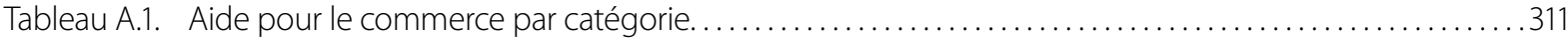

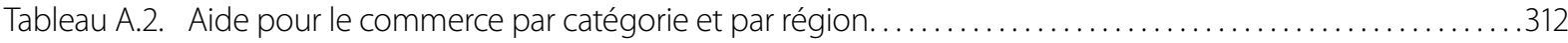

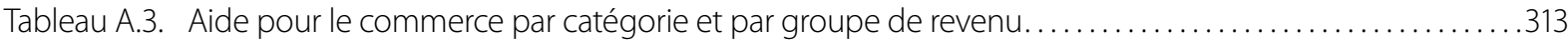

Tableau A.4. Aide pour le commerce par donateur.............................................. 314

Tableau A.5a. Les 20 principaux fournisseurs d'Aide pour le commerce en 2017, engagements..................316

Tableau A.5b. Les 20 principaux fournisseurs d'Aide pour le commerce en 2017, décaissements... ..................316

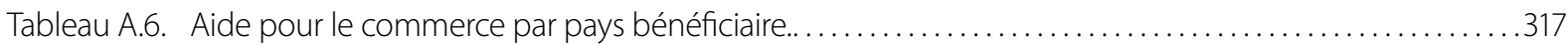

Tableau A.7a. Les 20 principaux bénéficiaires de l'Aide pour le commerce en 2017, engagements. ................321

Tableau A.7b. Les 20 principaux bénéficiaires de l'Aide pour le commerce en 2017, décaissements .................321

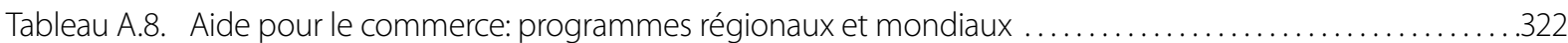

Tableau A.9. Aide pour le commerce: programmes régionaux et mondiaux par catégorie .....................322

Tableau A.10. Aide pour le commerce: dons et prêts par catégorie ...................................323

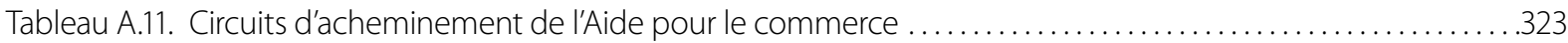

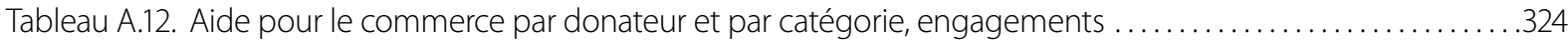

Tableau A.13. Aide pour le commerce par donateur et par catégorie, décaissements . . . . . . . . . . . . . . . . . 330

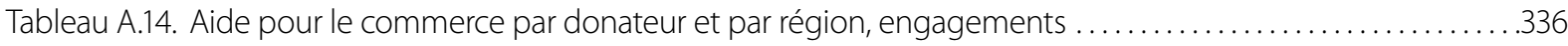

Tableau A.15. Aide pour le commerce par donateur et par région, décaissements . . . . . . . . . . . . . . . . . 342

Tableau A.16. Aide pour le commerce par donateur et par groupe de revenu, engagements . . . . . . . . . . . . . 348

Tableau A.17. Aide pour le commerce par donateur et par groupe de revenu, décaissements.................. 354

Tableau A.18. Autres apports du secteur public liés au commerce, par catégorie ........................... 360

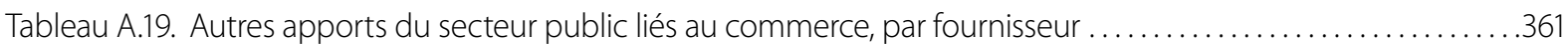

Tableau A.20. Autres apports du secteur public liés au commerce par pays bénéficiaire........................ 362

ANNEXE B LISTE DES BÉNÉFICIAIRES DE L'APD ÉTABLIE PAR LE CAD, PAR GROUPE DE REVENU _.......367

ANNEXE C LISTE DES BÉNÉFICIAIRES DE L'APD ÉTABLIE PAR LE CAD, PAR RÉGION . . . . . . . . . . . . . . . 369

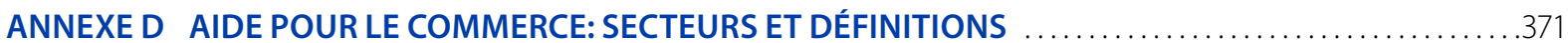




\section{TABLEAUX, FIGURES ET ENCADRÉS}

\section{CHAPITRE 1}

\section{Figures}

Figure 1.1. Diversification des exportations par pays et par catégories de produits . . . . . . . . . . . . . . . . 27

Figure 1.2. Diversification des exportations par marchés de destination et par pays . . . . . . . . . . . . . . . . 27

Figure 1.3. Progrès indiqués par les répondants en matière de diversification

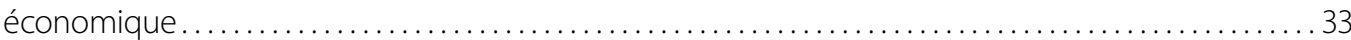

Figure 1.4. Évolution à long terme de la diversification des exportations et de la valeur

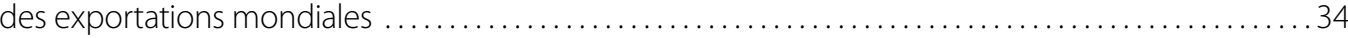

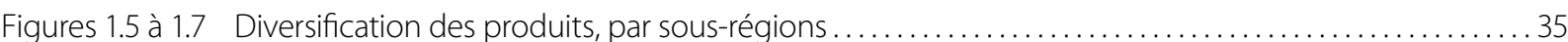

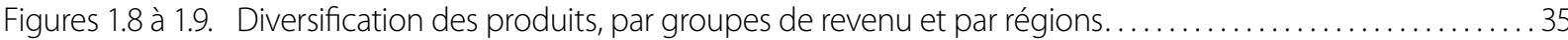

Figure 1.10. Diversification économique au niveau sectoriel, par régions . . . . . . . . . . . . . . . . . . . . . . . . . 36

Figure 1.11. Diversification des exportations de produits agricoles, par régions $\ldots \ldots \ldots \ldots \ldots \ldots \ldots \ldots \ldots \ldots \ldots \ldots \ldots \ldots \ldots$

Figure 1.12. Diversification des exportations de produits industriels, par régions . . . . . . . . . . . . . . . . . . 37

Figure 1.13. Principaux obstacles à la diversification économique des pays partenaires.................... 38

Figure 1.14. Principales entraves à la diversification économique des PDSL, PMA et PEID interrogés ........................................................... 38

Figure 1.15. Principaux obstacles à la diversification économique, par régions . . . . . . . . . . . . . . . . . . . 39

Figure 1.16. L'Aide pour le commerce peut concourir à la réalisation du Programme

\section{Encadrés}

Encadré 1.1. Importance de la diversification économique pour les pays en développement et les PMA . . ....29

Encadré 1.2. Quels sont les facteurs qui entravent la diversification économique? .......................40

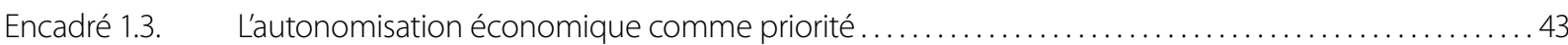

Encadré 1.4. Déclaration conjointe sur le commerce et l'autonomisation économique des femmes............46

\section{Tableaux}

Tableau 1.1. Méthodologie appliquée pour déterminer les priorités en matière de diversification économique et de diversification des exportations

\section{CHAPITRE 2}

\section{Figures}

Figure 2.1.

Financement transfrontières destiné aux pays en développement, 2000-2016 53

Figure 2.2.

Destinataires du financement extérieur en 2016. .54

Figure 2.3.

Disponibilité des sources de financement selon les niveaux de revenu. ...

Figure 2.4. Montants des financements mobilisés aux fins du développement auprès du secteur privé, 2012-2017, par groupe de revenu et par secteur . . . . . . . . . . . . . . . . . . . . . . . . . . . 56

Figure 2.5a. Fonds philanthropiques privés pour le développement du commerce, 2017, par secteur

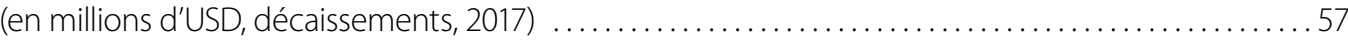

Figure 2.5b. Fonds philanthropiques privés pour le développement du commerce, 2017, par fournisseur (en millions d'USD, décaissements, 2017) ........................................ 57

Figure 2.6. Décaissements au titre de l'Aide pour le commerce par groupe de revenu, élément de libéralité

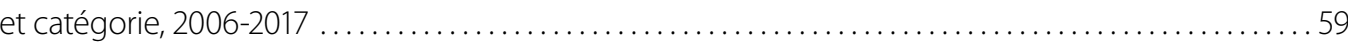

Figure 2.7. Décaissements au titre de l'Aide pour le commerce par région, 2006-2017 .....................60 
Figure 2.8. Décaissements au titre de l'Aide pour le commerce par groupe de revenu, 2006-2017 ........... 61

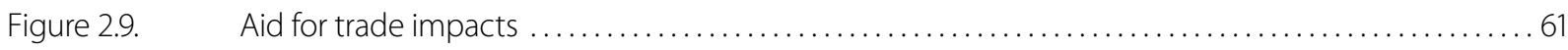

Figure 2.10. Facteurs de réussite de l'Aide pour le commerce .....................................64

Figure 2.11. Engagements au titre de l'APD pour le renforcement des capacités de production, 1973-2017 .....66

Figure 2.12. Engagements au titre de I'APD pour des infrastructures liées au commerce.....................73

Figure 2.13. Engagements au titre de l'Aide pour le commerce, en milliards d'USD, en prix constants

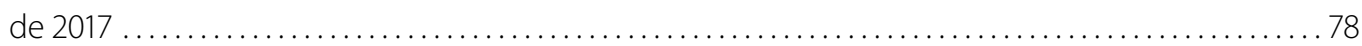

Figure 2.14. Engagements au titre des AASP liés au commerce, par catégorie, en milliards d'USD,

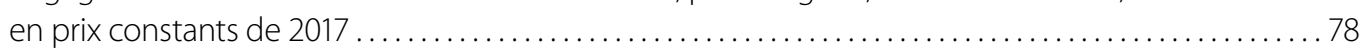

Figure 2.15. Engagements au titre de l'Aide pour le commerce, par région, en milliards d'USD,

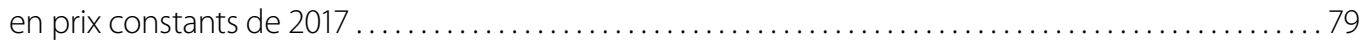

Figure 2.16. Engagements au titre des AASP liés au commerce, par région, en milliards d'USD,

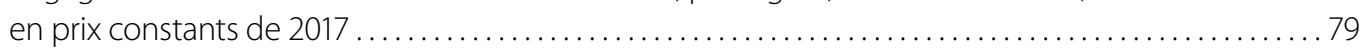

Figure 2.17. Engagements au titre de l'Aide pour le commerce, par groupe de revenu, en milliards d'USD,

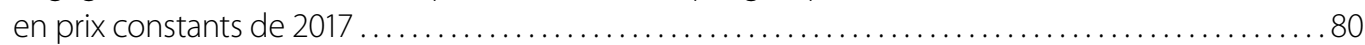

Figure 2.18. Engagements au titre des AASP liés au commerce, par groupe de revenu, en milliards d'USD,

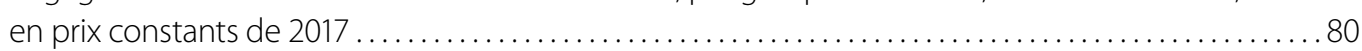

\section{Tableaux}

Tableau 2.1. Vues sur la manière dont l'Aide pour le commerce permet de mobiliser d'autres formes

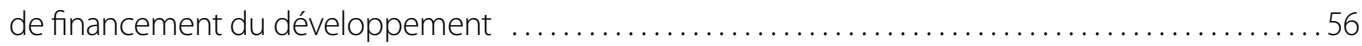

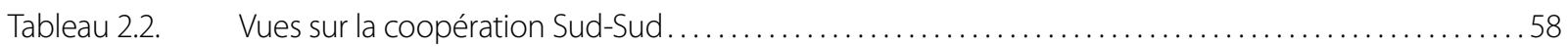

Tableau 2.3. Résultats empiriques concernant l'impact de l'Aide pour le commerce $\ldots \ldots \ldots \ldots \ldots \ldots \ldots \ldots . \ldots 2$

Tableau 2.4. Vues sur la diversification économique............................................. 65

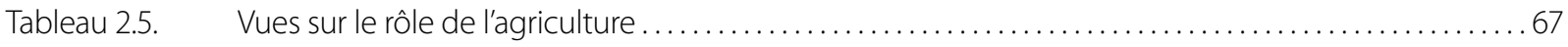

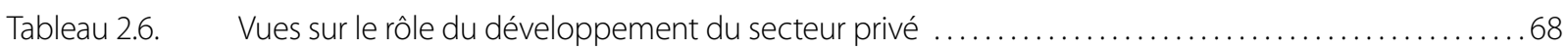

Tableau 2.7. Vues sur le rôle d'un cadre propice à l'activité commerciale ..................................69 69

Tableau 2.8. Vues sur l'amélioration de l'accès au financement ....................................... 70

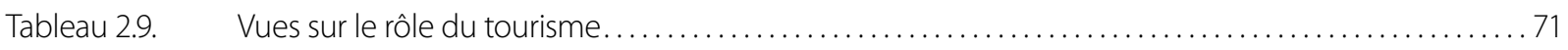

Tableau 2.10. Vues sur le développement du commerce...................................... 72

Tableau 2.11. Vues sur les infrastructures liées au commerce ..................................... 73

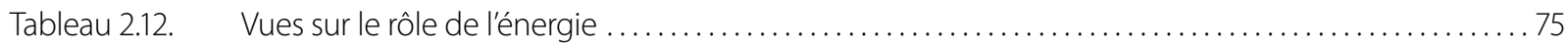

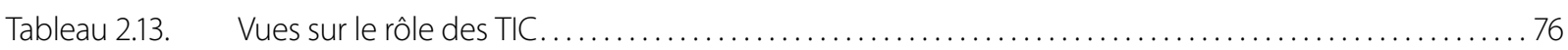

\section{CHAPITRE 3}

\section{Figures}

Figure 3.1. Lien entre la croissance du PIB et celle du secteur manufacturier, $1970-2017 \ldots \ldots \ldots \ldots \ldots \ldots . . . . .86$

Figure 3.2. Indice de l'augmentation de la productivité du travail : économies en développement...........87

Figure 3.3. Tendance à la hausse de la valeur ajoutée manufacturière mondiale, 1990-2017 ................ 88

Figure 3.4. Le cercle vertueux de consommation de produits manufacturés : l'économie mondiale..........990

Figure 3.5. Part des produits manufacturés sur les marchés d'exportation mondiaux .................... 92

Figure 3.6. Part du secteur manufacturier dans l'emploi, par groupe de développement................... 95

Figure 3.7. Emploi induit par le secteur manufacturier, en moyenne, par groupe de pays .................. 96 
Figure 3.8. Décomposition des émissions de CO2 générées de 1995 à $2003 \ldots \ldots \ldots \ldots \ldots \ldots \ldots \ldots \ldots \ldots \ldots$

Figure 3.9. Émissions de $\mathrm{CO} 2$ de l'industrie par unité de valeur ajoutée réelle ..........................99

Figure 3.10. Part de l'absorption intérieure dans la demande finale de produits manufacturés................ 100

Figure 3.11. Principales entraves à la diversification économique ................................. 104

Figure 3.12. Tendances de l'emploi formel dans le secteur manufacturier, par région, pour 1970, 1990,

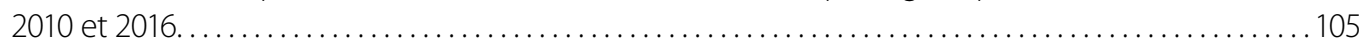

Figure 3.13. Utilisation de robots industriels dans différentes industries . . . . . . . . . . . . . . . . . . 106

\section{Encadrés}

Encadré 3.1. Région arabe: création d'un système régional d'accréditation pour surmonter les obstacles

techniques au commerce et promouvoir l'intégration régionale .......................... 93

Encadré 3.2. Infrastructure de la qualité pour la facilitation des échanges (Q/4TF) en tant que soutien de l'accès au marché .......................................................... 101

Encadré 3.3. Programme de partenariat pays (PCP) de l'ONUDI . . . . . . . . . . . . . . . . . . . . . . . . . 103

\section{CHAPITRE 4}

\section{Figures}

Figure 4.1.

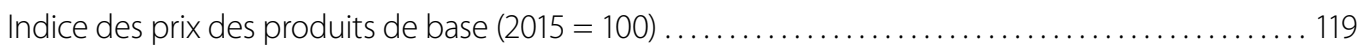

Figure 4.2. Échanges, envois de fonds et flux d'IED vers les PMA et les PMA membres du g7+, 2006-2017 .... 125

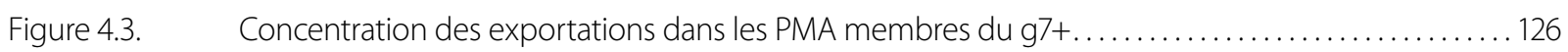

Figure 4.4. Flux d'Aide pour le commerce en faveur des PMA et des PMA membres du g7t, moyenne pour 2006-2017 ..................................................... 127

Figure 4.5. Décaissements au titre de l'Aide pour le commerce en faveur des PMA membres du g7t,

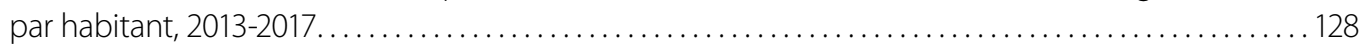

Figure 4.6. Décaissements par catégorie d'Aide pour le commerce, $2006-2017 \ldots \ldots \ldots \ldots \ldots \ldots \ldots \ldots \ldots . . . . . . .129$

Figure 4.7. Matrices des actions des EDIC: identifier les priorités des PMA membres du g7+ . . . . . . . . . . 129

Figure 4.8. Principaux secteurs des PMA soutenus au titre de l'Aide pour le commerce, 2006-2017 ........... 130

Figure 4.9. Répartition de l'APD entre les objectifs de consolidation de la paix et de renforcement de l'État du New Deal, par PSG, pour les PMA et les PMA membres du g7+, 2006-2017 . . . . . . . . . 131

\section{Encadrés}

Encadré 4.1. Encourager la diversification des exportations au Togo $\ldots \ldots \ldots \ldots \ldots \ldots \ldots \ldots \ldots \ldots \ldots \ldots \ldots \ldots$

Encadré 4.2. Diversification des exportations au Tchad: les promesses de la gomme arabique ................ 120

Encadré 4.3. Le New Deal pour l'engagement dans les États fragiles et les objectifs de consolidation

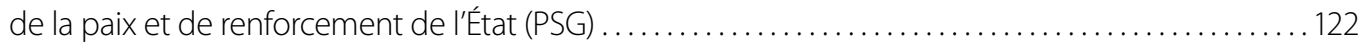

Encadré 4.4. Circuits par lesquels le commerce influe sur la stabilité politique et les conflits ................. 123

Encadré 4.5. Accroître la valeur ajoutée des principales cultures de rapport aux Comores................... 130

Encadré 4.6. Nouvelles possibilités d'emploi dans les PMA membres du g7+: les routes du développement .... 132

\section{Tableaux}

Tableau 4.A1. Emploi par secteur dans les PMA, certaines années (\% de l'emploi total) . ..................... 139

Tableau 4.A2. Composition par produit des exportations de marchandises, 2015-2017 (millions d'USD et \%)...... 139

Tableau 4.A3. Composition par produit des importations de marchandises, 2015-2017 (millions d'USD et \%) ..... 140

Tableau 4.A4. Accès à l'électricité dans les PMA, certaines années (\% de la population totale) .................. 140

Tableau 4.A5. Principaux produits exportés par les PMA membres du g7+ ........................... 141 


\section{CHAPITRE 5}

\section{Figures}

Figure 5.1.

Diversification en Afrique subsaharienne, 2017 .144

Figure 5.2.

Diversification des exportations dans certaines régions de pays en développement, 2017

Figure 5.3.

Distribution de l'emploi par secteurs agrégés, dans le monde et par groupe de revenus,

1991 et 2018 (pourcentages) . ...

Figure 5.4.

Politique de la concurrence et diversification économique.

\section{Encadrés}

Encadré 5.1.

Chili et Zambie: des trajectoires de diversification contrastées

Encadré 5.2. Rwanda: trajectoire de diversification des exportations

Encadré 5.3 .

Stimuler la montée en gamme des produits par des programmes de développement

en faveur des fournisseurs

\section{CHAPITRE 6}

\section{Figures}

Figure 6.1.

Répartition régionale des activités menées dans le cadre du TFSP (par nombre de pays)

Figure 6.2.

Mesures de I'AFE: plus forte demande en matière d'assistance technique et de renforcement des capacités

Figure 6.3.

Mesures de l'AFE: Types de soutien demandés.....

Figure 6.4.

Mesures de l'AFE: Demandes d'appui en matière de sensibilisation et de renforcement des capacités

Figure 6.5. Mesures de l'AFE: Principales demandes en matière d'appui à la législation

Figure 6.6.

Mesures de I'AFE: Demandes d'appui dans les domaines des TIC, de l'infrastructure

et de l'équipement. ...

Figure 6.7.

Pourcentage de pays recevant un appui concernant des mesures particulières de l'AFE

Figure 6.8.

Formes d'assistance fournies 2017-2018

Figure 6.9.

Bénéficiaires du soutien du secteur public

Figure 6.10.

Amélioration en pourcentage des indicateurs de facilitation des échanges

de la Banque mondiale dans les pays visés par le TFSP (2016-2019).

Figure 6.11. Un cadre de politiques de facilitation des échanges qui appuie les PME plutôt que les grandes entreprises dans les économies en développement....

Figure 6.12. Facteurs des politiques de facilitation des échanges qui sous-tendent les exportations

et importations des PME dans les économies en développements

Figure 6.13. Indicateurs de performance clés de la stratégie de facilitation des échanges du Monténégro pour la période 2018-2022 (extraits).

Figure 6.14. Montants de minimis des droits de douane dans 98 pays (Global Express Association) ............. 196

Figure 6.15 .

Article 7:1 de l'AFE Traitement avant arrivée: notifications concernant la mise en œuvre.

Figure 6.16.

Éléments très importants pour la création d'un environnement propice

au commerce électronique. ...

Figure 6.17. Corrélation entre l'utilisation d'Internet dans le cadre des transactions B2C

et la mise en œuvre de l'AFE (mesures relatives au commerce électronique)

Figure 6.18. Pourcentage moyen de mise en œuvre des mesures de l'AFE et du niveau d'utilisation

d'Internet dans le cadre des transactions B2C par région. .203 


\section{Encadrés}

Encadré 6.1. Programme sur la facilitation des échanges de la CNUCED $\ldots \ldots \ldots \ldots \ldots \ldots \ldots \ldots \ldots \ldots \ldots \ldots \ldots$

Encadré 6.2. Observations des pays en développement interrogés sur la facilitation des échanges

Encadré 6.3. Étude sur le temps nécessaire pour la mainlevée (TRS+) - un état des lieux plus précis des délais requis ........................................................ 183

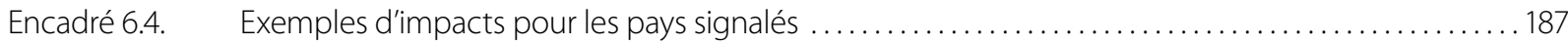

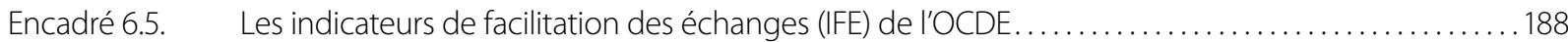

Encadré 6.6. Aider les PME à s'internationaliser grâce à la facilitation des échanges........................ 191

Encadré 6.7. Stratégie de facilitation des échanges mise en place par le Monténégro . ...................... 193

Encadré 6.8. Directives de l'OMD aux fins de la mainlevée immédiate. . . . . . . . . . . . . . . . . . . . . . . . . . 198

Encadré 6.9. Facilitation des échanges et commerce électronique: les deux aspects d'une même réalité .......201

Encadré 6.10. Corrélation entre la mise en œuvre de l'AFE et le niveau d'utilisation d'Internet

dans le cadre des transactions B2C par région .................................... 202

\section{Tableaux}

Tableau 6.1. Collaboration du TFSP avec d'autres organisations

Tableau 6.2. Pourcentage de pays alignés: comparaison entre les évaluations réalisées à l'aide de l'outil

de suivi et les notifications de catégorie A . ...................................... 186

Tableau 6.3. Résultats des études sur le temps nécessaire à la mainlevée ............................... 187

\section{CHAPITRE 7}

\section{Figures}

Figure 7.1.

Part des produits manufacturés dans les exportations, 1995-2017 . .................... 212

Figure 7.2. Indice de concentration des exportations d'Herfindahl-Hirschman, 1995-2017 ................. 212

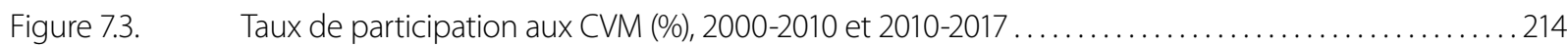

Figure 7.4. Exportations de services des principaux groupes d'économies, $2010-2018 \ldots \ldots \ldots \ldots \ldots \ldots \ldots . \ldots 215$

Figure 7.5. Emploi dans le secteur des services (\% de l'emploi total), 2000, 2010 et $2018 \ldots \ldots \ldots \ldots \ldots \ldots . . . .217$

Figure 7.6. Indice des restrictions au commerce des services par secteur, moyennes régionales............. 218

Figure 7.7. Exportations par catégorie de technologie et par partenaire, diverses régions, 1995-2017 ........220

Figure 7.8. Part des produits de moyenne et de haute technologie dans les exportations africaines,

par destination......................................................... 221

\section{Encadrés}

Encadré 7.1 .

\section{CHAPITRE 8}

\section{Figures}

Figure 8.1.

Taux de chômage des jeunes selon les pays 231

Figure 8.2.

Pénurie de main d'œuvre qualifiée et emploi des jeunes dans les PME .234

Figure 8.3.

Taux d'entrepreneuriat des jeunes par pays et par sexe ....

Figure 8.4. Les jeunes dirigeants embauchent plus de jeunes .238

Figure 8.5. Compétences entrepreneuriales autodéclarées chez les jeunes, par sexe .244

Figure 8.6. L'accès au financement est davantage un obstacle pour les entreprises dirigées par des jeunes . . 247

Figure 8.7. Comment I'Aide pour le commerce peut-elle contribuer au mieux à l'autonomisation économique des jeunes? 
Figure 8.8. Besoins d'effectifs dans le secteur du textile et de l'habillement en Tunisie ...................250

Figure 8.9. Obstacles à l'embauche des jeunes Gambiens, par secteur . . . . . . . . . . . . . . . . . . . . . . . 251

\section{Encadrés}

Encadré 8.1. Renforcement des compétences pour le tourisme au Myanmar: étude de cas du programme STED de l'OIT . .............................................235

Encadré 8.2. Mashrou3i, l'entrepreneuriat des jeunes en Tunisie ...................................239

Encadré 8.3. Start-up du secteur des TI créées par des jeunes dans le camp de réfugiés de Zaatari en Jordanie

\section{Tableaux}

Tableau 8.1. L Liste des meilleures pratiques en matière de compétences des jeunes pour l'employabilité et l'exportation .............................................236

Tableau 8.2. Liste des meilleures pratiques pour soutenir l'entrepreneuriat chez les jeunes...................245

Tableau 8.3. Liste des meilleures pratiques en matière de stratégie gouvernementale pour l'autonomisation économique des jeunes. ...

\section{CHAPITRE 9}

\section{Figures}

Figure 9.1.

Principaux objectifs que les donateurs et les pays partenaires veulent atteindre au moyen de l'Aide pour le commerce.................................................... 265

Figure 9.2. Points de vue sur la contribution de l'Aide pour le commerce aux ODD $\ldots \ldots \ldots \ldots \ldots \ldots \ldots . . \ldots 6$

Figure 9.3. Tendances de l'Aide pour le commerce intégrant la question du genre (en milliards d'USD, dollars constants de 2016)..................................... 268

Figure 9.4. Ventilation par secteur de l'Aide pour le commerce intégrant la question du genre pour 2016-2017 (en milliards d'USD, dollars constants de 2016) . ...

Figure 9.5. Ventilation par secteur de la proportion de l'Aide pour le commerce intégrantl

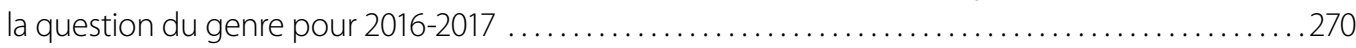

Figure 9.6. Domaines de l'Aide pour le commerce qui, selon les donateurs et les pays partenaires, peuvent le mieux contribuer à l'autonomisation économique des femmes. ....

Figure 9.7. Répartition du financement public du développement (FPD) intégrant la question du genre pour 2016-2017, par groupe de revenu et par région ................................ 272

Figure 9.8. Part moyenne de l'Aide pour le commerce intégrant la question du genre pour 2016-2017 . . ....273

\section{Encadrés}

Encadré 9.1. Programme d'action de Beijing de 1995, "Les femmes dans l'économie" . . ...................263

Encadré 9.2. Le marqueur relatif à l'égalité homme-femme ...................................... 267

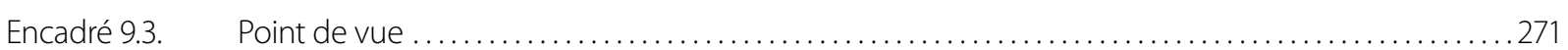

Encadré 9.4. L'autonomisation économique des femmes dans le cadre de l'Aide pour le commerce de l'Australie et de l'UE ..................................................... 274

Encadré 9.5. Application d'une perspective de genre pour appuyer l'investissement privé par les institutions de financement du développement du G-7 ....................... 276

Encadré 9.6. Lignes directrices sur le commerce, les infrastructures, les industries extractives et le tourisme ....277 Encadré 9.7. Opinion - Ann Linde, Ministre du commerce extérieur de la Suède ........................... 287

\section{Tableaux}

Tableau 9.1. Types d'activités intégrant la dimension de genre dans l'Aide pour le commerce 



\section{ACRONYMES ET ABRÉVIATIONS}

\begin{tabular}{|c|c|}
\hline AASP & Autres apports du secteur public \\
\hline ADPIC & Aspects des droits de propriété intellectuelle qui touchent au commerce \\
\hline AFD & Agence française de développement \\
\hline AFE & Accord sur la facilitation des échanges \\
\hline AfT & Aid for Trade \\
\hline AGCS & Accord général sur le commerce des services \\
\hline $\mathrm{ALC}$ & Amérique latine et Caraïbes \\
\hline APEC & Forum de coopération économique Asie Pacifique \\
\hline ASEAN & Association des nations de l'Asie du Sud-Est \\
\hline ATI & Accord sur les technologies de l'information \\
\hline BAfD & Banque africaine de développement \\
\hline BAsD & Banque asiatique de développement \\
\hline BEl & Banque européenne d'investissement \\
\hline BERD & Banque européenne pour la reconstruction et le développement \\
\hline BID & Banque interaméricaine de développement \\
\hline $\mathrm{BlsD}$ & Banque islamique de développement \\
\hline CAD & Comité d'aide au développement \\
\hline CAREC & Coopération économique régionale de l'Asie centrale \\
\hline CARICOM & Communauté des Caraïbes \\
\hline CE & Commission européenne \\
\hline CEA ONU & Commission économique des Nations Unies pour l'Afrique \\
\hline CEDEAO & Communauté économique des États de l'Afrique de l'Ouest \\
\hline CEE ONU & Commission économique des Nations Unies pour l'Europe \\
\hline CEI & Communauté d'États indépendants \\
\hline CER & Communautés économiques régionales \\
\hline CESAP & Commission économique et sociale pour l'Asie et le Pacifique \\
\hline$C \mid R$ & Cadre intégré renforcé \\
\hline CNUCED & Conférence des Nations Unies sur le commerce et le développement \\
\hline CNUDCl & Commission des Nations Unies pour le droit commercial international \\
\hline COMESA & Marché commun de l'Afrique orientale et australe \\
\hline CVM & Chaîne de valeur mondiale \\
\hline DFID & Département du développement international du Royaume-Uni \\
\hline DPI & Droits de propriété intellectuelle \\
\hline EDIC & Étude diagnostique sur l'intégration du commerce \\
\hline
\end{tabular}




\begin{tabular}{|c|c|}
\hline FMl & Fonds monétaire international \\
\hline IPL & Indice de performance logistique \\
\hline IRES & Indice de restrictivité des échanges de services \\
\hline ITC & Centre du commerce international \\
\hline JCA & Agence japonaise de coopération internationale \\
\hline MPME & Micro, petites et moyennes entreprises \\
\hline NEPAD & Nouveau partenariat pour le développement de l'Afrique \\
\hline OCDE & Organisation de coopération et de développement économiques \\
\hline ODD & Objectifs de développement durable \\
\hline OECO & Organisation des États des Caraïbes orientales \\
\hline OMC & Organisation mondiale du commerce \\
\hline OMD & Organisation mondiale des douanes \\
\hline OMT & Organisation mondiale du tourisme \\
\hline ONG & Organisation non gouvernementale \\
\hline ONU & Organisation des Nations Unies \\
\hline ONUDI & Organisation des Nations Unies pour le développement industriel \\
\hline OTC & Obstacles techniques au commerce \\
\hline PDSL & Pays en développement sans littoral \\
\hline PEID & Petits États insulaires en développement \\
\hline $\mathrm{PIB}$ & Produit intérieur brut \\
\hline PIFS & Secrétariat du Forum des îles du Pacifique \\
\hline PISA & Programme international pour le suivi des acquis des élèves \\
\hline PMA & Pays les moins avancés \\
\hline PME & Petites et moyennes entreprises \\
\hline PNUD & Programme des Nations Unies pour le développement \\
\hline PPA & Parité de pouvoir d'achat \\
\hline PPIAF & Service de conseil sur les infrastructures publiques et privées \\
\hline PPP & Partenariats public privé \\
\hline PTF & Productivité totale des facteurs \\
\hline $\mathrm{RDC}$ & République démocratique du Congo \\
\hline RDP lao & République démocratique populaire lao \\
\hline RMP & Réglementation des marchés de produits \\
\hline RNB & Revenu national brut \\
\hline SADC & Communauté de développement de l'Afrique australe \\
\hline SFI & Société financière internationale \\
\hline SIECA centrale & Secrétariat permanent du Traité général d'intégration économique de l'Amérique \\
\hline SIFC & Société islamique internationale de financement du commerce \\
\hline SMSI & Sommet mondial sur la société de l'information \\
\hline SP & Sanitaire et phytosanitaire \\
\hline
\end{tabular}


TIC

TMEA

TVA

UE

UIT

UNESCO

UPU

USAID

WAPP

WiMAX
Technologies de l'information et de la communication

TradeMark East Africa

Taxe sur la valeur ajoutée

Union européenne

Union internationale des télécommunications

Organisation des Nations Unies pour l'éducation, la science et la culture Union postale universelle

Agence des États-Unis pour le développement international

West Africa Power Pool

Worldwide interoperability for microwave access 



\section{RÉSUMÉ ANALYTIQUE}

L'exercice 2019 de suivi et d'évaluation de l'Aide pour le commerce montre que la diversification et l'autonomisation économiques sont des objectifs fondamentaux des stratégies et politiques commerciales et de développement des Membres de l'OMC et des observateurs. Bon nombre des 133 participants à l'exercice soulignent que la diversification économique ouvre la voie à l'autonomisation économique. Les réponses montrent également que cette relation entre la diversification et l'autonomisation fonctionne aussi dans l'autre sens. L'autonomisation, par le renforcement des compétences et la formation, est essentielle à la diversification économique, en particulier lorsqu'elle permet aux jeunes, aux femmes et aux micro, petites et moyennes entreprises (MPME) de participer au commerce international. Les réponses font état de progrès, qui ne sont toutefois pas uniformes, les pays les moins avancés, les pays sans littoral et les petits États insulaires en développement étant confrontés à des difficultés particulières. C'est aussi le cas des États fragiles et en conflit. Pour ces pays comme pour d'autres, la diversification économique est inextricablement liée à l'élévation des niveaux de productivité résultant de la réaffectation des ressources économiques à l'intérieur des différents secteurs de l'économie et entre ces secteurs.

La croissance passée du secteur manufacturier et des secteurs de services connexes a absorbé un grand nombre de travailleurs. Ce processus accroît l'emploi et contribue à la prospérité. Toutefois, après plusieurs décennies d'"hypermondialisation", le monde pourrait entrer dans une période caractérisée par un ralentissement de la croissance du commerce des produits physiques et par une baisse des flux d'investissement étranger direct. En outre, l'automatisation et la numérisation accrues des processus de production modifient la nature des activités manufacturières et l'avenir de l'industrialisation. II est probable que, là où il existe un potentiel d'expansion du commerce, la composante services soit significative. Des mesures visant à empêcher que des restrictions concernant les services affaiblissent ces perspectives de croissance sont nécessaires.

Le Programme de développement durable à I'horizon 2030, adopté par I'Organisation des Nations Unies, préconise une croissance économique inclusive et durable. Cela nécessite d'accorder plus d'attention aux conséquences sociales et environnementales de la diversification et de la croissance économiques. Bien que ce nouvel environnement engendre des difficultés, des politiques ciblées favorisant la diversification économique et la transformation structurelle peuvent créer de vastes possibilités de développement inclusif et durable. Ces politiques comprennent la mise en place de dispositifs d'incitation appropriés; des investissements et des réformes des politiques visant à réduire les coûts du commerce; des politiques favorisant l'ajustement et la réaffectation des ressources; et des interventions des pouvoirs publics destinées à remédier aux dysfonctionnements des marchés, des politiques et des institutions.

L'entrée en vigueur de I'Accord de l'OMC sur la facilitation des échanges illustre cette évolution. Des progrès sont en cours. Le niveau de conformité des pays en développement avec l'Accord augmente et on constate des améliorations notables en ce qui concerne la publication des mesures, l'automatisation et la simplification des procédures, et la coopération avec la communauté commerciale. On a également observé que ces réformes, soutenues par l'aide fournie, avaient des effets positifs. Les rapports par pays et les études périodiques sur le temps nécessaire pour la mainlevée montrent une diminution des inspections physiques des douanes, une suppression des documents inutiles, une automatisation des opérations manuelles de traitement et une réduction consécutive des délais de dédouanement. 
L'autonomisation économique peut être encouragée par des programmes visant spécifiquement à accroître la mesure dans laquelle les groupes marginalisés, y compris les femmes et les jeunes, participent au commerce international et en bénéficient. Dans le même temps, les petites et moyennes entreprises (PME) ont des difficultés à attirer les employés qualifiés dont elles ont besoin pour être compétitives et faire du commerce. Les deux problèmes du chômage des jeunes et de la compétitivité des PME peuvent et devraient être résolus ensemble; il existe en effet des synergies entre les objectifs d'autonomisation économique des jeunes et de compétitivité des PME. Autrement dit, la relation va dans les deux sens: le renforcement des compétences des jeunes et l'innovation favorisent la compétitivité et les exportations des PME, et des PME compétitives sur le plan international créent des emplois plus nombreux et de meilleure qualité pour les jeunes.

II est largement admis que l'autonomisation économique des femmes est l'un des principaux moteurs du développement durable. Les donateurs accordent une attention croissante aux aspects de l'Aide pour le commerce liés à l'égalité hommes-femmes. Les activités menées comprennent des études techniques et l'élaboration de projets visant spécifiquement à prendre en compte la question de l'égalité hommes-femmes dans le domaine ou l'activité concerné. Toutefois, les programmes à court terme des donateurs peuvent se révéler insuffisants pour induire des changements significatifs dans les politiques ou soutenir les activités économiques des femmes. Une approche pourrait consister à encourager le développement des activités de sensibilisation et de formation à la réalisation d'investissements tenant compte de la question de l'égalité hommes-femmes. Cette ligne de conduite répondrait à deux ODD: I'objectif 5, qui est axé sur la valorisation des soins et travaux domestiques non rémunérés par l'apport de services publics et d'infrastructures, et l'objectif 8, qui vise à promouvoir l'emploi productif pour les femmes.

De nombreux pays moins avancés ont réalisé d'importants progrès en matière de développement au cours des 30 dernières années. Cinq pays ont perdu le statut de PMA depuis 1971, date à laquelle ce statut a été créé, et le Vanuatu et l'Angola devraient le perdre en 2020-2021. Dix autres pays satisfont à certains des critères à remplir pour sortir de la catégorie des PMA, ce qui montre que le rythme auquel les PMA sortent de cette catégorie s'est accéléré ces dernières années. Toutefois, 35 PMA ne satisfont pour l'instant à aucun des critères susmentionnés. Pour pouvoir sortir de la catégorie des PMA, les pays doivent engager et maintenir un processus de transformation structurelle afin de générer une croissance économique qui profite aux populations pauvres et qui soit respectueuse de l'environnement.

Depuis le lancement de I'Initiative Aide pour le commerce en 2006, les donateurs ont décaissé 409 milliards d'USD d'aide publique au développement pour aider les pays en développement à renforcer leurs capacités commerciales. En outre, 346 milliards d'USD ont été décaissés au titre de prêts accordés à des conditions libérales. Un montant additionnel de près de 100 milliards d'USD pour ces deux types d'aide a été décaissé en 2017. D'après les estimations de I'OCDE, les fournisseurs Sud-Sud ont versé une contribution de 9 milliards d'USD. Les études empiriques et les évaluations des programmes montrent que ce soutien aide les pays en développement à améliorer leur compétitivité, à développer et à diversifier leurs échanges, à attirer l'investissement étranger direct et à créer des emplois.

Bien que la diversification économique soit un processus essentiellement mené au niveau national, la communauté internationale peut apporter son aide pour créer un environnement propice à l'intégration commerciale des pays en développement et remédier aux contraintes du côté de l'offre. Pour promouvoir l'autonomisation, les programmes d'aide doivent viser plus explicitement à aider les pays en développement à créer davantage de possibilités pour les femmes et les jeunes. L'emploi ou l'entrepreneuriat des jeunes peuvent être encouragés en remédiant aux dysfonctionnements du marché au niveau des entreprises et en améliorant l'écosystème économique. Une plus grande attention devrait être accordée à l'autonomisation des femmes, en particulier dans des secteurs tels que les transports, l'énergie, les services bancaires et financiers, l'extraction minière et l'industrie. Dans ce contexte, il serait utile d'élaborer des lignes directrices concrètes sur la manière de planifier, de suivre et d'évaluer les activités menées par les donateurs pour favoriser l'autonomisation économique des femmes par le biais de l'Aide pour le commerce. 


\title{
CHAPITRE 1. CONTEXTE
}

\section{Contribution de l'Organisation mondiale du commerce}

\begin{abstract}
Résumé: La diversification et l'autonomisation économiques sont la raison d'être de l'Initiative Aide pour le commerce. Le présent chapitre examine les conclusions issues de l'exercice de suivi et d'évaluation conjoint OCDE OMC qui, en 2019, était axé sur l'analyse de ces deux thèmes. Le point de départ de l'analyse est la divergence entre le nombre de marchandises, produits et services exportés par les pays à différents niveaux de développement et de revenu et avec des caractéristiques géographiques différentes. Dans ce contexte, l'exercice de suivi et d'évaluation indique que la diversification de l'économie et des exportations constitue un objectif central des politiques en matière de commerce et de développement des pays partenaires, en particulier les pays les moins avancés (PMA) et les pays en développement sans littoral (PDSL).

Dans leurs réponses à l'exercice de suivi et d'évaluation, les PMA et d'autres répondants font état de progrès dans la diversification de l'économie et des exportations - avancées que l'on retrouve également dans les statistiques commerciales. Néanmoins, les progrès évoqués ne sont pas uniformes, et certains pays relevant de la catégorie des petits États insulaires en développement sont aux prises avec des difficultés particulières. Bon nombre des 133 participants à l'exercice soulignent que la diversification économique ouvre la voie à l'autonomisation économique. Les réponses montrent également que cette relation entre la diversification et l'autonomisation fonctionne aussi dans l'autre sens. L'autonomisation, parle renforcement des compétences et la formation, est essentielle à la diversification économique, en particulier lorsqu'elle permet aux jeunes, aux femmes et aux micro, petites et moyennes entreprises (MPME) de participer au commerce international.
\end{abstract}




\section{INTRODUCTION}

De 6 à plus de 4 500. C'est l'ampleur de la fourchette des catégories de marchandises exportées.' À son extrémité inférieure se trouvent Sao Tomé-et-Principe et les Comores, qui indiquent avoir exporté en 2017 six et huit catégories de marchandises, respectivement. À l'extrémité supérieure de la série se trouvent les trois principales puissances commerciales (la Chine, les États-Unis d'Amérique et l'Union européenne), qui indiquent que leurs exportations de marchandises couvrent plus de 4500 catégories de produits.

Environ la moitié des pays classés par l'Organisation des Nations Unies (ONU) dans la catégorie des pays les moins avancés (PMA) exportent moins de 100 codes de produit. Ce chiffre est inférieur à la valeur médiane (ou point médian), qui s'établit à 359 catégories de produits d'après un calcul utilisant des données classées selon la nomenclature du Système harmonisé de désignation et de codification des marchandises (Système harmonisé ou SH) de l'Organisation mondiale des douanes (OMD). Parmi les petits États insulaires en développement (PEID), le nombre moyen de catégories de produits du SH est lui aussi en dessous de la valeur médiane.

Aucun PMA n'exporte un éventail de produits couvrant plus de 805 codes du SH. Le Cambodge, le Myanmar et le Bangladesh sont les trois PMA dont les exportations de marchandises sont les plus variées, puisque leurs échanges externes couvrent, respectivement, 542, 688 et 805 codes du SH. Aucun des répondants classés par l'ONU dans la catégorie des pays en développement sans littoral (PDSL) n'exporte un éventail de produits couvrant plus de 1100 catégories de produits du SH. La République du Kazakhstan, la Macédoine du Nord et Moldova sont les trois PDSL dont les exportations de marchandises sont les plus variées, couvrant respectivement 604, 721 et 1067 codes du SH. Les exportations des PDSL couvrent en moyenne 279 catégories de produits. La figure 1.1 ci-incluse illustre l'éventail de codes du SH que couvrent les exportations des 157 répondants.

De 7 à plus de 200. C'est la fourchette correspondant au nombre des marchés étrangers desservis. À l'extrémité inférieure de cet intervalle se trouve Cabo Verde, qui exporte vers sept marchés, tandis que Sao Tomé-et-Principe, le Soudan du Sud et les Tonga envoient leurs exportations vers neuf marchés étrangers. Les 3 principales puissances commerciales par catégorie de produits, mentionnées ci-dessus (la Chine, les États-Unis d'Amérique et l'Union européenne), atteignent plus de 200 marchés, tout comme 7 autres nations commerçantes : le Brésil, I'Inde, le Japon, la République de Corée, la Malaisie, la Suisse et la Turquie.

En moyenne, les PMA exportent vers 46 marchés étrangers, chiffre inférieur à la valeur médiane des relations avec les marchés d'exportation, qui s'établit à 73. Le Bangladesh, le PMA qui exporte des marchandises vers le plus grand nombre de marchés, exporte vers 106 marchés étrangers. Parmi les PDSL répondants, le Paraguay est celui qui exporte vers le plus grand nombre de marchés, puisqu'il en atteint 111 - un peu plus du double de la valeur moyenne de 54 marchés étrangers pour d'autres PDSL. En ce qui concerne les PEID, Singapour exporte vers le plus grand nombre de marchés (116), ce qui le place devant la République dominicaine (98) et Maurice (91). Le nombre moyen de marchés atteints par les PEID est de 43, soit 3 de moins que les PMA. La figure 1.2 expose le nombre de marchés desservis.

L'absence de séries de données comparables complique le calcul de valeurs analogues relatives à la diversification des exportations en ce qui concerne le commerce des services. Une série de données expérimentales de l'OMC sur le commerce des services compile et estime les statistiques du commerce des services dans trente-neuf (39) catégories de services. ${ }^{2}$ D'après un calcul fondé sur les données de 198 économies en 2017, la valeur médiane des catégories d'exportations de services est de vingt-six (26). Les exportations des PMA relèvent en moyenne de 17,3 catégories de services. Le Sénégal et le Bangladesh ont enregistré le plus important niveau de diversification de services, avec des exportations relevant respectivement de 35 et 33 catégories en 2017. Parmi les PEID, le nombre moyen de catégories d'exportation de services est de 19,4, chiffre inférieur à la moyenne de 26,6 qu'affichent les pays qui ne font pas partie de ce groupe. Les écarts sont considérables entre les PEID : Haïti et le Timor-Leste (pays relevant à la fois de la catégorie des PMA et 
Figure 1.1. Diversification des exportations par pays et par catégories de produits

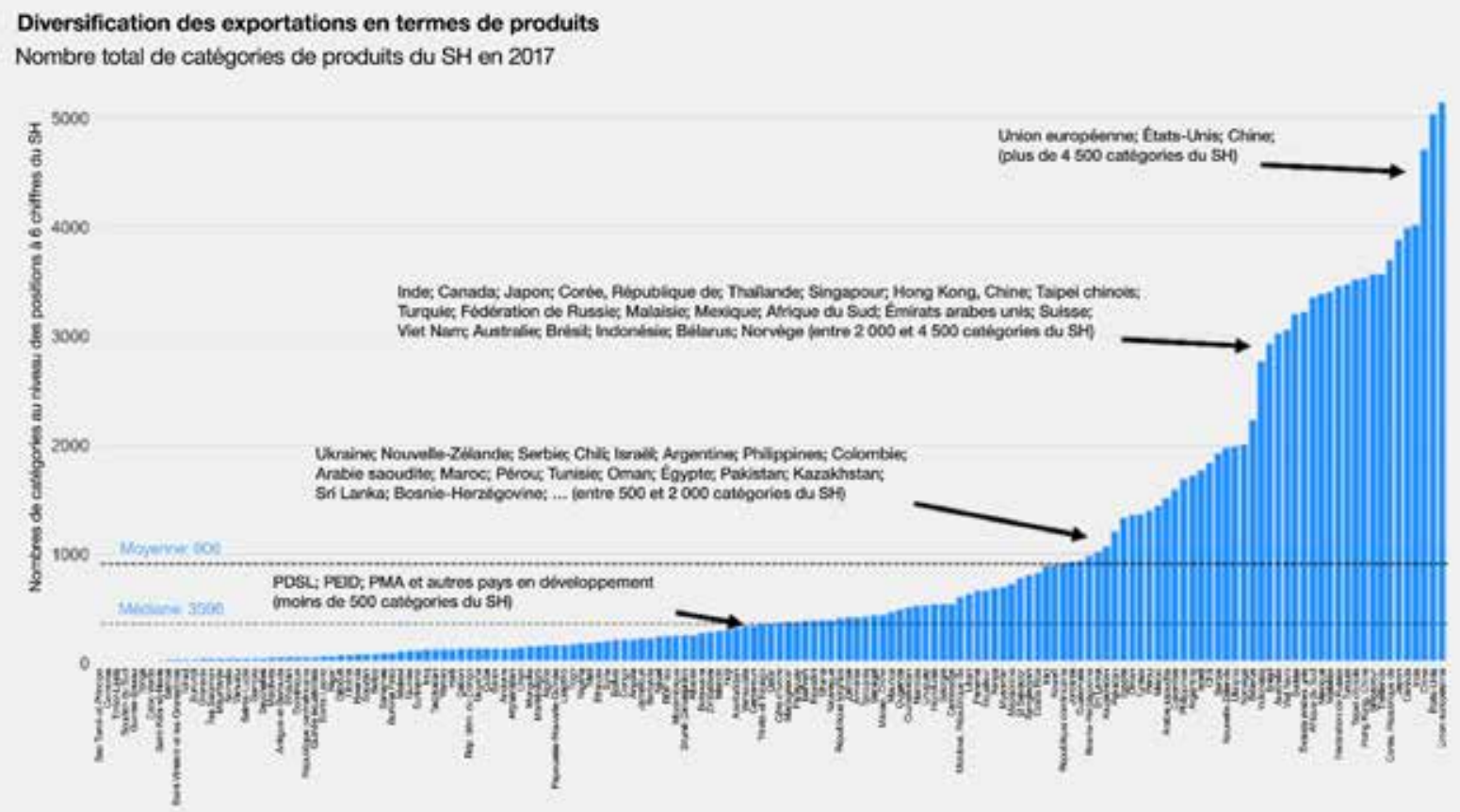

Source: Calcul du Secrétariat de I'OMC, sur la base de la BDI de l'OMC et de la base de données Comtrade de l'ONU.

\section{Figure 1.2. Diversification des exportations par marchés de destination et par pays}

\section{Diversification des exportations en termes de marchés de destination} Nombre de marchés d'exportation en 2017

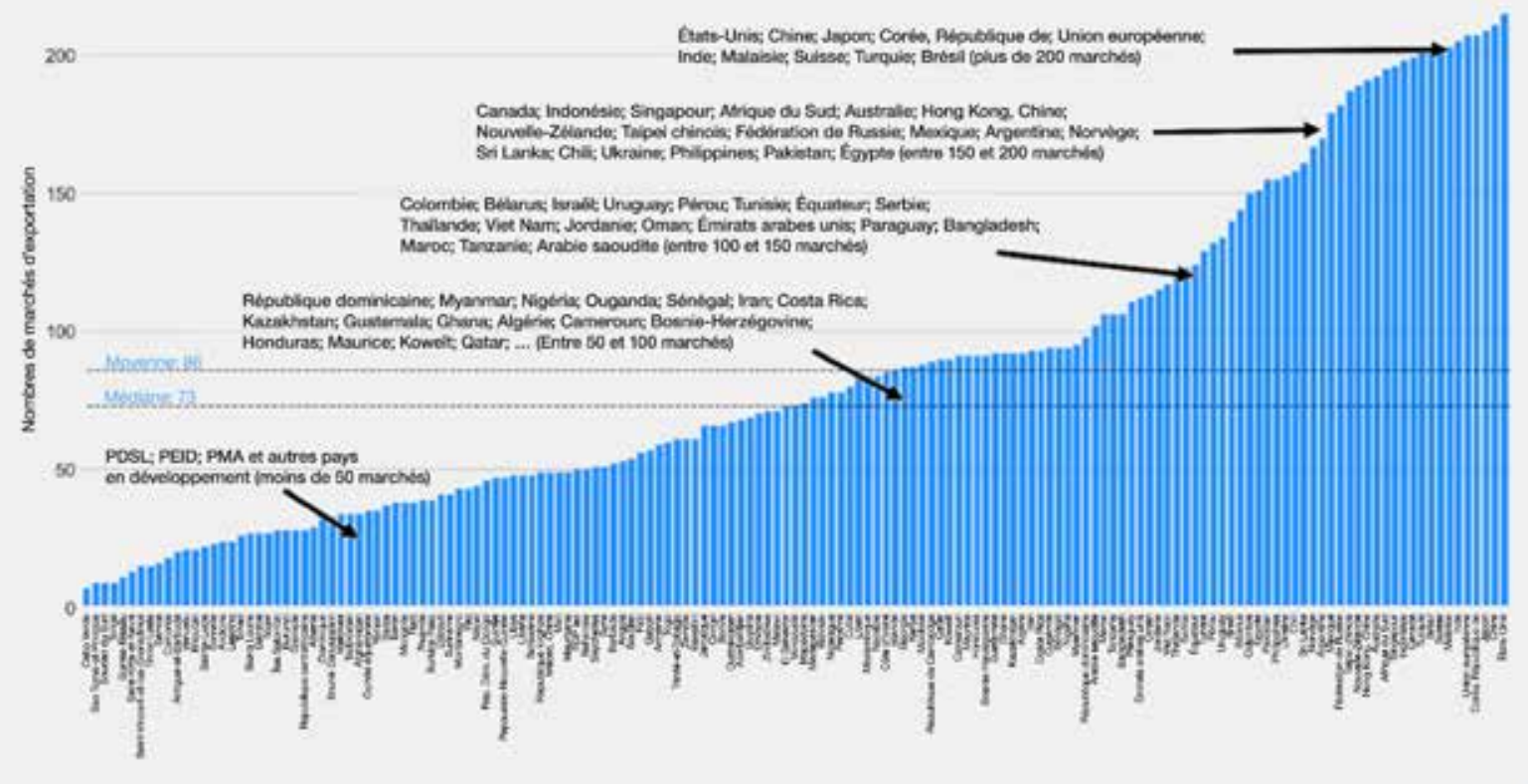

Source: Calcul du Secrétariat de l'OMC, sur la base de la BDI de l'OMC et de la base de données Comtrade de l'ONU. 
de celle des PEID) exportent respectivement des services relevant de trois (3) et six (6) catégories, contre trente-huit (38) pour Singapour. Les exportations des PDSL couvrent en moyenne 21 catégories de produits. Toutefois, en raison de contraintes de capacités des répondants, notamment les PMA et les PEID, il n'est pas possible de brosser un tableau plus précis des nouvelles tendances en matière de participation au commerce des services.

En 2006, l'Équipe spéciale chargée de l'Aide pour le commerce a établi que l'augmentation des exportations des biens et services était, en partie, la raison d'être de l'Aide pour le commerce. ${ }^{3}||$ a été avancé que, de son côté, une Aide pour le commerce efficace améliorerait les perspectives de croissance et réduirait la pauvreté dans les pays en développement. Le thème "Soutenir la diversification et l'autonomisation économiques pour un développement inclusif et durable grâce à l'Aide pour le commerce" est au cœur du programme de travail 2018-2019 et englobe les deux objectifs centraux que sont la croissance et la réduction de la pauvreté.

La transparence créée par le suivi et l'évaluation est au cœur de l'Initiative Aide pour le commerce. Dans le cadre de l'exercice de suivi et d'évaluation de 2019, des donateurs, des partenaires Sud-Sud, des organisations régionales et des pays partenaires se sont livrés à un exercice d'auto-évaluation par questionnaire, mené conjointement par l'Organisation de coopération et de développement économiques (OCDE) et l'Organisation mondiale du commerce (OMC). Au total, 133 réponses ont été reçues. Le questionnaire destiné aux pays partenaires a reçu quatre-vingt-huit (88) réponses, dont 38 émanaient de PMA. Les partenaires Sud-Sud ont présenté cinq réponses, le même total que les organisations régionales. Les donateurs bilatéraux et multilatéraux ont présenté 36 réponses en tout.

La suite du présent chapitre met en lumière les points essentiels qui ressortent des résultats de l'enquête. Sa structure suit celle des questionnaires d'auto-évaluation. Dans le questionnaire, les répondants étaient priés de fournir des renseignements sur les sujets suivants:

a) la diversification économique en tant que priorité dans les plans de développement nationaux et régionaux;

b) les progrès enregistrés en matière de diversification des exportations et les facteurs limitant cette diversification; et

c) l'autonomisation économique en tant que priorité politique dans les plans de développement nationaux et régionaux et des exemples de la façon dont l'Aide pour le commerce avait contribué à la réalisation des objectifs en matière d'autonomisation économique.

\section{LA DIVERSIFICATION ÉCONOMIQUE EN TANT QUE PRIORITÉ DE POLITIQUE}

L'exercice de suivi de l'Aide pour le commerce de 2019 souligne le caractère central de la diversification économique en tant qu'objectif de politique pour les répondants. Quatre-vingts (80) des quatre-vingt-huit (88) pays partenaires ayant répondu au questionnaire (soit 91\%) ont indiqué que la diversification économique était une priorité dans les stratégies de développement nationales ou régionales. Ce nombre était encore plus élevé chez les répondants des PMA et des PDSL (100\%), qui ont déclaré à l'unanimité que la diversification économique était une priorité. L'encadré 1.1 énumère quelques-unes des raisons avancées par un échantillon représentatif de répondants pour justifier la priorité qu'ils accordent à la diversification économique.

La diversification économique est considérée comme une composante essentielle du développement économique grâce à laquelle un pays s'oriente vers une structure de production et d'échanges plus variée. Le manque de diversifcation économique est associé à une vulnérabilité économique accrue telle que les chocs extérieurs peuvent compromettre le processus de développement. Étant donné que la structure des économies varie, il n'existe pas de modèle unique de ce qui constitue la diversification économique au niveau sectoriel (c'est-à-dire en termes de contribution de l'agriculture, du secteur manufacturier et des services). Cela étant, les structures économiques des PMA et des autres pays à faible revenu ont tendance à être les moins variées et sont souvent fortement dépendantes de l'agriculture et des ressources naturelles, comme le mazout, le gaz, le cuivre et d'autres métaux. 
Encadré 1.1. Importance de la diversification économique pour les pays en développement et les PMA

Dans les différents documents cités, la diversification économique est définie comme un élément essentiel à la réduction de la pauvreté dans le pays - Bénin

La République centrafricaine est dotée d'importantes ressources naturelles. Néanmoins, l'économie repose exclusivement sur certains produits (le café, le coton, les diamants, le bois). La diversification économique consiste à élargir ou à développer les sources de revenu pour le pays - République centrafricaine

La diversification est une composante essentielle des stratégies mises en place par le gouvernement pour sortir de I'ornière de la faible croissance économique dans laquelle se trouve El Salvador depuis plusieurs décennies - El Salvador

Notre pays se sert de la diversification économique pour améliorer l'inclusion et réduire la forte dépendance à l'égard des ressources naturelles - $\mathbf{R D P}$ lao

La diversification économique est une priorité du programme d'émergence national du nouveau gouvernement, qui est entré en fonction en janvier 2019 - Madagascar

La diversification des exportations est au cœur des efforts déployés par le gouvernement pour élargir la base d'exportation et promouvoir l'industrialisation, et la création de valeur ajoutée est considérée comme un moteur de la croissance économique et du développement durable - Malawi

L'article 2.1 de la Vision de développement durable de la Mongolie à l'horizon 2030 énonce que "l'économie sera diversifiée afin d'atteindre les objectifs de développement économique durable" - Mongolie

L'industrialisation et la diversification des produits sont importantes en raison de notre forte dépendance vis-à-vis des importations et de la nécessité urgente de combler l'énorme déficit commercial - Tonga

La baisse des prix du pétrole brut et de l'essence signifie que le pays doit chercher des moyens de diversifier son économie - Yémen

Selon la Banque mondiale, l'économie se diversifie lorsque la production nationale s'oriente vers de nouvelles activités au sein des secteurs et entre eux. Ce phénomène aboutit à une meilleure allocation des ressources et améliore la productivité générale. La diversification aura tendance à accroître la demande de main-d'œuvre et à créer des emplois, ce qui importe particulièrement dans les économies où les ressources naturelles occupent une place dominante et où la population jeune est nombreuse et le taux de chômage élevé. ${ }^{4}$ De leur côté, les exportations peuvent se diversifier par une augmentation de la variété et du volume des exportations et/ou des partenaires commerciaux (diversification de la marge extensive), ou par une augmentation de la proportion des produits et services qui sont exportés, et/ou par une augmentation des prix pour ces exportations (diversification de la marge intensive).

Sur le plan théorique, la diversification économique et la diversification des exportations sont deux notions distinctes. Dans la pratique, les réponses des décideurs publics révèlent qu'elles se rejoignent autour d'objectifs communs. On retrouve cette tendance dans des observations comme celle formulée par la Géorgie, selon laquelle la diversification économique couvre de nombreux secteurs et sous-secteurs de l'économie et implique la diversification des exportations, le développement des petites et moyennes entreprises (PME) et de l'agriculture, d'importantes mesures d'industrialisation, etc.

Un autre exemple vient de la Zambie, dont le septième plan national de développement fait de la diversification économique un mécanisme qui génèrera des emplois en établissant une base manufacturière solide et en créant de la valeur ajoutée grâce à des liens en aval, et en diversifiant ses exportations par un accent sur les exportations non traditionnelles. 
Certains répondants lient les objectifs de diversification à des cibles particulières. Parmi les objectifs les plus précis dont il a été fait état figurent ceux contenus dans la stratégie de développement nationale de l'Équateur. Les objectifs que le pays se propose d'atteindre d'ici 2021 consistent notamment "à porter de 1,26\% à 1,65\% le solde de la balance commerciale en proportion du produit intérieur brut à l'horizon 2021, à ramener le taux de concentration des exportations non pétrolières par produit de 0,1252 à 0,0799, à augmenter les exportations agricoles et agro-industrielles d'au moins 33\% et à faire passer de 55,2 à 74,5 USD les exportations par habitant de haute, moyenne ou basse intensité technologique". Ces objectifs s'inscrivent dans un plan plus large qui vise à consolider la viabilité du système économique, social et solidaire, et à asseoir la dollarisation.

D'autres répondants établissent un lien entre la diversification économique et des objectifs politiques précis. Par exemple, le Kirghizistan prévoit de diversifier son économie en attirant l'investissement étranger direct aux fins de la modernisation des installations de production.

Certains répondants considèrent que des instruments de politiques publiques particuliers peuvent favoriser la diversification économique. Le Lesotho prévoit d'exploiter son avantage comparatif actuel pour élargir les sources de croissance en soutenant la diversification économique et la compétitivité des exportations par le développement de pôles industriels dans les secteurs productifs. En outre, le pays doit créer des zones économiques spéciales. Le Libéria, qui a aussi mentionné le rôle des zones économiques spéciales, utilise le port de Buchanan pour "s'affranchir de sa dépendance à l'égard des principales industries extractives et essayer d'augmenter la production intérieure de produits manufacturiers, industriels et à valeur ajoutée". La Mauritanie dit compter sur la Zone franche de Nouadhibou pour stimuler ses échanges avec la Communauté économique des États de l'Afrique de l'Ouest (CEDEAO).

L'évitement de certains risques a également été défini comme un moteur de l'action en faveur de la diversification économique. La Mauritanie a indiqué qu'elle avait pour objectif de "réduire sa vulnérabilité aux chocs externes liés à la volatilité des prix des ressources naturelles et aux changements climatiques". Les îles Cook ont elles aussi indiqué que les changements climatiques avaient motivé leur action. Dans sa réponse, l'auteur a déclaré "qu'il était hasardeux que 70\% du PIB du pays repose sur le tourisme compte tenu de la vulnérabilité de ces îles aux changements climatiques". Le Mali, le Samoa et Saint-Kitts-et-Nevis ont aussi évoqué les changements climatiques dans leurs réponses. Le Secrétariat du Forum des îles du Pacifique a indiqué que les efforts de relèvement et de reconstruction consécutifs aux catastrophes naturelles fréquentes et sévères étaient un facteur influant sur la diversification économique.

\section{Tableau 1.1 Méthodologie appliquée pour déterminer les priorités en matière de diversification} économique et de diversification des exportations

Indice de la capacité de production

\begin{tabular}{lclc} 
Variable & Pondération & Variable & Pondération \\
Participation : \% de valeur ajoutée & $22,7 \%$ & Complexité & $33,1 \%$ \\
\hline Emploi & $20,3 \%$ & Croissance : \% des exportations sectorielles & $28,6 \%$ \\
\hline Entreprises & $19,6 \%$ & Entreprises exportatrices & $25,6 \%$ \\
\hline Croissance : \% de valeur ajoutée & $16,4 \%$ & Participation : \% des exportations sectorielles & $12,8 \%$ \\
\hline Liens & $11,6 \%$ & & \\
\hline Complexité & $9,4 \%$ & & \\
\hline
\end{tabular}

Source: Département national de la planification, Colombie. ${ }^{5}$ 
Le rôle que joue la politique commerciale à l'appui de la diversification économique est envisagé d'un point de vue très différent chez certains répondants. La vision qu'a le Pérou d'une "économie dynamique, diversifiée, de haute technologie et équilibrée sur le plan régional, caractérisée par le plein emploi et une forte productivité du travail" repose sur "une stratégie d'ouverture commerciale par la diversification sur de nouveaux marchés émergents et dans le cadre des accords commerciaux". Sur le plan des politiques, le Tadjikistan envisage "de remplacer les importations en ce qui concerne les biens de consommation, de diversifier les exportations et d'augmenter les possibilités d'investissement dans l'économie nationale". L'Angola a mis en place un programme d'appui à la production nationale, à la diversification des exportations et au remplacement des importations. De la même manière, la Côte d'Ivoire fait également connaître son intention "d'appliquer le modèle de remplacement des importations".

Certains répondants adoptent une approche multisectorielle de la diversification économique. Le Plan stratégique du Panama pour la période 2015-2019 vise à promouvoir "la diversification et la productivité de la base économique en s'appuyant sur le développement des secteurs de la logistique et du transport, de l'agriculture et du développement rural, du tourisme et des mines." La durabilité environnementale et l'aménagement du territoire sont également pris en considération. De même, le Plan national de développement du Togo envisage de procéder à un ajustement structurel par la croissance de la contribution des secteurs clés (commerce, agriculture et pêche, industrie et tourisme). Parallèlement, le Plan national de développement de la Gambie "met l'accent sur la modernisation du secteur agricole, le développement du capital humain et la nécessité d'offrir des services relatifs à l'énergie et à l'infrastructure modernes, fiables et efficaces".

Certains répondants ont une approche très ciblée des objectifs de diversification économique. Dans sa réponse, la Colombie a rappelé sa politique nationale de développement productif de 2016 et la méthode scientifique appliquée afin de repérer les activités productives ayant un potentiel de croissance. On expose dans le tableau 1.1 ci-dessous la méthodologie utilisée pour attribuer une valeur fondée sur les valeurs dérivées d'un indice de la capacité de production et de la capacité d'exportation afin de définir les objectifs de diversification des exportations.

D'autres répondants visent certaines chaînes de valeur ou produits. Par exemple, la République démocratique du Congo a choisi de développer les secteurs agricoles et industriels porteurs de croissance économique, tels que les secteurs du café, du cacao et de l'huile de palme. Le Niger a cité des études qui suggèrent qu'il existe des possibilités évidentes d'émergence de certaines chaînes de valeur et de développement de certains secteurs : l'élevage - viande, cuirs et peaux - les oignons, les pois à vache, les pommes de terre, l'ail et le poivre.

Certains répondants ont indiqué qu'ils souhaitaient parvenir à développer le secteur industriel. L'observation de I'Indonésie selon laquelle "l'industrialisation favorise la diversification économique" est reprise dans d'autres commentaires. L'Ouganda a indiqué dans sa réponse que la diversification économique était définie en termes de valeur ajoutée aux produits d'exportation traditionnels et mesurée par le pourcentage des exportations de produits manufacturés dans les exportations totales. Ce point de vue sur la diversification est aussi celui du Zimbabwe, qui est d'avis que l'on parvient à la diversification économique grâce à "l'exportation de davantage de lignes de produits, la création de nouvelles entreprises et la fabrication de nouveaux produits".

Au niveau régional, c'est l'Afrique qui enregistre la part la plus importante de répondants indiquant que la diversification économique constitue une priorité pour eux. Trente-quatre (34) des trente-cinq (35) répondants africains (97\%), dont 26 étaient un PMA, ont confirmé qu'ils accordaient la priorité à la diversification économique. Ces résultats sont en adéquation avec l'accent placé sur ce sujet dans le Cadre stratégique commun pour une croissance inclusive et un développement durable de la Commission de I'Union africaine intitulé "Agenda 2063 : L'Afrique que nous voulons". 
La réponse fournie par la CEDEAO souligne elle aussi l'importance de la diversification économique. Cette priorité est exprimée dans une série de stratégies régionales comprenant, entre autres, la politique industrielle et le plan d'action communs de la CEDEAO, la politique agricole, la stratégie de développement du secteur privé et la stratégie d'enseignement et de formation techniques et professionnels. Le plan directeur 2019-2033 révisé de la CEDEAO comporte des indicateurs de suivi de la performance de la politique industrielle et du plan d'action communs de la CEDEAO, tels que l'augmentation en pourcentage des exportations et l'augmentation en pourcentage de la part des secteurs industriels et manufacturiers dans le PIB, entre autres indicateurs.

D'autres répondants ont mis l'accent sur les services dans le cadre de la diversification des activités. Le Bhoutan a indiqué que ses efforts de diversification des produits et marchés d'exportation étaient davantage axés sur les secteurs de services tels que le tourisme. Dans leur réponse, les Tuvalu ont suggéré que le commerce ne pourrait pas exister tant que d'autres secteurs tels que le tourisme, la pêche, l'agriculture et la mobilité de la main-d'œuvre ne seront pas des priorités. Tous les secteurs sont liés et collaborent pour surmonter les obstacles auxquels se heurte le tourisme ou tout autre secteur.

Plusieurs États insulaires du Pacifique ont considéré que le secteur de la pêche était important pour la diversification économique. Outre les Tuvalu, qui ont déjà été cités, les îles Cook ont souligné que leur objectif premier était de diversifier leur économie grâce à la pêche, au commerce et aux services financiers offshore. Kiribati a elle aussi indiqué que le développement de la pêche figurait au nombre de ses priorités dans le cadre de l'Aide pour le commerce, ainsi que le tourisme.

Le développement de la pêche fait partie des priorités stratégiques du Plan national de développement de la Gambie. La pêche figure également parmi les objectifs d'autonomisation de Saint-Kitts-et-Nevis et, à ce titre, des activités de formation des pêcheurs à la navigation, à la plongée, à la transformation primaire du poisson et à la sécurité alimentaire ont lieu. De même, les Philippines considèrent la pêche comme un secteur important pour l'autonomisation des sous-secteurs et des populations marginalisés. La Zambie a évoqué un projet de développement d'entreprises d'aquaculture qui bénéficie aux jeunes en augmentant la productivité et en favorisant l'accès aux marchés pour les exportations de poisson.

\section{DIVERSIFICATION DES EXPORTATIONS : PROGRÈS ET DIFFICULTÉS}

\section{Progrès indiqués par les répondants}

Quarante-sept (47) des quatre-vingt-huit (88) répondants (53\%) au questionnaire destiné aux pays partenaires ont fait état de progrès en matière de diversification économique depuis le lancement de l'Initiative Aide pour le commerce en 2006. Parmi les différentes régions, I'Afrique enregistre la part la plus élevée, avec $71 \%$ des répondants ayant fait état de progrès en matière de diversification économique.

La part des PMA rendant compte de progrès est supérieure de 50\% à celle des autres répondants. Soixante-six \% (66\%) des PMA répondants ont fait part de progrès, contre quarante-quatre \% (44\%) pour les répondants qui ne sont pas des PMA.

Tous les répondants n'ont pas rapporté de tels progrès. Cinq répondants africains (le Burundi, les Comores, l'Éthiopie, la République centrafricaine et le Soudan du Sud) ont fait savoir qu'ils n'avaient réalisé aucun progrès en matière de diversification économique depuis 2006. Parmi les contraintes, qui seront examinées plus en détail dans la section suivante, on dénombre le manque de financement (Burundi), la crise de 2013 (République centrafricaine), des progrès limités dans la transformation des produits traditionnels et la dépendance vis-à-vis de quelques produits d'exportation (Comores). 


\section{Figure 1.3. Progrès indiqués par les répondants en matière de diversification économique}

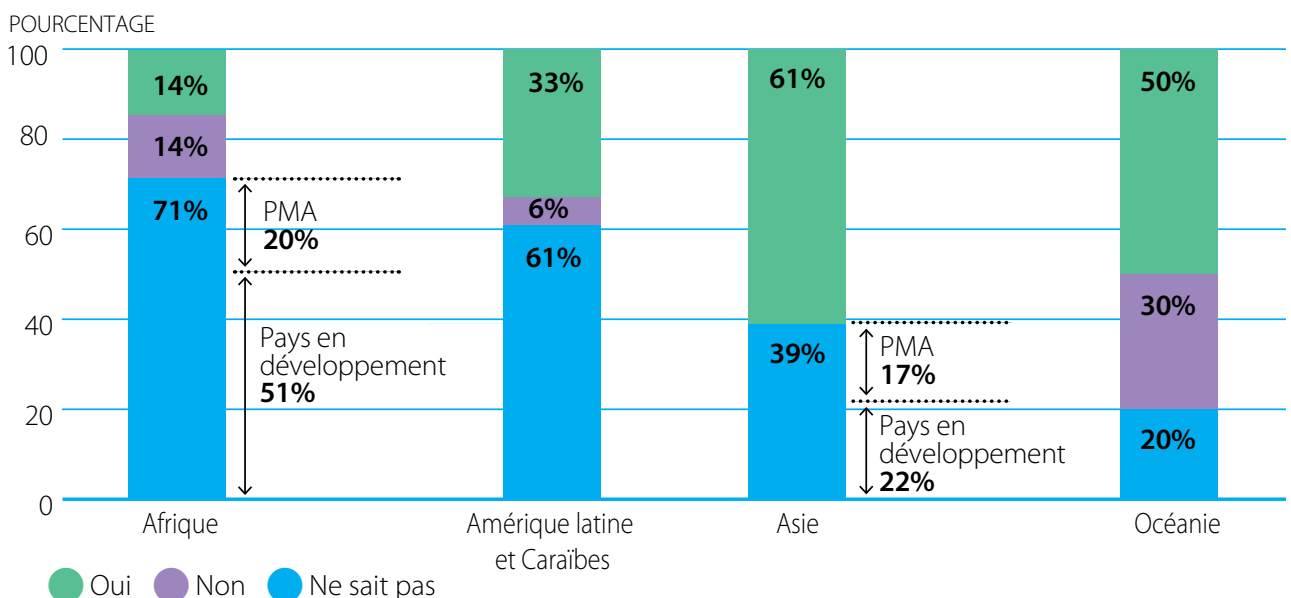

Source: Exercice de suivi de l'Aide pour le commerce OCDE-OMC (2019).

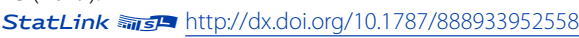

Neuf répondants asiatiques ont répondu par l'affirmative en ce qui concernait la diversification économique. Parmi eux, le Kazakhstan a souligné que la croissance de son commerce extérieur s'était multipliée par 12 et sa production industrielle par 20. La République démocratique populaire lao a rappelé que ses progrès étaient suivis dans le cadre d'un processus de sortie de la catégorie des PMA. Les répondants asiatiques ont été les plus nombreux à cocher la case "Ne sait pas". Il y avait aussi des divergences avec les réponses de la région du Pacifique.

Parmi les répondants du Pacifique, le nombre de "Ne sait pas" et de "Non" à la question de la diversification économique dépassait celui des "Oui", cochés par Kiribati et le Vanuatu. Dans leurs réponses, les Palaos, le Samoa et les Tonga ont indiqué qu'ils n'étaient pas parvenus à diversifier leur économie. Les autorités nationales des Tonga ont indiqué qu'un manque de technologie et de savoir-faire et le coût élevé des pièces détachées avaient grandement entravé leur capacité de diversifier leur économie.

Les réponses des pays du Pacifique reflètent une tendance plus générale parmi les PEID. La part de répondants relevant de la catégorie des PEID qui n'ont fait état d'aucun progrès en matière de diversification économique (17\%) était un peu plus de deux fois supérieure à la part de répondants ne faisant pas partie de cette catégorie (8\%). Cela étant, dix répondants des PEID ont indiqué avoir réalisé des progrès (42\%). Plus de la moitié des répondants formant partie de la catégorie des PDSL ont indiqué avoir progressé en matière de diversification économique. Treize répondants ont répondu par l'affirmative à l'auto-évaluation. Les trois répondants PDSL qui n'ont pas fait état de progrès sont le Burundi, la République centrafricaine et l'Éthiopie.

Dans la région de l'Amérique latine et des Caraïbes, onze répondants (61\%) ont fait état de progrès en matière de diversification économique depuis 2006. On peut citer à titre d'exemple le Paraguay qui, au cours des quatre dernières années, a connu une avancée importante dans le secteur industriel, lequel a accru sa contribution à la croissance de l'économie paraguayenne. Selon la Banque centrale du Paraguay, l'industrie manufacturière a clôturé l'année 2017 en hausse de 9,4\%. Pendant la période 2013-2017, en tout 104 industries d'exportation relevant du régime de production sous douane (maquila) ont été installées, soit une augmentation de 259\% par rapport à la précédente période de 5 ans. Un total de 9310 nouveaux emplois a été créé dans ce secteur, soit 156\% de plus que pendant la précédente période de 5 ans. 


\section{Figure 1.4. Évolution à long terme de la diversification des exportations et de la valeur des exportations mondiales}

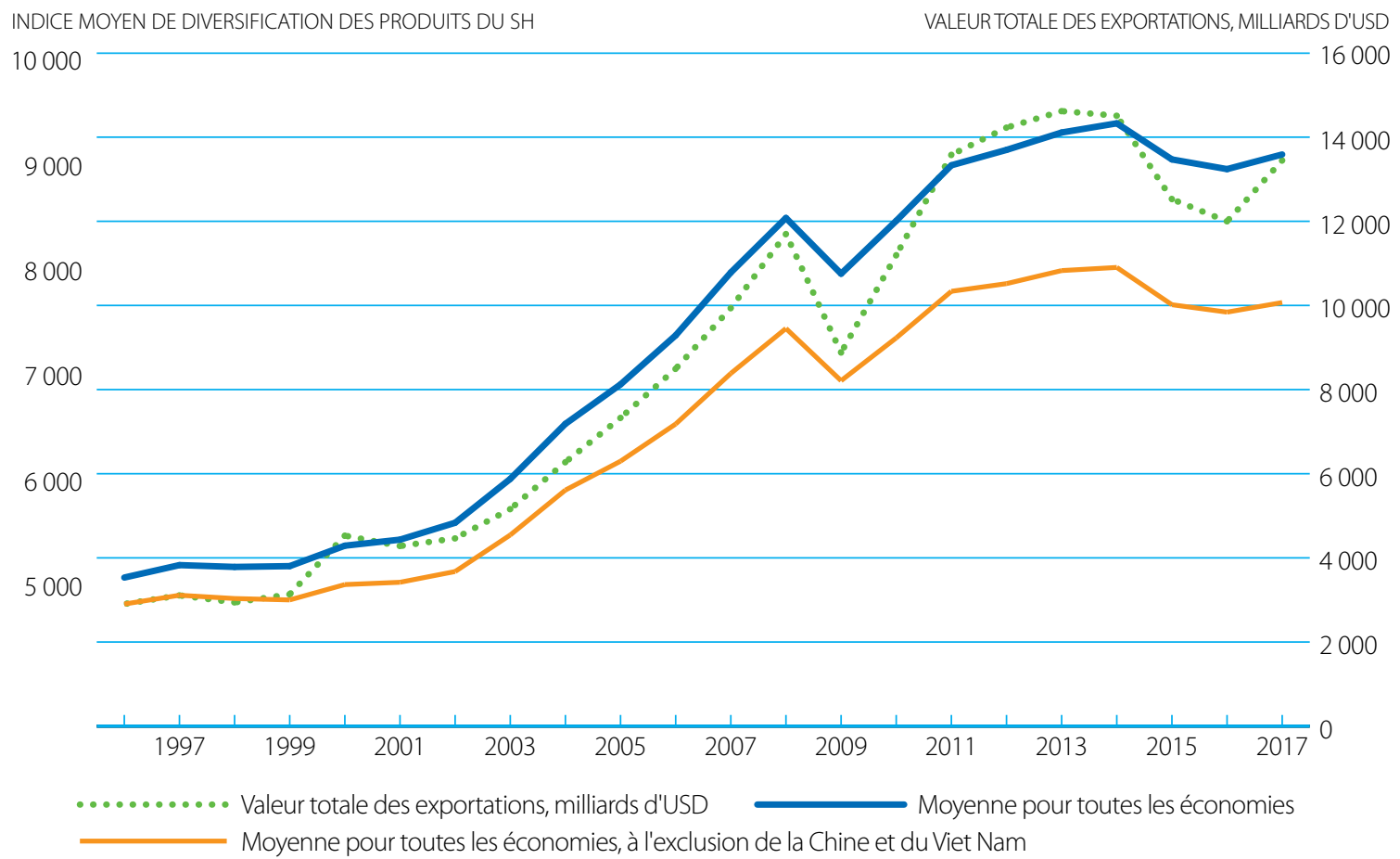

Source: Calcul du Secrétariat de I'OMC, sur la base de la BDI de l'OMC et de la base de données Comtrade de I'ONU.

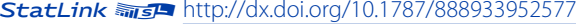

Dans l'ensemble, ces réponses s'accordent avec les tendances qui ressortent des statistiques commerciales sur la diversification des exportations. La figure 1.4 montre la tendance en matière de diversification des exportations de marchandises pour 157 pays au cours de la période 1996-2017, ainsi que la valeur totale des exportations annuelles au cours de la même période. ${ }^{6}$ Globalement, on observe une augmentation de la diversification dans le temps, associée à une expansion du commerce.

Une nette augmentation se produit après 2001, parallèlement à la croissance de la valeur des exportations, entrainée par les économies asiatiques, notamment la Chine. Cette tendance à la hausse s'est poursuivie jusqu'au début de la récession économique de 2008-2009. La chute des exportations qui a suivi a affecté le volume global des exportations mais elle a aussi conduit à une chute de la diversification des exportations.

Les figures 1.5 à 1.9 ci-incluses mettent en évidence des tendances analogues par revenu, région et certaines catégories de I'ONU, par exemple les pays sans littoral, les PEID et les PMA. Elles montrent le même effondrement d'après-crise financière.

D'après les participants, l'agriculture est le secteur dans lequel la diversification économique a le plus progressé, devant les services et l'industrie. Trente-quatre (34) des quatre-vingt-huit (88) répondants ont fait état de progrès dans l'agriculture, 29 dans les services et 28 dans l'industrie. Les PMA ont indiqué que l'agriculture était le secteur dans lequel la diversification économique avait le plus progressé. Au sein de ce groupe, ce sont les PMA africains qui font état de la plupart des progrès en matière de diversification économique du secteur agricole. La figure 1.10 ci-dessous met en avant la répartition sectorielle entre les différentes régions. Le secteur dans lequel la diversification économique a le plus progressé est l'agriculture en Afrique et les services dans la région de l'Amérique latine et des Caraïbes. Pour les répondants, principalement du groupe des PMA, qui ont signalé des progrès au niveau sectoriel en Asie, les secteurs dans lesquels la diversification économique a le plus progressé sont l'agriculture et l'industrie. 
Figures 1.5 à 1.7. Diversification des produits, par sous-régions

\section{ASIE}

INDICE MOYEN DE DIVERSIFICATION DES PRODUITS DU SH

120000

100000

80000

60000

40000

20000$$
\text { (1) }
$$

0

$20012003 \quad 2005 \quad 2007 \quad 20092011 \quad 2013 \quad 2015 \quad 2017$

Asie de l'Est — Asie du Sud-Est

Asie du Sud ........ Asie occidentale

Asie Centrale
AFRIQUE

INDICE MOYEN DE DIVERSIFICATION DES PRODUITS DU SH 5000

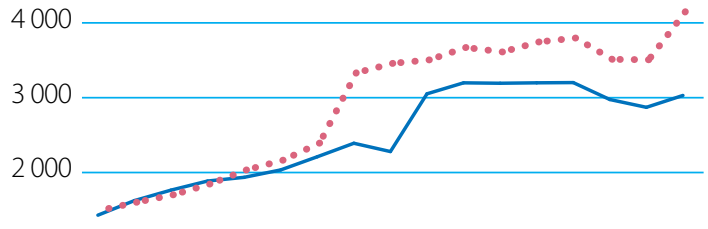

1000

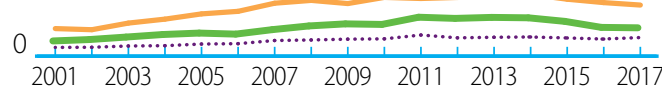

Afrique du Nord ........ Afrique australe

Afrique de l'Est

Afrique centrale

Afrique de l'Ouest

PAYS EN DÉVELOPPEMENT

INDICE MOYEN DE DIVERSIFICATION DES PRODUITS DU SH

15000

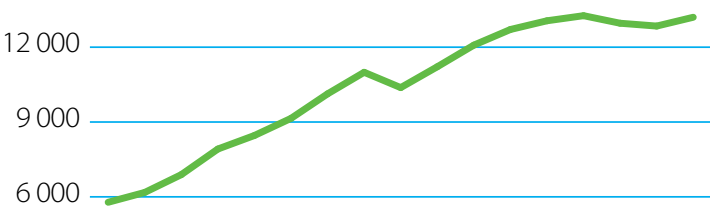

3000

$0 \begin{array}{llllllllll}2001 & 2003 & 2005 & 2007 & 2009 & 2011 & 2013 & 2015 & 2017\end{array}$

Autres pays en développement $\longrightarrow$ PEID

PDSL

PMA

Source: Calcul du Secrétariat de l'OMC, sur la base de la BDI de l'OMC et de la base de données Comtrade de l'ONU.

\section{Figures 1.8 à 1.9. Diversification des produits, par groupes de revenu et par régions}

\section{GROUPE DE REVENU}

INDICE MOYEN DE DIVERSIFICATION DES PRODUITS DU SH 30000

25000

20000

15000

10000

5000

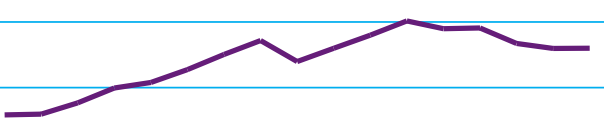

0

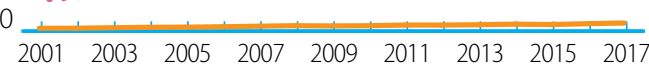

Revenu élevé

Revenu intermédiaire de la tranche supérieure

Revenu intermédiaire de la tranche inférieure .......

PMA

Source: Calcul du Secrétariat de l'OMC, sur la base de la BDI de l'OMC et de la base de données Comtrade de l'ONU. 
Figure 1.10. Diversification économique au niveau sectoriel, par régions

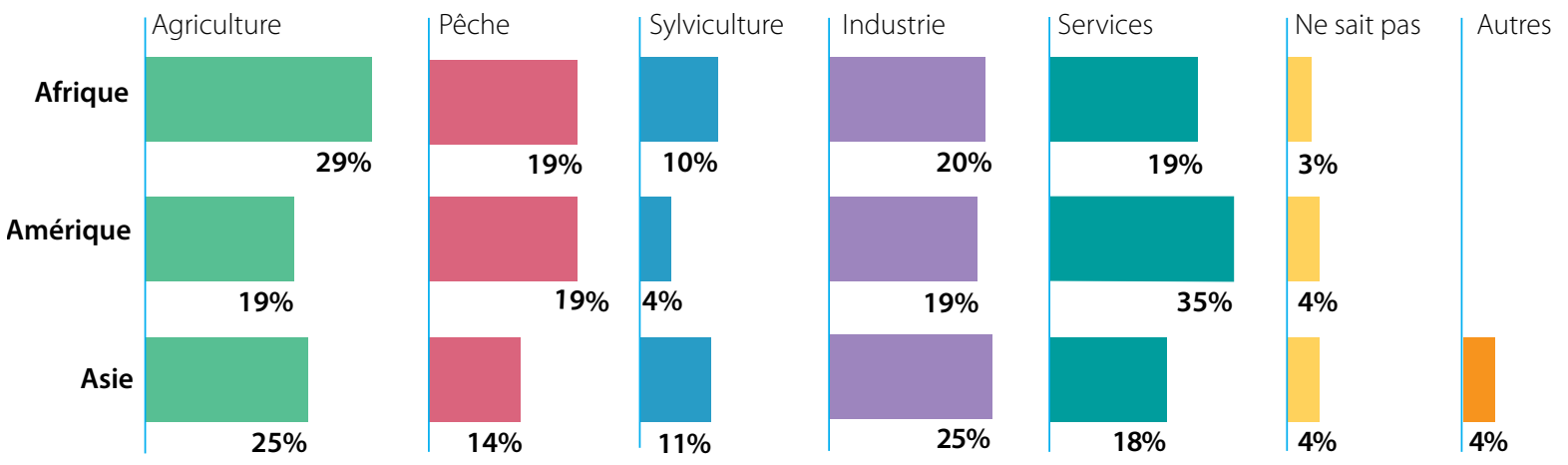

Source: Exercice de suivi de l'Aide pour le commerce OCDE-OMC (2019).

StatLink 司Ist $\mathrm{http}: / / \mathrm{dx}$.doi.org/10.1787/888933952596

De nouveau, ces résultats s'accordent dans l'ensemble avec les tendances qui ressortent des statistiques commerciales. Depuis 2000, I'Afrique a enregistré le plus fort taux de croissance (70\%) de toutes les régions pour ce qui est du nombre de catégories de produits agricoles exportées, puisqu'elle est passée de 54 à 92 catégories du SH exportées dans ce secteur entre 2000 et 2017.

\section{Figure 1.11. Diversification des exportations de produits agricoles, par régions}

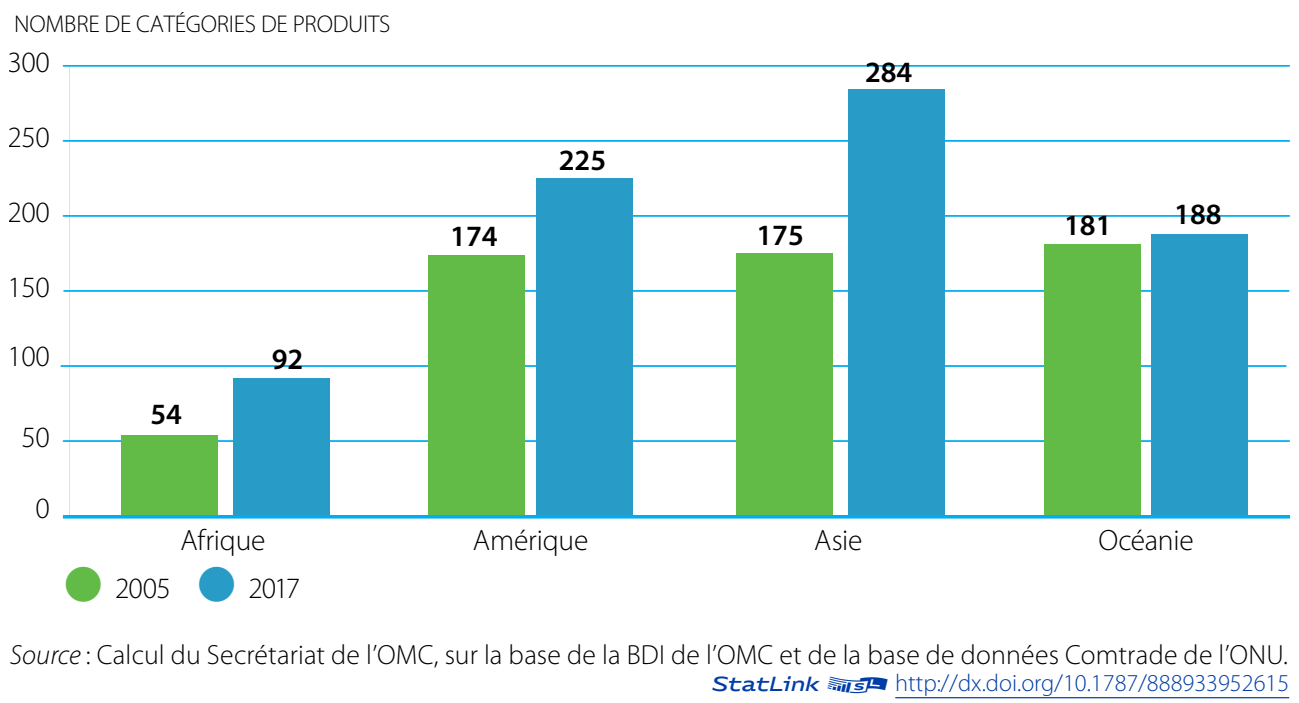

Parmi les répondants de la région d'Amérique latine et des Caraïbes, le Honduras a présenté son plan stratégique national qui favorise la diversification et la croissance de l'emploi dans le secteur de l'assemblage léger et des services, en particulier les centres d'appel et les centres de soutien administratif. Le Pérou a indiqué que les exportations de services se sont multipliées par 2,75 depuis 2006.

Les répondants asiatiques sont ceux qui ont le plus valorisé la diversification des exportations industrielles. Au vu des progrès considérables réalisés par des économies telles que le Cambodge, le Bangladesh et le Myanmar en matière de diversification, ces résultats ne sont peut-être pas surprenants. En ce qui concerne les statistiques commerciales, le taux de diversification des exportations industrielles africaines était plus élevé, mais partait d'une base de départ bien plus basse. 
Figure 1.12. Diversification des exportations de produits industriels, par régions

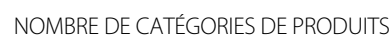

$1200 \longrightarrow 1128$

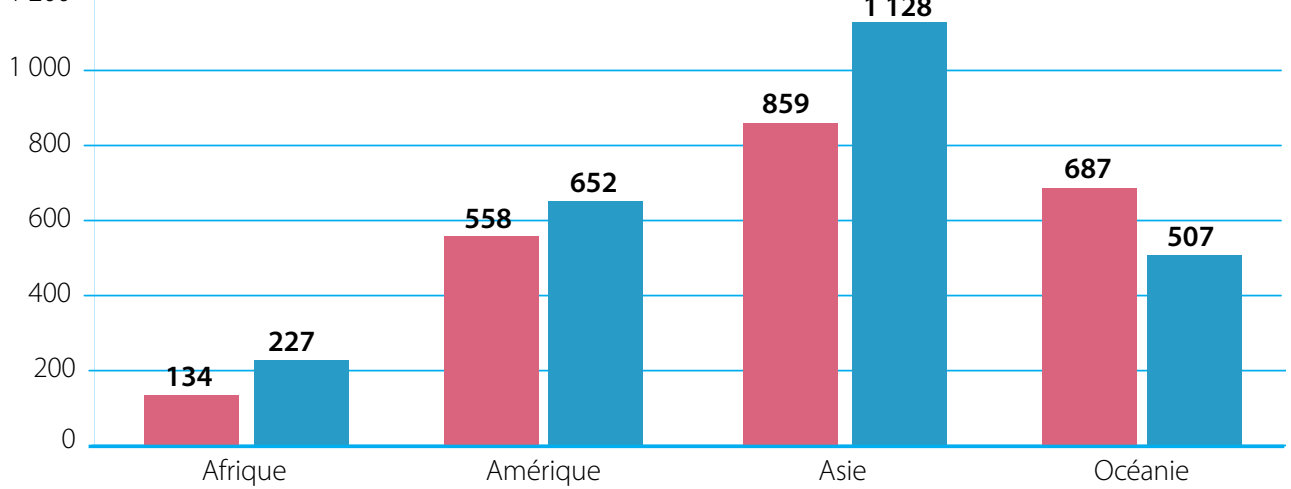

$2005 \bigcirc 2017$

Source: Calcul du Secrétariat de I'OMC, sur la base de la BDI de l'OMC et de la base de données Comtrade de I'ONU.

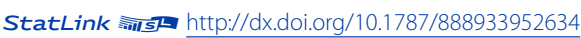

En Afrique, le nombre de catégories de produits industriels exportés a augmenté de 70\%, passant de 133,5 en 2000 à 226,5 en 2017. De toutes les régions, c'est l'Afrique qui enregistre le plus fort taux de croissance dans la diversification des exportations de produits industriels, devant l'Asie (31\%) et l'Amérique (17\%).

Par ailleurs, cette diversification diffère selon les régions; l'Afrique du Nord est en tête, en termes de niveau de diversification de produits, mais aussi de taux de croissance, puisqu'elle est parvenue à exporter plus de 4000 catégories de produits en 2017. L'Afrique australe se place en deuxième position pour ce qui est de la diversification des produits d'exportation, ses exportations ayant couvert plus de 3000 codes du SH. En revanche, les exportations d'Afrique centrale, d'Afrique orientale et d'Afrique de l'Ouest n'ont pas couvert plus de 700 catégories de produits cette même année.

\section{Entraves à la diversification économique et à la diversification des exportations}

Sur 88 répondants, 67 (soit 76\%) ont indiqué qu'une capacité industrielle ou manufacturière limitée était le principal obstacle à la diversification économique. De même, trente-sept (37) des trente-huit (38) répondants des PMA (97\%) ont indiqué que leur capacité industrielle ou manufacturière limitée était le principal obstacle à leur diversification économique. La figure 1.13 ci-après contient la liste des principaux obstacles à la diversification économique des pays partenaires, y compris ceux qui appartiennent aux catégories des PEID, des PDSL et des PMA.

Les coûts élevés du commerce figurent parmi les 3 obstacles les plus importants à la diversification économique, et sont cités par 14 des 22 répondants (64\%). Dans la catégorie des PEID, la taille du marché intérieur apparaît comme l'obstacle le plus important, comme l'ont indiqué 19 des 25 répondants. Maurice, par exemple, a cité son éloignement des principaux marchés, ainsi que ses ressources naturelles limitées, comme un obstacle à la diversification de son économie. L'encadré 1.2 ci-après expose certains des facteurs cités par les répondants dans leur réponse sur les facteurs entravant la diversification économique. 
Figure 1.13. Principaux obstacles à la diversification économique des pays partenaires

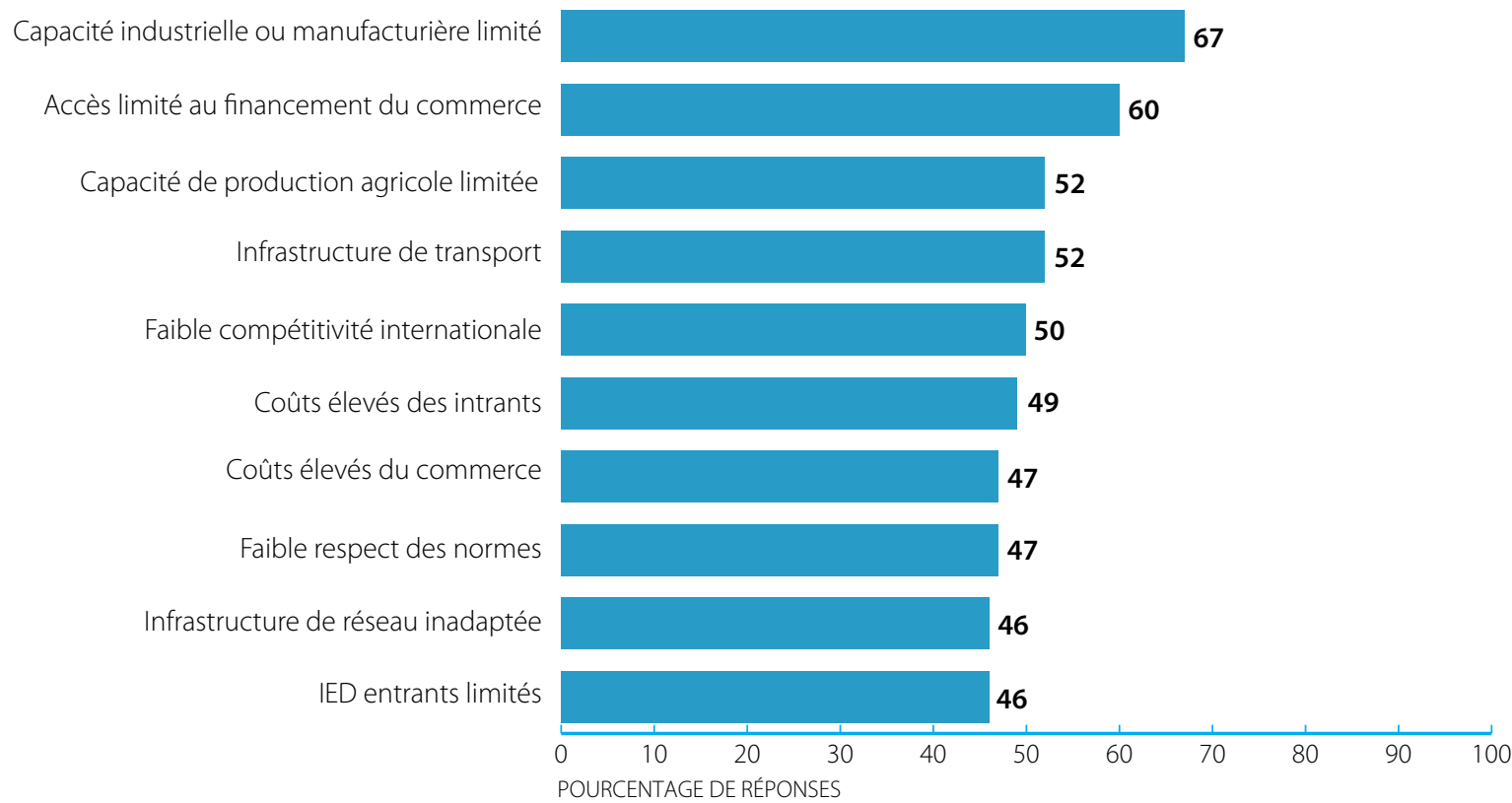

Source: Exercice de suivi de l'Aide pour le commerce OCDE-OMC (2019).

\section{Figure 1.14. Principales entraves à la diversification économique des PDSL, PMA et PEID interrogés}

PSDL

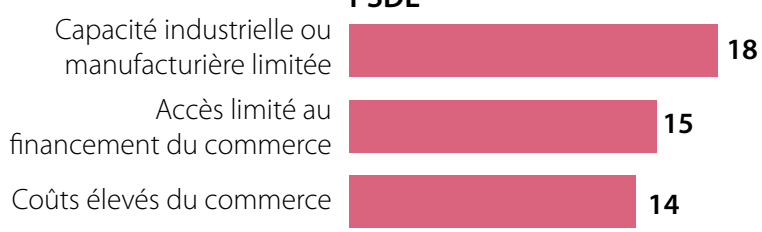

\section{PMA}

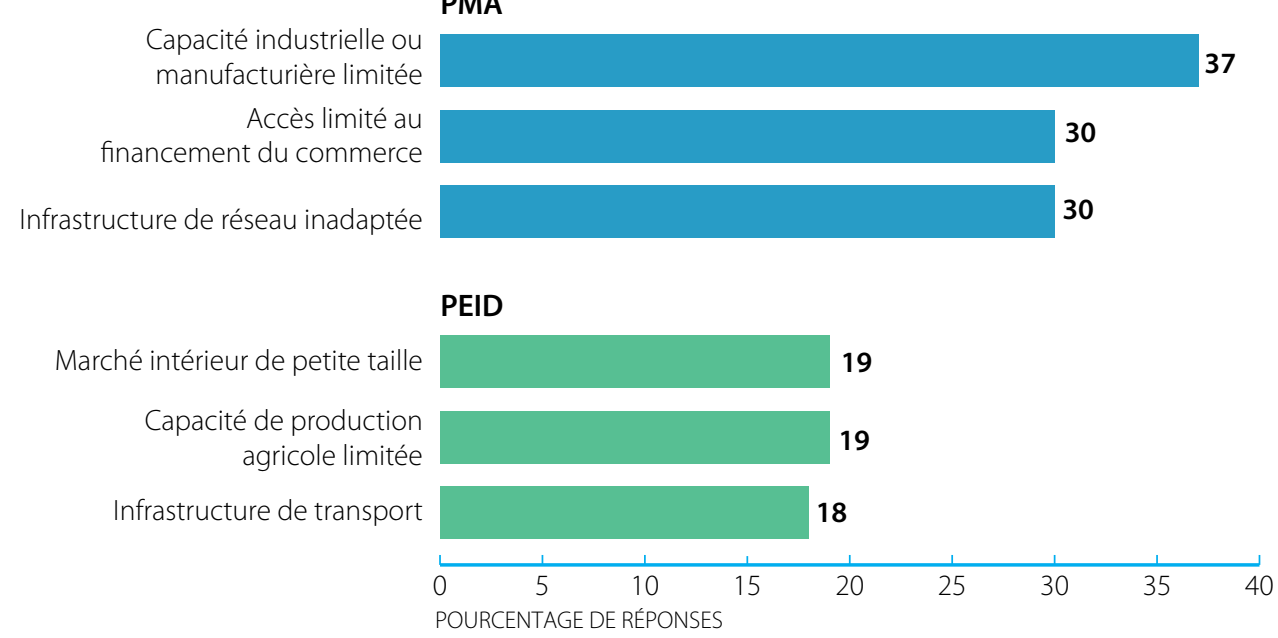

Source: Exercice de suivi de l'Aide pour le commerce OCDE-OMC (2019). 
Figure 1.15. Principaux obstacles à la diversification économique, par régions

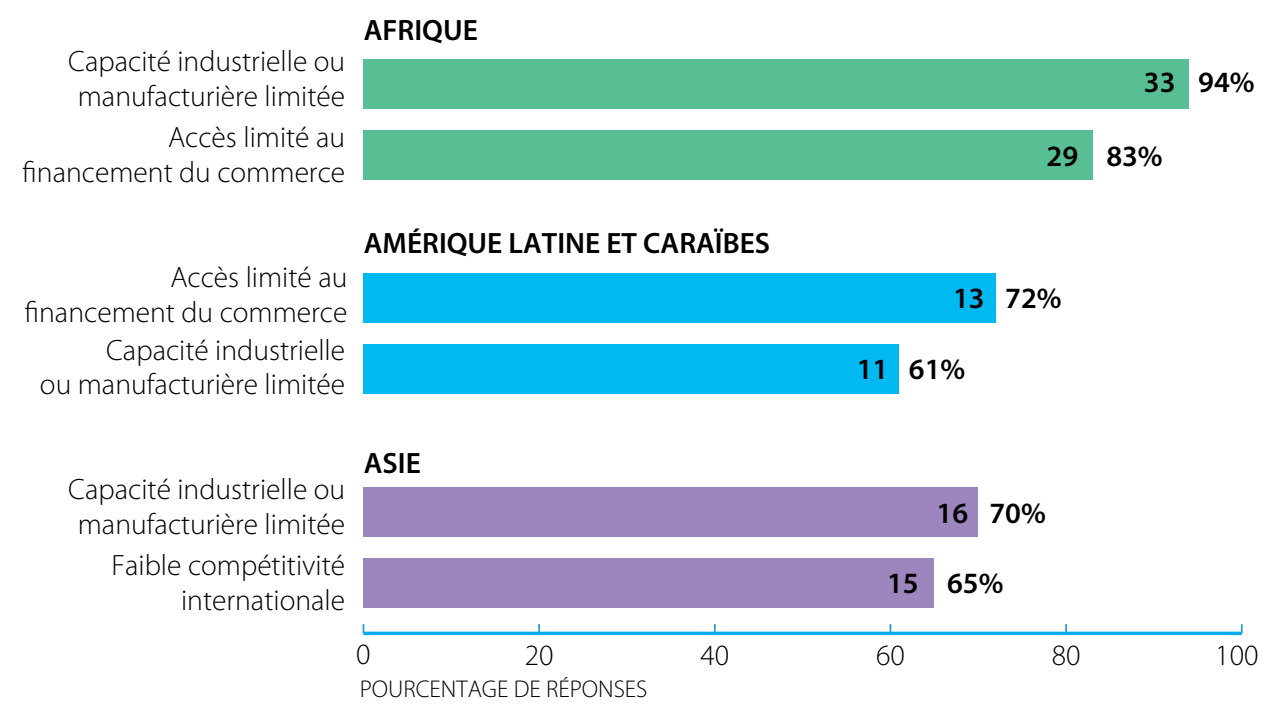

Source : Exercice de suivi de l'Aide pour le commerce OCDE-OMC (2019).

II ressort clairement de l'exercice de suivi de cette année que l'accès au financement du commerce est considéré comme une contrainte. L'accès au financement du commerce a été cité comme un obstacle par 60 des 88 répondants (68\%) du questionnaire destiné aux pays partenaires. Dans ses observations formulées dans le cadre du questionnaire d'auto-évaluation, Antigua-et-Barbuda a indiqué que l'accès au financement du commerce est devenu une priorité majeure compte tenu de l'impact du phénomène de réduction des risques qui a fait que de nombreuses banques locales des Caraïbes ont perdu des relations de correspondants bancaires. L'auteur a souligné que l'impact économique serait critique si la tendance continuait de peser sur le secteur financier de la région, compromettant leur capacité à participer au commerce international.

Les répondants d'Asie et d'Afrique ont indiqué que le principal obstacle qu'ils rencontraient était leur capacité industrielle ou manufacturière limitée. II est intéressant de constater que l'accès limité au financement du commerce est le principal obstacle dans la région Amérique latine et Caraïbes et le deuxième en Asie. En Asie, les répondants des PMA et d'autres pays en développement placent la capacité industrielle ou manufacturière limitée en première position. La figure 1.15 ci-dessus indique les principaux obstacles à la diversification économique, par régions.

Immédiatement après les dix principaux obstacles à la diversification économique cités par les répondants figurent les difficultés liées à la connectivité numérique et au commerce électronique. Quarante-quatre (44) des quatre-vingthuit (88) répondants (50\%) ont indiqué que l'un des principaux obstacles à la diversification économique était le fait qu'ils n'étaient pas armés pour participer au commerce électronique. Dans les observations, un lien a aussi été établi avec le développement des infrastructures de réseau. Par exemple, le Mali a souligné qu'il fallait accroître l'accès à l'électricité à moindre coût, promouvoir l'utilisation des TIC pour tous les secteurs et acteurs et étendre le réseau Internet et le réseau de téléphonie. Vingt-sept répondants, pour la plupart des PMA, ont indiqué que l'un des freins à la diversification économique était le manque d'accès abordable et fiable à l'électricité nécessaire à la connectivité numérique. 
Encadré 1.2. Quels sont les facteurs qui entravent la diversification économique?

Les infrastructures de réseau font cruellement défaut en République centrafricaine. Le taux d'accès à l'électricité est de 3\% seulement, et il est de ce fait compliqué de créer ou de gérer une entreprise, en particulier compte tenu de l'absence de littoral dans notre pays - République centrafricaine

Le manque d'infrastructure d'appui, le caractère limité de la connectivité et la pénurie d'approvisionnement énergétique sont d'importants freins à la diversification économique - République démocratique du Congo

Le niveau insuffisant de technicité et d'innovation pèse sur la diversification. En outre, les obstacles techniques au commerce et l'inadaptation de l'infrastructure font augmenter les coûts des exportations - Géorgie

Le manque d'infrastructures de base - eau, électricité et télécommunications -, conjugué à l'insuffisance de l'IED dans les secteurs productifs, a limité la capacité de diversification - Guinée

On dénombre parmi les difficultés dans le domaine du commerce électronique le faible niveau de sécurité des données, les capacités et infrastructures insuffisantes de recouvrement des recettes, la cybercriminalité, le coût élevé de la connexion à Internet, la mauvaise couverture réseau en particulier en zones rurales et les difficultés financières de mise en œuvre des initiatives de commerce électronique - Kenya

Le faible niveau de création de recettes internes découlant de la chute des prix des principales exportations, auquel s'ajoutent un manque d'infrastructure et des disparités sur le plan des capacités humaines et de la logistique - Libéria

En termes de diversification des exportations, nos infrastructures de développement de produits, de respect des normes et d'assurance de qualité sont limitées - Lesotho

Le manque d'infrastructures, de capacité de stockage et de moyens de transport, ainsi que la fourniture insuffisante d'énergie constituent des obstacles considérables à la diversification économique - Madagascar

La géographie accidentée du pays rend l'accès aux biens et services et aux marchés difficile, ce qui est problématique. L'environnement des activités économiques, favorisant notamment la création d'infrastructures de réseau et de transport, a limité la capacité de la population de s'essayer à d'autres domaines de développement - Papouasie-Nouvelle-Guinée

Au Sénégal, la faiblesse des secteurs de services essentiels, tels que les services de télécommunication et les services financiers, et l'accès limité aux facteurs de production et à des intrants de qualité sont devenus des obstacles déterminants à la promotion de la diversification économique. Ce phénomène est aggravé par une mauvaise dynamique du secteur privé, des retards dans la mise en œuvre des réformes dans le secteur de l'énergie et un faible niveau de productivité, ce qui continue à entraver les mesures prises pour diversifier l'économie - Sénégal

Le faible niveau de connaissances et l'accès limité à la technologie et aux ressources financières ont fait obstacle à la capacité du pays de se moderniser - Soudan

Dans notre pays, la part de l'industrie dans le PIB diminue faute de politique industrielle nationale et en raison de la faible rentabilité de la transformation des matières premières, des activités à faible valeur ajoutée et de la pénurie de travailleurs qualifiés - Tadjikistan

Des compétences et des capacités insuffisantes pour utiliser les vastes ressources naturelles du pays dans les secteurs de la sylviculture, de l'agriculture, des minéraux et de la pêche ont entraîné une faible diversification - Tanzanie

Les principaux obstacles à la diversification des exportations sont notamment l'insuffisance des infrastructures et le manque de compétences - Ouganda

Malgré un important potentiel de croissance des exportations, notre compétitivité est toujours entravée par la faible productivité, la concentration des marchés et des produits, un accès financier limité, une infrastructure matérielle qui se dégrade et la complexité des règlements et des procédures douanières - Ukraine

Source: OCDE-OMC Exercice de suivi de l'Aide pour le commerce (2019). 


\section{AUTONOMISATION ÉCONOMIQUE}

L'exercice de suivi de l'Aide pour le commerce de 2019 montre comment l'autonomisation économique est intégrée dans les cadres politiques nationaux et régionaux. Sur quatre-vingt-huit (88) pays partenaires ayant répondu, soixantedix-neuf (79) (soit 90\%) ont indiqué que la diversification économique était une priorité dans les stratégies de développement nationale ou régionale. Cette part est supérieure parmi les PMA (95\%) et les PDSL répondants (96\%), qui ont déclaré que l'autonomisation économique était une priorité.

L'Afrique enregistre le plus fort taux de répondants - 94\%, soit trente-trois (33) répondants sur trente-cinq (35) - qui ont confirmé que l'autonomisation économique était une priorité dans leur stratégie de développement nationale et régionale. Vingt-cinq (25) de ces répondants sont des PMA.

Les réponses au questionnaire font apparaître la variété d'approches adoptées pour intégrer l'autonomisation économique aux stratégies nationale et régionale. Le Plan national de développement du Togo a pour objectif de parvenir à l'autonomisation économique par l'inclusion financière. Une approche analogue est adoptée au Soudan et aux Maldives. En parallèle, la Zambie et le Bénin axent leur stratégie d'autonomisation économique sur le développement du capital humain et les compétences. Dans certains cas, les stratégies nationales de développement relient aussi l'autonomisation économique à un objectif de développement plus vaste. Par exemple, la République centrafricaine considère l'autonomisation économique comme un moyen de promouvoir une reprise commerciale et économique inclusive.

Nombre de répondants ont souligné l'importance de la diversification économique pour ouvrir la voie à l'autonomisation économique. Dans sa réponse, la République démocratique du Congo a indiqué que sa stratégie nationale de développement privilégiait "l'accès à de grands marchés et aux partenariats entre les différents acteurs du commerce régional, ce qui augmentera la richesse des acteurs vulnérables du commerce, y compris les femmes et les jeunes". Le Népal a aussi insisté sur l'idée que l'intégration de ses "produits dans les chaînes de valeur mondiales et la promotion des compétences des MPME dans les domaines du commerce et de l'entrepreneuriat étaient importantes" pour l'autonomisation.

Le plan national du Sénégal met l'emploi des jeunes et des femmes au cœur de sa stratégie de développement, et les projets sont exécutés en vue de promouvoir les activités à valeur ajoutée dans les domaines de l'agriculture, de la pêche, de l'élevage, de l'extraction, des plates-formes industrielles et logistiques, des services d'exportation "prêts à l'emploi", du tourisme et de l'artisanat. Dans sa réponse, Kiribati indique qu'elle considère que "l'automatisation économique est un catalyseur du commerce international dans la mesure où elle contribue au développement des chaînes de valeur nationales et mondiales".

Le lien étroit entre l'autonomisation économique, la diversification économique et la diversification des exportations trouve un écho dans la stratégie nationale de développement du Pérou, qui a pour objectif de parvenir à une productivité plus élevée en privilégiant des produits d'exportation compétitifs à forte valeur ajoutée, en appuyant les MPME dans les consortiums d'exportation, en favorisant les alliances public-privé en vue d'augmenter les investissements dans les infrastructures commerciales et en multipliant les emplois qui facilitent la modernisation inclusive. Le Pérou a également indiqué que "dans le but d'avoir une économie compétitive caractérisée par le plein emploi, les priorités étaient aussi axées sur l'amélioration de l'accès aux marchés du travail pour les femmes, les jeunes, les personnes âgées et les personnes handicapées".

Il est notamment ressorti de ces observations que la relation entre la diversification et l'autonomisation fonctionne aussi dans l'autre sens. Certains répondants sont d'avis que l'autonomisation contribue aussi activement à la diversification économique. Cette opinion est reprise dans une observation formulée par Cabo Verde, selon laquelle "l'autonomisation économique passe par l'amélioration des connaissances des TIC et du numérique, du savoir commercial, 
des compétences linguistiques et des infrastructures d'approvisionnement en eau". De la même façon, le Nigéria a fait valoir que "I'autonomisation économique nécessite de renforcer le cadre politique, de créer un environnement propice au commerce et d'améliorer l'infrastructure des TIC."

Dans sa réponse, le Togo a formulé l'une des observations les plus positives sur la mesure dans laquelle l'autonomisation peut contribuer à la diversification. La stratégie nationale de développement vise à "renforcer les capacités des femmes et des jeunes à mieux participer aux chaînes de valeur nationales, régionales et internationales". Les Philippines considèrent aussi que l'autonomisation et la réduction des inégalités favorisent la contribution des groupes marginalisés aux progrès économiques. La Zambie a aussi mis en avant que "les femmes, les MPME et les jeunes participent activement aux activités économiques susceptibles d'avoir des répercussions positives, telles que la génération de revenus, la création d'emplois et l'amélioration des moyens d'existence". Toutefois, ils constituent aussi "précisément le groupe qui se heurte à des obstacles du côté de l'offre et du côté de la demande".

La résolution des difficultés en matière d'autonomisation pourrait ouvrir de nouvelles possibilités commerciales. Le Vanuatu a souligné que "le potentiel de production d'huile de coco vierge, laquelle permettra en particulier aux femmes et aux MPME de participer à des activités à plus forte valeur ajoutée, est mal coordonné et, de manière générale, négligé". La levée de ces obstacles pourrait contribuer à faire augmenter les exportations d'un produit pour lequel la demande est forte dans le monde entier.

Soixante (60) des quatre-vingt-huit (88) répondants (68\%) ont indiqué que leur stratégie nationale ou régionale de développement prévoyait des indicateurs de suivi des progrès en matière d'autonomisation économique. Cette part est plus élevée chez les répondants qui sont des PMA (79\%). Parmi les régions, c'est l'Afrique qui enregistre le chiffre le plus élevé, puisque 25 des 35 (71\%) répondants de la région confirment qu'ils disposent d'un indicateur ou d'une cible consacré à l'autonomisation économique.

Les indicateurs utilisés pour mesurer l'autonomisation varient en envergure et en complexité. Parmi les indicateurs simples mentionnés par les répondants figurent ceux utilisés par la République centrafricaine concernant le nombre de femmes ou de jeunes ayant bénéficié d'activités de renforcement des capacités. Le Burkina Faso a évoqué des indicateurs comparables, qui évaluent le nombre de personnes diplômées ayant appris des techniques de recherche d'emploi. Ils contiennent même un système de mesure du nombre d'emplois créés, utilisé par plusieurs répondants.

Plusieurs répondants ont fait état de cibles liées à l'emploi, en particulier des jeunes et des femmes. Le plan national de développement de la Gambie contient des cibles visant à faire reculer le chômage des jeunes de 38\% à 30\% à l'horizon 2021. Le Togo s'est fixé comme objectif de réduire le taux de chômage des jeunes de 3,2\% en 2015 à 2,5\% en 2022. Le Mexique utilise le taux de participation des femmes au marché du travail comme un indicateur. II s'est fixé un objectif de 48\% en 2018, ainsi que d'autres objectifs, tels que la réduction de 75\% de la part des femmes employées sans accès à des services de garderie et l'abaissement de l'indice de discrimination salariale par secteur d'au moins 20\%. Les Philippines évaluent d'autres critères, outre la participation de la main-d'œuvre féminine, tels que le pourcentage de femmes titulaires de diplômes d'études supérieures sur le marché du travail. Plusieurs répondants ont évoqué des notions telles que le travail décent (Tonga) et l'emploi approprié (Pérou).

L'accès au crédit est un paramètre mesuré par plusieurs répondants, à la fois comme indicateur de l'autonomisation économique des femmes et comme indicateur applicable aux MPME. Le Togo s'est fixé comme objectif de "faire passer le nombre de femmes ayant accès au crédit de 44,4\% en 2015 à 60\% en 2022". La Papouasie-Nouvelle-Guinée mesure le nombre de femmes ayant un compte de crédit dans le cadre d'un ensemble plus large d'indicateurs qui comprend aussi l'emploi des jeunes, la participation des femmes aux PME, la part des MPME ayant accès à des crédits financiers et le nombre de MPME enregistrées. Les matrices des résultats du plan de développement des Philippines pour 2017-2022 mesurent la part des petites entreprises dans la valeur ajoutée industrielle totale, le nombre de MPME et la part du portefeuille de crédit bancaire allouée aux MPME, entre autres indicateurs. L'accès des femmes chefs d'entreprise au crédit est aussi cité par l'Iraq et Madagascar comme un problème à régler. 
En ce qui concerne l'utilisation de l'autonomisation économique, le Pérou appelle l'attention sur le manque de renseignements complémentaires et d'indicateurs, par exemple sur le nombre d'entreprises dirigées par des femmes et d'entreprises exportatrices, et sur la capacité de nombre de bureaux de la statistique de réunir les données correspondantes et de les suivre au fil du temps.

La suite de la présente section s'articule autour d'observations particulières formulées par des répondants sur l'autonomisation en ce qui concerne les jeunes, les femmes et les MPME.

\section{Encadré 1.3. L'autonomisation économique comme priorité}

L'autonomisation économique constitue l'un des axes principaux du troisième volet du Plan national de relèvement et de consolidation de la paix en vue de promouvoir le commerce inclusif et la reprise économique -

\section{République centrafricaine}

La Loi pour la promotion, la protection et l'essor des micro et petites entreprises dispose que les alliances stratégiques entre les MPME et la population salvadorienne résidant à l'étranger seront promues, dans le but de créer un système d'intermédiation et de stimuler les investissements qui favorisent la participation des entreprises aux marchés internationaux - El Salvador

L'appui à l'autonomisation économique des femmes, un développement équilibré et la création d'emploi font partie des critères qui permettent de définir les produits prioritaires présentant un potentiel d'exportation dans le cadre de l'exécution de la stratégie d'intégration commerciale 2016 du Népal - Népal

La plupart des MPME peinent à recevoir un appui financier de la part des banques et d'autres institutions financières. En outre, elles n'ont souvent pas la capacité de développer leur activité commerciale - Papouasie-Nouvelle-Guinée

Le secteur privé du Samoa est constitué principalement de MPME. Partant, les interventions visant à appuyer la diversification et l'autonomisation économiques devraient porter essentiellement sur l'autonomisation des MPME. Les modèles fondés sur la subsistance ou la communauté sont délaissés au profit de la création de start-ups et les microentreprises cèdent la place aux petites entités et à l'expansion des MPME dans le cadre de la diversification des exportations - Samoa

Les PME représentent 99,8\% de l'économie, preuve de l'importance qu'il convient de leur accorder. Le Sénégal a mis sur pied plusieurs programmes destinés à la jeunesse (ANPEJ, PAPEJF, ONFP, etc.). Toutefois, le dialogue et la coordination des mesures font défaut à certaines étapes, telles que l'orientation, l'intégration par l'emploi, le financement des chefs de projet, la formation et l'intégration par l'emploi indépendant - Sénégal

Dans notre pays, le programme met l'accent sur le crédit à petite échelle pour appuyer les femmes et les jeunes, de façon à encourager leur participation au processus de production - Soudan

Parmi les priorités figurent le développement de mécanismes institutionnels visant à incorporer les engagements nationaux et internationaux concernant l'égalité hommes-femmes et l'autonomisation des femmes dans les politiques sectorielles. En vue de promouvoir la création d'emplois productifs, une place prioritaire est aussi faite à l'appui aux PME, y compris pour les jeunes et les femmes, en particulier dans les industries de pointe innovantes - Tadjikistan

Notre stratégie tient compte de la problématique du genre et vise à accroître la participation des femmes aux secteurs productif et manufacturier. Elle fait aussi une large place aux activités de sensibilisation pour que les femmes et les groupes marginalisés aient accès à la finance pour stimuler leur participation au commerce régional et international - Ouganda

La politique de développement des micro, petites et moyennes entreprises dispose que le gouvernement, par l'intermédiaire d'organismes spécialisés et en collaboration avec les parties prenantes, facilitera l'accès des PME aux marchés locaux et internationaux - Zambie

Davantage de mesures devraient être prises pour garantir l'accès préférentiel des femmes à la finance, à l'appui commercial, aux renseignements commerciaux et aux locaux professionnels dans des bâtiments industriels. L'accent sera également mis sur la participation des femmes à des salons locaux, régionaux et internationaux dans le but de leur permettre de créer des liens commerciaux pour leurs produits et d'améliorer la mise en place de réseaux. À cet égard, un financement est nécessaire pour renforcer la mise en œuvre du régime commercial simplifié du COMESA - Zimbabwe

Source: OCDE-OMC Exercice de suivi de l'Aide pour le commerce (2019). 


\section{L'autonomisation des jeunes}

Plusieurs répondants ont fait référence à des objectifs d'autonomisation des jeunes, en particulier du point de vue de l'emploi. Par rapport à celles concernant les deux autres thèmes de l'enquête, à savoir l'autonomisation économique des femmes et les MPME, les observations relatives aux jeunes n'étaient pas aussi étoffées.

La Papouasie-Nouvelle-Guinée a insisté sur les difficultés rencontrées par les jeunes pour trouver un emploi après l'obtention de leur diplôme et la nécessité de les doter de compétences et de connaissances financières pour encourager leur participation à l'économie. De la même façon, Madagascar a cité "le manque d'expériences et de financement des start-up" comme d'importants obstacles à l'entrepreneuriat des jeunes. Cet élément a été incorporé en 2015 à la loi qui régit la politique nationale pour les jeunes de Madagascar, qui reconnaît que "les jeunes sont les premiers touchés par le chômage". À cette fin, "l'inclusion socioéconomique des jeunes et la promotion de l'entrepreneuriat des jeunes" sont inscrites dans la stratégie de Madagascar. Dans un ordre d'idée analogue, la Papouasie-Nouvelle-Guinée a noté que les jeunes n'avaient pas bénéficié d'un soutien suffisant dans tous les domaines pour leur garantir emploi et réelle participation aux activités économiques.

Parmi les mesures adoptées pour autonomiser les jeunes figurent les déclarations incorporées dans les stratégies de développement. Le Sénégal a fait observer que l'emploi des jeunes et des femmes avait été au cœur de sa stratégie de développement. En Zambie, le gouvernement a mis en place une stratégie d'autonomisation et d'emploi des jeunes prévoyant des interventions des pouvoirs publics visant à surmonter les obstacles qui s'opposent à l'autonomisation des jeunes.

D'autres mesures plus précises ont été citées, telles que les activités de formation professionnelle dispensées par la Guinée et les programmes d'entrepreneuriat exécutés par Saint-Kitts-et-Nevis. L'intégration des jeunes à des projets a été mis en lumière par la Zambie dans le cadre de ses projets de développement des entreprises d'aquaculture et de la chaîne de valeur du manioc.

\section{L'autonomisation des femmes}

La question de l'égalité est aussi un aspect qui est important pour l'Initiative Aide pour le commerce depuis ses débuts. Elle est évoquée à partir de 2006 dans les recommandations de l'Équipe spéciale chargée de l'Aide pour le commerce. Dans la Déclaration conjointe sur le commerce et l'autonomisation économique des femmes adoptée à la Conférence ministérielle de Buenos Aires en 2017, l'Aide pour le commerce a été définie comme un instrument d'analyse, de conception et de mise en œuvre de politiques commerciales plus soucieuses de l'égalité hommes-femmes.

L'exercice de suivi de l'Aide pour le commerce de 2019 montre comment l'autonomisation économique est intégrée dans les cadres politiques nationaux et régionaux par les pays partenaires et les organisations régionales, ainsi que par les donateurs et les partenaires Sud-Sud. II ressort des réponses à cet exercice que l'autonomisation économique des femmes est un élément essentiel de la croissance inclusive et durable.

Les données indiquent que les stratégies nationale et régionale de développement des pays partenaires mettent davantage l'accent sur l'autonomisation des femmes depuis le lancement de I'Initiative. Cette dernière tendance ressort clairement des réponses à l'exercice de suivi et d'évaluation conjoint OCDE-OMC 2019. De fait, il n'y a guère de différence entre les donateurs et les pays partenaires pour ce qui est de la promotion de l'autonomisation économique des femmes dans les plans de l'Aide pour le commerce (84\% des donateurs ont indiqué qu'il s'agissait d'une priorité) et des stratégies nationales ou régionales de développement (85\% des pays partenaires ont indiqué qu'il s'agissait d'un problème à régler). En outre, les deux groupes ont souligné que l'intégration de l'autonomisation économique des femmes encourageait l'actualisation de leurs stratégies. 
Les mesures d'autonomisation des femmes trouvent aussi écho dans diverses politiques visant à atteindre cet objectif. Par exemple, le Kazakhstan a mentionné "la politique d'appui législatif aux femmes, appliquée de longue date. En tant que premier pays d'Asie centrale à établir une entité nationale de promotion de l'égalité hommes-femmes, le Kazakhstan a approuvé en 2016 la politique relative à la famille et au genre à l'horizon 2030, en vue de prévenir la discrimination et les inégalités fondées sur le sexe".

L'intégration de l'autonomisation économique des femmes trouve une expression concrète dans les engagements nationaux et internationaux en la matière. C'est par exemple le cas des politiques sectorielles du Tadjikistan. L'importance d'intégrer l'autonomisation économique des femmes en tant que question transversale dans les politiques de développement a aussi été mise en relief. Dans ses réponses, la République démocratique du Congo a insisté sur l'importance de "prendre en considération la dimension du genre dans toutes les activités". À cette fin, dans les cinq prochaines années, les mesures nationales devraient "s'orienter vers le renforcement des capacités d'autonomisation des femmes et la promotion de l'application de lois en faveur des femmes".

Plusieurs répondants réaffirment le lien entre autonomisation économique et commerce international. La stratégie nationale de développement de la République démocratique du Congo "associe l'autonomisation économique à la participation des femmes et des jeunes au commerce international". Le Zimbabwe a conscience du "rôle important que jouent les femmes dans le commerce transfrontières informel" et de la nécessité "d'intégrer les questions relatives à l'égalité hommes-femmes à la mise en œuvre de la politique commerciale nationale". Au Malawi, "des préférences spéciales sont accordées aux femmes qui participent au commerce transfrontières". La Guinée continue "d'encourager les associations de femmes à participer à des activités de promotion du commerce, telles que des salons ou des expositions".

Dans certaines réponses, les répondants ont cité le potentiel que renferment les régimes commerciaux simplifiés et la rationalisation des procédures douanières pour stimuler l'autonomisation économique, en particulier des femmes et des MPME. Le Zimbabwe a insisté sur la nécessité d'acheminer davantage de "financements pour renforcer l'application du régime commercial simplifié du COMESA" pour mieux permettre aux femmes de créer des liens commerciaux. Le Kenya a déclaré que "les procédures douanières simplifiées en vigueur dans la CEA offraient des possibilités aux PME".

Les données d'expérience collectées dans certains pays montrent le rôle que le numérique pourrait jouer dans l'avancement de l'autonomisation économique des femmes. En Iraq, Internet, en particulier les réseaux sociaux, ont contribué à la promotion de l'autonomisation économique des femmes. La République démocratique du Congo attribue l'accroissement de la production des femmes et l'amélioration de leur accès aux marchés aux techniques de communication modernes. D'après les réponses, la situation dans ce domaine peut encore être améliorée. La Guinée, par exemple, a fait savoir qu'elle devait continuer d'appuyer la formation des femmes entrepreneurs en techniques commerciales modernes. Plus de 30 répondants ont indiqué que la connectivité numérique et les compétences en TIC étaient un moyen par lequel l'Aide pour le commerce pouvait contribuer à l'autonomisation économique des femmes.

L'Ukraine a indiqué avoir besoin d'une approche à trois volets, notamment pour que "les entreprises d'exportation respectent l'égalité hommes-femmes, en particulier dans la promotion et la prise de décision, pour que les femmes renforcent leurs capacités et pour que les entreprises dirigées par des femmes aient accès aux réseaux nationaux et internationaux d'entreprises qui offrent des possibilités de commerce et d'exportation". 
Encadré 1.4. Déclaration conjointe sur le commerce et l'autonomisation économique des femmes

Nous sommes convenus de collaborer pour faire en sorte que nos politiques commerciales et nos politiques de développement soient plus soucieuses de l'égalité hommes-femmes, notamment:

1. en partageant nos expériences respectives relatives aux politiques et aux programmes destinés à encourager la participation des femmes à l'économie nationale et internationale par des échanges d'informations dans le cadre de l'Organisation mondiale du commerce (OMC), le cas échéant, et par la présentation de rapports volontaires pendant le processus d'examen des politiques commerciales de l'OMC;

2. en partageant les meilleures pratiques pour effectuer une analyse des politiques commerciales basée sur le genre et pour en suivre les effets;

3. en partageant les méthodes et procédures pour la collecte de données ventilées par sexe, l'utilisation d'indicateurs et de méthodes de suivi et d'évaluation et l'analyse des statistiques relatives au commerce axées sur le genre;

4. en travaillant ensemble à l'OMC pour supprimer les obstacles à l'autonomisation économique des femmes et pour accroître leur participation au commerce; et

5. en faisant en sorte que l'Aide pour le commerce contribue aux outils et au savoir-faire nécessaires pour analyser, concevoir et appliquer des politiques commerciales plus soucieuses de l'égalité hommes-femmes.

Source: Déclaration conjointe sur le commerce et l'autonomisation économique des femmes à l'occasion de la Conférence ministérielle de l'OMC à Buenos Aires en décembre 2017.

\section{L'autonomisation des MPME}

L'une des motivations premières de l'autonomisation économique est le rôle de premier ordre que jouent les MPME dans les économies, dont elles sont l'épine dorsale. Par exemple, le Samoa indique que les MPME représentent la plus grande part de l'économie et dit qu'il faut orienter "les interventions vers la diversification et l'autonomisation économiques des MPME". Le Kazakhstan et les Maldives indiquent que les MPME sont d'importants employeurs. Dans sa réponse, le Sénégal dit que la part de l'emploi attribuée aux MPME (99,8\% de l'économie) devrait déterminer le niveau d'importance accordé à leur autonomisation économique. De la même façon, la Guinée considère que l'autonomisation des MPME est "le point de départ du développement, en particulier pour les PMA".

Dans les réponses, le lien entre les MPME et la diversification des exportations a aussi été mis en avant. La politique de développement des MPME de la Zambie met l'accent sur la facilitation de l'accès aux marchés locaux et internationaux. Le Honduras a fait remarquer que la réduction des coûts du commerce profiterait largement aux MPME - un argument dont le Kenya s'est fait l'écho en évoquant "les avantages des procédures douanières simplifiées en vigueur dans la CEA".

La viabilité des MPME dépend très largement de facteurs essentiels, tels que les compétences et l'accès au financement, les deux facteurs cités le plus fréquemment dans les réponses au questionnaire. Le Népal a souligné qu'il importait "de promouvoir les compétences des MPME dans les domaines du commerce et de l'entrepreneuriat". Le développement du capital humain fait partie intégrante de la stratégie de développement national et régional, l'objectif principal étant d'améliorer l'emploi dans certains pays, dont le Bénin, la Zambie et les Philippines. La Zambie a dit que "les femmes, les MPME et les jeunes participaient activement aux activités économiques susceptibles d'avoir des répercussions positives, telles que la génération de revenus, la création d'emplois et l'amélioration des moyens d'existence". Toutefois, ils constituent aussi précisément le groupe qui se heurte à des obstacles du côté de l'offre et du côté de la demande.

L'accès au financement est l'une des questions urgentes fréquemment mentionnées dans le cadre de l'autonomisation économique des MPME. II pose des difficultés en Papouasie-Nouvelle-Guinée, où les MPME ne peuvent pas obtenir d'appui financier de la part des banques et des institutions financières, ce qui entrave leurs progrès en matière d'autonomisation économique. Afin de faire face à de tels problèmes, en particulier les exigences élevées en matière de nantissement, les Maldives ont créé en février 2019 une banque pour les PME axée sur le financement et le développement de ces entreprises. Le Kazakhstan considère l'accès au financement comme un catalyseur de l'autonomisation des MPME. L'accès au financement s'avère important non seulement pour les MPME, mais aussi pour les femmes et les jeunes. Comme l'a déclaré l'Ouganda, il constitue aussi un moyen d'autonomiser les groupes marginalisés en facilitant leur participation au commerce régional et international. 
Figure 1.16. L'Aide pour le commerce peut concourir à la réalisation du Programme à I'horizon 2030

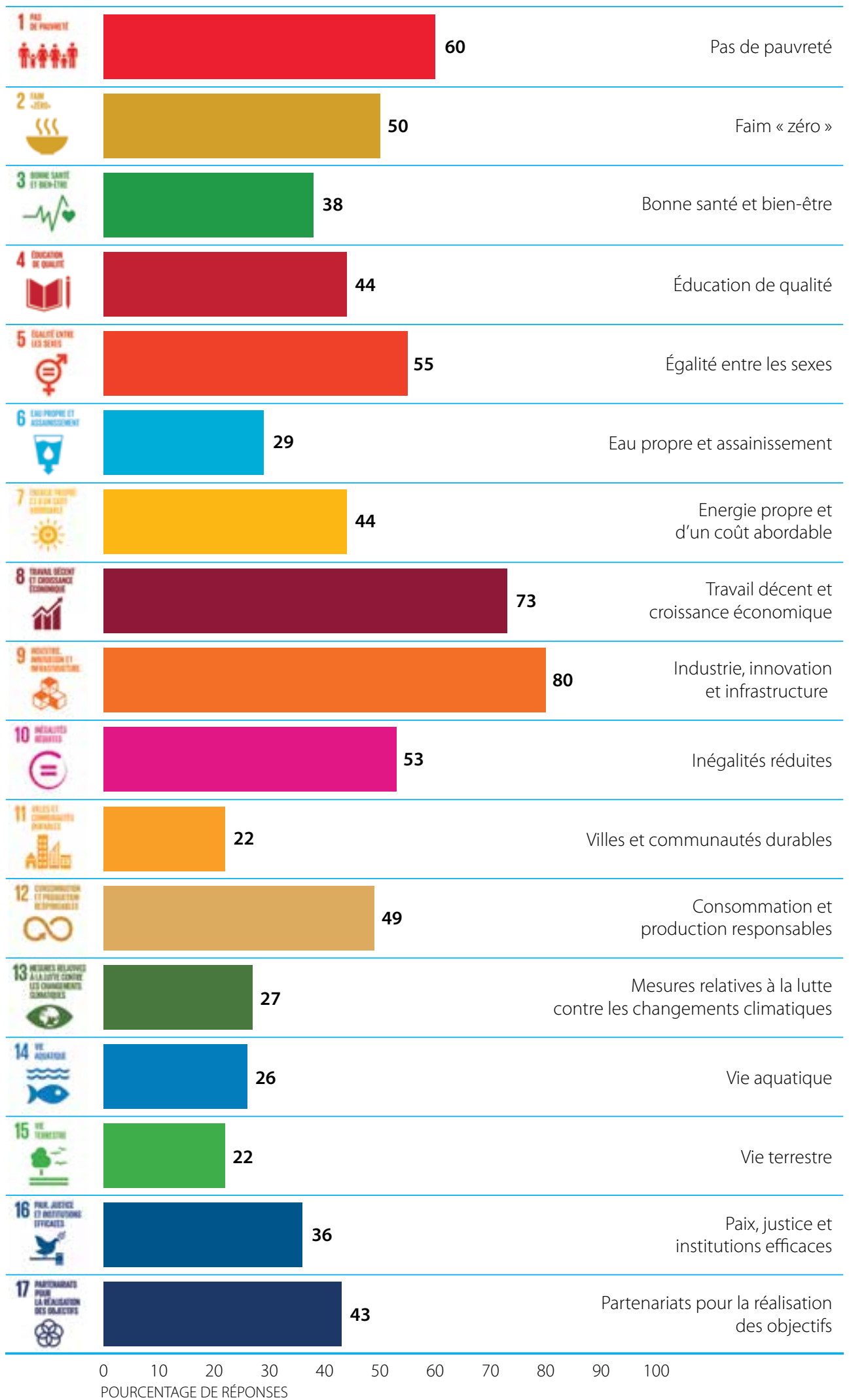




\section{CONCLUSIONS}

I| ressort de l'exercice de suivi de 2019 que les répondants ont clairement conscience que la diversification et l'autonomisation économiques renforcent la raison d'être de l'Aide pour le commerce en tant que moteur de croissance économique, d'industrialisation et d'innovation. Cela cadre avec l'objectif de l'Aide pour le commerce, énoncé pour la première fois par l'Équipe spéciale chargée de l'Aide pour le commerce (2006), à savoir : "Viser à aider les pays en développement, en particulier les PMA, à se doter de la capacité du côté de l'offre et de l'infrastructure liée au commerce dont ils ont besoin pour les aider à mettre en œuvre les Accords de l'OMC et en tirer profit et, plus généralement, pour accroître leur commerce".

Parmi les pays partenaires répondants, il existe une idée précise du rôle que l'Aide pour le commerce peut jouer pour ce qui est de contribuer à la réalisation du Programme de développement durable à l'horizon 2030, en particulier l'ODD 8 (Travail décent et croissance économique) et l'ODD 9 (Industrie, innovation et infrastructures). La figure 1.18 ci-après expose les réponses données par les pays partenaires. 


\section{NOTES}

1. Les flux d'exportation bilatéraux au niveau des positions à six chiffres du SH d'une valeur inférieure à 100000 USD sont exclus du décompte des produits.

2. L'ensemble de données de l'OMC portant sur le commerce des services par mode de fourniture comprend des estimations produites par le Secrétariat de I'OMC pour couvrir toutes les catégories de services. Une limite de 50000 USD est appliquée aux 39 rubriques de I'EBOPS, à savoir SA, SB, SC11, SC12, SC13, SC21, SC22, SC23, SC31, SC32, SC33, SC4, SDA, SDB1, SDB2, SDB3, SE1, SE2, SF, SG, SI1, SI2, SI3, SJ1, SJ21, SJ22, SJ311, SJ312, SJ313, SJ32, SJ33, SJ34, SJ35, SK1, SK21, SK22, SK23, SK24, SH.

3. WT/AFT/1.

4. Banque mondiale, "Economic Diversification Guidance Note, Trade and Competitiveness Global Practice", disponible à l'adresse suivante : http://ieg.worldbankgroup.org/sites/default/files/Data/reports/EconomicDiversification.pdf

5. Département national de la planification, Colombie "Metodología tipo de pre-identificación de apuestas productivas a nivel Departamental Ministerio" mars 2017, disponible à l'adresse suivante : https://colaboracion.dnp.gov.co/CDT/Desarrollo\%20Empresarial/Metodologia\%20Priorizacion\%20PDP\%20-\%20 FINAL.pdf

6. Une version révisée de l'indice de diversification du SH utilisée dans le document technique des Profils tarifaires dans le monde 2017. L'indice de diversification du SH est défini comme le total des flux d'exportation commerciaux au niveau des positions à six chiffres du SH avec tous les partenaires commerciaux (marchés de destination). Par conséquent, l'indice permet de mesurer à la fois l'étendue des catégories de produits et la diversité des marchés d'exportation. II convient de noter que l'indice ne tient pas compte du volume des échanges. II pourrait être utile de prendre en compte la valeur des échanges pour mesurer l'intensité plutôt que la diversité des produits, mais cela pourrait aussi fausser la mesure du potentiel d'exportation pur car celui-ci pourrait être sous-estimé si l'on accordait trop d'importance aux valeurs du commerce. 



\title{
CHAPITRE 2
}

\section{AIDE POUR LE COMMERCE, DIVERSIFICATION ET AUTONOMISATION ÉCONOMIQUES}

\author{
Contribution de l'Organisation pour la coopération \\ et le développement économiques
}

\begin{abstract}
Résumé : Depuis le lancement de l'Initiative Aide pour le commerce, les donateurs ont décaissé 409 milliards d'USD d'aide publique au développement (APD) pour aider les pays en développement à renforcer leurs capacités commerciales. En outre, 346 milliards d'USD ont été décaissés au titre de prêts accordés à des conditions libérales. En 2017, les engagements au titre de l'Aide pour le commerce ont atteint 57,7 milliards d'USD, un montant une fois et demie supérieur à la moyenne de référence. Les études empiriques et les évaluations montrent que ce soutien a aidé les pays en développement à améliorer leur compétitivité, à développer et à diversifier leurs échanges, à attirer l'investissement étranger direct et à créer des emplois pour les hommes comme pour les femmes. Malgré ces résultats positifs, nombre de ces pays restent spécialisés dans des activités à faible valeur ajoutée. Cela signifie que les programmes d'aide doivent aider plus explicitement ces pays à diversifier leur économie et à créer davantage de possibilités pour autonomiser les femmes et les jeunes.
\end{abstract}




\section{APERÇU}

De nombreux pays en développement, en particulier les moins avancés, continuent de se heurter à des problèmes de compétitivité majeurs lorsqu'ils s'efforcent de diversifier leur économie. Malgré les nouvelles possibilités qu'offrent la réduction des coûts du commerce et la diffusion des technologies de l'information et de la communication, nombre d'entre eux rencontrent toujours des difficultés considérables qui les empêchent d'exploiter pleinement leur potentiel économique. Dans ceux qui y parviennent, il peut être difficile de reproduire de tels résultats au niveau national. Cela pourrait entraîner l'apparition d"'îlots d'excellence", avec des niveaux de capitaux et de connaissances plus élevés que dans le reste de l'économie. Les facteurs qui influent sur la diversification économique sont variés et dépendent du contexte ou de la situation géographique (comme dans le cas des petites îles et des pays en développement sans littoral). Certains obstacles à la diversification économique font partie de ceux que l'Aide pour le commerce cherche à éliminer. Ils sont également ressortis des réponses fournies lors de l'exercice de suivi et d'évaluation réalisé par l'OCDE et l'OMC en 2019.

Depuis le lancement, en 2006, de l'Initiative Aide pour le commerce dirigée par l'OMC, les quelque 60 donateurs qui déclarent leur aide publique au développement (APD) dans le cadre du Système de notification des pays créanciers de I'OCDE ont décaissé 409 milliards d'USD pour renforcer les capacités et les infrastructures liées au commerce. Ils ont versé 5,7 milliards d'USD pour aider les pays en développement à élaborer des stratégies de développement du commerce et à négocier et mettre en œuvre des accords commerciaux. En outre, 91,6 milliards d'USD ont été décaissés pour améliorer l'approvisionnement en énergie; 125,4 milliards d'USD pour construire des routes, des ports et des réseaux de télécommunication; 180 milliards d'USD pour soutenir le secteur privé; et 230 millions d'USD pour aider les pays à supporter les coûts liés à la libéralisation des échanges. Par ailleurs, depuis 2006, 346 milliards d'USD ont été décaissés au titre de prêts accordés à des conditions libérales. En 2017, les engagements au titre de l'Aide pour le commerce ont augmenté de 12,1\% en termes réels et ont atteint 57 milliards d'USD, un montant près d'une fois et demie supérieur à la moyenne de référence de la période 2002-2006. À cette somme s'ajoutent 9 milliards d'USD provenant des fournisseurs Sud-Sud, qui deviennent une source de financement de plus en plus importante pour les pays en développement, même s'il est difficile de savoir quel montant a été alloué en faveur du commerce.

Des études empiriques montrent clairement que ce soutien a aidé les pays en développement à accroître et à diversifier leurs échanges, à améliorer leur compétitivité, à attirer l'investissement étranger direct et à créer des emplois pour les hommes comme pour les femmes. Ces résultats empiriques sont corroborés par des études de cas soumises dans le cadre des précédents exercices de suivi de l'Aide pour le commerce. Ils varient toutefois, en fonction du type de contribution au titre de l'Aide pour le commerce, du secteur auquel le soutien est accordé, et du niveau de revenu et de la situation géographique du pays bénéficiaire.

Les évaluations ont montré qu'un soutien ciblé, aussi bien conçu et mis en œuvre qu'il soit, n'entraînera probablement pas de gains durables pour les populations pauvres s'il ne s'accompagne pas d'une réforme politique et institutionnelle. Cependant, consacrer exclusivement le soutien à la création d'un environnement favorable ne tient pas compte du fait que les micro et petites entreprises ont rarement les capacités nécessaires pour exploiter de nouvelles possibilités commerciales. En outre, les femmes et les jeunes sont souvent désavantagés du point de vue de leurs capacités économiques, font l'objet de discriminations et n'ont pas de moyen d'expression politique pour influencer les décisions stratégiques. L'autonomisation est donc essentielle pour répondre aux différentes formes d'exclusion. Les politiques et l'investissement doivent être plus clairement axés sur l'élargissement des possibilités économiques pour les femmes et les jeunes. Ainsi, les programmes d'Aide pour le commerce devraient prendre en compte les facteurs d'économie politique qui influent sur la situation des femmes et des jeunes, en particulier en ce qui concerne les besoins d'emploi futurs. 
Le présent chapitre débute par une vue d'ensemble des flux de financement pour le développement qui fournira un contexte à une analyse plus approfondie des décaissements au titre de l'Aide pour le commerce depuis le lancement de I'initiative en 2006. II présente ensuite les conclusions d'études universitaires sur l'efficacité de l'Aide pour le commerce en ce qui concerne l'expansion et la diversification des échanges, la mobilisation des investissements et la promotion de la diversification et de l'autonomisation économiques. Il examine ensuite plus en détail les décaissements au titre de l'Aide pour le commerce considérés comme les plus pertinents s'agissant de la promotion de la diversification et de l'autonomisation économiques. Enfin, il présente les perspectives à court terme de l'Aide pour le commerce.

\section{FINANCEMENT DU DÉVELOPPEMENT DURABLE}

Le Programme de développement durable à l'horizon 2030 procède d'une vision à la fois large et ambitieuse; il appelle une stratégie de financement tout aussi large et ambitieuse. En 2002, la première Conférence internationale sur le financement du développement avait souligné que le commerce était souvent la première source extérieure de financement du développement. La Conférence de 2015 et le Programme d'action d'Addis-Abeba qui en est issu ne voient plus dans le commerce une source de financement du développement. Le Programme d'action mentionne les ressources nationales et l'investissement étranger direct (IED), tout en soulignant qu'il serait nécessaire que le secteur privé apporte une contribution additionnelle conséquente. Le commerce est décrit comme un moteur de la croissance et du développement. La réalisation des Objectifs de développement durable (ODD) et des objectifs commerciaux passe par des approches intégrées et des compromis. Cela signifie que l'Aide pour le commerce devrait aider les pays en développement à atteindre leurs objectifs économiques en aidant leurs entreprises à se connecter aux marchés internationaux, et en aidant les pays eux-mêmes à développer et diversifier leurs échanges. Elle devrait parallèlement contribuer à la réalisation d'objectifs sociaux en réduisant la pauvreté et les inégalités. Enfin, l'Aide pour le commerce devrait poursuivre des objectifs environnementaux en aidant les pays en développement à s'adapter aux changements climatiques, tout en tirant parti des avantages comparatifs des procédés de production sobres en carbone (Lammersen, 2019). La section suivante présente le contexte du financement du développement et donne un aperçu général des décaissements totaux effectués au titre de l'Aide pour le commerce depuis le lancement de l'initiative en 2006.

Figure 2.1. Financement transfrontières destiné aux pays en développement, 2000-2016

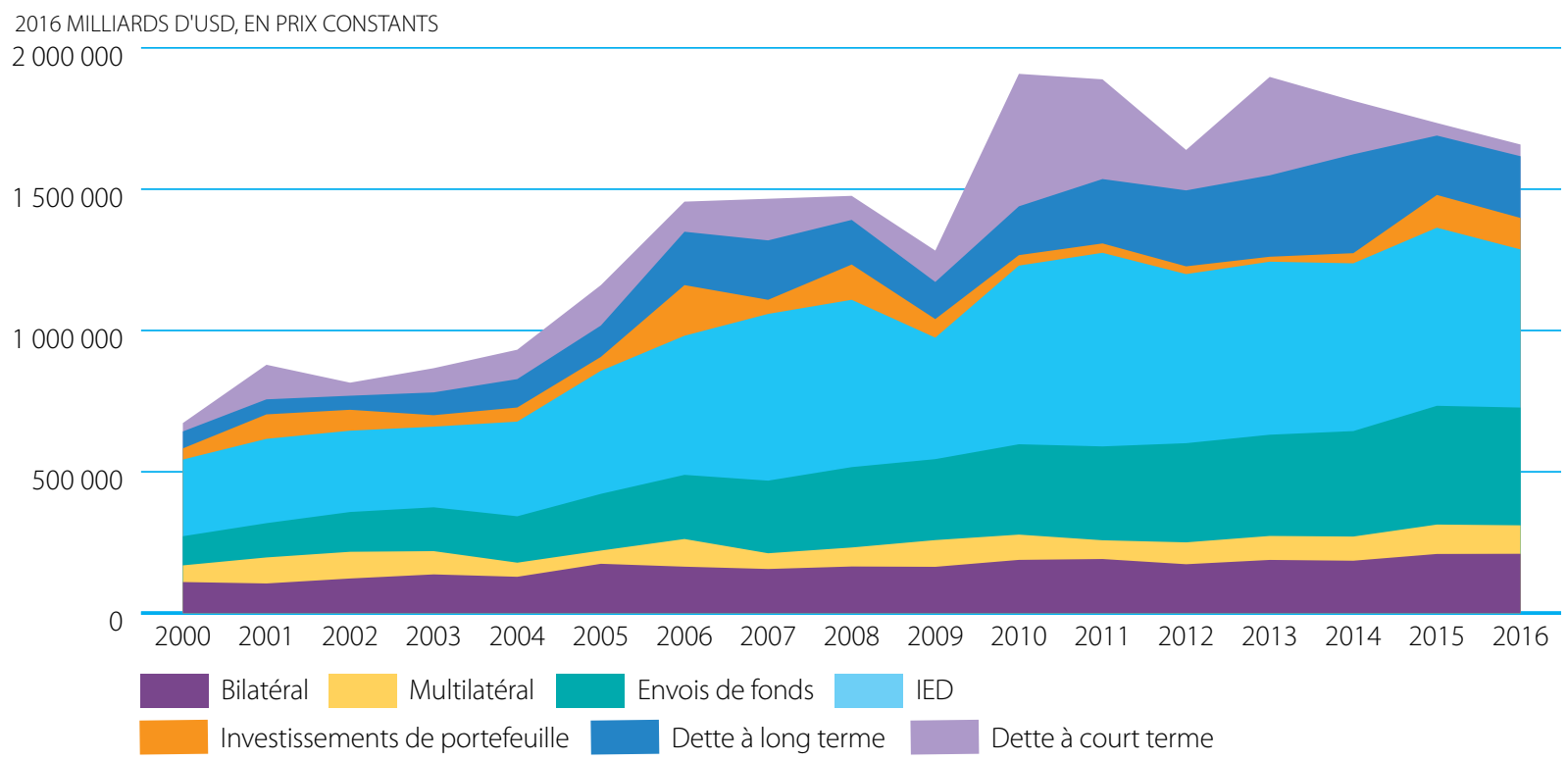

Source: Calculs de l'OCDE sur la base du Système de notification des pays créanciers de l'OCDE (2018) (base de données), https://stats.oecd.org/Index.aspx?DataSetCode=crs1; Banque mondiale (2018), données sur la migration et les envois de fonds,

http://www.worldbank.org/en/topic/ migrationremittancesdiasporaissues/brief/migration-remittances-data ; FMI (2017), base de données sur la balance des paiements, http://www.imf.org/external/datamapper/datasets/BOP. 
En 2016, le financement extérieur accordé aux pays en développement par les acteurs internationaux, tant du secteur public que du secteur privé, s'élevait à près de 1700 milliards d'USD, contre environ 675 milliards d'USD en 2000. Le secteur privé est le principal donateur, octroyant environ 750 millions d'USD sous différentes formes d'investissement. Les envois de fonds des migrants, qui s'élèvent à 416 milliards d'USD, sont également une source de financement importante, bien que seulement dans un nombre limité de pays en développement. Les fournisseurs d'aide publique, dont les ressources combinées s'élèvent à 310 milliards d'USD, ciblent la réduction de la pauvreté, les pays les plus pauvres et les programmes mondiaux. Les apports au titre de la coopération Sud-Sud des dix principaux pays en dehors du Comité d'aide au développement (CAD) s'élevaient à 9 milliards d'USD en 2017, contre 6,2 milliards d'USD en 2016 (figure 2.1).

Ces différents apports varient selon les destinataires. Les pays à faible revenu sont en général davantage tributaires des apports du secteur public, et plus particulièrement des apports à des conditions libérales, tandis que les envois de fonds sont la principale source de financement extérieur des pays à revenu intermédiaire de la tranche inférieure (PRITI). Les PRITI et pays à revenu intermédiaire de la tranche supérieure (PRITS) absorbent la plus grande part des apports publics à des conditions non libérales. Les PRITS attirent la majeure partie du financement privé, qui représente toutefois également une source de financement importante pour les PRITI. Ainsi, les types de financement extérieur semblent être fortement corrélés aux niveaux de revenu, la structure du financement transfrontières variant en fonction du niveau de développement. (OCDE, 2019) (figure 2.2).

\section{Figure 2.2. Destinataires du financement extérieur en 2016}

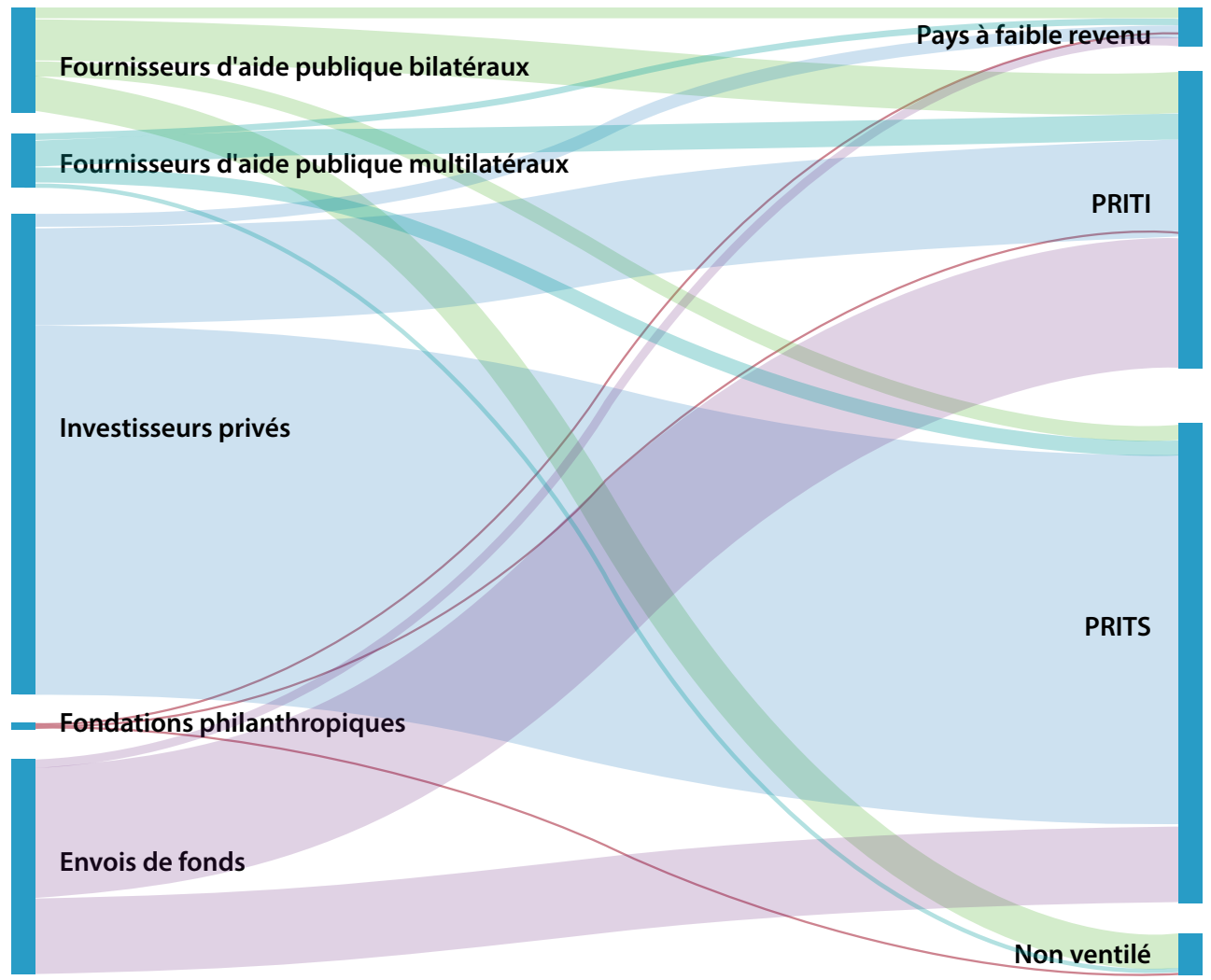

Source: Calculs de l'OCDE sur la base du Système de notification des pays créanciers de l'OCDE (2018) (base de données), https://stats.oecd.org/Index.aspx?DataSetCode=crs1 ; Banque mondiale (2018), données sur la migration et les envois de fonds; FMI (2017), balance des paiements. 
La part du financement public international diminue à mesure que le revenu national augmente. Laide publique au développement (APD), en particulier, est la principale source de financement extérieur pour les pays à faible revenu et les PRITI (entre 50\% et 60\% du total des apports extérieurs). L'APD et les autres apports du secteur public (AASP) perdent en importance dans les PRITS, où ils représentent moins de 10\% du financement extérieur. La part du financement privé s'accroît dans les pays à revenu plus élevé du fait qu'ils peuvent accéder aux marchés internationaux de capitaux. Si les envois de fonds sont importants pour les pays à faible revenu, c'est dans les PRITI et les PRITS que leur part du financement extérieur est la plus élevée. Les apports privés représentent environ 30\% du total du financement extérieur pour les pays à faible revenu et 70\% pour les pays les plus riches ou les PRITS (figure 2.3).

\section{Figure 2.3. Disponibilité des sources de financement selon les niveaux de revenu}

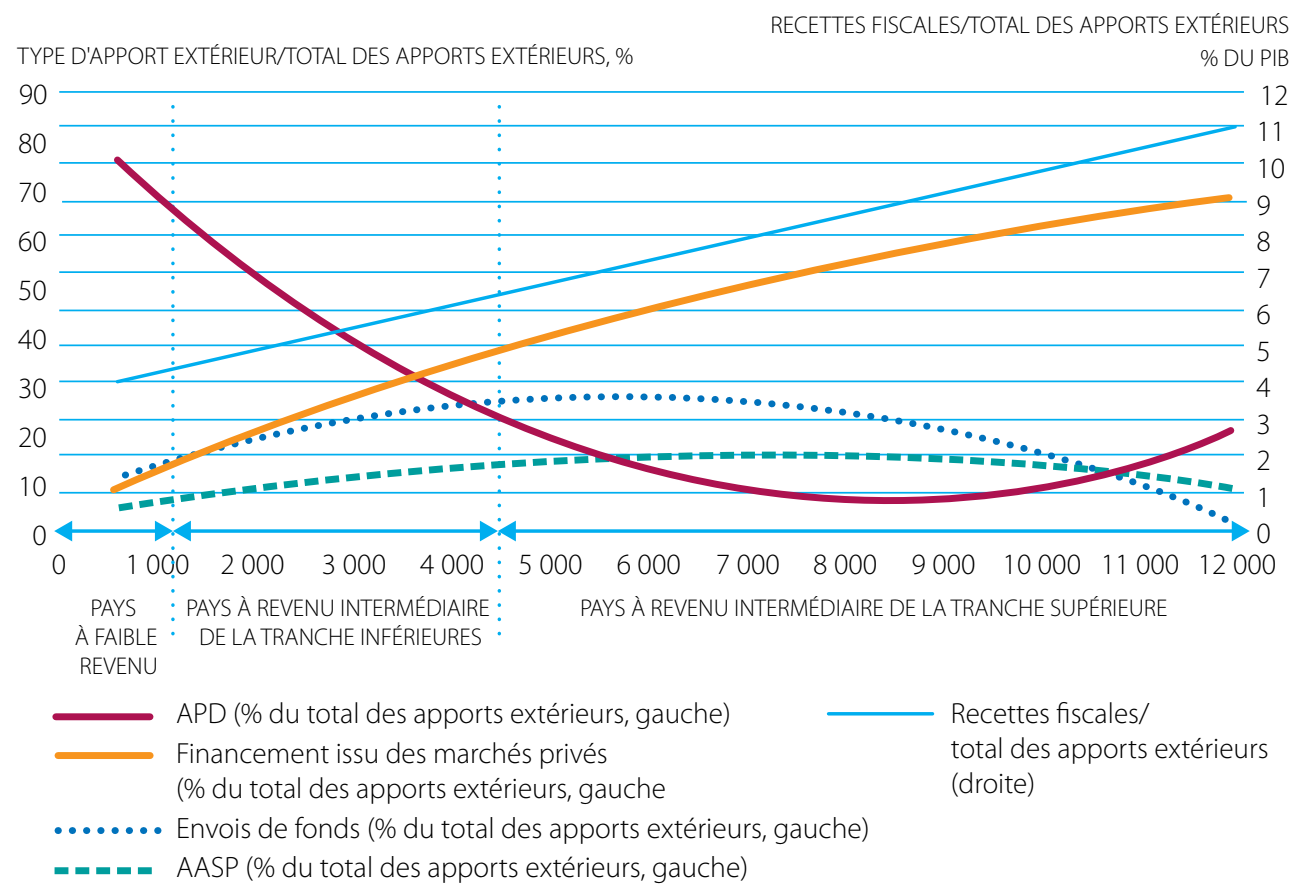

Source: OCDE (2018), Système de notification des pays créanciers de (base de données), https://stats.oecd.org/ Index.aspx?DataSetCode=crs1; Banque mondiale (2018), données sur la migration et les envois de fonds,

http://www.worldbank.org/en/topic/migrationremittancesdiasporaissues/brief/migration-remittances-data; F MI (2017), base de données sur la balance des paiements, http://www.imf.org/external/datamapper/datasets/BOP.

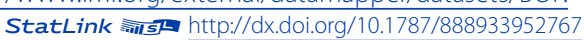

La contribution du secteur privé au financement du développement s'est élevée à 154 milliards d'USD pour la période 2012-2017. L'Afrique était le principal bénéficiaire (40,8 milliards d'USD), suivie de l'Asie (37,5 milliards d'USD), de l'Europe (32 milliards d'USD), de l'Amérique latine et des Caraïbes (25,1 milliards d'USD) et de l'Océanie (seulement 0,1 milliard d'USD). Dans ces différentes régions, la majeure partie des montants mobilisés ont été affectés à des projets dans les PRITS (54\%) et les PRITI (36\%), et seuls 10\% étaient destinés aux PMA et aux autres pays à faible revenu. Ce type de financement du développement était majoritairement destiné aux services bancaires et financiers (43,7 milliards d'USD), à l'énergie (38,9 milliards d'USD) et à l'industrie, aux activités minières et à la construction (28,8 milliards d'USD) (figure 2.4). 


\section{Figure 2.4. Montants des financements mobilisés aux fins du développement auprès du secteur privé, 2012-2017, par groupe de revenu et par secteur}

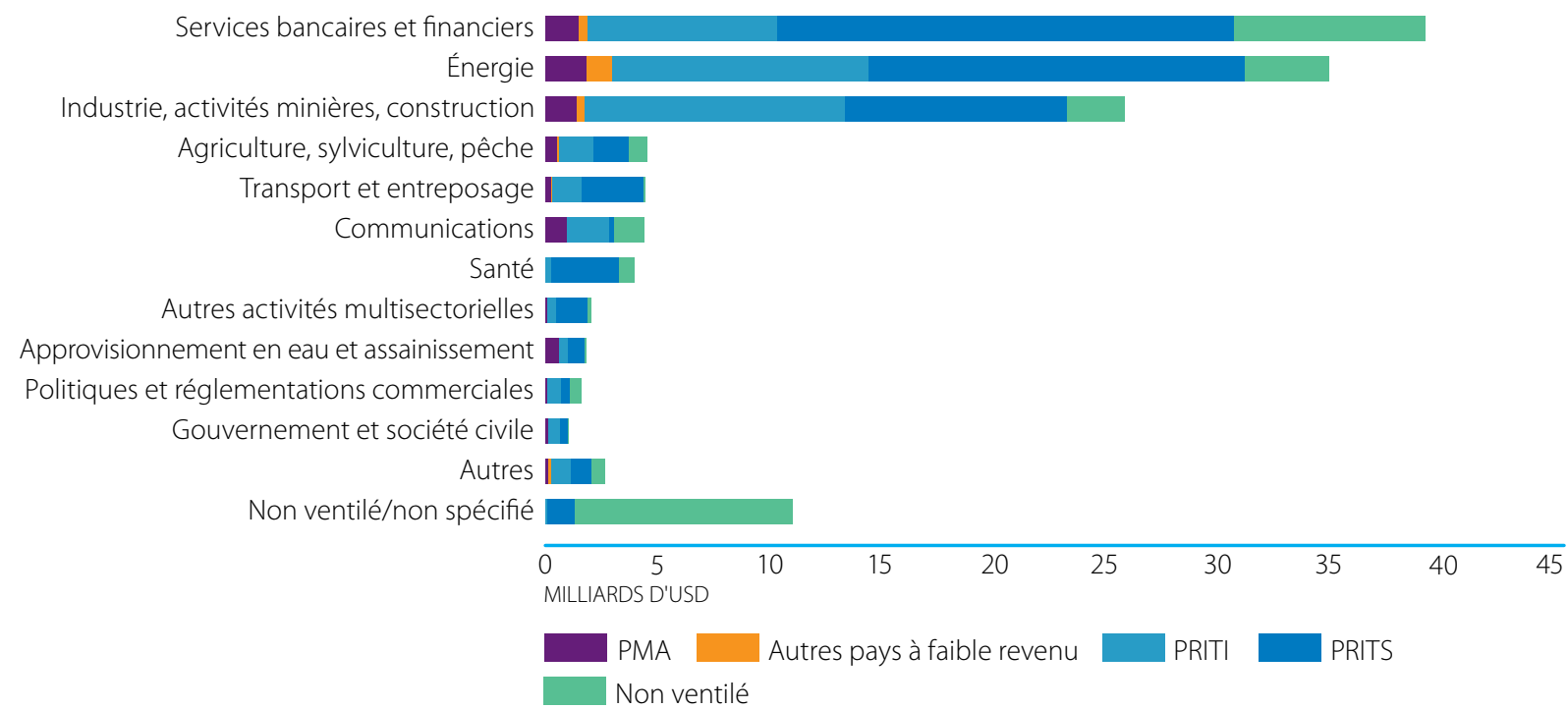

* Pour des questions de confidentialité, la Société financière internationale (SFI) n’a pas donné de renseignements ventilés par secteur et par zone géographique sur les fonds privés qu'elle avait mobilisés pour 2016 et 2017. Le montant s'élève à 10,3 milliards d'USD.

Sources: Benn, J., C. Sangaré et T. Hos (2017), "Amounts Mobilised from the Private Sector by Official Development Finance Interventions: Guarantees, syndicated loans, shares in collective investment vehicles, direct investment in companies, credit lines", OECD Development Co-operation Working Papers, No. 36, Éditions OCDE, Paris,

https://doi.org/10.1787/8135abde-en.

\section{Tableau 2.1. Vues sur la manière dont l'Aide pour le commerce permet de mobiliser d'autres formes} de financement du développement

"En raison de la crise politique prolongée, il est devenu plus difficile de mobiliser un financement étranger privé." -

\section{République centrafricaine}

"Le Cadre intégré renforcé est la seule source de financement, il n'y a eu pas eu de financement autre que concessionnel ni d'IED." - Sénégal

"Ces 10 dernières années, I'Union européenne a accordé environ 3,4 milliards d'EUR pour le financement de plus de 380 projets mixtes, ce qui a permis de mobiliser des prêts à hauteur de 26,2 milliards d'EUR et de débloquer 57,3 milliards d'EUR d'investissement dans les pays en développement." - Union européenne

"Un grand nombre d'opérations comprennent un cofinancement qui permet de mobiliser des sources de financement à des conditions libérales et non libérales à la fois au niveau local et international." - BERD

"En réduisant les risques liés aux investissements, les pays bénéficiaires peuvent mobiliser des sources additionnelles de financement du développement, en particulier l'IED, qui permet des gains durables en termes de diversification." -

\section{Banque mondiale}

"Notre aide, qui comprend des instruments du secteur privé, permet de mobiliser pleinement les capitaux privés." - Japon

Source: Exercice de suivi de l'Aide pour le commerce OCDE-OMC (2019). 
En réponse aux questionnaires de l'OCDE et de l'OMC pour 2019, 40 pays partenaires sur 88 et 24 donateurs sur 35 estimaient que l'Aide pour le commerce les avait aidés à mobiliser d'autres formes de financement du développement. Plus de la moitié des 40 pays partenaires sont des PMA. Parmi les pays du Sud qui ont répondu au questionnaire, la Turquie a souligné que l'Aide pour le commerce mobilisait d'autres formes de financement du développement.

Les dons d'organisations caritatives aux pays en développement s'élevaient à près de 8 milliards d'USD en moyenne par année au cours de la période 2015-2017. Les pays à revenu intermédiaire ont reçu 67\% des apports philanthropiques, 37\% étant destinés aux PRITI et 30\% aux PRITS. Le reste a été alloué aux pays à faible revenu. Environ 963 millions d'USD portent le marqueur du développement du commerce; plus de la moitié de ce montant était destiné à l'agriculture et à la pêche, et près du quart aux services bancaires et aux services connexes. L'appui fourni aux secteurs de l'énergie et de l'industrie ne concerne souvent pas en soi les activités de construction d'infrastructures ou de production, mais porte plutôt sur la transparence, la responsabilité et la participation démocratique (figure 2.5a). La moitié du financement provient de la Fondation Bill et Melinda Gates, même si d'autres fondations, telles que MasterCard et United Postcode Lotteries, sont également des pourvoyeurs importants (figure 2.5b).

Figure 2.5a. et 2.5b. Fonds philanthropiques privés pour le développement du commerce, 2017 (en millions d'USD, décaissements, 2017)

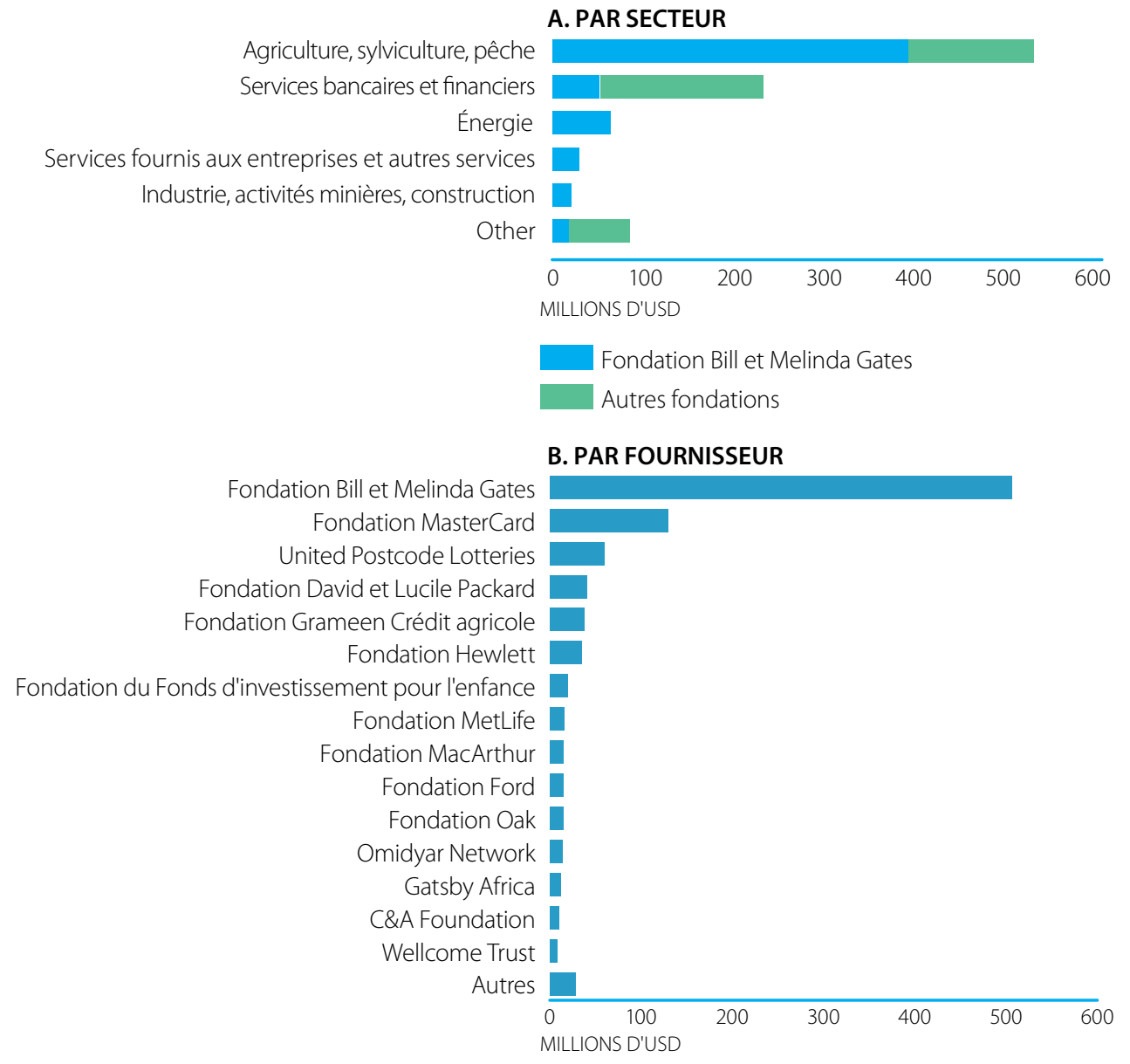

Source: OCDE (2018), La philanthropie privée pour le développement, Objectif développement, Editions OCDE, Paris, https://www.oecd-ilibrary.org/fr/development/la-philanthropie-privee-pour-le-developpement_9789264303973-fr" 
Plusieurs importants fournisseurs de coopération pour le développement ne notifient pas leurs apports financiers à I'OCDE. Selon une estimation prudente de celle-ci, les financements totaux bruts accordés à des conditions libérales par les dix pays qui ne communiquent pas de statistiques en la matière auraient atteint 9 milliards d'USD en 2017. II est difficile de déterminer quelle part de ce montant est allouée à des programmes ou des projets en lien avec le commerce. La deuxième Conférence de haut niveau des Nations Unies sur la coopération Sud-Sud a constaté que le commerce jouait un grand rôle dans la croissance et le développement économique des pays en développement et a pris note de la contribution importante de la coopération Sud-Sud et triangulaire dans le domaine du commerce, ainsi que de sa capacité de promouvoir le développement durable. Cinquante pays partenaires, dont 27 PMA, ont désigné la Chine comme étant le partenaire Sud-Sud qui accordait le financement le plus important pour la diversification économique, tandis que, pour 30 pays partenaires, il s'agissait de l'Inde. Les fournisseurs Sud-Sud ont indiqué que leur soutien à la diversification économique était principalement destiné aux pays suivants : Djibouti, Égypte, Mauritanie, Mozambique, Myanmar, Namibie, Népal, Nigéria, Papouasie-Nouvelle-Guinée et Tunisie.

\section{Tableau 2.2. Vues sur la coopération Sud-Sud}

"La Chine soutient la remise en état ou la construction de nos infrastructures liées au commerce." -

\section{République centrafricaine}

"L'Inde offre des programmes de renforcement des capacités liées au commerce à l'intention des fonctionnaires gouvernementaux, et la Chine soutient le développement en finançant la construction d'infrastructures." - Népal

"La Chine, l'Arabie saoudite, la Turquie, le Koweït et la Tunisie sont des partenaires de longue date." - Guinée

"Nous avons développé des relations économiques avec des partenaires Sud-Sud tels que la Chine, I'Iran, I'Inde et la Turquie." Sénégal

"L'Inde, le Brésil et l'Afrique du Sud aident à diversifier les activités économiques dans le secteur de la noix de coco." - Kiribati

"La Chine et I'Inde orientent leurs investissements vers les matières premières." - République démocratique du Congo

"Nous promouvons les modalités de la coopération Sud-Sud et en tirons parti afin de soutenir le développement durable dans le monde dans tous les domaines programmatiques." - Programme des Nations Unies pour le développement

(PNUD)

Source: Exercice de suivi de l'Aide pour le commerce OCDE-OMC (2019).

La coopération triangulaire combine différents types de ressources (financières, en nature, connaissances, technologie ou autres) et tire parti des avantages comparatifs de chaque partenaire en visant à obtenir un résultat qui soit supérieur à la somme des contributions individuelles. Elle a été introduite dans les années 1970 et des études et analyses montrent qu'elle est devenue plus populaire ces dernières années (OCDE, 2017). Ces tendances sont confirmées par les données du Secrétariat général ibéro-américain, qui indiquent que le nombre de projets de coopération triangulaire en Amérique latine et aux Caraïbes a été multiplié par 8 entre 2005 et 2015. Sept donateurs ont indiqué avoir des partenariats avec des fournisseurs Sud-Sud : quatre ont des partenariats avec l'Argentine, le Brésil et le Mexique; et trois avec le Chili, la Chine, I'Indonésie, la Malaisie, Singapour et la Thaïlande. L'Allemagne a fait observer qu'elle collaborait avec des fournisseurs Sud-Sud de plusieurs régions, dont l'Afrique du Sud, I'Arabie saoudite, le Chili, la Chine, I'Indonésie, et neuf autres. Le Japon s'associe à de nombreux partenaires, dont l'Argentine, l'Égypte, la Thaïlande et huit autres, pour fournir un financement aux fins de la diversification économique. Les États-Unis ont cité le Mexique et Singapour. 


\section{DÉCAISSEMENTS AU TITRE DE L'AIDE POUR LE COMMERCE DEPUIS 2006}

Le Programme d'action d'Addis-Abeba indique que l'Aide pour le commerce peut jouer un rôle majeur et devrait s'efforcer d'allouer une proportion grandissante des ressources aux pays les moins avancés. L'ODD 8 a renouvelé l'appel en faveur d'un accroissement de "l'appui apporté dans le cadre de I'Initiative Aide pour le commerce aux pays en développement, en particulier aux pays les moins avancés". Depuis le lancement de l'Initiative Aide pour le commerce dirigée par l'OMC, les quelque 60 donateurs qui déclarent leur APD dans le cadre du Système de notification des pays créanciers de l'OCDE ont décaissé au total 409 milliards d'USD au titre de l'APD pour renforcer les capacités et les infrastructures liées au commerce. Les décaissements ont connu une hausse moyenne annuelle de 9,3\%, passant de 14,9 milliards d'USD au cours de la période de référence 2002-2005 à 42,2 milliards d'USD en 2017.

\section{Figure 2.6. Décaissements au titre de l'Aide pour le commerce par groupe de revenu, élément de libéralité et catégorie, 2006-2017}

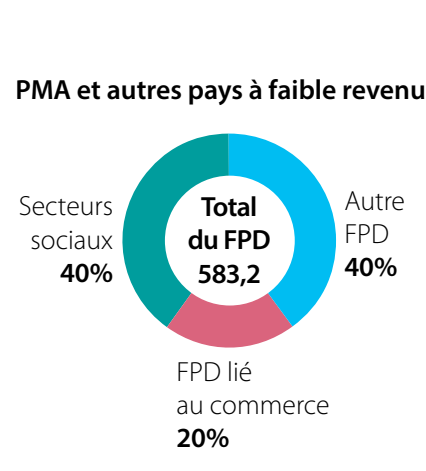

$$
\text { APD }
$$
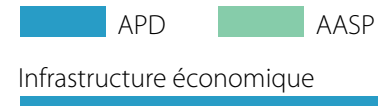

FPD, MILLIARDS D'USD,

Infrastructure économique
Services bancaires et entreprises

TOTAL 2006-2017
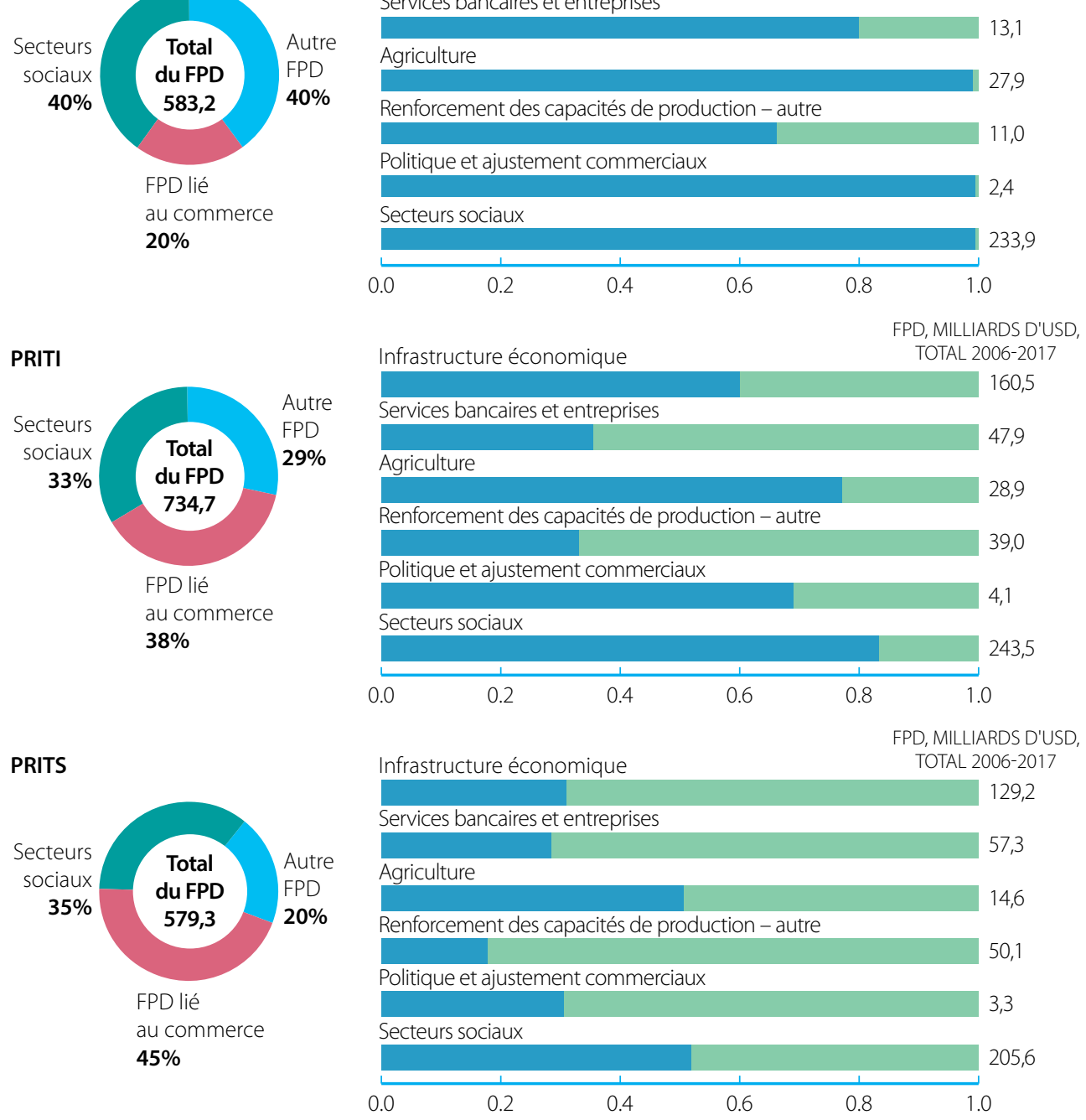

Source: Base de données du Système de notification des pays créanciers OCDE-CAD : activités d'aide (2019), DOI: http://dx.doi.org/10.1787/data-00061-en,(consulté le 6 février 2019).

StatLink 제인 http://dx.doi.org/10.1787/888933952824 
Cette APD a aidé les pays en développement dans plusieurs domaines : élaboration de stratégies de développement du commerce, négociation et mise en œuvre d'accords commerciaux (5,7 milliards d'USD), production d'énergie (91,6 milliards d'USD), construction de routes, de ports et de réseaux de télécommunication afin que les entreprises nationales puissent mieux se connecter aux marchés régionaux et mondiaux (125,4 milliards d'USD), soutien au secteur privé dans l'exploitation des avantages comparatifs et la diversification des activités commerciales (180 milliards d'USD), et contribution aux coûts associés à la libéralisation des échanges (230 millions d'USD) (figure 2.6).

Cent quarante-six pays ou territoires ont bénéficié de l'Aide pour le commerce, 154,7 milliards d'USD ayant été décaissés en Asie, 146 milliards d'USD en Afrique, 38,6 milliards d'USD en Europe, 32,7 milliards d'USD en Amérique latine et aux Caraïbes, et 5 milliards d'USD en Océanie (figure 2.7). Dans ces régions, les pays à faible revenu ont reçu 118 milliards d'USD (108,4 milliards d'USD pour les PMA et 10,2 milliards d'USD pour les autres pays à faible revenu); les PRITI, 143,8 milliards d'USD; et les PRITS, 83,4 milliards d'USD. Quant aux programmes régionaux et mondiaux, 63,5 milliards d'USD leur ont été alloués entre 2006 et 2017 (figure 2.8). En volume, les dix donateurs les plus importants de I'Aide pour le commerce (Japon, Union européenne, Banque mondiale, États-Unis, Allemagne, France, Royaume-Uni, Banque africaine de développement, Banque asiatique de développement et Pays-Bas) représentaient 82\% du total des décaissements réalisés depuis 2006. Toutefois, si l'on considère la part d'Aide pour le commerce dans l'aide programmable des pays, le classement n'est plus le même : le Fonds arabe pour le développement économique et social occupe la première place (80\% de son aide programmable), suivi du Fonds OPEP pour le développement international (66\%), de la Belgique (63\%), du Koweït (61\%), de l'Autriche (61\%) et de l'Union européenne (60\%). En 2014, l'Australie s'était fixé comme objectif d'augmenter à 20\% la part de son budget d'aide destinée à l'Aide pour le commerce d'ici à 2020. L'objectif a été atteint avant la date prévue, la part consacrée à l'Aide pour le commerce ayant atteint 23,3\% du budget total d'aide de l'Australie au cours de l'exercice 2016/17.

\section{Figure 2.7. Décaissements au titre de l'Aide pour le commerce par région, 2006-2017}

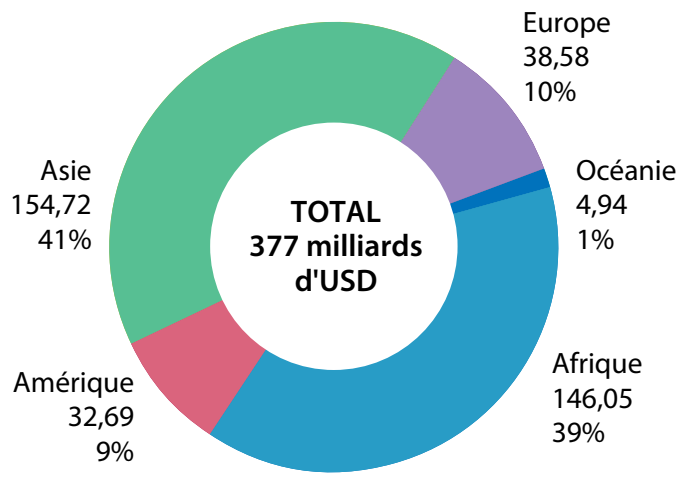

Source: Base de données du Système de notification des pays créanciers OCDE-CAD: activités d'aide (2019), DOI: http://dx.doi.org/10.1787/data-00061-en, (consulté le 6 février 2019).

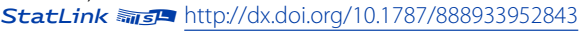

Les banques de développement et plusieurs donateurs bilatéraux (Union européenne, France, Allemagne et Corée) ont aussi fourni un total de 346 milliards d'USD sous la forme de prêts accordés à des conditions libérales ou d'AASP depuis 2006. Ces autres apports étaient essentiellement destinés aux pays à revenu intermédiaire (318 milliards d'USD) en Asie (42\%) et en Amérique latine et aux Caraïbes (23\%), pour le secteur des transports et de l'entreposage (84 milliards d'USD), des services bancaires et financiers (75 milliards d'USD), de la production et de la distribution d'énergie (75 milliards d'USD) et de l'industrie (55 milliards d'USD). 
Figure 2.8. Décaissements au titre de l'Aide pour le commerce par groupe de revenu, 2006-2017

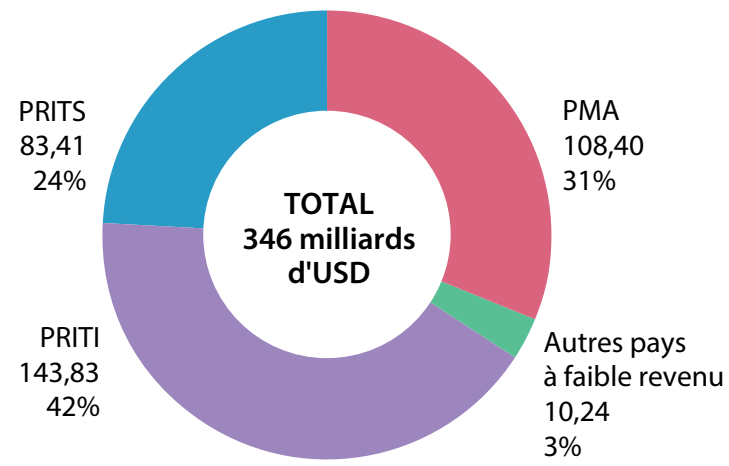

Source: Base de données du Système de notification des pays créanciers OCDE-CAD: activités d'aide (2019), DOI: http://dx.doi.org/10.1787/data-00061-en, (consulté le 6 février 2019).

StatLink न्माI http://dx.doi.org/10.1787/888933952862

\section{L'AIDE POUR LE COMMERCE EST-ELLE EFFICACE ?}

Selon de nombreuses études empiriques sur le commerce et le développement, l'Aide pour le commerce s'avère être efficace à la fois aux niveaux micro et macroéconomique (tableau 2.2). Plus précisément, l'OCDE a constaté que 1 dollar de plus investi dans l'Aide pour le commerce générait près de 8 dollars supplémentaires d'exportation pour l'ensemble des pays en développement, un montant qui passe à 20 dollars pour celles des pays les plus pauvres (OCDE/OMC, 2013). Les résultats peuvent toutefois varier considérablement selon le type d'intervention de l'Aide pour le commerce, le secteur qui reçoit l'aide, le niveau de revenu et la situation géographique du pays bénéficiaire.

Ces résultats empiriques sont corroborés par les évaluations des programmes et des projets d'Aide pour le commerce, et des études de cas soumises dans le cadre des précédents exercices de suivi de l'Aide pour le commerce (OCDE/ OMC, 2013, 2015 et 2017). L'exercice de suivi mené en 2019 montre que l'Aide pour le commerce a un impact positif sur la diversification de l'économie. Les pays partenaires ont indiqué que c'était avant tout dans le domaine de la facilitation des échanges, puis dans le secteur de l'agriculture, que le financement au titre de l'Aide pour le commerce avait eu le plus d'effets. Les donateurs estimaient, eux, que c'était dans le secteur de l'agriculture que le financement avait eu la plus forte incidence (figure 2.9).

\section{Figure 2.9. Aid for trade impacts}

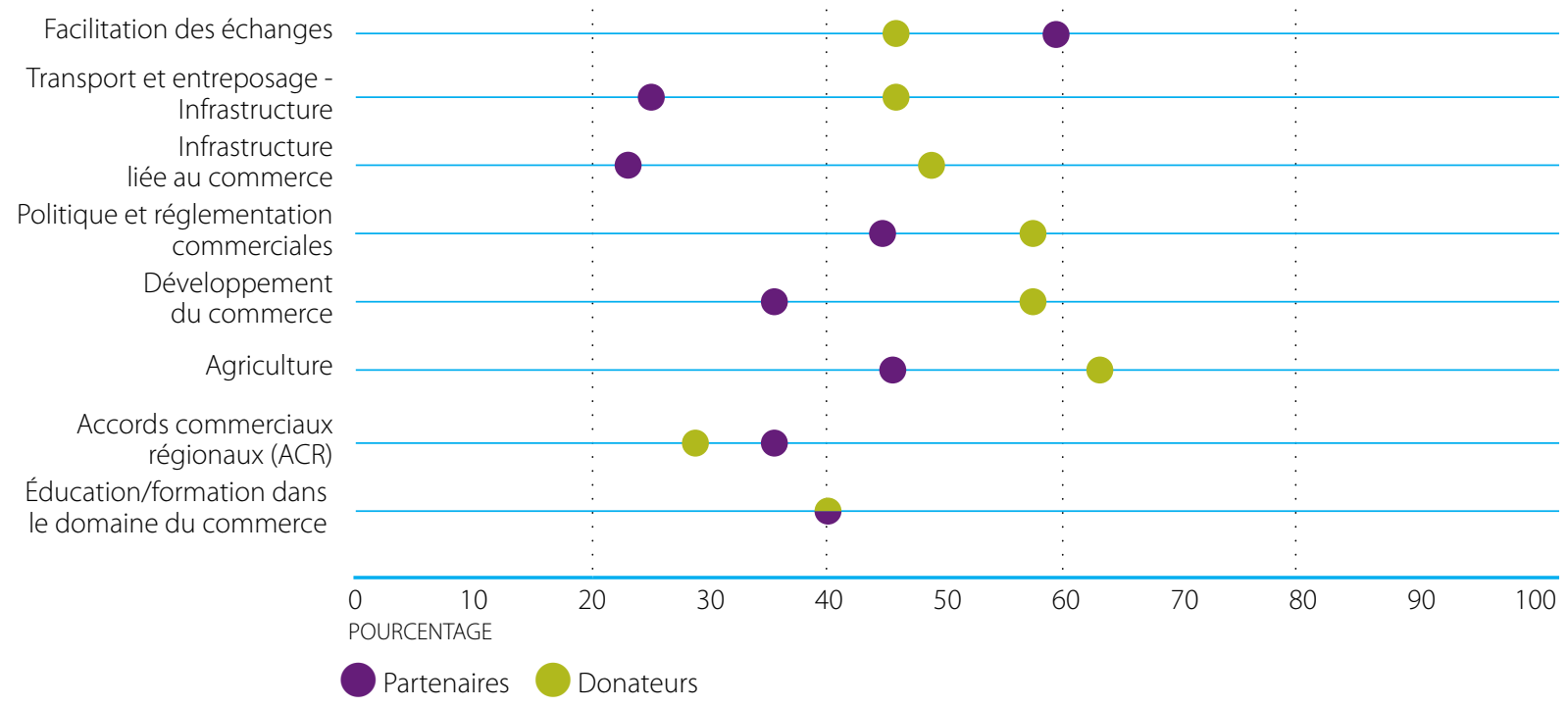


Tableau 2.3. Résultats empiriques concernant l'impact de l'Aide pour le commerce (à suivre)

\section{Constatation}

Les projets d'assistance technique par produit ont coïncidé avec une augmentation des exportations des gammes de produit bénéficiant du soutien.

De manière générale, l'Aide pour le commerce a une incidence positive et importante sur les exportations des pays bénéficiaires.

\section{Source}

Brenton, P. et Uexkull, E., (2009), Product Specific Technical Assistance for Exports - Has it been Effective?, Journal of International Trade and Economic Development, 18: pages 235 à 254, https://doi. org/10.1080/09638190902916444

Cali, M. et Te Velde, D. W. (2011), Does Aid for Trade Really Improve Trade Performance?, World Development, Elsevier, vol. 39(5), pages 725 à 740, https://econpapers.repec.org/article/eeewdevel/ v_3a39_3ay_3a2011_3ai_3a5_3ap_3a725-740.htm

Ferro, E., Portugal-Perez, et Wilson, J., (2012), Aid to the Services Sector: Does it Affect Manufacturing Exports?, Banque mondiale, http://www.ferdi.fr/ sites/www.ferdi.fr/files/DT_Ferro_Perrez_Wilson_Manufacturing\%20 Exports.pdf l'information et de la communication, de l'énergie et des services bancaires entraîne, dans les pays bénéficiaires, une hausse des exportations de produits manufacturés de $2,0 \%, 0,3 \%, 6,8 \%$ et $4,7 \%$, respectivement.

Une augmentation de 10\% des engagements d'aide à l'infrastructure par habitant dans les pays en développement entraîne une hausse moyenne de $2,34 \%$ du ratio des exportations au PIB.
Vijil, M. et Wagner, L., Does Aid for Trade Enhance Export Performance? Investigating the infrastructure channel, The World Economy, 35(7), pages 838 à 868, https://doi/full/10.1111/j.1467-9701.2012.01437.x
L'Aide pour le commerce peut constituer un outil puissant et efficace permettant de réduire les coûts du commerce dans les pays en développement et ainsi d'accroître les flux commerciaux.
Busse, M., Hoekstra, R. et Königer, J. (2012), The Impact of Aid for Trade Facilitation on the Costs of Trading, Kyklos, 65: pages 143 à 163, https:// doi:10.1111/j.1467-6435.2012.00531.x
Une hausse de $1 \%$ de l'aide à la facilitation des échanges pourrait entraîner une augmentation des échanges mondiaux de 415 milliards d'USD.
Helble, M.C., C.L. Mann et J.S. Wilson (2012), Aid-for-trade facilitation, Review of World Economics (Weltwirtschaftliches Archiv), Springer, vol. 148(2), pages 357 à 376, https://www.jstor.org/stable/41485799

Rueckert Brazys, S., (2013), Evidencing donor heterogeneity in Aid for Trade, Review of International Political Economy, 20:4, pages 947 à 978, https://DOI: 10.1080/09692290.2012.734254
Des différences dans lélaboration et la mise en œuvre de programmes peuvent engendrer des différences dans l'impact de l'Aide pour le commerce sur les exportations.
Il apparaît que les flux d'Aide pour le commerce ont eu une incidence statistiquement significative sur la réduction des délais d'exportation et d'importation en Afrique subsaharienne.
Cirera, X. et Winters, LA., (2015), Aid for Trade and Structural Transformation in Sub-Saharan Africa, Commonwealth Trade Policy Discussion Papers 2015/01, Secrétariat du Commonwealth, https://doi. org/10.14217/5js6b1lp69ms-en 
Tableau 2.3. Résultats empiriques concernant l'impact de l'Aide pour le commerce

L'Aide pour le commerce entraîne une hausse aussi bien des exportations des bénéficiaires vers les pays donateurs que des importations des bénéficiaires en provenance des pays donateurs. L'augmentation des exportations tend à l'emporter sur l'augmentation des importations, ce qui contredit l'avis des sceptiques selon lequel les donateurs accordent une aide avant tout pour promouvoir leurs propres intérêts en matière d'exportation.
Hühne, P., Meyer, B. et Nunnenkamp, P., (2014), Who benefits from aid for trade? Comparing the effects on recipient versus donor exports, The Journal of Development Studies, 50(9), pages 1275 à 1288,

https://doi.org/10.1080/00220388.2014.903246
L'Aide pour le commerce a un effet positif important sur de multiples mesures de la performance à l'exportation, mais affiche des rendements décroissants.
Ghimire S., D. Mukherjee et E. Alvi, (2016), Aid-for-rade and Export Performance of Developing Countries, Applied Econometrics and International Development, vol. 16-1, http://www.usc.es/economet/ journals1/aeid/aeid1613.pdf

Lee, H. H. et Ries, J., (2016), Aid for Trade and Greenfield Investment, World Development, volume 84, pages 206 à 218, https://www.sciencedirect.com/science/article/pii/S0305750X15301637 investissements axés sur la création d'activités entièrement nouvelles, et l'aide destinée aux infrastructures et à la capacité de production est étroitement associée à l'investissement.

L'Aide pour le commerce a une incidence solide et positive sur la réduction de la pauvreté, principalement dans les PMA, même si les effets varient selon les pays.
Durowah, O., (2017), The role of aid for trade and foreign direct investment in poverty reduction: a panel data analysis of 91 developing countries, South Dakota State University, http://openprairie.sdstate.edu/etd/1187 améliorer le cadre de politiques et à attirer I'IED nécessaire à la réalisation des ODD et au développement des infrastructures des TIC.

Les pays qui exportent moins en volume sont les principaux bénéficiaires de l'Aide pour le commerce.
L'Aide pour le commerce peut contribuer à

Roy, M., (2017), The contribution of services trade policies to connectivity in the context of aid for trade, Organisation mondiale du commerce, https://www.wto.org/english/res_e/reser_e/ersd201712_e.pdf

Martínez Zarzoso, I., Nowak Lehmann, D. F. et Rehwald, K., (2017), Is aid for trade effective? A panel quantile regression approach, Review of Development Economics, 2017; 21:e175-e203, https://doi.org/10.1111/ rode. 12322

L'Aide pour le commerce a un effet significatif et substantiel sur la promotion des flux entrants d'IED dans les pays bénéficiaires.

Lee, S., (2018), An empirical analysis of the effects of aid for trade on foreign direct investment, Seoul National University - Graduate School of International Studies, http://s-space.snu.ac.kr/ bitstream/10371/141690/1/000000150680.pdf

L'Aide pour le commerce a une incidence positive importante sur l'emploi total (hommes et femmes) et sur la part des femmes dans l'emploi, mais n'a pas d'effet significatif sur celle des hommes.

Kimm Gnangnon, S., (2018), Aid for Trade and Employment in Developing Countries: An Empirical Evidence, Labour - Review of Labour Economics and Industrial Relations, Volume 33, Issue 1, https://doi.org/10.1111/ $\underline{\text { labr.12139 }}$

Les flux entrants d'Aide pour le commerce ont des effets positifs importants sur les ratios d'exportation des pays bénéficiaires.
Kimm Gnangnon, S., (2018), Aid for Trade and Recipient Countries' Export Structure: Does Trade Policy Liberalisation Matter?, Journal of Economic Theory and Practice, https://doi.org/10.1177/0976747918806361 
Selon les opinions recueillies pendant l'exercice de suivi, l'alignement de l'Aide pour le commerce sur les priorités nationales ou régionales est un facteur clé de réussite. Soixante-deux pays partenaires estimaient que l'aide reçue pour la diversification de leur économie correspondait à leurs priorités. Cependant, les différences existant entre les priorités générales des partenaires et celles des donateurs faisaient toujours obstacle au succès de l'Aide pour le commerce, comme l'ont indiqué la moitié des pays partenaires ayant répondu au questionnaire. La plupart des donateurs étaient d'avis que la faible capacité institutionnelle était un obstacle majeur à la réussite de l'Aide pour le commerce (figure 2.10). Pour les partenaires Sud-Sud, les divergences entre les priorités des différents acteurs et le manque de coordination nationale ou régionale peuvent limiter la réussite de l'Aide pour le commerce.

La présente section a permis d'examiner les résultats et les facteurs de réussite de l'Aide pour le commerce à un niveau global. La prochaine section analysera plus en détail le soutien des donateurs en faveur de l'autonomisation grâce à la diversification économique.

\section{Figure 2.10. Facteurs de réussite de l'Aide pour le commerce}

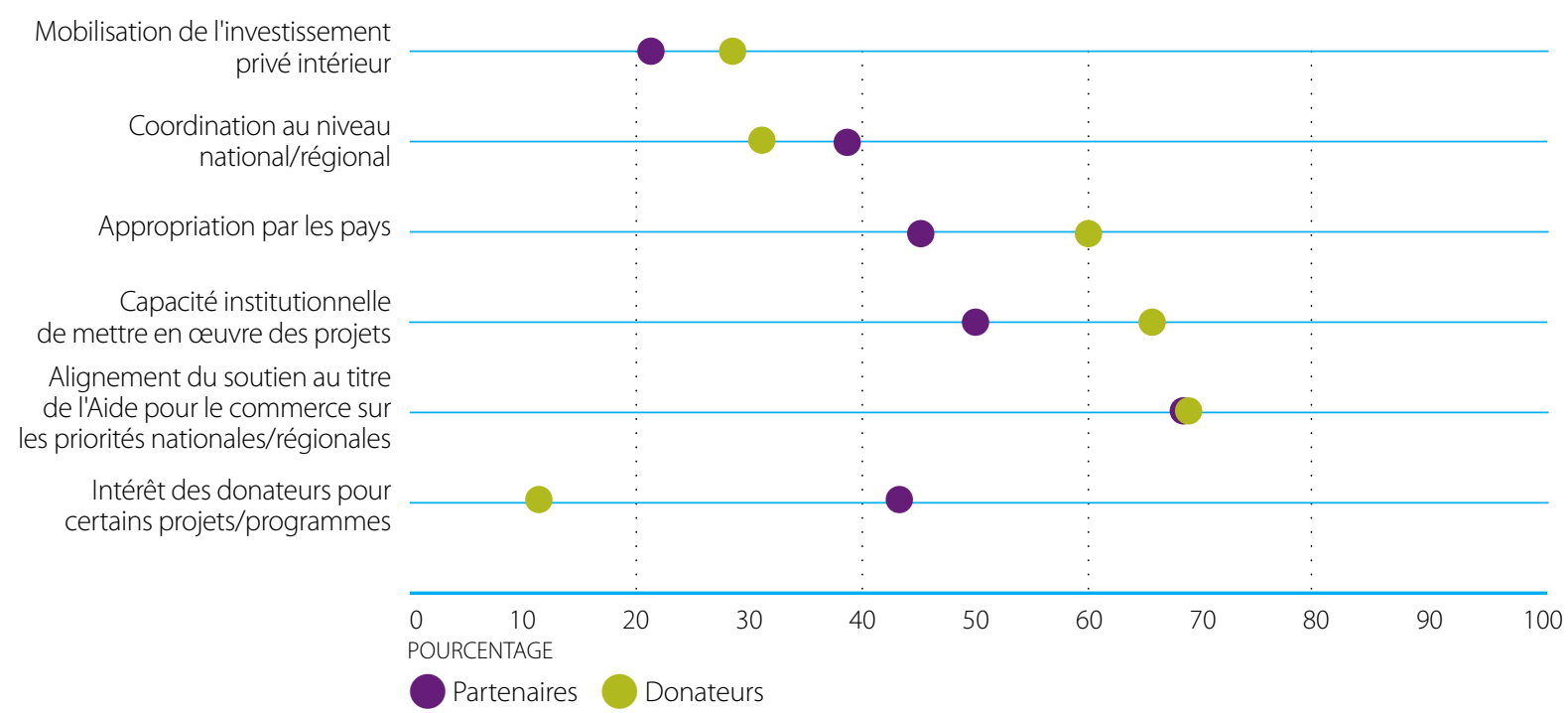

Source: Exercice de suivi de l'Aide pour le commerce OCDE-OMC (2019).

\section{L'AUTONOMISATION GRÂCE À LA DIVERSIFICATION ÉCONOMIQUE}

De nombreux pays en développement rencontrent toujours des difficultés considérables qui les empêchent d'exploiter pleinement leur potentiel économique. Dans ceux qui y parviennent, il peut être difficile de reproduire de tels résultats au niveau national. Cela pourrait entraîner l'apparition d'I'îlots d'excellence", avec des niveaux de capitaux et de connaissances plus élevés que dans le reste de l'économie. Les facteurs qui ont une incidence sur la diversification économique sont variés et dépendent du contexte ou de la situation géographique (comme dans le cas des petites îles et des pays en développement sans littoral). Certains des obstacles à la diversification économique, tels que le sous-développement du secteur privé ou un manque d'infrastructure, font également partie des problèmes que l'Aide pour le commerce cherche à éliminer. Le soutien fourni par les donateurs pour remédier à ces deux types de difficultés sera examiné dans la section suivante. D'autres types de soutien, tels que l'investissement dans l'éducation et les soins de santé, la création d'emplois ou la protection sociale, ne relèvent pas du mandat de l'Initiative Aide pour le commerce. Ils sont examinés plus avant dans d'autres parties de la publication. 
Tableau 2.4. Vues sur la diversification économique

"L'Aide pour le commerce nous a permis de diversifier notre portefeuille d'exportations et d'accorder une place moins importante au cuivre." - Zambie

"Diversifier notre production nous aiderait à garantir une croissance durable." - Kazakhstan

"La diversification économique fait depuis longtemps partie des objectifs de nos activités de soutien." - Suède

"L'amélioration du climat de l'investissement, l'accès aux marchés et les capacités locales de production sont les facteurs essentiels d'une diversification économique réussie." - Union européenne

"Entre 2012 et 2017, le Programme d'emploi saisonnier pour la région du Pacifique s'est traduit par un revenu net de plus de 144 millions d'AUD pour les pays insulaires du Pacifique et le Timor-Leste, ce qui est important pour la diversification de leurs économies." - Australie

"La diversification de l'économie suit son cours, mais doit être renforcée grâce au soutien technique et financier de partenaires." - UEMOA

"Les lacunes dans les infrastructures et les secteurs de l'énergie et de l'emploi, ainsi que dans les réglementations qui ont une incidence sur les conditions de l'activité des entreprises, représentent des obstacles majeurs à la diversification économique." - BERD

"La reprise ou la reconstruction suite aux catastrophes naturelles graves et fréquentes sont les principaux obstacles à la diversification économique." - Secrétariat du Forum des îles du Pacifique

"La diversification de l'économie est un élément clé de notre coopération commerciale avec les pays en développement, en particulier ceux qui dépendent des matières premières et les pays les plus pauvres." - Groupe de la Banque mondiale

"Le soutien apporté a pour but de remédier au peu de renseignements dont disposent les petites entreprises sur les possibilités de marché et les tendances concernant la croissance future." - PNUD

Source: Exercice de suivi de l'Aide pour le commerce OCDE-OMC (2019).

Vues de Sigrid Kaag, Ministre du commerce extérieur et de la coopération pour le développement, Pays-Bas

Améliorer les possibilités économiques des femmes et éliminer les obstacles à leur participation au commerce régional et international sont à mon sens essentiels pour promouvoir le développement économique et parvenir à des résultats plus équitables et qui profitent à toutes et tous. II s'agit là d'un des principes fondamentaux de la politique des Pays-Bas en matière de commerce extérieur et de coopération pour le développement.

Il est donc crucial de poursuivre les travaux débutés par la Déclaration de Buenos Aires sur l'égalité hommes-femmes et l'autonomisation économique des femmes. Nous devons parallèlement restés résolus à mettre en œuvre le programme d'Aide pour le commerce. L'autonomisation économique des femmes, les disparités entre hommes et femmes, l'entrepreneuriat féminin et la création de davantage d'emplois, et surtout de meilleurs emplois, pour les femmes font partie intégrante de ce programme. Les femmes sont toujours plus susceptibles que les hommes d'être confrontées à des conditions de travail défavorables, voire dangereuses.

L'entrepreneuriat peut être une voie prometteuse qui permettrait aux femmes de gagner leur vie, en particulier dans les pays à faible revenu et à revenu intermédiaire. Les femmes pourraient ainsi contribuer à l'égalité hommes-femmes en créant des emplois et en embauchant d'autres femmes. Cependant, pour faire de cela une réalité, les femmes entrepreneurs doivent jouir des mêmes droits et possibilités que les hommes, notamment en ce qui concerne l'accès aux services financiers et la possibilité de prendre part aux procédures de passation des marchés publics. La bonne nouvelle est que les technologies numériques contribuent à créer de telles possibilités.

Grâce à l'Aide pour le commerce, de nouveaux marchés sont à la portée des femmes entrepreneurs. Mais à eux seuls, ces éléments ne suffiront pas. Un grand nombre de femmes sont désavantagées en raison de leur faible niveau d'instruction et de leurs connaissances limitées des réglementations et procédures relatives au commerce transfrontières. C'est pourquoi l'accès à l'éducation, aux connaissances et aux compétences est essentiel.

En 2030, j'espère voir des femmes financièrement autonomes, capables d'exploiter leur potentiel économique, ayant les mêmes droits que les hommes et bénéficiant de bonnes conditions de travail. Nous ne pourrons réaliser les ODD que si personne n'est laissé de côté, et cela comprend aussi les femmes. Nous sommes sur la bonne voie, mais nous devons unir nos forces pour dynamiser et améliorer notre action. Mettons-nous à l'œuvre! 


\section{Diversifier la production agricole}

Une croissance de la productivité agricole est essentielle pour permettre à l'industrialisation de prendre son essor. Des études empiriques ont montré que la croissance du secteur agricole avait un lien de cause à effet avec la croissance des secteurs de l'industrie et des services. Ainsi, investir dans les nouvelles technologies agricoles permettra d'accroître la productivité agricole, moteur de la croissance dans les régions rurales. À mesure que s'opère cette transformation structurelle, la part de l'emploi et du revenu du secteur agricole commence à baisser (OCDE/OMC, 2013). L'agriculture jouant un rôle central dans les économies rurales en ce qu'elle est une source d'emplois et de revenu et contribue à la sécurité alimentaire, les donateurs manifestent un regain d'intérêt en faveur du soutien à ce secteur. La part d'APD ventilable par secteur pour l'agriculture a reculé, tombant de 25\% dans les années 1970 à un maigre 5,8\% en 2004. Elle est repartie à la hausse pour atteindre 8,5\% en réaction aux crises alimentaires survenues en 2007 et 2008, et s'élève à présent à 10\% (figure 2.11). Les investissements des donateurs visant à stimuler la productivité agricole contribuent plus efficacement à la réduction de la pauvreté et des inégalités lorsqu'ils ciblent spécifiquement les petits agriculteurs et l'agriculture à petite échelle. Il a été observé que les réformes agraires et la garantie des droits fonciers, le renforcement de l'infrastructure locale et des services publics, la consolidation des liens entre les zones urbaines et rurales et le soutien aux organisations agricoles étaient les instruments les plus efficaces à cet égard (IOB, 2018). Une grande partie des pays partenaires ayant répondu au questionnaire (34 répondants) et la majorité des donateurs (20 répondants) ont indiqué que l'agriculture était le secteur où la diversification économique avait le plus progressé grâce au soutien reçu au titre de l'Aide pour le commerce depuis 2006. En ce qui concerne l'avenir, les pays partenaires comme les donateurs estiment que l'agriculture sera le secteur dans lequel le soutien au titre de l'Aide pour le commerce sera le plus nécessaire.

\section{Figure 2.11. Engagements au titre de l'APD pour le renforcement des capacités de production, 1973-2017}

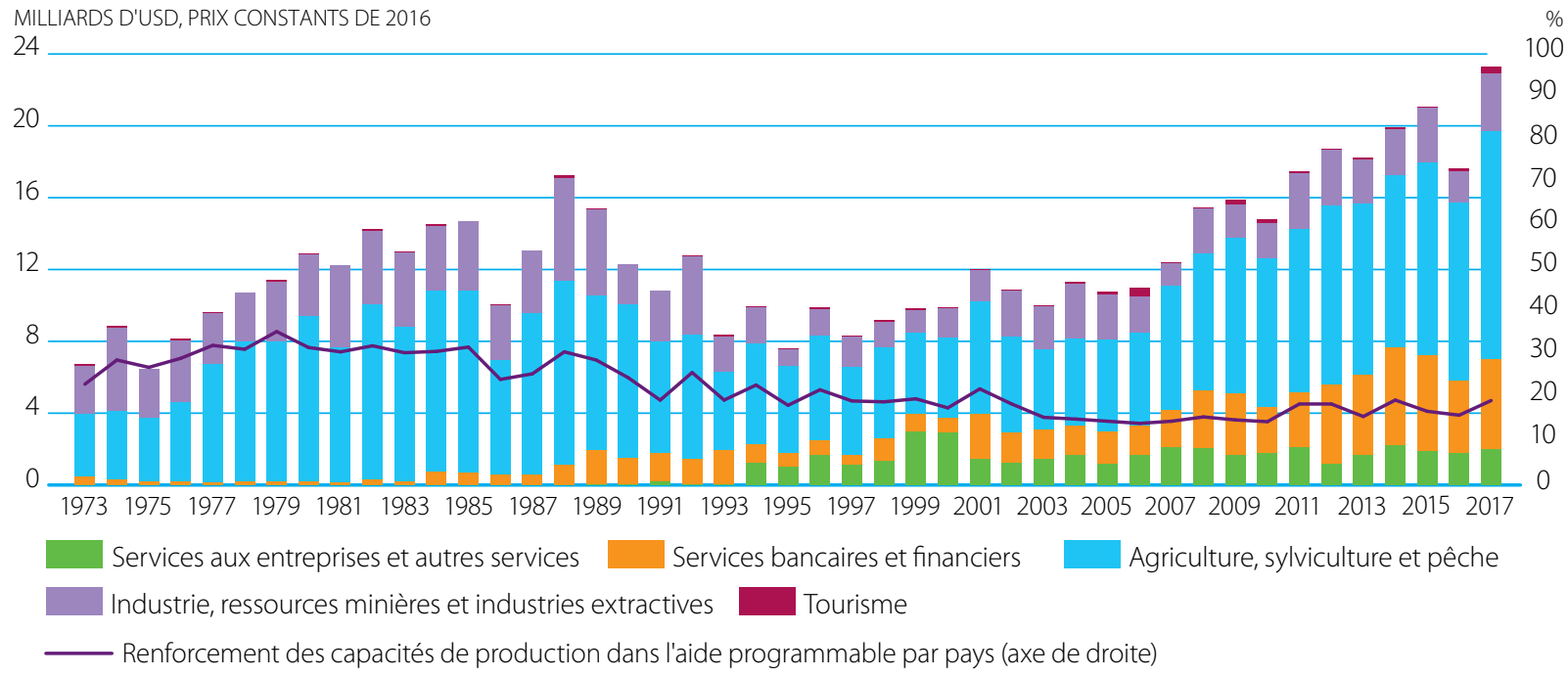

Source: Base de données du Système de notification des pays créanciers OCDE-CAD

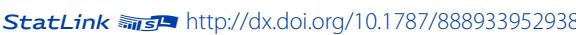

Au Sénégal, le chou est l'un des produits agricoles les plus importants. Or les expéditions de choux étaient souvent refusées aux frontières internationales en raison de la présence de résidus de pesticides toxiques. Un projet du Fonds pour l'application des normes et le développement du commerce (STDF) d'un montant de 577142 USD a aidé les producteurs locaux à accéder aux marchés en favorisant l'approvisionnement en intrants de qualité, en offrant une formation et un appui techniques en ce qui concerne les bonnes pratiques agricoles et en organisant des campagnes de commercialisation visant à promouvoir une production respectant les normes de sécurité sanitaire. Ce projet a permis d'accroître la productivité des agriculteurs, d'améliorer la qualité des choux et de rendre les prix plus compétitifs. 
S'agissant des échanges, le volume des exportations est passé de 1900 tonnes en 2008 à 6000 tonnes en 2014. Le projet a aussi favorisé la diversification des marchés, les producteurs ayant gagné de nouvelles parts de marché en Mauritanie, au Mali, en Gambie et en Guinée-Bissau.

Le Canada soutient l'accroissement de la productivité dans le secteur agroalimentaire aux Philippines. Les résultats intermédiaires de cette aide sont notamment les suivants : augmentation des revenus des petits agriculteurs, en particulier des femmes, accroissement des investissements dans les secteurs de l'agriculture et de l'agroalimentaire, et réduction des coûts liés à la mise en conformité et aux transactions. L'Australie a aidé 4121 petits agriculteurs au Cambodge à avoir accès à l'irrigation, ce qui a permis d'accroître la production de riz de 28769 tonnes et de faire évoluer les comportements sociaux à l'égard des femmes occupant des postes de responsabilité dans les communautés agricoles d'usagers de l'eau. La France a financé un projet en Haïti pour développer les chaînes de valeur agricoles, rendre le secteur du vétiver durable, diversifier les revenus des producteurs et renforcer les capacités des parties prenantes dans le domaine de la gestion de l'eau. L'Irlande développe des partenariats entre son secteur agroalimentaire et des entreprises africaines pour soutenir la croissance durable de l'industrie alimentaire locale, développer des marchés pour les produits locaux et appuyer le commerce mutuel. Le Taipei chinois fournit des semences de bambou à des entreprises au Nicaragua pour encourager la production de bambou et des équipements et machines pour la transformation du bambou afin d'accroître la productivité.

\section{Tableau 2.5. Vues sur le rôle de l'agriculture}

"Le soutien apporté au titre de l'Aide pour le commerce aux produits de la pêche et de l'agriculture renforce les liens au sein des chaînes de valeur nationales et mondiales dans les secteurs de production clés." - Kiribati

"Pour redynamiser les exportations de bananes, 2 variétés améliorées ont été introduites au Samoa en 2016, avec le soutien de I'Australie, de la Nouvelle-Zélande et du Groupe de la Banque mondiale. À ce jour, 2550 caisses ont été exportées en NouvelleZélande, mais il reste difficile de maintenir les plantations de bananes exempts de pesticides et de gérer les risques liés aux catastrophes naturelles." - Samoa

"Le projet de traçabilité de la filière du miel aide les petits producteurs à exporter vers l'Europe." - Guatemala

"Le soutien accordé par I'UE pour la traçabilité dans le secteur du bois et la production de café a contribué à une hausse de la diversification des exportations dans le pays." - République démocratique du Congo

"Le soutien au secteur agricole a favorisé la production de miel et de quelques autres produits agricoles." - Yémen

"L'assistance fournie par le CIR, la Banque mondiale et l'Organisation des Nations Unies pour l'alimentation et l'agriculture (FAO) a permis d'améliorer la productivité agricole, plus particulièrement dans la production de fruits et de légumes."

\section{- Lesotho}

"L'intervention du CIR dans le secteur de la noix de cajou a entraîné une forte hausse du revenu de plus de 10000 personnes, dont $90 \%$ sont des femmes. De même, 6679 employés des unités de transformation de la mangue, dont 80\% sont des femmes, ont vu leurs revenus augmenter considérablement." - Burkina Faso

"À lui seul, le secteur de l'agriculture, aussi développé qu'il soit, ne peut garantir le développement économique de la Guinée. L'industrie, la pêche et la sylviculture ont aussi un rôle important à jouer." - Guinée

"Le tissu industriel n'en est qu'à un stade embryonnaire, malgré les nombreuses ressources agricoles et forestières. Ces ressources sont généralement vendues ou exportées sans être transformées." - République centrafricaine

"C'est dans le domaine du respect des normes SPS que le soutien au titre de l'Aide pour le commerce en faveur de la diversification économique sera le plus nécessaire." - Saint-Kitts-et-Nevis

Source: Exercice de suivi de l'Aide pour le commerce OCDE-OMC (2019). 


\section{Développer un secteur privé dynamique}

II est essentiel de diversifier l'économie pour créer un nombre suffisant d'emplois pour les hommes et les femmes, en particulier les populations rurales pauvres et les jeunes qui entrent dans la vie active. Le secteur de l'agriculture ne peut à lui seul fournir ces emplois. En outre, l'augmentation de la productivité dans l'agriculture entraîne une baisse du besoin de main-d'œurre, c'est pourquoi il est nécessaire de créer des possibilités d'emplois productifs en développant le secteur des entreprises, dans l'industrie comme dans les services. Les stratégies et programmes de développement du secteur privé de la plupart des donateurs visent à promouvoir une croissance inclusive et durable. Dans les années 1970, les donateurs ont offert un soutien direct d'un montant d'environ 3 milliards d'USD à l'industrie et aux activités extractives. Cela équivalait à plus de $50 \%$ du total du soutien au renforcement des capacités de production. Même si le volume a continué de fluctuer entre 2 et 3 milliards d'USD, la part est tombée à environ 15\% ces dernières années (figure 2.11).

\section{Tableau 2.6. Vues sur le rôle du développement du secteur privé}

"S'agissant de la diversification économique, il y a un important potentiel de développement des services." - Samoa

La Communauté économique des États de l'Afrique de l'Ouest (CEDEAO) cible les jeunes dans ses interventions visant à développer le secteur privé en soutenant les services d'incubation d'entreprises et l'accès au financement pour les jeunes entrepreneurs et en appliquant une approche fondée sur le travail pour les projets d'infrastructure afin de promouvoir l'innovation et les inventions des jeunes.

Le Luxembourg renforce les systèmes de formation professionnelle et l'artisanat, en particulier en ce qui concerne les emplois dans les TIC et les emplois verts, en les alignant sur les besoins du marché du travail.

Le Danemark soutient le secteur privé au Ghana par l'intermédiaire d'un fonds de promotion des entreprises qui aide à diversifier les échanges et à intégrer l'économie dans le système commercial multilatéral. Les initiatives concernent notamment les licences commerciales et l'inscription au registre du commerce, des examens pour le tarif extérieur commun de la CEDEAO, la réduction des coûts de l'activité commerciale aux ports, la contrefaçon et le commerce illicite, et la ratification de l'Accord sur la facilitation des échanges.

La nouvelle stratégie de la Suisse pour le secteur privé a été adaptée et comprend davantage de mesures visant spécifiquement à améliorer les conditions de vie des groupes de population pauvres grâce à l'accès aux services de financement et aux technologies.

En 2018, la Suède a aidé 600 PME à Moldova à adopter les nouvelles technologies, à améliorer la qualité de leurs produits, à investir dans la formation de la main-d'œuvre, à garantir de meilleures conditions de travail, à augmenter les salaires et à développer leurs compétences commerciales afin qu'elles puissent tirer pleinement parti de l'accord de libre-échange complet conclu avec l'Union européenne.

La Lituanie a mis en ceuvre un projet de renforcement des capacités des PME ukrainiennes en matière de commerce international en partageant son expérience dans ce domaine.

Source: Exercice de suivi OCDE-OMC (2019).

\section{Créer un cadre propice à l'activité commerciale}

Au cours des 20 dernières années, les donateurs ont progressivement axé l'assistance technique accordée aux pays en développement sur la manière de créer des conditions propices à l'activité des entreprises et de renforcer l'inclusion des entreprises. Alors que ce type de soutien a connu des débuts timides au milieu des années 1990, sélevant au total à environ 1 milliard d'USD, il avait presque été multiplié par trois à la fin du siècle dernier. II représente aujourd'hui 2 milliards d'USD, soit 8,5\% du soutien total accordé au renforcement des capacités de production (figure 2.11). Les stratégies de développement du secteur privé des différents organismes de développement partagent de nombreux points communs. Toutes préconisent de réformer les conditions de l'activité des entreprises en réduisant la charge que représente la mise en conformité afin de permettre aux entreprises de créer des possibilités d'emploi pour les 
Tableau 2.7. Vues sur le rôle d'un cadre propice à l'activité commerciale

Une capacité institutionnelle solide est essentielle pour pérenniser le soutien des donateurs à la diversification économique. - Lesotho

La volonté politique de créer un environnement favorable est un des facteurs de réussite de l'Aide pour le commerce. - Kiribati

Le renforcement des capacités institutionnelles et humaines peut avoir une incidence positive sur l'investissement intérieur et étranger dans le développement de la production et de la productivité, la promotion des exportations et le développement des chaînes de valeur. - Népal

Le développement des PME peut passer par l'amélioration des conditions de l'activité des entreprises, le renforcement de leurs capacités et le développement d'une culture de l'entrepreneuriat et de l'innovation chez les femmes et les jeunes.

\section{- Côte d'Ivoire}

Il est important de soutenir les capacités et la coordination au niveau institutionnel à toutes les étapes des interventions en faveur de l'autonomisation économique des femmes. - TradeMark East Africa

Le soutien apporté par l'Estonie est orienté vers le renforcement des capacités institutionnelles au niveau national.

Le Luxembourg soutient des pays partenaires en créant un environnement favorable à une participation accrue du secteur privé.

La Fédération de Russie assiste le Bélarus dans son accession à l'OMC en l'aidant à renforcer ses capacités nationales et institutionnelles et ses compétences.

L'Union européenne aide la Côte d'Ivoire à établir un tribunal d'arbitrage, à adapter ses réglementations nationales aux contextes juridiques internationaux, à élaborer une politique commerciale qui lui soit propre qui identifie clairement les secteurs prioritaires, et à simplifier et à rendre plus transparentes ses procédures douanières afin que le pays puisse tirer parti du nouvel accord de partenariat économique et de ses préférences sur le marché de l'UE.

Source: Exercice de suivi OCDE-OMC (2019).

personnes pauvres. Par exemple, les États-Unis soutiennent le Viet Nam à hauteur de 42 millions d'USD dans le cadre de leur Stratégie de coopération au développement par pays dans le but de renforcer le cadre juridique et réglementaire du Viet Nam afin de promouvoir l'investissement et la croissance économique, et d'accroître les revenus. Cette aide vise à la fois à favoriser un processus d'élaboration des politiques publiques plus transparent et participatif, à créer des possibilités économiques, en particulier pour les populations sous-représentées et désavantagées, et à faire progresser l'autonomisation des femmes (Agence des États-Unis pour le développement international (USAID), 2018).

\section{Garantir un accès au financement}

Le manque de financement représente un obstacle tant pour la diversification de l'économie que pour l'autonomisation des personnes pauvres. Malgréles améliorations survenues ces dix dernières années, les systèmes financiers de nombreux pays en développement présentent toujours des lacunes et des dysfonctionnements, ce qui a des effets néfastes sur les conditions de l'activité des entreprises à plusieurs niveaux. II y a un manque d'instruments ou d'organismes adaptés aux besoins des entreprises locales, et les coûts du crédit sont souvent trop élevés faute de concurrence. Cela empêche les entreprises d'obtenir des prêts à moyen et long termes, tandis que la majorité de la population n'a pas accès aux services financiers formels de base (Buera, 2011). Tout en reconnaissant l'importance que revêt l'existence d'un environnement propice et d'organismes sur lesquels s'appuyer, certains donateurs considèrent qu'une intervention directe pourrait avoir des effets bénéfiques pour autant que les précautions nécessaires soient prises pour éviter une distorsion du marché. Les partenariats public-privé peuvent permettre aux donateurs et à leurs institutions financières de développement de participer directement au financement d'une activité ou à une structure de garantie pour celle-ci. Les donateurs et les institutions servent alors de catalyseurs pour attirer le financement privé. On considère que c'est là un moyen efficace 
Tableau 2.8. Vues sur l'amélioration de l'accès au financement

"L'Aide pour le commerce peut avoir un effet positif sur l'accès au financement pour les PME." - Angola

"L'accent devrait être mis sur l'accès au financement pour les femmes entrepreneurs à des taux attrayants et à des conditions moins strictes." - Madagascar

"L'accès au financement fait partie des facteurs de réussite de l'Aide pour le commerce." - Iraq

"Le soutien devrait être davantage axé sur la promotion de l'accès au financement." - Togo

"Les domaines prioritaires dans lesquels nous aurons besoin d'un financement sont les subventions directes aux producteurs, les fonds de garantie et les fonds de participation pour garantir l'accès au financement." - Guinée

"L'Aide pour le commerce peut contribuer à l'autonomisation économique des femmes de plusieurs manières, notamment via des programmes aidant les femmes à accéder au financement du commerce." - Kiribati

"L'Union européenne soutient, par l'intermédiaire de la Banque asiatique de développement, l'accès au financement des MPME au Samoa, aux Tonga, au Vanuatu et aux Îles Salomon."

"La BERD soutient les initiatives de financement portant sur un volume important et de longues durées. Cela comprend le financement du commerce Sud-Sud, en pleine expansion, et le commerce intrarégional avec Chypre, la Grèce et la Turquie."

Le Canada fournit des services de crédit et des services financiers aux populations pour lesquelles l'accès à ces services est insuffisant au Panama, en Tanzanie, en Tunisie et en Zambie.

L'Autriche offre un financement sous forme de prêts et de participation au capital social aux organismes des pays partenaires qui sont entièrement dédiés aux PME gérées par des femmes.

Source: Exercice de suivi OCDE-OMC (2019).

de maximiser l'effet multiplicateur de l'APD. Le soutien des donateurs aux services bancaires et financiers s'élevait à environ 1,5 milliard d'USD jusqu'à la crise financière de 2007-2008. Après l'épuisement des crédits, les donateurs sont intervenus et ont multiplié par deux leur soutien en 2009. L'aide a continué d'augmenter et a atteint 5 milliards d'USD en 2017. Aujourd'hui, près de $22 \%$ du soutien total accordé au renforcement des capacités de production est destiné aux services bancaires et financiers (figure 2.11).

\section{Promouvoir un tourisme inclusif}

Le tourisme est un important catalyseur de transformation structurelle dans plusieurs pays en développement. En raison du peu d'obstacles imposés à l'entrée de la main-d'œuvre et des faibles besoins en capital, le tourisme peut constituer un moyen alternatif de subsistance, en particulier dans les régions rurales. La croissance des services à forte intensité de main-d'œuvre associés au tourisme a permis de réaffecter l'excédent de main-d'œuvre du secteur agricole. II est essentiel de créer des liens solides entre les secteurs pour mieux cerner les dépenses des touristes, un élément déterminant qui permet de transférer plus facilement les avantages économiques du secteur aux communautés locales. Un approvisionnement en intrants locaux peut créer des possibilités commerciales pour les fournisseurs locaux, ce qui, en amont, permet de créer des emplois et, en aval, de stimuler les marchés des produits ou services consommés par les touristes. Ainsi, les liens entre le tourisme et d'autres secteurs de production peuvent stimuler l'emploi et contribuer à la lutte contre la pauvreté et l'exclusion sociale, notamment parmi les femmes et les jeunes (OCDE/Organisation mondiale du tourisme (OMT)/OMC, 2013). Le soutien direct des donateurs au tourisme est relativement modeste : il s'élève à environ 180 millions d'USD en moyenne par an depuis 2006 (figure 2.11). La plupart des fonds sont utilisés pour des activités d'assistance technique visant à soutenir l'élaboration de stratégies de promotion d'un tourisme durable et 
Tableau 2.9. Vues sur le rôle du tourisme

"Grâce au soutien des donateurs, les petites entreprises ont pu lancer leurs activités touristiques en ligne, ce qui montre que le tourisme est un secteur prometteur. Les communautés locales acquièrent de nouvelles connaissances, notamment en ce qui concerne la production de nourriture locale pour les touristes." - Vanuatu

"Plusieurs mesures ont été prises pour redynamiser le secteur du tourisme: suppression des visas d'entrée, construction d'un nouvel aéroport, octroi de crédits hôteliers pour financer les hébergements pour touristes, création d'un statut fiscal spécial pour les entreprises touristiques installées dans la Casamance, établissement de régions touristiques intégrées et amélioration de l'hébergement, entre autres." - Sénégal

"Les établissements touristiques ont fait l'objet d'un classement en étoiles pour attirer davantage de touristes. De plus, le système d'inscription au registre du commerce a été automatisé pour améliorer la facilité de faire des affaires dans le pays." - Lesotho

"Dans le secteur des voyages et du tourisme, l'indice d'ouverture sur les visas en Afrique a encouragé la réforme des politiques de visas pour les voyages intra-africains." - Banque africaine de développement

"Les indicateurs ou cibles relatifs à l'autonomisation économique pour le secteur du tourisme comprennent l'amélioration de l'accès au crédit pour les petits entrepreneurs, l'établissement d'un fonds en faveur de l'autonomisation des petites entreprises touristiques et l'octroi d'incitations pour le développement des petites entreprises dans le tourisme." - Saint-Kitts-et-Nevis

"Grâce au projet relatif à la compétitivité à Moldova, le secteur du tourisme a connu une hausse de 20\% en 2017." - Suède

"La Suisse finance, par l'intermédiaire du Groupe interinstitutions des Nations Unies sur le commerce, un projet visant à améliorer les moyens de subsistance en Tanzanie en favorisant l'adoption des critères régissant le tourisme responsable. Ce projet établit des liens en amont avec les secteurs locaux (principalement le secteur agroalimentaire) et promeut un tourisme responsable et un dialogue public-privé. II fait partie du volet relatif au tourisme du Programme de développement du commerce du gouvernement." - Suisse

"Certains pays dépendent d'un seul secteur pour leurs exportations; ces secteurs auront à l'avenir probablement besoin d'un soutien pour se diversifier. C'est notamment le cas, dans la région du Pacifique, des secteurs de l'extraction de pétrole, du tourisme et de la pêche." - Nouvelle-Zélande

Source: Exercice de suivi OCDE-OMC (2019).

à renforcer les liens en amont et en aval avec l'économie locale. Seize pays partenaires ayant répondu au questionnaire et 10 donateurs ont indiqué que le secteur des voyages et du tourisme était celui dans lequel l'Aide pour le commerce avait eu le plus d'effets. Quarante-huit pays partenaires et 10 donateurs estimaient qu'il était nécessaire de soutenir le secteur du tourisme au titre de l'Aide pour le commerce pour parvenir à une diversification de l'économie.

\section{Développement du commerce}

Selon le marqueur du développement du commerce, les décaissements effectués en 2017 équivalaient à 5,5 milliards d'USD, alors que les engagements étaient de 7,9 milliards d'USD. Ce marqueur a été introduit pour identifier les activités de la catégorie renforcement des capacités de production qui contribuent "principalement" ou "de façon significative" à l'essor du commerce. En 2017, 31\% du soutien total au secteur privé rentraient dans cette catégorie. Les activités étaient concentrées dans les secteurs des services fournis aux entreprises, de l'agriculture et de l'industrie, qui représentaient à eux trois plus de $75 \%$ du total des marqueurs du développement du commerce. 
Tableau 2.10. Vues sur le développement du commerce

"La politique de développement de la Finlande s'articule autour de 4 domaines de priorité. L'un deux concerne le soutien au développement et à la diversification des économies des pays en développement. Cela comprend notamment le développement du commerce, la facilitation des échanges, les chaînes de valeur, les capacités de négociation en matière de politique commerciale." - Finlande

"Le développement du commerce (services annexes fournis aux entreprises et services bancaires et financiers) et le soutien juridique aux MPME sont les 2 principaux piliers de l'autonomisation économique des MPME." - Portugal

"Le Centre pour le commerce et l'investissement en Afrique de l'Est de l'USAID vise à stimuler le commerce et l'investissement avec l'Afrique de l'Est et au sein de cette région. Pour ce faire, il promeut le commerce bilatéral avec les États-Unis dans le cadre de la Loi sur la croissance et les perspectives économiques de l'Afrique, facilite l'investissement, renforce l'intégration régionale et accroît la compétitivité de certaines chaînes de valeur agricoles." - États-Unis

"Le Programme de soutien au commerce en Angola vise à renforcer les capacités locales pour diversifier l'économie et négocier et mettre en ouvre les accords commerciaux régionaux et multilatéraux, en mettant l'accent sur le Protocole de la Communauté de développement de l'Afrique australe (SADC) sur le commerce et la participation de l'Angola à la zone de libre-échange de la SADC." - Union européenne

Source: Exercice de suivi OCDE-OMC (2019).

\section{RENFORCEMENT DE L'INFRASTRUCTURE LIÉE AU COMMERCE}

La faiblesse des infrastructures reste un problème majeur dans les pays en développement, malgré les investissements importants réalisés par le passé. En accroissant la productivité de la main-d'œuvre et en diminuant les coûts de transaction et de production, l'infrastructure économique (transport, énergie et TIC) encourage l'activité économique et, par là même, contribue à la diversification de l'économie. Les investissements dans les infrastructures, s'ils sont suffisamment ciblés, peuvent aussi contribuer à l'autonomisation. Par exemple, l'amélioration de l'infrastructure de transport et de communication encourage la mobilité de la main-d'œuvre dans les régions rurales. L'inadéquation de l'infrastructure a été citée comme le premier obstacle à la réussite de l'Aide pour le commerce en ce qui concerne la promotion de la diversification économique dans les PMA, 23 répondants ayant dit avoir des difficultés dans ce domaine. II s'agit également du principal problème entravant le succès de l'Aide pour le commerce dans les pays en développement sans littoral. En outre, 15 donateurs ont classé ce problème au troisième rang de leurs défis principaux.

\section{Améliorer les infrastructures de transport}

Les infrastructures de transport ont des effets sur la rentabilité, les niveaux de production, de revenu et d'emploi, en particulier pour les petites et moyennes entreprises, et les coûts du commerce, qui déterminent la compétitivité au niveau international. L'amélioration des transports engendrera une hausse de la rentabilité économique de la maind'œuvre en réduisant le temps consacré par les travailleurs à des activités non productives. Pour la même raison, le manque d'accès abordable à une infrastructure adéquate est un facteur déterminant de la nature et de la persistance de la pauvreté. Ainsi, grâce aux investissements réalisés dans les infrastructures de transport, il est possible de passer d'une croissance non génératrice d'emplois à une croissance à forte intensité de main-d’œuvre (Calderón, 2004). Au vu de ces retombées positives manifestes, les donateurs ont investi massivement pour aider les pays en développement à étendre et à améliorer leurs infrastructures de transport. En 2017, le soutien au secteur des transports et de l'entreposage s'élevait à 17,7 milliards d'USD, soit une augmentation de 10 milliards d'USD depuis le lancement de I'Initiative Aide pour le commerce (figure 2.12). 


\section{Tableau 2.11. Vues sur les infrastructures liées au commerce}

"La faiblesse des infrastructures peut limiter l'efficacité du soutien reçu au titre de l'Aide pour le commerce." - Libéria

"Le soutien aux infrastructures liées au commerce améliore les liens au sein des chaînes de valeur dans des secteurs productifs majeurs, ce qui engendre une hausse des exportations, de l'emploi, du revenu et des moyens de subsistance." - Kiribati

"Notre pays accuse un retard important en ce qui concerne l'industrialisation et le développement des infrastructures de base."

- République démocratique du Congo

"Les besoins en matière d'infrastructure liée au commerce sont extrêmement larges et les ressources sont très limitées."

- Vanuatu

"Nous apprécierions grandement de recevoir un soutien pour le développement d'infrastructures liées au commerce." - Népal

"Les infrastructures de réseau et de transport limitent la capacité des personnes de se lancer dans d'autres domaines du développement." - Papouasie-Nouvelle-Guinée

"Nous redonnons vie à la route de la soie en établissant un couloir de transport entre l'Europe occidentale et l'ouest de la Chine."

\section{- Kazakhstan}

"Un nouvel investissement d'un montant allant jusqu'à 500 millions de GBP permettra de construire des infrastructures essentielles, qui créeront de nouvelles possibilités dans des endroits où les entreprises ne pouvaient pas auparavant exercer leurs activités." - Royaume-Uni

"Dans le contexte de la Conférence internationale de Tokyo sur le développement de l'Afrique, les investissements du Japon en Afrique, d'un montant d'environ 30 milliards d'USD sous forme d'un partenariat public-privé, se concentrent, entre autres, sur le développement d'une infrastructure qualité." - Japon

"La Banque mondiale héberge le secrétariat de l'Alliance mondiale pour la connectivité des infrastructures, une initiative lancée par le G-20 en 2016 visant à combler le manque de ressources disponibles en lien avec la connectivité des infrastructures. Cette initiative promeut la coopération, l'échange de connaissance et la réalisation de progrès véritables dans l'interconnectivité à l'échelle mondiale." - Banque mondiale

Source: Exercice de suivi OCDE-OMC (2019).

\section{Figure 2.12. Engagements au titre de l'APD pour des infrastructures liées au commerce}

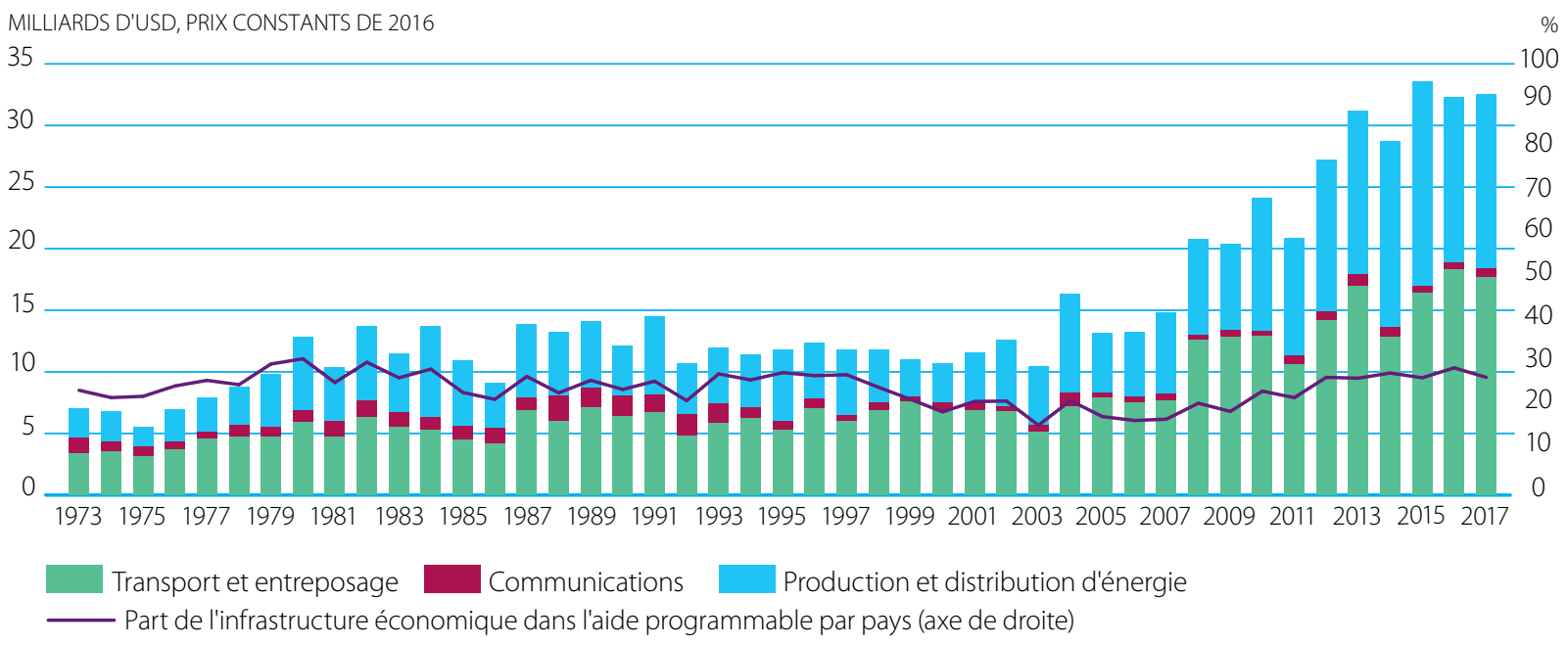

Source: Base de données du Système de notification des pays créanciers OCDE-CAD. 
L'initiative Ceinture et route vise à renforcer l'intégration économique entre les pays de la région eurasiatique. Elle comprend un certain nombre de couloirs : la "ceinture" relie la Chine à l'Europe en passant par l'Asie centrale et l'Asie du Sud, tandis que la "route" connecte la Chine à l'Asie du Sud-Est, à la région du Golfe, à l'Afrique de l'Est et du Nord et à l'Europe. Le projet requiert de lourds investissements : 8000 milliards d'USD sur la seule période 2010-2020, selon les estimations. Le gouvernement chinois a annoncé plusieurs engagements, y compris la création du Fonds de la route de la soie de 40 milliards d'USD pour des projets en Asie centrale (Lehmacher et Padilla, 2015). Selon Baniya (2019), cette initiative entraîne une hausse des flux commerciaux des pays participants allant jusqu'à 4,1\%. Ces effets pourraient être multipliés par trois en moyenne si l'amélioration de l'infrastructure des transports était accompagnée de réformes commerciales. Les gains commerciaux sont plus élevés pour les produits requérant des intrants sensibles au facteur temps et pour les pays qui sont très exposés aux nouvelles infrastructures et intégrés dans les chaînes de valeur mondiales. Plusieurs pays partenaires ayant répondu, dont le Venezuela, les Tonga, le Cambodge et le Kazakhstan, ont indiqué que le Fonds de la Route de la Soie était une source importante de financement pour la diversification de l'économie.

Un autre projet en lien avec les infrastructures de transport concerne le développement du port de Thilawa et de ses installations logistiques, et l'établissement d'une zone économique spéciale au Myanmar. Le Japon soutient ce projet à hauteur de 339 millions d'USD sous forme de prêts à des conditions libérales. L'évaluation d'un projet similaire en Indonésie réalisée a posteriori a mis en évidence la nécessité qu'il y avait de construire des infrastructures routières en périphérie parallèlement aux installations portuaires. Le Japon applique une approche intégrée de soutien aux infrastructures liées au commerce similaire au Viet Nam : il a récemment annoncé qu'il fournirait à ce pays une aide de 95 millions d'USD sous forme de prêts à des conditions libérales en vue de développer un port en eau profonde près de Haiphong et de soutenir la construction de routes à l'intérieur des terres et de ponts (exercice de suivi OCDE-OMC 2017, cas d'expérience n 161).

\section{Garantir un approvisionnement fiable en électricité}

Selon I'OCDE (2013), l'électricité constitue un obstacle plus grand encore que les infrastructures routières ou aériennes. Ce n'est pas tant l'accès à l'électricité qui pose problème, mais sa fiabilité. Ces conclusions sont confirmées par les entreprises des pays en développement qui ont indiqué que le manque de fiabilité du réseau électrique était un problème majeur pour elles. En effet, les producteurs peuvent remédier au manque d'électricité en utilisant des générateurs, une pratique largement répandue. Cependant, l'utilisation de telles installations engendre des coûts considérables : le coût marginal de l'électricité produite par des générateurs est bien plus élevé que l'électricité provenant du réseau, et le coût d'équipement d'un générateur s'ajoute au coût total des machines et appareils. Greenstone (2014) souligne qu'un accès plus large à un réseau d'énergie fiable transforme les vies et les économies de nombreuses manières, notamment en créant des revenus, en favorisant la diversification économique, la substitution du travail par un capital améliorant la productivité et la création de petites entreprises, en permettant aux ménages (en particulier aux femmes) d'affecter davantage de temps à l'amélioration de leur niveau d'instruction plutôt qu'à la fourniture d'énergie, et en favorisant l'accès à des marchés beaucoup plus vastes en raison de la diminution des coûts de transport et de communication.

Le soutien accordé par les donateurs à la production et à la distribution d'énergie a atteint 14,1 milliards d'USD en 2017, contre 9 milliards d'USD en 2016. La part moyenne de l'aide octroyée au secteur de l'énergie dans l'aide programmable par pays était de 12\% au cours des trois dernières années (figure 2.13). Par exemple, la France a accordé, avec la Banque africaine de développement et la Banque européenne d'investissements, un prêt de 60 millions d'euros pour la construction d'une ligne à haute tension entre Nairobi et Mombasa. Le projet améliore l'accès à un approvisionnement en électricité ayant un bon rapport coût-efficacité et à un réseau fiable, ce qui entraîne une diminution des pertes techniques et des coûts environnementaux. 
Tableau 2.12. Vues sur le rôle de l'énergie

"Le secteur de l'énergie a reçu un soutien considérable qui a favorisé la connexion des entreprises et du commerce et a promu le rôle du Kazakhstan en tant que route commerciale entre l'Asie centrale et l'Asie du Sud." - Kazakhstan

"L'amélioration de la situation énergétique a contribué de manière significative à la reprise des activités du secteur secondaire." - Sénégal

"Le soutien au secteur de l'énergie a aussi conduit à des investissements de la part du secteur privé." - Gambie

"L'électrification de la Guinée doit aussi être prise en compte pour garantir le développement économique du pays." - Guinée

Source: Exercice de suivi OCDE-OMC (2019).

Vingt-sept pays partenaires ayant répondu ont indiqué dans leur stratégie de développement nationale ou régionale que les prix et le manque de fiabilité de l'électricité représentaient un obstacle à la diversification de l'économie. Vingttrois pays, dont 9 PMA, ont confirmé recevoir un financement au titre de l'Aide pour le commerce dans le domaine de la production et de la distribution d'énergie. En outre, 19 pays ont signalé que ce soutien avait produit des résultats. De même, 12 donateurs ont indiqué fournir une aide à la production et à la distribution d'électricité, et 10 ont confirmé que cela avait des effets sur la diversification de l'économie. En ce qui concerne l'avenir, 44 pays partenaires, dont 26 PMA, ont souligné la nécessité d'affecter davantage de fonds à ce secteur au titre de l'Aide pour le commerce.

\section{Soutenir les technologies de l'information et de la communication}

Le rapport conjoint OCDE-OMC Panorama de I'Aide pour le commerce 2017 a abordé en détail comment les TIC aidaient les entreprises à devenir plus productives, les particuliers à trouver de meilleures possibilités d'emploi et les gouvernements à offrir de meilleurs services. Le rapport a souligné que les TIC diminuaient les coûts des transactions économiques et sociales pour les entreprises, les particuliers et le secteur public. Ces technologies favorisent l'innovation et accroissent l'efficacité en rendant les activités et les services existants moins coûteux, plus rapides et plus pratiques. Elles améliorent également l'inclusion, en permettant à certains d'accéder à des services auxquels ils n'avaient auparavant pas accès. Les donateurs aident à encourager l'investissement privé nécessaire pour combler la fracture numérique en offrant aux pays en développement une assistance technique et des mécanismes d'atténuation des risques pour attirer les fonds privés.

Les engagements au titre de l'Aide pour le commerce en faveur de projets relatifs aux TIC s'élevaient à 700 millions d'USD en 2017 (figure 2.11). La plupart de ces engagements prennent la forme d'une assistance technique en faveur d'une réforme de la réglementation. Une fois que le cadre réglementaire est en place, le secteur privé est disposé à investir dans l'infrastructure matérielle des TIC. Les donateurs ont également indiqué que ce domaine suscitait une demande croissante. On peut par exemple citer l'initiative Connect Africa, qui comprend la connectivité internationale par fibre optique, les initiatives nationales de réseau dorsal, les politiques et les réglementations, et les applications électroniques (Exercice 2017 de suivi de l'Aide pour le commerce OCDE-OMC, cas d'expérience du secteur public $n^{\circ}$ 16). Plus de la moitié des pays partenaires ayant répondu ont dit que l'inadéquation des infrastructures de réseau représentait un obstacle à la diversification économique, ce qui est également ressorti de leurs stratégies de développement nationales ou régionales. La moitié des donateurs considéraient cette question comme un des principaux domaines cibles de leurs stratégies d'Aide pour le commerce. Près de deux tiers d'entre eux considéraient que leur soutien dans ce domaine pourrait grandement contribuer à l'autonomisation économique des jeunes, un avis que partageaient 50 pays partenaires. 
Tableau 2.13. Vues sur le rôle des TIC

"Une infrastructure de réseau appropriée doit être disponible et pleinement accessible pour soutenir la production et la fourniture de services, notamment le développement du commerce électronique et la facilitation des échanges." - Samoa

"À l'avenir, le soutien à la diversification économique pourrait concerner les infrastructures de réseau et les transports transfrontières, les services, l'agriculture et l'industrie." - Gabon

"Le Luxembourg aidera les pays partenaires à promouvoir des solutions dans le domaine des TIC et des données fiables pour favoriser une croissance et un développement innovants et inclusifs." - Luxembourg

"L'Aide pour le commerce devrait soutenir le secteur des TIC en tirant parti des technologies numériques pour simplifier et réduire les coûts des procédures transnationales de certification et de traitement des documents pour les MPME." - Irlande

- Nouvelle-Zélande

"Pour que les PME trouvent des partenaires commerciaux, il est très important de diffuser des renseignements sur Internet et de créer différentes plates-formes en ligne permettant aux exportateurs d'échanger des informations." - Ukraine

"De nouvelles questions, telles que le commerce électronique, sont en train d'émerger et de prendre de l'importance."

- CEDEAO

"En raison des discussions récentes sur les conséquences du numérique et de l'automatisation pour la transformation structurelle et de l'augmentation des demandes à cet égard, nous accordons une plus grande attention à ces questions."

- Suède

"Le Taipei chinois accorde un prêt à Belize Telemedia Limited pour l'aider à financer son Plan national pour la large bande visant à remplacer son infrastructure d'accès fixe à Internet par un réseau à fibre optique dans le but d'améliorer la qualité des services d'Internet fixe et l'accès à ces services." - Taipei chinois

Source: Exercice de suivi OCDE-OMC (2019).

\section{Soutenir les politiques commerciales pour promouvoir la diversification économique}

Les stratégies de diversification économique devraient être fondées sur des avantages comparatifs et des mesures tarifaires et non tarifaires structurées de manière à soutenir le processus. Par exemple, les droits de douane imposés aux intrants industriels intermédiaires pour lesquels il n'existe pas de capacité de production régionale étant particulièrement élevés, il est nécessaire de réduire les coûts du commerce autres que les droits de douane pour remédier aux contraintes du côté de l'offre entravant l'industrialisation (Commission économique pour l'Afrique (CEA-ONU), 2017). Depuis 2006, les donateurs se sont engagés à fournir 7 milliards d'USD pour aider les pays en développement à définir, à négocier et à mettre en œuvre des accords commerciaux. Par exemple, la Suède fournit une aide dans ce domaine au Trade Law Center (TRALAC), un organisme de renforcement des capacités situé en Afrique. En menant des consultations avec les parties prenantes, le TRALAC établit de manière proactive des liens avec la zone de libre-échange continentale africaine et a déterminé qu'il était nécessaire d'accroître les capacités dans le domaine du commerce des services et de faire progresser la réflexion sur le commerce des services aux fins du développement industriel des pays africains (exercice de suivi OCDE-OMC (2017), cas d'expérience n²1).

\section{Ajustement lié au commerce}

Le soutien à l'ajustement lié au commerce est relativement faible, s'élevant à 230 millions d'USD en moyenne depuis le lancement de I'Initiative en 2006. Cela s'explique en partie par le fait que cette catégorie de soutien au titre de l'Aide pour le commerce est notifiée sous d'autres catégories. On peut prendre pour exemple le projet de développement du tourisme à Saint-Vincent-et-les Grenadines soutenu par le Fonds européen de développement à hauteur de 6,5 millions d'USD. Ce projet visait à améliorer la compétitivité du secteur touristique et à créer des possibilités d'emploi 
pour les communautés rurales afin d'aider le pays à s'adapter à la baisse de la production et des exportations de bananes. Les évaluations périodiques ont montré qu'il avait permis d'augmenter les possibilités d'emploi, d'améliorer la qualité des produits touristiques du pays et de renforcer les liens entre le tourisme et d'autres secteurs économiques (Exercice de suivi OCDE-OMC (2011), cas d'expérience $\left.n^{\circ} 264\right)$. Les efforts visant à garantir un cadre de facilitation des échanges efficace et compétitif devraient aussi continuer de recevoir une attention. Ils sont abordés plus avant dans le chapitre 6.

\section{LE SOUTIEN EN 2017}

Les engagements au titre de l'Aide pour le commerce sont des obligations fermes exprimées par écrit et appuyées par le financement nécessaire prises par un donateur public de fournir une aide déterminée à un pays bénéficiaire ou à une organisation multilatérale. En tant que tels, ils sont l'expression des priorités en cours du bénéficiaire et du donateur. Les engagements sont comptabilisés à hauteur du montant total du transfert prévu, quel que soit le délai requis pour effectuer les décaissements, qui peuvent prendre de nombreuses années dans certains cas. Le reste de cette section présente une analyse des engagements au titre de l'Aide pour le commerce jusqu'en 2017, dernière année pour laquelle des données détaillées sont disponibles. Elle met l'accent sur la répartition par secteur, région et groupe de revenu, et renseigne sur les donateurs et les modalités financières du soutien promis.

En 2017, les engagements au titre de l'Aide pour le commerce se sont élevés à 57,7 milliards d'USD, en hausse de 6,2 milliards d'USD en termes réels par rapport à 2016 et de 34,6 milliards d'USD par rapport à la moyenne de la période de référence 2002-2005. Les AASP liés au commerce ont diminué de 7 milliards d'USD en 2017, reculant à 60,1 milliards d'USD; malgré cela, ils restent plus de quatre fois plus élevés que la moyenne de la période de référence 2002-2005. Les engagements visant l'infrastructure économique ont atteint 32,8 milliards d'USD, soit une hausse de 143\% par rapport à la moyenne de la période de référence 2002-2005. En 2017, l'aide en faveur de la production et de la distribution d'énergie s'est accrue de plus de 759 millions d'USD pour s'établir à 14,3 milliards d'USD. Les engagements visant le secteur de l'information et de la communication ont eux aussi connu une hausse de 167 millions d'USD, atteignant 749 millions d'USD. Le soutien au transport et à l'entreposage a quant à lui diminué de 514 millions d'USD, et s'élève à présent à 17,1 milliards d'USD. Les AASP destinés à l'infrastructure économique ont diminué de 15,2\%, pour s'établir à 29,9 milliards d'USD. Cette baisse est en grande partie due à la réduction de l'aide accordée à la production et à la distribution d'énergie, qui a reculé de 6,7 milliards d'USD, tombant à 15,2 milliards d'USD en 2017 (figures 2.13 et 2.14).

D'un montant de 23,4 milliards d'USD, les engagements en faveur du renforcement des capacités de production ont augmenté de 5,3 milliards d'USD en termes réels par rapport à 2016. Comme les années précédentes, l'aide est allée pour l'essentiel à l'agriculture, qui a recueilli 10,6 milliards d'USD, soit 1,6 milliard d'USD de plus qu'en 2016. Le soutien en faveur des services bancaires et financiers et de l'industrie a augmenté de 1 milliard d'USD, et celui accordé à la pêche, de 465 millions d'USD. Le soutien au tourisme s'élève à 400 millions d'USD, soit une hausse de 50\% par rapport à 2016. Le marqueur du développement du commerce a été introduit pour identifier les activités de la catégorie renforcement des capacités de production qui contribuent "principalement" ou "de façon significative" à l'essor du commerce. Le marqueur est passé de 2,6 milliards d'USD en 2006 à 8,1 milliards d'USD. II couvre à présent près d'un quart du montant total octroyé au renforcement des capacités de production. Pour les deux tiers, ce soutien se concentre dans l'agriculture et les services aux entreprises. 
Figure 2.13. Engagements au titre de l'Aide pour le commerce, en milliards d'USD, en prix constants de 2017 70

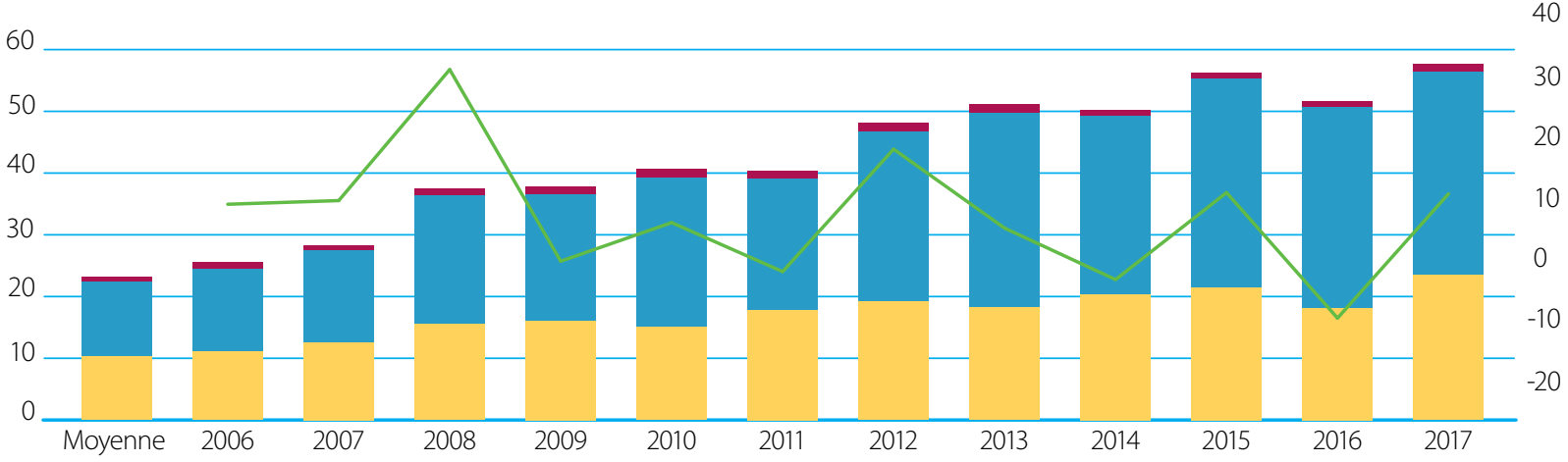
2002-2005

Infrastructure économique

Capacité de production

Taux de croissance de l'Aide pour le commerce totale

Politiques et réglementations commerciales, et ajustement lié au commerce

Source: Base de données du Système de notification des pays créanciers OCDE-CAD: activités d'aide (2018),

DOI: http://dx.doi.org/10.1787/data-00061-en, (consulté le 4 avril 2019).

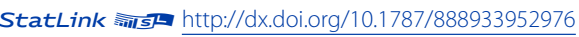

Figure 2.14. Engagements au titre des AASP liés au commerce, par catégorie, en milliards d'USD, en prix constants de 2017

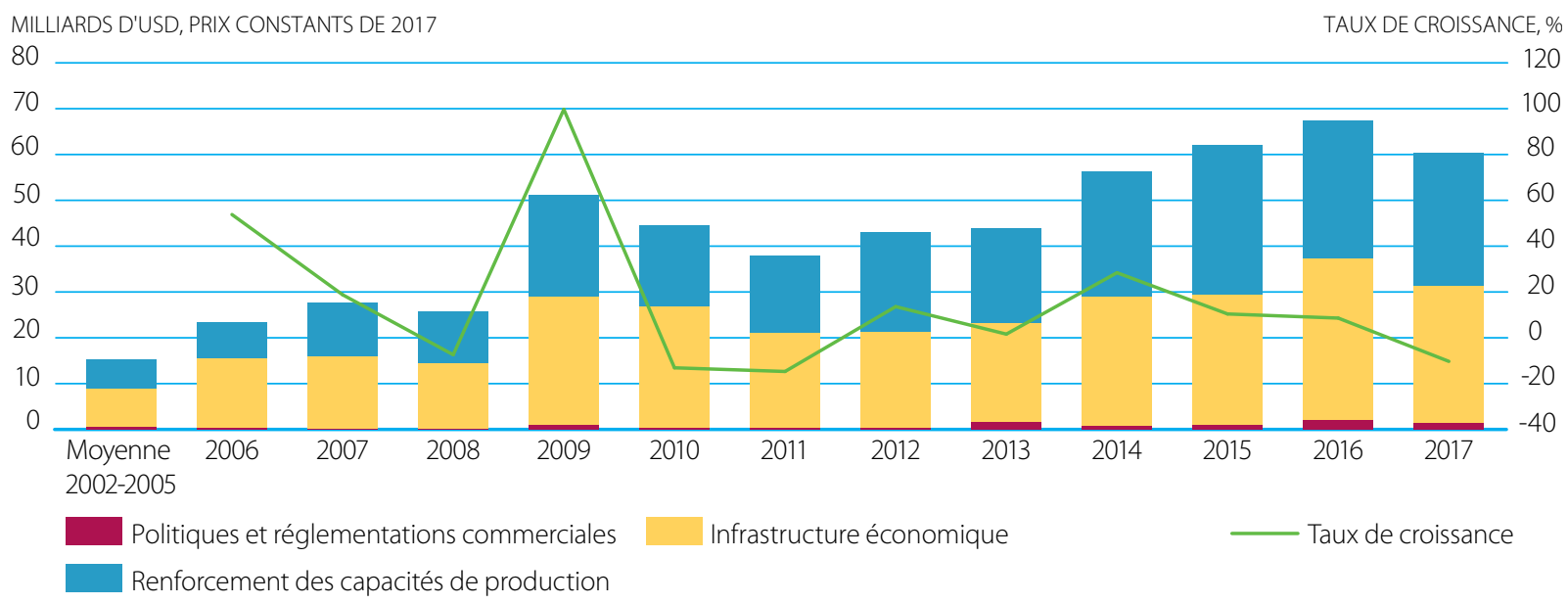

Base de données du Système de notification des pays créanciers OCDE-CAD : activités d'aide (2018), DOI: http://dx.doi.org/10.1787/data-00061-en, (consulté le 4 avril 2019).

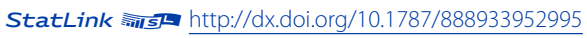

L'Aide pour le commerce au sens le plus étroit de soutien à la politique et à la réglementation commerciales a attiré 1,4 milliard d'USD en 2017, soit 42\% de plus qu'en 2016. La gestion de la politique commerciale et la facilitation des échanges ont bénéficié, respectivement, d'une progression de 224 millions d'USD et de 219 millions d'USD par rapport à leur niveau de 2016. L'aide accordée à l'éducation liée au commerce a enregistré une baisse de 11 millions d'USD. S'agissant des AASP liés au commerce, une baisse a été constatée tant en ce qui concerne la politique commerciale que le renforcement des capacités de production. Cette dernière catégorie a reculé de 30,1 milliards d'USD en 2016 à 29,2 milliards d'USD en 2017. Les autres apports en faveur de la politique commerciale s'élèvent à présent à 1,3 milliard d'USD, soit une baisse de $34 \%$. 
Figure 2.15. Engagements au titre de l'Aide pour le commerce, par région, en milliards d'USD, en prix constants de 2017

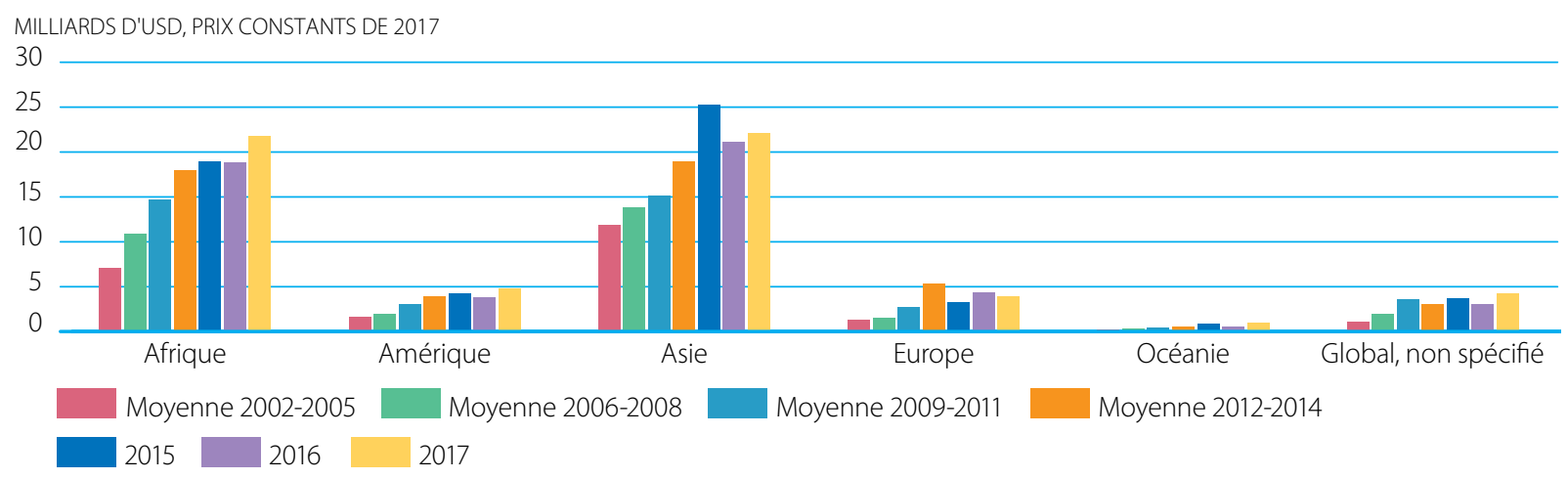

Source: Base de données du Système de notification des pays créanciers OCDE-CAD: activités d'aide (2018), DOI: http://dx.doi.org/10.1787/data-00061-en, (consulté le 4 avril 2019).

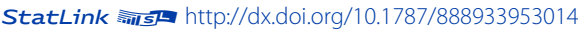

\section{Figure 2.16. Engagements au titre des AASP liés au commerce, par région, en milliards d'USD,} en prix constants de 2017

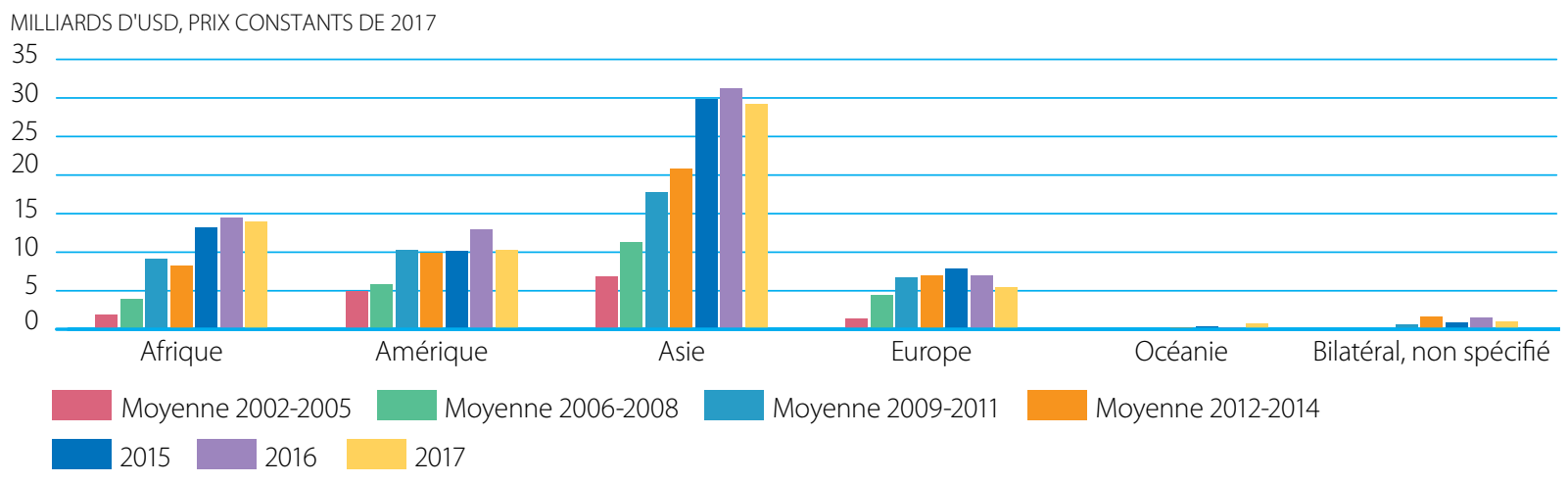

Source: Base de données du Système de notification des pays créanciers OCDE-CAD: activités d'aide (2017), DOI: http://dx.doi.org/10.1787/data-00061-en, (consulté le 4 avril 2019).

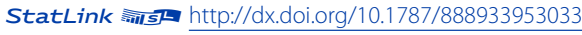

En 2017, 38\% du total des engagements au titre de l'Aide pour le commerce ont été affectés à l'Asie, pour un montant de 22,1 milliards d'USD, en hausse de 1 milliard d'USD par rapport à 2016. II convient toutefois de noter que la part de l'Asie fluctue beaucoup d'une année sur l'autre, généralement en raison des engagements biennaux élevés du Japon et de la Banque asiatique de développement dans le domaine de l'infrastructure économique. Les engagements en faveur de I'Afrique, qui représentaient 36,6\% du total, ont bondi, passant de 2,9 milliards d'USD en 2016 à 21,7 milliards d'USD. II en va de même pour ceux en faveur de l'Amérique latine et de l'Océanie, qui ont connu une hausse, respectivement, de 940 millions d'USD et de 460 millions d'USD. Par contre, les engagements au profit de l'Europe ont reculé de 420 millions d'USD (figure 2.15). La majeure partie des AASP liés au commerce est allée aux pays à revenu intermédiaire d'Asie (48,3\%), suivis de ceux d'Afrique (23\%), d'Amérique latine et des Caraïbes (17\%), d'Europe (9\%) et d'Océanie (1,2\%) (figure 2.16).

En 2017, un montant de 5,9 milliards d'USD a été alloué aux programmes régionaux et mondiaux d'Aide pour le commerce. Ce chiffre est près de trois fois supérieur à la moyenne de la période de référence 2002-2005. L'Aide pour le commerce au niveau régional offre un fort potentiel de catalyseur de la croissance, du développement et de la réduction de la pauvreté, mais les projets peinent souvent à se concrétiser. Cette aide se heurte à de nombreuses difficultés pratiques, mais l'expérience a montré que les problèmes rencontrés n'étaient pas insurmontables et exigeaient de la part des responsables politiques une planification rigoureuse ainsi qu'une formulation attentives des projets assortis de degrés de priorité (OCDE, 2014). 
Figure 2.17. Engagements au titre de l'Aide pour le commerce, par groupe de revenu, en milliards d'USD, en prix constants de 2017

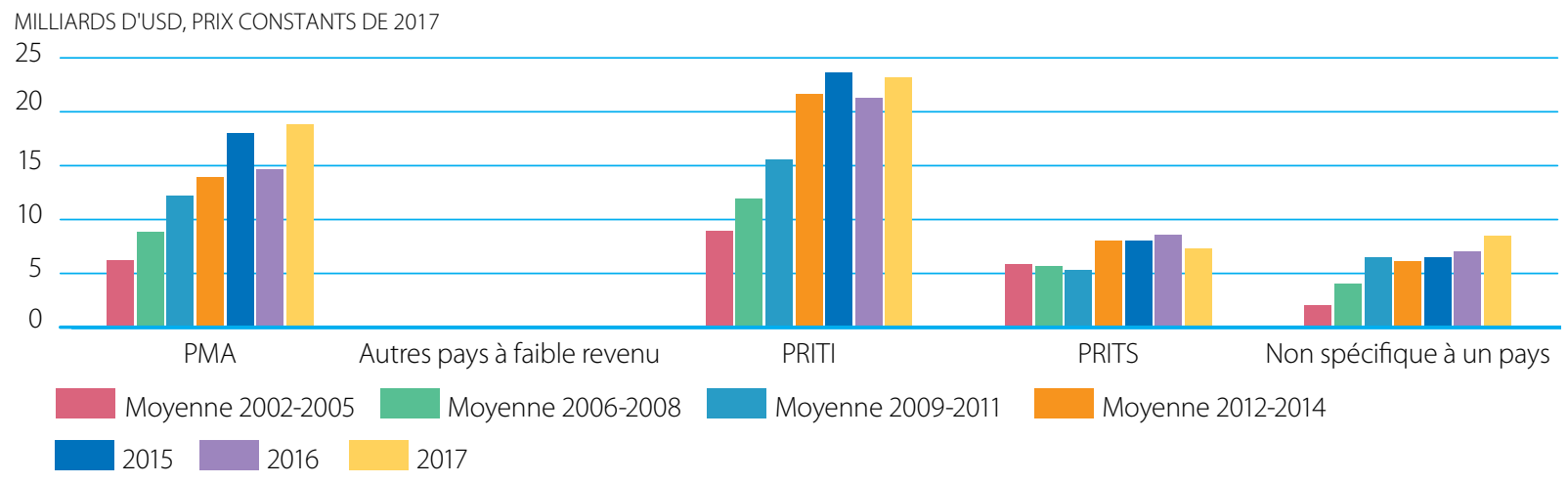

Source: Base de données du Système de notification des pays créanciers OCDE-CAD: activités d'aide (2018), DOI: http://dx.doi.org/10.1787/data-00061-en, (consulté le 4 avril 2019).

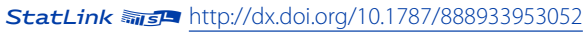

Figure 2.18. Engagements au titre des AASP liés au commerce, par groupe de revenu, en milliards d'USD, en prix constants de 2017

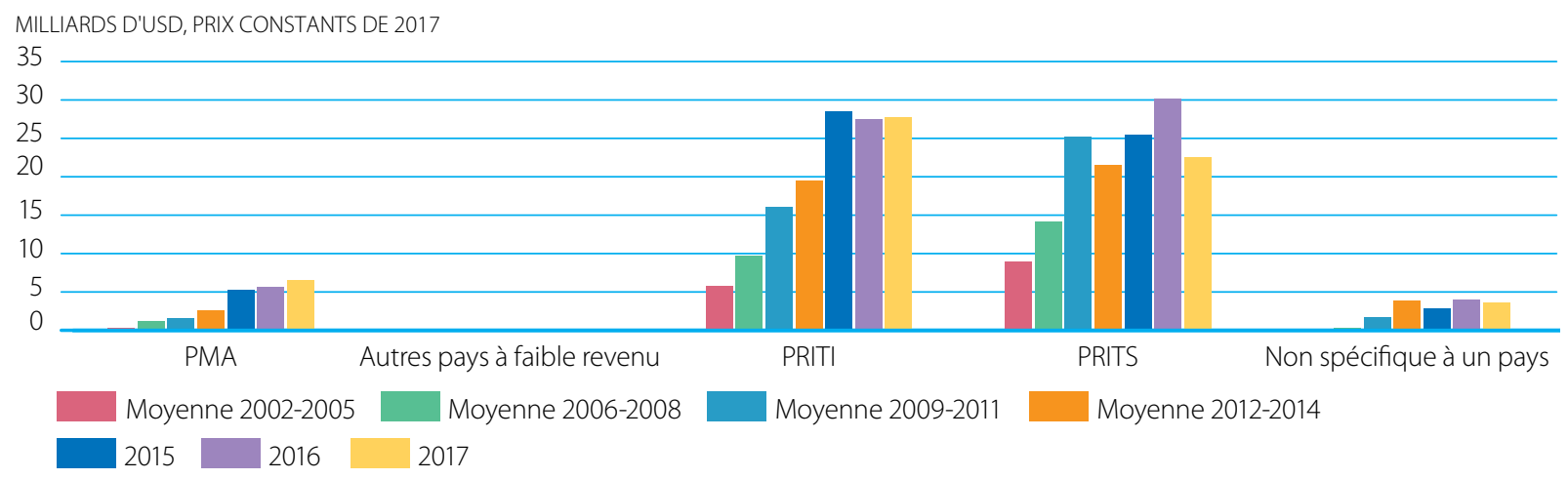

Source: Base de données du Système de notification des pays créanciers OCDE-CAD : activités d'aide (2019), DOI: http://dx.doi.org/10.1787/data-00061-en, (consulté le 4 avril 2019).

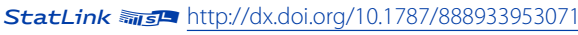

Les engagements au titre de l'Aide pour le commerce en faveur des PMA ont progressé de 4,1 milliards d'USD en 2017 pour atteindre 18,8 milliards d'USD (32,5\% du total des engagements). Les autres pays à faible revenu ont reçu une aide d'un montant de 80 millions d'USD. La part des engagements en faveur des pays à faible revenu dans leur ensemble a représenté 32,5\% des flux totaux d'Aide pour le commerce en 2017. Les principaux bénéficiaires de l'Aide pour le commerce ont été les PRITI (40,2\%), les engagements en faveur de ces pays étant passés de 1,9 milliard d'USD à 23,2 milliards d'USD, tandis que les PRITS ont vu les engagements en leur faveur reculer de 1,2 milliard d'USD, pour ne plus se chiffrer qu'à 7,3 milliards d'USD (figure 2.17). Les pays à revenu intermédiaire ont reçu de loin la plus grosse part des AASP liés au commerce. Avec 50 milliards d'USD, soit 83,3\% des engagements totaux, le montant a reculé de 7 milliards d'USD par rapport à 2016. Les AASP en faveur des pays à faible revenu sont passés de 5,7 milliards d'USD à 6,5 milliards d'USD (figure 2.18). 
En 2017, les donateurs bilatéraux ont assuré des engagements à hauteur de 31,7 milliards d'USD, soit 55\% de I'Aide pour le commerce totale. Le plus gros fournisseur est le Japon, qui, avec des engagements de 12,5 milliards d'USD, a destiné l'essentiel de ses financements à l'Asie, en faveur principalement des secteurs du transport et de l'entreposage et de l'énergie. Parmi les autres grands pourvoyeurs bilatéraux figurent l'Allemagne, avec 5,7 milliards d'USD, suivie de la France (3,2 milliards d'USD) et des États-Unis (2,4 milliards d'USD). La plupart des donateurs bilatéraux accordent la majeure partie de leur aide sous forme de dons, à l'exception de la France, de l'Allemagne, du Japon et de la Corée, qui accordent une grande partie de leur aide sous forme de prêts. Les fournisseurs multilatéraux ont eux aussi accru leurs engagements, de 4,2 milliards d'USD, pour les faire passer à 26 milliards d'USD. Les institutions de I'UE et le Groupe de la Banque mondiale restent les premiers contributeurs, avec près des deux tiers du total de l'Aide pour le commerce multilatérale. Les institutions multilatérales ont été les plus gros pourvoyeurs d'AASP liés au commerce, pour un montant de 50 milliards d'USD (83\% du total). Les principaux contributeurs sont la Banque asiatique de développement, la BERD, la SFl et le Groupe de la Banque mondiale.

En 2017, la part de l'Aide pour le commerce dans l'aide ventilable par secteur est passée d'une moyenne de 30,3\% au cours de la période de référence à 39,2\% en 2017. Ainsi, la part de l'Aide pour le commerce dans l'enveloppe budgétaire toujours plus importante de l'APD a connu une hausse encore plus marquée. Cette augmentation de 9 points de pourcentage, qui se traduit par des engagements supplémentaires de 75 milliards d'USD depuis 2006, pourrait être considérée comme des ressources additionnelles au titre de l'Aide pour le commerce; les trois quarts de ce soutien sont fournis par l'Union européenne, l'Allemagne, la France, le Japon et la Banque africaine de développement. 
CHAPITRE 2. AIDE POUR LE COMMERCE, DIVERSIFICATION ET AUTONOMISATION ÉCONOMIQUES

\section{BIBLIOGRAPHIE}

Baniya S., Rocha N. et Ruta M., (2019), Trade Effects of the New Silk Road: A Gravity Analysis, Policy Research Working Paper, https://doi.org/10.1596/1813-9450-8694

Bayraktar, N., (2018), Effectiveness of public investment on growth in sub-Saharan Africa, Eurasian Economic Review, n 86, https://doi.org/10.1007/s40822-018-0119-z

Buera, F. J., Kaboski, J. P. et Shin, Y., (2011), Finance and development: A tale of two sectors, American Economic Review, 101(5), pages 1964 à 2002, https://www.aeaweb.org/articles?id=10.1257/aer.101.5.1964

Benn, J., C. Sangaré et T. Hos (2017), "Amounts Mobilised from the Private Sector by Official Development Finance Interventions: Guarantees, syndicated loans, shares in collective investment vehicles, direct investment in companies, credit lines", OECD Development Co-operation Working Papers, n³6, Éditions OCDE, Paris,

https://doi.org/10.1787/8135abde-en

Calderón, C. et Servén, L., (2004), The Effects of Infrastructure Development on Growth and Income Distribution,

Policy Research Working Paper, https://doi.org/10.1596/1813-9450-3400

Donor Committee on Enterprise Development (2016), How to create an enabling environment for inclusive business?

Learning from experience and debates in private sector development, https://www.enterprise-development.org/

wp-content/uploads/DCED_Creating_An_Enabling_Environment_For_Inclusive_Business.pdf

Gesellschaft für Internationale Zusammenarbeit (2019), Responsible and Inclusive Business Hubs,

https://www.giz.de/en/worldwide/43855.html

Greenstone, G., (2014), Energy, growth and development, International Growth Centre,

https://www.theigc.org/wp-content/uploads/2014/09/IGCEvidencePaperEnergy.pdf

Société financière internationale, Global Trade Finance, https:/www.ifc.org/wps/wcm/connect/industry_ext_content/ ifc_external_corporate_site/financial+institutions/priorities/global+trade/gtsf2

Internationaal oinderzoek and beliedsevaluatie (IOB) (2018), Transition and inclusive development in Sub-Saharan Africa: An analysis of poverty and inequality in the context of transition, IOB Study, $n^{\circ} 422$

https://english.iob-evaluatie.nl/publications/publications/2018/04/01/422-\%E2\%80\%93-iob-\%E2\%80\%93-an-analysisof-poverty-and-inequality-in-the-context-of-transition-\%E2\%80\%93-transition-and-inclusive-development-in-subsaharan-africa

Lammersen F. et Hynes W. (2019), How trade and aid can help deliver sustainable development goals, Turkish Policy Quarterly, Volume $17, n^{\circ} 4$

http://turkishpolicy.com/article/944/how-trade-and-aid-can-help-deliver-sustainable-development-goals

Lehmacher, W. et Padilla, V., (2015), What can the New Silk Road do for global trade, Financial Times, Forum économique mondial, Genève, https://www.weforum.org/agenda/2015/09/what-can-the-new-silk-road-do-for-global-trade/

OCDE (2013a), Perspectives du développement mondial 2013: Les politiques industrielles dans un monde en mutation, Éditions OCDE, Paris, https://doi.org/10.1787/persp_glob_dev-2013-fr

OCDE (2013b), Succeeding with Trade Reforms: The Role of Aid for Trade, Objectif développement, Éditions OCDE, Paris, https://doi.org/10.1787/9789264201200-en 
OCDE (2014), Regional Perspectives on Aid for Trade, Objectif développement, Éditions OCDE, Paris, https://doi.org/10.1787/9789264216037-en

OCDE (2016), Private Sector Engagement for Sustainable Development: Lessons from the DAC, Éditions OCDE, Paris, https://doi.org/10.1787/9789264266889-en

OCDE (2018), La philanthropie privée pour le développement, Objectif développement, Éditions OCDE, Paris, https://www.oecd-ilibrary.org/development/la-philanthropie-privee-pour-le-developpement_9789264303973-fr

OCDE et OMC (2013), Panorama de l'aide pour le commerce 2013: Se connecter aux chaînes de valeur, OMC, Genève/Éditions OCDE, Paris, https://www.oecd-ilibrary.org/development/panorama-de-l-aide-pour-le-commerce-2013_aid_glance-2013-fr

OCDE et OMC (2015), Panorama de l'Aide pour le commerce 2015: Réduire les coûts du commerce pour une croissance durable et inclusive, OMC, Genève/Éditions OCDE, Paris,

https://www.oecd-ilibrary.org/development/panorama-de-l-aide-pour-le-commerce-2015_aid_glance-2015-fr

OCDE et OMC (2017), Panorama de l'Aide pour le commerce 2017: Promouvoir le commerce, l'inclusion et la connectivité pour un développement durable, OMC, Genève/Éditions OCDE, Paris,

https://www.oecd-ilibrary.org/development/panorama-de-l-aide-pour-le-commerce-2017_9789264311121-fr

OCDE, OMT et OMC (2013), Aid for Trade and Value Chains in Tourism, Éditions OCDE, Paris/Éditions OMT, Madrid/OMC, Genève, https://www.oecd.org/dac/aft/AidforTrade_SectorStudy_Tourism.pdf

OCDE et OMC (2013), Aid for Trade and Value Chains in Agrifood, Éditions OCDE, Paris/OMC, Genève, https://www.wto.org/english/tratop_e/devel_e/a4t_e/global_review13prog_e/tourism_28june.pdf

G-20 (2015), G20 Inclusive Business Framework, Groupe de travail du G-20 sur le développement - présidence turque, https://www.inclusivebusiness.net/sites/default/files/inline-files/G20\%2BInclusive\%2BBusiness\%2BFramework_Final.pdf

USAID (2018), Governance for Inclusive Growth, https://www.usaid.gov/sites/default/files/documents/1861/FS_ GovernanceforlnclusiveGrowth_Nov2018_Eng.pdf

Commission des Nations Unies pour l'Afrique (2017), Transforming African economies through smart trade and industrial policy, Commission économique pour l'Afrique - Section des publications, Éthiopie, https://www.uneca.org/sites/ default/files/PublicationFiles/transforming-african-economies_smart-trade_industrial-policy_eng.pdf 


\title{
CHAPITRE 3
}

\section{PROMOUVOIR LA DIVERSIFICATION ÉCONOMIQUE ET LA TRANSFORMATION STRUCTURELLE PAR L'INDUSTRIALISATION}

\author{
Contribution de l'Organisation des Nations Unies pour \\ le développement industriel
}

\begin{abstract}
Résumé : Le présent chapitre analyse les capacités de production, un élément essentiel pour assurer l'efficacité de l'Initiative Aide pour le commerce. La croissance passée du secteur manufacturier et des services connexes a permis à un grand nombre de travailleurs de décrocher des emplois productifs et accru la prospérité de leur famille et de leur communauté. L'industrialisation et la transformation structurelle demeurent au cœur de nombreuses stratégies nationales et régionales de développement économique. Dans la perspective d'une automatisation et d'une numérisation accrues, ce chapitre traite également des conséquences de la nature changeante de l'industrialisation et des processus de production pour l'avenir du développement du secteur manufacturier. Il dégage des enseignements pour remédier aux "contraintes du côté de l'offre" dans le secteur manufacturier au moyen de l'aide pour le commerce et contribuer ainsi à la transformation structurelle. L'un des thèmes récurrents qui sont abordés est celui des possibilités offertes par la politique industrielle pour un développement inclusif et durable. Les aspects environnementaux pertinents tels que les technologies vertes et l'efficacité énergétique sont également examinés dans le contexte de la compétitivité économique et de la croissance soutenue.
\end{abstract}




\section{INTRODUCTION}

Le secteur manufacturier et le processus d'industrialisation sont les principaux moteurs de la croissance et de la réduction de la pauvreté. Comme l'illustre la figure 3.1, il existe un lien positif entre la croissance de la valeur ajoutée manufacturière' et la croissance du produit intérieur brut (PIB). En raison de la plus forte augmentation de la productivité dans le secteur manufacturier, il est important que les pays en développement déplacent les activités du secteur agricole et du secteur des services à faible productivité vers le secteur manufacturier, afin d'opérer une transformation structurelle favorisant la croissance (figure 3.2). Dans les pays qui ont réussi à s'industrialiser, la croissance du secteur manufacturier et du secteur des services connexes a permis à un grand nombre de travailleurs des secteurs agricole et informel de décrocher des emplois productifs et a accru la prospérité de leur famille et de leur communauté (ONUDI, 2013).

Ainsi, l'industrialisation et la transformation structurelle demeurent au cœur de nombreuses stratégies nationales et régionales de développement économique, et l'ONU l'a reconnu dans l'objectif de développement durable (ODD) 9 : Bâtir une infrastructure résiliente, promouvoir une industrialisation durable qui profite à tous et encourager l'innovation.

\section{Figure 3.1. Lien entre la croissance du PIB et celle du secteur manufacturier, 1970-2017}

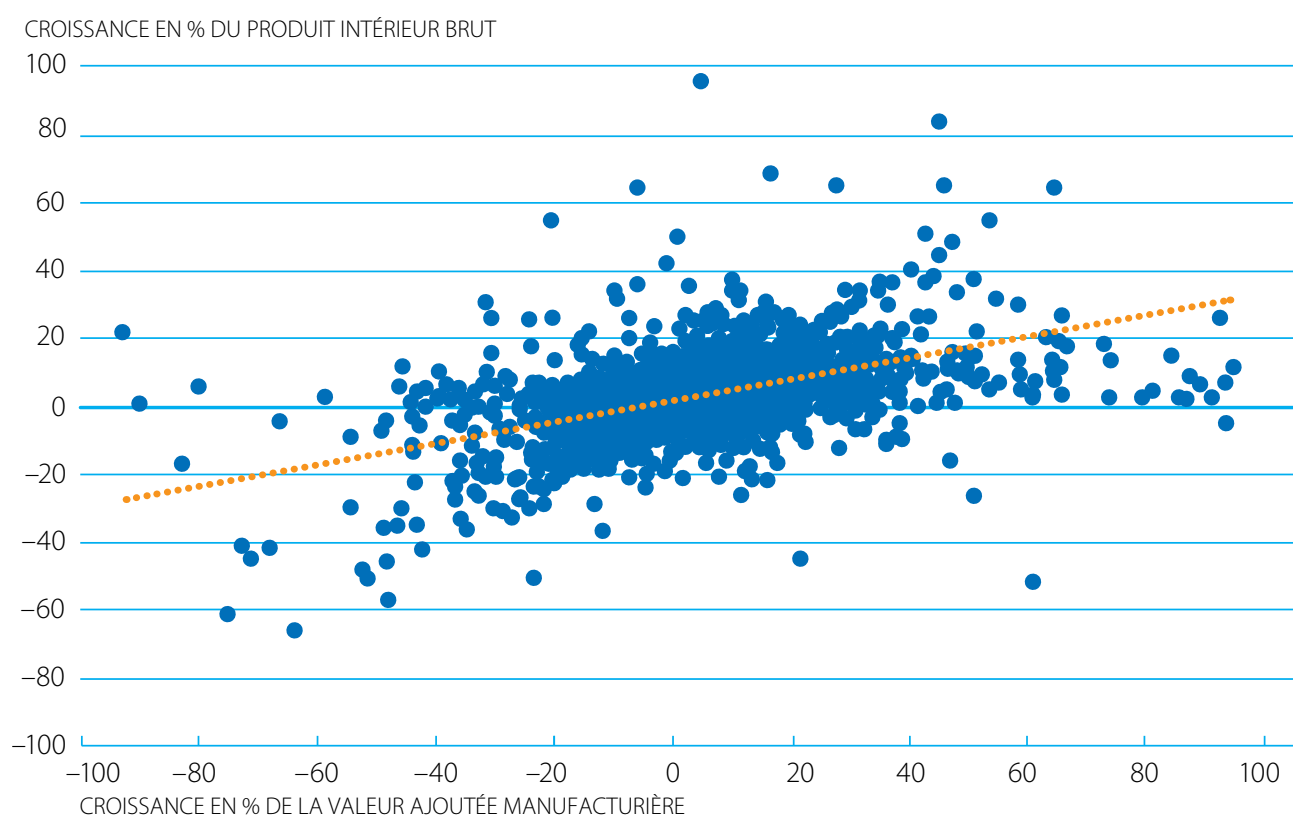

Toutes les valeurs sont exprimées en USD constants de 2010.

Source: ONUDI, d'après la base de données National Accounts Main Aggregates (2019) de la Division de statistique de I'ONU.

StatLink 제메 $\mathrm{http}: / / \mathrm{dx}$. doi.org/10.1787/888933953090

Compte tenu de l'importance du secteur manufacturier, le présent chapitre explore les processus de l'industrialisation et la manière dont l'expansion de ce secteur peut contribuer à un développement économique durable et inclusif. En outre, eu égard à l'émergence de nouvelles technologies, il traite également des conséquences de la nature changeante de l'industrialisation et des processus de production pour l'avenir du développement du secteur manufacturier. Par exemple, une automatisation et une numérisation accrues peuvent être source d'incertitude quant aux trajectoires futures du développement. Ce chapitre montre que l'incertitude latente qui découle du nouveau paradigme qui émerge peut se transformer en une opportunité pour les pays à tous les stades de développement. 
En outre, il dégage des enseignements dont il importe de tenir compte pour remédier aux contraintes du côté de l'offre dans le secteur manufacturier au moyen de l'aide au commerce et contribuer ainsi à la transformation structurelle et à la prospérité économique. L'un des thèmes récurrents qui sont abordés est celui des possibilités offertes par la politique industrielle pour un développement inclusif et durable. Les aspects environnementaux pertinents tels que les technologies vertes et l'efficacité énergétique dans le cadre d'une stratégie de croissance durable sont également examinés dans le contexte de l'expansion du secteur manufacturier.

\section{Figure 3.2. Indice de l'augmentation de la productivité du travail : économies en développement}

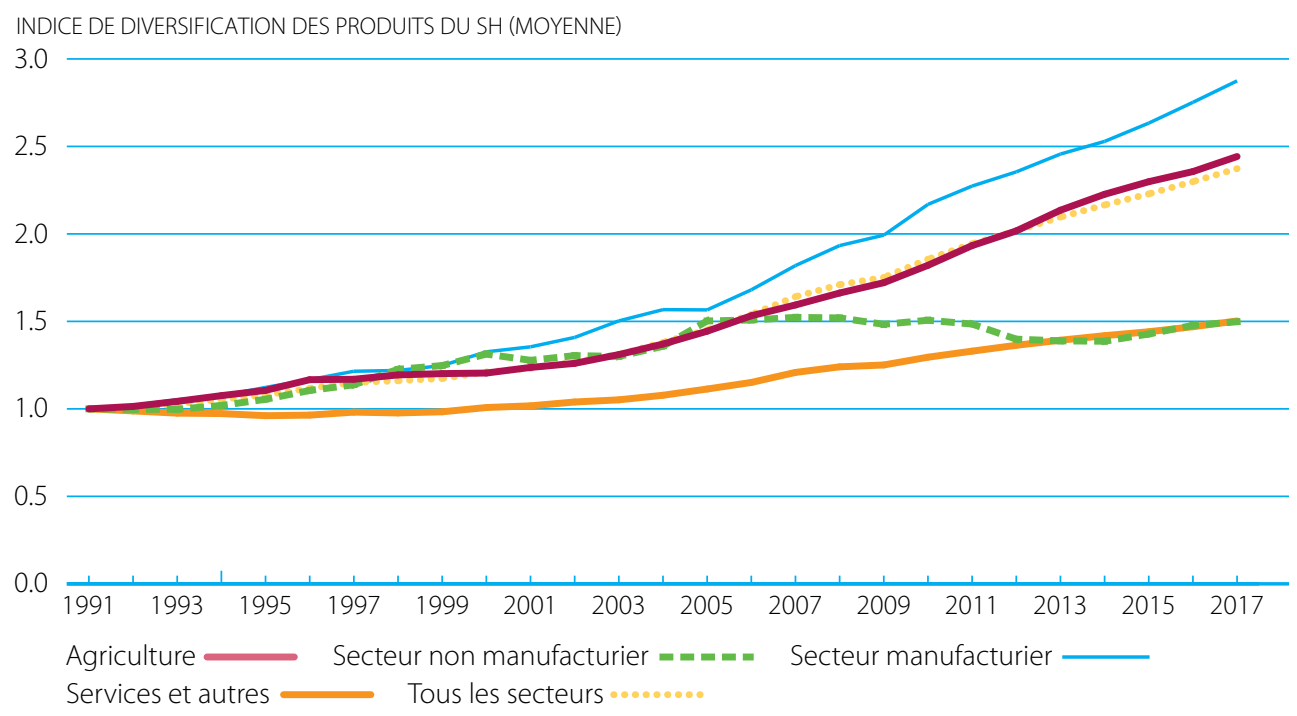

Source: ONUDI, d'après la base de données National Accounts Main Aggregates (2019) de la Division de statistique de I'ONU, et Organisation internationale du travail, estimations modélisées de I'OIT (2019).

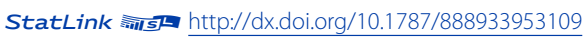

La deuxième section ci-après traite des concepts fondamentaux de l'industrialisation et de ses principales sources pour un développement inclusif et durable. Elle explore la manière dont la diversification industrielle influe sur les différents domaines du commerce, ce qui conduit à l'examen de questions telles que la création d'emplois, les aspects environnementaux de l'industrialisation ainsi que les contraintes et opportunités pour les pays en développement. La troisième section porte sur les perspectives qu'offrent la nature changeante de l'industrialisation et le nouveau paradigme technologique qui émerge, par exemple l'automatisation. La dernière section présente les conclusions.

\section{INDUSTRIALISATION EN FAVEUR DE LA DIVERSIFICATION ÉCONOMIQUE ET DE LA TRANSFORMATION STRUCTURELLE}

L'idée selon laquelle le secteur manufacturier est la locomotive de la croissance remonte aux lois de Nicholas Kaldor $(1966,1967)$ sur la croissance et reste valable aujourd'hui, comme le suggèrent des études récentes (ONUDI, 2015). ॥ a été reconnu que la croissance de la valeur ajoutée manufacturière contribuait pour beaucoup à la réduction de la pauvreté dans de nombreux pays industrialisés émergents et en développement. Cette section donne un aperçu de l'industrialisation et des forces motrices de la prospérité économique. Les pays en développement à faible revenu en particulier peuvent toujours compter sur les produits manufacturés pour stimuler la croissance car ceux-ci créent des emplois dans un secteur plus productif que celui de l'agriculture. Les revenus générés par les activités industrielles sont généralement supérieurs à ceux du secteur primaire : le processus d'industrialisation devrait donc entraîner une augmentation générale des revenus. 
L'analyse de l'évolution globale de la valeur ajoutée manufacturière montre une tendance à la hausse (figure 3.3). En particulier, les pays en développement semblent avoir enregistré des taux d'augmentation élevés et soutenus pour cette valeur depuis 1990, ce qui illustre les possibilités que peut offrir le secteur manufacturier.

Il est possible d'extrapoler la tendance à long terme du développement et de la diversification du secteur manufacturier en se fondant sur l'évolution que suivent la valeur ajoutée et l'emploi dans différents sous-secteurs à mesure que l'économie se développe (Haraguchi, 2019). L'examen des faits empiriques clés permet de mettre en évidence certains facteurs importants : dans les pays en développement, il existe une corrélation empirique entre le revenu par habitant et le degré d'industrialisation, alors que les pays à revenu élevé ont plutôt tendance à se désindustrialiser (ONUDI, 2015). Cette tendance s'explique par la nature même de l'industrialisation. L'expansion du secteur manufacturier permet d'absorber la main-d'œuvre excédentaire du secteur agricole, ce qui augmente la productivité de l'ensemble de l'économie grâce au développement de secteurs plus productifs. Parallèlement, le secteur agricole enregistre aussi une hausse de la productivité (Lewis, 1954).

\section{Figure 3.3. Tendance à la hausse de la valeur ajoutée manufacturière mondiale, 1990-2017}

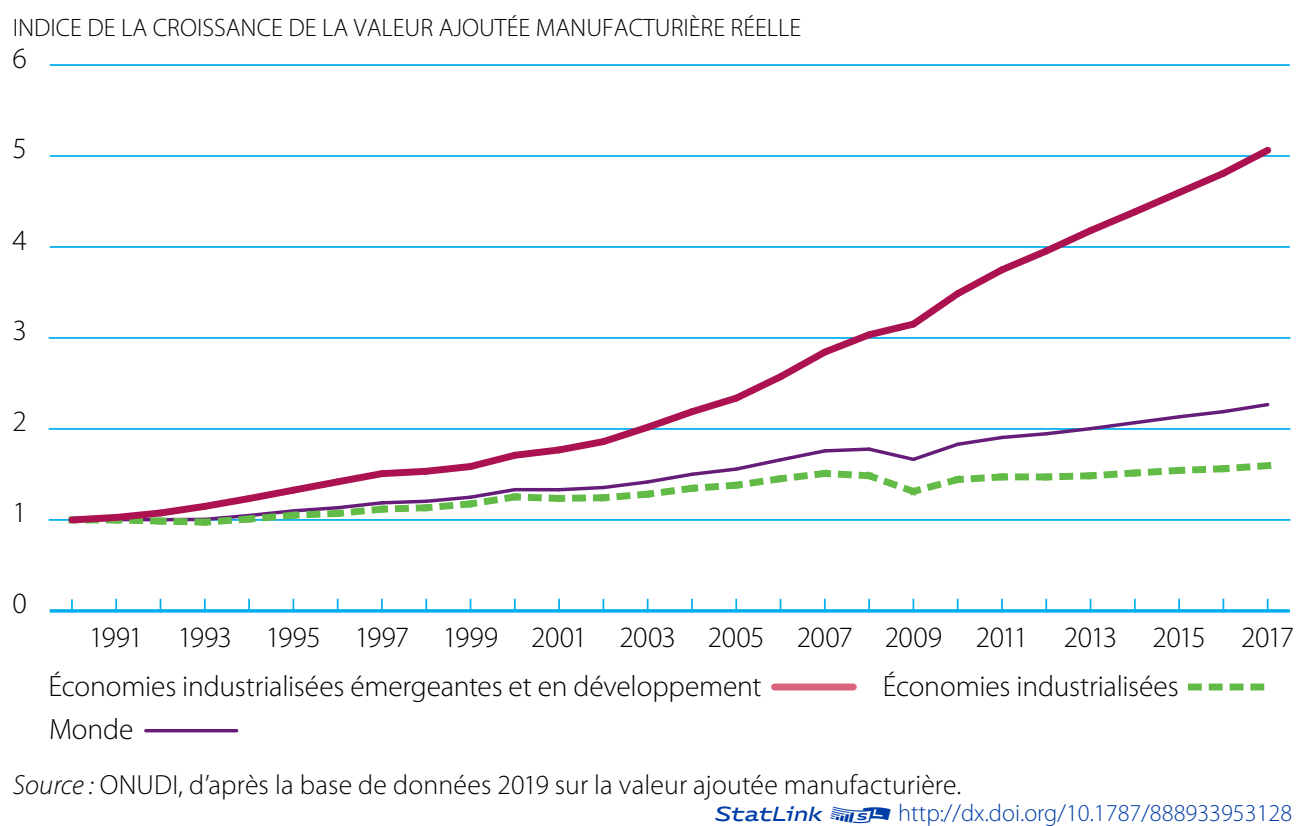

De toute évidence, le secteur manufacturier apporte des éléments essentiels, ce qui en fait un moteur puissant de la prospérité économique, avec une productivité et un taux d'augmentation de cette productivité supérieurs à ceux du secteur agricole (Szirmai, 2012). Les avantages qu'il présente peuvent se matérialiser sous la forme d'une accumulation de capital physique et grâce à l'exploitation des effets liés aux économies d'échelle. En outre, les changements technologiques induits par l'innovation et l'accumulation de capital humain résultant de l'industrialisation sont les principaux moteurs de la croissance économique globale. Enfin, à mesure que le revenu des économies augmente, la part des revenus consacrés aux produits agricoles tend à diminuer, ce qui entraîne une hausse des dépenses totales en produits manufacturés. Cela donne aux pays la possibilité de prendre part aux marchés mondiaux, du fait que la demande de produits manufacturés se diversifie, d'où la nécessité d'accroître les capacités de production. Cette évolution permet de répondre non seulement à la demande intérieure mais aussi à la nouvelle demande extérieure.

Bien que le secteur manufacturier en général joue un rôle important dans l'expansion économique des pays en développement, la contribution des différentes industries manufacturières à cette expansion varie en fonction du stade de développement économique de chaque nation. Au premier stade de développement, les industries à forte intensité 
de main-d'œuvre telles que l'alimentation et les boissons ainsi que le textile et l'habillement connaissent souvent une croissance rapide et représentent une part importante de la valeur ajoutée manufacturière et de l'emploi. Dans la phase de revenu intermédiaire, à mesure qu'apparaissent les industries à forte intensité de ressources, comme celles du coke, du pétrole raffiné, du papier, et des produits métallurgiques de base et ouvrages en métaux, la valeur ajoutée manufacturière de l'économie tend à augmenter. Dans la phase de revenu élevé, les industries des véhicules automobiles, des machines et de l'équipement, des machines électriques et des produits chimiques sont généralement celles qui contribuent le plus à la croissance de la valeur ajoutée manufacturière. Les progrès technologiques et l'augmentation de la productivité sont les principaux moteurs d'une croissance soutenue dans ces industries, qui s'engagent donc dans un développement reposant sur les compétences (Haraguchi, 2016).

\section{Pourquoi l'industrialisation est importante et comment elle favorise la diversification et la transformation structurelle}

Tant l'offre que la demande influent sur la transformation structurelle du secteur manufacturier décrite ci-dessus. Du côté de l'offre, les progrès technologiques et l'amélioration des compétences sont les deux principaux catalyseurs du renforcement et de l'expansion des capacités productives, ce qui est lié aux changements technologiques et à l'augmentation de la productivité dans certaines industries. L'innovation est donc un facteur important pour le développement durable. L'augmentation de la productivité et les effets d'économies d'échelle dépendent fortement des innovations en matière de produits et de procédés. Un procédé de production plus efficace permet d'augmenter la production tout en utilisant moins d'intrants, ce qui se traduit par une augmentation globale de la production et des capacités accrues. Toutefois, l'innovation requiert l'accès à une main-d'œuvre qualifiée et instruite, de sorte que la formation du personnel revêt une importance particulière. En outre, certains éléments tels que l'infrastructure ou le climat dans le milieu des investissements ou des affaires sont indispensables pour accroître la capacité d'offre du secteur manufacturier. En l'absence d'un ensemble de conditions fiables (notamment l'accès aux infrastructures de base), le développement des capacités est limité. Interrogés sur les obstacles à une diversification économique et à une industrialisation réussies lors de l'exercice de suivi réalisé par l'OCDE et l'OMC dans le cadre de l'Examen global de l'Aide pour le commerce (2019), les pays partenaires et donateurs ont fréquemment mentionné ces questions. II est donc crucial que des mesures adéquates, examinées dans les sections ci-après, soient prises pour surmonter ces obstacles au développement industriel.

Si toutes les conditions favorables sont réunies, les possibilités d'emploi dans le secteur manufacturier peuvent augmenter grâce à un déplacement d'activités du secteur agricole vers le secteur manufacturier et le secteur des services. Ce changement structurel permet d'absorber la main-d'œuvre excédentaire à faible productivité du secteur primaire et de donner aux travailleurs un accès à des emplois mieux rémunérés. Par conséquent, la productivité globale de l'économie augmente. Lorsqu'un pays augmente le niveau d'emploi dans un secteur où les salaires sont relativement plus élevés que dans le secteur agricole, son revenu total disponible augmente. L'augmentation des revenus des ménages et la baisse des prix des produits manufacturés résultant d'une hausse de la productivité influent donc sur la structure de la demande de tels produits. Un examen plus attentif du point de vue des consommateurs sur l'industrialisation permettrait de mettre en lumière les forces qui façonnent ces structures.

De manière générale, les biens manufacturés peuvent être classés en articles de première nécessité (alimentation et boissons, habillement/textiles) et en biens de consommation plus sophistiqués tels que les voitures et les appareils électriques. Un déplacement des revenus enclenche donc un cercle vertueux de consommation de produits manufacturés et de développement industriel, illustré par la figure 3.4 (ONUDI, 2017b). Cela montre que, dans certaines conditions, des boucles de rétroaction et des effets distincts sur le revenu et la demande peuvent interagir à différentes étapes du cercle, le mettant ainsi en mouvement. 
Figure 3.4. Le cercle vertueux de consommation de produits manufacturés : l'économie mondiale

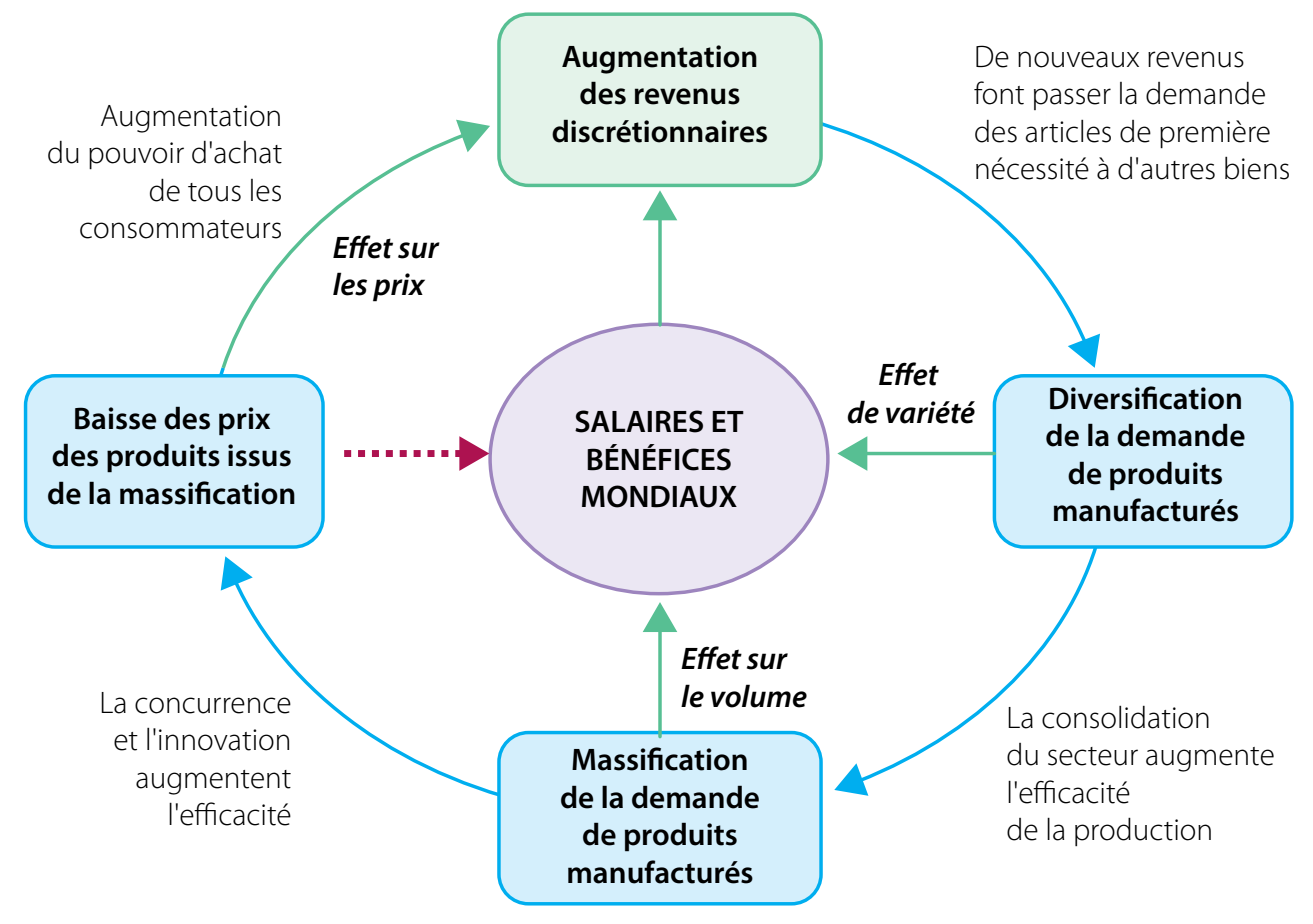

Source: ONUDI (2017b).

Les différentes étapes du cercle vertueux de consommation de produits manufacturés seront expliquées du point de vue de l'offre ci-après. Le processus d'industrialisation et ses effets positifs sur l'emploi entraînent une augmentation du revenu discrétionnaire (la part du revenu d'un ménage qui peut être affectée à des biens autres que les produits de première nécessité). Cela est principalement dû à la hausse des salaires et à la création d'emplois plus productifs dans le secteur manufacturier. L'augmentation du revenu discrétionnaire finit par déboucher sur une diversification de la demande de produits manufacturés à mesure que la demande, et par conséquent les dépenses, passent des produits agricoles aux produits manufacturés. Cette nouvelle demande conduit à son tour à la création de nouvelles industries et de nouvelles variétés de produits dans l'économie (processus de diversification), qui est une composante clé du développement économique durable à long terme (Saviotti et Pyka, 2004). La demande de nouveaux produits ainsi que le désir des entreprises de devenir plus rentables déclenchent un processus de diversification et de consolidation dans le secteur manufacturier. Cela peut se faire grâce à des innovations qui rendent les processus de production plus efficaces et améliorent la qualité des biens produits. En outre, les effets d'économies d'échelle, en plus d'augmenter les bénéfices des entreprises, font également baisser de façon significative les prix des biens, qui deviennent donc accessibles à un plus grand nombre de personnes. L'augmentation de la demande qui en résulte incite les entreprises à produire davantage, à condition qu'elles disposent des capacités suffisantes, et pourrait leur permettre d'atteindre un niveau de compétitivité propice à la spécialisation et à l'acquisition de compétences. Ainsi, la consommation de masse est largement tirée par l'augmentation de la productivité (Matsuyama, 2002; Foellmi et al., 2014). Dans la dernière étape du cercle de consommation des produits manufacturés, la baisse du prix des produits qui résulte du progrès technologique est essentielle car elle engendre une nouvelle hausse du pouvoir d'achat pour tous les consommateurs, qui fait à son tour augmenter le revenu discrétionnaire et permet au cercle vertueux de poursuivre sa course (DeLong, 2000; Jong, 2015). 
En résumé, trois facteurs génèrent les effets positifs du cercle vertueux qui conduisent à terme à une augmentation du revenu des ménages. Premièrement, la demande de nouveaux produits (effet de variété) augmente parce que ces produits deviennent plus abordables et disponibles. Deuxièmement, le processus de massification accroît considérablement le volume des biens produits et consommés. Enfin, la hausse de la productivité fait baisser les prix et fait donc augmenter les revenus discrétionnaires.

Outre la création de revenus et la massification, l'amélioration de la qualité des produits, qui s'accompagne d'une baisse simultanée des prix relatifs, joue un rôle important dans l'amélioration du bien-être des consommateurs et contribue ainsi pour beaucoup au développement durable. De nouveaux produits de meilleure qualité réduisent le coût de la vie et améliorent le niveau de vie de la population (Jong, 2015). Lélargissement des possibilités de consommation permet aux consommateurs d'adapter leurs préférences car ils peuvent choisir de consommer des biens qui les aident à améliorer leur qualité de vie (Nussbaum, 1992; Sen, 2001). En outre, le processus de spécialisation et de diversification peut également conduire à l'élaboration de nouvelles réglementations, normes et règles, qui viennent renforcer davantage le pouvoir des consommateurs et améliorer leur bien-être.

Dans le cadre de cette conception de la consommation de produits manufacturés, il convient d'examiner les questions de genre. Selon Sen (1990) et la Banque mondiale (2012), l'existence de disparités entre les sexes dans tous les aspects de la vie représente une menace grave pour le développement humain et économique.2 Par divers effets externes, l'industrialisation et la transformation structurelle peuvent contribuer à la promotion de l'égalité hommes-femmes dans plusieurs domaines de la vie. II s'agit en premier lieu des tâches ménagères et de l'éducation des enfants, dont la responsabilité incombe principalement aux femmes. Ce travail n'est pas rémunéré, prend une grande partie du temps discrétionnaire quotidien des femmes et réduit considérablement leurs chances de se faire entendre dans le monde politique (Kabeer, 1999). L'industrialisation et les technologies ménagères améliorées qu'elle rend plus abordables facilitent l'accès des femmes au marché du travail, créant ainsi de nouvelles possibilités de développement inclusif (Becker, 1965; Woersdorfer, 2017). Selon certaines études, plus de la moitié de l'augmentation du taux d'activité des femmes observée aux États-Unis entre 1900 et 1980 pourrait être attribuée aux progrès technologiques (Greenwood et al., 2005). Les pays en développement et les pays émergents, où le taux d'activité des femmes est faible, pourraient eux aussi bénéficier d'une telle augmentation.

Les mécanismes et concepts fondamentaux évoqués ci-dessus favorisent un développement industriel fondé sur l'interaction entre les facteurs liés à l'offre et les facteurs liés à la demande, qui est un moteur important de la diversification économique. Le processus de transformation structurelle peut être renforcé par la diversification, la massification et une baisse des prix. Des emplois mieux rémunérés dans le secteur industriel augmentent le revenu disponible des travailleurs, ce qui modifie la structure habituelle de la demande. L'augmentation de la consommation globale entraîne une hausse du revenu national. Le fait d'avoir un revenu disponible plus élevé engendre une nouvelle demande car les dépenses consacrées aux biens manufacturés se déplacent vers des biens plus sophistiqués. Les entreprises sont donc incitées à accroître continuellement leurs capacités de production et à innover afin de diversifier leur gamme de produits (ONUDI, 2017b).

\section{Changements structurels et développement}

Dans la précédente section, il a été question de la manière dont l'interaction entre les facteurs liés à l'offre et les facteurs liés à la demande façonne le processus de transformation structurelle. La spécialisation et la diversification sont les principaux résultats des processus qui changent l'ensemble de la structure du secteur manufacturier. Les changements structurels influent considérablement sur le développement économique et contribuent donc à rendre l'avenir plus inclusif et durable. La présente sous-section traite des répercussions de cette transformation sur le commerce international, les marchés du travail et la viabilité de l'environnement. Enfin, elle met en évidence les limites auxquelles se heurtent les pays en développement et les possibilités qui leur sont offertes. 


\section{Diversification industrielle et incidence sur le commerce}

La figure 3.5 présente la part des produits manufacturés sur les marchés d'exportation mondiaux entre 1988 et 2017. Alors que la part des pays industrialisés sur ces marchés a diminué au cours de cette période, celle des économies industrialisées émergentes a augmenté. Dans une certaine mesure, les pays les moins avancés ont également réussi à accroître leur part de produits manufacturés sur les marchés d'exportation mondiaux au cours de la dernière décennie. Cette participation accrue aux marchés mondiaux a des répercussions importantes sur la diversification industrielle et contribue ainsi au développement économique durable.

\section{Figure 3.5. Part des produits manufacturés sur les marchés d'exportation mondiaux}

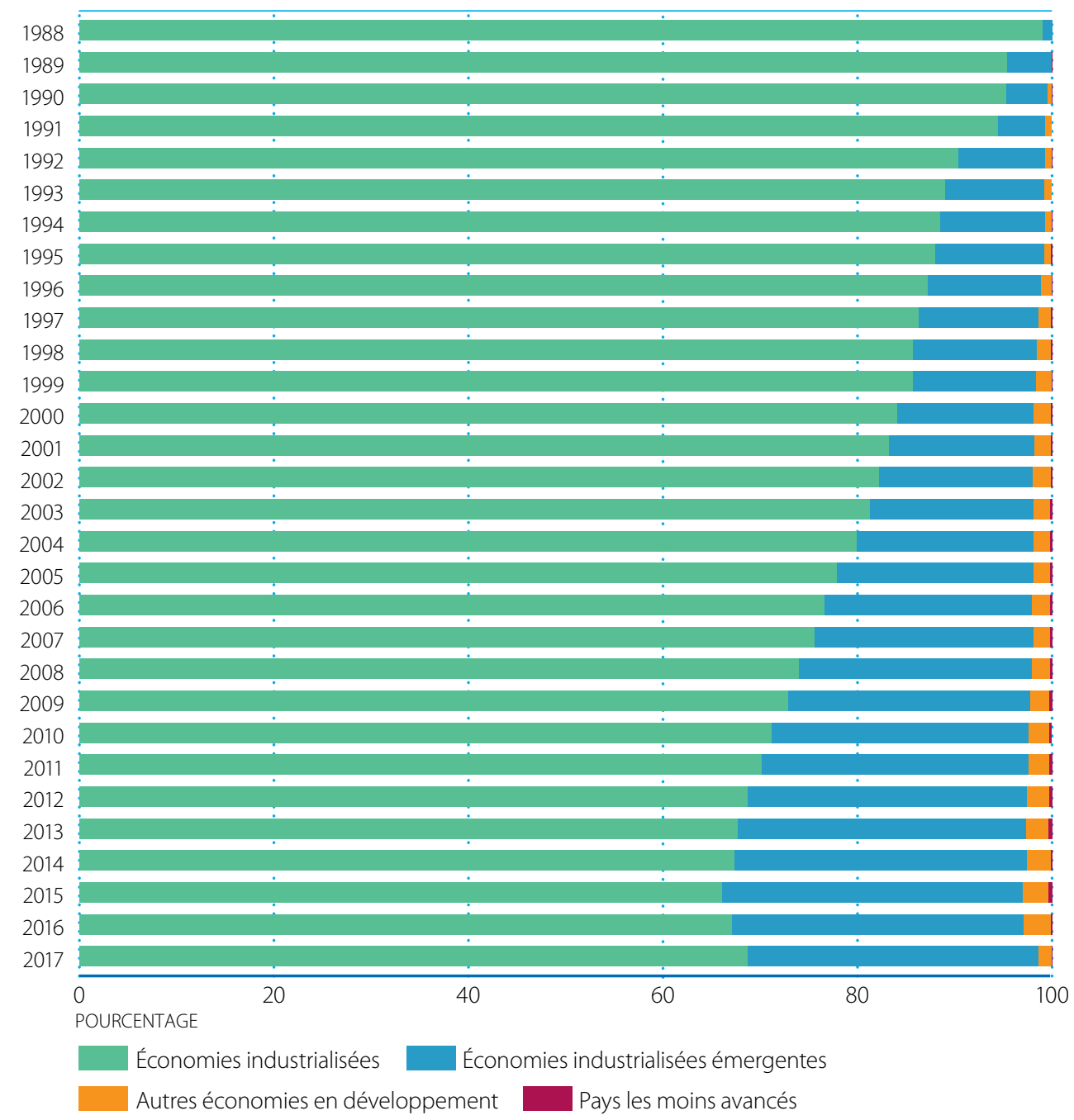

Source: ONUDI, d'après la base de données Comtrade de l'ONU (2018).

StatLink नiाls http://dx.doi.org/10.1787/888933953147

Le cercle vertueux dont il a été question plus haut est tributaire non seulement de facteurs nationaux mais aussi et surtout de facteurs mondiaux. Les éléments clés sont la stabilité et la croissance économiques, des réglementations commerciales favorables et un secteur manufacturier national doté de capacités suffisantes. Les obstacles au commerce restreignant l'accès aux marchés mondiaux réduisent les possibilités d'augmentation de la productivité et de croissance dans le secteur manufacturier. L'accès limité aux marchés mondiaux empêche la mise en œuvre de nouvelles technologies en raison d'un manque d'accès aux innovations, tandis que les obstacles au commerce entravent la création d'une demande pour de nouveaux produits. II ne peut y avoir d'industrialisation durable sans commerce. La demande 
Encadré 3.1. Région arabe : création d'un système régional d'accréditation pour surmonter les obstacles techniques au commerce et promouvoir l'intégration régionale

En 2010, la région arabe était la seule région du monde qui n'était pas dotée d'une structure régionale d'accréditation fournissant des services d'évaluation de la conformité (essais, certification et inspection). Dans ce contexte, l'Organisation arabe pour le développement industriel et les industries extractives (AIDMO), appuyée par l'Organisation des Nations Unies pour le développement industriel (ONUDI), a contribué à la création de la Coopération arabe pour l'accréditation (ARAC), plate-forme sur laquelle les pays arabes peuvent créer et développer leur infrastructure de certification.

Grâce au soutien fourni dans le cadre d'un projet financé par l'Agence suédoise de coopération internationale au développement (ASDI), I'ARAC suit désormais les meilleures pratiques internationales, et les États arabes peuvent recevoir le soutien de leur propre organisme régional au niveau national et n'ont plus besoin d'obtenir une reconnaissance en dehors de la région. L'ARAC a franchi des étapes importantes au cours des dernières années, puisque 17 pays l'ont rejointe et que des progrès considérables ont été réalisés sur la voie de la reconnaissance internationale et de la durabilité.

Grâce aux travaux intensifs et ambitieux réalisés par les membres de I'ARAC avec l'appui de leurs partenaires, les Accords de reconnaissance multilatérale (ARM) de I'ARAC ont été internationalement reconnus en 2017 par la Coopération internationale sur l'agrément de laboratoires d'essais (ILAC) et le Forum international de l'accréditation (IAF). Une fois les ARM de l'ARAC reconnus à l'échelle internationale, les rapports d'essais, de certification et d'inspection émis par les signataires de ces ARM sont aussi mondialement reconnus par tous les signataires des accords de I'ILAC et de I'IAF. En d'autres termes, les ARM de I'ARAC fonctionnent comme un passeport international pour le commerce.

Sur la base des progrès réalisés à ce jour, le projet AIDMO-ONUDI-ASDI continuera d'appuyer I'ARAC jusqu'en 2020 pour qu'elle devienne un moteur essentiel, durable et efficace de l'intégration commerciale régionale.

Source: Exercice de suivi réalisé dans le cadre de l'Examen global de l'Aide pour le commerce OCDE-OMC 2019.

intérieure fournit l'élan initial qui permettra au cercle vertueux de tourner et donc de relancer les économies d'échelle et la hausse de la productivité mais il faut avoir accès aux marchés mondiaux et aux technologies étrangères pour permettre une croissance durable du secteur manufacturier. Cet accès contribue à stimuler la demande et les gains de productivité de façon notable (ONUDI, 2017b). Plus précisément, les pays en développement peuvent mettre en œuvre des politiques industrielles axées sur certaines zones pour soutenir le renforcement de leurs capacités industrielles, ce qui peut les aider à pénétrer les marchés mondiaux. En particulier, les petits pays à faible revenu ne peuvent souvent pas compter uniquement sur la demande et l'offre intérieures d'intrants et de capital humain, de sorte que les politiques régionales et la priorité accordée à l'intégration régionale peuvent les aider à créer un secteur industriel durable en leur donnant accès à des marchés plus vastes (ONUDI, 2009). On trouvera dans l'encadré 3.1 un exemple de l'appui fourni par l'ONUDI à la facilitation du commerce et à l'intégration régionale au moyen de la création d'un organisme régional d'accréditation et du renforcement des capacités de cet organisme

Associée à une demande accrue, la pénétration de nouveaux marchés a une forte incidence sur le développement du secteur manufacturier car elle favorise les exportations. Alors que les industries de faible technologie telles que l'alimentation et les boissons ne nécessitent généralement qu'un petit nombre d'étapes de production dans la chaîne de valeur, les industries de moyenne ou de haute technologie (comme les véhicules automobiles ou les machines) comptent souvent un grand nombre d'activités qui ajoutent de la valeur lors de la fabrication du produit final. Par conséquent, tant la création d'un réseau mondial de production que la mise en place d'une chaîne d'approvisionnement mondiale devraient faire partie intégrante des stratégies nationales en faveur du développement des industries à forte intensité technologique (ONUDI, 2017b). Les pays à faible revenu ont un intérêt à intégrer un réseau mondial de production en se concentrant sur des tâches spécifiques telles que l'assemblage final car ils deviendront probablement des fournisseurs dans la chaîne de valeur mondiale.

Un autre aspect positif de l'industrialisation relatif aux exportations concerne la balance des paiements nationale. Des capacités productives suffisantes réduisent la dépendance à l'égard des importations car la production intérieure peut satisfaire à la demande intérieure. En outre, la production de biens de grande qualité à des prix compétitifs peut faire augmenter les ventes sur les marchés étrangers, améliorant ainsi la balance commerciale nationale. 
En outre, la libéralisation du commerce favorise l'investissement étranger direct (IED) dans les pays en développement (CNUCED, 2013). L'afflux d'IED apporte souvent des capitaux, des compétences et un savoir-faire en matière de gestion aux pays en développement et offrent aux entreprises nationales la possibilité de fournir des produits et des services aux entreprises à capitaux étrangers. Cela favorise une meilleure intégration des pays d'accueil dans les chaînes de valeur mondiales et facilite leur accès aux marchés étrangers (CNUCED, 2013).

L'un des effets positifs de la libéralisation du commerce est la tendance des pays à revenu élevé à délocaliser les processus à forte intensité de main-d'œuvre vers des pays en développement, qui ont ainsi la possibilité de créer un secteur manufacturier tourné vers l'exportation (ONUDI, 2017b). Aux premiers stades de l'industrialisation, les pays en développement ont généralement un avantage comparatif dans les industries à forte intensité de main-d'œuvre car les coûts de production dans les pays à revenu élevé sont beaucoup plus élevés, ce qui rend ces secteurs moins rentables. Il en résulte une dispersion géographique des échanges : l'ouverture des réseaux mondiaux de production donne aux pays à faible revenu la possibilité d'utiliser leur avantage comparatif dans les chaînes de valeur à forte intensité de maind'œuvre pour pénétrer ces réseaux à différents stades, y compris celui de l'assemblage final.

Le commerce international affecte directement et oriente indirectement les prix relatifs des produits manufacturés. La volatilité des prix à l'importation et la disponibilité accrue d'intrants intermédiaires peuvent avoir une incidence directe sur les prix relatifs des biens manufacturés. L'ouverture au commerce est généralement associée à une augmentation de la concurrence, qui entraîne souvent une baisse des prix relatifs des produits manufacturés (Pain et al., 2008), qui alimente à son tour le cercle vertueux. Si la diversification, induite par la nouvelle demande, peut être stimulée par la demande mondiale, il est également essentiel de renforcer la capacité de produire une large gamme de produits manufacturés. Un certain nombre d'études ont montré que l'effet de variété l'emporte sur l'effet de prix pour ce qui est de générer une plus grande part d'exportations. Les pays en développement en particulier peuvent accroître cette part en proposant une offre variée de produits plutôt qu'en réduisant les prix de leurs produits (voir, par exemple, Eicher et Kuenzel, 2016).

Les capacités d'exportation nouvellement créées contribuent également à une industrialisation inclusive. Les pays à revenu faible et à revenu intermédiaire qui parviennent à développer des industries à forte intensité de main-d'œuvre et à exporter les produits qui en sont issus peuvent voir le nombre d'emplois dans leur secteur manufacturier augmenter (Chataway et al., 2014). Dans ces pays, les femmes peuvent avoir un accès limité à l'emploi formel et ne font donc pas partie de la main-d'œuvre productive. L'augmentation de la demande de main-d'œuvre en raison de l'industrialisation et le passage d'emplois informels ou à faible productivité dans le secteur agricole à des emplois mieux rémunérés dans le secteur manufacturier créent de nouvelles possibilités, en particulier pour les femmes. Globalement, l'industrialisation devrait contribuer à réduire les inégalités de revenu entre les hommes et les femmes.

L'expansion des activités manufacturières par la participation aux marchés mondiaux influe considérablement sur les structures nationales, y compris le marché du travail, les salaires et les conditions d'emploi. La section ci-après examine de plus près les possibilités de création d'emplois offertes par la transformation structurelle.

\section{Création d'emplois}

La croissance de l'emploi, entre autres facteurs, joue un rôle important dans la croissance économique. Bien que la part du secteur manufacturier dans l'emploi total ait considérablement diminué dans les pays développés, elle connaît une augmentation constante depuis les années 1970 dans les pays en développement dans leur ensemble (figure 3.6). La plupart des pays avancés passent normalement par un processus de désindustrialisation au cours de leur transformation structurelle, tandis que dans les pays en développement le secteur manufacturier offre davantage de possibilités de création d'emplois (ONUDI, 2017a). 
Figure 3.6. Part du secteur manufacturier dans l'emploi, par groupe de développement

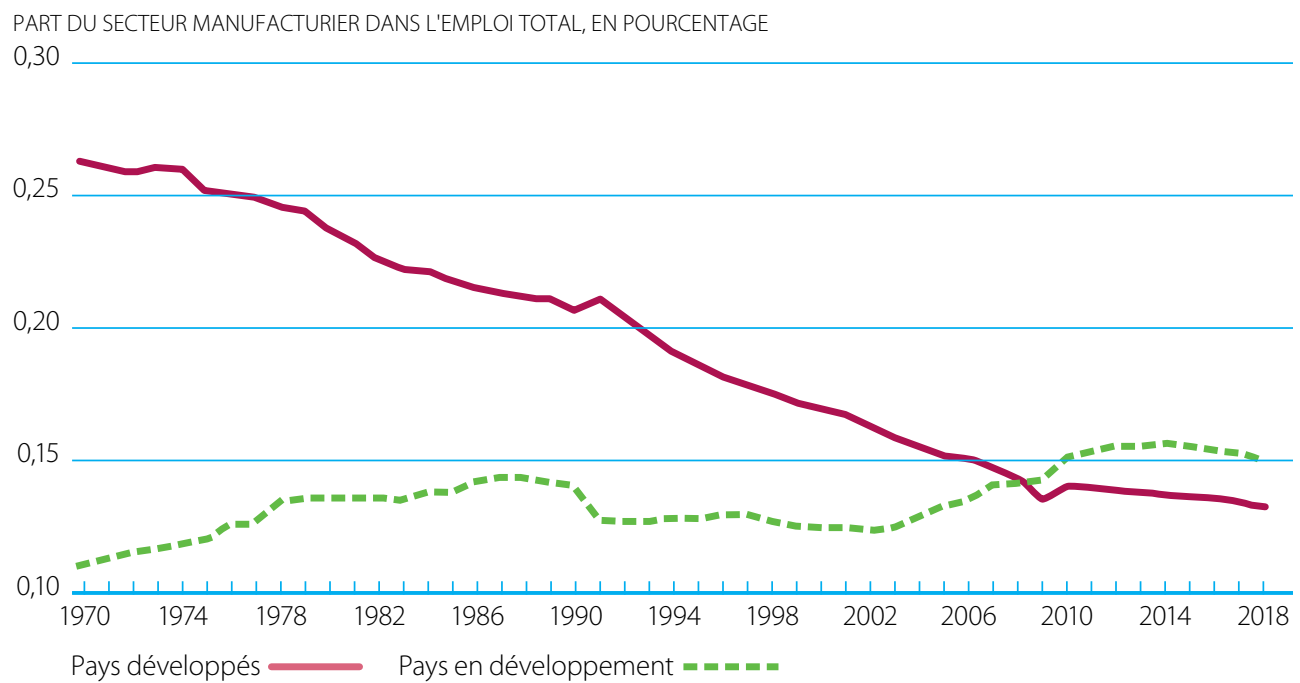

Source: ONUDI, d'après Haraguchi et al. (2017) et Organisation international du Travail, estimations modélisées de I'OIT (2019).

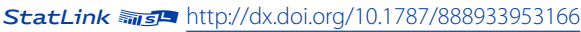

Selon I'ONUDI (2017a), certaines industries offrent des possibilités de création d'emploi différentes selon le niveau de revenu de chaque pays. Par exemple, les industries manufacturières liées à la production de biens de première nécessité, comme l'alimentation, les boissons et les textiles, ont généralement un potentiel de développement plus élevé lorsque les pays sont à un stade précoce de leur développement industriel, et ce, pour trois raisons. Premièrement, elles n'exigent pas un niveau élevé de technologies et de compétences; il est donc plus facile d'y entrer. Deuxièmement, même dans les pays à revenu faible ou intermédiaire, il existe une forte demande pour ces biens parce qu'ils répondent à des besoins humains fondamentaux. Troisièmement, l'existence de régimes préférentiels d'accès aux marchés (système de préférences généralisées et accès en franchise de droits et sans contingent pour les pays les moins avancés) facilite l'accès aux grands marchés de consommation si les règles d'origine et d'autres mesures non tarifaires sont bien utilisées. La demande de ces biens encourage donc les pays en développement à mettre en place et à développer des industries de faible technologie.

Les principales sources d'emploi sont les industries de l'alimentation et des boissons ainsi que celles du textile et de I'habillement (ONUDI, 2017a). Ces industries constituent un fondement solide pour la croissance future du secteur manufacturier car elles créent des possibilités d'emploi formels, génèrent une demande de produits et de services grâce à des liens en amont et contribuent à l'augmentation des revenus ainsi qu'à l'amélioration de l'éducation et de l'infrastructure à un stade précoce de développement. Toutefois, comme cette évolution coïncide avec la croissance du revenu national, les coûts de production finissent par augmenter. La croissance des industries émergentes atteint donc son point maximum car elle repose principalement sur la compétitivité des coûts. Par conséquent, à mesure que les revenus augmentent, il faut créer des industries à forte intensité de capital et de technologie, qui jouent un rôle clé dans la croissance de l'emploi à long terme, afin d'éviter le "piège du revenu intermédiaire", situation dans laquelle les pays ne peuvent concurrencer ni les industries à faible salaire des pays à faible revenu ni les industries de haute technologie des pays à revenu élevé (ONUDI, 2017a). Toutefois, la demande de biens produits par ces industries s'appuie sur un niveau élevé de revenu disponible des ménages, qui dépend quant à lui de la participation au marché du travail et de l'existence d'emplois mieux rémunérés.

Outre les possibilités d'emploi direct, le secteur manufacturier stimule l'emploi dans les autres secteurs grâce à des liens intersectoriels (graphique 3.7). 
Figure 3.7. Emploi induit par le secteur manufacturier, en moyenne, par groupe de pays

Alimentation, boissons et tabac, emploi national (en milliers)

PAYS AVANCÉS, PAR SECTEUR

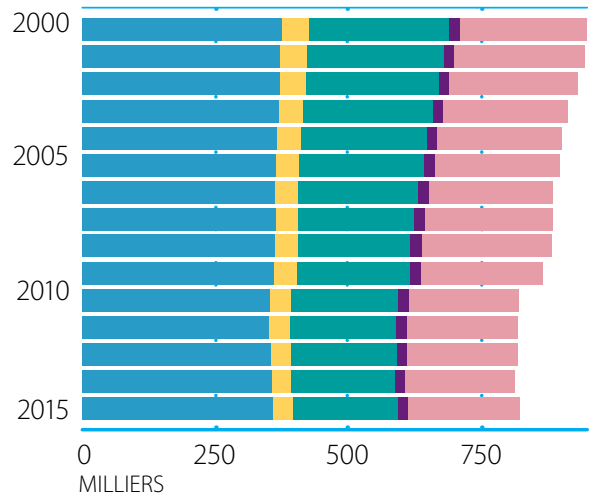

PAYS ÉMERGENTS, PAR SECTEUR

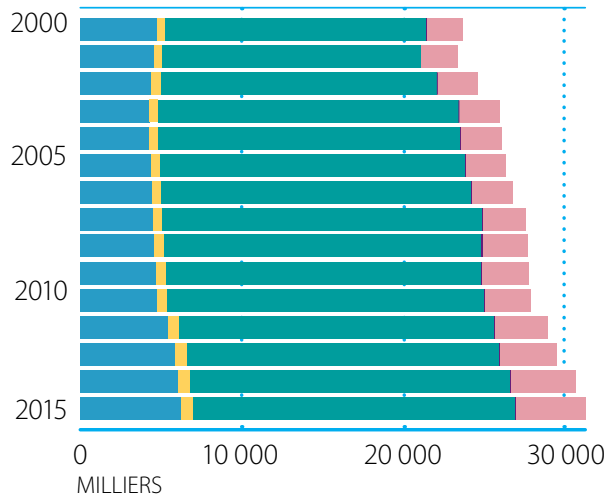

PAYS EN TRANSITION, PAR SECTEUR

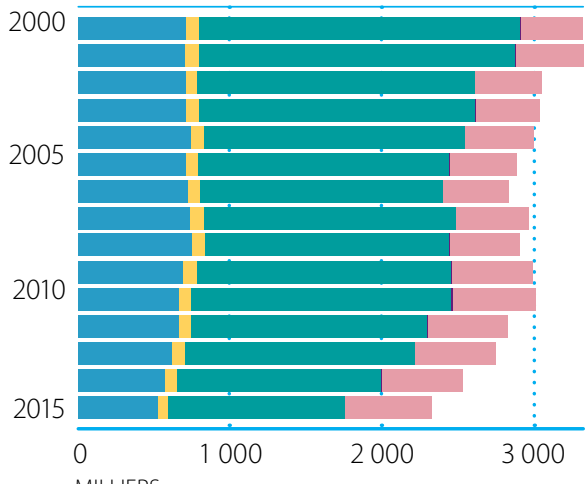
MILLIERS

Emploi direct Secteur manufacturier

Services aux entreprises
Véhicules automobiles, emploi national (en milliers)

PAYS AVANCÉS, PAR SECTEUR

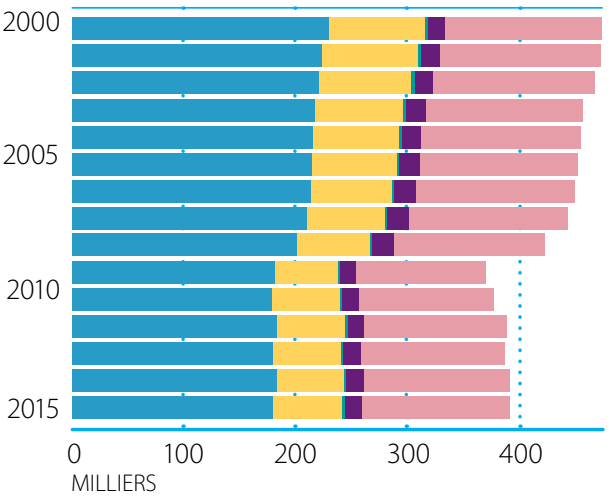

PAYS ÉMERGENTS, PAR SECTEUR

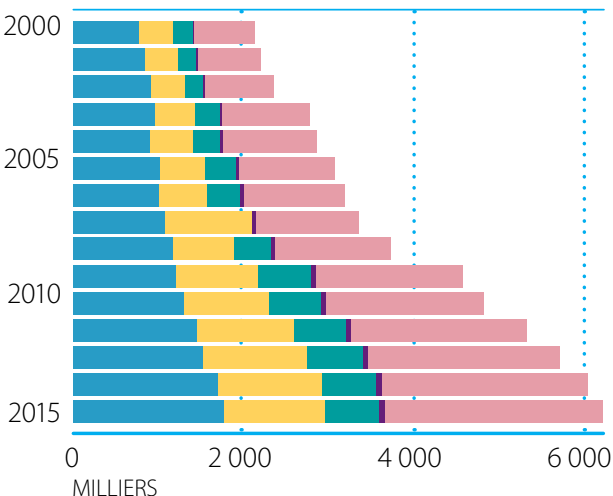

PAYS EN TRANSITION, PAR SECTEUR

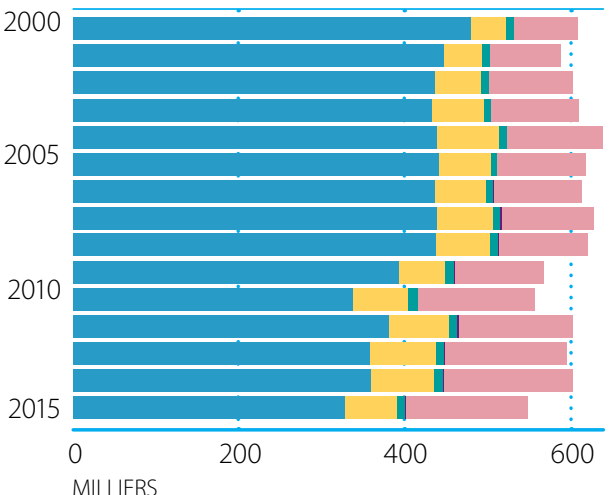

Secteur primaire

Source: ONUDI, d'après la Base de données mondiale sur les entrées-sorties (WIOD) 2016, tirée de Timmer, M. P., et al. (2015). 
Les graphiques illustrent le rapport de dépendance entre l'emploi créé par les autres secteurs et l'emploi créé par les industries de l'alimentation, des boissons et du tabac (panneau de gauche) et les industries de production automobile (panneau de droite) entre 2000 et 2014 dans les pays avancés, les pays émergents et les pays en transition. Le soussecteur de l'alimentation et des boissons, par exemple, dépend largement de l'offre agricole et présente donc un fort lien en amont avec le secteur primaire en termes d'emplois (barre verte). Dans les pays émergents et les pays en transition en particulier, le développement de ce sous-secteur manufacturier peut donc non seulement absorber des emplois mais aussi en créer dans le secteur agricole grâce au lien qui existe entre les deux sous-secteurs. Dans le secteur automobile, la main-d'œuvre est principalement occupée à la production directe (barre bleue), tandis que la production de ce soussecteur crée également des emplois dans d'autres industries d'amont (barre jaune). L'augmentation du volume de la production finale de ce secteur génère également des emplois dans le secteur des services (barres roses et violettes). Dans les pays émergents, le secteur des services peut largement tirer parti, en termes d'emplois, du développement de ce sous-secteur en particulier grâce aux services liés à la manufacture. Ainsi, le processus de "servicification", par lequel les services liés à la manufacture prennent de l'importance dans le secteur industriel, crée la demande nécessaire à la création d'un secteur de services compétitif dans une économie donnée (Guerrieri et Meliciani, 2005). Par conséquent, la mise en œuvre de mesures politiques visant à promouvoir le développement du secteur industriel a d'autres retombées sur l'emploi dans d'autres secteurs, comme en témoigne l'exercice de suivi réalisé par l'OCDE et l'OMC (2019), dans lequel les pays partenaires ont fréquemment mentionné le développement simultané du secteur industriel et du secteur des services comme une priorité de l'Aide pour le commerce.

Étant donné que les pays s'engagent dans un développement technologique reposant sur les compétences au fur et à mesure qu'ils s'industrialisent, la disponibilité de travailleurs qualifiés et formés est essentielle à la diversification. De nombreux pays investissent des sommes importantes dans la formation de capital humain afin que l'offre de travailleurs qualifiés soit suffisante. Cependant, l'éducation formelle n'est pas le seul facteur à jouer un rôle dans le processus d'accumulation de capital humain; l'apprentissage par la pratique et la formation en cours d'emploi ont aussi leur importance. La formation en cours d'emploi, proposée généralement aux employés ayant terminé leurs études scolaires, constitue un moyen efficace et peu coûteux de répondre aux besoins en compétences des industries. La réduction du chômage n'augmente pas seulement le revenu des ménages, elle a également des effets considérables sur le succès de la modernisation technologique des entreprises. La productivité dépend de la capacité des travailleurs de mettre en place et d'utiliser de nouvelles technologies. Donc, puisque les industries auront besoin de travailleurs ayant des compétences différentes tout au long du processus d'industrialisation, il faut mettre en œuvre des mesures appropriées pour que les travailleurs soient disponibles au moment opportun (ONUDI, 2017b).

Afin de promouvoir des possibilités d'emploi inclusives, une attention particulière doit être accordée aux groupes marginalisés, aux jeunes et aux femmes. Ces groupes sont généralement exposés à la pauvreté et à la discrimination car ils sont exclus du marché du travail. Le chômage des jeunes, en particulier, pèse énormément sur l'avenir des personnes directement touchées et sur l'économie dans son ensemble. Les jeunes qui sont sans emploi au début de leur vie active risquent davantage de se retrouver au chômage plus tard (ONUDI, 2013). Ainsi, l'économie dans son ensemble peut bénéficier du cercle vertueux de la consommation de produits manufacturés si les taux de participation au marché du travail de ces groupes augmentent. L'augmentation du niveau d'emploi au sein de ces groupes augmente non seulement leur revenu personnel mais aussi le revenu global de l'économie grâce à une augmentation générale de la consommation globale. D’après le cercle vertueux, la création d'une nouvelle demande dépend dans une large mesure du revenu discrétionnaire des ménages, qui dépend à son tour des possibilités d'emploi (ONUDI, 2017b).

Par conséquent, pour créer des possibilités d'emploi, il faudrait en priorité augmenter la production et la qualité de la croissance du secteur manufacturier. Cependant, ces mesures ont des répercussions sur l'environnement. 


\section{Viabilité de l'environnement}

L'industrialisation et l'augmentation de la production dans le secteur manufacturier ont de forts effets positifs sur l'emploi et la création de revenus, et contribuent à la réduction de la pauvreté. Toutefois, l'industrialisation et l'augmentation de la production de biens manufacturés sont souvent associées à une augmentation des émissions nocives de gaz à effet de serre tels que le $\mathrm{CO}_{2}$ et à une utilisation intensive des ressources naturelles. La gestion et la réduction de ces externalités sont des éléments fondamentaux du développement économique durable et de la transformation structurelle par l'industrialisation.

La figure 3.8 présente une décomposition, de 1995 à 2013, des taux d'augmentation du CO imputables à l'effet d'échelle, à l'effet de composition et à l'effet d'intensité dans le secteur manufacturier (ONUDI, 2017a). Dans l'ensemble, l'augmentation des émissions dans le secteur manufacturier a été significative dans toutes les catégories de revenus au cours de cette période. Les pays à revenu intermédiaire de la tranche supérieure et à revenu intermédiaire de la tranche inférieure ont connu la plus forte augmentation totale (barre violette), tandis que le taux d'augmentation dans le groupe de pays à revenu élevé était négligeable.

La décomposition révèle que l'augmentation du volume de l'économie (barre verte) et la lente augmentation de l'efficacité (barre bleue) sont les principales responsables de l'augmentation totale des émissions. L'effet de composition ne contribue pas de manière significative à l'augmentation totale (barre orange). Cette analyse désagrégée met en évidence les disparités qui existent d'un pays à l'autre en ce qui concerne l'effet d'échelle et l'effet d'intensité des émissions dues aux activités du secteur manufacturier.

\section{Figure 3.8. Décomposition des émissions de $\mathrm{CO}_{2}$ générées de 1995 à 2003}

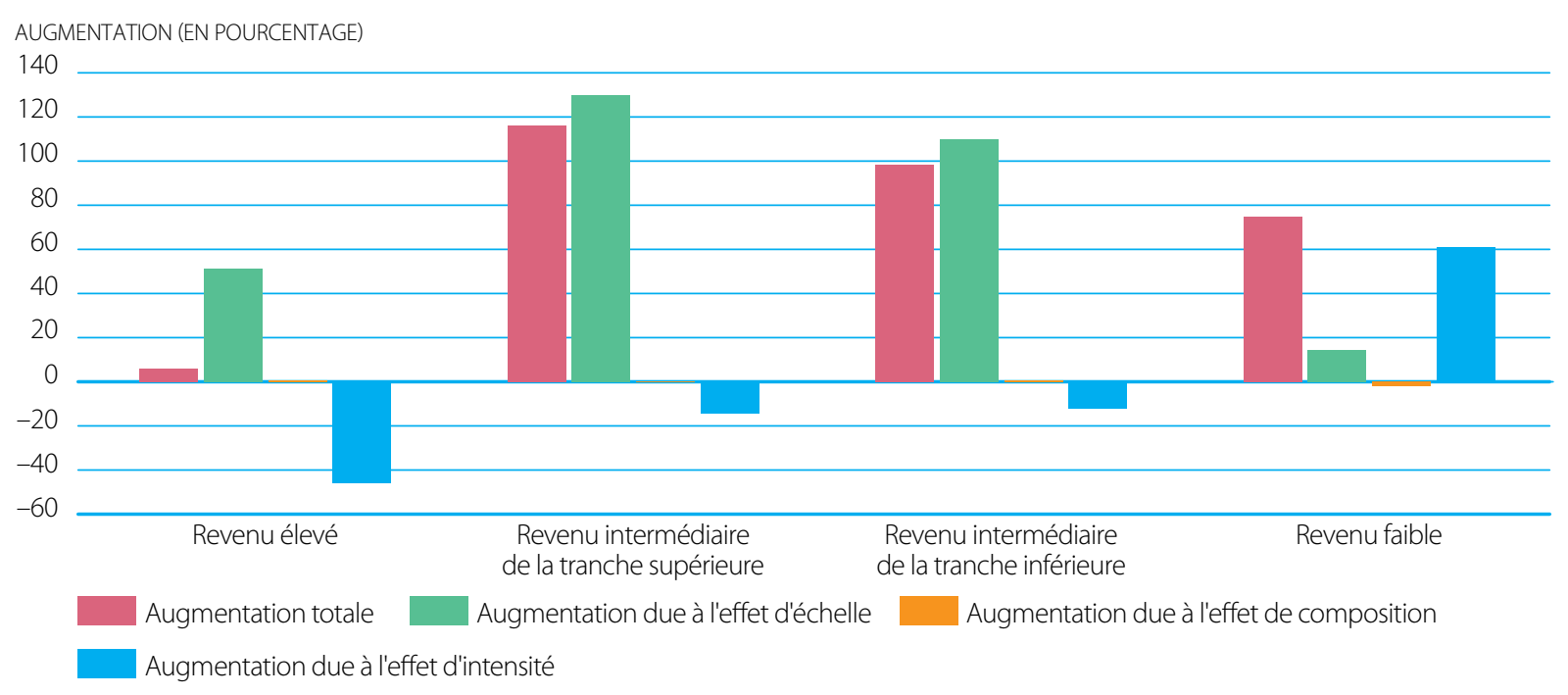

Source: ONUDI (2017a).

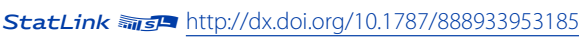

Les effets environnementaux et l'amélioration de l'efficacité dans le secteur manufacturier varient considérablement, tout comme les tendances générales et les améliorations (Mazzanti et Nicolli, 2017). Par exemple, la figure 3.9 montre que, dans de nombreuses industries, les émissions de $\mathrm{CO}_{2}$ par unité de valeur ajoutée réelle tendent à diminuer lorsque le revenu augmente. Les industries du caoutchouc et du plastique, des instruments de précision, des meubles, des métaux de base et des produits chimiques émettent d'importantes quantités de $\mathrm{CO}_{2}$ dans les pays à un stade précoce de développement. Lorsque leur revenu augmente, ces pays peuvent réduire les émissions de ces industries, qui deviennent relativement propres. Toutefois, certaines industries telles que celles de l'alimentation, des boissons, du textile et 
de l'habillement se caractérisent par un important niveau d'émissions qui ne diminue pas notablement à mesure que les revenus augmentent. Néanmoins, même si le secteur manufacturier dans son ensemble tend à diminuer l'intensité des émissions de $\mathrm{CO}_{2^{\prime}}$ les émissions totales pourraient tout de même augmenter considérablement, en particulier dans les phases de revenus intermédiaires, en raison d'une augmentation du volume de production (figure 3.8).

\section{Figure 3.9. Émissions de $\mathrm{CO}_{2}$ de l'industrie par unité de valeur ajoutée réelle}

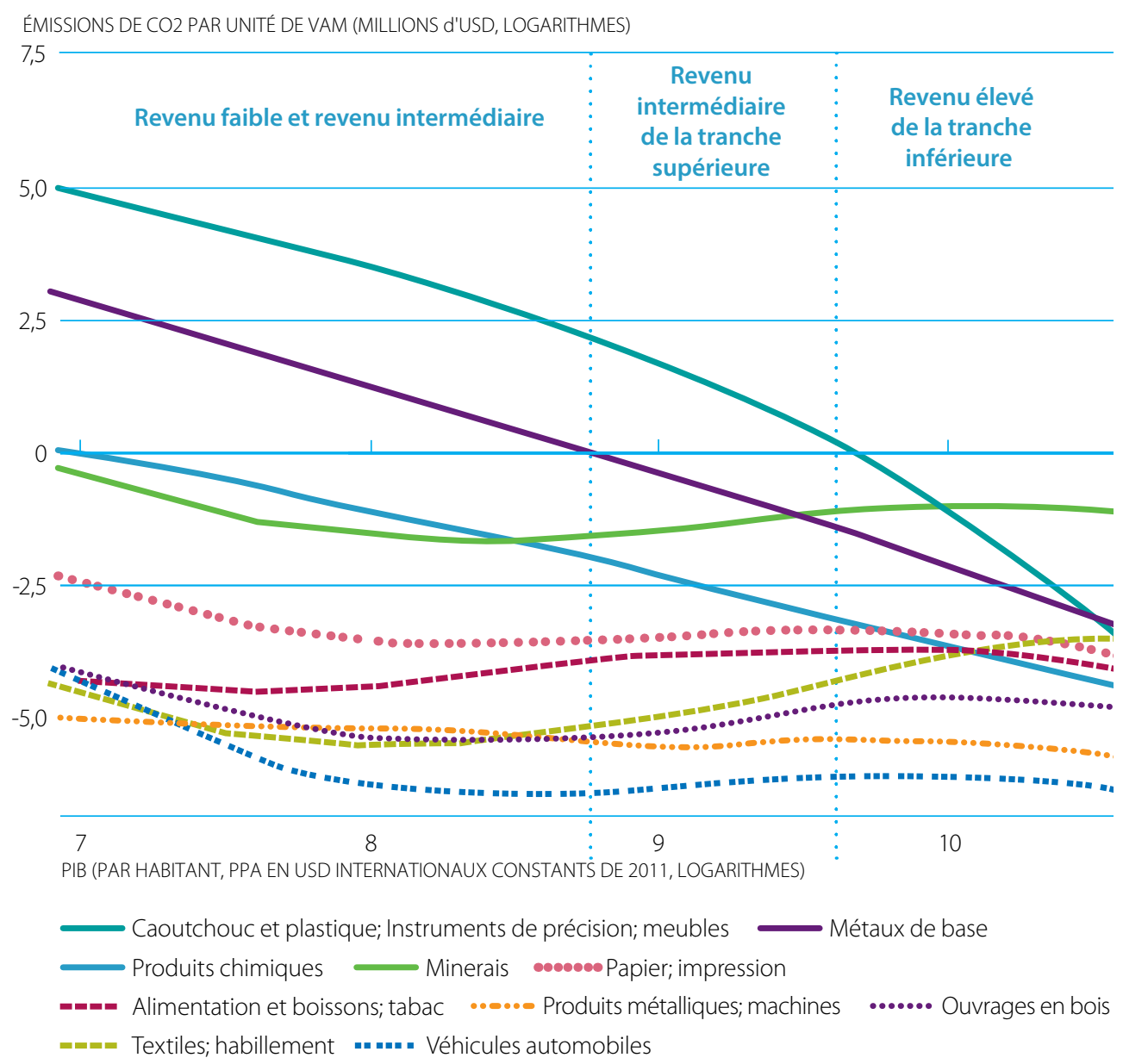

Source: ONUDI.

II ressort des conclusions des sections précédentes qu'il est possible d'éviter les compromis environnementaux et de tirer les leçons du passé pour réduire l'ampleur des émissions de $\mathrm{CO}_{2}$ tout en diminuant leur intensité dans le processus de production afin de minimiser les incidences sur l'environnement.

Les deux principaux canaux qui mènent à une meilleure viabilité de l'environnement sont le processus de production et la structure globale de la production (ONUDI, 2015). Le processus de production d'une entreprise donnée passe par certaines étapes au cours desquelles des technologies vertes peuvent être utilisées, par exemple, pour réduire les émissions nocives. II est possible de rendre la production plus efficace en vue de minimiser la consommation de ressources. En outre, le type d'énergie utilisé dans le processus de production joue un rôle crucial dans la réduction de l'impact environnemental des activités de fabrication. Par conséquent, les pouvoirs publics peuvent utiliser des instruments tels que des subventions ou des programmes fiscaux pour inciter à la transition des sources d'énergie fossiles à des sources d'énergie renouvelables (ONUDI, 2017a). En outre, donner la priorité au recyclage peut produire 
les deux effets, à savoir une réduction des émissions et une utilisation plus efficace des ressources. Des études récentes sur la notion d'économie circulaire, dans laquelle la conception des produits permet de prolonger leur durée de vie, de gérer très efficacement les ressources et de mettre l'accent sur le recyclage tout au long du développement du produit, indiquent qu'un tel modèle pourrait aider les pays à s'orienter vers un secteur industriel durable. Alors que les entreprises visent naturellement à minimiser les coûts de leurs intrants, la protection de l'environnement peut engendrer des dépenses et donc nécessiter des compromis. En ce sens, certains éléments de l'économie circulaire peuvent être très bénéfiques tant pour les consommateurs que pour les producteurs (ONUDI, 2017c). Autrement dit, le processus d'industrialisation et le schéma des changements structurels dessinent une courbe en forme de $U$ inversé en termes d'intensité des émissions. ${ }^{3}$ Cela peut s'expliquer par l'essor des industries à forte intensité énergétique et à forte intensité de ressources (métaux, minerais non métalliques, substances et produits chimiques) dans la phase de revenu intermédiaire ainsi que par une productivité environnementale accrue grâce aux technologies qui réduisent les émissions des industries manufacturières de haute technologie.

Les pays peuvent éviter de faire les mêmes compromis que par le passé et réaliser une croissance fondée sur les progrès technologiques et les innovations vertes sans sacrifier l'environnement. Cela nécessite toutefois un transfert de connaissances et de technologies, ainsi que des outils suffisamment simples pour que les pays en développement puissent réellement mettre ces technologies en place. L'ONUDI (2015) voit une possibilité pour les pays à faible revenu d'absorber une technologie à laquelle ils ont accès afin de promouvoir des procédés de production respectueux de l'environnement. Lorsque les pays se diversifient et se lancent dans des industries à forte intensité énergétique, ils peuvent tirer parti des technologies et innovations existantes pour éviter les compromis environnementaux.

\section{Limites auxquelles se heurtent les pays en développement et possibilités qui leur sont offertes}

À partir des modèles généraux de diversification industrielle et de transformation structurelle, il est possible de déduire certains éléments qui ouvrent des perspectives pour les pays en développement. Du côté de la demande, la figure 3.10 illustre l'importance de la demande intérieure pour les pays à différents stades de développement (ONUDI, 2017b). Elle présente la part de l'absorption intérieure dans la demande finale de produits manufacturés au cours de la période allant de 1990 à 2013

\section{Figure 3.10. Part de l'absorption intérieure dans la demande finale de produits manufacturés}

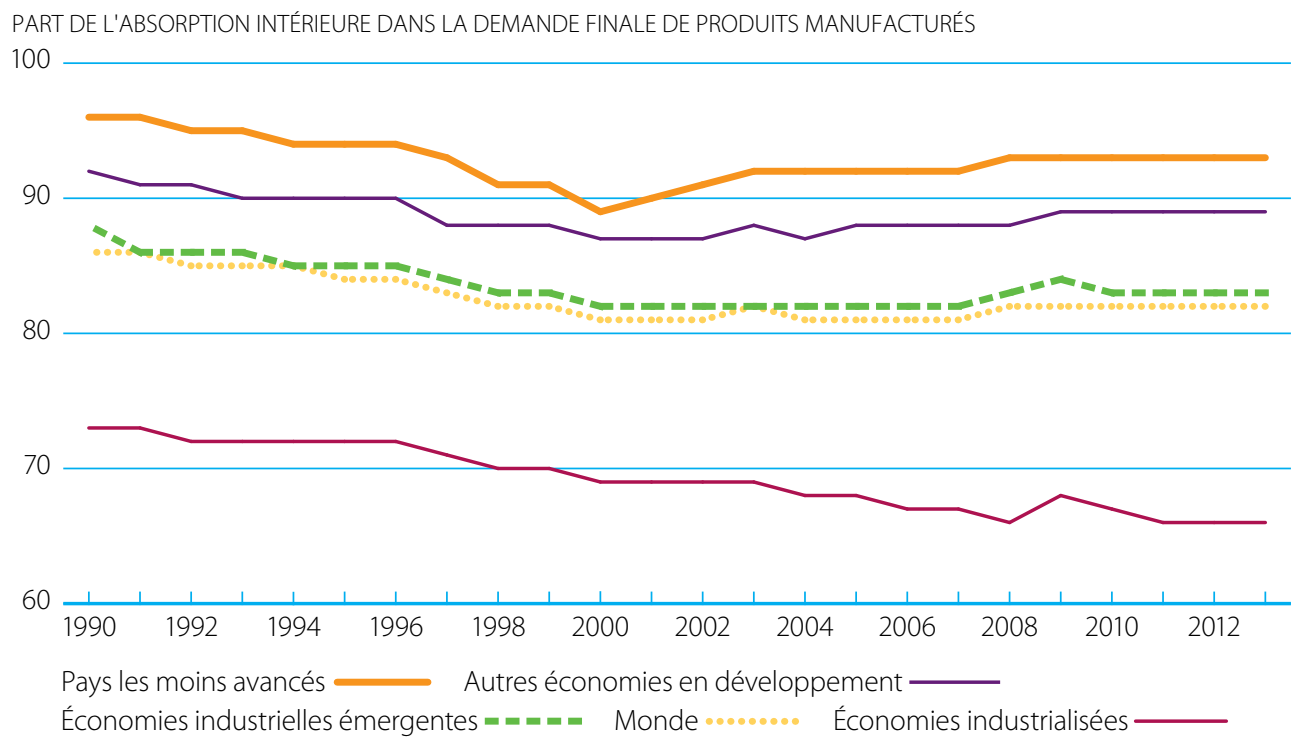

Source: ONUDI (2017b).

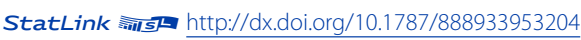


La facilitation des échanges, ou plutôt la circulation fluide des marchandises, repose sur le bon fonctionnement du Système d'infrastructure de la qualité, en particulier en ce qui concerne les essais, l'inspection et la certification, qui permet de démontrer qu'un produit est conforme aux exigences du marché et aux exigences d'acceptation mutuelle. Grâce à un financement du gouvernement allemand (Ministère fédéral de la coopération économique et du développement), I'ONUDI a créé un outil appelé "Infrastructure de la qualité pour la facilitation des échanges (Q/4TF)" pour identifier les lacunes des systèmes nationaux d'infrastructure de la qualité qui empêchent la mise en œuvre effective de l'Accord de I'OMC sur la facilitation des échanges (AFE).

Cet outil de diagnostic permet d'identifier les forces et les faiblesses auxquelles les pouvoirs publics et les industries seraient probablement confrontés en entrant sur le marché international des produits alimentaires. Son objectif est de permettre l'identification et la priorisation des lacunes les plus graves des systèmes nationaux d'infrastructure de la qualité qui entravent les échanges, tout en respectant les prescriptions de l'Accord sur les obstacles techniques au commerce (OTC) et l'Accord sur les mesures sanitaires et phytosanitaires (SPS). Cet outil est destiné à être appliqué à tous les produits agroalimentaires transformés de premier niveau qui passent d'un pays à l'autre.

Il a été mis à l'essai au Malawi et en Afrique du Sud avec le soutien du Comité national de la facilitation des échanges et d'autres parties prenantes. II a été fait appel à des organismes clés des secteurs public et privé pour qu'ils cernent les lacunes et les classent par ordre de priorité. Les résultats obtenus contribuent à appuyer les activités de renforcement des capacités nationales et de coopération technique, à mettre en œuvre des initiatives et à les axer sur les principaux besoins et lacunes.

Tout organisme national chargé de la facilitation des échanges peut se servir de cet outil pour procéder à une autoévaluation et préparer une feuille de route en vue de son utilisation.

Source: ONUDI.

Tous les groupes de pays dépendent fortement de la demande intérieure pour vendre des produits manufacturés. Les PMA ont la plus grosse part d'absorption intérieure, tandis que les pays à revenu élevé ont connu une augmentation de la demande extérieure pour leurs produits manufacturés.

Il est tout à fait possible d'améliorer la qualité et la compétitivité d'un produit grâce à des politiques axées sur la demande, comme le renforcement des réglementations en matière de sécurité et de qualité, pour s'approcher des normes internationales. Dans le cadre de l'exercice de suivi de l'Aide pour le commerce de 2019, l'incapacité de respecter les normes de qualité internationales a été identifiée par les pays, les donateurs et les partenaires Sud-Sud comme l'un des principaux obstacles à la diversification économique. Un outil de diagnostic permettant d'identifier les lacunes dans la qualité de l'infrastructure, comme celui de l'ONUDI, pourrait aider les pays à se conformer aux prescriptions de l'Accord sur les obstacles techniques au commerce et de l'Accord sur les mesures sanitaires et phytosanitaires en ce qui concerne la facilitation des échanges (encadré 3.2).

L'offre et la demande doivent toutes deux remplir leurs fonctions pour créer un cercle vertueux qui permette une industrialisation durable. En renforçant la capacité de l'offre, les producteurs peuvent concurrencer les importations et répondre à une grande partie de la demande intérieure. Le développement du secteur manufacturier et des secteurs connexes de l'agriculture et des services contribue à l'augmentation des revenus, ce qui accroît encore le volume de la demande et crée une demande pour des produits nouveaux et plus sophistiqués. L'évolution du comportement des consommateurs incite les entreprises à moderniser et à diversifier leurs gammes de produits. Certains éléments essentiels enclenchent ce cercle vertueux et le soutiennent. Par exemple, une infrastructure solide et un environnement commercial fiable peuvent inciter à investir dans de nouvelles capacités. Les capacités existantes peuvent être développées si elles ne sont pas limitées par des moyens de transport déficients et un approvisionnement électrique peu fiable. Pour favoriser ce développement par l'investissement, une condition préalable est l'accès au financement par 
des systèmes financiers et des intermédiaires efficaces. Les pouvoirs publics ont un rôle de soutien particulier. En outre, un niveau élevé d'imposition, des réglementations et des lois commerciales rigides ainsi que la corruption pèsent lourdement sur les décisions d'investissement par le biais des coûts de production (ONUDI, 2013). Du point de vue de la politique commerciale, les pays en développement et leurs partenaires commerciaux peuvent également bénéficier d'une ouverture bilatérale, régionale ou multilatérale.

Pour accroître leurs capacités manufacturières, les pays en développement peuvent aussi prendre part au commerce mondial, ce qui suppose d'utiliser la demande extérieure. Par exemple, l'ONUDI (2017b) estime que la demande mondiale de produits manufacturés est un outil essentiel pour favoriser le développement industriel et la croissance. Le renforcement des capacités dans le secteur manufacturier alimente donc le cercle vertueux de la consommation, conduisant à terme à la diversification des produits manufacturés. L'ouverture des économies nationales au commerce peut avoir un effet positif sur les salaires des travailleurs et les bénéfices des entreprises, et ce de deux manières. Premièrement, la demande mondiale pour des nouvelles variétés de produits conduit à une diversification des produits manufacturés. Deuxièmement, la demande croissante pour des variétés existantes de produits entraîne une massification des produits. Toutefois, une participation accrue au commerce mondial pourrait avoir un coût et freiner la croissance économique future. D'une part, la substitution des produits nationaux par des produits importés peut s'accompagner d'une fuite des revenus générés par la demande intérieure vers les producteurs étrangers. D'autre part, une baisse des prix mondiaux des produits nationaux exportés réduit les revenus nominaux de l'économie nationale (ONUDI, 2017b). En général, les pays à forte concentration de produits d'exportation (c'est-à-dire les pays qui n'exportent qu'un nombre limité de produits) sont particulièrement vulnérables à la volatilité des marchés mondiaux.

D'un point de vue plus concret, les questions qui concernent en particulier les entreprises comme la modernisation technologique, l'accès aux réseaux de fournisseurs ou la capacité de gestion globale sont des points importants dans l'amorce d'une diversification des gammes de produits. II faut de bonnes pratiques de gestion et un accès à des informations fiables sur les marchés (national et mondial) pour stimuler le développement industriel et s'engager sur la voie de la transformation structurelle. Pour que les entreprises et les usines réussissent leur modernisation technologique, il faut au préalable renforcer l'ensemble des compétences des travailleurs. La formation en cours d'emploi devrait donc faire partie intégrante des efforts déployés par les entreprises pour améliorer les compétences de leurs travailleurs. En particulier, dans les pays qui ne disposent pas de structures nationales permettant d'assurer une formation professionnelle appropriée, les zones économiques spéciales (ZES), dans lesquelles des régimes de commerce et d'incitations différents s'appliquent, peuvent fournir le soutien nécessaire à la formation en cours d'emploi (ONUDI, 2009). Les politiques visant à créer de telles zones peuvent donc être un complément sur la voie de l'utilisation productive des nouvelles technologies. Favoriser le développement des zones industrielles est l'une des principales caractéristiques du nouveau Programme de partenariat pays (PCP) de l'ONUDI. D'une façon générale, cet ensemble de services intégrés aide de diverses manières les pays d'accueil à accélérer le développement industriel inclusif et durable (encadré 3.3). Actuellement, l'un des domaines prioritaires du PCP mis en œuvre au Sénégal, au Pérou, au Cambodge et au Maroc est le développement de ces zones pour favoriser une diversification industrielle durable.

En d'autres termes, si les pays réussissent à tirer parti de l'industrialisation en surmontant les contraintes tant du côté de l'offre et que du côté de la demande, le secteur manufacturier pourra absorber un certain nombre de chômeurs ou de personnes occupant des emplois informels. Ce secteur est donc le moteur de la croissance et permet de passer de la catégorie de pays à faible revenu à celle de pays à revenu intermédiaire. En ce qui concerne le développement inclusif, l'émergence d'industries à forte intensité de main-d'œuvre aux premiers stades de l'industrialisation génère un grand nombre d'emplois formels qui peuvent être occupés par des femmes et des jeunes. L'emploi formel a pour avantage de réduire les risques économiques, ce qui diminue la volatilité des revenus et améliore l'accès aux assurances sociales (Braunstein, 2019). Toutefois, le taux d'emploi global des femmes affiché dans l'industrie manufacturière tend à diminuer 


\section{Encadré 3.3. Programme de partenariat pays (PCP) de l'ONUDI}

L'ONUDI fournit un nouveau service programmatique aux gouvernements sur les questions liées à l'industrie afin de mettre en œuvre un programme national sur mesure pour appuyer et accélérer un développement industriel inclusif et durable. Le PCP identifie les principales possibilités et contraintes pour ce qui est de faire avancer l'industrie et utilise cette analyse pour concevoir et développer un programme global visant à accélérer le développement industriel des pays bénéficiaires.

Grâce à la combinaison des services consultatifs et de l'assistance technique multidisciplinaire de l'ONUDI, le PCP tient compte du potentiel de création d'emplois de chaque pays, de ses possibilités d'exportation et de sa capacité d'attirer des investissements étrangers directs. En outre, le PCP facilite la mobilisation et la coordination des investissements du secteur public et du secteur privé pour soutenir les projets industriels à grande échelle dans des secteurs prioritaires.

Afin de créer des synergies entre les différents projets et programmes, divers acteurs tels que les partenaires de développement, les institutions financières, le secteur privé ainsi que des acteurs du milieu académique et de la société civile concluent un partenariat multipartite sous la direction du gouvernement bénéficiaire. L'ONUDI facilite la coordination générale du programme et, en fonction des besoins de chaque pays, apporte son soutien à l'élaboration de politiques et de stratégies, au développement de zones industrielles et de parcs éco-industriels ainsi qu'à la mise en œuvre de programmes de formation professionnelle.

Des ensembles de services intégrés sont actuellement fournis dans le cadre du PCP en Éthiopie, au Sénégal, au Pérou, au Cambodge, au Kirghizistan et au Maroc. En 2019, de nouveaux PCP seront élaborés pour la Côte d'Ivoire, l'Égypte, le Rwanda et la Zambie.

Source: ONUDI.

Pour de plus amples informations, prière de consulter la page :https:/www.unido.org/programme-country-partnership

lors de la transition vers des industries de moyenne et haute technologie (ONUDI, 2017a). Cela pourrait être dû au fait que les femmes ont un accès limité à l'éducation, ce qui les empêche d'acquérir les compétences nécessaires pour travailler dans des industries à forte intensité technologique. En outre, la discrimination hommes-femmes peut empêcher l'emploi de femmes ayant le même niveau de compétences que les hommes dans ces industries.

Braunstein (2019) propose une stratégie industrielle inclusive reposant sur trois grands principes. Premièrement, il convient d'éviter la ségrégation des femmes dans les industries les moins bien rémunérées (dont la plupart sont à forte intensité de main-d'œuvre) en leur donnant accès à des emplois à forte intensité de capital et de technologie. II est possible d'y parvenir en incitant les entreprises à employer des femmes ou en aidant directement les femmes à acquérir les compétences nécessaires. Deuxièmement, il faut établir des normes de travail solides, qui protègent le pouvoir de négociation des femmes et diminuent ainsi le risque de discrimination sexuelle. Troisièmement, il convient d'utiliser les conditions de salaire et d'emploi du secteur industriel comme référence pour l'emploi dans le secteur des services, dans lequel travaillent généralement des femmes. La prise en compte des questions d'égalité hommes-femmes est indispensable pour arriver à un développement industriel inclusif.

En ce qui concerne les aspects environnementaux de la question de l'avenir durable qui se pose aux pays en développement, la réduction tant des émissions et que de l'utilisation des ressources fait partie intégrante d'une trajectoire de croissance respectueuse de l'environnement. II faut s'attendre à ce que les niveaux d'émissions dans les pays en développement augmentent pendant le processus de transformation structurelle car l'industrialisation conduit à l'émergence d'industries à forte intensité d'émissions. II en résulte un déséquilibre mondial en termes d'émissions puisque les pays à revenu élevé affirment que l'efficacité des politiques de stabilisation des émissions dépend essentiellement de l'engagement des pays en développement en faveur de ces politiques. De nombreux pays à revenu élevé ont déjà mis en œuvre le Protocole de Kyoto en appliquant des stratégies peu coûteuses de réduction des émissions. 
Étant donné que les pays à faible revenu à un stade précoce de développement industriel commencent à peine à entreprendre des activités industrielles, ils jouent un rôle prépondérant dans la réalisation de l'objectif mondial de convergence des émissions par habitant. Le transfert de technologie des pays développés vers les pays en développement est indispensable pour atteindre cet objectif mondial de réduction des émissions. Ce transfert peut concerner des technologies industrielles particulières ou des technologies respectueuses de l'environnement et affecte à la fois l'ensemble de la structure de production et les différents processus de production (Cantore et Padilla, 2010). Le recyclage des déchets et des matériaux, par exemple, fait partie de ces technologies vertes. En transférant les innovations technologiques pertinentes et les connaissances nécessaires à la mise en œuvre de ces procédés, les pays à revenu élevé peuvent jouer un rôle vital dans l'écologisation du processus d'industrialisation des pays en développement (ONUDI, 2015). Une telle stratégie présente un autre avantage, à savoir le facteur coût des intrants, qui peut inciter à adopter des technologies plus respectueuses de l'environnement. Une utilisation plus efficace des intrants et, en même temps, une réduction des émissions bénéficient à la fois à l'environnement et aux entreprises manufacturières en termes de coûts (ONUDI, 2017a).

La figure 3.11 ci-dessous montre les principaux obstacles à la diversification économique que les pays en développement et leurs partenaires financiers ont mentionné dans les réponses qu'ils ont apportées à l'étude réalisée conjointement par I'OCDE et I'OMC.

\section{Figure 3.11. Principales entraves à la diversification économique}

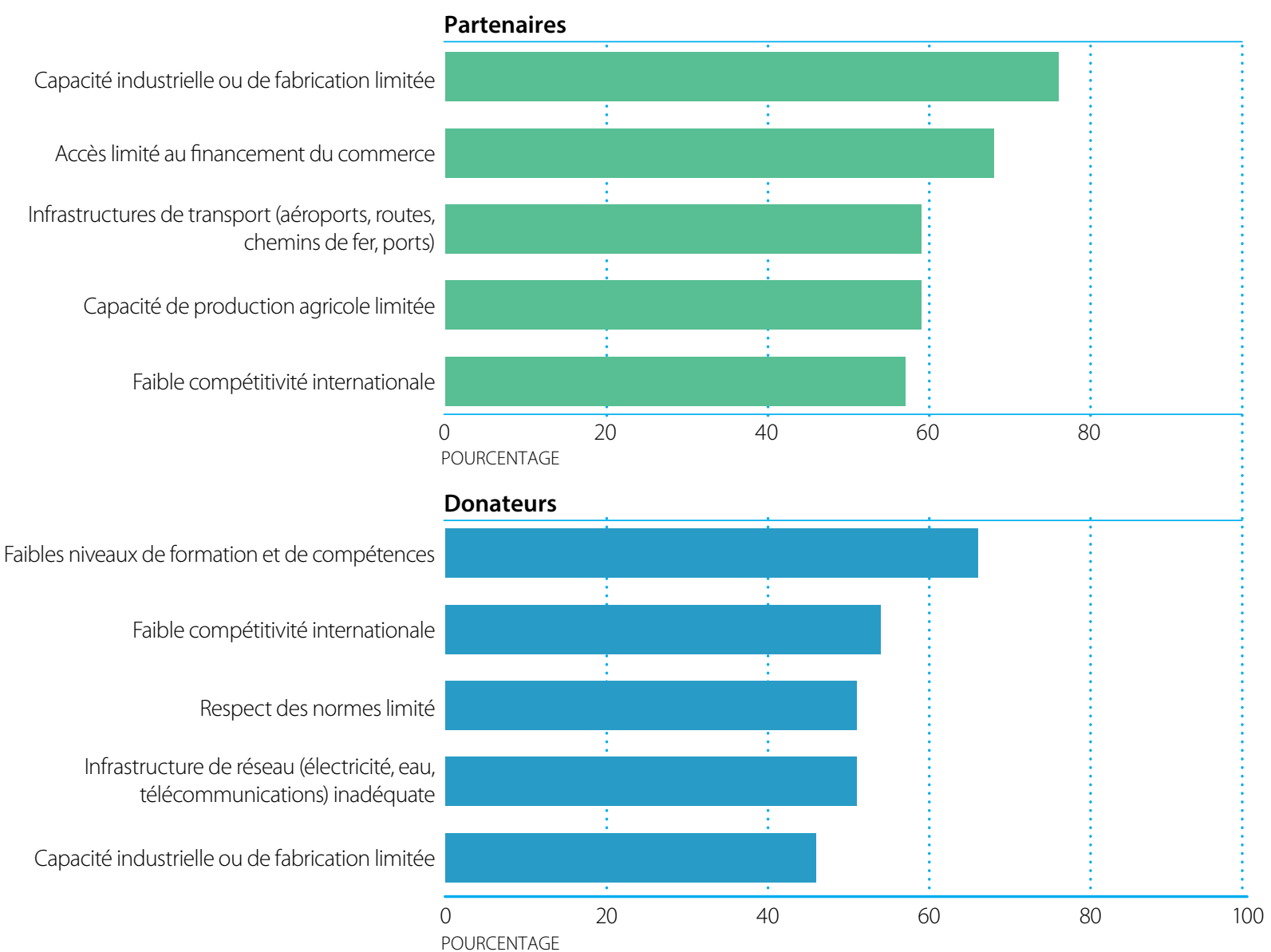

Source: Exercice de suivi de l'Aide pour le commerce OCDE-OMC (2019). 
Sur les 88 pays en développement ayant participé à l'exercice de suivi de l'Aide pour le commerce réalisé en 2019, 67 (soit 76\%) ont indiqué que la capacité de production industrielle limitée constituait la principale entrave à la diversification économique identifiée dans leur stratégie nationale ou régionale de développement. Toutefois, les donateurs interrogés ont classé cette même entrave au cinquième rang et indiqué que c'était les faibles niveaux de formation et de compétences qui posaient le plus de problèmes en la matière. Les partenaires Sud-Sud, tout comme les donateurs, ont indiqué que les principales difficultés étaient posées par les faibles niveaux de formation et de compétences, suivis par l'infrastructure de transport et de réseau limitée, l'état de préparation au commerce électronique insuffisant, les coûts élevés des intrants et du commerce, et le non-respect des normes. Jusqu'à présent, les concepts fondamentaux de l'industrialisation ont été analysés à la lumière du développement industriel inclusif et durable. Toutefois, l'émergence d'un nouveau paradigme technologique peut créer de nouvelles possibilités et difficultés. La section suivante traite donc des nouvelles technologies émergentes et de leurs incidences sur l'avenir du développement industriel.

\section{NATURE CHANGEANTE DE L'INDUSTRIALISATION ET DES PROCESSUS DE PRODUCTION}

Le principal moteur de la diversification économique et de la transformation structurelle est le développement du secteur manufacturier. L'industrialisation offre des avantages évidents en termes de valeur ajoutée et de possibilités d'emploi par rapport au secteur agricole, en particulier pour les pays émergents et les pays en développement. Cependant, elle n'est en aucun cas un phénomène homogène et dépend fortement des effets qu'elle produit dans chaque pays (par exemple, en fonction de la qualité des institutions, du cadre réglementaire ou de l'ensemble des mesures politiques), des ressources disponibles et du niveau de revenu de l'économie.

La figure 3.12 présente les tendances à long terme de l'emploi manufacturier formel par région pour 1970, 1990, 2010 et 2016. Bien que l'emploi manufacturier formel ait principalement diminué dans les pays industrialisés, une augmentation relativement forte a été observée dans plusieurs régions en développement et régions émergentes du monde, comme l'Asie de l'Est et le Pacifique. Des données empiriques montrent, par exemple, que les activités manufacturières à forte intensité de main-d'œuvre tendent à être concentrées dans les pays à faible coût de main-d'œuvre, tandis que les industries de haute technologie ont tendance à apparaître dans les pays riches, qui ont accès à une main-d'œuvre hautement qualifiée. Cela explique notamment pourquoi l'évolution de la structure de l'emploi dans le secteur manufacturier diffère selon la région du monde (ONUDI, 2017a).

\section{Figure 3.12. Tendances de l'emploi formel dans le secteur manufacturier, par région, pour 1970, 1990, 2010 et 2016}

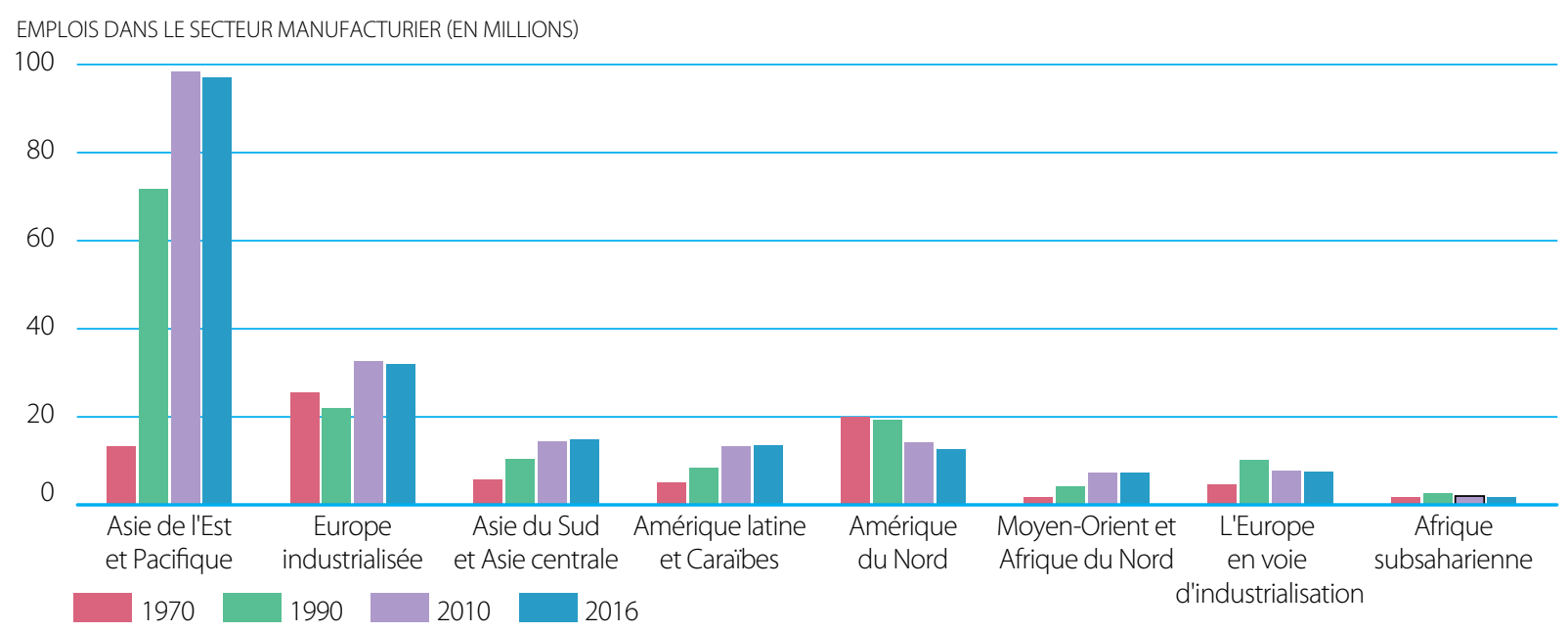

Source: ONUDI, d'après la base de données INDSTAT2 (2019). 
Cette vue d'ensemble illustre l'évolution de l'emploi manufacturier dans les différentes régions du monde mais ne montre pas les tendances récentes dans certaines industries.

Aux fins de l'analyse de la nature changeante de l'industrialisation et des processus de production, une vue d'ensemble plus détaillée du secteur manufacturier est présentée à la figure 3.13. Cette dernière illustre l'utilisation de robots industriels, qui s'inscrit dans la tendance récente à l'automatisation dans les différentes industries et montre que cette automatisation croissante joue un rôle particulier dans la transformation des modes de développement industriel grâce aux innovations technologiques. En raison de la diversité de leurs caractéristiques et de leurs processus de production, les différentes industries manufacturières ont des potentiels d'automatisation qui varient. Cette hétérogénéité se manifeste non seulement dans le secteur industriel mais aussi dans le temps, comme le montre la figure 3.13 (ONUDI, 2017a).

\section{Figure 3.13. Utilisation de robots industriels dans différentes industries}

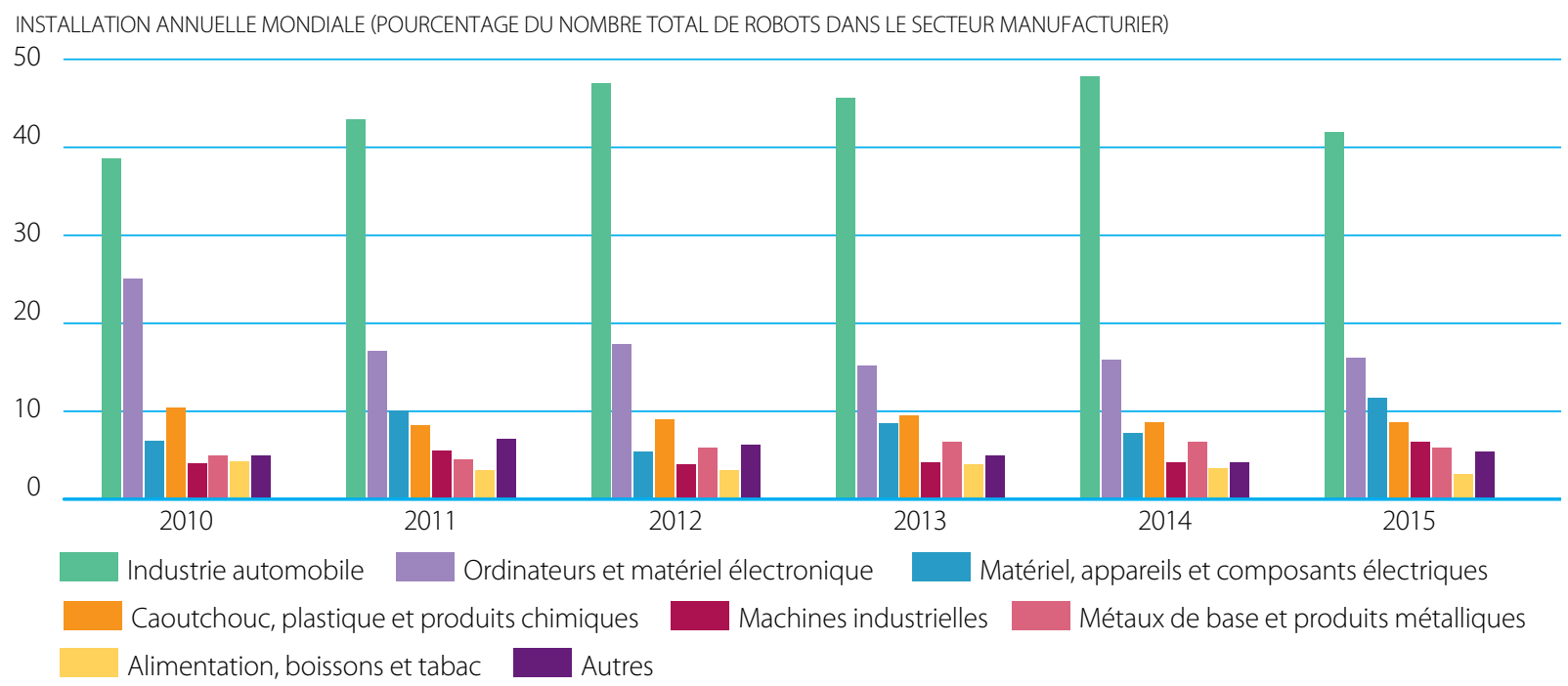

Source: CNUCED (2017), UNCTAD/TDR/2017, d'après la base de données National Accounts Main Aggregates, Division de statistique de I'ONU (2017).

La majorité des dispositifs d'automatisation sont installés dans trois industries à forte intensité de capital : 1) l'industrie automobile, 2) les ordinateurs et le matériel électronique et 3) le matériel, les appareils et les composants électriques. Selon la CNUCED (2017), les industries à faible intensité de technologie et à forte intensité de main-d'œuvre ne connaissent pas une automatisation intensive et offrent donc encore des possibilités de création d'emplois. Pour évaluer les possibilités d'emploi en général, il est nécessaire de comprendre l'impact des nouvelles technologies sur les processus de production au sein d'une industrie donnée ainsi que les tendances de la transformation structurelle aux différents stades de développement.

Par exemple, Autor (2015) considère que l'automatisation sur le lieu de travail est une tendance multidimensionnelle qui aura des effets hétérogènes sur l'évolution du marché du travail. Selon lui, l'automatisation pourrait en fait venir compléter la main-d'œuvre salariée et créer de nouvelles possibilités d'emploi, influant ainsi de différentes manières sur la génération de revenus. Toutefois, son effet sur la réduction des coûts est limité car certaines tâches ne peuvent pas encore être entièrement automatisées, la main-d'œuvre ne pouvant être remplacée par des machines ou des robots que dans une certaine mesure. Les tâches répétitives, par exemple, peuvent être entièrement accomplies par des robots tandis que les tâches plus complexes continueront, pour l'instant, d'être exécutées par de la maind'œuvre conventionnelle. Cela conduira dans un premier temps à un développement reposant sur les compétences. 
Les principales implications de la nature changeante de l'emploi, des tâches et des compétences requises montrent combien il est important de développer le capital humain de façon continue (Acemoglu et Restrepo, 2017). II est possible qu'à l'avenir, la nature de la production permette aux machines (robots ou autres dispositifs d'automatisation) et aux travailleurs d'interagir. Par exemple, les tâches essentiellement manuelles pourront être réparties entre l'être humain et la machine de sorte que le rôle des travailleurs se limitera à la supervision ou au contrôle des machines. Cette répartition du travail entre les ressources humaines et les machines pourrait accroître la productivité de chaque travailleur, puisque les tâches manuelles épuisantes pourront être effectuées par des machines. Le temps de travail libéré grâce au recours aux machines peut être réaffecté à des tâches qui exigent davantage de compétences cognitives. Ainsi, la semi-automatisation (interaction entre travailleurs et robots) peut atténuer les effets négatifs sur l'emploi que l'on associe souvent au concept d'automatisation industrielle (Lütkenhorst, 2018).

Une quantification plus précise de ces effets de l'automatisation sur l'emploi montre que le secteur manufacturier joue encore un rôle clé dans l'emploi total dans les différents secteurs et industries (Autor et Salomons, 2018). L'étude d'Autor et Salomons confirme que l'augmentation de la productivité induite par l'automatisation a effectivement un effet négatif sur l'emploi dans différentes industries. Toutefois, si l'on dissocie les effets directs des effets indirects, le résultat donne à penser que les effets entre industries et sur la demande finale peuvent compenser les effets négatifs sur la demande de main-d'œuvre. Ces effets peuvent être inversés, en particulier grâce aux liens entre les intrants et les extrants (en devenant fournisseur de biens intermédiaires pour une autre industrie). En outre, l'augmentation de la demande globale pourrait avoir un effet positif net sur l'emploi. Les estimations d'Autor et Salomons montrent que l'industrie du matériel électrique et optique et les industries des substances et produits chimiques ont enregistré d'importants effets négatifs sur l'emploi. Les effets indirects (liens entre les intrants et les extrants et la demande finale) sont en fait l'un des facteurs qui contribuent le plus à la création d'emplois dans l'ensemble de l'économie.

L'évolution des processus d'industrialisation donne à penser que les tendances de la technologie et de la mondialisation influent principalement sur les modes de développement traditionnels du secteur manufacturier. Toutefois, une étude de Hallward-Driemeier et Nayyar (2018, page 139) montre que le secteur manufacturier continuera vraisemblablement à afficher des résultats positifs en termes de productivité, d'économie d'échelle, de commerce et d'innovation, la seule différence étant qu'il emploiera moins de travailleurs. Ainsi, malgré l'émergence d'un nouveau paradigme, le secteur industriel continue de jouer un rôle important.

Les nouvelles tendances de l'industrialisation constituent des défis potentiels mais créent aussi des possibilités pour les pays en développement et les pays émergents. Mettre fortement l'accent sur le développement du capital humain et accélérer l'adoption des technologies peut transformer l'incertitude en possibilités. Par exemple, I'ONUDI (2017a) a constaté que la révolution des technologies de l'information et de la communication (TIC) qui a commencé à la fin des années 1970 a modifié l'ensemble des compétences que les travailleurs du secteur manufacturier devaient acquérir. De nouvelles compétences sont nécessaires pour tirer parti des avantages offerts par les nouvelles technologies. Les travailleurs qualifiés ainsi que l'infrastructure générale du pays jouent un rôle fondamental dans l'utilisation optimale de ces technologies. Une infrastructure de mauvaise qualité (par exemple, des connexions de transport ne répondant pas aux normes ou des réseaux de télécommunication peu fiables) constitue une difficulté supplémentaire que les pays en développement et les pays émergents doivent surmonter pour développer leur secteur manufacturier.

Pour créer de nouveaux systèmes de production et moderniser les systèmes existants, il faut une infrastructure solide et fiable capable d'absorber les nouvelles technologies (ONUDI, 2017a). Selon I'OCDE (2018), la mise en place rapide d'infrastructures numériques telles que des infrastructures de télécommunications fiables (accès Internet à haut débit) ou des technologies plus sophistiquées (par exemple, la technologie de la chaîne de blocs) peut permettre au secteur manufacturier de faire un bond en avant et favoriser ainsi un développement inclusif et durable. 
Une autre implication importante de la nature changeante de l'industrialisation concerne le canal de l'offre et de la demande, dont il a été question au début du chapitre. L'utilisation judicieuse des technologies de l'automatisation peut avoir deux grands effets sur les caractéristiques des biens produits. La spécialisation améliore la qualité des biens produits par la normalisation des procédés et des produits. L'augmentation de la demande du fait de la hausse de la qualité peut conduire à une massification des produits, qui entraîne à son tour une baisse des prix. Ces deux effets stimulent la demande et déclenchent donc le développement des capacités manufacturières. Cela peut compenser d'éventuelles externalités négatives telles que les baisses de salaires provoquées par l'automatisation.

Grâce à l'interaction entre les forces de l'offre et les forces de la demande, la mondialisation offre aux secteurs manufacturiers nationaux de nouvelles perspectives. Les progrès technologiques et l'innovation rendent les chaînes de valeur mondiales et les marchés étrangers beaucoup plus accessibles. Selon I'OCDE (2018), les pays en développement et les pays émergents ont gagné à participer aux chaînes de valeur mondiales et ce pour deux raisons. Premièrement, la production de biens intermédiaires pour les industries étrangères contribue au développement des industries qui fournissent les biens requis. Deuxièmement, l'accès aux marchés étrangers crée une nouvelle demande, alimentant le cercle vertueux de la consommation de produits manufacturés. Toutefois, il peut arriver que les nouvelles technologies réduisent l'avantage comparatif de certaines industries (principalement les industries à forte intensité de main-d'œuvre et à faible technologie) dans les pays en développement. Par exemple, le retour des usines de production délocalisées (relocalisation) dans les pays à revenu élevé en raison de l'automatisation pourrait constituer une menace à long terme pour les pays en développement (OCDE, 2018). Si la relocalisation se produit à grande échelle, elle pourrait empêcher les pays en développement d'établir avec succès des industries à forte intensité de main-d'œuvre, qui, traditionnellement, étaient à l'origine du processus d'industrialisation dans les pays en développement, en particulier en Asie.

En ce qui concerne les effets sur l'emploi, le nouveau paradigme technologique peut avoir des effets divers sur la répartition des revenus et les questions de genre. Le déplacement relatif de la demande de main-d'œuvre peu qualifiée vers une main-d'œuvre hautement qualifiée devrait creuser les inégalités de revenus (OCDE, 2018). II n'y a pas de consensus clair sur le niveau de gravité des effets de l'automatisation sur certains groupes sociaux, comme les femmes, les jeunes travailleurs ou les groupes marginalisés. En général, les travailleurs peu qualifiés et ceux qui exécutent principalement des tâches répétitives sont plus vulnérables face à l'automatisation et doivent donc faire l'objet d'une attention particulière dans le cadre du développement économique inclusif. Toutefois, d'un point de vue intersectoriel, l'automatisation pourrait en fait favoriser un développement manufacturier qui inclue les femmes, principalement parce qu'une automatisation avancée tendrait à remplacer les tâches nécessitant de la force physique. En outre, de nombreux gouvernements ont placé la création de possibilités d'emploi égales pour les hommes et les femmes au premier rang de leurs priorités, favorisant ainsi un développement inclusif pour l'avenir (Alibhai et al., 2017).

Enfin, une analyse minutieuse de chaque pays est nécessaire pour assurer un avenir durable à son secteur manufacturier. Une fois les possibilités offertes identifiées, la politique industrielle peut contribuer à promouvoir un développement bénéfique. Pour relever efficacement les défis que constituent l'automatisation et la numérisation dans le secteur manufacturier, les décideurs devraient donner la priorité au développement du capital humain et des compétences. Pour les pouvoirs publics et les décideurs politiques, la nature changeante de l'industrialisation peut représenter une possibilité de développement futur. II est rentable de donner la priorité à l'éducation et à la formation, en particulier lorsque l'automatisation du secteur manufacturier entraîne une diminution de la demande de main-d'œuvre peu qualifiée au profit d'une demande de main-d'œuvre qualifiée. De nouvelles compétences et des travailleurs bien formés sont des éléments essentiels pour la mise en œuvre et l'exploitation optimales des nouvelles technologies. 
Les décideurs devraient donc donner la priorité aux investissements publics dans les infrastructures éducatives et accroître ces investissements afin de relever efficacement le défi que constitue l'introduction de nouvelles technologies. Étant donné que l'automatisation peut avoir des effets négatifs sur l'emploi dans les industries à forte intensité de maind'œuvre, l'accent devrait être mis sur les mesures de reconversion et de redéploiement des travailleurs qui ont perdu leur emploi. Cela favoriserait un développement socialement inclusif tout en permettant une utilisation optimale des nouvelles technologies (CNUCED, 2016).

\section{CONCLUSIONS}

Le présent chapitre a montré que le processus d'industrialisation en général et le secteur manufacturier en particulier restent les principaux moteurs de la réduction de la pauvreté dans le monde. Le secteur manufacturier affiche une productivité et un taux d'augmentation de cette productivité supérieurs à ceux du secteur agricole et génère constamment des emplois et des revenus. La différence entre le côté de l'offre et le côté de la demande montre toute l'importance que revêt le développement des technologies et des compétences pour le renforcement des capacités de production. En outre, le cercle vertueux de la consommation de produits manufacturés, en tant qu'élément de la demande, met en évidence les forces motrices de la diversification et de la massification de la demande de produits manufacturés. L'interaction entre les forces de l'offre et les forces de la demande façonne le processus de transformation structurelle et influe donc fortement sur le développement de l'économie.

Si l'on commence par l'impact du commerce sur le processus de diversification industrielle, nous constatons que la pénétration de nouveaux marchés a une incidence considérable sur l'ensemble de l'économie grâce à la consommation de produits manufacturés. L'émergence d'une nouvelle demande, les effets indirects des technologies à l'échelle mondiale et l'accès à un réseau de production international établi jouent un rôle central dans le développement du secteur manufacturier. En outre, l'ouverture au commerce favorise l'afflux d'IED vers les pays en développement sous la forme de capitaux et de savoir-faire dont ils ont cruellement besoin, ce qui fait baisser les prix relatifs des produits manufacturés grâce à une concurrence accrue et à l'émergence de nouvelles variétés de produits, et relance ainsi le cercle vertueux de la consommation de produits manufacturés.

Ces forces créent des possibilités d'emploi, en particulier dans les pays en développement. Les principales sources d'emploi dans les pays sont les secteurs à faible technologie et à forte intensité de main-d'œuvre qui ciblent les besoins humains fondamentaux. La demande de produits manufacturés accroît les possibilités d'emploi formel et contribue donc de manière significative à l'augmentation des revenus. Cette perspective peut, à son tour, être utilisée pour encourager les investissements en capital humain (éducation et développement des compétences) et ainsi favoriser l'augmentation de la productivité en renforçant la capacité de la main-d'œuvre de mettre en œuvre de nouvelles innovations technologiques dans l'avenir. Les groupes marginalisés, les jeunes et les femmes, en particulier, peuvent tirer des avantages considérables d'une industrialisation réussie, ce qui fait du secteur industriel un élément déterminant d'un avenir économique durable et inclusif.

Le développement du secteur manufacturier est souvent associé à une augmentation des émissions nocives de gaz à effet de serre et à l'exploitation intensive des ressources naturelles. Le présent chapitre a proposé une stratégie pour éviter les compromis environnementaux, qui passe par l'utilisation des progrès technologiques dans les procédés et les structures de production. II est indispensable de garantir le transfert des innovations vertes et des connaissances pertinentes des pays à revenu élevé vers les pays à faible revenu. Cela permettra aux pays en développement en particulier de bénéficier des technologies existantes et de mettre en œuvre des processus de production respectueux de l'environnement. 
L'industrialisation étant un phénomène hétérogène, le présent chapitre a mis l'accent sur les tendances récentes relevées dans certaines industries. La nature changeante de l'industrialisation se caractérise par un processus d'automatisation et nous avons insisté sur la nécessité d'avoir une vue d'ensemble précise pour évaluer les effets réels de ce processus sur la structure de l'emploi. II s'avère qu'en dépit des effets négatifs directs sur l'emploi dans certaines industries, les effets sur la demande et les effets entre industries peuvent avoir un impact positif net et donc créer des possibilités d'emploi. En outre, mettre fortement l'accent sur le développement du capital humain et accélérer l'adoption des technologies peut transformer l'incertitude liée à ce nouveau paradigme en possibilités, en particulier pour les pays en développement.

Enfin, trois considérations politiques clé pour la transformation structurelle en faveur d'un développement industriel inclusif et durable ont été examinées dans le présent chapitre. Premièrement, pour développer les capacités dans les industries concernées, il convient de mettre en place des politiques visant à favoriser le développement des capacités de production dans les entreprises et à améliorer la redistribution des facteurs de production entre entreprises. Deuxièmement, pour capter la demande intérieure et la demande étrangère, les décideurs doivent attirer les investissements et créer un climat d'affaires qui permette la réalisation efficace des possibilités de développement. Troisièmement, il a été question de l'importance de la politique industrielle dans la mise en place d'un processus d'industrialisation inclusif et durable. 
CHAPITRE 3. PROMOUVOIR LA DIVERSIFICATION ÉCONOMIQUE ET LA TRANSFORMATION STRUCTURELLE PAR L'INDUSTRIALISATION

\section{NOTES}

1. II s'agit d'une mesure de la production nette totale estimée de toutes les unités nationales engagées dans des activités manufacturières, obtenue en additionnant les extrants et en soustrayant les intrants intermédiaires.

2. L'objectif 5 du développement durable ("Parvenir à l'égalité des sexes et autonomiser toutes les femmes et les filles") traite de cette question de manière beaucoup plus globale.

3. Cette relation est également connue sous le nom de courbe environnementale de Kuznets (voir Grossman et Krueger, 1991; Shafik et Bandyopadhyay, 1992). 
CHAPITRE 3. PROMOUVOIR LA DIVERSIFICATION ÉCONOMIQUE ET LA TRANSFORMATION STRUCTURELLE PAR L'INDUSTRIALISATION

\section{RÉFÉRENCES}

Acemoglu, D. et P. Restrepo (2018), Automation and New Tasks: The Implications of the Task Content of Technology for Labor Demand. Disponible à l'adresse : http://papers.nber.org/conf_papers/f114668.pdf [Consultée le 27 février 2018].

Alibhai, S., N. Buehren, S. Papineni et R. Pierotti (2017), Crossovers-Female Entrepreneurs Who Enter Male Sectors: Evidence from Ethiopia, Policy Research Working Paper n 8065, Banque mondiale, Washington, D.C.

Autor, D. (2015), Why Are There Still So Many Jobs? The History and Future of Workplace Automation, Journal of Economic Perspectives, 29/3, pages 3 à 30.

Autor, D. et A. Salomons (2018), Is Automation Labor-Displacing? Productivity Growth, Employment, and the Labor Share, NBER Working Paper n²4871, National Bureau of Economic Research, Cambridge, MA.

Banque mondiale (2012), World Development Report 2012, Gender Equality and Development, Washington, D.C.

Becker, G. S. (1965), A Theory of the Allocation of Time, The Economic Journal, n 75/299, pages 493 à 517.

Braunstein, E. (2019), Gender-Inclusive Industrialization for Growth and Development in the Context of Globalization, dans Gender equality and inclusive growth: Economic policies to achieve sustainable development, Elson, D. et S. Anuradha (éds), Entité des Nations Unies pour l'égalité des sexes et l'autonomisation des femmes (ONU-Femmes).

Cantore, N. et E. Padilla (2010), Emissions Distribution in Post-Kyoto International Negotiations: A Policy Perspective, Barcelone : Universitat Autonoma de Barcelona.

Chataway, J., R. Hanlin et R. Kaplinsky (2014), Inclusive Innovation: An Architecture for Policy Development, Innovation and Development, 1/4, pages 33 à 54.

CNUCED (2013), Trade and Development Report 2013: Adjusting to the Changing Dynamics of the World Economy, New York, NY et Genève : Nations Unies.

CNUCED (2017), Industrial Robots and Inclusive Growth, Policy Brief nº 60, Genève : Nations Unies.

DeLong, J.B. (2000), Cornucopia: The Pace of Economic Growth in the Twentieth Century, NBER Working Paper n 7602, National Bureau of Economic Research, Cambridge, MA.

Eicher, T.S. et D.J. Kuenzel (2016), The Elusive Effects of Trade on Growth: Export Diversity and Economic Take-off, Canadian Journal of Economics/Revue canadienne d'économique, 49/1, pages 264 à 295.

Foellmi, R., T. Wuergler et L. Zweimüller (2014), The Macroeconomics of Model T, Journal of Economic Theory, 153, pages 617 à 647

Greenwood, J., A. Seshadri et M. Yorukoglu (2005), Engines of Liberation, Review of Economic Studies, 72/1, pages 109 à 133 .

Grossman, G.M, et A.B. Krueger (1991), Environmental Impacts of a North American Free Trade Agreement, NBER Working Paper n 3914, National Bureau of Economic Research, Cambridge, MA.

Guerrieri, P. et V. Meliciani (2005), Technology and International Competitiveness: The Interdependence between Manufacturing and Producer Services, Structural Change and Economic Dynamics, 16/4, pages 489 à 502.

Hallward-Driemeier, M. et G. Nayyar (2018), Trouble in the making? The future of manufacturing-led development, Banque mondiale, Washington, D.C. 
CHAPITRE 3. PROMOUVOIR LA DIVERSIFICATION ÉCONOMIQUE ET LA TRANSFORMATION STRUCTURELLE PAR L'INDUSTRIALISATION

Haraguchi, N. (2016), Patterns of Structural Change and Manufacturing Development, dans Routledge Handbook of Industry and Development, Weiss, J. et M. Tribe (éds), New York, NY : Routledge, pages 38 à 64.

Haraguchi, N. (2019), Structural Transformation and Manufacturing Employment, Monga, C. et J. Lin (éds),

The Oxford Handbook of Structural Transformation, New York: Oxford University Press.

Haraguchi, N., C. F. C., Cheng et E. Smeets (2017), The importance of manufacturing in economic development: Has this changed?, World Development, 93, pages 293 à 315.

Jong, H. (2015), Living Standards in a Modernizing World-A Long-Run Perspective on Material Wellbeing and Human Development, dans Global Handbook of Quality of Life, Glatzer, W., L. Camfield, V. Møller et M. Rojas (eds.), Dordrecht, Heidelberg, New York, NY et Londres : Springer, pages 45 à 74.

Kabeer, N. (1999), Resources, Agency, Achievements: Reflectionson the Measurement of Women's Empowerment, Development and Change, 30/3, pages 435 à 464.

Kaldor, N. (1966), Causes of the Slow Rate of Economic Growth of the United Kingdom: An Inaugural Lecture, Cambridge: Cambridge University Press.

Kaldor, N. (1967), Strategic Factors in Economic Development, Ithaca, NY : New York State School of Industrial and Labor Relations, Cornell University.

Lewis, W. A. (1954), Economic Development with Unlimited Supplies of Labour, The Manchester School, 22, pages 139 à 191.

Lütkenhorst, W. (2018), Creating wealth without labour? Emerging contours of a new techno-economic landscape, Discussion Paper 11/2018, Bonne : German Development Institute / Deutsches Institut für Entwicklungspolitik (DIE). Matsuyama, K. (2002), The Rise of Mass Consumption Societies, Journal of Political Economy, 110/5, pages 1035 à 1070. Mazzanti, M. et F. Nicolli (2017), Structural Change and Manufacturing Sustainability, Note d'information élaborée pour le rapport Structural Change for Inclusive and Sustainable Industrial Development, Vienne : ONUDI.

Nussbaum, M.C. (1992), Human Functioning and Social Justice: In Defense of Aristotelian Essentialism, Political Theory, 20/2, pages 202 à 246.

OCDE (2018), Achieving Inclusive Growth in the Face of Digital Transformation and the Future of Work, Rapport de I'OCDE aux ministres des finances des pays du G-20, 19 mars 2018.

OCDE-OMC (2019) Exercice de suivi dans le cadre de l'Examen global de l'Aide pour le commerce.

ONUDI (2009), Industrial Development Report 2009, Breaking In and Moving Up: New Industrial Challenges for the Bottom Billion and the Middle-Income Countries, Vienne.

ONUDI (2013), Industrial Development Report 2013, Sustaining Employment Growth: The Role of Manufacturing and Structural Change, Vienne.

ONUDI (2015), Industrial Development Report 2016, The Role of Technology and Innovation in Inclusive and Sustainable Industrial Development, Vienne.

ONUDI (2017a), Structural Change for Inclusive and Sustainable Industrial Development, Vienne.

ONUDI (2017b), Industrial Development Report 2018, Demand for Manufacturing: Driving Inclusive and Sustainable Industrial Development, Vienne. 
CHAPITRE 3. PROMOUVOIR LA DIVERSIFICATION ÉCONOMIQUE ET LA TRANSFORMATION STRUCTURELLE PAR L'INDUSTRIALISATION

ONUDI (2017c), Circular Economy, Vienne.

Pain, N., I. Koske et M. Sollie (2008), Globalisation and OECD Consumer Price Inflation, OECD Journal : Economic Studies 2008/1, Paris : OECD Publishing, http://dx.doi.org/10.1787/eco_studies-v2008-art4-en.

Saviotti, P.P. et A. Pyka (2004), Economic Development by the Creation of New Sectors, Journal of Evolutionary Economics, 14/1, pages 1 à 35.

Sen, A. (1990), More Than 100 Million Women Are Missing, The New York Review of Books. Disponible à l'adresse : www.nybooks.com/articles/1990/12/20/more-than-100-million-women-are-missing [Consultée le 27 février 2018]. Sen, A. (2001), Development as Freedom, New York, NY : Oxford University Press.

Shafik, N. et S. Bandyopadhyay (1992), Economic Growth and Environmental Quality: Time Series and Cross-Country Evidence, Policy Research Working Papers WPS n 904, World Development Report, Washington, D.C. : Banque mondiale, http:// documents.worldbank.org/curated/en/833431468739515725/pdf/multi-page.pdf [Adresse consultée le 27 février 2018].

Szirmai, A. (2012), Industrialisation as an Engine of Growth in Developing Countries, 1950-2005, Structural Change and Economic Dynamics, 23/4, pages 406 à 420.

Timmer, M.P., E. Dietzenbacher, B. Los, R. Stehrer et G.J. de Vries (2015), An Illustrated User Guide to the World Input-Output Database: the Case of Global Automotive Production, Review of International Economics 23, pages 575 à 605.

Woersdorfer, J.S. (2017), The Evolution of Household Technology and Consumer Behavior, 1800-2000, Oxon et New York, NY : Routledge. 


\title{
CHAPITRE 4
}

\section{L'AIDE POUR LE COMMERCE DANS LES CONTEXTES DIFFICILES}

\author{
Contribution du Cadre intégré renforcé (CIR) et du Programme \\ des Nations Unies pour le développement (PNUD)'
}

Résumé : Les pays les moins avancés sont confrontés à des difficultés considérables pour tirer pleinement parti du potentiel de la diversification économique et de tous les avantages qu'elle peut apporter en termes de croissance économique, de développement et de réduction de la pauvreté. Si les flux commerciaux conservent une importance vitale pour l'économie des PMA, la part de ces derniers dans le commerce mondial reste inférieure à 1\%. Les exportations de marchandises des PMA sont dominées par un petit nombre de produits. Les produits primaires représentent plus de 60\% des exportations des PMA, ce qui rend ces pays très vulnérables face aux chocs extérieurs. Ces tendances sont encore plus marquées dans les PMA qui se sont autoproclamés États fragiles dans le cadre de l'initiative g7+. Dans ces pays, les trois principaux produits exportés représentent au moins 40\% des exportations de marchandises.

Le chapitre offre un aperçu des données existantes sur les liens entre la concentration des exportations et la fragilité. Tout en reconnaissant qu'il n'existe pas de solution unique pour tous, plusieurs options sont mises en avant pour faire face aux difficultés structurelles des économies des PMA. En s'appuyant sur les données de l'OCDE sur l'Aide pour le commerce, le chapitre souligne que les flux d'Aide pour le commerce destinés aux PMA sont fortement concentrés sur les principaux bénéficiaires, les secteurs clés et les principaux partenaires de développement. Au cours des cinq dernières années, les engagements ont fluctué, tandis que les décaissements sont restés stables. De manière générale, les flux destinés aux PMA membres du g7+ sont restés stables depuis cinq ans. Améliorer les réponses mises en oeuvre dans les situations de fragilité nécessite de renforcer la cohérence entre les efforts déployés à des fins humanitaires, de développement et de maintien de la paix. Dans le cadre de l'élaboration des futurs programmes d'Aide pour le commerce, il est essentiel de garder à l'esprit le contexte national, ainsi que les efforts pour le renforcement des institutions et de l'État, et la consolidation de la paix. 


\section{INTRODUCTION}

Les pays les moins avancés (PMA) ont accompli des progrès considérables en termes de développement ces 30 dernières années, l'Indice du développement humain ayant augmenté de 51\% en moyenne depuis 1990 (PNUD, 2018). Pourtant, de nombreuses difficultés demeurent parce que les progrès n'ont pas été uniformes entre les pays, ni en leur sein: plus de 300 millions de personnes vivent dans une pauvreté extrême dans les PMA et 237 millions sont sousalimentées (OHRLLS, 2018).

Le Programme d'action d'Istanbul en faveur des PMA pour 2011-2020 prévoit des étapes spécifiques sur le chemin de ces pays vers la réalisation des Objectifs de développement durable (ODD), y compris certains objectifs importants liés au commerce. Le Programme d'action d'Istanbul prévoit notamment que la moitié des PMA auront satisfait les critères à remplir pour sortir de la catégorie des PMA d'ici à 2020. À ce jour, cinq pays ont perdu le statut de PMA depuis 1971, date à laquelle ce statut a été créé, et le Vanuatu et l'Angola devraient le perdre en 2020-2021. Dix autres pays satisfont à certains des critères à remplir pour sortir de la catégorie des PMA², ce qui montre que le rythme auquel les PMA sortent de cette catégorie s'est accéléré ces dernières années.

Les décisions relatives au retrait de la liste des PMA sont prises par l'Assemblée générale des Nations Unies sur la base d'une recommandation du Comité des politiques de développement (CPD) validée par le Conseil économique et social (ECOSOC). Tous les trois ans, le CPD réexamine la catégorie des PMA pour donner un avis sur l'inscription ou le retrait des pays de la liste des PMA. Le réexamen est mené sur la base de trois critères: le revenu national brut (RNB) par habitant, l'indice du capital humain (ICH) et l'indice de vulnérabilité économique (IVE). Lorsqu'un un pays remplit deux des trois critères lors de deux réexamens triennaux de suite, le CDP examine son retrait de la liste des PMA. Le retrait d'un pays de la liste des PMA peut aussi être envisagé si son revenu par habitant atteint le double du seuil de revenu. À ce jour, 35 PMA n'ont encore jamais rempli au moins 2 des 3 critères pour que leur retrait de la liste des PMA puisse être envisagé.

De manière plus générale, pour pouvoir sortir de la catégorie des PMA, les pays doivent engager et maintenir un processus de transformation structurelle afin de générer une croissance qui profite aux populations pauvres et qui soit respectueuse de l'environnement. La diversification de l'économie et des exportations, l'ajout de valeur dans les exportations et la progression dans les chaînes de valeur sont généralement associés au processus de transformation économique (McKechnie, A. et al., 2018). Bien qu'il s'agisse d'un processus mené essentiellement au niveau national, la communauté internationale peut apporter son aide en créant un environnement propice à l'intégration des PMA à l'économie mondiale, notamment par le biais de mécanismes d'accès aux marchés préférentiels et de coopération pour le développement (par exemple les programmes d'Aide pour le commerce), qui contribuent à atténuer les contraintes dans ces pays.

Le présent chapitre examine les flux d'Aide pour le commerce en faveur des PMA et formule des recommandations en vue d'améliorer l'efficacité de I'Aide en tant qu'outil pour soutenir la diversification économique dans les PMA. Le chapitre considère la situation particulière des pays fragiles et touchés par des conflits, ainsi que les moyens d'accroître l'efficacité de l'Aide pour le commerce pour répondre à leurs besoins.

Cette approche fait écho à l'appel lancé par un groupe de PMA accédants lors de la onzième session de la Conférence ministérielle (CM11) de l'OMC, qui s'est tenue en 2017 à Buenos Aires (Argentine), dans le cadre d'une déclaration appelant l'attention sur les difficultés que posent la fragilité et les conflits pour le développement, la sécurité et la paix. Les pays ont souligné l'importance du commerce international pour la croissance économique, l'emploi et le développement, ainsi que la nécessité de renforcer la coopération pour leur permettre de participer efficacement au système commercial multilatéral (OMC, 2017).

Le chapitre est structuré comme suit: la section I examine les caractéristiques spécifiques des économies des PMA pour souligner que la diversification de l'économie et des exportations constitue une priorité pour le développement et la réduction de la pauvreté dans ces pays. Cette section met l'accent sur la situation particulière des PMA membres 
du g7+, qui est un groupe autoproclamé de pays fragiles et touchés par des conflits, afin de souligner l'importance de diversifier l'économie et les exportations pour promouvoir la stabilité et la paix dans ces contextes. La section Il examine les priorités des PMA et des PMA membres du g7+ dans le cadre de l'Aide pour le commerce en termes de diversification économique, ainsi que la manière dont l'Aide s'adapte à ces priorités. Cette section traite du soutien aux fondements économiques des PMA membres du g7+ et de la complexité d'encourager la diversification économique dans les contextes fragiles. La section III offre une conclusion.

\section{LA NÉCESSITÉ DE DIVERSIFIER L'ÉCONOMIE DANS LES PMA}

"Le commerce est un moteur pour la croissance économique dans le processus de développement et il est essentiel pour accroître la productivité, et favoriser ainsi une croissance économique tirée par les exportations." - Guinée, Exercice de suivi de l'Aide pour le commerce OCDE-OMC (2019).

\section{Développement et diversification de l'économie dans les PMA}

Le développement économique est associé à une transformation structurelle, qui peut être définie comme la réaffectation des ressources de secteurs à faible productivité vers des secteurs dont la productivité est plus élevée, ainsi que comme l'accroissement de la productivité au sein des secteurs (McMillan, M. et al., 2017). Le regain d'intérêt pour le processus de transformation structurelle découle des expériences de croissance récentes dans les pays en développement, notamment certains PMA en Afrique, qui ne sont pas parvenus à générer une croissance économique, des emplois et une réduction de la pauvreté à grande échelle. Cela a concentré l'attention des responsables politiques sur les modalités et la qualité de la croissance.

La théorie et la pratique montrent, qu'aux premiers stades du développement, la transformation structurelle nécessite une diversification économique et commerciale (Papageorgiou, C., et al., 2012). Si, au fil du temps, certains PMA ont réussi à modifier la structure de leur base de production et d'exportation, le processus a été inégal selon les PMA et, de manière générale, le rythme.

L'Agriculture reste un secteur économique majeur pour les PMA. Le secteur représente 22\% de la valeur ajoutée dans le PIB dans les PMA contre 8,5\% seulement dans d'autres pays en développement (CNUCED, 2018). En outre, le rythme auquel les emplois sont détruits dans l'agriculture dans les PMA est bien moindre que dans les autres pays en développement: entre 2000 et 2017, la part moyenne de l'agriculture dans l'emploi a diminué de 73\% dans les autres pays en développement, mais de seulement 17\% dans les PMA (voir le tableau 4.A1 en annexe). Par ailleurs, la productivité du travail dans l'agriculture dans les PMA ne représente qu'une fraction de celle observée dans d'autres pays en développement (18,7\% entre 2011 et 2013) et l'écart se creuse, ce qui explique l'évolution variable des niveaux de revenu (CNUCED, 2015).

"L'agriculture est la principale source d'emplois et de revenus pour le pays, et elle contribue également à nourrir la population. Il est nécessaire de soutenir ce secteur pour garantir l'approvisionnement alimentaire." - Yémen, Exercice de suivi de l'Aide pour le commerce OCDE-OMC (2019).

Les PMA représentent 13\% de la population mondiale, mais moins de 1\% du commerce mondial. La participation des PMA au commerce mondial reste marginale et elle est tombée récemment au-dessous du seuil de 1\%. En outre, trois PMA, l'Angola, le Bangladesh et le Myanmar, représentent plus de la moitié de la part de ces pays dans les exportations de marchandises. Les dix principaux PMA exportateurs de services commerciaux étaient à l'origine de plus de 70\% des recettes du groupe provenant des services (OMC, 2018). Ces chiffres révèlent la structure très inégale de la participation des PMA au commerce mondial. 
Encadré 4.1. Encourager la diversification des exportations au Togo

L'agriculture demeure essentielle pour accroître la valeur ajoutée de l'économie togolaise, puisqu'elle représente 40\% du PIB et emploie plus de la moitié de la population. Si la part du secteur minier dans les exportations de marchandises demeure importante, de plus en plus, le Togo devient un pôle pour les services grâce à ses infrastructures aériennes et de transport.

Les exportations togolaises sont concentrées sur 10 à 15 produits clés. Les progrès en matière de diversification des exportations sont notables pour deux produits: I'huile de palme et les graines oléagineuses (fèves de soja). Bien que l'impact macroéconomique demeure limité, ces 2 secteurs présentent un fort potentiel pour réduire la pauvreté.

Le secteur privé et les partenaires de développement jouent tous un rôle important dans le soutien au développement des chaînes de valeur de l'huile de palme et du soja. Kalyan Agrovet Investissements a investi 65 millions d'USD dans le secteur de l'huile de palme au Togo pour construire une usine de transformation de l'huile de palme. Grâce à un investissement du CIR de 3 millions d'USD, les producteurs de fèves de soja ont doublé leur production en 2018 et amélioré leur capacité de commercialisation, que $84 \%$ d'entre eux avaient identifié comme un problème dans une enquête récente.

Source: D'après la mise à jour de l'EDIC du Togo (2017).

La composition des exportations des PMA varie fortement selon les pays. Les combustibles et les minéraux sont les principaux produits exportés par les PMA africains (47\%), tandis que les PMA asiatiques exportent principalement des produits manufacturés (72\%). Les petits PMA insulaires exportent principalement des produits alimentaires et agricoles (82\%) (tableau 4.A2 de l'annexe). II n'y a pas de différence notable dans la composition des importations des PMA, les produits manufacturés représentant plus des deux tiers des importations (tableau 4.A3 de l'annexe).

La composition diversifiée des exportations des PMA reflète les différences en termes d'approche, et de rythme de la diversification économique et de la transformation structurelle entre ces pays (CNUCED, 2014). Par exemple, les gains de productivité ont doublé dans les PMA d'Asie qui exportent des produits manufacturés, alors que les PMA africains exportent principalement des combustibles et des produits minéraux. Kucera et Jiang (2018) reconnaissent l'importance du secteur manufacturier dans la réduction de la part de l'emploi agricole. La CNUCED note que les gains de productivité les plus importants ont été obtenus grâce à une réaffectation des ressources de l'agriculture vers les services. Toutefois, la hausse des emplois dans ce dernier secteur s'est concentrée dans l'économie informelle, avec une productivité globale inférieure à celle du secteur manufacturier, ce qui n'a pas permis de générer une hausse de la productivité et une croissance dans l'ensemble de l'économie. Dans le même temps, tant Guerrieri et Meliciani (2005), qu'Andreoni et Gomez (2012), fournissent des éléments indiquant que la complémentarité entre les services et le secteur manufacturier, en particulier les services axés sur les TIC et les industries manufacturières à forte intensité de connaissances, crée de nouveaux débouchés.

Les analyses empiriques montrent que la complexité de la production et des exportations joue un rôle dans la croissance économique (McMillan et al., 2017) et que la diversification est tributaire de l'approche adoptée. L'analyse dite de "l'espace produit" de Hausmann et al. (2007) suggère que les pays peuvent diversifier leurs économies et leurs exportations en s'appuyant sur les compétences et les capacités productives existantes. Par ailleurs, les travaux de Rodrick (2013) sur la convergence inconditionnelle suggèrent que la productivité du travail dans les activités manufacturières convergera dans les différents pays indépendamment de leurs caractéristiques propres, comme les politiques, les institutions, etc. Cela signifierait que le renforcement de la capacité de production dans le secteur manufacturier serait particulièrement utile pour améliorer la qualité future de la production et des exportations, et converger vers des niveaux de revenus élevés. 
Mishra, S. et al. (2011) étudient la question de savoir si la diversification des exportations de services, et en particulier leur complexité, peut être un moteur de croissance économique comme dans le secteur manufacturier. Leurs résultats donnent à penser qu'en effet, la complexité des exportations de services est associée à une forte croissance et que ces conclusions persistent après qu'il a été tenu compte de la taille du secteur des services dans le pays et de la complexité des marchandises. En outre, leurs résultats sont analogues pour les pays à faible revenu, ce qui les mène à penser que mettre l'accent sur des services de grande qualité peut offrir une solution pour diversifier l'économie et les exportations dans les pays pauvres.

Les exportations de services commerciaux des PMA augmentent à un rythme rapide, mais restent négligeables. Les exportations de services commerciaux des PMA d'Asie ont augmenté au taux annuel de 8,5\% entre 2009 et 2016. Le taux de croissance pour les petits PMA insulaires $(6,9 \%)$, Haïti $(5,4 \%)$ et les PMA africains $(11,1 \%)$ est également élevé (UNCTADStat, 2019).

Les échanges de marchandises des PMA tendent à être irréguliers en raison de la composition des exportations et de leur degré élevé de concentration. $64 \%$ des exportations des PMA se composent de produits primaires soumis à une assez forte instabilité des prix (figure 4.1). En 2015, par exemple, le prix du pétrole a chuté de 47\%, en sus d'une baisse initiale de 7,5\% en 2014 (encadré 4.2). Les prix d'autres produits primaires, tels que les minéraux, les minerais, les métaux et les matières premières agricoles, ont également diminué, ce qui a entamé la croissance économique des PMA cette année-là, la croissance du PIB réel ayant été estimée à 3,5\%, son plus bas niveau depuis 1994 (CNUCED, 2016). Par ailleurs, un niveau élevé des prix des produits de base qui entraîne une appréciation du taux de change nuit à la compétitivité des autres secteurs, ainsi qu'à la diversification de l'économie et des exportations.

"L'économie tchadienne repose principalement sur les cultures de rapport (notamment le coton) et les industries extractives (secteurs minier et pétrolier). La forte croissance économique - 7,4\% entre 2003 et 2015 - était principalement due à l'utilisation des ressources pétrolières. Le pays est extrêmement vulnérable face aux chocs extérieurs, notamment aux fluctuations des prix des produits de base. Pour diversifier son économie, le pays s'appuiera sur les secteurs présentant un fort potentiel d'exportation, notamment le cuir, le sésame et la gomme arabique, qui sont mentionnés dans la mise à jour de l'EDIC du Tchad. Améliorer l'organisation de ces secteurs contribuera à accroître les économies d'échelle et, partant, à renforcer l'intégration dans les chaînes de valeur mondiales." - Tchad, Exercice de suivi de l'Aide pour le commerce OCDE-OMC (2019).

\section{Figure 4.1. Indice des prix des produits de base $(2015=100)$}

INDICE DES PRIX DES PRODUITS DE BASE $(2015=100)$ 250

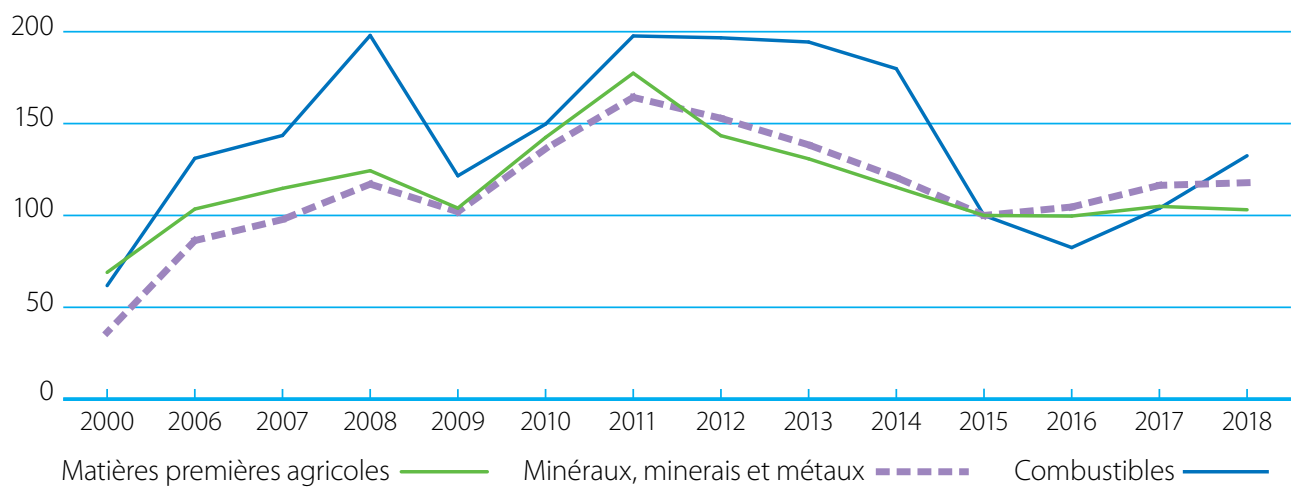




\section{Encadré 4.2. Diversification des exportations au Tchad: les promesses de la gomme arabique}

Le secteur des industries extractives - principalement le pétrole - est le premier moteur de l'économie du Tchad. Toutefois, les efforts déployés pour diversifier l'économie ont fait du Tchad un acteur important du commerce mondial de la gomme arabique, qui est un additif présent dans les boissons gazeuses, les produits alimentaires et les cosmétiques, et dont le Tchad est l'un des 3 premiers exportateurs au monde. Le marché tchadien est dominé par 2 types de gomme arabique: la gomme dure, ou Kitir, et la gomme friable, qui se vend au tiers du prix du Kitir (IRAM, 2013).

Entre 2014 et 2016, le Tchad a exporté plus de 13000 t de gomme arabique brute par l'aéroport de N’Djamena ou le port de Douala au Cameroun (CNUCED 2018).

En collaboration avec le CIR, I'ONUDI, le PNUD et l'ITC, le Tchad a fortement progressé dans la chaîne de valeur de la gomme arabique. Aujourd'hui, un nouveau label de commercialisation, "Cristal du Tchad", atteint de nouveaux marchés d'exportation. Selon l'ITC (2017), le volume des exportations devrait doubler dans les 5 prochaines années, I'Inde figurant parmi les principaux marchés cibles.

Replanter des acacias s'est avéré essentiel pour assurer la durabilité des ressources dans le secteur de la gomme arabique et prévenir ainsi les risques futurs pour l'environnement.

Source: D'après le questionnaire du Tchad pour l'Exercice de suivi de l'Aide pour le commerce OCDE/OMC (2019), ITC (2017), CNUCED (2018) et IRAM (2013).

Diversifier l'économie et les exportations aiderait les PMA à amortir les effets des chocs extérieurs. Koren, M. et al. (2007) notent que la diversification économique peut accroître la résilience des pays à faible revenu face aux chocs extérieurs, notamment en réduisant la part de secteurs fortement volatiles et corrélés, comme les industries extractives et l'agriculture. Papageorgiou, C. et al. (2012) affirment en outre que la diversification des exportations est associée à une moindre instabilité des termes de l'échange et que la diversification des marchés renforce aussi la résilience face aux chocs extérieurs.

Les services d'infrastructure, y compris des réseaux d'électricité et de transport fiables, sont des facteurs essentiels qui viennent appuyer la diversification de l'économie et des échanges (Hoeffler, A., 1999). Le manque de fiabilité et la mauvaise qualité des infrastructures augmentent les coûts pour les entreprises privées, ce qui entrave le développement du secteur privé.

"Le pays souffre d'un manque d'infrastructures pour soutenir la production et la commercialisation des marchandises et des services, de difficultés pour assurer I a connectivité entre différentes entités, ainsi que d'un déficit de l'approvisionnement en énergie." - République démocratique du Congo (RDC), Exercice de suivi de l'Aide pour le commerce OCDE/OMC (2019).

L'accès insuffisant à l'électricité dans les activités productives reste un obstacle à la diversification de l'économie et à la transformation structurelle des PMA. En dépit de progrès notables en termes d'accès à l'énergie (45\% de la population en moyenne dans les PMA), l'accès reste nettement inférieur à celui relevé dans d'autres pays en développement (92\%) (tableau 4.A5 de l'annexe). En outre, les deux tiers de la consommation d'énergie dans les PMA relèvent d'un usage résidentiel et proviennent principalement de sources traditionnelles de biomasse, comme le charbon de bois et le bois de chauffage (CNUCED, 2017), ce qui renvoie à l'utilisation limitée de sources d'électricité modernes pour des activités économiques productives dans ces pays. 
En Afrique, la capacité de production d'électricité est faible et une partie de la capacité existante n'est pas disponible en raison d'un mauvais entretien. La fourniture d'électricité d'urgence ou l'autoproduction dans des centrales diesel représente une lourde charge pour l'économie, estimée à 1\% du PIB (McKechnie, A. et al., 2018).

Les infrastructures de transport constituent une autre contrainte importante pour les PMA. La densité routière médiane est de $2147 \mathrm{~km}$ pour 1 million de personnes dans les PMA, contre $3446 \mathrm{~km}$ pour 1 million de personnes dans 58 pays en développement (CNUCED, 2017). En outre, seules 22\% des routes des PMA sont pavées.

L'indice de performance logistique (IPL) est un indicateur synthétique de l'efficacité du secteur de la logistique à permettre aux marchandises de franchir les frontières; il est fondé sur la perception des opérateurs internationaux du secteur. L'indice évalue six éléments, dont les infrastructures commerciales et de transport, et l'efficacité des procédures douanières et du dédouanement. Le classement moyen des PMA dans I'IPL agrégé ${ }^{3}$ est de 128, soit le quatrième quintile sur 167 pays, ce qui révèle que la connectivité des économies des PMA est limitée.

Par ailleurs, les PMA ont réalisé des progrès considérables dans le domaine des technologies de l'information et de la communication (TIC). Dans l'ensemble, ces pays ont à la fois fortement augmenté l'accès à Internet et réduit les coûts associés. Selon I'UIT (2018), les PMA devraient atteindre un taux de couverture moyen de 97\% de la population pour les services mobiles à large bande et ramener les tarifs Internet à moins de 5\% du RNB mensuel par habitant d'ici à 2020. Cependant, seule une personne sur quatre utilisera Internet par manque de compétences nécessaires.

\section{Les institutions chargées de la gouvernance économique facilitent la diversification économique et la trans-} formation structurelle. Un climat de l'investissement favorable offre aux entreprises des débouchés et des incitations pour investir de façon productive, créer des emplois et se développer, et par conséquent, promouvoir la croissance économique et réduire la pauvreté (Sinha, S. et al., 2013).

En utilisant le classement de la Banque mondiale concernant la facilité de faire des affaires comme indicateur de la qualité des conditions de l'activité des entreprises, on constate qu'en moyenne, les PMA se classent au 147̀me rang (sur 190), ce qui leur laisse une marge d'amélioration globale. Toutefois, le classement varie d'un PMA à l'autre. En outre, I'Afghanistan, Djibouti, le Rwanda et le Togo figurent parmi les dix principaux pays réformateurs dans le rapport Doing Business 2019, ce qui révèle une conscience croissante de l'importance des réformes et le dynamisme de la situation.

La discussion qui précède souligne l'importance de la diversification de l'économie et des exportations pour les PMA afin d'appuyer une croissance économique soutenue. II est essentiel de réaffecter les ressources d'un secteur agricole faiblement productif vers des activités plus productives dans l'agriculture, les services et le secteur manufacturier pour parvenir à un développement économique plus inclusif et durable. En outre, la production de produits et de services de grande qualité irait de pair avec une croissance économique plus élevée et, dans le cas du secteur manufacturier, permettrait une convergence inconditionnelle vers des niveaux de revenu plus élevés. Diversifier l'économie et les exportations permettrait aux PMA d'amortir les effets de l'instabilité des termes de l'échange, augmentant ainsi la stabilité de la croissance. Les arguments présentés par Papageorgiou, C., et al. (2012) sur les expériences des pays suggèrent que, pour être efficaces, les politiques et les réformes visant à soutenir la diversification de l'économie devraient être mises en œuvre par "vagues", en s'adaptant à l'évolution de l'environnement extérieur et de la situation des pays.

Le processus de diversification économique et de transformation structurelle exige des investissements productifs dans les PMA, tant dans le secteur public que privé. Les mécanismes destinés à renforcer la mobilisation des ressources nationales sont donc importants dans ce contexte. Réformer les conditions de l'activité des entreprises serait essentiel pour mobiliser les investissements privés nationaux et étrangers. L'investissement étranger direct (IED) peut aider les PMA à se connecter aux chaînes de valeur régionales et mondiales, créant ainsi des possibilités de diversification économique. 
Outre les fondamentaux de la politique générale, des efforts de politique plus ciblés sont nécessaires (CNUCED, 2014, et McMillan, M., et al., 2017) et la communauté internationale peut apporter un soutien dans ce contexte. Le développement du capital humain et des compétences, en particulier chez les femmes et les jeunes, est nécessaire pour leur permettre de bénéficier des nouveaux débouchés économiques. Des compétences dans le domaine des TIC sont notamment essentielles pour participer à l'économie numérique qui se met en place.

Les différents chapitres de cet ouvrage abordent en détail les politiques et les stratégies visant à soutenir la diversification économique dans les pays en développement, y compris les PMA.

\section{Diversification économique dans les pays fragiles et touchés par des conflits}

Lors de la CM11, plusieurs PMA prenant part au processus d'accession à l'OMC ont réaffirmé leur attachement au processus de réforme qui sous-tend l'accession, tout en appelant à une coopération accrue pour faciliter leur participation effective au système commercial multilatéral.

Tous sont membres du g7t, qui comprend des PMA et d'autres pays en développement qui se sont autoproclamés pays fragiles et touchés par des conflits. Ils travaillent avec les partenaires de développement pour accroître l'efficacité de l'aide publique au développement (APD) dans les contextes fragiles. Leurs engagements sont inscrits dans le New Deal pour l'engagement dans les États fragiles, adopté lors du Forum de haut niveau sur l'efficacité de l'aide organisé à Busan (République de Corée) en 2011.

Cette section examine pourquoi, outre les avantages découlant de la transformation structurelle des PMA mentionnés plus haut, il est important pour les pays fragiles et touchés par des conflits de diversifier leurs économies.

Encadré 4.3. Le New Deal pour l'engagement dans les États fragiles et les objectifs de consolidation de la paix et de renforcement de l'État (PSG)

Le New Deal récapitule les engagements souscrits par les pays en situation de fragilité et de conflit, emmenés par le groupe g7t, les partenaires de développement et la société civile, en vue d'améliorer les politiques et les pratiques en matière de développement dans les contextes fragiles. Les partenaires dans le cadre du New Deal se sont engagés à élaborer un plan incarnant une vision partagée et un engagement en faveur de la transparence, de la responsabilité, de la prévisibilité du financement, d'une gestion partagée des risques, et du renforcement et de l'utilisation des systèmes nationaux.

Le g7+ propose une échelle d'intensité de la fragilité à 5 niveaux, allant des situations de crise, jusqu'à la reconstruction et la réforme, la transition, la transformation et la résilience, lesquelles transcendent 5 des objectifs et que le New Deal pour l'engagement dans les États fragiles cherche à classer par ordre de priorité:

- PSG 1 - Légitimité politique: encourager des accords politiques inclusifs et la résolution des conflits;

- PSG 2 - Sécurité: établir et renforcer la sécurité des personnes;

- PSG 3 - Justice: remédier aux injustices et accroître l'accès des personnes à la justice;

- PSG 4 - Fondements économiques: créer des emplois et améliorer les moyens de subsistance; et

- PSG 5 - Revenus et services: gérer les revenus et renforcer les capacités de prestation de services responsables et équitables.

Le groupe g7+ compte 20 pays* qui échangent des données d'expérience, se soutiennent les uns les autres et prônent des processus conduits et pris en charge par les pays pour faire face à la fragilité et aux conflits.

* Les pays du g7+ sont les suivants: Afghanistan, Burundi, République centrafricaine, Tchad, Comores, Côte d'Ivoire, RDC, Guinée, GuinéeBissau, Haïti, Libéria, Papouasie-Nouvelle-Guinée, Sao-Tomé-Et-Principe, Sierra Leone, Îles Salomon, Somalie, Soudan du Sud, Timor-Leste, Togo et Yémen.

Source: g7+ 2019 http://g7plus.org/, https://www.pbsbdialogue.org/en/new-deal/about-new-deal/. 


\section{Fragilité et conflits}

Les pays du g7+ partenaires dans le cadre du New Deal définissent la fragilité comme "une période dans l'histoire de la nation au cours de laquelle, pour parvenir à un développement socioéconomique durable, il est nécessaire de mettre davantage l'accent sur des activités complémentaires de consolidation de la paix et de renforcement de l'État" (g7+, 2013). Le groupe propose une échelle d'intensité de la fragilité à cinq niveaux, allant de la crise, associée principalement au conflit, jusqu'à la résilience (encadré 4.3).

L'adoption des ODD a renforcé les principes du New Deal en reconnaissant que des sociétés pacifiques et inclusives, l'accès à la justice pour tous, et des institutions efficaces, responsables et inclusives à tous les niveaux, comme prévu dans I'ODD 16, sont des objectifs d'application universelle et essentiels pour faire avancer le développement durable.

\section{Encadré 4.4. Circuits par lesquels le commerce influe sur la stabilité politique et les conflits}

Le mécanisme du coût d'opportunité renvoie aux variations du revenu réel et à la manière dont celles-ci peuvent augmenter ou réduire la valeur relative des actes de violence. La baisse des prix à l'exportation, la hausse des prix à l'importation et la baisse de la demande extérieure, qui réduisent les revenus réels, et donc le manque à gagner lié à la décision de commettre des actes de violence, accroissent le risque de conflit.

L'effet de rapacité désigne l'incitation à se battre pour le contrôle de ressources précieuses. Cet effet est particulièrement marqué pour les produits de base de source ponctuelle lorsque les prix augmentent.

L'effet ressources fait référence au mécanisme par lequel la hausse du prix de produits de base sous le contrôle (imposition) de parties au conflit (par exemple le gouvernement ou des groupes rebelles) peut financer les moyens de mettre fin à la lutte de l'une ou de l'autre des parties au conflit, ou de l'intensifier.

Source: Cali, M. (2015). Trading Away from Conflict. Using trade to increase resilience in fragile states, Banque mondiale, Washington, D.C.

\section{Diversification économique dans les pays fragiles et touchés par des conflits}

La section qui précède a souligné l'importance de la diversification économique dans les PMA pour la transformation structurelle et le développement. Dans les situations de fragilité et de conflit, la diversification de l'économie pourrait également être importante pour la paix. Les recherches et les analyses empiriques suggèrent qu'une spécialisation de l'économie dans certains produits et l'irrégularité des flux commerciaux dans certaines circonstances pourraient accroître le risque de violence et de conflit.

Cette section présente les mécanismes liés aux incitations économiques qui poussent les acteurs à la violence et au conflit, en utilisant le cadre fourni par Cali, M. (2015) et en s'appuyant sur les travaux de Collier, P., A. Hoeffler et al. (2004). Cali décrit trois mécanismes par lesquels les variations des flux commerciaux peuvent influer sur la stabilité politique et les conflits (encadré 4.4).

Le cadre effectue également une distinction entre les produits de base "de source ponctuelle", comme le pétrole et les minéraux, qui sont très précieux, ne créent pas beaucoup d'emplois et peuvent être facilement contrôlés, et les "produits de base dispersés", notamment dans l'agriculture, qui sont à forte intensité de main-d'œuvre et plus difficiles à contrôler, mais qui peuvent être importants pour financer des groupes armés qui contrôlent des zones locales (par le biais de l'imposition). Une hausse des prix des produits de base de source ponctuelle incite davantage à lutter pour leur contrôle (effet de rapacité). Une augmentation du prix des produits de base dispersés augmenterait les revenus des producteurs locaux et, par suite, le coût d'opportunité des actes de violence, ce qui réduirait le risque de conflit. Une diminution du prix des produits de base dispersés aurait l'effet inverse, c'est-à-dire qu'elle augmenterait les risques de conflit (effet du coût d'opportunité), même si cela pourrait aider les groupes armés à financer leurs activités (effet ressources), accroissant ainsi le risque de conflit ou sa durée. 
L'analyse transnationale de Cali fournit des arguments plus solides en faveur de l'effet de rapacité et indique que les variations des prix des produits de base influent sur la probabilité d'un conflit en intensifiant la concurrence pour les produits de base de source ponctuelle dont les prix augmentent. Une analyse de la CNUCED concernant la relation entre le commerce international et les conflits civils suggère de même que certains produits de base exportés ont une influence plus marquée que d'autres sur les conflits. Ce serait le cas du pétrole et du gaz, et des activités à forte intensité de main-d'œuvre, pour lesquels il existe un commerce illicite lucratif (CNUCED, 2004), parce que le commerce de ces produits peut financer les conflits (principalement grâce au financement des groupes armés) (effet ressources).

Un autre axe de recherche a souligné les liens entre, d'une part, une spécialisation économique et une concentration des exportations dans les produits primaires et, d'autre part, la qualité des institutions. Fearon, J. (2005) fait valoir que l'existence de recettes pétrolières incite moins à renforcer les compétences administratives et le contrôle sur le territoire national dans les pays tributaires du pétrole et que c'est la faiblesse relative des institutions publiques par rapport à des pays où le revenu par habitant est identique qui rend certains pays vulnérables face aux conflits. Ses données suggèrent qu'en moyenne, on peut avancer le même argument pour les exportations d'autres produits primaires, pour lesquelles les recettes publiques dépendent de l'imposition, même si les données sont moins convaincantes que pour le pétrole brut. Dans un cas comme dans l'autre, l'avantage lié au contrôle d'une ressource précieuse favorise les actes de violence et les conflits (effet de rapacité).

D'autres recherches ont mis l'accent sur les implications de l'instabilité des recettes en tant que cause sous-jacente de conflit. Guillaumont, P. et al. (2005) suggèrent que c'est l'instabilité causée par les chocs extérieurs qui importe dans les conflits, par opposition à une spécialisation dans certains produits spécifiques. S'appuyant sur les travaux de Collier, P. et Hoeffler, A. (2004) sur les liens entre les produits primaires et les conflits, Guillaumont, P. et al. (2005) concluent que "Iorsqu'on introduit l'instabilité des exportations, pondérée par le degré d'ouverture, dans le modèle de Collier-Hoeffler sur la survenance des conflits, non seulement le coefficient de détermination augmente fortement, mais la part des produits primaires dans les exportations devient également insignifiante." Guillaumont, P. (2007) fait en outre valoir que "les politiques sont affaiblies par l'instabilité structurelle", par exemple du fait de pressions sur la dette publique, de la qualité et du taux des investissements, etc., ce qui implique que, dans le temps, l'instabilité affecte la capacité des pays à réagir aux chocs avec des politiques adéquates.

Cali affirme que les flux commerciaux dans les pays fragiles sont 'différents' parce qu'ils sont i) plus importants que les autres flux extérieurs et ii) particulièrement irréguliers, en partie en raison de leur concentration sur les produits primaires. Ces deux facteurs amplifieraient l'impact des variations des flux commerciaux dans les contextes fragiles. Les flux commerciaux des PMA membres du g7+ semblent refléter ces constatations.

Avec le groupe des PMA comme point de comparaison, la figure 4.2 montre que l'importance relative du commerce est plus élevée pour les PMA membres du g7+ et qu'elle n'est pas descendue à moins de 70\% du financement extérieur au cours des dix dernières années. La figure 4.3 présente l'indice de concentration des exportations pour les PMA du g7+ et les PMA. La figure montre que la concentration des exportations de tous les PMA membres du g7+ est globalement supérieure à la moyenne des PMA, et que, si les PMA ont réduit le degré de concentration moyen de leurs exportations depuis 2006, la concentration des exportations des PMA du g7+ n'a pas beaucoup varié dans le temps, sauf pour le Yémen. Le tableau 4.A5 de l'annexe présente les trois principaux produits exportés par les PMA membres du g7+. Ces produits représentent au moins $40 \%$ des exportations totales de marchandises de tous ces pays, une proportion qui atteint 99\% pour le Soudan du Sud. Enfin, la figure 4.1 (ci-dessus) indique la variation annuelle de l'indice des prix des produits de base. Elle montre que, sur la période allant de 2006 à 2017, le prix des combustibles a été particulièrement instable. L'exposition des PMA membres du g7+ aux flux commerciaux et à leur irrégularité suggère que les variations des flux commerciaux peuvent avoir des effets particulièrement déstabilisants dans ces pays. 
Figure 4.2. Échanges, envois de fonds et flux d'IED vers les PMA et les PMA membres du g7+, 2006-2017

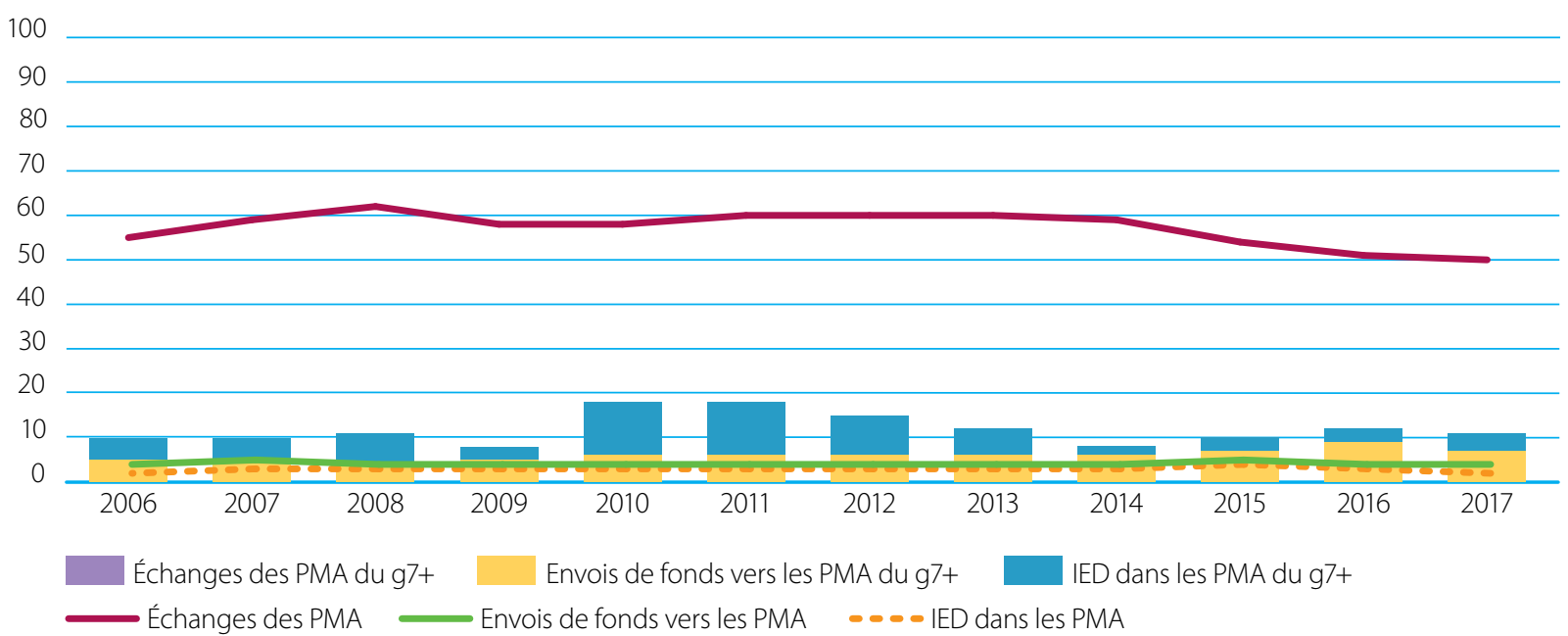

Source: Banque mondiale (2019, 2019a, 2019b) (consulté en février 2019).

StatLink 前

Les effets déstabilisants liés à l'irrégularité des recettes d'exportation peuvent être amortis grâce à différents mécanismes, comme les fonds de stabilisation qui permettraient de lisser l'investissement et la consommation lorsque les prix sont bas. Afin de réduire l'incitation à prendre le contrôle d'une ressource précieuse, comme le pétrole ou d'autres produits de base de source ponctuelle, il conviendrait d'axer les efforts sur le renforcement de la responsabilité et de la transparence dans le domaine de la gestion des ressources naturelles.

Une réponse complémentaire plus structurelle consisterait à diversifier la production et les exportations pour réduire la part des produits primaires, en particulier dans l'agriculture et les industries extractives, afin de réduire l'exposition aux risques associés aux fluctuations des flux commerciaux et renforcer ainsi la résilience face aux chocs extérieurs (Koren, $M$. et Tenreyro, S., 2007, et Papageorgiou, 2012).

Toutefois, une spécialisation économique dans les ressources naturelles ne condamne pas les pays au conflit, comme en témoigne l'expérience de pays riches en ressources, comme le Botswana, le Chili ou d'autres. De même, la diversification de l'économie ne suffirait pas non plus à elle seule à éliminer le risque de conflit. La violence et les conflits résultent de l'interaction entre plusieurs facteurs contextuels d'ordre socioéconomique, institutionnel, politique et autre, qui déterminent la manière dont des événements particuliers, y compris les variations des flux commerciaux, peuvent influer sur la violence et les conflits.

Les inégalités - en particulier horizontales - et l'exclusion peuvent créer un terrain propice où se développent les griefs qui fragilisent la cohésion sociale et conduisent à la violence (Nations Unies/Banque mondiale, 2018). Les inégalités horizontales font référence à un accès inégal aux débouchés ou aux ressources, telles que les terres ou d'autres ressources naturelles, et aux différences de niveau de vie dans certains groupes, etc., ce qui peut générer de la frustration et de l'insatisfaction, et mener un groupe à se mobiliser et à recourir à la violence (Stewart, F., 2008).

Un taux de chômage ou de sous-emploi élevé, en particulier chez les jeunes, a été associé à un risque de conflit accru. L'absence de perspectives économiques et la présence d'obstacles économiques et politiques sous-jacents à la participation des jeunes dans la société peuvent engendrer un sentiment d'aliénation et rendre les jeunes vulnérables à une mobilisation violente afin de se garantir des moyens de subsistance (Stewart, F., 2008). La diversification économique peut réduire le coût d'opportunité du recours à la violence en augmentant les possibilités d'emploi dans d'autres secteurs, notamment pour les jeunes, comme cela est examiné plus en détail au chapitre 8. 
Figure 4.3. Concentration des exportations dans les PMA membres du g7+

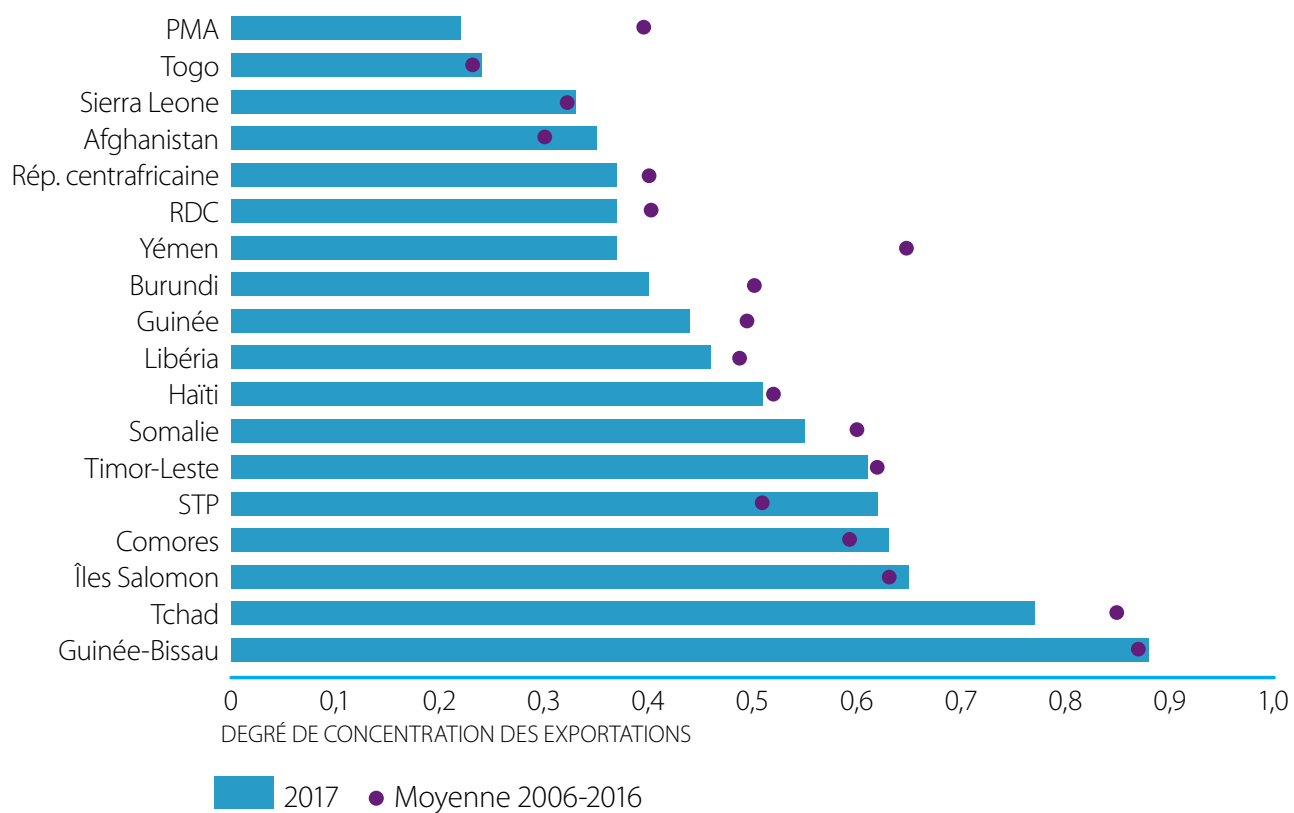

Note: Des valeurs d'indice plus élevées indiquent une plus forte concentration des exportations sur quelques produits.

Source: Base de données UNCTADStat (consultée en février 2019).

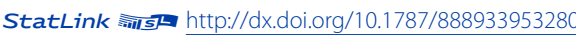

Par ailleurs, l'inclusion contribue à prévenir les conflits, à y mettre fin, et à éviter qu'ils ne s'aggravent ou ne reprennent (Paffenholz et al., 2017). Ménager des espaces pour la participation économique, sociale et politique des jeunes et des femmes pourrait également contribuer à accroître la stabilité (Nations Unies/Banque mondiale, 2018).

Les recettes d'exportation représentent une source de financement extérieur majeure pour les PMA membres du g7+ et la concentration de leurs exportations sur un très petit nombre de produits assez instables les rend vulnérables face aux chocs extérieurs. La composition des exportations de certains produits de base précieux peut constituer une incitation à lutter contre les institutions publiques, et à leur nuire, ainsi qu'à la qualité des politiques publiques, y compris celles visant à promouvoir un environnement économique favorable au développement du secteur privé et à favoriser la diversification de l'économie. La question de savoir si l'instabilité découlant des fluctuations des flux commerciaux génère des conflits dépend toutefois de facteurs contextuels. Des politiques favorisant l'inclusion et réduisant les inégalités amélioreraient la résilience des pays et des sociétés face au risque de conflit.

\section{L'AIDE POUR LE COMMERCE DESTINÉE À SOUTENIR LA DIVERSIFICATION DE L'ÉCONOMIE DANS LES PMA}

"La capacité du Tchad à accroître sa production de marchandises et de services est fondamentale pour renforcer à la fois le commerce national et international, avec tous les avantages que cela peut apporter pour stimuler les recettes publiques et la création d'emplois. L'Aide pour le commerce joue un rôle vital dans le renforcement du capital humain, des institutions et des infrastructures, et le soutien au secteur privé afin d'atteindre les objectifs de développement durable." - S.E. Mahamat Hamid Koua, Ministre du pétrole et de lénergie, au nom du Ministre des mines, du développement commercial et industriel, et de la promotion du secteur privé. 


\section{Aide pour le commerce}

La communauté internationale contribue aux efforts des pays en développement et des PMA en faveur de la diversification économique et de la transformation structurelle grâce à des programmes de développement, dont l'Aide pour le commerce. Depuis 2006, plus de 400 milliards d'USD ont été décaissés au titre de l'APD pour renforcer les capacités commerciales dans les pays en développement et les PMA.

Cette section examine les flux d'Aide pour le commerce vers les PMA et les PMA membres du g7+ sous le prisme de la diversification économique.

"Parmi les grandes priorités des Comores, les efforts suivis en faveur de la diversification économique visent à élargir la base d'exportation de trois grands produits d'exportation et à satisfaire la demande intérieure, tout en ciblant les marchés régionaux". - Comores, Exercice de suivi de l'Aide pour le commerce OCDE-OMC (2019).

Les PMA représentent $\mathbf{2 7 \%}$ de l'Aide pour le commerce totale. Ils sont les deuxièmes bénéficiaires de l'Aide pour le commerce, avec une part inférieure de 12\% à celle des pays à revenu intermédiaire de la tranche inférieure. L'Aide pour le commerce en faveur des PMA suit la même tendance que I'Aide pour le commerce totale: au cours des cinq dernières années, les engagements ont varié, mais les décaissements sont restés stables. Les engagements en faveur des PMA ont augmenté de 28\% en 2017, après avoir diminué en 2016 (figure 4.4). Les PMA d'Afrique représentent 63\% de l'Aide pour le commerce accordée aux PMA depuis 2006. Les PMA membres du g7+ représentent près d'un quart de l'Aide pour le commerce totale en faveur des PMA, les flux étant restés globalement stables depuis 2009.

Figure 4.4. Flux d'Aide pour le commerce en faveur des PMA et des PMA membres du g7t, moyenne pour 2006-2017

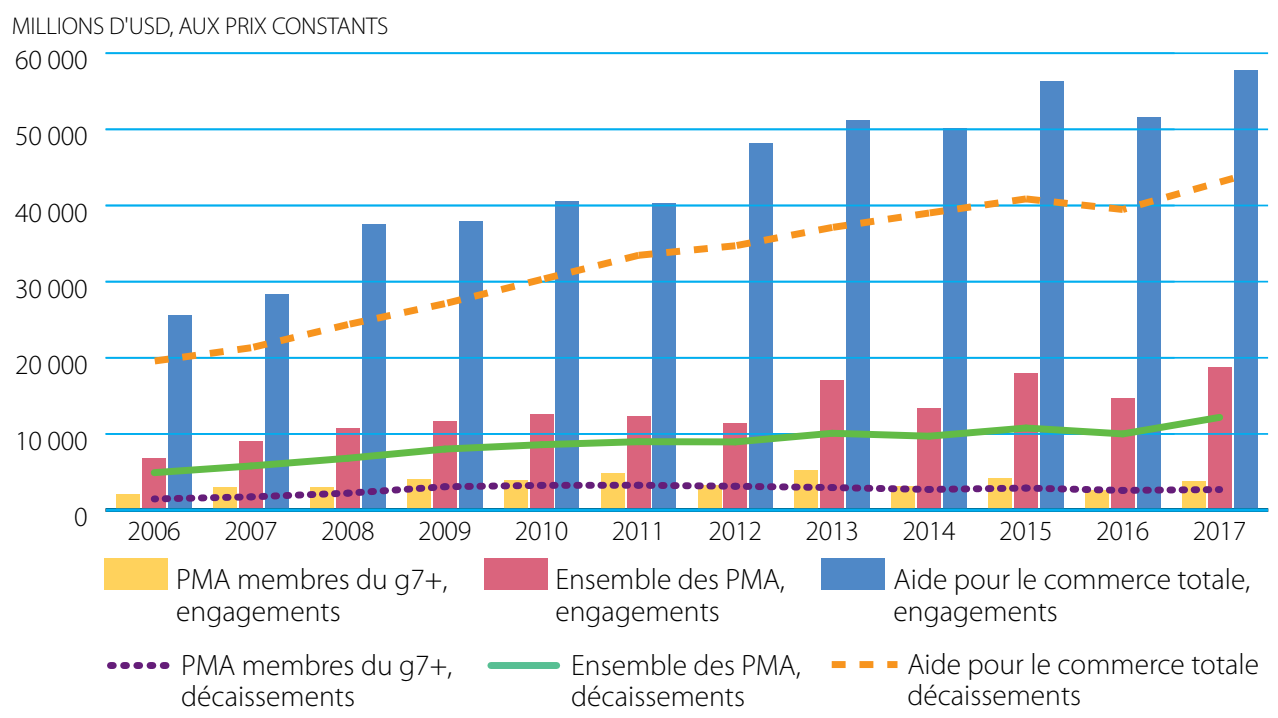

Source: SNPC de l'OCDE-CAD: base de données sur les activités d'aide (2019) (consultée en avril 2019). 
L'Aide pour le commerce est répartie de façon inégale entre les PMA. Les cinq principaux bénéficiaires Afghanistan, Bangladesh, Éthiopie, Mozambique, Tanzanie - ont représenté plus de 40\% des décaissements totaux au titre de l'Aide pour le commerce en faveur des PMA entre 2006 et 2017. Quatre des PMA du g7+ - Afghanistan, RDC, Haïti et Yémen - reçoivent plus de la moitié de l'Aide pour le commerce accordée au groupe.

La situation est plus nuancée lorsqu'on examine les flux par habitant: les petits États insulaires en développement (PEID) et le Timor-Leste arrivent en tête, nettement au-dessus de la moyenne des PMA, ce qui est dû à la taille réduite de leur population et au fait que le coût d'acheminement de l'aide est intrinsèquement plus élevé lorsque les populations sont dispersées géographiquement (OCDE, 2018) (figure 4.5). Pour la plupart des PMA membres du g7t, les montants par habitant alloués au titre de l'Aide pour le commerce sont inférieurs à la moyenne des PMA. Les réponses du Burundi, de la République centrafricaine et des Comores à l'exercice de suivi de l'Aide pour le commerce OCDE/OMC (2019) reconnaissent des progrès limités en termes de diversification économique en raison de l'insuffisance des financements au titre de l'Aide pour le commerce.

\section{Figure 4.5. Décaissements au titre de l'Aide pour le commerce en faveur des PMA membres du g7+, par habitant, 2013-2017}

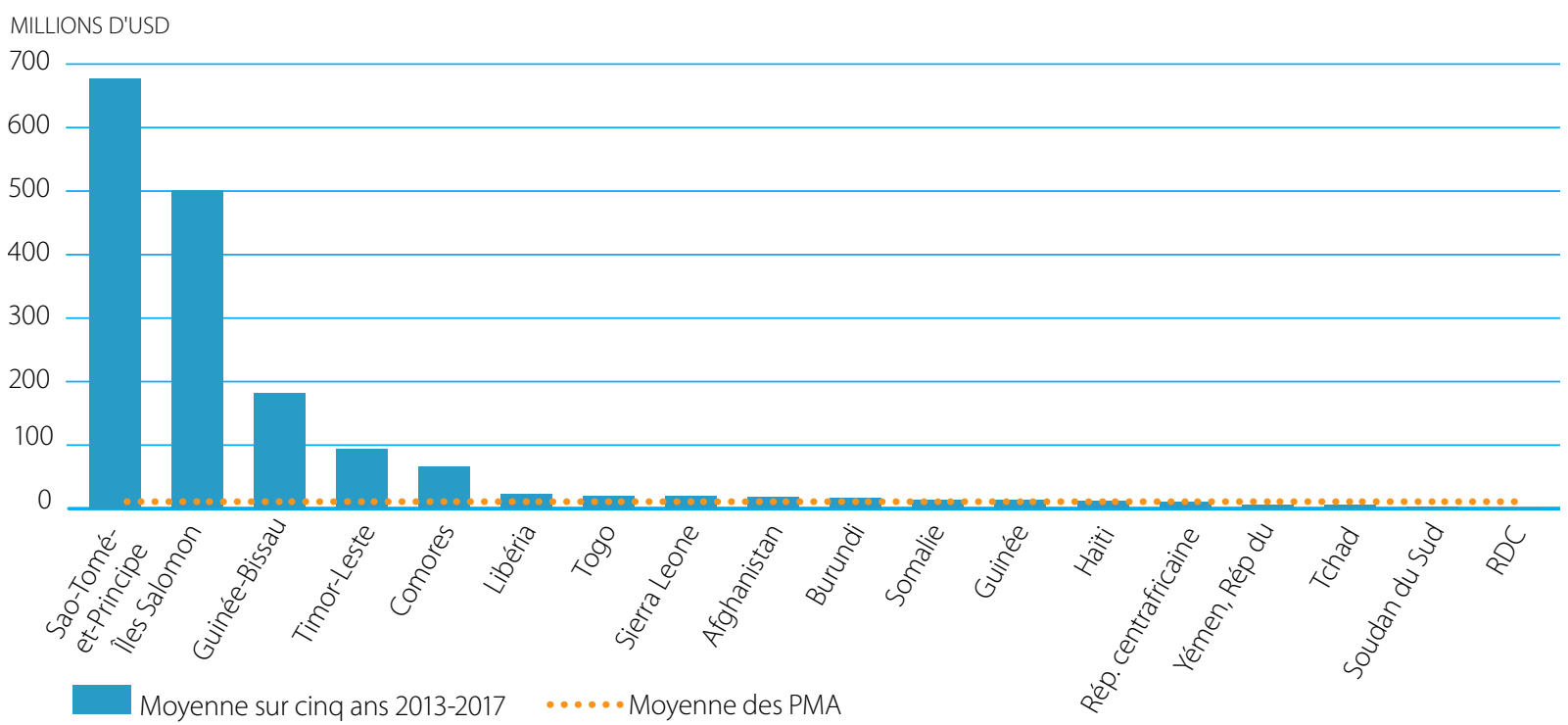

Source: SNPC de I'OCDE-CAD: base de données sur les activités d'aide (2019); Banque mondiale (2019d) (consultée en avril 2019).

Quelques partenaires de développement fournissent l'essentiel de l'Aide pour le commerce en faveur des PMA. Depuis 2006, la Banque mondiale, le Japon, les États-Unis d'Amérique et l'Union européenne fournissent plus de 60\% des décaissements au titre de l'Aide pour le commerce en faveur des PMA. La Banque mondiale, les États-Unis et l'UE sont les principaux fournisseurs d'Aide pour le commerce pour les PMA membres du g7t, avec 70\% des décaissements sur la même période.

La plupart de l'Aide pour le commerce accordée aux PMA est destinée aux infrastructures. La plupart des décaissements au titre de l'Aide pour le commerce en faveur des PMA sont destinés aux infrastructures (55\%) et au renforcement de la capacité de production (43\%). Les décaissements en faveur des PMA du g7+ affichent une structure semblable, les infrastructures représentant 56\% de l'Aide pour le commerce accordée à ces pays (figure 4.6). Sur la même période, le soutien à la politique et à la réglementation commerciales, y compris la facilitation des échanges, représente $2 \%$ et 3\%, respectivement, pour les PMA et les PMA membres du g7+. La part de l'ajustement lié au commerce reste extrêmement limitée. 
Figure 4.6. Décaissements par catégorie d'Aide pour le commerce, 2006-2017

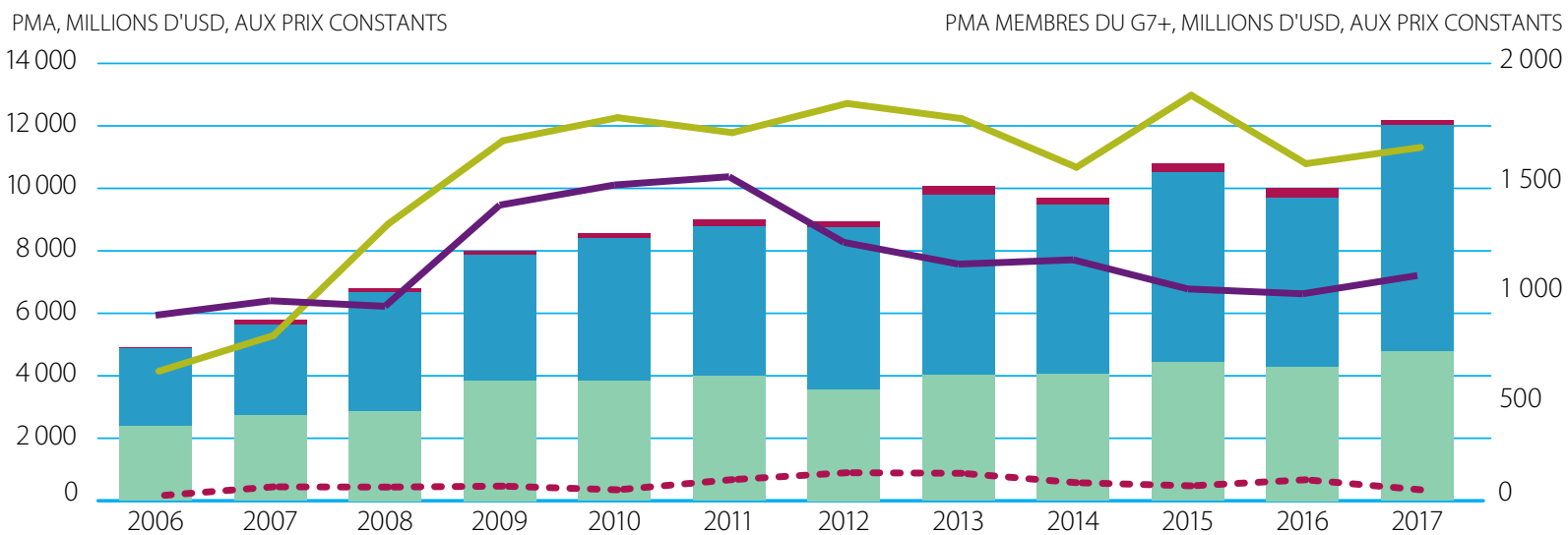

Renforcement de la capacité de production des PMA___ Infrastructures économiques des PMA

Politique et réglementation commerciales des PMA

- Renforcement de la capacité de production des PMA du g7+

Infrastructures économiques des PMA du g7+

-.-Politique et réglementation commerciales des PMA du g7+

Source: SNPC de I'OCDE-CAD: base de données sur les activités d'aide (2019) (consultée en avril 2019).

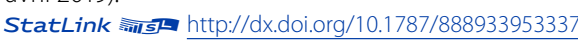

Dans l'exercice de suivi de l'Aide pour le commerce OCDE/OMC (2019), les PMA identifient les infrastructures comme étant une contrainte majeure pour la diversification de l'économie; viennent ensuite l'accès au financement (PMA) et les coûts élevés du commerce (PMA membres du g7+).

"Le soutien devrait être axé davantage sur la promotion de l'accès au financement et le renforcement des capacités productives et commerciales du pays." - Togo, Exercice de suivi de l'Aide pour le commerce OCDE-OMC (2019).

Par ailleurs, les EDIC des PMA membres du g7+ réalisées sous l'égide du CIR ${ }^{4}$ soulignent les besoins en termes d'assistance technique afin d'améliorer l'élaboration et la mise en œuvre de la politique commerciale, et de mener des réformes en matière de facilitation des échanges dans ces pays (figure 4.7).

Figure 4.7. Matrices des actions des EDIC: identifier les priorités des PMA membres du g7+

Politique et institutions en matière de commerce

Facilitation des échanges

Développement des compétences

Agriculture

Conditions de l'activité des entreprises

Services, y compris le tourisme

Infrastructures

Industries extractives

Pêche

Développement du secteur privé

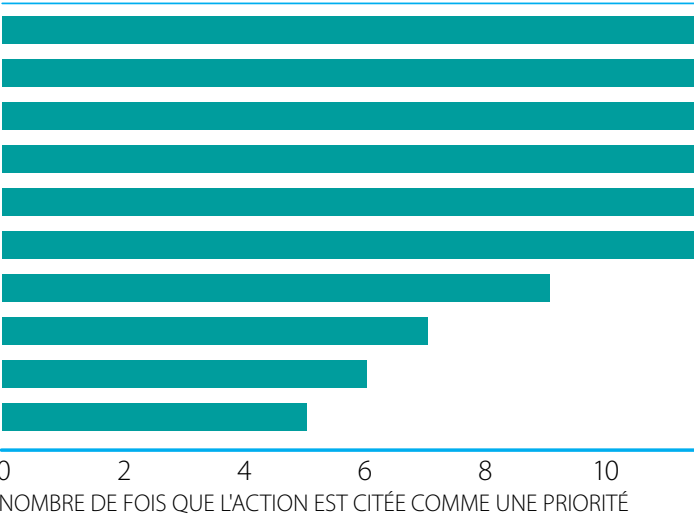

Source: CIR, Études diagnostiques sur l'intégration du commerce.

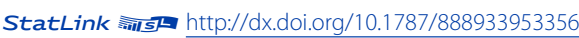


Encadré 4.5. Accroître la valeur ajoutée des principales cultures de rapport aux Comores

Aux Comores, près de la moitié de la population travaille pour la récolte, la transformation ou l'exportation de 3 cultures de rapport: ylang-ylang, clou de girofle et vanille. Ces 3 produits représentent $80 \%$ des exportations du pays. La coopération entre le PNUD, I'ITC et le CIR a offert de nouveaux débouchés aux producteurs d'ylang-ylang, aux distillateurs et aux petits entrepreneurs des Comores. Aujourd'hui, ils sont mieux organisés dans différentes coopératives et collaborent pour améliorer la productivité et accroître les revenus.

Une coopérative créée récemment pour l'ylang-ylang compte 250 cueilleuses, 50 planteuses et 47 distillateurs. En outre, de petites entreprises semblables à Nectalab peuvent désormais créer de la valeur ajoutée dans le pays, grâce aux huiles essentielles et aux produits de beauté produits directement aux Comores. Les résultats prennent de l'ampleur dans le secteur de la vanille grâce au Programme intégré pour le commerce aux Comores de la Société internationale islamique de financement du commerce.

Source: D'après l'EDIC des Comores (2015) et l'exercice de suivi de l'Aide pour le commerce OCDE/OMC (2019) des Comores.

Les transports et l'entreposage reçoivent la majeure partie des décaissements au titre de l'Aide pour le commerce accordés aux PMA, soit plus de 30\% depuis 2006, devant l'agriculture (encadré 4.5). La répartition par secteur est la même pour les PMA membres du g7+, même si les transports et l'entreposage, ainsi que les services aux entreprises et autres services, sont relativement plus importants dans ces pays que dans l'ensemble des PMA (figure 4.8).

Figure 4.8. Principaux secteurs des PMA soutenus au titre de l'Aide pour le commerce, 2006-2017

\section{PMA}

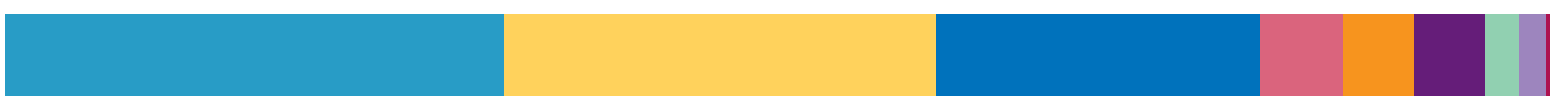

\section{PMA membres du g7+}

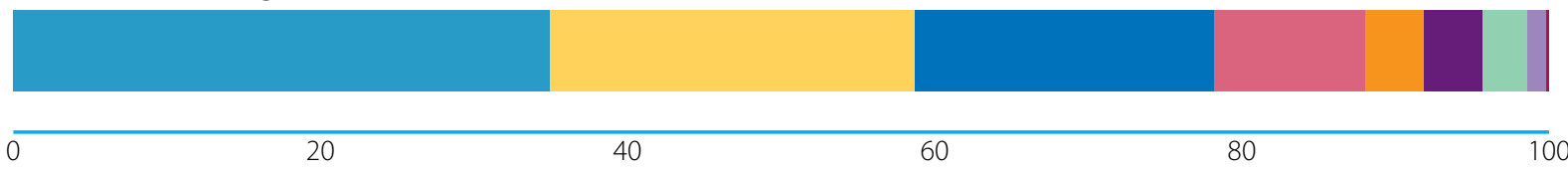

POURCENTAGE

II.1. Transport et entreposage III.1. Agriculture, sylviculture et pêche

I.3. Énergie

II.5. Services aux entreprises et autres services III.2. Industrie, activités extractives et construction

II.4. Services bancaires et financiers _ III.3.a. Politique et réglementation commerciales

Il.2. Communications III.3.b. Tourisme

Source: SNPC de l'OCDE-CAD: base de données sur les activités d'aide (2019) (consultée en avril 2019).

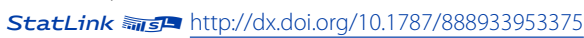

\section{Soutenir les fondements économiques des PMA membres du g7+}

Près de 60\% de l'APD totale accordée aux PMA membres du g7+ depuis 2006 ont financé des interventions associées aux objectifs de consolidation de la paix et de renforcement de l'État. ${ }^{5}$ S'agissant de la répartition entre les PSG, les investissements les plus élevés concernent les fondements économiques, ainsi que les recettes et les services, mais ces flux sont relativement plus importants dans les PMA que dans les PMA du g7+. Ce phénomène peut s'expliquer par le fait que ces PSG "recouvrent un large éventail de pratiques classiques de développement fondées sur la croissance économique [et qu'il] est plus facile de réaliser des projets en plus grand nombre et sur une plus grande échelle dans les situations où il n'y a pas de fragilité" (OCDE, 2018) (figure 4.9). 


\section{Figure 4.9. Répartition de l'APD entre les objectifs de consolidation de la paix et de renforcement de l'État du New Deal, par PSG, pour les PMA et les PMA membres du g7+, 2006-2017}

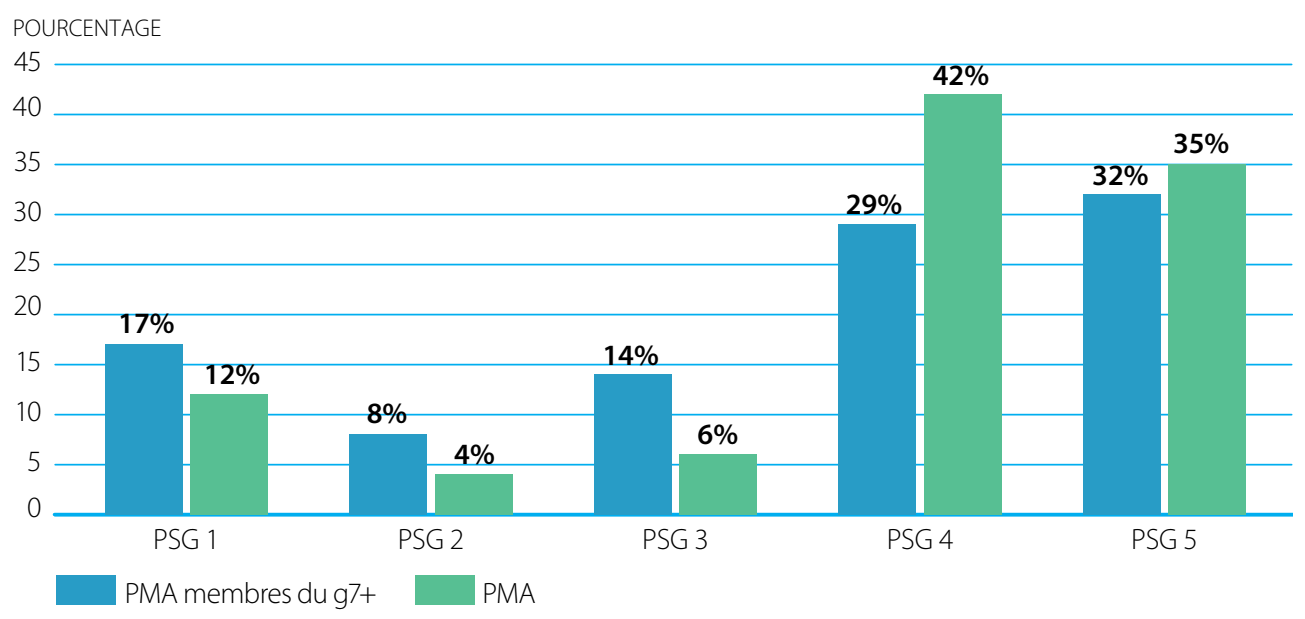

Source: SNPC de l'OCDE-CAD: base de données sur les activités d'aide (2019) (consultée en avril 2019).

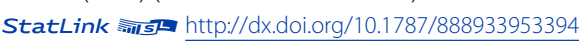

Inversement, les PSG concernant la légitimité politique, la sécurité et la justice reçoivent des investissements relativement plus importants dans les PMA du g7+ que dans l'ensemble des PMA. Cela laisse à penser que, d'une certaine manière, ces PSG sont hiérarchisés par les PMA membres du g7t, qui ont pris des engagements avec leurs partenaires. La question de savoir si les PSG bénéficient, dans leur ensemble et individuellement, d'un financement suffisant est de nature très contextuelle dans la mesure où les coûts de programmation, ainsi que les besoins, varient selon la dimension de la fragilité visée, et d'un contexte à l'autre (OCDE, 2018).

Néanmoins, la part de l'aide humanitaire accordée aux PMA membres du g7+ au titre de l'aide au développement totale a progressivement augmenté depuis 2006 et elle a atteint 29\% en moyenne en 2017. La hausse de l'aide humanitaire et les autres tendances de l'APD ont réduit le montant global de l'aide programmable, qui est tombée sous le seuil de 50\% en 2015 (Nations Unies, 2018). Cette tendance générale inquiète les PMA et les pays fragiles car I'APD est essentielle pour soutenir les investissements stratégiques permettant d'atteindre les ODD dans ces pays.

\section{Soutenir la diversification de l'économie dans les PMA membres du g7+ grâce à l'Aide pour le commerce}

Dans les pays fragiles et touchés par des conflits, réduire l'instabilité causée par les chocs commerciaux pourrait contribuer à réduire la violence et les conflits, qui sont liés à l'importance des produits précieux issus des industries extractives dans le profil économique et commercial de ces pays. Toutefois, il est particulièrement difficile de déclencher les processus de diversification économique et de transformation structurelle dans ces contextes.

Dans les pays fragiles et touchés par des conflits, les infrastructures physiques et la sécurité constituent des obstacles majeurs au développement du secteur privé, mais les politiques publiques et la réglementation jouent également un rôle important. Dans le même temps, faire avancer la réforme des politiques et des institutions dans ces environnements fragiles et touchés par des conflits peut être clivant et générer une résistance plus fondamentale que ce que l'on peut attendre dans le cadre de tout processus de changement s'inscrivant dans les contextes de développement ordinaires. \|l est nécessaire de bien comprendre l'économie politique des réformes et la dynamique qui les entoure. 
Le secteur privé peut avoir des comportements prédateurs lorsque le cadre institutionnel est faible (Utterwulghe, S., 2014). Les efforts en matière de politique et de réglementation peuvent, par exemple, inciter les entreprises à se tourner vers des activités productives plutôt que des activités qui génèrent des rentes, et renforcer la transparence; soutenir les micro, petites et moyennes entreprises, qui représentent la majorité des entreprises dans les pays à faible revenu, contribue à un partage plus large des bénéfices de la croissance économique. Établir des "mécanismes de surveillance équitables pour l'utilisation et la gestion des produits des industries extractives [...] peut désamorcer les tensions; le rôle du secteur privé est essentiel" (Nations Unies/Banque mondiale, 2018).

L'expansion rapide des emplois productifs est essentielle en termes de stabilisation, de développement à long terme et d'autonomisation économique (encadré 4.6). Citant des éléments tirés de programmes et de recherches sur les pays fragiles et touchés par des conflits, Dubwick, N. et al. (2013) défendent une approche plus proactive de la création d'emploi dans ces contextes de fragilité et de conflit, laquelle exigerait de modifier la chronologie traditionnelle des actions, en commençant par améliorer l'environnement politique et macroéconomique, et par renforcer la primauté du droit, etc., et ce, avant de lancer des programmes pour le développement du secteur privé. Une approche qui fonctionnerait plutôt en parallèle serait souhaitable. La politique des Nations Unies sur l'emploi après les conflits suit cette approche et repose sur trois axes de travail: i) stabilisation de la création de revenus et des emplois d'urgence, ii) relance de l'économie locale pour les possibilités d'emploi et la réinsertion, et iii) création d'emplois durables et décents (Nations Unies, 2009). Les trois axes fonctionnent en parallèle, mais pas au même rythme, qui varie dans le temps en fonction de l'évolution des besoins sur le terrain et du passage de la crise à la résilience, conformément à l'échelle d'intensité établie par les PMA membres du g7t.

Les chaînes de valeur peuvent contribuer à retisser les liens avec les marchés et à développer la confiance entre différents groupes sociaux (DAES, 2010). Un rapport de synthèse de I'USAID sur les enseignements tirés des programmes consacrés aux chaînes de valeur dans les situations de conflit souligne la même chose et note que les activités qui renforcent la confiance, telles que les associations ou les groupes de travail sur les chaînes de valeur, permettent de développer la confiance et les liens entre entreprises reliées horizontalement et verticalement dans la chaîne.

Encadré 4.6. Nouvelles possibilités d'emploi dans les PMA membres du g7+: les routes du développement

L'année 2017 a été marquée par un résultat important pour la communauté internationale du développement suite à l'attention croissante portée aux contextes fragiles: I'adoption par l'Organisation internationale du travail (OIT) de la Recommandation $n^{\circ} 205$ sur l'emploi et le travail décent au service de la paix et de la résilience. La Recommandation n² 205 a remplacé la Recommandation n 71 sur la "Transition de la guerre à la paix" adoptée après la Seconde Guerre mondiale qui intégrait la dimension de conflit interne. La nouvelle recommandation met l'accent sur le redressement et la reconstruction dans les situations post-conflit, sur les causes profondes de la fragilité et sur les mesures pour renforcer la résilience. Elle appelle à intensifier la coopération internationale, la coordination et la cohérence. Elle insiste également sur la promotion de l'emploi, le développement des capacités et le renforcement des institutions. Sur la base de cette recommandation, le programme de I'OIT sur des emplois au service de la paix et de la résilience se concentre sur la création d'emplois, le développement des compétences et l'esprit d'entreprise, et contribue ainsi à la cohésion sociale.

Depuis 2012, le Timor-Leste, soutenu par l'Australie et l'OIT, a réussi à construire plus de 300 kilomètres de routes rurales et à rénover plus d'un quart du réseau, contribuant ainsi à relier les régions éloignées du pays aux marchés, améliorant l'accès aux écoles et aux hôpitaux, et créant des emplois dont le pays a grand besoin. Déterminé à poursuivre le renforcement de la connectivité routière, le gouvernement du Timor-Leste finance l'ensemble des travaux routiers restants, tandis que I'Australie continue de soutenir l'assistance technique accordée au pays par l'OIT jusqu'en 2021

Au fil des ans, 14 PMA membres du g7+ ont bénéficié du soutien de l'OlT, et notamment l'Afghanistan, le Burundi, la République centrafricaine, les Comores, la République démocratique du Congo, la Guinée, Haïti, le Libéria, la Sierra Leone, les Îles Salomon, la Somalie, le Soudan du sud et le Timor-Leste.

Source: D'après I'OIT (2017), (2017a). 
Toutefois, l'intégration dans les chaînes de valeur mondiales accroît l'exposition aux chocs extérieurs dans la mesure où l'implantation des tâches dans différents lieux le long de la chaîne de valeur évolue en fonction de l'évaluation que font les grandes entreprises des coûts de production relatifs dans les différents emplacements (CNUCED, 2013).

Les chaînes de valeur peuvent également accroître les inégalités si elles excluent certains segments de la population, notamment les petits agriculteurs, ceux qui sont relativement isolés ou qui n'ont pas les moyens de production nécessaires pour participer. Pour que les programmes contribuent davantage à la résilience, ils devraient plutôt être conçus en vue de créer des débouchés pour les pauvres, en particulier les jeunes et ceux qui sont affectés par des conflits.

L'Aide pour le commerce en faveur des PMA et des PMA membres du g7+ soutient le développement de la capacité de production et des infrastructures dans ces pays, ce qui est important pour diversifier l'économie. Plus d'un tiers des investissements sont concentrés dans le secteur agricole, ce qui est essentiel pour réduire la pauvreté et ouvre une voie vers la diversification de l'économie dans les pays à faible revenu. Néanmoins, une répartition sectorielle plus équilibrée de l'Aide pour le commerce pourrait également soutenir la diversification grâce à des solutions prometteuses en dehors de l'agriculture. L'Aide pour le commerce est fortement concentrée dans quelques PMA et si le montant total des décaissements effectués à ce titre en faveur des PMA a progressivement augmenté, les décaissements en faveur des PMA membres du g7+ sont restés stables au cours des cinq dernières années. Pour la plupart des PMA membres du g7t, les montants alloués par habitant sont inférieurs à la moyenne des PMA.

Soutenir la diversification économique dans les PMA membres du g7+ peut contribuer à la paix, la stabilité et la réalisation des ODD. Toutefois, il est particulièrement difficile de déclencher la transformation de l'économie par le biais de la diversification économique dans les contextes fragiles. Dans ces situations, les programmes devraient tenir spécifiquement compte de l'économie politique des réformes. II peut être particulièrement utile de mettre l'accent sur la création d'emplois, notamment grâce à des programmes qui ciblent certains secteurs et certaines chaînes de valeur, et contribuent à renforcer la confiance entre les acteurs. La participation des parties prenantes locales, y compris les jeunes, les femmes et les personnes affectées par le conflit et la fragilité, est essentielle pour développer la résilience et éviter que les conflits ne reprennent.

\section{CONCLUSIONS}

Dans le cadre des réflexions sur l'importance de la diversification économique pour le développement durable et sur le rôle de l'Aide pour le commerce, le présent chapitre s'est concentré sur la situation particulière des PMA. Une des principales conclusions est que l'absence de diversification de l'économie et des exportations est une cause essentielle de la vulnérabilité structurelle des économies des PMA et qu'elle a des conséquences importantes sur la capacité de ces pays à maintenir une croissance économique qui crée des débouchés pour tous, et réduit ainsi la pauvreté et les inégalités. Le transfert des ressources d'activités à faible productivité au profit d'activités à forte productivité dans l'agriculture, les services et le secteur manufacturier favorisera une plus forte croissance économique et une convergence vers de plus hauts niveaux de revenu dans les PMA. Les investissements publics dans les infrastructures et le capital humain sont importants, de même que les réformes politiques qui créent un environnement propice aux investissements productifs privés et les politiques ciblées visant à promouvoir les secteurs qui présentent un potentiel en termes de diversification et de création d'emplois.

Le chapitre conclut également que les efforts en faveur de la diversification de l'économie et des exportations dans les PMA membres du g7+ présente l'avantage supplémentaire de favoriser la stabilité et de promouvoir l'inclusion dans la mesure où la diversification économique améliore les moyens de subsistance et les emplois pour la population, en particulier les jeunes, les femmes et les personnes affectées par les conflits. Cependant, il est particulièrement difficile de promouvoir la diversification de l'économie dans les situations de fragilité en raison des clivages politiques et de la faiblesse des cadres et des capacités institutionnels résultant de la fragilité et des conflits. Les programmes visant 
à soutenir la diversification de l'économie et des exportations doivent tenir compte des sensibilités de l'économie politique et former des coalitions en faveur de réformes qui contribuent aux activités économiques productives du secteur privé, à la création d'emplois et à la réduction de la pauvreté.

Enfin, l'analyse conclut que l'Aide pour le commerce soutient les efforts déployés par les PMA eux-mêmes pour diversifier leurs économies et leurs exportations par le biais d'investissements dans les infrastructures et les capacités de production. Néanmoins, la stagnation de l'Aide pour le commerce accordée aux PMA et aux PMA membres du g7+, ainsi que sa forte concentration dans quelques pays, posent la question du niveau adéquat des flux vers ces pays. Pour la plupart des PMA membres du g7+ en situation de fragilité, I'Aide pour le commerce par habitant est inférieure à la moyenne des PMA. Dans ce cadre, il serait important d'accroître l'Aide accordée aux PMA dans la mesure prévue par les engagements internationaux.

Pour lutter contre le risque de violence, il est nécessaire de mieux aligner les efforts déployés à des fins humanitaires, de développement et de consolidation de la paix. Les programmes d'Aide pour le commerce dans les situations fragiles devraient tenir particulièrement compte de la manière dont les programmes pourraient interagir avec le contexte local, et soutenir les efforts plus larges de renforcement de l'État et de consolidation de la paix. Les PMA membres du g7+ accordent à ces domaines un certain degré de priorité 


\section{NOTES}

1. Nous souhaitons remercier Frans Lammersen et Rachel Scott pour leurs orientations stratégiques, et Aussama Bejraoui d'avoir partagé les dernières données sur l'Aide pour le commerce (OCDE), ainsi que Ratnakar Adhikari (CIR), Michael Roberts et Evgeniia Shannon (OMC), David Kucera (OIT) et Riad Meddeb du PNUD pour leurs précieuses observations.

2. Bangladesh, Bhoutan, Kiribati, RDP lao, Myanmar, Népal, Sao Tomé-et-Principe, Îles Salomon, Timor-Leste et Tuvalu.

3. L'IPL agrégé regroupe en une seule mesure les résultats pour les six composantes obtenus lors des quatre dernières enquêtes; https://lpi.worldbank.org/.

4. D'après les EDIC de 16 PMA membres du g7+. L'EDIC de la Somalie est en cours de planification, tandis que celle de la République centrafricaine a été mise en attente.

5. Cette analyse repose sur les catégories utilisées dans les États de fragilité 2018 de l'OCDE pour les codes SNPC dans le cadre des PSG. Voir: http://www.oecd.org/fr/c'est-à-dire/etats-de-fragilite-2018-9789264308916-fr.htm. 


\section{RÉFÉRENCES}

Andreoni, A., et C.L. Gomez (2012). Can we live on services? Exploring manufacturing-services interfaces and their implications for industrial policy design. http://druid8.sit.aau.dk/acc_papers/j2uc1c7qnybes5rm57hueffrhhaj.pdf, consulté le 4 mars 2019.

Cali, M. (2015). Trading away from conflict. Using trade to increase resilience in fragile states, Banque mondiale, Washington, D.C.

Collier, P., et A. Hoeffle (2004). "Aid, Policy and Growth in Post-Conflict Societies", European Economic Review, vol. 46, $n^{\circ} 8$, pages 1475 à 1500 .

Dubwick, N., R. Srinivasan, J. Cuesta et D. Madani (2013). Creating jobs in Africa's Fragile States. Are value chains the answer?, Banque mondiale, Washington, D.C.

Guerrieri, P., et V. Meliciani (2005). Technology and international competitiveness: The interdependence between manufacturing and producer services. Structural Change and Economic Dynamics, vol. 16, n 4, pages 489 à 502.

Guillaumont, P., et S. Guillaumont Jeanneney. State fragility and economic vulnerability: what is measured and why? 2009.18.2011.

Hidalgo, C.A., B. Klinger, A.-L. Barabasi et R. Hausmann (2007). "The product space conditions the development of nations", Science, vol. 317, pages 482 à 487.

Hoeffler, A. (1999). Challenges of Infrastructure Rehabilitation and Reconstruction in War-affected Economies, Document d'information pour le rapport de la Banque africaine de développement, REP/ 2000-2.

OIT (2017). Recommandation n² 205 sur l'emploi et le travail décent au service de la paix et de la résilience, 2017.

OIT. Genève. https://www.lo.org/dyn/normlex/fr/f?p=NORMLEXPUB:12100:0::NO::P12100_ILO_CODE:R205, consulté le 1er mars 2019.

OIT (2017a). Rural Road development for better rural employment and economy, OIT, Genève, https://www.lo.org/ wcmsp5/groups/public/---asia/---ro-bangkok/---ilo-jakarta/documents/publication/wcms_548653.pdf, consulté le 15 février 2019.

IRAM (2013). Appuyer la transition vers une filière gomme arabique plus durable, Institut de recherches et d'applications des méthodes de développement. IRAM.

https://www.iram-fr.org/ouverturepdf.php?file=628-1485716241.pdf, consulté le 15 février 2019.

ITC (2017). Rapport final: projet de renforcement des capacités commerciales de la filière gomme arabique tchadienne (PRCCFGAT), ITC, Genève.

UIT (2018). Achieving universal and affordable internet in the Least Developed Countries. ICTs, LDCs and the SDGs, UIT. Koren, M., et S. Tenreyro (2007). "Volatility and Development", Quarterly Journal of Economics, vol. 122, pages 243 à 287.

Koren, M., and S. Tenreyro (2007). 'Volatility and Development', Quarterly Journal of Economics, Vol. 122, pages 243 à 287.

Kucera D., X. Jiang (2018). Structural transformation in emerging economies: leading sectors and the balanced growth hypothesis, Oxford Development Studies. https://doi.org/10.1080/13600818.2018.1533934, consulté le 4 mars 2019.

McKechnie, A., A. Lightner, et D.W. te Velde (2018). Economic Development in Fragile contexts. Learning from success and failure, ODI, https://set.odi.org/wp-content/uploads/2018/05/SET-Econ-Development-in-Fragile-States_Finalreport.pdf. 
McMillan, M., J. Page, D. Booth et D.W. te Velde (2017). Supporting economic transformation: An approach paper. Supporting Economic Transformation Report, Overseas Development Institute, Londres.

Mishra, S., Lundstrom, S. et Anand, R. (2011). Services Export Sophistication and Economic Growth, http://siteresources. worldbank.org/INTRANETTRADE/Resources/Internal-Training/287823-1285275962946/Service_Export_Growth.pdf, consulté le 10 février 2019.

OCDE (2018). États de fragilité 2018, Éditions OCDE, Paris, https://www.oecd-ilibrary.org/fr/development/etats-defragilite-2018_9789264308916-fr, consulté le 11 février 2019.

Paffenholz, T., A. Hirblinger, D. Landau, F. Fritsch et C. Dijkstra (2017). "Preventing Violence through Inclusion: From Building Political Momentum to Sustaining Peace." Note d'information pour l'étude phare des Nations Unies et de la Banque mondiale, Pathways for Peace: Inclusive Approaches to Preventing Violent Conflict, Banque mondiale, Washington, D.C.

Papageorgiou, C., et S. Nikola (2012). Economic Diversification in LDCs: Stylized Facts and Macroeconomic Implications, IMF Staff Discussion Note, SDN/12/13, FMI.

Parker, J.C. (2008). A synthesis of practical lessons from value chain projects in conflict-affected environments, microREPORT\#105, USAID, Washington, D.C.

Rodrik, D. (2013). "Unconditional convergence in manufacturing", The Quarterly Journal of Economics, pages 165 à 204.

Sinha, S., J. Holmberg et T. Mark (2013). What works for market development: A review of the evidence, UTV Working Paper 2013:1, Sida.

Stewart, F., et J.F.E. Ohiorhenuam (2008), Post-conflict economic recovery. Enabling local ingenuity, PNUD, New York.

CNUCED (2013). Global Value Chains and Development. investment and value-added trade in the global economy, Nations Unies, https://unctad.org/en/PublicationsLibrary/diae2013d1_en.pdf, consulté le 20 février 2019.

CNUCED (2014). Rapport 2014 sur les pays les moins avancés. Croissance et transformation structurelle: un programme de développement pour l'après-2015, Nations Unies, https://unctad.org/fr/PublicationsLibrary/ldc2014_fr.pdf, consulté le 20 février 2019.

CNUCED (2015). Rapport 2015 sur les pays les moins avancés. Transformer l'économie rurale, Nations Unies, https://unctad.org/fr/PublicationsLibrary/ldc2015_fr.pdf, consulté le 20 février 2019.

CNUCED (2016). Rapport 2016 sur les pays les moins avancés. Le processus de reclassement et au-delà: tirer parti de la dynamique. Nations Unies, https://unctad.org/fr/pages/PublicationWebflyer.aspx?publicationid=1664, consulté le 20 février 2019.

CNUCED (2017). Améliorer la mise en œuvre des objectifs et buts du Programme d'action d'Istanbul concernant les capacités productives et le doublement de la part des pays les moins avancés dans les exportations mondiales, TD/B/C.I/EM.9/2, Nations Unies, https://unctad.org/meetings/fr/SessionalDocuments/ciem9d2_fr.pdf, consulté le 20 février 2019.

CNUCED (2018). Statistical Tables in the LDCs Report 2018. https://unctad.org/en/Pages/ALDC/Least\%20 Developed\%20Countries/LDC-Statistics.aspx, consulté le 15 février 2019.

PNUD (2018). Human Development Indices and Indicators. 2018 Statistical Update, PNUD, New York.

Nations Unies (2009). Policy for Post-conflict employment creation, income generation and reintegration, Nations Unies, Genève. 
Nations Unies (2018). Manuel relatif à la catégorie des pays les moins avancés: inscription, retrait et mesures spéciales de soutien, troisième édition, Comité des politiques de développement et Département des affaires économiques et sociales des Nations Unies, New York.

Nations Unies et Banque mondiale (2018). Pathways for Peace: Inclusive Approaches to Preventing Violent Conflict (Chemins pour la paix: Approches inclusives pour la prévention des conflits violents), Banque mondiale, Washington, D.C., https://openknowledge.worldbank.org/handle/10986/28337, consulté le 10 février 2019.

Utterwulghe, S. (2014), Fostering Private Sector Development in Fragile States: A Piece of Cake?, https://blogs.worldbank.org/psd/water/fostering-private-sector-development-fragile-states-piece-cake consulté le 20 février 2019.

Banque mondiale (2019). Commerce de marchandises (\% du PIB), https://donnees.banquemondiale.org/indicateur/he.trd.gnfs.zs (consulté le 20 février 2019).

Banque mondiale (2019a). Envois de fonds des travailleurs et rémunérations des salariés, reçus (\% du PIB), https://donnees.banquemondiale.org/indicateur/bx.trf.pwkr.dt.gd.zs (consulté le 20 février 2019).

Banque mondiale (2019b). Investissement étranger direct, flux entrants nets (\% du PIB), https://donnees.banquemondiale.org/indicateur/bx.klt.dinv.wd.gd.zs (consulté le 20 février 2019).

OMC (2017). Déclaration ministérielle adoptée à la première réunion des ministres du commerce du groupe g7+ es accessions à I'OMC, WTO/MIN (17)/51.

OMC (2018), Accès aux marchés pour les produits et services dont l'exportation présente un intérêt pour les PMA, Sous-Comité des pays les moins avancés, Note du secrétariat, OMC, Genève, 2 octobre 2018, WT/COMTD/LDC/W/66. 


\section{ANNEXE}

\begin{tabular}{|c|c|c|c|c|c|c|c|c|}
\hline \multirow[t]{2}{*}{$\begin{array}{l}\text { Catégorie } \\
\text { de pays }\end{array}$} & \multicolumn{2}{|c|}{$\begin{array}{l}\text { Emploi dans } \\
\text { l'agriculture }\end{array}$} & \multicolumn{2}{|c|}{$\begin{array}{l}\text { Emploi dans } \\
\text { l'industrie }\end{array}$} & \multicolumn{2}{|c|}{$\begin{array}{c}\text { Emploi dans } \\
\text { le secteur manufacturier }\end{array}$} & \multicolumn{2}{|c|}{$\begin{array}{l}\text { Emploi dans } \\
\text { les services }\end{array}$} \\
\hline & 2000 & 2017 & 2000 & 2017 & 2000 & 2017 & 2000 & 2017 \\
\hline $\begin{array}{l}\text { PMA membres } \\
\text { du G7+ }\end{array}$ & 66,9 & 60,9 & 9,3 & 10,5 & 6,0 & 6,4 & 23,7 & 28,5 \\
\hline PMA $^{*}$ & 72,7 & 60,2 & 8,6 & 12,6 & 6,2 & 7,8 & 18,7 & 27,2 \\
\hline $\begin{array}{l}\text { Autres pays en } \\
\text { développement }\end{array}$ & 43,8 & 26,4 & 22,3 & 23,9 & 16,7 & 13,9 & 33,9 & 49,7 \\
\hline
\end{tabular}

Note: ${ }^{*}$ Chiffres agrégés pour les PMA, hors Kiribati et Tuvalu, pour lesquels il n'y a pas de données.

Source: ILOSTAT, Modèles économétriques de tendances, estimations et projections de l'OIT (consulté en novembre 2018).

D’après les tableaux statistiques de la CNUCED issus du rapport 2018 sur les PMA.

\section{Tableau 4.A2. Composition par produit des exportations de marchandises, 2015-2017 (millions d'USD et \%)}

\begin{tabular}{|c|c|c|c|c|c|c|c|c|c|c|c|}
\hline \multirow[b]{2}{*}{ Pays } & \multirow[b]{2}{*}{$\begin{array}{l}\text { Exportations } \\
\text { totales } \\
\text { (millions } \\
\text { d'USD) }\end{array}$} & \multicolumn{4}{|c|}{ PRODUITS PRIMAIRES } & \multicolumn{5}{|c|}{ PRODUITS MANUFACTURÉS } & \multirow[b]{2}{*}{$\begin{array}{c}\text { Non } \\
\text { alloué }\end{array}$} \\
\hline & & Total & $\begin{array}{l}\text { Produits } \\
\text { alimentaires } \\
\text { et agricoles }\end{array}$ & Combustibles & $\begin{array}{l}\text { Minéraux, } \\
\text { minerais } \\
\text { et métaux }\end{array}$ & Total & $\begin{array}{l}\text { Produits } \\
\text { manufacturés à } \\
\text { forte intensité } \\
\text { de main- } \\
\text { d'œuvre et de } \\
\text { ressources }\end{array}$ & $\begin{array}{l}\text { Produits } \\
\text { manufacturés à } \\
\text { forte intensité } \\
\text { de technologie } \\
\text { nécessitant une } \\
\text { main-d'œuvre } \\
\text { peu qualifiée }\end{array}$ & $\begin{array}{l}\text { Produits } \\
\text { manufacturés à } \\
\text { forte intensité } \\
\text { de technologie } \\
\text { nécessitant une } \\
\text { main-d'œuvre } \\
\text { moyennement } \\
\text { qualifiée }\end{array}$ & $\begin{array}{l}\text { Produits } \\
\text { manufacturés à } \\
\text { forte intensité } \\
\text { de technologie } \\
\text { nécessitant une } \\
\text { main-d'œuvre } \\
\text { hautement } \\
\text { qualifiée }\end{array}$ & \\
\hline PMA & 153328,9 & 64,2 & 17,0 & 28,0 & 19,2 & 35,1 & 29,7 & 1,5 & 1,5 & 2,8 & 0,7 \\
\hline $\begin{array}{l}\text { PMA } \\
\text { africains et } \\
\text { Haïti }\end{array}$ & $90,047,3$ & 90,2 & 18,9 & 41,6 & 29,6 & 9,4 & 4,0 & 1,1 & 1,4 & 3,1 & 0,5 \\
\hline $\begin{array}{l}\text { PMA } \\
\text { asiatiques }\end{array}$ & $62,723,3$ & 26,8 & 13,7 & 8,7 & 4,4 & 72,3 & 66,9 & 2,0 & 1,5 & 2,4 & 0,9 \\
\hline $\begin{array}{l}\text { PMA } \\
\text { insulaires }\end{array}$ & 558,3 & 89,1 & 82,9 & 2,2 & 4,0 & 6,7 & 1,8 & 2,7 & 0,8 & 1,8 & 4,2 \\
\hline $\begin{array}{l}\text { Autres } \\
\text { pays en } \\
\text { dévelop- } \\
\text { pement }\end{array}$ & 7280988,1 & 28,5 & 8,7 & 13,1 & 6,8 & 70,8 & 14,4 & 6,9 & 19,6 & 32,2 & 0,7 \\
\hline
\end{tabular}

Note: Données basées sur la matrice du commerce des marchandises de la CNUCED, y compris les estimations.

Source: CNUCED, base de données UNCTADStat (consultée en novembre 2018). 
Tableau 4.A3. Composition par produit des importations de marchandises, 2015-2017 (millions d'USD et \%)

\begin{tabular}{|c|c|c|c|c|c|c|c|c|c|c|c|}
\hline \multirow[b]{2}{*}{ Pays } & \multirow[b]{2}{*}{$\begin{array}{l}\text { Exportations } \\
\text { totales } \\
\text { (millions } \\
\text { d'USD) }\end{array}$} & \multicolumn{4}{|c|}{ PRODUITS PRIMAIRES } & \multicolumn{5}{|c|}{ PRODUITS MANUFACTURÉS } & \multirow[b]{2}{*}{$\begin{array}{l}\text { Non } \\
\text { alloués }\end{array}$} \\
\hline & & Total & $\begin{array}{l}\text { Produits } \\
\text { alimentaires } \\
\text { et agricoles }\end{array}$ & Combustibles & $\begin{array}{l}\text { Minéraux, } \\
\text { minerais } \\
\text { et métaux }\end{array}$ & Total & $\begin{array}{l}\text { Produits } \\
\text { manufacturés à } \\
\text { forte intensité } \\
\text { de main- } \\
\text { d'œuvre et de } \\
\text { ressources }\end{array}$ & $\begin{array}{l}\text { Produits } \\
\text { manufacturés à } \\
\text { forte intensité } \\
\text { de technologie } \\
\text { nécessitant une } \\
\text { main-d'œuvre } \\
\text { peu qualifiée }\end{array}$ & $\begin{array}{l}\text { Produits } \\
\text { manufacturés à } \\
\text { forte intensité } \\
\text { de technologie } \\
\text { nécessitant une } \\
\text { main-d'œuvre } \\
\text { moyennement } \\
\text { qualifiée }\end{array}$ & $\begin{array}{l}\text { Produits } \\
\text { manufacturés à } \\
\text { forte intensité } \\
\text { de technologie } \\
\text { nécessitant une } \\
\text { main-d'œuvre } \\
\text { hautement } \\
\text { qualifiée }\end{array}$ & \\
\hline PMA & 234381,6 & 33,4 & 19,7 & 10,7 & 3,0 & 65,0 & 18,6 & 10,9 & 21,5 & 17,8 & 1,7 \\
\hline $\begin{array}{l}\text { PMA } \\
\text { africains et } \\
\text { Haïti }\end{array}$ & 125591,0 & 32,0 & 18,1 & 11,7 & 2,3 & 66,0 & 15,7 & 11,2 & 24,0 & 19,5 & 1,9 \\
\hline $\begin{array}{l}\text { PMA } \\
\text { asiatiques }\end{array}$ & 106584,3 & 34,8 & 21,4 & 9,6 & 3,8 & 63,9 & 22,1 & 10,6 & 18,6 & 16,0 & 1,3 \\
\hline $\begin{array}{l}\text { PMA } \\
\text { insulaires }\end{array}$ & 2206,2 & 40,5 & 29,7 & 9,7 & 1,1 & 53,5 & 13,0 & 12,1 & 19,8 & 12,3 & 6,0 \\
\hline $\begin{array}{l}\text { Autres } \\
\text { pays en } \\
\text { dévelop- } \\
\text { pement }\end{array}$ & 6789945,3 & 30,7 & 9,5 & 12,1 & 9,1 & 68,0 & 8,3 & 5,8 & 21,1 & 34,8 & 1,3 \\
\hline
\end{tabular}

Note: Données basées sur la matrice du commerce des marchandises de la CNUCED, y compris les estimations.

Source: CNUCED, base de données UNCTADStat (consultée en novembre 2018).

Tableau 4.A4. Accès à l'électricité dans les PMA, certaines années (\% de la population totale)

Accès à l'électricité, total

\begin{tabular}{lccc} 
& $\mathbf{2 0 0 0}$ & $\mathbf{2 0 1 0}$ & $\mathbf{2 0 1 6}$ \\
\hline PMA membres du g7+ & $\mathbf{1 5}$ & $\mathbf{2 6}$ & 37 \\
\hline PMA & 20 & 33 & 45 \\
\hline
\end{tabular}

Autres pays en développement

80

88

92

Source: Banque mondiale, base de données des Indicateurs du développement dans le monde (consultée en novembre 2018). 
Tableau 4.A5. Principaux produits exportés par les PMA membres du g7+

\begin{tabular}{|c|c|c|c|c|c|c|}
\hline Pays & $\begin{array}{l}\text { PIB par } \\
\text { habitant, } \\
\text { USD }\end{array}$ & $\begin{array}{l}\text { Principaux produits } \\
\text { exportés } \\
\text { (SH à } 4 \text { chiffres) }\end{array}$ & $\begin{array}{l}\text { Part des } \\
\text { exportations } \\
\text { totales de } \\
\text { marchandises }\end{array}$ & $\begin{array}{l}\text { Principaux produits } \\
\text { importés }\end{array}$ & $\begin{array}{l}\text { Principaux } \\
\text { marchés } \\
\text { d'exportation }\end{array}$ & $\begin{array}{l}\text { Principales } \\
\text { sources des } \\
\text { importations }\end{array}$ \\
\hline Afghanistan & 1940 & $\begin{array}{l}\text { Raisins, fruits } \\
\text { tropicaux, } \\
\text { résines d'insectes }\end{array}$ & $40 \%$ & $\begin{array}{l}\text { Matériel de } \\
\text { radiodiffusion, } \\
\text { farines de blé, } \\
\text { tourbe }\end{array}$ & $\begin{array}{l}\text { Pakistan, Inde, } \\
\text { Émirats arabes } \\
\text { unis (É.A.U.) }\end{array}$ & $\begin{array}{l}\text { É.A.U., } \\
\text { États-Unis, } \\
\text { Iran }\end{array}$ \\
\hline Burundi & 777 & Or, café, thé & $62 \%$ & $\begin{array}{l}\text { Produits } \\
\text { pétroliers raffinés, } \\
\text { médicaments } \\
\text { conditionnés, } \\
\text { camions de livraison }\end{array}$ & $\begin{array}{l}\text { É.A.U., Pakistan, } \\
\text { Allemagne }\end{array}$ & $\begin{array}{l}\text { Tanzanie, } \\
\text { Ouganda, } \\
\text { Chine }\end{array}$ \\
\hline Comores & 1520 & $\begin{array}{l}\text { Girofles, vanille, } \\
\text { huiles essentielles }\end{array}$ & $90 \%$ & $\begin{array}{l}\text { Autres meubles, } \\
\text { vêtements usagés, } \\
\text { petits récipients } \\
\text { en fer }\end{array}$ & $\begin{array}{l}\text { Inde, É.A.U., } \\
\text { France }\end{array}$ & $\begin{array}{l}\text { Tanzanie, } \\
\text { Chine, É.A.U. }\end{array}$ \\
\hline Guinée & 1970 & $\begin{array}{l}\text { Or, minerai } \\
\text { d'aluminium, } \\
\text { gaz de pétrole }\end{array}$ & $88,2 \%$ & $\begin{array}{l}\text { Produits pétroliers } \\
\text { raffinés, riz, } \\
\text { médicaments } \\
\text { conditionnés }\end{array}$ & $\begin{array}{l}\text { É.A.U., Chine, } \\
\text { Inde }\end{array}$ & $\begin{array}{l}\text { Chine, } \\
\text { Pays-Bas, } \\
\text { Inde }\end{array}$ \\
\hline Guinée-Bissau & 1610 & $\begin{array}{l}\text { Noix de coco, } \\
\text { noix du Brésil, } \\
\text { noix de cajou, } \\
\text { poisson congelé } \\
\text { autrement qu'en } \\
\text { filets }\end{array}$ & $92 \%$ & $\begin{array}{l}\text { Produits pétroliers } \\
\text { raffinés, riz, extraits } \\
\text { de malt }\end{array}$ & $\begin{array}{l}\text { Inde, Bélarus, } \\
\text { Ghana }\end{array}$ & $\begin{array}{l}\text { Portugal, } \\
\text { Gambie, } \\
\text { Sénégal }\end{array}$ \\
\hline Haïti & 1780 & $\begin{array}{l}\text { T-shirts et chandails } \\
\text { en bonneterie, } \\
\text { costumes pour } \\
\text { homme autres } \\
\text { qu'en bonneterie }\end{array}$ & $71 \%$ & $\begin{array}{l}\text { Riz, T-shirts en } \\
\text { bonneterie, étoffes } \\
\text { de bonneterie } \\
\text { légèrement } \\
\text { caoutchoutées }\end{array}$ & $\begin{array}{l}\text { États-Unis, } \\
\text { République } \\
\text { dominicaine, } \\
\text { Mexique }\end{array}$ & $\begin{array}{l}\text { République } \\
\text { dominicaine, } \\
\text { États-Unis, } \\
\text { Chine }\end{array}$ \\
\hline Îles Salomon & 2240 & $\begin{array}{l}\text { Bois brut, poisson } \\
\text { transformé, } \\
\text { huile de palme }\end{array}$ & $79,6 \%$ & $\begin{array}{l}\text { Pétrole raffiné, riz, } \\
\text { voitures }\end{array}$ & $\begin{array}{l}\text { Chine, Inde, } \\
\text { Italie }\end{array}$ & $\begin{array}{l}\text { Australie, } \\
\text { Chine, } \\
\text { Singapour }\end{array}$ \\
\hline Libéria & 812 & $\begin{array}{l}\text { Navires pour } \\
\text { le transport } \\
\text { de passagers et } \\
\text { de marchandises, } \\
\text { or, caoutchouc }\end{array}$ & $75 \%$ & $\begin{array}{l}\text { Navires pour } \\
\text { le transport de } \\
\text { passagers et de } \\
\text { marchandises, } \\
\text { produits pétroliers } \\
\text { raffinés, hélices de } \\
\text { bateau }\end{array}$ & $\begin{array}{l}\text { Pologne, É.A.U., } \\
\text { Suisse }\end{array}$ & $\begin{array}{l}\text { Corée du } \\
\text { Sud, Chine, } \\
\text { Japon }\end{array}$ \\
\hline $\begin{array}{l}\text { République } \\
\text { centrafricaine }\end{array}$ & 698 & $\begin{array}{l}\text { Bois brut, bois scié, } \\
\text { diamants }\end{array}$ & $63 \%$ & $\begin{array}{l}\text { Voitures, } \\
\text { médicaments } \\
\text { conditionnés, } \\
\text { véhicules blindés }\end{array}$ & $\begin{array}{l}\text { France, Bélarus, } \\
\text { Chine }\end{array}$ & $\begin{array}{l}\text { France, } \\
\text { Japon, } \\
\text { États-Unis }\end{array}$ \\
\hline
\end{tabular}


Tableau 4.A5. Principaux produits exportés par les PMA membres du g7+

\begin{tabular}{|c|c|c|c|c|c|c|}
\hline Pays & $\begin{array}{l}\text { PIB par } \\
\text { habitant, } \\
\text { USD }\end{array}$ & $\begin{array}{l}\text { Principaux produits } \\
\text { exportés } \\
\text { (SH à } 4 \text { chiffres) }\end{array}$ & $\begin{array}{l}\text { Part des } \\
\text { exportations } \\
\text { totales de } \\
\text { marchandises }\end{array}$ & $\begin{array}{l}\text { Principaux produits } \\
\text { importés }\end{array}$ & $\begin{array}{l}\text { Principaux } \\
\text { marchés } \\
\text { d'exportation }\end{array}$ & $\begin{array}{l}\text { Principales } \\
\text { sources des } \\
\text { importations }\end{array}$ \\
\hline $\mathrm{RDC}$ & 801 & $\begin{array}{l}\text { Cuivre affiné, cobalt, } \\
\text { minerai de cuivre }\end{array}$ & $64 \%$ & $\begin{array}{l}\text { Médicaments } \\
\text { conditionnés, } \\
\text { bouteilles en verre, } \\
\text { produits pétroliers } \\
\text { raffinés }\end{array}$ & $\begin{array}{l}\text { Chine, Arabie } \\
\text { saoudite, } \\
\text { Corée du Sud }\end{array}$ & $\begin{array}{l}\text { Chine, } \\
\text { Afrique } \\
\text { du Sud, } \\
\text { Belgique }\end{array}$ \\
\hline $\begin{array}{l}\text { Sao Tomé-et- } \\
\text { Principe }\end{array}$ & 3240 & $\begin{array}{l}\text { Cacao en fèves, } \\
\text { autres produits en } \\
\text { fer, constructions } \\
\text { en fer }\end{array}$ & $69,7 \%$ & $\begin{array}{l}\text { Autres navires } \\
\text { pour la navigation } \\
\text { maritime, voitures, } \\
\text { riz }\end{array}$ & $\begin{array}{l}\text { Pologne, } \\
\text { Belgique, } \\
\text { Espagne }\end{array}$ & $\begin{array}{l}\text { Portugal, } \\
\text { Afrique du } \\
\text { Sud, Chine }\end{array}$ \\
\hline Sierra Leone & 1480 & $\begin{array}{l}\text { Minerai de fer, } \\
\text { minerai de titane, } \\
\text { diamants }\end{array}$ & $54 \%$ & $\begin{array}{l}\text { Riz, médicaments } \\
\text { conditionnés, } \\
\text { voitures }\end{array}$ & $\begin{array}{l}\text { Chine, } \\
\text { Belgique, } \\
\text { Côte d'lvoire }\end{array}$ & $\begin{array}{l}\text { Chine, États- } \\
\text { Unis, Inde }\end{array}$ \\
\hline Somalie & 434 & $\begin{array}{l}\text { Viande ovine, } \\
\text { caprine et bovine, } \\
\text { résines d'insectes }\end{array}$ & $79 \%$ & $\begin{array}{l}\text { Sucre brut, riz, } \\
\text { chaussures en } \\
\text { caoutchouc }\end{array}$ & $\begin{array}{l}\text { Oman, É.A.U., } \\
\text { Hong Kong, } \\
\text { Chine }\end{array}$ & $\begin{array}{l}\text { É.A.U., Inde, } \\
\text { Chine }\end{array}$ \\
\hline Soudan du Sud & 994 & $\begin{array}{l}\text { Pétrole brut, } \\
\text { autres semences } \\
\text { oléagineuses }\end{array}$ & $99 \%$ & $\begin{array}{l}\text { Sucre brut, } \\
\text { médicaments } \\
\text { conditionnés, } \\
\text { voitures }\end{array}$ & $\begin{array}{l}\text { Chine, Algérie, } \\
\text { Pakistan }\end{array}$ & $\begin{array}{l}\text { Ouganda, } \\
\text { Chine, } \\
\text { Pakistan }\end{array}$ \\
\hline Tchad & 1990 & $\begin{array}{l}\text { Pétrole brut, or, } \\
\text { coton brut }\end{array}$ & $92 \%$ & $\begin{array}{l}\text { Médicaments } \\
\text { conditionnés, } \\
\text { voitures, } \\
\text { farine de blé }\end{array}$ & $\begin{array}{l}\text { États-Unis, } \\
\text { É.A.U., Inde }\end{array}$ & $\begin{array}{l}\text { France, } \\
\text { Chine, É.A.U. }\end{array}$ \\
\hline Timor-Leste & 2140 & $\begin{array}{l}\text { Pétrole brut, café, } \\
\text { vêtements usagés }\end{array}$ & $89,2 \%$ & $\begin{array}{l}\text { Camions } \\
\text { de livraison, } \\
\text { voitures, ciment }\end{array}$ & $\begin{array}{l}\text { Thaïlande, } \\
\text { États-Unis, } \\
\text { Singapour }\end{array}$ & $\begin{array}{l}\text { Indonésie, } \\
\text { Chine, } \\
\text { Singapour }\end{array}$ \\
\hline Togo & 1490 & $\begin{array}{l}\text { Or, ciment, produits } \\
\text { pétroliers raffinés }\end{array}$ & $40 \%$ & $\begin{array}{l}\text { Produits pétroliers } \\
\text { raffinés, motocycles, } \\
\text { pétrole brut }\end{array}$ & $\begin{array}{l}\text { É.A.U., Bénin, } \\
\text { Liban }\end{array}$ & $\begin{array}{l}\text { Chine, } \\
\text { Belgique, } \\
\text { Pays-Bas }\end{array}$ \\
\hline Yémen, Rép. du & 2510 & $\begin{array}{l}\text { Or, pétrole brut, } \\
\text { autres fruits }\end{array}$ & $75,3 \%$ & $\begin{array}{l}\text { Blé, produits } \\
\text { pétroliers raffinés, } \\
\text { sucre brut }\end{array}$ & $\begin{array}{l}\text { Oman, É.A.U., } \\
\text { Chine }\end{array}$ & $\begin{array}{l}\text { Chine, } \\
\text { Turquie, } \\
\text { Oman }\end{array}$ \\
\hline
\end{tabular}

Source: MIT, 2019, https://atlas.media.mit.edu/en/. 


\title{
CHAPITRE 5
}

\section{DIVERSIFICATION ÉCONOMIQUE : LES LEÇONS DE L'EXPÉRIENCE}

\author{
Contribution du Groupe de la Banque mondiale
}

\begin{abstract}
Résumé: La diversification économique reste un défi pour la plupart des pays en développement et sans doute plus encore pour les pays ayant les plus faibles revenus, les petits pays, les pays sans littoral ou ceux dont l'économie est très dépendante des produits de base. Pour ces pays, la diversification économique est inextricablement liée à la transformation structurelle de leurs économies et à l'élévation des niveaux de productivité résultant de la circulation des ressources économiques à l'intérieur des différents secteurs de l'économie et entre ces secteurs. Le présent chapitre, qui s'appuie sur des exemples de l'appui fourni par le Groupe de la Banque mondiale, délimite le champ du débat sur la diversification économiqueen proposant une définition qui englobe deux aspects connexes de la diversification: i) la diversification des échanges commerciaux (exportation de produits nouveaux ou améliorés ou vers de nouveaux marchés) et ii) la diversification de la production nationale (rééquilibrage de la production avec réaffectation des ressources entre les différents secteurs et, au sein des secteurs, entre les entreprises, pour accroître la productivité totale des facteurs). Le chapitre attire l'attention sur la complexité du processus de diversification et sur l'état des connaissances en matière de diversification économique. Bien que l'environnement mondial actuel recèle des défis considérables pour les pays pauvres, de petite taille, sans littoral et/ou tributaires des ressources naturelles, tous ces pays peuvent explorer de nouvelles voies pour diversifier leur économie. Ils devront néanmoins tenir compte de quatre facteurs décisifs pour le succès de leurs stratégies de diversification, que les partenaires du développement et les organisations internationales peuvent soutenir au moyen d'interventions ciblées dans le cadre de l'Aide pour le commerce. Ces facteurs sont i) l'établissement de cadres incitatifs appropriés; ii) des investissements et des réformes des politiques destinés à réduire les coûts du commerce; iii) des politiques efficaces favorisant l'ajustement et la réaffectation des ressources au profit de nouvelles activités; et iv) des interventions des pouvoirs publics ciblant certains dysfonctionnements du marché, des politiques et des institutions.
\end{abstract}




\section{IMPORTANCE DE LA DIVERSIFICATION ÉCONOMIQUE}

La diversification économique est une composante essentielle du développement économique grâce à laquelle un pays s'oriente vers une structure de production et d'échanges plus variée. Une diversification économique insuffisante se traduit fréquemment par une plus grande vulnérabilité face aux chocs extérieurs, qui peut compromettre les perspectives de croissance économique à long terme. Les pays les plus pauvres de la planète, qui sont souvent petits ou géographiquement isolés, sans littoral et/ou fortement dépendants de l'agriculture primaire ou des minéraux, présentent généralement les structures économiques les plus concentrées. Cela crée des difficultés en termes d'exposition aux chocs sectoriels, comme les événements météorologiques dans le secteur de l'agriculture ou les chocs soudains sur les prix des minéraux.

Figure 5.1. Diversification en Afrique subsaharienne, 2017

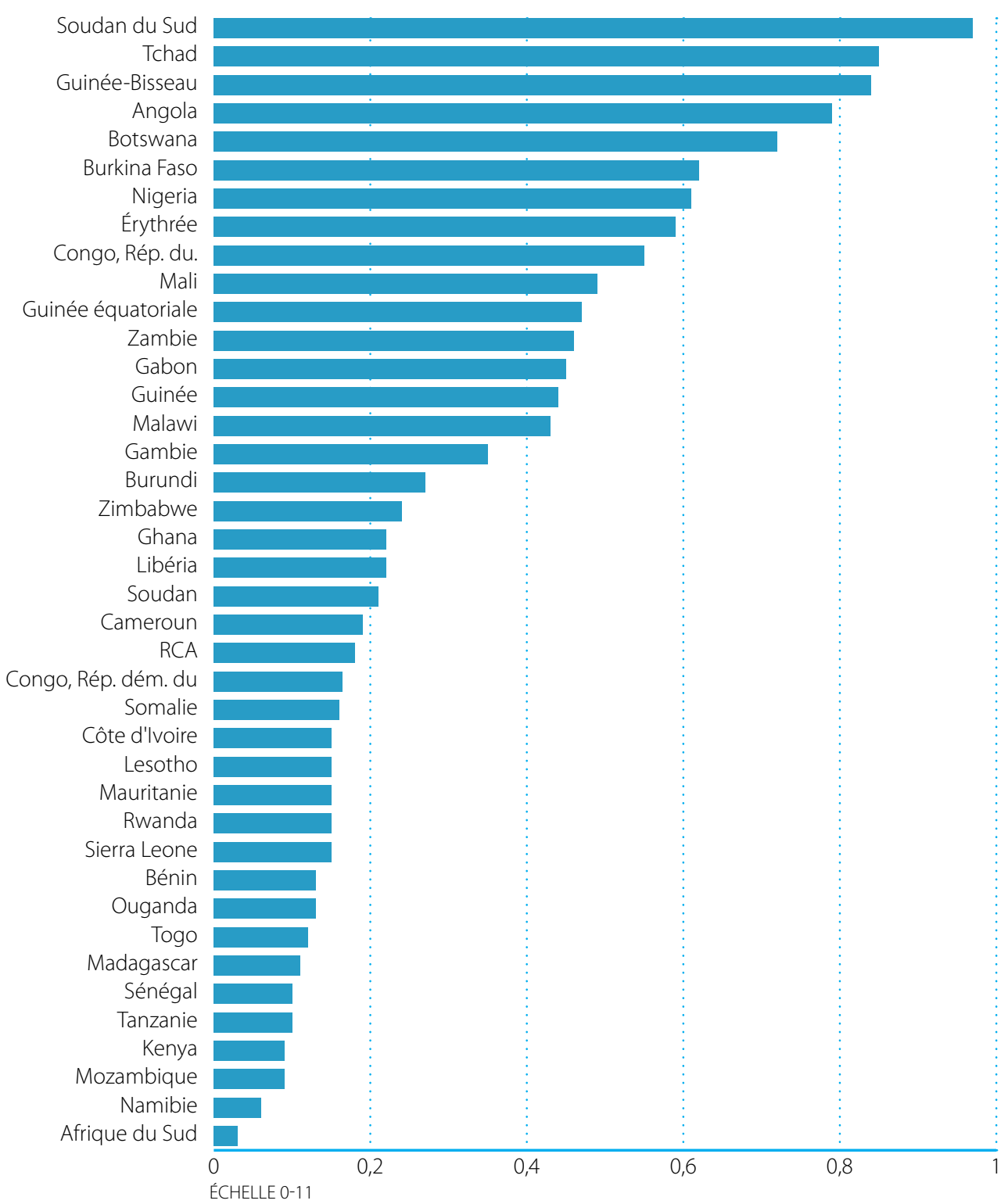

Source:: Calculs des auteurs. 
La croissance tend aussi à être déséquilibrée dans le cas des pays tributaires des ressources minérales ou lente et difficile à maintenir dans les pays agraires. II est particulièrement difficile de parvenir à une croissance induite par le commerce, qui réduit la pauvreté, dans les pays dont l'économie dépend fortement des produits de base. Les pays qui sont pour des raisons géographiques pénalisés par un manque de connectivité aux marchés régionaux ou mondiaux ont aussi du mal à diversifier leur production et à modifier la physionomie de leurs exportations. Les figures 5.1 et 5.2 offrent un aperçu des degrés de diversification dans différentes régions du monde en développement, exprimés par les indices de Herfindahl-Hirschman de concentration du marché. ${ }^{2}$

\section{Figure 5.2. Diversification des exportations dans certaines régions de pays en développement, 2017}

(à suivre)

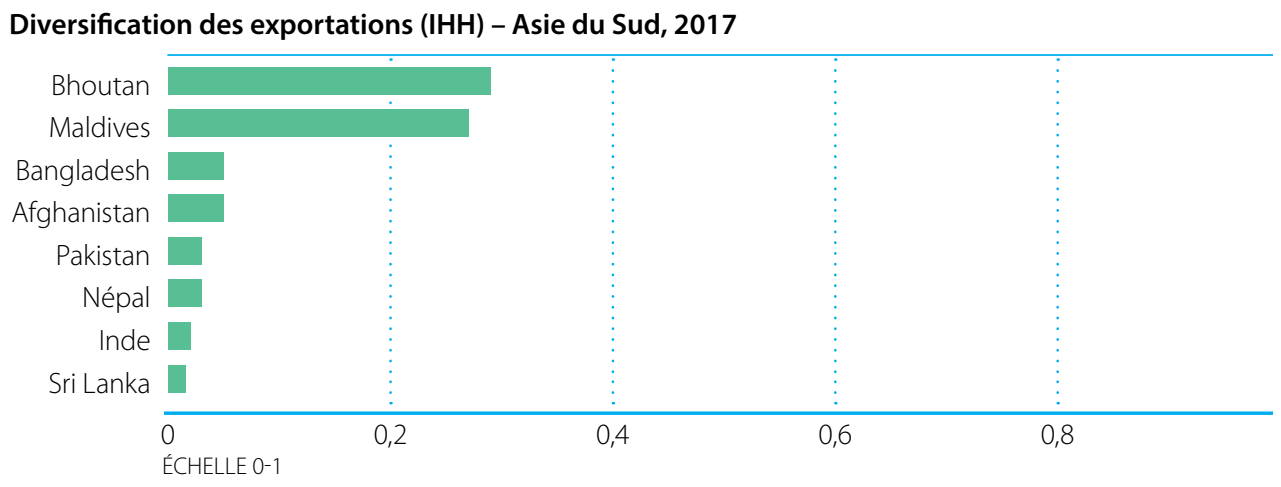

Diversification des exportations (IHH) - Europe centrale et orientale, 2017

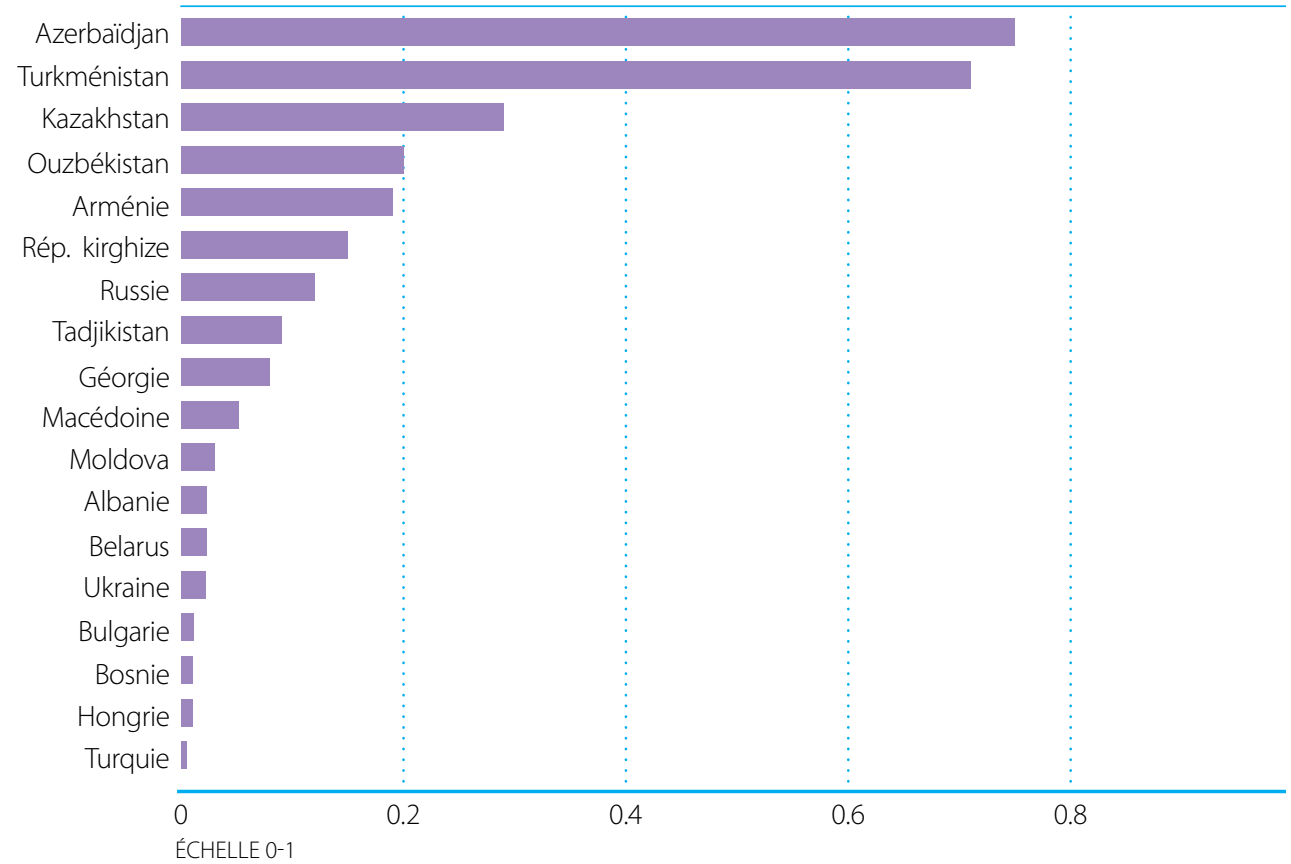


Figure 5.2. Diversification des exportations dans certaines régions de pays en développement, 2017

(à suivre)

Diversification des exportations (IHH) - Asie de l'Est et Pacifique, 2017

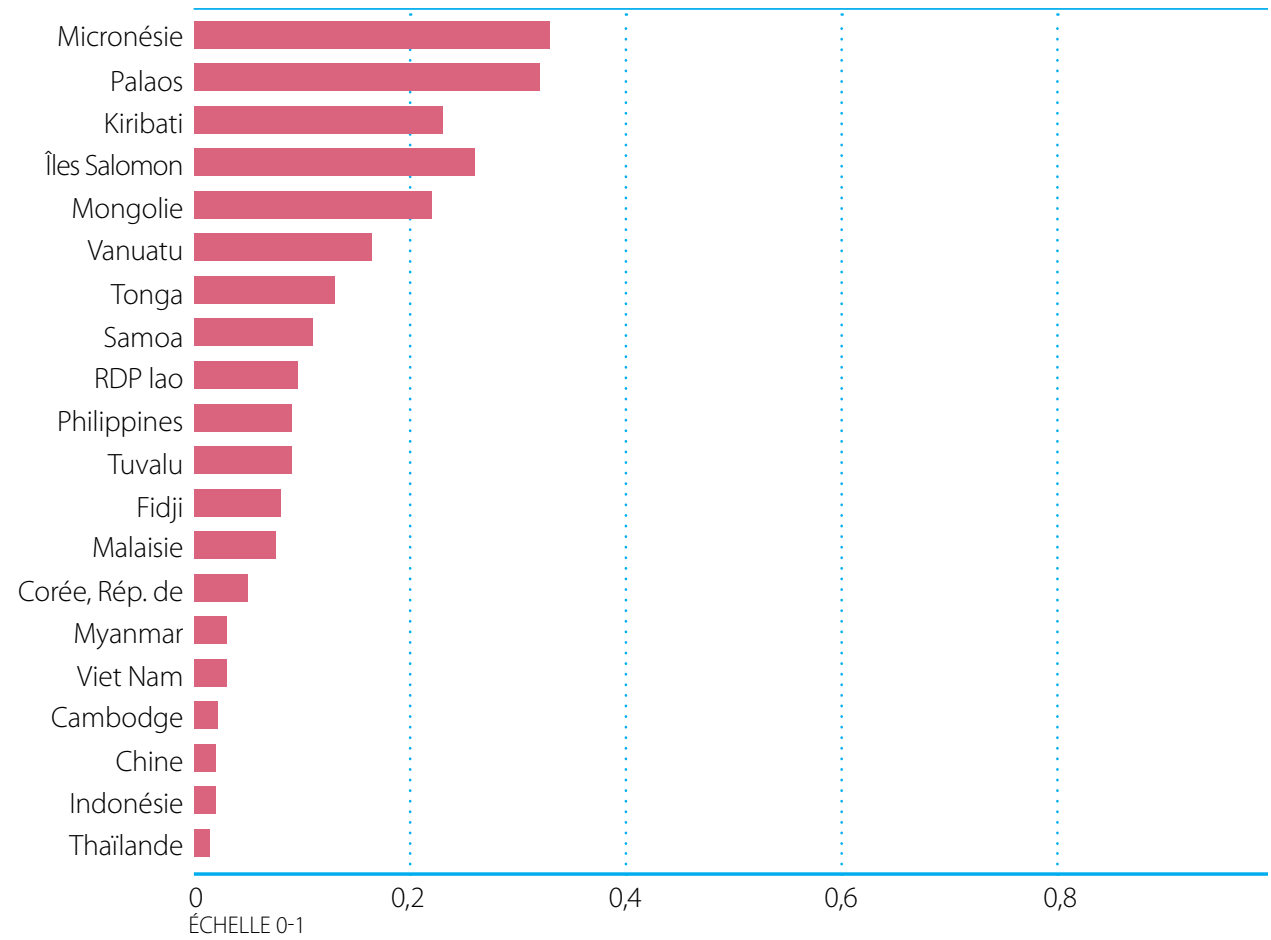

Diversification des exportations (IHH) - Moyen-Orient et Afrique du Nord, 2017

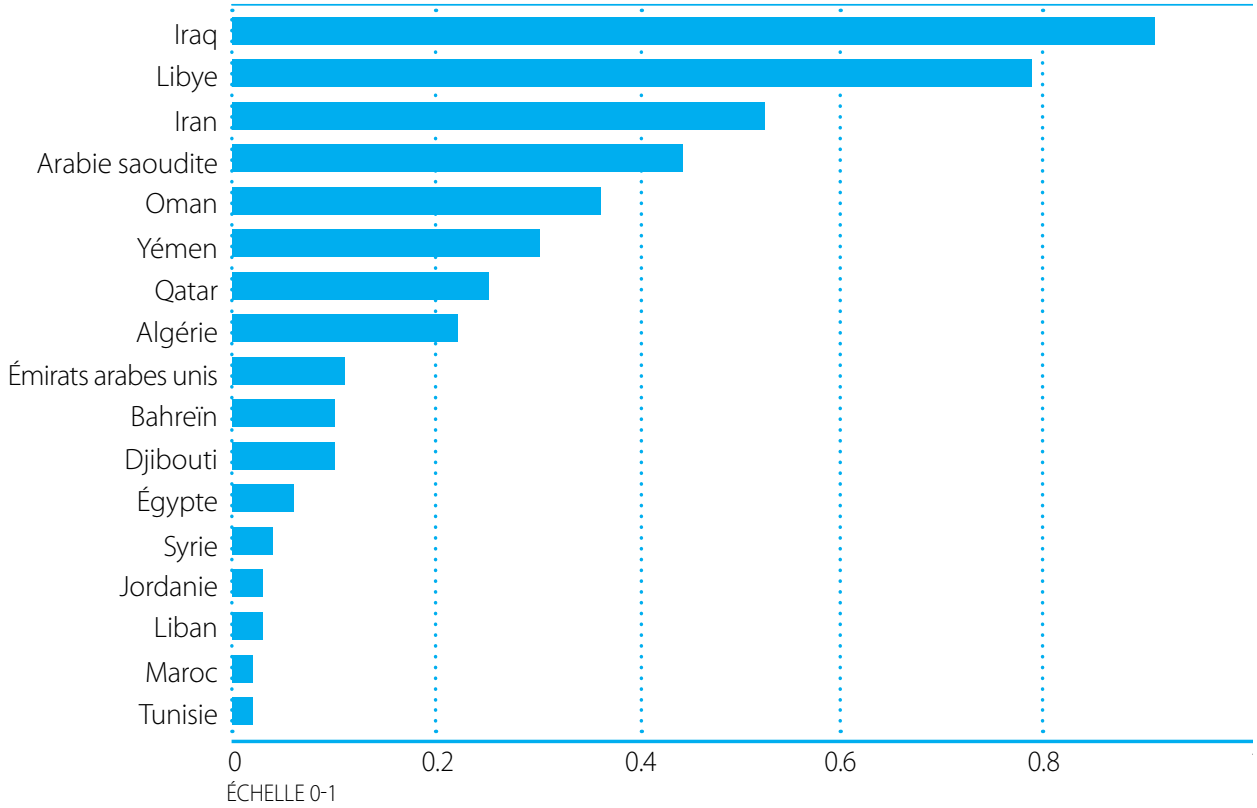


Figure 5.2. Diversification des exportations dans certaines régions de pays en développement, 2017

(suite de la page précédente)

Diversification des exportations (IHH) - Amérique latine et Caraïbes, 2017

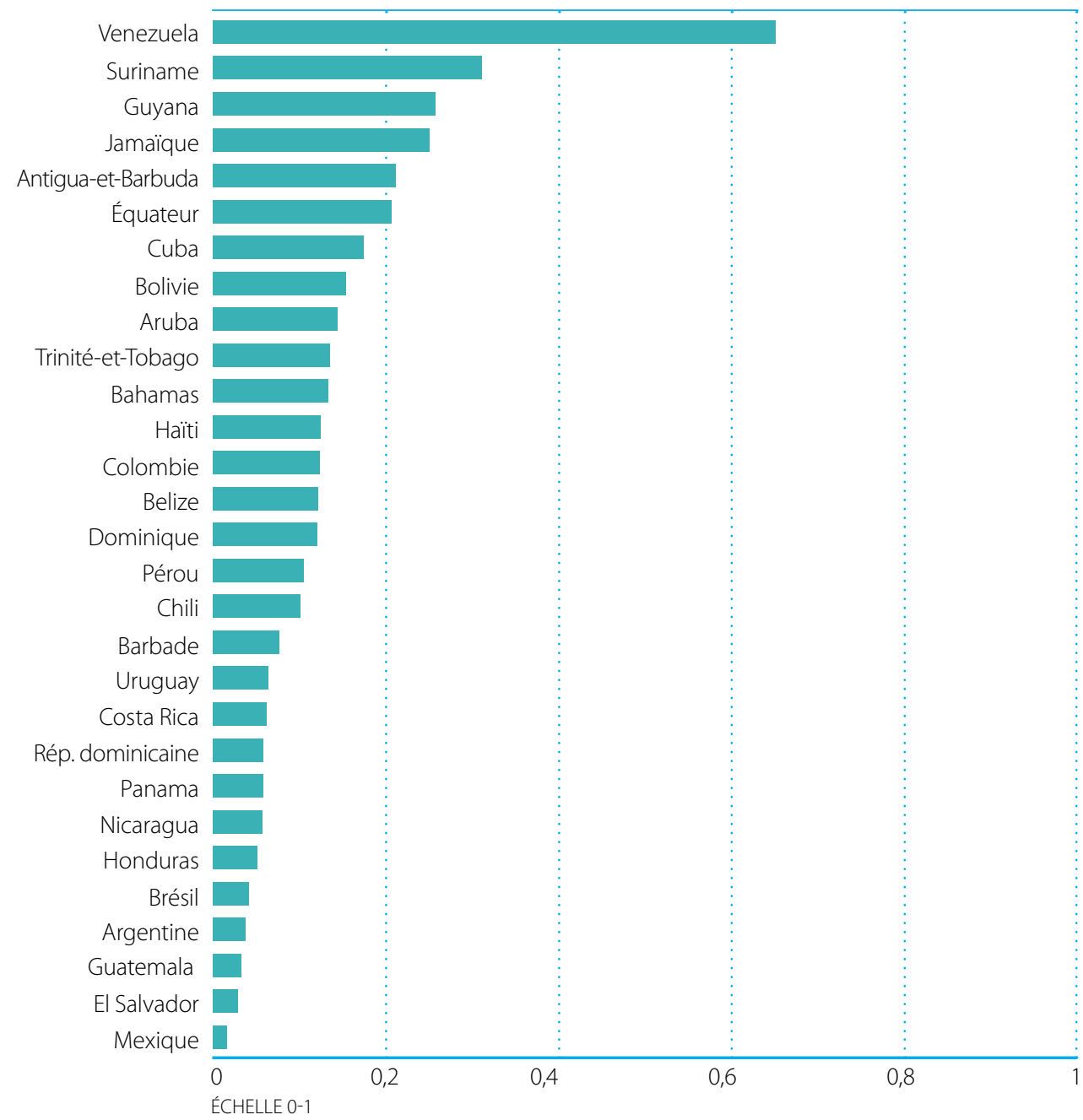

Source: Calculs des auteurs.

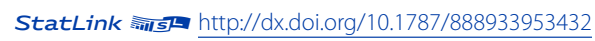

La diversification aide à gérer la volatilité et offre une voie plus stable vers une croissance et un développement équitables. Le succès de la diversification est d'autant plus important aujourd'hui que la croissance mondiale ralentit et que, dans de nombreux pays en développement, il devient impératif d'accroître la quantité et la qualité des emplois. L'expansion du commerce joue un rôle central dans la création de nouveaux emplois à plus forte productivité qui faciliteront la croissance grâce à la transformation structurelle. Pour favoriser une croissance durable, il est indispensable de passer des emplois à faible productivité, que l'on trouve principalement dans l'agriculture, à des emplois à plus forte productivité dans un ensemble d'activités essentiellement urbaines caractérisées par des économies de forte agglomération. Les pays est-asiatiques ont accompli cette transition dans les années 1990, en s'appuyant sur des exportations de produits manufacturés à forte intensité de main-d'œuvre. Pour de nombreux pays, le défi actuel consiste non seulement à accroître la production manufacturière à forte intensité de main-d'œuvre mais aussi à développer 
l'agroalimentaire, l'horticulture et certains services, autant d'activités qui sont à la fois à forte intensité de main-d'œuvre, échangeables et à valeur ajoutée. Si l'accroissement rapide de la population active offre à de nombreux pays en développement la possibilité de bénéficier d'un dividende démographique, il peut être difficile de concrétiser cette possibilité en l'absence de diversification économique et de croissance du secteur privé, lequel crée des emplois. L'action des pouvoirs publics demeure cruciale; elle passe par des investissements publics bien pensés et des réformes efficaces à l'appui d'une économie plus diversifiée.

La diversification économique et la transformation structurelle (déplacement des facteurs de production dans les différents secteurs et entre eux, vers des usages à plus forte productivité) sont des phénomènes étroitement liés. La transformation structurelle peut désigner le transfert de ressources de l'agriculture vers des secteurs non agricoles ou des activités manufacturières vers les services. Le déclin progressif du rôle de l'agriculture s'accompagnant d'une augmentation initiale puis d'un recul des activités manufacturières et d'une progression équivalente des services est une tendance générale et attestée dans de nombreux pays, qui fait partie intégrante du processus de développement économique (Herrendorf, Rogerson et Valentinyi, 2014). Cette tendance est sans doute beaucoup plus visible sur les marchés du travail mondiaux.

La part de l'agriculture dans l'emploi total se contracte dans tous les groupes de pays classés par revenu. À l'échelle mondiale, elle a diminué de près d'un tiers, passant de 44\% en 1991 à 28\% en 2018, un recul principalement imputable aux pays à revenu intermédiaire (voir figure 5.3). ${ }^{3}$ La part de l'emploi manufacturier a reculé aussi au niveau mondial et a enregistré une légère baisse, de 16\% en 1991 à 14\% en 2018, essentiellement du fait des pays à revenu élevé, où la robotique de pointe et l'adoption d'autres technologies économes en main-d'œuvre ont le plus progressé (Banque mondiale, 2017). Les secteurs où l'emploi s'est le plus développé ces dernières décennies sont tous en rapport avec les services, la construction, les services (publics) non marchands mais surtout de nombreux services marchands (OIT, 2019).

\section{Figure 5.3. Distribution de l'emploi par secteurs agrégés, dans le monde et par groupe de revenus, 1991 et 2018 (pourcentages)}

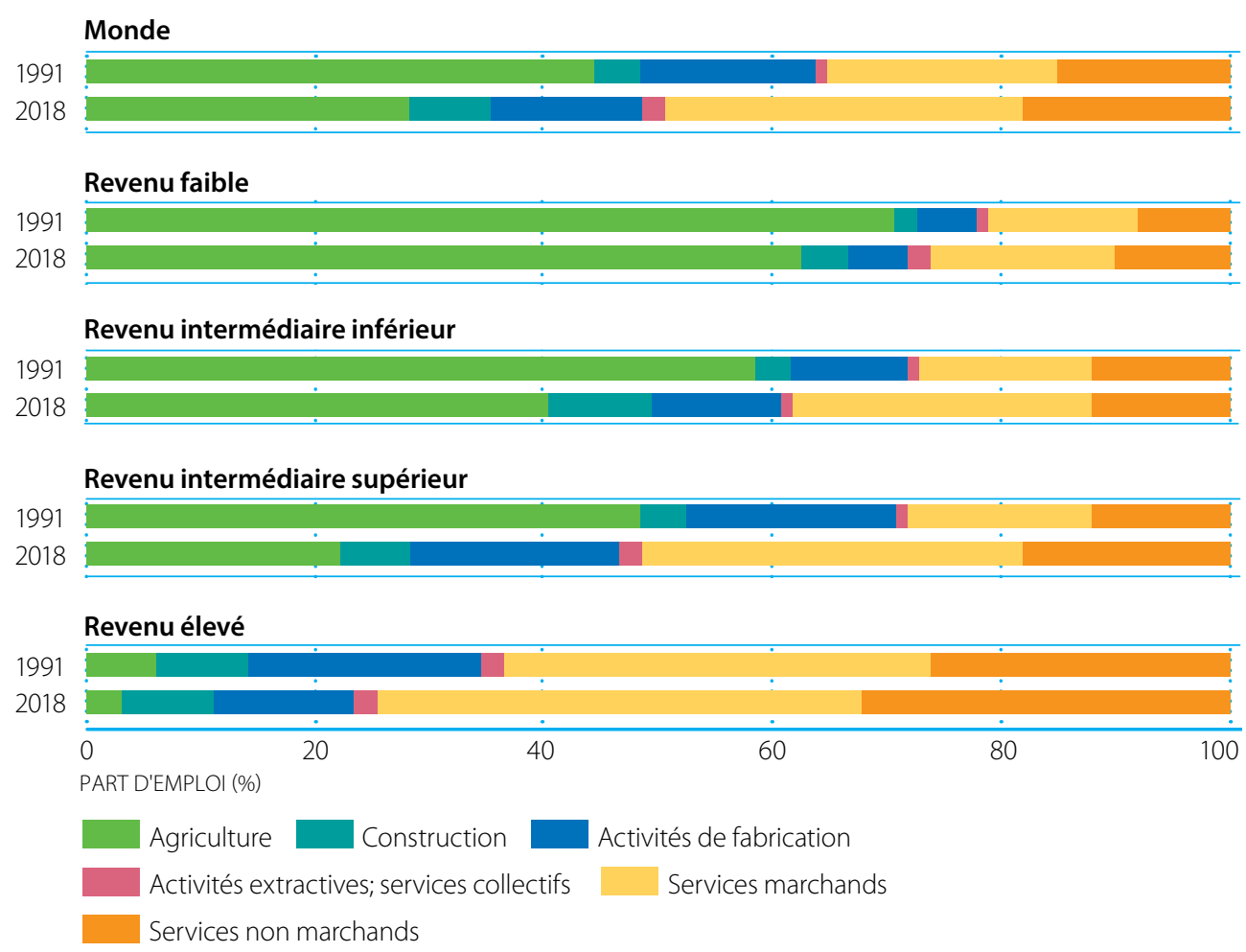

Source: OIT (2019). 
Les efforts de diversification économique donneraient des résultats plus manifestes si les nouvelles technologies et l'automatisation encourageaient la relocalisation de la production manufacturière dans les pays avancés. Mais le progrès technologique et la mondialisation créent aussi de nouvelles possibilités de réorienter les ressources à l'intérieur du secteur agricole vers des activités à plus forte productivité; en outre, les services tout comme les industries manufacturières peuvent être des moteurs de la diversification et de la transformation structurelle (Hallward Driemeir et Nayaar, 2017). Depuis quelques années, le poids économique des services a notablement augmenté dans tous les pays, quel que soit leur niveau de développement: le progrès technologique est le principal levier de la "servicification" de l'économie mondiale (Direction nationale du commerce, 2010).

\section{Encadré 5.1. Chili et Zambie: des trajectoires de diversification contrastées}

Le Chili et la Zambie sont deux pays disposant d'abondants gisements de cuivre, leur principal produit d'exportation. Ils ont également des populations de taille comparable mais diffèrent sensiblement sur le plan du revenu. Au Chili, le revenu par habitant (PPA) est supérieur à 21000 USD, contre à peine plus de 3800 USD pour la Zambie. II y a 50 ans, les 2 pays produisaient des quantités de cuivre similaires et leurs modèles de propriété des gisements de cuivre étaient également identiques, avec un rôle prépondérant joué par les entreprises publiques. Pourtant, leurs résultats économiques à moyen terme ont été très différents. Le Chili n'a cessé d'augmenter sa production de cuivre, tandis que celle de la Zambie stagnait, si l'on excepte le redressement amorcé depuis 2000. Alors que le Chili a progressivement diminué sa dépendance à l'égard de cette ressource, la Zambie en est plus fortement tributaire: le cuivre représente aujourd'hui 50\% des exportations chiliennes et $80 \%$ des exportations zambiennes.

Le Chili a suivi une stratégie de diversification selon deux axes: i) une diversification intrasectorielle (augmentation de la valeur ajoutée dans le secteur du cuivre en améliorant la qualité de l'extraction et en exportant les produits transformés et en développant à titre complémentaire des services annexes/logistiques nationaux); et ii) une diversification intersectorielle (développement de pêcheries pour l'exportation de saumon de grande qualité, augmentation des exportations de produits agricoles à forte valeur ajoutée: production de fruits, de légumes, de vins, etc.). Le Chili a également créé des mécanismes lui permettant d'épargner la rente tirée des minéraux et d'investir dans des dépenses essentielles pour la croissance. II s'agit plus précisément i) d'une règle d'excédent budgétaire structurel qui stérilise le niveau des dépenses du pays contre les fluctuations du cuivre, ce qui assure la stabilité macroéconomique et permet d'accumuler des richesses quand les prix du cuivre sont élevés; et ii) de fonds souverains pour administrer les rentes épargnées. Le Chili a investi une partie significative de cette épargne dans des formations de spécialisation (bourses permettant à des Chiliens de s'inscrire dans des universités internationales prestigieuses, par exemple) et dans le financement et le parrainage de jeunes pousses à forte croissance.

Contrairement au Chili, qui est bordé de côtes, la Zambie est un pays sans littoral pour lequel les coûts du commerce et du transport sont élevés. La croissance n'a pas été inclusive et la pauvreté y est endémique: on estime que 61,2\% de la population vit au-dessous du seuil de pauvreté national. Malgré une croissance soutenue et une grande stabilité politique, le niveau de vie des Zambiens n'a que peu progressé. La contribution de la croissance économique à la réduction de la pauvreté a été modeste, car les fruits de la croissance ont surtout bénéficié à la population qui vivait déjà au-dessus du seuil de pauvreté. Les principaux moteurs de la croissance - activités extractives, construction et services financiers - n'ont pas été très efficaces en termes de création d'emplois et d'élargissement des perspectives, à part pour la main-d'œuvre, relativement peu nombreuse, qui travaillait déjà dans ces secteurs. Pour la Zambie, par conséquent, la diversification économique demeure un objectif essentiel en vue d'assurer une croissance plus équitable, dans un contexte de baisse des prix du cuivre, et de créer des emplois pour sa population jeune et urbaine qui s'accroît rapidement.

Source: Meller et Simpasa (2011). 
L'innovation technologique dans les services tels que les communications mobiles et les services à valeur ajoutée qui y sont associés (commerce et paiements électroniques, par exemple), l'accès à l'informatique en nuage et le stockage de données modifient rapidement l'économie même de la fourniture de services et la géographie du commerce et de l'investissement dans le secteur. Baldwin (2018) décrit des technologies de "présence virtuelle" et de traduction automatique instantanée qui, dans le futur, pourraient permettre à des étrangers très qualifiés de proposer leurs services depuis des bureaux et des espaces de travail installés dans d'autres pays. Ces évolutions pourraient avoir des conséquences importantes sur le bien-être des ménages et en particulier des femmes; elles peuvent en effet considérablement augmenter la capacité des petites entreprises à être compétitives sur les marchés et à fournir de nouveaux produits en améliorant leur accès à l'information, ainsi que les possibilités de vendre des biens et des services à des clients/acheteurs à une échelle incomparablement plus grande. Les nouvelles technologies permettent à de petites entreprises de vendre leurs produits sur des marchés mondiaux et d'offrir leurs services à de plus grandes entreprises qui participent aux chaînes de valeur régionales et mondiales, ainsi qu'aux consommateurs du marché intérieur (ITC, 2018). Ces tendances illustrent la pertinence des débats en cours sur le commerce électronique et les micro, petites et moyennes entreprises (MPME) au sein de l'Organisation mondiale du commerce et leur importance croissante dans les accords commerciaux préférentiels (ACPr) de dernière génération.

En dépit des avantages qu'elle paraît présenter, tous les pays en développement ne recherchent pas la diversification et ils sont encore moins nombreux à avoir surmonté leur dépendance vis-à-vis des ressources naturelles et des produits de base ou à avoir triomphé des obstacles géographiques. Dans de nombreux pays en développement, le secteur des activités extractives influence la dynamique politique et inversement. Le fait que les dirigeants aient privilégié les rentes à court terme procurées par ces ressources naturelles en considérant leur distribution comme un gage de survie en politique les a parfois détournés des mesures et des investissements nécessaires à la croissance à long terme et a souvent attisé des conflits intérieurs, au détriment de la diversification. Certains pays riches en ressources naturelles sont toutefois parvenus à diversifier leur économie. Les pays riches en ressources peuvent taxer les rentes issues de l'extraction des matières premières pour financer des investissements essentiels dans le capital humain, l'infrastructure et les institutions. L'encadré 5.1 présente les trajectoires de diversification contrastées du Chili et de la Zambie.

\section{DÉFINIR LA DIVERSIFICATION ÉCONOMIQUE}

La diversification économique peut être définie comme la transition vers une structure plus variée de la production nationale et des échanges, en vue d'augmenter la productivité, de créer des emplois et de jeter les bases d'une croissance soutenue permettant de réduire la pauvreté. La diversification de la production nationale résulte du déplacement de la production entre les secteurs, les industries et les entreprises. Elle reflète la dynamique de la transformation structurelle, car la diversification réussie de la production nationale implique une redistribution intra et intersectorielle des ressources, des activités à faible productivité vers les activités à plus forte productivité. De son côté, la diversification commerciale s'opère de trois manières: a) exportation (ou importation) de nouveaux produits (biens ou services); b) exportation ou importation de produits existants vers ou en provenance de nouveaux marchés; et c) amélioration qualitative des produits exportés (ou importés).

La diversification commerciale, l'amélioration de la qualité et la diversification sectorielle de la production nationale sont fréquemment liées. Le commerce est souvent l'un des facteurs clés de la diversification économique. De fait, l'intégration dans l'économie mondiale est à l'origine du succès des pays est-asiatiques qui ont réussi à se diversifier dans les activités de fabrication, ce qui a entraîné un recul sans précédent de la pauvreté. La diversification des exportations constitue un objectif en soi pour réduire la vulnérabilité aux chocs commerciaux et stabiliser les recettes d'exportation et elle conduit à la diversification de la production. En effet, elle semble associée à une baisse de la volatilité de la production dans les pays à faible revenu, ainsi qu'à une réaffectation sectorielle plus rapide. Les données empiriques montrent aussi que la montée en gamme des produits d'exportation est étroitement corrélée avec un impact plus important de la diversification de la production nationale sur l'augmentation de la productivité (FMl, 2014). 
La diversification économique n'est plus simplement associée à la nécessité de faire émerger de nouveaux secteurs d'activité. Par le passé, l'accent était mis sur le développement de secteurs entiers et le déplacement des ressources entre les secteurs anciens (à faible productivité) et les nouveaux secteurs, à plus forte productivité. II fallait alors généralement investir dans tous les éléments de production du secteur concerné. Aujourd'hui, la diversification de l'économie emprunte de nombreuses autres voies.

En premier lieu, les efforts se portent de plus en plus sur les entreprises, leurs caractéristiques et leurs résultats, et sur le processus de réaffectation des ressources entre les entreprises à faible productivité et les entreprises à forte productivité, y compris au sein de secteurs d'activité existants. Par exemple, de très nombreux éléments semblent désormais montrer que, dans un même secteur, les entreprises exportatrices affichent des productivités et des salaires plus élevés que les autres. Deuxièmement, le progrès technologique et la baisse persistante des coûts de transport ont entraîné un éclatement de la production et l'apparition de chaînes de valeur régionales et mondiales où des activités et des tâches distinctes sont réalisées dans différents pays en fonction du lieu où il est le plus rentable de les implanter et de gérer la chaîne de valeur. Troisièmement, des réformes réglementaires proconcurrentielles et la baisse des coûts de communication ont permis aux pays en développement de participer beaucoup plus au commerce international des services, avec des activités caractérisées par une productivité relativement supérieure à celle des activités agricoles ou manufacturières traditionnelles. Dans le monde, sur cinq emplois occupés par des femmes, trois sont des emplois de service et la proportion est de quatre sur cinq dans les pays du G-20, qui représentent $80 \%$ du commerce mondial; la tendance à des formes de développement de plus en plus centrées sur les services s'accompagne ainsi de progrès importants en termes d'inclusion (Lan et Shepherd, 2018; Sauvé, 2019).

Les considérations qui précèdent nous rappellent qu'il ne suffit peut-être pas de se concentrer sur la production des secteurs manufacturiers pour identifier toutes les possibilités de diversification économique. En outre, du fait de l'éclatement des chaînes de valeur, les pays ne devraient pas uniquement chercher à exploiter les possibilités de produire ou d'exporter des produits finis mais aussi réfléchir aux perspectives offertes par les intrants intermédiaires. La diversification de la gamme et de la qualité des intrants importés peut aider à améliorer la qualité et doper la productivité dans les secteurs existants et permettre la conception de nouvelles variétés de produits. Les producteurs d'intrants peuvent envisager de densifier leurs chaînes de valeur (diversification des usages d'un produit existant) pour se créer de nouveaux débouchés et être mieux préparés en cas de choc lié à un produit en particulier. Cela ouvre le champ du débat sur la diversification mais indique aussi qu'il faut disposer d'un plus large éventail d'instruments pour mesurer la diversification.

\section{QUEL CADRE POLITIQUE ET INSTITUTIONNEL POUR LA DIVERSIFICATION?}

II n'existe pas de recette miracle pour diversifier une économie. En revanche, de multiples voies peuvent être suivies pour réussir la diversification. Dans les pays très peu développés sur le plan économique, la priorité est généralement d'asseoir l'économie sur des bases solides. Plus un pays se développe, plus les trajectoires de diversification économique qui s'offrent à lui sont nombreuses. L'économie de la Malaisie, par exemple, reposait auparavant sur les produits primaires. Aujourd'hui, elle est intégrée aux chaînes de valeur mondiales dans une large gamme de secteurs (manufacturiers, pour la plupart), a développé de nouveaux produits et pris pied sur de nouveaux marchés et son panier d'exportations contient davantage de produits plus élaborés. Le Chili a choisi de moderniser son secteur exportateur traditionnel dominé par les ressources naturelles (développement de services annexes et logistiques pour soutenir l'essor des exportations de cuivre), et de diversifier sa production nationale pour exporter de nouveaux produits agricoles (développement de la salmoniculture et des exportations de vins, par exemple). Après avoir longtemps exporté un nombre limité de produits de base agricoles (bananes et café non transformé), le Costa Rica a depuis quelques décennies axé sa stratégie de développement sur l'insertion dans les chaînes de valeur régionales et sur les mesures destinées à attirer I'IED nécessaire pour atteindre cet objectif. Récemment, le pays exportait plus de 4000 produits différents, en particulier 
des dispositifs médicaux et des composants informatiques ainsi que divers services à haute valeur ajoutée. Tout comme le Costa Rica, les Émirats arabes unis possèdent plusieurs atouts, parmi lesquels une administration efficace, un cadre macroéconomique stable, de bonnes infrastructures et une localisation privilégiée. Ils ont suivi une stratégie de diversification centrée sur l'exportation de nouveaux services aux entreprises, l'exploitation des externalités d'agglomération et la construction d'une plate-forme commerciale à bas coût (Gelb, 2010).

Partout, le programme de la politique du commerce et de l'investissement constitue le pivot de la stratégie de diversification économique. Il est essentiel de construire le socle de la transformation structurelle et d'une croissance tirée par le secteur privé pour pouvoir ensuite élargir les bases de l'activité économique. Aucun pays n'a pu afficher une croissance soutenue et obtenir une réduction importante de la pauvreté sans s'intégrer au préalable dans l'économie mondiale. Les partenaires du développement peuvent aider les pays en développement à mettre en place les éléments fondamentaux suivants

(i) un cadre incitatif approprié résultant de réformes des conditions de l'activité des entreprises et du climat de l'investissement: réexamen des politiques commerciale et d'investissement afin de supprimer les facteurs faisant obstacle aux exportations et garantie d'une concurrence efficace sur les marchés de produits et de facteurs et dans les services clés (transport, finance, énergie, communications, etc.);

(ii) des investissements et des réformes des politiques pour réduire les coûts du commerce: la baisse de ces coûts et l'efficacité de la logistique commerciale ont contribué de manière décisive à l'intégration réussie des pays est-asiatiques dans l'économie mondiale et à une diversification économique qui leur a permis de créer des emplois plus nombreux mais aussi de meilleure qualité;

(iii) des politiques efficaces favorisant l'ajustement et la réaffectation des ressources au profit des nouvelles activités et des nouveaux arrivants sur le marché du travail, en délaissant les secteurs en déclin et le secteur informel;

(iv) des interventions des pouvoirs publics ciblant certains dysfonctionnements du marché, des politiques et des institutions.

Cette démarche fournit une base d'analyse dont les pays peuvent se servir pour définir une stratégie et prendre les mesures indispensables à une diversification tirée par le secteur privé. Chaque pays devrait bien entendu suivre sa propre trajectoire pour élargir sa gamme d'activités commerciales et productives et faire en sorte qu'elle reflète ses atouts, ses avantages comparatifs et ses caractéristiques nationales: profil de la pauvreté, compétences disponibles, institutions, gouvernance et obstacles liés à l'économie politique. Cela se traduit généralement par une palette de mesures transversales, sectorielles et ciblées géographiquement qui varie selon les pays et qui est, dans l'idéal, définie en consultation étroite avec le secteur privé (national et étranger) et affinée régulièrement en fonction des progrès du développement. Ainsi, le processus de diversification d'un petit pays riche en ressources naturelles où les salaires sont élevés sera sans doute très différent de celui que suivra un grand pays riche en ressources naturelles où les salaires sont bas.

L'approche décrite ci-dessus prévoit aussi une programmation par étapes des mesures prioritaires. Chaque pays devrait tout d'abord créer un dispositif d'incitation, car il n'y a guère d'intérêt à investir massivement dans l'infrastructure pour réduire les coûts du commerce ou à concevoir des mesures pour accompagner l'affectation des ressources ou cibler des dysfonctionnements spécifiques du marché, si le cadre incitatif continue de présenter de multiples distorsions et que de nombreux facteurs entravent les exportations ou si les secteurs font face à d'importantes barrières à l'entrée sous la forme de droits de douane ou d'obstacles non tarifaires. Dans de tels cas, les politiques pourraient accentuer la mauvaise affectation des ressources. En revanche, dans les pays qui ont su se doter d'un dispositif d'incitation approprié et ont des services clés efficaces et des coûts du commerce relativement faibles, les pouvoirs publics peuvent davantage se consacrer à faciliter l'ajustement et cibler des dysfonctionnements plus spécifiques du marché. 
L'échelonnement des mesures visant à diversifier l'économie devrait aussi tenir compte des capacités de mise en œuvre des pouvoirs publics. Par exemple, les politiques industrielles sont souvent assez mal appliquées en raison de la relative méconnaissance des externalités et des répercussions qui justifient des interventions sectorielles spécifiques et du fait que ces interventions s'accompagnent d'un risque de corruption, de manipulation et de recherche de rente. Les pays aux institutions fragiles et dont la capacité à conduire des politiques complexes est restreinte (qui sont généralement des pays à revenu plutôt faible) prendront sans doute plus de risques en mettant en œuvre des politiques industrielles qu'en consacrant leurs ressources limitées à supprimer les freins à la diversification et à fournir des biens publics essentiels.

Les pays aux institutions fragiles doivent souvent relever des défis considérables sur le plan de l'économie politique quand ils mettent en œuvre leur stratégie de diversification. Dans les pays dont la base économique est restreinte, en particulier parce qu'ils sont dépendants de minéraux précieux, il est fréquent de constater que les activités politiques sont essentiellement influencées par des comportements de recherche de rente et d'exploitation des rentes économiques existantes. Malgré les arguments économiques solides plaidant en faveur des avantages à long terme de la diversification, un tel environnement complique la mise en œuvre des réformes économiques nécessaires. Une stratégie de diversification efficace doit donc reposer sur une connaissance approfondie du contexte politique, des principaux acteurs et de leur mode d'exercice du pouvoir, des institutions qui influencent la manière dont ce pouvoir est modéré et de l'incidence potentielle de facteurs extérieurs comme les institutions régionales et les partenaires tels que la Banque mondiale et d'autres organismes de développement. Pour de nombreux pays, le respect des règles de I'OMC, l'accession à l'organisme mondial chargé du commerce, les mécanismes d'intégration régionale et les accords préférentiels approfondis conclus avec des partenaires commerciaux essentiels peuvent représenter autant de facteurs d'ancrage puissants susceptibles de vaincre les résistances au changement. Les engagements contraignants qui en découlent contribuent à verrouiller les réformes indispensables à la diversification.

Une collaboration efficace entre les partenaires de développement et les organisations internationales est essentielle pour soutenir la mise en œuvre de la stratégie de diversification. Une série de questions appelle des interventions collaboratives, par exemple pour s'attaquer aux obstacles infrastructurels qui majorent les coûts du commerce et du transport, en coordination avec des réformes qui abaissent les barrières commerciales et intensifient la concurrence entre les prestataires de services liés à cette infrastructure pour le commerce. Pour que les réformes visant à corriger les dysfonctionnements des politiques soient efficaces, il faut évaluer soigneusement les restrictions ayant trait à la gouvernance et les obstacles liés à l'économie politique. L'efficience de la réaffectation des ressources entre les différents secteurs ou les différentes entreprises dépend entre autres choses des politiques du marché du travail et de l'accès aux financements.

\section{CADRE D'INCITATION À LA DIVERSIFICATION}

D'après l'expérience du Groupe de la Banque mondiale, qui conseille les gouvernements en matière de diversification économique, trois grands domaines interconnectés influent sur le cadre d'incitations économiques en faveur de la diversification. II s'agit: i) de la réglementation des activités commerciales et de la politique d'investissement; ii) de la formulation de la politique commerciale; et iii) de la politique de la concurrence.

\section{Réglementation commerciale et politique d'investissement}

Des règles commerciales qui soient à la fois claires, transparentes et prévisibles et assurent l'égalité des chances à tous les investisseurs (petits et gros, nationaux et étrangers) sont essentielles pour la diversification économique. Les règles qui régissent les marchés du crédit, l'embauche et le licenciement, les normes de qualité, les procédures et autorisations nécessaires pour créer une entreprise, le respect des contrats et l'insolvabilité constituent un volet essentiel du cadre incitatif visant à encourager l'investissement dans de nouvelles activités. Quand les conditions sont peu propices à 
l'investissement, le manque de fournisseurs nationaux compétitifs combiné aux inefficacités sur les marchés de facteurs et aux contraintes institutionnelles en matière de capacités entravent la diversification (Farole et Winkler, 2012). La réglementation des activités commerciales et le climat de l'investissement influent de trois manières sur les incitations à la diversification:

- en réduisant le coût des investissements dans de nouvelles activités et en permettant aux ressources de circuler plus efficacement des entreprises et des secteurs en déclin vers les entreprises et les secteurs plus dynamiques. Le délai et le coût de démarrage d'une entreprise peuvent freiner l'entrepreneuriat et restreindre la capacité des entreprises à tirer parti de nouvelles possibilités dans des secteurs existants ou émergents. De même, des régimes de faillite efficaces qui facilitent la sortie et encouragent la prise de risque constituent une incitation importante à entrer sur le marché. L'efficacité des règles d'entrée et de sortie peut aussi favoriser la concurrence entre les entreprises en place et les inciter à investir et innover. Les règles de sortie déterminent la rapidité avec laquelle les ressources piégées au sein d'entreprises non viables peuvent être réaffectées à des utilisations plus performantes. Des règles d'entrée restrictives pénalisent de façon disproportionnée les industries où l'expérimentation occupe une place plus importante, comme les secteurs à forte intensité de TIC (Andrews et Cingano, 2014; Aghion et al., 2006);

- en influant sur les activités commerciales courantes et les décisions d'investissement. Il s'agit notamment de la réglementation fiscale ainsi que de la réglementation des marchés du crédit et du travail. Lapplication uniforme de ces règles est importante pour une répartition efficiente des ressources entre les secteurs et entre les entreprises. Si des règles discriminatoires permettent aux entreprises moins productives de survivre et de prospérer au détriment d'entreprises plus productives, les efforts de diversification seront sans doute voués à l'échec (Bartelsman et al., 2010; Hseih et Klenow, 2009). Des résultats similaires peuvent être observés quand des entreprises inefficientes, y compris publiques, sont renflouées grâce à des pratiques de subventionnement induisant des effets de distorsion; et

- en favorisant la transparence et la prévisibilité des conditions de l'activité des entreprises et en réduisant es risques associés à l'essai de nouveaux produits et marchés. Le respect effectif des règles et l'existence de droits de propriété intellectuels bien établis permettent aux entreprises d'internaliser les avantages économiques de l'innovation, ce qui encourage l'investissement. Un cadre réglementaire transparent et non discriminatoire, y compris des lois assurant une protection appropriée des investisseurs, peuvent promouvoir l'investissement dans des activités plus risquées potentiellement rentables à long terme. Les études récentes sur l'incertitude de la politique économique tendent à montrer que la prévisibilité a des effets positifs sur l'investissement, en particulier dans les grandes entreprises et dans les secteurs où les investissements sont irréversibles (Baker et al., 2015; Bartelsman et al., 2010).

\section{Politique commerciale}

La nature et la structure de la protection sur les marchés étrangers déterminent les possibilités de diversification des exportations dans les pays en développement. C'est particulièrement le cas si la protection à l'étranger est biaisée en faveur de produits pour lesquels le pays concerné jouit d'un avantage comparatif. Par exemple, la progressivité des droits (effet en cascade des droits d'importation en fonction du degré de transformation) dans les pays développés a longtemps restreint les possibilités des pays en développement d'ajouter de la valeur aux produits agricoles et minéraux et de développer des activités annexes. ${ }^{4}$ De même, pour l'industrie légère, les droits d'importation sur des produits tels que les vêtements et les chaussures sont généralement beaucoup plus élevés que sur les tissus et le cuir. 
Dans une certaine mesure, cette contrainte a été atténuée par la libéralisation du commerce multilatéral dans le cadre de l'Organisation mondiale du commerce (OMC), qui a permis de réduire les crêtes tarifaires dans les pays riches, et par l'octroi de préférences tarifaires non réciproques aux pays en développement. Ces préférences tarifaires sont néanmoins souvent contrebalancées par des règles d'origine excessivement restrictives. II reste néanmoins un défi important à relever pour les pays en développement, en particulier les plus pauvres: exploiter plus efficacement les préférences commerciales pour favoriser la diversification des exportations.

L'intégration régionale et l'approfondissement du commerce Sud-Sud constituent également des mécanismes efficaces pour développer les débouchés commerciaux des entreprises exportatrices. II est souvent plus difficile de diversifier les exportations vers des marchés à revenu plus élevé que de diversifier les exportations vers les marchés régionaux. Les normes sont généralement plus strictes et il faut par conséquent des investissements plus importants pour améliorer la qualité et se conformer aux prescriptions en matière de santé et de sécurité (ITC, 2016). Les acheteurs des pays développés peuvent aussi demander l'expédition de très gros volumes, ce qui nécessite des investissements substantiels pour augmenter les capacités. C'est pourquoi la diversification à travers les exportations vers des pays voisins où les préférences des consommateurs sont similaires et les prescriptions réglementaires comparables - et par conséquent les coûts de mise en conformité potentiellement inférieurs - peut s'avérer plus facile. C'est aussi le cas pour le commerce Sud-Sud. L'expansion sur ces marchés peut ensuite servir de tremplin à un pays donné pour élargir son accès au marché mondial, une fois qu'il a une plus grande expérience de l'exportation et une meilleure connaissance des prescriptions relatives aux produits sur les autres marchés.

Les droits d'importation peuvent faire obstacle à la diversification des exportations et à l'intégration durable dans les réseaux de production régionaux ou mondiaux. Le niveau de protection des importations détermine les incitations à produire des biens exportables en relevant directement le prix intérieur des importations par rapport aux exportations. On connaît depuis longtemps la symétrie (ou l'équivalence) qui existe entre les effets d'un droit d'importation et ceux d'une taxe à l'exportation sur les prix relatifs intérieurs. Les droits d'importation influent aussi indirectement sur le prix des exportations par rapport au prix des produits (non échangés) fabriqués uniquement pour le marché intérieur. Comme un droit majore le prix des importations, les consommateurs reportent leur consommation sur des biens ne faisant pas l'objet d'échanges internationaux et font augmenter leur prix si ces deux types de biens sont des substituts. Par conséquent, un droit d'importation minorera le prix des exportations par rapport au prix des biens non échangés et détournera la production des exportations. En outre, les droits sur les intrants intermédiaires utilisés par les exportateurs en l'absence de systèmes de ristourne de droits efficaces augmentent le coût de production des biens destinés à l'exportation et, par conséquent, réduisent la production des biens échangeables. Les droits sur les intrants intermédiaires sont un élément crucial pour une participation fructueuse aux chaînes de valeur régionales et mondiales.

Il est également important de se pencher sur les mesures non tarifaires dans le cadre d'une stratégie de diversification. Les règles et réglementations sur les marchés étrangers qui régissent certaines questions comme les procédures à la frontière, les règlements techniques et les normes, peuvent accroître les coûts du commerce et limiter l'entrée de nouveaux exportateurs, en particulier lorsqu'elles sont conçues et/ou mises en œuvre d'une manière discriminatoire pour le commerce. Le manque d'information et les incertitudes concernant les prescriptions applicables aux exportations peuvent diminuer les chances de survie des entreprises exportatrices. Les normes peuvent faciliter les exportations et la montée en gamme des produits en codifiant les prescriptions incontournables pour pouvoir exporter vers des marchés où les attentes en termes de santé, de sécurité et de qualité diffèrent de celles du marché intérieur. Les mesures non tarifaires qui freinent les importations vers le marché intérieur peuvent aussi pénaliser les exportations en limitant la concurrence entre les fournisseurs d'intrants essentiels et donc l'accès aux nouvelles technologies. L'OMC prévoit les disciplines nécessaires pour régir les mesures réglementaires discriminatoires et établit un cadre permettant de contester, au titre de l'Accord OTC, les réglementations qui imposent une discrimination arbitraire aux fournisseurs et, au titre de l'Accord SPS, les mesures non fondées sur des données scientifiques qui concernent la sécurité sanitaire des produits alimentaires, la santé animale et la préservation des végétaux. 
Plus récemment, l'Accord de I'OMC sur la facilitation des échanges a mis en place un mécanisme pour l'adoption à l'échelle mondiale des meilleures pratiques relatives aux procédures douanières ainsi qu'un cadre permettant de contester les pratiques discriminatoires. Les accords commerciaux préférentiels qui comportent des dispositions sur I'harmonisation ou la reconnaissance mutuelle des normes de produits peuvent aussi contribuer à réduire les coûts associés à la diversité réglementaire et appuyer la diversification.

\section{Encadré 5.2. Rwanda: trajectoire de diversification des exportations}

Le cadre de politique générale du Rwanda lui a permis de diversifier avec succès ses exportations tout en augmentant la valeur des exportations traditionnelles de produits de base. Le Rwanda a réussi à accroître ses exportations d'environ 20\% par an entre 2000 et 2016. Pendant cette période, le secteur exportateur est devenu moins tributaire des trois produits d'exportation traditionnels: le thé, le café et les minéraux. Si la part de ces produits dans les exportations a chuté de $41 \%$ à 25\%, en valeur, leurs exportations a plus que triplé, passant de 415 millions à 4125 millions d'USD. La politique commerciale axée sur l'ajout de valeur a permis d'atténuer les effets des fluctuations des cours mondiaux des produits de base. Par exemple, dans le secteur du café, la stratégie du gouvernement visant à améliorer la qualité du produit a abouti, pour certaines variétés, à un quintuplement du prix au producteur. Ces efforts ont aidé à compenser les baisses des cours mondiaux intervenues entre 2011 et 2015. En continuant de créer de la valeur ajoutée, le Rwanda a posé les bases qui ont permis la hausse des revenus agricoles après la remontée des prix des produits de base.

De même, le Rwanda s'est transformé en une économie de services, l'objectif étant de pallier l'absence de littoral du pays en le transformant en un pôle régional pour les services professionnels et les services aux entreprises. Les recettes d'exportation rwandaises proviennent déjà pour moitié des services, le tourisme lié à l'observation des gorilles des montagnes arrivant en tête, suivi des transports, des TIC, de la construction et de la finance. En même temps, I'amélioration de la qualité et l'élargissement de la gamme des services utilisés comme intrants contribuent très largement à ce que les exportations de marchandises du pays soient plus compétitives.

Le secteur industriel rwandais (hors minéraux) a également commencé à exporter, en particulier la filière agroalimentaire. Bien que la part de l'industrie légère dans les exportations soit restée globalement constante, la valeur des exportations a quadruplé depuis 2005, suite à la hausse des exportations dans un certain nombre de nouveaux secteurs, dont les vêtements et les articles en cuir, les appareils mécaniques et les boissons.

Les marchés régionaux ont joué un rôle important dans les efforts de diversification du Rwanda. Le pays a vu son commerce intrarégional de marchandises augmenter considérablement après son accession à la Communauté de I'Afrique de l'Est (CAE) en 2009, ce qui est largement dû à l'amélioration de la connectivité aux ports de Mombasa (Kenya) et Dar es-Salaam (Tanzanie). Bien que le conflit en République démocratique du Congo (RDC) ait limité le commerce jusqu'en 2007, la plus grande stabilité régionale s'est traduite par une nette reprise des relations commerciales. En 2016, le Rwanda exportait plus de marchandises et de services vers la RDC que vers la CAE.

Source: Banque mondiale (2019).

Les politiques relatives au commerce des services peuvent stimuler la diversification grâce au développement des exportations de services. Elles peuvent aussi promouvoir la diversification des exportations de marchandises en améliorant l'accès à une gamme élargie d'intrants de services produits de manière plus efficiente. Les coûts élevés de l'énergie, des télécommunications, de la logistique et des finances nuisent à la compétitivité des entreprises et les empêchent de diversifier leur production et leurs exportations. À mesure que les pays se développent, la libéralisation du secteur des services peut aider les entreprises à répondre aux besoins en approvisionnement, à se diversifier et à s'intégrer dans les chaînes de valeur régionales et mondiales sur les marchés des marchandises comme des services. Des services efficaces sont également essentiels pour tirer parti des circuits de distribution modernes. Par exemple, les producteurs utilisent de plus en plus le commerce électronique pour vendre directement leurs produits aux consommateurs via des points de vente en ligne. La diversification vers les exportations de services peut toutefois être entravée par l'hétérogénéité des 
réglementations, qui a une incidence sur le coût fixe de l'entrée sur un nouveau marché ainsi que sur les coûts variables liés à la desserte de ce marché (Kox et Nordas, 2007). En vue de résoudre ce problème, les réformes du secteur des services devraient non seulement être axées sur l'ouverture des échanges mais aussi se concentrer sur la simplification, I'harmonisation, le rapprochement ou la reconnaissance mutuelle des réglementations nationales (Gari, 2018; Polanco Lazo et Sauvé, 2017).

La trajectoire de développement suivie dernièrement par le Rwanda illustre les avantages qui peuvent résulter pour toute l'économie d'une volonté déterminée de privilégier la diversification et la valeur ajoutée en les plaçant au centre de la politique commerciale (voir encadré 5.2).

\section{Politique de la concurrence}

La politique de la concurrence joue un rôle important dans l'essor d'un secteur privé efficace et diversifié. Au-delà de la mise en place d'un cadre juridique régissant la lutte contre les positions dominantes, la collusion et la concurrence déloyale ainsi que les enquêtes antitrust, elle traite aussi des moyens de faire respecter la loi, de la défense de la concurrence et de l'efficacité des institutions. Les comportements anticoncurrentiels peuvent sérieusement restreindre la portée et l'efficacité des incitations à innover et diversifier (voir figure 5.4). Des lois antitrust et sur la concurrence claires, appliquées de manière effective et prévisible, sont nécessaires pour compléter les réglementations qui permettent aux entreprises d'entrer sur le marché et de soutenir la concurrence. S'ils ne sont pas détectés, les ententes et les abus de position dominante peuvent faire augmenter les prix et dissuader les entreprises d'investir dans des produits nouveaux ou de meilleure qualité. Des données empiriques montrent qu'en moyenne une intensification de la concurrence sur le marché encourage l'innovation. En plus d'inciter davantage les entreprises à se lancer dans l'innovation de procédé", promouvoir la concurrence encourage également l'innovation de produit".

\section{Figure 5.4. Politique de la concurrence et diversification économique}

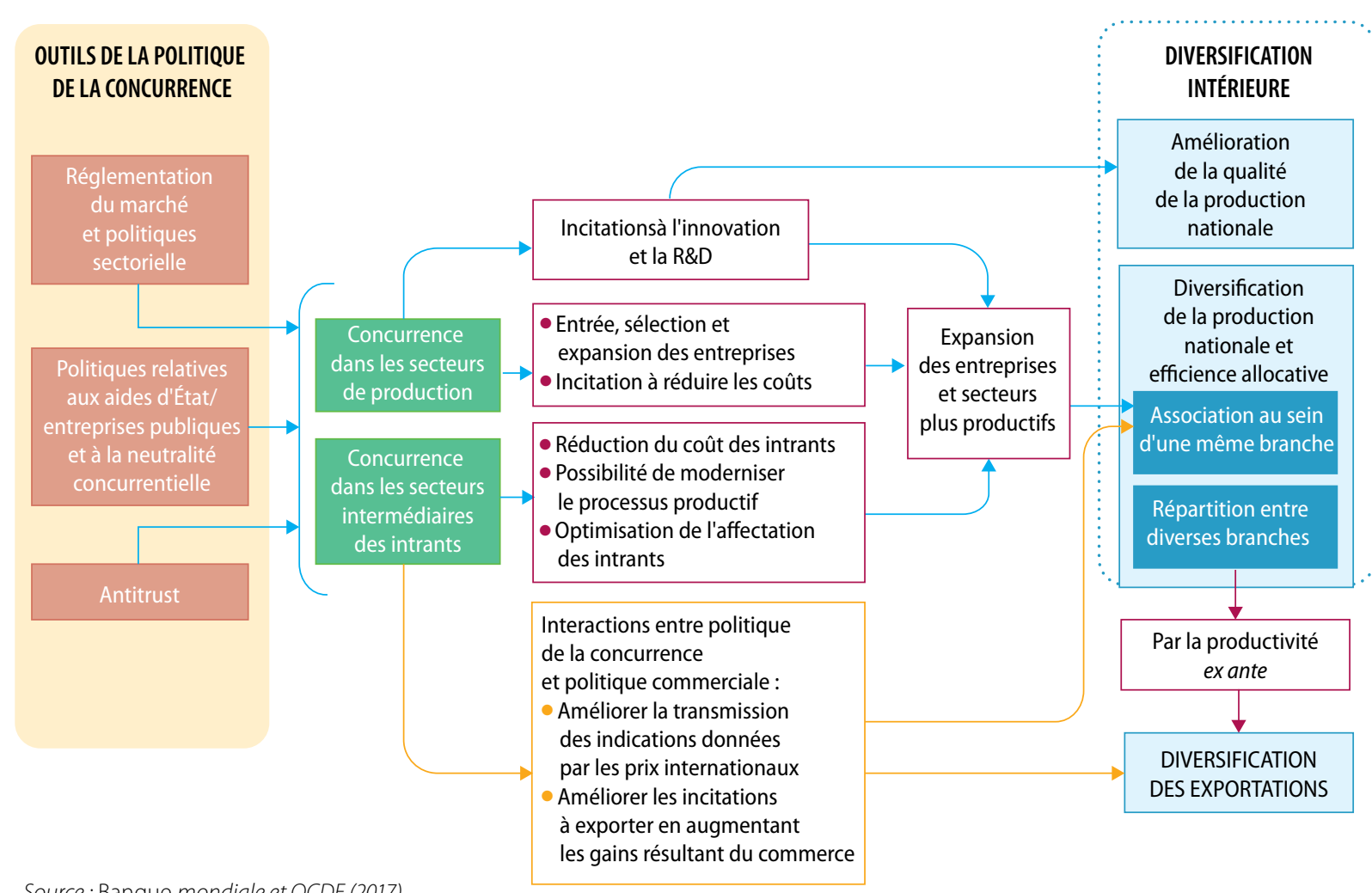

Source: Banque mondiale et OCDE (2017). 
La politique de la concurrence peut aussi soutenir l'"innovations de rupture", par exemple dans les secteurs de services utilisant les technologies mobiles. Elle peut aussi amplifier l'impact des programmes d'innovation sur la diversification économique. Au Moldova, par exemple, l'introduction de principes de concurrence (critères d'attribution transparents) dans les programmes d'incitations en faveur de la recherche-développement a réduit le biais de sélection qui avantageait les entreprises connectées, permettant à de jeunes pousses moins connectées d'accéder à ces programmes. L'application de règles qui garantissent la neutralité concurrentielle avec les entreprises publiques peut aider les entreprises à entrer sur un marché, à s'y développer et à se diversifier en fonction de leurs propres avantages. En revanche, les règles qui établissent des discriminations à l'égard de certaines entreprises et privilégient des intérêts particuliers peuvent freiner la diversification économique. L'absence de volonté politique ou les facteurs limitant les capacités institutionnelles peuvent diminuer l'efficacité des réformes de la politique de la concurrence.

La politique de la concurrence peut aussi jouer un rôle essentiel en augmentant l'efficience des branches de production nationales qui fournissent des intrants et peut soutenir la multiplication des liaisons en amont et en aval qui favorisent la diversification. Les réformes qui stimulent la concurrence sur les marchés d'intrants ont des retombées sur les entreprises en aval. Dans de nombreux pays en développement, les marchés d'intrants (engrais, ciment, énergie, financements, télécommunications, etc.) sont souvent pénalisés par des obstacles à l'entrée et des comportements anticoncurrentiels en raison d'économies d'échelle, d'effets de réseau et de la présence d'entreprises publiques.

Favoriser une concurrence plus intense entre les fournisseurs de services peut se révéler particulièrement efficace pour faire baisser les prix à la consommation et à la production. Si divers autres facteurs (petite échelle, garanties moins importantes sur les actifs incorporels, accès insuffisant aux financements, carences de la réglementation) réduisent l'efficacité du secteur des services, des études montrent que les gains résultant d'une concurrence et d'une efficience accrues pourraient être importants. Le développement du commerce des services présente un double avantage: les exportations de services représentent une source potentiellement importante de recettes en devises qui soutiennent les efforts de diversification. Dans le même temps, les importations de services peuvent déboucher sur des conditions plus concurrentielles, une baisse des prix et une augmentation de la qualité, renforçant ainsi les gains d'efficience et la compétitivité du processus (Roy, 2019). D'après Hoekman et Shepherd (2015), l'exposition accrue des marchés de services à la concurrence améliore l'efficience allocative globale en créant des avantages substantiels pour les utilisateurs en aval, surtout dans l'industrie manufacturière. Sur la base de données internationales pour le monde et l'Afrique de l'Est, ces auteurs constatent qu'une inflexion de 10\% dans la politique des services (sous la forme d'une baisse de l'indice de restrictivité des échanges de services (IRES)) est associée à une hausse de 4,4\% des exportations de produits manufacturés dans un pays comme le Rwanda.

Réformer la politique de la concurrence peut avoir des effets tangibles sur la diversification, comme le montrent les exemples suivants:

- En Inde, les entreprises manufacturières en aval ont diversifié leur production après les vastes réformes dans le secteur des services des années 1990, qui encourageaient la concurrence sur des marchés d'intrants essentiels (libéralisation des marchés des télécommunications, du transport et de l'énergie, en particulier).

- Au Kenya, la réforme de la politique de la concurrence a joué un rôle central dans l'apparition des services bancaires mobiles. L'arrivée des opérateurs de réseaux virtuels mobiles dans le secteur bancaire a débouché sur l'offre de nouveaux produits, favorisé l'entrée de nouvelles petites entreprises et permis des progrès notables en matière d'inclusion financière.

- Au Honduras, la réforme de la politique de la concurrence a favorisé l'arrivée de nouvelles entreprises sur les marchés d'intrants agricoles (engrais et pesticides). Elle a supprimé les procédures discrétionnaires et ramené les délais d'enregistrement de 3 ans à 90 jours. Depuis l'adoption des réformes, 300 nouveaux produits ont été enregistrés et le prix de certains pesticides a chuté de $9 \%$. 
- Aux Philippines, la réforme de la politique de la concurrence dans le secteur du transport a empêché les entreprises en place de dissuader les nouvelles entreprises de desservir certains trajets. La réforme devrait permettre des économies non négligeables sur le plan des coûts logistiques. En outre, l'arrivée de nouveaux acteurs dans le secteur du transport maritime pourrait améliorer la qualité des services et promouvoir la diversification vers de nouvelles activités, comme les services de transport réfrigéré

\section{RÉDUIRE IMPÉRATIVEMENT LES COÛTS DU COMMERCE}

L'élément le plus important de la croissance à long terme du commerce est la réduction du coût d'acheminement des marchandises jusqu'au marché et l'approvisionnement des producteurs locaux en intrants au moindre coût. Pour les pays sans littoral et les petits pays insulaires, les coûts de transport peuvent majorer les coûts d'exportation et d'approvisionnement en intrants de parfois 50\%. Bien que la distance reste la principale composante des coûts du transport, l'absence de mesures de facilitation à la frontière, la fragmentation des chaînes d'approvisionnement et l'accès limité à des frets aériens ou des corridors de transport terrestre abordables sont autant de facteurs qui contribuent au coût élevé du commerce transfrontalier (Rastogi et al., 2014). Investir dans les infrastructures liées au commerce en coordination avec des réformes pertinentes et une meilleure gouvernance est capital pour contribuer à réduire les coûts du commerce et soutenir la diversification des échanges commerciaux. D'après des estimations concernant neuf pays d'Amérique latine, une baisse de 10\% des coûts moyens du transport se traduirait par une augmentation de plus de 10\% du nombre de produits exportés (Moreira et al., 2008). Dans les PMA, la priorité devrait être de garantir la mise en place des infrastructures portuaires, frontalières et intermodales de base. Les meilleures pratiques mises en œuvre dans le cadre de projets pour le commerce et le développement de la Banque mondiale et d'autres partenaires du développement montrent qu'il est important de coordonner les interventions liées aux infrastructures avec une Aide pour le commerce articulée autour: i) de mesures visant à simplifier les procédures à la frontière et à améliorer la prise en charge des négociants et des fonctionnaires, notamment par des formations et d'autres mesures de renforcement des capacités; et ii) de programmes visant à corriger les faiblesses institutionnelles et les problèmes de gouvernance dans les ministères en charge des questions commerciales et dans les services de dédouanement, par exemple en introduisant la gestion axée sur les résultats dans les organismes présents aux frontières.

Les services de logistique commerciale constituent un élément décisif pour la connectivité d'un pays avec les marchés régionaux et mondiaux et pour la compétitivité. La logistique commerciale a pris de l'importance avec la division de la production à l'échelle mondiale et la sensibilité croissante du commerce aux coûts du transport et de la logistique. Les décisions des entreprises au sujet du pays où elles vont s'installer, des fournisseurs auprès desquels elles s'approvisionneront et des marchés de consommation sur lesquels elles prendront pied sont toutes influencées par la qualité de la logistique. Par conséquent, le coût, la gamme et la qualité des services logistiques à la disposition des exportateurs peuvent définir la portée de la diversification des exportations. Une logistique lente et coûteuse, par exemple, peut empêcher des fournisseurs par ailleurs compétitifs d'entrer dans les chaînes d'approvisionnement en flux tendus. La qualité de la logistique commerciale est cruciale pour la compétitivité des activités qui dépendent d'intrants importés.

La logistique reste un domaine où l'amélioration des résultats peut soutenir les priorités de diversification des pays en développement. Les données empiriques disponibles paraissent indiquer que la concentration des exportations va souvent de pair avec une mauvaise logistique (Banque mondiale, 2017). De fait, une série d'études a montré l'importance de la logistique pour la compétitivité et pour l'essor des industries légères (vêtements, articles en cuir, produits agroalimentaires, etc.) qui peuvent être des moteurs de la diversification (Huria et Brenton, 2016).

Le secteur de la logistique commerciale se caractérise souvent par une fragmentation réglementaire et institutionnelle et un manque de coordination qui peuvent être aussi coûteux pour les chaînes d'approvisionnement que les coûts directs du transport. Ce secteur décline un large éventail d'activités qui inclut toutes les sortes de services de transport et 
une palette de services annexes, dont les services de transitaires, de distribution, d'emballage, d'entreposage, de gestion du transport et de conseil pour la chaîne d'approvisionnement. Les fournisseurs de services logistiques ont également besoin d'avoir accès aux principales infrastructures de transport (ports, aéroports, routes) de façon non discriminatoire et sont tributaires des délais et des coûts liés aux formalités à la frontière. Cela signifie que les services logistiques sont soumis à de multiples règles et règlements relevant de différentes autorités qui ont chacune des objectifs réglementaires différents et travaillent rarement en coordination. Cette fragmentation fragilise le réseau concerné, alourdit les coûts et diminue l'efficience. Elle aggrave également le désavantage concurrentiel que subissent certains pays en raison de leur localisation géographique.

Les réglementations qui favorisent une concurrence accrue dans le secteur logistique et une simplification des exigences requises pour atteindre des objectifs légitimes de politique publique peuvent réduire le coût de la logistique commerciale, améliorer la qualité, accroître la variété et donc soutenir une production et une base d'exportation diversifiées. Même si des obstacles importants subsistent dans un certain nombre de pays, les services de transport ont connu une certaine libéralisation dans les pays en développement, ce qui a diminué les obstacles qui limitent la participation étrangère ou établissent des discriminations à l'égard des fournisseurs de services étrangers. D'autres composantes de la chaîne des services logistiques (manutention de fret, transitaires, etc.) font toujours face à d'importantes barrières à l'entrée. En outre, le cadre réglementaire régissant le fonctionnement des services logistiques est fréquemment complexe. Bien qu'une réglementation soit souvent nécessaire pour atteindre des objectifs tels que la sécurité, elle peut être conçue de manière à protéger les intérêts des branches de production nationales. À cet égard, la pleine mise en œuvre de l'Accord de l'OMC sur la facilitation des échanges et le renforcement des engagements de libéralisation dans le groupe précité de services liés au transport et à la logistique revêtent une importance particulière, car ils sont complémentaires des politiques mises en œuvre.

\section{INTERVENTIONS CIBLANT CERTAINS DYSFONCTIONNEMENTS DU MARCHÉ, DES POLITIQUES ET DES INSTITUTIONS}

Pour soutenir efficacement la diversification économique, les interventions des pouvoirs publics doivent se fonder sur un dialogue fluide et une coordination étroite avec le secteur privé, tant national qu'étranger. II faut des dispositifs institutionnels appropriés pour obtenir des informations auprès du secteur privé sur les possibilités de diversification économique; sur les goulets d'étranglement existants qui empêchent un pays d'exploiter ces possibilités; et sur les actions concrètes et les politiques les plus à même de supprimer ces obstacles. De surcroît, les institutions doivent être capables de relever le défi consistant à prolonger les interventions dans le temps et à composer avec le risque de capture et de recherche de rente souvent inhérent aux interactions public-privé. Comme les capacités institutionnelles varient considérablement d'un pays à l'autre, les gouvernements doivent veiller à opter pour des politiques correspondant aux capacités existantes. Les types d'interventions des pouvoirs publics qui peuvent soutenir la diversification comprennent les éléments suivants.

\section{Organismes de promotion des exportations}

Les organismes et les initiatives de promotion des exportations peuvent remédier aux problèmes d'information qui gênent l'entrée des entreprises et leur survie sur les marchés étrangers. Les faibles taux d'entrée et/ou de survie des entreprises exportatrices peuvent s'expliquer par des asymétries d'information, par exemple des difficultés à obtenir des renseignements sur les normes de produits appliquées sur les marchés de destination. Le problème peut être atténué par une plus forte présence d'exportateurs du même pays travaillant sur les mêmes marchés d'exportation ou ayant davantage d'expérience dans l'exportation des mêmes produits. Quand ces renseignements sont difficilement 
accessibles, les organismes de promotion des exportations peuvent utilement combler les lacunes. Ces institutions peuvent notamment fournir les informations manquantes aux entreprises des secteurs non traditionnels, y compris si ces dernières n'exportent pas encore.

Le bilan des organismes de promotion des exportations est toutefois mitigé en ce qui concerne la promotion de la diversification. Bien que certains d'entre eux aient largement contribué à l'amélioration des résultats d'exportation des pays qui les financent, ces modèles ne sont pas toujours faciles à répliquer. Au vu des éléments disponibles, plusieurs caractéristiques contribuent à une promotion réussie des exportations. Premièrement, il faut que l'environnement politique ne décourage pas trop l'exportation (taux de change surévalué, droits de douane élevés constituant une protection théorique ou de fait, coût élevé des activités commerciales, etc.). Des procédures spéciales telles que les zones industrielles d'exportation ou les mécanismes spéciaux de financement des exportations peuvent protéger les exportateurs d'un cadre de politique commerciale défavorable, mais elles devraient peut-être comprendre des clauses d'extinction et des rétributions au lieu de choisir des bénéficiaires (Lederman et al., 2010). Deuxièmement, les organismes de promotion des exportations sont les plus efficaces lorsqu'ils fonctionnent de façon autonome et souple et maintiennent un dialogue ouvert avec le secteur privé pour accompagner une stratégie tirée par la demande. Troisièmement, mieux vaut financer les activités de promotion des exportations par les recettes générales que par des taxes sur les exportations.

\section{Organismes de promotion de l'investissement}

La politique d'investissement et les mesures de promotion peuvent soutenir la diversification en stimulant l'investissement étranger direct (IED). La bonne démarche consiste à s'abstenir de recourir à des prescriptions obligatoires relatives à la teneur en éléments locaux (Sauvé, 2016); à promouvoir la cohérence des politiques entre l'IED dans les entreprises locales et les incitations à investir, notamment au travers de programmes de développement bien conçus en faveur des fournisseurs (voir encadré 5.3); et à prévoir une série de "services après-vente" pour les investisseurs, y compris des services en lien avec d'éventuelles sources de tension entre les pays d'accueil et les entreprises étrangères (Groupe de la Banque mondiale, 2018). L'allégement des procédures pour la création d'entreprises de droit national à capitaux étrangers et des restrictions imposées aux arbitrages en matière d'IED vont de pair avec la hausse des stocks d'IED (Qiang et al., 2015). II est attesté que les règles relatives aux investissements internationaux, en particulier celles qui figurent dans les ACPr stimulent l'IED dans les pays participants. En revanche, les restrictions concernant les acquisitions étrangères, les discriminations en matière de licences, les restrictions relatives au rapatriement des bénéfices de même que des cadres juridiques insuffisants pour faire appel des décisions réglementaires peuvent facilement dissuader les investisseurs étrangers.

Le rôle de l'IED comme facilitateur de la diversification dépend du type d'investissement. Tous les investissements étrangers n'ont pas les mêmes retombées positives sur le reste de l'économie. En ce qui concerne le secteur minier, les liens sont moins nombreux que pour l'agroalimentaire. Les coentreprises réunissant des entreprises étrangères et des entreprises locales ont davantage de répercussions que les projets financés et gérés uniquement par des étrangers. Il en va de même pour les projets auxquels participent des investisseurs de pays voisins qui, en général, connaissent mieux le pays destinataire. Les publications sur le sujet distinguent quatre types d'IED: i) l'investissement visant l'exploration de ressources naturelles (centré sur l'exploitation des ressources naturelles); ii) l'investissement visant la conquête de marchés (pour desservir de grands marchés nationaux ou régionaux); iii) l'investissement de recherche d'actifs stratégiques ('investisseur veut se procurer des actifs stratégiques au moyen de fusions et d'acquisitions); et iv) l'investissement axé sur la recherche d'efficience du rendement (axé sur la production destinée à l'exportation). 
Encadré 5.3. Stimuler la montée en gamme des produits par des programmes de développement en faveur des fournisseurs

Un moyen de plus en plus efficace de stimuler les exportations est d'approfondir la chaîne d'approvisionnement nationale de la valeur ajoutée. Dans la mesure où les produits des fournisseurs nationaux peuvent remplacer les importations qui sont actuellement incorporées aux exportations, l'augmentation de valeur ajoutée se retrouve dans les exportations. II est nécessaire, pour ce faire, d'augmenter la qualité des produits afin d'améliorer les liens entre les fournisseurs locaux et les grandes entreprises internationales "phares". C'est d'autant plus important que les entreprises phares ont souvent un cahier des charges précis pour leurs produits, que ce soit sur le plan technique ou de la qualité, et leurs exigences peuvent différer des certifications de qualité en général. Il est fréquent que les producteurs bénéficiant d'une notoriété internationale et ayant des marques à défendre demandent à leurs fournisseurs de respecter des normes privées supplémentaires liées à des normes relatives aux questions sociales ou environnementales, au travail, à l'égalité entre les sexes ou à la sécurité, qui peuvent être plus strictes que les prescriptions des législations nationales (ONUDI, 2013; Steenbergen et Sutton, 2017).

Un programme de développement en faveur des fournisseurs peut permettre de développer les chaînes d'approvisionnement nationales et promouvoir des retombées importantes dans les pays bénéficiaires de l'IED. ॥ faut pour cela réunir les grandes entreprises phares et les fournisseurs locaux potentiels - ce que les organismes de promotion de l'investissement peuvent parfaitement faire - puis proposer un soutien et des incitations supplémentaires pour que les fournisseurs bénéficient d'une formation appropriée et d'une assistance à la montée en gamme afin que leurs produits répondent aux exigences de qualité de l'entreprise phare. Le programme chilien propose un modèle prévoyant différentes façons de favoriser les chaînes d'approvisionnement nationales tout en soutenant le marché. ॥ évite les règles imposées (et non conformes aux règles de l'OMC) concernant la valeur ajoutée et vise en priorité à améliorer les liens commerciaux entre les PME et de gros clients étrangers en s'appuyant sur divers services de conseil en partenariat/mise en relation, des crédits bonifiés et d'autres incitations fiscales pour promouvoir les liens. Arraiz et al. (2013) ont établi que ce programme s'était révélé très efficace pour doper les ventes, l'emploi et les taux de survie des petits et moyens fournisseurs. Des programmes similaires ont été lancés en El Salvador, en Colombie et en Malaisie.

Comme il est indiqué plus haut, l'IED axé sur la recherche d'efficience est particulièrement propice à la diversification. Ce type d'investissement est généralement tourné vers l'exportation et met à profit les facteurs de production locaux pour réduire les coûts de production. II implique le transfert de savoir-faire en matière de production et de gestion et améliore l'accès aux réseaux de distribution et aux sources de financement. Les pays à faible revenu et à revenu intermédiaire qui parviennent à attirer les l'IED axé sur la recherche d'efficience réussissent mieux à diversifier leur structure d'exportation.

Au Honduras, par exemple, l'ED a contribué au décollage de l'industrie légère et à la diversification des exportations pendant la dernière décennie. Grâce à l'ED et les liens qu'il crée avec les entreprises nationales, le Mexique a développé son secteur aérospatial en moins de deux décennies, profitant de liens régionaux plus étroits (au sein de l'ALENA) pour faire entrer des producteurs locaux dans les réseaux de production continentaux du secteur.

L'impact de l'ED sur la diversification dépend aussi beaucoup du comportement du pays bénéficiaire. Les pays dans lesquels le niveau d'instruction est plus faible qu'ailleurs ou qui accusent un retard technologique plus marqué ont généralement plus de difficultés à recueillir les effets de l'investissement étranger entrant. L'impact de l'investissement étranger sur l'économie en général dépend en dernier ressort des conditions de l'activité des entreprises: toutes choses égales par ailleurs, les pays où la réglementation applicable aux entreprises est mieux pensée tendent à attirer plus d'IED. C'est la raison pour laquelle les investissements étrangers dans l'industrie minière chilienne, l'agriculture vietnamienne et le secteur informatique mauricien ont permis de diversifier davantage la production et d'améliorer la productivité des travailleurs et des entreprises, y compris dans les secteurs ne recevant pas d'IED. 


\section{Politiques d’aménagement du territoire}

Les politiques d'aménagement du territoire peuvent jouer un rôle important quand la croissance est mal répartie à l'échelle régionale et que certaines zones d'un pays sont à la traîne (Moreira et al., 2013). Ces politiques se fondent sur des interventions des pouvoirs publics qui sont destinées à stimuler le développement économique de certaines zones d'un pays en attirant des entreprises productives et innovantes. Les principales caractéristiques des politiques d'aménagement sont les suivantes: i) ciblage d'une zone en particulier; ii) adaptation au contexte et à l'histoire spécifiques d'une localité; iii) mesures visant à remédier aux problèmes de coordination entre les différents acteurs; et iv) participation fréquente des parties prenantes, à l'échelle nationale et locale, aux phases d'évaluation, d'élaboration et de mise en œuvre. Ces activités peuvent être articulées autour de quatre types d'interventions: i) pôles de croissance; ii) zones économiques spéciales; iii) corridors économiques; et iv) grappes.

Les pôles de croissance s'articulent autour d'un site central où sont implantés une ou plusieurs industries essentielles ou un groupe d'entreprises. Ce noyau central correspond souvent à une ville ou une zone où d'importantes économies d'agglomération sont réalisées, ce qui permet aux entreprises dynamiques d'échanger et de diffuser les nouveaux savoirs, d'innover, de partager une réserve de main-d'œuvre qualifiée et des infrastructures, tout en réduisant le plus possible le coût de la fourniture de biens et de services publics. Dans les pôles de croissance, les investissements publics stratégiques dans l'infrastructure peuvent contribuer à révéler le potentiel économique de certains sites et avoir un effet catalyseur sur les secteurs situés en amont et en aval. Le surcroît d'activité économique, l'innovation et la croissance économique sont censés ensuite dynamiser l'économie dans les zones voisines, par la diffusion de ces activités.

Les zones économiques spéciales (ZES) ont été utilisées pour soutenir la diversification. Elles sont généralement créées en vue d'atteindre un ou plusieurs des objectifs suivants: i) attirer l'IED; ii) servir de "soupapes de décharge" pour atténuer le chômage de masse; iii) appuyer une stratégie plus vaste de réformes économiques; et iv) faire office de zones d'expérimentation pour la mise en œuvre de nouvelles politiques et démarches (Farole, 2011). Les ZES telles que les zones industrielles d'exportation ou les parcs industriels combinent habituellement des incitations financières (allégements fiscaux, subventions, etc.), des infrastructures (continuité de l'approvisionnement en électricité, par exemple), des mesures de facilitation des échanges (formalités douanières accélérées, accès en franchise de droits pour les intrants importés), un accès à la propriété foncière et une protection contre l'interférence de l'État, afin d'inciter une masse critique d'entreprises privées à démarrer une activité, à investir et à diversifier l'activité économique. Les données empiriques concernant leur efficacité sont toutefois mitigées. Les ZES atteignent leurs objectifs quand elles attirent des investissements qui exploitent une source d'avantage comparatif majeure, par exemple la main-d'œuvre bon marché dans les pays en développement. Ainsi, outre la Chine et la Malaisie qui ont eu de très bons résultats, d'autres économies comme la République dominicaine, le Honduras, la République de Corée, Madagascar, Maurice, le Taipei chinois et le Viet Nam ont constaté que les zones industrielles d'exportation avaient créé un grand nombre d'emplois manufacturiers. Cela étant, de nombreuses études ont également traité de l'échec des zones économiques spéciales qui n'avaient créé aucune activité économique (Lederman et Maloney, 2012). Le succès des ZES dépend de la souplesse de la méthode appliquée, qui ne doit pas se cantonner à des incitations fiscales, une réglementation limitée du travail et une modération salariale, mais doit aussi englober plus largement la création d'un cadre propice aux affaires, le renforcement de la compétitivité des entreprises, les liens avec l'économie nationale, l'innovation et la durabilité en matière sociale et environnementale.

Les corridors économiques se caractérisent par le raccordement de deux centres économiques au moyen d'infrastructures de connexion. L'objectif est d'exploiter et d'intensifier le potentiel de croissance du nœud situé à chacune des deux extrémités du corridor en encourageant l'agglomération des activités économiques entre les deux nœuds, le long de l'infrastructure matérielle les reliant. Les corridors économiques peuvent comprendre plusieurs nœuds plus petits et pourraient, dans certains cas, évoluer vers une structure ramifiée. Les corridors peuvent être 
essentiellement infranationaux (reliant des plates-formes infrarégionales, comme le corridor économique de Sulawesi, en Indonésie), nationaux, voire internationaux (comme le Corridor Est-Ouest reliant le Myanmar, la Thaïlande, la République démocratique populaire lao et le Viet Nam). La plupart des corridors sont multisectoriels, même s'il existe également des corridors propres à un secteur, celui de l'agriculture par exemple. ${ }^{5}$ Les interventions spécifiques de l'État en lien avec un corridor économique comprennent généralement des investissements publics et privés. Les investissements dans des infrastructures de transport (souvent multimodales) qui permettent de relier les deux nœuds économiques sont cruciaux. Les projets d'investissement dans le secteur privé, combinés à des réformes des politiques commerciale et réglementaire visant à améliorer les conditions globales de l'activité des entreprises du corridor, sont réalisés parallèlement à la création de l'infrastructure de base ou juste après. De plus, l'élaboration de plans de développement sectoriels peut aider à doper la compétitivité de certains secteurs d'activité représentés dans le corridor.

Les grappes sont des concentrations géographiques de sociétés et d'institutions interconnectées relevant d'un même secteur. L'industrie financière londonienne en est un exemple célèbre, comme la grappe informatique à Bangalore ou le secteur du cuir en Italie. En règle générale, une grappe se compose d'entreprises faisant partie du même secteur ou de secteurs étroitement liés ainsi que des mêmes réseaux de fournisseurs spécialisés et de prestataires de services; elle comprend aussi des infrastructures précisément adaptées aux besoins des entreprises et des industries qui la composent. L'une des caractéristiques essentielles des grappes est l'existence de liens de collaboration étroits entre toutes les parties prenantes (entreprises, associations professionnelles, organismes gouvernementaux, universités, centres de recherche, etc.). Au sein des grappes, les entreprises privées tendent à collaborer les unes avec les autres. Les mécanismes de collaboration peuvent consister à investir dans des instituts conduisant des recherches thématiques et produisant des connaissances qui contribuent à promouvoir le secteur au cœur de la grappe ou les secteurs connexes. La mise en commun des ressources pour améliorer la qualité des produits de la grappe, leur commercialisation et leur mise sur le marché constitue un autre exemple de collaboration. Il est fréquent aussi que les centres de recherche, les universités et les consultants locaux proposent des formations sectorielles spécifiques et des travaux de recherche fondamentale et appliquée dans le domaine concerné. Les organismes gouvernementaux peuvent soutenir la création d'infrastructures et d'un cadre réglementaire solide.

Dans les grappes qui fonctionnent bien, les entreprises peuvent bénéficier des économies d'agglomération décrites plus haut, avec la mise en commun des marchés du travail, des effets d'entraînement en amont et en aval et la diffusion des savoirs. Certaines grappes peuvent apparaître spontanément, par le simple jeu des forces du marché. Dans d'autres cas, en revanche, une planification et un soutien attentifs sont nécessaires pour qu'elles se forment et se développent, surtout dans les zones où la densité économique n'est pas suffisante ou celles où la coordination entre les parties prenantes est difficile en raison d'une densité limitée, d'une frontière technologique trop éloignée ou de carences institutionnelles. Des mesures doivent alors être prises par les pouvoirs publics pour inciter à créer de nouvelles grappes, renforcer les grappes nouvellement créées et permettre aux grappes existantes de continuer à se spécialiser. Encourager les plates-formes de réseaux pour améliorer la coordination et permettre la diffusion des connaissances, et investir dans des infrastructures et des programmes spécifiques pour favoriser la collaboration entre le monde universitaire et le secteur privé sont deux exemples d'interventions particulières des pouvoirs publics susceptibles d'amorcer la formation d'une grappe ou de relancer le dynamisme économique de grappes existantes. 


\section{POLITIQUES D'AIDE À L'AJUSTEMENT}

Le marché du travail est souvent un facteur clé du processus d'ajustement. L'ampleur et la vitesse des déplacements de main-d'œuvre d'une profession, d'une entreprise, d'une industrie et d'une région à une autre, ainsi que l'importance des coûts d'ajustement supportés par les travailleurs touchés, dépendent pour une bonne part du fonctionnement du marché du travail. En général, investir dans l'éducation et les compétences contribue positivement à la diversification économique, comme en témoignent la croissance du secteur des logiciels en Inde, la sophistication accrue des exportations chinoises ou encore l'augmentation des exportations philippines de services aux entreprises (Agosin et al., 2012). Des taux élevés d'inscription dans l'enseignement secondaire et supérieur ne sont toutefois pas forcément synonymes d'un apprentissage de qualité. L'acquisition des compétences dépend de la qualité des apports éducatifs et du ciblage des résultats escomptés. Les établissements d'enseignement secondaire et les universités peuvent produire des diplômés ayant peu de compétences différentes ou spécialisés dans des domaines ne correspondant plus à une forte demande du marché. Il est crucial de suivre de près la demande sur le marché du travail pour corriger l'inadéquation des compétences et soutenir la diversification économique. S'attaquer aux asymétries de compétences se révèle particulièrement déterminant pour assurer le décollage numérique.

II faut améliorer la coordination public-privé pour mieux identifier les compétences qui sont et seront recherchées sur le marché du travail. Bien que le niveau d'instruction des travailleurs progresse depuis 50 ans, les entreprises peinent toujours à trouver le personnel possédant les qualifications requises. De nombreux pays ont des systèmes d'éducation et de formation qui ne développent pas les compétences dont a besoin le secteur privé. II s'agit des compétences qui permettent aux entreprises de livrer les produits et les services demandés par les marchés, qui sont de plus en plus mondialisés. Par conséquent, la formation à plus long terme et la réforme du travail doivent s'accompagner de systèmes plus performants en termes de développement des compétences, en particulier la formation professionnelle. Ces systèmes doivent être connecté au secteur privé pour pouvoir proposer l'éventail des qualifications correspondant aux attentes changeantes du marché et recherchées par les entreprises susceptibles de créer de la croissance et de doper la productivité à proche et moyen termes.

Les inégalités hommes-femmes entravent les efforts de diversification. Des inégalités importantes dans ce domaine sont associées à des niveaux d'exportations plus bas et une moindre diversification de la production; en outre, les données disponibles semblent montrer qu'une faible diversification peut s'expliquer, entre autres, par un problème d'inégalité des sexes (Kazandjian et al., 2016). L'inégalité des chances, par exemple en matière d'éducation, limite la réserve de capital humain qui peut être un des moteurs de la diversification. La discrimination qui restreint la participation des femmes à la population active (limitation quantitative et sur le plan de la nature des emplois) réduit le réservoir de talents dans lequel les employeurs peuvent puiser. Elle limite également le nombre de femmes entrepreneurs. Lidentification et la suppression des disparités hommes-femmes ainsi que des obstacles existant dans l'éducation, la formation, l'accès aux financements et aux réseaux d'information et sur le marché du travail sont donc des composantes importantes de toute stratégie de diversification inclusive.

Le bon fonctionnement du secteur financier est un autre élément clé pour la diversification. Les instruments financiers, les intermédiaires et les marchés peuvent faciliter la négociation, la couverture ainsi que le partage des risques qu'encourent les entreprises quand elles choisissent de se diversifier. L'approfondissement des marchés financiers et la diversité des sources de financement proposées peuvent soutenir la diversification vers des marchandises plus élaborées et des gammes plus variées en permettant aux entreprises d'avoir accès à des capitaux à long terme et en finançant des investissements plus risqués. En Afrique, par exemple, le manque de profondeur des secteurs financiers a été un obstacle majeur aux efforts de diversification de l'économie, car les entreprises deviennent excessivement dépendantes d'un petit nombre de prêteurs ayant une aversion pour le risque, des banques en général. Les obstacles d'ordre financier incluent les procédures complexes de demande de crédit, l'absence de sûretés, les coûts d'emprunt élevés, le capital-risque insuffisant et les nouvelles sources de financement non bancaires, ainsi que les échéances courtes dans un contexte de faibles capacités financières qui empêchent les entreprises d'avoir accès aux financements. 
Les politiques favorables à l'innovation et l'entrepreneuriat et à la réaffectation des ressources aux entreprises innovantes peuvent jouer un rôle important en soutenant la transition vers une gamme plus large de biens et de services de meilleure qualité. Investir dans l'innovation augmente les capacités des entreprises, en facilitant l'adoption de nouvelles technologies qui améliorent la productivité et la qualité des produits. L'innovation en matière de produits et de procédés peut aider les entreprises à se diversifier en réduisant les coûts de production et en libérant des ressources qui pourraient être réorientées vers des activités innovantes.

\section{RÉFLEXIONS FINALES}

Il ressort de ce chapitre consacré aux défis de la diversification et aux trajectoires empruntées dans ce domaine par différents pays en développement qu'il n'existe pas de formule unique pour favoriser un processus ordonné de changements structurels capable de renforcer la résilience des économies face aux chocs extérieurs et d'offrir aux citoyens les possibilités d'emplois plus productifs dont ils ont besoin. Quel que soit le domaine concerné, les politiques doivent toujours être adaptées aux circonstances particulières, aux situations géographiques et aux dotations en ressources diverses ainsi qu'aux capacités institutionnelles, de gouvernance et de mise en œuvre contrastées des pays qui se trouvent à divers stades de développement. Le succès des efforts de diversification dépend en fin de compte de la combinaison, de l'échelonnement et du calendrier des investissements, des réformes de politique et du renforcement des institutions, ainsi que de leur cohérence avec les ressources sous-jacentes et les avantages comparatifs correspondants de chaque pays. Les investissements dans les compétences, les infrastructures, les institutions et la qualité de la gouvernance - c'est-à-dire l'amélioration de la transparence, de la responsabilité et de la prévisibilité dans le processus décisionnel gouvernemental - augmentent les chances de réussite de la diversification et sont à leur tour impactés par l'ampleur de la diversification

Chaque pays emprunte un chemin différent pour se diversifier, mais les exemples concluants de changement structurel tiré par le commerce font ressortir plusieurs aspects communs. L'expérience de divers pays montre que les éléments ci-après sont des moteurs de réussite importants dans les efforts de diversification:

(i) un niveau élevé d'engagement politique de la part du gouvernement et un soutien de la société à l'égard des objectifs de développement économique, de réduction de la pauvreté et de stabilité sociale;

(ii) une attention prioritaire accordée à la croissance des exportations, à la mobilisation de l'IED et à l'élargissement de la gamme de marchandises et de services exportés;

(iii) l'importance d'une administration solide et dotée des capacités techniques nécessaires pour gérer le processus de diversification;

(iv) la présence de parties prenantes influentes ayant des intérêts dans des secteurs exportateurs autres que le secteur minier, pour compenser en partie l'influence politique du ou des secteurs dominants;

(v) l'importance du renforcement du capital humain et des capacités institutionnelles (Gelb, 2010).

Dans de nombreux cas, soutenir un effort de diversification nécessitera une approche à plusieurs volets conçue pour stimuler les exportations de produits agricoles et manufacturés et de services. Dans la plupart des contextes nationaux, la croissance des exportations ne peut (ni ne devrait) être assurée par un seul secteur. De même, il existe entre les secteurs des interdépendances importantes et croissantes, notamment entre les services et l'industrie manufacturière, de sorte qu'un secteur ne peut pas trop se développer sans recevoir d'intrants suffisamment compétitifs des autres secteurs. 
L'environnement mondial actuel pose des défis considérables aux pays pauvres, de petite taille, sans littoral et/ou tributaires des ressources naturelles, mais ce chapitre a montré que plusieurs voies de diversification pouvaient être suivies. Pour qu'elles mènent au succès, cependant, les pouvoirs publics doivent prêter attention à quatre déterminants essentiels des stratégies de diversification, que les partenaires de développement et les organisations internationales peuvent soutenir par des interventions ciblées dans le cadre de l'Aide pour le commerce. Les déterminants en question sont les suivants:

(i) la mise en place de dispositifs d'incitation appropriés;

(ii) des investissements et des réformes visant à réduire les coûts du commerce;

(iii) des politiques efficaces favorisant l'ajustement et la réaffectation des ressources au profit de nouvelles activités; et

(iv) des interventions des pouvoirs publics ciblant certains dysfonctionnements du marché, des politiques et des institutions. 


\section{NOTES}

1. Ce chapitre a été rédigé par Paul Brenton, lan Gillson et Pierre Sauvé, du Groupe de la Banque mondiale (Macroeconomics, Trade and Investment Global Practice). Les auteurs remercient Michael Roberts et Sarah Mohan pour leurs précieux commentaires et suggestions. Auteur correspondant: psauve@worldbank.org.

2. L'indice de Herfindahl (ou indice de Herfindahl-Hirschman, $\mid H H$ ) est une mesure de la taille des entreprises par rapport au secteur dont elles relèvent et un indicateur du degré de concurrence entre elles. Ce concept économique, qui doit son nom aux économistes Orris C. Herfindahl et A/bert O. Hirschman, est largement utilisé pour analyser le droit de la concurrence. L'IHH est défini comme la somme des carrés des parts de marchés des entreprises d'un secteur, où les parts de marché sont exprimées sous forme de fractions. Le résultat est proportionnel à la part de marché moyenne, pondérée par la part de marché. II va de 0 à 1,0 (d'une kyrielle de très petites entreprises à un seul producteur en situation de monopole). Une élévation de l'indice de Herfindahl indique généralement un recul de la concurrence et une augmentation de la puissance de marché, et inversement.

3. Dans les pays à faible revenu, $63 \%$ des actifs relevaient encore du secteur agricole en 2018 , soit à peine 8 points de moins qu'en 1991 (voir figure 1).

4. La vitalité croissante du commerce Sud-Sud attire de plus en plus l'attention sur le fait que la structure tarifaire des grands pays émergents comporte aussi des aspects punitifs de progressivité des droits.

5. Un exemple probant en est fourni par le Corridor Sud de croissance agricole de la Tanzanie (SAGCOT), un partenariat public-privé lancé à Dar es-Salaam en 2010, lors du Sommet sur l'Afrique du Forum économique mondial, qui sera mis en œuvre sur 20 ans, jusqu'en 2030. Son objectif ultime est de stimuler la productivité agricole, d'améliorer la sécurité alimentaire, de réduire la pauvreté et de garantir la durabilité environnementale grâce à la commercialisation des produits de l'agriculture paysanne. Voir http://sagcot.co.tz/. 


\section{RÉFÉRENCES}

Aghion, P., Blundell, R., Griffith, R., Howitt, P. et Prantl, S. (2006), "The effects of entry on incumbent innovation and productivity". NBER Working Paper n 12027, Cambridge (Massachussetts).

Agosin, M., R. Alvarez et C. Bravo-Ortega (2012), "Determinants of Export Diversification around the World: 1962-2000", dans The World Economy, 35(3), pages 295 à 315.

Andrews, Dan, et Federico Cingano (2014), "Public policy and resource allocation: evidence from firms in OECD countries", dans Economic Policy, n²9, pages 253 à 296.

Araiz, I., F. Henriquez et P. Stucchi (2013), "Supplier Development Programs and Firm Performance: Evidence from Chile", dans Small Business Economics, nº 41, pages 277 à 93.

Baker, S. R., Bloom, N., \& Davis, S. J. (2015), "Measuring economic policy uncertainty”, NBER Working Paper n²1633, National Bureau of Economic Research, Cambridge (Massachussets).

Baldwin, Richard (2016), The Great Convergence: Information Technology and the New Globalization, Harvard University Press, Cambridge (Massachussets).

Banque mondiale (2017), "Economic Diversification: Guidance Note", polycopié, Trade and Competitiveness Global Practice, Groupe de la Banque mondiale.

Banque mondiale (2018), Global Investment Competitiveness Report 2017-18: Foreign Investor Perspectives and Policy Implications, Groupe de la Banque mondiale, Washington, (D.C.). Voir: https://openknowledge.worldbank.org/ handle/10986/28493.

Banque mondiale (2019), Future Drivers of Growth in Rwanda: Innovation, Integration, Agglomeration, and Competition, édition destinée à la conférence, Groupe de la Banque mondiale, Washington, (D.C.).

Voir: https://openknowledge.worldbank.org/handle/10986/30732.

Banque mondiale et Organisation de coopération et de développement économiques (2017), A Step Ahead: Competition Policy for Shared Prosperity and Inclusive Growth, Groupe de la Banque mondiale, Washington, (D.C.). Voir: https://openknowledge.worldbank.org/handle/10986/27527.

Bartelsman, E., Haltiwanger, J., \& Scarpetta, S. (2010), "Cross-country and within-country differences in the business climate", dans International Journal of Industrial Organization, 28(4), pages 368 à 371.

Centre du commerce international (2016), SME Competitiveness Outlook 2016: Meeting the Standard for Trade, Genève. Voir: http://www.intracen.org/publication/SME-Competitiveness-Outlook-Meeting-the-Standard-for-Trade/.

Centre du commerce international (2018), SME Competitiveness Outlook 2018: Business Ecosystems for the Digital Age, Genève. Voir: http://www.intracen.org/publication/smeco2018/.

Farole T. (2011), "Special Economic Zones in Africa: Comparing Performance and Learning from Global Experience", Directions in Development: Trade, Banque mondiale, Washington, (D.C.).

Farole, T. et D. et Winkler (2012), "Foreign Firm Characteristics, Absorptive Capacity and the Institutional Framework: The Role of Mediating Factors for FDI Spillovers in Low- and Middle-Income Countries", Policy Research Working Paper $n^{\circ} 6265$, Banque mondiale, Washington, (D.C.).

FMI (2014), "Assurer la croissance à long terme et la stabilité macroéconomique dans les pays à faible revenu: rôle de la transformation structurelle et de la diversification", IMF Policy Paper (mars), Fonds monétaire international, Washington, (D.C.). 
Gari, Gabriel (2018), "Recent Preferential Trade Agreements' Disciplines for Tackling Regulatory Divergence in Services: How Far beyond GATS?", dans World Trade Review (novembre), pages 1 à 29, doi: 10.1017/S147475618000368.

Gelb, A. (2010), "Economic Diversification in Resources Rich Countries", Centre for Global Development, Washington, (D.C.).

Hallward-Driemeier, M. et G. Nayyar (2017), Trouble in the Making? The Future of Manufacturing-Led Development, Banque mondiale, Washington. (D.C.). Voir: file:///C:/Users/wb16765/Downloads/9781464811746\%20(3).pdf.

Herrendorf, B., R. Rogerson et Á. Valentinyi (2014), "Growth and Structural Transformation”, chapitre 6 dans Aghion, P. et S.N. Durlauf, Handbook of Economic Growth, Elsevier, Amsterdam, pages 855 à 941.

Hoekman, B. et B. Shepherd (2015), "Services Productivity, Trade Policy, and Manufacturing Exports," RSCAS Working Papers n’ 2015/07, European University Institute.

Hsieh, C.T., Klenow, P.J. (2009), "Misallocation and manufacturing productivity in China and India", dans Quarterly Journal of Economics 124 (4), pages 1403 à 1448.

Huria, A et P. Brenton (2016), "Export Diversification in Africa: The Importance of Good Trade Logistics", Banque mondiale, Washington, (D.C.). Voir: https://openknowledge.worldbank.org/handle/10986/22346.

Kazandjian, Romina et Kolovich, Lisa et Newiak, Monique et Kochhar, Kalpana (2016), "Gender Equality and Economic Diversification", IMF Working Paper nº 16/140, Fonds monétaire international, Washington, (D.C.).

Voir SSRN: https://ssrn.com/abstract=2882575.

Kox, H., et H. K. Nordås, (2007), "Services Trade and Domestic Regulation", Trade Policy Working Paper n 49, Organisation de coopération et de développement économiques, Paris.

Lan, J. et B. Shepherd (2018), "Women and the Services Sector: Gender, Structural Transformation and Deindustrialization", polycopié, Organisation mondiale du commerce, Genève.

Lederman, D. et W. Maloney (2012), "Does what you export matter? In Search of Empirical Guidance for Industrial Policies", Banque mondiale, Washington, (D.C.).

Lederman, D. Olarreaga, M., et Payton L. (2010), "Export Promotion Agencies: do they work?", dans Journal of Development Economics, vol. 91, n² 2, pages 257 à 265.

Meller, P. et A. Simpasa (en collaboration avec Bernardo Lara \& Gonzalo Valdés) (2011), "The role of copper in the Chilean \& Zambian economies: main economic and policy issues", GDN Working Paper Series n 43, Global Development Network, New Delhi.

Moreira, M. M., C. Volpe et J. S. Blyde (2008), Unclogging the Arteries: The Impact of Transport Costs on Latin American and Caribbean Trade, Banque interaméricaine de développement, Washington, (D.C.).

Moreira, M. M. et al., éds. (2013), Too far to export: domestic transport cost and regional export disparities in Latin America and the Caribbean, Banque interaméricaine de développement, Washington, (D.C.).

National Board of Trade (2010), "Servificification of Swedish manufacturing, Kommerskollegium", Stockholm. Voir: https://www.kommers.se/Documents/dokumentarkiv/publikationer/2010/skriftserien/report-2010-1-servicification-of-swedish-manufacturing.pdf.

OIT (2019), Emploi et questions sociales dans le monde: tendances 2019, OIT, Genève.

ONUDI (2013), "The UNIDO Approach to Sustainable Supplier Development: Promoting CSRs for SMEs in a Global Supply Chain Context", document technique, Organisation des Nations Unies pour le développement industriel, Vienne. 
Polanco Lazo, Rodrigo et Pierre Sauvé (2017), "The Treatment of Regulatory Convergence in Preferential Trade Agreements" dans World Trade Review (décembre), pages 1 à 33. Voir: https://www.cambridge.org/core/journals/worldtrade-review/article/treatment-of-regulatory-convergence-in-preferential-trade-agreements/35BC4EC5C6FA309ADF27 291085CC684D.

Roy, Martin (2019), "Elevating Services: Services Trade Policy, WTO Commitments, and their Role in Economic Development and Trade Integration", G-24 Working Paper, (janvier), Groupe intergouvernemental des Vingt-Quatre, Washington, (D.C.). Voir: https://www.g24.org/wp-content/uploads/2019/02/Roy_G24_paper__Jan_2019.pdf.

Sauvé, Pierre (2016), "Life beyond local content: exploring alternative measures of industry support in the context of WTO accession" dans Journal of International Trade, vol. 1, numéro 1, pages 1 à 28.

Voir: http://wtocentre.ifft.ac.in/journal/pdf/Article1_Pierre_Sauve.pdf.

Sauvé, Pierre (2019), "Gendered Perspectives on Services Trade and Investment", polycopié, article destiné à servir de document de référence pour un rapport conjoint du Groupe de la Banque mondiale et de l'Organisation mondiale du commerce sur le commerce et l'égalité des sexes, Groupe de la Banque mondiale, Genève.

Steenbergen, V. et J. Sutton (2017), "Establishing a Local Content Unit for Rwanda", International Growth Centre, Oxford et Londres. 



\title{
CHAPITRE 6
}

\section{LE RÔLE ESSENTIEL DE LA FACILITATION DES ÉCHANGES DANS LA PROMOTION DE LA DIVERSIFICATION ÉCONOMIQUE ET DES RÉFORMES STRUCTURELLES}

\author{
Contribution de la Banque mondiale, de la Conférence des Nations Unies \\ sur le commerce et le développement et de l'Organisation de coopération \\ et de développement économiques
}

\begin{abstract}
Résumé : Deux ans après l'entrée en vigueur de l'Accord de l'OMC sur la facilitation des échanges, l'heure est venue de faire un premier bilan. Le Programme de soutien pour la facilitation des échanges (TFSP) $d u$ Groupe de la Banque mondiale et le Programme sur la facilitation des échanges de la CNUCED, deux fournisseurs majeurs d'assistance liée au commerce, ainsi que les travaux d'analyse de l'OCDE, fournissent des éléments de réponse intéressants.
\end{abstract}

Pendant ces premières années de mise en cuuvre, l'aide a été généralement orientée vers les mesures "fondatrices" de l'Accord, comme celles qui concernent les comités nationaux de la facilitation des échanges. Ces comités superviseront la mise en ceuvre, les études sur le temps nécessaire pour la mainlevée, qui fournissent des valeurs de référence pour mesurer les progrès, ainsi que les politiques et procédures de gestion des risques, une condition préalable à la mise en ceuvre de processus simplifiés de contrôle et de mainlevée. Des progrès sont en cours. D'après les recherches menées dans le cadre du TFSP et par I'OCDE, le niveau d'harmonisation avec l'Accord augmente, et on constate des améliorations notables s'agissant de la publication des mesures, de l'automatisation et de la rationalisation des procédures, ainsi que de la coopération avec la communauté commerciale.

On a également observéque ces réformes, soutenues parl'Aide pour le commerce, avaient des répercussions positives. Les rapports par pays et les études périodiques sur le temps nécessaire pour la mainlevée montrent une diminution des inspections matérielles des douanes, une suppression des documents inutiles, une automatisation des opérations manuelles de traitement et une réduction consécutive des délais de dédouanement. Les études de la Banque mondiale (indice de performance logistique (IPL) et le rapport "Doing Business") indiquent elles aussi une tendance positive dans ces pays bénéficiant d'une aide. 
CHAPITRE 6. LE RÔLE ESSENTIEL DE LA FACILITATION DES ÉCHANGES DANS LA PROMOTION DE LA DIVERSIFICATION ÉCONOMIQUE ET DES RÉFORMES STRUCTURELLES

\section{INTRODUCTION}

Deux ans après l'entrée en vigueur de l'Accord de l'OMC sur la facilitation des échanges (AFE), un premier bilan est établi sur les progrès accomplis par les pays en développement et les pays les moins avancés (PMA) en matière de mise en œuvre de l'Accord et sur les conséquences de l'aide en la matière. L'AFE a été ratifié par 141 Membres de l'OMC, soit 86\% de l'ensemble des Membres.' Quatre-vingt-six pays en développement et PMA Membres ont fait connaître leur intention de tirer profit des dispositions de l'Accord en matière de traitement spécial et différencié et ont défini les mesures pour lesquelles ils nécessitent une assistance technique externe et un renforcement de leurs capacités destinés à soutenir leurs efforts de mise en œuvre. Dans leurs réponses à l'exercice 2019 de suivi et d'évaluation mené conjointement par l'OCDE et I'OMC, 62 pays en développement ont indiqué que la facilitation des échanges était une des principales priorités de l'Aide pour le commerce. Pour ce qui est des Membres donateurs de I'OMC, il ressort de leurs notifications que plus de 1,6 milliard d'USD a été décaissé dans le monde depuis 2014 pour financer des projets portant sur la facilitation des échanges. ${ }^{2}$

Dans le présent chapitre, nous examinons la façon dont l'Aide pour le commerce contribue à la mise en œuvre de l'AFE et d'autres réformes de facilitation des échanges. La partie II porte sur le type d'aide apportée à ce jour en matière d'assistance technique et de renforcement des capacités et sur sa justification, sur les progrès accomplis par les pays bénéficiaires en vue de la mise en œuvre de l'AFE, et sur les conséquences qu'ont eues à ce stade initial les réformes de facilitation des échanges soutenues par l'aide fournie. Ces questions seront examinées au regard du Programme de soutien pour la facilitation des échanges du Groupe de la Banque mondiale, l'une des instances de mise en œuvre et l'un des principaux moyens par lesquels est octroyé le soutien des donateurs aux pays en développement et PMA Membres de I'OMC. Dans la partie III du présent chapitre, nous procédons à un examen prospectif de la facilitation des échanges. En particulier, nous étudions la façon dont les fonctions douanières et autres missions de dédouanement s'adaptent au défi que représente le commerce électronique et la façon dont l'Aide pour le commerce peut appuyer ce processus et en quoi elle le fait.

\section{SOUTIEN EN MATIÈRE D'ASSISTANCE TECHNIQUE ET DE RENFORCEMENT DES CAPACITÉS ET IMPACTS PRODUITS}

\section{Le Programme de soutien pour la facilitation des échanges du Groupe de la Banque mondiale}

Le Programme de soutien pour la facilitation des échanges (TFSP), géré par le Pôle mondial d'expertise en macroéconomie, commerce et investissement du Groupe de la Banque mondiale, apporte un appui aux pays qui sollicitent une assistance pour aligner leurs pratiques commerciales sur l'AFE. Dans ce cadre, l'assistance est accordée en priorité aux pays dont l'accès à un autre soutien des donateurs est limité, en particulier les pays admis à emprunter à l'Association internationale de développement (IDA), aux pays à faible revenu, fragiles et touchés par des conflits, et aux pays à revenu intermédiaire qui sont un point d'accès à des pays les moins avancés et/ou dont les performances influencent grandement celles des PMA de la région. Le programme est financé par neuf partenaires de développement, qui ont décaissé plus de 45 millions d'USD depuis le lancement du programme en 2014. ${ }^{3}$ Depuis sa création, le TFSP a apporté un soutien à 47 pays, dont environ 40\% sont des PMA. Environ un quart des pays relevant du programme se trouvent en Afrique subsaharienne.

Le programme aide aussi les organisations régionales, telles que la Communauté des Caraïbes (CARICOM) et I'Union douanière centraméricaine, à "résoudre les difficultés rencontrées aux niveaux régional et sous-régional" par leurs membres dans le cadre de la mise en œuvre de mesures de facilitation des échanges et à "promouvoir l'intégration à ces niveaux", tel que le dispose I'AFE.4 Fréquemment, l'assistance technique du TFSP est apportée en collaboration avec d'autres organisations de l'annexe $D^{5}$ ou organisations techniques ou donatrices, ou à l'appui des projets de prêt du Groupe de la Banque mondiale visant la facilitation des échanges. Cette collaboration peut consister en une prestation conjointe d'appui technique, ou peut se matérialiser séparément mais être conçue pour compléter les activités de ces autres organisations. 
CHAPITRE 6. LE RÔLE ESSENTIEL DE LA FACILITATION DES ÉCHANGES DANS LA PROMOTION DE LA DIVERSIFICATION ÉCONOMIQUE ET DES RÉFORMES STRUCTURELLES

\section{Figure 6.1. Répartition régionale des activités menées dans le cadre du TFSP (par nombre de pays)}

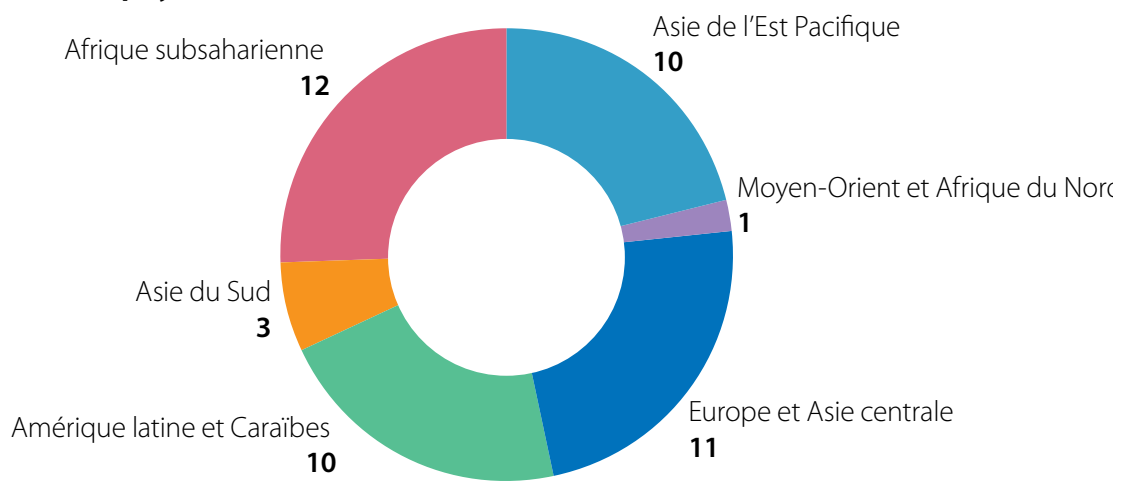

Source: Données du TFSP.

StatLink त्ञाज http://dx.doi.org/10.1787/888933953451

\section{Tableau 6.1 Collaboration du TFSP avec d'autres organisations}

\begin{tabular}{|c|c|}
\hline Partenaire & Domaines de collaboration (à titre d'exemple) \\
\hline Service fiscal et douanier de Sa Majesté & Évaluation des lacunes au regard de l'AFE \\
\hline $\begin{array}{l}\text { Association du transport aérien international } \\
\text { (IATA) }\end{array}$ & Fret aérien, mesures d'envois accélérés \\
\hline $\begin{array}{l}\text { Convention internationale pour la protection des } \\
\text { végétaux (CIPV) }\end{array}$ & $\begin{array}{l}\text { - Mise en œuvre expérimentale des activités de "certification } \\
\text { phytosanitaire électronique" } \\
\text { Diagnostics sanitaires et phytosanitaires (SPS) }\end{array}$ \\
\hline Centre du commerce international (ITC) & $\begin{array}{l}\text { Plans de facilitation des échanges } \\
\text { Planification du guichet unique national }\end{array}$ \\
\hline TradeMark East Africa & Évaluation des lacunes au regard de l'AFE \\
\hline $\begin{array}{l}\text { Conférence des Nations Unies sur le commerce et } \\
\text { le développement (CNUCED) }\end{array}$ & $\begin{array}{l}\text { Évaluations des lacunes au regard de l'AFE } \\
\text { Comités nationaux de la facilitation des échanges } \\
\text { Gestion des risques (SYDONIA) }\end{array}$ \\
\hline $\begin{array}{l}\text { Commission économique des Nations Unies pour } \\
\text { l'Europe (CEE) }\end{array}$ & Renforcement des capacités \\
\hline $\begin{array}{l}\text { Agence des États-Unis pour le développement } \\
\text { international (USAID) }\end{array}$ & $\begin{array}{l}\text { Évaluation des lacunes au regard de l'AFE } \\
\text { Études sur le temps nécessaire à la mainlevée } \\
\text { Comités nationaux de la facilitation des échanges (CNFE) }\end{array}$ \\
\hline Organisation mondiale des douanes (OMD) & $\begin{array}{l}\text { - Évaluation des lacunes au regard de l'AFE } \\
\text { [ Études sur le temps nécessaire à la mainlevée } \\
\text { Gestion des risques } \\
\text { - Programmes d'opérateurs agréés }\end{array}$ \\
\hline Organisation mondiale du commerce & $\begin{array}{l}\text { Mise à disposition de renseignements sur l'AFE } \\
\text { Coordination du soutien apporté en matière d'assistance technique et } \\
\text { de renforcement des capacités } \\
\text { Gestion des connaissances et renforcement des capacités }\end{array}$ \\
\hline
\end{tabular}


Le présent chapitre porte sur les activités déployées dans le cadre du TFSP. Les pays en développement et PMA Membres de I'OMC reçoivent aussi une aide à la facilitation des échanges en matière d'assistance technique et de renforcement des capacités dans le cadre de programmes d'autres organisations, notamment de l'annexe $D$, telles que le Programme de facilitation des échanges de la CNUCED. Ainsi, quand nous évaluerons ci-après la relation entre l'Aide pour le commerce, les progrès de mise en œuvre et les conséquences des réformes, il importera de prendre en considération l'ensemble des contributions de tous ces partenaires de développement et organisations en termes d'assistance technique et de soutien pour le renforcement des capacités.

\section{Demande des États Membres de l'OMC en matière d'appui à la mise en œuvre de l'AFE}

Les notifications présentées par les pays en développement et PMA Membres au Comité de la facilitation des échanges de l'OMC mettent en lumière les mesures de l'AFE suscitant le plus de demandes de soutien en matière d'assistance technique et de renforcement des capacités, ainsi que le type et l'orientation du soutien demandé. Au titre des dispositions de l'Accord en matière de traitement spécial et différencié, un pays en développement ou un PMA Membre de I'OMC peut, par notification au Comité de la facilitation des échanges de I'OMC dans les délais prévus, désigner

- les dispositions de l'AFE qu'il entend mettre en œuvre au moment de l'entrée en vigueur ("Catégorie A"),

- les dispositions qu'il entend mettre en œuvre à l'issue d'un délai de son choix ("Catégorie B"), et

- les dispositions dont la mise en œuvre nécessitera un soutien en matière d'assistance technique et de renforcement des capacités et aura lieu à l'issue d'un délai ("Catégorie C").

L'établissement de listes d'engagements est un processus collaboratif mené avec des organisations de l'annexe $D$ et d'autres organisations apportant un soutien en matière d'assistance technique et de renforcement des capacités. Le Programme de facilitation des échanges de la CNUCED est présenté dans l'encadré 6.1

\section{Figure 6.2. Mesures de l'AFE: plus forte demande en matière d'assistance technique et de renforcement des capacités}

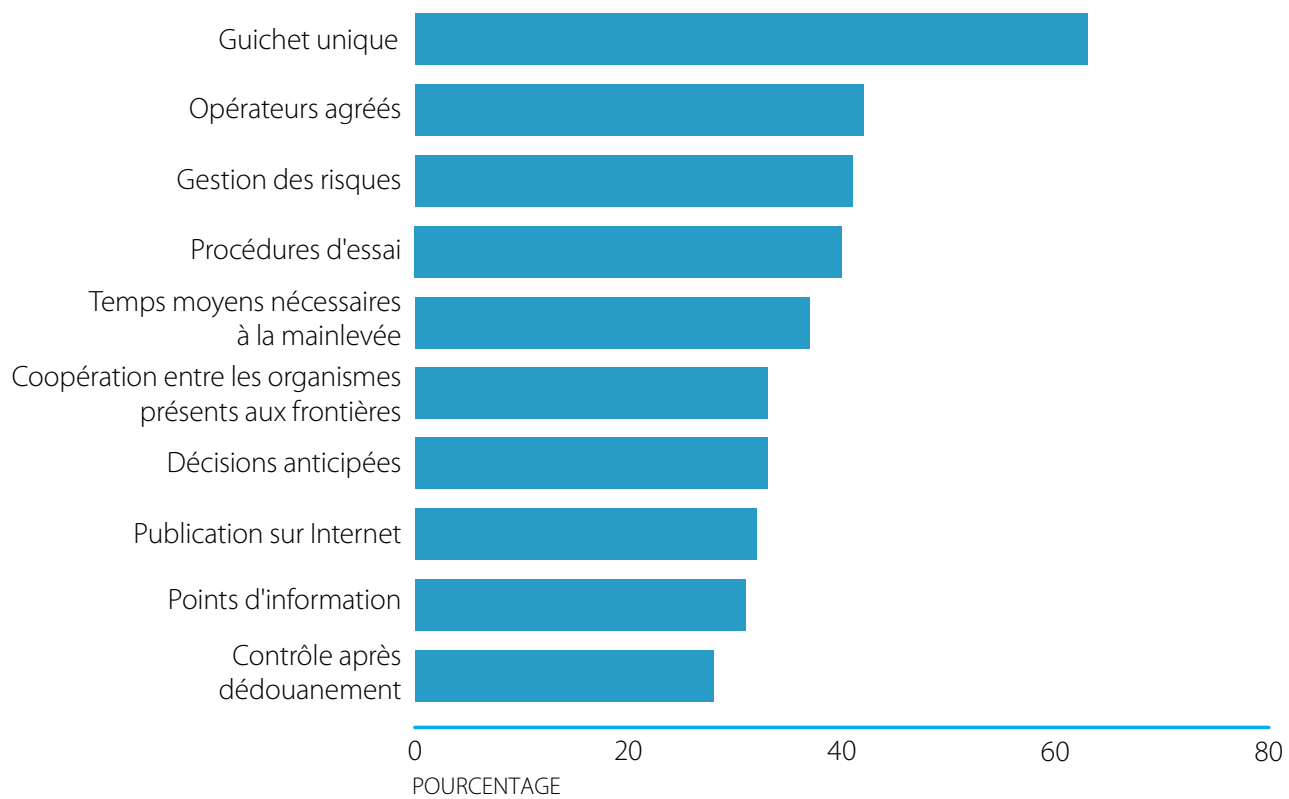

Source: Base de données du Mécanisme pour l'Accord sur la facilitation des échanges de l'OMC.

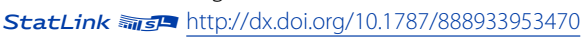




\section{Encadré 6.1. Progamme de facilitation des échanges de la CNUCED}

Forte de plus de 40 ans d'expérience dans le domaine de la facilitation des échanges, la CNUCED a aidé plus de 55 pays à élaborer leurs plans nationaux de facilitation des échanges, à constituer des comités nationaux de la facilitation des échanges et à en former les membres, et à établir des plans d'action pour la mise en œuvre de l'AFE de l'OMC. La plupart de ces mesures ont été exécutées récemment dans le cadre du Programme de la CNUCED pour le renforcement des comités nationaux de la facilitation des échanges, qui prévoit des activités de formation sur le transfert des connaissances garantissant des résultats durables. Les modules qui composent ce programme sont adaptés aux besoins des pays et mis au point par des experts internationaux. En 2018, ce programme avait été exécuté dans 21 pays; il sera lancé dans 6 autres pays en 2019 (unctad.org/eptf).

Pour appuyer les travaux des pays en développement et des PMA en matière de facilitation des échanges, la CNUCED a continué de recueillir et d'actualiser des renseignements sur plus de 130 comités nationaux de la facilitation des échanges partout dans le monde. Ces informations ont été mises à disposition dans la base de données en ligne de la CNUCED (unctad.org/tfc). En outre, la CNUCED a publié 23 notes techniques, qui exposent la portée, la raison d'être et les avantages des mesures de facilitation des échanges, ainsi que les possibilités qu'elles offrent, le rôle des différents organismes et comités nationaux de la facilitation des échanges, et les directives et les prochaines étapes visant à la mise en œuvre de l'AFE de l'OMC.

Aux fins de l'automatisation douanière, le programme SYDONIA de la CNUCED a renforcé les capacités des administrations des douanes d'environ 115 pays, dont 80\% utilisent déjà SYDONIA. Avec 51 projets opérationnels, dont 7 projets régionaux et interrégionaux, SYDONIA représente le programme de coopération technique le plus important de la CNUCED (asycuda.org).

Les travaux de la CNUCED relatifs aux portails de renseignements en ligne sur les procédures commerciales étrangères, qui favorisent la transparence au sein des gouvernements de sorte à faciliter le commerce, les échanges et l'investissement, ont abouti à l'implantation de 68 systèmes dans 37 pays et à la mise en ligne de renseignements sur environ 3000 procédures. Ainsi, le nombre de procédures, formulaires et documents d'enregistrement des sociétés a diminué de $80 \%$ (businessfacilitation.org).

Vous trouverez de plus amples renseignements sur les travaux de la CNUCED dans le domaine de la facilitation des échanges à l'adresse suivante: http://unctad.org/tf.

En février 2019, 114 pays en développement et PMA Membres de l'OMC ont présenté de telles notifications, de manière partielle ou totale. Sur ce total, 63 Membres avaient classé les mesures dans la catégorie C, ce qui signifie qu'ils ont besoin d'un soutien en matière d'assistance technique et de renforcement des capacités. Toutes les mesures de I'Accord, sans exception, ont fait l'objet d'une demande d'appui à la mise en œuvre par au moins un Membre de l'OMC. Toutefois, certaines mesures font l'objet de davantage de demandes que d'autres. Celles dont la mise en œuvre a suscité, de la part des pays en développement et des PMA Membres de l'OMC, le plus de demandes de soutien en matière d'assistance technique et de renforcement des capacités sont énumérées dans la figure 6.2 ci-dessous. ${ }^{6}$

La mesure relative au guichet unique est celle pour laquelle une nette majorité de pays en développement et PMA Membres présentant des notifications de catégorie C ont exprimé le besoin de recevoir un appui à la mise en œuvre. Le nombre élevé de demandes relatives à cette mesure en particulier tient probablement à la complexité de la conception et de la mise en service d'un guichet unique national, qui, en général, nécessitent l'intégration des procédures et des contrôles de multiples organismes présents aux frontières, comprennent une composante TIC et nécessitent un cadre de gouvernance et un cadre législatif, entre autres conditions. 
Cette liste de mesures faisant l'objet d'une forte demande en matière d'assistance technique et de renforcement des capacités peut aussi indiquer les autorités des pays en développement et des PMA qui ont particulièrement besoin de soutien. L'un des points communs de la majorité des mesures énumérées est que leur mise en œuvre relève de la responsabilité d'autorités présentes aux frontières dont les attributions sont distinctes de celles de l'administration des douanes chargée des contrôles ou les complètent (telles que les autorités présentes aux frontières responsables des normes sanitaires et phytosanitaires (SPS) et de la mise en application des normes de produits et des règlements techniques (c'est-à-dire les mesures qui s'inscrivent dans le cadre de l'Accord sur les obstacles techniques au commerce)) et/ ou nécessite une coordination entre plusieurs organismes. Ce besoin concorde avec les données d'expérience issues des pays en développement et des PMA où, fréquemment, l'administration des douanes a davantage progressé sur le programme de facilitation des échanges que ses homologues présents aux frontières.

Au titre de l'article 16 de l'AFE, les notifications de catégorie C doivent comprendre "à des fins de transparence" une indication des types d'appui à la mise en œuvre dont le Membre de I'OMC a besoin par mesure de I'AFE.8 Dix-neuf des 63 pays qui ont présenté des notifications de catégorie $C$ à ce jour n'ont pas inclus cette information. ${ }^{9}$ Toutefois, en ce qui concerne les 44 pays restants, quand ce renseignement est fourni, les types d'assistance les plus demandés sont ceux énumérés dans la figure 6.3.10

Figure 6.3. Mesures de l'AFE: Types de soutien demandés

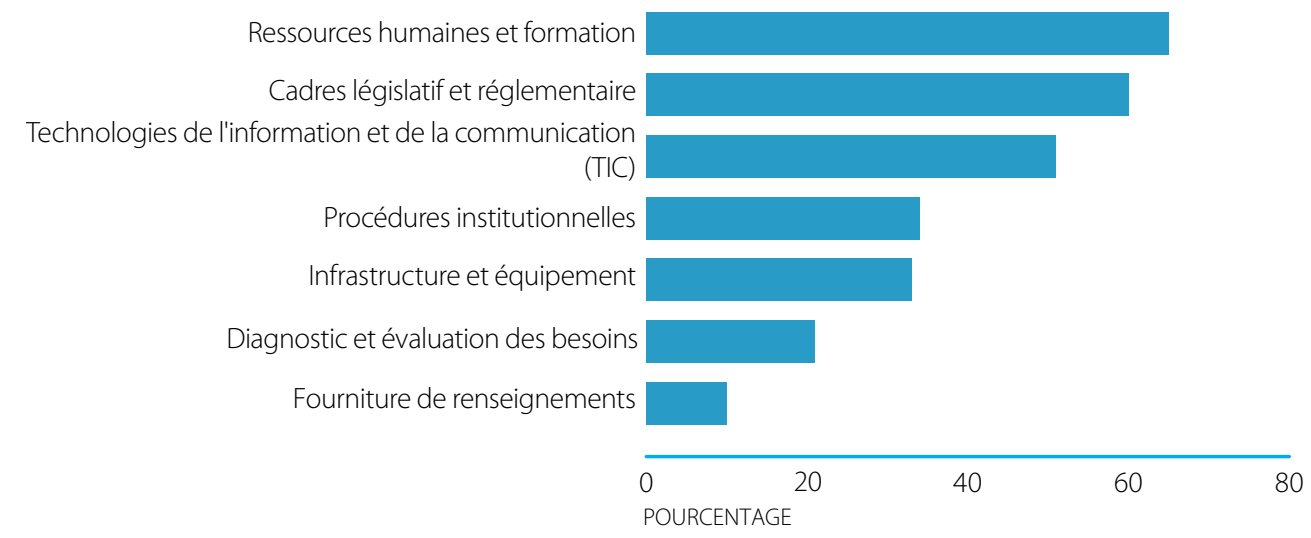

Source: Base de données du Mécanisme pour l'Accord sur la facilitation des échanges de l'OMC.

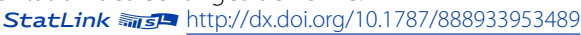

Comme indiqué dans la figure 6.3 , plus de $75 \%$ des notifications de catégorie $C$ nécessitent un soutien en matière de renforcement des capacités et/ou des renseignements sur certaines ou l'ensemble des mesures visées. Les mesures de I'AFE suscitant le plus de demandes pour un tel soutien en matière de renforcement des capacités apparaissent dans la figure 6.4.

Les demandes d'appui en matière d'évaluation et d'élaboration de lois et de règlements d'application favorables sont aussi relativement nombreuses. Outre les décisions anticipées - une procédure propre aux douanes - ces nombreuses demandes d'assistance technique et de renforcement des capacités semblent indiquer qu'un soutien est nécessaire dans le domaine de l'élaboration de lois et règlements qui sont distincts de la législation douanière ou qui s'y ajoutent (par exemple la législation administrative générale sur la publication, les recours administratifs ou lélaboration de règles). 
CHAPITRE 6. LE RÔLE ESSENTIEL DE LA FACILITATION DES ÉCHANGES DANS LA PROMOTION DE LA DIVERSIFICATION ÉCONOMIQUE ET DES RÉFORMES STRUCTURELLES

\section{Figure 6.4. Mesures de l'AFE: Demandes d'appui en matière de sensibilisation et de renforcement des capacités}

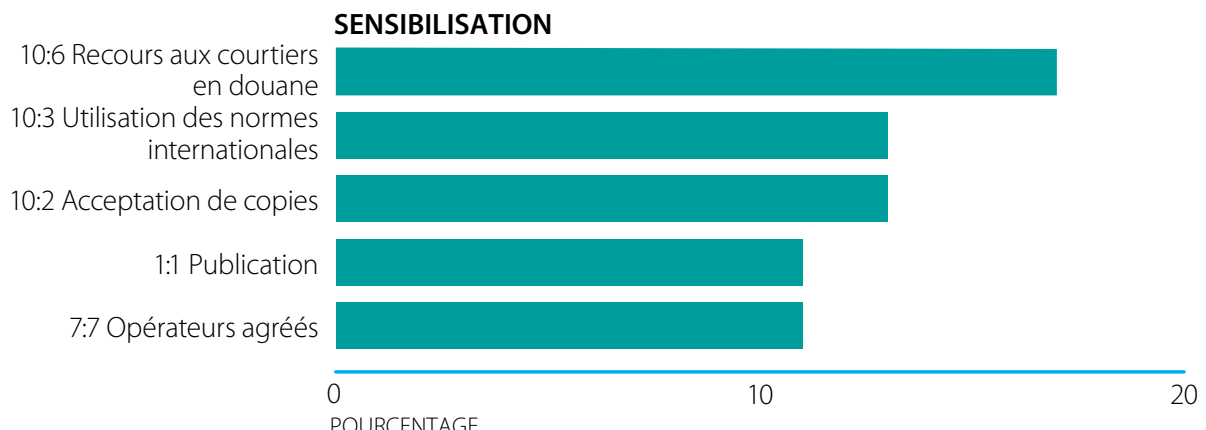

\section{RENFORCEMENT DES CAPACITÉS}

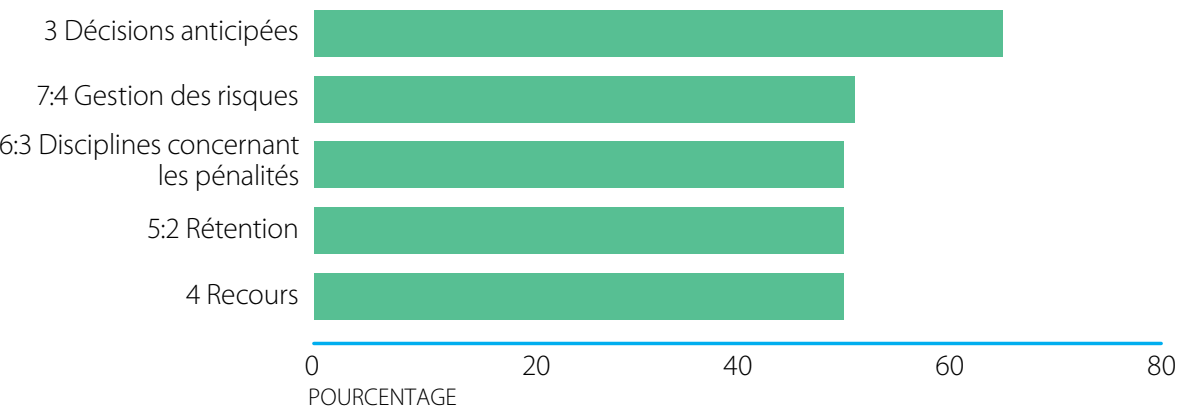

Source: Base de données du Mécanisme pour l'Accord sur la facilitation des échanges de l'OMC.

Figure 6.5. Mesures de l'AFE: Principales demandes en matière d'appui à la législation

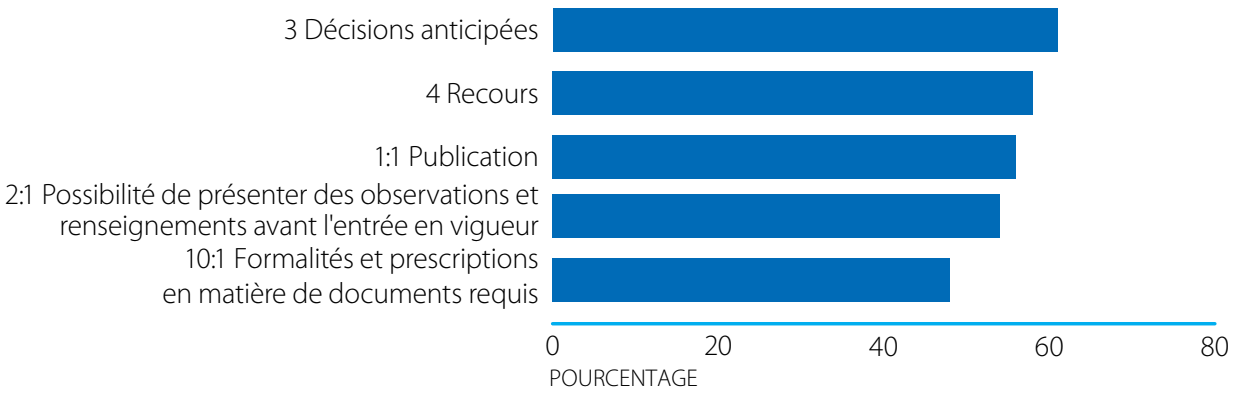

Source: Base de données du Mécanisme pour l'Accord sur la facilitation des échanges de l'OMC.

StatLink iㅔㅇㅔ $\mathrm{http} / / / \mathrm{dx}$.doi.org/10.1787/888933953527

Les demandes de matériel lié à la facilitation des échanges - par exemple du matériel, notamment informatique, des infrastructures physiques - semblent être principalement liées à la mise en œuvre des mesures liées à la transparence, telles que la création d'un site Web pour s'acquitter de l'obligation de publication ou la fourniture de services informatiques à l'appui de la mise sur pied d'un guichet unique, et aux mesures de I'AFE qui sont généralement mises en œuvre par les autorités techniques présentes aux frontières autres que les douanes (par exemple l'autorité chargée des activités de phytoquarantaine et des normes SPS) telles que les mesures relatives aux équipements de laboratoire et aux installations d'essai, aux installations d'entreposage pour les marchandises périssables et à un appui informatique à la création d'un mécanisme d'"alerte rapide" pour les denrées alimentaires et aliments pour animaux. 


\section{Encadré 6.2. Observations des pays en développement interrogés sur la facilitation des échanges}

"Les priorités de l'Aide pour le commerce que nos partenaires de développement et nous-mêmes avons prises en considération sont la mise en ceuvre de l'Accord sur la facilitation des échanges dans le cadre de l'Organisation mondiale du commerce et la mise en ceuvre de l'accord de libre-échange de la SADC." - Angola

"La facilitation des échanges importe pour l'intégration aux chaînes de valeur régionales et mondiales. L'une des difficultés réside notamment dans la coordination de multiples acteurs. On dénombre parmi les politiques clés le Code des douanes de la CEDEAO et le Schéma de libéralisation des échanges de la Communauté. L'aide apportée au titre de l'Aide pour le commerce a utilement contribué à la construction et à la livraison de deux postes frontière communs." - Secrétariat de la Communauté

\section{économique des États de l'Afrique de l'Ouest}

"El Salvador poursuit la mise en ceuvre de l'Accord sur la facilitation des échanges et de la Stratégie régionale de facilitation des échanges et de compétitivité et continue de faire avancer le processus d'intégration régionale, dans le but de renforcer les capacités des micro, petites et moyennes entreprises aux fins de leur intégration au commerce international et de tirer parti des possibilités commerciales découlant des accords de libre-échange." - El Salvador

"En termes de facilitation des échanges, nous souhaitons que nos pratiques soient en harmonie avec les principes du système multilatéral en place pour faciliter les échanges." - Gabon

"La facilitation des échanges est un objectif majeur du processus de développement économique de la Guinée, car elle contribue à la promotion et au renforcement des capacités commerciales du pays. La facilitation des échanges, les activités de formation et les renseignements relatifs aux techniques commerciales modernes et destinés aux femmes (respect des normes d'exportation et des prescriptions en matière de documents requis) aident grandement les femmes dans leur autonomisation." - Guinée

"Nous nous efforçons de faciliter les échanges pour améliorer notre commerce transfrontières avec notre unique voisin, la République sud-africaine. Nous avons besoin de financements pour accélérer le processus." - Lesotho

"La création du Comité de la facilitation des échanges et sa mise à l'épreuve, le renforcement des capacités du guichet unique en vue de la numérisation de ses opérations et de son interconnexion avec les structures concernées (douanes, administration fiscale, assurances, banques, Direction nationale des services vétérinaires, Direction nationale de l'agriculture, Direction nationale de l'industrie) et le traitement des produits essentiels dans le cadre du portail pour le commerce, appuient le programme MERCATOR au niveau des douanes." - Mali

"En contribuant à rationaliser et à réduire les coûts du commerce, le PENX (Plan stratégique national pour l'exportation) reconnaît que la facilitation des échanges importe en raison de son impact sur la compétitivité. La facilitation des échanges constitue l'un des volets du PENX. De la même façon, la politique nationale pour la compétitivité et la productivité propose de consolider le système de facilitation des échanges et de coordination entre les organismes concernés, ainsi que les mécanismes de lutte contre les infractions douanières, telles que la contrebande, qui sont liées à un niveau d'informalité élevé et à un niveau réduit d'intermédiation financière." - Pérou

"En ce qui concerne la facilitation des échanges, compte tenu de sa position stratégique et du fait qu'il dessert les pays sans littoral depuis le port autonome de Lomé, le Togo aspire à devenir une plate-forme logistique d'excellence et un centre d'affaires de premier ordre dans la sous-région (axe stratégique 1 du Plan national de développement)." - Togo

"Le Zimbabwe a demandé à bénéficier des activités de renforcement des capacités de I'OMC, de la CNUCED et de l'ONUDI dans le domaine de la facilitation des échanges, du commerce des services et de la mise en cuvre de la politique industrielle."

\section{- Zimbabwe}

Source: Exercice 2019 de suivi et d'évaluation mené conjointement par l'OCDE et l'OMC. 
CHAPITRE 6. LE RÔLE ESSENTIEL DE LA FACILITATION DES ÉCHANGES DANS LA PROMOTION DE LA DIVERSIFICATION ÉCONOMIQUE ET DES RÉFORMES STRUCTURELLES

Figure 6.6. Mesures de l'AFE: Demandes d'appui dans les domaines des TIC, de l'infrastructure et de l'équipement

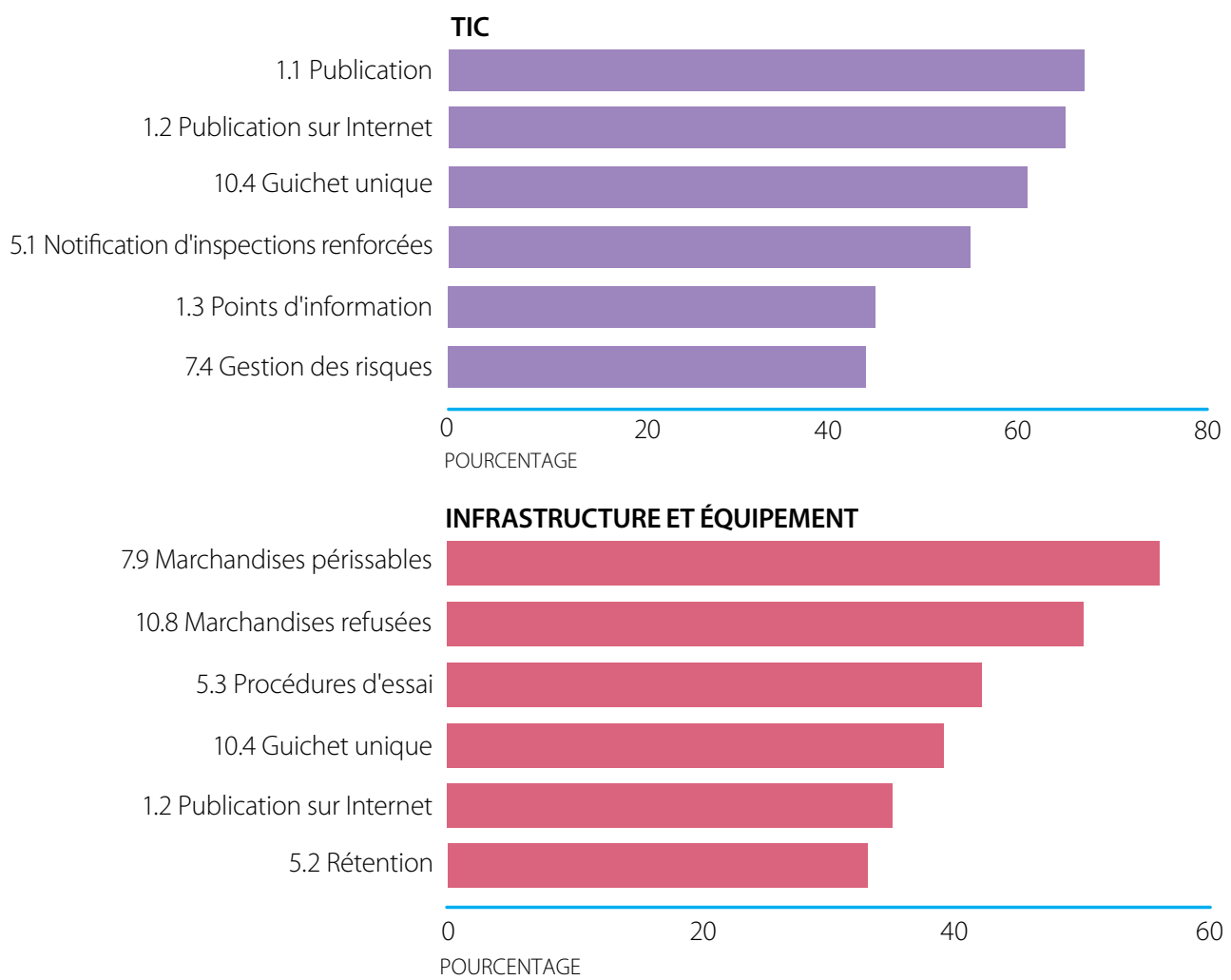

Source: Base de données du Mécanisme pour l'Accord sur la facilitation des échanges de l'OMC.

Enfin, nous constatons que 22 Membres de l'OMC - dont 12 sont des PMA - n'ont pas encore ratifié l'Accord. Une quarantaine de Membres de l'OMC n'ont pas encore présenté ou achevé la notification de leurs catégories. En outre, quand un PMA Membre de I'OMC a présenté des notifications de catégorie $C$, il indique le plus souvent que les types d'assistance technique dont il a besoin aux fins de la mise en œuvre restent "à déterminer". Ces lacunes laissent à penser qu'il demeure nécessaire d'apporter une assistance technique pour aider ces Membres de I'OMC à s'acquitter pleinement de leurs obligations en matière de ratification et de notification et pour cerner leurs exigences en matière d'appui à la mise en œuvre. L'exercice de suivi et d'évaluation mené conjointement par l'OCDE et l'OMC a mis en avant la raison sous-jacente pour laquelle des Membres et certaines communautés économiques régionales menaient des réformes de facilitation des échanges. De plus amples renseignements sont apportés dans l'encadré 6.2.

\section{Point sur les activités menées dans le cadre du TFSP}

Dans les années qui ont précédé l'entrée en vigueur de l'Accord (et après, mais dans une moindre mesure), les Membres ont principalement demandé de l'aide pour déterminer si le régime commercial de leur pays était en adéquation avec les dispositions de l'Accord, définir les besoins et priorités potentiels en matière d'assistance technique et de renforcement des capacités, achever les engagements des catégories A, B et C, et élaborer les stratégies et plans d'action nationaux de mise en œuvre. Depuis son lancement, le TFSP a permis de mener à ces fins plus de 50 missions d'évaluation des lacunes. 
À mesure que les pays avancent de la phase d'évaluation à la phase de planification, la demande d'appui technique porte davantage sur la mise en œuvre. Ainsi qu'il ressort clairement des notifications présentées au Comité de la facilitation des échanges de l'OMC et des résultats des évaluations des besoins nationaux menées avant l'entrée en vigueur de l'Accord, le niveau d'harmonisation et les besoins d'appui varient d'un pays à l'autre et, dans un même pays, d'un organisme présent aux frontières à l'autre. Néanmoins, certaines tendances générales ont été dégagées en matière de fourniture d'appui. Actuellement, les principales mesures de soutien en matière d'assistance technique et de renforcement des capacités sont généralement axées sur un certain nombre de mesures de l'Accord. Cette concentration de la demande n'est pas un hasard, mais le résultat de la demande des clients associée à la stratégie d'échelonnement des activités appliquée par les pays concernés.

Par conséquent, comme indiqué dans la figure 6.7, plus d'un tiers de l'ensemble des pays du programme ont reçu un appui technique pour créer leur comité national de la facilitation des échanges ou améliorer son fonctionnement. La priorité est accordée à la création du comité, car il s'agit d'une obligation de l'Accord faite à tous les Membres de l'OMC à partir de la date de l'entrée en vigueur de l'AFE. En outre, conformément à l'Accord, les pays concernés et les organisations donatrices considèrent qu'il est essentiel de créer un comité national de la facilitation des échanges opérationnel pour superviser et gérer la mise en œuvre de l'Accord, y compris concernant la définition des priorités et la coordination des réformes et de l'assistance technique. La concentration à ce jour sur les autres mesures contenues dans la figure 6.7 se justifie essentiellement par une logique d'échelonnement analogue.

\section{Figure 6.7. Pourcentage de pays recevant un appui concernant des mesures particulières de l'AFE}

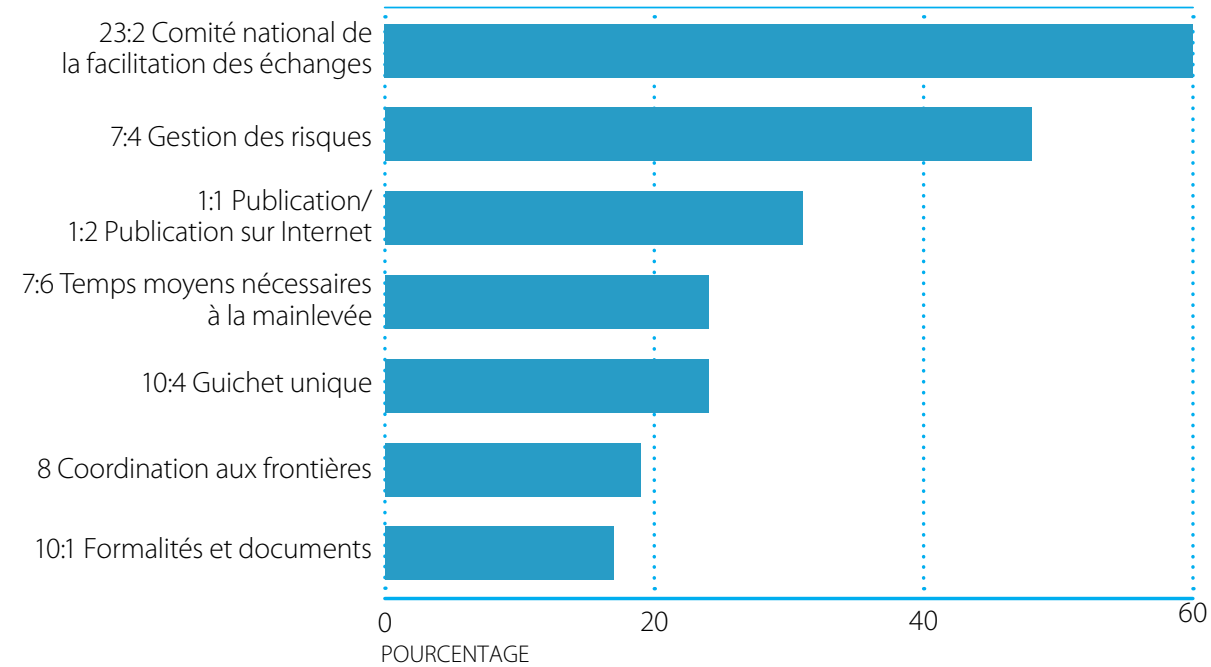

Source: Données issues du Programme de soutien pour la facilitation des échanges de la banque mondiale.

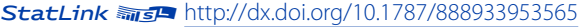

La gestion des risques, principe fondamental de l'inspection et du contrôle aux frontières, est un prérequis au bon fonctionnement d'autres mesures de l'AFE relatives aux douanes, par exemple sur les opérateurs agréés et le contrôle après dédouanement, et a des conséquences directes sur le temps et le coût du dédouanement. II existe par conséquent une demande hautement prioritaire en matière d'assistance technique et de renforcement des capacités pour mettre en place les systèmes et procédures de gestion des risques des douanes et autres organismes présents aux frontières, tels que les autorités vétérinaires et les autorités responsables de la sécurité sanitaire des produits alimentaires, ainsi que pour intégrer ces contrôles. 
Encadré 6.3 Étude sur le temps nécessaire pour la mainlevée (TRS+) - un état des lieux plus précis des délais requis

Il est important de connaître le délai nécessaire pour que des marchandises traversent une frontière et le temps nécessaire pour s'acquitter d'autres prescriptions réglementaires préalables à l'importation ou à l'exportation, de sorte à déterminer les principaux obstacles à la facilitation et à la modernisation des échanges et les domaines dans lesquels ces progrès sont possibles. L'Étude de l'Organisation mondiale des douanes sur le temps nécessaire à la mainlevée est un examen qui permet de mesurer le temps nécessaire à la bonne réalisation de l'ensemble des procédures à la frontière relatives au dédouanement et à la mainlevée des marchandises exportées, importées et en transit.

Néanmoins, cette étude ne mesure pas le temps que passent les entreprises à s'acquitter d'obligations réglementaires avant que les marchandises ne soient présentées à la frontière. Ces obligations sont notamment l'obtention des certificats, licences et permis nécessaires et le respect des exigences douanières en matière d'importation et d'exportation. Ces procédures prennent du temps et, à ce titre, ont un coût pour les entreprises.

Pour avoir une idée plus précise du temps nécessaire pour satisfaire aux exigences commerciales, le TFSP a mis au point une "Étude sur le temps nécessaire pour la mainlevée plus (TRS+)", qui mesure le temps nécessaire aux procédures de dédouanement et de mainlevée d'une part, et aux procédures réglementaires "ailleurs qu'à la frontière" d'autre part. La méthode a été appliquée à titre expérimental en Eswatini et au Lesotho et partagée avec l'OMD en vue d'une collaboration sur l'application de cette technique améliorée dans des projets à venir.

Une étude sur le temps nécessaire pour la mainlevée fournit au pays des valeurs de référence initiales à l'aune desquelles il peut mesurer les progrès et les impacts de la mise en œuvre de réformes de facilitation des échanges; elle joue de ce fait un rôle important pour une mise en œuvre rapide. À ce jour, le TFSP a appuyé des études de références et l'étude consécutive sur le temps nécessaire pour la mainlevée dans une douzaine de pays.

L'analyse des formalités et des prescriptions actuelles en matière de documents requis constitue une première étape vers la rationalisation et la coordination des procédures des organismes présents aux frontières et est nécessaire pour la mise en place d'un guichet unique, par exemple. II ressort des données d'expérience des pays que cette rationalisation des documents et des formalités constitue souvent la suite et le résultat de l'analyse d'une étude sur le temps nécessaire pour la mainlevée, qui révèle les obstacles et les procédures inefficaces.

Le guichet unique est défini dans les notifications des pays en développement et des PMA comme la mesure de l'AFE suscitant le plus de demandes d'appui à la mise en œuvre"1, phénomène que l'on constate également dans le groupe de pays appuyés par le TFSP. Dans un premier temps, c'est la planification stratégique qui suscite le plus de demandes d'appui dans le cadre de l'instauration d'un guichet unique, en particulier pour ce qui est d'aider les divers organismes gouvernementaux participant à l'institution et au fonctionnement du guichet unique national et les représentants du secteur privé à instaurer dès le départ une "vision" commune de tous les points essentiels - la gouvernance, les modèles et stratégies juridiques, fonctionnels, opérationnels et financiers, la portée technique et le renforcement des capacités - pour que la mise en œuvre soit conforme aux attentes.

Les demandes d'appui concernant les mesures de transparence de l'Accord ont porté sur la création ou l'entretien de portails d'information commerciale, ou de portails électroniques donnant facilement accès aux informations transfrontières, telles que les informations sur les normes. À cette fin, le TFSP a favorisé la création et la conception de six portails dans des pays d'Asie de l'Est, d'Asie du Sud, d'Afrique subsaharienne et des Caraïbes, ou contribué à leur mise en œuvre.

À ce jour, le type d'appui le plus fréquemment demandé dans le cadre du TFSP en lien avec la mise en place de ces mesures prioritaires concerne les services d'experts techniques, tels que le savoir-faire et l'expérience en matière de "pratiques optimales" internationales nécessaires à la conception et à la réalisation d'une étude sur le temps nécessaire pour la mainlevée, à l'élaboration d'un cadre d'échantillonnage fondé sur les risques pour la santé animale, ou à l'instauration d'un mécanisme de consultation efficace des parties prenantes, pour citer quelques-unes des activités d'appui technique les plus courantes entreprises jusqu'ici. 
Figure 6.8. Formes d'assistance fournies 2017-2018

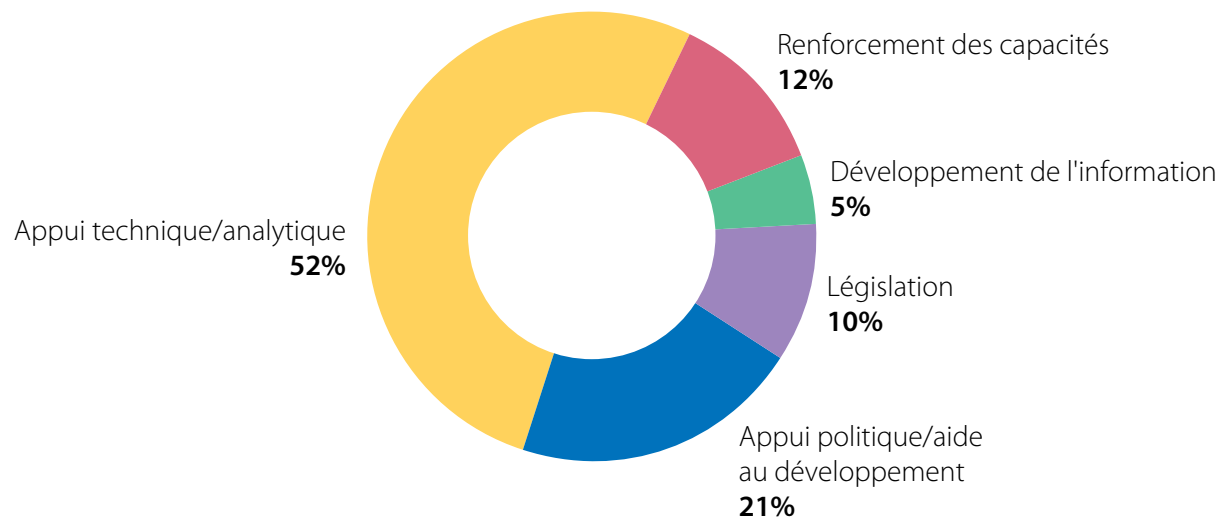

Source: Données issues du Programme de soutien pour la facilitation des échanges de la Banque mondiale. StatLink 部

Dans ces premières années de mise en œuvre de l'AFE, la demande de conseils relatifs à la création d'un cadre d'action général et d'un cadre stratégique aux fins de réformes de facilitation des échanges a été élevée, et axée en particulier sur l'appui à l'élaboration ou à la validation de plans stratégiques pour la facilitation des échanges et de plans d'action à portée nationale et régionale, et sur les travaux de conception du guichet unique décrits plus haut. La demande d'appui au réexamen de lois et, lorsqu'il y avait lieu, à l'élaboration de modifications ou d'une nouvelle législation pour permettre la bonne mise en œuvre de l'Accord a aussi été importante. Un appui a par exemple été fourni pour la révision d'une législation douanière, d'un texte visant à permettre l'échange électronique de renseignements, de lois sur la santé animale et la quarantaine et de mesures juridiques de mise en place du comité national de la facilitation des échanges, entre autres.

La demande de renforcement des capacités est aussi importante et augmentera probablement à mesure qu'entreront en vigueur des législations, politiques et procédures nouvelles ou modifiées.

Pour l'heure, l'assistance technique et le renforcement des capacités s'adressent principalement au secteur public. Comme indiqué dans la figure 6.9, le gouvernement - qui désigne ici le pouvoir exécutif et les ministères du commerce, des échanges et des affaires étrangères - est l'entité du secteur public avec laquelle les activités d'appui ont été le plus souvent menées au cours de cette période initiale. Ces activités sont notamment un appui à l'élaboration ou à la validation d'une stratégie et de plans de mise en œuvre, la mise en place du comité national de la facilitation des échanges, l'établissement de notifications de l'Accord et la ratification du texte.

À mesure que la mise en œuvre de l'Accord progressera, l'appui portera davantage sur les douanes et les autres organismes présents aux frontières. Étant donné que nombre des dispositions de l'Accord relèvent de la responsabilité de mise en œuvre des douanes, celles-ci exigent et continueront probablement d'exiger une part importante de l'appui. Néanmoins, des mesures ont été prises pour diriger les efforts vers les organismes techniques, en particulier les autorités SPS et les autorités des normes, dont les interventions aux frontières peuvent être lourdes de conséquences pour la durée et le coût des échanges. Comme indiqué précédemment, il n'est pas rare que ces autorités techniques ne connaissent pas aussi bien le programme de facilitation des échanges que l'autorité douanière nationale ou ne soient pas aussi avancées qu'elle sur la question. Les douanes ont souvent eu accès à la Convention de Kyoto révisée et à d'autres instruments de facilitation des échanges de l'OMD et/ou les ont mis en œuvre, ont reçu un appui au renforcement des capacités de facilitation des échanges et, par conséquent, sont fréquemment bien plus avancées en termes de procédures, de contrôles et de technologies de facilitation modernisés. Par exemple, les procédures de l'autorité douanière sont, de manière générale, partiellement ou totalement automatisées tandis que d'autres autorités présentes aux frontières fonctionnent encore manuellement à partir de documents imprimés. 
CHAPITRE 6. LE RÔLE ESSENTIEL DE LA FACILITATION DES ÉCHANGES DANS LA PROMOTION DE LA DIVERSIFICATION ÉCONOMIQUE ET DES RÉFORMES STRUCTURELLES

Figure 6.9. Bénéficiaires du soutien du secteur public

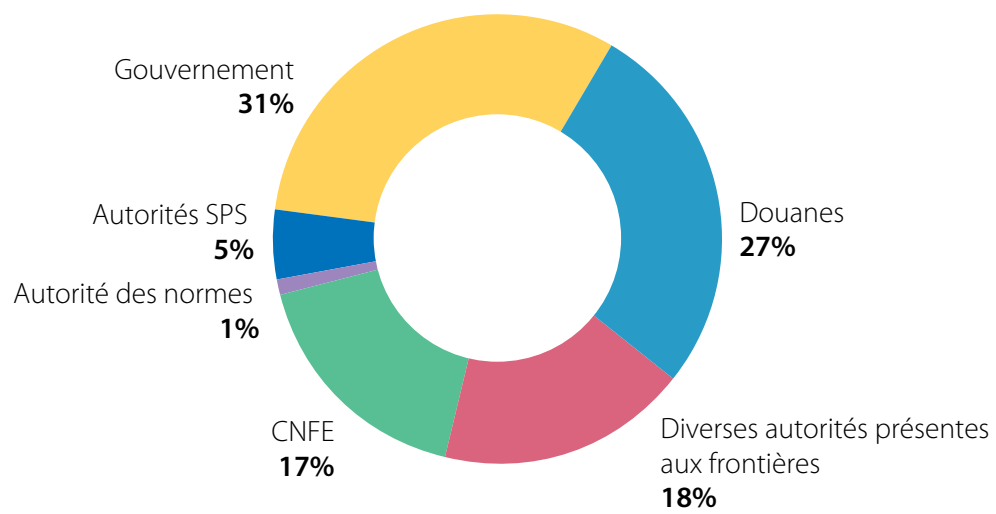

Source: Données issues du Programme de soutien pour la facilitation des échanges de la Banque mondiale.

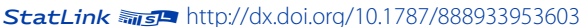

\section{Progrès concernant la mise en œuvre et impact des réformes}

Dans la présente section, nous examinerons les progrès et les impacts de la mise en œuvre.

Nous entendons par "progrès" la mesure dans laquelle chaque pays a harmonisé son régime de facilitation des échanges avec les dispositions de l'AFE de l'OMC. L'impact" désigne les effets, économiques ou autres, qui découlent des progrès de la mise en œuvre dans ces pays.

\section{Progrès concernant la mise en œuvre}

En vue d'aider les pays à suivre les progrès qu'ils réalisent dans la mise en œuvre de l'AFE, le TFSP a mis au point un "Outil de suivi d'alignement avec I'AFE". Cet outil permet aux pays de mesurer la conformité avec chacune des mesures techniques de l'AFE dans trois domaines:

- la mesure dans laquelle les dispositions juridiques ou politiques nécessaires pour permettre la mise en œuvre d'une mesure donnée sont en place;

- la mesure dans laquelle les procédures opérationnelles ou administratives ont été élaborées pour mettre en œuvre la disposition de l'AFE;

- la mesure dans laquelle la disposition est appliquée dans les faits.

L'outil est appliqué au niveau du gouvernement dans son ensemble, ce qui signifie que tous les organismes concernés par la disposition de facilitation des échanges devraient être alignés sur les dispositions de l'AFE pour qu'un pays reçoive la note maximale.12 En outre, il mesure les progrès au regard d'une mise en œuvre complète et effective de l'Accord. En d'autres termes, même si l'obligation juridique découlant de l'AFE pour certaines mesures peut se limiter à un "effort maximal", un pays tirera de plus importants bénéfices de la facilitation des échanges s'il adopte une approche de mise en œuvre plus ambitieuse..$^{13}$ Par exemple, même si l'article 7:4 dispose que les autorités présentes aux frontières autres que les douanes doivent axer leurs contrôles sur les envois présentant un risque élevé et accélérer la mainlevée des envois présentant un risque faible "dans la mesure du possible", I'outil de suivi considère que la pratique d'un pays est pleinement harmonisée avec l'article 7:4 uniquement si lesdites autorités présentes aux frontières adoptent et appliquent de fait ces principes de gestion des risques. 
Depuis 2015, des mesures de référence ont été enregistrées pour 24 pays; elles ont été actualisées pour 18 pays. Ces mesures, limitées à ce jour, révèlent que des progrès ont été réalisés et qu'ils indiquent que la conformité générale avec I'AFE est passée d'une moyenne de 45\% à 53\%, la majeure partie des avancées ayant eu lieu se rapportant à l'application des mesures de l'AFE sur la publication et au Comité national de la facilitation des échanges.

En plus de mesurer les progrès réalisés, l'outil et la méthode de suivi du TFSP donnent un aperçu utile de l'état de mise en œuvre effective sur le terrain. II semblerait qu'il existe des différences entre l'état de mise en œuvre mesuré par l'outil de suivi et les notifications présentées par les pays en développement et les PMA Membres.

Tableau 6.2. Pourcentage de pays alignés: comparaison entre les évaluations réalisées à l'aide de l'outil de suivi et les notifications de catégorie $A$

\begin{tabular}{llcc} 
& & $\begin{array}{c}\text { Référence de l'outil } \\
\text { de suivi du TFSP } \\
\text { (\% de pays } \\
\text { pleinement alignés) }\end{array}$ & $\begin{array}{c}\text { Notifications de catégorie A } \\
\text { (\% de pays } \\
\text { pleinement alignés) }\end{array}$ \\
\hline 10.1 & Formalités et documents & 0 & $61 \%$ \\
\hline 7.6 & Temps moyens nécessaires à la mainlevée & $7 \%$ & $52 \%$ \\
\hline 10.4 & Guichet unique & $3 \%$ & $39 \%$ \\
\hline 1.3 & Points d'information & 0 & $54 \%$ \\
\hline 6.1 & Disciplines générales & 0 & $60 \%$ \\
\hline 5.1 & Notification d'inspections renforcées & $3 \%$ & $61 \%$ \\
\hline 6.2 & Disciplines spécifiques concernant les redevances & $7 \%$ & $66 \%$ \\
\hline 7.7 & Opérateurs agréés & 0 & $46 \%$ \\
\hline 2.2 & Consultations & $7 \%$ & $62 \%$ \\
\hline 10.2 & Copies & $7 \%$ & $64 \%$ \\
\hline
\end{tabular}

Le tableau 6.2 énumère les dix dernières mesures de l'AFE (les moins alignées) en termes d'alignement moyen le plus faible de tous les pays suivis. II ressort de la comparaison avec les données issues des notifications de l'OMC qu'il existe d'autres différences en ce qui concerne l'alignement.14

Ces écarts peuvent s'expliquer par des différences dans les populations évaluées. Les pays visés par le TFSP constituent un sous-ensemble des 114 pays Membres de I'OMC qui ont présenté des notifications de catégorie A, et le TFSP vise une part plus importante de PMA. Ces écarts peuvent aussi s'expliquer par l'utilisation d'une norme d'alignement différente. Comme indiqué, I'outil de suivi du TFSP mesure l'alignement en termes d'application "intégrale et effective" de I'Accord, alors que les notifications de catégorie A peuvent avoir été présentées par les pays concernés sur le fondement d'autres facteurs, y compris une évaluation de la conformité juridique technique.

\section{Impact des réformes}

II ressort des données disponibles que l'assistance technique et le renforcement des capacités ont un impact positif sur des facteurs qui influent sur le temps et les coûts de dédouanement des marchandises. Ces facteurs sont notamment le nombre d'inspections matérielles et de vérifications des documents (réduit du fait de la mise en œuvre de contrôles fondés sur les risques), le montant des frais et le nombre de documents requis aux fins du dédouanement (réduit ou supprimé grâce à la simplification des procédures) et le nombre d'opérations manuelles (réduit grâce à la numérisation des documents et à l'automatisation des procédures). 


\section{Encadré 6.4. Exemples $d$ 'impacts pour les pays signalés}

Marchandises importées empruntant le circuit rouge (inspection matérielle) réduites de 48\% (Éthiopie 2014-2018)

Obligation de produire des exemplaires de récépissés fiscaux et de certificats de connaissement pour les exportations supprimée (Éthiopie 2017)

Certificat d'origine automatisé (Éthiopie 2017)

Nombre de produits nécessitant un permis d'importation réduit (Libéria 2016)

Nombre de documents requis pour l'exportation réduit; frais de manutention des cargaisons dans les terminaux supprimés par la mise en place d’une procédure de dédouanement «locale» simplifiée (Monténégro 2018)

Marchandises importées empruntant le «circuit vert» (aucune inspection) augmentées de 32\% (Népal 2016-2017)

Marchandises importées empruntant le circuit rouge (inspection matérielle) réduites de 54\%

(São Tomé-et-Príncipe 2018)

Plusieurs mesures peuvent être utilisées pour mettre en évidence l'impact des réformes de facilitation des échanges à terme et, ainsi, faire apparaître l'efficacité de l'assistance technique et du renforcement des capacités. Il s'agit notamment des études sur le temps nécessaire à la mainlevée, des enquêtes sur la facilitation des échanges; et des indicateurs de performance définis au niveau national (ou régional). Ces mesures sont examinées dans les sections suivantes.

\section{- Évaluer l'impact grâce aux études sur le temps nécessaire à la mainlevée}

Étant donné que l'objectif général de facilitation des échanges de l'Accord est "d'accélérer encore le mouvement, la mainlevée et le dédouanement des marchandises, y compris les marchandises en transit", le temps est une mesure essentielle pour mettre en évidence l'impact général des réformes.

\section{Tableau 6.3 Résultats des études sur le temps nécessaire à la mainlevée}

Pays Réformes appuyées par l'assistance technique et Réduction des délais le renforcement des capacités

1. Bangladesh (port de Chittagong)
Simplification des procédures

- Coordination des organismes nationaux présents aux frontières

- Gestion des risques

Portail sur le commerce

CNFE

- Informatique

(module d'octroi de licences en ligne)

Étude sur le temps nécessaire à la mainlevée

- Législation

\begin{tabular}{|c|c|c|}
\hline $\begin{array}{l}\text { 2. Timor-Leste } \\
\text { (port de Dili)) }\end{array}$ & $\begin{array}{l}\text { Gestion des risques } \\
\text { CNFE } \\
\text { Étude sur le temps nécessaire à la mainlevée } \\
\text { Législation }\end{array}$ & $\begin{array}{l}62,6 \% \\
(15,06 \text { jours } \rightarrow 5,63 \text { jours })\end{array}$ \\
\hline $\begin{array}{l}\text { 3. Guatemala-Honduras } \\
\text { (frontière terrestre/étude pilote) }\end{array}$ & $\begin{array}{l}\text { Coordination transfrontières } \\
\text { (poste frontière commun) } \\
\text { Document électronique } \\
\text { - Simplification/intégration des procédures } \\
\text { Informatique (système de traitement douanier) } \\
\text { Législation }\end{array}$ & $\begin{array}{l}97,5 \% \\
\text { (10 heures } \rightarrow 15 \text { minutes) }\end{array}$ \\
\hline
\end{tabular}


En principe, une étude sur le temps nécessaire à la mainlevée structurée correctement - menée périodiquement et de manière cohérente sur la période pendant laquelle les réformes sont mises en œuvre - fournira des données fiables pour cette mesure. ${ }^{16}$

Si quelque 30 pays ont achevé les premières études sur le temps nécessaire à la mainlevée ont été achevées grâce au soutien en matière d'assistance technique et de renforcement des capacités, ils sont moins nombreux à les avoir répétées, mais dans ceux qui l'ont fait, les résultats initiaux suggèrent que l'assistance technique et le renforcement des capacités ont effectivement contribué à réduire considérablement les délais de dédouanement.

\section{- Évaluation de l'impact au moyen des études et indicateurs par pays de la Banque mondiale et de l'OCDE}

Il est également possible d'évaluer l'impact des réformes de facilitation des échanges au moyen des études périodiques par pays de la Banque mondiale - le rapport annuel "Doing Business" et l'indice de performance logistique (IPL) biennal - et les indicateurs du commerce de l'OCDE, actualisés tous les deux ans.

\section{Encadré 6.5 Les indicateurs de facilitation des échanges (IFE) de l'OCDE}

Les IFE de l'OCDE ont été mis au point pour appuyer la négociation et la mise en œuvre de l'AFE. À ce jour, ils constituent l'instrument le plus précis pour suivre et comparer les performances des pays en matière de facilitation des échanges à l'échelle mondiale.

Les IFE reflètent les dispositions de fond visées à la section I de l'AFE, qui va de l'article premier intitulé «Publication et disponibilité des renseignements» à l'article 12 intitulé «Coopération douanière». Chaque indicateur comporte plusieurs variables particulières et factuelles concernant les politiques et réglementations en vigueur liées au commerce et leur mise en œuvre concrète. Les IFE permettent de chiffrer la mesure dans laquelle les pays ont effectivement introduit et mis en œuvre des mesures de facilitation des échanges et leur efficacité par rapport aux autres.

La base de données sur les IFE vise 163 pays, qui comprennent des économies à tous les niveaux de revenu et de toutes les régions géographiques. Tous les deux ans, des renseignements publiés et des présentations directes par les pays sont associés à des données factuelles émanant du secteur privé, de façon à établir un parallèle entre les réglementations applicables et le compte rendu, par un praticien, de la réalité sur le terrain. L'OCDE enquête sur les discordances pour fournir des renseignements exacts qui soient comparables sur le plan géographique et cohérents sur la durée.

Les IFE sont utilisés pour suivre et comparer les performances des pays en matière de facilitation des échanges, ce qui aide les décideurs à faire le point sur leurs efforts de facilitation des échanges, à mettre en évidence les difficultés et à répertorier les possibilités de progrès. Ces indicateurs sont aussi une aide précieuse pour ce qui est de recenser et de hiérarchiser les besoins en matière d'assistance technique et de renforcement des capacités.

Les données issues des IFE permettent d'effectuer des comparaisons entre groupes de revenu, groupes géographiques et membres d'un groupement régional, d'établir le bilan de chaque mesure de facilitation des échanges et d'évaluer l'évolution des résultats au fil du temps. Elles sont aussi utilisées comme un outil d'évaluation de l'impact économique produit par les réformes en matière de facilitation des échanges, en particulier la mise en œuvre de l'AFE.

II est ressorti des données de 2017 qu'à l'époque de l'entrée en vigueur de l'AFE, l'exécution des mesures visées par l'Accord était bien engagée, même si les résultats variaient d'un groupe de revenu à l'autre et au sein d'un même groupe dans la plupart des domaines d'action. Rapidement, des améliorations ont eu lieu dans des domaines tels que l'automatisation et la simplification des procédures, et la coopération avec la communauté commerciale. Les plus grandes difficultés résident sans conteste dans les domaines de la coopération nationale et internationale entre les organismes présents aux frontières. L'introduction et l'utilisation des technologies de l'information et l'instauration d'un guichet unique font partie des éléments les plus coûteux de la facilitation des échanges; toutefois, les principaux obstacles se rapportant au changement des mentalités et des cultures en matière de procédures à la frontière, la formation revêt une importance capitale.

Source: OCDE (2018) 
Le rapport "Doing Business" de la Banque mondiale fait l'inventaire du temps et des coûts associés au processus logistique d'exportation et d'importation de marchandises. Un résultat unique en matière de "commerce transfrontalier" ("Trading Across Borders") est calculé tous les ans pour chaque pays compte tenu du temps et des coûts (à l'exclusion des droits de douane) associés aux prescriptions documentaires (c'est-à-dire obtenir, élaborer, traiter et présenter les documents requis de la part de tous les organismes gouvernementaux pour mener à bien la transaction) et aux procédures aux frontières (c'est-à-dire le dédouanement et les procédures d'inspection menées par d'autres organismes). L'étude de la Banque mondiale sur l'IPL comprend une évaluation de "I'efficacité" de la procédure de dédouanement, intégrant la vitesse, la simplicité et la prévisibilité des formalités intéressant les douanes et autres organismes présents aux frontières.

On observe effectivement des améliorations de l'indice de facilité de faire des affaires et de l'IPL dans les pays qui mettent en œuvre l'AFE avec l'appui du TFSP, comme indiqué dans la figure 6.10.

II faut parfois du temps avant que les activités de réforme engagées au titre de l'AFE se traduisent par une amélioration de ces indicateurs. Ceux-ci mesurent le temps et le coût des procédures en s'appuyant sur des enquêtes réalisées auprès d'entreprises de logistique et de commerce qui exercent leur activité dans le pays, et il peut y avoir un décalage entre le moment où une réforme est mise en place et celui où les répondants du secteur des entreprises en prennent conscience. En outre, la dernière enquête IPL a eu lieu entre février 2017 et février 2018, soit la première année de mise en œuvre de l'AFE; de la même façon, les données contenues dans le rapport "Doing Business" de 2019 datent du 1er mai 2018. Néanmoins, une tendance positive encourageante se dégage de ces résultats, même s'ils ont été obtenus dans les premiers temps de l'application de l'AFE.

\section{Figure 6.10. Amélioration en pourcentage des indicateurs de facilitation des échanges de la Banque mondiale dans les pays visés par le TFSP (2016-2019)}

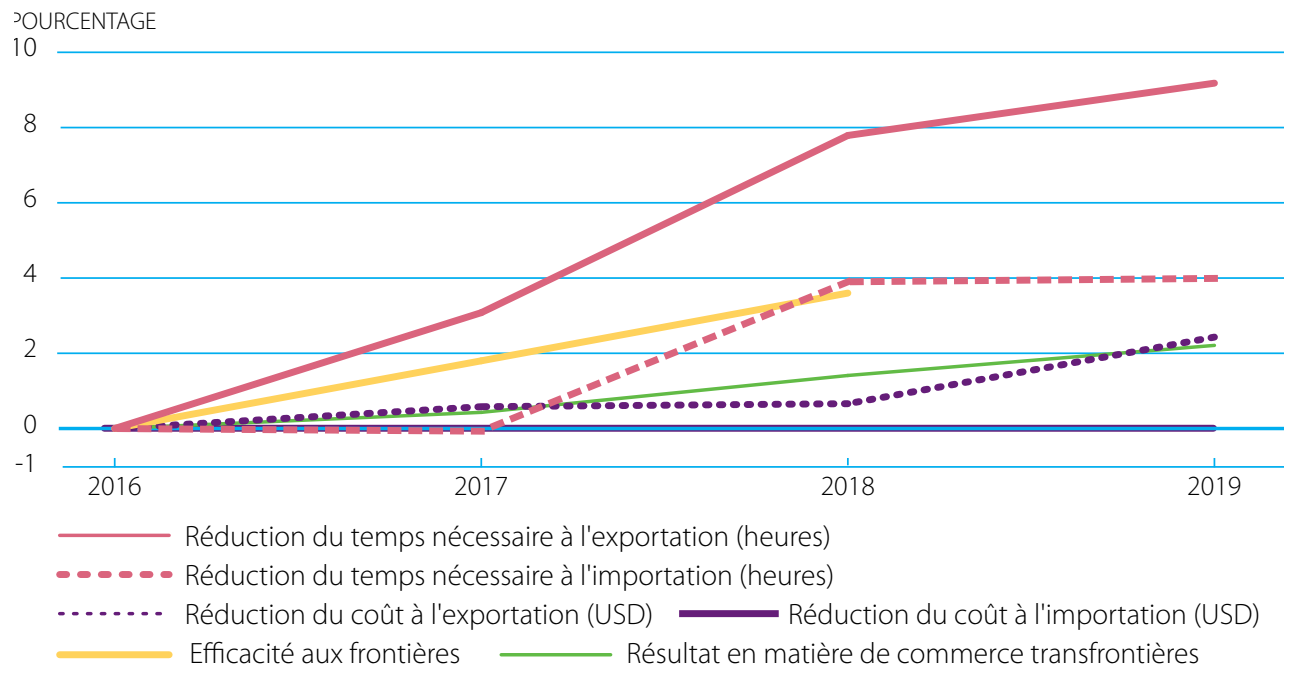

Source: Données issues du rapport de la Banque mondiale "Doing Business" et de I'IPL. 
CHAPITRE 6. LE RÔLE ESSENTIEL DE LA FACILITATION DES ÉCHANGES DANS LA PROMOTION DE LA DIVERSIFICATION ÉCONOMIQUE ET DES RÉFORMES STRUCTURELLES

\section{- Autres approches (Évaluation de l'impact au moyen d'indicateurs de performance définis aux niveaux national ou régional)}

Les études sur le temps nécessaire à la mainlevée et les enquêtes et bases de données internationales examinées dans les paragraphes suivants évaluent l'impact des réformes en termes de temps et de coût du commerce et, plus généralement, du point de vue des entreprises, ce qui se justifie compte tenu des objectifs de l'Accord. Toutefois, il existe également un point de vue national distinct: les pays espèrent grâce à la réforme de la facilitation des échanges atteindre des objectifs de développement économique et social qui dépassent la réduction du temps nécessaire aux affaires et du coût du commerce. Ces objectifs plus larges pourraient comprendre, par exemple, l'intégration régionale, l'amélioration de l'accès des petites et moyennes entreprises (PME) aux marchés internationaux, la diversification des exportations, l'égalité des sexes et l'autonomisation des femmes, etc.

Les travaux de recherche de l'OCDE soulignent l'importance de la contribution des PME à l'activité économique et à l'emploi dans les pays développés et en développement. Néanmoins, leur participation au commerce international et, par conséquent, leur capacité de tirer profit de la mondialisation demeurent limitées par rapport aux plus grandes entreprises. En effet, même si elles constituent la majorité des entreprises, les PME comptent en moyenne pour 33\% des exportations dans certains pays développés, et pour seulement 18\% des exportations dans certains pays en développement. Une tendance analogue se dessine en ce qui concerne les importations; les PME représentent, en moyenne, 40\% des importations dans les pays développés et environ 34\% dans divers pays en développement.

Les PME étant limitées en termes d'expérience, de productivité et d'accès au financement, il leur est plus compliqué de s'adapter à des objectifs internationaux, qu'il s'agisse d'importations ou d'exportations. En outre, les coûts inhérents à l'expédition transfrontières de marchandises peuvent être particulièrement élevés pour les petites entreprises, qui n'ont pas les ressources humaines spécialisées pour s'occuper des aspects de procédure et dont les expéditions peuvent être occasionnelles ou porter sur de petits volumes. Ces éléments rendent la facilitation des échanges particulièrement importante pour les PME qui souhaitent participer au commerce international. Des mesures peuvent être prises pour définir les coûts fixes ou variables du commerce, ce qui agit sur la capacité des PME d'importer ou d'exporter (la marge extensive) ou sur la quantité qu'elles importent ou exportent (la marge intensive), respectivement. L'encadré 6.6 ci-dessous met en lumière les travaux de recherche de I'OCDE sur les résultats obtenus par les PME en matière d'internationalisation grâce à la facilitation des échanges.

II ressort des travaux de recherche de l'OCDE que tout ne dépend pas uniquement de l'environnement de la facilitation des échanges dans l'économie nationale. Le contexte dans lequel se trouvent les PME sur les marchés d'exportation ou dans les économies d'origine de leurs intrants importés joue également sur leur participation au commerce et sur les gains qu'elles en tirent. Cet état de fait montre à quel point les réformes de la facilitation des échanges peuvent profiter à tous les pays, à plus forte raison s'ils agissent de concert. En outre, l'amélioration du contexte en matière de facilitation des échanges au profit de grandes entreprises pourrait également favoriser la participation indirecte des PME au commerce international. Les liens en amont et en aval avec des entreprises plus importantes peuvent être vitaux pour de nombreuses PME, en particulier dans le contexte des chaînes de valeur mondiales et régionales.

Fondamentalement, l'analyse de l'OCDE suggère que les réformes de la facilitation des échanges, outre qu'elles améliorent l'efficacité des entreprises de toutes tailles, favorisent des résultats plus inclusifs en contribuant à instaurer des règles uniformes entre grandes et petites entreprises. Un message encourageant ressort également de l'exercice de suivi et d'évaluation mené conjointement par l'OCDE et l'OMC, à savoir que le financement de l'Aide pour le commerce aux fins de la facilitation des échanges a été considéré par 50 pays partenaires interrogés comme l'un des meilleurs moyens d'appuyer l'autonomisation économique des PME. Cinquante et un pays partenaires interrogés ont également indiqué que la facilitation des échanges était un domaine dans lequel l'appui fourni au titre de l'Aide pour le commerce avait agi sur la diversification économique. 
Encadré 6.6 Aider les PME à s'internationaliser grâce à la facilitation des échanges (suite à la page suivante)

L'OCDE a cherché à analyser la relation entre l'environnement de la facilitation des échanges aux frontières - tel que mesuré au moyen des IFE de l'OCDE - et les mesures visant l'internationalisation des PME (en utilisant l'Enquête auprès des entreprises de la Banque mondiale, et les statistiques du commerce en fonction des caractéristiques de l'entreprise - TEC, de l'OCDE). Plusieurs tendances sur la relation entre les PME et la facilitation des échanges se sont dégagées de cette analyse. Si les entreprises de toutes tailles, des économies développées et en développement, tirent profit des améliorations du contexte général en matière de facilitation des échanges, les plus petites entreprises semblent en profiter plutôt davantage que les grandes

Figure 6.11. Un cadre de politiques de facilitation des échanges qui appuie les PME plutôt que les grandes entreprises dans les économies en développement

Effet d'une amélioration de $0,1 \%$ des IFE (indice moyen des onze domaines de facilitation des échanges) sur la probabilité de devenir un exportateur ou un importateur

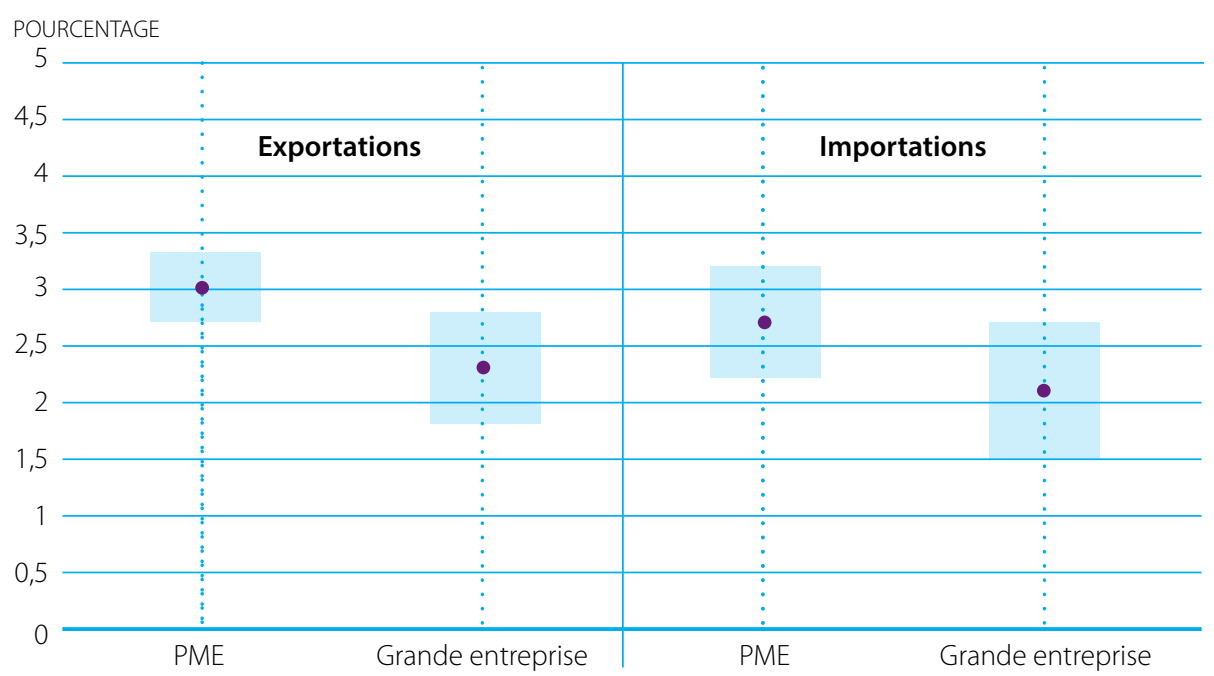

Note: La figure présente les améliorations en pourcentage de la probabilité d'exporter (ou d'importer) par rapport aux effets marginaux d'un ou de plusieurs modèles probits. La zone grisée représente l'intervalle de confiance de 95\% autour de l'effet estimé de l'indicateur.

Source: Estimations de l'OCDE (2019a) fondées sur les données issues de l'enquête de la Banque mondiale auprès des entreprises.

Dans les économies développées comme dans les économies en développement, des mesures telles que l'inclusion des PME aux processus de consultation ou l'efficacité des procédures de recours - mesures qui peuvent être associées à des coûts fixes du commerce plus élevés - ont une incidence plus importante sur la propension des entreprises à exporter et à importer ou sur la probabilité qu'elles deviennent exportatrices ou importatrices. En revanche, les mesures telles que les droits et redevances, la rationalisation des procédures et l'automatisation des procédures aux frontières, mesures qui sont généralement associées à des réductions des coûts variables, ont une incidence plus importante sur les valeurs des exportations et des importations des entreprises. 
Encadré 6.6 Aider les PME à s'internationaliser grâce à la facilitation des échanges

(suite de la page précédente)

Figure 6.12. Facteurs des politiques de facilitation des échanges qui sous-tendent les exportations et importations des PME dans les économies en développements

Groupe A: Effet d'une amélioration de 0,1\% des IFE (par domaine) sur la probabilité de devenir un exportateur

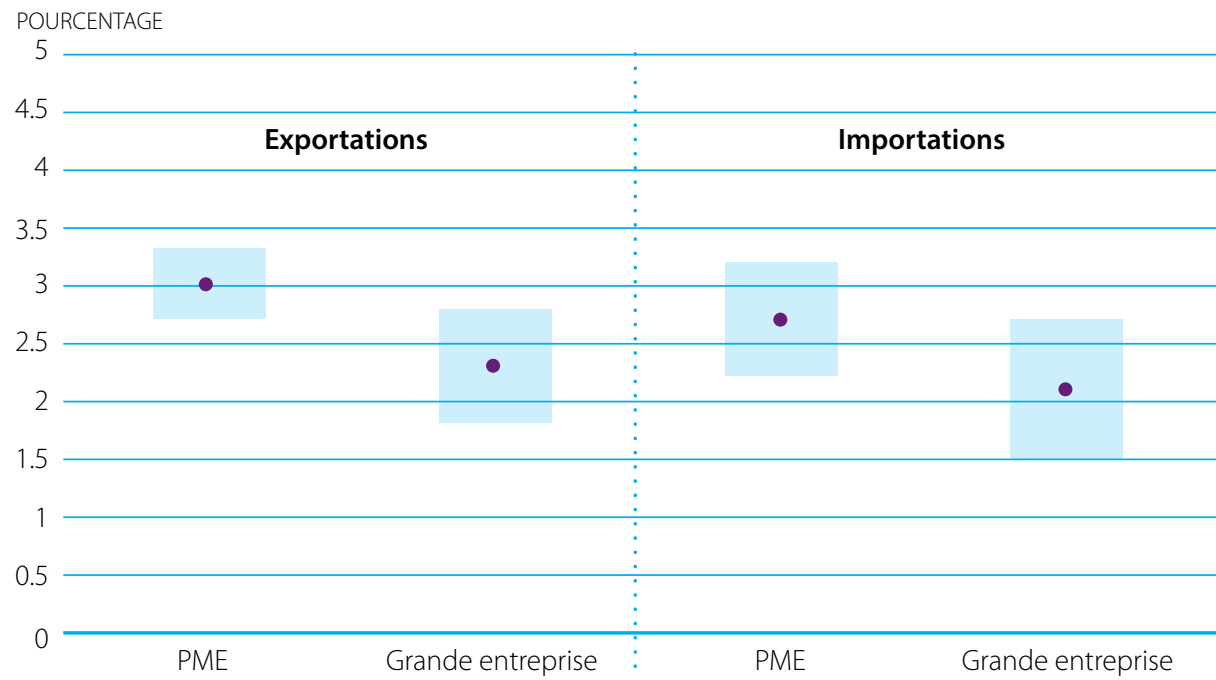

Groupe B: Effet d'une amélioration de $0,1 \%$ des IFE (par domaine) sur la probabilité de devenir un importateur

POURCENTAGE

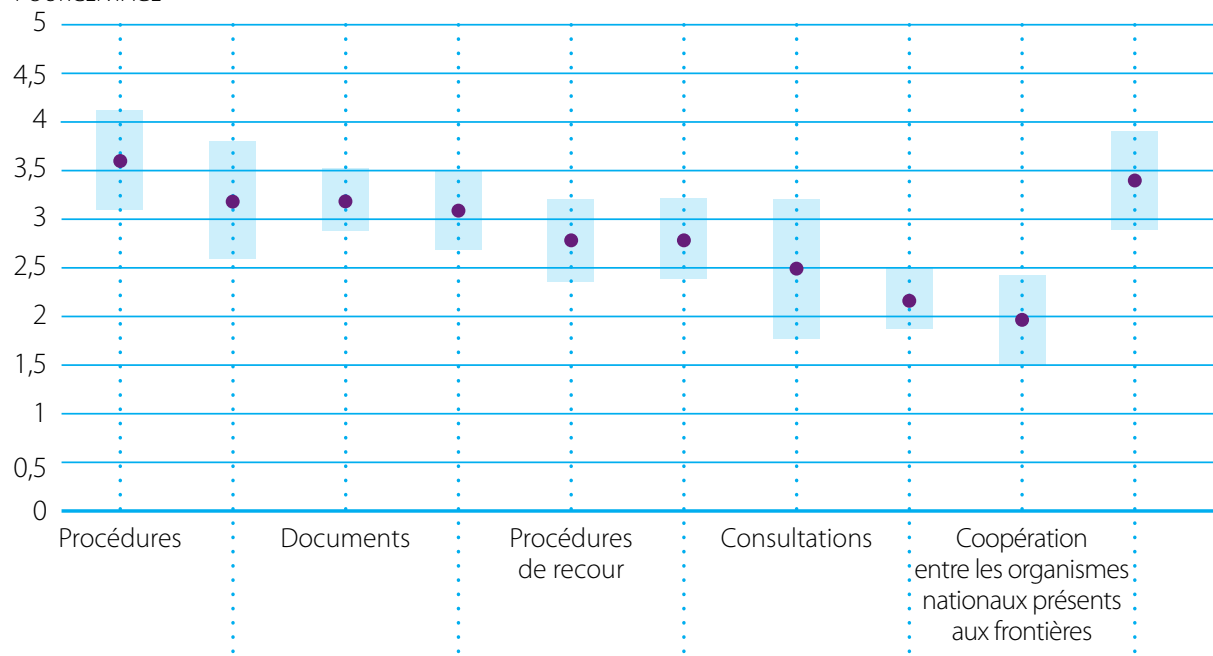

Décisions Droits et Automatisation Disponibilité Performance

Note: Le groupe A présente les améliorations en pourcentage de la probabilité d'exporter par rapport aux effets marginaux du modèle probit. Le groupe B présente les améliorations en pourcentage de la probabilité d'importer par rapport aux effets marginaux du modèle probit. La zone grisée représente l'intervalle de confiance de 95\% autour de l'effet estimé de l'indicateur.

Source: Estimations de l'OCDE (2019a et b) fondées sur les données issues de l'enquête de la Banque mondiale auprès des entreprises 
Toutefois, pour que les PME tirent pleinement parti des avantages du commerce, il convient de compléter les réformes dans les domaines de facilitation des échanges identifiés en réalisant des réformes et des investissements dans d'autres domaines liés à la capacité des entreprises de tirer parti des nouvelles possibilités commerciales, notamment la mise en place d'infrastructures numériques, le soutien à l'adoption de nouvelles technologies et le renforcement des capacités.

Les travaux de recherche de l'OCDE en Asie du Sud-Est montrent que, si une participation plus importante des PME de la région aux chaînes de valeur mondiales et régionales est liée à la création d'emplois, les avantages ne sont pas toujours répartis équitablement entre les sexes. Si les PME importatrices d'Indonésie ont créé plus d'emplois pour les femmes que toute autre catégorie d'entreprises commerciales ou non commerciales, elles ont créé encore plus d'emplois pour les hommes. ${ }^{17}$ Les rapports présentés dans le cadre de l'exercice de suivi et d'évaluation mené conjointement par l'OCDE et I'OMC souligne cette tendance. Le financement de l'Aide pour le commerce aux fins de la facilitation des échanges a été considéré comme un moyen d'appuyer l'autonomisation économique des femmes par 38 pays partenaires interrogés.

La création d'un cadre de suivi et d'évaluation est une étape essentielle de la planification de la mise en œuvre nationale. Toutefois, il faut produire les données nécessaires pour mesurer les progrès et les conséquences de la mise en œuvre à l'aune des objectifs nationaux plus vastes. L'une des activités importantes menées dans le cadre de la planification de la mise en œuvre nationale consiste à arrêter ces objectifs nationaux, à définir et à hiérarchiser les mesures de facilitation des échanges qui permettront de les atteindre et à établir les indicateurs et les procédures qui seront utilisés pour mesurer les progrès et l'impact de la mise en œuvre au vu de ces objectifs nationaux. Le Comité national de la facilitation des échanges, auquel participera largement le secteur privé, se chargera de mener à bien cette activité, dont il ressortira une stratégie nationale de facilitation des échanges officielle et convenue ou un plan d'action analogue.

Encadré 6.7. Stratégie de facilitation des échanges mise en place par le Monténégro (suite à la page suivante)

En mars 2018, le gouvernement du Monténégro a officiellement adopté sa Stratégie nationale de facilitation des échanges définissant les orientations et les priorités des réformes pour la période 2018-2022. La stratégie était nécessaire étant donné que le pays avait pris plusieurs engagements à un niveau international et régional, notamment l'AFE, ratifié par le Monténégro en 2016, le Protocole additionnel nº 5 à l'Accord de libre-échange d'Europe centrale (ALEEC), qui comprend des mesures de facilitation des échanges outre celles contenues dans l'AFE, et les obligations découlant de l'adhésion du Monténégro à l'UE.

La stratégie visait à mettre au point une approche réaliste et cohérente pour honorer ces engagements de sorte à atteindre au mieux les objectifs nationaux de développement économique du Monténégro. En outre, il a fallu tenir compte des investissements dans les programmes de réforme en cours des organismes présents aux frontières - tels que les travaux sur la gestion intégrée des frontières et les plans d'activité à long terme des douanes - et des ressources disponibles limitées.

La stratégie a été mise au point sur une période de huit mois par le Comité national de la facilitation des échanges, avec l'appui technique de la Banque mondiale. Les autorités présentes aux frontières et les autorités gouvernementales compétentes, ainsi que des représentants du secteur privé, ont pris part à l'élaboration de la stratégie dans le cadre d'une série d'ateliers visant à échanger des vues et à élaborer et à peaufiner le document correspondant.

Le résultat final - composé d'une stratégie et d'un plan d'action détaillé - définit les mesures prioritaires de facilitation des échanges à mettre en œuvre d'ici à 2023, les responsabilités des organismes présents aux frontières (ainsi que du secteur privé) en matière de mise en œuvre, les mesures à prendre et les délais à respecter. Qui plus est, la stratégie nationale établit des indicateurs de performance clés correspondant à chaque mesure, convenus par les parties prenantes, qui seront utilisés par le Comité national de la facilitation des échanges pour mesurer les progrès et les impacts de la mise en œuvre. 
Encadré 6.7. Stratégie de facilitation des échanges mise en place par le Monténégro

(suite de la page précédente)

Figure 6.13. Indicateurs de performance clés de la stratégie de facilitation des échanges du Monténégro pour la période 2018-2022 (extraits)

\section{MESURE 1.1. FACILITER L'ACCÈS AUX INFORMATIONS ET EN AMÉLIORER LA QUALITÉ}

Les autorités gouvernementales compétentes publieront et actualiseront régulièrement les informations et formulaires concernant les prescriptions en matière d'importation, d'exportation et de transit, conformément à l'AFE et au Protocole additionnel $n^{\circ} 5$ à l'ALEEC.

\begin{tabular}{|c|c|c|c|c|c|}
\hline Indicateur & \multicolumn{2}{|c|}{ Valeur } & \multicolumn{2}{|c|}{ Période } & Résultat \\
\hline \multirow{2}{*}{$\begin{array}{l}\text { 1. Pourcentage d'informations } \\
\text { publiées conformément } \\
\text { aux articles 1:1 et 1:2 de } \\
\text { l'Accord sur la facilitation des } \\
\text { échanges et au Protocole } \\
\text { additionnel n } 5 \text { à l'ALEEC; }\end{array}$} & $\begin{array}{l}\text { Point de } \\
\text { départ }\end{array}$ & Objectif & $\begin{array}{c}\text { Année } \\
\text { de début }\end{array}$ & $\begin{array}{l}\text { Année } \\
\text { de fin }\end{array}$ & \multirow{2}{*}{$\begin{array}{l}\text { Toutes les informations devant être } \\
\text { publiées au titre de l'article 1:1 de } \\
\text { l'AFE et du Protocole additionnel } \\
\text { n } 5 \text { à l'ALEEC sont facilement } \\
\text { accessibles sur les sites Web des } \\
\text { autorités gouvernementales } \\
\text { compétentes, y compris la } \\
\text { description des procédures } \\
\text { d'importation, d'exportation et de } \\
\text { transit, les procédures de recours } \\
\text { ou de révision, les formulaires et } \\
\text { documents nécessaires, etc. }\end{array}$} \\
\hline & À définir & $100 \%$ & $\frac{\frac{\text { Article 1:1 }}{\text { et }}}{\frac{\text { Protocole }}{\text { additionnel }}}$ & $\frac{\frac{\text { Article 1:1 }}{\text { et }}}{\frac{\text { Protocole }}{\text { additionnel }}}$ & \\
\hline
\end{tabular}

\section{MESURE 3.2. GÉNÉRALISER L'USAGE DES PROCÉDURES SIMPLIFIÉES}

L'administration des douanes, en collaboration avec l'autorité chargée de la sécurité sanitaire des produits alimentaires et des affaires vétérinaires et phytosanitaires et les associations professionnelles, élaborera et mettra en place des programmes visant à accroître le recours, par les opérateurs économiques, aux procédures simplifiées à l'importation et à l'exportation.

\begin{tabular}{|l|c|c|c|c|c|}
\hline \multicolumn{1}{|c|}{ Indicateur } & \multicolumn{2}{|c|}{ Valeur } & \multicolumn{2}{c|}{ Période } & \multicolumn{2}{c|}{ Résultat } \\
\hline $\begin{array}{l}\text { 1. Pourcentage de déclarations } \\
\text { traitées dans le cadre de } \\
\text { procédures simplifiées par } \\
\text { rapport au nombre total de } \\
\text { déclarations. }\end{array}$ & $\begin{array}{c}\text { Point de } \\
\text { départ }\end{array}$ & Objectif & $\begin{array}{c}\text { Année } \\
\text { de début }\end{array}$ & $\begin{array}{c}\text { Année } \\
\text { de fin }\end{array}$ & $\begin{array}{l}\text { Au moins 40\% du total des } \\
\text { déclarations sont faites dans le cadre } \\
\text { de procédures simplifiées. }\end{array}$ \\
\cline { 2 - 6 } & $2 \%$ & $\begin{array}{l}\text { Minimum } \\
40 \%\end{array}$ & 2018 & 2020 & \\
\hline
\end{tabular}

L'autorité chargée de la sécurité sanitaire des produits alimentaires et des affaires vétérinaires et phytosanitaires mettra au point un système automatisé pour appuyer les activités de contrôle aux frontières des agents d'inspection vétérinaire, sanitaire et phytosanitaire et permettre le traitement dématérialisé des documents justificatifs requis pour l'importation, l'exportation et le transit des marchandises soumises aux prescriptions SPS, sans avoir à fournir une copie papier.

\begin{tabular}{|c|c|c|c|c|c|}
\hline Indicateur & \multicolumn{2}{|c|}{ Valeur } & \multicolumn{2}{|c|}{ Période } & Résultat \\
\hline \multirow{2}{*}{$\begin{array}{l}\text { 1. Pourcentage de transactions } \\
\text { automatisées par rapport au } \\
\text { nombre total de transactions } \\
\text { de l'autorité chargée de } \\
\text { la sécurité sanitaire des } \\
\text { produits alimentaires et } \\
\text { des affaires vétérinaires et } \\
\text { phytosanitaire. }\end{array}$} & $\begin{array}{l}\text { Point de } \\
\text { départ }\end{array}$ & Objectif & $\begin{array}{c}\text { Année } \\
\text { de début }\end{array}$ & $\begin{array}{l}\text { Année } \\
\text { de fin }\end{array}$ & \multirow{2}{*}{$\begin{array}{l}70 \% \text { des transactions de l'autorité } \\
\text { chargée de la sécurité sanitaire des } \\
\text { produits alimentaires et des affaires } \\
\text { vétérinaires et phytosanitaire sont } \\
\text { totalement automatisées. }\end{array}$} \\
\hline & 0 & $70 \%$ & 2019 & 2022 & \\
\hline
\end{tabular}

La Stratégie nationale de facilitation des échanges est publiée sur les sites Web du gouvernement du Monténégro. 
CHAPITRE 6. LE RÔLE ESSENTIEL DE LA FACILITATION DES ÉCHANGES DANS LA PROMOTION DE LA DIVERSIFICATION ÉCONOMIQUE ET DES RÉFORMES STRUCTURELLES

\section{FACILITATION DU COMMERCE ÉLECTRONIQUE}

Dans la présente section, nous examinerons la façon dont les fonctions douanières et autres fonctions de dédouanement s'adaptent au défi que représente le commerce électronique et la façon dont l'Aide pour le commerce appuie ce processus.

Même si le "commerce électronique", tel qu'il est couramment défini, comprend à la fois les ventes nationales et internationales de biens et services', les présentes observations sont axées uniquement sur les aspects des transactions commerciales électroniques relatifs à la facilitation des échanges, à savoir la livraison transfrontières de produits physiques achetés en ligne.

\section{Caractéristiques générales}

Les caractéristiques du marché du commerce électronique transfrontières ont fait l'objet de précédentes études et analyses. ${ }^{19}$ La majeure partie du marché du commerce électronique de détail consiste en des colis individuels de petite taille contenant des marchandises de faible valeur. En général, le vendeur s'engage à livrer la marchandise directement chez le consommateur ou dans un "point de retrait" local, en passant un contrat avec le service postal ou un opérateur d'envois à livraison rapide qui se charge du dédouanement à l'exportation et à l'importation. ${ }^{20}$ La fiabilité du vendeur, la vitesse de livraison, le suivi et la traçabilité d'un colis du point d'expédition au point de livraison et la possibilité de renvoyer les marchandises facilement font partie des principales exigences des consommateurs du commerce électronique. Étant donné que la vitesse de livraison est un élément essentiel, les entreprises utilisent généralement le transport aérien.

Selon les informations disponibles, le marché du commerce électronique est important et connaît une croissance rapide. Même si la mesure du commerce électronique pose problème, les renseignements dont on dispose donnent au moins une indication des proportions et de la tendance du marché. II ressort d'enquêtes et d'autres données provenant de cabinets de conseil, par exemple, que d'ici à 2021, les ventes de commerce de détail en ligne augmenteront de plus de $250 \%$ pour s'établir à 4800 milliards d'USD, contre 1300 milliards d'USD en 2014. ${ }^{21}$ L'envergure du marché du commerce électronique entre entreprises (B2B) semble encore plus impressionnante; on estime que dans certains pays les ventes B2B en ligne représentent au total 60 à $90 \%$ de l'ensemble du marché du commerce électronique. ${ }^{22}$ Les ventes transfrontières représentent une part importante et croissante du marché du commerce électronique. En 2015, les ventes transfrontières constituaient 15\% du marché du commerce électronique; elles devraient croître pour représenter environ 22\% du commerce électronique mondial d'ici à 2020.23

Les plates-formes ou places de marché en ligne (telles qu'Amazon, eBay, Alibaba et Wish, ainsi que les plates-formes locales des pays en développement telles que Jumia) fournissent une infrastructure prête à l'emploi d'un bon rapport qualité-prix qui permet aux entreprises des pays en développement et des pays les moins avancés d'accéder aux marchés mondiaux. En donnant aux entreprises la possibilité de se mettre en rapport avec des acheteurs étrangers directement via Internet, les coûts de déplacement ou de la présence physique sur les marchés d'exportation ou I'utilisation d'intermédiaires sont réduits ou supprimés. En outre, ces places de marché de commerce électronique proposent des services qui permettent aux vendeurs de traiter plus facilement avec des tierces parties concernant la logistique et la livraison de marchandises.

Le marché du commerce électronique crée donc de nouvelles possibilités d'exportation pour les PME, qui représentent la majeure partie des entreprises dans la plupart des pays en développement, profite aux consommateurs grâce à des prix plus bas et à un choix plus vaste et sert les intérêts du gouvernement grâce à la création de nouveaux emplois, à l'augmentation des exportations et à la pression concurrentielle dans l'économie. ${ }^{24}$ Toutefois, l'accroissement rapide des volumes du commerce électronique et la nature de ces échanges engendrent des difficultés particulières pour les douanes et autres organismes présents aux frontières, lesquelles peuvent nécessiter qu'un accent particulier soit placé sur la mise en œuvre des mesures de facilitation des échanges. Ces mesures sont examinées dans les sections suivantes. 
CHAPITRE 6. LE RÔLE ESSENTIEL DE LA FACILITATION DES ÉCHANGES DANS LA PROMOTION DE LA DIVERSIFICATION ÉCONOMIQUE ET DES RÉFORMES STRUCTURELLES

\section{Facilitation du commerce électronique transfrontières}

De manière générale, les problèmes de facilitation des échanges que soulève la livraison transfrontières de marchandises achetées sur un site Web sont identiques à ceux qui surviennent quand la vente à l'exportation est conclue en personne, par écrit ou par d'autres moyens classiques de ce type. Ainsi, les marchandises envoyées par un vendeur en ligne sont soumises aux mêmes contrôles aux frontières, exigences en matière de documents et de données, formalités douanières, droits, etc., que ceux nécessaires à la mainlevée et au dédouanement des marchandises vendues par les voies traditionnelles. Une mise en œuvre pleine et efficace des mesures de l'AFE visant à supprimer les inefficacités du processus de dédouanement, à rationaliser les droits, à améliorer la transparence des prescriptions, à intégrer les activités de traitement et de contrôle des organismes présents aux frontières, etc., permettra de réduire les coûts du commerce et donc d'accroître la compétitivité des entreprises sur les marchés internationaux et de réduire les prix payés par les consommateurs, indépendamment de la façon dont la marchandise a été achetée.

Toutefois, il est également reconnu que certaines mesures de facilitation revêtent une importance particulière pour ce qui est de soutenir le commerce électronique transfrontières, compte tenu de ses caractéristiques particulières, et que les gouvernements devraient donc leur accorder la priorité dans le cadre de la mise en œuvre de l'AFE pour favoriser la croissance de ce commerce. Ces mesures essentielles de facilitation du commerce électronique sont les suivantes -

\section{Droit de minimis et exonérations fiscales}

Aux termes de l'AFE, les Membres de l'OMC "prévoiront, dans la mesure du possible, une valeur d'envoi ou un montant imposable de minimis, pour lesquels ni droits de douane ni taxes ne seront recouvrés". ${ }^{25}$ Comme l'indiquent les dispositions de la mesure, le seuil de minimis peut être défini en termes de valeur des marchandises ou, moins souvent, selon le montant des droits et taxes exigibles ou une combinaison de la valeur des marchandises et du montant des droits et taxes.

Figure 6.14. Montants de minimis des droits de douane dans 98 pays (Global Express Association) ${ }^{26}$

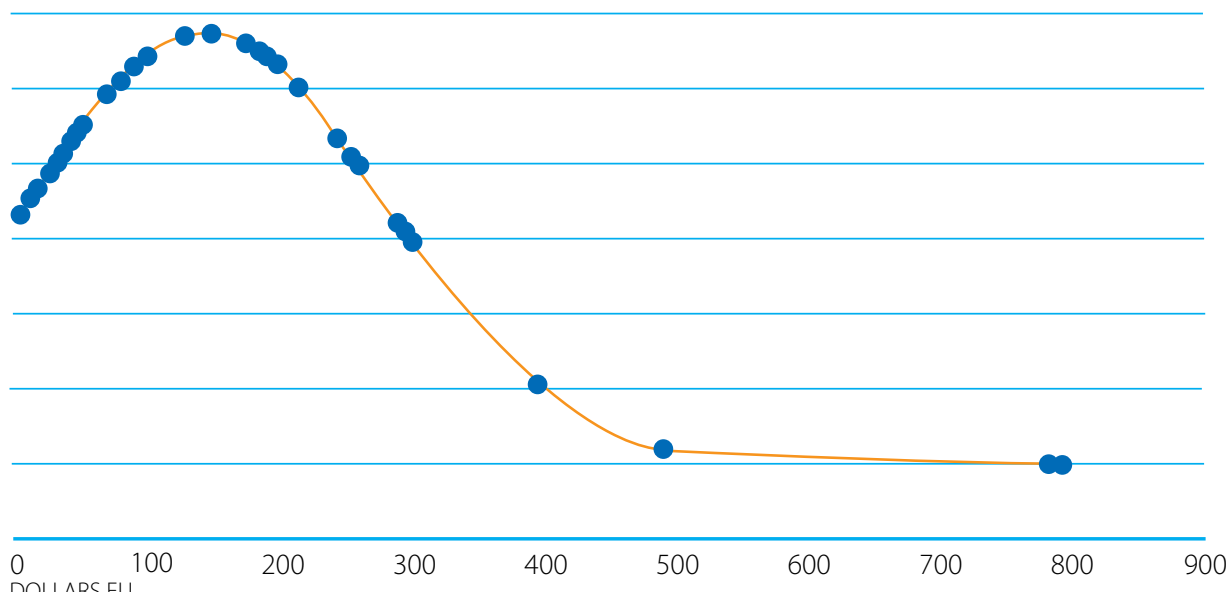

DOLLARS EU

Source: https://global-express.org/assets/files/Customs\%20Committee/de-minimis/GEA\%20overview\%20 on\%20de\%20minimis_28\%20March\%202018.pdf 
L'exemption de minimis importe tout particulièrement pour le commerce électronique entre entreprises et consommateurs (B2C). Ainsi qu'indiqué précédemment, la majeure partie des colis livrés dans le cadre d'échanges B2C contiennent des marchandises de faible valeur et ce type d'échanges tirerait donc parti d'une exemption ou d'une dérogation de minimis adaptée. De plus, outre les économies en matière de taxes et de droits, l'application d'un seuil de minimis peut réduire le temps et les coûts des procédures de dédouanement en supprimant des étapes qui, autrement, auraient été nécessaires pour le paiement et le recouvrement. Par ailleurs, comme nous le verrons par la suite, il est important de disposer d'une règle de minimis pour appuyer la mise en œuvre de certaines procédures simplifiées de mainlevée.

Comme indiqué dans la figure 6.14, certains pays ne disposent pas encore de règle de minimis. Quand elle existe, la valeur de seuil autorisée peut être minimale ou soumise à des conditions restrictives. En outre, quand la valeur est inscrite dans la loi, il peut arriver qu'aucun mécanisme juridique ou administratif ne soit désigné aux fins de l'ajustement périodique, et la règle peut ainsi perdre son effet de facilitation au fil du temps (faute de modification périodique du régime douanier).

D'ordinaire, on justifie l'exonération par le fait que les coûts administratifs que supposent pour le négociant et les douanes l'évaluation, le paiement et le recouvrement équivaudraient au montant des droits et taxes en jeu ou le dépasseraient. Toutefois, il importerait de fixer un seuil pour examiner non seulement ces économies administratives, mais aussi leurs conséquences économiques générales, telles que les avantages économiques positifs d'une augmentation des transactions commerciales électroniques.

Une des difficultés auxquelles se heurtent les pays en développement et les pays les moins avancés au moment d'appliquer une règle de minimis est son effet sur le recouvrement des recettes et, éventuellement, sur les producteurs nationaux. On s'inquiète en outre de l'utilisation frauduleuse de l'exonération, qui peut prendre la forme, par exemple, d'une déclaration erronée du prix payé. L'appui en matière d'assistance technique et de renforcement des capacités sera très utile pour aider le gouvernement à analyser ces conséquences, à adopter un seuil facilitateur de minimis adapté et à mettre au point le protocole de gestion des risques et les procédures qui s'imposent pour réduire les risques d'utilisation impropre.

\section{- Procédures simplifiées de mainlevée}

L'AFE fait obligation aux Membres de l'OMC de mettre au point des documents et des procédures simplifiés aux fins de la mainlevée des envois accélérés, tels que les colis envoyés via des services de livraison rapide par voie aérienne, une catégorie dont font partie bon nombre des envois résultant de transactions électroniques transfrontières. ${ }^{27}$ Cette disposition de l'AFE prévoit qu'il est possible de procéder au dédouanement et à la mainlevée des envois accélérés en se fondant uniquement sur les documents de fret aérien ou une déclaration simplifiée, et de procéder à la mainlevée avant de faire une déclaration et de mettre en œuvre les procédures de dédouanement (par exemple pour l'évaluation et le paiement des droits et taxes dus). Il est en outre envisagé que les pays permettent l'utilisation de ces simplifications uniquement aux personnes ou organismes autorisés, tels que les opérateurs d'envois accélérés dotés des systèmes et procédures nécessaires pour assurer le bon déroulement des activités et permettre la surveillance douanière.

Les Directives de I'OMD aux fins de la mainlevée immédiate des envois constituent le principal instrument d'orientation de la mise en œuvre de ces principes de l'AFE. ${ }^{28}$

Les simplifications décrites dans le cadre de la catégorie 2, qui concerne l'exception de minimis examinée plus haut, et celles de la catégorie 3, couvrent d'ordinaire une part importante des transactions B2C. Néanmoins, comme indiqué dans lesdites Directives, le pays concerné a toute latitude pour élaborer ces simplifications et définir les conditions de leur utilisation d'une façon adaptée aux besoins et à l'environnement qui lui sont propres. 
Les besoins d'assistance technique et d'appui au renforcement des capacités aux pays en développement et aux PMA Membres qui n'ont pas encore mis en œuvre ces simplifications sont importants. La mise en place de ces procédures peut modifier radicalement les procédures de dédouanement classiques existantes. Le savoir-faire et le renforcement des capacités seront importants pour la conception des procédures et des prescriptions minimales en matière de documents et de données, pour l'établissement de critères de qualification et de contrôles des prestataires de livraisons rapides et des autres utilisateurs potentiels de ces simplifications, pour la mise en œuvre d'un système de garanties adapté et pour l'évaluation et les ajustements des systèmes informatiques douaniers, etc.

\section{Encadré 6.8. Directives de l'OMD aux fins de la mainlevée immédiate}

Les Directives de I'OMD sont des recommandations destinées aux administrations des douanes et qui visent à les aider à mettre au point les procédures nationales qui leur permettront de faire face à la croissance du volume de petits envois transfrontières résultant de l'expansion du marché du commerce électronique. Ces directives se proposent d'être d'éventuelles «solutions» visant à permettre aux administrations d'associer la mainlevée immédiate de ces envois à un contrôle pertinent et approprié.

II est recommandé dans les Directives de classer les envois selon quatre catégories, auxquelles correspondent des suggestions de mainlevée et d'exigences en matière de données et de documents.

\section{Catégorie 1: Correspondances et documents}

- Le dédouanement et la mainlevée ont lieu simultanément (c'est-à-dire: aucun document ni aucune procédure après la mainlevée).

- La mainlevée est accordée compte tenu d'une "déclaration globale", telle qu'un manifeste ou une lettre de voiture.

- Le nombre de données exigées est minime.

\section{Catégorie 2: Envois de faible valeur, exonérés de droits et taxes (seuil de minimis)}

- Le dédouanement et la mainlevée ont lieu simultanément.

- La mainlevée est accordée compte tenu d'une "déclaration globale" ou d'une déclaration simplifiée.

- Chaque article de l'envoi est déclaré.

\section{— Catégorie 3: Envois de faible valeur, imposables (déclaration de marchandises simplifiée)}

- Le dédouanement et la mainlevée ont lieu simultanément, pour autant qu'une déclaration simplifiée ou complète soit présentée avant l'arrivée des envois et l'évaluation et le paiement des droits et taxes.

- À défaut, la mainlevée a lieu immédiatement compte tenu d'un manifeste, d'une lettre de voiture ou d'une déclaration provisoire, sous réserve qu'une garantie ait été fournie et que l'obligation de présenter une déclaration simplifiée (même périodique) après la mainlevée ait été honorée et que les droits et taxes aient été payés.

\section{- Catégorie 4 - Envois de valeur élevée (déclaration complète)}

- Les procédures normales de dédouanement et de mainlevée s'appliquent

Dans toutes les catégories, les douanes peuvent procéder à une vérification documentaire ou matérielle en recourant aux techniques de gestion des risques.

Les Directives contiennent une liste indicative des éléments de données exigés au titre des catégories 1 et 3. 
CHAPITRE 6. LE RÔLE ESSENTIEL DE LA FACILITATION DES ÉCHANGES DANS LA PROMOTION DE LA DIVERSIFICATION ÉCONOMIQUE ET DES RÉFORMES STRUCTURELLES

\section{- Renseignements avant l'arrivée}

L'AFE fait obligation aux Membres de I'OMC de permettre de présenter les documents relatifs à l'importation et les autres renseignements requis - y compris les manifestes, la déclaration de marchandises et les renseignements connexes avant l'arrivée des marchandises de sorte à permettre aux douanes et autres autorités présentes aux frontières de traiter les informations (définir les contrôles nécessaires, évaluer les droits et les taxes, etc.) préalablement et, par conséquent, d'accélérer la mainlevée. En outre, il convient de prendre des dispositions, "selon qu'il sera approprié", aux fins de la transmission électronique de ces informations préliminaires.

Dans leurs notifications au Comité de l'OMC, la majorité des pays en développement et PMA Membres de I'OMC indiquent qu'ils ont, en fait, déjà mis en place ces dispositions sur le traitement avant arrivée (catégorie A).

En outre, sur les 16 pays qui ont notifié au Comité de l'OMC qu'ils comptaient instaurer la procédure à l'issue d'un certain laps de temps mais qu'ils n'avaient pas besoin d'assistance technique externe (catégorie B), plus de la moitié font savoir que la mesure sera adoptée d'ici à la fin de 2020.

\section{Figure 6.15. Article 7:1 de l'AFE traitement avant arrivée: notifications concernant la mise en œuvre}

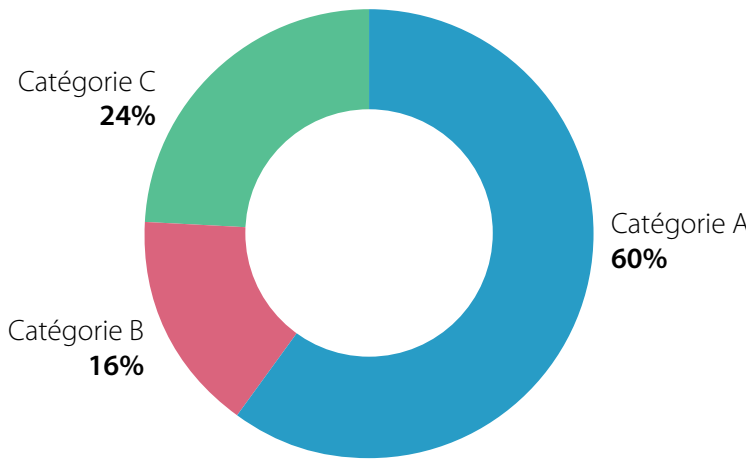

Source: Base de données du Mécanisme pour l'Accord sur la facilitation des échanges de l'OMC.

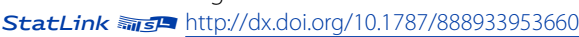

La mise en œuvre pleine et effective du traitement avant arrivée dans le cadre du commerce électronique suppose pour les douanes et autres autorités présentes aux frontières des pays en développement et des PMA des difficultés particulières qui ne se posent pas de façon aussi aiguë dans les circuits classiques. Compte tenu des niveaux d'automatisation, il est peu probable que les déclarations pour les petits colis transitant par voie postale internationale soient présentées sous forme électronique ou à l'avance. Étant donné que la législation nationale autorise généralement la mainlevée des marchandises de faible valeur sur présentation de déclarations simplifiées (par exemple en application des procédures de mainlevée immédiate décrites ci-dessus), les autorités présentes aux frontières disposent de moins de données aux fins de l'analyse des risques. Les expéditeurs occasionnels qui participent à des transactions commerciales électroniques ne sont parfois pas connus des douanes (c'est-à-dire qu'ils n'ont pas d'antécédents en matière de respect des prescriptions) et ne connaissent généralement pas bien les exigences douanières, de sorte que les données qu'ils fournissent risquent de manque de fiabilité. Ainsi, bien que le taux de mise en œuvre de l'article 7:1 de l'AFE semble élevé, il serait peut-être nécessaire de s'attacher davantage, avec un soutien approprié en matière d'assistance technique et de renforcement des capacités, à surmonter ces difficultés particulières qui s'opposent à la mainlevée accélérée des marchandises dans la sphère du commerce électronique. En particulier, la mise en œuvre des diverses initiatives de I'OMD et de I'Union postale universelle (UPU) pour l'échange électronique préalable de données postales pourrait être appuyée. ${ }^{29}$ 


\section{- Procédures simplifiées pour la ré-exportation/la ré-importation des marchandises renvoyées}

Pour développer le marché transfrontières du commerce électronique, les vendeurs répondent à la demande des consommateurs, qui exigent que la procédure de renvoi des marchandises soit facilitée et, éventuellement, que des produits de remplacement soient envoyés. La mise en œuvre de procédures douanières simplifiées visant à accélérer la réexportation (par le consommateur) et la réimportation (par le vendeur) ainsi que l'instauration d'une exonération de droits et de taxes, y compris un régime simplifié de restitution des droits de douane seraient donc importantes pour répondre à cette demande.

\section{Coordination des organismes présents aux frontières}

II est essentiel de mettre pleinement et effectivement en œuvre les dispositions de l'AFE sur la coordination et la coopération des organismes présents aux frontières. La mainlevée immédiate d'une livraison rapide par fret aérien présente des avantages limités si l'opérateur doit attendre l'accord d'autres autorités présentes aux frontières, comme les services de quarantaine. Aux fins de l'accélération de la mainlevée, il est essentiel que la présence et les heures de travail du personnel des autorités présentes aux frontières dans les installations de fret aérien soient harmonisées, que les traitements et contrôles de ces autorités soient intégrés et que les informations avant arrivée et relatives aux risques soient diffusées.

La coordination avec les services postaux nationaux (publics et privés) revêt une importance particulière compte tenu du volume important et croissant de colis et d'envois par EMS qui transitent par la chaîne logistique postale internationale et du fait que le dédouanement de ces envois postaux relève à la fois des douanes et du service postal. Étant donné que, souvent, les procédures postales sont manuelles et nécessitent des documents imprimés, il est manifestement nécessaire d'apporter une assistance technique ou autre en vue de simplifier et d'intégrer les processus de dédouanement et de permettre un échange automatisé de données avec les douanes, conformément aux normes et recommandations de I'UPU et de I'OMD.

\section{L'Assistance technique et le renforcement des capacités au service du commerce électronique}

Les éléments essentiels d'une transaction commerciale électronique B2C sont i) un vendeur présent sur Internet (disposant d'une page Web) pour accepter les commandes en ligne, ii) un acheteur ayant accès à Internet pour passer la commande, iii) un mode de paiement (carte de crédit, portefeuille électronique, paiement à la livraison, etc.) et iv) la livraison des marchandises..$^{30}$ Outre les questions de facilitation des échanges découlant de la livraison transfrontières des marchandises mentionnées ci-dessus, les pays en développement et les PMA se heurtent à des difficultés particulières en rapport avec ces différents aspects. Parmi ces obstacles figurent le manque de fiabilité de l'infrastructure informatique et de l'approvisionnement en électricité, l'accès limité aux systèmes de paiement électronique internationaux, la faiblesse du cadre juridique régissant les transactions électroniques et la déficience des infrastructures de distribution et de logistique. L'évaluation de l'état de préparation au commerce électronique élaborée par la CNUCED est une ressource précieuse qui peut aider ces pays à détecter certains obstacles et à délimiter l'assistance technique et l'appui aux capacités nécessaires à une meilleure participation au marché du commerce électronique.

Les notifications des pays en développement et des PMA Membres de I'OMC indiquent que la demande d'assistance technique aux fins de la mise en œuvre des dispositions de l'AFE propres aux transactions commerciales électroniques n'est pas particulièrement élevée. 25 \% seulement des pays en développement et des PMA Membres de l'OMC ont fait savoir qu'ils avaient besoin d'un soutien externe pour mettre en œuvre les dispositions de l'AFE relatives à la livraison rapide, notamment les procédures de mainlevée immédiate, la dérogation ou l'exemption de minimis et d'autres simplifications décrites ci-dessus. ${ }^{31}$ Une évaluation de l'état de préparation au commerce électronique peut être utile pour aider le gouvernement et les parties prenantes à confirmer la situation actuelle, à mieux comprendre le potentiel de développement et les obstacles au développement du marché du commerce électronique et, au besoin, à revoir les priorités en matière d'application et les besoins de soutien technique. 
Le commerce électronique suppose d'acheter et de vendre en ligne, mais il dépend toujours de la livraison matérielle des marchandises. La médiocrité des services logistiques demeure un obstacle aux transactions commerciales électroniques transfrontières dans nombre d'économies en développement. S'il est vrai que les coûts de transport diminuent et que la connectivité des transports maritimes s'est améliorée, l'écart entre les pays les mieux connectés et les moins bien connectés se creuse et les coûts de transport et les délais de livraison restent souvent trop élevés. Plus que jamais, l'amélioration du dédouanement, la simplification des procédures aux frontières, la facilitation du commerce électronique et l'amélioration de l'interopérabilité entre les fournisseurs de services de transport constituent des priorités absolues pour ces économies.

C'est compte tenu de ces éléments que la CNUCED a procédé à l'évaluation de l'état de préparation au commerce électronique dans 17 PMA. Les conclusions des rapports d'évaluation mettent en avant certains éléments qui font partie des mesures relatives à la logistique commerciale. Les questions allant du guichet unique à la coordination entre les institutions d'appui au commerce ont été considérées comme très importantes.

II ressort des résultats de l'enquête que la logistique commerciale et les mesures de facilitation des échanges transfrontières revêtent une importance capitale pour ce qui est de créer un domaine du commerce électronique à part entière. Cet état de fait démontre que les décideurs politiques doivent particulièrement axer leurs réformes de facilitation des échanges sur la logistique commerciale et sur les mesures de facilitation des échanges, et ce tant à l'intérieur du pays qu'au-delà de la frontière. La numérisation et le renforcement de la coordination entre les institutions d'appui au commerce peuvent contribuer à favoriser un régime de commerce électronique durable et concurrentiel.

\section{Figure 6.16. Éléments très importants pour la création d'un environnement propice au commerce électronique}

\section{(Le graphique montre les réponses de 9 PMA dans le cadre de l'évaluation de la CNUCED relative à l'état de préparation au commerce électronique.)}

POURCENTAGE MOYEN

100

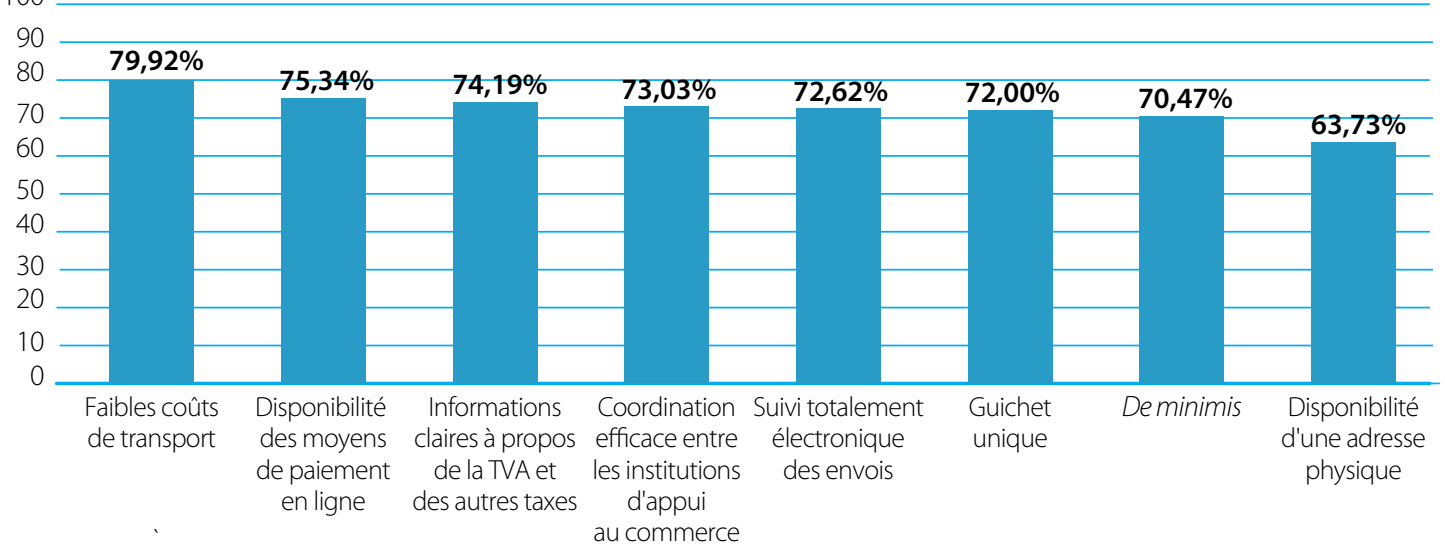

Source: UNCTAD

Les transactions commerciales électroniques posent aux autorités présentes aux frontières des difficultés particulières par rapport aux circuits classiques. L'augmentation du nombre de micro, petites et moyennes entreprises et de consommateurs dans la chaîne d'approvisionnement du commerce électronique B2C, au sujet desquels les informations sont limitées, constitue une difficulté particulière pour l'évaluation des risques par les douanes. ${ }^{32}$ Le service postal national, qui fonctionne généralement manuellement à partir de documents papier, est un organisme présent aux frontières avec lequel la coordination et la coopération sont extrêmement importantes pour les transactions électroniques. Les PME, qui ne participent généralement que de manière occasionnelle au commerce électronique transfrontières, sont soumises à des exigences en matière d'information et ont recours à des modalités d'accès aux informations qui ne sont pas les mêmes que celles des entreprises qui participent régulièrement à des transactions classiques d'importation ou d'exportation. 
Encadré 6.10. Corrélation entre la mise en œuvre de l'AFE et le niveau d'utilisation d'Internet dans le cadre des transactions $\mathrm{B} 2 \mathrm{C}$ par région (suite à la page suivante)

Il existe une corrélation entre la mise en œuvre des mesures de l'AFE ${ }^{33}$ relatives au commerce électronique et l'utilisation $d^{\prime}$ Internet dans le cadre de transactions $\mathrm{B}^{2} \mathrm{C}^{34}$ au sein des pays.

Comme illustré dans la figure 6.17, les pays dans lesquels l'utilisation d'Internet dans le cadre de transactions B2C est plus fréquente font en règle générale état d'un taux plus élevé de mise en œuvre des mesures relatives au commerce électronique ${ }^{35}$ notifiées comme des engagements de catégorie A. L'utilisation très fréquente d'Internet par les entreprises et les consommateurs facilite la mise en place de réformes de facilitation des échanges qui profitent à de telles transactions.

\section{Figure 6.17. Corrélation entre l'utilisation d'Internet dans le cadre des transactions B2C et la mise en œuvre de l'AFE (mesures relatives au commerce électronique)}

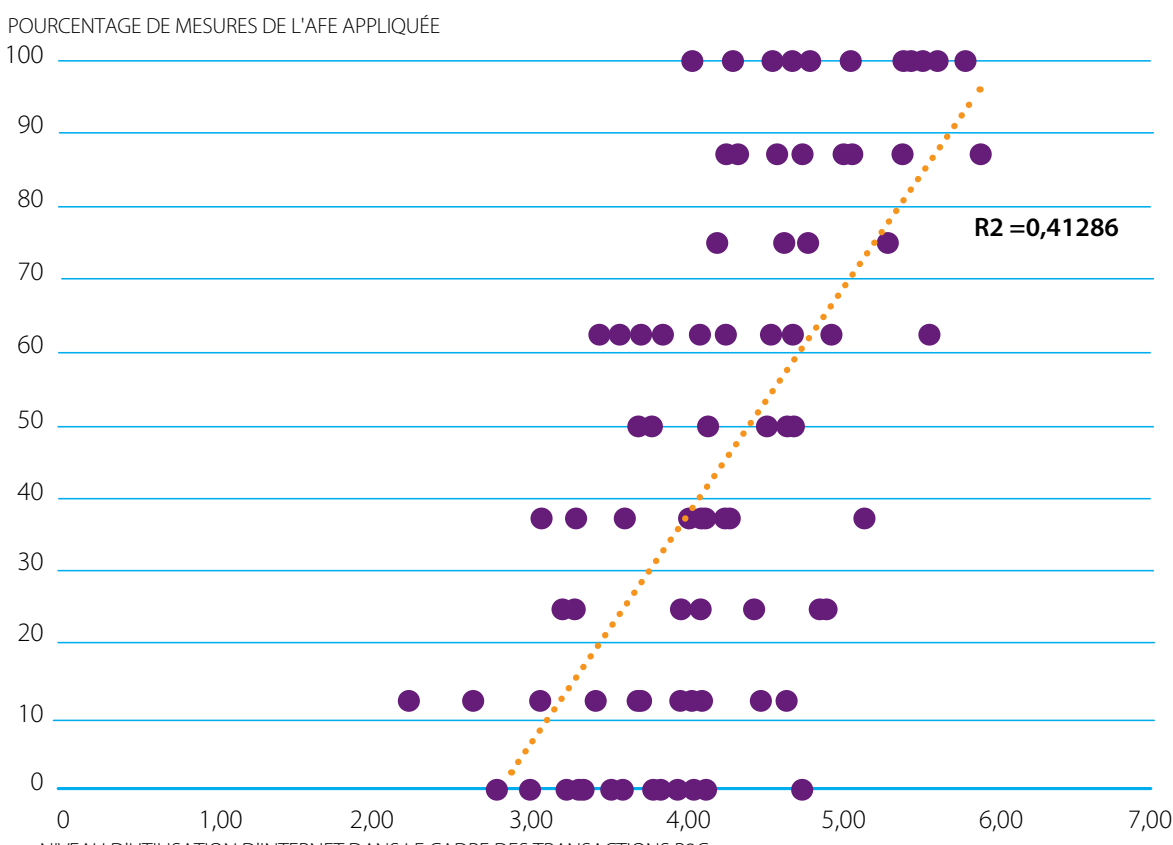

Plus un pays a notifié sa mise en œuvre de l'AFE tôt, plus son niveau d'utilisation d'Internet dans le cadre des transactions B2C est élevé. Les pays qui ont notifié la mise en œuvre de mesures de facilitation des échanges en 2014 ont un niveau moyen d'utilisation d'Internet dans le cadre des transactions B2C de 4,54 alors que l'indice s'établit à 3,44 seulement pour les pays qui ont présenté leur notification en 2018.

II ressort d'un examen régional, tel qu'il ressort de la figure 6.18, que presque toutes les régions ont mis en œuvre en moyenne au moins la moitié des mesures de l'AFE relatives au commerce électronique. L'Afrique affiche le plus faible taux moyen de mise en œuvre des mesures de l'AFE et le plus faible niveau moyen d'utilisation d'Internet dans le cadre des transactions B2C.

Une meilleure conformité avec les mesures de l'AFE peut favoriser le commerce électronique dans la mesure où elle favorise un environnement sûr, transparent et moins coûteux à la fois pour les entreprises et les consommateurs. 
Encadré 6.10. Corrélation entre la mise en œuvre de l'AFE et le niveau d'utilisation d'Internet dans le cadre des transactions B2C par région (suite de la page précédente)

\section{Figure 6.18. Pourcentage moyen de mise en œuvre des mesures de l'AFE et du niveau d'utilisation d'Internet dans le cadre des transactions B2C par région}

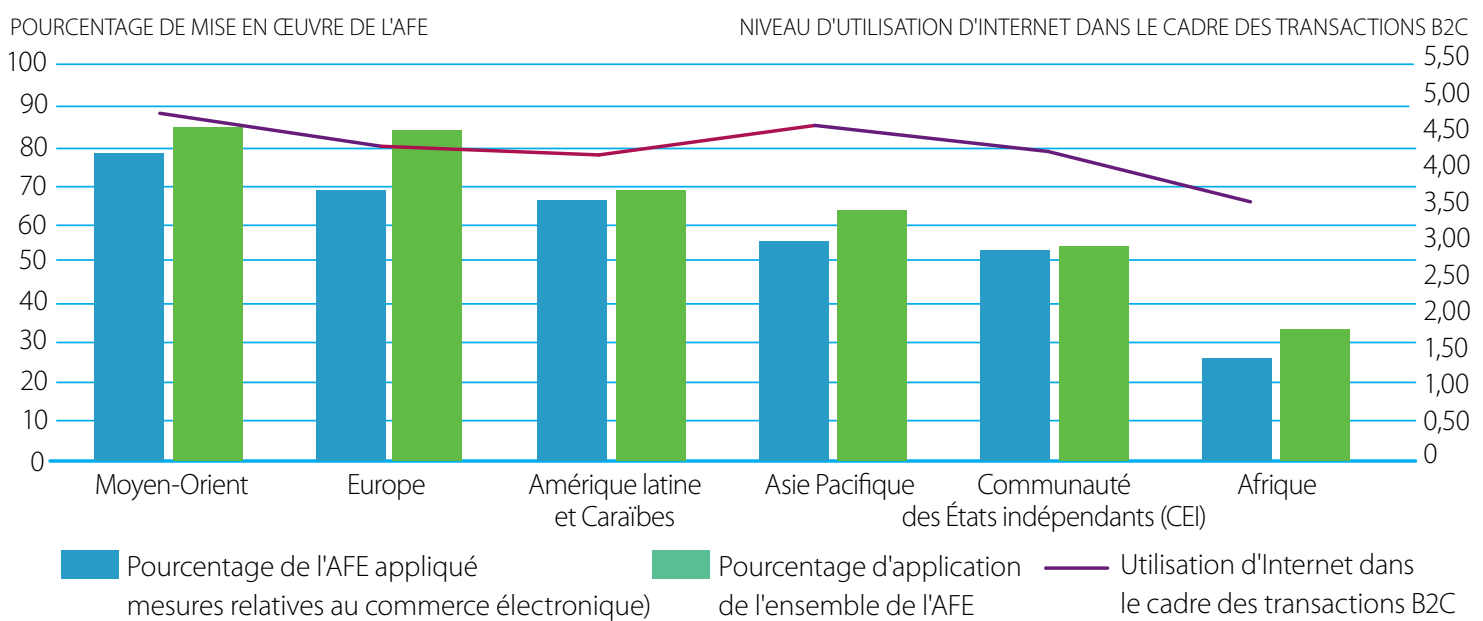

Source: UNCTAD

Une meilleure conformité avec les mesures de l'AFE peut favoriser le commerce électronique dans la mesure où elle favorise un environnement sûr, transparent et moins coûteux à la fois pour les entreprises et les consommateurs.

Néanmoins, les fondements généraux à partir desquels ces difficultés particulières peuvent être surmontées sont posés grâce à l'assistance technique et au renforcement des capacités. Ainsi, comme indiqué à la partie Il du présent chapitre, les pays en développement et les PMA Membres reçoivent un appui technique pour établir ou améliorer les systèmes et procédures de gestion des risques de leurs douanes ou autre organisme présent aux frontières et pour affiner la technique d'analyse des risques, qui seront essentiels pour permettre la mainlevée immédiate des marchandises présentant un risque faible. De la même façon, l'amélioration de la coordination des contrôles et des échanges d'informations entre les organismes présents aux frontières, sur la voie de l'institution d'un guichet unique, favorise l'accélération de la mainlevée des marchandises présentant un risque faible, qu'elles arrivent par la filière du commerce électronique ou autrement. La mise en place de portails d'information commerciale et la publication de guides des prescriptions rédigés en des termes simples - autre priorité de l'appui au stade initial - importent particulièrement pour permettre aux PME de respecter les exigences des organismes présents aux frontières (qu'elles connaissent d'ordinaire beaucoup moins bien que les entreprises de plus grande envergure, d'autant qu'elles disposent de moins de ressources pour la recherche) et de tirer parti des simplifications en matière de mainlevée.

Les données laissent à entendre que de telles améliorations dans l'environnement de facilitation des échanges pourraient servir de catalyseur pour le commerce électronique.

À l'avenir, pour mieux faciliter les transactions commerciales électroniques, il convient d'étendre les réformes entreprises actuellement en matière de gestion des risques, de transparence, de coordination aux frontières et autres et de les axer sur les difficultés particulières que présentent les transactions commerciales électroniques. Comme précédemment suggéré, une évaluation de l'état de préparation au commerce électronique ou autre constituerait un point de départ utile pour identifier les lacunes et les besoins de soutien à cet égard. 
CHAPITRE 6. LE RÔLE ESSENTIEL DE LA FACILITATION DES ÉCHANGES DANS LA PROMOTION DE LA DIVERSIFICATION ÉCONOMIQUE ET DES RÉFORMES STRUCTURELLES

\section{CONCLUSION}

Une aide considérable en matière d'assistance technique et de renforcement des capacités a été fournie pour aider les pays en développement et les PMA Membres de I'OMC à mettre en œuvre I'AFE. Comment ce financement contribuet-il à la mise en œuvre de l'Accord, quels progrès ont été accomplis et quels résultats ont été enregistrés?

Le TFSP du Groupe de la Banque mondiale et le Programme sur la facilitation des échanges de la CNUCED, deux fournisseurs d'assistance liée au commerce, ainsi que les travaux d'analyse de l'OCDE, fournissent des éléments de réponse à ces questions.

Comme nous l'avons vu en détail dans le présent chapitre, l'appui a été orienté en fonction de la demande du client et de la logique d'échelonnement des activités suggérée par l'Accord, c'est-à-dire que la priorité est accordée à certaines mesures essentielles pour permettre la mise en œuvre d'autres mesures. De manière générale, la priorité a donc été accordée à la création de comités nationaux de la facilitation des échanges, qui sont les organes nationaux chargés de superviser la mise en œuvre, de mener des études sur le temps nécessaire à la mainlevée, lesquelles donnent aux pays un point de départ à partir duquel mesurer les progrès accomplis, et à l'application de politiques et de procédures de gestion des risques, lesquelles sont une condition préalable à la mise en œuvre de processus simplifiés de contrôle et de mainlevée. Le type d'appui demandé en ce qui concerne ces mesures est généralement le savoir-faire technique et analytique, et il est en grande partie destiné aux pouvoirs exécutifs et aux administrations des douanes.

L'orientation actuelle et future de l'aide est aussi indiquée par les notifications faites par les pays en développement et les PMA Membres de I'OMC au titre des dispositions de l'AFE relatives au traitement spécial et différencié. Ces pays sont très demandeurs d'une assistance technique leur permettant de mettre en œuvre les mesures de l'AFE relatives au guichet unique, à la gestion des risques, aux études sur le temps nécessaire à la mainlevée et aux mesures en matière de transparence. Les types d'appui les plus fréquemment requis en matière de notification se rapportent notamment au renforcement des capacités, à l'appui législatif et à l'informatique. Le présent chapitre suggère que ces notifications attestent d'une préoccupation particulière en ce qui concerne les capacités et les ressources dont disposent les organismes techniques présents aux frontières aux fins de la mise en œuvre, qui ne sont d'ordinaire pas aussi avancés sur le programme de facilitation des échanges que l'administration des douanes.

Un élément d'appui important est la création de mécanismes chargés de mesurer les progrès en matière de mise en œuvre et d'évaluer les résultats. Dans le cadre du TFSP, un outil de suivi de l'alignement avec l'AFE a été mis au point pour permettre aux pays de mesurer leurs progrès sur la voie d'une application "intégrale et effective" de toutes les mesures de l'Accord. Les mesures de références effectuées à l'aide de l'outil suggèrent que l'Aide pour le commerce a eu des effets positifs sur l'amélioration du taux de conformité avec l'AFE dans les pays qui reçoivent un appui de la part du TFSP.

Parallèlement, il ressort des IFE de I'OCDE que la mise en œuvre de l'AFE est bien engagée, même si les résultats varient d'un groupe de revenu à l'autre et au sein d'un même groupe. Des améliorations apparaissent rapidement dans des domaines tels que l'automatisation et la rationalisation des procédures et la coopération avec la communauté commerciale; les plus grandes difficultés à éliminer concernent la coopération entre les autorités nationales présentes aux frontières et leurs homologues situés de l'autre côté de la frontière.

Les réformes en matière de facilitation des échanges ont des retombées positives. D'après les données issues des rapports de pays, les inspections matérielles sont moins nombreuses, les documents inutiles ont été supprimés et les opérations manuelles de traitement ont été automatisées grâce à la mise en œuvre des mesures de l'AFE. II ressort des résultats des études périodiques sur le temps nécessaire pour la mainlevée que les délais de dédouanement ont diminué. Les études générales de la Banque mondiale sur la facilitation des échanges indiquent également que des améliorations sont apportées en termes de réduction des temps et des coûts dans les pays qui reçoivent un appui. Les travaux 
de recherche de l'OCDE mettent en avant l'impact positif de la facilitation des échanges pour l'internationalisation des PME - un message repris dans les réponses des pays en développement à l'exercice de suivi et d'évaluation mené conjointement par l'OCDE et l'OMC. Afin de doter les pays en développement et PMA Membres de meilleurs moyens de suivre et de démontrer les progrès et les impacts des réformes, le présent chapitre conclut qu'il est nécessaire de poursuivre l'appui à la création de systèmes et d'outils de suivi et d'évaluation adaptés.

Enfin, dans le présent chapitre, nous nous sommes interrogés précisément sur la façon dont l'Aide pour le commerce pouvait contribuer à la facilitation des échanges de marchandises vendues en ligne, un marché au potentiel d'exportation énorme pour les PME, qui constituent la plus grande partie des entreprises dans la plupart des pays en développement et des PMA.

Les difficultés en matière de facilitation des échanges qui découlent des échanges transfrontières de marchandises vendues en ligne sont généralement les mêmes que celles qui se posent dans le cadre des circuits classiques. La même réponse s'impose, et elle préconise la mise en œuvre intégrale et effective des mesures de l'AFE. Toutefois, étant donné la nature des transactions commerciales électroniques, certaines réformes de facilitation des échanges, en particulier issues de l'AFE, revêtent une importance particulière pour le développement de ce marché, notamment la mise en œuvre d'une exception de minimis visant à faciliter les échanges, la simplification des procédures de mainlevée prévue par l'AFE pour les envois aériens, les procédures de l'AFE avant arrivée et le resserrement de la coordination entre les organismes présents aux frontières, notamment entre l'administration des douanes et le service postal national. Dans le présent chapitre, il est suggéré que, pour favoriser le développement des marchés du commerce électronique, I'Aide pour le commerce pourrait utilement servir à étendre les réformes entreprises en matière de gestion des risques, de transparence, de coordination aux frontières et autres et à les axer sur les difficultés particulières que présentent les transactions commerciales électroniques. 
CHAPITRE 6. LE RÔLE ESSENTIEL DE LA FACILITATION DES ÉCHANGES DANS LA PROMOTION DE LA DIVERSIFICATION ÉCONOMIQUE ET DES RÉFORMES STRUCTURELLES

\section{NOTES}

1. Base de données du Mécanisme pour l'Accord sur la facilitation des échanges de l'OMC, https://www.tfadatabase.org/. Les renseignements extraits de la Base de données du Mécanisme pour l'Accord sur la facilitation des échanges et figurant dans le présent chapitre datent du 15 février 2019.

2. Base de données du Mécanisme pour l'Accord sur la facilitation des échanges. Les estimations reposent sur les notifications présentées par les Membres de l'OMC conformément à l'article 22:1 de l'AFE. Les estimations sont probablement sous-évaluées car les notifications au titre de l'article 22:1 pour 2017 et 2018 ne sont pas complètes et les estimations ne tiennent pas compte du soutien fourni mais ne devant pas être obligatoirement notifié (par exemple le soutien fourni par les pays en développement Membres de I'OMC).

3. Les partenaires de développement du TFSP sont le Département des affaires étrangères et du commerce d'Australie, Affaires mondiales Canada, I'Union européenne, le Ministère des affaires étrangères des Pays-Bas, le Ministère des affaires étrangères de Norvège, I'Agence suédoise de coopération pour le développement international, le Secrétariat d'État à l'économie de la Suisse, le Département du développement international du Royaume Uni (DFID) et l'Agence des États-Unis pour le développement international (USAID).

4. Article 21:3 b) de l'AFE.

5. Les Membres de I'OMC sont officiellement convenus de lancer des négociations sur la facilitation des échanges en juillet 2004 sur la base des modalités contenues dans l'annexe D dudit "ensemble de résultats de juillet". Les organisations internationales ayant un rôle dans la mise en œuvre des réformes relatives à la facilitation des échanges et mentionnées dans ladite annexe sont désignées ci-après sous le terme "Organisations de l'annexe D". II s'agit notamment du FMI, de I'OCDE, de la CNUCED et de I'OMD. Organisation mondiale du commerce, Programme de travail de Doha, annexe D, WT/L/579 (2 août 2004).

6. Base de données du Mécanisme pour l'Accord sur la facilitation des échanges. Dans ces notifications, certains pays Membres de l'OMC désignent une disposition de l'AFE en partie au titre d'une catégorie et en partie au titre d'une autre. Aux fins de la présente discussion, un pays est considéré avoir notifié une disposition complète de I'AFE au titre d'une catégorie particulière si le pays a classé cette disposition entièrement ou partiellement dans cette catégorie.

7. Dans la présente figure et dans d'autres de la présente sous-section, le pourcentage représente le nombre de demandes (par exemple d'appui au guichet unique) par rapport au nombre total de notifications de catégorie C pour toutes les mesures.

8. Les délais pour présenter cette notification diffèrent entre les pays en développement et les PMA Membres.

Catégorie $C$ pour les pays en développement Membres

(c) Dès l'entrée en vigueur du présent accord, chaque pays en développement Membre notifiera au Comité les dispositions qu'il aura désignées comme relevant de la catégorie $C$ et ses dates indicatives correspondantes pour la mise en œuvre. À des fins de transparence, les notifications présentées incluront des renseignements sur l'assistance et le soutien pour le renforcement des capacités dont le Membre aura besoin pour la mise en œuvre.

Catégorie $\mathrm{C}$ pour les pays les moins avancés Membres

(c) À des fins de transparence et pour faciliter les arrangements avec les donateurs, un an après l'entrée en vigueur du présent accord, chaque pays moins avancé Membre notifiera au Comité les dispositions qu'il aura désignées comme relevant de la catégorie $C$, en tenant compte des flexibilités maximales ménagées aux pays les moins avancés Membres. 
CHAPITRE 6. LE RÔLE ESSENTIEL DE LA FACILITATION DES ÉCHANGES DANS LA PROMOTION DE LA DIVERSIFICATION ÉCONOMIQUE ET DES RÉFORMES STRUCTURELLES

(d) Un an après la date mentionnée à l'alinéa c), les pays les moins avancés Membres notifieront des renseignements sur l'assistance et le soutien pour le renforcement des capacités dont le Membre aura besoin pour la mise en œuvre.

9. II est généralement déclaré dans ces notifications que ces informations sont "à déterminer". Toutes les notifications de ce type ont été présentées par des PMA. Le délai prévu par l'Accord pour que les PMA fournissent ces renseignements (voir note de bas de page 8) n'a pas encore pris fin.

10. II convient néanmoins de noter que ces 44 pays ne comprennent que 2 PMA Membres et qu'il est donc possible que les besoins d'assistance technique examinés en l'espèce ne correspondent pas pleinement au point de vue d'un PMA.

11. Voir la figure 6.2, plus haut.

12. Pour que la mise en œuvre demeure faisable, quatre organismes sont désignés par pays en tant que représentants de l'ensemble du gouvernement: 1) les douanes; 2) I'organisme chargé de la protection phytosanitaire et de la phytoquarantaine; 3) I'Office de normalisation et 4) I'organisme responsable des questions sanitaires.

13. Dans le cadre de la conception de l'outil, il a été supposé que l'objectif de mise en œuvre était l'obtention d'un bénéfice économique maximal grâce à la facilitation plutôt que la conformité juridique technique avec l'Accord. En utilisant les indicateurs de facilitation des échanges (IFE) de l'OCDE pour suivre les progrès réalisés par le pays dans la mise en œuvre de l'AFE, I'OCDE estime que la réduction des coûts qui pourrait résulter de la mise en œuvre "intégrale" de l'AFE de l'OMC serait de 16,5\% du total des coûts pour les pays à faible revenu, de 17,4\% pour les pays à revenu intermédiaire de la tranche inférieure et de 14,6\% pour les pays à revenu intermédiaire de la tranche supérieure. Toutefois, dans le cadre d'une mise en œuvre moins ambitieuse, limitée à la conformité avec les dispositions obligatoires de l'Accord, la réduction potentielle atteint 12,6\% pour les pays à faible revenu, 13,7\% pour les pays à revenu intermédiaire de la tranche inférieure et 12,8\% pour les pays à revenu intermédiaire de la tranche supérieure. OCDE (2018), "Trade Facilitation and the Global Economy", Éditions OCDE, Paris.

14. D'après la Base de données du Mécanisme pour l'Accord sur la facilitation des échanges, les mesures présentant le plus faible taux de mise en œuvre sont

L'article 10:4 - Guichet unique

L'article 7:7 - Opérateurs agréés

L'article 5:3 - Procédures d'essai

L'article 3 - Décisions anticipées

L'article 7:6 - Temps moyens nécessaires à la mainlevée

L'article 8 - Coopération entre les organismes présents aux frontières

L'article 1:3 - Points d'information

L'article 1:2 - Renseignements disponibles sur Internet

L'article 7:4 - Gestion des risques

15. WTO Trade Facilitation Agreement Preamble

16. De la même façon, dans le cadre de l'Accord, "les Membres sont encouragés à mesurer et à publier le temps moyen qui leur est nécessaire pour la mainlevée des marchandises, périodiquement et d'une manière uniforme, au moyen d'outils tels que, entre autres, l'Étude sur le temps nécessaire pour la mainlevée de l'Organisation mondiale des douanes". Article 7:6, Accord de I'OMC sur la facilitation des échanges (Établissement et publication des temps moyens nécessaires à la mainlevée). 
CHAPITRE 6. LE RÔLE ESSENTIEL DE LA FACILITATION DES ÉCHANGES DANS LA PROMOTION DE LA DIVERSIFICATION ÉCONOMIQUE ET DES RÉFORMES STRUCTURELLES

17. D'importantes lacunes dans les données subsistent quant à la nature exacte des obstacles à la participation des femmes aux échanges transfrontières et sur l'impact, ventilé par sexe, de l'amélioration des procédures douanières et des procédures à la frontière. Il est essentiel de combler ces lacunes pour optimiser la conception et la mise en œuvre de réformes et de programmes d'intervention efficaces qui maximisent les bénéfices que le commerce peut apporter à tous. À cette fin, des travaux ont été entamés dans le cadre du TFSP pour contribuer à combler certains des déficits de connaissances en recueillant des données dans le cadre d'enquêtes en face à face. Ces travaux sont mis à l'essai dans la région de l'Asie de l'Est et du Pacifique.

18. L'OCDE définit le commerce électronique comme « la vente ou l'achat de biens ou de services, effectué sur des réseaux informatiques par des méthodes spécifiquement conçues pour la réception ou la passation de commandes. Les biens et services sont commandés par ces méthodes, mais le paiement et la livraison proprement dite des biens ou services ne se font pas nécessairement en ligne. La transaction de commerce électronique peut se faire entre entreprises, ménages, particuliers, administrations ou d'autres organismes publics ou privés." Glossaire des termes statistiques de https://stats.oecd.org/glossary/detail.asp?!D=4721

19. Voir, par exemple, CNUCED, "Rapport 2015 sur l'économie de l'information; Libérer le potentiel du commerce électronique pour les pays en développement" (2015); Centre du commerce international, "Bringing SMEs onto the E-Commerce Highway" (2016); Organisation mondiale des douanes, "Rapport d'étude sur le commerce électronique transfrontalier" (mars 2017). Ces observations s'appuient également sur une note à paraître du Groupe de la Banque mondiale intitulée "Facilitation and Logistics for E-commerce" (élaborée par Ankur Huria).

20. Selon une étude sur les consommateurs ayant recours au commerce électronique transfrontières, $61 \%$ des colis envoyés sont estimés à moins de 50 euros et $84 \%$ pèsent deux kilogrammes ou moins. International Post Corporation, "Cross-Border E-Commerce Shopper Survey 2018" (janvier 2019).

21. eMarketer; Statista.

22. CNUCED, "Rapport 2015 sur l'économie de l'information", page 12.

23. DHL, Le commerce des épices du XXle siècle - Un guide sur les opportunités du commerce électronique transfrontalier (2016).

24. CNUCED, "Rapport 2015 sur l'économie de l'information”, page 6.

25. "8.2 Sous réserve des paragraphes 8.1 et 8.3, les Membres:... d) prévoiront, dans la mesure du possible, une valeur d'envoi ou un montant imposable de minimis, pour lesquels ni droits de douane ni taxes ne seront recouvrés, sauf pour certaines marchandises prescrites. Les taxes intérieures, telles que les taxes sur la valeur ajoutée et les droits d'accise, appliquées aux importations d'une manière compatible avec l'article III du GATT de 1994, ne sont pas visées par cette disposition.". Article 7:8 de l'AFE.

26. Étude mondiale de la Global Express Association (comprenant 28 pays de I'UE) sur les montants de minimis des droits de douane, convertis en dollars EU (https://global-express.org/index.php?id=14). Le montant de minimis moyen des pays interrogés s'établit aux alentours de 150 dollars EU.

27. "8.2 Sous réserve des paragraphes 8.1 et 8.3 , les Membres:

a) réduiront au minimum les documents requis pour la mainlevée des envois accélérés, conformément au paragraphe 1 de l'article 10 et, dans la mesure du possible, prévoiront la mainlevée sur la base d'une présentation unique de renseignements concernant certains envois;

b) prévoiront la mainlevée des envois accélérés dans des circonstances normales le plus rapidement possible après l'arrivée, à condition que les renseignements requis pour la mainlevée aient été présentés; 
CHAPITRE 6. LE RÔLE ESSENTIEL DE LA FACILITATION DES ÉCHANGES DANS LA PROMOTION DE LA DIVERSIFICATION ÉCONOMIQUE ET DES RÉFORMES STRUCTURELLES

c) s'efforceront d'appliquer le traitement prévu aux alinéas a) et b) aux envois, quels que soient leur poids ou leur valeur, en reconnaissant qu'un Membre est autorisé à prescrire des procédures d'entrée additionnelles, y compris la présentation de déclarations et de documents justificatifs et le paiement de droits et de taxes, et de limiter ce traitement en fonction du type de marchandises à condition que le traitement ne soit pas limité à des marchandises de faible valeur telles que des documents[.]"

28. Organisation mondiale des douanes, Directives aux fins de la mainlevée immédiate des envois par la douane, version III (juin 2018).

29. Ces initiatives comprennent notamment le projet de Directives conjointes OMD-UPU sur l'échange de données électroniques préalables entre les postes et les douanes. Selon l'OMD, les directives "ont vocation à fournir des orientations de politique générale et de nature technique aux opérateurs postaux désignés et aux administrations des douanes sur la façon de mettre en place des mécanismes d'échange de données électroniques préalables mais aussi sur la manière de susciter le soutien des organisations respectives en faveur de l'adoption prioritaire de ce projet. Elles devraient être publiées en juin 2019, une fois approuvées par le Conseil de l'OMD. http://www.wcoomd.org/fr/media/newsroom/2018/november/wco-upu-contact-committeeendorses-joint-guidelines.aspx

30. CNUCED, indice du commerce électronique B2C 2017 (octobre 2017).

31. Base de données du Mécanisme pour l'Accord sur la facilitation des échanges. Cinquante-neuf (60\%) des pays en développement et PMA Membres de l'OMC ont classé l'article 7:8 de l'AFE (envois accélérés) dans la catégorie A, ce qui indique que la mesure est pleinement mise en œuvre.

32. Organisation mondiale des douanes, Rapport d'étude sur le commerce électronique transfrontalier

33. Les données montrent les mesures notifiées par les Membres de l'OMC dans la catégorie A, à supposer qu'ils les ont mises en œuvre.

34. Données de l'Indice de préparation aux réseaux du Forum économique mondial.

35. Pour toutes les analyses, les mesures de l'AFE relatives au commerce électronique employées sont les articles 7:1, $7: 2,7: 4,7: 6,7: 8,8,10: 1$ et 10:4 
CHAPITRE 6. LE RÔLE ESSENTIEL DE LA FACILITATION DES ÉCHANGES DANS LA PROMOTION DE LA DIVERSIFICATION ÉCONOMIQUE ET DES RÉFORMES STRUCTURELLES

\section{RÉFÉRENCES}

OCDE (2018), "Trade Facilitation and the Global Economy", Éditions OCDE, Paris.

OCDE (2019a), "Helping SMEs internationalise through trade facilitation".

OCDE (2019b), "Participation and benefits of SMES in GVCs in Southeast Asia". 


\title{
CHAPITRE 7
}

\section{LA DIVERSIFICATION DES EXPORTATIONS À L'HEURE DE LA "MONDIALISATION LENTE"}

\author{
Contribution de la Conférence des Nations Unies sur le commerce \\ et le développement
}

Resumé : La diversification des exportations reste un objectif de développement important pour de nombreux pays en développement tributaires des produits de base. Toutefois, les tendances économiques mondiales actuelles semblent indiquer que nous pourrions entrer dans une période de "mondialisation lente" (slowbalisation en anglais) caractérisée par un ralentissement de la croissance des échanges, de l'investissement étranger direct et des flux de capitaux. Les préoccupations environnementales grandissantes soulèvent également des questions quant aux chances de réussite si l'on reproduit le modèle de croissance massive des exportations suivi par certains pays en développement pendant les dernières décennies. L'évolution des modèles de croissance économique exige des pays en développement qu'ils orientent différemment leurs stratégies de diversification des exportations. Le présent chapitre explique qu'il existe dans deux domaines - le commerce des services et le commerce Sud-Sud - un potentiel inexploité qui permettrait aux pays en développement de poursuivre la diversification de leurs exportations. Il étudie ensuite la façon dont la coopération réglementaire régionale Sud-Sud pourrait permettre d'améliorer le commerce des services et de réduire les effets de distorsion des échanges des mesures non tarifaires. Enfin, le chapitre examine comment l'Aide pour le commerce stimule la diversification des exportations au travers de la coopération régionale. 


\section{LES STRATÉGIES DE DIVERSIFICATION DES EXPORTATIONS - HIER ET AUJOURD’HUI}

La diversification des exportations relève d'un processus dynamique de croissance et de diversification économiques. Pour de nombreux pays en développement tributaires des produits de base, le fait d'élargir leur offre à l'exportation en ajoutant de nouveaux produits manufacturés ou services témoigne d'un ajout de valeur et d'une transformation structurelle réussie. Entre 1995 et 2017, la part des exportations de produits manufacturés dans les exportations totales des pays en développement a augmenté, passant de 65\% à 74\%.

Figure 7.1. Part des produits manufacturés dans les exportations, 1995-2017

PART DES PRODUITS MANUFACTURÉS, \%

100

90

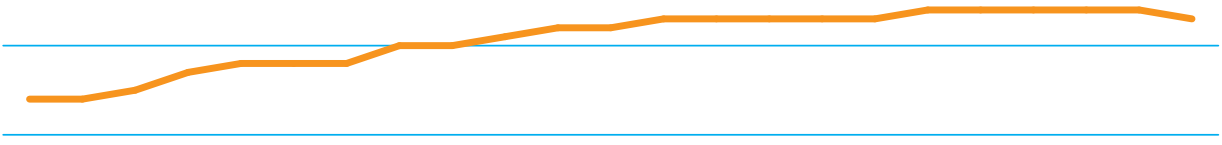

80

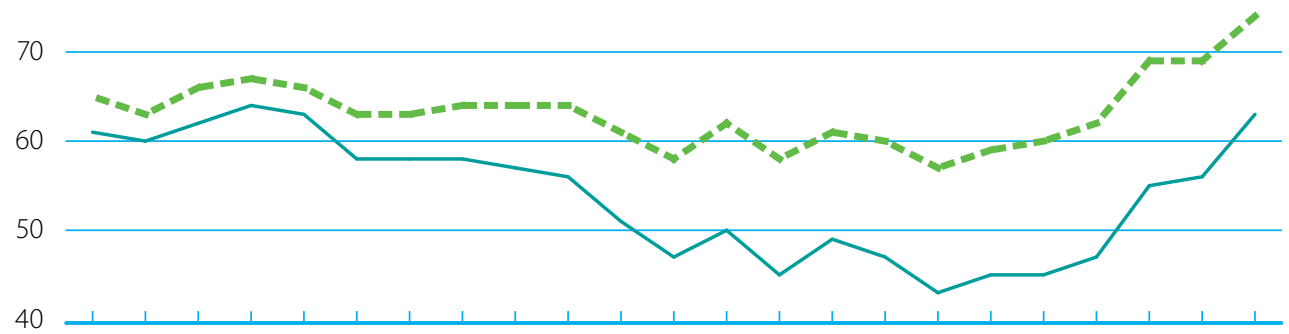

19951996199719981999200020012002200320042005200620072008200920102011201220132014201520162017

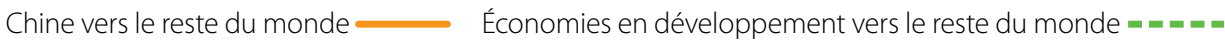
Économies en développement (hors Chine) vers le reste du monde

Source: Système Intrastat de la CNUCED.

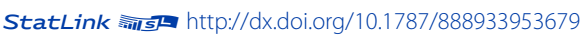

Figure 7.2. Indice de concentration des exportations d'Herfindahl-Hirschman, 1995-2017

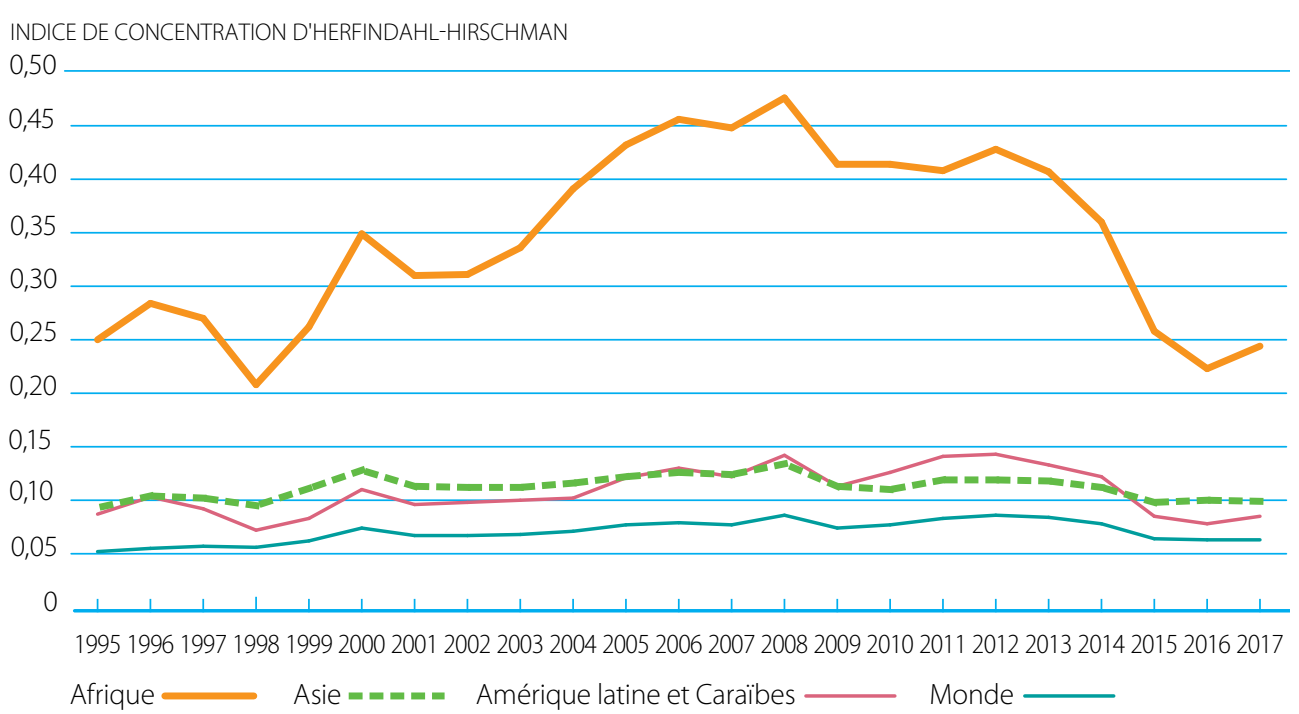

Source: Système Intrastat de la CNUCED.

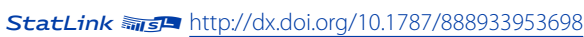


Néanmoins, cette augmentation traduisait essentiellement l'accélération de la croissance et la transformation structurelle de quelques économies émergentes en Asie, notamment la Chine (figure 7.1). En 2017, I'Asie était à l'origine de 88\% des exportations manufacturières des pays en développement et de 94\% des exportations manufacturières "Sud-Sud", et l'Asie de l'Est seule était à l'origine de 65\% et 69\% de ces exportations, respectivement. En revanche, les exportations africaines se sont plus concentrées que diversifiées, en particulier pendant les années du "supercyle des produits de base" (2000-2008), lequel était fortement tiré par la hausse de la demande de produits primaires de la Chine (figure 7.2).

La concentration des exportations sur un petit nombre de produits primaires rend un pays plus vulnérable aux chocs extérieurs et peut avoir une incidence négative sur les possibilités d'emploi dans les pays exportateurs. II peut exister une corrélation étroite entre une diversification limitée des exportations et de faibles créations d'emplois (CNUCED 2018a). Par exemple, la faible diversification observée en Afrique est un important facteur de chômage dans la région. L'Afrique a la structure démographique la plus jeune au monde. On estime que sur les 420 millions de jeunes africains (entre 15 et 35 ans), environ 31\% sont au chômage et plus de 70\% sont sous-employés (Betcherman et Khan, 2015). D'après les projections de la Banque africaine de développement, il faudrait que 18 millions d'emplois soient créés chaque année entre 2015 et 2035 pour absorber le nombre de jeunes arrivant sur le marché du travail pour la première fois (Banque africaine de développement, 2016).

Ainsi, la diversification des exportations reste un objectif de développement important pour les pays en développement, particulièrement en Afrique où la majorité des pays est tributaire des produits de base. Ces dernières années, bon nombre de pays en développement ont fondé leurs stratégies de diversification des exportations sur des mesures visant à accroître leur participation aux chaînes de valeur mondiales (CVM), prenant souvent la forme de régimes de zones industrielles d'exportation (ZIE). II s'agissait d'un choix logique, notamment sur la période 1995-2008 qui était caractérisée par la multiplication des CVM et l'expansion rapide du commerce des biens intermédiaires.

Toutefois, les tendances économiques mondiales actuelles semblent indiquer que nous pourrions entrer dans une période de "mondialisation lente" caractérisée par un ralentissement de la croissance ou une contraction des échanges, de l'investissement étranger direct (IED) et des flux de capitaux.' Depuis la fin de l'année 2018, les organisations internationales ont, à maintes reprises, revu à la baisse leurs perspectives économiques mondiales. ${ }^{2}$ Dans sa publication mensuelle de mars 2019, la Banque mondiale a indiqué que la dynamique de croissance du commerce mondial de marchandises enregistrée en 2017 avait disparu. La croissance en glissement annuel du volume du trafic de conteneurs est tombée de 5\% en février 2018 à 2\% en février 2019. De la même façon, la croissance annuelle des nouvelles commandes à l'exportation est devenue négative en février 2019. ${ }^{3}$ En ce qui concerne les flux d'IED, leur valeur totale a chuté de près de 20\%, passant de 1470 milliards d'USD en 2017 à un niveau estimé de 1200 milliards d'USD en 2018, ce qui équivaut à la valeur de de l'IED juste après la crise financière mondiale en 2009 (CNUCED, 2019a).

Le manque de dynamisme du commerce et de l'IED est étroitement liéà la perte de vitesse des CVM (Constantinescu etal., 2018). La croissance des CVM a pris fin. La part de la valeur ajoutée étrangère dans les exportations mondiales soit la valeur des marchandises et services importés incorporée dans les exportations - a reculé, passant de 31\% en 2010 à 30\% en 2017 (CNUCED, 2018c). Au cours de la dernière décennie, la croissance de la participation des pays en développement aux CVM a considérablement ralenti (figure 7.3). ${ }^{4}$ Pendant la première décennie du XXIe siècle, les pays en développement ont accru leur participation aux CVM de 13\% par an en moyenne. Sur la période allant de 2010 à 2017, ce chiffre est tombé à 3\%. La baisse de la croissance de la participation aux CVM a été particulièrement importante en Afrique et dans les PMA. Lincertitude grandissante que suscite une éventuelle guerre commerciale entre les États-Unis et la Chine pourrait exacerber encore davantage ces tendances. D'après les estimations de la CNUCED, l'important volume des exportations chinoises affectées par les droits de douane des États-Unis pourrait entraîner une contraction des chaînes de valeur de l'Asie de l'Est d'environ 160 milliards d'USD. ${ }^{5}$ 
Figure 7.3. Taux de participation aux CVM (\%), 2000-2010 et 2010-2017

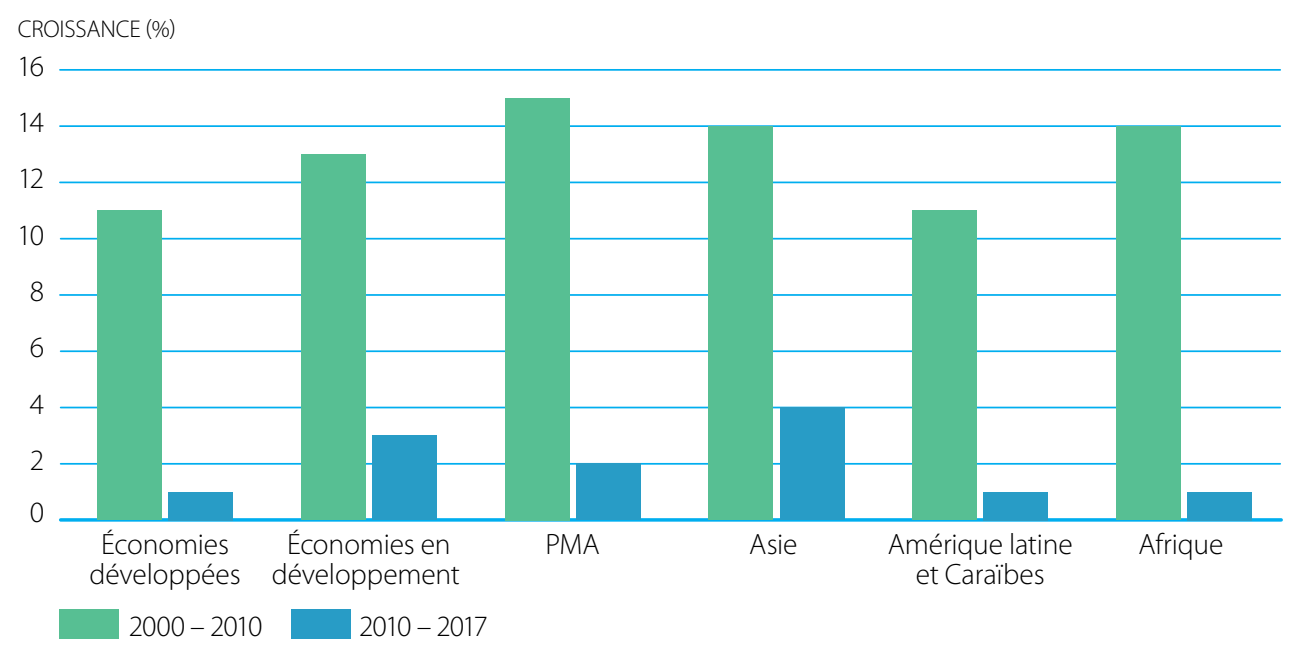

Source: Rapport sur l'investissement dans le monde 2018 (CNUCED, 2018c).

StatLink नinls http://dx.doi.org/10.1787/888933953717

La perspective d'une croissance rapide des échanges dans les années à venir semble peu probable, non seulement à cause de l'incertitude grandissante concernant une guerre commerciale, mais aussi parce que le phénomène majeur de libéralisation des droits de douane observé dans le monde entier pendant les années qui ont suivi le Cycle d'Uruguay semble avoir marqué le pas. En 2017, la moyenne simple des droits NPF (nation la plus favorisée) au niveau mondial pour les produits manufacturés n'était que légèrement inférieure à ce qu'elle était dix années auparavant, et n'avait pas changé du tout si l'on se basait sur une moyenne pondérée en fonction des échanges. Le même constat peut être fait s'agissant de la moyenne des droits préférentiels - droits fixés au titre d'accords commerciaux préférentiels, y compris les accords commerciaux régionaux (ACR) et bilatéraux (CNUCED, 2019c).

Les préoccupations environnementales grandissantes soulèvent également des questions quant aux chances de réussite des politiques économiques reproduisant le modèle de croissance massive des exportations - de produits primaires, agricoles ou manufacturés - suivi par certains pays en développement pendant les dernières décennies. Au cours des dernières décennies, la mondialisation effrénée a radicalement modifié les conditions environnementales auxquelles nous sommes confrontés, entraînant notamment des changements climatiques et la "sixième extinction" en termes de perte de biodiversité. En 2012, il a été avancé que si les sept milliards d'habitants de la planète consommaient autant que la moyenne des citoyens des États-Unis, quatre planètes Terre seraient nécessaires pour faire face à cette consommation. ${ }^{6}$

En décembre 2018, les États membres de la Convention-cadre des Nations Unies sur les changements climatiques (CCNUCC) ont adopté, à la vingt-quatrième Conférence des Parties (COP24), un ensemble de règles pour la mise en œuvre de l'Accord de Paris, dont l'objectif est de maintenir la hausse des températures mondiales durant le siècle en cours en dessous de $2{ }^{\circ} \mathrm{C}$ par rapport aux niveaux préindustriels, en réduisant significativement les émissions de gaz à effet de serre (GES). Le commerce international est considéré comme l'un des principaux émetteurs de GES en raison de la nécessité de transporter les marchandises par voie terrestre, maritime ou aérienne (les transports étant toujours fortement tributaires des énergies fossiles) et parce qu'il encourage économiquement la production agricole et industrielle à grande échelle. En revanche, par le biais du commerce international, les pays exportent des marchandises et services fabriqués sur la base de leur avantage comparatif ou compétitif, et achètent ceux qu'ils ne produisent pas, ce qui aboutit à une réaffectation efficace des ressources entre les secteurs. 
D'après le modèle actuel de développement durable, détaillé dans le Programme de développement durable à I'horizon 2030 et les Objectifs de développement durable (ODD), les stratégies de diversification des échanges et des exportations devraient s'inscrire dans une politique plus large de développement durable. Cela semble indiquer que les pays en développement, en particulier les pays tributaires des produits de base, les pays africains et les PMA, pourraient avoir à délaisser leurs stratégies de diversification des exportations basées sur la participation aux CVM au profit d'approches qui favorisent les échanges et la croissance économique d'un point de vue quantitatif mais aussi structurel, tout en respectant l'environnement et en incluant tous les groupes de population?

La section ci-après examine en quoi le commerce des services et le commerce intrarégional Sud-Sud sont des domaines susceptibles de continuer à fournir des débouchés de marché, voire à offrir de nouvelles possibilités de marché, s'agissant de la diversification des exportations et du développement durable.

\section{COMMERCE DES SERVICES ET COMMERCE INTERRÉGIONAL SUD-SUD}

\section{Commerce des services}

Le secteur des services est devenu le segment le plus important de la plupart des économies nationales; il contribue de plus en plus au PIB, au commerce et à l'emploi, et devient une force motrice de l'économie mondiale. Le commerce des services affiche un potentiel de croissance constant, même face au ralentissement économique mondial. La CNUCED et l'OMC ont estimé qu'en 2018, le commerce mondial des services avait connu une croissance annuelle de 8\% (contre $3 \%$ pour le volume du commerce mondial de marchandises), jusqu'à atteindre près de 6000 milliards d'USD (la valeur du commerce de marchandises était de 19500 milliards d'USD) (figure 7.4). ${ }^{8}$ Plusieurs pays en développement ont grandement tiré parti des débouchés commerciaux dans le secteur des services, y compris des services aux entreprises modernes et exportables, et du mouvement temporaire des personnes physiques fournissant des services. Néanmoins, les pays en développement à plus faible revenu doivent encore acquérir les capacités essentielles pour en faire autant, car ils dépendent largement des services traditionnels, non-marchands et de faible productivité, notamment de l'économie informelle (CNUCED, 2018f).

\section{Figure 7.4. Exportations de services des principaux groupes d'économies, 2010-2018}

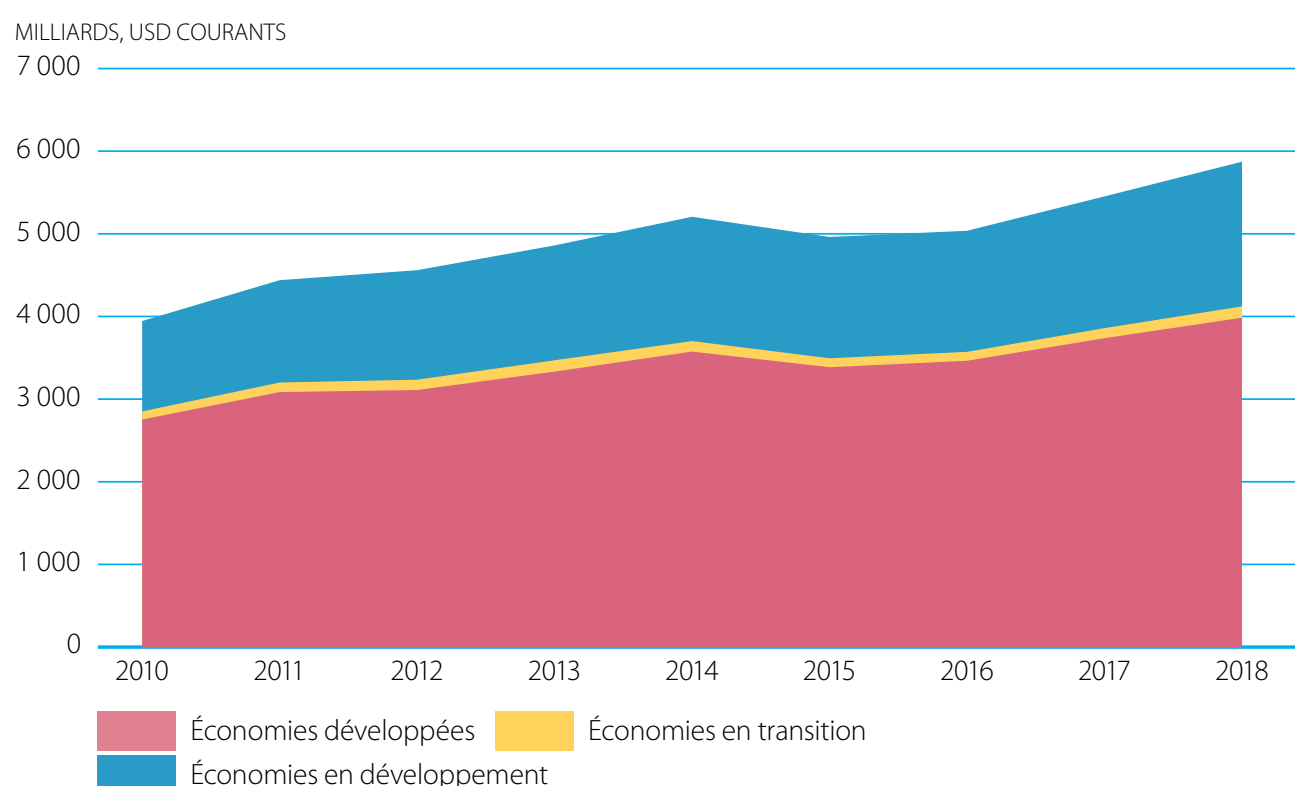

Source: UNCTADStats.

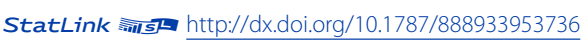


Le secteur des services est devenu le premier pourvoyeur d'emplois dans bon nombre de pays en développement, à mesure que les chaînes de valeur du secteur manufacturier sont externalisées vers les fournisseurs de services et que la demande des consommateurs finaux augmente, en même temps que les niveaux de revenu. Aujourd'hui, le secteur des services absorbe près de la moitié de l'emploi mondial. Dans toutes les régions en développement, la part de l'emploi dans le secteur des services dans l'emploi total a augmenté durant la dernière décennie. Toutefois, la contribution du secteur des services à l'emploi varie considérablement selon les régions en développement (figure 7.5).

Avec plus de 60\% de l'emploi total, le secteur des services est particulièrement important en Amérique latine et dans les Caraïbes. En Afrique, la part de l'emploi dans le secteur des services a connu une augmentation progressive, mais reste inférieure à celle qu'affichent d'autres régions en développement. Cela illustre la faible importance des services dans l'économie globale en Afrique.9 Une étude de la CNUCED confirme que le potentiel du commerce des services en matière de création d'emplois dans le secteur des services est supérieur, en termes absolus, à celui du commerce des produits manufacturés (encadré 7.1.).

Encadré 7.1. Commerce des services et emploi

En 2018, la CNUCED a mené une étude intitulée "Trade in Services and Employment" (UNCTAD, 2018f), qui portait sur le potentiel du commerce des services dans le domaine de l'emploi.

L'étude confirme que l'impact global du commerce des services sur l'emploi est plus faible que celui du commerce des marchandises. Mais cela est lié au fait que, dans de nombreux pays en développement, le secteur des services demeure assez limité.

Si l'on tient compte du fait que le secteur des services représente une part moins importante du commerce international que le secteur manufacturier, le secteur des services pourrait permettre de créer davantage d'emplois en termes absolus que le secteur manufacturier. L'étude estime qu'un milliard d'USD d'exportations à valeur ajoutée supplémentaires dans le secteur des services aboutiraient à la création de 112000 emplois au Mexique, tandis que des exportations d'un même montant dans le secteur manufacturier ne génèreraient que 36000 emplois. De la même façon, une augmentation des exportations de services de 1\% se traduit par une hausse de l'emploi dans le secteur de 42000 emplois, tandis que la même augmentation dans le secteur manufacturier aboutit à la création de 32000 emplois.

Cependant, les résultats ne sont pas uniformes dans tous les pays de l'échantillon visé par de l'étude. Les résultats observés au Royaume-Uni, en France, au Brésil, au Japon, en Allemagne et aux États-Unis sont analogues à ceux du Mexique, mais des résultats différents ont été enregistrés pour la Turquie, I'Inde et la Chine. Dans le dernier groupe de pays, même l'effet absolu de la croissance des exportations est plus important pour le secteur manufacturier que pour le secteur des services. La différence entre ces deux groupes de pays est liée à la part des services dans l'emploi total. Cela permet de penser que dans les pays d'Afrique, les résultats seraient analogues à ceux du dernier groupe.

Ces conclusions semblent indiquer que, du point de vue de la création d'emplois, la diversification des exportations vers les services devrait compléter la diversification des exportations vers les marchandises et non la remplacer, tant que le secteur des services représente une faible part de l'économie d'un pays. De plus, certains secteurs de services nécessitent de nombreux travailleurs hautement qualifiés et ne pourront probablement pas absorber une importante main-d'œuvre non-qualifiée - dans ce cas, la diversification pourrait ne pas entraîner une croissance inclusive des échanges.

Il convient également de noter que le secteur des services attire généralement, en proportion, davantage de femmes que d'hommes. Ainsi, une expansion du secteur des services améliorerait les possibilités d'emploi pour les femmes, mais son impact en matière de développement devrait être interprété avec précaution. La création d'emploi résultant de l'ouverture des échanges, par exemple, a parfois eu une incidence négative sur l'écart de rémunération entre les sexes, la main-d'œuvre féminine ayant tendance à se concentrer dans les secteurs peu rémunérateurs qui sont stimulés par l'augmentation des échanges (voir le Programme relatif au commerce, aux questions de genre et au développement de la CNUCED). 


\section{Figure 7.5. Emploi dans le secteur des services (\% de l'emploi total), 2000, 2010 et 2018}

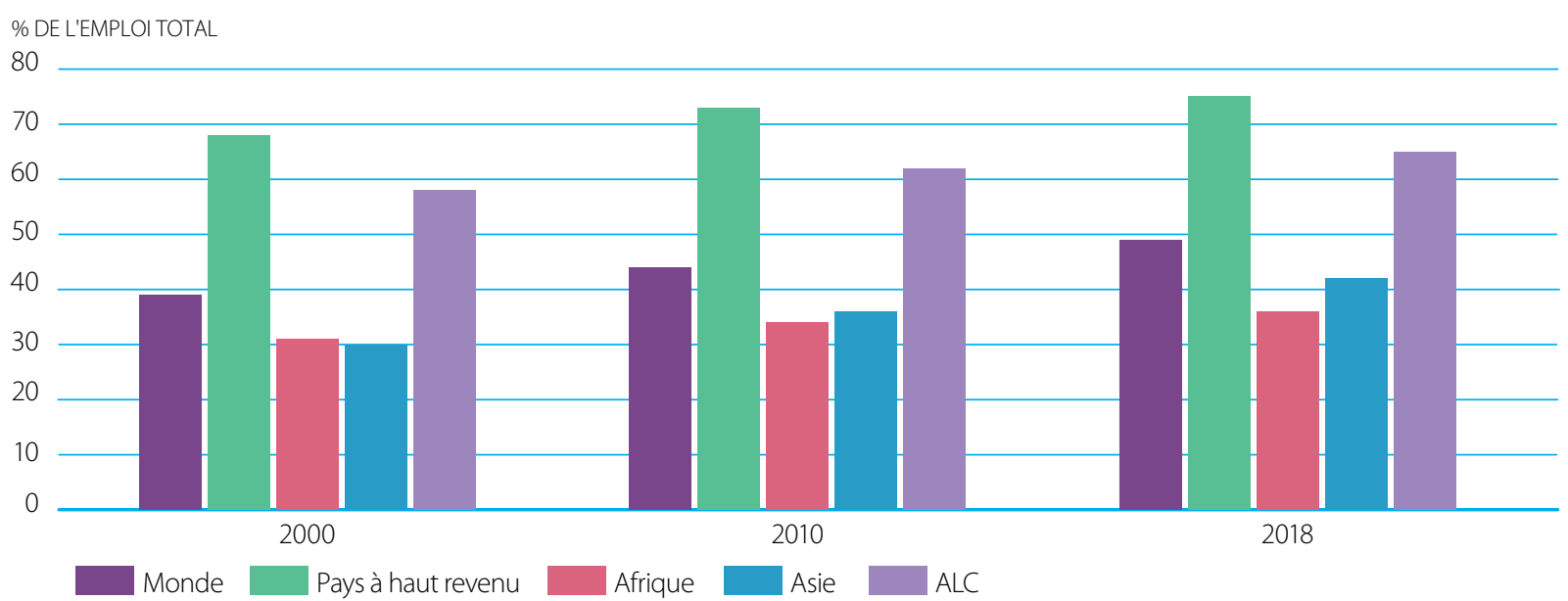

Source: Base de données ILOSTAT.

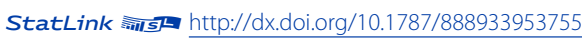

Le commerce des services peut contribuer à la diversification des exportations de deux manières: les services peuvent être exportés ou être incorporés dans les activités économiques en tant qu'intrants. Lorsque les services sont exportés, cela peut contribuer directement à la diversification verticale des exportations, puisque ces dernières sont alors moins concentrées sur les produits primaires. De cette manière, les pays pourraient diversifier leurs exportations sans passer par une phase d'industrialisation (Ghani et O'Connell 2014). La négociabilité des services augmente également avec les progrès des technologies de l'information et de la communication (TIC) (Ghani et Kharas 2010), car les innovations dans les TIC continuent de faire baisser les coûts associés au commerce des services (Ghani et O'Connell 2014). À la base, les progrès des TIC influençaient uniquement les services financiers (via les transactions en ligne, par exemple), mais ils favorisent à présent l'essor du commerce de différents services, y compris les services d'éducation et de santé. ${ }^{10}$

En tant qu'intrants, les services jouent un rôle essentiel non seulement pour relier les différents maillons des chaînes de valeur (services de transport, par exemple), mais aussi en tant qu'intrants directs dans la production de marchandises (par exemple, recherche, services financiers, etc.). Au cours des dernières décennies, la "servicification" croissante de l'industrie manufacturière, qui désigne le recours accru aux services dans le secteur manufacturier, a renforcé la pertinence des services en tant qu'intrants." La réforme des services ayant facilité l'accès à des intrants de services compétitifs a permis d'accroître la productivité et la compétitivité du secteur manufacturier, par exemple en Inde (Arnold et al. 2016) et au Chili (Fernandes et Paunov 2012).

Pour continuer d'améliorer le commerce des services, la politique commerciale a son importance. En effet, le commerce des services continue de se heurter à d'importants obstacles liés aux politiques, d'importance variable selon les pays et secteurs concernés. D'après l'indice des restrictions au commerce des services, certains pays asiatiques à croissance rapide appliquent des politiques très restrictives en matière de commerce des services, tandis que d'autres pays en développement font preuve d'une grande ouverture. En général, le commerce des services professionnels et des services de transports continue de faire l'objet de restrictions, tandis que les services financiers et les services de commerce de détail sont plus ouverts (figure 7.6). Par ailleurs, le niveau des restrictions peut considérablement varier selon le mode concerné et d'un pays ou secteur à l'autre, ce qui rend le commerce des services encore plus complexe (Borchert, Gootiiz et Mattoo 2012).'2 
Figure 7.6. Indice des restrictions au commerce des services par secteur, moyennes régionales

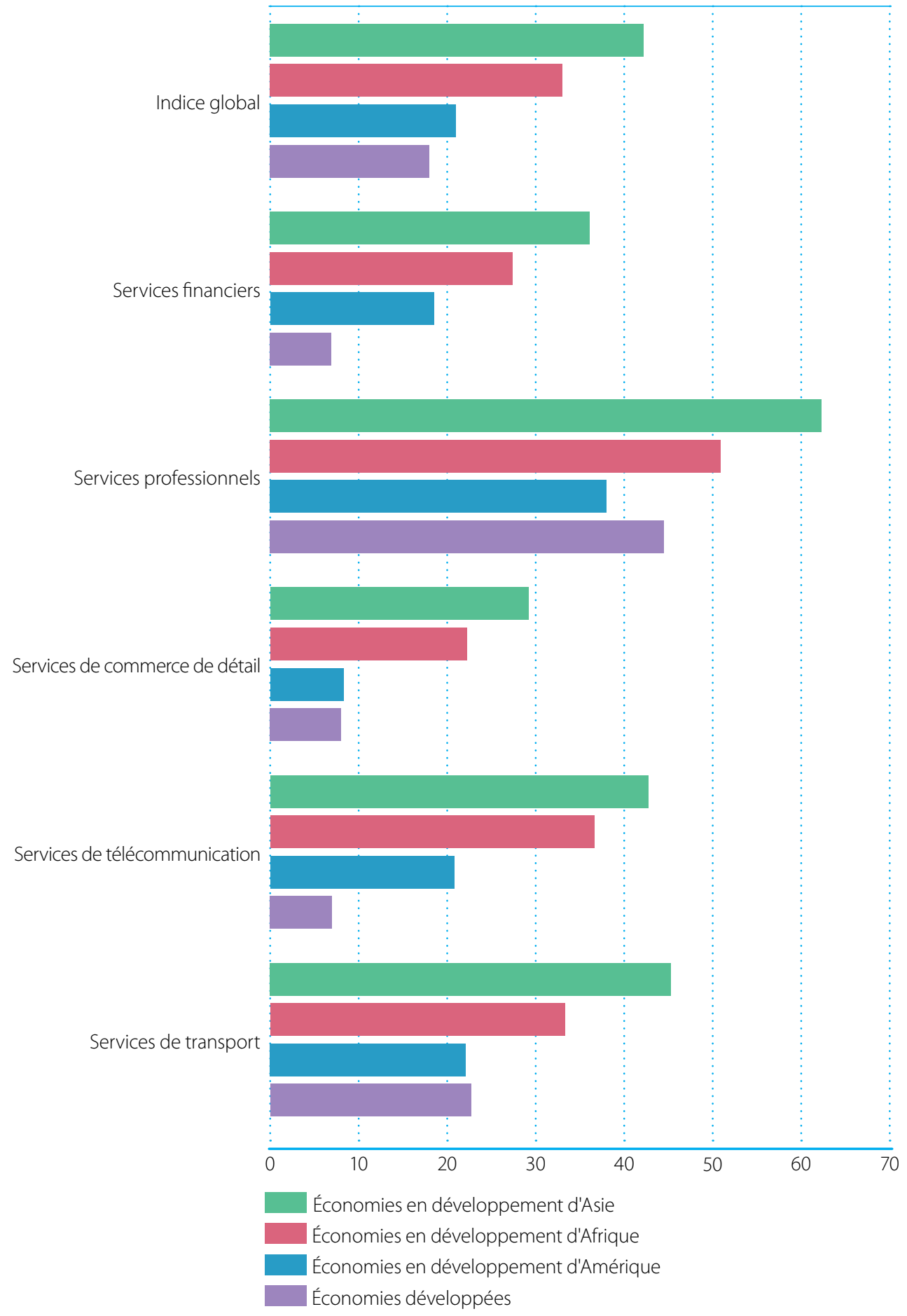

Note: Cette figure compare le caractère restrictif de la politique relative au commerce des services entre les régions sur la base des moyennes simples de l'indice des restrictions au commerce des services de la Banque mondiale dans les pays, qui est compris entre 0 et 100. La base de données de la Banque mondiale sur les restrictions au commerce des services couvre 103 pays (79 pays en développement) ainsi que les services financiers, les services de télécommunication de base, les services de transport, les services de distribution et certains services professionnels. Les renseignements pour la base de données ont été collectés entre 2008 et 2010.

Source: Base de données de la Banque mondiale sur les restrictions au commerce des services. 


\section{COMMERCE INTRARÉGIONAL SUD-SUD}

Le deuxième domaine susceptible de stimuler la diversification des exportations des pays en développement dans les années à venir est le commerce intrarégional Sud-Sud. Les pays en développement exportent déjà davantage de produits divers, y compris des produits transformés, vers les pays voisins que vers leurs partenaires commerciaux traditionnels faisant partie des pays développés.

La figure 7.7 illustre de façon détaillée l'évolution de la composition des exportations des différents groupes de pays en développement dans les années allant de 1995 à 2017. Les produits exportés sont regroupés en cinq catégories: produits de haute technologie, produits de moyenne technologie, produits provenant des ressources naturelles et produits de faible technologie, produits primaires, et autres produits, d'après la définition donnée par Lall (Lall, 2000).13 L'axe de droite correspond à la part des exportations sur chaque marché. Depuis 1995, les exportations africaines vers le Sud ont considérablement augmenté, passant d'à peine plus de 20\% à près de 50\% du total entre 1995 et 2017. Les exportations de l'Afrique vers le Sud incluent davantage de produits de faible et de moyenne technologie que ses exportations vers le Nord, mais les produits primaires restent prépondérants. Cela peut être lié à la forte concentration dans le secteur primaire des exportations africaines vers la Chine, qui représentent environ 10\% des exportations totales de l'Afrique.

S'agissant du commerce intra-africain, la répartition des produits échangés est très différente de ce que l'on a vu précédemment. En Afrique, la part du commerce intrarégional dans les exportations totales augmente progressivement mais constamment, et a atteint 20\% en 2017. Le commerce intrarégional est aussi plus diversifié et contient une proportion bien plus importante de produits de faible et de haute technologie. La figure 7.8 décrit l'évolution de la part des produits de moyenne et de haute technologie dans les exportations totales de l'Afrique en 2005, 2010 et 2017, selon la destination. La part des exportations de produits de moyenne et de haute technologie vers le reste du monde est passée de 9\% en 2005 à 15\% en 2017. En revanche, les exportations de produits de moyenne et de haute technologie représentaient près d'un quart des échanges intrarégionaux de l'Afrique en 2017, soit une augmentation de plus de 7 points de pourcentage depuis 2005. Cette tendance à l'augmentation de la diversification des exportations dans le commerce intrarégional se retrouve dans différentes régions en développement au fil des années. Le commerce intrarégional semble encourager la diversification des exportations intrasectorielles, et les exportations à plus forte intensité technologique plutôt que les exportations vers le reste du monde, comme le confirme l'exemple de l'Afrique de l'Est dans ( $\mathrm{Na}, 2019)$.

Dans le commerce intrarégional Sud-Sud, on a observé une plus grande diversification des exportations, malgré des conditions qui ne sont pas toujours favorables au commerce s'agissant de l'accès aux marchés ou de la facilitation des échanges. La CESAP, par exemple, estime que le potentiel du commerce intrarégional en Asie du Sud avoisine 81 milliards d'USD, et qu'un tiers seulement de ce potentiel est réalisé en raison du coût élevé du commerce, entre autres obstacles..$^{14}$ Les coûts du commerce semblent pouvoir être encore abaissés dans les configurations régionales Sud-Sud (OMC, 2018b).

S'agissant des conditions d'accès aux marchés, les mesures réglementaires techniques appliquées par les pays importateurs, telles que les mesures liées aux obstacles techniques au commerce (OTC) ou les mesures sanitaires et phytosanitaires (SPS), ont une incidence significative sur la hausse des coûts du commerce. Les mesures OTC et SPS sont des mesures techniques nationales répondant à des objectifs de politique légitimes comme la protection de la santé des personnes et des animaux, la sécurité et la préservation de l'environnement. Les mesures OTC et SPS découlent d'objectifs non liés au commerce, mais du fait de leur impact important sur les flux d'échanges, ces mesures techniques peuvent constituer des mesures non tarifaires (MNT) qui font grimper les coûts du commerce, notamment à cause du coût élevé de la mise en conformité (par exemple, essais en laboratoire et certification). 
Figure 7.7. Exportations par catégorie de technologie et par partenaire, diverses régions, 1995-2017

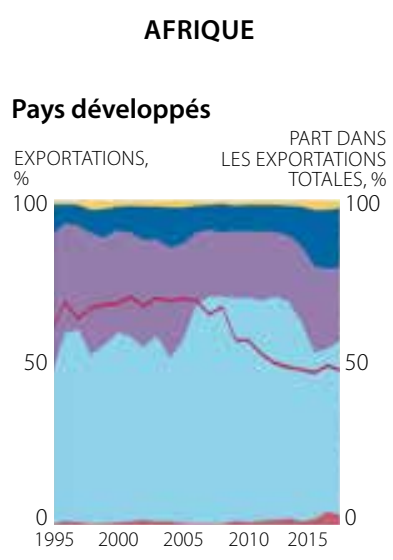

\section{Pays en développement}
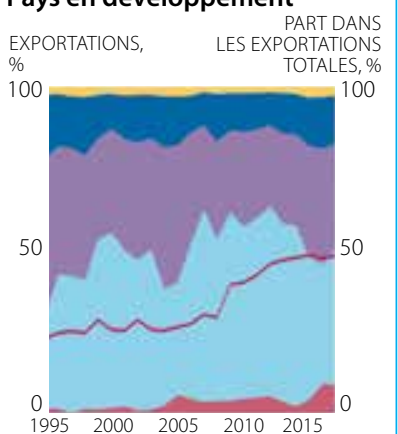

\section{Commerce intrarégional}

\begin{tabular}{l} 
PART DANS \\
EXPORTATIONS, $\quad$ LES EXPORTATIONS \\
\hline
\end{tabular}

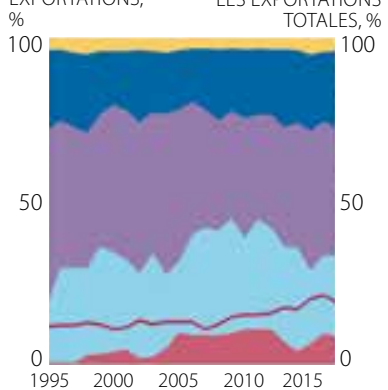

\section{Chine}

EXPORTATIONS,

$\%$

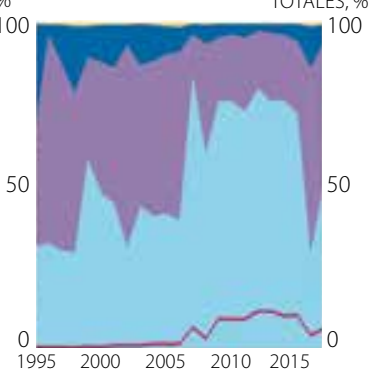

AMÉRIQUE LATINE ET CARAÏBES

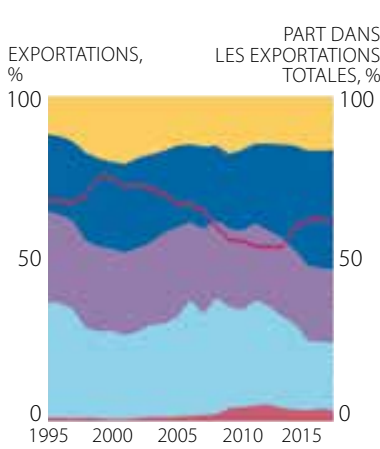

PART DANS
EXPORTATIONS, $\quad$ LES EXPORTATIONS
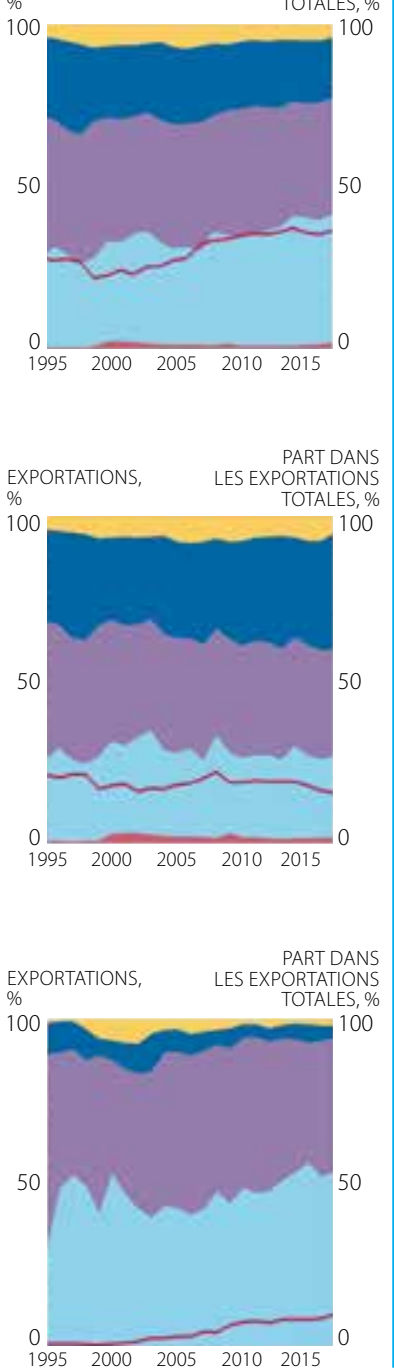

\section{ASIE DE L'EST, DU SUD \\ ET DU SUD-EST (HORS CHINE)}
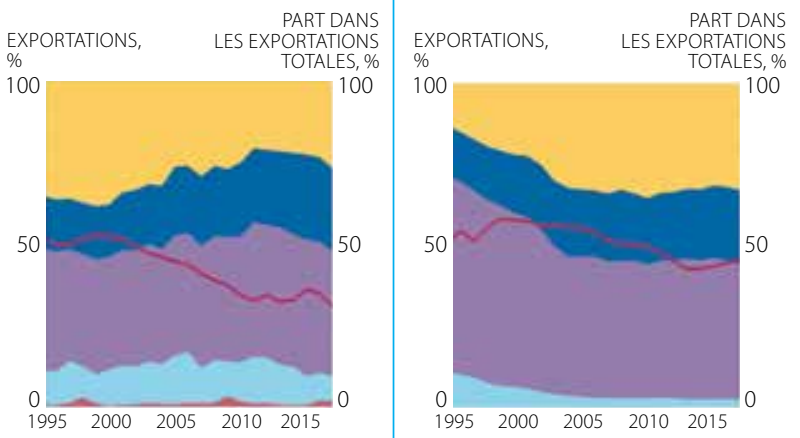

EXPORTATIONS

$\%$
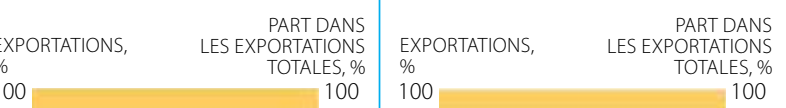

50
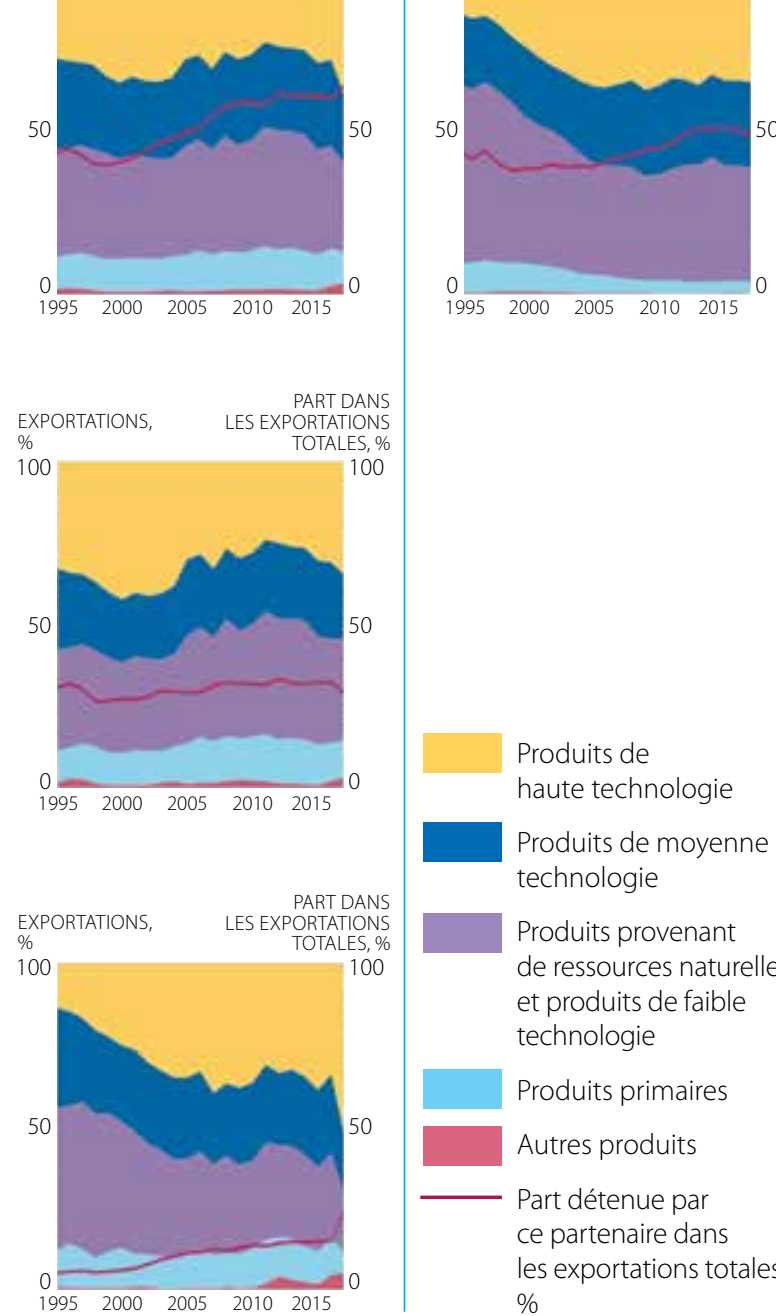

CHINE

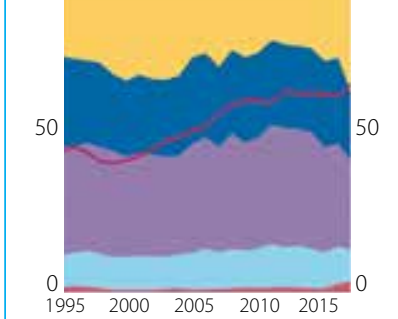

Produits de

haute technologie

Produits de moyenne technologie

Produits provenant de ressources naturelles et produits de faible technologie

Produits primaires

Autres produits

Part détenue par ce partenaire dans les exportations totales, $\%$

Note: EL'Asie de l'Est, du Sud et du Sud-Est n'inclut pas la Chine. Les catégories de produits sont basées sur la classification élaborée par Lall (Lall, 2000).

Source: Base de données COMTRADE de l'ONU. 


\section{Figure 7.8. Part des produits de moyenne et de haute technologie dans les exportations africaines, par destination}

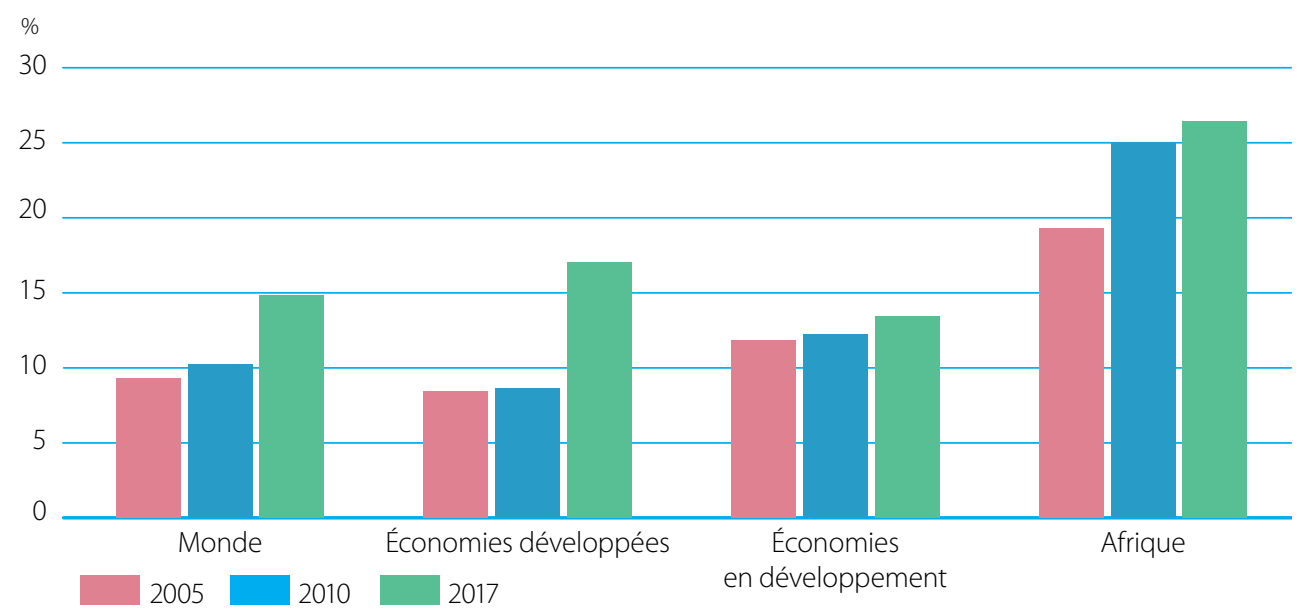

Source: UNCTADStat. Key Statistics and Trends in Regional Trade in Africa (CNUCED, 2019b).

Plusieurs études ont montré que les MNT ont un impact plus important sur les coûts du commerce que les droits de douane. ${ }^{5}$ Les effets de distorsion des échanges des MNT peuvent être mesurés en estimant l'équivalent ad valorem (EAV) du coût lié au respect des MNT, qui correspond à un pourcentage du prix à l'importation. Une étude indique que les MNT appliquées dans les secteurs de l'alimentation et de l'agriculture en Afrique pourraient faire augmenter la valeur unitaire des produits échangés à l'intérieur de la région de 15 à 30\%, tandis que la moyenne des droits de douane intrarégionaux dans ces secteurs est d'environ 7\% (CNUCED, 2019b). D'après les estimations, l'EAV moyen des MNT dans le secteur manufacturier est compris entre 5\% et 20\%, par rapport à un droit moyen intra-africain de 5,4\%.16

Les mesures techniques sont généralement plus coûteuses et contraignantes pour les producteurs et entreprises de petite taille que pour les entreprises plus grandes. D'après le Centre du commerce international (ITC), dans les pays en développement, les petites et moyennes entreprises (PME) sont affectées de façon disproportionnée par les obstacles procéduraux et les MNT, car elles sont souvent dépourvues des ressources nécessaires pour surmonter ces obstacles (Rollo, 2016).

\section{COOPÉRATION RÉGLEMENTAIRE RÉGIONALE SUD-SUD}

Les restrictions concernant les services, les MNT techniques et, plus généralement, les divergences réglementaires entre les pays, peuvent empêcher la réalisation d'économies d'échelle sur les marchés internationaux pour les biens et services. Par exemple, les coûts liés à la fourniture de services professionnels (par exemple, délivrance de licences ou de diplômes pour les comptables, les médecins, etc.) doivent être payés séparément sur chaque marché, au lieu d'être répartis sur les différentes destinations. Cependant, les restrictions concernant les services ou les MNT techniques ne peuvent pas être simplement supprimées, car il s'agit généralement de mesures nationales légitimes qui répondent aux objectifs socioéconomiques et environnementaux d'un pays. Dans la mesure où les normes économiques, sociales et environnementales incorporées unilatéralement dans la réglementation nationale d'un pays peuvent malencontreusement affecter les producteurs, les consommateurs et les concurrents nationaux et étrangers, la convergence ou la coopération réglementaire peut présenter des avantages. 
La coopération réglementaire régionale (et mondiale) peut stimuler le commerce des services et les échanges intrarégionaux, et réduire ainsi le risque que la réglementation ait des effets involontaires sur les marchés nationaux et les partenaires commerciaux. En ce sens, elle peut favoriser la diversification des exportations en faisant baisser les coûts de transaction associés au commerce des services et au commerce intrarégional. ${ }^{17}$ La coopération réglementaire dans le commerce des services, par exemple la promotion d'infrastructures de communication conjointes et d'établissement de réseaux, peut permettre d'instaurer un environnement plus favorable.

II existe déjà, dans les régions en développement, de multiples accords régionaux commerciaux (ACR), et nombreux sont ceux qui contiennent des dispositions sur les restrictions au commerce des services et les MNT techniques. Les ACR existants et ceux qui sont en cours d'élaboration, comme la zone de libre-échange continentale africaine (ZLECAf), peuvent servir de plate-forme à la poursuite de la coopération réglementaire et ainsi favoriser l'amélioration des conditions d'accès aux marchés régionaux tout en augmentant les probabilités de diversification des exportations. ${ }^{18}$ Des cadres réglementaires mieux adaptés aux conditions et priorités nationales sont essentiels au bon fonctionnement des secteurs de services, en particulier les services d'infrastructure dont l'efficacité dépend fortement de la qualité des règlements.

Au-delà des dispositions des ACR existants, la coopération réglementaire peut aussi prendre la forme d'actions de reconnaissance mutuelle des mesures réglementaires ou d'harmonisation, entre autres. La coopération réglementaire prend diverses formes, en fonction de plusieurs facteurs: les règlements existants, les ressources financières et techniques, la façon dont les pays concilient objectifs sociaux et concurrence dans le secteur des services, et les services ou marchandises concernés. Par exemple, la coopération dans le domaine des services financiers prend plus fréquemment la forme d'actions d'harmonisation de la réglementation prudentielle, éventuellement au travers de l'adoption de normes internationales comme le dispositif de Bâle III, tandis que dans le domaine des services professionnels, la reconnaissance mutuelle est sans doute plus appropriée. En ce qui concerne les marchandises, les données montrent que les accords de reconnaissance mutuelle (ARM) pour les MNT techniques ont une incidence positive plus importante sur le commerce dans les secteurs à forte intensité technologique (Jang, 2018).19

De nombreuses actions vont actuellement dans le sens de la reconnaissance mutuelle et de l'harmonisation de la réglementation régionale. Par exemple, entre 2003 et 2014, les pays de l'Association des nations de l'Asie du Sud-Est (ASEAN) ont signé des accords de reconnaissance mutuelle (ARM) dans les domaines du tourisme, de la comptabilité, de l'architecture, de l'odontologie, de l'ingénierie, de la médecine et des soins infirmiers. Bien qu'il soit trop tôt pour évaluer avec certitude l'incidence de ces ARM sur le commerce, ils ont déjà déclenché dans les États membres un effort de renforcement des capacités en vue de moderniser la réglementation nationale et les normes de formation (Mendoza et al., 2016). S'agissant des MNT visant les marchandises, plusieurs projets dans le cadre du Fonds pour l'application des normes et le développement du commerce (FANDC) qui encouragent l'utilisation des bonnes pratiques réglementaires (BPR) dans l'élaboration ou l'examen des mesures SPS ont favorisé la convergence régionale en matière de réglementation. Par exemple, le Programme régional sur la sécurité sanitaire des produits destinés à l'alimentation humaine et animale avait pour objectif d'accroître l'harmonisation de la réglementation dans le domaine du commerce des aliments pour animaux, dans dix pays d'Amérique latine et des Caraïbes. Dans cette optique, différents outils spécifiques ont été mis au point - glossaires communs et analyses comparatives de la réglementation nationale et régionale, par exemple -, en plus d'autres activités comme le renforcement des capacités. ${ }^{20}$

Lorsque la reconnaissance mutuelle ou l'harmonisation des règlements régionaux est trop difficile, le simple fait d'accroître la transparence réglementaire entre les pays peut déjà constituer une avancée importante pour la coopération réglementaire régionale. Des approches innovantes visant à accroitre la transparence réglementaire ont été suivies dans le cadre d'ACR Sud-Sud, comme l'établissement, par les communautés économiques régionales (CER) africaines, de la zone de libre-échange tripartite qui rassemble trois CER africaines, à savoir le Marché commun de l'Afrique orientale et australe (COMESA), la Communauté de l'Afrique de l'Est (CAE) et la Communauté de développement de l'Afrique australe (SADC). 
En s'appuyant sur la classification internationale des MNT élaborée par la CNUCED et l'équipe d'appui multi-organisations, la zone de libre-échange tripartite a mis au point un système de déclaration en ligne (www.tradebarriers.org) grâce auquel les acteurs du secteur privé peuvent signaler directement les ONT ou les obstacles au commerce liés aux MNT qu'ils rencontrent lors de l'exportation vers des pays membres. ${ }^{21}$

La coopération réglementaire régionale peut générer des avantages économiques considérables. D'après une étude de la CNUCED sur la Communauté économique des États de l'Afrique de l'Ouest (CEDEAO), la coopération réglementaire sur les MNT peut permettre de réduire les restrictions au commerce de plus de $25 \%$, ce qui peut se traduire par une augmentation du commerce intra-CEDEAO de 15\% et des revenus totaux de 300 millions d'USD par an (CNUCED, 2018d). Une autre étude a estimé que la coopération réglementaire est susceptible d'engendrer une augmentation du bien-être de 21 milliards d'USD dans la ZLECAf et de 23 milliards d'USD dans le groupe des États d'Afrique, des Caraïbes et du Pacifique (ACP). Cela correspond à plus de cinq fois le bénéfice pouvant être retiré d'une élimination totale des droits de douane (Vanzetti, Peters et Knebel, 2017).

La coopération réglementaire régionale peut aussi avoir d'autres avantages, comme la création d'emplois et de revenus, la rentabilité des intrants et des services dans la région, et l'amélioration de la compétitivité liée à l'augmentation de la concurrence dans la région, que permet l'approfondissement de l'intégration des marchés régionaux. Cela peut, par la suite, encourager les avancées des pays africains vers la réalisation des ODD. La sphère régionale est une enceinte particulièrementadaptéeàl'incorporation des dimensions environnementales et sociales dans la politique commerciale. Les problèmes de développement tels que les inégalités salariales, les inégalités entre hommes et femmes, la rareté de l'eau et la dégradation de l'environnement, peuvent être résolus plus efficacement si une coopération réglementaire régionale est mise en place que s'ils sont traités individuellement. C'est pourquoi le Programme d'action d'AddisAbeba indique ce qui suit: "Nous constatons que l'intégration économique et l'interconnectivité régionales peuvent de façon appréciable promouvoir la croissance et le développement durable profitant à tous et nous nous engageons à renforcer les accords de coopération régionale et les accords commerciaux régionaux".22

\section{LE RÔLE DE L'AIDE POUR LE COMMERCE}

Comme souligné dans (Lamersen, Muoio, \& Roberts, 2019), le temps, les ressources et les conditions préalables nécessaires à la réussite d'un processus d'intégration régionale justifient l'intervention de l'Aide pour le commerce au titre de plusieurs thèmes: amélioration de l'infrastructure liée au commerce, facilitation des échanges, création d'un environnement propice aux échanges et renforcement des capacités de production. Ainsi, même si sur la période 20062017, 11\% à 19\% seulement des décaissements au titre de l'Aide pour le commerce étaient spécifiquement alloués à des programmes régionaux ou mondiaux, bon nombre des décaissements affectés à des programmes nationaux ont encouragé la mise en place des conditions préalables nécessaires à l'intégration régionale. ${ }^{23}$

Les programmes d'Aide pour le commerce ayant une orientation mondiale ou régionale spécifique ne représentent qu'une faible part des flux totaux d'Aide pour le commerce, mais le montant absolu des fonds qui leur sont consacrés a été multiplié par trois entre 2006 et 2017, passant de 2,2 à 6,6 milliards d'USD. ${ }^{24}$ Ces fonds ont été principalement dédiés au renforcement des capacités de production (60-80\%) et à l'infrastructure économique (12-29\%).

Les fonds destinés à soutenir les efforts de coopération réglementaire régionale, de reconnaissance mutuelle et d'harmonisation seraient probablement classés dans la catégorie des fonds mondiaux ou régionaux affectés à la politique et à la réglementation commerciales. Les dépenses engagées au titre de cette catégorie de l'Aide pour le commerce sont passées de 248 millions en 2006 à 565 millions d'USD en 2017, mais restent assez stables depuis 2011. En particulier, la rubrique ACR de cette catégorie (code SNPC 33130), qui englobe les travaux menés sur les mesures OTC et SPS au niveau régional, a reçu entre 49 et 125 millions d'USD depuis 2006. Même si l'ensemble des fonds affectés à la rubrique ACR étaient consacrés aux travaux régionaux sur les MNT techniques, cela paraîtrait faible au regard des bénéfices économiques potentiels de la coopération réglementaire régionale..$^{25}$ 
Le fait que la plupart des fonds de l'Aide pour le commerce continuent d'être affectés au niveau national, malgré les avantages potentiels notables de certains programmes régionaux, s'explique par plusieurs raisons, qui sont détaillées dans (Lamersen, Muoio, \& Roberts, 2019). Dans certains cas, l'appropriation des externalités régionales peut être difficile, d'où la négligence de programmes potentiellement bénéfiques. En outre, les programmes régionaux sont plus délicats à mettre en œuvre, à cause de certaines de leurs caractéristiques. Les pays affichant des niveaux de développement différents et des environnements politiques distincts rencontreront des difficultés supplémentaires dans la coordination de la mise en œuvre régionale. De la même façon, les différences entre les coûts réels ou perçus et les bénéfices de la mise en œuvre pour chaque pays peuvent compliquer la mise en œuvre d'un programme régional. De plus, les pays participent généralement à plusieurs processus d'intégration en même temps, et il est donc plus difficile d'harmoniser les actions nationales et régionales. Par ailleurs, il arrive fréquemment que la mise en œuvre réussie d'un programme régional nécessite la coordination de plusieurs donateurs, du secteur privé et de la société civile.

II convient également de souligner que les pays partenaires ayant participé à l'exercice 2017 de suivi et d'évaluation de l'Aide pour le commerce ont régulièrement cité la diversification des exportations et l'intégration régionale parmi leurs grandes priorités dans le cadre de l'Aide pour le commerce. ${ }^{26}$ Les priorités des pays partenaires ainsi que les bénéfices potentiels de l'intégration réglementaire régionale donnent à penser que ce thème doit bénéficier d'une attention prioritaire, malgré les difficultés de mise en œuvre. L'Aide pour le commerce a un rôle constant à jouer pour ce qui est d'encourager l'élaboration de mécanismes institutionnels et le renforcement des capacités qui facilitent la coordination nationale des programmes régionaux. 


\section{NOTES}

1. Bien que mentionnée pour la première fois en 2015 par Adjiedj Bakas, un observateur néerlandais, l'expression "slowbalisation" n'a commencé à être fréquemment utilisée que depuis son apparition récente dans un article de The Economist paru le 24 janvier 2019 et intitulé "Globalisation has faltered". Toutefois, les tendances sous-jacentes de commerce et d'IED que recouvre ce terme sont étudiées depuis longtemps, comme indiqué en détail ci-après.

2. D'après le rapport World Economic Situation and Prospects 2019, l'activité économique mondiale progressera de 3\% en 2019 mais la croissance a peut-être atteint son niveau record dans un contexte d'intensification des différends commerciaux, de risques de difficultés et d'instabilité financières et de tensions géopolitiques latentes (ONU, 2019).

3. Groupe de la Banque mondiale, Global Monthly, mars 2019.

4. Participation aux CVM telle que définie dans (Koopman et al., 2014).

5. Communiqué de presse de la CNUCED, Guerres commerciales: les gagnants et les perdants, 4 février 2019.

6. Tim De Chante, "If the world population lived like...", 8 août 2012. De Chante a utilisé un sous-ensemble de données produites par le réseau Global Footprint Network (GFN).

7. Paragraphe 9, Transformer notre monde: le Programme de développement durable à l'horizon 2030.

8. CNUCED, Trade in Services, 2018: First Annual Estimate, 2 avril 2019.

9. En Afrique, l'agriculture continue de représenter une part notable - environ 58\% - de l'emploi total.

10. Par exemple, des services de télémédecine spécifiques fournis grâce à la technologie de la large bande sont de plus en plus utilisés en Afghanistan (Rocha 2017).

11. Nous nous basons ici sur la définition de "servicification" utilisée dans (Miroudot 2017), qui désigne la dépendance accrue du secteur manufacturier à l'égard des services, qu'ils soient intégrés en tant qu'intrants ou regroupés avec les produits.

12. Le commerce des services est défini en fonction du mode de fourniture: le mode 1 correspond à la fourniture transfrontières, le mode 2 à la consommation à l'étranger, le mode 3 à la présence commerciale et le mode 4 à la présence de personnes physiques.

13. Les produits exportés sont classés selon la classification $\mathrm{CTCl}$ à trois chiffres, révision 2. Pour en savoir plus sur la classification des exportations selon leur intensité technologique, voir Lall (2000).

14. CESAP (2018), communiqué de presse, "Regional Cooperation Critical for Sustainable Trade", 16 octobre 2018.

15. Par exemple, voir Kee, Nicita et Olarreaga (2008).

16. Cadot et al. (2015) ont estimé que l'EAV moyen de toutes les MNT existantes dans les secteurs des produits animaux et végétaux est de l'ordre de 26-27\%. En d'autres termes, le respect des MNT imposées par les pays importateurs lors de l'exportation de produits animaux ou végétaux coûterait en moyenne 26-27\% du prix du produit. Ce chiffre est sensiblement plus élevé que l'obstacle tarifaire moyen dans le même secteur, qui est de l'ordre de $7-8 \%$.

17. La coopération réglementaire est en effet une composante importante de la facilitation des échanges. L'amélioration de la facilitation des échanges est associée à un élargissement de la gamme de produits exportés (Dennis et Shepherd, 2011; Beverelli et al., 2015). 
18. Les travaux de recherche consacrés aux accords commerciaux préférentiels (ACPr) donnent à penser qu'en termes de gains de parts de marché, la coopération réglementaire peut être relativement plus avantageuse pour les petites que pour les grandes entreprises (Baccini, Pinto, et Weymouth, 2017). En outre, un nombre grandissant d'ACPr contient des dispositions qui mentionnent explicitement les MPME, que ce soit pour promouvoir la coopération dans ce domaine ou pour exonérer ces dernières des obligations découlant des ACPr (OMC, 2016). En ce qui concerne l'autonomisation des femmes, les nouveaux ACPr contiennent de plus en plus souvent des considérations qui portent explicitement sur les questions de genre, généralement dans les dispositions sur le travail. Les éléments de preuve montrent que les accords qui prévoient des dispositions sur le travail contribuent à réduire les écarts entre hommes et femmes s'agissant de la participation à la main-d'œuvre et, du moins pour certains pays, s'agissant également des inégalités salariales (BIT, 2017).

19. Fait intéressant, les effets sont aussi plus importants pour le commerce entre les pays non membres de l'OCDE.

20. http://www.feedfoodseguro.org/el-proyecto

21. L'équipe d'appui multi-organisations est composée des organisations internationales suivantes: Organisation pour I'alimentation et l'agriculture (FAO), Fonds monétaire international (FMI), Centre du Commerce international (ITC), Organisation de coopération et de développement économiques (OCDE), Conférence des Nations Unies sur le commerce et le développement (CNUCED), Organisation des Nations Unies pour le développement industriel (ONUDI), Banque mondiale et Organisation mondiale du commerce.

22. Paragraphe $87 \mathrm{du}$ Programme d'action d'Addis-Abeba de la troisième Conférence internationale sur le financement du développement (juillet 2015).

23. Les fonds de l'Aide pour le commerce étaient majoritairement destinés à l'infrastructure économique et au renforcement des capacités de production, ces deux volets ayant reçu respectivement 51-62\% et 36-47\% des décaissements totaux entre 2005 et 2017.

24. Ces chiffres sont exprimés en prix de 2017.

25. es exemples mentionnés précédemment à ce sujet sont une augmentation des échanges de 300 millions d'USD par an dans la CEDEAO (CNUCED, 2018d), et une augmentation du bien-être de 23 milliards d'USD dans le groupe des États d'Afrique, des Caraïbes et du Pacifique (ACP) (Vanzetti, Peters et Knebel, 2017).

26. Interrogés sur leurs cinq priorités en matière d'Aide pour le commerce, 65 participants sur 86 ont cité la diversification des exportations, et 35 ont aussi mentionné l'intégration régionale (respectivement les cinquième et quatrième priorités les plus citées). 


\section{RÉFÉRENCES}

Arnold, J. M., Javorcik, B., Lipscomb, M. et A. Mattoo (2016). "Services Reform and Manufacturing Performance: Evidence from India". The Economic Journal, 126 (590): pages 1-39.

Baccini, L., Pinto, P. M., et S. Weymouth (2017). "The distributional consequences of preferential trade liberalization: firm-level evidence", International Organization, 71 2), pages 373-395.

Banque africaine de développement (2016), Stratégie du Groupe de la Banque pour l'emploi des jeunes en Afrique 2016- 2025. Banque africaine de développement, Abidjan.

Banque mondiale, Global Economic Prospects: Darkening Skies, janvier 2019, Washington DC.

Betcherman, G. et Khan, T (2015), Youth Employment in Sub-Sahara Africa.

Beverelli C., Neumueller, S. et R. Teh (2015). "Export diversification effects of the WTO Trade Facilitation Agreement". World Development, 76 C): pages 293-310.

BIT(2017). Handbook on Assessment of Labour Provisions in Trade and Investment Arrangements. Bureau international du travail, Genève.

Borchert, I., Gootiiz, B. et A. Mattoo (2012). "Policy Barriers to International Trade in Services: Evidence from a New Database". Policy Research Working Paper, nº 6109. Banque mondiale, Washington, D.C.

Cadot, O., Asprilla, A., Gourdon, J., Knebel, C. et R. Peters (2015). "Deep Regional Integration and Non-Tariff Measures: A Methodology for Data Analysis". UNCTAD/ITCD/TAB/71, CNUCED, Genève.

CESAP (2018). "Policy development and potential impacts of trade tensions in Asia and the Pacific", dans Asia-Pacific Trade and Investment Report 2018: Recent trends and developments, CESAP, Bangkok.

CNUCED (2018a). Export Diversification and Employment in Africa. (UNCTAD/ALDC/2018/3),

CNUCED, Genève.

CNUCED (2018c). World Investment Report 2018. CNUCED, Genève.

CNUCED (2018d). "Intégration régionale et mesures non tarifaires au sein de la Communauté économique des États de l'Afrique de I'Ouest (CEDEAO)". (UNCTAD/DITC/TAB/2018/1), CNUCED, Genève.

CNUCED (2018e). Rapport sur le commerce et le développement 2018: Pouvoir, plate-formes et lillusion du libre-échange. (UNCTAD/TDR/2018), CNUCED, Genève.

CNUCED (2018f). "Trade in Services and Employment". (UNCTAD/DITC/TNCD/2018/1), Genève.

CNUCED (2019a). Global Investment Trends Monitor, n 31, janvier 2019, Genève.

CNUCED (2019b). "Key Statistics and Trends in Regional Trade in Africa”. (UNCTAD/DITC/TAB/2019/3), CNUCED Genève.

CNUCED (2019c). Key Statistics and Trends in Trade Policy 2018: Trade Tensions, Implications for Developing Countries. (UNCTAD/ DITC/TAB/2019/1), CNUCED Genève.

Constantinescu, C., Mattoo, A., et M. Ruta (2018). "The Global Trade Slowdown: Cyclical or Structural?".

The World Bank Economic Review, Ihx027, https://doi.org/10.1093/wber/lhx027.

Dennis, A. et B. Shepherd (2011). "Trade facilitation and export diversification". The World Economy, 34 1):

pages 101-122. 
Fernandes, A.M., et C. Paunov (2012). "Foreign Direct Investment in Services and Manufacturing Productivity: Evidence for Chile". Journal of Development Economics 97 2): pages 305-321.

Ghani, E. et H. Kharas (2010). "The Service Revolution". Economic Premise, n 14. Banque mondiale, Washington, D.C. Ghani, E. et S. D. O'Connell (2014). "Can Service Be a Growth Escalator in Low-Income Countries?" Policy Research Working Paper, n 6971. Banque mondiale, Washington, D.C.

Jang, Y. J. (2018). "How do mutual recognition agreements influence trade?". Review of Development Economics, 22 3), e95-e114.

Kee, H.L., Nicita, A. et M. Olarreaga (2008). "Estimating trade restrictiveness indices". The Economic Journal 119.534 (2008): pages 172-199.

Lall, S. (2000). "The Technological Structure and Performance of Developing Country Manufactured Exports, 1985-1998". QEH Working Paper Series, n Queen Elizabeth House, University of Oxford, Oxford.

Lamersen, F., Muoio, R., et Roberts, M. (2019). "Regional Aid for Trade in Africa: a catalyst for economic integration and development" dans Luke, D. et J. Macleod (éds.) (2019). Inclusive Trade in Africa. Routledge, New York, 2019.

Mendoza, D. R., Desiderio, M. V., Sugiyarto, G., et B. Salant (2016). Open Windows, Closed Doors: Mutual Recognition Arrangements on Professional Services in the ASEAN Region. Banque asiatique de développement, Manille, Philippines.

Miroudot, S. (2017). "The Servicification of Global Value Chains", réunion d'experts pluriannuelle sur le commerce, les services et le développement, CNUCED, Genève.

$\mathrm{Na}, \mathrm{H}$. (2019). "Is intraregional trade an opportunity for industrial upgrading in East Africa?". Oxford Development Studies, pages 1-15.

OCDE (2014). Regional Perspectives on Aid for Trade. Éditions OCDE, Paris.

OCDE (2018). "International Regulatory Cooperation", Policy Brief, octobre 2018.

OCDE/OMC (2017). Panorama de l'Aide pour le commerce 2017: Promouvoir le commerce, l'inclusion et la connectivité pour un développement durable. OMC, Genève/Éditions OCDE, Paris.

OMC (2016). Rapport sur le commerce mondial 2016: Égaliser les conditions du commerce pour les PME. Organisation mondiale du commerce, Genève.

OMC (2018a). Tour d'horizon de l'évolution de l'environnement commercial international, Rapport annuel du Directeur général (WT/TPR/OV/21), décembre 2018, Genève.

OMC (2018b). World Trade Statistical Review 2018. Organisation mondiale du commerce, Genève.

ONU (2015). Transformer notre monde: le Programme de développement durable à l'horizon 2030, résolution adoptée par l'Assemblée générale le 25 septembre 2015 (A/RES/70/1), Organisation des Nations Unies, New York.

ONU (2019). World Economic Situation and Prospects 2019. Organisation des Nations Unies, New York.

Rocha, Nadia (2017). "Trade as a Vehicle for Growth in Afghanistan: Challenges and Opportunities". Document de travail. Banque mondiale, Washington, D.C.

Rollo, V. (2016). "Technical regulations affect exporters' performance: firm-level evidence from developing countries". ITC Working Paper Series, WP-02-2016.E. Centre du commerce international, Genève.

Vanzetti, D., Peters, R. et C. Knebel (2017). "Non-tariff measures: lifting CFTA and ACP trade to the next level”. (UNCTAD/ SER.RP/2017/14), Genève. 


\title{
CHAPITRE 8
}

\section{AUTONOMISER LES JEUNES POUR UN COMMERCE DURABLE}

\author{
Contribution du Centre du commerce international
}

\begin{abstract}
Resumé : L'autonomisation économique des jeunes est liée à l'avenir des petites et moyennes entreprises (PME). Le présent chapitre étudie le rôle que jouent les PME compétitives sur le plan international dans la création d'emplois pour les jeunes et examine comment l'amélioration des compétences des jeunes et l'innovation renforcent la capacité d'exportation des PME. Des données recueillies auprès des entreprises montrent que l'accès au financement est plus difficile pour les entreprises dirigées par des jeunes que pour celles dont les dirigeants sont plus âgés. Selon les constatations du présent chapitre, les programmes d'Aide pour le commerce qui améliorent l'accès des jeunes entrepreneurs aux services financiers et les compétences des jeunes favorisent la compétitivité commerciale des PME, tout en aidant les jeunes à trouver un emploi rémunérateur.
\end{abstract}




\section{INTRODUCTION}

La question de savoir si et comment le commerce contribue à une croissance inclusive reste une priorité pour les pouvoirs publics. Des décennies de libéralisation des échanges ont contribué à réduire la pauvreté, s'accompagnant toutefois dans de nombreux pays d'un écart croissant entre riches et pauvres (Draper, 2017; OCDE, 2015; Winters et Martuscelli, 2014). Bien que les économies soient de plus en plus interconnectées, la croissance du commerce mondial semble stagner (OMC, 2019).

Cela a amené certains à s'interroger sur la capacité du commerce à apporter des avantages à tous. Les politiques qui stimulent la participation des femmes, des jeunes et d'autres groupes marginalisés au commerce mondial peuvent rendre le commerce plus inclusif et promouvoir l'autonomisation économique.

Il est particulièrement pertinent aujourd'hui de mettre l'accent sur le rôle des jeunes dans le commerce, étant donné que ces derniers représentent une part importante et croissante de la population dans de nombreux pays en développement. On compte 1,2 milliard de jeunes âgés de 15 à 24 ans dans le monde (DAES de I'ONU, 2015), mais 66 millions de jeunes hommes et femmes sont au chômage et 145 millions ont un emploi mais sont en situation de pauvreté (ITC, 2019a). Les jeunes ont trois fois plus de risques d'être touchés par le chômage que les adultes (OIT, 2017), ce qui peut entraîner des pressions migratoires.

Dans le même temps, les petites et moyennes entreprises (PME) peinent à trouver les employés qualifiés dont elles ont besoin pour être compétitives et faire du commerce. Bien que les PME représentent plus d'un tiers du produit intérieur brut (PIB) des pays en développement, les pénuries de compétences limitent leur capacité à évoluer, à être compétitives et à se connecter aux marchés clés.

Les deux problèmes du chômage des jeunes et de la compétitivité des PME peuvent et doivent être résolus ensemble. L'autonomisation économique des jeunes est un objectif à lui seul: en effet, l'Objectif de développement durable (ODD) 8 appelle la communauté internationale à assurer le "plein emploi productif et [un] travail décent" aux jeunes.

Les jeunes se sentent autonomes sur le plan économique lorsqu'ils ont des emplois bien rémunérés et intéressants. Cela a plus de chances de se produire lorsque les entreprises sont compétitives et recrutent des jeunes. Étant donné que les PME représentent la plupart des emplois dans les pays en développement, elles sont bien placées pour embaucher des jeunes issus des populations locales et leur offrir une formation et une expérience sur le tas, qui peuvent conduire à une carrière. De fait, I'ODD 8 souligne que la croissance des PME est vitale pour le développement durable. Toutefois, pour croître et pouvoir embaucher dans l'économie mondialisée actuelle, les petites entreprises doivent renforcer leur compétitivité et leur attractivité afin que les jeunes les considèrent comme un choix de carrière viable.

Dans ce chapitre, nous examinerons les liens entre l'autonomisation économique des jeunes et la compétitivité internationale des petites entreprises. Nous constaterons qu'il existe des synergies entre les objectifs d'autonomisation économique des jeunes et de compétitivité des PME - autrement dit, la relation va dans les deux sens: le renforcement des compétences des jeunes et l'innovation favorisent la compétitivité et les exportations des PME, et des PME compétitives sur le plan international créent des emplois plus nombreux et de meilleure qualité pour les jeunes. Nous évaluerons également les caractéristiques des programmes d'autonomisation économique des jeunes qui sont essentielles pour les aider à trouver un emploi rémunérateur dans de petites entreprises en tant que travailleurs ou entrepreneurs. 


\section{DONNER AUX ENTREPRISES LES MOYENS D’EXPORTER GRÂCE AUX COMPÉTENCES DES JEUNES}

Léducation et les compétences sont importantes pour le développement des jeunes, et elles influent sur les résultats économiques et sociaux. Dans la littérature économique, le concept de capital humain d'une personne englobe les capacités, l'éducation et les qualifications formelles (qu'elles soient académiques ou professionnelles), ainsi que les aptitudes, les compétences et l'expérience professionnelle (Blundell et al., 1999). Le capital humain des jeunes est particulièrement important, compte tenu de leur rôle, actuel et futur, dans les économies nationales.

Une personne sur trois dans le monde aujourd'hui est âgée de moins de 25 ans (Khokhar, n.d.). Lorsque les taux de mortalité infantile diminuent mais que les taux de fécondité restent élevés, il en résulte ce qu'on appelle l'explosion démographique de la jeunesse, c'est-à-dire une forte proportion de jeunes dans le pays. Dans les 48 pays les moins avancés du monde, les enfants et les adolescents constituent la majorité de la population (Gupta et al., 2014). En revanche, dans les pays développés, une plus faible proportion de la population se situe dans la tranche d'âge des 15-29 ans: plus précisément 7 points de pourcentage de moins (Yifu Lin, 2012). En 2014, 90\% des jeunes de 10 à 24 ans vivaient dans des pays en développement (Gupta et al., 2014).

Lorsque les jeunes, qui sont de plus en plus nombreux, trouvent des emplois de qualité correctement rémunérés, la société dans son ensemble profite de ce que l'on appelle le "dividende démographique". Toutefois, dans de nombreux cas, cela n'est pas le cas.

Au Moyen-Orient et en Afrique du Nord, par exemple, environ 25\% des jeunes sont au chômage (Purfield et al., 2018) et les pays en développement enregistrent fréquemment des taux de chômage à deux chiffres chez les jeunes (voir la figure 8.1). L'Organisation internationale du travail estime que 13\% des jeunes âgés de 15 à 24 ans sont au chômage dans le monde (O'Higgins, 2017).

\section{Figure 8.1. Taux de chômage des jeunes selon les pays}

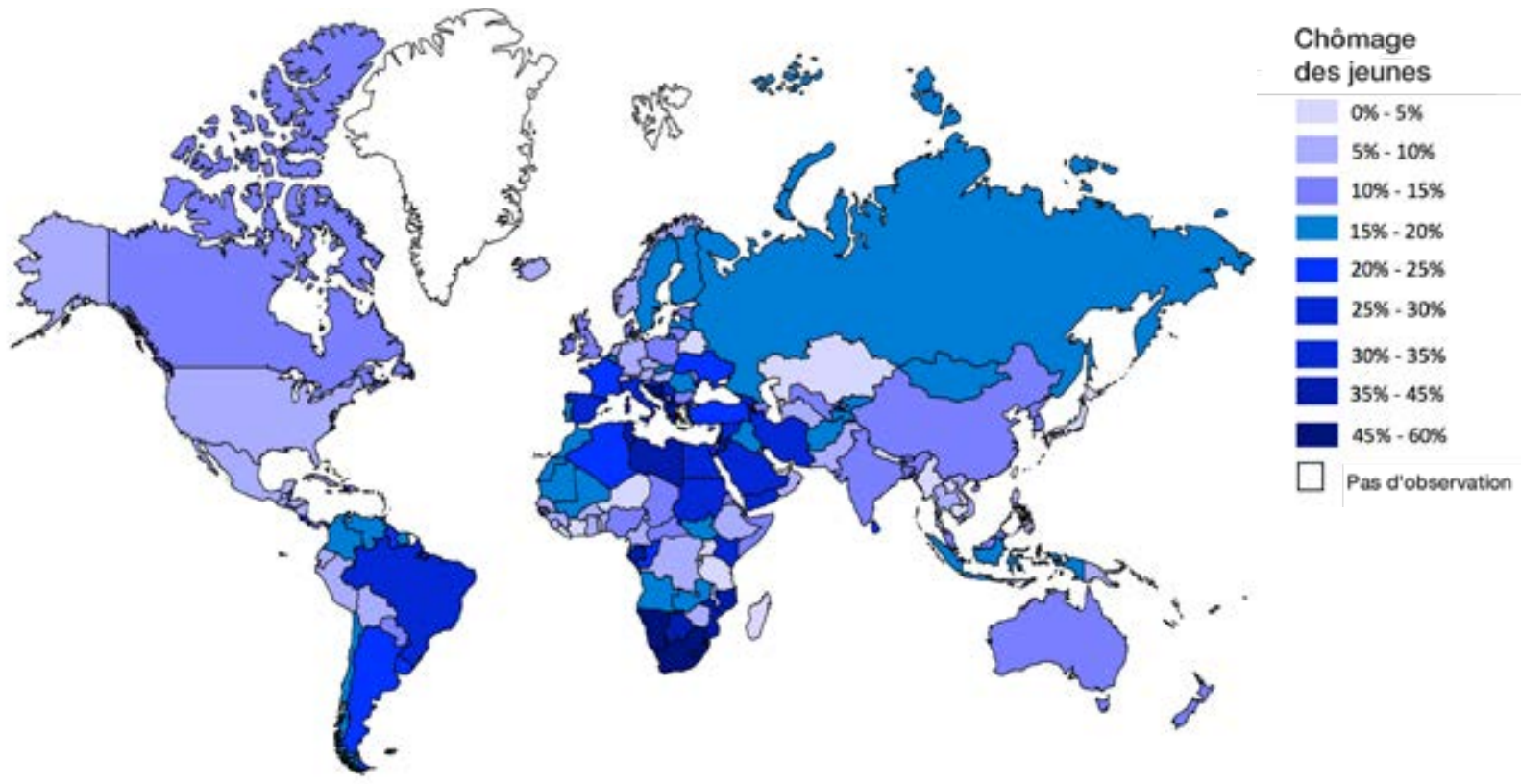

Note: Chômage, total des jeunes (\% de la population active totale âgée de 15 à 24 ans) (estimation modélisée OIT). Le chômage des jeunes désigne la proportion de la population active âgée de 15 à 24 qui n'a pas de travail mais qui est prête à travailler et recherche un emploi. Les appellations employées dans la présente publication et la présentation des données qui y figurent n'impliquent de la part du Centre du commerce international aucune prise de position quant au statut juridique des pays, territoires, villes ou zones ou de leurs autorités, ni quant au tracé de leurs frontières ou limites.

Source: Indicateurs de développement de la Banque mondiale, à partir de la base de données ILOSTAT de I'Organisation internationale du travail. Données extraites en septembre 2018. 
Même lorsque les jeunes ont un emploi, il peut s'agir d'emplois de qualité médiocre, mal rémunérés, impliquant de longues heures de travail ou des conditions de travail précaires. De longues périodes de chômage et de sous-emploi peuvent nuire de façon permanente aux perspectives d'évolution professionnelle à long terme d'une personne (Pikoko et Phiri, 2018; Weidenkaff, 2018).

Les recherches soulignent les risques associés au grand nombre de jeunes sans emploi ou sous-employés. Le mécontentement des jeunes au chômage peut être source d'agitation sociale et d'instabilité politique (Banque mondiale, 2011). Les jeunes - définis ici comme les personnes âgées de 15 à 24 ans, sauf indication contraire - sont plus susceptibles d'émigrer s'ils n'ont pas d'emploi dans leur pays d'origine, ce qui a une incidence tant sur leur pays d'origine que sur le pays de destination (Fernando, 2018).

Quelque 600 millions d'emplois seront nécessaires d'ici à 2028 pour absorber le nombre actuel de chômeurs dans le monde (Banque mondiale, 2012) et pour offrir des possibilités d'emploi aux 40 millions de personnes - principalement des jeunes - qui entrent chaque année sur le marché du travail (OIT, 2012). L'ampleur et l'importance de ce défi ont été clairement soulignées dans le Programme de développement durable à l'horizon 2030, qui appelle la communauté internationale à "réduire considérablement la proportion de jeunes non scolarisés et sans emploi ni formation" (cible 8.6 des ODD). Il est donc crucial de s'attaquer au chômage et au sous-emploi des jeunes afin de favoriser la croissance à long terme et d'éviter des résultats sociaux indésirables.

\section{Les petites entreprises ont un rôle clé à jouer}

Les PME présentent un fort potentiel en matière de création d'emplois pour les jeunes dans les pays en développement. Elles sont la pierre angulaire de la plupart des économies. Les petites et moyennes entreprises emploient plus de 70\% de la main-d'œuvre d'un pays, représentent 35\% du PIB et génèrent 34\% des exportations (OMC, 2016). Dans les pays en développement, ces entreprises emploient généralement les segments plus pauvres et plus vulnérables de la société (ITC, 2015a).

Dans les économies en développement, les petites entreprises emploient un grand nombre de jeunes. Les données des enquêtes de l'ITC sur la compétitivité des PME menées dans 9 pays en développement indiquent qu'un employé sur 4 des petites et moyennes entreprises a entre 18 et 24 ans.' Les PME offrent d'importantes possibilités d'absorber l'explosion démographique et de la transformer en dividende.

\section{Les compétences des jeunes peuvent aider les entreprises à s'internationaliser}

Néanmoins, les PME souffrent de graves pénuries de main-d'œuvre qualifiée qui les empêchent de recruter des jeunes et nuisent à leur compétitivité. La mondialisation et les échanges offrent de nouveaux débouchés commerciaux, mais ils ont également accru la pression concurrentielle qui s'exerce sur les entreprises. Les connaissances pertinentes pour un emploi et les qualités personnelles des travailleurs, ainsi que leur compréhension de ce qui est nécessaire pour effectuer le travail demandé (Bacchetta et al., 2017, page 24), affectent la capacité d'une entreprise à répondre aux exigences en matière de coûts, de quantité et de temps pour être compétitive.

Le capital humain peut être particulièrement important dans des environnements économiques dynamiques, où les technologies évoluent rapidement et de manière imprévisible. Dans ce cas, un capital humain plus important peut encourager la diffusion des technologies tant dans l'entreprise que dans l'économie, favorisant ainsi la croissance économique (Barro, 1991). Cela est lié au fait qu'une main-d'œuvre qualifiée peut aider une entreprise à anticiper et à s'adapter aux évolutions de l'environnement commercial (Woessmann, 2011). 
Les investissements dans le capital humain, tels que la formation initiale et la formation en cours d'emploi, améliorent la productivité des PME (Miller et Upadhyay, 2000; Vandenberg et Trinh, 2016), contribuant ainsi à leur compétitivité sur le plan international. L'incidence du capital humain sur la productivité et la compétitivité explique en partie pourquoi il s'agit d'un facteur important de la croissance économique (Woessmann, 2011).

Certaines recherches laissent à penser qu'il existe une relation positive significative entre le niveau de capital humain des PME et leur tendance à s'internationaliser (Onkelinx et al., 2015). Les entreprises employant des travailleurs hautement qualifiés peuvent être mieux à même d'adapter leurs produits et leurs technologies à l'environnement économique national, ce qui facilite la diversification de l'économie nationale et l'exportation de produits adaptés vers les pays voisins (Bacchetta et al., 2017; ITC, 2017a). Dans une perspective empirique, des niveaux plus élevés de capital humain sont associés à des taux plus importants de diversification des exportations (Cadot et al., 2011).

Les travailleurs ayant suivi des études ou une formation peuvent permettre aux entreprises des pays en développement d'améliorer leur position dans les chaînes de valeur mondiales, notamment en les aidant à respecter les normes de qualité des clients étrangers (Jansen et Lanz, 2013). De plus, l'internationalisation peut exiger des compétences relationnelles, comme la présentation et la communication, et les compétences linguistiques (CEDEFOP, 2010).

Investir dans les compétences des jeunes est une stratégie prometteuse pour stimuler le capital humain dans la perspective du commerce. De nombreux pays en développement comptent un nombre important de jeunes sousemployés et au chômage qui pourraient être qualifiés pour répondre aux besoins futurs du marché du travail. Comme indiqué plus haut, les objectifs de développement durable mettent l'accent sur le lien entre les compétences des jeunes et l'emploi. L'ODD 4.4, par exemple, appelle à augmenter considérablement le nombre de jeunes disposant des compétences, notamment techniques et professionnelles, nécessaires à l'emploi, à l'obtention d'un travail décent et à l'entrepreneuriat.

Dans sa réponse au questionnaire de l'enquête de suivi OCDE-OMC sur l'Aide pour le commerce de 2019, le gouvernement de Papouasie-Nouvelle-Guinée a souligné les difficultés rencontrées par les jeunes du pays pour obtenir un emploi après l'obtention de leur diplôme, et la nécessité de doter les jeunes des compétences nécessaires pour encourager leur participation à l'économie. L'investissement dans l'éducation et la formation des jeunes présente des avantages manifestes à long terme en ce qui concerne l'augmentation de la productivité des employés.

\section{La pénurie et l'inadéquation des compétences limitent l'emploi}

Les employeurs des pays développés et en développement disent avoir du mal à trouver des travailleurs possédant les compétences dont ils ont besoin. En Europe, environ quatre entreprises sur dix déclarent rencontrer de tels problèmes. Environ 30\% des employeurs au Pérou et en Colombie affirment qu'il est difficile de pourvoir les postes vacants. On observe des chiffres similaires, voire plus élevés, dans d'autres pays en développement, notamment au Panama (40\%), au Mexique (40\%), en Inde (60\%) et au Brésil (70\%) (Forum économique mondial, 2014).

L'inadéquation des compétences apparaît généralement lorsque les compétences acquises dans les établissements d'enseignement ne correspondent pas aux exigences du marché du travail. II s'agit d'une cause bien connue d'inefficacité économique (Jansen et Lanz, 2013), qui coûte cher à l'économie et à la société, et génère surtout du chômage chez les jeunes.

Les PME qui ne parviennent pas à trouver des employés possédant les compétences dont elles ont besoin ont tendance à moins embaucher de travailleurs, y compris de jeunes. Inversement, les entreprises embauchent plus volontiers lorsqu'elles parviennent à trouver des jeunes ou d'autres demandeurs d'emploi disposant des compétences appropriées. En effet, d'après une étude réalisée auprès des entreprises, les entreprises qui attachent beaucoup d'importance à la disponibilité de travailleurs qualifiés ont tendance à embaucher davantage de jeunes travailleurs (voir la figure 8.2). 
Lorsque les compétences ne sont pas adéquates, les entreprises peuvent embaucher du personnel non formé. En effet, un adulte sur quatre interrogé dans les pays de l'OCDE fait état d'un décalage entre les compétences dont il dispose et celles dont il a besoin pour son emploi actuel (Forum économique mondial, 2017). Dans une enquête menée dans six pays en développement, environ $28 \%$ des chefs d'entreprise ont déclaré que les compétences de leur personnel n'étaient pas en adéquation avec les besoins de leur entreprise. ${ }^{2}$

\section{Figure 8.2. Pénurie de main d'œuvre qualifiée et emploi des jeunes dans les PME}

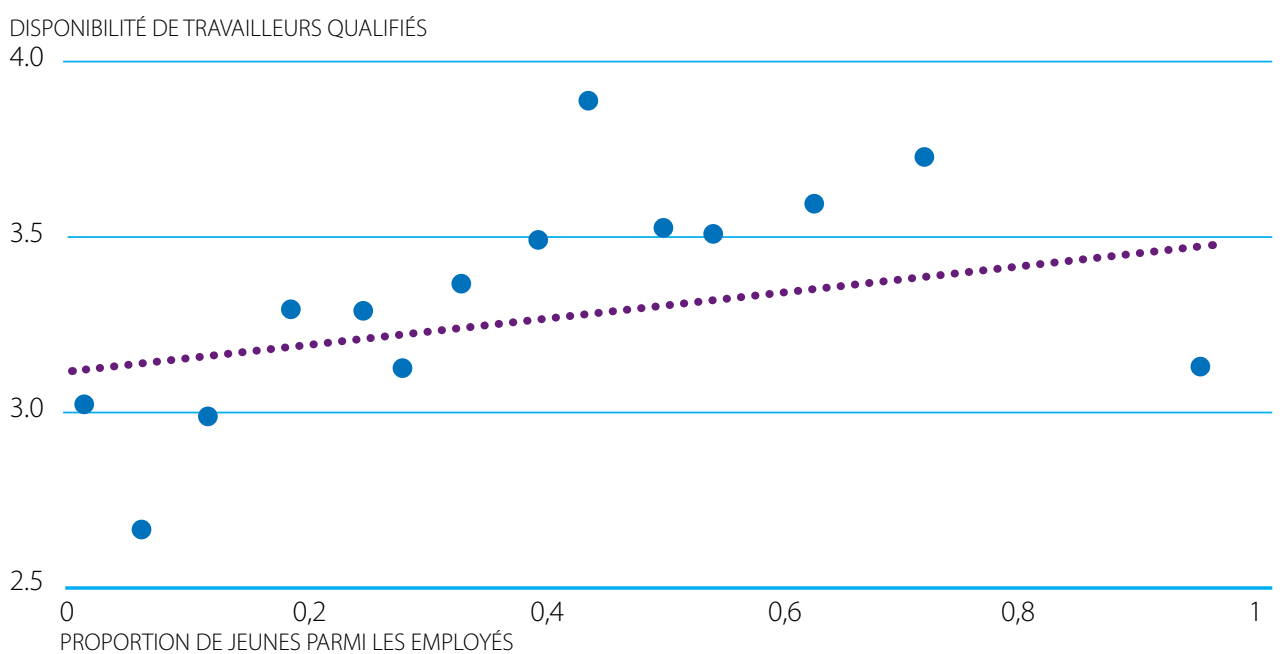

\footnotetext{
Note: Réponse des entreprises à la question "Comment évaluez-vous la disponibilité de travailleurs qualifiés en recherche d'emploi?". Les réponses possibles étaient les suivantes: 0 = pénurie de travailleurs qualifiés, 1, 2, 3, 4 et 5 = abondance de travailleurs qualifiés. L'axe des abscisses montre le pourcentage d'employés à temps plein âgés de moins de 25 ans. La relation entre les deux variables est le résultat d'un graphique de dispersion. ${ }^{3}$ Au total, 1784 entreprises ont été interrogées au Ghana, au Kenya, à Sainte-Lucie, en Ukraine et en Zambie, en 2017 et 2018.

Source: Enquêtes de I'ITC sur la compétitivité des PME.
}

L'absence de combinaisons de compétences adéquates sur le marché du travail risque d'affecter davantage les PME car elles ne disposent que de ressources très limitées à investir dans la formation. Les données de l'enquête de l'ITC indiquent que plus de la moitié des grandes entreprises en Gambie offrent une formation interne, contre seulement $38 \%$ des micro et petites entreprises et 33\% des moyennes entreprises (ITC, 2018a). Cette situation est similaire à celle de certains pays de I'OCDE, où les PME proposent moins de formation que les grandes entreprises (Almeida et al., 2012; Green et Martinez-Solano, 2011; Kubisz, 2011).

\section{Donner aux jeunes les compétences appropriées}

Veiller à ce que les jeunes reçoivent une formation appropriée peut contribuer à prévenir les inadéquations de compétences et le manque de préparation qui en résulte pour les employés. De nombreuses analyses se concentrent sur les moyens efficaces d'autonomiser les jeunes en leur donnant les compétences dont les PME ont besoin pour s'internationaliser.

L'aide publique au développement a contribué à remédier aux pénuries de main-d'œuvre qualifiée afin de renforcer la capacité des entreprises à faire du commerce. Toutefois, les définitions actuelles de l'Aide pour le commerce excluent le soutien aux compétences techniques et professionnelles ainsi que les programmes d'entrepreneuriat. En tant que telle, l'assistance visant à améliorer les compétences des jeunes pour le commerce n'est pas prise en compte dans les mesures multilatérales de l'Aide pour le commerce. 
Les initiatives visant à remédier aux pénuries de main-d'œuvre qualifiée ont facilité les consultations entre les parties prenantes publiques et privées. Une telle collaboration peut créer des solutions pour remédier à l'inadéquation des compétences et favoriser la mise en œuvre de programmes visant à soutenir des formations techniques et professionnelles des jeunes qui correspondent au marché.

Fournir des compétences de base peut être un atout considérable de ces programmes. Les compétences en technologies de l'information et de la communication peuvent aider les jeunes à trouver un emploi et à réussir en tant qu'entrepreneurs (Coward et al., 2014). De plus, des connaissances financières et des compétences nécessaires à la vie courante peuvent aider les jeunes à se préparer à de nouvelles possibilités économiques.

Encadré 8.1. Renforcement des compétences pour le tourisme au Myanmar: étude de cas du programme STED de l'OIT

En 2017, l'Organisation internationale du travail s'est associée au gouvernement du Myanmar pour évaluer les futurs besoins de compétences du secteur touristique. L'outil d'assistance technique de l'OIT appelé "Compétences professionnelles pour le commerce et la diversification économique" (STED) a fourni des orientations stratégiques pour l'évaluation des besoins en matière de développement des compétences. L'outil anticipe les possibilités de croissance sectorielle en se basant sur la position concurrentielle mondiale et l'évolution du marché. Associé à une analyse de l'offre et de la demande de compétences, le programme STED prévoit les pénuries de compétences actuelles et futures et soutient la création de compétences pour lesquelles il existe une demande sur le marché du travail, aidant ainsi à éviter les inadéquations de compétences et à lutter contre le chômage chez les jeunes.

Le programme a été utilisé pour mener une analyse approfondie du secteur du tourisme et de ses perspectives, qui a permis d'évaluer sa trajectoire de croissance et les contraintes de développement commercial auxquelles sont confrontés les guides touristiques. Cela a permis de prévoir le nombre de guides touristiques qui seraient nécessaires à l'avenir et d'identifier les lacunes dans leurs compétences actuelles.

Le projet a mis en évidence le besoin de formation en ce qui concerne la fourniture de services de qualité aux clients, l'organisation et la gestion des groupes en fonction de leur taille, l'utilisation des réseaux sociaux et d'autres technologies et le respect de normes pour un tourisme de qualité et/ou durable. Il a également identifié un écart entre la formation des guides touristiques offerte par le gouvernement et les exigences du secteur en termes de programmes et de spécialisation, par exemple en matière d'interprétation culturelle, de patrimoine et d'histoire.

Les recommandations formulées préconisaient notamment au gouvernement de continuer à élaborer des politiques pour le secteur des guides touristiques. Le projet a également indiqué que la mise en place de mécanismes entre le secteur public et le secteur privé pourrait faciliter le partage des connaissances et des perceptions du secteur avec les décideurs politiques, pour faire en sorte que les guides touristiques au Myanmar reçoivent une formation professionnelle appropriée.

Source: Steve Noakes, Paul Rogers, Ma. Concepcion Sardaña, Qingrui Huang, Sandar Win. (2016), "Skills for Trade and Economic Diversification: Tourist Guides Sector, Myanmar", Genève, OIT.

\section{Établir des partenariats efficaces}

Les partenariats entre le secteur privé, les gouvernements et les établissements d'enseignement locaux sont essentiels à l'amélioration des compétences et la reconversion. Les programmes d'apprentissage sont plus efficaces lorsque toutes les parties prenantes sont impliquées - les modèles cofinancés présentent ainsi un grand potentiel. Ce sont des exemples typiques de systèmes de formation professionnelle qui ont fait leurs preuves, comme c'est le cas en Allemagne (ITC, 2018b). Les programmes d'Aide pour le commerce qui renforcent la capacité des établissements d'enseignement et de formation techniques et professionnels (EFTP) à répondre aux besoins des entreprises ont des effets positifs et significatifs avérés sur l'emploi des jeunes (Tripney et al., 2013).

Néanmoins, la mise en place de partenariats public-privé durables pour la formation et l'enseignement professionnels n'est pas chose aisée. Par exemple, il n'est pas évident de reproduire dans un pays un système d'apprentissage qui a fait ses preuves dans un autre ne disposant pas des mécanismes institutionnels établis pertinents. 


\section{Établir un lien entre les programmes de formation et le placement professionnel}

Des mécanismes formels de collaboration entre entreprises privées et établissements d'enseignement contribuent à garantir que la formation débouche effectivement sur l'emploi. Les liens entre les établissements d'EFTP et les entreprises, qu'ils aient une visée informative ou opérationnelle, permettent au secteur privé de participer à l'élaboration d'une formation destinée aux jeunes et adaptée au marché. Cela signifie que les programmes qui accordent une place importante aux secteurs, aux compétences et aux technologies peuvent doter les diplômés des aptitudes que les entreprises recherchent lors de l'embauche.

Le risque d'inadéquation entre la formation et le marché du travail peut être réduit autant que possible en améliorant la conception des programmes, par exemple (Mastercard Foundation, 2015). Le Fonds pour les compétences et l'emploi des jeunes est une approche de financement compétitive axée sur les résultats qui vise à faciliter la transition entre les programmes de formation professionnelle et le monde du travail. Pour obtenir un soutien par le biais du Fonds (lancé en février 2017 par l'ITC et l'Autorité nationale d'accréditation et d'assurance de la qualité de la Gambie), les programmes de formation doivent viser des domaines dans lesquels des pénuries de compétences ont été identifiées et déboucher sur un emploi ou sur la création de petites entreprises viables. Pour ce faire, les EFTP participants doivent collaborer étroitement avec les entreprises afin d'assurer un placement après la formation et comprendre le potentiel et les possibilités qu'offrent les start-up. En outre, pour que ces programmes aient des résultats mesurables, une partie du financement n'est octroyée que si les EFTP apportent la preuve que les participants à la formation ont réussi leur insertion professionnelle ou exercent avec succès un travail indépendant.

\section{Adapter les programmes de développement de compétences pour garantir l'inclusion}

Les possibilités de développer des compétences ne sont pas accessibles à tous. Les jeunes ruraux, par exemple, peinent souvent à trouver une formation appropriée (ITC, 2018, page 42). Des programmes de formation spécialisés pourraient être créés, ou des modules de formation spécialisés pourraient être adaptés afin d'inclure les jeunes défavorisés.

Le programme A Ganar Vencedoras a utilisé des financements provenant de donateurs pour offrir une formation professionnelle à des jeunes Brésiliennes. Le programme a constaté qu'elles étaient confrontées à des problèmes spécifiques - tels que la violence domestique, le manque d'estime de soi ou des difficultés de garde d'enfants - qui entravaient leur entrée sur le marché du travail. Les membres du programme se sont rendu compte que la formation devait être adaptée pour lutter contre ces problèmes, afin de maintenir la participation des jeunes filles au programme (Fonds multilatéral d'investissement, 2012, page 14). De même, la formation des jeunes handicapés et des groupes autochtones devrait être adaptée pour répondre à leurs besoins particuliers.

Tableau 8.1. Liste des meilleures pratiques en matière de compétences des jeunes pour l'employabilité et l'exportation

\section{Assurer la collaboration entre secteurs public et privé pour identifier les inadéquations de compétences et élaborer des formations}

$\checkmark$ Favoriser la collaboration informelle et/ou institutionnalisée entre les EFTP et les entreprises du secteur privé

$\checkmark$ Identifier les compétences manquantes

$\checkmark$ Élaborer des programmes de formation appropriés

\section{Veiller à ce que les jeunes formés obtiennent un emploi en renforçant les établissements de formation}

$\checkmark$ Améliorer la capacité des EFTP à dispenser des programmes de formation adaptés à l'emploi

$\checkmark$ Effectuer le suivi du placement des participants pour s'assurer qu'ils ont trouvé un emploi ou exercent une activité entrepreneuriale

\section{Adapter les programmes de formation aux besoins des jeunes défavorisés}

$\checkmark$ Veiller à ce que la structure et la logistique du programme facilitent la participation des jeunes femmes et des jeunes ruraux

$\checkmark$ Remédier aux difficultés qu'ils rencontrent en matière d'employabilité 


\section{Figure 8.3. Taux d'entrepreneuriat des jeunes par pays et par sexe}

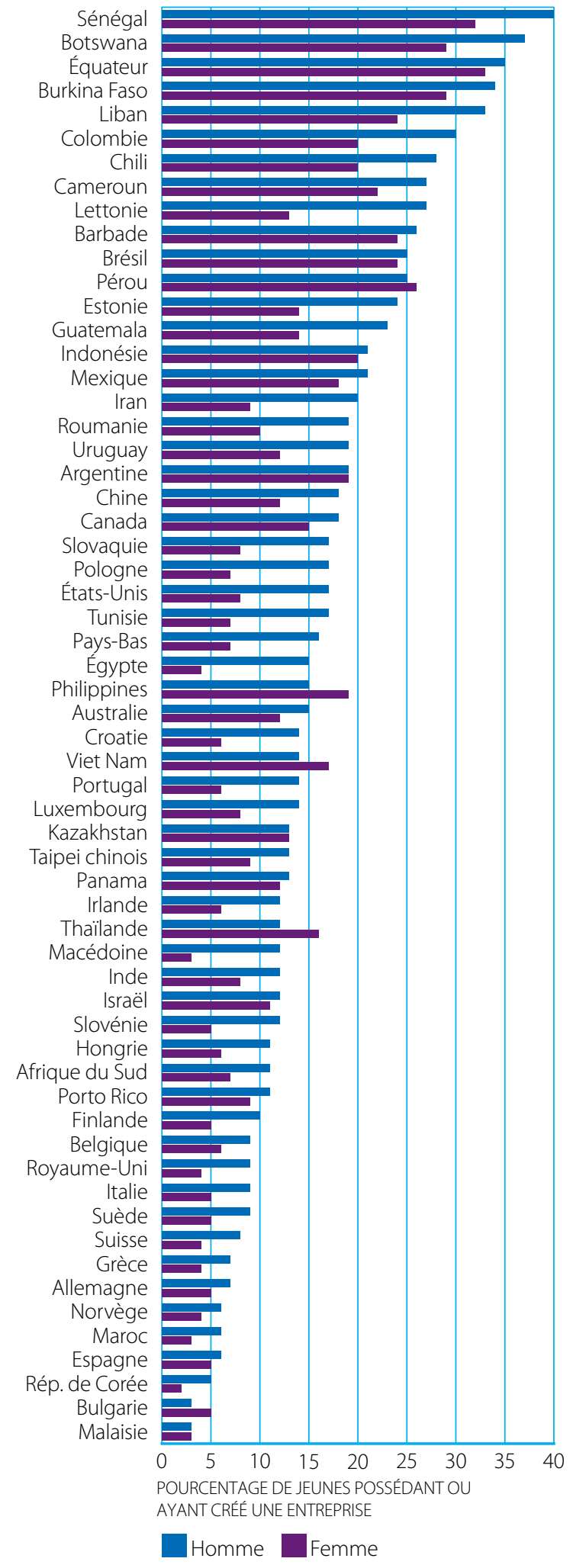

Note: Jeunes entre 18 et 34 ans.

Source: Calculs de I'ITC basés sur les données "APS Global Individual Level" de l'étude GEM 2015.

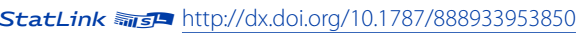

\section{PROMOUVOIR LE TRAVAIL INDÉPENDANT ET L'ENTREPRENEURIAT}

Certains jeunes sont des acteurs du changement dans leur société car ils génèrent de l'emploi et résolvent des problèmes sociaux grâce aux entreprises qu'ils créent. Les jeunes sont 1,6 fois plus susceptibles de lancer une nouvelle entreprise que les personnes de plus de 35 ans (Schott et al., 2015). De nombreuses nouvelles entreprises sont créées dans les pays en développement, qui comptent en moyenne plus d'entreprises naissantes ou jeunes que d'entreprises établies (Kew et al., 2013).

Dans ce contexte, le travail indépendant et l'entrepreneuriat peuvent être des possibilités de carrière attractives pour les jeunes. En effet, $60 \%$ des jeunes des pays en développement considèrent l'entrepreneuriat comme un bon choix de carrière et estiment que le fait d'avoir une entreprise prospère permet de jouir d'un statut plus élevé dans la société (Kew et al., 2013).

Un jeune sur quatre dans le monde est entrepreneur ou travailleur indépendant, selon une enquête menée en 2015 par Global Entrepreneurship Monitor (GEM). ${ }^{4}$ Cette section reprend la définition utilisée par le GEM et la littérature connexe, et définit les jeunes entrepreneurs comme étant des personnes âgées de 18 à 34 ans. Bien que certains jeunes se tournent vers l'entrepreneuriat en raison d'un marché du travail limité, d'autres le font par choix. Environ 40\% des jeunes qui créent leur propre entreprise le font par nécessité. Les 60\% restants cherchent à tirer parti d'une opportunité qu'ils ont identifiée (Schott et al., 2015).

Lorsque les jeunes se tournent vers le travail indépendant par nécessité, ils risquent d'être exposés à de mauvaises conditions de travail et d'éprouver des difficultés pour subsister. De nombreux jeunes sont des travailleurs indépendants exerçant des activités précaires dans le secteur informel, dans une situation d'emploi vulnérable (BIT, 2010). Dans ce contexte, le soutien apporté doit aider les jeunes à trouver un meilleur emploi, correspondant à des conditions de travail décentes. Dans d'autres cas, l'entrepreneuriat des jeunes s'accompagne de conditions de travail décentes et peut présenter un réel potentiel d'amélioration des moyens de subsistance, de compétitivité et de participation au commerce international. 


\section{L'entrepreneuriat, populaire mais difficile}

L'activité entrepreneuriale varie considérablement d'un pays à l'autre. La figure 8.3 classe 60 pays selon le pourcentage de jeunes âgés de 18 à 34 ans qui sont en train de créer une entreprise ou en possèdent déjà une. Au Sénégal, 40\% des jeunes hommes exercent une activité entrepreneuriale, contre seulement 1,6\% en Malaisie.

L'exercice d'une activité entrepreneuriale varie également selon le sexe, les hommes étant plus enclins que les femmes à créer leur propre entreprise. Néanmoins, il existe des différences significatives entre les pays en ce qui concerne le ratio de l'activité entrepreneuriale chez les jeunes hommes par rapport à celui des jeunes femmes. Aux Philippines et au Pérou, par exemple, les jeunes femmes sont plus impliquées dans l'entrepreneuriat que les hommes, alors que c'est l'inverse au Chili et au Liban.

Compte tenu des taux élevés d'entrepreneuriat chez les jeunes, il n'est pas surprenant que les entreprises dirigées par des jeunes représentent une part importante des nouvelles entreprises. Près de $44 \%$ des entrepreneurs dans le monde ont entre 18 et 35 ans. Pourtant, de nombreuses start-up dirigées par des jeunes ne survivent pas: les données indiquent que la proportion de jeunes à la tête d'entreprises bien établies est nettement inférieure à celle des adultes (Emploi décent des jeunes, n.d., page 4).

L'analyse des données de différents pays indique que les jeunes entrepreneurs sont, en moyenne, davantage orientés vers l'exportation que les entrepreneurs plus âgés (Schott et al., 2015). La propension relative des entreprises dirigées par des jeunes à importer et à exporter, comparativement aux entreprises dirigées par des entrepreneurs plus âgés, semble varier selon le pays, le secteur et la durée depuis laquelle l'entreprise exerce des activités.

\section{Figure 8.4. Les jeunes dirigeants embauchent plus de jeunes}

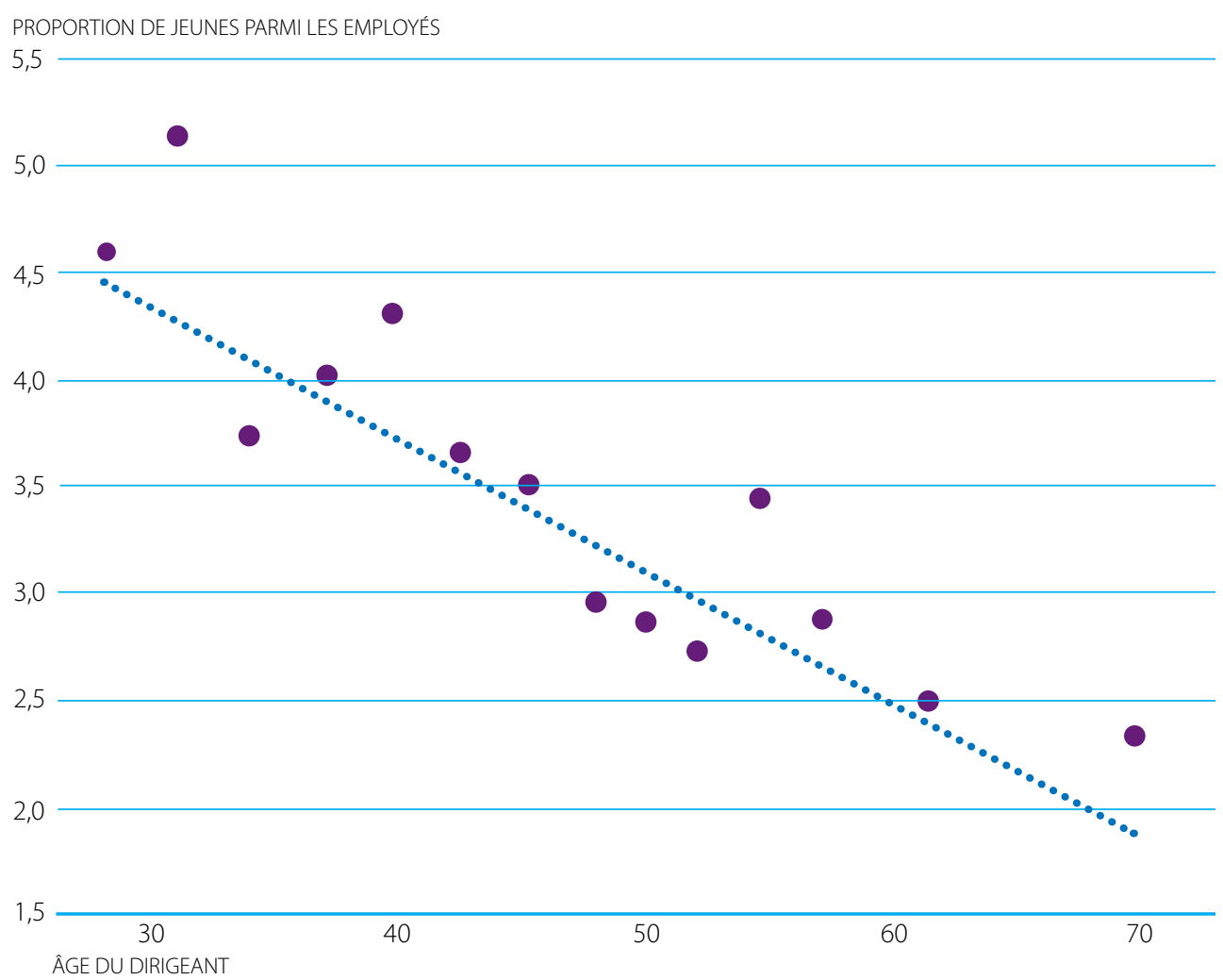

Note: Enquêtes de I'ITC sur la compétitivité des PME. Au total, 2047 entreprises ont été interrogées au Maroc, en Argentine, en Hongrie, en Gambie, au Kenya, au Ghana, en Zambie et en Ukraine entre 2016 et 2018.

Source: Enquêtes de I'ITC sur la compétitivité des PME entre 2016 et 2018 menées au Maroc, en Argentine, à Sainte-Lucie, en Hongrie, en Gambie, au Kenya, au Ghana, en Zambie et en Ukraine. 
Les données recueillies auprès des entreprises dans le cadre des enquêtes de I'ITC sur la compétitivité des PME fournissent des réponses contrastées quant à la question de savoir si les entreprises dirigées par des jeunes sont plus ou moins susceptibles de s'internationaliser. Les entreprises dirigées par des jeunes au Ghana et en Hongrie sont moins susceptibles d'exporter que les entreprises dirigées par des personnes plus âgées, mais c'est l'inverse au Kenya. Les données de GEM montrent que les entreprises dirigées par des jeunes exportent relativement moins dans les secteurs manufacturier et primaire, alors qu'elles semblent exporter autant que d'autres entreprises dans le secteur des services.

Enfin, les jeunes entrepreneurs ont tendance à embaucher davantage de jeunes travailleurs, selon les données recueillies auprès des entreprises (voir la figure 8.4).

\section{Les compétences en gestion sont essentielles à la compétitivité}

Étant donné que les jeunes dirigent une part importante des nouvelles entreprises et contribuent aux capacités d'innovation des PME, les obstacles qu'ils rencontrent constituent un frein important à la croissance économique. Dans le monde entier, les jeunes identifient des obstacles communs auxquels ils se heurtent dans le cadre de l'entrepreneuriat, notamment l'accès au financement et le manque de compétences, d'infrastructures, de structures de soutien et de mentorat appropriés. En effet, dans sa réponse à l'exercice de suivi de l'Aide pour le commerce OCDE/OMC de 2019, Madagascar a cité le "manque d'expérience et de financement initial" comme obstacles majeurs à l'entrepreneuriat des jeunes.

Les recherches indiquent qu'une proportion importante de jeunes qui démarrent une entreprise n'ont pas de formation à l'entrepreneuriat et, à ce titre, manquent de connaissances sur les possibilités de financement et les services de soutien aux entreprises, ainsi que sur les capacités managériales nécessaires pour réussir (Schoof, 2006; Schott et al., 2015, page 27). Les entreprises dirigées par des jeunes ne sont pas les seules à être confrontées au problème des compétences managériales inadéquates; de nombreuses petites entreprises font faillite pour cette raison.

Ainsi, de nombreuses PME sont limitées par l'inaptitude de leurs gérants à élaborer et à mettre en œuvre des plans de développement des compétences, à adopter de nouvelles stratégies et technologies, à étendre leur activité dans de nouveaux secteurs ou sur de nouveaux marchés, et même à préparer de bons dossiers de financement. Leur croissance en est limitée, d'où un taux de faillite plus élevé.

\section{Encadré 8.2. Mashrou3i, I'entrepreneuriat des jeunes en Tunisie}

Mashrou3i (qui signifie "mon projet" en arabe) est un projet conjoint de l'Organisation des Nations Unies pour le développement industriel (ONUDI), de l'Agence des États-Unis pour le développement international, de la Coopération italienne pour le développement et de la Fondation HP. Mashroußi est destiné à faciliter l'emploi des jeunes en Tunisie et à soutenir la création et la croissance des entreprises.

Mashrou3i permet aux aspirants entrepreneurs de réussir à gérer leur propre entreprise, en créant des emplois pour euxmêmes et pour les autres. Le projet s'appuie surl'initiative HP pour les entrepreneurs (HP LIFE), un programme d'apprentissage en ligne qui vise à doter les jeunes des compétences entrepreneuriales et de l'esprit d'entreprise nécessaires pour démarrer et développer leur entreprise. Il offre également un coaching d'affaires approfondi et une assistance technique aux start-up et aux entreprises existantes dans des domaines tels que la finance, la communication et le marketing.

Le projet met également l'accent sur la nécessité de s'assurer que les jeunes disposent des informations et des réseaux dont ils ont besoin pour mener à bien leurs projets d'entreprise. Pour renforcer l'écosystème entrepreneurial, Mashrou3i renforce les capacités des institutions locales de soutien aux entreprises et enrichit les programmes des établissements d'enseignement supérieur avec des outils commerciaux et informatiques.

Source:ONUDI. https://mashrou3i.tn/wp-content/uploads/2017/07/Mashrou3i_Brochure_EN_WEB.pdf 
L'acquisition de compétences de gestion, même élémentaires, en planification, marketing et finances peut améliorer les pratiques de gestion, encourager les dirigeants de PME à payer des formations de suivi, et accroître les chances de survie des entreprises (Otsuka et Sonobe, 2011; Sonobe et Otsuka, 2006). Les recherches indiquent que les résultats d'une entreprise sont étroitement liés aux compétences de son dirigeant (Hambrick et Mason, 1984). Les pratiques de gestion peuvent améliorer la productivité (Syverson, 2011), ainsi que la croissance et la longévité de l'entreprise (Bloom et Van Reenen, 2010).

Bien que des initiatives soient mises en place pour enseigner des compétences de gestion appropriées, il y a peu de données empiriques concernant leur incidence. L'impact de ces formations est cependant beaucoup plus important si elles sont dispensées à des dirigeants d'entreprises en difficulté, et pour qui le manque de compétences en gestion est un obstacle majeur à l'innovation et à la croissance (Yoshino, 2011). En tant que tels, les programmes de formation à l'entrepreneuriat destinés aux entreprises dirigées par des jeunes et qui peinent à survivre peuvent constituer une forme précieuse d'assistance technique, dans la mesure où ils comblent des lacunes dans les capacités de gestion qui, autrement, décimeraient le secteur des PME dirigées par des jeunes.

\section{L'entrepreneuriat des jeunes stimule l'innovation et favorise la diversification}

Les investissements dans l'entrepreneuriat des jeunes apportent des avantages qui ne concernent pas seulement les jeunes. Les entreprises dirigées par des jeunes peuvent stimuler l'innovation dans l'ensemble du secteur des PME. La mondialisation et les avancées rapides des nouvelles technologies ont mis la création et la réalisation de produits et services novateurs sur le devant de la scène concurrentielle. Les entreprises doivent innover pour renforcer leur compétitivité.

La capacité d'innovation d'une entreprise - c'est-à-dire sa capacité à générer des extrants innovants (Neely et al., 2001) ou plus largement sa capacité à transformer continuellement les connaissances et les idées en nouveaux produits, processus et systèmes au profit de l'entreprise et de ses parties prenantes (Lawson et Samson, 2001) - est fortement liée à ses capacités technologiques.

Les jeunes entrepreneurs peuvent transformer le paysage commercial en apportant des nouvelles technologies qui peuvent aider les PME à se connecter aux marchés mondiaux. Ils utilisent des technologies fondamentales, telles que l'informatique privative et les outils de productivité, ainsi que des outils de connectivité comme Internet et la technologie mobile. Ils sont présents en ligne et utilisent les réseaux sociaux, parallèlement aux services en nuage pour les entreprises.

En outre, en tant que jeunes diplômés, ils peuvent avoir une expérience récente de la recherche-développement, ce qui est prometteur pour l'innovation. Bien que les jeunes entrepreneurs fondent souvent leur entreprise sur de nouvelles idées avec un potentiel d'innovation intrinsèque, leur capacité à investir dans la recherche-développement dépend de leur accès au financement, de la taille de l'entreprise et de son âge.

Les jeunes innovent pour faire face aux problèmes et saisir les possibilités qui se présentent au niveau local. Ils sont profondément enracinés dans le contexte social et économique de leur pays et élaborent des solutions innovantes qu'ils commercialisent grâce à leur esprit d'entreprise. En tant que "natifs du numérique" ayant grandi avec les technologies en ligne (McPherson, 2008), ils adaptent les technologies de l'information et de la communication (TIC) aux conditions locales, contribuant ainsi à créer des TIC adaptées à la compétitivité des entreprises (EY, 2016). En Gambie, par exemple, les jeunes (moins de 35 ans) détenaient la moitié des entreprises du secteur des TIC interrogées en 2017 dans le cadre de l'enquête de l'ITC sur la compétitivité des PME (ITC, 2018a). 
Encadré 8.3. Start-up du secteur des TI créées par des jeunes dans le camp de réfugiés de Zaatari en Jordanie

La population jordanienne est d'environ 7,9 millions d'habitants et compte un nombre de réfugiés syriens estimé à 1,3 million. ${ }^{5}$ L'Initiative pour l'emploi et les compétences des réfugiés du Centre du commerce international vise à aider la Jordanie à améliorer la résilience économique des réfugiés et à leur donner les compétences nécessaires pour pouvoir rentrer chez eux et percevoir un salaire lorsque la paix sera rétablie.

Le projet offre une formation professionnelle pour aider les jeunes réfugiés du camp de Zaatari, situé au nord de la Jordanie, à développer leur capacité à travailler comme entrepreneurs indépendants dans le secteur des services en ligne. Pendant le programme de formation, les participants apprennent à s'inscrire à des plates-formes numériques, à promouvoir leurs activités sur les marchés en ligne et à gérer les transactions et les ventes en ligne. Ils développent des capacités spécifiques au domaine des services en ligne, telles que la conception graphique et le développement Web, avec un accompagnement en ligne et un mentorat individuel. Outre le renforcement des compétences, le projet aide les jeunes à générer des sources de revenus durables.

Par ailleurs, I'TTC s'associe à un groupe d'entreprises jordaniennes sélectionnées, pour inclure des contributions spécifiques de réfugiés syriens et les intégrer dans les chaînes de valeur d'exportation pour les services d'externalisation des fonctions de l'entreprise. En parallèle, le projet évalue le positionnement de la Jordanie et son offre en ce qui concerne ces services d'externalisation destinés à l'exportation, analyse la structure du secteur et identifie les lacunes spécifiques dans des domaines peu exigeants en qualifications qui peuvent être comblées grâce à la capacité des réfugiés syriens à aider les ressortissants jordaniens.

Source: ITC

Les jeunes entrepreneurs sont de plus en plus associés aux efforts visant à trouver des solutions commerciales aux défis sociaux et à tirer parti des nouvelles technologies. En effet, on note une plus grande proportion d'entrepreneurs sociaux que de nouveaux entrepreneurs commerciaux parmi les personnes âgées de 18 à 34 ans, au Moyen-Orient et en Afrique du Nord, en Afrique subsaharienne et en Europe occidentale (Fernando, 2018). En outre, de jeunes Africains ayant des approches novatrices sur la manière de traiter les problèmes sociaux et environnementaux dirigent de nombreuses start-up qui participent à des accélérateurs dans la "Yabacon Valley" du Nigéria (ITC, 2019b).

L'entrepreneuriat chez les jeunes peut aussi favoriser la diversification économique. Les entreprises dirigées par des jeunes stimulent les activités économiques dans de nouveaux secteurs et activités à forte croissance (ITC, 2015, page 22).

Des recherches ont montré qu'en Chine, par exemple, les jeunes migrants de retour dans le sud de Jiangxi créent de nouvelles entreprises dans leurs communautés natales qui favorisent la diversification économique de la région (Murphy, 2000). Le Nigéria oriente ses efforts vers des réformes de l'éducation et de l'environnement des affaires en vue de faciliter l'entrepreneuriat des jeunes, pour favoriser la diversification économique dans de nouveaux secteurs (Akpomujere, 2017; Joel et al., 2017).

Les jeunes entrepreneurs sont également encouragés à tirer parti des possibilités de diversification des exportations grâce à une évolution progressive des activités au sein de secteurs d'exportation existants. Dans plusieurs pays d'Afrique, par exemple, les entreprises dirigées par des jeunes sont pionnières dans des activités agro-industrielles qui s'appuient sur l'expertise existante du secteur agricole et l'étendent à des exportations à plus forte valeur ajoutée et plus stables dans les chaînes de valeur mondiales. 


\section{Les entreprises dirigées par des jeunes ont besoin d'un écosystème d'affaires favorable}

Le succès des jeunes entrepreneurs dépend du soutien que leur écosystème d'affaires leur apporte (Business 20, 2015). Un jeune pionnier du commerce électronique peut-il bénéficier d'une formation aux notions financières? Un financement est-il disponible? Pour aider les entreprises dirigées par des jeunes à s'internationaliser et à se développer, il est indispensable de renforcer l'environnement dans lequel les jeunes entrepreneurs opèrent ainsi que le niveau de l'aide qu'ils reçoivent.

Les composantes d'un écosystème d'affaires diffèrent selon qu'elles soutiennent une petite ou une grande entreprise, une start-up ou une entreprise déjà bien établie, une entreprise de haute technologie ou une entreprise utilisant des technologies peu avancées (ITC, 2018b). L'écosystème d'affaires des jeunes entrepreneurs comprend des institutions formelles et informelles. Les organisations à but lucratif - y compris les acheteurs, les fournisseurs, les distributeurs, les acteurs financiers et les organismes de certification - et les organismes à but non lucratif - y compris les fournisseurs de services d'enseignement, les organismes de normalisation et les chambres de commerce - constituent leur écosystème d'affaires.

Les infrastructures locales font également partie de l'écosystème d'affaires des jeunes entrepreneurs. En effet, des infrastructures numériques et de transport locales de grande qualité sont un prérequis à l'utilisation de nouvelles technologies numériques pour innover et participer au commerce international. En somme, l'écosystème d'affaires commence à la limite de l'entreprise, et se termine aux frontières du pays avec les institutions ou réglementations nationales (ITC, 2018b).

\section{Faciliter l'accès au financement et aux institutions de soutien aux entreprises}

Des préjugés profondément enracinés en ce qui concerne l'octroi de prêts aux jeunes et aux groupes défavorisés, ainsi que les garanties et autres exigences (examinées plus en détail ci-dessous), empêchent de nombreux jeunes d'accéder aux services financiers. Le financement par les amis et la famille les aide dans une certaine mesure, en particulier lors des premières étapes. Une enquête a révélé qu'en moyenne 51\% du financement des start-up dirigées par des jeunes provient de leur épargne personnelle, tandis que 22\% provient de l'épargne familiale, 19\% d'une banque ou autre institution financière, 3\% d'amis et 5\% d'autres sources (Schott et al., 2015, page 22). D'autres sources de financement sont nécessaires à mesure que les entreprises se développent et gagnent en maturité, mais elles ne sont pas toujours disponibles (ITC, 2019b).

Les accélérateurs du commerce des jeunes peuvent aider à résoudre ce problème en offrant une formation, un encadrement et un mentorat, un soutien institutionnel et un accès au financement aux jeunes aspirants entrepreneurs. Les programmes créent un écosystème d'institutions, de conseillers, de mentors et d'investisseurs pour soutenir les PME détenues par des jeunes en leur fournissant des services sur mesure, qui leur serviront de tremplin pour accéder aux marchés internationaux. Ces institutions peuvent aider les jeunes à obtenir des informations appropriées, notamment sur les marchés, le réseautage et les investissements.

En l'absence d'accélérateurs et d'autres programmes axés sur les jeunes, les institutions de soutien aux entreprises peuvent fournir un accès à une formation aux notions financières et à des services de soutien au développement des entreprises. Cela est essentiel pour que les jeunes entrepreneurs puissent créer et développer des entreprises, et élargir leurs activités. 


\section{Les réseaux sociaux peuvent favoriser l'esprit d'entreprise}

Les normes sociales peuvent influencer l'attitude des jeunes vis-à-vis de l'entrepreneuriat, de la prise d'initiatives et du leadership, ce qui influe sur leur décision de créer une entreprise et sur leurs choix ultérieurs en tant que propriétaires d'entreprise (Schoof, 2006).

L'une des normes sociales qui peut dissuader les entrepreneurs potentiels de créer une entreprise est la peur de l'échec. Le rapport mondial 2015 du Global Entrepreneurship Monitor révèle que les participants à l'étude provenant de I'Union européenne étaient ceux qui craignaient le plus l'échec (40,7\%), suivis par les participants d'Asie et d'Océanie (37,5\%). Cette peur peut être aggravée par la pression négative des pairs, la stigmatisation sociale, le manque de confiance dû à l'insuffisance des connaissances et des compétences, l'absence d'issues respectables sans pénalités économiques, et le manque d'aspirations (CESAP-ONU, 2012).

L'acquisition de compétences entrepreneuriales peut, dans une certaine mesure, remédier à ces craintes. Le GEM a constaté que les personnes qui sont convaincues qu'elles possèdent les compétences nécessaires pour démarrer une entreprise sont quatre à six fois plus susceptibles de prendre part à une activité entrepreneuriale (Kew et al., 2013, page 17).

Les réseaux sociaux auxquels les jeunes appartiennent peuvent également atténuer les effets décourageants de certaines normes sociales, tout en créant des liens favorables à la réussite des PME. Les réseaux et le soutien entre pairs fournissent aux jeunes chefs d'entreprise des sources de motivation, des idées, des informations, des partenaires commerciaux, des employés, des clients et des conseils. Les réseaux peuvent aider à identifier les possibilités prometteuses, mobiliser des ressources financières, diffuser des informations, trouver des technologies abordables et encourager l'innovation (Stuart et Sorenson, 2005). La nature des réseaux varie considérablement, allant des réseaux privés (famille et amis) et des réseaux de marché (collaborateurs d'affaires) aux réseaux basés sur l'identité (appartenance ethnique par exemple), tout comme la force des liens entre les acteurs (OCDE, 2014).

D'après ce qui a pu être observé en Inde, les activités de conseil et d'assistance aux entreprises ont eu un impact significatif et immédiat sur l'activité commerciale des femmes participantes - mais seulement si elles ont été formées en présence d'une personne amie. Les participantes étaient alors plus susceptibles de contracter de nouveaux prêts commerciaux (Field et al., 2015). En effet, les entrepreneurs qui nouent des contacts avec un nouveau propriétaire d'entreprise avant de créer eux-mêmes une entreprise sont plus aptes à découvrir et à exploiter des possibilités internationales et, éventuellement, à exporter (Evald et al., 2011).

La disponibilité d'un mentorat de haute qualité a été un élément central du succès des initiatives visant à aider les jeunes entrepreneurs à s'internationaliser. Les données d'enquête menées auprès de jeunes entrepreneurs montrent que les programmes qui comprennent un mentorat permettent aux entrepreneurs d'améliorer leur confiance en eux, leurs compétences en matière de prise de décision, le développement de leur entreprise et leur connaissance de soi, ce qui a en fin de compte entraîné des avantages, notamment en termes de créations d'entreprises réussies et d'augmentation du chiffre d'affaires (Middlesex University et Youth Business International, 2016).

Les mentors donnent aux jeunes entrepreneurs des conseils d'experts provenant de réseaux d'affaires pertinents. Bien que les accélérateurs pour les jeunes et les autres forums physiques jouent un rôle crucial à cet égard, tous les jeunes n'ont pas accès à un espace physique pour l'entrepreneuriat. Les forums d'apprentissage et de collaboration en ligne sont donc essentiels. ${ }^{6}$ L'école libyenne d'entrepreneuriat en ligne (Libyan Online Entrepreneurship School), par exemple, est un espace d'apprentissage virtuel qui facilite la croissance continue pour les jeunes entrepreneurs libyens. Cette plate-forme leur donne la possibilité d'assister à des cours, d'accéder à des ressources, d'échanger des idées et de communiquer avec leurs mentors et entre eux. 


\section{Adapter le soutien aux jeunes femmes entrepreneurs}

Il est possible de mieux intégrer la question de l'égalité hommes-femmes dans les initiatives d'Aide pour le commerce en faveur de l'entrepreneuriat des jeunes. Des données récentes suggèrent que les jeunes hommes et les jeunes femmes utilisent des approches différentes et n'ont pas les mêmes besoins lorsqu'ils créent une entreprise. Certaines études indiquent que les jeunes femmes d'affaires font preuve d'un plus grand esprit d'entreprise que leurs homologues masculins. Cela s'explique notamment par le fait que les jeunes femmes semblent apprécier leur indépendance et la possibilité d'élargir leurs possibilités plus que les jeunes hommes, qui se tournent souvent vers les activités commerciales parce que les perspectives d'emploi formel sont limitées (OIT/CEA, 2009; Solomon, 2010).

Les femmes des pays à faible revenu ont tendance à être plus confiantes dans leur capacité à devenir entrepreneurs que les femmes des pays développés. Elles ont également moins peur d'échouer que les femmes des pays à revenu intermédiaire et élevé. Les taux d'entrepreneuriat féminin sont généralement plus élevés dans les pays en développement que dans les économies développées, peut-être parce que dans les pays en développement les femmes se heurtent à des obstacles plus importants pour entrer sur le marché du travail formel et se tournent à la place vers l'entrepreneuriat (Minniti et Naudé, 2010a).

Néanmoins, les jeunes femmes déclarent avoir moins de compétences entrepreneuriales que les jeunes hommes (voir la la figure 8.5), qui sont 1,2 fois plus susceptibles d'être confiants dans leur capacité à diriger une entreprise ("sentiment d'être à la hauteur") et 1,3 fois plus susceptibles de connaître personnellement un fondateur de start-up que les jeunes femmes (Schott et al., 2015).

\section{Figure 8.5. Compétences entrepreneuriales autodéclarées chez les jeunes, par sexe}

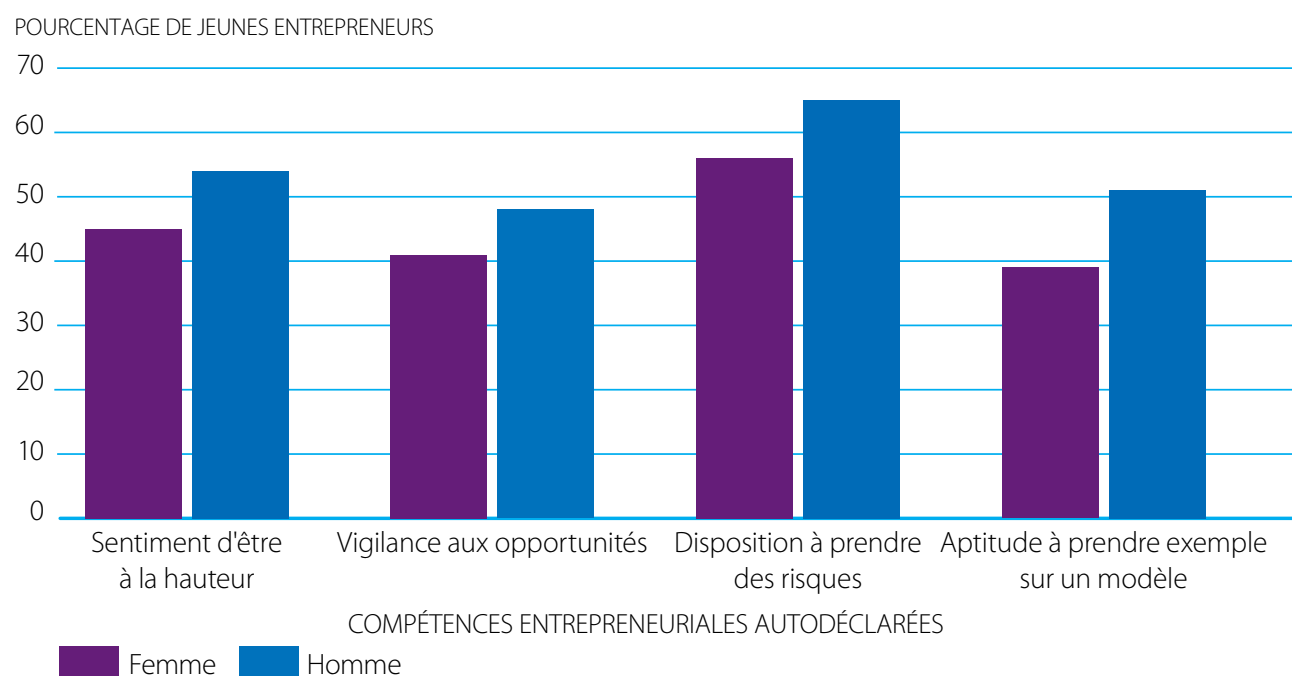

Note: Pourcentage de femmes et d'hommes entrepreneurs âgés de 18 à 35 ans interrogés qui ont déclaré posséder cette compétence, 2012-2014.

Source: Global Entrepreneurship Monitor (2015), "Future Potential - A GEM perspective on youth entrepreneurship", page 24.

Même lorsque les femmes possèdent les compétences et les connaissances nécessaires, certaines possibilités et incitations peuvent les empêcher de créer une entreprise ou de poursuivre des activités commerciales. Les jeunes mères ont plus tendance que les femmes célibataires à devenir entrepreneurs, mais elles sont aussi plus susceptibles de quitter volontairement une entreprise. En outre, des données montrent que les femmes entrepreneurs dans les pays en développement sont impliquées dans de multiples projets. Ce sont des entrepreneurs qui gèrent plusieurs projets en parallèle (par opposition à ceux dont les entreprises se succèdent), qui tentent de diversifier leurs sources de revenus (Minniti et Naudé, 2010b). 
Ces résultats suggèrent que de nombreuses jeunes femmes choisissent l'entrepreneuriat comme moyen d'échapper au chômage et à la pauvreté. Néanmoins, bien que les données confirment que les jeunes femmes sont plus susceptibles que les jeunes hommes de lancer une entreprise par nécessité, la différence est minime: $41 \%$ des femmes citent la nécessité comme raison pour laquelle elles ont lancé leur entreprise, contre 35\% des hommes (Schott et al., 2015, page 25).

Néanmoins, il est clair que la stratégie d'entreprise de certaines femmes est principalement motivée par la survie plutôt que la croissance. Aider ces entreprises peut avoir une incidence particulièrement forte sur les objectifs de développement durable car les revenus perçus par les femmes ont plus de chances d'être investis dans l'éducation, la santé et la nutrition des enfants (Morrison et al., 2007).

Des interventions peuvent aider ces entreprises à progresser en matière de développement des activités, en passant d'une approche axée sur la survie à une approche axée sur la croissance et l'exportation. Dans le même temps, il convient de garder à l'esprit que certaines entreprises dirigées par des femmes dans les pays en développement démarrent dans le but de croître et d'innover.

Quelles que soient les motivations et les origines des jeunes femmes entrepreneurs, il est nécessaire de comprendre leur environnement commercial particulier pour pouvoir les soutenir.

Les femmes entrepreneurs sont confrontées à des défis spécifiques lorsqu'elles cherchent à créer une entreprise d'exportation et à la faire prospérer (ITC, 2015b). La discrimination généralisée et persistante affecte leur relation avec les clients, leur sécurité sur le marché et leur accès aux services (Solomon, 2010). La discrimination exclut également les jeunes femmes des réseaux sociaux que les jeunes hommes utilisent pour obtenir des informations, des conseils et des financements (Schott et al., 2015, page 25). Dans certains pays, il existe des obstacles juridiques qui empêchent les femmes de détenir une entreprise et entravent leur succès, comme le fait que l'approbation d'un membre masculin de la famille soit nécessaire pour l'enregistrement d'une entreprise et l'absence de sanctions gouvernementales concernant la prise de décisions fondées sur le sexe dans les institutions financières.

En Indonésie, plus des trois quarts des femmes entrepreneurs interrogées par l'TC ont déclaré que les entreprises dirigées par des femmes ne s'internationalisaient pas autant que celles détenues ou dirigées par des hommes. Certaines d'entre elles ont mis en cause la perpétuation des rôles attribués à chaque sexe. Cependant, d'autres femmes interrogées ont affirmé que cela était dû au fait que les femmes avaient moins confiance en elles et avaient moins l'esprit de compétition, et 80\% ont déclaré que le fait qu'une entreprise soit détenue par une femme nuisait à sa crédibilité (ITC, 2017b).

\section{Tableau 8.2. Liste des meilleures pratiques pour soutenir l'entrepreneuriat chez les jeunes}

\section{Améliorer l'accès des jeunes entrepreneurs aux compétences pertinentes}

$\checkmark$ Améliorer la portée et la qualité de la formation à l'entrepreneuriat, du perfectionnement des compétences entrepreneuriales, de l'encadrement et du mentorat

$\checkmark$ Faciliter l'acquisition de compétences en gestion et de connaissances financières $\checkmark$ Créer des accélérateurs pour les jeunes et d'autres centres de soutien physiques

$\checkmark$ Soutenir les réseaux de pairs et de mentorat

$\checkmark$ Promouvoir et améliorer les plates-formes et les communautés en ligne pour les jeunes entrepreneurs

\section{Adapter le soutien pour remédier aux obstacles auxquels se heurtent les jeunes femmes entrepreneurs}

$\checkmark$ Lever les obstacles juridiques

$\checkmark$ Réduire les obstacles procéduraux

$\checkmark$ Faire en sorte que la politique commerciale tienne compte de la problématique hommes-femmes

Source: ITC et l'Initiative mondiale pour l'emploi décent des jeunes, document pour action sur le thème des jeunes entrepreneurs et travailleurs indépendants (ITC, OIT, ONUDI, FENU, CNUCED). 
Les enquêtes réalisées par l'ITC auprès des entreprises sur les mesures non tarifaires montrent que les entreprises exportatrices dirigées par des femmes signalent plus fréquemment des obstacles procéduraux au commerce que celles dirigées par des hommes. Les microentreprises appartenant à des femmes signalent en particulier une proportion plus élevée d'obstacles procéduraux dus aux "paiements informels ou élevés" et aux "comportements discriminatoires" que les microentreprises appartenant à des hommes (ITC, 2016, page 50).

En outre, les politiques commerciales qui ne tiennent pas compte des différences entre les sexes peuvent avoir des effets discriminatoires à l'égard des femmes - par exemple par le biais de droits plus élevés sur les marchandises produites par les femmes (comme les textiles et les vêtements) et d'obstacles non tarifaires particulièrement rigoureux dans les secteurs à prédominance féminine (comme l'agriculture). La prise en considération de ces facteurs lors de la négociation et de l'application des règles commerciales peut faciliter l'élaboration d'un système de politique commerciale qui tiendrait compte de la problématique hommes-femmes (Avsar et Piovani, 2019).

Les initiatives d'Aide pour le commerce commencent à aborder les contraintes auxquelles les jeunes femmes sont confrontées lorsqu'elles créent une entreprise dans les pays en développement. La formation et le mentorat par les pairs, ainsi que la prise en compte des contraintes auxquelles sont confrontées les jeunes femmes d'affaires lors de l'élaboration d'initiatives de formation, améliorent l'efficacité du programme (OIT/CEA, 2009; Solomon, 2010). Linitiative SheTrades de l'ITC offre aux jeunes femmes entrepreneurs du monde entier un réseau et une plate-forme uniques pour se connecter aux marchés.

\section{LES GOUVERNEMENTS PEUVENT FAVORISER L'AUTONOMISATION DES JEUNES}

La compétitivité des entreprises qui embauchent des jeunes (et qui sont dirigées par eux) est affectée par l'environnement national dans lequel elles exercent leurs activités. Jusqu'ici, le présent chapitre a examiné le rôle des capacités au niveau des entreprises et celui de l'écosystème d'affaires dans l'autonomisation économique des jeunes. Néanmoins, le contexte national plus large - et l'action des pouvoirs publics en particulier - a également une incidence sur le fait que les entreprises embauchent des jeunes ou non, et sur le fait que ces entreprises prospèrent et se mondialisent.

Les gouvernements ont un rôle important à jouer pour promouvoir l'autonomisation économique des jeunes grâce à un environnement politique national favorable. Les politiques publiques peuvent remédier aux défaillances du marché qui empêchent les jeunes de participer au soutien de la compétitivité du pays sur les marchés internationaux.

De plus, les gouvernements sont particulièrement bien placés pour évaluer les possibilités futures sur les marchés mondiaux. Grâce à des consultations avec diverses parties prenantes, ils peuvent identifier les chaînes de valeur dans lesquelles les programmes ciblés mis en œuvre aujourd'hui pourraient préparer les jeunes aux exportations de demain.

\section{Les politiques peuvent contribuer à remédier aux défaillances du marché qui excluent les jeunes}

Plusieurs catégories de défaillances du marché peuvent limiter la capacité des jeunes à contribuer à la compétitivité internationale du pays.

Comme nous l'avons vu plus haut, l'inadéquation des compétences peut nuire à l'emploi des jeunes et à la compétitivité des PME. Les gouvernements peuvent contribuer à réduire cette inadéquation en établissant des programmes d'enseignement nationaux appropriés et en facilitant la collaboration entre les institutions liées au commerce et celles liées à l'éducation.

À Singapour, par exemple, le Ministère du commerce et de l'industrie et le Conseil national de la main-d'œuvre ont créé un système de communication et d'interaction imbriqué entre les organismes publics, le secteur privé et les établissements d'enseignement supérieur et de formation, pour faire en sorte que les besoins en ce qui concerne les compétences de la main-d'œuvre se traduisent par une évolution de l'ensemble des compétences dont dispose la population. Ces initiatives ont joué un rôle déterminant dans l'amélioration des compétences de la main-d'œuvre du pays au cours des 40 dernières années (Kuruvilla et al., 2002). 
Les défaillances des marchés financiers peuvent exclure les jeunes de l'accès au crédit institutionnel. Les jeunes ne disposent souvent pas des garanties et des antécédents de crédit que les banques exigent pour accorder un crédit. C'est pourquoi les start-up fondées par des jeunes de 18 à 24 ans ont 6\% de chances en moins d'avoir recours au financement des banques et d'autres institutions financières que celles gérées par des personnes de 35 à 64 ans (Schott et al., 2015, page 25).

D'après une étude réalisée auprès des entreprises par l'ITC, les entreprises dirigées par des jeunes ont un accès plus limité au financement, et 76\% d'entre elles déclarent que l'accès aux institutions financières est un obstacle aux activités courantes, contre $59 \%$ des entreprises qui ne sont pas dirigées par des jeunes (voir la figure 8.6). Il apparaît que certaines start-up établies gérées par des jeunes peuvent recourir à l'épargne personnelle et familiale pour compenser le manque de financement du secteur formel. Cependant, aucune donnée n'est disponible sur le nombre d'entreprises dirigées par des jeunes qui n'ont pas été créées ou dont le potentiel a été sérieusement affecté en raison de contraintes financières.

\section{Figure 8.6. L'accès au financement est davantage un obstacle pour les entreprises dirigées par des jeunes}

\section{Entreprises dirigées par des jeunes}

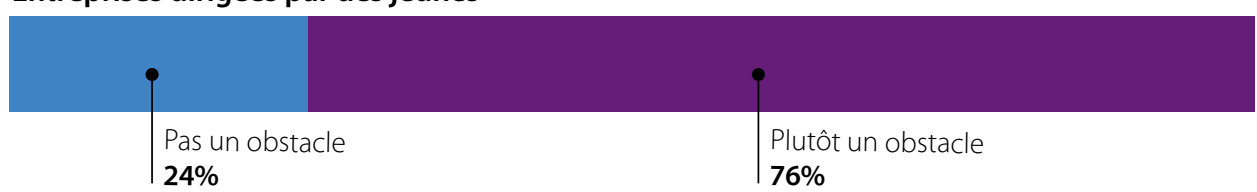

Autres entreprises

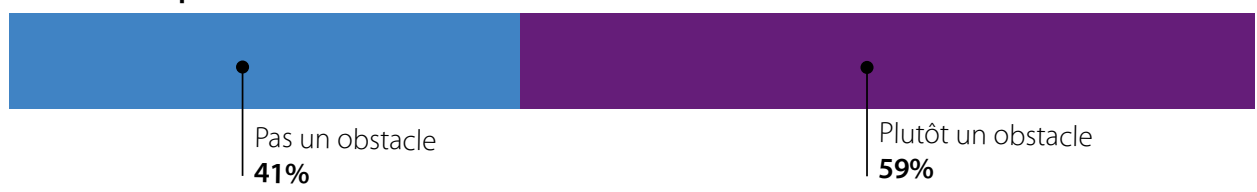

Note: Réponses des entreprises à la question "Dans quelle mesure l'accès aux institutions financières est-il un obstacle aux activités courantes?" Les possibilités de réponse étaient $5=$ "obstacle majeur"; 4 = "obstacle très important ", 3 = "obstacle important ", 2 = "plutôt un obstacle", 1 = "léger obstacle", 0 = "pas un obstacle", et "je ne sais pas". Tous les répondants qui ont choisi autre chose que "pas un obstacle" sont classés comme ayant choisi "plutôt un obstacle". Les entreprises sont considérées comme dirigées par des jeunes si leur dirigeant est âgé de moins de 35 ans.

Source: Enquêtes de l'ITC sur la compétitivité des PME. Au total, 1308 entreprises ont été interrogées en Argentine, en Hongrie, au Kenya, au Maroc et en Gambie en 2017 et 2018.

StatLink 헤곰 http://dx.doi.org/10.1787/888933953888

Les gouvernements peuvent intervenir pour corriger les défaillances des marchés financiers par le biais de programmes de garantie de crédit, de capital de démarrage et d'initiatives en faveur de l'acquisition de notions financières. Le gouvernement du Kazakhstan, par exemple, a fourni des garanties de crédit aux jeunes entrepreneurs en soutenant le Fonds "Damu" pour la promotion des entreprises (OCDE, 2018). Le gouvernement de Maurice a fourni un capital de démarrage à un fonds d'actions destiné aux PME, qui investit dans des PME nationales en phase de démarrage. En Afrique du Sud, I'Office des services financiers du secteur public a collaboré avec l'Association des assurances d'Afrique du Sud pour élaborer du matériel pédagogique pour l'éducation financière et a formé de nombreux enseignants et apprenants à son utilisation en classe (Sibanda et Sibanda, 2016, page 15).

Des restrictions juridiques et sociales peuvent empêcher les jeunes, et en particulier les femmes, de posséder des terres et/ou des entreprises. Les règlements qui interdisent la discrimination fondée sur l'âge et le sexe peuvent aider les jeunes à prendre le contrôle des actifs dont ils ont besoin pour stimuler la productivité, innover et devenir compétitifs à l'échelle mondiale. 
Investir dans les infrastructures des technologies de l'information et de la communication, et de fait dans les infrastructures de base, peut améliorer la compétitivité des PME grâce à l'accès à des portails en ligne dédiés à l'emploi pour identifier les jeunes qualifiés. Lamélioration des infrastructures des TIC est également cruciale pour la capacité des entreprises dirigées par des jeunes à se mondialiser car elle peut les aider à accéder aux marchés étrangers.

Les téléphones mobiles se sont avérés être un outil commercial important, en particulier pour les jeunes femmes entrepreneurs en milieu rural, car ils leur permettent de développer leurs activités grâce à un marketing plus efficace, la localisation des clients, une meilleure communication et un gain de temps (CNUCED, 2014). En plus d'améliorer l'information et la connectivité, les TIC peuvent permettre aux jeunes de multiplier les avantages qu'ils retirent de l'accès aux nouvelles technologies telles que les technologies vertes, le financement participatif et les plates-formes de crédit.

\section{Figure 8.7. Comment l'Aide pour le commerce peut-elle contribuer au mieux à l'autonomisation économique des jeunes?}

\section{PRIORITÉ DE L'AIDE POUR LE COMMERCE}

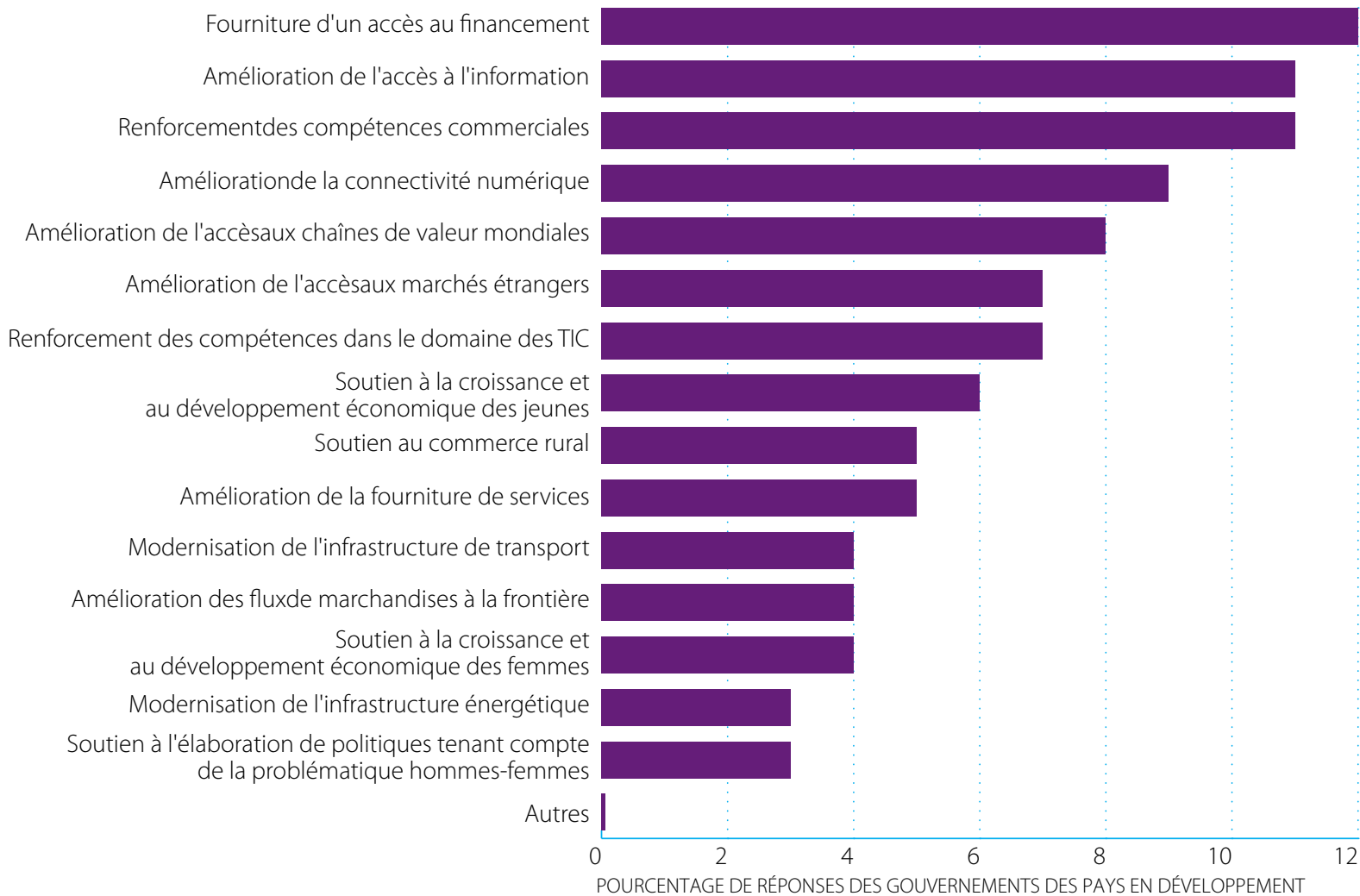

Note: Il a été demandé aux gouvernements des pays en développement, dans le cadre de l'enquête de suivi et d'évaluation de l'Aide pour le commerce, "Comment l'Aide pour le commerce peut-elle contribuer au mieux à l'autonomisation économique des jeunes?" Ils pouvaient choisir jusqu'à cinq propositions. Au total, 84 gouvernements ont répondu. La figure 8.7 présente le pourcentage correspondant au nombre de fois que chaque proposition a été choisie.

Source: Exercice de suivi de l'Aide pour le commerce OCDE-OMC (2019).

StatLink ants http://dx.doi.org/10.1787/888933953907

L'aide publique au développement peut également contribuer à résoudre ces problèmes. En effet, lorsqu'on a demandé aux gouvernements des pays en développement comment l'Aide pour le commerce pouvait contribuer au mieux à l'autonomisation économique des jeunes, ils ont réaffirmé ces priorités (voir la figure 8.7). Une grande partie des réponses ont souligné de quelle façon l'Aide pour le commerce pouvait aider à fournir un accès au financement, à renforcer les 
compétences et à améliorer l'accès à l'information et la connectivité numérique, ce qui rejoint la nécessité de remédier aux défaillances du marché évoquée dans la présente sous-section. Les participants à l'enquête ont également souligné les possibilités d'améliorer l'accès aux chaînes de valeur mondiales, ce qui, comme le souligne la sous-section suivante, peut être facilité par l'Aide pour le commerce destinée aux stratégies sectorielles en faveur des jeunes adoptées par les gouvernements.

\section{Stratégies pour identifier et créer des opportunités pour les jeunes}

Une stratégie gouvernementale cohérente permet d'identifier les secteurs prioritaires et les compétences qui présentent un potentiel d'exportation et un intérêt pour les jeunes. En plus de créer des emplois pour les jeunes et d'aider les PME à devenir plus compétitives, cela peut améliorer la balance commerciale nationale et encourager la croissance.

Le Centre du commerce international a collaboré avec plusieurs gouvernements à l'élaboration de feuilles de route pour les jeunes et le commerce. En mettant l'accent sur le rôle des jeunes dans des secteurs clés, les stratégies axées sur les jeunes et le commerce peuvent stimuler la diversification de la production, la création de valeur ajoutée et les exportations.

\section{Les parties prenantes peuvent guider les décisions relatives aux stratégies commerciales en faveur des jeunes}

Les consultations avec les parties prenantes non seulement génèrent des informations quantitatives sur l'économie, mais elles attirent aussi l'attention sur les possibilités stratégiques disponibles pour les jeunes au sein de l'économie. Les consultations sollicitent la contribution des décideurs politiques, des institutions de soutien au commerce et à l'investissement, du secteur privé et de la société civile lors de réunions qui aident à identifier les secteurs et les activités dans lesquels les jeunes peuvent promouvoir les exportations du pays (ITC, 2018d).

II est essentiel d'écouter les jeunes et de leur donner les moyens de résoudre les problèmes auxquels ils sont confrontés lors du processus de consultation et d'élaboration des stratégies. Le Ministère de l'éducation du Libéria, par exemple, a organisé un "Dialogue politique national sur l'éducation pour le développement des compétences des jeunes pour l'emploi", qui a réuni le gouvernement, l'industrie et des organisations de jeunes (Arai, 2010; Association pour le développement de l'éducation en Afrique, n.d.). Le fait d'inclure les jeunes lors de la formulation des politiques garantit que les solutions sont appropriées à leurs besoins et suscitent leur intérêt. L'implication continue des jeunes dans l'élaboration des politiques constitue un objectif en soi qui peut également améliorer le soutien aux politiques et faciliter leur mise en œuvre.

Les gouvernements, avec le soutien de l'ITC, mettent au point des stratégies pour les jeunes et le commerce qui ciblent les secteurs prioritaires, à l'aide d'informations recueillies lors des consultations avec les parties prenantes. Les secteurs prioritaires sont choisis en fonction de leur contribution à un objectif de développement (comme la création d'emplois, la réduction de la pauvreté ou l'inclusion régionale), de leur capacité à promouvoir le potentiel de compétitivité à long terme du pays et de leur capacité à offrir aux jeunes des emplois et des possibilités d'entrepreneuriat.

Pour chaque secteur, une analyse de la chaîne de valeur est effectuée pour prévoir les meilleures possibilités pour les jeunes. Identifier les activités pertinentes pour les jeunes au sein des chaînes de valeur sectorielles peut mettre en évidence les perspectives d'emploi en ce qui concerne la préproduction, la transformation et le marché final.

En Tunisie, par exemple, le fort potentiel que représente le secteur du textile et de l'habillement en matière d'exportation et d'autonomisation des jeunes a conduit l'TTC à participer à l'élaboration d'une stratégie. L'analyse des données recueillies auprès des entreprises a révélé un cruel manque d'opérateurs de machines et de superviseurs (voir la figure 8.8). Ces informations permettent d'adapter les programmes d'enseignement et de formation pour les jeunes tunisiens (ITC, 2019C). 
Après avoir identifié les principales professions touchées par des pénuries dans les secteurs cibles, la méthodologie d'élaboration de stratégies pour les jeunes et le commerce de l'ITC analyse les lacunes en ce qui concerne les compétences. L'évaluation des compétences et des niveaux de préparation nécessaires dans les secteurs prioritaires sera prise en compte dans les futurs programmes des EFTP afin de s'assurer que les établissements de formation aident les jeunes à développer leurs capacités pour de futures possibilités d'emploi. Cette évaluation est complétée par une analyse sectorielle des contraintes qui pèsent sur l'emploi des jeunes.

Figure 8.8. Besoins d'effectifs dans le secteur du textile et de l'habillement en Tunisie

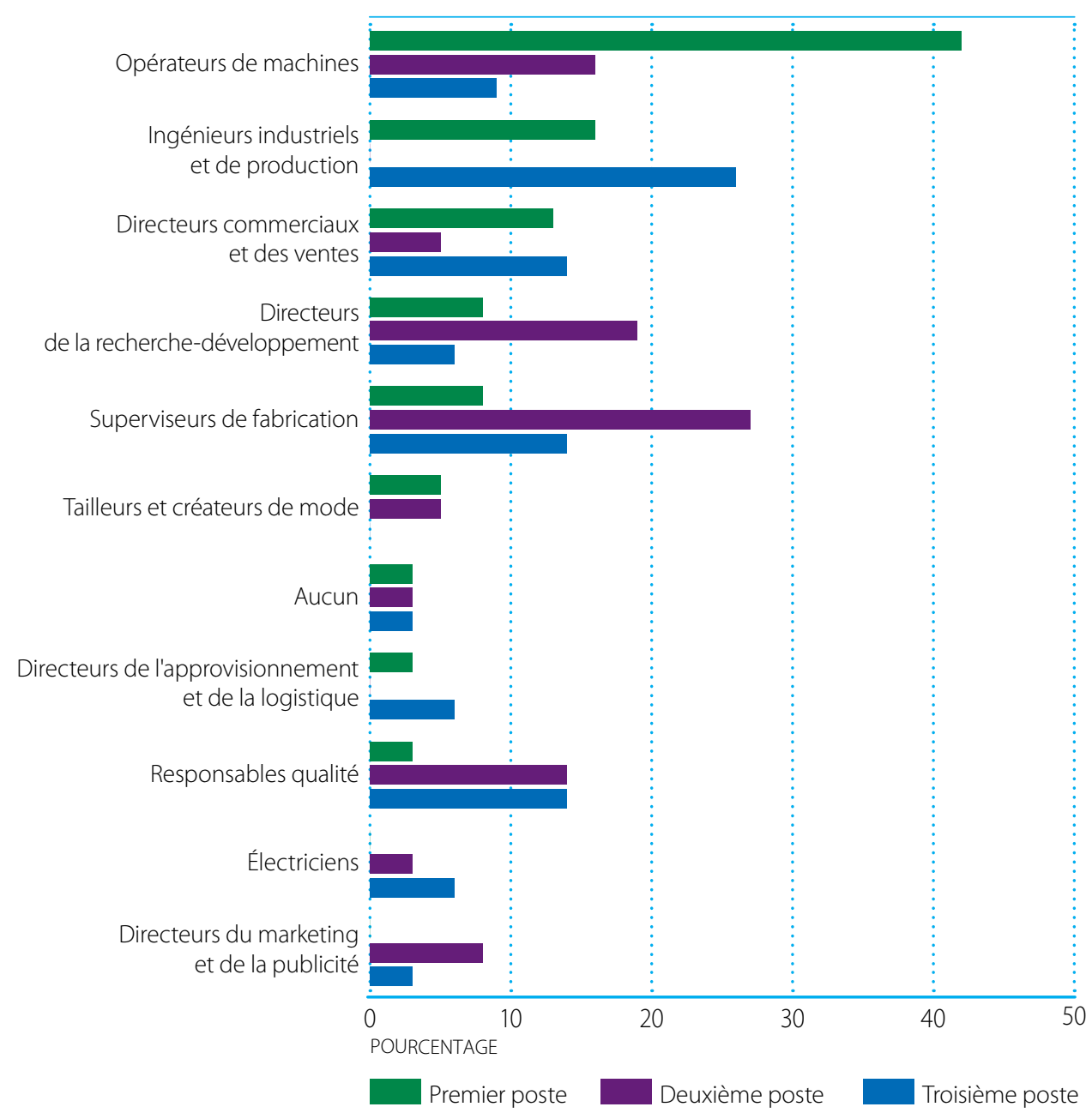

\footnotetext{
Note: Dans le cadre de l'enquête menée auprès d'entreprises du secteur tunisien du textile et de l'habillement, il a été demandé aux entreprises quels étaient les trois principaux postes qu'elles cherchaient à pourvoir. Par exemple, $42 \%$ des entreprises interrogées ont indiqué qu'elles avaient principalement besoin d'opérateurs de machines, et 27\% d'entre elles ont déclaré que le deuxième poste pour lequel des candidats étaient les plus recherchés était celui de superviseur de fabrication.

Source: ITC. Stratégie sur l'intégration et l'employabilité des jeunes dans le secteur du textile et de l'habillement. StatLink 部实 http://dx.doi.org/10.1787/888933953926
}

En Gambie, par exemple, plus de la moitié des entreprises du secteur du tourisme ont cité des qualifications inadaptées et le coût des travailleurs comme principaux obstacles à l'embauche des jeunes. Les qualifications n'étaient pas un problème majeur dans le secteur des technologies de l'information et de la communication, bien que l'éthique professionnelle des jeunes ait été décrite comme un obstacle à l'embauche par les entreprises des secteurs des TIC et de l'agriculture (voir la figure 8.9). 
Enfin, une analyse des prescriptions à l'exportation dans les secteurs prioritaires est utilisée pour aider les entreprises dirigées par des jeunes à se spécialiser dans un créneau, sur des marchés d'exportation en pleine croissance (ITC, 2018d).

Figure 8.9. Obstacles à l'embauche des jeunes Gambiens, par secteur

TIC

\section{Tourisme}

\section{Agriculture}

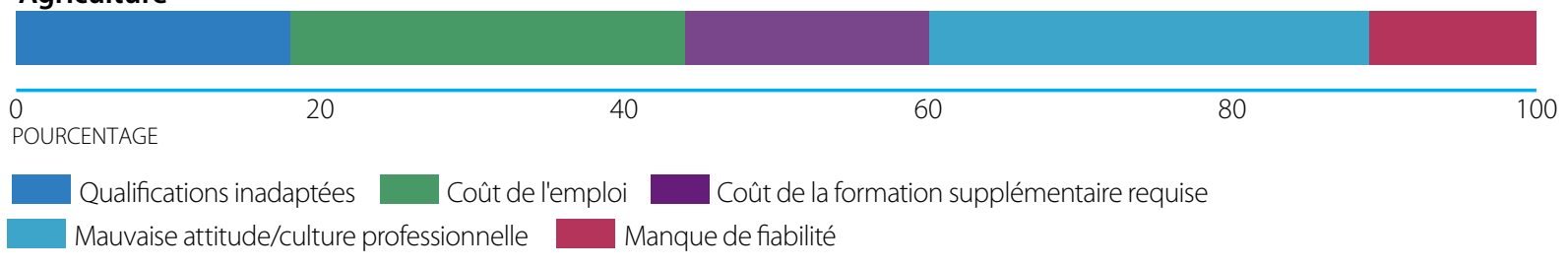

Note: Le graphique est basé sur les réponses des entreprises à la question suivante: "Selon vous, quel est le plus grand obstacle à l'emploi des jeunes parmi les options suivantes?"

Source: ITC, Enquête sur la compétitivité des PME, Gambie (2017).

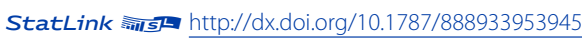

\section{Créer une vision et un plan communs pour l'autonomisation économique des jeunes}

Une stratégie gouvernementale cohérente peut guider les décideurs, les institutions et le secteur privé vers une autonomisation économique progressive des jeunes. Une stratégie avec une vision claire et des actions prioritaires peut faciliter l'inclusion des jeunes dans les activités d'exportation et d'importation.

Tableau 8.3. Liste des meilleures pratiques en matière de stratégie gouvernementale pour l'autonomisation économique des jeunes

1. Faciliter l'accès au financement $\checkmark$ Accroitre la disponibilité de services financiers ciblant spécifiquement les jeunes

$\checkmark$ Accroître l'accès au financement pour les jeunes entrepreneurs grâce à des mécanismes financiers innovants

$\checkmark$ Doter les jeunes entrepreneurs de compétences financières $\checkmark$ Faciliter la collaboration entre les institutions commerciales et les établissements d'enseignement

$\checkmark$ Lutter contre la discrimination fondée sur l'âge et le sexe

$\checkmark$ Fournir les TIC et les infrastructures de base
3. Établir un ordre de priorité dans les secteurs $\checkmark$ Faciliter la consultation inclusive

$\checkmark$ Choisir des secteurs qui présentent un fort potentiel pour l'exportation et pour les jeunes

$\checkmark$ Renforcer les liens commerciaux et l'intégration dans les chaînes de valeur et identifier les besoins de développement des chaînes de valeur Mettre en adéquation les programmes de formation professionnelle et $\checkmark$ de soutien à l'entrepreneuriat

\section{4. Élaborer un plan stratégique}

$\checkmark$ Créer une vision commune pour les jeunes dans le commerce

$\checkmark$ Établir un plan d'action dans les secteurs cibles et dans l'ensemble de l'économie

$\checkmark$ Définir clairement les ressources et les responsabilités

$\checkmark$ Suivre les progrès 
Une analyse menée au niveau national évalue les principaux éléments transversaux qui favorisent l'inclusion des jeunes dans le développement axé sur les exportations. Cette partie de la stratégie expose la vision et définit des priorités en matière de commerce et de compétitivité axées sur les jeunes. Les priorités politiques nationales visant à éliminer les obstacles à l'autonomisation économique des jeunes peuvent également être définies à ce moment-là. Il peut s'agir par exemple d'améliorer la qualité de l'écosystème d'affaires pour les jeunes grâce aux procédures commerciales, d'offrir des incitations en faveur de la recherche et du développement, de développer des compétences axées sur le marché et de créer des instances institutionnelles pour la représentation et la collaboration des jeunes.

Les stratégies déterminent également les secteurs et les compétences qui ont été identifiés comme présentant un potentiel d'exportation et un intérêt pour les jeunes. Elles décrivent de façon détaillée une approche visant à attirer les jeunes vers les secteurs et les activités économiques qui tirent parti des avantages comparatifs et compétitifs du pays (ITC, 2018d).

Chaque feuille de route de l'ITC consacrée aux jeunes et au commerce comprend un plan d'action stratégique précisant les mesures concrètes à prendre pour atteindre les objectifs nationaux et sectoriels de la stratégie pour la jeunesse et le commerce. Un plan directeur de mise en œuvre complète les stratégies propres aux secteurs et aux acteurs qui transforment les défis et les possibilités identifiés en mesures concrètes.

Lorsque les ressources sont limitées, des objectifs réalistes sont fixés pour faciliter l'affectation efficace de ces ressources aux secteurs et aux initiatives qui ont de l'importance. En Gambie, par exemple, les décideurs ont concentré leurs ressources sur les programmes dédiés à l'entrepreneuriat des jeunes dans le secteur des TIC, où les jeunes entrepreneurs étaient nombreux.

Les ressources et les exigences institutionnelles nécessaires à la mise en œuvre devraient être complétées par un cadre de suivi qui comprendrait des indicateurs cibles réalistes. Un calendrier précis mais qui peut être respecté peut faciliter une action coordonnée.

\section{CONCLUSIONS ET RECOMMANDATIONS}

Le présent chapitre a attiré l'attention sur le double problème du chômage des jeunes et de la compétitivité des PME. Les PME qui manquent de personnel resteront peu compétitives sur les marchés intérieurs et mondiaux, ce qui limitera leur capacité à créer des emplois, à se développer et à faire du commerce. Il est non seulement souhaitable d'exploiter le potentiel des jeunes gens - femmes et hommes-, mais c'est également essentiel pour atteindre les objectifs de développement durable (notamment I'ODD 8).

L'autonomisation économique des jeunes dans les PME pourrait résoudre ces deux problèmes. Dans les pays en développement, les petites entreprises embauchent des jeunes issus des populations locales et leur offrent une formation et une expérience sur le tas, qui peut conduire à une carrière et favoriser ainsi la réalisation de l'ODD 8, qui vise à promouvoir le travail décent pour les jeunes. Dans le même temps, les jeunes peuvent aider les pays en développement à accroître leurs exportations en dynamisant le capital humain des entreprises et en encourageant l'innovation, et promouvoir ainsi la réalisation de I'ODD 9 relatif à l'innovation et de I'ODD 17, qui porte sur le commerce international. L'Aide pour le commerce axée sur l'autonomisation économique des jeunes constitue une solution mutuellement avantageuse pour favoriser le bien-être des jeunes et promouvoir le commerce international aux fins du développement économique.

Pour que cela se concrétise, l'une des solutions consiste à adapter les compétences des jeunes aux besoins des entreprises. Les programmes faisant en sorte que les compétences enseignées dans les établissements éducatifs correspondent aux besoins des PME peuvent aider les jeunes à trouver un emploi. En effet, une étude réalisée auprès des entreprises montre que les entreprises qui déclarent que l'offre de travailleurs qualifiés est adéquate ont eu tendance à embaucher davantage de jeunes salariés. 
Dans le même temps, l'amélioration des compétences des jeunes entraîne une augmentation du capital humain au niveau des entreprises. D'après la littérature économique, cela encourage les exportations et favorise leur diversification.

S'attaquer aux obstacles à l'entrepreneuriat des jeunes peut également soutenir la compétitivité des PME et l'autonomisation économique des jeunes. Environ un quart des jeunes dans le monde sont des travailleurs indépendants ou des entrepreneurs, mais nombre d'entre eux ne disposent pas des compétences et des réseaux nécessaires pour lancer leur activité. L'Aide pour le commerce peut les aider à développer leur activité, y compris en renforçant leurs compétences en matière de gestion pour améliorer la compétitivité de leurs entreprises. Cela permet d'assurer la survie de nombreuses PME et peut ainsi favoriser la croissance économique.

Les entreprises dirigées par des jeunes femmes ont des besoins et un potentiel spécifiques. Les jeunes femmes peuvent être intéressées par l'entrepreneuriat, mais elles manquent parfois de confiance dans leur capacité à gérer une entreprise. En outre, elles peuvent être exclues des réseaux sociaux que leurs pairs masculins utilisent pour obtenir des informations, des conseils et des financements, et peuvent être victimes de discrimination dans les politiques et pratiques commerciales. Des programmes adaptés aux jeunes femmes peuvent tenir compte de ce contexte et avoir d'importantes retombées positives en matière de développement durable.

Les gouvernements jouent un rôle clé pour ce qui est de promouvoir l'autonomisation économique des jeunes aux fins du commerce international. Ils peuvent remédier aux défaillances du marché qui entravent particulièrement les entreprises dirigées par des jeunes, comme l'accès limité au financement. Selon des enquêtes menées auprès des entreprises, $76 \%$ des entreprises dirigées par des jeunes se heurtent à des obstacles financiers dans le cadre de leurs activités, contre seulement 59\% des entreprises dirigées par des personnes plus âgées. Il est évident qu'il faut faire davantage d'efforts pour lutter contre l'exclusion des jeunes des services financiers.

L'Aide pour le commerce peut jouer un rôle à cet égard. Dans le cadre de l'exercice 2019 de suivi et d'évaluation mené par I'OCDE et I'OMC, I'amélioration de l'accès au financement a été identifiée comme la contribution la plus importante que l'Aide pour le commerce puisse fournir pour renforcer l'autonomisation des jeunes.

Enfin, les gouvernements peuvent définir la voie à suivre à l'aide de feuilles de route pour les jeunes et le commerce. Ces feuilles de route peuvent remodeler la structure des échanges de l'économie en identifiant les secteurs qui présentent un potentiel d'exportation et un intérêt pour les jeunes. Grâce à des consultations participatives et à un plan pratique, les feuilles de route peuvent garantir que les jeunes hommes et les jeunes femmes ont les moyens de participer au commerce international. 


\section{NOTES}

1. Les données proviennent d'enquêtes menées auprès des entreprises en 2017 et 2018 dans les pays suivants: Sainte-Lucie, Zambie, Hongrie, Ukraine, Argentine, Maroc, Ghana, Kenya et Gambie.

2. Enquêtes sur la compétitivité des PME menées en Argentine, à Sainte-Lucie, au Kenya, au Ghana, en Zambie et en Ukraine. Les réponses allaient de 0 à 5, 0 correspondant à une "mauvaise adéquation" et 5 à une "bonne adéquation".

3. Les diagrammes de dispersion sont une méthode non paramétrique qui permet de représenter la fonction d'espérance conditionnelle (qui décrit la valeur moyenne de y pour chaque valeur de x). Pour générer un graphique de dispersion avec données groupées, le programme Binscatter regroupe la variable de l'axe des abscisses en 20 groupes de taille égale, calcule la moyenne des variables de l'axe des abscisses et de l'axe des ordonnées dans chaque groupe, puis crée un graphique de dispersion avec ces points de données. Par défaut, Binscatter trace également une courbe linéaire en utilisant la méthode des moindres carrés ordinaires, qui représente la meilleure approximation linéaire de la fonction d'espérance conditionnelle.

4. Les travailleurs indépendants travaillent comme propriétaires d'une entreprise établie depuis un certain temps, tandis que les entrepreneurs se consacrent à la planification, à la création et au développement de nouvelles entreprises. Bien que les deux concepts soient donc techniquement distincts, la plupart des jeunes qui travaillent pour leur propre compte s'identifient comme des entrepreneurs. Partant de cette simplification, nous utilisons les deux termes de façon interchangeable dans le présent chapitre.

5. Ces chiffres datent de 2015, l'année la plus récente pour laquelle des données sont disponibles sur les réfugiés syriens enregistrés et non enregistrés en Jordanie. Les dénombrements ultérieurs ne mesurent que la part des réfugiés qui sont officiellement enregistrés auprès du Haut Commissariat des Nations Unies pour les réfugiés et, en tant que tels, ne permettent pas de mesurer leur proportion générale dans la population.

6. Un exemple de ce type de forums est MicroMentor, une initiative en ligne à but non lucratif qui offre des conseils gratuits à de nombreux jeunes entrepreneurs et les met en contact avec des mentors d'affaires. Cette initiative est disponible à l'adresse suivante: $\underline{w w w . m i c r o m e n t o r . o r g}$ 


\section{RÉFÉRENCES}

Akpomujere, O. (2017), "Contemporary Issues in Diversification of Nigerian Economy through Entrepreneurship", Journal of Technology Management and Business, vol. 4, pages 40 à 49.

Almeida, R., Behrman, J., Robalino, D. (éds.) (2012), "The Right Skills for the Job? Rethinking Training Policies for Workers", Banque mondiale, Washington, D.C. https://doi.org/10.1596/978-0-8213-8714-6.

Arai, Y. (2010), "Promouvoir l'emploi pour les jeunes dans les entreprises multinationales: emploi des jeunes au Libéria”. Association pour le développement de l'éducation en Afrique (n.d.), "Dialogue politique national sur l'éducation pour le développement des compétences des jeunes pour l'emploi", Monrovia.

Avsar, N.A., Piovani, C. (2019), "Making trade policies gender-responsive: Data requirements, methodological developments and challenges", Conférence des Nations Unies sur le commerce et le développement (CNUCED), Genève.

Bacchetta, M., Gregg, C., Rubinova, S., Klok, B.T. (2017), "Investir dans les compétences pour un commerce inclusif", Organisation mondiale du commerce, Genève.

Banque mondiale (2012), World Development Report 2013: Jobs (Rapport sur le développement dans le monde 2013: Emplois), Banque mondiale, Washington, D.C.

Banque mondiale (2011), "Rapport sur le développement dans le monde 2011: Conflits, sécurité et développement", Banque mondiale, Washington, D.C.

Barro, R.J. (1991), "Economic growth in a cross section of countries", Quarterly Journal of Economics, vol.106, pages 407 à 443.

BIT (2012), "Tendances mondiales de l'emploi 2012", Bureau international du travail, Genève.

BIT (2010), "Global Employment Trends, January 2010", Bureau international du travail, Genève.

Bloom, N., Van Reenen, J. (2010), "Why Do Management Practices Differ across Firms and Countries?", Journal of Economic Perspectives, vol. 24, pages 203 à 224. https://doi.org/10.1257/jep.24.1.203

Blundell, R., Dearden, L., Meghir, C., Sianesi, B. (1999), “Human Capital Investment: The Returns from Education and Training to the Individual, the Firm and the Economy", Fiscal Studies, vol. 20, pages 1 à 23.

Business 20 (2015), "B20 SMEs \& Entrepreneurship Taskforce Policy Paper”, The Business 20 (B20), Turquie.

Cadot, O., Carrere, C., Strauss-Kahn, V. (2011), "Export diversification: What's behind the hump?", Review of Economics and Statistics, vol. 93, pages 590 à 605.

CEDEFOP (2010), "The skill matching challenge: analysing skill mismatch and policy implications", Centre européen pour le développement de la formation professionnelle, Luxembourg.

CESAP-ONU (2012), "Policy guidebook for SME development in Asia and the Pacific", Commission économique et sociale des Nations Unies pour l'Asie et le Pacifique, Bangkok.

CNUCED (2014), "Empowering Women Entrepreneurs through Information and Communications Technologies", Conférence des Nations Unies sur le commerce et le développement, Genève.

Coward, C., Caicedo, S., Rauch, H., Vega, N.R. (2014), "Les débouchés du numérique: des solutions innovantes utilisant les TIC au service de l'emploi des jeunes", Union internationale des télécommunications (UIT). 
Département des affaires économiques et sociales (DAES) de I'ONU (2015), "Population Facts".

Draper, P. (2017), "Trade, Inclusiveness, Inequality and the WTO” (Discussion Paper), Global Economic Governance Africa.

Éditions OCDE (2015), "Tous concernés: Pourquoi moins d'inégalité profite à tous", OCDE, Paris.

Emploi décent des jeunes (n.d.), "Youth Entrepreneurship \& Self-Employment: Unleashing the Potential of Youth to Succeed in Business and to Access Decent Work".

Evald, M.R., Klyver, K., Christensen, P.R. (2011), "The effect of human capital, social capital, and perceptual values on nascent entrepreneurs' export intentions", Journal of International Entrepreneurship, vol. 9, pages 1 à 19. https://doi.org/10.1007/s10843-010-0069-3

EY (2016), "Beyond disruption: Policy action to grow digital entrepreneurship".

Fernando, M. (2018), "Creating opportunities for and with youth", Forum du commerce international, pages 14 à 15.

Field, E., Jayachandran, S., Pande, R., Rigol, N. (2015), "Friendship at work: Can peer effects catalyze female entrepreneurship?", National Bureau of Economic Research, nº w21093.

Fonds multilatéral d'investissement (2012), "Give Youth a Chance: an Agenda for Action".

Forum économique mondial (2017), "Accelerating Workforce Reskilling for the Fourth Industrial Revolution: An Agenda for Leaders to Shape the Future of Education, Gender and Work".

Forum économique mondial (2014), "Matching Skills and Labour Market Needs".

Green, A. E., Martinez-Solano, L. (2011) "Leveraging Training Skills Development in SMEs: An Analysis of the West Midlands, England, UK", OCDE, Paris.

Gupta, M.D., Engelman, R., Levy, J., Luchsinger, G., Merrick, T., Rosen, J.E. (2014), "Le pouvoir de 1,8 milliard d'adolescents et de jeunes et la transformation de l'avenir", État de la population mondiale 2014, UNFPA.

Hambrick, D.C., Mason, P.A. (1984), "Upper Echelons: The Organization as a Reflection of Its Top Managers",

The Academy of Management Review, vol. 9, pages 193 à 206. https://doi.org/10.2307/258434

ITC (2019a), prospectus sur le programme Youth and Trade.

ITC (2019b), "SME Competitiveness Outlook 2019: Big Money for Small Business - Financing the Sustainable Development Goals" (Perspective de la compétitivité des PME 2019: Financements solides pour petites entreprises Financer les Objectifs de développement durable), Centre du commerce international, Genève.

ITC (2019c), "Stratégie sur l'intégration et l'employabilité des jeunes dans le secteur textile et habillement Tunisienne", ITC.

ITC (2018a), "Promoting SME Competitiveness in Africa: Data for de-risking investment".

ITC (2018b), "SME Competitiveness Outlook 2018: Business ecosystem for the digital age", Centre du commerce international.

ITC (2018c), "Strategic Youth and Trade Development Roadmap of the Gambia (2018-2022)".

ITC (2018d), "Youth and Trade Roadmap: Creating economic opportunities for youth in value chains".

ITC (2017a), "SME Competitiveness Outlook 2017 - The region: A door to global trade" (Perspective de la compétitivité des PME 2017 - Régions: Une porte vers les échanges mondiaux), Centre du commerce international, Genève, Suisse.

ITC (2017b), "SheTrades: Promoting SME Competitiveness in Indonesia", Centre du commerce international, Genève. 
ITC (2016), "SME Competitiveness Outlook 2016: Meeting the Standard for Trade" (Perspective de la compétitivité des PME 2016: Se mettre aux normes pour échanger), Centre du commerce international, Genève, Suisse.

ITC (2015a), "Perspective de la compétitivité des PME 2015: Connectivité, concurrence et changement pour une croissance solidaire", Centre du commerce international, Genève.

ITC (2015b), "Libérer l'accès des femmes entrepreneurs aux marchés", Centre du commerce international, Genève. Jansen, M., Lanz, R. (2013), "Skills and export competitiveness for small and medium-sized enterprises", Organisation mondiale du commerce, Genève.

Joel, A.D., Jonah, C.T., Boma, A.K. (2017), "Leveraging entrepreneurship development for Nigeria economic diversification: the role of selected government agencies", Advance Research Journal of Multi-Disciplinary Discoveries, vol. 16, pages 24 à 29 .

Kew, J., Herrington, M., Litovsky, Y., Gale, H. (2013), "Generation Entrepreneur? The state of global youth entrepreneurship", Youth Business International and Global Entrepreneurship Monitor.

Khokhar, T. (n.d), "Chart: How Is the World's Youth Population Changing?", Blog de données, voir: https://blogs.worldbank.org/ opendata/chart-how-worlds-youth-population-changing

Kubisz, M. (2011), "Leveraging Training Skills Development in SMEs: An Analysis of Zaglebie Sub-Region, Poland", Local Economic and Employment Development (LEED) working Paper 2011/06, OCDE, Paris.

Kuruvilla, S., Erickson, C.L., Hwang, A. (2002), "An Assessment of the Singapore Skills Development System: Does it Constitute a Viable Model for Other Developing Countries?" World Development, vol. 30, pages 1461 à 1476. https://doi.org/10.1016/ S0305-750X(02)00046-3

Lawson, B., Samson, D. (2001), "Developing Innovation Capability in Organisations: A Dynamic Capabilities Approach", International Journal of Innovation Management, vol. 05, pages 377 à 400. https://doi.org/10.1142/S1363919601000427

McPherson, T. (2008), "Digital Youth, Innovation, and the unexpected", MIT Press, États-Unis.

Middlesex University et Youth Business International (2016), "Exploring the impact of voluntary business mentoring on young entrepreneurs", Youth Business International.

Miller, S.M., Upadhyay, M.P. (2000), "The effects of openness, trade orientation, and human capital on total factor productivity", Journal of Development Economics, vol. 63, pages 399 à 423.

https://doi.org/10.1016/S0304-3878(00)00112-7

Minniti, M., Naudé, W. (2010a), "Special Section: Female Entrepreneurship across Countries and in Development", European Journal of Development Research, vol. 22.

Minniti, M., Naudé, W. (2010b), "Female Entrepreneurship in Developing Countries”, WIDERAngle, voir: https://www.wider.unu.edu/publication/female-entrepreneurship-developing-countries

Morrison, A., Raju, D., Sinha, N. (2007), "Gender Equality, Poverty and Economic Growth".

Murphy, R. (2000), "Return migrant entrepreneurs and economic diversification in two counties in South Jiangxi, China", Journal of International Development, vol. 11, pages 661 à 672.

Neely, A., Adams, C., Crowe, P. (2001), "The performance prism in practice”, Measuring Business Excellence, vol. 5, pages 6 à 13. https://doi. org/10.1108/13683040110385142

OCDE (2018), "SME and Entrepeneurship Policy in Kazakhstan 2018", Organisation de coopération et de développement économiques, Paris. 
OCDE (2014), "Supporting Youth in Entrepreneurship: Summary report of a policy development seminar organised by the OECD and the European Commission, Brussels, 22nd-23rd September 2014", OCDE, Paris.

O'Higgins, N. (2017), "Rising to the youth employment challenge: new evidence on key policy issues", Organisation internationale du travail (OIT).

OIT (2017), "Global Employment Trends for Youth 2017 - Paths to a better working future", Organisation internationale du travail, Genève.

OIT/CEA (2009), "Report on Youth Employment Opportunities in Africa: The Impact of Young Women's Vulnerabilities on Opportunities to become an Entrepreneur A case study of Ethiopia".

OMC (2019), "Indicateur des perspectives du commerce mondial 2019", Indicateur des perspectives du commerce mondial.

Onkelinx, J., Manolova, T.S., Edelman, L.F. (2015), "Human Capital and SME Internationalization: Empirical Evidence from Belgium", International Small Business Journal, vol. 34, pages 818 à 837.

Organisation mondiale du commerce (2016), "Rapport sur le commerce mondial 2016: Égaliser les conditions du commerce pour les PME", Organisation mondiale du commerce, Genève.

Otsuka, K., Sonobe, T. (2011), "A cluster-based industrial development policy for low-income countries".

Pikoko, V., Phiri, A. (2018), "Is there hysteresis in South African unemployment? Evidence from the post-recessionary period", Munich University Working Paper.

Purfield, C., Finger, H., Ongley, K., Baduel, B., Castellanos, C., Pierre, G., Stepanyan, V., Roos, E. (2018), “Opportunités pour tous: Croissance et inclusion au Moyen-Orient et en Afrique du Nord" (Document N 18/11 du Départment MCD du FMI), Fonds monétaire international, Washington, D.C.

Schoof, U. (2006) "Stimulating Youth Entrepreneurship: Barriers and Incentives to Enterprise Start-Ups by Young People", Bureau international du travail.

Schott, T., Kew, P., Cheraghi, M. (2015), "Future Potential: a GEM perspective on youth entrepreneurship", Global Entrepreneurship Monitor.

Sibanda, S., Sibanda, T. (2016), "Financial Education in South Africa: Overview of key initiatives and actors", OIT, Genève.

Solomon, D., (2010). "Desk Review of Studies Conducted on Women Entrepreneurs in Ethiopia", Chambre de commerce d'Addis-Abeba.

Sonobe, T., Otsuka, K. (2006), "Cluster-Based Industrial Development: An East Asian Model”.

Stuart, T.E., Sorenson, O. (2005), "Social Networks and Entrepreneurship" dans "Handbook of Entrepreneurship Research", Disciplinary Perspectives, Springer, New York, pages 233 à 252.

Syverson, C. (2011), "What Determines Productivity?" Journal of Economic Literature, vol. 49, pages 326-365. https://doi.org/10.1257/jel.49.2.326

The Mastercard Foundation (2015), "Youth at Work: Building Economic Opportunities for Young People in Africa", The Mastercard Foundation.

Tripney, J., Hombrados, J., Newman, M., Hovish, K., Brown, C., Steinka-Fry, K., Wilkey, E. (2013), "Technical and vocational education and training (TVET) interventions to improve the employability and employment of young people in low- and middle-income countries: a Systematic Review", Campbell Systematic Reviews, 2013, vol. 9, The Campbell Collaboration. https://doi.org/10.4073/csr.2013.9 
Vandenberg, P., Trinh, L.Q. (2016), "Small Firms, Human Capital, and Productivity in Asia”, working Paper n582, Institut de la Banque asiatique de développement.

Weidenkaff, F. (2018), "Scaling up action on youth employment with the Global Goals", Forum du commerce international, numéro 2, pages 26 et 27.

Winters, L.A., Martuscelli, A. (2014) "Trade Liberalization and Poverty: What Have We Learned in a Decade?", document de travail n 9947, présenté au Centre for Economic Policy Research.

Woessmann, L. (2011), “Education policies to make globalization more inclusive, dans: Making Globalization Socially Sustainable", Organisation mondiale du commerce et Bureau international du travail, pages 297 à 316.

Yifu Lin, J. (2012), "Youth Bulge: A Demographic Dividend or a Demographic Bomb in Developing

Countries?", Let's Talk Development, voir: http://blogs.worldbank.org/developmenttalk/ youth-bulge-a-demographic-dividend-or-a-demographic-bomb-in-developing-countries.

Yoshino, Y. (2011), "Industrial Clusters and Micro and Small Enterprises in Africa: From Survival to Growth", Directions in Development, $n^{\circ}$ 58850, Banque mondiale, Washington, D.C. 



\title{
CHAPITRE 9
}

\section{ENSEIGNEMENTS À TIRER DE L'AIDE POUR LE COMMERCE EN FAVEUR DE L'AUTONOMISATION ÉCONOMIQUE DES FEMMES}

\author{
Contribution de l'Organisation de coopération \\ et de développement économiques
}

\begin{abstract}
Resumé : Le présent chapitre examine la façon dont les donateurs prennent en compte les perspectives de genre dans l'Aide pour le commerce, car l'autonomisation économique des femmes est l'un des principaux moteurs du développement durable. II présente des données qui montrent que les donateurs ont augmenté leur Aide pour le commerce intégrant la question du genre. Dans le même temps, il indique que des améliorations sont possibles, en particulier dans des domaines tels que les transports, l'énergie, la finance et les affaires, l'extraction minière et l'industrie, dans lesquels la part de l'Aide pour le commerce intégrant la question du genre est faible. II met en lumière de bons exemples donnés par quelques donateurs pour montrer la voie à d'autres qui peinent à intégrer les perspectives de genre dans ces domaines. Ces exemples révèlent que de nombreux projets prévoient la formation de femmes en tant que fonctionnaires ou que bénéficiaires de projets, en particulier pour des activités génératrices de revenus. D'autres activités comprennent des études ou l'élaboration de projets qui tiennent compte de la question du genre dans un domaine particulier. Dans le contexte de la Déclaration conjointe sur le commerce et l'autonomisation économique des femmes, les donateurs doivent constituer une base de données factuelles, mettre en place un système adéquat de suivi et d'évaluation et veiller à ce qu'il soit rendu compte des progrès dans l'autonomisation économique des femmes.
\end{abstract}




\section{CONTEXTE}

L'autonomisation économique des femmes a été reconnue comme l'un des principaux moteurs du développement durable et de l'égalité des sexes (Ferrant 2011; Cuberes, Teigner 2016; Gonzalez et al. 2015; Ostry et al. 2014; Banque mondiale 2012; Knowles et al. 2002). Des études indiquent que si les femmes ont plus de contrôle sur les ressources du ménage, cela se traduit par un investissement accru dans la santé et l'éducation. En outre, cela entraîne des niveaux de croissance plus élevés et plus durables. À cet égard, le Programme d'action de Beijing de 1995 a favorisé l'autonomisation économique des femmes et stimulé les progrès tant dans les pays développés que dans les pays en développement (voir encadré 9.1). Par ailleurs, l'Objectif du Millénaire pour le développement (OMD) 3 (promouvoir l'égalité des sexes et l'autonomisation des femmes) concerne principalement les pays en développement et est axé sur l'éducation, et en particulier sur l'augmentation du nombre d'inscriptions des filles à l'école primaire.

Compte tenu en partie de la portée limitée de l'OMD 3 et du fait que la communauté du développement comprend mieux les effets positifs de l'autonomisation économique des femmes pour obtenir des résultats dans le domaine du développement, l'objectif de développement durable (ODD) 5, qui est énoncé dans le Programme 2030, définit une portée plus large et vise à "parvenir à l'égalité des sexes et [à] autonomiser toutes les femmes et les filles" (Mason, King 2001; Morrison et al. 2007; Banque mondiale 2012; ONU 2015; Forum mondial sur l'éducation 2015). À titre d'exemple, cet objectif souligne la nécessité, entre autres, de donner aux femmes l'accès à la propriété foncière et aux services financiers, de les aider à faire une meilleure utilisation des technologies de l'information et de la communication (TIC), de valoriser les tâches domestiques et de soins non rémunérées en mettant en place des infrastructures et de renforcer les politiques et la législation pour promouvoir l'égalité des sexes et l'autonomisation des femmes. D’autres objectifs traitent de l'autonomisation des femmes, notamment l'ODD 8 relatif au travail décent et à la croissance économique, qui porte sur l'emploi productif, le travail décent pour les femmes et la ventilation des données par sexe.

Plus récemment, en 2016, le Groupe de haut niveau sur l'autonomisation économique des femmes, établi par le Secrétaire général de l'ONU, a présenté des mesures visant à accélérer l'autonomisation économique des femmes, reconnaissant que cette question était une pierre angulaire des ODD et jouait un rôle essentiel pour parvenir à l'égalité des sexes (ONU-Femmes 2018). Ces mesures visaient notamment à partager la charge des activités de soins non rémunérées; à garantir l'accès des femmes aux services financiers, aux nouvelles technologies et à la justice; à modifier les pratiques en matière d'emploi; et à ratifier les principaux accords internationaux sur les droits des travailleuses, notamment dans le secteur informel et dans le domaine du travail domestique.

Cependant, malgré ces engagements pris au niveau mondial, les femmes continuent de se heurter à des obstacles pour exercer une activité économique rémunérée, en conséquence de quoi elles obtiennent de moins bons résultats que les hommes pour de nombreux indicateurs économiques clés. Dans les pays en développement en particulier, les femmes occupent encore une grande partie des emplois vulnérables et informels (OIT 2018). Elles ont souvent moins facilement accès que les hommes à la terre, aux finances, aux machines agricoles et aux technologies de production, ce qui contribue aux écarts de revenu et de productivité entre les hommes et les femmes (Palacios-López, Ramón López 2015; Banque asiatique de développement 2018; Banque mondiale 2015a et 2015b; Sahay 2018; OIT 2016). Les femmes qui travaillent dans le secteur informel peuvent être confrontées à des difficultés encore plus grandes, par exemple en ce qui concerne l'accès aux prêts accordés par les établissements financiers formels (Osondu et al. 2015; Kasseeah, Tandrayen-Ragoobur, 2015). De plus, les femmes effectuent une part importante des tâches domestiques et de soins non rémunérées, y compris les tâches chronophages comme aller chercher de l'eau ou cuisiner en grande quantité, ce qui leur laisse moins de temps pour exercer des activités rémunérées, suivre une formation et recevoir une éducation (OCDE 2019a). En outre, les femmes sont concentrées dans les secteurs moins bien rémunérés (ONU 2016). 
Encadré 9.1. Programme d'action de Beijing de 1995, “Les femmes dans l'économie”

Le Programme d'action de Beijing de 1995 comprenait une initiative sur les femmes dans l'économie, dans le cadre de laquelle les États se sont engagés à prendre les mesures suivantes:

- Promouvoir les droits et l'indépendance économiques des femmes, y compris l'accès à l'emploi et à des conditions de travail appropriées et le contrôle des ressources économiques. Exemple: "Adopter et appliquer des lois consacrant le principe de la rémunération égale des femmes et des hommes pour un travail égal ou de valeur égale".

- Garantir l'égalité d'accès des femmes aux ressources, à l'emploi, aux marchés et au commerce. Exemple: "Prêter une attention particulière aux besoins des femmes lorsqu'ils diffusent des informations sur les marchés, les échanges commerciaux et les ressources, et leur dispenser des formations appropriées dans ces domaines".

Assurer services aux entreprises, formation et accès aux marchés, à l'information et à la technologie, en particulier pour les femmes à faible revenu. Exemple: "Créer des services d'appui non discriminatoires, notamment des fonds de placement, à l'intention des entreprises dirigées par des femmes, et élaborer des programmes de promotion du commerce axés sur les femmes, notamment les femmes à faible revenu".

- Renforcer les capacités économiques et les réseaux commerciaux des femmes. Exemple: "Offrir aux entreprises dirigées par des femmes, y compris dans le secteur travaillant pour l'exportation, des services, notamment de commercialisation et d'information sur le commerce, de conception des produits et d'innovation, de transfert de technologie et de contrôle de la qualité".

Éliminer la ségrégation professionnelle et toutes les formes de discrimination dans l'emploi. Exemple: "Redoubler d'efforts pour réduire les écarts de salaires entre hommes et femmes, prendre les mesures nécessaires pour faire appliquer le principe de la rémunération égale pour un travail équivalent de valeur égale, en renforçant la législation, et notamment en l'harmonisant avec les normes et codes internationaux du travail, et encourager la mise en place de systèmes d'évaluation du travail fondés sur des critères non sexistes".

- Promouvoir l'harmonisation des responsabilités professionnelles et familiales des femmes et des hommes. Exemple: "Favoriser le développement technologique et améliorer l'accès aux techniques qui facilitent les tâches ménagères et professionnelles, encouragent l'autonomie, créent des revenus, modifient les rôles traditionnellement attribués aux femmes et aux hommes dans la production et permettent aux femmes de n'être plus reléguées dans les emplois mal payés".

Source: Adapté du Programme d'action de Beijing (1995) http://www.un.org/womenwatch/daw/beijing/platform/economy.htm

L'élimination de ces disparités entre hommes et femmes pourrait permettre de réduire la pauvreté et avoir d'autres répercussions positives sur les femmes, leurs familles et leurs communautés, par exemple, une augmentation de la production agricole et une amélioration des résultats obtenus par les femmes et les enfants en matière de santé et d'éducation (Banque mondiale 2012, 2015a). Les investissements dans les infrastructures, en particulier, peuvent aider les femmes à exercer des activités rémunérées puisqu'ils facilitent leurs déplacements grâce à des moyens de transport améliorés et sûrs ou leur permettre de dégager du temps consacré auparavant à des activités non rémunérées telles que la collecte de bois de chauffage lorsque des sources d'énergie modernes sont disponibles (Banque mondiale 2012).

Dans ce contexte, le commerce peut potentiellement apporter des avantages aux femmes. Par exemple, outre l'augmentation des revenus, la création de nouveaux emplois pour les femmes dans le secteur manufacturier a aussi eu des effets positifs sur le pouvoir de négociation des femmes au sein des ménages. Plus particulièrement, la production de textiles et de vêtements axée sur l'exportation a permis de renforcer l'indépendance et le pouvoir de décision de nombreuses femmes concernant la répartition des ressources du ménage (Korinek2005). Demême, I'arrivée de l'industrie du vêtement, où les femmes sont souvent surreprésentées, a eu des retombées positives dans d'autres domaines, comme l'éducation, puisqu'elle a permis d'augmenter les chances de scolarisation des filles (Heath, Mobarak 2015). 
Les chaînes de valeur agroalimentaires peuvent également profiter aux femmes si les entreprises prennent en compte les questions de genre dans l'application des normes du travail et lorsqu'elles ont accès à des technologies permettant d'économiser de la main-d'œuvre et à des formations pour améliorer leurs compétences (SFI 2016; FAO, OIT, FIDA 2010; Banque mondiale, gouvernement du Liberia 2010). D'autres études montrent que l'expansion du commerce peut réduire les inégalités entre les sexes si une série de politiques commerciales et d'autres politiques économiques appropriées sont mises en œuvre dans un ordre adapté (Elson et al. 2007).

Parallèlement, étant donné que les femmes ne constituent pas un groupe homogène, le commerce a sur elles des effets différents en fonction, entre autres, de leur situation géographique, de leur statut socioéconomique, de leur niveau d'éducation et de leur éventuel handicap. Par conséquent, comme cela a été souligné dans le Programme d'action de Beijing', une attention particulière doit être accordée aux éventuelles conséquences négatives imprévues de la libéralisation des échanges pour certains groupes de femmes. À titre d'exemple, des emplois de mauvaise qualité exercés par des travailleurs peu qualifiés dans des environnements peu sûrs peuvent avoir un effet négatif sur les femmes, notamment en les exposant davantage à la violence. Cette situation peut être aggravée par la pression de la concurrence internationale (ONU-Femmes 2015). L'augmentation des importations due à la libéralisation des échanges dans l'agriculture peut être préjudiciable pour les femmes qui travaillent dans l'agriculture à petite échelle. Certains secteurs d'exportation requérant une main-d'œuvre plus qualifiée recrutent plus facilement des hommes lorsqu'il existe des disparités importantes entre hommes et femmes en matière d'éducation (Korinek 2005). Même lorsque le commerce offre des possibilités d'emploi aux femmes, la charge de travail totale de celles-ci peut augmenter si le temps dont elles ont besoin pour exercer leurs tâches domestiques et de soins non rémunérées reste le même (Çagatay 2001). Dans certains pays, des lois et des normes sociales discriminatoires limitent l'accès des femmes au financement, aux nouvelles technologies et aux connaissances en matière de commercialisation, ce qui les empêche de tirer pleinement parti des nouvelles possibilités offertes par la libéralisation des échanges (Banque mondiale 2018).

Dans ce contexte, I'Aide pour le commerce peut améliorer les possibilités économiques qui s'offrent aux femmes de participer à des activités d'exportation et d'importation, notamment par le biais de micro, petites et moyennes entreprises (MPME), et contribuer ainsi à leur autonomisation économique² (Kimm Gnangnon 2019). L'Aide pour le commerce peut également favoriser l'élimination d'obstacles au commerce tels que l'absence d'infrastructures et empêcher que les femmes ne subissent un impact négatif dans le cadre d'activités d'exportation, notamment sous la forme de mauvaises conditions de travail et de bas salaires (OIT 2017). Depuis la création de l'Équipe spéciale de l'OMC chargée de l'Aide pour le commerce en 2006, on a reconnu la nécessité de tenir compte de la question de l'égalité des sexes et de l'objectif global du développement durable. Ainsi, la prise en compte de cette question a été établie comme l'un des principes directeurs de l'Équipe spéciale (Équipe spéciale de l'OMC chargée de l'Aide pour le commerce 2006).

En outre, en 2017, dans la Déclaration conjointe sur le commerce et l'autonomisation économique des femmes adoptée en marge de la Conférence ministérielle de I'OMC à Buenos Aires, il a été reconnu que "des politiques commerciales inclusives [pouvaient] contribuer à la progression de l'égalité hommes-femmes et de l'autonomisation économique des femmes". La Déclaration comprend un certain nombre de recommandations ${ }^{3}$, notamment la nécessité de faire en sorte que l'Aide pour commerce contribue aux outils et aux connaissances nécessaires pour analyser, concevoir et appliquer des politiques commerciales plus soucieuses de l'égalité hommes-femmes. L'Équipe spéciale est tenue de faire rapport à I'OMC sur les progrès accomplis dans la mise en œuvre des recommandations de la Déclaration conjointe en 2020. 


\section{ÉVALUATION DE L'INTÉGRATION DES PERSPECTIVES DE GENRE DANS L'AIDE POUR LE COMMERCE}

\section{Points de vue sur l'importance de la dimension de genre dans l'Aide pour le commerce}

Dans les exercices semestriels de suivi et d'évaluation (S\&E) de l'Aide pour le commerce effectués de 2011 à 2019, on a fait le point sur la question de l'égalité des sexes, y compris sur la prise en compte de cette question et de l'autonomisation économique des femmes par les donateurs et les pays partenaires. Dans l'exercice de S\&E de 2019, la majorité des donateurs qui ont répondu considéraient l'autonomisation économique des femmes comme une priorité dans l'Aide pour le commerce. Toutefois, la Corée, la Lettonie et le Portugal ne savaient pas quel rang de priorité accorder à cette question et la République tchèque, la France et la Hongrie ne la considéraient pas comme une priorité (OCDE-OMC 2019). En outre, l'exercice de S\&E de 2011 a montré que la plupart des donateurs considéraient que parvenir à une plus grande égalité hommes-femmes était un objectif "important" de l'Aide pour le commerce, et la Norvège a été le seul donateur à considérer qu'il s'agissait d'un objectif "très important". Néanmoins, cet objectif arrivait en avant-dernière place dans le classement (voir figure 9.1). Ce même exercice de S\&E de $2011^{4}$ a montré que, pour les pays partenaires qui ont répondu, une plus grande égalité hommes-femmes était l'objectif le moins important parmi ceux qu'ils souhaitaient atteindre grâce à l'Aide pour le commerce. Cet objectif passait après une plus grande viabilité environnementale, la réduction de la pauvreté, l'accélération de la croissance économique et la diversification des exportations (OCDE-OMC 2011).

\section{Figure 9.1. Principaux objectifs que les donateurs et les pays partenaires veulent atteindre au moyen de l'Aide pour le commerce}

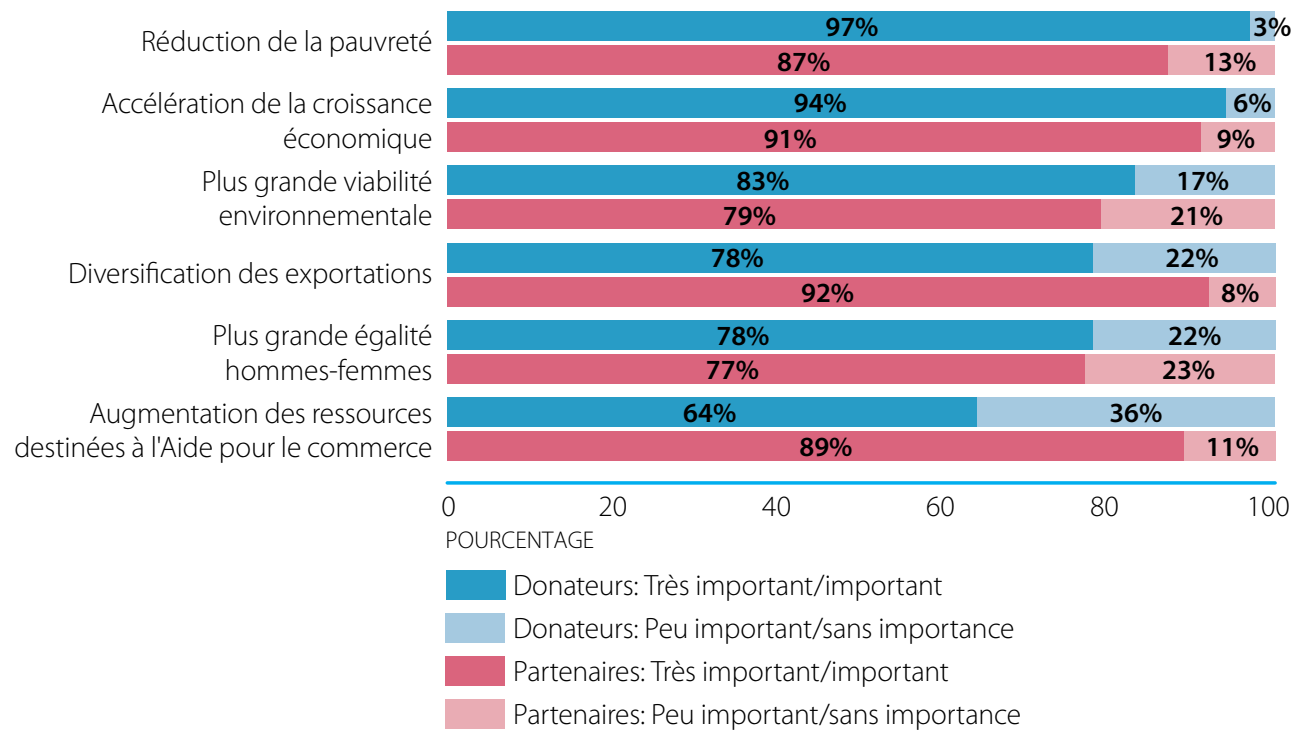

Source: OCDE-OMC (2011), Exercice de suivi de l'Aide pour le commerce 2011 (questionnaires).

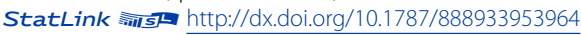

En outre, l'exercice de S\&E de 2017 a montré que seuls 48\% des donateurs ayant répondu estimaient que l'Aide pour le commerce contribuerait à la réalisation de l'ODD 5 relatif à l'égalité des sexes et à l'autonomisation des femmes (voir figure 9.2) (OCDE-OMC 2017), soit mieux que pour I'ODD 13 relatif à la lutte contre les changements climatiques, mais nettement moins bien que pour I'ODD 10 relatif à la réduction des inégalités, l'ODD 8 relatif au travail décent et à la croissance économique et I'ODD 9 relatif à l'industrie, à l'innovation et aux infrastructures. Par contre, les attentes des donateurs quant à la contribution de l'Aide pour le commerce à la réalisation de l'ODD 5 étaient encore plus élevées que celles des pays partenaires (38\%). Il en est ainsi malgré le fait que, dans la Déclaration de Buenos Aires, les pays en développement ont reconnu, rappelant le Programme de développement durable à I'horizon 2030, que des politiques 
commerciales inclusives pouvaient contribuer à la progression de l'égalité hommes-femmes et de l'autonomisation économique des femmes, ce qui avait un effet positif sur la croissance économique et aidait à réduire la pauvreté. En outre, certains pays en développement déploient des efforts conséquents pour favoriser l'autonomisation économique des femmes. ${ }^{5}$

Il est possible que les exercices de S\&E rendent compte des opinions des fonctionnaires qui ont répondu aux questionnaires, lesquels ne reflètent pas nécessairement celle du gouvernement. Le faible degré de priorité accordé par les pays partenaires et le faible niveau de leurs attentes pourraient s'expliquer par le fait qu'ils ne perçoivent pas véritablement les femmes comme des agents économiques et qu'ils ignorent les effets positifs que l'Aide pour le commerce pourrait avoir sur les femmes, peut-être en raison de leurs préjugés sexistes, ou par le manque de communication de la part des donateurs ou le fait qu'ils ne présentent pas suffisamment d'éléments de preuve. La communauté des donateurs pourrait donc avoir à relever le défi de promouvoir l'autonomisation économique des femmes tout en en alignant ses investissements sur les priorités des pays partenaires, conformément à la Déclaration de Paris sur l'efficacité de l'aide (2005) et à l'Accord de partenariat de Busan (2011), ainsi qu'au Partenariat mondial pour une coopération efficace au service du développement.

Figure 9.2. Points de vue sur la contribution de l'Aide pour le commerce aux ODD

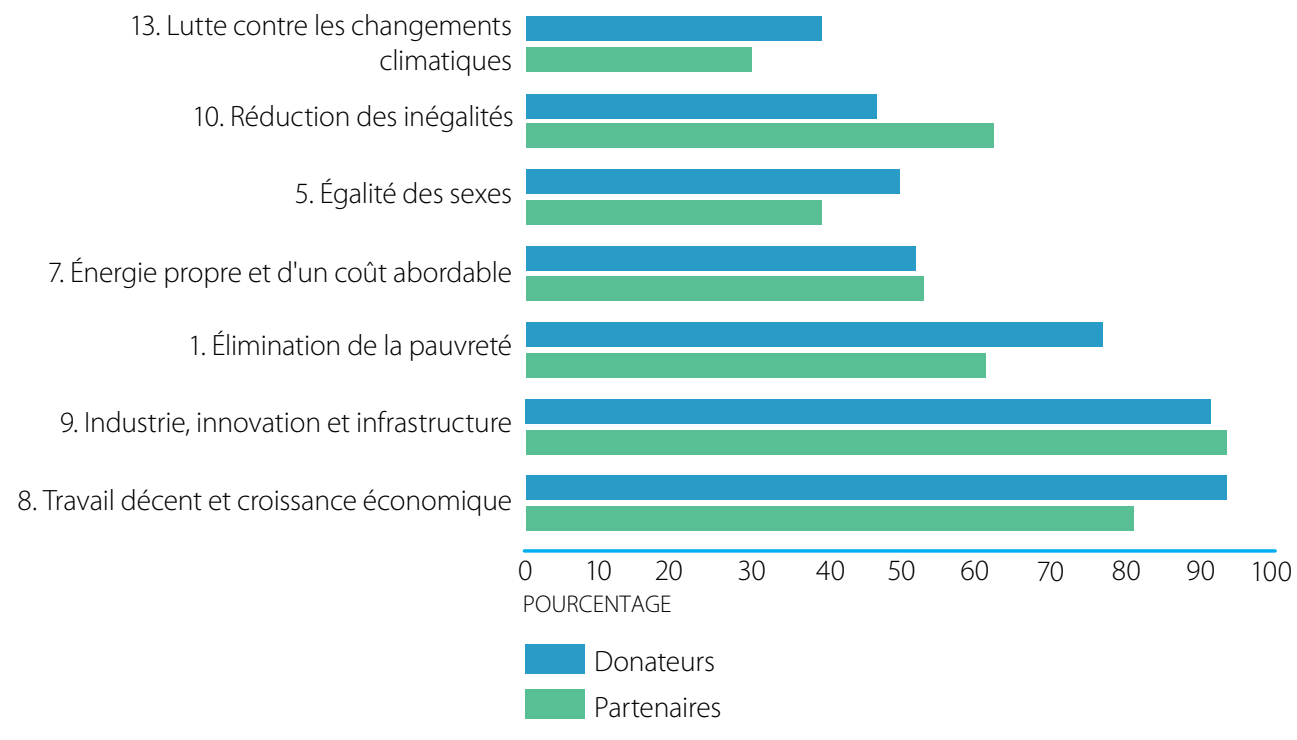

Source: OCDE-OMC (2017), Exercice de suivi de l'Aide pour le commerce 2017 (questionnaires).

StatLink 刑Is http://dx.doi.org/10.1787/888933953983

\section{Tendances de l'intégration des perspectives de genre dans l'Aide pour le commerce}

Compte tenu des résultats susmentionnés des exercices de S\&E, les donateurs bilatéraux et multilatéraux ont augmenté régulièrement leur part de l'Aide pour le commerce intégrant la question du genre, telle que mesurée par le marqueur de la politique d'aide à l'appui de l'égalité homme-femme établi par le CAD (marqueur relatif à l'égalité homme-femme) (voir encadré 9.2 et figure 9.3). Sur la base des données pertinentes, le montant total des engagements ${ }^{6}$ en matière d'Aide pour le commerce qui ont été évalués au moyen du marqueur relatif à l'égalité homme-femme (objectif significatif et objectif principal) est passé de 3 milliards d'USD par an en moyenne en 2006-2007 à 12 milliards d'USD par an en 2016-2017. Plus particulièrement, entre 2012-2013 et 2014-2015, les montants de l'Aide pour le commerce intégrant la question du genre ont connu une augmentation rapide, principalement en raison du fait que le Japon a multiplié par huit son aide intégrant cette question, notamment dans des secteurs comme les transports. Il s'agit là d'un progrès significatif puisque, pendant de nombreuses années, les donateurs bilatéraux et multilatéraux ont été plus enclins à intégrer l'égalité des sexes et l'autonomisation des femmes dans les secteurs sociaux.? 
Encadré 9.2. Le marqueur relatif à l'égalité homme-femme

L'OCDE suit l'aide en faveur de l'égalité des sexes et des droits des femmes grâce au marqueur du Comité d'aide au développement (CAD) relatif à l'égalité homme-femme, un outil statistique qualitatif utilisé pour enregistrer les activités d'aide ayant pour objectif politique l'égalité des sexes. Il est basé sur un système de notation à trois points:

Objectif principal (valeur 2): L'égalité entre les femmes et les hommes est l'objectif principal du projet et elle joue un rôle fondamental dans la conception de celui-ci et dans les résultats qui en sont attendus. Le projet n'aurait pas été entrepris sans cet objectif.

Objectif significatif (valeur 1): L'égalité entre les femmes et les hommes est un objectif important et délibéré, mais elle n'est pas le principal motif de la réalisation du projet. L'objectif de l'égalité homme-femme doit être mentionné de manière explicite dans la documentation relative au projet et sa présence ne peut être implicite ni supposée. Outre les autres objectifs qu'il vise, le projet est destiné à produire un impact positif pour le progrès de l'égalité entre les sexes ou l'autonomisation des femmes. Les critères minimums qui doivent être remplis sont:

- Une analyse sexospécifique du projet a été effectuée.

- Les conclusions de l'analyse sexospécifique ont servi à étayer la conception du projet.

- Présence d'au moins un objectif explicite concernant l'égalité homme-femme, auquel est associé au moins un indicateur sexospécifique.

- Les données et les indicateurs sont ventilés par sexe lorsqu'il y a lieu.

— Engagement de déterminer de façon suivie les résultats produits par le projet sur le plan de l'égalité homme-femme et d'en rendre compte lors de la phase d'évaluation.

Non orienté vers l'objectif (valeur 0): Le projet a été examiné au regard du marqueur, mais il n'a pas été constaté qu'il visait l'objectif de l'égalité homme-femme.

Dans le présent rapport, l'expression "aide intégrant la question de l'égalité hommes-femmes" désigne le financement public du développement (aide publique au développement (APD) et autres flux officiels) de valeur 1 (significatif) ou de valeur 2 (principal). Le marqueur relatifà l'égalité homme-femme est utilisé ici comme indicateur indirect pour examiner les secteurs dans lesquels les donateurs intègrent la question de l'égalité des sexes en adhérant au principe directeur de l'Équipe spéciale chargée de l'Aide pour le commerce évoqué plus haut. Dans ce contexte, le marqueur est principalement utilisé pour filtrer les projets plutôt que pour analyser le montant de l'aide en soi, d'autant plus que le Réseau du CAD sur l'égalité hommefemme $(G E N D E R N E T)^{8}$ a récemment mené une étude sur les montants de l'aide destinée à favoriser l'autonomisation économique des femmes (OCDE 2018). ${ }^{9}$ En outre, ce chapitre met l'accent sur l'autonomisation économique des femmes, conformément au thème de l'Examen de l'Aide pour le commerce de 2019, plutôt que sur l'évaluation des efforts déployés par les donateurs pour réduire et mesurer les inégalités entre les sexes, bien que cette question soit étroitement liée à l'autonomisation économique des femmes et constitue un élément clé du développement durable.

Compte tenu de la part relativement faible de l'Aide pour le commerce intégrant la question du genre et des niveaux encore plus faibles de financement spécifique (valeur 2) (1\% en 2016-2017), le GENDERNET encourage les donateurs à augmenter les fonds consacrés à l'égalité des sexes et à l'autonomisation des femmes, en particulier dans les secteurs de l'Aide pour le commerce où elle est restée constamment faible. II sera essentiel d'accroître les investissements dans ces domaines pour réaliser l'ODD5, en particulier la cible 5.4, qui est axée sur la valorisation des tâches domestiques et de soins non rémunérées par l'apport de services publics et d'infrastructures, et l'ODD 8, qui vise à promouvoir l'emploi productif pour les femmes. Les contributions des donateurs mettent de plus en plus en évidence les limites de l'intégration de la question de genre pour corriger les déséquilibres sous-jacents qui alimentent les inégalités entre les sexes et nuisent à l'autonomisation des femmes. Par exemple, une étude récente de la Suisse a montré que les projets spécifiquement axés sur le genre étaient efficaces à 73\% dans la promotion de l'égalité entre les sexes, contre 31\% pour les projets ayant l'égalité homme-femme comme thème transversal (DFAE Suisse 2018). La prise en compte de la question de l'égalité des sexes devrait donc être associée à d'autres efforts pour lutter contre la discrimination et les inégalités fondées sur le sexe, comme la remise en cause des normes sociales discriminatoires, notamment en s'attaquant avec la participation des hommes et des garçons aux déséquilibres de pouvoir qui peuvent entraver l'autonomisation économique des femmes.

Le Manuel relatif au marqueur de la politique d'aide à l'appui de l'égalité homme-femme établi par le CAD de I'OCDE fournit davantage d'informations sur la manière dont les membres devraient utiliser le marqueur. L'OCDE collabore avec les donateurs pour assurer la cohérence et la comparabilité des rapports.

Source: Adapté de DFAE Suisse (2018) et Réseau du CAD de l'OCDE sur l'égalité homme-femme (2016). 
En outre, cette augmentation s'appliquait non seulement en valeur absolue, mais aussi pour ce qui est de la part de I'Aide pour le commerce intégrant la question du genre, qui est passée de 9\% en moyenne en 2006-2007 à 24\% en moyenne en 2016-2017. La croissance globale s'explique par l'augmentation de la part de l'aide intégrant cette question par pratiquement tous les donateurs, ce qui correspond à la tendance générale à la hausse de la part de cette aide dans l'aide totale des membres du CAD - y compris pour les secteurs qui ne sont pas couverts par l'Aide pour le commerce, comme la santé et l'éducation. Plus particulièrement, outre le Japon, la Finlande a elle aussi régulièrement augmenté sa part de l'Aide pour le commerce intégrant la question du genre, la portant de 12\% en 2012-2013 à 43\% en 2016-2017, de même que l'Irlande, dont la part est passée de $47 \%$ à $86 \%$.

\section{Figure 9.3. Tendances de l'Aide pour le commerce intégrant la question du genre (en milliards d'USD, dollars constants de 2016)}

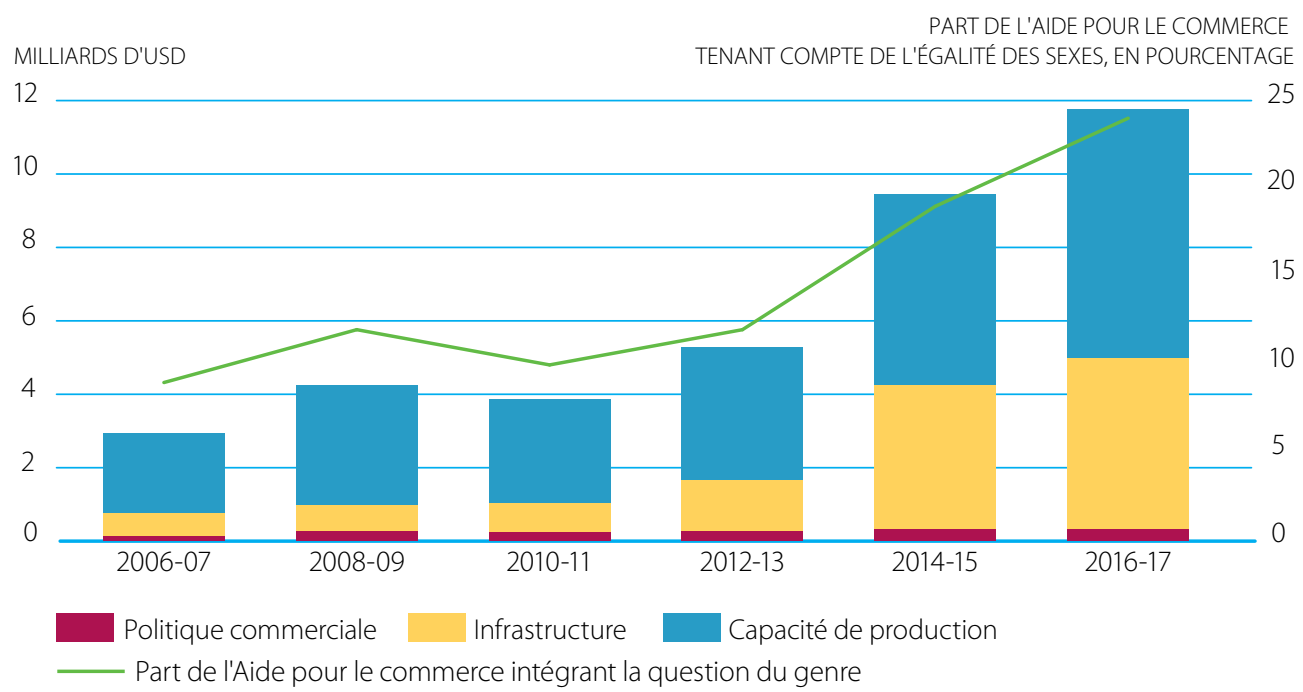

Note: APD et autres flux officiels. Membres du CAD seulement, en raison de la disponibilité des données.

Source: CAD-OCDE: base de données sur les activités d'aide (2019).

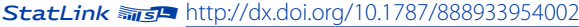

Dans I'Initiative Aide pour le commerce, les secteurs pertinents sont regroupés en trois grandes catégories: politique commerciale, infrastructure économique et capacité de production..$^{10}$ La répartition de l'Aide pour le commerce intégrant la question du genre dans ces trois catégories est restée la même au cours de la décennie, la catégorie détenant la plus grande part étant la capacité de production et celle détenant la plus petite part étant la politique commerciale. La part correspondant à la catégorie "infrastructure économique" a quant à elle été multipliée par sept, principalement en raison de l'augmentation du Japon, celle pour la catégorie "capacité de production" a été multipliée par trois, et celle pour la catégorie "politique commerciale" a seulement doublé en dix ans. La part de l'Aide pour le commerce intégrant la question du genre de la catégorie "politique commerciale" est faible parmi les trois autres catégories car la majorité des projets sont généralement des projets d'assistance technique peu coûteux. En revanche, dans la catégorie "infrastructure économique", qui comprend les transports, l'énergie et les communications, on a tendance à avoir des coûts de matériel informatique élevés. La catégorie "capacité de production" comprend un large éventail de secteurs, à savoir l'agriculture, la pêche, l'extraction minière, l'industrie, la finance et les affaires. 


\section{Répartition de l'Aide pour le commerce intégrant la question du genre}

Malgré la tendance croissante de l'Aide pour le commerce intégrant la question du genre, le taux de respect par les donateurs de leur engagement d'intégrer pleinement cette question dans cette aide reste faible. Comme cela a été mentionné plus haut, si le montant de l'Aide pour le commerce intégrant la question du genre a augmenté au cours de la dernière décennie, il ne représentait encore que $24 \%$ du total des engagements au titre de l'Aide pour le commerce en 2016-2017. En d'autres termes, 76\% de l'Aide pour le commerce n'intégrait pas la question du genre (56\% n'était pas orientée vers l'objectif et 20\% n'avait pas été examinée dans ce contexte). En termes de volume et de ventilation par secteur, les secteurs dans lesquels le montant de l'Aide pour le commerce intégrant la question du genre était le plus important en 2016-2017 étaient l'agriculture (environ 5,5 milliards d'USD, voir figure 9.4), puis les transports (5 milliards d'USD) et enfin l'énergie (3 milliards d'USD).

\section{Figure 9.4. Ventilation par secteur de l'Aide pour le commerce intégrant la question du genre pour 2016-2017 (en milliards d'USD, dollars constants de 2016)}

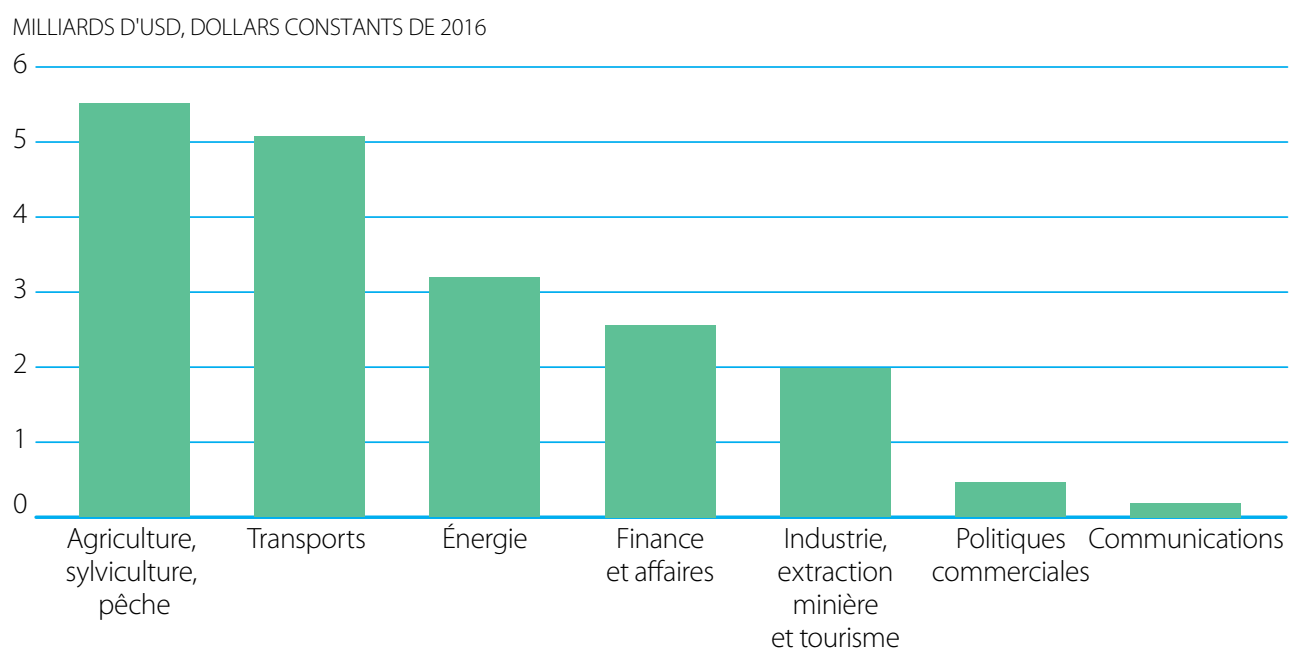

Note: Membres du CAD, BAsD, BERD, BID, Banque mondiale, OIT et PNUD.

Source: CAD-OCDE: base de données sur les activités d'aide (2019).)

StatLink 部 $\mathrm{http} / / \mathrm{dx}$.doi.org/10.1787/888933954021

Pour ce qui est de la part de l'aide intégrant la question du genre dans l'aide totale engagée pour les différents secteurs, c'est également celle de l'agriculture qui était la plus élevée, avec environ 47\% en 2016-2017 (voir figure 9.5). Venaient ensuite les politiques commerciales (25\%) et les transports (20\%). Il est possible que la part allouée aux politiques commerciales soit un peu plus importante que celle des autres secteurs du fait que les activités consistent souvent en cours de formation à l'intention des gouvernements partenaires auxquels participent des femmes fonctionnaires. De nombreuses études sur les politiques commerciales et les politiques en matière de transport ont également été réalisées pour examiner la question du genre dans ces domaines. Dans le secteur des transports - principalement routier - de nombreux projets ont consisté à faire participer les femmes en tant qu'intervenantes dans la planification ou en tant qu'ouvrières dans la construction.

D’autre part, malgré des montants totaux des engagements intégrant la question du genre relativement élevés, en proportion, seulement 14\% des engagements dans le secteur de l'énergie intégraient la question du genre. Le montant absolu et la part des engagements intégrant la question du genre étaient également faibles dans le secteur des communications." Par conséquent, la faiblesse des parts des montants de l'aide intégrant la question du genre dans nombre de ces secteurs d'Aide pour le commerce montre que la situation peut être améliorée. Toutefois, si l'on analyse la taille 
des projets, les résultats indiquent que ceux qui intègrent la question du genre dans des secteurs tels que l'énergie, l'extraction minière et l'industrie, la finance et les affaires sont en moyenne moins importants (c'est-à-dire de montants inférieurs) que les projets dans les mêmes secteurs qui n'intègrent pas la question du genre.12 Par conséquent, on pourrait examiner dans des études futures si les projets plus petits ont davantage tendance à cibler les femmes que les projets plus grands comptant plus de bénéficiaires. En outre, on pourrait également étudier comment mieux intégrer la question du genre dans des projets de plus grande envergure pour faire en sorte qu'ils n'aient pas d'effets négatifs sur les femmes et pour identifier des points de départ en vue de promouvoir l'autonomisation économique des femmes.

\section{Figure 9.5. Ventilation par secteur de la proportion de l'Aide pour le commerce intégrant la question du genre pour 2016-2017}

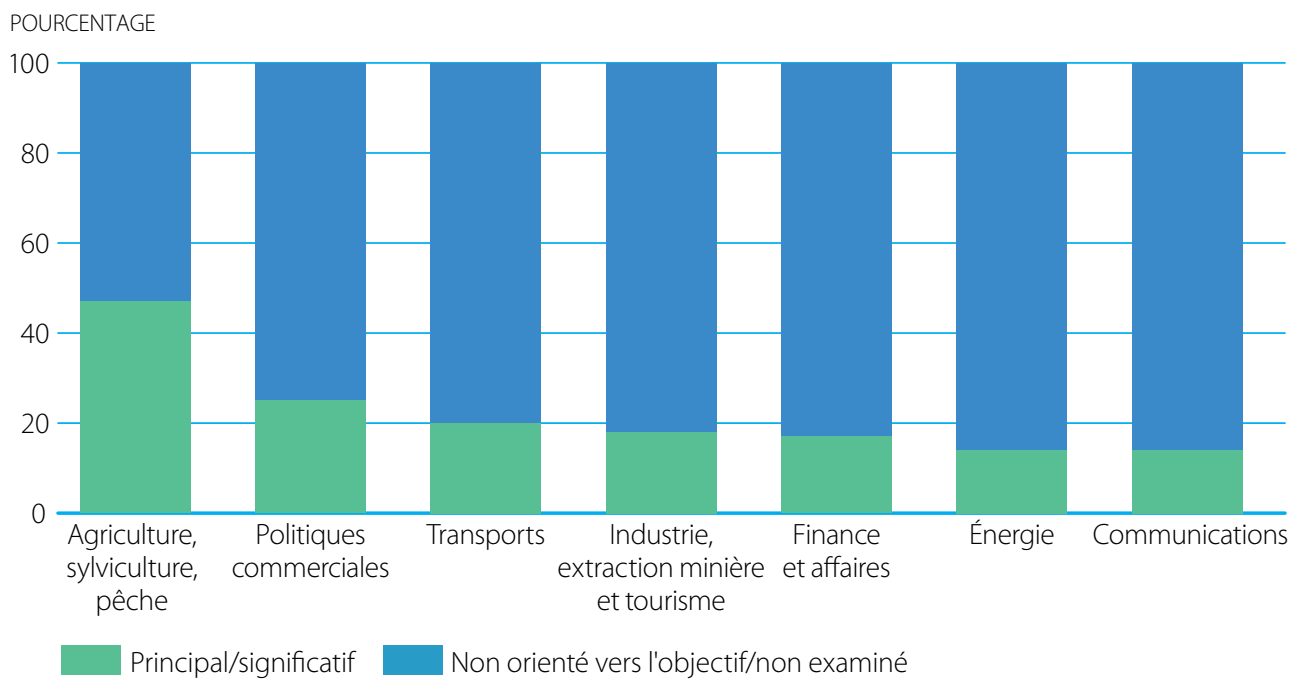

Note: Membres du CAD, BAsD, BERD, BID, Banque mondiale, OIT et PNUD.

Source: CAD-OCDE: base de données sur les activités d'aide (2019).

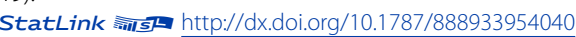

Une ventilation plus détaillée permet de voir les domaines spécifiques dans lesquels les donateurs ont activement intégré les perspectives de genre pour chaque secteur. C'était le cas par exemple des réformes agraires, des coopératives agricoles, de la vulgarisation agricole, des industries artisanales, des produits de l'artisanat, des PME, de la microfinance et du tourisme, où les femmes travaillent souvent déjà de façon informelle. Dans ces domaines, un niveau relativement élevé de soutien peut être accordé à l'autonomisation économique des femmes, car les donateurs peuvent cibler les femmes en tant que bénéficiaires. À titre d'exemple, les donateurs utilisent souvent la microfinance pour fournir une aide aux femmes du secteur informel qui n'ont pas accès aux prêts ou aux mécanismes d'épargne des institutions financières formelles.

Les cas d'expérience présentés dans le cadre de l'Initiative Aide pour le commerce décrivent de nombreux projets, tels que ceux menés par le Centre du commerce international (ITC), visant à intégrer les femmes dans les marchés d'exportation et les chaînes de valeur, notamment par le biais du commerce électronique (OCDE-OMC 2011, 2017). Par exemple, certaines entreprises ont servi d'intermédiaires pour aider des groupes de femmes artisans - par exemple des couturières - à pénétrer le marché. Un autre projet de I'TTC visait à dispenser à des femmes issues de communautés rurales une formation aux techniques de marketing numérique à l'aide de téléphones mobiles. D'autre part, des domaines tels que l'énergie et les communications, dans lesquels l'aide tient peu compte de la question du genre, sont souvent considérés comme étant "neutres du point de vue du genre" et ne nécessitant donc pas l'application d'une 
perspective de genre. Il en est ainsi malgré les preuves que l'amélioration de l'accès des femmes à une énergie fiable et d'un coût abordable peut, par exemple, réduire leur charge de travail non rémunérée et leur permettre de dégager du temps pour pouvoir exercer des activités rémunérées (Banque mondiale 2012).

L'exercice de S\&E de 2019 a montré que, lorsqu'on avait demandé aux donateurs et aux pays partenaires de sélectionner les domaines spécifiques dans lesquels ils considéraient que l'Aide pour le commerce favorisait le plus l'autonomisation économique des femmes, leurs réponses s'étaient orientées vers des secteurs similaires. Un grand nombre d'entre eux avaient cité l'éducation et la formation dans le domaine du commerce, l'agriculture, les affaires, le secteur bancaire, la politique commerciale et la facilitation des échanges (voir la figure 9.6). Plusieurs pays partenaires avaient évoqué des domaines plus précis dans lesquels ils estimaient que l'Aide pour le commerce pouvait contribuer à l'autonomisation économique des femmes (encadré 9.3). Par ailleurs, peu de donateurs et de pays partenaires avaient considéré que la foresterie, les ressources minérales, les accords commerciaux régionaux, l'énergie et les communications étaient les domaines qui favorisaient le mieux l'autonomisation économique des femmes.

\section{Encadré 9.3. Point de vue}

Certains pays partenaires considèrent que I'Aide pour le commerce peut contribuer à l'autonomisation économique des femmes par les mesures suivantes:

\section{Cabo Verde}

— apprentissage des conditions et procédures d'importation et d'exportation;

renforcement des compétences dans le domaine numérique et dans le domaine des TIC;

amélioration des compétences en langues étrangères pour favoriser le commerce mondial; et

amélioration des infrastructures d'approvisionnement en eau.

\section{Maurice}

définition d'un cadre cohérent pour renforcer la capacité de production des MPME; et

élaboration de programmes de mentorat et de conseil pour connecter les MPME à des marchés inexploités et potentiels au niveau international.

Source: Adapté de OCDE-OMC (2019), exercice de suivi de l'Aide pour le commerce 2019 (questionnaires).

Figure 9.6. Domaines de l'Aide pour le commerce qui, selon les donateurs et les pays partenaires, peuvent le mieux contribuer à l'autonomisation économique des femmes

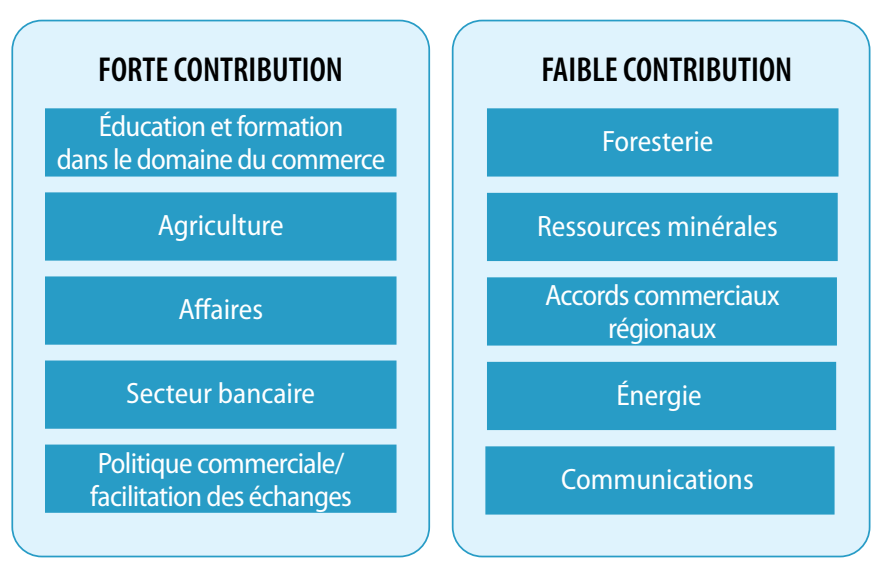

Source: OCDE-OMC (2019), Exercice de suivi de l'Aide pour le commerce 2019 (questionnaires).

StatLink 解象 $\mathrm{http}: / / \mathrm{dx}$.doi.org/10.1787/888933954059 
En termes de niveaux de revenu, la catégorie de pays qui a reçu la plus grande part de l'Aide pour le commerce intégrant la question du genre en 2016-2017 était les pays à revenu intermédiaire de la tranche inférieure (PRITI), suivis des pays les moins avancés (PMA) et enfin des pays à revenu intermédiaire de la tranche supérieure (PRITS) (voir figure 9.7). Toutefois, la part de l'Aide pour le commerce intégrant la question du genre dans le volume total de l'aide reçue par les PMA était proportionnellement plus importante, tandis que celle des PRITS était proportionnellement moins importante. Cela s'explique par le fait que les PMA détenaient une part relativement élevée du secteur de l'agriculture - le secteur qui compte la plus grande part d'Aide pour le commerce intégrant la question du genre - alors que les PRITS détenaient une part relativement élevée du secteur des infrastructures (transport et énergie), secteur dans lequel il est généralement peu tenu compte de la question du genre. Cela se reflète également dans la répartition par région ${ }^{13}$, qui montre que la part de l'Aide pour le commerce intégrant la question du genre dans le volume total de l'aide reçue par l'Afrique est proportionnellement plus importante, tandis que celles de l'Amérique latine et de l'Europe est moins importante. Cela s'explique par le nombre élevé de projets agricoles dans la première région et par le nombre élevé de projets dans les infrastructures, la finance et les affaires dans les deux autres régions.

Figure 9.7. Répartition du financement public du développement (FPD) intégrant la question du genre pour 2016-2017, par groupe de revenu et par région

\section{RÉPARTITION PAR GROUPE DE REVENU}

Répartition du FPD intégrant la question du genre

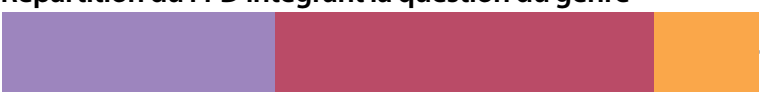

Répartition du FPD

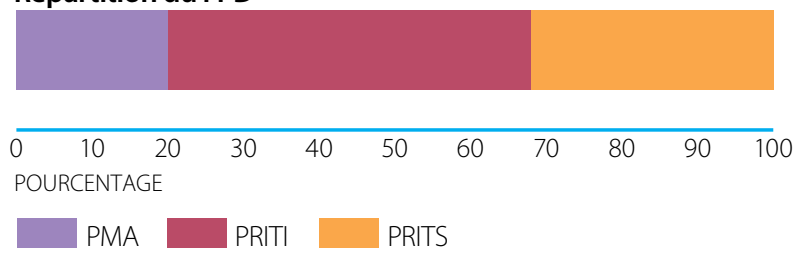

\section{RÉPARTITION PAR RÉGION}

Répartition du FPD intégrant la question du genre

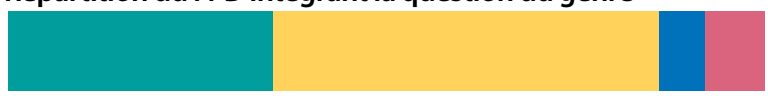

Répartition du FPD

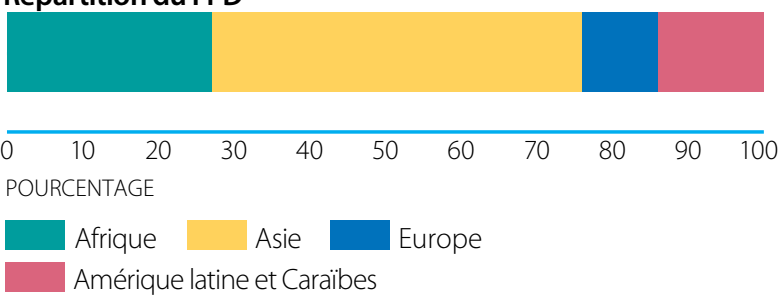

Note: Membres du CAD, BAsD, BERD, BID, Banque mondiale, OIT et PNUD.

Source: CAD-OCDE: base de données sur les activités d'aide (2019).

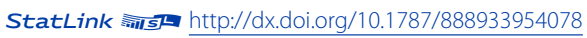

En ce qui concerne l'Aide pour le commerce intégrant la question du genre fournie par les donateurs bilatéraux en 2016-2017, les donateurs les plus importants en valeur absolue étaient le Japon, les institutions de l'UE, I'Allemagne, les États-Unis et le Royaume-Uni, qui étaient également d'importants donateurs d'Aide pour le commerce. Cependant, la figure 9.8 montre que l'Irlande était le pays dont la part de l'Aide pour le commerce intégrant la question du genre était la plus élevée (près de 90\%), suivie par le Canada, l'Espagne, les Pays-Bas, la Suède et le Royaume-Uni. En outre, les parts de l'Aide pour le commerce de l'Espagne, de la Suède, de l'Australie et des États-Unis ayant comme objectif principal l'égalité des sexes et l'autonomisation des femmes étaient relativement importantes. Parmi les donateurs dont les parts étaient élevées, l'Irlande et le Canada mettaient fortement l'accent sur l'agriculture, un secteur dans lequel les niveaux d'aide intégrant la question du genre sont globalement plus élevés. 


\section{Figure 9.8. Part moyenne de l'Aide pour le commerce intégrant la question du genre pour 2016-2017}

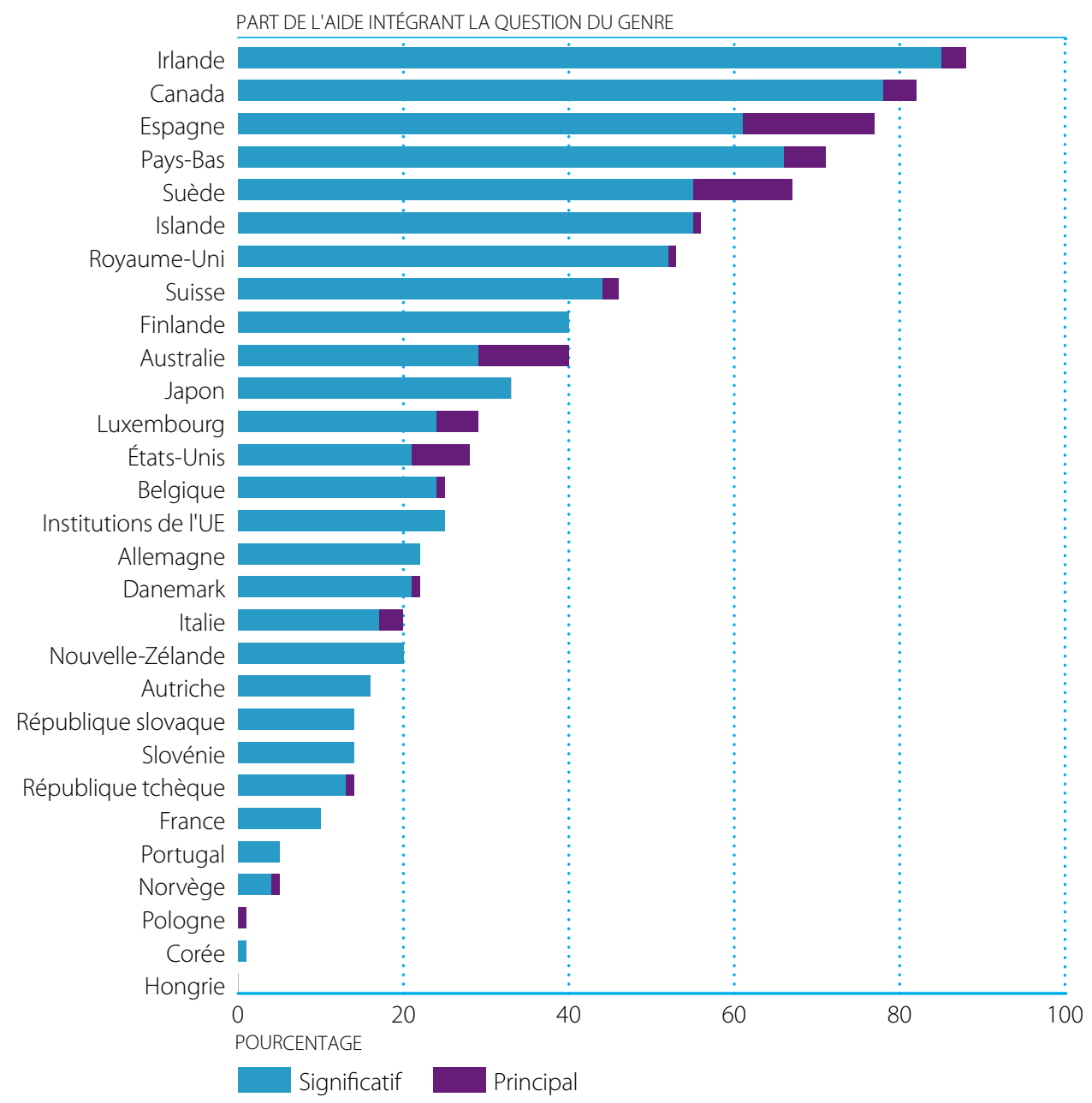

Note: Membres du CAD seulement.

Source: CAD-OCDE: base de données sur les activités d'aide (2019).

StatLink तiाs http://dx.doi.org/10.1787/888933954097

En revanche, les parts de l'Aide pour le commerce intégrant la question du genre de la Hongrie, de la Corée, de la Pologne, de la Norvège, du Portugal, de la France, de la République tchèque, de la Slovénie, de l'Autriche, de la Nouvelle-Zélande et de l'Italie représentaient moins de 20\% du volume total de leur Aide pour le commerce respective. II est possible que certains de ces donateurs qui sont relativement nouveaux n'aient pas accordé la priorité aux projets intégrant la question du genre ou qu'ils connaissent mal l'approche à adopter concernant ces projets, malgré l'importance qu'ils accordent à l'agriculture. La France, l'Italie et la Norvège, qui soutiennent principalement les secteurs des infrastructures tels que l'énergie et les transports, ont enregistré des niveaux moins élevés d'aide intégrant la question du genre. II en est ainsi malgré le fait que, par exemple, la France dispose d'un cadre et d'indicateurs pour mesurer les progrès accomplis dans l'intégration de la dimension de genre dans l'Aide pour le commerce. 
Encadré 9.4. L'autonomisation économique des femmes dans le cadre de l'Aide pour le commerce de l'Australie et de I'UE

\section{Australie}

L'autonomisation économique des femmes fait partie des priorités de la stratégie de 2015 de l'Australie en matière d'investissements au titre de l'Aide pour le commerce (Strategy for Australia's Aid for Trade Investments). Selon cette stratégie, la question de l'autonomisation des femmes doit être intégrée dans tous les investissements, car l'Aide pour le commerce peut aider les femmes à participer pleinement et efficacement au commerce des marchandises dans des secteurs comme l'agriculture et la pêche, ainsi que les services. La stratégie de 2016 de l'Australie pour l'égalité des sexes et l'autonomisation des femmes (Gender Equality and Women's Empowerment Strategy) accorde elle aussi la priorité à l'autonomisation économique des femmes et précise les domaines dans lesquels l'Aide pour le commerce peut profiter aux femmes. Ces stratégies sont axées sur les éléments suivants:

Amélioration des salaires, des conditions de travail et de la sécurité, et élimination de la discrimination dans les secteurs où les travailleurs et les commerçants sont principalement des femmes

- Compétences professionnelles et commerciales, en particulier pour les personnes défavorisées

- Chaînes de valeur mondiales

Élimination des obstacles rencontrés par les femmes entrepreneurs, y compris l'accès au financement

- Ressources et innovations pour améliorer la productivité et les revenus agricoles

- Promotion de la femme dans le secteur privé

- Environnement économique et juridique des femmes entrepreneurs

- Investissements dans l'infrastructure pour faciliter l'accès des femmes aux possibilités économiques et au commerce

\section{UE}

La Stratégie conjointe de I'UE de 2007 en faveur de l'Aide pour le commerce accorde une importance particulière à l'émancipation économique des femmes. En 2017, I'UE a étendu son champ d'action, en particulier pour soutenir l'accès des femmes à un travail décent, aux services financiers, à la terre et à l'entrepreneuriat. La stratégie souligne la nécessité des éléments suivants:

- Intégration des questions de genre dans les évaluations des besoins en matière de commerce, en particulier en encourageant la participation active des organisations communautaires concernées

- Participation d'associations de petites et moyennes entreprises, de petits exploitants agricoles et de groupes de femmes à la conception et à la mise en cuvre de programmes d'Aide pour le commerce

- Élaboration d'indicateurs qualitatifs et quantitatifs sur le genre à des fins de suivi et d'évaluation

- Accès au financement, aux services de conseil, aux réseaux de femmes entrepreneurs et à la technologie numérique

- Conduite systématique d'une analyse fondée sur le genre pour chaque projet d'Aide pour le commerce

Dans son premier rapport de suivi publié en décembre 2018, I'UE illustre de nombreuses bonnes pratiques qui montrent que les institutions de l'UE et des États membres ont intégré la dimension de genre dans l'Aide pour le commerce et que cela a eu des effets positifs sur l'autonomisation économique des femmes. Le rapport souligne également les lacunes qui subsistent dans la prise en compte de la dimension de genre dans les projets de l'Aide pour le commerce. Par exemple, 38\% seulement des 68 délégations de l'UE ont déclaré que les projets de l'Aide pour le commerce faisaient systématiquement l'objet d'analyses fondées sur le genre et promouvaient l'autonomisation économique des femmes.

Sources: Adapté de Ministère des affaires étrangères et du commerce de l'Australie $(2015,2016,2017)$ et Union européenne $(2007$, 2017, 2018). 


\section{STRATÉGIES ET LIGNES DIRECTRICES POUR L'INTÉGRATION DES PERSPECTIVES DE GENRE DANS L'AIDE POUR LE COMMERCE}

Étant donné que l'Aide pour le commerce englobe un large éventail de secteurs - agriculture, transports, énergie, industrie, etc. - seuls quelques donateurs, comme l'Australie et l'UE, disposent d'une stratégie spécifique visant à intégrer les perspectives de genre dans I'Aide pour le commerce" de manière globale (voir encadré 9.4). D'autres donateurs ont intégré ces perspectives dans leurs activités de coopération au développement liée au commerce ou en ont fait une priorité transversale. Par exemple, le cadre politique de la Suède pour la coopération au développement vise à faire en sorte que tant les hommes que les femmes tirent parti du commerce, l'un de ses principaux domaines prioritaires. En outre, d'autres donateurs ont élaboré des stratégies ou des plans d'action globaux pour soutenir l'autonomisation économique des femmes dans le cadre de priorités thématiques telles que la promotion des droits économiques et sociaux des femmes, la participation du secteur privé à l'autonomisation économique des femmes ou l'augmentation de leur taux d'activité. Ces mesures sont principalement mises en œuvre dans les domaines de l'agriculture, du développement rural, des PME et de l'accès au financement.

À titre d'exemple, dans l'exercice de S\&E de 2019, le Canada a fait référence à sa Politique d'aide internationale féministe, qui vise à encourager les femmes et les filles à développer leurs compétences, à accéder aux postes de décision et à contribuer à la croissance économique de leurs communautés, notamment en soutenant la formation technique et professionnelle et l'entrepreneuriat. En outre, certaines institutions de financement du développement (IFD) tentent d'axer leur soutien au secteur privé sur les femmes. Un exemple en est le Défi 2X lancé par les IFD des pays du G-7 qui se sont engagées à mobiliser d'ici à 20203 milliards d'USD d'investissements en faveur des femmes. Dans ce contexte, elles ont défini des lignes directrices et des critères relatifs au genre pour la sélection des projets (voir encadré 9.5).

En outre, quelques donateurs disposent de lignes directrices concernant l'aide intégrant la question du genre dans des secteurs spécifiques tels que l'agriculture, les PME, la microfinance, le tourisme, les industries extractives, l'énergie, les transports et les communications. II s'agit, entre autres, de la Nouvelle-Zélande, de la Banque asiatique de développement (BAsD), de la Banque africaine de développement (BAD), de la Banque interaméricaine de développement (BID), de la Banque mondiale, de I'Organisation des Nations Unies pour le développement industriel (ONUDI), du Programme des Nations Unies pour le développement (PNUD) (voir encadré 9.6). Nombre de ces donateurs soulignent la nécessité, entre autres, de recueillir des données ventilées par sexe, d'effectuer des analyses ex ante fondées sur le genre et d'assurer le suivi et l'évaluation des résultats et de l'impact sur les femmes. S'agissant de la mise en œuvre, la plupart des donateurs déclarent appliquer une "double approche" en intégrant l'égalité des sexes dans différents secteurs et en axant spécifiquement la programmation sur l'égalité des sexes et l'autonomisation des femmes, conformément aux Lignes directrices du CAD pour l'égalité homme-femme et le renforcement du pouvoir des femmes (CAD-OCDE 1999).

Sur un plan plus collectif, en 2004, le GENDERNET a élaboré un guide sur l'importance du genre dans les infrastructures pour l'énergie, les transports, l'eau et l'assainissement (Why Gender Matters in Infrastructure, OECD CAD, 2004). Ce guide présente des mesures générales telles que l'intégration d'objectifs tenant compte de la question de l'égalité des sexes dans la conception des projets; l'utilisation de l'analyse selon le genre et de données ventilées par sexe pour élaborer des stratégies en faveur de l'égalité des sexes tout au long des projets; la participation des femmes au moyen de la consultation et de la prise de décisions; et le suivi des objectifs tenant compte de la question de l'égalité des sexes des projets.

Plus récemment, I'OCDE, avec la participation de certains membres du GENDERNET, a élaboré des lignes directrices à l'intention des donateurs et des gouvernements des pays partenaires ${ }^{14}$ pour soutenir l'autonomisation économique des femmes, notamment dans le domaine des infrastructures, dans le but précis de résoudre le problème de la part disproportionnée des tâches domestiques et de soins non rémunérées accomplies par des femmes (OCDE 2019a). 


\section{Encadré 9.5. Application d'une perspective de genre pour appuyer l'investissement privé par les institutions de financement du développement du G-7}

Les IFD des pays du G-7 ont lancé le Défi 2X lors du Sommet du G-7 de 2018 qui s'est tenu à Charlevoix, au Canada. Le Défi $2 X$ engage les IFD des pays du G-7 à mobiliser 3 milliards d'USD avec des partenaires du secteur privé pour investir dans les femmes en fournissant des prêts, des fonds propres, des garanties et une assurance risques politiques.

Un projet est admissible au Défi 2X s'il remplit au moins l'un des critères suivants:

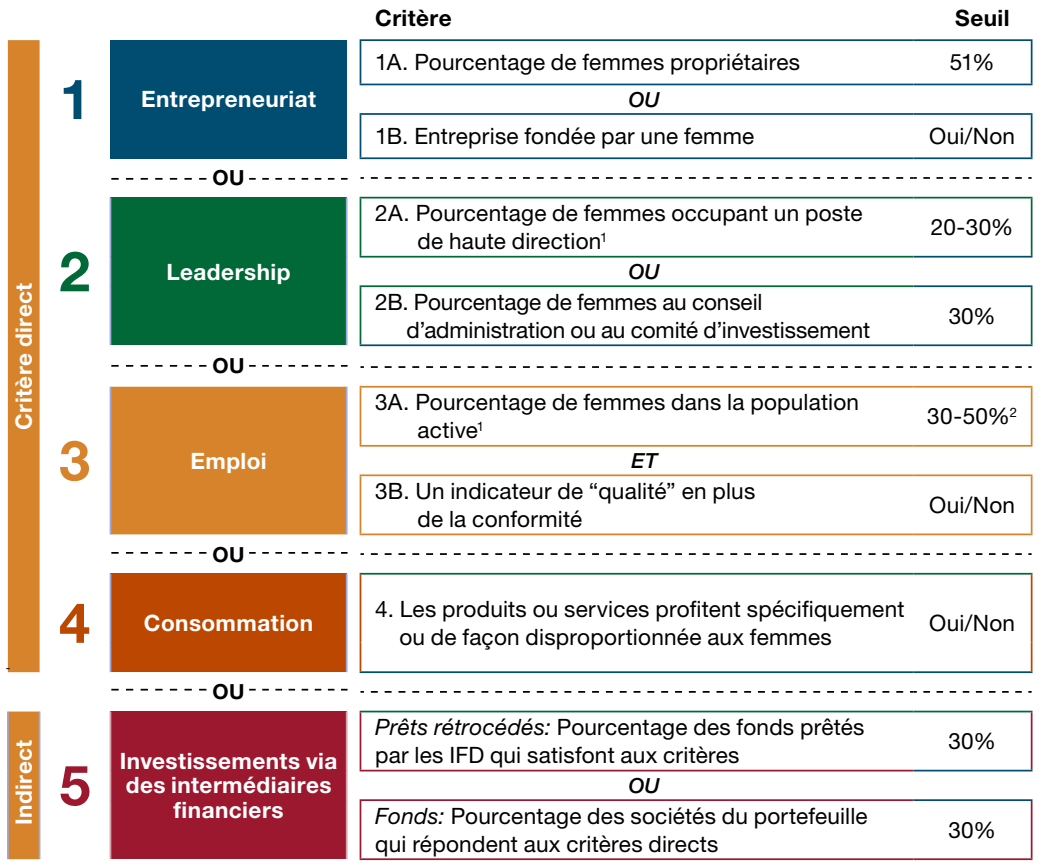

Seuils par secteur

\begin{tabular}{|c|c|c|}
\hline \multicolumn{3}{|c|}{$\begin{array}{l}\text { 2.A. Femmes occupant un poste de haute } \\
\text { direction* }\end{array}$} \\
\hline Groupe & Secteur & $\%$ \\
\hline Faible & $\begin{array}{l}\text { Infrastructures, énergie, } \\
\text { télécommunications }\end{array}$ & $20 \%$ \\
\hline Moyen & $\begin{array}{l}\text { Services financiers, industrie } \\
\text { manufacturière, agro- } \\
\text { industrie et alimentation, } \\
\text { services professionnels, } \\
\text { services aux consommateurs }\end{array}$ & $25 \%$ \\
\hline Élevé & Soins de santé, éducation & $30 \%$ \\
\hline \multicolumn{3}{|c|}{ 3.A. Femmes dans la population active* } \\
\hline Groupe & Secteur & $\%$ \\
\hline Faible & $\begin{array}{l}\text { Infrastructures, énergie, } \\
\text { télécommunications }\end{array}$ & $30 \%$ \\
\hline Moyen & $\begin{array}{l}\text { Services financiers } \\
\text { intermédiaires, industrie } \\
\text { (lourde), agro-industrie } \\
\text { et alimentation, services } \\
\text { professionnels }\end{array}$ & $40 \%$ \\
\hline Élevé & $\begin{array}{l}\text { Soins de santé, } \\
\text { éducation, services aux } \\
\text { consommateurs, industrie } \\
\text { (légère) }\end{array}$ & $50 \%$ \\
\hline
\end{tabular}

Le Défi $2 X$ promeut la transparence et la responsabilité. Toutes les transactions admissibles à un financement seront publiées sur le site Web du Défi 2 ( (www.2XChallenge.org), avec des informations détaillées sur les critères d'admissibilité, le secteur concerné et les engagements en capital.

Source: Adapté de OPIC $(2018,2019)$ et site Web de 2X Challenge, https://www.2xchallenge.org/

Elle souligne également la nécessité de proposer des mesures de sauvegarde appropriées pour assurer la sécurité des femmes, en particulier dans les grands projets d'infrastructure, d'offrir des services de garde d'enfants de qualité pour permettre aux femmes d'exercer une activité rémunérée, de prendre en compte les tâches de soins non rémunérées dans les évaluations ou diagnostics axés sur le genre et de s'attacher à réduire les disparités entre hommes et femmes dans l'emploi dans les secteurs des infrastructures. Hormis ceux mentionnés ci-dessus, cependant, peu de donateurs disposent de lignes directrices spécifiques sur la manière d'intégrer les perspectives de genre dans plusieurs secteurs clés de l'Aide pour le commerce tels que les transports, l'énergie, les communications, la finance et les affaires, ou l'industrie. 
Encadré 9.6. Lignes directrices sur le commerce, les infrastructures, les industries extractives et le tourisme

Guide sur l'intégration de la question du genre dans les projets de renforcement des capacités dans le domaine du commerce, ONUDI, 2015

- Veiller à ce que les femmes et les hommes tirent les mêmes avantages des projets de renforcement des capacités dans le domaine du commerce aux différentes étapes de ces projets (formulation, mise en œuvre, suivi et évaluation), au moyen de l'analyse selon le genre et de l'identification de parties prenantes et de partenaires potentiels.

- Les indicateurs de la capacité commerciale intégrant la question du genre comprennent: le rapport entre le revenu des femmes et celui des hommes dans des segments comparables de la chaîne de valeur; le pourcentage de femmes occupant des postes mieux rémunérés dans tous les segments de la chaîne de valeur; la proportion de femmes s'inscrivant à une formation au renforcement des capacités commerciales par rapport aux hommes; et le nombre de contrats d'achat conclus à la suite de la certification d'une entreprise appartenant à des femmes.

\section{Intégration de la question du genre dans les infrastructures, BAD, 2009}

- Indicateurs de conception et indicateurs portant sur les intrants: prise en compte des contraintes en matière d'infrastructures qui pèsent sur les rôles économique, domestique, communautaire et de gestion des femmes.

Indicateurs de mise en œuvre: planification et mise en œuvre de projets participatifs avec les femmes dans les communautés.

- Indicateurs de résultats: augmentation du nombre de femmes participant à des activités de projet telles que la construction et l'entretien des routes, augmentation de la proportion de femmes ayant accès à l'emploi et à des activités génératrices de revenus.

Indicateurs d'impact: augmentation du nombre de femmes entrepreneurs dans les activités routières.

\section{Boîte à outils interne pour l'intégration de la question du genre dans les activités d'infrastructures, BID}

La BID dispose d'une boîte à outils interne en ligne pour l'intégration de la question du genre dans les activités d'infrastructures. Cette boîte à outils est en train d'être intégrée dans un site Web en accès libre. Elle comprend des guides sur la prise en compte des perspectives de genre qui incluent des exemples de références pour la conception de projets, 150 activités intégrant la question du genre et 600 indicateurs de produits et de résultats.

\section{Intégration de la question du genre dans les industries extractives, Banque mondiale, 2009}

- Indicateurs de performance: capacité juridique des femmes de posséder et d'exploiter des mines, réglementations favorables aux femmes dans le secteur bancaire et en matière de propriété foncière; et activités de sensibilisation à la question du genre.

Indicateurs d'impact: part du programme communautaire des entreprises de l'industrie extractive consacrée à des projets liés aux femmes, nombre de femmes employées et écart salarial entre les hommes et les femmes occupant le même emploi dans l'entreprise.

\section{Égalité des sexes dans le tourisme, Nouvelle-Zélande, 2016}

- Assurer la participation des femmes aux consultations, à la gouvernance, à l'élaboration des politiques et à la planification du tourisme par les autorités locales et renforcer les capacités des PME à associer les femmes aux consultations et à la prise de décisions.

- Favoriser les possibilités économiques pour les femmes dans le secteur des services (restauration, services de guide touristique, transport, hébergement et approvisionnement en nourriture). Réduire au minimum les stéréotypes associés aux femmes concernant les travaux de ménage, vaisselle et services de chambres.

- Promouvoir les bourses d'études et la formation dans les domaines de l'accueil, du marketing, du recrutement, de la gestion et des services financiers (assurances, opérations bancaires et prêts) pour les femmes.

- Veiller à ce que les femmes soient en mesure de négocier leurs conditions d'emploi, y compris les heures de travail, en fonction de leurs responsabilités familiales et communautaires.

Sources: Adapté de BAD (2009), Banque mondiale (2009), Ministère des affaires étrangères et du commerce de la Nouvelle-Zélande (2012) et ONUDI (2015). 


\title{
Exemples d'intégration des perspectives de genre dans les domaines de l'Aide pour le commerce
}

Cette section présente quelques exemples parlants ${ }^{15}$ de donateurs qui intègrent des perspectives de genre dans différents secteurs de l'Aide pour le commerce. Ces exemples concernent des domaines dans lesquels la part de l'aide intégrant la question du genre est relativement élevée, tels que l'agriculture, les PME, le tourisme et l'habillement, ainsi que des domaines dans lesquels cette part est relativement faible, tels que le commerce, les infrastructures, la finance et les affaires et l'industrie. Les donateurs qui sont confrontés à des difficultés dans des domaines similaires pourraient s'inspirer de ces exemples. Dans la plupart des projets décrits ci-après, l'égalité des sexes et l'autonomisation des femmes ont été considérées comme des objectifs significatifs (valeur 1) et non comme des objectifs principaux (valeur 2) (voir OCDE CAD 2018 pour la répartition).

\section{Politique commerciale}

La Suède et la CNUCED ont mis au point une boîte à outils sur le commerce et le genre qui fournit un cadre et une méthodologie pour évaluer l'impact sur les femmes des réformes commerciales, par exemple la mise en œuvre d'un accord commercial préférentiel. La méthodologie repose sur quatre éléments: l'évaluation des inégalités entre les sexes dans le contexte économique du pays; l'analyse quantitative des conséquences attendues de la réforme commerciale sur l'économie et les femmes; des indicateurs de suivi intégrant la question du genre; et un indice relatif au commerce et au genre permettant d'évaluer l'impact de l'ouverture commerciale sur le genre. La méthodologie a été appliquée dans le cadre de l'accord de partenariat économique entre I'UE et la Communauté de l'Afrique de l'Est pour évaluer l'impact sur les femmes kenyanes des réformes commerciales dans différents secteurs.

\begin{abstract}
L'Australie et la Banque mondiale s'efforcent d'améliorer les possibilités économiques des femmes et la connectivité transfrontières par le biais du Programme régional de facilitation des échanges en Asie du Sud (SARTFP), notamment au Bangladesh, au Bhoutan, en Inde et au Népal. Le SARTFP se fonde sur la reconnaissance du fait que les femmes et les hommes peuvent être affectés différemment par la facilitation des échanges, d'où la nécessité de collecter des données ventilées par sexe et d'effectuer des recherches, analyses, activités de suivi et évaluations solides dans ce domaine en tenant compte de la question du genre. Le SARTFP a permis l'adoption par les gouvernements de politiques de facilitation des échanges tenant compte de la problématique hommes femmes dans des domaines tels que les marchés transfrontières, l'accès aux installations, le transport fluvial et la politique touristique.
\end{abstract}

La Suède a également financé une étude visant à analyser l'incidence sur l'égalité hommes-femmes du futur accord d'association entre la Géorgie, Moldova et l'Ukraine et l'UE. Le rapport de l'étude souligne l'impact négatif potentiel de la concurrence à l'importation due à l'accord commercial préférentiel dans les domaines qui emploient de nombreuses femmes, tels que certains secteurs agricoles, l'industrie alimentaire et la fabrication de produits électroniques. En outre, il recense des opportunités pour les femmes dans d'autres domaines tels que le textile, I'habillement et divers services. L'étude conclut que, pour que les femmes puissent tirer parti des secteurs à plus forte intensité de capital, comme les services financiers ou les services liés aux TIC, il faudrait leur offrir davantage de possibilités d'acquérir les compétences nécessaires.

Les cas d'expérience présentés dans le cadre des exercices de S\&E font référence à de nombreux projets de recherche sur le commerce et les femmes (OCDE-OMC 2011, 2017). Par exemple, I'USAID a évalué les contraintes et les opportunités associées au commerce transfrontières entre le Malawi et le Botswana. L'étude a révélé que les femmes manquaient généralement d'information sur les procédures aux frontières liées au commerce, qu'elles devaient payer des coûts de transaction plus élevés et qu'elles avaient un accès limité aux transports. Elle montre également que les femmes sont exposées au harcèlement et à différentes formes de violence sexiste, y compris des relations sexuelles sous contrainte, souvent exercée par des agents des douanes, lorsqu'elles doivent passer la nuit aux frontières. 
Dans le cadre du projet de réforme et de modernisation des douanes de l'Organisation mondiale des douanes $(\mathrm{OMD})$ dans la région de l'Afrique de l'Est et de l'Afrique australe, la Finlande a financé, avec la participation du Kenya, de l'Eswatini, de l'Afrique du Sud, du Rwanda, de I'Ouganda, du Malawi, du Zimbabwe, de Maurice et des Seychelles, des ateliers sur l'intégration de la question du genre dans les procédures en douane à l'intention des agents des douanes. L'OMD a lancé un outil d'évaluation organisationnelle en matière d'égalité entre les sexes, qui aide les administrations à évaluer leurs propres politiques, procédures et pratiques en matière d'égalité des sexes. En outre, un module d'apprentissage en ligne a été mis au point pour mieux faire connaître les moyens de promouvoir l'égalité des sexes dans les procédures douanières.

Le Canada et les Pays-Bas ont financé l'initiative Trade Mark East Africa (TMEA) en vue d'atténuer les contraintes qui limitent la participation des femmes commerçantes d'Afrique de l'Est aux activités économiques et au commerce transfrontières, par exemple en organisant des formations de sensibilisation à la question de l'égalité des sexes à l'intention des douaniers dans 12 postes frontière. D'autres activités ont été menées avec les objectifs suivants: création de conditions favorables par la simplification, la traduction et la diffusion de la documentation sur les prescriptions en matière de commerce pour les petits commerçants, qui sont pour la plupart des femmes; adoption de chartes commerciales transfrontières intégrant la question du genre; création de coopératives et de plates-formes d'accès au marché pour les femmes commerçantes; élaboration d'un mécanisme de signalement pour les cas de violence faite aux femmes; collecte de données ventilées par sexe; et conduite de recherches fondées sur des éléments factuels concernant des problèmes affectant les femmes commerçantes. L'une des activités avait pour but d'augmenter de 30\% l'utilisation des circuits commerciaux formels par les femmes commerçantes ciblées afin d'augmenter leurs revenus de 10\%.

Dans le domaine de la facilitation deséchanges, la Banque mondiale afourni un appuià la République démocratique populaire lao en vue de simplifier la réglementation commerciale, de faciliter le commerce et d'améliorer la compétitivité des entreprises. Plus précisément, elle a appuyé la prestation de services consultatifs gratuits aux entreprises, y compris des entreprises dirigées par des femmes, et l'introduction d'ordinateurs dans les bureaux des provinces pour faciliter la présentation des documents et leur enregistrement. Les résultats doivent être mesurés par l'augmentation du nombre de licences d'exploitation dans les secteurs d'intérêt pour les femmes ${ }^{16}$ et la diminution du nombre de procédures pour les entreprises qui ont été créées par des femmes. En trois ans et demi, le projet a dépassé son objectif et atteint 34\% des entreprises appartenant à des femmes.

\section{Infrastructure économique}

Dans le secteur des transports, la BID a encouragé l'emploi de femmes dans les travaux impliquant l'utilisation de machines lourdes pour la construction de routes en Amérique latine. Par exemple, en Bolivie, au Nicaragua et au Paraguay, les femmes employées dans des entreprises de construction et d'entretien des routes ont bénéficié d'une aide sous la forme de formations et de programmes de stages visant à développer leurs capacités techniques. Le projet prévoyait une évaluation fondée sur le genre de la demande de personnel qualifié sur le marché; la prise en compte des besoins spécifiques des femmes en termes de moyens de subsistance et de compétences afin d'accroître leur employabilité dans le secteur; et l'établissement de liens avec les opérations de prêt de la BID dans le domaine des transports pour obtenir le soutien des homologues gouvernementaux et des communautés locales pendant la mise en œuvre. L'un des résultats montre que $57 \%$ des femmes formées en Bolivie ont obtenu des résultats très élevés contre seulement $5 \%$ des hommes formés.

S'agissant du transport aérien, la BAsD a encouragé l'emploi de femmes dans les travaux de gestion et d'ingénierie visant à moderniser les aéroports et les marchés connexes en Papouasie-Nouvelle-Guinée. Elle a introduit une disposition relative à la diligence raisonnable afin d'identifier les mesures en faveur de l'égalité des sexes et d'assurer la participation des femmes au développement des compétences et à la conception des aéroports. Les résultats de ces mesures seront examinés dans les rapports d'activité et le rapport d'achèvement du projet. 
Au Nicaragua, le Danemark a appuyé un projet de construction et d'entretien d'infrastructures routières rurales visant à améliorer l'accès aux zones rurales. Des femmes ont participé à la conception et aux travaux du projet en tant que membres du comité sur les routes; elles ont représenté 30\% des personnes employées, dépassant ainsi l'objectif de 20\%. L'évaluation souligne que les revenus ainsi perçus par les femmes leur ont permis d'investir dans leur potager pour cultiver des légumes et produire de la volaille et du porc pour la vente.

Le Royaume-Uni a financé un programme de recherche sur l'énergie durable, l'accès à l'énergie et l'égalité des sexes, qui comprenait plusieurs projets de recherche axés notamment sur la dimension de genre dans l'économie politique de la dynamique du secteur de l'énergie, la réforme des subventions en faveur de l'égalité des sexes et en faveur des combustibles fossiles, et la constitution d'une base de données factuelles pour l'autonomisation des femmes et l'entrepreneuriat féminin afin d'améliorer l'efficacité des opérations dans le domaine de l'énergie. Les résultats montrent que les systèmes de fourniture d'énergie ne sont pas neutres sur le plan du genre; par exemple, les hommes sont plus susceptibles de prendre des décisions sur les ressources énergétiques lorsque les systèmes de fourniture sont centralisés, comme dans le cas des réseaux centraux. Les systèmes décentralisés de fourniture d'énergie, comme ceux de l'énergie solaire, fournissent de l'énergie à plus petite échelle, ce qui permet aux femmes de participer davantage à la gestion de l'énergie.

Dans le domaine de la politique énergétique, I'Islande, en collaboration avec ONU Environnement et d'autres partenaires, a organisé un atelier sur les femmes entrepreneurs et l'énergie durable au Gabon afin de promouvoir des politiques énergétiques intégrant la question du genre sur tout le continent africain. Cet atelier a mis en lumière le rôle des femmes dans la chaîne de valeur de l'énergie afin d'accroître les possibilités économiques et d'améliorer l'accès à l'énergie. Les gouvernements africains se sont notamment engagés à prendre des mesures dans les domaines suivants: politiques énergétiques respectueuses de l'environnement et intégrant la question du genre; amélioration de l'accès au financement et aux marchés pour les femmes entrepreneurs dans la chaîne de valeur; et renforcement des capacités, création de compétences et autonomisation des femmes entrepreneurs. L'atelier a en outre abouti à la création d'un cadre pour les femmes africaines entrepreneurs dans le secteur de l'énergie, qui sert de plate-forme pour l'échange de connaissances, l'accès au financement et l'accélération du passage à l'énergie durable.

Le Canada met en œuvre un projet au Burkina Faso qui fournit un appui dans le domaine de l'électrification rurale, notamment par la promotion de l'énergie solaire, ainsi que le développement d'entreprises connexes pour les femmes. L'installation d'équipements pour l'utilisation de l'énergie solaire permettra d'augmenter la production, la transformation et le stockage de l'oignon, du poulet et du poisson, des activités économiques importantes dans la région. Le projet devrait profiter à 40000 personnes, en particulier des femmes, grâce à la participation de groupes de femmes.

L'UE met actuellement en œuvre un programme régional au Kirghizistan et au Tadjikistan pour traiter les déchets d'uranium provenant d'anciens sites miniers d'uranium. Le programme prévoit notamment des activités de sensibilisation à la radioprotection et tient compte des problèmes de temps, de mobilité et de ressources auxquelles les femmes sont confrontées. De plus, les femmes ont été encouragées à participer à des ateliers de formation des formateurs. En outre, il a été tenu compte de la dimension de genre lors de la conception du matériel de formation et d'information ainsi que de la campagne de sensibilisation du public. Ainsi, $60 \%$ des représentants des collectivités participant aux événements organisés dans le cadre de la campagne et $85 \%$ des participants aux ateliers destinés aux enseignants et au personnel médical étaient des femmes. 
Dans le cadre du programme Finnpartnership, la Finlande a fourni un appui financier à la société Solar Fire Concentration pour qu'elle investisse dans de petits entrepreneurs, en particulier des femmes, au Kenya et en Tanzanie, afin de réduire les coûts énergétiques grâce à la technologie solaire. Dans ces pays, les femmes passent beaucoup de temps à ramasser du bois de chauffage pour cuisiner et sont alors exposées à des fumées dangereuses. L'énergie thermique solaire est plus facile à utiliser et plus propre et elle fait gagner du temps aux femmes, ce qui leur permet de gérer de petites entreprises telles que des boulangeries ou des services de déshydratation de produits agricoles. En outre, des fours utilisant la chaleur solaire pour la transformation des aliments ont été installés pour permettre aux femmes d'économiser l'argent qu'elles dépensaient en charbon de bois. Ces fours étaient utilisés par des coopératives de femmes pour griller des arachides ou des noix de cajou et sécher des bananes, mais aussi dans les boulangeries gérées par des femmes. Le projet prévoyait également des formations à l'installation d'appareils électriques à énergie solaire pour les résidents, ce qui exigeait la participation des femmes.

S'agissant de la production d'énergie, l'Italie a dispensé des formations à la construction et à l'utilisation de petits systèmes d'énergie solaire pour les femmes au Burundi. En outre, grâce à la fourniture d'électricité, le projet a spécifiquement soutenu des entreprises de broderie et d'habillement appartenant à des femmes qui utilisaient des machines à coudre électriques pour fabriquer des draps et des vêtements, et a promu l'utilisation de pompes à eau pour augmenter la production agricole. L'ONUDI a également formé des femmes et des jeunes à l'utilisation d'énergies renouvelables à des fins de production en Gambie, ce qui a permis la participation de plus de 1000 femmes au programme.

\section{Capacité de production}

La BID a appuyé le projet de renouvellement et de modernisation du secteur du café en Colombie pour contribuer à l'augmentation des rendements et de la qualité du café de 2000 petits producteurs, dont plus de la moitié sont des femmes. Grâce à ce financement, la coopérative accordera des prêts aux producteurs de café pour l'achat de petits moulins, la construction de parcs de séchage ou la réparation d'équipements existants. Une assistance technique sera fournie aux caféiculteurs pour les aider à se conformer aux normes de certification. Tout cela devrait permettre d'augmenter de $8 \%$ le rendement des grains de café et de réduire la quantité de grains endommagés.

Un projet mené par I'USAID et I'Organisation des Nations Unies pour I'alimentation et l'agriculture en Afghanistan était spécifiquement axé sur les femmes travaillant dans la chaîne de valeur avicole. Le projet visait à augmenter leurs revenus par le biais d'une formation technique intensive sur l'élevage des volailles et la vaccination, ainsi que par des intrants durables tels qu'aliments pour animaux et médicaments, et par la mise en place d'un réseau de commercialisation pour les femmes, qui relie les aviculteurs des villages aux marchés urbains. Après deux ans, le projet avait formé plus de 21000 femmes à la gestion avicole et organisé 850 groupes de producteurs. Selon une évaluation, les formations et le développement organisationnel ont permis à plus de 15000 productrices d'œufs d'augmenter leur revenu familial.

La Société belge d'investissement pour les pays en développement (BIO) a fourni des crédits à la Société ivoirienne de traitement de l'anacarde (SITA) en Côte d'Ivoire. L'entreprise, qui est dirigée par une femme, employait principalement des femmes pour la transformation des noix de cajou. Aujourd'hui, l'entreprise est le leader de l'industrie de la noix de cajou dans le pays, qui est le deuxième exportateur mondial de ce produit après l'Inde. Dans le cadre d'un projet de l'Université de Cordoue financé par l'Agence andalouse de coopération pour le développement international, l'Espagne a apporté son soutien à l'organisation d'un cours sur la gestion des ressources naturelles dans deux universités du Mozambique. Le cours comportait un module spécifique sur l'intégration d'une perspective de genre. Ce projet comprenait notamment une publication sur la gestion des ressources forestières et la production d'énergie par les ménages et accordait une attention particulière au rôle des femmes dans les communautés rurales. 
La BAsD a octroyé une subvention à la Chambre de commerce et d'industrie des femmes du Bangladesh pour promouvoir l'entrepreneuriat féminin. Le projet a permis à 900 femmes entrepreneurs de recevoir une formation sur les demandes de prêts. Par conséquent, 91 femmes ont reçu des prêts et un grand nombre d'entre elles ont créé une entreprise. En outre, 600 fonctionnaires d'institutions financières ont reçu une formation sur les politiques gouvernementales en faveur des femmes. Sur la base de ce projet, la BAsD met actuellement en œuvre un projet de développement des PME qui prévoit que 10\% des crédits seront alloués à des PME dirigées par des femmes.

En Cisjordanie et dans la bande de Gaza, la Banque mondiale a financé la création du projet Abraham Path, qui prévoit des randonnées de longue distance avec hébergement dans des familles palestiniennes locales et guides locaux. Les hôtes, qui doivent gérer et préparer le logement et la nourriture le long du sentier d'Abraham, sont le plus souvent des femmes. Le projet offre également aux femmes artisans locales la possibilité de vendre leurs produits aux randonneurs qui traversent leur village ou y séjournent. La Banque mondiale a financé l'établissement de l'itinéraire, la formation des guides et des hôtes, ainsi que la commercialisation du projet par le biais d'un centre d'information en ligne, de cartographies et des médias sociaux. Les femmes bénéficient de programmes de formation en tourisme et en langues et de préparation à l'emploi. Le dernier rapport de suivi indique que 196 emplois ont été créés depuis le lancement de l'initiative en 2014, dont 57\% sont occupés par des femmes.

Les cas d'expérience présentés dans le cadre de l'Initiative Aide pour le commerce montrent que de nombreux projets intégrant les perspectives de genre concernent les domaines de l'agriculture et des PME, et plus précisément la formation, l'accès à la microfinance et l'amélioration de la qualité des produits pour se conformer aux normes ou certifications internationales (OCDE-OMC 2011, 2015, 2017). Ils montrent également des exemples concrets de l'activité des donateurs dans les secteurs du textile et de l'habillement, où les femmes sont surreprésentées. Les projets sont axés sur la garantie de conditions de travail décentes pour les femmes grâce à la mise en œuvre de bonnes pratiques en matière de normes du travail dans les usines, la réalisation de contrôles ponctuels, l'organisation de formations sur les compétences de supervision et l'intégration dans les syndicats (OCDE-OMC 2011).

La BAsD a soutenu les réformes gouvernementales en matière de politique industrielle aux Philippines afin de contribuer à stimuler la compétitivité du pays. Le projet comprenait des formations du personnel des agences nationales axées sur les partenariats public-privé et les femmes ont représenté plus de $50 \%$ des bénéficiaires, dépassant ainsi l'objectif fixé. La Fondation interaméricaine des États-Unis a appuyé un projet relatif à l'exploration minière en Bolivie, qui visait à aider les femmes de coopératives minières à améliorer leur productivité et leurs revenus. Le projet prévoyait la fourniture de machines, d'équipement, d'outils, de matériel de sécurité et l'organisation d'une formation connexe.

Au Mozambique, la Norvège a appuyé un projet dans le secteur pétrolier et gazier visant à renforcer les capacités techniques des jeunes Mozambicains afin qu'ils puissent profiter des possibilités d'emploi dans ce secteur ou des investissements connexes. L'objectif était de former 500 personnes par an afin qu'elles obtiennent les qualifications exigées par l'industrie pétrolière et gazière, avec un objectif de 50\% de femmes en deux ans. Au cours des 18 premiers mois, 47\% des 450 personnes qui ont suivi le cours étaient des femmes. De plus, environ 25\% des animateurs du projet, souvent recrutés dans le centre de formation, étaient également des femmes.

La Suisse a accordé une subvention à la Société financière internationale (SFI) pour l'élaboration d'un programme au Maroc, en Tunisie et en Égypte visant à améliorer l'accès des femmes aux services financiers et non financiers en fournissant des services consultatifs aux institutions financières, telles que les banques et les institutions de microfinance. A titre d'exemple, la SFI aide les institutions financières à élargir leur offre aux entreprises dirigées par des femmes, notamment pour les services financiers mais aussi pour les services non financiers comme les possibilités de création de réseaux de coopération et les cours de formation. Elle sensibilise également les institutions financières aux meilleures pratiques en matière de services bancaires pour les femmes et en fait la promotion. L'ONUDI a également mené un projet similaire dans la région afin d'accroître la création de réseaux de coopération et le renforcement des capacités des associations de femmes. 
Les Pays-Bas ont appuyé la création de Global Banking Alliance (GBA) for Women, un consortium international composé de 46 membres - pour la plupart des institutions financières - qui s'est engagé à promouvoir l'autonomisation économique des femmes. Son objectif est d'améliorer l'accès des femmes aux capitaux, aux marchés et à la formation. La GBA mène des études de marché sur "l'économie des femmes" et a également créé une bibliothèque en ligne rassemblant d'autres recherches connexes. En outre, elle organise des sommets annuels réunissant des femmes entrepreneurs, des universitaires, des banquières et d'autres parties prenantes pour passer en revue les meilleures pratiques et les innovations du marché en faveur de l'autonomisation économique des femmes. En Turquie, la France a accordé un prêt à la TSKB, une banque privée turque de développement et d'investissement, pour qu'elle ouvre une ligne de crédit destinée aux entreprises qui emploient activement des femmes ou pour qu'elle se conforme aux réglementations turques en matière de santé et de sécurité au travail. La banque a indiqué que la ligne de crédit avait contribué à l'embauche d'environ 700 femmes.

Les cas d'expérience présentés dans le cadre des exercices de S\&E indiquent également que le Groupe de développement des infrastructures privées (PIDG) a financé un projet multisectoriel qui prévoyait la mise en service de transbordeurs, la réfection de routes et la fourniture d'électricité solaire pour desservir les habitants de lî̂le de Kalangala en Ouganda, afin d'accroître le tourisme sur lîle. La formation dispensée dans le cadre du projet a permis de former les premières femmes marins certifiées en Ouganda. Aux Philippines, l'Allemagne a mené un projet de gestion des ressources côtières dans le cadre duquel $60 \%$ des pisciculteurs étaient des femmes. Ce projet visait à aider les femmes et les hommes à éviter la surexploitation des zones de pêche grâce à des activités de formation et d'apprentissage par les pairs. Grâce à ce projet, des femmes ont été nommées à des postes clés dans des groupes locaux de gestion durable des ressources et ont pris part à des discussions sur le cadre réglementaire et financier du gouvernement, les aires marines protégées et le développement des capacités des organisations de pêcheurs.

\section{Synthèse et évaluation des activités des donateurs}

En résumé, ce qui précède montre qu'il existe plusieurs bons exemples d'activités d'aide pour le commerce intégrant la question du genre menées par les donateurs, notamment dans les domaines des transports, de l'énergie, de la finance et des affaires et de l'industrie. Ces projets sont généralement de moindre envergure que les projets qui n'intègrent pas la dimension genre dans les mêmes secteurs. De nombreux projets prévoient la formation des femmes, soit en tant que fonctionnaires du gouvernement chargées de l'élaboration ou de la mise en œuvre de politiques, soit en tant que bénéficiaires d'activités pour l'amélioration de la génération de revenus. Beaucoup établissent des objectifs ou des quotas pour s'assurer que les femmes représentent une proportion suffisante des personnes formées ou de la maind'œuvre locale employée dans la construction. D’autres activités sont organisées, notamment la réalisation d'études ou la conception de projets qui intégreraient les perspectives de genre dans le domaine ou l'activité en question. Si certains projets visent également à aider les femmes à pénétrer le marché mondial, ils se limitent souvent au segment à faible valeur ajoutée dans l'agriculture, l'artisanat et l'habillement.

Ces projets peuvent être classés en deux catégories: les projets de politique publique en amont, qui tiennent compte de la dimension de genre, et les projets en aval, qui visent à aider directement les femmes bénéficiaires. En d'autres termes, certains projets sont "sur les femmes" (sujet de formation), "pour les femmes" (personnes formées ou bénéficiaires), ou "par les femmes" (femmes décideurs ou formatrices) (voir tableau 9.1). Outre les projets bilatéraux traditionnels, les donateurs financent également des organismes internationaux spécialisés tels que I'ITC, I'ONUDI et le TMEA, et contribuent à la création de plates-formes mondiales telles que la GBA, afin de promouvoir l'autonomisation économique des femmes aux niveaux régional ou mondial. En outre, des efforts sont déployés pour inciter le secteur privé à fournir un financement en faveur de l'autonomisation économique des femmes, notamment par la BIO, le PIDG, le programme Finnpartnership et les IFD du G-7. 
Tableau 9.1. Types d'activités intégrant la dimension de genre dans l'Aide pour le commerce (à suivre)

\begin{tabular}{|c|c|c|c|c|}
\hline Catégorie & Secteur & Sur les femmes & Pour les femmes & Par les femmes \\
\hline $\begin{array}{l}\text { Politiques } \\
\text { commerciales }\end{array}$ & $\begin{array}{l}\text { Politiques } \\
\text { commerciales }\end{array}$ & $\begin{array}{l}\text { Outils/formations/études } \\
\text { sur la sensibilisation à l'égalité } \\
\text { des sexes } \\
\text { Intégration des questions de } \\
\text { genre dans les APE/politiques } \\
\text { Intégration de la dimension } \\
\text { de genre dans les réformes } \\
\text { douanières }\end{array}$ & $\begin{array}{l}\text { Formation, y compris pour les femmes } \\
\text { fonctionnaires } \\
\text { Simplification de l'enregistrement, y } \\
\text { compris pour les femmes entrepreneurs } \\
\text { Services de conseil gratuits, y compris } \\
\text { pour les femmes entrepreneurs }\end{array}$ & \\
\hline \multirow[t]{7}{*}{$\begin{array}{l}\text { Infrastructure } \\
\text { économique }\end{array}$} & Routes & & $\begin{array}{l}\text { Emplois pour les ouvrières } \\
\text { Formation pour les femmes sur } \\
\text { l'entretien des routes }\end{array}$ & $\begin{array}{l}\text { Femmes membres } \\
\text { de comités pour } \\
\text { la conception de } \\
\text { routes }\end{array}$ \\
\hline & Aéroports & & $\begin{array}{l}\text { Emploi dans la mise à niveau } \\
\text { et les marchés } \\
\text { Formation et prestation de services }\end{array}$ & $\begin{array}{l}\text { Femmes } \\
\text { décideurs dans } \\
\text { la planification } \\
\text { aéroportuaire } \\
\end{array}$ \\
\hline & Énergie & $\begin{array}{l}\text { Atelier sur la politique } \\
\text { énergétique intégrant } \\
\text { la question du genre } \\
\text { Études sur la dimension } \\
\text { de genre dans le secteur } \\
\text { de l'énergie }\end{array}$ & $\begin{array}{l}\text { Plate-forme pour les femmes } \\
\text { dans la chaîne de valeur de l'énergie } \\
\text { Fourniture d'énergie solaire } \\
\text { à des femmes entrepreneurs } \\
\text { Formation de femmes à l'utilisation } \\
\text { de l'énergie pour des entreprises } \\
\text { détenues par des femmes }\end{array}$ & $\begin{array}{l}\text { Femmes } \\
\text { formatrices }\end{array}$ \\
\hline & $\begin{array}{l}\text { Politique } \\
\text { industrielle }\end{array}$ & $\begin{array}{l}\text { Étude de marché sur } \\
\text { les entreprises détenues } \\
\text { par des femmes }\end{array}$ & $\begin{array}{l}\text { Formation sur les partenariats public- } \\
\text { privé, y compris pour les femmes } \\
\text { fonctionnaires }\end{array}$ & $\begin{array}{l}\text { Femmes } \\
\text { facilitatrices }\end{array}$ \\
\hline & $\begin{array}{l}\text { Ressources } \\
\text { naturelles }\end{array}$ & & $\begin{array}{l}\text { Formation et fourniture de machines } \\
\text { pour l'exploitation minière, y compris } \\
\text { pour les femmes } \\
\text { Formation à l'exploitation pétrolière, } \\
\text { y compris pour les femmes }\end{array}$ & \\
\hline & $\begin{array}{l}\text { Secteur } \\
\text { financier }\end{array}$ & $\begin{array}{l}\text { Mise en place d'une plate- } \\
\text { forme pour les femmes dans } \\
\text { le secteur bancaire } \\
\text { Sensibilisation des institutions } \\
\text { financières sur les questions } \\
\text { de genre }\end{array}$ & $\begin{array}{l}\text { Crédits pour les femmes entrepreneurs } \\
\text { Formation à la gestion financière pour } \\
\text { les entrepreneurs }\end{array}$ & \\
\hline & Entrepreneuriat & & $\begin{array}{l}\text { Formation sur l'énergie solaire } \\
\text { et la génération de revenus pour } \\
\text { les entrepreneurs }\end{array}$ & \\
\hline
\end{tabular}

Sur le plan de la procédure, la plupart des donateurs se sont engagés à collecter des données ventilées par sexe; à réaliser des analyses ex ante du contexte sectoriel/institutionnel et des bénéficiaires des projets; et à effectuer un suivi et une évaluation de la dimension de genre. Dans le même temps, tous les donateurs n'entreprennent pas ces activités de façon systématique. Par exemple, les seuls donateurs qui, en général, ventilent par sexe le nombre de personnes qui reçoivent de l'électricité sont I'UE, les Pays-Bas, la Nouvelle-Zélande, la BAD et la Banque mondiale (OCDE 2019b). Étant donné que la collecte de données sur l'accès à l'énergie par les citoyens et les consommateurs relève, entre autres, de la responsabilité du gouvernement national, dans de nombreux cas, les donateurs doivent encourager les pays partenaires à ventiler les données par sexe. En outre, certains donateurs mettent l'accent sur les indicateurs de processus pour l'intégration de la dimension de genre dans leurs institutions internes - sans rapport avec l'impact sur les pays partenaires - comme dans le cas du renforcement de la formation du personnel de la coopération au développement en matière de sensibilisation à la question du genre, la proportion de femmes cadres dans les organismes d'aide et l'organisation de réunions sur l'intégration de la question du genre dans les administrations. 
Tableau 9.1. Types d'activités intégrant la dimension de genre dans l'Aide pour le commerce

\begin{tabular}{|c|c|c|c|c|}
\hline Catégorie & Secteur & Sur les femmes & Pour les femmes & Par les femmes \\
\hline \multirow[t]{4}{*}{$\begin{array}{l}\text { Capacité } \\
\text { de production }\end{array}$} & Tourisme & & $\begin{array}{l}\text { Formation de femmes à l'accueil } \\
\text { des touristes } \\
\text { Formation de femmes à la gestion } \\
\text { des ressources maritimes }\end{array}$ & \\
\hline & Textiles & $\begin{array}{l}\text { Application des normes } \\
\text { du travail dans les entreprises } \\
\text { qui emploient des femmes } \\
\text { Formation sur les compétences } \\
\text { de supervision dans les } \\
\text { entreprises qui emploient } \\
\text { des femmes }\end{array}$ & Intégration des femmes dans les syndicats & \\
\hline & Agriculture & & $\begin{array}{l}\text { Coopération technique ou prêts } \\
\text { pour accroitre le rendement des cultures } \\
\text { pour les agricultrices } \\
\text { Investissement dans une entreprise de } \\
\text { transformation des noix de cajou dirigée } \\
\text { par une femme } \\
\text { Formation sur les produits de } \\
\text { l'exploitation forestière pour des groupes } \\
\text { de femmes }\end{array}$ & \\
\hline & Pêche & & $\begin{array}{l}\text { Formation sur la gestion des ressources } \\
\text { côtières pour les pisciculteurs } \\
\text { Nomination de femmes dans } \\
\text { des groupes locaux }\end{array}$ & $\begin{array}{l}\text { Femmes décideurs } \\
\text { dans les groupes } \\
\text { de pêche }\end{array}$ \\
\hline
\end{tabular}

D'autres donateurs disposent d'indicateurs de résultats tels que le nombre de femmes qui ont reçu une formation, le nombre de celles qui ont accès à l'énergie ou le nombre de celles qui bénéficient de services consultatifs financiers. Cependant, ils sont peu nombreux à utiliser des indicateurs axés davantage sur les résultats. Cela se reflète dans l'exercice de S\&E de 2019 qui a montré que seulement la moitié des donateurs avaient déclaré qu'ils disposaient d'indicateurs permettant de suivre l'autonomisation économique des femmes dans l'Aide pour le commerce. Les quelques donateurs qui ont indiqué qu'ils disposaient de ces indicateurs se réfèrent principalement à des données ventilées par sexe, comme le nombre ou la proportion de femmes qui sont parvenues à être recrutées à des postes non qualifiés, techniques, de gestion ou de supervision, celles qui possèdent des titres fonciers ou celles qui ont obtenu un financement. D'autres indicateurs de résultats concernent le nombre de ménages qui ont adopté des technologies d'économie d'énergie ou les entreprises enregistrées appartenant exclusivement ou conjointement à des femmes.

Les activités visant à promouvoir l'autonomisation économique des femmes dans certains secteurs de l'Aide pour le commerce sont particulièrement importantes dans les contextes où les normes sociales pourraient limiter l'accès des femmes au marché ou au financement, notamment pour les plus pauvres et les marginalisées. Par conséquent, certains donateurs estiment que l'Aide pour le commerce tenant compte de la question du genre devrait être associée à d'autres efforts de lutte contre la pauvreté et les inégalités afin d'avoir le plus d'effets positifs. D'autres soulignent l'importance de promouvoir l'emploi des femmes dans les professions à prédominance masculine, en particulier dans le secteur des transports, où peu de femmes travaillent et généralement à des postes mal rémunérés, comme le nettoyage ou la signalisation routière. Le développement professionnel et les possibilités économiques des femmes dans certains secteurs sont limités par des stéréotypes discriminatoires et les rôles restrictifs attribués à chaque sexe qui déterminent les emplois qui conviennent aux femmes. 
Dans le même temps, les formations à court terme et l'emploi dans le cadre de projets peuvent ne pas suffire pour changer les politiques ou soutenir les activités économiques des femmes, et l'efficacité des interventions des donateurs en est ainsi limitée (Buvinic et Furst-Nichols, 2014). En plus de réaliser l'objectif consistant à amener les femmes à participer à des cours de formation ou à des processus de consultation, ces activités pourraient indiquer a posteriori si les politiques ou la conception des projets ont été modifiées du fait d'une participation accrue des femmes. En outre, il faudrait également étendre la portée des projets ciblant les femmes, que ce soit en tant que bénéficiaires de prêts, productrices de biens commercialisables ou employées dans des professions à prédominance masculine susceptibles de favoriser la création de revenus et l'esprit d'entreprise, afin qu'ils aient un impact plus important. Pour ce faire, une coopération sera également nécessaire en vue d'aider les gouvernements partenaires à améliorer l'environnement politique et juridique.

En outre, les donateurs devraient veiller à collecter systématiquement des données ventilées par sexe, à effectuer des analyses ex ante et à inclure des indicateurs liés au genre dans leurs cadres de résultats, en s'alignant dans la mesure du possible sur les indicateurs des ODD et sur les cadres de résultats des pays partenaires. À cet égard, les donateurs pourraient également contribuer à renforcer les systèmes statistiques et les systèmes de gestion axés sur les résultats des pays partenaires, en particulier en ce qui concerne la prise en compte de la dimension de genre. En plus d'établir un système approprié de suivi et d'évaluation, les donateurs devraient également utiliser les informations sur les résultats générés par ces systèmes pour savoir ce qui fonctionne et ce qui ne fonctionne pas. En particulier, il est important de mieux comprendre comment l'intégration d'une perspective de genre dans les secteurs clés de l'Aide pour le commerce peut produire des résultats durables et à long terme pour l'autonomisation économique des femmes. Enfin, il est également essentiel de reproduire les bonnes pratiques et d'améliorer la programmation, en plus de communiquer les résultats.

\section{RÉSUMÉ ET CONCLUSIONS}

L'autonomisation économique des femmes a été reconnue comme l'un des principaux moteurs du développement durable et de l'égalité des sexes. Dans ce contexte, le commerce peut permettre aux femmes de faire valoir leur position en tant qu'acteurs économiques et d'en retirer des avantages pour elles et leur famille. Par ailleurs, une attention particulière doit être accordée aux conséquences négatives de la libéralisation des échanges pour les femmes. L'Aide pour le commerce devrait donc permettre aux femmes de tirer profit du commerce, en particulier grâce à une participation active et significative dans les secteurs pertinents, et réduire au minimum les effets négatifs découlant de la recherche de possibilités économiques. Dans ce contexte, I'Équipe spéciale de l'OMC chargée de l'Aide pour le commerce a établi un principe directeur visant à intégrer la question de l'égalité hommes-femmes dans l'Aide pour le commerce afin de promouvoir le rôle des femmes dans le développement durable et inclusif.

Ces dernières années, les donateurs ont en général augmenté leur aide pour le commerce tenant compte de la question du genre. Plus particulièrement, les donateurs tiennent assez bien compte de cette question dans les domaines de l'agriculture, de l'artisanat, des PME et du microfinancement. Certains donateurs disposent de stratégies et de lignes directrices claires pour promouvoir l'autonomisation économique des femmes dans ces domaines. En revanche, la question de l'égalité hommes-femmes n'est pas aussi bien prise en considération dans les secteurs tels que les transports, l'énergie, les communications, l'industrie, la finance et les affaires. De nombreux donateurs bilatéraux n'ont généralement ni stratégies ni lignes directrices sur la promotion de l'autonomisation économique des femmes dans ces domaines.

Néanmoins, il existe de bons exemples d'aide pour le commerce tenant compte de la question du genre dans des domaines problématiques qui pourraient être partagés avec d'autres donateurs dont les approches ne sont pas aussi développées. Les activités concernées sont les suivantes: inclusion des femmes dans les programmes de formation, projets générateurs de revenus pour les femmes, augmentation de l'accès au financement et de l'emploi pour les 
femmes, et études sur le renforcement des aspects d'une politique sectorielle donnée relatifs à l'égalité hommesfemmes. Dans le même temps, de nombreux donateurs ne disposent toujours pas d'indicateurs ou de systèmes de suivi et d'évaluation appropriés permettant de mesurer l'impact sur l'autonomisation économique des femmes dans ces domaines. Ces mécanismes permettront de mieux comprendre comment les activités intégrant la question du genre peuvent mieux contribuer à l'autonomisation économique des femmes.

Dans le guide du GENDERNET intitulé Why Gender Matters in Infrastructure, de 2004, il est indiqué ce qui suit:

Bien que l'égalité des sexes soit considérée comme essentielle à la viabilité des projets et à la réalisation des OMD dans les politiques de nombreux organismes d'aide, ces organismes éprouvent souvent de réelles difficultés à traduire leurs engagements politiques et décisionnels dans la pratique. C'est particulièrement le cas pour les grands projets d'infrastructures.

\section{Encadré 9.7. Opinion - Ann Linde, Ministre du commerce extérieur de la Suède}

Le Programme 2030 souligne la pertinence du commerce international en tant qu'objectif et moyen pour le développement durable et reconnaît l'importance de l'Aide pour le commerce. Mon gouvernement est très attaché à ces engagements, comme l'illustre notre ferme soutien à l'Initiative Aide pour le commerce. En outre, en tant que Ministre du commerce du premier gouvernement officiellement féministe du monde, j'utilise les plates-formes disponibles pour faire avancer la question de l'égalité des sexes, principalement l'OMC et les accords de libre-échange de l'UE, mais aussi l'Aide pour le commerce. La Suède déploie des efforts en faveur d'une intégration globale de la dimension de genre dans toutes les activités de coopération au développement. C'est ce qui ressort, par exemple, du cadre politique du gouvernement en matière de coopération au développement. En outre, depuis 2018, la Suède s'est dotée d'une stratégie globale de coopération au développement pour l'égalité des sexes et les droits des femmes et des filles.

Historiquement, le commerce s'est révélé être un moteur du développement et de réduction de la pauvreté en stimulant la croissance, en particulier dans les pays en développement. Le monde a connu une énorme transformation économique au cours des 3 dernières décennies. Les biens, les services, les capitaux et les personnes circulent entre les pays plus rapidement que jamais auparavant, de sorte que l'information et le savoir sont devenus des marchandises mondiales. En outre, la révolution numérique a offert de grandes possibilités en matière de croissance, d'emploi et de développement durable dans le monde entier. Dans le même temps, I'OCDE a constaté qu'à travers le monde le nombre de femmes connectées était inférieur d'environ 250 millions à celui des hommes, dont beaucoup vivaient dans les pays en développement. Cela se produit à un moment où de nombreux éléments donnent à penser que l'accès au monde numérique peut contribuer à stimuler le développement personnel des femmes et à accroître leur prospérité. Le rapport Women and the Web d'Intel a révélé que l'amélioration de l'accès à Internet dans les pays en développement se traduirait par une contribution estimée entre 13 et 18 milliards de dollars au PIB annuel de 144 pays.

Étant donné que les ODD mettent fortement l'accent sur le rôle que joue le commerce dans la réalisation des objectifs mondiaux et du Programme 2030, il était étonnant de lire que seule une petite partie de l'Aide pour le commerce intégrant la question du genre entrait dans la catégorie "politique commerciale". J'ai également été surprise d'apprendre que peu de donateurs intégraient les perspectives de genre dans les secteurs clés de l'Aide pour le commerce, notamment celui des TIC. Si cela est dû à l'absence de lignes directrices, nous devons commencer à en formuler dans des domaines essentiels pour contribuer à l'autonomisation économique des femmes ainsi qu'à la réalisation des objectifs mondiaux et du Programme 2030.

Ce type d'analyse est très pertinent et utile, et c'est précisément le genre d'effort qui est nécessaire pour passer de la parole aux actes. En fait, il s'agit là d'un signal d'alarme pour les donateurs et les pays, qui doivent accorder l'importance requise aux questions d'égalité des sexes dans le commerce. En ce sens, le marqueur relatif à l'égalité homme-femme est un outil utile, et nous sommes conscients du travail d'assurance qualité que le CAD de l'OCDE ne cesse de mettre en œuvre pour assurer une application harmonisée de ce marqueur au sein des donateurs. 
Quinze ans plus tard, la citation est toujours valable, non seulement pour les infrastructures, mais aussi pour de nombreux autres domaines de l'Aide pour le commerce, quoique dans une moindre mesure pour l'agriculture, les PME, l'artisanat et la microfinance. Des recherches et des analyses plus approfondies sont nécessaires pour établir une base de données factuelles sur la manière dont les donateurs peuvent contribuer à l'autonomisation économique des femmes - au-delà de la formation à court terme pour les femmes et de l'emploi dans le cadre de projets - et pour examiner comment étendre la portée des projets générateurs de revenus afin de renforcer leur impact et leur durabilité. Dans ce contexte, il pourrait être utile de partager ou de mieux appliquer les orientations sur la manière de planifier, de suivre et d'évaluer les activités des donateurs afin de contribuer à l'autonomisation économique des femmes grâce à l'Aide pour le commerce, en particulier dans des domaines tels que les transports, l'énergie, les communications, la finance et les affaires, l'extraction minière et l'industrie (voir l'encadré 9.7) sur la base des travaux du GENDERNET du CAD.

Ces lignes directrices pourraient inclure une méthode pour la réalisation d'évaluations ou de diagnostics sur l'égalité hommes-femmes qui prendraient en considération l'incidence des infrastructures sur les activités de soins non rémunérés assurées par les femmes, en examinant les schémas de mobilité ou de consommation d'énergie, en particulier chez les populations pauvres des zones rurales. Elles pourraient aussi encourager le développement d'activités de sensibilisation et de formation destinées aux hommes et aux femmes afin que les investissements dans les infrastructures tiennent compte de la question de l'égalité hommes-femmes (OCDE 2019a). En outre, certains donateurs soulignent la nécessité d'avoir une direction et une volonté politique fortes pour assurer la mise en œuvre de ce programme; de disposer de ressources adéquates et d'un nombre suffisant d'experts possédant les compétences et l'expérience requises pour renforcer les capacités d'intégration de la dimension de genre; de sélectionner rigoureusement les partenaires de mise en œuvre ayant des objectifs communs; et d'assurer qu'il soit rendu compte des activités entreprises. Tous ces efforts pourraient en particulier contribuer à la réalisation de deux ODD: I'ODD 5, qui concerne l'autonomisation des femmes, notamment l'accès à la propriété foncière et aux services financiers ainsi que les soins non rémunérés, au moyen de la fourniture d'infrastructures, et l'ODD 8, qui vise à promouvoir l'emploi productif pour les femmes. 


\section{NOTES}

1. Paragraphe 157 "Si la mondialisation de l'économie a ouvert de nouvelles possibilités d'emploi aux femmes, d'autres tendances ont exacerbé les inégalités entre les sexes. D'un autre côté, la mondialisation, et notamment l'intégration économique, peut créer des pressions favorisant un ajustement de l'emploi des femmes et la recherche de nouvelles sources d'emploi au fur et à mesure que se modifie la structure des échanges. II faudrait analyser plus à fond les effets de la mondialisation sur la condition économique des femmes."

2. Dans l'exercice de S\&E de 2013, le Canada, les Pays-Bas et le Royaume-Uni ont déclaré qu'il était ressorti des évaluations des impacts de leurs projets de chaîne de valeur sur l'autonomisation économique des femmes qu'en général il y avait eu des changements positifs.

3. Les autres recommandations étaient les suivantes: 1) partager nos expériences respectives relatives aux politiques et aux programmes destinés à encourager la participation des femmes à l'économie nationale et internationale par des échanges d'informations dans le cadre de l'OMC, le cas échéant, et par la présentation de rapports volontaires pendant le processus d'examen des politiques commerciales de I'OMC; 2) partager les meilleures pratiques pour effectuer une analyse des politiques commerciales basée sur le genre et pour en suivre les effets; 3 ) partager les méthodes et procédures pour la collecte de données ventilées par sexe, l'utilisation d'indicateurs et de méthodes de suivi et d'évaluation et l'analyse des statistiques relatives au commerce axées sur le genre; et 4) travailler ensemble à l'OMC pour supprimer les obstacles à l'autonomisation économique des femmes et pour accroître leur participation au commerce.

4. Cette question n'a plus été posée dans les exercices de S\&E des années ultérieures.

5. Voir https://www.empowerwomen.org/en/who-we-are/initiatives/sg-high-level-panel-on-womenseconomic-empowerment

6. Y compris l'aide publique au développement concessionnelle et les autres flux officiels d'aide au développement non concessionnelle

7. Entre 1998 et 2017 , le financement public du développement en faveur de la santé, de l'éducation, du gouvernement, de la société civile et de l'eau a représenté entre $42 \%$ et $61 \%$ des engagements bilatéraux préaffectés en faveur de l'égalité des sexes.

8. L'objectif de GENDERNET est d'améliorer les politiques et les pratiques visant à renforcer l'égalité des sexes dans les programmes de développement et à garantir les droits des femmes et des filles en contribuant à la réalisation du Programme de développement durable à l'horizon 2030.

http://www.oecd.org/dac/gender-development/about-gendernet.htm

9. Les données utilisées pour How Does Aid Support Women's Economic Empowerment? comprennent uniquement I'APD et les flux des membres du CAD, alors que les données du présent chapitre englobent à la fois l'APD et les autres flux officiels des membres du CAD et des banques multilatérales de développement. Par ailleurs, la première publication couvre un éventail plus large de secteurs tels que le développement urbain, la gestion des finances publiques et les politiques en matière d'emploi, qui ne sont pas couverts par le présent chapitre car ils ne font pas partie des secteurs de l'Aide pour le commerce. 
10. Selon la définition donnée par l'Équipe spéciale de l'OMC chargée de l'Aide pour le commerce, les projets et programmes relèvent de l'Aide pour le commerce s'ils sont désignés comme des priorités de développement liées au commerce dans les stratégies nationales de développement des pays partenaires. Par ailleurs, pour mesurer les flux d'aide pour le commerce, l'Équipe spéciale a retenu les catégories suivantes: assistance technique pour la politique et la réglementation commerciales, infrastructure liée au commerce, renforcement de la capacité de production (y compris le développement du commerce), ajustement lié au commerce et autres besoins liés au commerce. La base de données en ligne du CAD (Système de notification des pays créanciers - SNPC) a été reconnue comme la meilleure source de données disponible pour le suivi des apports globaux d'aide pour le commerce. II convient de garder à l'esprit que les données du SNPC ne correspondent pas exactement à chacune des catégories d'aide pour le commerce mentionnées plus haut. En fait, le SNPC fournit des données supplétives concernant quatre rubriques: politique et réglementation commerciales, infrastructure économique, renforcement de la capacité de production et ajustement lié au commerce. Le SNPC couvre l'ensemble de l'APD, mais seules les activités notifiées dans les quatre catégories susmentionnées sont considérées comme relevant de l'aide pour le commerce. II n'est pas possible de distinguer les activités relatives aux "autres besoins liés au commerce". Pour estimer le volume de ces "autres" engagements, les donateurs doivent examiner les projets d'aide dans les secteurs autres que ceux qui ont été pris en compte jusque-là - par exemple dans les domaines de la santé et de l'éducation - et indiquer, le cas échéant, la part de ces activités ayant une importante composante commerciale. Un programme en matière de santé, par exemple, peut permettre un accroissement du commerce à partir de localités où la charge de morbidité constituait un obstacle au commerce. Par conséquent, pour suivre l'aide pour le commerce de manière rigoureuse, il faudrait comparer les données du SNPC et les auto-évaluations des donateurs et des pays partenaires. La liste des secteurs couverts par l'aide pour le commerce est disponible à l'adresse suivante: http://www.oecd.org/dac/aft/Aid-for-trade-sector-codes.pdf.

11. Les communications ne comprennent pas l'assistance en matière de TIC dans d'autres secteurs tels que la santé, l'éducation, les entreprises, la gestion des finances publiques, etc.

12. Le budget annuel moyen pour la période 2014-2017 des projets intégrant la question du genre par rapport à celui des projets n'intégrant pas cette question était, respectivement, de 2 millions d'USD contre 4 millions d'USD dans le secteur de l'énergie, de 0,9 million d'USD contre 3 millions d'USD dans le secteur de l'extraction minière et de I'industrie, et de 3 millions d'USD et 4 millions d'USD dans le secteur des finances et des entreprises.

13. Les données pour l'Afrique comprennent les données pour l'Afrique, le Moyen-Orient, le nord du Sahara et le sud du Sahara. Les données pour l'Amérique latine et les Caraïbes comprennent les données pour l'Amérique, I'Amérique du Nord, l'Amérique centrale et l'Amérique du Sud. Les données pour l'Asie comprennent les données pour l'Asie, I'Extrême-Orient, l'Océanie et l'Asie du Sud et centrale.

14. Ce travail a été dirigé par le Centre de développement de l'OCDE, qui compte de nombreux pays en développement membres, mais pas tous les membres du CAD.

15. La plupart des projets ont été identifiés à partir du système de notification des pays créanciers du CAD. Des informations supplémentaires ont été obtenues par le biais de sources en ligne ou dans le cadre d'échanges avec les donateurs concernés.

16. Les secteurs concernés ne sont pas précisés dans le document de la Banque mondiale. 


\section{RÉFÉRENCES}

2X Challenge, site web https://www.2xchallenge.org/

2X Challenge (2018), 2X Criteria, https://static1.squarespace.com/static/5b180402c3c16a6fe0001e45/ t/5bdc3ef321c67c31 502108f4/1541160694250/2X+Challenge+Criteria+ pour cent2818+October+2018 pour cent29.pdf Abukumail, A.H. (2017) West Bank and Gaza - Abraham Path: Economic Development across Fragile Communities: P147235 Implementation Status Results Report: Sequence 06, Groupe de la Banque mondiale.

http://documents.worldbank. org/curated/en/761131496943874637/West-Bank-and-Gaza-Abraham-Path-EconomicDevelopment-across-Fragile- Communities-P147235-Implementation-Status-Results-Report-Sequence-06, Washington, D.C.

Asia Foundation (2018) Emerging Lessons on Women's Entrepreneurship in Asia and the Pacific: Case Studies from the Asian Development Bank and The Asia Foundation, Banque asiatique de développement, http://hdl.handle.net/11540/8796

Banque africaine de développement (2009), Checklist for Gender Mainstreaming in the Infrastructure Sector, Groupe de la Banque africaine de développement. https://www.afdb.org/fileadmin/uploads/afdb/Documents/Policy-Documents/ Checklist\%20for\%20Gender\%20Maintstreaming\%20in\%20the\%20Infrastructure\%20Sector.pdf

Banque asiatique de développement, Papua New Guinea: Civil Aviation Development Investment Program, informations sur le projet, https://www.adb.org/projects/43141-013/main

Banque asiatique de développement, Philippines: Increasing Competitiveness for Inclusive Growth Program, informations sur le projet, https://www.adb.org/projects/43396-014/main\#project-pds

Banque mondiale (2009), Mainstreaming Gender into Extractive Industries Projects Guidance, Note for Task Team Leaders, publication de la série Extractive Industries and Development, $n^{\circ}$ 9, http://siteresources.worldbank.org/EXTOGMC/ Resources/eifd9_gender_guidance.pdf, Washington, D.C.

Banque mondiale (2012), World Development Report 2012: Gender Equality and Development, https://openknowledge. worldbank.org/handle/10986/4391, Washington, D.C.

Banque mondiale (2015a). The cost of the gender gap in agricultural productivity in Malawi, Tanzania, and Uganda, Groupe de la Banque mondiale, http://documents.worldbank.org/curated/en/847131467987832287/The-cost-of-the-gendergap-in- agricultural-productivity-in-Malawi-Tanzania-and-Uganda, Washington, D.C.

Banque mondiale, (2015b) World Bank Group gender strategy (FY16-23): gender equality, poverty reduction and inclusive growth, Groupe de la Banque mondiale, http://documents.worldbank.org/curated/en/820851467992505410/World-Bank-Groupgender-strategy-FY16-23-gender-equality-poverty-reduction-and-inclusive-growth, Washington, D.C.

Banque mondiale, Gouvernement du Libéria (2010) Gender aware Programs and Women's Roles in Agricultural Value Chains in Liberia, https://siteresources.worldbank.org/EXTGENDER/Resources/LibSum-fin-rev1.pdf

BIT (2016) Closing the gender pay gap: a review of the issues, policy mechanisms and international evidence, Bureau international du travail, https://www.lo.org/wcmsp5/groups/public/---dgreports/---gender/documents/ publication/ wcms_540889.pdf, Genève

BIT (2017), World Employment and Social Outlook: Trends 2017, Bureau international du travail, https://www.lo.org/global/research/global-reports/weso/2017/WCMS_541211/lang--en/index.htm, Genève BIT (2018), Emploi et questions sociales dans le monde - Tendances pour les femmes 2018, Aperçu global, Bureau international du travail, https://www.lo.org/wcmsp5/groups/public/---dgreports/---dcomm/---publ/documents/ publication/wcms_619597.pdf, Genève 
CHAPITRE 9. ENSEIGNEMENTS À TIRER DE L'AIDE POUR LE COMMERCE EN FAVEUR DE L'AUTONOMISATION ÉCONOMIQUE DES FEMMES

Buvinic, M., R. Furst-Nichols, (2014) Promoting Women's Economic Empowerment: What Works?, Policy Research Working Paper No. 7087, Groupe de la Banque mondiale, Washington, D.C.

CAD-OCDE (1999), "Lignes directrices du CAD pour l'égalité homme-femme et le renforcement du pouvoir des femmes dans le cadre de la coopération pour le développement", publication de la série Development Co-operation Guidelines, Éditions OCDE, http://www.oecd.org/fr/c'est-à-dire/femmes-developpement/28313893.pdf, Paris

CAD-OCDE (2004), Why Gender Matters in Infrastructure, Réseau du CAD de I'OCDE sur l'égalité homme-femme, https:// www.ssatp.org/sites/ssatp/files/publications/HTML/Gender-RG/Source\%20\%20documents/Issue\%20and pour cent20 Strategy\%20Papers/G\&T\%20Rationale/ISGT10\%20Why20Gender\%20matters\%20in\%20infrastructure\%200ECD\%20 DAC\%202004.pdf

Çagatay, N. (2001), Trade, Gender and Poverty, Document d'information du Programme des Nations Unies pour le développement, Groupe sur le développement social, Bureau de la politique de développement

Cuberes, D. et M. Teignier (2016), "Aggregate Effects of Gender Gaps in the Labor Market: A Quantitative Estimate", Journal of Human Capital 10 (1), pages 1 à 32

Département fédéral des affaires étrangères de la Suisse (2018), Rapport sur l'efficacité Coopération internationale de la Suisse dans le domaine de l'égalité des genres 2007-2016, Direction du développement et de la coopération (DDC), https://www.eda.admin.ch/dam/deza/fr/documents/publikationen/Wirkungsberichte/Wirkungsbericht-Geschlechter gleichstellung-2007-2016_FR.pdf, Berne

Elson et al. (2007), Feminist Economics of Trade, Routledge IAFFE Advances in Feminist Economics (Volume 5), Routledge; première édition (16 août 2007), 352 pages.

Équipe spéciale de l'OMC chargée de l'Aide pour le commerce (2006), Recommandations de l'Équipe spéciale

chargée de l'Aide pour le commerce, WT/AFT/1, 27 juillet 2006

http://docsonline.wto.org/imrd/directdoc.asp?DDFDocuments/t/WT/AFT/1.doc

FEM (2015), The Global Gender Gap Report 2015, Forum économique mondial, Genève

http://reports.weforum.org/global-gender-gap-report-2015/

Ferrant, G. (2011), How Gender Inequalities Hinder Development: Cross-Country Evidence, document de travail du CES, Centre d'Économie de la Sorbonne, (ISSN: 1955-611X. 2011)

Gonzales, C., S. Jain-Chandra, K. Kochhar, M. Newiak, et T. Zeinullayev (2015) Women and Tackling Income Inequality, Fonds monétaire international, Staff Discussion Notes No. 15/20

Heath, R. et M. Mobarak (2015) "Manufacturing, Manufacturing growth and the lives of Bangladeshi women", Journal of Development Economics No. 115, pages 1 à 15

lqbal, S. (2018) Women, Business, and the Law 2018, Groupe de la Banque mondiale, http://documents.worldbank.org/ curated/ en/926401524803880673/Women-Business-and-the-Law-2018, Washington, D.C.

Kasseeah H. et V. Tandrayen-Ragoobur (2015) "Self-employed women and their access to finance: perspectives from the informal sector", African Journal of Science, Technology, Innovation and Development, 7:4, pages 247 à 254

Kimm Gnangnon, S. (2018) "Aid for Trade and Employment in Developing Countries: An empirical evidence", Review of Labour Economics and Industrial Relations, 33 (1), pages 77 à 100

Knowles, S., P. Lorgelly, D. Owen (2002), "Are educational gender gaps a brake on economic development? Some crosscountry empirical evidence", Oxford Economic Papers, 54 (1), pages 118 à 149, Oxford University Press

Korinek, J. (2005), "Trade and Gender: Issues and Interactions", OCDE, Trade Policy Working Paper, nº 24 
Mason, A.D., E.M. King, (2001) Engendering development through gender equality in rights, resources, and voice, Banque mondiale, rapport sur les politiques de développement, http://documents.worldbank.org/curated/ en/512911468327401785/Engendering- development-through-gender-equality-in-rights-resources-and-voice, Washington, D.C.

Ministère des affaires étrangères et du commerce de l'Australie (2015), Strategy for Australia's Aid for Trade Investments, https://dfat.gov.au/about-us/publications/Documents/strategy-for-australias-aid-for-trade-investments.pdf

Ministère des affaires étrangères et du commerce de l'Australie (2016), Gender equality and women's empowerment strategy, https://dfat.gov.au/about-us/publications/Documents/gender-equality-and-womens-empowermentstrategy.pdf

Ministère des affaires étrangères et du commerce de l'Australie (2017), Australia advancing women's economic empowerment through aid, trade and economic diplomacy,

http://www.google.com/url?sa=t\&rct=j\&q=\&esrc=s\&source=web\&cd=2\&ved=2ahUKEwjUv8aTtdnhAAhWK3OAKHfY TDqAQFjABegQIAxAC\&url=http\%3A\%2F\%2Fdfat.gov.au\%2Fabout-us \% 2Fpublications\%2FDocuments\%2Faustraliaadvancing-womens-economic-empowerment-aid-trade-economic- diplomacy.pdf\&usg=AOvVaw3gMYsSsP5u1PO3M xBITxwm

Ministère des affaires étrangères et du commerce extérieur de la Nouvelle-Zélande, (2012), Tourism and Gender Equality Knowledge Note, Aid \& Development, https://www.mfat.govt.nz/assets/Aid-Prog-docs/Tools-and-guides/Gender-Knowledge-Note-Tourism. pdf

Morrison, A., R. Dhushyanth et S. Nistha (2007) Gender equality, poverty and economic growth, Banque mondiale, Policy Research working paper, WPS 4349, http://documents.worldbank.org/curated/en/758041468340239015/ Genderequality-poverty-and-economic-growth, Washington, D.C.

Nilufer, C. (2001) Trade, Gender and Poverty, document d'information sur le projet du PNUD relative au commerce et au développement humain durable, Programme des Nations Unies pour le développement (PNUD)

OCDE-OMC (2011), Exercice de suivi de l'Aide pour le commerce (questionnaires) www.oecd.org/aidfortrade/countryprofiles/

OCDE-OMC (2011), Exercice de suivi de l'Aide pour le commerce (cas d'expérience) http://www.oecd.org/aidfortrade/casestories/

OCDE-OMC (2015), Exercice de suivi de l'Aide pour le commerce (questionnaires) www.oecd.org/aidfortrade/countryprofiles/

OCDE-OMC (2015), Exercice de suivi de l'Aide pour le commerce (cas d'expérience) http://www.oecd.org/aidfortrade/casestories/

OCDE-OMC (2017), Exercice de suivi de l'Aide pour le commerce (questionnaires) www.oecd.org/aidfortrade/countryprofiles/

OCDE-OMC (2017), Exercice de suivi de l'Aide pour le commerce (cas d'expérience) http://www.oecd.org/aidfortrade/casestories/

OCDE-OMC (2019), Exercice de suivi de l'Aide pour le commerce (questionnaires) www.oecd.org/aidfortrade/countryprofiles/

OCDE (2019), "Système de notification des pays créanciers du CAD de I'OCDE: activités d'aide", Statistiques de l'OCDE sur le développement international (base de données)., DOI: https://www.oecd-ilibrary.org/fr/development/data/ systeme-de-notification-des-pays-creanciers/activites-d-aide_data-00061-fr (consulté le 25 janvier 2019) 
CHAPITRE 9. ENSEIGNEMENTS À TIRER DE L'AIDE POUR LE COMMERCE EN FAVEUR DE L'AUTONOMISATION ÉCONOMIQUE DES FEMMES

OCDE (2019a), "Breaking down Barriers to Women's Economics Empowerment: Policy Approaches to Unpaid Care Work", OECD Development, Policy Papers, No. 18, OECD Publishing, https://www.oecd-ilibrary.org/development/ breaking-down-barriers-to-women-s-economic-empowerment_c4ff3ddb-en, Paris

OCDE (2019, b), Using the SDGs as a shared framework for results, SDG indicator 7.1.1: Electricity Access, projet de rapport technique, atelier de Result Community de l'OCDE-DAC, 4 - 5 avril 2019, https://www.oecd.org/dac/resultsdevelopment/docs/Results_SDG_Case_studies_technical_report_7.1.1_draft_web.pdf

OMC, (2017) Déclaration conjointe sur le commerce et l'autonomisation économique des femmes à l'occasion de la Conférence ministérielle de Buenos Aires en décembre 2017

https://www.wto.org/english/thewto_e/minist_e/mc11_e/genderdeclarationmc11_e.pdf

Omi, M. (2013), Trade Liberalization and Women: A Feminist Analysis of the WTO System (en japonais), Shogakusha; première édition (28 juin 2013), Tokyo, 262 pages

ONU (1995), Déclaration de la quatrième Conférence mondiale des Nations Unies sur les femmes, Beijing (Chine) https:// www.un.org/womenwatch/daw/beijing/platform/economy.htm

ONU (2015), site Web des Objectifs de développement durable, Programme de développement durable, https://www.un.org/sustainabledevelopment/development-agenda/

ONU (2017) Leave no one behind: Taking Action for Transformational Change on Women's Economic Empowerment, deuxième rapport du Groupe de réflexion de haut niveau du Secrétaire général de I'ONU sur l'autonomisation économique des femmes, Nations Unies, https://www.unscn.org/uploads/web/news/UNSG-HLP-WEE-2nd-Report-.pdf, New York

ONU-Femmes (2015), Le progrès des femmes dans le monde 2015-2016: Transformer les économies, réaliser les droits, Nations Unies, https://www.unwomen.org///media/headquarters/attachments/sections/library/publications/2015/poww2015-2016-fr.pdf?la=fr\&vs=1639, New York

ONU-Femmes (2018), Site Web d'Empower Women, https://www.empowerwomen.org/en/who-we-are/initiatives/ sg-high-level-panel-on-womens-economic-empowerment

ONUDI (2015), Guide on Gender Mainstreaming Trade Capacity-Building Projects, UNIDO Gender, https://www.unido.org/sites/default/files/2015-02/Gender_TCB_Guide_0.pdf, Office des Nations Unies à Vienne

OPIC (2019), fiche d'information sur l'initiative 2X pour les femmes, http://opic-2x.sage-dev.net/

Organisation des Nations Unies pour l'alimentation et l'agriculture, Fonds international de développement agricole, Bureau international du travail (2010), Développement de la chaîne de valeur agricole: menace ou opportunité pour l'emploi des femmes?, Document d'orientation sur les sexospécificités et l'emploi rural, https://www.lo.org/wcmsp5/groups/public/---ed_emp/documents/publication/wcms_176240.pdf

Ostry, J.D., A. Berg, et C.G. Tsangarides (2014), Redistribution, Inequality, and Growth, Fonds monétaire international, Staff Discussion Notes, No. 14/02

Osundu, C.K., S. I. Ogbonna et C. O. Emerole (2015), "Level and Determinants of Women Farmers Access to Informal Credit in Abia State, Nigéria", Asian Journal of Agricultural Extension, Economics \& Sociology, 7(1), pages 1 à 10

Palacios-López, A. et R. López (2015), "The Gender Gap in Agricultural Productivity: The Role of Market Imperfections", The Journal of Development Studies, 51(9), pages 1175 à 1192, DOl: 10.1080/00220388.2015.1028539

Réseau du CAD de I'OCDE sur l'égalité homme-femme (2016), Handbook on the OECD-DAC Gender Equality Policy Marker, https:// www.oecd.org/dac/gender-development/Handbook-OECD-DAC-Gender-Equality-Policy-Marker.pdf 
Réseau du CAD de l'OCDE sur l'égalité homme-femme (2018), How Does Aid Support Women's Economic Empowerment?, http://www.oecd.org/dac/gender-development/How-Does-Aid-Support-Womens-Economic-Empowerment.pdf Sahay, R., M. Čihák, et autres fonctionnaires du FMI (2018), “Women in Finance: A Case for Closing Gaps", Fonds monétaire international, Staff Discussion Note, SDN/18/05

SFI (2016) Investing in Women along Agribusiness Value Chains, Société financière internationale, https://www.ifc.org/wps/wcm/connect/d19235d7-2ba7-4f7b-b0c6-5198fe9e4d30/Women+in+Agri+VC_Report_ FINAL.pdf?MOD=AJPERES, Washington

Terada-Hagiwara, A., Shiela, F. Camingue-Romance, et J.E. Zveglich, Jr. (2018), Gender Pay Gap: A Macro Perspective, Banque asiatique de développement, publication de la série Economics working paper, No. 538

Union européenne (2007), Stratégie conjointe de l'UE en faveur de l'aide pour le commerce, Conseil de l'Union européenne, Secrétariat général, Note 14470/07, http://register.consilium.europa.eu/doc/srv?!=FR\&f=ST\%2014470\%202007\%20INIT, Bruxelles

Union européenne (2015), Gender Equality and Women's Empowerment: Transforming the Lives of Girls and Women through EU External Relations 2016-2020, document de travail SWD(2015) 182 final, Commission européenne, Haut Représentant de l'Union pour les affaires étrangères et la politique de sécurité, https://ec.europa.eu/europeaid/sites/devco/files/150921_final_swd_gap.pdf

Union européenne (2017), Parvenir à la prospérité par le commerce et les investissements. Mise à jour de la stratégie conjointe de l'UE de 2007 en faveur de l'aide pour le commerce, Communication de la Commission COM (2017) 667 du 13 novembre 2017 et conclusions du Conseil 15573/17 du 11 décembre 2017, https://eur-lex.europa.eu/legal-content/FR/TXT/PDF/?uri=CELEX:52017DC0667\&from=FR

Union européenne (2018), EU Aid for Trade Progress Report 2018, European Commission, Direction Générale pour la Coopération internationale et le développement, https://ec.europa.eu/europeaid/eu-aid-trade-progress-report-2018_en 


\section{PROFILS DE PAYS ÉTABLIS DANS LE CADRE DE L'AIDE POUR LE COMMERCE}

Sont disponibles en ligne en version anglaise : https://www.wto.org/english/res_e/booksp_e/aid4trade19_profiles_e.pdf

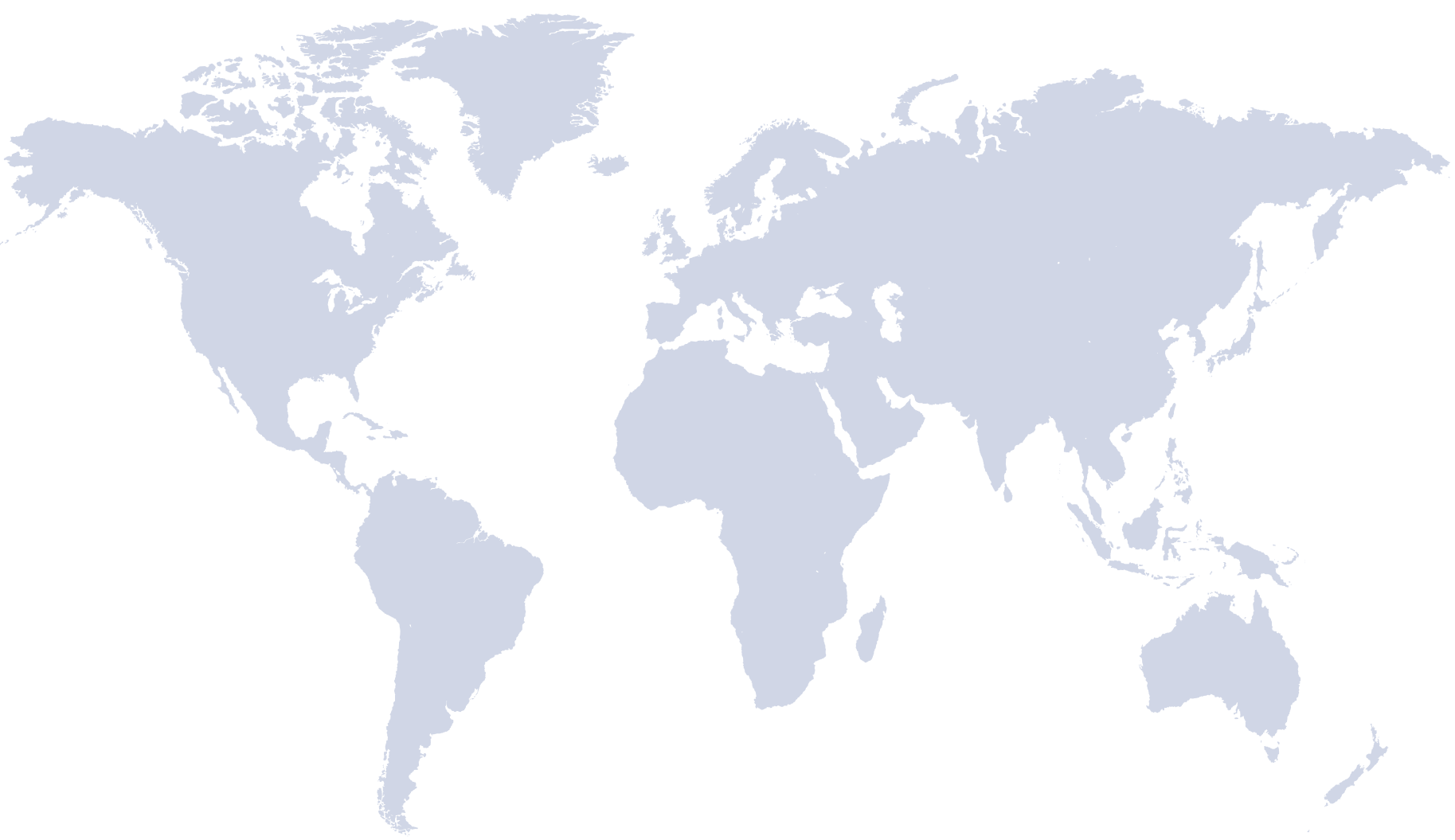





\section{NOTES EXPLICATIVES SUR LES PROFILS DE PAYS ÉTABLIS DANS LE CADRE DE L'AIDE POUR LE COMMERCE}

Les profils de pays établis dans le cadre de l'Aide pour le commerce donnent des informations factuelles destinées à stimuler le débat sur les tendances observées concernant l'Aide pour le commerce, les coûts du commerce, les résultats commerciaux et le développement au niveau des pays. L'objectif est de comparer les résultats d'un pays sur la base de quatre catégories d'indicateurs suivis sur la période 2006-2017 et, pour certains indicateurs, au regard de groupes de pays servant de points de référence.

Les profils de pays sont structurés suivant le modèle de la chaîne de résultats généralement utilisé dans les interventions de développement basées sur des projets. Le modèle de la chaîne de résultats illustre la séquence causale des interventions de développement sur la base de quatre éléments principaux : i) les apports et les activités créent ii) des produits directs, qui à leur tour conduisent à iii) des résultats intermédiaires qui contribuent à iv) des impacts à long terme.

Les profils de pays transposent l'idée sous-jacente à cet outil analytique basé sur des projets au niveau macroéconomique et retracent une séquence causale possible des interventions d'Aide pour le commerce pour atteindre les objectifs en matière de commerce et de développement. Les profils de pays présentent donc des indicateurs dans quatre sections : A. Financement du développement; B. Coûts du commerce; C. Résultats commerciaux; et D. Indicateurs du développement. Une grande partie de l'aide pour le commerce est consacrée à la réduction des coûts du commerce; des coûts du commerce plus faibles améliorent la connectivité et se traduisent par de meilleurs résultats commerciaux en termes de croissance et de diversification, et de meilleurs résultats commerciaux peuvent aider à améliorer les indicateurs du développement à long terme, notamment par le biais de la création d'emplois et de la réduction de la pauvreté

Les profils de pays n'établissent pas l'existence de liens de causalité; ils ne cherchent pas à vérifier ou à estimer l'impact de l'Aide pour le commerce au niveau macroéconomique. Ils donnent plutôt une perspective dynamique sur le développement d'un pays. En ce sens, la séquence retracée est une séquence de contribution, et non d'imputation. Lorsqu'il est possible d'établir cette contribution, les profils de pays fournissent une base pour mener une recherche approfondie fondée sur le pays. En ce sens, les profils de pays aident à mieux comprendre le rôle important que jouent les flux d'Aide pour le commerce dans la réalisation par un pays des objectifs en matière de commerce et de développement visés par ces flux.

La plupart des indicateurs des profils de pays offrent une comparaison entre 2006 et 2017. Toutefois, la période couverte est adaptée aux données disponibles au niveau tant des indicateurs que des pays. Pour un certain nombre d'indicateurs, des comparaisons au regard de groupes de référence sont indiquées. Les groupes de pays utilisés comme références sont les pays les moins avancés (PMA), les pays à revenu intermédiaire de la tranche inférieure (PRITI), les pays à revenu intermédiaire de la tranche supérieure (PRITS) et les pays à revenu élevé (PRE), conformément à la liste actuelle des PMA maintenue par les Nations Unies et à la classification par groupe de revenu de la Banque mondiale pour 2017. Les groupes de pays ne se chevauchent pas, ce qui signifie que les PMA ne sont pas inclus dans les groupes de revenu. Le Tadjikistan et le Zimbabwe, qui sont des pays à faible revenu mais pas des PMA, sont évalués par rapport aux PRITI. La composition des quatre groupes de pays diffère entre les indicateurs en fonction des données disponibles. Le nombre de pays inclus dans les quatre groupes pour un indicateur donné est précisé dans les descriptions des indicateurs figurant ci-dessous. 
Les profils de pays comprennent les quatre sections suivantes:

\section{A. FINANCEMENT DU DÉVELOPPEMENT}

Le financement du développement constitue une source essentielle de financement extérieur pour de nombreux pays en développement dans la mesure où il comprend les flux d'investissement étranger direct (FDI), les envois de fonds, l'aide publique au développement (APD) et les autres apports du secteur public (AASP). Le financement du développement est utilisé pour financer des investissements ainsi que la consommation privée et publique, et il est donc à la base de la croissance économique et du développement.

Cette section illustre la façon dont les flux d'Aide pour le commerce ont évolué au fil du temps, leur importance par rapport à d'autres flux de financement du développement, et l'importance de cette aide pour un pays par rapport à d'autres pays. En outre, la section montre les tendances observées dans les versements au titre de l'Aide pour le commerce au cours du temps au niveau global et au niveau des secteurs et des donateurs. Les flux de financement du développement sont présentés pour les périodes 2006-2008 et 2014-2016 (moyennes sur trois ans) et pour l'année 2017.

\section{Indicateurs et source}

L'IED désigne une relation à long terme et un intérêt durable assorti de l'exercice d'un contrôle sous la forme d'une participation acquise par une entité résidant dans un pays déterminé (l'investisseur étranger direct ou la société mère) dans une entreprise résidant dans un pays autre que celui de l'investisseur étranger direct (société étrangère affiliée). Les flux d'IED mesurent les capitaux nets (capitaux propres, bénéfices réinvestis et prêts interentreprises) fournis par un investisseur étranger direct à une société étrangère affiliée. Source : CNUCED, UNCTADstat.

Les envois de fonds comprennent les transferts personnels et la rémunération des employés. Les transferts personnels se composent de l'ensemble des transferts en espèces ou en nature que des ménages résidents reçoivent de la part de ménages non résidents. La rémunération des employés fait référence aux revenus des travailleurs frontaliers et saisonniers et autres travailleurs temporaires qui sont employés dans une économie autre que celle dont ils sont résidents, et à ceux des résidents employés par des entités non résidentes. La rémunération des employés représente généralement une part élevée des envois de fonds dans le cas des pays en développement qui sont proches d'une grande économie, comme le Lesotho, qui est frontalier de l'Afrique du Sud, ou qui se caractérisent par la présence d'institutions non résidentes, comme l'Afghanistan. Source : Banque mondiale, Indicateurs du développement dans le monde.

L'aide publique au développement (APD) comprend les prêts et les dons octroyés par le secteur public dans le but principal de promouvoir le développement économique et le bien-être des pays en développement. L'APD a un caractère libéral et comporte une partie de don d'au moins 25\% (calculé avec un taux d'escompte de 10\%). L'Aide pour le commerce est une sous-catégorie de l'APD et elle peut être classée dans les quatre catégories suivantes: politique et réglementation commerciales, infrastructure économique, renforcement des capacités de production et ajustement lié au commerce. L'APD et les apports d'aide pour le commerce sont déclarés comme des décaissements bruts. Source : OCDE, base de données sur les activités d'aide du CAD (SNPC).

Les autres apports du secteur public (AASP) sont les transactions du secteur public qui ne remplissent pas les conditions requises pour être comptabilisées comme APD, soit parce qu'elles n'ont pas principalement pour objectif le développement, soit parce que leur élément de libéralité est inférieur à 25\%. Les AASP liés au commerce sont une sous-catégorie des AASP et ils peuvent être classés dans les quatre catégories suivantes : politique et réglementation commerciales, infrastructure économique, renforcement des capacités de production et ajustement lié au commerce. Les AASP et les AASP liés au commerce sont déclarés comme des décaissements bruts. Source : OCDE, base de données sur les activités d'aide du CAD (SNPC). 
Les trois premières priorités en matière d'Aide pour le commerce sont basées sur le classement des catégories d'Aide pour le commerce réalisé par les pays dans les questionnaires d'auto-évaluation. Source : Questionnaire OCDE/ OMC destiné aux pays partenaires.

La part de l'Aide pour le commerce dans le financement du développement indique la dépendance d'un pays à l'égard de l'Aide pour le commerce par rapport aux autres flux de financement du développement. Le financement du développement correspond à la somme des flux d'IED, des envois de fonds, des AASP et de I'APD. Pour les périodes 2006-2008 et 2014-2016, le financement du développement est calculé comme la somme des moyennes sur trois ans de ces quatre flux. Nombre de pays inclus dans les groupes de référence : PMA (36), PRITI (25), PRITS (42). Sources: OCDE, base de données sur les activités d'aide du CAD (SNPC); CNUCED, UNCTADstat; Banque mondiale, Indicateurs du développement dans le monde.

La part de l'Aide pour le commerce dans la formation brute de capital fixe indique l'importance de l'Aide pour le commerce dans le financement de la formation brute de capital fixe. La formation brute de capital fixe comprend les améliorations foncières; les achats d'installations, de machines et d'équipements; et la construction de routes, de voies ferrées et d'autres infrastructures, y compris les écoles, les bureaux, les hôpitaux, les logements résidentiels privés et les bâtiments commerciaux et industriels. Nombre de pays inclus dans les groupes de référence : PMA (29), PRITI (26), PRITS (35). Sources: OCDE, base de données sur les activités d'aide du CAD (SNPC); Banque mondiale, Indicateurs du développement dans le monde.

\section{B. COÛTS DU COMMERCE}

Dans la chaîne de résultats, les apports et les activités qui les accompagnent donnent des produits. L'un des principaux objectifs des projets d'Aide pour le commerce est de réduire les coûts du commerce. La section consacrée aux coûts du commerce couvre les indicateurs qui permettent d'évaluer comment les coûts du commerce liés à l'infrastructure et à la politique d'un pays ont évolué au fil du temps et quel est le niveau des coûts du commerce par rapport à un groupe de pays de référence.

\section{Indicateurs et source}

Droits de douane : Les moyennes simples et pondérées des droits d'importation appliqués mesurent les droits de la nation la plus favorisée (NPF) appliqués, qui sont calculés sous forme de moyenne simple ou de moyenne pondérée en utilisant les flux d'importation au niveau à six chiffres du Système harmonisé (SH) comme pondération. La moyenne pondérée des droits d'exportation prend en compte les préférences et mesure le droit moyen pondéré appliqué au pays sur ses cinq principaux marchés d'exportation pour les produits agricoles et non agricoles, respectivement. La part des exportations en franchise de droits mesure la part des exportations qui atteignent ces principaux marchés d'exportation de produits agricoles et non agricoles en franchise de droits. Source : OMC, Profils tarifaires dans le monde.

Connectivité aux technologies de l'information et de la communication (TIC) (pourcentage de la population) : Les abonnements à des services à large bande mobiles (fixes) indiquent le pourcentage d'habitants qui disposent d'un abonnement actif à des services à large bande mobiles (fixes). Les utilisateurs d'Internet désignent le pourcentage de la population qui utilise Internet. Source : Union internationale des télécommunications (UIT), indicateurs des télécommunications/TIC dans le monde.

Coût du commerce et durée des transactions : II s'agit du coût en USD et du temps en heures que représentent la conformité documentaire et la conformité à la frontière douanière et lorsqu'une économie importe un lot standardisé de pièces automobiles en provenance de son partenaire d'importation naturel ou exporte son produit le plus important en valeur (sauf le pétrole et les produits des industries extractives) vers son partenaire d'exportation naturel. 
La conformité documentaire tient compte du coût et du temps associés au respect des prescriptions en matière de documents de tous les organismes gouvernementaux du pays d'origine, du pays de destination et, le cas échéant, du pays de transit. Il est également tenu compte du coût et du temps nécessaires pour obtenir, préparer, traiter, présenter et soumettre des documents. La conformité à la frontière tient compte du coût et du temps associés au respect des réglementations douanières du pays et des règlements relatifs aux inspections obligatoires à la frontière, par exemple au regard des normes sanitaires et phytosanitaires, ainsi que du coût et du temps nécessaires pour le traitement au port ou à la frontière. Nombre de pays inclus dans les groupes de référence : PMA (44), PRITI (31), PRITS (51), PRE (58). Source : Banque mondiale, Doing Business.

L'indice de performance logistique (IPL) (1-5) : L'IPL global" est un indicateur composite fondé sur la perception de la logistique d'un pays sur la base des six éléments suivants : l'efficacité du processus de dédouanement ("Douanes"), la qualité de l'infrastructure commerciale et de transport ("Infrastructure"), la facilité d'organiser des expéditions à des prix compétitifs ("Expéditions internationales"), la compétence et la qualité des services logistiques ("Compétences logistiques"), la capacité de suivre et de localiser les expéditions ("Suivi et localisation") et la fréquence à laquelle les expéditions arrivent à leurs destinataires dans les délais fixés ("Respect des délais"). L'indice et ses composantes vont de 1 à 5, une note plus élevée représentant une meilleure performance. Nombre de pays inclus dans les groupes de référence : PMA (39), PRITI (25), PRITS (41), PRE (51). Source : Banque mondiale, Indice de performance logistique.

Indicateurs de compétitivité (1-7) : Les indicateurs de compétitivité mesurent la perception par les dirigeants d'entreprise de l'accès au financement des PME, de l'efficacité des services de transport ferroviaire, de la qualité des routes, de l'efficacité des services de port maritime, de l'efficacité des services de transport aérien et de la concurrence dans les services de réseau. Les notes vont de 1 (faible) à 7 (meilleure). Nombre de pays inclus dans les groupes de référence : PMA (27), PRITI (25), PRITS (34), PRE (52). Source : Forum économique mondial, Global Competitiveness Report 2018.

Coûts du commerce (ad valorem, pourcentage) : Ces indicateurs mesurent les coûts ad valorem du commerce total, intrarégional et extrarégional d'un pays, en pourcentage, sur la base des moyennes simples des coûts du commerce ad valorem bilatéral. Compte tenu de la faible quantité de données disponibles, le nombre de partenaires utilisé pour le calcul des coûts du commerce moyens varie entre les pays. La mesure donne donc des informations sur l'évolution des coûts du commerce d'un pays dans le temps mais les comparaisons entre pays doivent être faites avec une grande prudence. Les coûts du commerce bilatéral sont obtenus à partir des flux commerciaux observables représentant la moyenne géométrique des coûts du commerce international entre deux pays par rapport aux coûts du commerce intérieur dans chaque pays. L'idée sous-jacente de la mesure est que si le commerce bilatéral augmente par rapport aux flux commerciaux intérieurs, les coûts du commerce bilatéral ont diminué. La base de données utilisée et le calcul des coûts du commerce bilatéral sont décrits dans Arvis et al. (2013). Pour calculer les coûts du commerce intrarégional et extrarégional, les partenaires commerciaux sont regroupés selon la classification de l'OMC dans les régions suivantes: Afrique, Asie, Communauté d'États indépendants (CEI), Europe, Moyen-Orient, Amérique du Nord, Amérique du Sud et Amérique centrale (y compris les Caraïbes). Source : Calculs de l'auteur à l'aide de la base de données CESAP/Banque mondiale sur les coûts du commerce.

Indicateurs de la facilitation des échanges (0-2) : Les indicateurs de la facilitation des échanges sont des indicateurs composites qui mesurent divers aspects de la facilitation des échanges, dont la plupart sont étroitement liés à I'Accord sur la facilitation des échanges de I'OMC, selon une note allant de 0 (faible) à 2 (meilleure). Les profils de pays présentent les six indicateurs suivants (sur un total de onze indicateurs) pour lesquels on dispose du plus de données : disponibilité des renseignements (publication des renseignements sur le commerce, y compris sur Internet; points d'information), décisions anticipées (engagement préalable de la part de l'administration suite à la demande d'un négociant concernant la manière dont la classification, l'origine, la méthode d'évaluation, etc., seront appliquées à des marchandises au moment de leur importation; les règles et les processus appliqués à cet engagement), procédures d'appel (conditions et modalités pour faire appel des décisions administratives prises par les agences frontalières), 
automatisation (échange électronique de données; procédures frontalières automatisées; utilisation des procédures de gestion des risques), procédures (rationalisation des contrôles aux frontières; guichets uniques; contrôles après dédouanement; opérateurs économiques agréés), gouvernance et impartialité (structures et fonctions des douanes; responsabilisation; déontologie). Nombre de pays inclus dans les groupes de référence : PMA (36), PRITI (28), PRITS (43), PRE (54). Source : Indicateurs sur la facilitation des échanges de l'OCDE.

\section{RÉSULTATS COMMERCIAUX}

Les interventions au titre de l'Aide pour le commerce visent à améliorer les résultats commerciaux des entreprises et des pays en remédiant aux contraintes nationales du côté de l'offre afin de réduire les coûts du commerce ou d'améliorer la capacité de production des entreprises. Cette section contient des indicateurs qui permettent d'évaluer les résultats commerciaux des pays en termes de valeur, de croissance, de structure et de diversification.

\section{Indicateurs et source}

Le ratio du commerce au PIB correspond au commerce total de marchandises et de services commerciaux (exportations + importations sur la base de la balance des paiements) d'un pays divisé par son PIB. Source : Secrétariat de l'OMC.

L'indicateur Services commerciaux en pourcentage des exportations (importations) totales mesure la part des services commerciaux dans les exportations (importations) mondiales de marchandises et de services commerciaux. Les flux commerciaux sont mesurés par les statistiques de la balance des paiements selon les principes énoncés dans la sixième édition du Manuel de la balance des paiements (MBP6). Source : Secrétariat de l'OMC.

L'indicateur Produits intermédiaires hors combustibles (pourcentage des exportations (importations) de marchandises) mesure la part des produits intermédiaires hors combustibles dans les exportations (importations) de marchandises en se fondant sur les statistiques douanières. Les produits intermédiaires sont classés selon la Classification par grandes catégories économiques de l'Organisation des Nations Unies. Les combustibles ne sont pas classés comme produits intermédiaires mais ils sont inclus dans les exportations totales de marchandises. Source : Base de données Comtrade des Nations Unies.

La rubrique Flux commerciaux (en milliards de dollars EU courants) fait référence aux exportations et aux importations de marchandises et de services commerciaux, mesurées par les statistiques de la balance des paiements selon les principes du MBP6. Les statistiques de la balance des paiements prennent en compte les transactions entre les résidents d'un pays et des non-résidents qui entraînent un changement de propriétaire. Source : Secrétariat de I'OMC.

Nombre de produits et de marchés : Le nombre de produits exportés et importés et le nombre de marchés d'exportation et d'importation donnent des mesures simples de la diversification des produits et des marchés, respectivement. Le nombre maximal de marchés est de 237 , tandis que le nombre maximal de produits, définis au niveau à quatre chiffres du Système harmonisé (SH) de 2002, est de 1 245. Source : Calculs de l'auteur à partir des données provenant de la base de données Comtrade des Nations Unies.

Indice de concentration de Hirschman-Herfindahl (IHH) : L'indice de concentration de Hirschman-Herfindahl mesure la concentration, ou la diversification, du commerce d'un pays en termes de produits ou de marchés. L'indice de concentration des produits d'exportation (importation) est calculé en additionnant le carré des parts des produits dans les exportations (importations) d'un pays, puis normalisé pour être compris entre 0 et 1 . L'indice de concentration du marché est calculé de manière analogue. Un indice de concentration des produits d'exportation et d'importation dont le score est proche de zéro indique un portefeuille de produits diversifié, c'est-à-dire réparti de façon égale, tandis qu'un score proche de 1 indique une forte concentration sur quelques produits. De même, dans le cas de l'indice de concentration des marchés d'exportation et d'importation, un score proche de 0 indique que le commerce est diversifié, c'està-dire réparti de façon égale sur les différents marchés, tandis qu'un score proche de 1 indique une concentration sur 
un petit nombre de marchés. II convient de noter que l'IHH donne uniquement des indications sur la distribution des échanges, et pas sur les nombres sous-jacents de produits et de marchés. L'évaluation, par exemple, de la diversification des exportations devrait donc prendre en compte à la fois le nombre de produits exportés et de marchés d'exportation et l'IHH indiquant dans quelle mesure les échanges sont répartis de manière égale entre ces produits et ces marchés. Source : Calculs de l'auteur à partir des données provenant de la base de données Comtrade des Nations Unies.

L'indicateur Structure du commerce des marchandises présente les exportations et les importations de marchandises ventilées par principaux groupes de produits selon les définitions des Statistiques du commerce international de l'OMC : les produits agricoles désignent les produits alimentaires (sections 0,1 et 4 et division 22 de la CITI Rev.3) et les matières premières (divisions 21, 23, 24, 25 et 26 de la CITI Rev.3). Les combustibles et les produits des industries extractives comprennent les minerais et autres minéraux, les combustibles et les métaux non ferreux. Les produits manufacturés comprennent le fer et l'acier, les produits chimiques, les autres produits semi-manufacturés, les machines et le matériel de transport, les textiles, les vêtements et les autres produits de consommation. La somme des parts est égale à 100\% dans la mesure où les flux commerciaux qui ne sont pas classés dans l'un de ces groupes de produits, comme l'or non monétaire, ne sont pas pris en compte dans le calcul. Source : Secrétariat de l'OMC.

La rubrique Structure du commerce des services indique la part des services relatifs aux voyages, des services de transport, des services liés aux marchandises et des autres services commerciaux dans les exportations et les importations de services commerciaux. Les services liés aux marchandises, entre autres, comprennent les activités de fabrication sous contrat, comme le traitement, l'assemblage, l'étiquetage et l'emballage ("services de fabrication fournis sur des intrants physiques détenus par des tiers"). Les autres services commerciaux désignent les services de communications, les services de construction, les services d'assurance, les services financiers, les services informatiques, les services d'information, les autres services fournis aux entreprises et les services culturels et récréatifs, ainsi que les redevances et droits de licence. Le commerce des services est mesuré par les statistiques de la balance des paiements selon les principes du MBP6. Source : Secrétariat de I'OMC.

La rubrique Cinq premiers marchés pour les exportations et les importations de marchandises (pourcentage) indique les cinq principaux marchés d'exportation et d'importation d'un pays selon les statistiques basées sur les données douanières. Les parts de marché des États membres de l'UE sont indiquées au niveau national selon le concept national, et elles peuvent donc différer des données harmonisées conformément au concept communautaire. Les origines ou les destinations non spécifiées (régions n.d.a., soutes et zones franches) ne sont pas indiquées si elles figurent parmi les cinq premiers marchés. Source : Base de données Comtrade des Nations Unies.

La rubrique Cinq premiers produits importés et exportés (pourcentage) indique les parts en pourcentage des cinq principaux produits exportés et importés par un pays selon les statistiques basées sur les données douanières. Les produits sont classés selon la troisième révision de la Classification type pour le commerce international (CITI Rev.3). Source : Base de données Comtrade des Nations Unies.

\section{INDICATEURS DU DÉVELOPPEMENT}

L'Aide pour le commerce a pour objectif de produire un impact à long-terme sur le développement par le biais d'une participation accrue des pays au commerce international. Cette section décrit les tendances des indicateurs du développement liés au développement humain et économique, y compris la pauvreté et les inégalités.

\section{Indicateurs et source}

L'indicateur Chômage (pourcentage de la population active totale) montre la part de la population active qui n'a pas de travail mais qui est prête à travailler et recherche un emploi. Les taux de chômage sont des estimations harmonisées de l'Organisation internationale du travail (OIT) qui permettent des comparaisons entre les pays et dans le temps. Source : OIT, ILOSTAT. 
L'indicateur Taux d'activité des femmes (pourcentage) indique dans quelle mesure les femmes participent au marché du travail. II mesure la part de la population féminine d'un pays âgée de 15 ans et plus qui est active sur le marché du travail, c'est-à-dire qui travaille ou est à la recherche d'un emploi. Source : OIT, ILOSTAT.

APD (pourcentage du produit national brut) : La part de l'APD nette dans le produit national brut (PNB) indique dans quelle mesure un pays dépend de l'aide au développement. Source : OCDE, base de données sur les activités d'aide du CAD (SNPC).

Droits d'importation perçus (pourcentage des recettes fiscales) : La part des droits d'importation dans les recettes fiscales indique dans quelle mesure un pays est tributaire des droits d'importation pour financer son budget public. Source : Banque mondiale, Indicateurs du développement dans le monde.

Service total de la dette (pourcentage des exportations totales) : Le service total de la dette est la somme des remboursements du capital et des intérêts payés sur la dette à long terme, des intérêts payés sur la dette à court terme et des remboursements (rachats et commissions) auprès du FMI. La dette extérieure tant publique que privée est incluse. La dette extérieure affecte la solvabilité d'un pays et les perceptions qu'en ont les investisseurs. Le ratio du service total de la dette aux exportations totales aide à évaluer la viabilité de la charge du service de la dette d'un pays, s'agissant en particulier de la capacité d'un pays à obtenir des devises grâce aux exportations. Source : Banque mondiale, Indicateurs du développement dans le monde.

Indice du développement humain (IDH) : L'IDH va de zéro (niveau minimal de développement) à un (niveau maximal de développement) et il résume les trois dimensions fondamentales du développement, à savoir la santé, l'éducation et le niveau de vie. Source : Programme des Nations Unies pour le développement (PNUD), Indicateurs internationaux du développement humain : indice du développement humain. Indice du développement humain

PIB par habitant, en PPA (en dollars internationaux constants de 2011) : Le PIB par habitant est converti en dollars internationaux en utilisant les taux de parité de pouvoir d'achat. Un dollar international a le même pouvoir d'achat par rapport au PIB que le dollar EU aux États-Unis. Nombre de pays inclus dans les groupes de référence: PMA (43), PRITI (31), PRITS (51), PRE (61). Source : Banque mondiale, Indicateurs du développement dans le monde.

Structure économique : L'évolution de la structure économique d'un pays est reflétée par la part de l'agriculture, de l'industrie et des services dans le PIB en 2006 et 2017. Source : Banque mondiale, Indicateurs du développement dans le monde.

Pauvreté: Le pourcentage de la population vivant avec moins de 1,90 dollar (3,20 dollars) par jour aux prix internationaux de 2011. Source : Banque mondiale, Indicateurs du développement dans le monde.

Inégalités : La part des revenus détenue par les deux déciles (quatre déciles) inférieurs de la population correspond au pourcentage des revenus qui reviennent aux sous-groupes de population figurant dans les déciles en question. Source : Banque mondiale, Indicateurs du développement dans le monde.

\section{Légende :}

"-" Sans objet

"..." Données non disponibles ou non communiquées 


\section{RÉFÉRENCES}

Arvis, J. F., Y. Duval, B. Shepherd et C. Utoktham (2013), "Trade costs in the developing world: 1995-2010", Banque mondiale, Policy Research Working Paper n 6309. 


\section{NOTES STATISTIQUES}

Selon la définition donnée par l'Équipe spéciale de l'OMC chargée de l'Aide pour le commerce, les projets et programmes relèvent de l'Aide pour le commerce s'ils sont désignés comme des priorités de développement liées au commerce dans les stratégies nationales de développement des pays partenaires. Par ailleurs, pour mesurer les flux d'Aide pour le commerce, l'Équipe spéciale a retenu les catégories suivantes:

a) assistance technique pour la politique et la réglementation commerciales : par exemple aider les pays à élaborer des stratégies commerciales, à négocier des accords commerciaux et à les mettre en œuvre;

b) nfrastructure liée au commerce : par exemple construction de routes, de ports et de réseaux de télécommunication pour mettre les marchés intérieurs en relation avec l'économie mondiale;

c) renforcement de la capacité de production (y compris le développement du commerce) : par exemple octroi d'un soutien au secteur privé pour qu'il exploite ses avantages comparatifs et diversifie ses exportations;

d) ajustement lié au commerce : aider les pays en développement à faire face aux coûts de la libéralisation du commerce (abaissement des droits de douane, érosion des préférences ou détérioration des termes de l'échange, par exemple); et

e) autres besoins liés au commerce : s'ils sont mentionnés comme des priorités de développement liées au commerce dans les stratégies nationales de développement des pays partenaires.

La base de données en ligne sur les activités d'aide du CAD de l'OCDE (Système de notification des pays créanciers - SNPC), qui couvre environ 90\% de l'aide publique au développement, est reconnue comme la meilleure source de données disponible pour le suivi des apports globaux d'Aide pour le commerce. Elle a été créée en 1967 et recueille des renseignements sur l'aide publique au développement (APD) et d'autres apports du secteur public destinés aux pays en développement. C'est la source de données de référence au niveau international sur les activités d'aide (ventilations géographiques et sectorielles), et elle est largement utilisée par les gouvernements, les organisations et les chercheurs qui s'occupent du développement. Pour I'OCDE, le SNPC est un moyen de suivre certaines questions de politique générale, dont l'Aide pour le commerce. II permet de suivre les engagements et les décaissements au titre de l'aide et fournit des données comparables dans le temps et entre pays. L'utilisation de cette base de données existante a permis d'économiser beaucoup de temps et de ressources pour le suivi effectif des apports d'Aide pour le commerce. Les principes et les directives concernant la communication d'informations au SNPC sont approuvés par les membres du CAD représentés au Groupe de travail sur les statistiques du CAD (WP STAT). L'OCDE collecte et compile les données, vérifie leur cohérence et maintient la base de données.

Il convient de garder à l'esprit que les données du SNPC ne correspondent pas exactement à chacune des catégories d'Aide pour le commerce mentionnées plus haut. En fait, le SNPC fournit des données supplétives concernant quatre rubriques:

- Politique et réglementation commerciales. Cinq codes objets sont utilisés dans le SNPC pour couvrir les activités en matière de politique et de réglementation commerciales. Ces sous-catégories sont les suivantes : politique commerciale et gestion administrative; facilitation des échanges; accords commerciaux régionaux; négociations commerciales multilatérales; et éducation/formation dans le domaine du commerce. 
- Infrastructure économique. Les montants destinés à l'infrastructure liée au commerce sont indiqués dans le SNPC par des données inscrites sous la rubrique "Infrastructure et services économiques" et couvrent les secteurs du transport et de l'entreposage, des communications et de la production et de la distribution d'énergie.

- Renforcement de la capacité de production, y compris le développement du commerce. Le SNPC intègre l'ensemble des données relatives aux secteurs de la production et des services, tels que l'agriculture, l'industrie, les industries extractives, les entreprises et la banque. Les activités de développement du commerce sont identifiées au moyen du marqueur du développement du commerce et figurent séparément dans le recueil de données du SNPC depuis 2007. Ces activités entrent dans la catégorie du renforcement de la capacité productive et sont marquées comme contribuant principalement ou de façon significative au développement du commerce. Toutefois, au moment de la notification, certains donateurs peuvent avoir des difficultés à déterminer quelles activités ont une composante commerciale clairement définie, ce qui peut avoir une incidence sur la fiabilité des données. Par conséquent, les montants indiqués sous la rubrique développement du commerce sont au mieux approximatifs.

- Ajustement lié au commerce. Cette nouvelle sous-rubrique a été introduite dans le SNPC en 2007 pour suivre les apports correspondant à l'ajustement lié au commerce. Elle indique les contributions versées aux budgets des pays en développement pour les aider à mettre en œuvre des réformes commerciales et des ajustements liés aux mesures commerciales prises par d'autres pays, et pour remédier aux déficits de la balance des paiements dus à l'évolution de l'environnement commercial mondial.

Le SNPC couvre l'ensemble de l'APD, mais seules les activités notifiées dans les quatre catégories susmentionnées sont considérées comme relevant de l'Aide pour le commerce. II n'est pas possible de distinguer les activités relatives aux "autres besoins liés au commerce". Pour estimer le volume de ces "autres" activités, il serait nécessaire d'examiner les projets d'aide dans les secteurs autres que ceux qui ont été pris en compte jusque-là - par exemple dans les domaines de la santé et de l'éducation - et d'indiquer, le cas échéant, la part de ces activités ayant une importante composante commerciale. Un programme en matière de santé, par exemple, peut permettre un accroissement du commerce à partir de localités où la charge de morbidité constituait un obstacle au commerce. Par conséquent, pour suivre l'Aide pour le commerce de manière rigoureuse, il faudrait comparer les données du SNPC et les auto-évaluations des fournisseurs d'aide et des pays partenaires.

\section{NOTES RELATIVES AUX TABLEAUX DE L'ANNEXE A}

La plupart des données indiquées dans l'annexe A proviennent du SNPC. Pour voir l'ensemble des données du SNPC, veuillez consulter l'adresse : $\underline{w w w . o e c d . o r g / d a c / s t a t s / i d s o n l i n e ~}$

\section{Fournisseurs d'aide pour le commerce et d'autres apports du secteur public liés au commerce :}

La liste des fournisseurs d'aide est divisée en trois rubriques, à savoir pays membres du CAD, autres donateurs bilatéraux et organisations multilatérales. Le nom complet des organisations figure dans la section "Acronymes".

La Corée est devenue membre du CAD en 2010 et elle a été rejointe en 2013 par I'Islande, la Pologne, la République slovaque, la Slovénie et la République tchèque. Les données relatives à ces pays portant sur les années précédentes peuvent être partielles. 
Les données provenant du CIR, de la FAO, du FMl, de I'ITC, de la CESAP, de la CESAO, de I'ONUDI, de l'OMC et de la Turquie correspondent aux données spécialisées sur les flux d'Aide pour le commerce communiquées depuis 2007. Elles peuvent ne pas représenter la totalité des apports individuels.

La Banque interaméricaine de développement (BID) a modifié sa méthode de notification au SNPC pour les apports 2009 et suivants.

Les données figurant sous la rubrique "Autres donateurs multilatéraux" englobent de petits montants provenant de plusieurs institutions multilatérales (GGGl, ACICl, Fonds nordique de développement, UNPBF, UNICEF).

\section{Bénéficiaires de l'aide :}

La liste des bénéficiaires d'aide publique au développement établie par le CAD énumère les pays et les territoires admis à bénéficier de l'aide publique au développement (APD). II s'agit de pays à faible revenu et à revenu intermédiaire, sur la base du revenu national brut (RNB) par habitant tel qu'il est publié par la Banque mondiale, à l'exception des membres du G-8, des membres de l'UE et des pays pour lesquels une date fixe d'adhésion à l'UE est prévue. Les pays à faible revenu comprennent les pays les moins avancés (PMA) tels que définis par l'Organisation des Nations Unies. La liste des bénéficiaires d'APD classés par groupe de revenu et par région qui a été établie par le CAD figure dans les annexes. L'historique complet des inscriptions et radiations de la liste des pays bénéficiaires est disponible à l'adresse : http://www.oecd.org/dac/stats/daclist.htm

\section{Circuits d'acheminement :}

La liste donnée dans le tableau A.11 reprend les principales catégories de circuits d'acheminement du SNPC. La liste complète pour chaque catégorie (mise à jour le 6 juillet 2016) est disponible à l'adresse : http://www.oecd.org/dac/stats/ annex2.htm.

La catégorie "Autres" correspond à des circuits d'acheminement tels qu'universités, lycées et autres établissements d'enseignement, instituts de recherche ou groupes de réflexion.

\section{Aide ventilable par secteur :}

Depuis 2010, la méthode utilisée pour calculer l'aide ventilable par secteur a changé. Pour évaluer l'intention des donateurs, le calcul est désormais basé sur le type d'aide. Cela permet d'inclure l'aide imprévisible qui répond à une politique spécifique. Par exemple, l'aide humanitaire est imprévisible mais elle permet des pratiques axées sur l'égalité entre les sexes. L'aide dont l'utilisation n'est pas contrôlée par le donateur, comme le soutien budgétaire sectoriel et les contributions aux budgets réguliers des ONG, n'est plus incluse.

\section{Légende :}
".." zéro.
0,0 montants inférieurs à 0,5 million d'USD.
0,0\% pourcentage inférieur à 0,5\%. 



\section{ANNEXE A}

\section{PRINCIPALES DONNÉES SUR L'AIDE POUR LE COMMERCE}

Millions d'USD (constants de 2017)

Tableau A.1. Aide pour le commerce par catégorie

ENGAGEMENTS

\begin{tabular}{l|l|l|l|l} 
Moyenne & Moyenne & Moyenne & Moyenne & 2015
\end{tabular} 2002-2005 2006-2008 $2009-2011 \quad 2012-2014$
DÉCAISSEMENTS

\begin{tabular}{l|l|l|l|l|l} 
Moyenne & Moyenne & Moyenne & 2015 & 2016 & 2017
\end{tabular} 2006-2008 $2009-2011 \quad 2012-2014$

\section{Politique et réglementation commerciales}

\begin{tabular}{|c|c|c|c|c|c|c|c|c|c|c|c|c|c|}
\hline $\begin{array}{l}\text { Politique commerciale et gestion } \\
\text { administrative }\end{array}$ & 581,9 & 666,0 & 635,8 & 529,3 & 676,7 & 472,4 & 700,2 & 468,9 & 523,7 & 500,0 & 426,4 & 546,4 & 738 \\
\hline Facilitation des échanges & 68,7 & 173,9 & 393,1 & 515,0 & 327,9 & 430,0 & 649,8 & 114,4 & 262,9 & 430,5 & 425,2 & 411,2 & 362,8 \\
\hline Accords commerciaux régionaux & 74,2 & 115,3 & 232,5 & 175,5 & 41,0 & 31,8 & 42,4 & 64,0 & 124,8 & 149,2 & 96,4 & 141,6 & 1,9 \\
\hline Négociations commerciales multilatérales & 14,4 & 39,6 & 17,8 & 9,2 & 7,7 & 7,8 & 5,6 & 23,7 & 32,5 & 18,9 & 16,1 & 13,6 & \\
\hline $\begin{array}{l}\text { Éducation/formation } \\
\text { dans le domaine du commerce }\end{array}$ & 9,7 & 30,2 & 32,7 & 21,5 & 34,3 & 30,2 & 26,3 & 20,7 & 30,6 & 23,6 & 33,0 & 34,6 & \\
\hline Sous-total & 748,8 & 1025,0 & 1311,9 & 1250,5 & 1087,6 & 972,1 & 1424,3 & 691,7 & 974,5 & 1122,3 & 997,0 & 1147,4 & 1216 \\
\hline \multicolumn{14}{|l|}{ Infrastructure économique } \\
\hline Transport et entreposage & 6297,9 & 9309,9 & 12084,7 & 14719,0 & 16381,1 & 18277,6 & 17773,3 & 5882,3 & 8677,6 & 11309,1 & 11123,8 & 10970,4 & 1231 \\
\hline Communications & 601,5 & 473,4 & 609,0 & 819,3 & 579,3 & 582,2 & 749,2 & 459,5 & 551,9 & 649,1 & 457,3 & 554,7 & \\
\hline Production et distribution d'énergie & 5206,0 & 6566,4 & 9235,9 & 13771,4 & 16748,8 & 13587,9 & 14347,9 & 4544,3 & 6186,3 & 8290,9 & 9778,9 & 9640,8 & 1089 \\
\hline Sous-total & 12105,4 & 16349,7 & 21929,6 & 29309,6 & 33709,2 & 32447,7 & 32870,3 & 10886,1 & 15415,8 & 20249,0 & 21359,9 & 21165,9 & 238 \\
\hline
\end{tabular}

Renforcement des capacités de production

\begin{tabular}{|c|c|c|c|c|c|c|c|c|c|c|c|c|c|}
\hline Entreprises et autres services & 1293,3 & 1969,4 & 1888,2 & 1719,3 & 1952,3 & 1902,0 & 2085,0 & 1795,1 & 1558,2 & 1584,4 & 2050,8 & 1846,4 & 1570,8 \\
\hline Banque et services financiers & 1643,7 & 2330,1 & 3069,7 & 4892,7 & 5401,7 & 4099,4 & 5152,2 & 2007,4 & 3183,5 & 4134,6 & 5633,3 & 4697,9 & 4472,2 \\
\hline Agriculture & 3908,3 & 5680,9 & 7712,0 & 8731,4 & 9842,4 & 8979,1 & 10634,9 & 3897,8 & 6027,5 & 6276,5 & 7400,8 & 7644,3 & 7484,7 \\
\hline Sylviculture & 515,3 & 596,4 & 675,3 & 741,7 & 767,6 & 648,5 & 983,2 & 518,1 & 723,0 & 628,9 & 753,8 & 561,3 & 805,0 \\
\hline Pêche & 242,7 & 333,6 & 445,0 & 338,2 & 351,7 & 498,0 & 963,5 & 258,4 & 327,3 & 280,5 & 234,8 & 364,6 & 544,2 \\
\hline Industrie & 1776,3 & 1563,8 & 1940,0 & 2150,0 & 2482,3 & 1665,6 & 2692,8 & 1192,4 & 1619,9 & 1748,5 & 1801,3 & 1442,0 & 2427,5 \\
\hline Industries extr & 832,2 & 388,7 & 426,0 & 558,8 & 578,8 & 157,8 & 575,4 & 431,8 & 284,1 & 737,3 & 450,7 & 405,0 & 481,4 \\
\hline Tourisme & 94,3 & 201,7 & 169,6 & 117,0 & 92,7 & 196,1 & 401,3 & 66,5 & 134,4 & 171,9 & 168,1 & 190,3 & 197,0 \\
\hline Sous-total & 0306,1 & 13064,6 & 16325,8 & 19249,2 & 21469,7 & 18146,6 & 23488,3 & 10167,4 & 13857,9 & 15562,6 & 18493,7 & 17151,9 & 17982,8 \\
\hline \multicolumn{14}{|l|}{ Ajustement lié au commerce } \\
\hline Ajustement lié au commerce &. & 2,0 & 20,7 & 2,2 & 2,3 & 21,3 & 0,8 & 7,8 & 36,4 & 14,6 & 13,5 & 10,5 & 5,4 \\
\hline Sous-total & .. & 2,0 & 20,7 & 2,2 & 2,3 & 21,3 & 0,8 & 7,8 & 36,4 & 14,6 & 13,5 & 10,5 & 5,4 \\
\hline AIDE POUR LE COMMERCE TOTALE & 23160,4 & 30441,3 & 39588,0 & 49811,5 & 56268,7 & 51587,7 & 57783,8 & 21753,0 & 30284,5 & 36948,5 & 40864,2 & 39475,7 & 43066,9 \\
\hline \multicolumn{14}{|c|}{ Priorité donnée au développement du commerce } \\
\hline Objectif principal &. & 1001,4 & 2478,6 & 2950,9 & 3771,5 & 2995,4 & 3546,3 & 907,3 & 2006,6 & 2910,0 & 3647,5 & 4046,5 & 3230,1 \\
\hline Objectif significatif &.. & 1330,9 & 2568,3 & 1814,8 & 2578,3 & 2519,4 & 4572,5 & 568,8 & 2112,1 & 1713,5 & 2191,5 & 1847,7 & 2584,5 \\
\hline TOTAL & .. & 2332,3 & 5046,9 & 4765,7 & 6349,8 & 5514,8 & 8118,7 & 1476,2 & 4118,6 & 4623,5 & 5839,0 & 5894,2 & 5814,6 \\
\hline \multicolumn{14}{|c|}{ Parts dans I'Aide pour le commerce totale } \\
\hline $\begin{array}{l}\text { Politique et réglementation } \\
\text { commerciales }\end{array}$ & $3,2 \%$ & $3,4 \%$ & $3,3 \%$ & $2,5 \%$ & $1,9 \%$ & $1,9 \%$ & $2,4 \%$ & $3,2 \%$ & $3,2 \%$ & $3,0 \%$ & $2,4 \%$ & $2,9 \%$ & $2,8 \%$ \\
\hline Infrastructure économique & $52,3 \%$ & $53,7 \%$ & $55,4 \%$ & $58,8 \%$ & $59,9 \%$ & $62,9 \%$ & $56,9 \%$ & $50,0 \%$ & $50,9 \%$ & $54,8 \%$ & $52,3 \%$ & $53,6 \%$ & $55,4 \%$ \\
\hline $\begin{array}{l}\text { Renforcement des capacités } \\
\text { de production }\end{array}$ & $44,5 \%$ & $42,9 \%$ & $41,2 \%$ & $38,6 \%$ & $38,2 \%$ & $35,2 \%$ & $40,7 \%$ & $46,7 \%$ & $45,8 \%$ & $42,1 \%$ & $45,3 \%$ & $43,4 \%$ & $41,8 \%$ \\
\hline Ajustement lié au commerce &. & $0,0 \%$ & $0,1 \%$ & $0,0 \%$ & $0,0 \%$ & $0,0 \%$ & $0,0 \%$ & $0,0 \%$ & $0,7 \%$ & $0,0 \%$ & $0,0 \%$ & $0,0 \%$ & $0,0 \%$ \\
\hline $\begin{array}{l}\text { Part dans l'aide ventilable } \\
\text { par secteur }\end{array}$ & $30,6 \%$ & $31,2 \%$ & $33,3 \%$ & $38,8 \%$ & $38,3 \%$ & $38,0 \%$ & $39,8 \%$ & $28,6 \%$ & $30,6 \%$ & $34,3 \%$ & $35,6 \%$ & $33,4 \%$ & $34,7 \%$ \\
\hline Part dans I'APD totale & $19,8 \%$ & $26,1 \%$ & $25,9 \%$ & $30,2 \%$ & $28,3 \%$ & $27,1 \%$ & $29,4 \%$ & $22,9 \%$ & $22,1 \%$ & $25,0 \%$ & $22,9 \%$ & $21,4 \%$ & $22,6 \%$ \\
\hline
\end{tabular}

Source: CAD de l'OCDE : base de données sur les activités d'aide (2019). 
Millions d'USD (constants de 2017)

Tableau A.2. Aide pour le commerce par catégorie et par région

ENGAGEMENTS

\begin{tabular}{l|l|l|l|l} 
Moyenne & Moyenne & Moyenne & Moyenne & 2015
\end{tabular} 2002-2005 2006-2008 2009-2011 2012-2014

\section{DÉCAISSEMENTS}

\begin{tabular}{l|l|l|l|l|l} 
Moyenne & Moyenne & Moyenne & 2015 & 2016 & 2017
\end{tabular} 2006-2008 $2009-2011 \quad 2012-2014$

\section{Afrique}

Politique et réglementation commerciales

Infrastructure économique

Renforcement des capacités

de production

Ajustement lié au commerce

Sous-total

\begin{tabular}{|r|r|r|r|r|r|r|r|r|r|r|r|r|}
\hline 370,9 & 352,9 & 425,7 & 427,0 & 490,4 & 291,1 & 470,0 & 203,3 & 317,1 & 387,2 & 377,6 & 418,7 & 320,0 \\
\hline 3459,5 & 5955,5 & 8205,5 & 10336,8 & 10755,0 & 10775,5 & 11756,8 & 3592,3 & 5353,0 & 7402,5 & 7922,3 & 8148,1 & 7982,4 \\
\hline 3267,7 & 4548,5 & 6047,0 & 7177,3 & 7722,7 & 7717,9 & 9514,8 & 3354,6 & 5060,4 & 5843,3 & 6064,2 & 6174,3 & 6900,4 \\
\hline.. & 1,4 & 4,8 & 0,0 & 0,0 & 2,3 & 0,3 & 7,5 & 26,2 & 1,2 & 0,3 & 0,1 & 0,6 \\
\hline $\mathbf{7 0 9 8 , 2}$ & $\mathbf{1 0 8 5 8 , 3}$ & $\mathbf{1 4 6 8 3 , 1}$ & $\mathbf{1 7 9 4 1 , 2}$ & $\mathbf{1 8 9 6 8 , 1}$ & $\mathbf{1 8 7 8 6 , 8}$ & $\mathbf{2 1 7 4 1 , 9}$ & $\mathbf{7 1 5 7 , 7}$ & $\mathbf{1 0 7 5 6 , 7}$ & $\mathbf{1 3 6 3 4 , 2}$ & $\mathbf{1 4 3 6 4 , 3}$ & $\mathbf{1 4 7 4 1 , 2}$ & $\mathbf{1 5 2 0 3 , 4}$ \\
\hline
\end{tabular}

Amérique

Politique et réglementation

commerciales

Infrastructure économique

Renforcement des capacités

de production

Ajustement lié au commerce

Sous-total

\begin{tabular}{|r|r|r|r|r|r|r|r|r|r|r|r|r|}
\hline 62,7 & 109,5 & 169,4 & 75,4 & 71,3 & 66,7 & 34,4 & 83,0 & 93,3 & 94,8 & 89,7 & 68,6 & 59,6 \\
\hline 451,8 & 720,1 & 1319,8 & 2385,9 & 2647,4 & 2295,8 & 3346,7 & 421,0 & 1147,6 & 1714,8 & 1589,9 & 1575,6 & 2096,7 \\
\hline $\mathbf{1 0 9 3 , 3}$ & 1126,1 & 1492,8 & 1417,0 & 1504,4 & 1410,4 & 1365,0 & 1024,9 & 1418,3 & 1242,8 & 1202,6 & 1524,2 & 1145,5 \\
\hline.. & 0,3 & 12,8 & 0,0 & 0,0 & 18,7 & 0,1 & 0,0 & 5,7 & 9,2 & 11,4 & 7,6 & 3,0 \\
\hline $\mathbf{1 6 0 7 , 8}$ & $\mathbf{1 9 5 6 , 0}$ & $\mathbf{2 9 9 4 , 6}$ & $\mathbf{3 8 7 8 , 4}$ & $\mathbf{4 2 2 3 , 1}$ & $\mathbf{3 7 9 1 , 7}$ & $\mathbf{4 7 4 6 , 2}$ & $\mathbf{1 5 2 8 , 9}$ & $\mathbf{2 6 6 4 , 9}$ & $\mathbf{3 0 6 1 , 7}$ & $\mathbf{2 8 9 3 , 6}$ & $\mathbf{3} \mathbf{3 1 7 6 , 0}$ & $\mathbf{3 3 0 4 , 7}$ \\
\hline
\end{tabular}

Asie

Politique et réglementation commerciales

Infrastructure économique

Renforcement des capacités

de production

Ajustement lié au commerce

\section{Sous-total}

2073

\section{Europe}

Politique et réglementation commerciales

Infrastructure économique

Renforcement des capacités de production

Ajustement lié au commerce

Sous-total

\begin{tabular}{|r|r|r|r|r|r|r|r|r|r|r|r|r|}
\hline 151,4 & 247,3 & 295,2 & 361,7 & 181,7 & 352,2 & 631,5 & 173,2 & 261,2 & 280,1 & 245,7 & 379,3 & 508,1 \\
\hline 7168,8 & 8440,8 & 9922,2 & 13163,1 & 18284,7 & 16444,4 & 14974,5 & 5897,2 & 6588,7 & 8610,4 & 10005,8 & 8940,7 & 11421,0 \\
\hline 4499,2 & 5154,2 & 4924,3 & 5454,2 & 6804,4 & 4304,4 & 6508,5 & 4052,7 & 4378,3 & 4119,3 & 5232,2 & 4079,8 & 4701,4 \\
\hline.. & 0,2 & 2,9 & 0,3 & 0,0 & 0,3 & 0,1 & 0,4 & 3,0 & 2,1 & 0,1 & 1,1 & 0,9 \\
\hline $\mathbf{1 1 8 1 9 , 4}$ & $\mathbf{1 3 8 4 2 , 6}$ & $\mathbf{1 5 1 4 4 , 6}$ & $\mathbf{1 8 9 7 9 , 3}$ & $\mathbf{2 5 2 7 0 , 8}$ & $\mathbf{2 1} \mathbf{1 0 1 , 3}$ & $\mathbf{2 2} \mathbf{1 1 4 4 6}$ & $\mathbf{1 0} \mathbf{1 2 3 , 5}$ & $\mathbf{1 1 2 3 1 , 2}$ & $\mathbf{1 3 0 1 1 , 9}$ & $\mathbf{1 5 4 8 3 , 9}$ & $\mathbf{1 3 4 0 0 , 9}$ & $\mathbf{1 6 6 3 1 , 4}$ \\
\hline
\end{tabular}

\section{Océanie}

Politique et réglementation commerciales

Infrastructure économique

Renforcement des capacités

de production

Ajustement lié au commerce

\section{Sous-total}

\begin{tabular}{|r|r|r|r|r|r|r|r|r|r|r|r|r|}
\hline 24,8 & 76,0 & 63,2 & 72,8 & 23,4 & 25,0 & 63,8 & 25,1 & 49,9 & 51,0 & 39,7 & 28,4 & 86,0 \\
\hline 702,3 & 769,3 & 1472,4 & 2647,0 & 914,7 & 2170,6 & 1608,8 & 668,1 & 1491,5 & 1915,5 & 1276,0 & 1850,4 & 1620,1 \\
\hline 579,0 & 650,5 & 1176,3 & 2639,1 & 2302,2 & 2186,4 & 2286,9 & 501,5 & 1102,0 & 2254,2 & 2649,5 & 2310,4 & 2196,0 \\
\hline.. & 0,0 & 0,2 & 1,8 & 2,2 & 0,0 & 0,3 & 0,0 & 1,1 & 2,0 & 1,7 & 1,7 & 0,7 \\
\hline $\mathbf{1 3 0 6 , 1}$ & $\mathbf{1 4 9 5 , 8}$ & $\mathbf{2 7 1 2 , 1}$ & $\mathbf{5 3 6 0 , 7}$ & $\mathbf{3 2 4 2 , 5}$ & $\mathbf{4 3 8 2 , 0}$ & $\mathbf{3 9 5 9 , 8}$ & $\mathbf{1 1 9 4 , 7}$ & $\mathbf{2 6 4 4 , 5}$ & $\mathbf{4 2 2 2 , 8}$ & $\mathbf{3 9 6 6 , 9}$ & $\mathbf{4 1 9 1 , 0}$ & $\mathbf{3 9 0 2 , 8}$ \\
\hline
\end{tabular}

Non spécifique à une région

Politique et réglementation

commerciales

Infrastructure économique

Renforcement des capacités

de production

Ajustement lié au commerce

Sous-total

AIDE POUR LE COMMERCE TOTALE

\begin{tabular}{|r|r|r|r|r|r|r|r|r|r|r|r|r|}
\hline 3,3 & 4,5 & 33,1 & 15,7 & 10,9 & 14,1 & 37,9 & 2,4 & 10,0 & 19,3 & 21,0 & 10,4 & 13,2 \\
\hline 130,3 & 219,3 & 288,0 & 390,0 & 703,6 & 365,2 & 560,7 & 137,2 & 200,7 & 281,8 & 359,1 & 345,1 & 381,8 \\
\hline 105,9 & 133,1 & 156,3 & 157,8 & 169,8 & 133,5 & 375,1 & 116,4 & 112,5 & 126,5 & 180,2 & 134,6 & 298,3 \\
\hline.. & 0,0 & 0,0 & 0,0 &.. & 0,0 &.. & 0,0 & 0,3 & 0,0 &.. & 0,0 &.. \\
\hline $\mathbf{2 3 9 , 5}$ & $\mathbf{3 5 6 , 8}$ & $\mathbf{4 7 7 , 4}$ & $\mathbf{5 6 3 , 5}$ & $\mathbf{8 8 4 , 3}$ & $\mathbf{5 1 2 , 8}$ & $\mathbf{9 7 3 , 8}$ & $\mathbf{2 5 6 , 1}$ & $\mathbf{3 2 3 , 4}$ & $\mathbf{4 2 7 , 5}$ & $\mathbf{5 6 0 , 3}$ & $\mathbf{4 9 0 , 1}$ & $\mathbf{6 9 3 , 3}$ \\
\hline
\end{tabular}

Source: CAD de l'OCDE : base de données sur les activités d'aide (2019).

\begin{tabular}{|c|c|c|c|c|c|c|c|c|c|c|c|c|}
\hline 135,7 & 234,9 & 325,3 & 297,9 & 309,9 & 223,0 & 186,6 & 204,7 & 243,1 & 289,8 & 223,2 & 242,0 & 230,0 \\
\hline 192,9 & 244,7 & 721,7 & 386,8 & 403,9 & 396,1 & 622,8 & 170,2 & 634,2 & 324,1 & 206,8 & 305,9 & 359,7 \\
\hline 760,9 & 1452,2 & 2529,3 & 2403,7 & 2966,1 & 2393,9 & 3438,0 & 1117,3 & 1786,5 & 1976,4 & 3165,0 & 2928,5 & 2741,3 \\
\hline & 0,0 & 0,0 & 0,0 & 0,0 & .. & 0,1 & 0,0 & 0,0 & 0,0 & 0,0 & & 0,3 \\
\hline 1089,5 & 1931,8 & 3576,2 & 3088,4 & 3679,9 & 3013,0 & 4247,5 & 1492,2 & 2663,7 & 2590,3 & 3595,1 & 3476,4 & 3331,2 \\
\hline 23160,4 & 30441,3 & 39588,0 & 49811,5 & 56268,7 & 51587,7 & 57783,8 & 21753,0 & 30284,5 & 36948,5 & 40864,2 & 39475,7 & 43066,9 \\
\hline
\end{tabular}

StatLink न्ता st http://dx.doi.org/10.1787/888933962134 
Millions d'USD (constants de 2017)

Tableau A.3. Aide pour le commerce par catégorie et par groupe de revenu

ENGAGEMENTS

\begin{tabular}{l|l|l|l|l} 
Moyenne & Moyenne & Moyenne & Moyenne & 2015
\end{tabular}

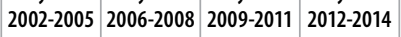

\section{DÉCAISSEMENTS}

\begin{tabular}{l|l|l|l|l|l} 
Moyenne & Moyenne & Moyenne & 2015 & 2016 & 2017
\end{tabular} 2006-2008 2009-2011 2012-2014

\section{Pays les moins avancés}

Politique et réglementation commerciales

Infrastructure économique

Renforcement des capacités

de production

Ajustement lié au commerce

Sous-total

\begin{tabular}{|r|r|r|r|r|r|r|r|r|r|r|r|r|r|}
\hline 83,3 & 210,0 & 226,6 & 334,9 & 237,6 & 152,6 & 486,5 & 118,4 & 148,8 & 244,9 & 253,1 & 299,4 & 162,0 \\
\hline 3441,8 & 5154,4 & 6973,5 & 8488,9 & 11224,6 & 8920,3 & 11746,6 & 3047,1 & 4460,3 & 5454,8 & 6104,0 & 5414,2 & 7229,3 \\
\hline 2722,1 & 3448,6 & 4963,0 & 5083,5 & 6522,2 & 5552,7 & 6553,8 & 2666,2 & 3894,0 & 3879,3 & 4418,5 & 4289,7 & 4782,8 \\
\hline.. & 1,5 & 2,3 & 0,0 & 0,0 & 2,3 & 0,0 & 7,7 & 24,7 & 2,0 & 0,3 & 1,0 & 1,1 \\
\hline $\mathbf{6 2 4 7 , 2}$ & $\mathbf{8 8 1 4 , 5}$ & $\mathbf{1 2 1 6 5 , 4}$ & $\mathbf{1 3 9 0 7 , 3}$ & $\mathbf{1 7 9 8 4 , 4}$ & $\mathbf{1 4 6 2 7 , 8}$ & $\mathbf{1 8 7 8 6 , 8}$ & $\mathbf{5 8 3 9 , 4}$ & $\mathbf{8 5 2 7 , 7}$ & $\mathbf{9 5 5 8 1 , 0}$ & $\mathbf{1 0 7 7 5 , 9}$ & $\mathbf{1 0 0 0 4 , 3}$ & $\mathbf{1 2 1 7 5 , 2}$ \\
\hline
\end{tabular}

Autres pays à faible revenu (APFR)

\begin{tabular}{|c|c|c|c|c|c|c|c|c|c|c|c|c|c|}
\hline $\begin{array}{l}\text { Politique et réglementation } \\
\text { commerciales }\end{array}$ & 0,2 & 0,8 & 2,2 & 2,6 & 1,0 & 0,2 & 0,2 & 0,5 & 0,7 & 2,8 & 2,6 & 2,5 & 0,2 \\
\hline Infrastructure économique & 32,9 & 6,5 & 10,7 & 13,9 & 1,0 & 1,3 & 26,1 & 6,8 & 9,5 & 11,7 & 5,7 & 7,1 & 11,2 \\
\hline $\begin{array}{l}\text { Renforcement des capacités } \\
\text { de production }\end{array}$ & 12,5 & 16,5 & 85,3 & 56,2 & 113,6 & 53,4 & 57,6 & 12,3 & 60,1 & 64,9 & 56,4 & 57,2 & 51,0 \\
\hline Ajustement lié au commerce & & 0,0 & 0,0 & & .. & .. & & 0,0 & 1,3 & & .. & .. & \\
\hline Sous-total & 45,6 & 23,9 & 98,2 & 72,7 & 115,6 & 54,9 & 83,9 & 19,6 & 71,7 & 79,3 & 64,6 & 66,8 & 62,4 \\
\hline
\end{tabular}

Pays à revenu intermédiaire de la tranche inférieure (PRITI)

\begin{tabular}{|c|c|c|c|c|c|c|c|c|c|c|c|c|c|}
\hline $\begin{array}{l}\text { Politique et réglementation } \\
\text { commerciales }\end{array}$ & 337,7 & 220,2 & 249,3 & 292,9 & 291,0 & 330,9 & 348,3 & 159,0 & 214,3 & 242,3 & 199,9 & 345,5 & 441,5 \\
\hline Infrastructure économique & 4958,2 & 7064,1 & 10372,0 & 15065,9 & 16657,4 & 15791,3 & 14820,4 & 4312,3 & 6854,8 & 9878,1 & 11149,8 & 10546,5 & 11402,9 \\
\hline $\begin{array}{l}\text { Renforcement des capacités } \\
\text { de production }\end{array}$ & 3654,7 & 4660,5 & 4928,9 & 6293,2 & 6711,0 & 5185,1 & 8034,7 & 3152,5 & 4161,5 & 4794,4 & 5548,0 & 4636,3 & 5673,8 \\
\hline Ajustement lié au commerce &.. & 0,0 & 2,1 & 1,1 & 0,0 & 0,0 & 0,2 & 0,0 & 2,8 & 2,3 & 0,5 & 0,5 & 0,3 \\
\hline Sous-total & 8950,5 & 11944,8 & 15552,3 & 21653,1 & 23659,3 & 21307,2 & 23203,7 & 7623,8 & 11233,3 & 14917,0 & 16898,1 & 15528,7 & 17518,4 \\
\hline
\end{tabular}

Pays à revenu intermédiaire de la tranche supérieure (PRITS)

Politique et réglementation

commerciales

Infrastructure économique

Renforcement des capacités

de production

Ajustement lié au commerce

Sous-total

\begin{tabular}{|r|r|r|r|r|r|r|r|r|r|r|r|r|r|r|r|}
\hline & 79,4 & 126,0 & 115,3 & 85,9 & 35,6 & 21,1 & 37,4 & 84,2 & 83,8 & 94,6 & 65,1 & 38,4 & 48,0 \\
\hline & 3221,1 & 3239,9 & 2874,6 & 4275,0 & 4693,0 & 5822,8 & 4214,4 & 3057,1 & 2794,0 & 3777,1 & 3337,0 & 3993,7 & 3837,5 \\
\hline & 2545,6 & 2264,2 & 2285,2 & 3670,6 & 3280,8 & 2673,3 & 3020,2 & 2179,0 & 2271,9 & 3295,1 & 3384,1 & 3187,2 & 2760,8 \\
\hline & & 0,3 & 12,8 & 0,8 & 0,4 & 18,6 & 0,4 & 0,2 & 7,2 & 10,1 & 11,9 & 8,3 & 3,3 \\
\hline
\end{tabular}

Non spécifique à un pays

Politique et réglementation

commerciales

Infrastructure économique

Renforcement des capacités

de production

Ajustement lié au commerce

Sous-total

AIDE POUR

LE COMMERCE TOTALE

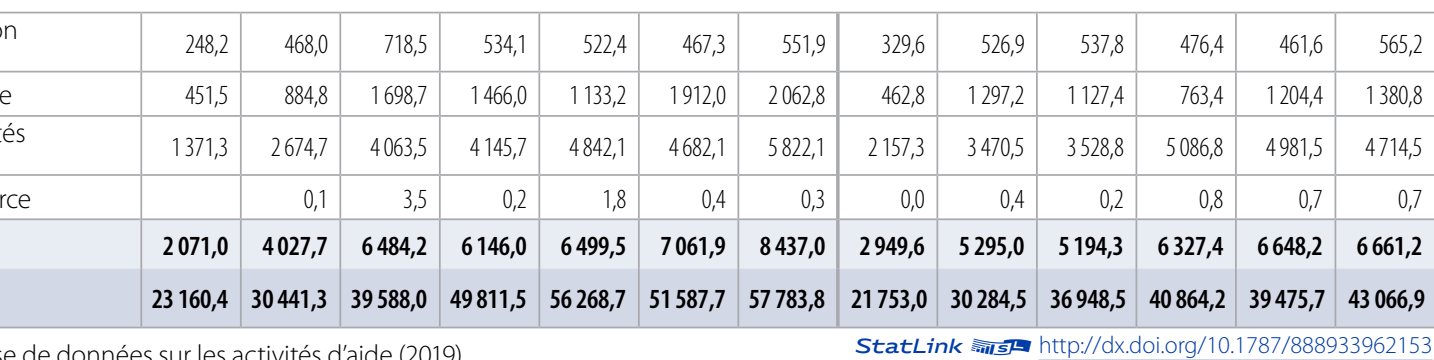

Source: CAD de l'OCDE : base de données sur les activités d'aide (2019). 
Millions d'USD (constants de 2017)

Tableau A.4. Aide pour le commerce par donateur (page 1 sur 2)

ENGAGEMENTS

Moyenne Moyenne Moyenne Moyenne 2015

2002-2005 2006-2008 2009-2011 2012-2014
DÉCAISSEMENTS

\begin{tabular}{|l|c|c|c|c|c|} 
Moyenne & Moyenne & Moyenne & 2015 & 2015 & 2017 \\
\hline
\end{tabular} 2006-2008 2009-2011 2012-2014

\begin{tabular}{|c|c|c|c|c|c|c|c|c|c|c|c|c|c|}
\hline \multicolumn{14}{|l|}{ Pays CAD } \\
\hline Allemagne & 1217,6 & 2033,4 & 3317,0 & 4866,1 & 5887,8 & 6093,6 & 5696,6 & 1673,2 & 2558,5 & 3182,4 & 5193,9 & 4613,7 & 4522,4 \\
\hline Australie & 206,6 & 311,3 & 494,4 & 385,6 & 412,2 & 394,3 & 427,8 & 253,8 & 391,1 & 385,6 & 412,2 & 394,3 & 427,8 \\
\hline Autriche & 45,2 & 52,7 & 74,3 & 86,5 & 71,1 & 75,5 & 75,8 & 38,7 & 59,8 & 58,9 & 47,5 & 48,4 & 64,5 \\
\hline Belgique & 229,9 & 254,6 & 431,8 & 184,9 & 215,6 & 164,8 & 217,0 & 175,8 & 382,5 & 204,4 & 214,5 & 195,7 & 192,7 \\
\hline Canada & 327,6 & 359,8 & 552,5 & 504,2 & 722,7 & 555,6 & 186,4 & 272,8 & 566,2 & 441,3 & 347,3 & 393,8 & 463,5 \\
\hline Corée & & 490,3 & 941,1 & 877,6 & 930,8 & 1061,0 & 1183,7 & 200,7 & 373,3 & 518,5 & 613,1 & 590,9 & 556,5 \\
\hline Danemark & 413,6 & 269,5 & 303,1 & 371,1 & 124,6 & 255,4 & 203,5 & 260,4 & 330,3 & 335,9 & 269,1 & 255,0 & 232,4 \\
\hline Espagne & 359,8 & 658,0 & 817,1 & 90,0 & 52,0 & 42,9 & 105,6 & 460,5 & 808,2 & 111,5 & 69,6 & 79,7 & 90,3 \\
\hline États-Unis & 4278,2 & 6094,8 & 4696,0 & 3469,0 & 3487,4 & 2975,3 & 2416,9 & 4403,2 & 4332,0 & 3550,3 & 2922,1 & 2748,0 & 2406,5 \\
\hline Finlande & 78,7 & 126,8 & 291,8 & 131,7 & 91,9 & 70,2 & 223,3 & 61,1 & 136,4 & 155,2 & 155,7 & 126,7 & 168,7 \\
\hline France & 656,9 & 1405,8 & 1347,1 & 2501,2 & 2913,7 & 2510,3 & 3225,0 & 839,0 & 1092,9 & 1746,1 & 1504,2 & 1928,8 & 2470,8 \\
\hline Grèce & 11,4 & 16,7 & 15,5 & 0,1 & 0,0 & 0,0 & 0,0 & 16,7 & 15,5 & 0,1 & 0,0 & 0,0 & 0,0 \\
\hline Hongrie & & 0,0 & 0,0 & 0,0 & 0,4 & 3,9 & 2,4 & 0,0 & 0,0 & 2,1 & 0,4 & 3,9 & 2,4 \\
\hline Irlande & 26,6 & 42,2 & 58,4 & 47,8 & 33,0 & 40,2 & 42,7 & 42,2 & 58,4 & 47,8 & 33,0 & 40,2 & 42,7 \\
\hline Islande & & 0,0 & 3,3 & 12,0 & 8,4 & 8,7 & 8,4 & 0,0 & 3,3 & 12,0 & 8,4 & 8,7 & 8,4 \\
\hline Italie & 249,7 & 228,7 & 164,9 & 117,4 & 189,9 & 77,5 & 352,6 & 240,0 & 142,8 & 87,2 & 201,0 & 98,4 & 290,3 \\
\hline Japon & 4492,8 & 5661,4 & 6073,6 & 8321,9 & 12683,5 & 11268,9 & 12510,7 & 4040,3 & 4761,0 & 5906,4 & 6407,7 & 6317,1 & 8264,1 \\
\hline Luxembourg & 16,9 & 31,4 & 34,0 & 38,9 & 33,9 & 38,6 & 55,2 & 31,4 & 34,0 & 38,9 & 33,9 & 38,6 & 55,2 \\
\hline Norvège & 246,3 & 399,0 & 502,6 & 527,1 & 338,1 & 348,9 & 497,4 & 378,6 & 383,7 & 484,0 & 482,3 & 404,3 & 426,9 \\
\hline Nouvelle-Zélande & 22,5 & 45,7 & 97,9 & 120,6 & 145,0 & 128,6 & 162,0 & 31,0 & 53,6 & 98,1 & 114,3 & 105,6 & 98,3 \\
\hline Pays-Bas & 533,3 & 686,9 & 698,9 & 865,0 & 607,6 & 511,7 & 655,0 & 476,9 & 474,8 & 618,5 & 540,5 & 616,0 & 542,3 \\
\hline Pologne & & 0,0 & 0,0 & 8,8 & 31,9 & 80,5 & 16,0 & 0,0 & 0,0 & 8,8 & 31,7 & 80,3 & 16,0 \\
\hline Portugal & 43,3 & 28,1 & 51,0 & 27,8 & 25,3 & 4,2 & 3,4 & 35,6 & 52,5 & 41,1 & 23,5 & 5,1 & 3,9 \\
\hline République slovaque & & 0,0 & 0,0 & 0,6 & 0,9 & 0,8 & 0,8 & 0,0 & 0,0 & 0,5 & 0,8 & 1,1 & 0,7 \\
\hline République tchèque & & 0,0 & 3,5 & 7,8 & 11,2 & 6,9 & 9,0 & 0,0 & 3,4 & 7,9 & 11,2 & 6,3 & 8,4 \\
\hline Royaume-Uni & 646,0 & 806,7 & 1107,1 & 851,3 & 1513,7 & 811,6 & 1136,5 & 827,6 & 1177,5 & 1293,4 & 1960,6 & 1815,7 & 1918,9 \\
\hline Slovénie & & 0,0 & 2,1 & 1,2 & 0,1 & 1,2 & 1,0 & 0,0 & 2,1 & 0,8 & 0,6 & 1,7 & 1,2 \\
\hline Suède & 225,5 & 326,3 & 330,5 & 374,0 & 292,1 & 345,6 & 382,8 & 328,2 & 346,2 & 396,8 & 337,3 & 334,8 & 441,5 \\
\hline Suisse & 295,4 & 266,1 & 282,7 & 374,5 & 305,1 & 353,8 & 695,0 & 245,9 & 224,8 & 295,6 & 370,4 & 370,9 & 331,9 \\
\hline Sous-total & 14623,8 & 20596,1 & 22692,4 & 25164,6 & 31130,1 & 28230,7 & 30492,4 & 15333,6 & 18764,8 & 20029,9 & 22306,7 & 21623,7 & 24049,3 \\
\hline \multicolumn{14}{|c|}{ Autres donateurs bilatéraux } \\
\hline Arabie saoudite &. &.. &.. &. & 481,0 & 843,4 & 546,4 &. & 0,0 & 0,0 & 6,8 & 3,8 & .. \\
\hline Azerbaïdjan &.. &.. &.. & .. &.. &.. & 2,3 & .. &.. & 0,1 & 0,2 & 1,8 & 2,3 \\
\hline Croatie & & & & & & & 0,5 &. &. & .. & .. &.. & 0,5 \\
\hline Émirats arabes unis &.. &.. & 233,4 & 891,5 & 907,3 & 71,7 & 437,8 &.. & 88,6 & 703,9 & 897,6 & 429,3 & 584,3 \\
\hline Estonie &.. &.. &.. & 1,5 & 1,2 & 2,1 & 2,0 &. &.. & 1,0 & 1,4 & 1,1 & 1,9 \\
\hline Kazakhstan &.. &.. &.. &.. &.. &.. & .. &.. &.. & 0,1 & 0,7 & 1,8 & 0,1 \\
\hline Koweït (KFAED) &.. &.. & 313,7 & 534,2 & 399,2 & 718,9 & 277,9 &.. & 251,2 & 269,6 & 408,7 & 692,9 & 373,2 \\
\hline Lettonie &.. &.. &.. &.. &.. & 0,2 & 0,0 &.. & 0,0 & 0,0 & & 0,2 & 0,0 \\
\hline Lituanie &.. & &.. & 0,0 & 0,7 & 0,5 & 0,5 & .. & 0,0 & 0,1 & 0,6 & 0,5 & 0,5 \\
\hline Roumanie & & & & 0,1 & 0,5 & 1,3 & &.. & 0,0 & 0,3 & 0,5 & 1,3 & .. \\
\hline Taipei chinois &.. &.. &.. &.. &.. &.. &. &.. &.. & .. &. & 8,7 & .. \\
\hline Thaïlande &.. &.. &.. &.. &.. &.. &. & & 0,0 & 0,0 & .. & 18,5 & 18,7 \\
\hline Turquie & & & 34,4 & .. &.. &.. &. & .. & 34,4 & 0,0 & .. &.. & .. \\
\hline Sous-total & &.. & 581,5 & 1427,4 & 1789,9 & 1638,0 & 1267,4 &.. & 374,2 & 975,1 & 1316,5 & 1160,0 & 981,5 \\
\hline
\end{tabular}


Millions d'USD (constants de 2017)

Tableau A.4. Aide pour le commerce par donateur (page 2 sur 2)

ENGAGEMENTS

\section{DÉCAISSEMENTS}

Moyenne Moyenne Moyenne Moyenne 2015

2002-2005 2006-2008 2009-2011 2012-2014

Moyenne Moyenne Moyenne 2015

2006-2008 2009-2011 2012-2014

\section{Donateurs multilatéraux}

\begin{tabular}{|c|c|c|c|c|c|c|c|c|c|c|c|c|c|}
\hline BAfD & 149,0 & 706,4 & 1498,2 & 1578,6 & 1824,1 & 806,7 & 1062,6 & 379,7 & 1204,9 & 1004,7 & 1238,6 & 1003,4 & 1443,5 \\
\hline $\begin{array}{l}\text { Banque de développement } \\
\text { des Caraïbes }\end{array}$ & & 0,0 & 0,0 & 0,0 & 4,1 & 35,5 & 12,9 &.. & .. & .. &.. &.. & .. \\
\hline $\begin{array}{l}\text { Banque islamique } \\
\text { de développement }\end{array}$ & 190,4 & 252,3 & 188,9 & 138,2 & 236,7 & 261,2 & 149,7 &.. & .. &.. &.. & .. & .. \\
\hline Banque mondiale & 4467,9 & 4235,5 & 6098,7 & 7117,1 & 7718,2 & 6267,1 & 10284,3 & 3324,1 & 3854,7 & 4808,6 & 5682,2 & 4673,4 & 5888,0 \\
\hline BAsD & 747,7 & 521,1 & 1198,4 & 1783,8 & 1690,1 & 1723,7 & 1614,7 &.. & 486,7 & 1252,0 & 1573,2 & 1498,7 & 1379,9 \\
\hline $\mathrm{BID}$ & 242,3 & 110,9 & 433,2 & 585,8 & 797,9 & 446,9 & 475,0 & 0,0 & 354,9 & 563,5 & 521,3 & 373,9 & 737,8 \\
\hline CEB & & 0,0 & 0,0 & 0,0 & 2,8 & & &.. & 12,6 & 2,0 & 1,4 & 1,4 & \\
\hline CEE-ONU & & 1,3 & 4,2 & 3,5 & 5,2 & 5,5 & 5,7 & 1,3 & 4,2 & 3,5 & 5,2 & 5,5 & 5,7 \\
\hline CESAO & & 0,1 & 0,2 & 0,3 & 0,4 & 0,2 & 0,2 & 0,1 & 0,2 & 0,3 & 0,3 & 0,2 & 0,2 \\
\hline CESAP & & 0,3 & 0,5 & 0,6 & 0,7 & 0,4 & 0,8 & 0,2 & 0,5 & 0,5 & 0,7 & 0,4 & 0,8 \\
\hline $\begin{array}{l}\text { Fonds d'investissement pour } \\
\text { le climat }\end{array}$ & & 0,0 & 0,0 & 783,8 & 668,7 & 610,5 & 570,8 &.. &.. & 65,0 & 210,3 & 40,2 & 245,0 \\
\hline Cadre intégré renforcé (CIR) & & 0,0 & 13,1 & 26,3 & 18,6 & 3,6 & 11,7 &.. & 10,2 & 16,0 & 7,6 & 23,3 & 15,4 \\
\hline $\mathrm{FAO}$ & & 131,7 & 273,6 & 271,7 & 316,7 & & & 131,7 & 273,6 & 271,7 & 316,7 &.. & .. \\
\hline FIDA & 268,8 & 375,8 & 581,0 & 540,9 & 927,3 & 536,8 & 934,0 & 0,0 & 0,0 & 13,0 & 15,1 & 14,2 & 18,4 \\
\hline FMI & & 10,2 & 13,6 & 9,5 & & & & 0,0 & 0,0 & 0,7 & & & \\
\hline FODI & & 0,0 & 346,8 & 419,2 & 515,2 & 606,4 & 493,3 & 0,0 & 168,2 & 224,1 & 297,9 & 368,8 & 355,3 \\
\hline Fonds arabe (FADES) & & 388,3 & 1010,3 & 769,0 & 1351,3 & 962,2 & 1031,6 & 233,6 & 696,7 & 670,6 & 493,0 & 441,2 & 528,6 \\
\hline $\begin{array}{l}\text { Fonds pour l'environnement } \\
\text { mondial }\end{array}$ & & 0,0 & 120,0 & 274,9 & 112,6 & 119,4 & 624,5 & 65,7 & 96,0 & 125,7 & 164,6 & 113,7 & 65,5 \\
\hline Fonds vert pour le climat & & 0,0 & 0,0 & 0,0 & 12,8 & 163,7 & 186,9 &.. &. &.. &.. &.. & .. \\
\hline Institutions de l'UE & 2457,6 & 3013,4 & 4320,7 & 8642,2 & 6953,8 & 8891,2 & 8361,0 & 2215,3 & 3859,8 & 6719,9 & 6491,9 & 7919,1 & 7151,6 \\
\hline ITC & & 30,1 & 54,2 & 64,9 & 68,9 & 57,4 & 51,4 & 29,6 & 51,9 & 58,0 & 66,2 & 54,9 & 52,8 \\
\hline PNUD & 11,9 & 24,0 & 33,5 & 30,6 & 26,2 & 7,0 & 8,7 & 23,3 & 33,4 & 30,6 & 26,2 & 7,0 & 8,7 \\
\hline OMC & & 12,7 & 15,6 & 11,9 & 11,7 & 23,0 & 12,3 & 12,7 & 15,5 & 11,9 & 11,7 & 23,0 & 12,3 \\
\hline ONUDI & & 27,0 & 61,5 & 12,9 &.. & 82,6 & 13,5 &.. & .. &.. &.. & 48,6 & 57,5 \\
\hline Organisation mondiale du tourisme &.. &.. &.. &.. &.. &.. & .. &.. & .. &.. &.. & 13,2 & 12,7 \\
\hline Autres donateurs multilatéraux & 1,0 & 4,1 & 47,9 & 153,9 & 85,0 & 107,9 & 118,2 & 2,2 & 21,6 & 101,3 & 116,8 & 67,8 & 56,2 \\
\hline Sous-total & 8536,6 & 9845,2 & 16314,1 & 23219,5 & 23348,8 & 21719,0 & 26024,0 & 6419,4 & 11145,6 & 15943,5 & 17241,0 & 16692,0 & 18036,0 \\
\hline $\begin{array}{l}\text { AIDE POUR LE COMMERCE } \\
\text { TOTALE }\end{array}$ & 23160,4 & 30441,3 & 39588,0 & 49811,5 & 56268,7 & 51587,7 & 57783,8 & 21753,0 & 30284,5 & 36948,5 & 40864,2 & 39475,7 & 43066,9 \\
\hline \multicolumn{14}{|c|}{ Parts dans l'Aide pour le commerce totale } \\
\hline Pays CAD & $63,1 \%$ & $67,7 \%$ & $57,3 \%$ & $50,5 \%$ & $55,3 \%$ & $54,7 \%$ & $52,8 \%$ & $70,5 \%$ & $62,0 \%$ & $54,2 \%$ & $54,6 \%$ & $54,8 \%$ & $55,8 \%$ \\
\hline Autres donateurs bilatéraux & &.. & $1,5 \%$ & $2,9 \%$ & $3,2 \%$ & $3,2 \%$ & $2,2 \%$ &.. & $1,2 \%$ & $2,6 \%$ & $3,2 \%$ & $2,9 \%$ & $2,3 \%$ \\
\hline Donateurs multilatéraux & $36,9 \%$ & $32,3 \%$ & $41,2 \%$ & $46,6 \%$ & $41,5 \%$ & $42,1 \%$ & $45,0 \%$ & $29,5 \%$ & $36,8 \%$ & $43,2 \%$ & $42,2 \%$ & $42,3 \%$ & $41,9 \%$ \\
\hline
\end{tabular}

Source: CAD de I'OCDE : base de données sur les activités d'aide (2019).

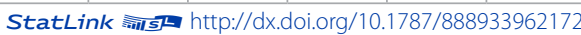


Millions d'USD (constants de 2017)

Tableau A.5a. Les 20 principaux fournisseurs d'Aide pour le commerce en 2017, engagements

\begin{tabular}{|c|c|c|c|c|c|c|c|}
\hline & \multicolumn{7}{|c|}{ ENGAGEMENTS } \\
\hline & $\begin{array}{l}\text { Moyenne } \\
2002-2005\end{array}$ & $\begin{array}{c}\text { Moyenne } \\
2006-2008\end{array}$ & $\begin{array}{c}\text { Moyenne } \\
\text { 2009-2011 }\end{array}$ & $\begin{array}{l}\text { Moyenne } \\
\text { 2012-2014 }\end{array}$ & 2015 & 2016 & 2017 \\
\hline Japon & 4492,8 & 5661,4 & 6073,6 & 8321,9 & 12683,5 & 11268,9 & 12510,7 \\
\hline Banque mondiale & 4467,9 & 4235,5 & 6098,7 & 7117,1 & 7718,2 & 6267,1 & 10284,3 \\
\hline Institutions de l'UE & 2457,6 & 3013,4 & 4320,7 & 8642,2 & 6953,8 & 8891,2 & 8361,0 \\
\hline Allemagne & 1217,6 & 2033,4 & 3317,0 & 4866,1 & 5887,8 & 6093,6 & 5696,6 \\
\hline France & 656,9 & 1405,8 & 1347,1 & 2501,2 & 2913,7 & 2510,3 & 3225,0 \\
\hline États-Unis & 4278,2 & 6094,8 & 4696,0 & 3469,0 & 3487,4 & 2975,3 & 2416,9 \\
\hline Banque asiatique de développement & 747,7 & 521,1 & 1198,4 & 1783,8 & 1690,1 & 1723,7 & 1614,7 \\
\hline Corée & & 490,3 & 941,1 & 877,6 & 930,8 & 1061,0 & 1183,7 \\
\hline Royaume-Uni & 646,0 & 806,7 & 1107,1 & 851,3 & 1513,7 & 811,6 & 1136,5 \\
\hline BAfD & 149,0 & 706,4 & 1496,5 & 1564,0 & 1807,0 & 794,6 & 1052,6 \\
\hline Fonds arabe (FADES) & & 388,3 & 1010,3 & 769,0 & 1351,3 & 962,2 & 1031,6 \\
\hline FIDA & 268,8 & 375,8 & 581,0 & 540,9 & 927,3 & 536,8 & 934,0 \\
\hline Suisse & 295,4 & 266,1 & 282,7 & 374,5 & 305,1 & 353,8 & 695,0 \\
\hline Pays-Bas & 533,3 & 686,9 & 698,9 & 865,0 & 607,6 & 511,7 & 655,0 \\
\hline Fonds pour l'environnement mondial &.. &.. & 120,0 & 274,9 & 112,6 & 119,4 & 624,5 \\
\hline Fonds d'investissement pour le climat & .. &. &. & 783,8 & 668,7 & 610,5 & 570,8 \\
\hline Arabie saoudite & .. &. & .. &.. & 481,0 & 843,4 & 546,4 \\
\hline Norvège & 246,3 & 399,0 & 502,6 & 527,1 & 338,1 & 348,9 & 497,4 \\
\hline Fonds de I'OPEP pour le développement international & .. & .. & 346,8 & 419,2 & 515,2 & 606,4 & 493,3 \\
\hline $\mathrm{BID}$ & 242,3 & 110,9 & 433,2 & 585,8 & 797,9 & 446,9 & 475,0 \\
\hline Sous-total & 20699,8 & 27195,7 & 34571,7 & 45134,2 & 51690,6 & 47737,4 & 54004,9 \\
\hline AIDE POUR LE COMMERCE TOTALE & 23160,4 & 30441,3 & 39588,0 & 49811,5 & 56268,7 & 51587,7 & 57783,8 \\
\hline $\begin{array}{l}\text { Part des } 20 \text { principaux fournisseurs } \\
\text { dans l'Aide pour le commerce totale }\end{array}$ & $89,4 \%$ & $89,3 \%$ & $87,3 \%$ & $90,6 \%$ & $91,9 \%$ & $92,5 \%$ & $93,5 \%$ \\
\hline
\end{tabular}

Millions d'USD (constants de 2017)

Tableau A.5b. Les 20 principaux fournisseurs d'aide pour le commerce en 2017, décaissements

\begin{tabular}{|c|c|c|c|c|c|c|c|}
\hline & \multicolumn{7}{|c|}{ DÉCAISSEMENTS } \\
\hline & $\begin{array}{l}\text { Moyenne } \\
2002-2005\end{array}$ & $\begin{array}{c}\text { Moyenne } \\
2006-2008\end{array}$ & $\begin{array}{l}\text { Moyenne } \\
\text { 2009-2011 }\end{array}$ & $\begin{array}{c}\text { Moyenne } \\
\text { 2012-2014 }\end{array}$ & 2015 & 2016 & 2017 \\
\hline Japon & 4040,3 & 4761,0 & 5906,4 & 6407,7 & 6317,1 & 8264,1 & 6269,7 \\
\hline Institutions de l'UE & 2215,3 & 3859,8 & 6719,9 & 6491,9 & 7919,1 & 7151,6 & 5938,4 \\
\hline Association internationale de développement & 3324,1 & 3854,7 & 4808,6 & 5682,2 & 4673,4 & 5888,0 & 5611,0 \\
\hline Allemagne & 1673,2 & 2558,5 & 3182,4 & 5193,9 & 4613,7 & 4522,4 & 4965,7 \\
\hline France & 839,0 & 1092,9 & 1746,1 & 1504,2 & 1928,8 & 2470,8 & 2836,6 \\
\hline États-Unis & 4403,2 & 4332,0 & 3550,3 & 2922,1 & 2748,0 & 2406,5 & 2234,0 \\
\hline Royaume-Uni & 827,6 & 1177,5 & 1293,4 & 1960,6 & 1815,7 & 1918,9 & 1553,4 \\
\hline BAfD & 379,7 & 1203,7 & 1001,1 & 1232,0 & 995,6 & 1425,4 & 1467,6 \\
\hline BAsD & .. & 486,7 & 1252,0 & 1573,2 & 1498,7 & 1379,9 & 1223,1 \\
\hline BID &.. & 354,9 & 563,5 & 521,3 & 373,9 & 737,8 & 886,4 \\
\hline Émirats arabes unis &.. & 88,6 & 703,9 & 897,6 & 429,3 & 584,3 & 587,6 \\
\hline Corée & 200,7 & 373,3 & 518,5 & 613,1 & 590,9 & 556,5 & 523,3 \\
\hline Pays-Bas & 476,9 & 474,8 & 618,5 & 540,5 & 616,0 & 542,3 & 514,7 \\
\hline Fonds arabe (FADES) & 233,6 & 696,7 & 670,6 & 493,0 & 441,2 & 528,6 & 486,9 \\
\hline Canada & 272,8 & 566,2 & 441,3 & 347,3 & 393,8 & 463,5 & 481,7 \\
\hline Suède & 328,2 & 346,2 & 396,8 & 337,3 & 334,8 & 441,5 & 403,6 \\
\hline Australie & 253,8 & 391,1 & 385,6 & 412,2 & 394,3 & 427,8 & 386,0 \\
\hline Norvège & 378,6 & 383,7 & 484,0 & 482,3 & 404,3 & 426,9 & 383,0 \\
\hline Koweït &.. & 251,2 & 269,6 & 408,7 & 692,9 & 373,2 & 342,7 \\
\hline $\begin{array}{l}\text { Fonds de I'OPEP pour le développement } \\
\text { international }\end{array}$ &. & 168,2 & 224,1 & 297,9 & 368,8 & 355,3 & 329,1 \\
\hline Sous-total & 19847,0 & 27421,6 & 34736,5 & 38318,9 & 37550,3 & 40865,6 & 37424,3 \\
\hline AIDE POUR LE COMMERCE TOTALE & 21753,0 & 30284,5 & 36948,5 & 40864,2 & 39475,7 & 43066,9 & 39815,5 \\
\hline $\begin{array}{l}\text { Part des } 20 \text { principaux fournisseurs } \\
\text { dans I'Aide pour le commerce totale }\end{array}$ & $91,2 \%$ & $90,5 \%$ & $94,0 \%$ & $93,8 \%$ & $95,1 \%$ & $94,9 \%$ & $94,0 \%$ \\
\hline
\end{tabular}

Source: CAD de l'OCDE : base de données sur les activités d'aide (2019).

StatLink 需正 http://dx.doi.org/10.1787/888933962191 
Millions d'USD (constants de 2017)

Tableau A.6. Aide pour le commerce par pays bénéficiaire (page 1 sur 4)

\begin{tabular}{|c|c|c|c|c|c|c|c|c|c|c|c|c|c|}
\hline & \multicolumn{7}{|c|}{ ENGAGEMENTS } & \multicolumn{6}{|c|}{ DÉCAISSEMENTS } \\
\hline & $\begin{array}{c}\text { Moyenne } \\
\text { 2002-2005 }\end{array}$ & $\begin{array}{c}\text { Moyenne } \\
2006-2008\end{array}$ & $\begin{array}{l}\text { Moyenne } \\
\text { 2009-2011 }\end{array}$ & $\begin{array}{c}\text { Moyenne } \\
\text { 2012-2014 }\end{array}$ & 2015 & 2016 & 2017 & $\begin{array}{c}\text { Moyenne } \\
\text { 2006-2008 }\end{array}$ & $\begin{array}{l}\text { Moyenne } \\
\text { 2009-2011 }\end{array}$ & $\begin{array}{l}\text { Moyenne } \\
\text { 2012-2014 }\end{array}$ & 2015 & 2016 & 2017 \\
\hline Afghanistan & 779,1 & 1593,0 & 1841,9 & 1636,2 & 1283,3 & 896,8 & 992,1 & 1055,6 & 1843,2 & 1175,5 & 856,6 & 818,4 & 809,6 \\
\hline Afrique du Sud & 118,8 & 147,5 & 146,7 & 228,9 & 999,7 & 192,7 & 225,5 & 177,9 & 154,3 & 197,2 & 616,6 & 462,7 & 211,8 \\
\hline Albanie & 129,5 & 120,7 & 140,5 & 57,5 & 102,4 & 156,8 & 118,4 & 87,9 & 144,3 & 113,9 & 110,0 & 54,8 & 34,0 \\
\hline Algérie & 93,4 & 128,7 & 23,5 & 21,6 & 5,9 & 18,5 & 22,6 & 109,0 & 59,7 & 32,2 & 16,1 & 16,2 & 17,1 \\
\hline Angola & 17,6 & 79,4 & 35,7 & 29,3 & 217,9 & 29,1 & 13,1 & 32,1 & 57,0 & 33,2 & 227,9 & 18,3 & 12,7 \\
\hline Antigua-et-Barbuda & 2,2 & 0,2 & 4,6 & 1,8 & 12,4 & 0,2 & 20,4 & 0,9 & 5,1 & 0,4 & 0,6 & 4,9 & 1,3 \\
\hline Argentine & 41,8 & 24,0 & 37,2 & 44,5 & 10,1 & 23,9 & 13,7 & 32,2 & 34,3 & 45,9 & 12,4 & 11,4 & 14,1 \\
\hline Arménie & 107,1 & 229,3 & 136,9 & 189,2 & 251,9 & 227,2 & 133,0 & 101,9 & 163,9 & 104,6 & 204,0 & 168,2 & 201,0 \\
\hline Azerbaïdjan & 131,7 & 92,1 & 115,9 & 21,8 & 24,9 & 9,7 & 150,8 & 80,3 & 96,0 & 132,5 & 23,9 & 24,7 & 70,8 \\
\hline Bangladesh & 731,3 & 765,4 & 1169,9 & 1399,3 & 2513,8 & 2657,1 & 2958,5 & 357,9 & 378,8 & 853,5 & 945,5 & 1055,4 & 1884,8 \\
\hline Bélarus & 0,5 & 7,5 & 27,9 & 8,2 & 5,2 & 25,7 & 18,4 & 4,0 & 14,7 & 12,2 & 14,1 & 15,7 & 22,3 \\
\hline Belize & 8,2 & 8,7 & 17,5 & 22,4 & 40,5 & 4,7 & 54,7 & 5,5 & 9,3 & 15,6 & 11,1 & 23,1 & 13,9 \\
\hline Bénin & 106,4 & 195,1 & 209,4 & 118,4 & 239,3 & 146,1 & 738,5 & 110,4 & 212,0 & 156,6 & 171,0 & 150,5 & 206,2 \\
\hline Bhoutan & 40,0 & 39,0 & 50,9 & 57,5 & 135,6 & 66,0 & 46,1 & 26,4 & 57,5 & 66,9 & 59,3 & 30,8 & 53,9 \\
\hline Bolivie & 240,4 & 154,0 & 315,3 & 297,0 & 474,8 & 183,3 & 994,0 & 139,9 & 214,3 & 239,4 & 246,2 & 208,1 & 376,5 \\
\hline Bosnie-Herzégovine & 109,1 & 154,6 & 213,7 & 377,0 & 74,7 & 60,2 & 195,5 & 88,9 & 162,5 & 254,0 & 144,6 & 213,8 & 217,9 \\
\hline Botswana & 14,5 & 5,2 & 8,9 & 33,3 & 2,9 & 7,6 & 8,3 & 10,8 & 18,8 & 9,7 & 5,1 & 10,6 & 11,5 \\
\hline Brésil & 47,4 & 62,8 & 218,1 & 667,2 & 786,5 & 251,1 & 591,6 & 73,3 & 230,2 & 482,3 & 685,2 & 353,4 & 398,1 \\
\hline Burkina Faso & 231,9 & 184,2 & 407,4 & 353,8 & 310,9 & 400,7 & 477,7 & 187,8 & 218,3 & 333,1 & 305,8 & 291,2 & 319,1 \\
\hline Burundi & 48,0 & 81,2 & 163,0 & 207,5 & 143,4 & 92,3 & 226,4 & 71,5 & 100,8 & 146,5 & 91,9 & 83,6 & 79,0 \\
\hline Cabo Verde & 78,9 & 61,0 & 70,5 & 59,9 & 45,9 & 14,9 & 57,7 & 59,2 & 102,3 & 68,1 & 54,1 & 41,9 & 26,6 \\
\hline Cambodge & 177,4 & 202,3 & 288,3 & 416,2 & 431,0 & 495,0 & 525,5 & 123,0 & 181,5 & 265,8 & 223,4 & 237,9 & 339,0 \\
\hline Cameroun & 115,8 & 269,4 & 285,8 & 315,4 & 134,7 & 190,0 & 445,1 & 128,6 & 136,4 & 253,5 & 201,7 & 215,3 & 226,7 \\
\hline Chili & 36,1 & 31,5 & 58,9 & 222,3 & 77,4 & 157,9 & 16,7 & 48,4 & 75,4 & 83,4 & 20,3 & 173,2 & 49,5 \\
\hline Chine (République populaire de) & 714,6 & 523,7 & 420,0 & 318,7 & 509,3 & 780,7 & 281,7 & 737,9 & 507,4 & 361,0 & 386,1 & 276,9 & 300,3 \\
\hline Cisjordanie et bande de Gaza & 61,1 & 90,7 & 165,4 & 107,2 & 142,8 & 139,5 & 121,3 & 67,8 & 174,1 & 95,3 & 99,3 & 124,4 & 217,7 \\
\hline Colombie & 89,2 & 156,4 & 230,5 & 226,1 & 248,2 & 130,6 & 252,7 & 135,5 & 192,3 & 159,9 & 212,6 & 212,1 & 162,7 \\
\hline Comores & 3,3 & 5,8 & 14,0 & 25,8 & 23,3 & 0,3 & 39,6 & 3,4 & 5,5 & 11,4 & 13,9 & 11,8 & 22,4 \\
\hline Congo & 36,1 & 34,9 & 49,4 & 43,8 & 89,2 & 16,5 & 116,0 & 26,9 & 26,5 & 34,1 & 28,3 & 25,3 & 27,2 \\
\hline Costa Rica & 46,0 & 20,2 & 25,1 & 63,6 & 66,6 & 24,4 & 252,2 & 39,1 & 50,6 & 12,5 & 53,4 & 69,5 & 53,1 \\
\hline Côte d'Ivoire & 55,0 & 104,1 & 219,4 & 132,6 & 406,1 & 339,3 & 752,9 & 89,8 & 158,5 & 115,9 & 222,2 & 170,1 & 212,8 \\
\hline Cuba & 8,2 & 10,4 & 15,5 & 15,4 & 23,6 & 46,9 & 152,9 & 10,7 & 22,7 & 16,1 & 12,7 & 13,4 & 25,3 \\
\hline Djibouti & 20,9 & 10,2 & 40,6 & 62,4 & 68,5 & 112,2 & 71,5 & 8,3 & 27,7 & 23,5 & 56,2 & 72,0 & 46,4 \\
\hline Dominique & 12,8 & 5,9 & 2,5 & 19,1 & 2,1 & 0,0 & 17,1 & 8,5 & 16,5 & 11,3 & 3,9 & 4,8 & 10,4 \\
\hline Égypte & 577,1 & 793,4 & 951,3 & 1640,1 & 1558,7 & 2528,6 & 1069,1 & 558,6 & 671,7 & 1349,2 & 883,4 & 1125,7 & 807,5 \\
\hline El Salvador & 27,2 & 212,4 & 78,6 & 79,4 & 171,1 & 66,5 & 31,1 & 48,8 & 121,7 & 71,0 & 20,8 & 42,3 & 33,2 \\
\hline Équateur & 47,9 & 54,8 & 62,6 & 72,7 & 353,8 & 66,9 & 227,4 & 37,7 & 58,1 & 57,6 & 248,3 & 114,7 & 68,5 \\
\hline Érythrée & 46,5 & 32,5 & 25,3 & 7,2 & 31,0 & 24,1 & 111,4 & 17,4 & 16,1 & 6,1 & 10,9 & 11,8 & 10,2 \\
\hline Eswatini & 16,2 & 20,1 & 36,8 & 10,1 & 58,9 & 7,7 & 0,5 & 11,1 & 14,1 & 25,6 & 27,0 & 33,9 & 24,8 \\
\hline Éthiopie & 490,8 & 706,5 & 662,4 & 1228,0 & 1409,7 & 1355,0 & 1081,6 & 481,4 & 688,1 & 693,5 & 770,8 & 924,9 & 917,1 \\
\hline Fidji & 7,0 & 10,8 & 13,3 & 26,8 & 24,3 & 12,1 & 15,1 & 8,3 & 7,8 & 11,9 & 28,4 & 18,6 & 30,4 \\
\hline Gabon & 36,8 & 48,7 & 18,6 & 23,7 & 1,6 & 121,8 & 3,8 & 21,6 & 28,6 & 32,3 & 67,2 & 12,4 & 8,7 \\
\hline
\end{tabular}


Millions d'USD (constants de 2017)

Tableau A.6. Aide pour le commerce par pays bénéficiaire (page 2 sur 4)

\begin{tabular}{|c|c|c|c|c|c|c|c|c|c|c|c|c|c|}
\hline & $\begin{array}{l}\text { Moyenne } \\
\text { 2002-2005 }\end{array}$ & $\begin{array}{c}\text { Moyenne } \\
2006-2008\end{array}$ & $\begin{array}{c}\text { Moyenne } \\
\text { 2009-2011 }\end{array}$ & $\begin{array}{l}\text { Moyenne } \\
\text { 2012-2014 }\end{array}$ & 2015 & 2016 & 2017 & $\begin{array}{c}\text { Moyenne } \\
\text { 2006-2008 }\end{array}$ & $\begin{array}{l}\text { Moyenne } \\
\text { 2009-2011 }\end{array}$ & $\begin{array}{l}\text { Moyenne } \\
\text { 2012-2014 }\end{array}$ & 2015 & 2016 & 2017 \\
\hline Gambie & 32,5 & 17,3 & 55,4 & 81,8 & 73,5 & 77,0 & 120,2 & 14,5 & 38,6 & 40,5 & 37,2 & 34,1 & 80,3 \\
\hline Géorgie & 101,1 & 246,2 & 303,2 & 313,2 & 63,5 & 131,1 & 306,2 & 153,0 & 223,0 & 299,9 & 246,8 & 231,2 & 199,4 \\
\hline Ghana & 257,9 & 590,6 & 659,3 & 392,4 & 342,0 & 1027,0 & 636,3 & 318,7 & 531,8 & 524,3 & 474,8 & 429,3 & 427,0 \\
\hline Grenade & 7,2 & 1,4 & 8,8 & 9,9 & 10,1 & 22,9 & 29,3 & 0,8 & 6,0 & 4,3 & 12,5 & 5,0 & 3,6 \\
\hline Guatemala & 27,2 & 50,0 & 64,7 & 123,2 & 74,5 & 45,2 & 32,3 & 25,3 & 58,5 & 80,3 & 57,2 & 58,5 & 47,9 \\
\hline Guinée & 66,5 & 70,0 & 53,8 & 128,3 & 146,5 & 116,6 & 160,5 & 42,6 & 58,5 & 66,8 & 54,4 & 85,3 & 120,2 \\
\hline Guinée-Bissau & 24,3 & 14,5 & 16,3 & 11,5 & 116,1 & 2,6 & 77,2 & 31,3 & 21,9 & 11,2 & 10,3 & 10,5 & 27,7 \\
\hline Guinée équatoriale & 0,8 & 0,3 & 0,9 & 1,3 & 0,1 & 0,1 & 0,4 & 0,4 & 0,7 & 0,5 & 0,1 & 0,0 & 0,3 \\
\hline Guyana & 40,9 & 51,9 & 53,0 & 42,7 & 3,0 & 27,6 & 12,0 & 16,2 & 53,4 & 44,5 & 4,5 & 40,1 & 11,9 \\
\hline Haïti & 81,1 & 90,2 & 371,5 & 270,6 & 367,8 & 101,7 & 224,6 & 53,8 & 250,2 & 247,9 & 255,2 & 187,3 & 192,8 \\
\hline Honduras & 180,8 & 66,1 & 193,1 & 230,1 & 346,9 & 153,7 & 168,4 & 73,9 & 179,1 & 228,1 & 146,9 & 149,1 & 162,2 \\
\hline Îles Cook & 1,5 & 0,5 & 10,0 & 12,0 & 6,1 & 4,4 & 10,9 & 1,4 & 4,4 & 11,0 & 10,9 & 0,2 & 4,4 \\
\hline Îles Marshall & 4,9 & 1,2 & 6,7 & 9,8 & 7,8 & 11,1 & 61,4 & 1,6 & 5,2 & 6,5 & 5,0 & 1,2 & 4,0 \\
\hline Îles Salomon & 11,2 & 24,0 & 35,9 & 55,2 & 65,5 & 51,5 & 121,9 & 16,6 & 29,1 & 38,9 & 44,2 & 47,5 & 57,2 \\
\hline Inde & 1438,3 & 2158,2 & 2466,4 & 4234,1 & 2918,7 & 4238,1 & 5274,9 & 1148,4 & 1807,9 & 1868,8 & 3240,5 & 2769,2 & 3707,8 \\
\hline Indonésie & 1010,0 & 769,7 & 780,8 & 515,4 & 2347,7 & 329,5 & 2945,8 & 736,8 & 765,0 & 555,3 & 922,2 & 506,3 & 1184,4 \\
\hline Iran & 4,5 & 3,1 & 6,4 & 2,8 & 3,9 & 7,7 & 13,3 & 2,0 & 3,8 & 5,0 & 6,3 & 4,3 & 4,8 \\
\hline Iraq & 2345,8 & 2192,4 & 421,2 & 357,3 & 668,4 & 8,2 & 593,3 & 2008,8 & 429,1 & 447,5 & 213,9 & 259,8 & 364,2 \\
\hline Jamaïque & 32,1 & 33,5 & 43,0 & 21,8 & 4,7 & 24,3 & 47,5 & 42,8 & 47,0 & 33,2 & 26,8 & 18,5 & 8,0 \\
\hline Jordanie & 39,7 & 116,1 & 179,7 & 462,1 & 581,3 & 301,7 & 395,3 & 65,1 & 213,2 & 270,9 & 292,4 & 315,6 & 329,1 \\
\hline Kazakhstan & 39,3 & 115,6 & 84,8 & 30,1 & 15,9 & 5,5 & 17,5 & 100,3 & 58,5 & 33,8 & 15,9 & 34,2 & 7,8 \\
\hline Kenya & 290,6 & 458,1 & 1049,8 & 1252,6 & 1706,5 & 934,6 & 1213,1 & 272,6 & 389,8 & 912,5 & 953,3 & 843,7 & 932,3 \\
\hline Kirghizistan & 51,9 & 91,7 & 156,6 & 186,7 & 285,3 & 312,0 & 172,3 & 54,5 & 82,6 & 129,6 & 156,2 & 114,8 & 129,2 \\
\hline Kiribati & 6,9 & 7,1 & 35,5 & 15,2 & 15,7 & 63,4 & 39,8 & 9,3 & 7,5 & 31,1 & 26,5 & 31,2 & 29,3 \\
\hline Kosovo & & 0,0 & 82,8 & 69,1 & 72,3 & 60,2 & 130,1 & 0,0 & 53,9 & 71,2 & 84,9 & 68,9 & 72,1 \\
\hline Liban & 26,7 & 77,9 & 52,4 & 59,3 & 174,1 & 140,2 & 50,5 & 50,0 & 97,9 & 87,5 & 65,7 & 81,8 & 96,7 \\
\hline Libéria & 0,9 & 96,9 & 192,8 & 266,0 & 637,2 & 141,2 & 265,9 & 66,0 & 96,3 & 161,3 & 174,2 & 278,7 & 227,6 \\
\hline Libye & 2,1 & 4,7 & 10,6 & 11,2 & 1,8 & 0,0 & 7,4 & 11,3 & 14,4 & 2,2 & 1,5 & 4,3 & 7,4 \\
\hline Lesotho & 6,3 & 30,9 & 27,2 & 25,2 & 1,9 & 25,7 & 40,8 & 17,0 & 23,2 & 17,1 & 14,7 & 10,1 & 9,7 \\
\hline Macédoine du Nord & 48,8 & 45,4 & 65,7 & 152,0 & 95,3 & 50,0 & 31,4 & 31,9 & 44,8 & 117,2 & 144,5 & 54,5 & 19,5 \\
\hline Madagascar & 276,8 & 244,0 & 47,8 & 216,9 & 217,4 & 277,4 & 866,8 & 271,3 & 126,2 & 101,8 & 134,0 & 155,7 & 205,6 \\
\hline Malaisie & 11,4 & 41,6 & 23,0 & 14,9 & 15,0 & 6,4 & 7,1 & 127,2 & 46,2 & 10,8 & 9,5 & 10,3 & 10,8 \\
\hline Malawi & 105,9 & 132,3 & 226,6 & 355,3 & 379,6 & 225,5 & 545,6 & 98,7 & 149,9 & 196,1 & 247,5 & 279,9 & 445,6 \\
\hline Maldives & 9,8 & 14,7 & 13,7 & 31,7 & 110,1 & 138,5 & 69,7 & 3,6 & 15,4 & 4,9 & 7,7 & 13,7 & 29,6 \\
\hline Mali & 176,2 & 512,8 & 382,0 & 274,7 & 193,2 & 351,3 & 309,0 & 227,9 & 348,5 & 269,6 & 256,2 & 272,5 & 296,7 \\
\hline Maroc & 292,3 & 831,5 & 899,7 & 1624,8 & 958,7 & 1133,6 & 1398,8 & 401,0 & 720,8 & 1177,9 & 995,7 & 1722,7 & 1752,1 \\
\hline Maurice & 48,7 & 31,0 & 44,8 & 89,7 & 42,8 & 40,3 & 9,1 & 6,1 & 20,6 & 66,7 & 69,5 & 25,7 & 26,0 \\
\hline Mauritanie & 115,7 & 138,5 & 132,1 & 173,6 & 177,6 & 332,4 & 503,4 & 74,8 & 124,2 & 113,3 & 103,9 & 122,6 & 125,3 \\
\hline Mexique & 24,5 & 49,0 & 110,6 & 312,6 & 198,3 & 481,6 & 330,0 & 25,5 & 85,4 & 227,1 & 105,8 & 504,2 & 375,2 \\
\hline Micronésie & 13,1 & 16,2 & 7,3 & 35,0 & 9,2 & 12,0 & 26,0 & 9,1 & 13,3 & 10,6 & 13,4 & 15,7 & 9,2 \\
\hline
\end{tabular}

ENGAGEMENTS

DÉCAISSEMENTS 
Millions d'USD (constants de 2017)

Tableau A.6. Aide pour le commerce par pays bénéficiaire (page 3 sur 4)

\section{ENGAGEMENTS}

\begin{tabular}{|c|c|c|c|c|c|c|c|c|c|c|c|c|c|}
\hline & $\begin{array}{l}\text { Moyenne } \\
\text { 2002-2005 }\end{array}$ & $\begin{array}{c}\text { Moyenne } \\
2006-2008\end{array}$ & $\begin{array}{l}\text { Moyenne } \\
\text { 2009-2011 }\end{array}$ & $\begin{array}{c}\text { Moyenne } \\
\text { 2012-2014 }\end{array}$ & 2015 & 2016 & 2017 & $\begin{array}{c}\text { Moyenne } \\
2006-2008\end{array}$ & $\begin{array}{l}\text { Moyenne } \\
\text { 2009-2011 }\end{array}$ & $\begin{array}{l}\text { Moyenne } \\
\text { 2012-2014 }\end{array}$ & 2015 & 2016 & 2017 \\
\hline Moldova & 63,3 & 43,2 & 188,1 & 243,2 & 77,5 & 281,9 & 106,1 & 39,7 & 79,2 & 184,4 & 165,6 & 122,5 & 84,0 \\
\hline Mongolie & 55,6 & 251,7 & 169,0 & 94,5 & 429,5 & 214,8 & 155,6 & 65,4 & 127,6 & 199,8 & 146,9 & 221,5 & 276,4 \\
\hline Monténégro & 6,4 & 28,6 & 24,4 & 75,2 & 137,5 & 48,2 & 108,1 & 22,3 & 35,1 & 46,1 & 91,5 & 67,8 & 116,1 \\
\hline Montserrat & 6,9 & 10,8 & 1,4 & 10,0 & 22,4 & 9,1 & 2,2 & 4,2 & 9,1 & 13,3 & 17,0 & 9,1 & 12,2 \\
\hline Mozambique & 321,0 & 439,9 & 419,5 & 599,7 & 720,0 & 270,6 & 603,7 & 329,4 & 320,2 & 500,9 & 569,5 & 445,6 & 486,6 \\
\hline Myanmar & 9,9 & 15,4 & 32,8 & 697,3 & 2281,2 & 609,9 & 1191,5 & 15,9 & 45,5 & 174,3 & 328,9 & 474,6 & 529,0 \\
\hline Namibie & 30,1 & 72,8 & 91,6 & 36,7 & 92,1 & 47,8 & 110,9 & 28,6 & 69,9 & 58,1 & 53,3 & 58,6 & 54,8 \\
\hline Nauru & 2,2 & 10,0 & 2,6 & 3,6 & 14,3 & 4,5 & 33,5 & 9,7 & 2,9 & 3,9 & 8,4 & 2,5 & 6,0 \\
\hline Népal & 158,7 & 195,7 & 370,0 & 630,3 & 331,1 & 465,1 & 765,6 & 121,4 & 207,4 & 278,8 & 400,3 & 282,3 & 488,6 \\
\hline Nicaragua & 183,2 & 197,9 & 215,2 & 220,4 & 308,6 & 364,7 & 391,3 & 132,4 & 203,9 & 187,2 & 246,9 & 199,1 & 343,9 \\
\hline Niger & 108,3 & 108,2 & 109,2 & 268,7 & 321,9 & 576,4 & 424,7 & 86,8 & 97,6 & 133,6 & 109,0 & 205,9 & 283,2 \\
\hline Nigéria & 227,3 & 331,4 & 560,7 & 898,6 & 293,4 & 249,5 & 804,3 & 225,7 & 322,6 & 467,2 & 590,2 & 406,1 & 695,4 \\
\hline Nioué & 2,3 & 2,0 & 5,9 & 3,8 & 9,8 & 1,0 & 15,5 & 2,2 & 4,8 & 3,8 & 10,0 & 2,6 & 4,2 \\
\hline Ouganda & 245,2 & 373,4 & 680,4 & 511,6 & 830,9 & 640,8 & 340,2 & 370,3 & 414,4 & 422,3 & 437,1 & 346,0 & 390,6 \\
\hline Ouzbékistan & 137,8 & 54,2 & 201,7 & 601,1 & 502,5 & 323,7 & 495,4 & 50,7 & 70,2 & 130,6 & 280,8 & 267,4 & 482,3 \\
\hline Pakistan & 564,4 & 681,7 & 755,8 & 1532,8 & 1755,3 & 1079,4 & 884,8 & 340,1 & 425,9 & 1083,4 & 1759,3 & 900,0 & 928,3 \\
\hline Palaos & 6,0 & 5,8 & 3,5 & 6,9 & 6,0 & 15,7 & 5,2 & 7,5 & 3,8 & 6,4 & 5,5 & 4,1 & 9,4 \\
\hline Panama & 9,6 & 12,2 & 17,4 & 7,0 & 6,6 & 269,1 & 14,4 & 7,4 & 12,4 & 7,9 & 3,8 & 9,4 & 12,6 \\
\hline Papouasie-Nouvelle-Guinée & 121,4 & 132,3 & 191,9 & 196,7 & 380,7 & 136,0 & 220,6 & 96,3 & 108,1 & 159,2 & 194,8 & 171,0 & 155,4 \\
\hline Paraguay & 15,2 & 83,7 & 84,5 & 92,6 & 63,7 & 140,2 & 83,4 & 32,8 & 43,9 & 46,4 & 44,0 & 75,6 & 108,3 \\
\hline Pérou & 129,8 & 125,0 & 144,7 & 173,9 & 96,2 & 401,3 & 193,0 & 176,6 & 131,0 & 125,2 & 98,8 & 119,9 & 253,6 \\
\hline Philippines & 313,1 & 220,2 & 573,0 & 630,9 & 2846,4 & 266,0 & 294,0 & 462,0 & 369,5 & 220,7 & 366,4 & 362,0 & 274,8 \\
\hline République arabe syrienne & 15,8 & 26,6 & 177,4 & 1,9 & 4,6 & 15,0 & 13,4 & 43,2 & 94,5 & 14,6 & 4,6 & 14,7 & 14,7 \\
\hline République centrafricaine & 32,2 & 55,5 & 60,8 & 47,1 & 0,3 & 9,6 & 51,2 & 34,8 & 46,9 & 30,6 & 18,9 & 24,3 & 11,4 \\
\hline $\begin{array}{l}\text { République démocratique } \\
\text { du Congo }\end{array}$ & 468,7 & 280,9 & 680,1 & 437,1 & 401,9 & 570,7 & 486,9 & 192,9 & 356,4 & 510,6 & 467,7 & 483,0 & 429,0 \\
\hline $\begin{array}{l}\text { République démocratique } \\
\text { populaire de Corée }\end{array}$ & 36,1 & 9,2 & 1,6 & 9,1 & 2,5 & 1,2 & 4,1 & 9,2 & 3,4 & 2,5 & 6,1 & 2,5 & 8,7 \\
\hline $\begin{array}{l}\text { République démocratique } \\
\text { populaire lao }\end{array}$ & 144,8 & 119,4 & 191,1 & 246,7 & 257,4 & 150,3 & 135,9 & 112,5 & 123,0 & 133,7 & 211,4 & 168,7 & 208,3 \\
\hline République dominicaine & 39,1 & 33,2 & 136,1 & 53,2 & 23,9 & 28,7 & 34,1 & 52,3 & 79,5 & 74,6 & 28,8 & 53,9 & 27,0 \\
\hline Rwanda & 71,4 & 122,1 & 287,0 & 310,1 & 356,2 & 868,4 & 468,5 & 101,7 & 205,8 & 198,2 & 340,5 & 335,9 & 527,1 \\
\hline Sainte-Hélène & 36,4 & 13,4 & 28,4 & 12,5 & 24,1 & 82,1 & 3,9 & 13,2 & 29,8 & 92,8 & 42,5 & 44,6 & 25,1 \\
\hline Sainte-Lucie & 8,4 & 7,7 & 3,5 & 17,9 & 12,2 & 17,2 & 21,1 & 6,6 & 15,3 & 6,5 & 4,1 & 8,7 & 6,3 \\
\hline Saint-Vincent-et-les Grenadines & 6,1 & 6,7 & 0,7 & 8,7 & 0,5 & 50,1 & 19,3 & 8,8 & 7,3 & 1,5 & 1,9 & 8,0 & 4,1 \\
\hline Samoa & 14,4 & 25,7 & 18,0 & 41,9 & 65,6 & 32,4 & 45,9 & 8,6 & 25,6 & 26,4 & 32,5 & 37,6 & 75,3 \\
\hline Sao Tomé-et-Principe & 7,1 & 6,1 & 16,1 & 4,9 & 31,2 & 23,3 & 5,6 & 6,2 & 8,2 & 9,8 & 16,4 & 9,1 & 7,7 \\
\hline Sénégal & 181,3 & 232,2 & 501,3 & 350,0 & 617,6 & 251,4 & 959,1 & 208,0 & 237,7 & 337,3 & 427,7 & 292,0 & 376,5 \\
\hline Serbie & 411,3 & 276,1 & 593,4 & 715,2 & 559,8 & 225,5 & 621,8 & 230,5 & 435,6 & 535,8 & 420,6 & 440,8 & 475,6 \\
\hline Seychelles & 2,9 & 5,2 & 1,5 & 4,8 & 28,2 & 19,3 & 6,9 & 3,0 & 6,4 & 11,3 & 3,0 & 3,9 & 9,8 \\
\hline Sierra Leone & 92,1 & 83,6 & 90,5 & 122,4 & 56,2 & 222,2 & 154,9 & 49,7 & 97,9 & 92,3 & 65,9 & 101,6 & 98,3 \\
\hline Somalie & 4,0 & 13,3 & 28,7 & 67,0 & 58,8 & 34,4 & 28,7 & 5,7 & 22,9 & 49,5 & 70,8 & 54,6 & 50,1 \\
\hline Soudan & 27,5 & 219,1 & 403,3 & 257,0 & 207,1 & 225,8 & 211,1 & 80,5 & 257,3 & 182,4 & 269,7 & 59,0 & 121,4 \\
\hline
\end{tabular}

DÉCAISSEMENTS 
Millions d'USD (constants de 2017)

\section{Tableau A.6. Aide pour le commerce par pays bénéficiaire (page 4 sur 4)}

\section{ENGAGEMENTS}

\begin{tabular}{|c|c|c|c|c|c|c|c|c|c|c|c|c|c|}
\hline & $\begin{array}{l}\text { Moyenne } \\
\text { 2002-2005 }\end{array}$ & $\begin{array}{l}\text { Moyenne } \\
\text { 2006-2008 }\end{array}$ & $\begin{array}{l}\text { Moyenne } \\
\text { 2009-2011 }\end{array}$ & $\begin{array}{l}\text { Moyenne } \\
\text { 2012-2014 }\end{array}$ & 2015 & 2016 & 2017 & $\begin{array}{c}\text { Moyenne } \\
2006-2008\end{array}$ & $\begin{array}{l}\text { Moyenne } \\
\text { 2009-2011 }\end{array}$ & $\begin{array}{l}\text { Moyenne } \\
\text { 2012-2014 }\end{array}$ & 2015 & 2016 & 2017 \\
\hline Soudan du Sud & & 0,0 & 21,6 & 165,4 & 100,9 & 11,8 & 119,5 & 0,0 & 6,2 & 87,2 & 134,6 & 72,2 & 97,9 \\
\hline Sri Lanka & 451,5 & 347,8 & 391,9 & 597,6 & 473,1 & 969,2 & 484,0 & 273,8 & 359,3 & 390,1 & 390,2 & 297,4 & 262,1 \\
\hline Suriname & 21,1 & 16,3 & 19,6 & 4,7 & 0,4 & 22,4 & 0,5 & 21,2 & 30,1 & 13,5 & 2,1 & 5,5 & 8,5 \\
\hline Tadjikistan & 100,4 & 120,7 & 188,3 & 199,2 & 260,6 & 188,5 & 439,2 & 47,5 & 115,2 & 155,7 & 230,3 & 196,1 & 186,0 \\
\hline Tanzanie & 374,8 & 751,8 & 851,0 & 960,5 & 1133,1 & 871,9 & 962,2 & 381,5 & 611,0 & 863,6 & 863,4 & 750,1 & 797,5 \\
\hline Tchad & 95,0 & 38,8 & 89,8 & 79,4 & 120,4 & 53,5 & 38,6 & 48,0 & 50,7 & 44,5 & 89,9 & 79,2 & 35,5 \\
\hline Thaïlande & 325,7 & 222,9 & 306,3 & 57,5 & 354,4 & 1498,0 & 52,2 & 164,5 & 151,1 & 359,9 & 145,6 & 377,4 & 370,6 \\
\hline Timor-Leste & 31,0 & 31,7 & 54,1 & 83,8 & 59,8 & 144,6 & 62,6 & 22,7 & 37,9 & 57,0 & 72,0 & 75,3 & 75,9 \\
\hline Togo & 8,3 & 39,8 & 93,6 & 61,8 & 81,9 & 108,7 & 189,8 & 33,9 & 35,0 & 46,0 & 86,5 & 32,9 & 77,9 \\
\hline Tokélaou & 1,6 & 1,3 & 3,8 & 9,0 & 0,8 & 0,1 & 17,6 & 2,6 & 2,6 & 8,8 & 2,8 & 0,1 & 1,7 \\
\hline Tonga & 2,7 & 13,1 & 34,6 & 27,9 & 54,0 & 12,8 & 29,4 & 6,8 & 17,8 & 28,0 & 28,4 & 34,0 & 36,5 \\
\hline Tunisie & 196,9 & 257,6 & 327,7 & 1003,4 & 746,6 & 336,5 & 1072,7 & 186,4 & 357,3 & 503,9 & 401,8 & 485,1 & 702,7 \\
\hline Turquie & 407,8 & 371,8 & 989,5 & 2973,2 & 1700,5 & 2533,8 & 1933,2 & 353,4 & 1199,8 & 2528,5 & 2344,8 & 2699,5 & 2299,3 \\
\hline Turkménistan & 2,6 & 1,9 & 8,9 & 6,8 & 2,0 & 1,7 & 1,3 & 2,1 & 3,5 & 5,5 & 5,6 & 6,0 & 5,8 \\
\hline Tuvalu & 3,8 & 5,3 & 6,1 & 21,2 & 14,2 & 7,9 & 21,6 & 4,9 & 3,5 & 8,2 & 26,0 & 10,3 & 17,6 \\
\hline Ukraine & 79,3 & 230,3 & 228,3 & 588,9 & 192,3 & 764,0 & 250,4 & 159,4 & 273,4 & 251,2 & 214,0 & 328,9 & 243,9 \\
\hline Uruguay & 5,6 & 3,9 & 9,0 & 50,5 & 3,2 & 6,0 & 0,9 & 6,2 & 13,1 & 28,8 & 26,1 & 3,2 & 27,8 \\
\hline Vanuatu & 6,0 & 42,2 & 20,6 & 38,7 & 145,8 & 47,3 & 50,4 & 22,2 & 33,6 & 18,4 & 39,5 & 54,4 & 66,6 \\
\hline Venezuela & 2,3 & 1,5 & 1,7 & 4,4 & 0,8 & 0,3 & 1,3 & 2,1 & 1,9 & 1,4 & 2,3 & 2,1 & 0,7 \\
\hline Viet Nam & 1421,1 & 1684,4 & 2226,8 & 2521,3 & 2346,7 & 3725,3 & 1154,0 & 1007,9 & 1501,5 & 2474,2 & 2332,6 & 2176,7 & 1760,0 \\
\hline Wallis-et-Futuna & 6,6 & 1,5 & 3,7 & 11,7 & 2,0 & 7,4 & 3,8 & 1,5 & 5,7 & 6,9 & 4,5 & 7,7 & 4,1 \\
\hline Yémen & 57,0 & 155,7 & 414,8 & 200,1 & 425,5 & 61,8 & 516,8 & 72,3 & 124,2 & 144,9 & 367,6 & 129,6 & 276,5 \\
\hline Zambie & 201,4 & 211,2 & 257,3 & 330,6 & 231,3 & 360,3 & 440,0 & 139,4 & 123,7 & 195,7 & 270,9 & 295,5 & 203,5 \\
\hline Zimbabwe & 9,5 & 14,6 & 96,6 & 63,6 & 113,0 & 53,7 & 79,8 & 10,5 & 68,3 & 76,8 & 58,5 & 64,4 & 53,7 \\
\hline Total pays bénéficiaires & 21089,4 & 26413,6 & 33103,7 & 43665,4 & 49769,2 & 44525,8 & 49346,7 & 18803,3 & 24989,5 & 31754,2 & 34536,7 & 32827,5 & 36405,7 \\
\hline Non spécifique à un pays & 2071,0 & 4027,7 & 6484,2 & 6146,0 & 6499,5 & 7061,9 & 8437,0 & 2949,6 & 5295,0 & 5194,3 & 6327,4 & 6648,2 & 6661,2 \\
\hline $\begin{array}{l}\text { AIDE POUR LE COMMERCE } \\
\text { TOTALE }\end{array}$ & 23160,4 & 30441,3 & 39588,0 & 49811,5 & 56268,7 & 51587,7 & 57783,8 & 21753,0 & 30284,5 & 36948,5 & 40864,2 & 39475,7 & 43066,9 \\
\hline
\end{tabular}

Source: CAD de l'OCDE : base de données sur les activités d'aide (2019). 
Millions d'USD (constants de 2017)

Tableau A.7a. Les 20 principaux bénéficiaires de l'aide pour le commerce en 2017, engagements

\section{ENGAGEMENTS}

\begin{tabular}{|c|c|c|c|c|c|c|c|c|c|}
\hline & \\
\hline & Région & $\begin{array}{c}\text { Groupe } \\
\text { de revenu }\end{array}$ & $\begin{array}{c}\text { Moyenne } \\
2002-2005\end{array}$ & $\begin{array}{c}\text { Moyenne } \\
2006-2008\end{array}$ & $\begin{array}{c}\text { Moyenne } \\
2009-2011\end{array}$ & $\begin{array}{c}\text { Moyenne } \\
2012-2014\end{array}$ & 2015 & 2016 & 2017 \\
\hline Inde & Asie & PRITI & 1438,3 & 2158,2 & 2466,4 & 4234,1 & 2918,7 & 4238,1 & 5274,9 \\
\hline Bangladesh & Asie & PMA & 731,3 & 765,4 & 1169,9 & 1399,3 & 2513,8 & 2657,1 & 2958,5 \\
\hline Indonésie & Asie & PRITI & 1010,0 & 769,7 & 780,8 & 515,4 & 2347,7 & 329,5 & 2945,8 \\
\hline Turquie & Europe & PRITS & 407,8 & 371,8 & 989,5 & 2973,2 & 1700,5 & 2533,8 & 1933,2 \\
\hline Maroc & Afrique & PRITI & 292,3 & 831,5 & 899,7 & 1624,8 & 958,7 & 1133,6 & 1398,8 \\
\hline Kenya & Afrique & PRITI & 290,6 & 458,1 & 1049,8 & 1252,6 & 1706,5 & 934,6 & 1213,1 \\
\hline Myanmar & Asie & PMA & 9,9 & 15,4 & 32,8 & 697,3 & 2281,2 & 609,9 & 1191,5 \\
\hline Viet Nam & Afrique & PRITI & 1421,1 & 1684,4 & 2226,8 & 2521,3 & 2346,7 & 3725,3 & 1154,0 \\
\hline Éthiopie & Afrique & PMA & 490,8 & 706,5 & 662,4 & 1228,0 & 1409,7 & 1355,0 & 1081,6 \\
\hline Tunisie & Afrique & PRITI & 196,9 & 257,6 & 327,7 & 1003,4 & 746,6 & 336,5 & 1072,7 \\
\hline Égypte & Afrique & PRITI & 577,1 & 793,4 & 951,3 & 1640,1 & 1558,7 & 2528,6 & 1069,1 \\
\hline Bolivie & Amérique & PRITI & 240,4 & 154,0 & 315,3 & 297,0 & 474,8 & 183,3 & 994,0 \\
\hline Afghanistan & Asie & PMA & 779,1 & 1593,0 & 1841,9 & 1636,2 & 1283,3 & 896,8 & 992,1 \\
\hline Tanzanie & Afrique & PMA & 374,8 & 751,8 & 851,0 & 960,5 & 1133,1 & 871,9 & 962,2 \\
\hline Sénégal & Afrique & PMA & 181,3 & 232,2 & 501,3 & 350,0 & 617,6 & 251,4 & 959,1 \\
\hline Pakistan & Asie & PRITI & 564,4 & 681,7 & 755,8 & 1532,8 & 1755,3 & 1079,4 & 884,8 \\
\hline Madagascar & Afrique & PMA & 276,8 & 244,0 & 47,8 & 216,9 & 217,4 & 277,4 & 866,8 \\
\hline Nigéria & Afrique & PRITI & 227,3 & 331,4 & 560,7 & 898,6 & 293,4 & 249,5 & 804,3 \\
\hline Népal & Asie & PMA & 158,7 & 195,7 & 370,0 & 630,3 & 331,1 & 465,1 & 765,6 \\
\hline Côte d'Ivoire & Afrique & PRITI & 55,0 & 104,1 & 219,4 & 132,6 & 406,1 & 339,3 & 752,9 \\
\hline \multicolumn{3}{|l|}{ Sous-total } & 9724,0 & 13099,7 & 17020,3 & 25744,7 & 27000,7 & 24996,2 & 29275,1 \\
\hline \multicolumn{3}{|c|}{ AIDE POUR LE COMMERCE TOTALE } & 23160,4 & 30441,3 & 39588,0 & 49811,5 & 56268,7 & 51587,7 & 57759,8 \\
\hline \multicolumn{3}{|c|}{$\begin{array}{l}\text { Part des } 20 \text { principaux bénéficiaires dans l'Aide } \\
\text { pour le commerce totale }\end{array}$} & $42,0 \%$ & $43,0 \%$ & $43,0 \%$ & $51,7 \%$ & $48,0 \%$ & $48,5 \%$ & $50,7 \%$ \\
\hline
\end{tabular}

Millions d'USD (constants de 2017)

\section{Tableau A.7b. Les 20 principaux bénéficiaires de l'aide pour le commerce en 2017, décaissements}

\begin{tabular}{|c|c|c|c|c|c|c|c|c|c|}
\hline & \multicolumn{9}{|c|}{ DÉCAISSEMENTS } \\
\hline & Région & $\begin{array}{c}\text { Groupe } \\
\text { de revenu }\end{array}$ & $\begin{array}{l}\text { Moyenne } \\
2006-2008\end{array}$ & $\begin{array}{l}\text { Moyenne } \\
2009-2011\end{array}$ & $\begin{array}{l}\text { Moyenne } \\
2012-2014\end{array}$ & 2015 & 2016 & 2017 & 2017 \\
\hline Inde & Asie & PRITI & 1148,4 & 1807,9 & 1868,8 & 3240,5 & 2769,2 & 3707,8 & 5274,9 \\
\hline Turquie & Europe & PRITS & 353,4 & 1199,8 & 2528,5 & 2344,8 & 2699,5 & 2299,3 & 2958,5 \\
\hline Bangladesh & Asie & PMA & 357,9 & 378,8 & 853,5 & 945,5 & 1055,4 & 1884,8 & 2945,8 \\
\hline Viet Nam & Asie & PRITI & 1007,9 & 1501,5 & 2474,2 & 2332,6 & 2176,7 & 1760,0 & 1933,2 \\
\hline Maroc & Afrique & PRITI & 401,0 & 720,8 & 1177,9 & 995,7 & 1722,7 & 1752,1 & 1398,8 \\
\hline Indonésie & Asie & PRITI & 736,8 & 765,0 & 555,3 & 922,2 & 506,3 & 1184,4 & 1213,1 \\
\hline Kenya & Afrique & PRITI & 272,6 & 389,8 & 912,5 & 953,3 & 843,7 & 932,3 & 1191,5 \\
\hline Pakistan & Asie & PRITI & 340,1 & 425,9 & 1083,4 & 1759,3 & 900,0 & 928,3 & 1154,0 \\
\hline Éthiopie & Afrique & PMA & 481,4 & 688,1 & 693,5 & 770,8 & 924,9 & 917,1 & 1081,6 \\
\hline Afghanistan & Asie & PMA & 1055,6 & 1843,2 & 1175,5 & 856,6 & 818,4 & 809,6 & 1072,7 \\
\hline Égypte & Afrique & PRITI & 558,6 & 671,7 & 1349,2 & 883,4 & 1125,7 & 807,5 & 1069,1 \\
\hline Tanzanie & Afrique & PMA & 381,5 & 611,0 & 863,6 & 863,4 & 750,1 & 797,5 & 994,0 \\
\hline Tunisie & Afrique & PRITI & 186,4 & 357,3 & 503,9 & 401,8 & 485,1 & 702,7 & 992,1 \\
\hline Nigéria & Afrique & PRITI & 225,7 & 322,6 & 467,2 & 590,2 & 406,1 & 695,4 & 962,2 \\
\hline Myanmar & Asie & PMA & 15,9 & 45,5 & 174,3 & 328,9 & 474,6 & 529,0 & 959,1 \\
\hline Rwanda & Afrique & PMA & 101,7 & 205,8 & 198,2 & 340,5 & 335,9 & 527,1 & 884,8 \\
\hline Népal & Asie & PMA & 121,4 & 207,4 & 278,8 & 400,3 & 282,3 & 488,6 & 866,8 \\
\hline Mozambique & Afrique & PMA & 329,4 & 320,2 & 500,9 & 569,5 & 445,6 & 486,6 & 804,3 \\
\hline Ouzbékistan & Asie & PRITI & 50,7 & 70,2 & 130,6 & 280,8 & 267,4 & 482,3 & 765,6 \\
\hline Serbie & Europe & PRITS & 230,5 & 435,6 & 535,8 & 420,6 & 440,8 & 475,6 & 752,9 \\
\hline \multicolumn{3}{|l|}{ Sous-total } & 8356,8 & 12968,3 & 18325,6 & 20200,5 & 19430,3 & 22168,1 & 29275,1 \\
\hline \multicolumn{3}{|c|}{ AIDE POUR LE COMMERCE TOTALE } & 21753,0 & 30284,5 & 36948,5 & 40864,2 & 39475,7 & 43066,9 & 57759,8 \\
\hline \multicolumn{3}{|c|}{$\begin{array}{l}\text { Part des } 20 \text { principaux bénéficiaires dans l'Aide pour } \\
\text { le commerce totale }\end{array}$} & $38,4 \%$ & $42,8 \%$ & $49,6 \%$ & $49,4 \%$ & $49,2 \%$ & $51,5 \%$ & $50,7 \%$ \\
\hline
\end{tabular}

Source: CAD de l'OCDE : base de données sur les activités d'aide (2019). 
Millions d'USD (constants de 2017)

Tableau A.8. Aide pour le commerce: programmes régionaux et mondiaux

ENGAGEMENTS

\begin{tabular}{|c|c|c|c|c|c|c|c|c|c|c|c|c|c|}
\hline & \multicolumn{7}{|c|}{ ENGAGEMENTS } & \multicolumn{6}{|c|}{ DÉCAISSEMENTS } \\
\hline & $\begin{array}{c}\text { Moyenne } \\
2002-2005\end{array}$ & $\begin{array}{c}\text { Moyenne } \\
2006-2008\end{array}$ & $\begin{array}{c}\text { Moyenne } \\
\text { 2009-2011 }\end{array}$ & $\begin{array}{c}\text { Moyenne } \\
2012-2014\end{array}$ & 2015 & 2016 & 2017 & $\begin{array}{c}\text { Moyenne } \\
2006-2008\end{array}$ & $\begin{array}{c}\text { Moyenne } \\
2009-2011\end{array}$ & $\begin{array}{c}\text { Moyenne } \\
2012-2014\end{array}$ & 2015 & 2016 & 2017 \\
\hline Afrique & 551,5 & 1106,1 & 1818,7 & 1901,2 & 1658,5 & 2615,1 & 2562,9 & 661,8 & 1649,0 & 1536,2 & 1679,0 & 2138,1 & 1796,0 \\
\hline Amérique & 179,3 & 373,6 & 449,8 & 492,6 & 412,2 & 669,4 & 515,8 & 259,5 & 407,3 & 494,9 & 281,3 & 487,7 & 491,5 \\
\hline Asie & 173,0 & 340,9 & 403,9 & 514,4 & 461,6 & 495,5 & 409,4 & 312,1 & 326,4 & 417,1 & 460,5 & 370,9 & 542,5 \\
\hline Europe & 50,1 & 217,4 & 157,8 & 101,1 & 224,9 & 175,6 & 446,3 & 176,6 & 201,2 & 108,2 & 232,2 & 123,7 & 318,0 \\
\hline Océanie & 27,7 & 57,8 & 77,8 & 48,3 & 62,4 & 93,2 & 255,1 & 47,4 & 47,5 & 47,5 & 79,4 & 51,3 & 182,1 \\
\hline $\begin{array}{l}\text { Non spécifique } \\
\text { à une région }\end{array}$ & 1089,5 & 1931,8 & 3576,2 & 3088,4 & 3679,9 & 3013,0 & 4247,5 & 1492,2 & 2663,7 & 2590,3 & 3595,1 & 3476,4 & 3331,2 \\
\hline TOTAL & 2071,0 & 4027,7 & 6484,2 & 6146,0 & 6499,5 & 7061,9 & 8437,0 & 2949,6 & 5295,0 & 5194,3 & 6327,4 & 6648,2 & 6661,2 \\
\hline
\end{tabular}

Part dans le total

\begin{tabular}{|c|c|c|c|c|c|c|c|c|c|c|c|c|c|}
\hline Afrique & $26,6 \%$ & $27,5 \%$ & $28,0 \%$ & $30,9 \%$ & $25,5 \%$ & $37,0 \%$ & $30,4 \%$ & $22,4 \%$ & $31,1 \%$ & $29,6 \%$ & $26,5 \%$ & $32,2 \%$ & $27,0 \%$ \\
\hline Amérique & $8,7 \%$ & $9,3 \%$ & $6,9 \%$ & $8,0 \%$ & $6,3 \%$ & $9,5 \%$ & $6,1 \%$ & $8,8 \%$ & $7,7 \%$ & $9,5 \%$ & $4,4 \%$ & $7,3 \%$ & $7,4 \%$ \\
\hline Asie & $8,4 \%$ & $8,5 \%$ & $6,2 \%$ & $8,4 \%$ & $7,1 \%$ & $7,0 \%$ & $4,9 \%$ & $10,6 \%$ & $6,2 \%$ & $8,0 \%$ & $7,3 \%$ & $5,6 \%$ & $8,1 \%$ \\
\hline Europe & $2,4 \%$ & $5,4 \%$ & $2,4 \%$ & $1,6 \%$ & $3,5 \%$ & $2,5 \%$ & $5,3 \%$ & $6,0 \%$ & $3,8 \%$ & $2,1 \%$ & $3,7 \%$ & $1,9 \%$ & $4,8 \%$ \\
\hline Océanie & $1,3 \%$ & $1,4 \%$ & $1,2 \%$ & $0,8 \%$ & $1,0 \%$ & $1,3 \%$ & $3,0 \%$ & $1,6 \%$ & $0,9 \%$ & $0,9 \%$ & $1,3 \%$ & $0,8 \%$ & $2,7 \%$ \\
\hline $\begin{array}{l}\text { Non spécifique } \\
\text { à une région }\end{array}$ & $52,6 \%$ & $48,0 \%$ & $55,2 \%$ & $50,2 \%$ & $56,6 \%$ & $42,7 \%$ & $50,3 \%$ & $50,6 \%$ & $50,3 \%$ & $49,9 \%$ & $56,8 \%$ & $52,3 \%$ & $50,0 \%$ \\
\hline
\end{tabular}

Source: CAD de l'OCDE : base de données sur les activités d'aide (2019).

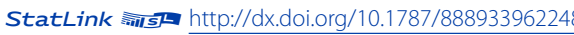

Tableau A.9. Aide pour le commerce: programmes régionaux et mondiaux par catégorie

\begin{tabular}{|c|c|c|c|c|c|c|c|c|c|c|c|c|c|}
\hline & \multicolumn{7}{|c|}{ ENGAGEMENTS } & \multicolumn{6}{|c|}{ DÉCAISSEMENTS } \\
\hline & $\begin{array}{c}\text { Moyenne } \\
2002-2005\end{array}$ & $\begin{array}{c}\text { Moyenne } \\
2006-2008\end{array}$ & $\begin{array}{l}\text { Moyenne } \\
2009-2011\end{array}$ & $\begin{array}{l}\text { Moyenne } \\
2012-2014\end{array}$ & 2015 & 2016 & 2017 & $\begin{array}{c}\text { Moyenne } \\
2006-2008\end{array}$ & $\begin{array}{c}\text { Moyenne } \\
2009-2011\end{array}$ & $\begin{array}{l}\text { Moyenne } \\
2012-2014\end{array}$ & 2015 & 2016 & 2017 \\
\hline $\begin{array}{l}\text { Politique et } \\
\text { réglementation } \\
\text { commerciales }\end{array}$ & 248,2 & 468,0 & 718,5 & 534,1 & 522,4 & 467,3 & 551,9 & 329,6 & 526,9 & 537,8 & 476,4 & 461,6 & 565,2 \\
\hline $\begin{array}{l}\text { Infrastructure } \\
\text { économique }\end{array}$ & 451,5 & 884,8 & 1698,7 & 1466,0 & 1133,2 & 1912,0 & 2062,8 & 462,8 & 1297,2 & 1127,4 & 763,4 & 1204,4 & 1380,8 \\
\hline $\begin{array}{l}\text { Renforcement } \\
\text { des capacités } \\
\text { de production }\end{array}$ & 1371,3 & 2674,7 & 4063,5 & 4145,7 & 4842,1 & 4682,1 & 5822,1 & 2157,3 & 3470,5 & 3528,8 & 5086,8 & 4981,5 & 4714,5 \\
\hline $\begin{array}{l}\text { Ajustement lié } \\
\text { au commerce }\end{array}$ & .. & 0,1 & 3,5 & 0,2 & 1,8 & 0,4 & 0,3 & 0,0 & 0,4 & 0,2 & 0,8 & 0,7 & 0,7 \\
\hline TOTAL & 2071,0 & 4027,7 & 6484,2 & 6146,0 & 6499,5 & 7061,9 & 8437,0 & 2949,6 & 5295,0 & 5194,3 & 6327,4 & 6648,2 & 6661,2 \\
\hline
\end{tabular}

\section{Share in total}

\begin{tabular}{|c|c|c|c|c|c|c|c|c|c|c|c|c|c|}
\hline $\begin{array}{l}\text { Politiqueet } \\
\text { réglementation } \\
\text { commerciales }\end{array}$ & $12,0 \%$ & $11,6 \%$ & $11,1 \%$ & $8,7 \%$ & $8,0 \%$ & $6,6 \%$ & $6,5 \%$ & $11,2 \%$ & $10,0 \%$ & $10,4 \%$ & $7,5 \%$ & $6,9 \%$ & $8,5 \%$ \\
\hline $\begin{array}{l}\text { Infrastructure } \\
\text { économique }\end{array}$ & $21,8 \%$ & $22,0 \%$ & $26,2 \%$ & $23,9 \%$ & $17,4 \%$ & $27,1 \%$ & $24,4 \%$ & $15,7 \%$ & $24,5 \%$ & $21,7 \%$ & $12,1 \%$ & $18,1 \%$ & $20,7 \%$ \\
\hline $\begin{array}{l}\text { Renforcement } \\
\text { des capacités } \\
\text { de production }\end{array}$ & $66,2 \%$ & $66,4 \%$ & $62,7 \%$ & $67,5 \%$ & $74,5 \%$ & $66,3 \%$ & $69,0 \%$ & $73,1 \%$ & $65,5 \%$ & $67,9 \%$ & $80,4 \%$ & $74,9 \%$ & $70,8 \%$ \\
\hline $\begin{array}{l}\text { Ajustement lié } \\
\text { au commerce }\end{array}$ & & $0,0 \%$ & $0,1 \%$ & $0,0 \%$ & $0,0 \%$ & $0,0 \%$ & $0,0 \%$ & $0,0 \%$ & $0,0 \%$ & $0,0 \%$ & $0,0 \%$ & $0,0 \%$ & $0,0 \%$ \\
\hline
\end{tabular}

Source: CAD de l'OCDE : base de données sur les activités d'aide (2019). 
Millions d'USD (constants de 2017)

Tableau A.10. Aide pour le commerce: dons et prêts par catégorie

\section{ENGAGEMENTS}

Moyenne Moyenne Moyenne Moyenne

2002-2005 2006-2008 2009-2011 2012-2014

\section{Politique et réglementation commerciales}

\begin{tabular}{|c|c|c|c|c|c|c|c|c|c|c|c|c|c|}
\hline Dons & 671,6 & 984,3 & 1246,6 & 1100,5 & 865,0 & 667,9 & 801,7 & 658,8 & 910,5 & 1008,7 & 874,2 & 823,1 & 903,2 \\
\hline Prêts & 77,3 & 40,8 & 65,2 & 149,9 & 222,6 & 304,2 & 622,6 & 32,9 & 64,0 & 113,6 & 122,9 & 324,3 & 313,7 \\
\hline Sous-total & 748,8 & 1025,0 & 1311,9 & 1250,5 & 1087,6 & 972,1 & 1424,3 & 691,7 & 974,5 & 1122,3 & 997,0 & 1147,4 & 1216,9 \\
\hline \multicolumn{14}{|c|}{ Infrastructure économique } \\
\hline Dons & 4917,8 & 7276,3 & 7350,8 & 6840,9 & 6137,8 & 5991,2 & 6270,7 & 5181,2 & 5942,2 & 6121,6 & 5718,0 & 5826,4 & 5354,0 \\
\hline Prêts & 7187,6 & 9073,4 & 14578,8 & 22468,8 & 27571,4 & 26456,5 & 26599,7 & 5704,8 & 9473,5 & 14127,5 & 15641,9 & 15339,5 & 18507,7 \\
\hline Sous-total & 12105,4 & 16349,7 & 21929,6 & 29309,6 & 33709,2 & 32447,7 & 32870,3 & 10886,1 & 15415,8 & 20249,0 & 21359,9 & 21165,9 & 23861,7 \\
\hline
\end{tabular}

Renforcement des capacités de production

\begin{tabular}{|c|c|c|c|c|c|c|c|c|c|c|c|c|c|}
\hline Dons & 6129,8 & 7869,6 & 10061,8 & 9631,5 & 10106,3 & 9189,9 & 10853,4 & 6698,9 & 8775,9 & 8509,9 & 9696,3 & 9627,4 & 9494,9 \\
\hline Prêts & 4176,3 & 5195,0 & 6264,1 & 9617,7 & 11363,4 & 8956,7 & 12634,9 & 3468,5 & 5082,0 & 7052,7 & 8797,5 & 7524,5 & 8488,0 \\
\hline Sous-total & 10306,1 & 13064,6 & 16325,8 & 19249,2 & 21469,7 & 18146,6 & 23488,3 & 10167,4 & 13857,9 & 15562,6 & 18493,7 & 17151,9 & 17982,8 \\
\hline
\end{tabular}

Ajustement lié au commerce

\begin{tabular}{|c|c|c|c|c|c|c|c|c|c|c|c|c|c|}
\hline Dons & .. & 2,0 & 17,5 & 2,2 & 2,3 & 21,3 & 0,8 & 7,8 & 36,0 & 14,6 & 13,5 & 9,5 & 4,6 \\
\hline Prêts & .. & .. & 3,2 & .. & .. & 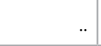 & .. & 0,0 & 0,4 & 0,0 & 0,0 & 1,0 & 0,8 \\
\hline Sous-total & .. & 2,0 & 20,7 & 2,2 & 2,3 & 21,3 & 0,8 & 7,8 & 36,4 & 14,6 & 13,5 & 10,5 & 5,4 \\
\hline $\begin{array}{l}\text { AIDE POUR LE COMMERCE } \\
\text { TOTALE }\end{array}$ & 23160,4 & 30441,3 & 39588,0 & 49811,5 & 56268,7 & 51587,7 & 57783,8 & 21753,0 & 30284,5 & 36948,5 & 40864,2 & 39475,7 & 43066,9 \\
\hline
\end{tabular}

Parts dans l'Aide pour le commerce totale

\begin{tabular}{l|r|r|r|r|r|r|r|r|r|r|r|r|r|r|r|}
\hline Dons & $50,6 \%$ & $53,0 \%$ & $47,2 \%$ & $35,3 \%$ & $30,4 \%$ & $30,8 \%$ & $31,0 \%$ & $57,7 \%$ & $51,7 \%$ & $42,4 \%$ & $39,9 \%$ & $41,3 \%$ & $36,6 \%$ \\
\hline Prêts & $49,4 \%$ & $47,0 \%$ & $52,8 \%$ & $64,7 \%$ & $69,6 \%$ & $69,2 \%$ & $69,0 \%$ & $42,3 \%$ & $48,3 \%$ & $57,6 \%$ & $60,1 \%$ & $58,7 \%$ & $63,4 \%$ \\
\hline
\end{tabular}

Source: CAD de l'OCDE : base de données sur les activités d'aide (2019).

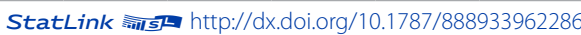

Millions d'USD (constants de 2017)

Tableau A.11. Circuits d'acheminement de l'Aide pour le commerce

\begin{tabular}{|c|c|c|c|c|c|c|c|c|c|c|c|c|c|}
\hline & \multicolumn{7}{|c|}{ ENGAGEMENTS } & \multicolumn{6}{|c|}{ DÉCAISSEMENTS } \\
\hline & $\begin{array}{l}\text { Moyenne } \\
2002-2005\end{array}$ & $\begin{array}{l}\text { Moyenne } \\
2006-2008\end{array}$ & $\begin{array}{l}\text { Moyenne } \\
\text { 2009-2011 }\end{array}$ & $\begin{array}{l}\text { Moyenne } \\
\text { 2012-2014 }\end{array}$ & 2015 & 2016 & 2017 & $\begin{array}{c}\text { Moyenne } \\
2006-2008\end{array}$ & $\begin{array}{l}\text { Moyenne } \\
\text { 2009-2011 }\end{array}$ & $\begin{array}{l}\text { Moyenne } \\
\text { 2012-2014 }\end{array}$ & 2015 & 2016 & 2017 \\
\hline Institutions du secteur public & 1404,2 & 21392,7 & 27571,6 & 33926,0 & 41008,4 & 38416,8 & 44876,2 & 10080,5 & 19976,6 & 23944,2 & 28979,2 & 28064,5 & 31862,7 \\
\hline ONG et société civile & 95,8 & 875,0 & 1554,2 & 1867,4 & 2438,6 & 1801,2 & 1584,6 & 819,0 & 1712,3 & 1700,0 & 2155,1 & 1945,2 & 1937,4 \\
\hline $\begin{array}{l}\text { Partenariats et réseaux } \\
\text { public-privé }\end{array}$ & 0,9 & 4,8 & 289,3 & 185,4 & 374,6 & 290,7 & 360,0 & 5,7 & 323,3 & 207,1 & 315,1 & 407,6 & 364,8 \\
\hline Organisations multilatérales & 201,8 & 1309,6 & 3660,8 & 7932,1 & 4053,7 & 4365,0 & 5291,6 & 1176,6 & 3167,5 & 6028,1 & 3759,7 & 3631,0 & 3821,3 \\
\hline Autres & 1872,0 & 2165,1 & 4120,2 & 3884,0 & 5465,9 & 5218,7 & 4986,5 & 2777,2 & 3961,1 & 4075,8 & 4984,2 & 5003,2 & 4696,1 \\
\hline Circuits non notifiés & 19585,7 & 4694,2 & 2391,8 & 2016,6 & 2927,5 & 1495,4 & 684,8 & 6894,0 & 1143,8 & 993,3 & 670,7 & 424,2 & 384,6 \\
\hline $\begin{array}{l}\text { AIDE POUR LE COMMERCE } \\
\text { TOTALE }\end{array}$ & 23160,4 & 30441,3 & 39588,0 & 49811,5 & 56268,7 & 51587,7 & 57783,8 & 21753,0 & 30284,5 & 36948,5 & 40864,2 & 39475,7 & 43066,9 \\
\hline
\end{tabular}

Source: CAD de l'OCDE : base de données sur les activités d'aide (2019).

StatLink 完开S http://dx.doi.org/10.1787/888933962305 
Millions d'USD (constants de 2017)

Tableau A.12. Aide pour le commerce par donateur et par catégorie, engagements (page 1 sur 6 )

AIDE POUR LE COMMERCE TOTALE

\begin{tabular}{|c|c|c|c|c|c|c|c|}
\hline & \\
\hline & $\begin{array}{c}\text { Moyenne } \\
2002-2005\end{array}$ & $\begin{array}{c}\text { Moyenne } \\
\text { 2006-2008 }\end{array}$ & $\begin{array}{c}\text { Moyenne } \\
\text { 2009-2011 }\end{array}$ & $\begin{array}{c}\text { Moyenne } \\
\text { 2012-2014 }\end{array}$ & 2015 & 2016 & 2017 \\
\hline \multicolumn{8}{|l|}{ Pays CAD } \\
\hline Allemagne & 1217,6 & 2033,4 & 3317,0 & 4866,1 & 5887,8 & 6093,6 & 5696,6 \\
\hline Australie & 206,6 & 311,3 & 494,4 & 385,6 & 412,2 & 394,3 & 427,8 \\
\hline Autriche & 45,2 & 52,7 & 74,3 & 86,5 & 71,1 & 75,5 & 75,8 \\
\hline Belgique & 229,9 & 254,6 & 431,8 & 184,9 & 215,6 & 164,8 & 217,0 \\
\hline Canada & 327,6 & 359,8 & 552,5 & 504,2 & 722,7 & 555,6 & 186,4 \\
\hline Corée & & 490,3 & 941,1 & 877,6 & 930,8 & 1061,0 & 1183,7 \\
\hline Danemark & 413,6 & 269,5 & 303,1 & 371,1 & 124,6 & 255,4 & 203,5 \\
\hline Espagne & 359,8 & 658,0 & 817,1 & 90,0 & 52,0 & 42,9 & 105,6 \\
\hline États-Unis & 4278,2 & 6094,8 & 4696,0 & 3469,0 & 3487,4 & 2975,3 & 2416,9 \\
\hline Finlande & 78,7 & 126,8 & 291,8 & 131,7 & 91,9 & 70,2 & 223,3 \\
\hline France & 656,9 & 1405,8 & 1347,1 & 2501,2 & 2913,7 & 2510,3 & 3225,0 \\
\hline Grèce & 11,4 & 16,7 & 15,5 & 0,1 & 0,0 & 0,0 & 0,0 \\
\hline Hongrie &.. & 0,0 & 0,0 & 0,0 & 0,4 & 3,9 & 2,4 \\
\hline Irlande & 26,6 & 42,2 & 58,4 & 47,8 & 33,0 & 40,2 & 42,7 \\
\hline Islande &.. & 0,0 & 3,3 & 12,0 & 8,4 & 8,7 & 8,4 \\
\hline Italie & 249,7 & 228,7 & 164,9 & 117,4 & 189,9 & 77,5 & 352,6 \\
\hline Japon & 4492,8 & 5661,4 & 6073,6 & 8321,9 & 12683,5 & 11268,9 & 12510,7 \\
\hline Luxembourg & 16,9 & 31,4 & 34,0 & 38,9 & 33,9 & 38,6 & 55,2 \\
\hline Norvège & 246,3 & 399,0 & 502,6 & 527,1 & 338,1 & 348,9 & 497,4 \\
\hline Nouvelle-Zélande & 22,5 & 45,7 & 97,9 & 120,6 & 145,0 & 128,6 & 162,0 \\
\hline Pays-Bas & 533,3 & 686,9 & 698,9 & 865,0 & 607,6 & 511,7 & 655,0 \\
\hline Pologne & & 0,0 & 0,0 & 8,8 & 31,9 & 80,5 & 16,0 \\
\hline Portugal & 43,3 & 28,1 & 51,0 & 27,8 & 25,3 & 4,2 & 3,4 \\
\hline République slovaque &.. & 0,0 & 0,0 & 0,6 & 0,9 & 0,8 & 0,8 \\
\hline République tchèque &.. & .. & 3,5 & 7,8 & 11,2 & 6,9 & 9,0 \\
\hline Royaume-Uni & 646,0 & 806,7 & 1107,1 & 851,3 & 1513,7 & 811,6 & 1136,5 \\
\hline Slovénie &.. & 0,0 & 2,1 & 1,2 & 0,1 & 1,2 & 1,0 \\
\hline Suède & 225,5 & 326,3 & 330,5 & 374,0 & 292,1 & 345,6 & 382,8 \\
\hline Suisse & 295,4 & 266,1 & 282,7 & 374,5 & 305,1 & 353,8 & 695,0 \\
\hline Sous-total & 14623,8 & 20596,1 & 22692,4 & 25164,6 & 31130,1 & 28230,7 & 30492,4 \\
\hline \multicolumn{8}{|c|}{ Autres donateurs bilatéraux } \\
\hline Arabie saoudite & .. &.. & .. &.. & 481,0 & 843,4 & 546,4 \\
\hline Azerbaïdjan &.. & .. &.. & .. & .. & .. & 2,3 \\
\hline Croatie & .. &.. & .. & .. & .. & .. & 0,5 \\
\hline Émirats arabes unis &.. &. & 233,4 & 891,5 & 907,3 & 71,7 & 437,8 \\
\hline Estonie & &.. &.. & 1,5 & 1,2 & 2,1 & 2,0 \\
\hline Kazakhstan & 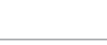 &. &.. & .. & .. &. &. \\
\hline Koweït & . &.. & 313,7 & 534,2 & 399,2 & 718,9 & 277,9 \\
\hline Lettonie & 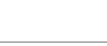 &. &.. & .. & .. & 0,2 & 0,0 \\
\hline Lituanie & . &. &.. & 0,0 & 0,7 & 0,5 & 0,5 \\
\hline Roumanie &.. &. &.. & 0,1 & 0,5 & 1,3 & .. \\
\hline Taipei chinois &.. & .. &.. & .. & .. &. &. \\
\hline Thaïlande &.. &.. &.. & .. & .. &.. &. \\
\hline Turquie &. &. & 34,4 & .. & .. & .. &. \\
\hline Sous-total &.. & .. & 581,5 & 1427,4 & 1789,9 & 1638,0 & 1267,4 \\
\hline
\end{tabular}


Tableau A.12. Aide pour le commerce par donateur et par catégorie, engagements (page 2 sur 6 )

\section{AIDE POUR LE COMMERCE TOTALE}

\begin{tabular}{|c|c|c|c|c|c|c|c|}
\hline & $\begin{array}{c}\text { Moyenne } \\
2002-2005\end{array}$ & $\begin{array}{l}\text { Moyenne } \\
2006-2008\end{array}$ & $\begin{array}{l}\text { Moyenne } \\
\text { 2009-2011 }\end{array}$ & $\begin{array}{l}\text { Moyenne } \\
\text { 2012-2014 }\end{array}$ & 2015 & 2016 & 2017 \\
\hline \multicolumn{8}{|l|}{ Donateurs multilatéraux } \\
\hline BADEA & .. &. &. &. & 4,1 & 35,5 & 12,9 \\
\hline BAfD & 149,0 & 706,4 & 1498,2 & 1578,6 & 1824,1 & 806,7 & 1062,6 \\
\hline $\begin{array}{l}\text { Banque de développement } \\
\text { des Caraïbes }\end{array}$ &. &. &. &. & 2,8 &. & .. \\
\hline Banque islamique de développement & 190,4 & 252,3 & 188,9 & 138,2 & 236,7 & 261,2 & 149,7 \\
\hline Banque mondiale & 4467,9 & 4235,5 & 6098,7 & 7117,1 & 7718,2 & 6267,1 & 10284,3 \\
\hline BAsD & 747,7 & 521,1 & 1198,4 & 1783,8 & 1690,1 & 1723,7 & 1614,7 \\
\hline $\mathrm{BID}$ & 242,3 & 110,9 & 433,2 & 585,8 & 797,9 & 446,9 & 475,0 \\
\hline Cadre intégré renforcé (CIR) & 2457,6 & 3013,4 & 4320,7 & 8642,2 & 6953,8 & 8891,2 & 8361,0 \\
\hline CEB &. &. &.. & 783,8 & 668,7 & 610,5 & 570,8 \\
\hline CEE-ONU & .. & 1,3 & 4,2 & 3,5 & 5,2 & 5,5 & 5,7 \\
\hline CESAO &. & 0,1 & 0,2 & 0,3 & 0,4 & 0,2 & 0,2 \\
\hline CESAP &. & 0,3 & 0,5 & 0,6 & 0,7 & 0,4 & 0,8 \\
\hline $\mathrm{FAO}$ &. &. & 120,0 & 274,9 & 112,6 & 119,4 & 624,5 \\
\hline FIDA & 268,8 & 375,8 & 581,0 & 540,9 & 927,3 & 536,8 & 934,0 \\
\hline FMl &.. & 10,2 & 13,6 & 9,5 &. &. & .. \\
\hline FODI &.. &.. & 346,8 & 419,2 & 515,2 & 606,4 & 493,3 \\
\hline Fonds arabe (FADES) &.. & 388,3 & 1010,3 & 769,0 & 1351,3 & 962,2 & 1031,6 \\
\hline $\begin{array}{l}\text { Fonds d'investissement pour le climat } \\
\text { (FIC) }\end{array}$ & $\cdot$. &. & 13,1 & 26,3 & 18,6 & 3,6 & 11,7 \\
\hline Fonds pour l'environnement mondial &. &. &. &. & 12,8 & 163,7 & 186,9 \\
\hline Institutions de l'UE &. & 131,7 & 273,6 & 271,7 & 316,7 &. & .. \\
\hline ITC &. & 30,1 & 54,2 & 64,9 & 68,9 & 57,4 & 51,4 \\
\hline OMC &. & 12,7 & 15,6 & 11,9 & 11,7 & 23,0 & 12,3 \\
\hline ONUDI &. & 27,0 & 61,5 & 12,9 &. & 82,6 & 13,5 \\
\hline Organisation mondiale du tourisme &. &. &. &. &. &.. & .. \\
\hline PNUD & 11,9 & 24,0 & 33,5 & 30,6 & 26,2 & 7,0 & 8,7 \\
\hline Autres donateurs multilatéraux & 1,0 & 4,1 & 47,9 & 153,9 & 85,0 & 107,9 & 118,2 \\
\hline Sous-total & 8536,6 & 9845,2 & 16314,1 & 23219,5 & 23348,8 & 21719,0 & 26024,0 \\
\hline AIDE POUR LE COMMERCE TOTALE & 23160,4 & 30441,3 & 39588,0 & 49811,5 & 56268,7 & 51587,7 & 57783,8 \\
\hline
\end{tabular}


Millions d'USD (constants de 2017)

Tableau A.12. Aide pour le commerce par donateur et par catégorie, engagements (page 3 sur 6 ) POLITIQUE ET RÉGLEMENTATION COMMERCIALES

\begin{tabular}{l|l|l|l|l|l|l} 
Moyenne & Moyenne & Moyenne & Moyenne & 2015 & 2016 & 2017
\end{tabular} 2002-2005 2006-2008 $2009-2011 \quad 2012-2014$
INFRASTRUCTURE ÉCONOMIQUE

\begin{tabular}{l|l|l|l|l|l} 
Moyenne & Moyenne & Moyenne & Moyenne & 2015 & 2016
\end{tabular} 2002-2005 $2006-2008$ 2009-2011 $2012-2014$

\section{Pays CAD}

Allemagne

\begin{tabular}{|l|r|r|r|r|r|r|r|r|r|r|r|r|r|}
\hline 13,7 & 34,2 & 33,7 & 38,4 & 43,3 & 82,1 & 301,0 & 556,5 & 873,5 & 1733,8 & 2448,9 & 3129,6 & 3768,0 & 2961,8 \\
\hline
\end{tabular}

Australie

Autriche

Belgique

\begin{tabular}{|r|r|r|r|r|r|r|r|r|r|r|r|r|r|}
\hline 9,6 & 6,1 & 28,5 & 18,6 & 38,8 & 31,6 & 29,2 & 69,9 & 144,5 & 244,5 & 160,2 & 182,8 & 143,4 & 134,3 \\
\hline
\end{tabular}

Canada

\begin{tabular}{|r|r|r|r|r|r|r|r|r|r|r|r|r|r|r|}
\hline 3,9 & 4,9 & 10,5 & 10,7 & 0,7 & 0,7 & 4,5 & 52,9 & 74,0 & 89,2 & 42,8 & 35,5 & 37,4 & 62,0 \\
\hline
\end{tabular}

Corée

Danemark

Espagne

États-Unis

Finlande

France

Grèce

Hongrie

Irlande

Islande

Italie

Japon

Luxembourg

Norvège

\begin{tabular}{|r|r|r|r|r|r|r|}
\hline 18,6 & 20,0 & 30,2 & 16,7 & 35,1 & 24,0 & 8,6 \\
\hline & 7,1 & 4,4 & 8,1 & 9,6 & 3,8 & 12,3 \\
\hline
\end{tabular}

Nouvelle-Zélande

\begin{tabular}{|l|r|r|r|r|r|r|r|r|r|r|r|r|r|}
\hline 0,4 & 2,9 & 11,4 & 5,1 & 2,1 & 6,5 & 9,0 & 200,0 & 109,1 & 68,7 & 90,4 & 7,9 & 23,9 & 42,8 \\
\hline
\end{tabular}

Pays-Bas

Pologne

Portugal

République slovaque

République tchèque

Royaume-Uni

Slovénie

Suède

Suisse

Sous-total

\begin{tabular}{|r|r|r|}
\hline 1,3 & 4,2 & 3,3 \\
\hline 270,7 & 270,4 & 200,8 \\
\hline
\end{tabular}

0,5

\begin{tabular}{|r|r|r|r|}
\hline 270,7 & 270,4 & 200,8 \\
\hline 2,4 & 6,3 & 11,6 \\
\hline 41 & 2,6 & 1,2 \\
\hline
\end{tabular}

Autres donateurs bilatéraux

\begin{tabular}{|c|c|c|c|c|c|c|c|c|c|c|c|c|c|c|}
\hline Arabie saoudite & .. & .. &.. &.. &.. & .. &.. & .. & .. & .. & 481,0 & 688,6 & 429,7 & .. \\
\hline Azerbaïdjan & .. & .. &.. &.. &.. & 2,1 & .. & .. & .. & .. & ." & .. & 0,1 & .. \\
\hline Croatie & .. & .. & .. & .. &.. & .. &.. & .. & .. & .. &.. & .. & 0,3 & .. \\
\hline Émirats arabes unis & .. & .. &.. &.. &.. &.. & .. & .. & 216,8 & 539,2 & 575,8 & 71,3 & 284,7 & .. \\
\hline Estonie & .. & .. & 0,0 & 0,0 &.. &.. &.. & .. & .. & 0,8 & 0,3 & 0,2 & 1,0 & .. \\
\hline Kazakhstan & .. & .. & &.. &.. & .. & .. & .. & .. & . &.. & .. & 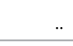 & .. \\
\hline Koweït & .. & .. &.. &.. &.. &.. & .. & .. & 298,1 & 477,8 & 330,9 & 503,2 & 257,7 & .. \\
\hline Lettonie & .. & .. & .. &.. &.. & .. & .. & .. & .. & .. &.. & .. & .. & .. \\
\hline Lituanie & .. & .. & 0,0 & 0,1 & 0,1 & 0,1 & .. & .. & .. & 0,0 & 0,5 & 0,3 & 0,2 & .. \\
\hline Roumanie & .. & .. & .. &.. & 0,0 & .. & .. & .. & . &.. & .. & 1,1 & .. & .. \\
\hline Taipei chinois & .. & .. & .. &.. &.. & .. & .. & .. & .. & .. &.. & .. & .. & .. \\
\hline Thaïlande & .. & .. & .. &.. &.. & .. & .. & .. & .. & .. & .. & .. & .. & .. \\
\hline Turquie & .. & 31,8 &.. &.. &.. &.. &.. & .. & 0,4 &.. & .. & .. & .. & .. \\
\hline Sous-total & .. & 31,8 & 0,0 & 0,1 & 0,1 & 2,3 & 0,0 & .. & 515,3 & 1017,7 & 1388,3 & 1264,8 & 973,8 & .. \\
\hline
\end{tabular}


Millions d'USD (constants de 2017)

Tableau A.12. Aide pour le commerce par donateur et par catégorie, engagements (page 4 sur 6 ) POLITIQUE ET RÉGLEMENTATION COMMERCIALES

\begin{tabular}{l|l|l|l|l|l|l} 
Moyenne & Moyenne & Moyenne & Moyenne & 2015 & 2016 & 2017
\end{tabular}

2002-2005 2006-2008 2009-2011 2012-2014

\section{INFRASTRUCTURE ÉCONOMIQUE}

\begin{tabular}{l|l|l|l|l|l} 
Moyenne & Moyenne & Moyenne & Moyenne & 2015 & 2016
\end{tabular} 2002-2005 2006-2008 2009-2011 2012-2014

\begin{tabular}{|c|c|c|c|c|c|c|c|c|c|c|c|c|c|c|}
\hline \multicolumn{15}{|l|}{ Donateurs multilatéraux } \\
\hline BADEA &.. &.. &. &.. &.. & 0,0 & 0,4 &.. &. & .. &.. & 0,4 & 25,0 & 2,2 \\
\hline BAfD & 22,9 & .. & & 0,1 &.. & 1,5 & 2,5 & 61,3 & 539,0 & 1207,1 & 1329,8 & 1279,6 & 619,7 & 940,0 \\
\hline $\begin{array}{l}\text { Banque de développement } \\
\text { des Caraïbes }\end{array}$ & $\cdot$ &. & &.. &.. &. & .. & & & & $\cdot$. & . & & \\
\hline $\begin{array}{l}\text { Banque islamique } \\
\text { de développement }\end{array}$ &. & .. & 0,3 & 0,0 &. & 1,1 & .. & 115,5 & 140,1 & 82,5 & 73,3 & 156,0 & 186,5 & 26,8 \\
\hline Banque mondiale & 56,0 & 40,1 & 105,4 & 172,0 & 222,6 & 247,7 & 376,6 & 2280,6 & 2362,7 & 3451,1 & 4210,8 & 4245,7 & 3396,0 & 5252,3 \\
\hline BAsD & 8,4 & 1,7 & 8,0 & 13,6 & 1,9 & 57,6 & 28,0 & 358,4 & 291,2 & 925,8 & 1260,5 & 1144,8 & 1309,3 & 1236,7 \\
\hline BID &.. & 0,6 & 7,1 & 7,8 & 2,2 & 1,3 & 1,8 & 122,3 & 87,8 & 299,8 & 424,1 & 610,4 & 241,1 & 317,9 \\
\hline Cadre intégré renforcé (CIR) & 179,7 & 326,6 & 316,3 & 232,5 & 187,6 & 97,2 & 187,8 & 1270,8 & 1686,1 & 1935,6 & 4423,3 & 3108,6 & 4968,1 & 3848,3 \\
\hline CEB &. &.. &.. &.. &.. & .. &.. &.. &.. & $"$ & 704,5 & 618,7 & 517,0 & 462,3 \\
\hline CEE-ONU &.. & 0,3 & 0,1 & 0,3 & 0,2 & 0,1 & 0,2 &.. & 0,9 & 3,4 & 1,9 & 3,6 & 4,4 & 4,6 \\
\hline CESAO &.. & 0,1 & 0,0 & 0,2 & 0,3 & 0,1 & 0,2 &.. & 0,0 & 0,0 & 0,0 & 0,1 & 0,0 & 0,0 \\
\hline CESAP &.. & 0,1 & 0,4 & 0,5 & 0,6 & 0,4 & 0,8 &.. &.. & .. & 0,0 &.. &.. &. \\
\hline FAO &.. &.. &.. & 1,2 &.. &.. &.. &.. &.. & 61,5 & 129,3 & 85,2 &.. & 108,6 \\
\hline FODI &.. & .. &.. &.. &.. & .. & 0,1 &.. &.. & 253,9 & 361,3 & 445,6 & 435,6 & 327,9 \\
\hline Fonds arabe (FADES) &. & .. &.. &.. &.. & .. &.. &.. & 288,7 & 888,1 & 692,8 & 1140,5 & 589,7 & 922,0 \\
\hline $\begin{array}{l}\text { Fonds d'investissement pour } \\
\text { le climat (FIC) }\end{array}$ &. & $\cdot$ & 13,1 & 7,7 & 5,5 & 3,6 & 7,2 &.. &.. & .. &.. &. &.. & .. \\
\hline $\begin{array}{l}\text { Fonds pour l'environnement } \\
\text { mondial }\end{array}$ &.. &. &.. &.. &. & .. & $\cdot$ &.. &.. & .. &.. & 5,1 & 123,7 & 89,6 \\
\hline FIDA &.. & .. &.. &.. &.. &.. &.. & 12,7 & 20,9 & 43,9 & 26,4 & 48,2 & 9,3 & 2,3 \\
\hline FMl &.. & 10,2 & 13,6 & 9,5 &.. &.. &.. &.. &.. &. &.. & .. &.. & .. \\
\hline Institutions de I'UE &.. & 19,0 & 40,3 & 24,9 & 32,8 &. &.. &.. &.. &. &.. &.. &.. & .. \\
\hline ITC &.. & .. &.. &.. &.. &.. &.. &.. &. & .. &.. &.. &.. & .. \\
\hline OMC &.. & 12,7 & 15,6 & 11,8 & 11,7 & 23,0 & 12,3 &.. &.. & &.. &.. &.. & .. \\
\hline ONUDI &. & 3,8 & 7,4 & 4,4 &. & 1,7 & 1,1 &.. & 1,3 & 8,2 & 0,2 & .. & 36,5 & 1,5 \\
\hline $\begin{array}{l}\text { Organisation mondiale } \\
\text { du tourisme }\end{array}$ &.. & $\cdot$ & $\cdot$ & $\cdot$ & $\cdot$ & $\cdot$ & $\cdot$ & $\cdot$. & $\cdot$ & $\cdot$ & $\cdot \cdot$ & $\cdot$ & $\cdot$ & .. \\
\hline PNUD & 1,5 & 3,1 & 2,9 & 0,8 & 0,0 & .. &.. & 2,1 & 5,2 & 8,9 & 8,8 & 16,1 & 7,0 & 8,7 \\
\hline Autres donateurs multilatéraux &. & 0,8 & 0,2 &.. &.. &.. &. & 1,0 & 2,8 & 39,0 & 107,4 & 40,6 & 54,7 & 59,4 \\
\hline Sous-total & 268,5 & 419,2 & 530,8 & 487,0 & 465,4 & 435,3 & 619,0 & 4224,7 & 5426,7 & 9208,6 & 13754,4 & 12949,1 & 12523,6 & 13611,1 \\
\hline $\begin{array}{l}\text { AIDE POUR LE COMMERCE } \\
\text { TOTALE }\end{array}$ & 748,8 & 1056,8 & 1280,1 & 1250,5 & 1087,6 & 974,4 & 1422,0 & 12105,4 & 16865,0 & 22432,0 & 29680,3 & 33585,6 & 32156,7 & 31896,6 \\
\hline
\end{tabular}


Millions d'USD (constants de 2017)

Tableau A.12. Aide pour le commerce par donateur et par catégorie, engagements (page 5 sur 6 )

RENFORCEMENT DE LA CAPACITÉ DE PRODUCTION

\begin{tabular}{l|l|l|l|l|l|l} 
Moyenne & Moyenne & Moyenne & Moyenne & 2015 & 2016 & 2017
\end{tabular}

2002-2005 2006-2008 $2009-2011 \quad 2012-2014$
AJUSTEMENT LIÉ AU COMMERCE

\begin{tabular}{l|l|l|l|l|l} 
Moyenne & Moyenne & Moyenne & 2015 & 2016 & 2017
\end{tabular}

2002-2005 $2006-2008 \quad 2009-2011$

\begin{tabular}{|c|c|c|c|c|c|c|c|c|c|c|c|c|c|}
\hline \multicolumn{14}{|l|}{ Pays CAD } \\
\hline Allemagne & 647,5 & 1125,7 & 1549,5 & 2378,9 & 2714,9 & 2243,6 & 2433,5 & .. &.. & 0,0 & 0,0 &.. & 0,2 \\
\hline Australie & 127,0 & 160,5 & 221,1 & 206,9 & 190,7 & 219,4 & 264,4 & 0,2 & 0,4 & .. &.. &.. & 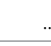 \\
\hline Autriche & 21,4 & 32,6 & 48,2 & 56,2 & 35,9 & 49,0 & 49,9 & .. &.. & & .. &.. & . \\
\hline Belgique & 173,1 & 175,7 & 332,2 & 131,3 & 179,5 & 126,8 & 150,6 &.. &.. & .. &.. &.. & . \\
\hline Canada & 265,5 & 266,1 & 431,6 & 394,3 & 647,9 & 386,7 & 122,3 & 0,1 & 0,0 & 0,2 &.. & 0,4 & 0,1 \\
\hline Corée & & 79,5 & 118,0 & 234,4 & 143,3 & 153,0 & 207,9 &.. &.. & 0,0 &.. &.. & .. \\
\hline Danemark & 213,1 & 157,5 & 222,9 & 275,7 & 114,6 & 225,1 & 151,7 &. &.. & .. &.. &.. & . \\
\hline Espagne & 139,5 & 248,7 & 557,7 & 83,0 & 37,0 & 38,7 & 76,0 &.. &.. & .. &.. &.. & . \\
\hline États-Unis & 2023,4 & 2586,8 & 2533,2 & 1993,4 & 2057,9 & 1709,9 & 1305,4 &.. &.. & .. &.. &.. & . \\
\hline Finlande & 46,9 & 101,0 & 187,9 & 78,6 & 57,2 & 53,4 & 49,5 &.. & 3,2 & .. &.. &.. & . \\
\hline France & 322,5 & 613,3 & 616,8 & 454,5 & 785,7 & 1109,2 & 1001,5 &.. &.. & 0,0 &.. & 2,3 & - \\
\hline Grèce & 4,6 & 9,3 & 2,4 &.. &. &.. &.. &.. &.. & .. & .. &.. & . \\
\hline Hongrie &.. & .. &.. & .. & 0,4 & 3,9 & 2,4 &.. &.. & .. &.. &.. & .. \\
\hline Irlande & 19,7 & 38,7 & 56,9 & 46,5 & 32,3 & 39,4 & 41,9 &.. &.. & .. &.. &.. & .. \\
\hline Islande & .. & .. & 2,2 & 7,1 & 4,5 & 4,3 & 4,4 & .. &.. & .. & .. &.. & .. \\
\hline Italie & 101,5 & 114,0 & 116,2 & 87,4 & 128,1 & 48,0 & 82,0 &.. &.. & .. &.. &.. & .. \\
\hline Japon & 905,1 & 1613,2 & 907,8 & 1279,8 & 1538,8 & 878,1 & 2628,7 &.. & 0,1 & 0,1 & .. &.. & 0,0 \\
\hline Luxembourg & 15,7 & 25,4 & 30,3 & 32,9 & 31,2 & 35,6 & 43,6 &. &.. & .. & .. &.. & . \\
\hline Norvège & 151,0 & 226,0 & 296,6 & 318,8 & 283,8 & 259,7 & 413,1 & .. &.. & .. & .. &.. & 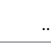 \\
\hline Nouvelle-Zélande & 16,3 & 26,4 & 46,3 & 63,4 & 111,9 & 95,8 & 68,4 & 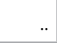 &.. & .. & .. &.. & .. \\
\hline Pays-Bas & 380,1 & 457,0 & 404,7 & 711,9 & 423,5 & 405,3 & 547,1 &.. &.. & .. &.. &.. & .. \\
\hline Pologne & & 0,0 & 0,0 & 8,2 & 29,7 & 80,0 & 15,7 &.. &. & .. & .. &.. & $\cdot$ \\
\hline Portugal & 7,3 & 3,4 & 3,5 & 1,9 & 3,2 & 2,0 & 2,4 & .. &.. & .. &.. &.. & .. \\
\hline République slovaque &.. & 0,0 & 0,0 & 0,5 & 0,7 & 0,6 & 0,6 &.. &.. & .. & .. &.. & . \\
\hline République tchèque &. & & 2,1 & 5,3 & 6,2 & 5,1 & 7,1 & &.. & .. & .. &. & \\
\hline Royaume-Uni & 357,1 & 599,5 & 624,3 & 450,6 & 1219,2 & 349,0 & 873,9 & .. &.. & .. &.. &.. & 0,0 \\
\hline Slovénie & & 0,0 & 1,2 & 0,8 & 0,2 & 1,1 & 0,5 & .. &.. & .. & .. &.. & .. \\
\hline Suède & 106,5 & 204,5 & 214,2 & 284,9 & 123,9 & 229,0 & 273,4 &.. & 0,7 & 0,9 & 1,8 &.. & 0,1 \\
\hline Suisse & 218,1 & 202,0 & 203,9 & 274,8 & 232,0 & 261,6 & 585,1 &.. & 1,7 & 0,6 & 0,4 & 18,6 & 0,3 \\
\hline Sous-total & 6262,8 & 9066,9 & 9731,3 & 9861,8 & 11134,0 & 9013,4 & 11403,0 & 0,3 & 6,1 & 1,8 & 2,3 & 21,2 & 0,8 \\
\hline
\end{tabular}

\section{Autres donateurs bilatéraux}

\begin{tabular}{|c|c|c|c|c|c|c|c|c|c|c|c|c|c|}
\hline Arabie saoudite &.. &.. &.. &.. & 154,8 & 116,7 & .. &.. &.. &.. & .. &.. & .. \\
\hline Azerbaïdjan &.. &.. &.. &.. & .. & 0,1 &.. & .. &.. &.. & .. &.. & .. \\
\hline Croatie &.. &.. &.. &.. &.. & 0,2 &.. & .. &.. &.. & .. &.. & .. \\
\hline Émirats arabes unis &.. & 16,5 & 352,3 & 331,5 & 0,4 & 153,1 & .. & .. & .. & .. & .. &.. & .. \\
\hline Estonie &.. &.. & 0,7 & 0,9 & 1,8 & 1,0 & .. & .. & .. & .. & .. &.. & .. \\
\hline Kazakhstan &.. &.. &.. & .. &.. &.. & .. & .. & .. &.. & .. &.. & .. \\
\hline Koweït &.. & 15,6 & 56,4 & 68,3 & 215,7 & 20,1 & .. & .. & .. & .. & .. &.. & .. \\
\hline Lettonie &.. &.. &.. & .. & 0,2 & 0,0 & .. & .. &.. & .. & .. & & .. \\
\hline Lituanie &.. &.. & 0,0 & 0,2 & 0,1 & 0,1 & .. & .. & .. & .. & .. & 0,0 & .. \\
\hline Roumanie & . & . & 0,1 & 0,5 & 0,2 & ". & . & .. & .. & . & .. & .. & .. \\
\hline Taipei chinois &.. &.. &.. &.. &.. &.. & .. & .. & .. & .. & .. &.. & .. \\
\hline Thaïlande & .. &.. & .. & .. & .. & .. & .. & .. & .. & .. & .. & .. & .. \\
\hline Turquie &.. & 2,2 &.. & .. &.. &.. & .. &.. &.. & .. &.. & .. & .. \\
\hline Sous-total &.. & 34,4 & 409,6 & 401,5 & 373,1 & 291,3 & .. & .. & .. & .. & .. & 0,0 & .. \\
\hline
\end{tabular}


Tableau A.12. Aide pour le commerce par donateur et par catégorie, engagements (page 6 sur 6 )

Millions d'USD (constants de 2017)

\begin{tabular}{|c|c|c|c|c|c|c|c|c|c|c|c|c|c|}
\hline & \multicolumn{7}{|c|}{ RENFORCEMENT DE LA CAPACITÉ DE PRODUCTION } & \multicolumn{6}{|c|}{ AJUSTEMENT LIÉ AU COMMERCE } \\
\hline & $\begin{array}{l}\text { Moyenne } \\
\text { 2002-2005 }\end{array}$ & $\begin{array}{l}\text { Moyenne } \\
2006-2008\end{array}$ & \begin{tabular}{|c} 
Moyenne \\
2009-2011
\end{tabular} & \begin{tabular}{|l} 
Moyenne \\
2012-2014
\end{tabular} & 2015 & 2016 & 2017 & $\begin{array}{l}\text { Moyenne } \\
\text { 2002-2005 }\end{array}$ & $\begin{array}{l}\text { Moyenne } \\
\text { 2006-2008 }\end{array}$ & $\begin{array}{l}\text { Moyenne } \\
2009-2011\end{array}$ & 2015 & 2016 & 2017 \\
\hline \multicolumn{14}{|l|}{ Donateurs multilatéraux } \\
\hline BADEA & .. & .. & .. & .. & 3,7 & 10,5 & 10,3 & .. & .. & .. & .. & .. &. \\
\hline BAfD & 64,7 & 167,5 & 291,1 & 248,7 & 544,5 & 185,5 & 120,2 & .. & .. & .. & .. & &. \\
\hline $\begin{array}{l}\text { Banque de développement } \\
\text { des Caraïbes }\end{array}$ & .. & .. & . & $\cdot$ & 2,8 &. & & & $\cdot$. & .. &. & &. \\
\hline $\begin{array}{l}\text { Banque islamique } \\
\text { de développement }\end{array}$ & 74,9 & 112,2 & 106,1 & 64,9 & 80,8 & 73,5 & 122,9 & &. & .. & .. & . & .. \\
\hline Banque mondiale & 2131,3 & 1832,7 & 2540,4 & 2734,3 & 3249,9 & 2623,4 & 4655,4 & .. & 1,9 & .. & & & .. \\
\hline BAsD & 381,0 & 228,2 & 264,6 & 509,7 & 543,4 & 356,8 & 350,1 & .. & .. & .. & .. & .. &. \\
\hline BID & 120,1 & 22,5 & 126,2 & 154,0 & 185,3 & 204,5 & 155,3 & .. & .. & .. & .. &.. &. \\
\hline Cadre intégré renforcé (CIR) & 1007,1 & 999,0 & 2056,1 & 3986,4 & 3657,6 & 3825,9 & 4324,9 & 1,7 & 12,7 & 0,1 & .. & .. &. \\
\hline CEB & .. & .. & .. & 79,2 & 50,0 & 93,5 & 108,6 & .. & .. & .. & .. &. &. \\
\hline CEE-ONU & .. & 0,1 & 0,7 & 1,1 & 1,5 & 0,9 & 0,9 &. & .. & 0,2 & .. & 0,0 & .. \\
\hline CESAO & .. & .. & 0,2 & 0,1 & 0,0 & 0,0 & .. &. & .. & .. & .. &. & .. \\
\hline CESAP & .. & 0,2 & 0,1 & 0,0 & 0,1 & .. & .. & .. & .. & .. & .. & 0,0 & .. \\
\hline $\mathrm{FAO}$ & .. & .. & 58,6 & 144,4 & 27,3 & 119,4 & 515,9 & .. &. & .. & & .. & .. \\
\hline FIDA & 256,1 & 354,9 & 537,1 & 514,5 & 879,1 & 527,5 & 931,7 & .. & .. & .. & & .. & .. \\
\hline FMl & .. & .. & .. & .. & .. & & .. & .. & .. & .. & & .. & .. \\
\hline FODI & .. & .. & 92,9 & 57,9 & 69,6 & 170,9 & 165,3 & .. & .. & .. & .. & .. & .. \\
\hline Fonds arabe (FADES) & .. & 99,6 & 122,1 & 76,2 & 210,8 & 372,6 & 109,6 & .. & .. & .. & .. & .. & .. \\
\hline $\begin{array}{l}\text { Fonds d'investissement pour } \\
\text { le climat (FIC) }\end{array}$ & .. & . & .. & 18,6 & 13,1 & & 4,6 & .. & . & . & .. & .. &. \\
\hline $\begin{array}{l}\text { Fonds pour l'environnement } \\
\text { mondial }\end{array}$ & .. & .. & . & .. & 7,7 & 40,0 & 97,3 & .. & .. & .. & .. & .. & .. \\
\hline Institutions de l'UE & .. & 112,7 & 233,3 & 246,8 & 283,8 & & .. & .. & .. & .. & .. & .. & .. \\
\hline ITC & .. & 30,1 & 54,2 & 64,9 & 68,9 & 57,4 & 51,4 & .. & .. & .. & .. & .. & .. \\
\hline ONUDI & .. & 21,9 & 45,9 & 8,3 & & 44,4 & 10,9 & .. & .. & .. & .. & .. & \\
\hline OMC & .. & .. & .. & 0,2 & & .. & .. & .. & .. & .. & .. & .. & \\
\hline Organisation mondiale du tourisme & .. & .. & .. & .. & .. & .. & .. & .. & .. & .. & & .. & .. \\
\hline PNUD & 8,3 & 15,7 & 21,7 & 21,0 & 10,1 & .. & .. & .. & .. & .. & .. & & \\
\hline Autres donateurs multilatéraux & .. & 0,5 & 8,7 & 46,5 & 44,4 & 53,2 & 58,7 & .. & .. & .. & .. & .. & .. \\
\hline Sous-total & 4043,3 & 3997,7 & 6560,1 & 8977,8 & 9934,2 & 8760,0 & 11793,9 & 1,7 & 14,6 & 0,3 & .. & 0,0 & .. \\
\hline $\begin{array}{l}\text { AIDE POUR LE COMMERCE } \\
\text { TOTALE }\end{array}$ & 10306,1 & 13099,0 & 16701,1 & 19241,1 & 21441,3 & 18064,8 & 23197,0 & 2,0 & 20,7 & 2,2 & 2,3 & 21,3 & 0,8 \\
\hline
\end{tabular}


Millions d'USD (constants de 2017)

Tableau A.13. Aide pour le commerce par donateur et par catégorie, décaissements (page 1 sur 6 )

AIDE POUR LE COMMERCE TOTALE

\begin{tabular}{l|l|l|l|l|l} 
Moyenne 2006-2008 & Moyenne 2009-2011 & Moyenne 2012-2014 & 2015 & 2016 & 2017
\end{tabular}

\begin{tabular}{|c|c|c|c|c|c|c|}
\hline \multicolumn{7}{|l|}{ Pays CAD } \\
\hline Allemagne & 1673,2 & 2558,5 & 3182,4 & 5193,9 & 4613,7 & 4522,4 \\
\hline Australie & 253,8 & 391,1 & 385,6 & 412,2 & 394,3 & 427,8 \\
\hline Autriche & 38,7 & 59,8 & 58,9 & 47,5 & 48,4 & 64,5 \\
\hline Belgique & 175,8 & 382,5 & 204,4 & 214,5 & 195,7 & 192,7 \\
\hline Canada & 272,8 & 566,2 & 441,3 & 347,3 & 393,8 & 463,5 \\
\hline Corée & 200,7 & 373,3 & 518,5 & 613,1 & 590,9 & 556,5 \\
\hline Danemark & 260,4 & 330,3 & 335,9 & 269,1 & 255,0 & 232,4 \\
\hline Espagne & 460,5 & 808,2 & 111,5 & 69,6 & 79,7 & 90,3 \\
\hline États-Unis & 4403,2 & 4332,0 & 3550,3 & 2922,1 & 2748,0 & 2406,5 \\
\hline Finlande & 61,1 & 136,4 & 155,2 & 155,7 & 126,7 & 168,7 \\
\hline France & 839,0 & 1092,9 & 1746,1 & 1504,2 & 1928,8 & 2470,8 \\
\hline Grèce & 16,7 & 15,5 & 0,1 & 0,0 & 0,0 & 0,0 \\
\hline Hongrie & .. &.. & 2,1 & 0,4 & 3,9 & 2,4 \\
\hline Irlande & 42,2 & 58,4 & 47,8 & 33,0 & 40,2 & 42,7 \\
\hline Islande & .. & 3,3 & 12,0 & 8,4 & 8,7 & 8,4 \\
\hline Italie & 240,0 & 142,8 & 87,2 & 201,0 & 98,4 & 290,3 \\
\hline Japon & 4040,3 & 4761,0 & 5906,4 & 6407,7 & 6317,1 & 8264,1 \\
\hline Luxembourg & 31,4 & 34,0 & 38,9 & 33,9 & 38,6 & 55,2 \\
\hline Norvège & 378,6 & 383,7 & 484,0 & 482,3 & 404,3 & 426,9 \\
\hline Nouvelle-Zélande & 31,0 & 53,6 & 98,1 & 114,3 & 105,6 & 98,3 \\
\hline Pays-Bas & 476,9 & 474,8 & 618,5 & 540,5 & 616,0 & 542,3 \\
\hline Pologne & .. &. & 8,8 & 31,7 & 80,3 & 16,0 \\
\hline Portugal & 35,6 & 52,5 & 41,1 & 23,5 & 5,1 & 3,9 \\
\hline République slovaque & .. & .. & 0,5 & 0,8 & 1,1 & 0,7 \\
\hline République tchèque & .. & 3,4 & 7,9 & 11,2 & 6,3 & 8,4 \\
\hline Royaume-Uni & 827,6 & 1177,5 & 1293,4 & 1960,6 & 1815,7 & 1918,9 \\
\hline Slovénie & .. & 2,1 & 0,8 & 0,6 & 1,7 & 1,2 \\
\hline Suède & 328,2 & 346,2 & 396,8 & 337,3 & 334,8 & 441,5 \\
\hline Suisse & 245,9 & 224,8 & 295,6 & 370,4 & 370,9 & 331,9 \\
\hline Sous-total & 15333,6 & 18764,8 & 20029,9 & 22306,7 & 21623,7 & 24049,3 \\
\hline \multicolumn{7}{|c|}{ Autres donateurs bilatéraux } \\
\hline Arabie saoudite & .. & .. & .. & 6,8 & 3,8 & .. \\
\hline Azerbaïdjan & .. & & 0,1 & 0,2 & 1,8 & 2,3 \\
\hline Croatie & .. & .. & .. & .. &. & 0,5 \\
\hline Émirats arabes unis & .. & 88,6 & 703,9 & 897,6 & 429,3 & 584,3 \\
\hline Estonie & .. & .. & 1,0 & 1,4 & 1,1 & 1,9 \\
\hline Kazakhstan & .. &. & 0,1 & 0,7 & 1,8 & 0,1 \\
\hline Koweït & .. & 251,2 & 269,6 & 408,7 & 692,9 & 373,2 \\
\hline Lettonie & .. & .. & .. & .. & 0,2 & 0,0 \\
\hline Lituanie & .. & .. & 0,1 & 0,6 & 0,5 & 0,5 \\
\hline Roumanie & .. & .. & 0,3 & 0,5 & 1,3 & .. \\
\hline Taipei chinois &.. & .. & .. & .. & 8,7 &. \\
\hline Thaïlande &.. &.. &. & .. & 18,5 & 18,7 \\
\hline Turquie & .. & 34,4 &. & .. &. &. \\
\hline Sous-total &.. & 374,2 & 975,1 & 1316,5 & 1160,0 & 981,5 \\
\hline
\end{tabular}


Millions d'USD (constants de 2017)

Tableau A.13. Aide pour le commerce par donateur et par catégorie, décaissements (page 2 sur 6 )

AIDE POUR LE COMMERCE TOTALE

\begin{tabular}{|c|c|c|c|c|c|c|}
\hline & \\
\hline & Moyenne 2006-2008 & Moyenne 2009-2011 & Moyenne 2012-2014 & 2015 & 2016 & 2017 \\
\hline \multicolumn{7}{|l|}{ Donateurs multilatéraux } \\
\hline BADEA &.. & .. &.. & .. &. & 12,9 \\
\hline BAfD & 1204,9 & 1004,7 & 1238,6 & 1003,4 & 1443,5 & 1062,6 \\
\hline $\begin{array}{l}\text { Banque de développement } \\
\text { des Caraïbes }\end{array}$ & 12,6 & 2,0 & 1,4 & 1,4 & .. & .. \\
\hline Banque islamique de développement & .. & .. &. & .. &. & 149,7 \\
\hline Banque mondiale & 3854,7 & 4808,6 & 5682,2 & 4673,4 & 5888,0 & 10284,3 \\
\hline BAsD & 486,7 & 1252,0 & 1573,2 & 1498,7 & 1379,9 & 1614,7 \\
\hline BID & 354,9 & 563,5 & 521,3 & 373,9 & 737,8 & 475,0 \\
\hline Cadre intégré renforcé (CIR) & 3859,8 & 6719,9 & 6491,9 & 7919,1 & 7151,6 & 8361,0 \\
\hline CEB &. & 65,0 & 210,3 & 40,2 & 245,0 & 570,8 \\
\hline CEE-ONU & 4,2 & 3,5 & 5,2 & 5,5 & 5,7 & 5,7 \\
\hline CESAO & 0,2 & 0,3 & 0,3 & 0,2 & 0,2 & 0,2 \\
\hline CESAP & 0,5 & 0,5 & 0,7 & 0,4 & 0,8 & 0,8 \\
\hline FAO & 96,0 & 125,7 & 164,6 & 113,7 & 65,5 & 624,5 \\
\hline FIDA &. & .. &. & .. &.. & 934,0 \\
\hline FMl &. & 0,7 &. &. &. & .. \\
\hline FODI & 168,2 & 224,1 & 297,9 & 368,8 & 355,3 & 493,3 \\
\hline Fonds arabe (FADES) & 696,7 & 670,6 & 493,0 & 441,2 & 528,6 & 1031,6 \\
\hline $\begin{array}{l}\text { Fonds d'investissement pour le climat } \\
\text { (FIC) }\end{array}$ & 10,2 & 16,0 & 7,6 & 23,3 & 15,4 & 11,7 \\
\hline Fonds pour l'environnement mondial & .. & .. & .. &. &.. & 186,9 \\
\hline Institutions de l'UE & 273,6 & 271,7 & 316,7 &. &.. & .. \\
\hline ITC & 51,9 & 58,0 & 66,2 & 54,9 & 52,8 & 51,4 \\
\hline OMC & 15,5 & 11,9 & 11,7 & 23,0 & 12,3 & 12,3 \\
\hline ONUDI &. &. &. & 48,6 & 57,5 & 13,5 \\
\hline Organisation mondiale du tourisme &. &. &. & 13,2 & 12,7 & .. \\
\hline PNUD & 33,4 & 30,6 & 26,2 & 7,0 & 8,7 & 8,7 \\
\hline Autres donateurs multilatéraux & 21,6 & 114,3 & 132,0 & 82,0 & 74,7 & 118,2 \\
\hline Sous-total & 11145,6 & 15943,5 & 17241,0 & 16692,0 & 18036,0 & 26024,0 \\
\hline AIDE POUR LE COMMERCE TOTALE & 30284,5 & 36948,5 & 40864,2 & 39475,7 & 43066,9 & 57783,8 \\
\hline
\end{tabular}


Millions d'USD (constants de 2017)

Tableau A.13. Aide pour le commerce par donateur et par catégorie, décaissements (page 3 sur 6)

\begin{tabular}{|c|c|c|c|c|c|c|c|c|c|c|c|}
\hline \multicolumn{6}{|c|}{ POLITIQUE ET RÉGLEMENTATION COMMERCIALES } & \multicolumn{6}{|c|}{ INFRASTRUCTURE ÉCONOMIQUE } \\
\hline $\begin{array}{c}2006-08 \\
\text { avg. }\end{array}$ & $\begin{array}{c}2009-11 \\
\text { avg. }\end{array}$ & $\begin{array}{c}2012-14 \\
\text { avg. }\end{array}$ & 2015 & 2016 & 2017 & $\begin{array}{c}2006-08 \\
\text { avg. }\end{array}$ & $\begin{array}{l}2009-11 \\
\text { avg. }\end{array}$ & $\begin{array}{c}2012-14 \\
\text { avg. }\end{array}$ & 2015 & 2016 & 2017 \\
\hline
\end{tabular}

\begin{tabular}{|c|c|c|c|c|c|c|c|c|c|c|c|c|}
\hline \multicolumn{13}{|l|}{ Pays CAD } \\
\hline Allemagne & 24,0 & 27,9 & 31,9 & 37,7 & 53,2 & 288,8 & 620,5 & 1228,3 & 1357,8 & 2413,0 & 2393,5 & 1986,9 \\
\hline Australie & 5,7 & 12,0 & 18,6 & 38,8 & 31,6 & 29,2 & 105,1 & 175,2 & 160,2 & 182,8 & 143,4 & 134,3 \\
\hline Autriche & 1,3 & 0,1 & 0,0 & 0,0 & 0,1 & 0,0 & 9,4 & 14,9 & 14,8 & 18,4 & 16,5 & 22,1 \\
\hline Belgique & 3,7 & 9,1 & 7,1 & 1,9 & 6,1 & 0,5 & 32,2 & 82,9 & 46,3 & 41,5 & 31,0 & 40,6 \\
\hline Canada & 14,8 & 30,2 & 20,9 & 18,5 & 15,9 & 14,9 & 46,9 & 118,1 & 91,5 & 41,4 & 27,1 & 135,5 \\
\hline Corée & 9,8 & 7,1 & 8,6 & 7,2 & 6,4 & 6,3 & 137,2 & 291,6 & 387,8 & 458,8 & 439,0 & 404,7 \\
\hline Danemark & 0,7 & 3,3 & 12,5 & 4,9 & 5,7 & 13,5 & 128,6 & 125,7 & 103,3 & 44,6 & 37,3 & 50,8 \\
\hline Espagne & 4,0 & 3,0 & 0,3 & 0,2 & 0,1 & 0,3 & 248,7 & 340,4 & 17,2 & 11,3 & 11,0 & 20,4 \\
\hline États-Unis & 152,2 & 205,2 & 268,4 & 200,3 & 117,6 & 219,5 & 2154,6 & 1891,0 & 1234,5 & 852,3 & 762,2 & 607,6 \\
\hline Finlande & 5,3 & 6,9 & 7,4 & 8,6 & 13,0 & 4,2 & 12,9 & 33,3 & 46,0 & 38,5 & 21,8 & 95,7 \\
\hline France & 2,2 & 3,5 & 2,6 & 4,3 & 4,3 & 3,4 & 335,0 & 564,0 & 1275,5 & 1110,4 & 1253,0 & 1601,5 \\
\hline Grèce & 0,5 & 0,2 &.. &.. &. & .. & 6,9 & 12,9 & 0,1 & 0,0 & 0,0 & 0,0 \\
\hline Hongrie &. &. &.. & 0,0 &. & 0,0 &. & .. & 0,0 & 0,0 &. & 0,0 \\
\hline Irlande & 1,0 & 0,3 & 1,0 & 0,6 & 0,6 & 0,6 & 2,5 & 1,3 & 0,3 & 0,0 & 0,2 & 0,2 \\
\hline Islande & .. &.. &.. &.. &. & .. &.. & 1,2 & 4,9 & 3,9 & 4,4 & 4,0 \\
\hline Italie & 0,3 & 0,2 & 0,1 & 0,2 & 0,2 & 0,2 & 144,7 & 66,6 & 30,8 & 63,6 & 20,2 & 162,1 \\
\hline Japon & 47,9 & 49,2 & 95,1 & 53,4 & 69,1 & 41,5 & 2873,5 & 3568,8 & 4668,6 & 5075,1 & 5027,5 & 6834,6 \\
\hline Luxembourg & 0,4 & 1,3 &. & .. & 2,3 & 0,1 & 5,6 & 2,4 & 6,0 & 2,7 & 0,8 & 11,5 \\
\hline Norvège & 15,8 & 16,2 & 11,5 & 11,6 & 10,1 & 9,7 & 193,0 & 142,8 & 195,5 & 120,7 & 87,6 & 71,0 \\
\hline Nouvelle-Zélande & 2,6 & 3,2 & 4,1 & 4,6 & 2,4 & 2,6 & 8,4 & 23,0 & 50,7 & 39,6 & 30,3 & 35,3 \\
\hline Pays-Bas & 43,5 & 55,1 & 85,2 & 64,0 & 89,4 & 61,9 & 114,0 & 129,0 & 100,9 & 49,6 & 58,6 & 65,6 \\
\hline Pologne &.. & & & .. & 0,0 &. & .. & .. & 0,6 & 2,1 & 0,4 & 0,3 \\
\hline Portugal & 0,1 & 0,0 & 0,0 & .. & 0,0 & 0,1 & 32,1 & 48,9 & 39,2 & 20,4 & 3,0 & 1,2 \\
\hline République slovaque &. & & 0,0 & 0,0 & 0,0 & 0,0 & .. & .. & 0,1 & 0,1 & 0,3 & 0,2 \\
\hline République tchèque &.. & 0,0 & 0,1 & 0,0 & 0,0 & 0,0 & .. & 1,4 & 2,5 & 5,0 & 1,6 & 1,8 \\
\hline Royaume-Uni & 42,8 & 109,9 & 89,4 & 72,1 & 60,3 & 102,4 & 128,3 & 371,0 & 489,6 & 360,7 & 486,3 & 435,4 \\
\hline Slovénie &. & 0,4 & 0,0 &. &. & 0,0 & .. & 0,5 & 0,4 & 0,0 & 0,2 & 0,4 \\
\hline Suède & 25,7 & 42,1 & 42,9 & 46,9 & 31,3 & 41,2 & 88,4 & 84,7 & 91,4 & 111,9 & 60,9 & 101,3 \\
\hline Suisse & 24,1 & 21,6 & 38,6 & 32,4 & 23,2 & 29,9 & 40,4 & 28,6 & 47,9 & 39,9 & 48,0 & 44,1 \\
\hline Sous-total & 428,3 & 607,8 & 746,2 & 608,2 & 543,1 & 870,8 & 7469,2 & 9348,6 & 10464,0 & 11 108,5 & 10966,0 & 12869,2 \\
\hline
\end{tabular}

\begin{tabular}{|c|c|c|c|c|c|c|c|c|c|c|c|c|}
\hline Arabie saoudite & .. &. &. &. & .. &.. & .. &. &. & 0,9 &. & .. \\
\hline Azerbaïdjan & .. & .. & 0,1 & 0,1 & 1,7 & 2,1 & .. &.. & 0,0 & 0,1 & 0,1 & 0,1 \\
\hline Croatie & .. & .. & .. & .. & .. &.. & .. & .. & .. &. &.. & 0,3 \\
\hline Émirats arabes unis & .. & .. & 3,4 & .. & .. &.. & .. & 72,7 & 268,9 & 624,9 & 382,0 & 359,6 \\
\hline Estonie & .. & .. & 0,0 & 0,0 & .. &.. & .. &. & 0,5 & 0,4 & 0,2 & 0,9 \\
\hline Kazakhstan & .. & .. & .. & .. & .. & .. & .. & .. & 0,1 & 0,5 & 1,8 & 0,1 \\
\hline Koweït & .. & .. & .. & .. & .. &.. & .. & 227,5 & 225,6 & 384,8 & 663,9 & 344,8 \\
\hline Lettonie & .. & .. & .. & .. & .. &. & .. &. & .. &. & .. &. \\
\hline Lituanie & .. & .. & 0,0 & 0,1 & 0,1 & 0,1 &.. &. & 0,0 & 0,3 & 0,3 & 0,2 \\
\hline Roumanie & .. & .. & .. & 0,0 & 0,0 &.. & .. &.. & .. &. & 1,1 & .. \\
\hline Taipei chinois & .. & .. & .. & .. & .. &. & .. &. &. &. & 8,7 & .. \\
\hline Thaïlande & .. & .. & .. & .. & .. &. & .. &. &. &. & 18,4 & 18,7 \\
\hline Turquie & .. & 31,8 & .. & .. & .. &. & .. & 0,4 & .. &.. & .. &. \\
\hline Sous-total & .. & 31,8 & 3,5 & 0,2 & 1,7 & 2,3 &.. & 300,5 & 495,1 & 1011,9 & 1076,5 & 724,7 \\
\hline
\end{tabular}


Millions d'USD (constants de 2017)

Tableau A.13. Aide pour le commerce par donateur et par catégorie, décaissements (page 4 sur 6 )

POLITIQUE ET RÉGLEMENTATION COMMERCIALES

\begin{tabular}{l|l|l|l|l|l} 
Moyenne & Moyenne & Moyenne & 2015 & 2016 & 2017
\end{tabular}

2006-2008 2009-2011 $2012-2014$
INFRASTRUCTURE ÉCONOMIQUE

\begin{tabular}{l|l|l|l|l} 
Moyenne & Moyenne & Moyenne & 2015 & 2016
\end{tabular}

2006-2008 2009-2011 2012-2014

\begin{tabular}{|c|c|c|c|c|c|c|c|c|c|c|c|c|}
\hline \multicolumn{13}{|l|}{ Donateurs multilatéraux } \\
\hline BAfD & 0,4 & 0,6 & 0,1 & .. &.. & 0,9 & 176,9 & 554,6 & 803,7 & 1063,2 & 803,1 & 1129,8 \\
\hline $\begin{array}{l}\text { Banque de développement } \\
\text { des Caraïbes }\end{array}$ & .. &.. &. & .. &.. & .. & &.. & &. &.. &.. \\
\hline Banque islamique de développement & .. & .. &.. & .. &.. &.. &.. &.. &.. &.. & .. & .. \\
\hline Banque mondiale & 31,0 & 55,2 & 123,7 & 131,8 & 360,9 & 79,2 & 1781,9 & 1994,8 & 2903,4 & 2968,8 & 2467,0 & 3090,2 \\
\hline BAsD & .. & 3,2 & 4,3 & 4,0 & 6,1 & 18,1 &.. & 335,7 & 868,2 & 1174,4 & 974,0 & 853,2 \\
\hline $\mathrm{BID}$ & .. & 5,2 & 9,3 & 14,8 & 3,9 & 8,1 &.. & 211,5 & 377,7 & 402,1 & 254,0 & 537,1 \\
\hline Cadre intégré renforcé (CIR) & .. & 10,2 & 9,6 & 3,8 & 12,4 & 6,2 &.. &.. &.. &.. & .. & .. \\
\hline CEB & .. & .. &.. & .. &.. & .. & .. & 12,6 & 2,0 &.. & .. & .. \\
\hline CEE-ONU & 0,3 & 0,1 & 0,3 & 0,2 & 0,1 & 0,2 & 0,9 & 3,4 & 1,9 & 3,6 & 4,4 & 4,6 \\
\hline CESAO & 0,1 & 0,0 & 0,1 & 0,2 & 0,1 & 0,2 & 0,0 & 0,0 & 0,0 & 0,0 & 0,0 & 0,0 \\
\hline CESAP & 0,1 & 0,4 & 0,5 & 0,6 & 0,4 & 0,8 & .. &.. & 0,0 &.. & .. & .. \\
\hline FAO & 19,0 & 40,3 & 24,9 & 32,8 &.. & .. &.. &.. &.. &.. & .. & .. \\
\hline FIDA & .. & .. &.. & .. &.. & .. & .. &.. &.. &.. & .. & .. \\
\hline FMI &.. & .. & 0,7 & .. &.. &.. &.. &.. &.. &.. &.. & .. \\
\hline FODI & .. & .. &.. & .. &.. & .. & .. & 123,0 & 172,4 & 222,5 & 297,3 & 294,1 \\
\hline Fonds arabe (FADES) & .. & 0,3 &.. & .. & .. & .. & 206,3 & 590,9 & 560,4 & 394,0 & 346,1 & 454,1 \\
\hline Fonds d'investissement pour le climat & .. & .. &.. & .. &.. & .. & .. &.. & 62,6 & 204,9 & 28,4 & 174,0 \\
\hline Fonds pour l'environnement mondial & .. & .. &.. & .. &.. & .. & 9,0 & 17,3 & 34,9 & 44,3 & 30,7 & 55,4 \\
\hline Fonds vert pour le climat & .. & .. &.. & .. &.. & .. & .. &.. & .. &.. & .. & .. \\
\hline Institutions de l'UE & 196,0 & 200,7 & 186,7 & 188,9 & 187,2 & 211,4 & 1235,5 & 1898,6 & 3412,7 & 2651,4 & 3863,4 & 3626,5 \\
\hline ITC & .. & .. &.. & .. &.. & .. & .. &.. & .. &. & .. & .. \\
\hline OMC & 12,7 & 15,5 & 11,8 & 11,7 & 23,0 & 12,3 & .. &.. &.. &.. & .. & .. \\
\hline ONUDI & .. & .. & .. & .. & 8,4 & 6,5 & .. & .. & .. & .. & 1,9 & 3,1 \\
\hline Organisation mondiale du tourisme & .. & .. & .. & .. & .. & & .. & .. & .. & .. & .. & .. \\
\hline PNUD & 3,0 & 2,9 & 0,8 & 0,0 & .. & .. & 5,1 & 8,9 & 8,8 & 16,1 & 7,0 & 8,7 \\
\hline Autres donateurs multilatéraux & 0,8 & 0,2 & .. & .. &.. & .. & 1,2 & 15,4 & 81,1 & 94,4 & 46,1 & 36,8 \\
\hline Sous-total & 263,4 & 334,9 & 372,6 & 388,7 & 602,6 & 343,8 & 3416,9 & 5766,7 & 9289,9 & 9239,6 & 9123,4 & 10267,7 \\
\hline AIDE POUR LE COMMERCE TOTALE & 691,7 & 974,5 & 1122,3 & 997,0 & 1147,4 & 1216,9 & 10886,1 & 15415,8 & 20249,0 & 21359,9 & 21165,9 & 23861,7 \\
\hline
\end{tabular}


Millions d'USD (constants de 2017)

Tableau A.13. Aide pour le commerce par donateur et par catégorie, décaissements (page 5 sur 6 )

RENFORCEMENT DE LA CAPACITÉ DE PRODUCTION

\begin{tabular}{l|l|l|l|l|l|} 
Moyenne & Moyenne & Moyenne & 2015 & 2016 & 2017
\end{tabular}

2006-2008 $2009-2011 \quad 2012-2014$
AJUSTEMENT LIÉ AU COMMERCE

\begin{tabular}{l|l|l|l|l} 
Moyenne & Moyenne & Moyenne & 2015 & 2016
\end{tabular}

\begin{tabular}{|l|l|l|l|l|} 
Moyenne & Moyenne & Moyenne & 2015 & 2016 \\
\hline
\end{tabular}

\section{Pays CAD}

Allemagne

Australie

Autriche

Belgique

Canada

Corée

Danemark

Espagne

États-Unis

Finlande

France

Grèce

Hongrie

Irlande

Islande

Italie

Japon

Luxembourg

Norvège

Nouvelle-Zélande

Pays-Bas

Pologne

Portugal

République slovaque

République tchèque

Slovénie

Suède

Suisse

Royaume-Uni

Sous-total

1028,7

1302,3

1792,3

2742,8

21670

\begin{tabular}{|r|r|}
\hline 142,9 & 203,7 \\
\hline 28,0 & 44,8 \\
\hline
\end{tabular}

\begin{tabular}{l|l}
206,9 & 190,7
\end{tabular}

\begin{tabular}{l|l|}
139,8 & 290,5 \\
\hline
\end{tabular}

44,1

211,0

151,1

29,0

\begin{tabular}{|l|l|}
\hline 19,7 & 219,4 \\
\hline
\end{tabular}

\begin{tabular}{|l|l|}
\hline 53,7 & 74,6 \\
\hline 131,2 & 201,3 \\
\hline
\end{tabular}

131,

\begin{tabular}{l|l}
207,7 & 464, \\
\hline
\end{tabular}

2096,4

\begin{tabular}{|r|r|r|r|r|r|}
\hline 2096,4 & 2235,7 & 2047,4 & 1869,5 & 1868,2 & 1579,4 \\
\hline 42,9 & 95,9 & 101,8 & 108,6 & 91,9 & 68,9 \\
\hline 501,8 & 525,3 & 468,0 & 389,5 & 671,5 & 865,7 \\
\hline
\end{tabular}

\begin{tabular}{l}
$9,3 \quad 2,4$ \\
\hline
\end{tabular}

(2.7.

\section{Autres donateurs bilatéraux}

\begin{tabular}{|c|c|c|c|c|c|c|c|c|c|c|c|c|}
\hline Arabie saoudite & .. & .. & .. & 5,9 & 3,8 &. & .. & .. & .. & .. &. &. \\
\hline Azerbaïdjan & .. & .. & .. &.. & 0,0 & 0,1 & .. & .. & .. & .. & .. & .. \\
\hline Croatie & .. & .. & .. &. & .. & 0,2 & .. & .. & .. & .. & .. & .. \\
\hline Émirats arabes unis & .. & 16,0 & 431,7 & 272,7 & 47,4 & 224,7 &.. & .. & .. & .. &. &. \\
\hline Estonie & .. & .. & 0,5 & 1,0 & 0,9 & 1,0 &.. & .. & .. & .. &. &. \\
\hline Kazakhstan & .. & .. &. & 0,2 & 0,1 & 0,0 & .. & .. & .. & .. & .. & .. \\
\hline Koweït & .. & 23,7 & 44,0 & 23,9 & 29,0 & 28,3 &.. & .. & .. & .. & .. &. \\
\hline Lettonie & .. & .. & .. &.. & 0,2 & 0,0 & .. & .. & .. & .. &. &. \\
\hline Lituanie & .. & .. & 0,0 & 0,2 & 0,1 & 0,1 & .. & .. & .. & .. & 0,0 &. \\
\hline Roumanie & .. & .. & 0,3 & 0,5 & 0,2 &.. & .. & .. & .. & .. & &.. \\
\hline Taipei chinois & .. & .. & .. &.. & .. &. & .. & .. & .. & .. &.. &. \\
\hline Thaïlande & .. & .. & .. &.. & 0,1 &. & .. & .. & .. & .. & .. &. \\
\hline Turquie & .. & 2,2 & .. &.. &.. &.. & .. & .. & .. & .. & .. & .. \\
\hline Sous-total & .. & 41,9 & 476,5 & 304,4 & 81,8 & 254,5 & .. & .. & .. & .. & 0,0 & .. \\
\hline
\end{tabular}


Tableau A.13. Aide pour le commerce par donateur et par catégorie, décaissements (page 6 sur 6 )

RENFORCEMENT DE LA CAPACITÉ DE PRODUCTION

Moyenne Moyenne Moyenne

2006-2008 2009-2011 2012-2014
AJUSTEMENT LIÉ AU COMMERCE

\begin{tabular}{l|l|l|l|l} 
Moyenne & Moyenne & Moyenne & 2015 & 2016
\end{tabular} 2006-2008 2009-2011 2012-2014

Donateurs multilatéraux

\begin{tabular}{|c|c|c|c|c|c|c|c|c|c|c|c|c|}
\hline BAfD & 202,3 & 649,6 & 200,9 & 175,5 & 200,3 & 312,8 & .. & .. & .. & .. & .. & .. \\
\hline Fonds arabe (FADES) & 27,3 & 105,5 & 110,3 & 99,0 & 95,2 & 74,5 & .. & .. &.. &.. &.. & .. \\
\hline BAsD & .. & 147,7 & 379,5 & 394,8 & 518,5 & 508,6 & .. &.. & .. & .. &.. & .. \\
\hline $\begin{array}{l}\text { Banque de développement } \\
\text { des Caraïbes }\end{array}$ &.. &.. & .. & .. &.. &.. &. &.. &. &.. &. & .. \\
\hline CEB & .. & .. & .. & 1,4 & 1,4 &.. & .. & .. & .. &.. & .. & .. \\
\hline Fonds d'investissement pour le climat & .. & .. & 2,3 & 5,5 & 11,8 & 71,0 &.. & .. & .. &.. & .. & .. \\
\hline Cadre intégré renforcé (CIR) & .. & .. & 6,4 & 3,9 & 10,9 & 9,1 & .. & .. & .. & .. & .. & .. \\
\hline Institutions de l'UE & 776,1 & 1726,2 & 3108,5 & 3639,5 & 3867,2 & 3313,5 & 7,6 & 34,2 & 12,0 & 12,1 & 1,3 & 0,2 \\
\hline FAO & 112,7 & 233,3 & 246,8 & 283,8 & .. & .. & .. & .. &.. & .. & .. & .. \\
\hline Fonds pour l'environnement mondial & 56,8 & 78,8 & 90,9 & 120,3 & 83,0 & 10,1 & .. & .. & .. & .. & .. & .. \\
\hline Fonds vert pour le climat & .. & .. & .. & .. & .. & .. & .. & .. & .. & .. & .. & .. \\
\hline IADB & .. & 138,1 & 176,5 & 104,3 & 116,0 & 192,6 & .. & .. & .. & .. & .. & .. \\
\hline FIDA & .. & .. & .. & .. & .. & .. & .. & .. & .. & .. & .. & .. \\
\hline FMI & .. & .. & .. & .. & .. & .. & .. & .. & .. & .. & .. & .. \\
\hline Banque islamique de développement & .. & .. & .. & .. & .. & .. & .. & .. & .. &.. & .. & .. \\
\hline ITC & 29,6 & 51,9 & 58,0 & 66,2 & 54,9 & 52,8 & .. & .. & .. & .. &.. & .. \\
\hline FODI &.. & 45,2 & 51,6 & 75,5 & 71,5 & 61,2 & .. & .. & .. & .. & .. & .. \\
\hline PNUD & 15,2 & 21,6 & 21,0 & 10,1 & .. & .. & .. & .. & .. &.. & .. & .. \\
\hline CEE-ONU & 0,1 & 0,7 & 1,1 & 1,5 & 0,9 & 0,9 &.. & .. & 0,2 & .. & 0,0 & .. \\
\hline CESAP & 0,1 & 0,1 & 0,0 & 0,1 & .. & .. & .. & .. & .. & .. & 0,0 & .. \\
\hline CESAO & .. & 0,2 & 0,1 & 0,0 & 0,0 & .. & .. & .. &.. & .. & .. & .. \\
\hline ONUDI & .. & .. & .. &.. & 38,4 & 47,9 & .. & .. & .. & .. &.. & .. \\
\hline Banque mondiale & 1511,1 & 1804,3 & 1780,2 & 2581,7 & 1844,5 & 2717,8 & .. & 0,4 & 1,4 & .. & 1,0 & 0,8 \\
\hline Organisation mondiale du tourisme & .. &.. &.. &.. & 13,2 & 12,7 & .. & .. & .. & .. &.. & .. \\
\hline OMC & .. & .. & 0,2 & .. & .. & .. & .. & .. & .. & .. & .. & .. \\
\hline Autres donateurs multilatéraux & 0,2 & 6,1 & 33,1 & 37,5 & 36,0 & 37,9 & .. &.. & .. & .. &.. & .. \\
\hline Sous-total & 2731,5 & 5009,4 & 6267,4 & 7600,6 & 6963,7 & 7423,5 & 7,6 & 34,7 & 13,7 & 12,1 & 2,3 & 1,0 \\
\hline AIDE POUR LE COMMERCE TOTALE & 10167,4 & 13857,9 & 15562,6 & 18493,7 & 17151,9 & 17982,8 & 7,8 & 36,4 & 14,6 & 13,5 & 10,5 & 5,4 \\
\hline
\end{tabular}

Source: CAD de l'OCDE : base de données sur les activités d'aide (2019).

StatLink iोist http://dx.doi.org/10.1787/888933962343 
Millions d'USD (constants de 2017)

Tableau A.14. Aide pour le commerce par donateur et par région, engagements (page 1 sur 6)

\section{AFRIQUE}

\begin{tabular}{|l|l|l|l|l|l|} 
Moyenne & Moyenne & Moyenne & Moyenne & 2015 & 2016
\end{tabular}

2002-2005 2006-2008 $2009-2011 \quad 2012-2014$
AMÉRIQUE

\begin{tabular}{l|l|l|l|l|l|l} 
Moyenne & Moyenne & Moyenne & Moyenne & 2015 & 2016 & 2017
\end{tabular} 2002-2005 2006-2008 2009-2011 2012-2014

\section{Pays CAD}

Allemagne

\begin{tabular}{|r|r|r|r|r|r|r|}
\hline 375,9 & 421,7 & 741,9 & 1469,1 & 1903,8 & 1576,5 & 1763,6 \\
\hline
\end{tabular}

Australie

Autriche

Belgique

Canada

Corée

Danemark

Espagne

États-Unis

Finlande

France

Grèce

Hongrie

Irlande

Islande

Italie

Japon

Luxembourg

Norvège

Nouvelle-Zélande

Pays-Bas

Pologne

Portugal

République slovaque

République tchèque

Royaume-Uni

Slovénie

Suède

Suisse

Sous-total

\begin{tabular}{|l|l|l|l|l|l|l|}
\hline 10,2 & 0,6 & 22,5 & 33,0 & 12,3 & 6,8 & 10,4 \\
\hline 9
\end{tabular}

\begin{tabular}{|r|r|}
\hline 86,1 & 257,6 \\
\hline 0,2 & 0,2
\end{tabular}

\begin{tabular}{|r|r|}
\hline 57,6 & 357,6 \\
\hline
\end{tabular}

\begin{tabular}{|r|r|r|r|}
\hline 760,5 & 702,6 & 1017,4 & 668,8 \\
\hline
\end{tabular}

\begin{tabular}{|r|r|r|r|r|r|r|}
\hline 9,1 & 14,8 & 18,5 & 31,9 & 24,5 & 27,2 & 15,7 \\
\hline 111,5 & 163,2 & 225,9 & 116,6 & 148,0 & 98,4 & 146,6 \\
\hline
\end{tabular}

\begin{tabular}{r|r}
0,2 & 0,2 \\
\hline 4,6 & 5,4
\end{tabular}

\begin{tabular}{|l|l|r|}
\hline 137,1 & 115,1 & 243,8 \\
\hline
\end{tabular}

\begin{tabular}{|l|l|}
232,6 & 349,3 \\
\hline
\end{tabular}

\begin{tabular}{|l|r|}
\hline 394,4 & 44,6
\end{tabular}

\begin{tabular}{l|l}
44,1 & 33,4 \\
\hline
\end{tabular}

62,4

\begin{tabular}{|r|r|r|r|r|r|r|}
\hline 234,8 & 165,6 & 217,7 & 218,5 & 92,2 & 68,6 & 86,1 \\
\hline
\end{tabular}

\begin{tabular}{|l|r|r|r|r|r|r||}
\hline 106,3 & 297,7 & 354,5 & 29,0 & 10,0 & 16,3 & 21,1 \\
\hline
\end{tabular}

\begin{tabular}{|r|r|r|r|r|r|r|}
\hline 598,3 & 1542,5 & 1271,6 & 966,1 & 1212,4 & 1418,2 & 1126,8 \\
\hline
\end{tabular}

\begin{tabular}{|r|r|r|r|r|r|r|}
\hline 21,0 & 47,5 & 154,2 & 53,5 & 62,6 & 44,5 & 40,1 \\
\hline 375,6 & 793,0 & 732,2 & 1282,6 & 1393,4 & 1262,1 & 1513,3 \\
\hline
\end{tabular}

Autres donateurs bilatéraux

\begin{tabular}{|c|c|c|c|c|c|c|c|c|c|c|c|c|c|c|}
\hline Arabie saoudite &. & .. &. &. & 204,6 & 773,8 & 293,7 &. &.. &.. &.. &. &. & 26,7 \\
\hline Azerbaïdjan &. &. &.. &.. &. &. &. &. &.. &. &.. & .. &.. &. \\
\hline Croatie & .. & &. &. & & .. & .. &. &. &.. &.. & &. &. \\
\hline Émirats arabes unis & .. &. & 78,3 & 595,1 & 387,7 & 40,7 & 321,9 &. &.. &.. &.. & 15,2 & 30,5 & 59,0 \\
\hline Estonie &. & .. &.. & 0,1 &. & 0,1 & .. &.. &.. &.. &.. & 0,0 &. & .. \\
\hline Kazakhstan & .. & .. &. &. & .. & .. & .. &.. &. &. &.. &. &.. &. \\
\hline Koweït &.. & .. & 204,7 & 393,1 & 262,4 & 546,5 & 236,8 & .. &.. & 3,0 & 0,6 & 25,3 & 30,8 & 13,2 \\
\hline Lettonie &. & .. &. & .. & .. & .. & .. &.. &.. &.. &.. & &. &. \\
\hline Lituanie &.. &.. &.. & .. & .. & .. & 0,0 &.. &.. &.. &.. &. &.. &.. \\
\hline Roumanie & .. &. &. &. & 0,1 &. & .. &.. &.. &.. &.. &. &.. &. \\
\hline Taipei chinois &. &.. &.. &. & .. &. & .. &.. &.. &.. &.. &.. &.. &. \\
\hline Thaillande &. &. &.. &. & .. &. & .. &.. &.. &.. &.. &. &.. &. \\
\hline Turquie & .. & .. & 0,4 &. & .. &. & .. &. &.. & .. &. &.. &.. & .. \\
\hline Sous-total &.. & .. & 283,4 & 988,3 & 854,7 & 1361,2 & 852,4 & 0,0 & 0,0 & 3,0 & 0,6 & 40,5 & 61,4 & 98,9 \\
\hline
\end{tabular}


Millions d'USD (constants de 2017)

Tableau A.14. Aide pour le commerce par donateur et par région, engagements (page 2 sur 6 )

\section{AFRIQUE}

Moyenne Moyenne $\mid$ Moyenne $\mid$ Moyenne

2002-2005 2006-2008 $2009-2011 \quad 2012-2014$
AMÉRIQUE

\begin{tabular}{l|l|l|l|l|l|l} 
Moyenne & Moyenne & Moyenne & Moyenne & 2015 & 2016 & 2017
\end{tabular} 2002-2005 2006-2008 2009-2011 2012-2014

\begin{tabular}{|c|c|c|c|c|c|c|c|c|c|c|c|c|c|c|}
\hline \multicolumn{15}{|l|}{ Donateurs multilatéraux } \\
\hline BAfD & 149,0 & 706,4 & 1498,2 & 1578,6 & 1824,1 & 806,7 & 1062,6 &.. &.. & .. & .. & .. &.. & .. \\
\hline $\begin{array}{l}\text { Banque de développement } \\
\text { des Caraïbes }\end{array}$ &.. & $\cdot$ &.. &.. &.. &.. &.. &.. &.. &.. & .. & 4,1 & 35,5 & 12,9 \\
\hline $\begin{array}{l}\text { Banque islamique } \\
\text { de développement }\end{array}$ & 140,5 & 144,3 & 105,7 & 98,9 & 69,6 & 134,5 & 146,6 &.. &.. &.. & 0,0 &.. & 0,0 & 0,1 \\
\hline Banque mondiale & 2070,6 & 2333,9 & 3559,4 & 3880,8 & 3602,0 & 2856,8 & 6366,6 & 130,8 & 89,3 & 151,7 & 96,2 & 92,7 & 22,8 & 214,6 \\
\hline BAsD &.. &.. &.. &.. &.. &.. & .. &.. &.. & .. & .. & .. &.. & .. \\
\hline BID &.. & ". &.. &.. &.. &.. & .. & 242,3 & 110,9 & 433,2 & 585,8 & 797,9 & 446,9 & 475,0 \\
\hline Cadre intégré renforcé (CIR) &.. &.. & 10,1 & 17,2 & 13,1 & 2,8 & 6,9 &.. &.. & 0,1 & 0,3 &.. & .. & 0,3 \\
\hline CEB & .. &.. &.. &.. & .. &.. &.. &.. &.. &.. & .. &.. & .. & .. \\
\hline CEE-ONU & .. &.. &.. &.. &.. & .. & .. &.. &.. &.. & .. &.. &.. & .. \\
\hline CESAO & .. & .. &.. & 0,0 & .. &.. & 0,0 &.. &.. &.. &.. &.. & .. & .. \\
\hline CESAP & .. &.. &.. &.. & .. & .. & .. &.. &.. &.. & .. & .. & .. & .. \\
\hline FAO & .. &.. &.. &.. &.. & .. & .. &.. &.. & .. &.. &.. & .. & .. \\
\hline FIDA & 139,7 & 189,8 & 352,7 & 279,0 & 545,8 & 317,7 & 470,4 & 12,0 & 17,9 & 17,2 & 15,9 & 18,1 & 23,5 & 47,4 \\
\hline FMI &.. & 4,0 & 6,3 & 4,0 &.. & .. & .. &.. & 1,9 & 1,9 & 2,1 & .. & .. & .. \\
\hline FODI &.. &.. & 155,0 & 199,3 & 296,6 & 184,0 & 179,2 &.. &.. & 109,8 & 45,6 & 170,3 & 175,2 & 229,4 \\
\hline Fonds arabe (FADES) &.. & 276,9 & 693,8 & 641,7 & 959,5 & 960,6 & 931,0 &.. &.. &.. & .. & .. &.. & .. \\
\hline $\begin{array}{l}\text { Fonds d'investissement pour } \\
\text { le climat }\end{array}$ &.. & &.. & 83,4 & 107,4 & 96,8 & 219,9 &.. &.. & .. & 117,5 & 144,5 & 28,0 & 159,5 \\
\hline $\begin{array}{l}\text { Fonds pour l'environnement } \\
\text { mondial }\end{array}$ &.. &.. & 30,3 & 81,0 & 21,4 & 46,4 & 282,0 &.. &.. & 18,3 & 46,0 & 6,2 & 27,3 & 118,0 \\
\hline Fonds vert pour le climat & .. &.. &.. &.. & 12,8 & 89,2 & 73,3 &.. &.. &.. &.. &.. & 1,7 & 2,1 \\
\hline Institutions de l'UE & 1541,8 & 1743,1 & 1557,0 & 2973,7 & 2226,3 & 3580,9 & 3377,1 & 236,9 & 245,3 & 410,0 & 615,1 & 826,8 & 449,6 & 711,3 \\
\hline ITC &.. &.. &.. &.. &.. &.. & .. &.. &.. &.. & .. & .. & .. & .. \\
\hline OMC &.. & 4,5 & 4,2 & 2,0 & 1,7 & 3,7 & 1,4 &.. & 2,5 & 1,7 & 0,9 & 1,4 & 3,2 & 1,9 \\
\hline ONUDI &.. & 15,5 & 23,6 & 6,5 & .. & 25,8 & 8,1 &.. & 2,0 & 4,0 & 0,4 &.. & 6,3 & 0,1 \\
\hline $\begin{array}{l}\text { Organisation mondiale } \\
\text { du tourisme }\end{array}$ &.. & &.. &.. &.. & & &.. &.. &.. & & &.. &.. \\
\hline PNUD & 4,6 & 12,7 & 15,6 & 16,2 & 16,0 & 4,8 & 3,9 & 0,2 & 0,7 & 0,7 & 1,4 & 2,0 & 0,2 & 0,2 \\
\hline $\begin{array}{l}\text { Autres donateurs } \\
\text { multilatéraux }\end{array}$ & 0,6 & 3,5 & 35,4 & 118,4 & 31,9 & 59,3 & 61,1 & 0,1 & 0,1 & 6,7 & 10,3 & 24,0 & 3,5 & 30,7 \\
\hline Sous-total & 4046,8 & 5434,7 & 8047,4 & 9980,9 & 9728,3 & 9169,9 & 13190,1 & 622,3 & 470,6 & 1155,3 & 1537,5 & 2088,0 & 1223,8 & 2003,5 \\
\hline $\begin{array}{l}\text { AIDE POUR LE COMMERCE } \\
\text { TOTALE }\end{array}$ & 7098,2 & 10858,3 & 14683,1 & 17941,2 & 18968,1 & 18786,8 & 21741,9 & 1607,8 & 1956,0 & 2994,6 & 3878,4 & 4223,1 & 3791,7 & 4746,2 \\
\hline
\end{tabular}


Millions d'USD (constants de 2017)

Tableau A.14. Aide pour le commerce par donateur et par région, engagements (page 3 sur 6 )

\section{ASIE}

\begin{tabular}{l|l|l|l|l|l} 
Moyenne & Moyenne & Moyenne & Moyenne & 2015 & 2016
\end{tabular} 2002-2005 2006-2008 2009-2011 2012-2014
EUROPE

\begin{tabular}{l|l|l|l|l|l|l} 
Moyenne & Moyenne & Moyenne & Moyenne & 2015 & 2016 & 2017
\end{tabular} 2002-2005 2006-2008 2009-2011 2012-2014

\section{Pays CAD}

Allemagne

Australie

\begin{tabular}{|l|l|l|l}
\hline 583,6 & 944,9 & 1186,4 & 1725,6
\end{tabular}

Autriche

Belgique

Canada

Corée

Danemark

Espagne

États-Unis

Finlande

France

Grèce

Hongrie

Irlande

Islande

Italie

Japon

Luxembourg

Norvège

Nouvelle-Zélande

Pays-Bas

Pologne

Portugal

République slovaque

République tchèque

Royaume-Uni

Slovénie

Suède

Suisse

Sous-total

\begin{tabular}{|l|l|l|l|l|}
\hline 583,6 & 944,9 & 1186,4 & 1725,6 & 2093,9 \\
\hline
\end{tabular}

$2235,1 \quad 2085$,

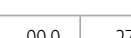

\begin{tabular}{|l|l|l|l|l|r|}
\hline & 394,1 & 547,7 & 596,1 & 537,6 & 543,2 \\
\hline
\end{tabular}

\begin{tabular}{|r|r|r|r|r|r|r|}
\hline 96,4 & 155,8 & 285,7 & 196,2 & 213,6 & 188,7 & 227,0 \\
\hline
\end{tabular}

\begin{tabular}{|r|r|r|r|r|r|r|}
\hline.. & 0,0 &.. &.. &.. & 0,3 & 0,3 \\
\hline
\end{tabular}

\begin{tabular}{|l|l|l|l|l|l|l|}
\hline 30,3 & 18,7 & 32,4 & 12,5 & 5,3 & 5,1 & 4,6 \\
\hline
\end{tabular}

\begin{tabular}{l|l|l|}
\hline 3,1 & 11,7 & 15,8 \\
\hline
\end{tabular}

\begin{tabular}{|l|l|l|l|l|r|r|}
\hline 114,7 & 118,4 & 88,0 & 103,3 & 185,2 & 86,0 & 91,1 \\
\hline
\end{tabular}

\begin{tabular}{|r|r|r|r|r|r|r|}
\hline.. & 391,7 & 613,7 & 606,7 & 713,5 & 663,7 & 740,0 \\
\hline 115,5 & 84,6 & 44,8 & 104,4 & 10,6 & 81,9 & 73,1 \\
\hline 94,5 & 96,1 & 74,9 & 7,5 & 1,6 & 2,7 & 1,1 \\
\hline
\end{tabular}

1,7

$2,6 \quad 0,9$

\begin{tabular}{|l|l|l|l|l|l|l|}
\hline 3051,2 & 3651,1 & 2482,8 & 1719,6 & 1343,5 & 920,7 & 622,1 \\
\hline
\end{tabular}

\begin{tabular}{|r|r|r|r|r|r|r|}
\hline 33,0 & 38,2 & 55,3 & 25,2 & 5,6 & 14,9 & 20,6 \\
\hline 164,8 & 337,2 & 201,3 & 546,5 & 1147,5 & 328,7 & 679,1 \\
\hline
\end{tabular}

Autres donateurs bilatéraux

\begin{tabular}{|c|c|c|c|c|c|c|c|c|c|c|c|c|c|c|}
\hline Arabie saoudite & .. & & .. & .. & 276,4 & 69,6 & 196,0 & .. & .. &.. &.. & .. &.. & 30,0 \\
\hline Azerbaïdjan & .. &. & .. & .. & .. & .. & .. & .. & .. &.. & .. &.. &.. & . \\
\hline Croatie & .. &.. & .. & .. & .. &.. & .. & .. & .. &.. &.. &.. &.. & 0,5 \\
\hline Émirats arabes unis & .. &.. & 137,2 & 249,4 & 433,0 & 0,4 & 51,1 & .. & .. & 15,0 & 29,5 & 50,6 &.. & . \\
\hline Estonie &.. & .. & .. & 0,7 & 0,6 & 0,9 & 0,4 & .. & .. &.. & 0,5 & 0,6 & 0,9 & 1,0 \\
\hline Kazakhstan & .. & .. & .. &.. & .. & .. & .. & .. & .. &.. & .. &.. &.. & .. \\
\hline Koweït & .. & .. & 105,6 & 129,5 & 110,5 & 101,1 & 27,2 & .. & .. & 0,4 & 11,0 & .. & 40,4 & 0,7 \\
\hline Lettonie & .. &.. & .. &.. & .. & .. & 0,0 & .. & .. & .. &.. &.. & 0,2 & 0,0 \\
\hline Lituanie &.. & .. & .. & 0,0 & 0,3 & 0,2 & 0,3 & .. & .. & .. & 0,0 & 0,4 & 0,3 & 0,1 \\
\hline Roumanie &.. & .. & .. &.. & 0,1 & 0,1 & .. & .. & .. & .. & 0,1 & 0,4 & 1,2 & .. \\
\hline Taipei chinois &.. &.. & .. & .. & .. & .. & .. & .. & .. &.. &.. &.. &.. & . \\
\hline Thaïlande & .. & .. & .. & .. & .. & .. & .. & .. & .. &.. &.. &.. &.. & .. \\
\hline Turquie & .. & .. & 33,0 & .. & .. & .. & .. & .. & .. & 0,9 &.. &.. &.. & . \\
\hline Sous-total & .. & .. & 275,8 & 379,6 & 820,8 & 172,2 & 275,0 & .. & .. & 16,3 & 41,1 & 52,0 & 43,0 & 32,3 \\
\hline
\end{tabular}


Millions d'USD (constants de 2017)

Tableau A.14. Aide pour le commerce par donateur et par région, engagements (page 4 sur 6 )

ASIE

\begin{tabular}{l|l|l|l|l|l|} 
Moyenne & Moyenne & Moyenne & Moyenne & 2015 & 2016
\end{tabular} 2002-2005 2006-2008 2009-2011 2012-2014
EUROPE

\begin{tabular}{l|l|l|l|l|l|l} 
Moyenne & Moyenne & Moyenne & Moyenne & 2015 & 2016 & 2017
\end{tabular} 2002-2005 2006-2008 2009-2011 2012-2014

\begin{tabular}{|c|c|c|c|c|c|c|c|c|c|c|c|c|c|c|}
\hline \multicolumn{15}{|l|}{ Donateurs multilatéraux } \\
\hline BAfD & .. & &.. &.. &.. & .. & & .. & .. & .. & .. & &.. & .. \\
\hline $\begin{array}{l}\text { Banque de développement } \\
\text { des Caraïbes }\end{array}$ &.$\cdot$ & & . &.. &.. &.. & & & .. & .. & .. & & & .. \\
\hline $\begin{array}{l}\text { Banque islamique } \\
\text { de développement }\end{array}$ & 44,3 & 90,4 & 71,5 & 35,6 & 165,3 & 123,1 & 0,5 & 2,8 & 9,5 & 4,9 & 0,1 &.. & .. & 0,0 \\
\hline Banque mondiale & 2031,5 & 1704,9 & 2287,3 & 2974,5 & 3905,0 & 3282,1 & 3494,6 & 229,9 & 75,1 & 29,4 & 57,8 & 52,7 & 41,5 & 60,2 \\
\hline BAsD & 723,8 & 502,6 & 1097,5 & 1720,5 & 1636,8 & 1606,8 & 1510,3 & .. &.. & .. &.. &.. & .. & .. \\
\hline $\mathrm{BID}$ &.. &.. &.. &.. &.. & & .. & .. & .. & .. & .. &.. & .. & \\
\hline Cadre intégré renforcé (CIR) & .. &.. & 2,5 & 6,5 & 1,8 & 0,7 & 3,0 & .. & .. & .. & .. & .. & .. & .. \\
\hline CEB & .. &.. & .. & .. & .. & .. & .. & .. & .. &.. & .. & 2,8 & .. & .. \\
\hline CEE-ONU & .. & 0,0 & 0,1 & 0,2 & .. & 0,0 & 0,3 & .. & 1,3 & 4,1 & 3,3 & 5,2 & 5,5 & 5,2 \\
\hline CESAO & .. & 0,0 & .. & 0,3 & 0,4 & 0,2 & 0,2 & .. & .. & .. & .. &.. & .. & .. \\
\hline CESAP &.. & 0,1 & 0,5 & 0,6 & 0,7 & 0,4 & 0,8 & .. & .. &.. & .. & .. & .. & .. \\
\hline FAO & .. &.. & .. & .. &.. & .. & & .. & .. &. & .. &.. & .. & .. \\
\hline FIDA & 107,2 & 153,8 & 196,9 & 235,2 & 358,8 & 176,9 & 347,7 & 9,9 & 14,3 & 9,4 & 3,4 & .. & 18,7 & 48,1 \\
\hline FMl & .. & 3,0 & 3,3 & 2,6 &.. & .. & .. & .. & 1,0 & 1,4 & 0,6 & .. & .. & .. \\
\hline FODI & .. &.. & 66,3 & 140,4 & 47,1 & 218,7 & 83,1 & .. & .. & 11,3 & 32,8 &.. & 27,4 & .. \\
\hline Fonds arabe (FADES) & .. & 111,4 & 311,0 & 126,0 & 391,8 & .. & 100,6 & .. & .. & .. &.. & .. & .. & .. \\
\hline $\begin{array}{l}\text { Fonds d'investissement pour } \\
\text { le climat }\end{array}$ &.. &.. &.. & 423,5 & 175,6 & 448,4 & 175,4 & .. & .. &. & 143,1 & 85,4 & .. & 9,3 \\
\hline $\begin{array}{l}\text { Fonds pour l'environnement } \\
\text { mondial }\end{array}$ & .. &.. & 43,4 & 105,1 & 53,8 & 42,3 & 111,2 & .. & .. & 5,3 & 17,6 & 3,9 & 3,3 & 19,2 \\
\hline Fonds vert pour le climat &.. &.. &.. &.. &.. & 20,9 & 53,6 & .. & .. &.. & .. &.. &.. & .. \\
\hline Institutions de l'UE & 253,4 & 275,6 & 305,8 & 603,5 & 1409,0 & 1418,2 & 898,4 & 259,2 & 508,3 & 1472,7 & 4132,4 & 2227,3 & 3175,7 & 2899,3 \\
\hline ITC & .. & .. & .. & .. & .. &. &.. & .. & .. & .. & .. & .. & .. & .. \\
\hline OMC &.. & 1,4 & 2,0 & 1,6 & 2,2 & 3,6 & 2,4 & .. & 0,4 & 0,1 & 0,0 & 0,0 & 0,0 & 0,0 \\
\hline ONUDI & .. & 5,6 & 22,5 & 4,1 & .. & 24,4 & 2,9 & .. & 0,5 & 1,5 & 0,2 &.. & 11,0 & 0,8 \\
\hline $\begin{array}{l}\text { Organisation mondiale } \\
\text { du tourisme }\end{array}$ & .. &.. &.. &.. &.. & .. &.$\cdot$ & .. & .. &.. &.. &.. & .. & .. \\
\hline PNUD & 6,5 & 9,8 & 12,9 & 9,1 & 6,9 & 1,7 & 4,3 & 0,4 & 0,6 & 0,6 & 0,8 & 0,6 & 0,3 & 0,3 \\
\hline $\begin{array}{l}\text { Autres donateurs } \\
\text { multilatéraux }\end{array}$ & 0,2 & 0,1 & 5,6 & 12,0 & 15,1 & 30,1 & 5,8 & .. & .. & 0,0 & 0,3 & 0,6 & 1,2 & 0,6 \\
\hline Sous-total & 3167,0 & 2858,7 & 4429,1 & 6401,3 & 8170,1 & 7398,6 & 6794,9 & 502,1 & 610,8 & 1540,7 & 4392,4 & 2378,5 & 3284,5 & 3043,1 \\
\hline $\begin{array}{l}\text { AIDE POUR LE COMMERCE } \\
\text { TOTALE }\end{array}$ & 11819,4 & 13842,6 & 15144,6 & 18979,3 & 25270,8 & 21 101,3 & 22114,6 & 1306,1 & 1495,8 & 2712,1 & 5360,7 & 3242,5 & 4382,0 & 3959,8 \\
\hline
\end{tabular}


Tableau A.14. Aide pour le commerce par donateur et par région, engagements (page 5 sur 6 )

\section{OCÉANIE}

\begin{tabular}{l|l|l|l|l|l|} 
Moyenne & Moyenne & Moyenne & Moyenne & 2015 & 2016 \\
\hline
\end{tabular} 2002-2005 2006-2008 2009-2011 2012-2014

\section{NON SPÉCIFIQUE À UNE RÉGION}

2017

\begin{tabular}{c|c|c|c|c|c} 
Moyenne & Moyenne & Moyenne & Moyenne & 2015 & 2016
\end{tabular} 2002-2005 2006-2008 2009-2011 2012-2014

\section{Pays CAD}

Allemagne

Australie

Autriche

Belgique

Canada

Corée

Danemark

Espagne

États-Unis

Finlande

France

Grèce

Hongrie

Irlande

Islande

Italie

Japon

Luxembourg

Norvège

Nouvelle-Zélande

Pays-Bas

Pologne

Portugal

République slovaque

République tchèque

Royaume-Uni

Slovénie

Suède

Suisse

Sous-total

\begin{tabular}{|r|r|r|r}
\hline 1,6 & 0,6 & 2,6 & \\
\hline 95,5 & 108,4 & 102,0 & 105 \\
\hline 0,0 & 0,1 & 0,3 & 0 \\
\hline 0,0 &.. & 0,0 & \\
\hline 0,2 & 0,0 & 1,3 \\
\hline.. & 1,1 & 2,1 \\
\hline
\end{tabular}

\begin{tabular}{|r|r|r|r|}
\hline 1,7 & 18,0 & 0,6 & 11,3 \\
\hline 105,2 & 150,0 & 128,7 & 157,6 \\
\hline 0,1 &.. & 0,7 &.. \\
\hline.. &.. &.. &.. \\
\hline 0,1 & 0,2 & 0,4 & 3,8 \\
\hline 2,1 & 3,6 & 2,0 & 33,4 \\
\hline.. &.. &.. &.. \\
\hline
\end{tabular}

\begin{tabular}{|r|r|r|r|r|r|r}
\hline 70,4 & 137,7 & 634,5 & 361,4 & 573,3 & 726,6 & 624,5 \\
\hline 4,2 & 46,3 & 81,1 & 47,3 & 36,1 & 69,2 & 32,0 \\
\hline 1,2 & 4,6 & 17,3 & 11,9 & 16,7 & 9,9 & 7,4 \\
\hline 42,3 & 36,7 & 127,2 & 41,7 & 48,0 & 46,6 & 48,5 \\
\hline
\end{tabular}

Autres donateurs bilatéraux

\begin{tabular}{|c|c|c|c|c|c|c|c|c|c|c|c|c|c|c|}
\hline Arabie saoudite & .. & . &. &.. &.. & .. & .. & .. &.. &. &. &.. &. &. \\
\hline Azerbaïdjan & .. & .. &. &. &.. & .. & .. & .. &.. & .. &. &. &. & 2,3 \\
\hline Croatie & .. & .. &.. &.. &.. & .. & .. & .. &.. & .. &. & .. &. &. \\
\hline Émirats arabes unis & .. & .. & 1,5 & 15,1 & 20,8 & .. & 5,8 &.. &.. & 1,3 & 2,4 &. &. & .. \\
\hline Estonie & .. & .. & .. & .. & .. & .. & .. & .. &.. & .. & 0,2 &.. & 0,2 & 0,6 \\
\hline Kazakhstan & .. &.. &. &. &.. & .. &. &.. &.. &. &.. &. &. &. \\
\hline Koweit & .. & .. & .. & .. & .. & .. &. &.. &.. & 0,0 & .. & 1,0 & .. & .. \\
\hline Lettonie & .. & .. &. &. &. & .. &. & .. &. & .. &. &.. & .. &. \\
\hline Lituanie & .. & .. &.. &.. &.. & .. &. & .. &.. &.. &.. & 0,0 &.. & 0,1 \\
\hline Roumanie & .. & .. &.. & .. &.. & .. & .. & .. &.. & .. &. & 0,0 & 0,0 & .. \\
\hline Taipei chinois & .. &. &. &. &. & .. &. &. &.. &. &.. &.. &. & .. \\
\hline Thaïlande & .. &. & .. & .. &. & .. &. &. &.. &. &. &. &. & .. \\
\hline Turquie & .. &.. & 0,1 & .. &.. & .. & .. & .. &.. & 0,0 & .. &.. &.. & .. \\
\hline Sous-total & .. & .. & 1,6 & 15,1 & 20,8 & .. & 5,8 &.. &.. & 1,3 & 2,6 & 1,1 & 0,2 & 2,9 \\
\hline
\end{tabular}


Millions d'USD (constants de 2017)

Tableau A.14. Aide pour le commerce par donateur et par région, engagements (page 6 sur 6 )

OCÉANIE

\begin{tabular}{c|c|c|c|c|c|c|c|c|c|c|c|c|c|} 
Moyenne & Moyenne & Moyenne & Moyenne & 2015 & 2016 & 2017 & $\begin{array}{c}\text { Moyenne } \\
\text { 2002-2005 }\end{array}$ & $\begin{array}{c}\text { Moyenne } \\
2006-2008\end{array}$ & $\begin{array}{c}\text { Moyenne } \\
2009-2011\end{array}$ & $\begin{array}{c}\text { Moyenne } \\
2012-2014\end{array}$ & 2015 & 2016 & 2017 \\
\hline $2005-2005$ & $2006-2008$ & $2009-2011$ & $2012-2014$ & & & &
\end{tabular}

\section{Donateurs multilatéraux}

\begin{tabular}{|c|c|c|c|c|c|c|c|c|c|c|c|c|c|c|}
\hline BAfD &.. &.. & &.. &.. &.. & & &.. &.. &.. & & & .. \\
\hline $\begin{array}{l}\text { Banque de développement } \\
\text { des Caraïbes }\end{array}$ &.. &.$\cdot$ & &. &.. &.. & $\cdot$ & &.. &.. &. & & & .. \\
\hline $\begin{array}{l}\text { Banque islamique de } \\
\text { développement }\end{array}$ &.. &.. & .. &.. &.. &.. &.. & 2,8 & 8,1 & 6,8 & 3,6 & 1,8 & 3,6 & 2,6 \\
\hline Banque mondiale & 5,1 & 32,3 & 70,9 & 107,8 & 65,8 & 63,8 & 148,3 & .. &.. &.. &.. &.. &.. & .. \\
\hline BAsD & 23,9 & 18,5 & 100,9 & 63,3 & 53,4 & 116,9 & 104,4 & .. & .. & .. &.. &.. & .. &. \\
\hline $\mathrm{BID}$ &.. &.. &.. &.. &.. &.. &.. & .. &.. &.. &.. &.. &.. & .. \\
\hline Cadre intégré renforcé (CIR) &.. &.. & 0,4 & 2,3 & 3,7 &.. & 1,5 & .. &.. &.. &.. &.. &.. & .. \\
\hline CEB &.. &.. &.. &.. &.. &.. &.. & .. &.. &.. &. &.. &.. &. \\
\hline CEE-ONU &.. &.. &.. &.. &.. &.. &.. &. &.. &.. &.. &.. &.. & 0,2 \\
\hline CESAO &.. &.. &.. &.. &.. &.. &.. & .. & 0,0 & 0,2 & 0,1 &.. &.. &. \\
\hline CESAP &.. &.. &.. &.. &.. &.. &.. & .. & 0,2 &.. &.. &.. &.. & .. \\
\hline $\mathrm{FAO}$ &.. &.. &.. &.. &.. &.. &.. & .. & 131,7 & 273,6 & 271,7 & 316,7 &.. & .. \\
\hline FIDA &.. &.. & 4,8 & 7,4 & 4,6 &.. & 20,4 &. &.. &.. &. &.. &.. &. \\
\hline FMl &.. & 0,2 & 0,6 & 0,2 &.. &.. &.. &.. & 0,2 &.. &. &.. &.. & .. \\
\hline FODI &.. &.. & 3,6 &.. &.. &.. &.. &.. &.. & 0,8 & 1,1 & 1,2 & 1,2 & 1,6 \\
\hline Fonds arabe (FADES) &.. &.. &.. &.. &.. &.. &.. &.. & 0,0 & 5,5 & 1,3 & & 1,7 & .. \\
\hline $\begin{array}{l}\text { Fonds d'investissement pour } \\
\text { le climat }\end{array}$ &.. &.. &.. & 4,6 & 9,0 & 6,8 & 6,8 & .. &.. &.. & 11,7 & 146,8 & 30,5 & .. \\
\hline $\begin{array}{l}\text { Fonds pour l'environnement } \\
\text { mondial }\end{array}$ &.. &.. & 3,3 & 6,3 & 10,1 &.. & 16,1 & .. &.. & 19,4 & 18,8 & 17,3 &.. & 78,0 \\
\hline Fonds vert pour le climat &.. &.. &.. &.. &.. & 17,3 & 42,9 & .. &.. &.. &. &.. & 34,6 & 15,0 \\
\hline Institutions de l'UE & 35,7 & 22,6 & 40,0 & 49,2 & 23,0 & 16,9 & 62,0 & 130,6 & 218,4 & 535,1 & 268,3 & 241,5 & 250,1 & 412,8 \\
\hline ITC &.. &.. &.. &.. &.. &.. &.. &.. & 30,1 & 54,2 & 64,9 & 68,9 & 57,4 & 51,4 \\
\hline OMC &.. & 0,3 & 0,2 & 0,2 & 0,0 & 0,0 & 0,1 &.. & 3,5 & 7,4 & 7,2 & 6,3 & 12,5 & 6,5 \\
\hline ONUDI &.. &.. & 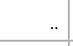 &.. &.. &.. & 0,0 & & 3,4 & 10,0 & 1,7 & & 15,1 & 1,7 \\
\hline $\begin{array}{l}\text { Organisation mondiale du } \\
\text { tourisme }\end{array}$ &.. &.. &.. &.. &.. &.. &.. & .. &.. &.. &.. &.. &.. & .. \\
\hline PNUD & 0,2 & 0,2 & 0,1 & 0,0 & 0,1 & 0,0 &.. & &.. & 3,6 & 3,1 & 0,4 &.. & .. \\
\hline $\begin{array}{l}\text { Autres donateurs } \\
\text { multilatéraux }\end{array}$ & 0,1 & 0,0 & 0,0 & 0,3 & 0,8 & 0,8 & 3,9 & & 0,5 & 0,1 & 12,6 & 12,6 & 12,9 & 16,1 \\
\hline Sous-total & 64,9 & 74,1 & 224,7 & 241,5 & 170,4 & 222,5 & 406,5 & 133,3 & 396,3 & 916,8 & 666,0 & 813,5 & 419,7 & 585,9 \\
\hline $\begin{array}{l}\text { AIDE POUR LE COMMERCE } \\
\text { TOTALE }\end{array}$ & 239,5 & 356,8 & 477,4 & 563,5 & 884,3 & 512,8 & 973,8 & 1089,5 & 1931,8 & 3576,2 & 3088,4 & 3679,9 & 3013,0 & 4247,5 \\
\hline
\end{tabular}

Source: CAD de l'OCDE : base de données sur les activités d'aide (2019).

StatLink 部实 http://dx.doi.org/10.1787/888933962362 
Millions d'USD (constants de 2017)

Tableau A.15. Aide pour le commerce par donateur et par région, décaissements (page 1 sur 6 )

AFRIQUE

\begin{tabular}{l|l|l|l|l|} 
Moyenne & Moyenne & Moyenne & 2015 & 2016
\end{tabular}

2006-2008 $2009-2011 \quad 2012-2014$
AMÉRIQUE

\begin{tabular}{l|l|l|l|l|l} 
Moyenne & Moyenne & Moyenne & 2015 & 2016 & 2017
\end{tabular} 2006-2008 $2009-2011 \quad 2012-2014$

\section{Pays CAD}

Allemagne

\begin{tabular}{|l|l|l|l|l|l|}
\hline 375,9 & 421,7 & 741,9 & 1469,1 & 1903,8 & 1763,6 \\
\hline
\end{tabular}

Australie

Autriche

Belgique

Canada

Corée

Danemark

Espagne

États-Unis

Finlande

France

Grèce

Hongrie

Irlande

Islande

Italie

Japon

Luxembourg

Norvège

Nouvelle-Zélande

Pays-Bas

Pologne

Portugal

République slovaque

République tchèque

Royaume-Uni

Slovénie

Suède

Suisse

Sous-total

\begin{tabular}{|c|c|c|c|c|c|}
\hline 375,9 & 421,7 & 741,9 & 1469,1 & 1903,8 & 1763,6 \\
\hline 10,2 & 0,6 & 22,5 & 33,0 & 12,3 & 10,4 \\
\hline 9,1 & 14,8 & 18,5 & 31,9 & 24,5 & 15,7 \\
\hline 111,5 & 163,2 & 225,9 & 116,6 & 148,0 & 146,6 \\
\hline 137,1 & 115,1 & 243,8 & 232,6 & 349,3 & 44,6 \\
\hline. & 74,4 & 232,0 & 195,1 & 140,6 & 332,0 \\
\hline 234,8 & 165,6 & 217,7 & 218,5 & 92,2 & 86,1 \\
\hline 106,3 & 297,7 & 354,5 & 29,0 & 10,0 & 21,1 \\
\hline 598,3 & 1542,5 & 1271,6 & 966,1 & 1212,4 & 1126,8 \\
\hline 21,0 & 47,5 & 154,2 & 53,5 & 62,6 & 40,1 \\
\hline 375,6 & 793,0 & 732,2 & 1282,6 & 1393,4 & 1513,3 \\
\hline 0,7 & 1,0 & 0,8 & .. &.. &.. \\
\hline. & .. & .. & .. & 0,0 & 0,0 \\
\hline 21,6 & 29,0 & 43,4 & 35,6 & 28,5 & 30,4 \\
\hline .. & .. & 1,6 & 5,5 & 3,1 & 2,2 \\
\hline 136,4 & 94,9 & 22,7 & 67,0 & 87,1 & 81,7 \\
\hline 320,7 & 882,4 & 946,1 & 1075,5 & 1829,6 & 1594,8 \\
\hline 7,7 & 16,9 & 12,0 & 16,7 & 10,8 & 28,4 \\
\hline 116,7 & 169,2 & 269,4 & 296,9 & 75,8 & 130,6 \\
\hline 0,2 & 0,1 & 0,8 & 6,3 & 1,4 & 8,8 \\
\hline 81,2 & 104,7 & 106,3 & 216,5 & 310,7 & 204,5 \\
\hline .. & .. & .. & 6,8 & 27,5 & 12,8 \\
\hline 24,0 & 25,8 & 49,3 & 25,9 & 24,2 & 2,4 \\
\hline. &. & .. & 0,4 & 0,6 & 0,3 \\
\hline. &. & 0,7 & 1,1 & 1,3 & 2,2 \\
\hline 206,9 & 257,0 & 499,2 & 343,4 & 377,6 & 173,3 \\
\hline. &. & 0,0 &.. & .. &. \\
\hline 84,8 & 140,9 & 127,8 & 105,5 & 144,6 & 189,9 \\
\hline 70,5 & 65,4 & 57,4 & 141,2 & 113,1 & 136,7 \\
\hline 3051,3 & 5423,5 & 6352,3 & 6972,0 & 8385,1 & 7699,3 \\
\hline
\end{tabular}

\begin{tabular}{|r|r|r|r|r|r|}
\hline 187,6 & 361,7 & 592,3 & 499,1 & 801,6 & 510,0 \\
\hline 0,2 & 3,1 & 3,9 & 0,2 & 0,6 & 0,6 \\
\hline 5,1 & 6,9 & 3,7 & 2,4 & 2,9 & 3,2 \\
\hline 28,0 & 50,1 & 25,3 & 21,3 & 17,7 & 17,5 \\
\hline 51,1 & 103,2 & 126,5 & 93,7 & 97,7 & 82,0 \\
\hline 22,9 & 18,2 & 29,9 & 43,5 & 76,2 & 83,8 \\
\hline 26,9 & 22,4 & 12,2 & 14,3 & 11,0 & 39,2 \\
\hline 119,3 & 169,8 & 43,7 & 33,3 & 39,6 & 54,4 \\
\hline
\end{tabular}

Autres donateurs bilatéraux

\begin{tabular}{|c|c|c|c|c|c|c|c|c|c|c|c|c|}
\hline Arabie saoudite &. & .. & .. & .. & 204,6 & 293,7 & .. & .. &. &.. &. & .. \\
\hline Azerbaïdjan & .. & .. &. & .. &.. & .. & .. &. & .. & .. & .. & .. \\
\hline Croatie &.. & .. &.. & .. &. & .. & .. & .. & .. &. &. & .. \\
\hline Émirats arabes unis & & & 78,3 & 595,1 & 387,7 & 321,9 & .. & .. &. &. & 0,0 & 2,7 \\
\hline Estonie &. & .. & .. & 0,1 &. & .. & .. & .. &. & 0,0 & .. & .. \\
\hline Kazakhstan &. & .. & .. & .. &.. & .. & .. & .. & .. &. & .. & .. \\
\hline Koweït & .. & .. & 204,7 & 393,1 & 262,4 & 236,8 & .. & 4,6 & 7,8 & 4,3 & 8,7 & 3,8 \\
\hline Lettonie & .. & .. & .. & .. &.. & .. & .. & .. & .. & .. & .. & .. \\
\hline Lituanie & .. & .. & .. & .. &.. & 0,0 & .. & .. &. & .. &. & .. \\
\hline Roumanie & .. & .. & .. & .. & 0,1 &. & .. & .. &. & .. &.. & .. \\
\hline Taipei chinois & .. & .. &. & .. &.. &.. & .. &. &.. &. &.. & .. \\
\hline Thaïlande & .. & .. &. & .. &.. &.. & .. &. &.. &. &.. & .. \\
\hline Turquie & .. & .. & 0,4 & .. & .. & .. & .. & .. & .. & .. & .. & .. \\
\hline Sous-total & .. & .. & 283,4 & 988,3 & 854,7 & 852,4 & .. & 4,6 & 7,8 & 4,3 & 8,7 & 6,5 \\
\hline
\end{tabular}


Millions d'USD (constants de 2017)

Tableau A.15. Aide pour le commerce par donateur et par région, décaissements (page 2 sur 6 )

\begin{tabular}{|c|c|c|c|c|c|c|c|c|c|c|c|c|}
\hline & \multicolumn{6}{|c|}{ AFRIQUE } & \multicolumn{6}{|c|}{ AMÉRIQUE } \\
\hline & $\begin{array}{c}\text { Moyenne } \\
2006-2008\end{array}$ & $\begin{array}{c}\text { Moyenne } \\
\text { 2009-2011 }\end{array}$ & $\begin{array}{c}\text { Moyenne } \\
2012-2014\end{array}$ & 2015 & 2016 & 2017 & $\begin{array}{c}\text { Moyenne } \\
2006-2008\end{array}$ & $\begin{array}{c}\text { Moyenne } \\
2009-2011\end{array}$ & $\begin{array}{c}\text { Moyenne } \\
\text { 2012-2014 }\end{array}$ & 2015 & 2016 & 2017 \\
\hline \multicolumn{13}{|l|}{ Donateurs multilatéraux } \\
\hline BADEA &.. &. &.. &.. &.. &.. &.. & .. &.. &.. &.. & \\
\hline BAfD & 379,7 & 1204,9 & 1004,7 & 1238,6 & 1003,4 & 1443,5 & .. & .. &.. &.. & & \\
\hline $\begin{array}{l}\text { Banque de développement } \\
\text { des Caraïbes }\end{array}$ & $\cdot$ & $\cdot$ & $\cdot$ & $\cdot$ & $\cdot$ & $\cdot$ & $\cdot$ & $\cdot \cdot$ & $\cdot$. &. & $\cdot$. & \\
\hline Banque islamique de développement &.. &.. &.. & &.. &.. &.. &.. &.. &.. &.. & . \\
\hline Banque mondiale &.. &. &.. & & 0,9 & 0,8 &.. & .. &.. &.. & 0,6 & 0,4 \\
\hline BAsD & .. &.. &.. & &.. &.. &.. &.. &.. &.. &.. & 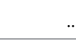 \\
\hline BID & .. &.. &.. & &.. &.. &.. & 354,9 & 563,5 & 521,3 & 373,9 & 737,8 \\
\hline Cadre intégré renforcé (CIR) & 1365,6 & 1525,1 & 2441,7 & 2007,0 & 2876,5 & 2484,4 & 271,1 & 400,5 & 402,8 & 632,1 & 524,6 & 799,6 \\
\hline CEB & .. &.. & 45,7 & 202,6 & 35,4 & 57,7 &.. &.. & 0,7 & 4,8 & 4,8 & 28,9 \\
\hline CEE-ONU &.. &.. &.. & .. &.. &.. &.. &.. &.. &.. &.. & .. \\
\hline CESAO & .. &.. &.. & .. & 23,8 & 27,8 &.. &.. &.. &.. & 1,5 & 2,0 \\
\hline CESAP &. &.. & 0,0 &. &. & 0,0 &.. &.. &.. &.. &.. & .. \\
\hline FAO & 34,2 & 48,2 & 33,6 & 35,2 & 28,2 & 12,1 & 10,6 & 17,3 & 24,5 & 30,0 & 19,8 & 16,4 \\
\hline FIDA &. &.. &.. &. &.. &. &.. & .. &. & .. &.. & $\vec{u}$ \\
\hline FMl & .. &.. &.. &. &. &.. &.. & .. &. & .. &. & . \\
\hline FODI & 12,4 & 15,6 & 16,2 & 16,0 & 4,8 & 3,9 & 0,6 & 0,7 & 1,4 & 2,0 & 0,2 & 0,2 \\
\hline Fonds arabe (FADES) & 154,9 & 481,3 & 492,2 & 432,8 & 390,2 & 456,8 &.. & .. &.. & &.. & .. \\
\hline $\begin{array}{l}\text { Fonds d'investissement pour le climat } \\
\text { (FIC) }\end{array}$ &. & 5,7 & 10,9 & 6,6 & 17,9 & 10,2 &.. & 0,1 & 0,1 & & 0,3 & 0,2 \\
\hline Fonds pour l'environnement mondial &.. &.. &.. & .. &.. &.. &.. &.. &.. &.. &.. & 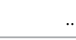 \\
\hline Institutions de l'UE & .. &.. &.. & .. &.. &.. &.. & .. &.. &.. &.. & .. \\
\hline ITC &.. & 91,5 & 108,7 & 138,7 & 140,6 & 152,1 &.. & 22,8 & 43,5 & 61,8 & 72,3 & 76,4 \\
\hline OIT & .. &.. & 0,3 & .. &.. &.. &.. &.. & 0,2 & .. &.. & .. \\
\hline OMC & 4,5 & 4,2 & 2,0 & 1,7 & 3,7 & 1,4 & 2,5 & 1,7 & 0,9 & 1,4 & 3,2 & 1,9 \\
\hline ONUDI & 1734,4 & 2179,7 & 2684,3 & 2946,0 & 2633,4 & 3213,6 & 70,6 & 96,3 & 105,6 & 142,4 & 90,8 & 70,9 \\
\hline PNUD &.. &.. &.. & .. &.. &.. &.. &.. &.. &.. &. & .. \\
\hline Autres donateurs multilatéraux & 1,6 & 18,4 & 77,6 & 91,7 & 39,9 & 39,3 & 0,1 & 1,1 & 13,3 & 12,1 & 10,5 & 9,9 \\
\hline Sous-total & 3687,3 & 5574,5 & 6918,0 & 7117,1 & 7198,8 & 7903,5 & 355,6 & 895,3 & 1156,4 & 1408,0 & 1102,6 & 1744,8 \\
\hline AIDE POUR LE COMMERCE TOTALE & 7157,7 & 10756,7 & 13634,2 & 14364,3 & 14741,2 & 15102,7 & 1528,9 & 2664,9 & 3061,7 & 2893,6 & 3176,0 & 3304,7 \\
\hline
\end{tabular}


Millions d'USD (constants de 2017)

Tableau A.15. Aide pour le commerce par donateur et par région, décaissements (page 3 sur 6 )

ASIE

Moyenne Moyenne $\mid$ Moyenne $\mid{ }^{2}$

\begin{tabular}{cc|c|} 
2006-2008 & Moyenne & Moyenne \\
$2009-2011$ & $2012-2014$
\end{tabular}
EUROPE

\begin{tabular}{l|l|l|l|l|l} 
Moyenne & Moyenne & Moyenne & 2015 & 2016 & 2017
\end{tabular} 2006-2008 $2009-2011 \quad 2012-2014$

\section{Pays CAD}

Allemagne

Australie

Autriche

Belgique

Canada

Corée

Danemark

Espagne

États-Unis

Finlande

France

Grèce

Hongrie

Irlande

Islande

Italie

Japon

Luxembourg

Norvège

Nouvelle-Zélande

Pays-Bas

Pologne

Portugal

République slovaque

République tchèque

Royaume-Uni

Slovénie

Suède

Suisse

Sous-total

\begin{tabular}{|r|r|r|r|}
\hline 713,4 & 955,5 & 1149,7 & 1986,8 \\
\hline
\end{tabular}

\begin{tabular}{l|r|}
993,1 & 1488,5 \\
\hline
\end{tabular}

\begin{tabular}{|r|r|r|r|r|r|}
\hline 176,0 & 252,3 & 362,9 & 658,2 & 264,5 & 524,3 \\
\hline
\end{tabular}

\begin{tabular}{|r|r|r|r|r|r|r|}
\hline 116,0 & 188,3 & 196,2 & 213,6 & 188,7 & 227,0 \\
\hline
\end{tabular}

Autres donateurs bilatéraux

\begin{tabular}{|c|c|c|c|c|c|c|c|c|c|c|c|c|}
\hline Arabie saoudite & .. &.. &. & 6,8 & 3,7 &. & .. &. & .. &. & .. & .. \\
\hline Azerbaïdjan & .. &. & .. & .. &.. &.. & .. &.. &.. & 0,0 &.. & .. \\
\hline Croatie &. & & .. & &.. &.. & .. &.. & .. &. & & 0,5 \\
\hline Émirats arabes unis &. & 57,9 & 126,0 & 481,3 & 235,9 & 178,9 & .. &.. & 14,6 & 17,0 & 0,1 & 17,1 \\
\hline Estonie &. &.. & 0,5 & 0,7 & 0,5 & 0,5 & .. &.. & 0,3 & 0,6 & 0,5 & 0,9 \\
\hline Kazakhstan &. &.. & 0,0 & 0,4 & 0,2 & 0,1 & .. &. & &. & & .. \\
\hline Koweït &. & 63,5 & 66,3 & 83,7 & 142,0 & 76,1 & .. & 2,3 & 6,6 & 27,0 & 9,2 & 8,3 \\
\hline Lettonie &. &. &. & .. &. & 0,0 & .. &. &. &. & 0,2 & 0,0 \\
\hline Lituanie &.. &.. & 0,0 & 0,1 & 0,2 & 0,3 & .. &.. & 0,0 & 0,4 & 0,3 & 0,1 \\
\hline Roumanie &. &.. &. & 0,1 & 0,1 &. & .. &.. & 0,3 & 0,4 & 1,2 &. \\
\hline Taipei chinois &. &. &. & .. &.. &. & .. &. &. &. &.. & .. \\
\hline Thaïlande &.. &.. & .. & .. & 18,5 & 18,7 & .. & .. & .. &. &. & .. \\
\hline Turquie &. & 33,0 &. &. &.. &. & .. & 0,9 &.. &.. &.. & .. \\
\hline Sous-total &.. & 154,4 & 192,9 & 573,0 & 401,1 & 274,6 & .. & 3,2 & 21,9 & 45,4 & 11,4 & 27,0 \\
\hline
\end{tabular}


Millions d'USD (constants de 2017)

Tableau A.15. Aide pour le commerce par donateur et par région, décaissements (page 4 sur 6 )

\begin{tabular}{|c|c|c|c|c|c|c|c|c|c|c|c|c|}
\hline & \multicolumn{6}{|c|}{ ASIE } & \multicolumn{6}{|c|}{ EUROPE } \\
\hline & $\begin{array}{c}\text { Moyenne } \\
2006-2008\end{array}$ & \begin{tabular}{|c|} 
Moyenne \\
2009-2011
\end{tabular} & \begin{tabular}{|c|} 
Moyenne \\
2012-2014
\end{tabular} & 2015 & 2016 & 2017 & $\begin{array}{c}\text { Moyenne } \\
2006-2008\end{array}$ & \begin{tabular}{|c|} 
Moyenne \\
2009-2011
\end{tabular} & \begin{tabular}{|c|} 
Moyenne \\
2012-2014
\end{tabular} & 2015 & 2016 & 2017 \\
\hline \multicolumn{13}{|l|}{ Donateurs multilatéraux } \\
\hline BADEA & .. & .. & .. & .. & .. & .. & .. &.. & .. & .. & .. & .. \\
\hline BAfD & .. & .. & .. & .. & .. & .. & .. &.. & .. & .. & .. &. \\
\hline $\begin{array}{l}\text { Banque de développement } \\
\text { des Caraïbes }\end{array}$ & .. & .. &. & .. & $\cdot$ & ." &. & 12,6 & 2,0 & 1,4 & 1,4 & . \\
\hline Banque islamique de développement & .. & .. & .. & .. & .. & .. & .. &.. &. & .. & .. & .. \\
\hline Banque mondiale & .. & .. & .. & .. & 1,5 & 1,2 & .. &.. &. & .. & 0,4 & 0,4 \\
\hline BAsD & .. & 470,3 & 1169,1 & 1493,5 & 1421,5 & 1290,8 & .. &.. & .. & .. & .. & .. \\
\hline BID & .. & .. & .. & .. & .. & .. & .. &. & .. & .. & .. & . \\
\hline Cadre intégré renforcé (CIR) & 207,2 & 295,6 & 401,2 & 842,6 & 893,2 & 1100,7 & 248,8 & 1475,0 & 3336,4 & 2872,7 & 3509,2 & 2629,2 \\
\hline CEB & .. & .. & 18,3 & 2,6 & .. & 141,2 & .. &.. &.. & .. &.. & 12,8 \\
\hline CEE-ONU & 0,1 & 0,5 & 0,5 & 0,7 & 0,4 & 0,8 & .. &.. &. & .. & .. & .. \\
\hline CESAO & .. & .. & .. & .. & 13,1 & 13,7 & .. &.. &.. & .. & 1,3 & 1,7 \\
\hline CESAP & 0,0 & .. & 0,2 & 0,3 & 0,2 & 0,2 & .. &. & .. & .. & .. & .. \\
\hline FAO & 13,4 & 19,1 & 40,0 & 61,4 & 40,9 & 20,4 & 0,5 & 2,1 & 8,0 & 11,5 & 8,2 & 6,6 \\
\hline FIDA & .. & .. & .. & .. & .. &.. & .. & .. & .. & .. &. & .. \\
\hline FMl & .. & .. & .. & .. & .. &.. & .. &. & .. & .. & .. & .. \\
\hline FODI & 9,6 & 12,8 & 9,1 & 6,9 & 1,7 & 4,3 & 0,6 & 0,6 & 0,8 & 0,6 & 0,3 & 0,3 \\
\hline Fonds arabe (FADES) & 78,4 & 211,6 & 175,5 & 60,2 & 49,1 & 71,8 & .. & .. & .. & .. &. & .. \\
\hline $\begin{array}{l}\text { Fonds d'investissement pour le climat } \\
\text { (FIC) }\end{array}$ & .. & 4,3 & 4,4 & 0,5 & 2,8 & 2,4 &. &. &. &. &. & . \\
\hline Fonds pour l'environnement mondial & .. & .. & .. & .. & .. & .. & .. &. & .. & .. & .. & .. \\
\hline Institutions de l'UE & .. & .. & .. & .. &. &. & .. &. & .. & .. & .. & .. \\
\hline ITC & .. & 46,6 & 58,6 & 90,0 & 129,9 & 119,4 & .. & 6,9 & 8,8 & 5,0 & 22,4 & 6,1 \\
\hline OIT & .. & .. & 0,1 & .. & .. & .. & .. & .. & .. & .. &. &. \\
\hline OMC & 1,4 & 2,0 & 1,6 & 2,2 & 3,6 & 2,4 & 0,4 & 0,1 & 0,0 & 0,0 & 0,0 & 0,0 \\
\hline ONUDI & 1427,3 & 1476,9 & 1932,3 & 2498,6 & 1831,4 & 2493,8 & 88,5 & 80,1 & 42,4 & 25,2 & 40,8 & 29,3 \\
\hline PNUD & 0,0 & 0,1 & 0,2 & .. & 0,0 & 0,3 & 1,3 & 4,1 & 3,3 & 5,2 & 5,5 & 5,2 \\
\hline Autres donateurs multilatéraux & 0,1 & 2,1 & 10,2 & 14,1 & 16,7 & 7,5 & .. & 0,0 & 0,3 & 0,6 & 1,2 & 0,6 \\
\hline Sous-total & 1737,3 & 2541,8 & 3821,4 & 5073,7 & 4406,0 & 5270,8 & 340,1 & 1581,6 & 3402,1 & 2922,3 & 3590,6 & 2692,4 \\
\hline AIDE POUR LE COMMERCE TOTALE & 10123,5 & 11231,2 & 13011,9 & 15483,9 & 13400,9 & 16631,4 & 1194,7 & 2644,5 & 4222,8 & 3966,9 & 4191,0 & 3902,8 \\
\hline
\end{tabular}


Millions d'USD (constants de 2017)

Tableau A.15. Aide pour le commerce par donateur et par région, décaissements (page 5 sur 6 )

OCÉANIE

\begin{tabular}{l|l|l|r} 
Moyenne & Moyenne & Moyenne & 2015 \\
\hline
\end{tabular}

2006-2008 $\quad 2009-2011 \quad 2012-2014$
NON SPÉCIFIQUE À UNE RÉGION

\begin{tabular}{l|l|l|l|l|l} 
Moyenne & Moyenne & Moyenne & 2015 & 2016 & 2017
\end{tabular} 2006-2008 $2009-2011 \quad 2012-2014$

\section{Pays CAD}

Allemagne

Australie

Autriche

Belgique

Canada

Corée

Danemark

Espagne

États-Unis

Finlande

France

Grèce

Hongrie

Irlande

Islande

Italie

Japon

Luxembourg

Norvège

Nouvelle-Zélande

Pays-Bas

Pologne

Portugal

République slovaque

République tchèque

Royaume-Uni

Slovénie

Suède

Suisse

Sous-total

\begin{tabular}{|r|r|r|r|r|r|}
\hline 0,3 & 0,9 & 2,2 & 18,7 & 1,0 & 1,3 \\
\hline 107,4 & 108,9 & 105,2 & 150,0 & 128,7 & 157,6 \\
\hline 0,1 & 0,3 & 0,0 & 0,1 & 0,4 & 0,1 \\
\hline.. & 0,0 &.. &.. &.. &.. \\
\hline 0,0 & 1,0 & 0,4 & 0,2 & 0,1 & 5,7 \\
\hline 1,1 & 1,9 & 1,8 & 2,6 & 2,1 & 1,8 \\
\hline
\end{tabular}

\begin{tabular}{|r|r|r|r|r|r|}
\hline 115,1 & 488,7 & 266,0 & 569,4 & 745,1 & 568,3 \\
\hline 27,3 & 70,6 & 47,3 & 36,1 & 69,2 & 32,0 \\
\hline
\end{tabular}

Autres donateurs bilatéraux

\begin{tabular}{|c|c|c|c|c|c|c|c|c|c|c|c|c|}
\hline Arabie saoudite & .. & .. & .. & .. & .. & .. & .. & .. & .. & .. & .. & .. \\
\hline Azerbaïdjan & .. & .. & .. & .. & .. & .. & .. & .. & 0,1 & 0,1 & 1,8 & 2,3 \\
\hline Croatie & .. & .. & .. & .. & .. & .. & .. & .. & .. & .. & .. & .. \\
\hline Émirats arabes unis & .. & .. & 4,4 & 26,2 & 3,2 & 1,1 & .. & 1,3 & 3,4 & .. & 6,6 & 13,7 \\
\hline Estonie & .. & .. & .. & .. & .. & .. & .. & .. & 0,1 & 0,2 & 0,1 & 0,4 \\
\hline Kazakhstan & .. & .. & .. & .. & .. & .. & .. & .. & 0,0 & 0,3 & 1,7 & 0,0 \\
\hline Koweit & .. & .. & .. & .. & .. & .. & .. & 0,0 & 0,0 & .. & .. & .. \\
\hline Lettonie & .. & .. & .. & .. & .. & .. & .. & .. & .. & .. & .. &. \\
\hline Lituanie & .. & .. & .. & .. &. & .. & .. & .. & .. & 0,0 & .. & 0,1 \\
\hline Roumanie & .. & .. & .. & .. & .. & .. & .. &. & .. & 0,0 & 0,0 & ." \\
\hline Taipei chinois & .. & .. & .. & .. & 8,7 & .. & .. & .. & .. & .. & .. & .. \\
\hline Thaïlande & .. & .. & .. & .. & .. & .. & .. & .. & .. & .. & .. & .. \\
\hline Turquie & .. & 0,1 & .. & .. & .. & .. & .. & 0,0 & .. & .. & .. & .. \\
\hline Sous-total & .. & 0,1 & 4,4 & 26,2 & 12,0 & 1,1 & .. & 1,3 & 3,7 & 0,6 & 10,1 & 16,5 \\
\hline
\end{tabular}


Millions d'USD (constants de 2017)

Tableau A.15. Aide pour le commerce par donateur et par région, décaissements (page 6 sur 6 )

\begin{tabular}{|c|c|c|c|c|c|c|c|c|c|c|c|c|}
\hline & \multicolumn{6}{|c|}{ OCÉANIE } & \multicolumn{6}{|c|}{ NON SPÉCIFIQUE À UNE RÉGION } \\
\hline & $\begin{array}{c}\text { Moyenne } \\
\text { 2006-2008 }\end{array}$ & $\begin{array}{c}\text { Moyenne } \\
2009-2011\end{array}$ & $\begin{array}{l}\text { Moyenne } \\
\text { 2012-2014 }\end{array}$ & 2015 & 2016 & 2017 & $\begin{array}{c}\text { Moyenne } \\
2006-2008\end{array}$ & $\begin{array}{c}\text { Moyenne } \\
\text { 2009-2011 }\end{array}$ & $\begin{array}{l}\text { Moyenne } \\
2012-2014\end{array}$ & 2015 & 2016 & 2017 \\
\hline \multicolumn{13}{|l|}{ Donateurs multilatéraux } \\
\hline BADEA & .. & .. &.. & .. & .. & .. & .. & .. & .. & .. & .. & .. \\
\hline BAfD & .. & .. & .. & .. & .. & .. & .. & .. & .. & & .. & \\
\hline $\begin{array}{l}\text { Banque de développement } \\
\text { des Caraïbes }\end{array}$ & . & . & .. & $\cdot$ & $\cdot$ & $\cdot$ & $\cdot$ & $\cdot$ & $\cdot$. & $\cdot$ &. & $\cdot$ \\
\hline Banque islamique de développement &. & .. &.. & .. &.. & .. & 29,6 & 51,9 & 58,0 & 66,2 & 54,9 & 52,8 \\
\hline Banque mondiale &. & .. &.. &. & .. & .. & .. & .. & .. & .. & 9,9 & 9,9 \\
\hline BAsD &. & 16,4 & 82,9 & 79,7 & 77,1 & 89,1 &. &. &. &. &. & .. \\
\hline BID &. & .. & .. & .. & .. & .. & .. &.. & .. &.. & .. & .. \\
\hline Cadre intégré renforcé (CIR) & 26,3 & 24,0 & 33,9 & 45,4 & 19,9 & 26,1 & 96,3 & 139,6 & 103,9 & 92,1 & 95,6 & 111,7 \\
\hline CEB & .. & .. & 0,3 & 0,4 & & 1,0 &. &.. & 0,0 & & .. & 3,4 \\
\hline CEE-ONU & .. &. &.. &. &. & .. & 0,1 & .. &.. &. & .. & .. \\
\hline CESAO & .. &. &.. & .. &.. & 0,0 &.. &.. &.. & .. & 9,0 & 12,3 \\
\hline CESAP &. &. & .. &.. &. &. & 0,0 & 0,2 & 0,0 &. &. &. \\
\hline FAO &.. & 3,3 & 7,0 & 6,9 & 1,7 & 2,4 & 7,0 & 6,1 & 12,6 & 19,6 & 14,8 & 7,5 \\
\hline FIDA & .. & .. &. & .. & .. &. &. &. &. &. &.. &. \\
\hline FMl &.. & .. & .. &.. & .. &. &.. &.. & .. &.. &.. & .. \\
\hline FODI & 0,2 & 0,1 & 0,0 & 0,1 & 0,0 & .. & .. & 3,6 & 3,1 & 0,4 & .. & .. \\
\hline Fonds arabe (FADES) &.. & .. & .. & .. & .. & .. & 0,4 & 3,8 & 3,0 &.. & 1,9 & .. \\
\hline $\begin{array}{l}\text { Fonds d'investissement pour le climat } \\
\text { (FIC) }\end{array}$ &. & 0,1 & 0,6 & 0,5 & 2,3 & 2,6 &. & .. &. &. &. & .. \\
\hline Fonds pour l'environnement mondial & .. & .. & .. & .. & .. & .. & .. &. & &. &. & .. \\
\hline Institutions de I'UE &. &. & .. & .. & .. &. & 131,7 & 273,6 & 271,7 & 316,7 &. & .. \\
\hline ITC &. & 0,3 & 3,7 & 1,5 & 3,0 & .. & .. & 0,2 & 0,7 & 0,9 & 0,6 & 1,3 \\
\hline OIT &. & .. & .. & .. &. & .. & .. &. & & &. & .. \\
\hline $\mathrm{OMC}$ & 0,3 & 0,2 & 0,2 & 0,0 & 0,0 & 0,1 & 3,5 & 7,4 & 7,2 & 6,3 & 12,5 & 6,5 \\
\hline ONUDI & 3,3 & 21,6 & 44,0 & 69,9 & 77,0 & 80,4 &. &. & .. & .. & .. & .. \\
\hline PNUD &. & .. & .. & .. & .. & .. & .. & .. & & & .. & 0,2 \\
\hline Autres donateurs multilatéraux & 0,0 & 0,0 & 0,3 & 0,8 & 0,8 & 1,8 & 0,5 & 0,1 & 12,6 & 12,6 & 12,9 & 15,5 \\
\hline Sous-total & 30,0 & 66,0 & 172,8 & 205,1 & 181,9 & 203,5 & 269,2 & 486,6 & 472,8 & 514,8 & 212,1 & 221,1 \\
\hline AIDE POUR LE COMMERCE TOTALE & 256,1 & 323,4 & 427,5 & 560,3 & 490,1 & 693,3 & 1492,2 & 2663,7 & 2590,3 & 3595,1 & 3476,4 & 3331,2 \\
\hline
\end{tabular}

Source: CAD de l'OCDE : base de données sur les activités d'aide (2019).

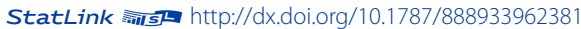


Millions d'USD (constants de 2017)

Tableau A.16. Aide pour le commerce par donateur et par groupe de revenu, engagements (page 1 of 6 ) PAYS LES MOINS AVANCÉS

\begin{tabular}{l|l|l|l|l|l|} 
Moyenne & Moyenne & Moyenne & Moyenne & 2015 & 2016 \\
\hline
\end{tabular} 2002-2005 2006-2008 2009-2011 2012-2014

\section{AUTRES PAYS À FAIBLE REVENU}

\begin{tabular}{l|l|l|l|l|l|l} 
Moyenne & Moyenne & Moyenne & Moyenne & 2015 & 2016 & 2017
\end{tabular} 2002-2005 2006-2008 2009-2011 2012-2014

\begin{tabular}{|c|c|c|c|c|c|c|c|c|c|c|c|c|c|c|}
\hline \multicolumn{15}{|l|}{ Pays CAD } \\
\hline Allemagne & 210,3 & 207,6 & 276,5 & 434,4 & 505,6 & 627,6 & 677,6 & 2,9 & 2,0 & 6,4 & 1,8 & 5,9 & 2,6 & 5,5 \\
\hline Australie & 24,0 & 29,6 & 74,5 & 106,4 & 94,7 & 87,1 & 115,7 & 1,2 & 0,0 & 9,3 & 5,2 & 0,4 & 0,3 & 0,5 \\
\hline Autriche & 15,9 & 10,0 & 6,7 & 21,0 & 11,0 & 9,6 & 17,6 & 0,2 & 0,1 & 0,0 & 0,0 &.. & 0,0 & 0,0 \\
\hline Belgique & 65,0 & 100,6 & 178,2 & 95,5 & 128,2 & 64,3 & 123,3 & 0,9 & 0,1 & 0,1 & .. & .. &. & .. \\
\hline Canada & 86,3 & 165,8 & 233,3 & 145,9 & 266,7 & 116,5 & 28,4 & 0,3 & 0,3 & 0,5 & 0,3 & 0,2 & 0,1 & 0,0 \\
\hline Corée & .. & 191,7 & 349,9 & 425,9 & 451,9 & 325,1 & 207,5 &.. & 1,2 & 0,6 & 0,3 & 0,5 & 0,7 & 0,5 \\
\hline Danemark & 211,7 & 169,9 & 96,6 & 266,8 & 41,8 & 56,9 & 87,2 &.. & .. & 13,4 & 12,6 & 7,1 &. & .. \\
\hline Espagne & 37,4 & 50,7 & 102,8 & 23,5 & 10,0 & 14,4 & 20,5 &.. & 0,1 & 0,2 & 0,2 & 0,0 & 0,0 & 0,0 \\
\hline États-Unis & 589,8 & 2093,8 & 2075,3 & 1533,8 & 1688,7 & 1035,7 & 936,4 & 30,8 & 5,3 & 18,0 & 10,0 & 12,9 & 7,4 & 3,7 \\
\hline Finlande & 9,0 & 28,4 & 85,0 & 29,8 & 26,9 & 33,0 & 11,1 & 0,2 & 0,3 & 0,2 & 0,2 & 0,0 & 0,2 & .. \\
\hline France & 125,7 & 184,3 & 206,0 & 285,6 & 574,8 & 294,7 & 486,9 & 0,2 & 4,1 & 1,8 & 0,9 & 0,9 & 0,7 & 0,7 \\
\hline Grèce & 0,1 & 0,1 & 0,2 & .. & .. & .. & .. &. & 0,1 &.. & .. &. & .. & .. \\
\hline Hongrie &. &. & .. & .. & 0,4 & 3,8 & 2,2 &.. & .. &.. & .. & .. &.. & .. \\
\hline Irlande & 21,7 & 30,9 & 42,8 & 33,4 & 24,0 & 27,0 & 26,3 & 0,2 & 0,8 & 0,7 & 1,0 & 1,9 & 1,4 & 1,7 \\
\hline Islande & .. & .. & 1,3 & 4,1 & 1,8 & 1,4 & 1,0 &.. & .. &.. & .. & .. & .. & .. \\
\hline Italie & 98,5 & 67,1 & 48,4 & 52,9 & 49,2 & 17,3 & 128,7 & 0,4 & 0,0 & 0,0 & 0,4 & 0,4 & .. & 0,0 \\
\hline Japon & 311,8 & 496,3 & 1036,9 & 1838,2 & 3667,7 & 2494,9 & 3772,8 & 1,0 & 1,0 & 0,4 & 0,9 & 17,5 & 2,0 & 1,8 \\
\hline Luxembourg & 5,0 & 9,2 & 10,2 & 15,1 & 11,7 & 12,6 & 27,4 &. & .. &.. & .. &. & .. & .. \\
\hline Norvège & 111,0 & 149,0 & 203,2 & 282,8 & 65,0 & 91,0 & 102,0 & 1,3 & 0,0 & 1,5 & 1,6 & 0,8 & 0,1 & 0,2 \\
\hline Nouvelle-Zélande & 4,1 & 18,8 & 40,3 & 34,5 & 57,7 & 38,2 & 35,6 & 0,0 & .. &.. & .. & .. & .. & .. \\
\hline Pays-Bas & 74,0 & 67,0 & 80,1 & 138,0 & 147,7 & 61,2 & 134,4 & 0,5 & 0,3 & 0,2 & .. & .. & .. & .. \\
\hline Pologne &. & .. & .. & 6,7 & 27,5 & 68,1 & 11,8 & .. & .. & .. & 0,0 & 0,0 &. & 0,0 \\
\hline Portugal & 8,7 & 5,2 & 5,0 & 3,2 & 16,8 & 2,1 & 1,8 &.. &. &.. & .. &. &. & .. \\
\hline République slovaque & .. & .. & .. & 0,2 & 0,0 & 0,1 & 0,1 &. &. &.. & .. & .. & .. &. \\
\hline République tchèque &. & .. & 1,1 & 2,3 & 2,0 & 2,2 & 3,0 &. &. &.. & 0,0 & 0,0 & 0,0 & .. \\
\hline Royaume-Uni & 154,4 & 211,7 & 237,7 & 179,5 & 271,2 & 172,2 & 168,0 & 1,7 & 0,3 & 27,2 & 8,8 & 3,1 & 0,1 & 1,9 \\
\hline Slovénie & .. & .. & 0,1 & 0,0 & .. & 0,0 & .. &. &. &.. & .. & .. & .. & .. \\
\hline Suède & 65,3 & 91,2 & 95,0 & 74,4 & 132,7 & 137,6 & 152,2 & 0,4 & 0,0 & 0,4 & 0,1 & 1,2 & 0,5 & 8,9 \\
\hline Suisse & 62,3 & 54,5 & 52,6 & 87,4 & 70,3 & 67,4 & 118,4 & 2,0 & 2,5 & 1,6 & 0,5 & 1,3 & 0,2 & 0,7 \\
\hline Sous-total & 2292,0 & 4433,4 & 5539,4 & 6121,3 & 8345,9 & 5861,9 & 7397,9 & 44,2 & 18,8 & 82,5 & 44,6 & 54,2 & 16,4 & 26,1 \\
\hline \multicolumn{15}{|c|}{ Autres donateurs bilatéraux } \\
\hline Arabie saoudite &. &. &. & .. & 104,3 & 102,2 & 309,7 &.. & .. &.. & .. &.. &. &. \\
\hline Azerbaïdjan & .. & .. &. & .. &. &. & .. & .. & .. &.. & .. & .. &. &. \\
\hline Croatie & .. &. &. & .. & .. &. & .. &. &. &. & .. &. & .. & .. \\
\hline Émirats arabes unis & .. & .. & 142,5 & 104,2 & 430,1 & 0,4 & 12,0 &.. & .. &.. & .. & .. & .. & .. \\
\hline Estonie & .. & .. & .. & 0,1 & .. & 0,1 & .. & .. & .. &.. & .. & .. & .. & .. \\
\hline Kazakhstan &. & .. & .. & .. & .. &. & .. &. & .. & .. & .. &. & .. & .. \\
\hline Koweït & .. & .. & 112,7 & 274,2 & 159,2 & 256,1 & 166,9 &. &. &.. & 6,6 &. &. & 19,8 \\
\hline Lettonie & .. & .. & .. & .. & .. & .. & .. &. & .. &.. & .. & .. &.. & .. \\
\hline Lituanie & .. & .. & .. & .. & .. & .. & .. &.. &.. &.. & .. & .. & .. & .. \\
\hline Roumanie &. &.. &.. & .. & .. &.. & .. &. &. &. &.. &. & .. & .. \\
\hline Taipei chinois & .. & .. & .. & .. & .. &.. & .. &. &. &.. &.. & .. &. & .. \\
\hline Thaillande &. & .. &.. & .. &.. &.. & .. &. &. &.. &.. &. &.. & .. \\
\hline Turquie & .. &.. & 0,5 & .. &.. &.. & .. &. &. &.. & .. &. & .. & .. \\
\hline Sous-total &.. &.. & 255,7 & 378,5 & 693,7 & 358,7 & 488,6 & .. & .. &.. & 6,6 &.. & .. & 19,8 \\
\hline
\end{tabular}


Millions d'USD (constants de 2017)

Tableau A.16. Aide pour le commerce par donateur et par groupe de revenu, engagements (page 2 of 6 )

PAYS LES MOINS AVANCÉS

\begin{tabular}{l|l|l|l|l} 
Moyenne & Moyenne & Moyenne & Moyenne & 2015
\end{tabular}

2002-2005 2006-2008 2009-2011 2012-2014
AUTRES PAYS À FAIBLE REVENU

\begin{tabular}{l|l|l|l|l|l|l} 
Moyenne & Moyenne & Moyenne & Moyenne & 2015 & 2016 & 2017
\end{tabular} 2002-2005 2006-2008 2009-2011 2012-2014

\begin{tabular}{|c|c|c|c|c|c|c|c|c|c|c|c|c|c|c|}
\hline \multicolumn{15}{|l|}{ Donateurs multilatéraux } \\
\hline BAfD & 110,6 & 363,6 & 812,5 & 890,2 & 1338,2 & 546,6 & 773,3 &.. & .. & .. & 0,4 & & 4,1 & 17,0 \\
\hline $\begin{array}{l}\text { Banque de développement } \\
\text { des Caraïbes }\end{array}$ &.. &.. & &.. &.. & 8,1 & & .. &.. &.. &. & & .. & .. \\
\hline $\begin{array}{l}\text { Banque islamique } \\
\text { de développement }\end{array}$ & 140,6 & 166,8 & 108,4 & 89,5 & 77,9 & 205,7 & 119,3 &.. &. &.. &.. & $\cdot$ &.. & .. \\
\hline Banque mondiale & 2181,8 & 2168,8 & 3054,8 & 3476,7 & 4461,3 & 3601,3 & 6311,2 &.. & .. &.. &.. &.. & .. & .. \\
\hline BAsD & 361,8 & 150,6 & 542,5 & 893,7 & 787,8 & 771,5 & 1091,5 &.. & .. & .. & .. &.. & .. & .. \\
\hline BID & 37,1 & 5,9 & 99,1 & 118,3 & 154,1 & 23,3 & 57,4 &.. & & .. & .. & .. &.. & .. \\
\hline Cadre intégré renforcé (CIR) &.. &.. & 12,5 & 24,6 & 18,4 & 3,0 & 11,4 &.. &.. & .. & .. & .. & .. & .. \\
\hline CEB &.. &.. &.. & .. &.. &.. & .. &.. &. & .. & .. & .. & .. & .. \\
\hline CEE-ONU &.. &.. &.. &.. &.. & .. &.. &.. &.. & .. & .. & .. & .. & .. \\
\hline CESAO & .. & 0,0 &.. & 0,0 & .. &.. & 0,0 &.. &.. & .. & .. & .. & .. & .. \\
\hline CESAP &.. & 0,0 &.. & 0,0 & 0,1 &.. & .. &.. &.. &.. & .. & .. & .. & .. \\
\hline FAO & .. &.. &.. & .. &.. & .. & .. &.. & .. & .. & .. & .. &.. & .. \\
\hline FIDA & 146,0 & 183,8 & 337,7 & 311,1 & 612,2 & 332,8 & 350,9 &.. & .. &.. & .. & .. & 25,9 & .. \\
\hline FMI &.. & 3,6 & 5,5 & 3,7 &.. &.. & .. &.. &.. & 0,2 & 0,0 & .. & .. & .. \\
\hline FODI &.. &.. & 141,4 & 145,6 & 235,8 & 162,5 & 170,7 &.. &.. & .. & 0,1 &.. & .. & 15,0 \\
\hline Fonds arabe (FADES) &.. & 258,8 & 360,5 & 264,4 & 235,7 & 421,2 & 415,9 &.. & .. & .. & .. & 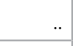 & .. & .. \\
\hline $\begin{array}{l}\text { Fonds d'investissement pour } \\
\text { le climat }\end{array}$ &.. &.. &.. & 76,6 & 86,1 & 90,8 & 211,1 &.. &. &.. &.$\cdot$ &.. &.. & .. \\
\hline $\begin{array}{l}\text { Fonds pour l'environnement } \\
\text { mondial }\end{array}$ &.. &.. & 19,6 & 66,5 & 15,0 & 28,4 & 240,1 &.. &. &.. & 0,0 &.. &.. & 0,1 \\
\hline Fonds vert pour le climat &.. &.. &.. &.. & 7,7 & 18,8 & 52,5 &.. & .. & .. & .. &.. & .. & .. \\
\hline Institutions de l'UE & 971,0 & 1047,9 & 816,5 & 921,7 & 866,8 & 2120,9 & 1059,3 & 0,9 & 4,5 & 13,5 & 19,0 & 60,9 & 8,0 & 3,4 \\
\hline ITC &.. &.. &.. &.. &.. & .. & .. & .. &.. &. & .. &.. & .. & .. \\
\hline OMC &.. & 2,5 & 1,0 & 0,5 & 0,3 & 0,8 & 0,3 &.. & 0,0 & 0,0 & 0,0 & 0,0 & 0,0 & 0,0 \\
\hline ONUDI &.. & 10,7 & 12,6 & 5,2 &.. & 9,6 & 7,0 &.. & 0,0 & 0,0 & .. & . & .. & .. \\
\hline $\begin{array}{l}\text { Organisation mondiale } \\
\text { du tourisme }\end{array}$ &.. &.. &.. &.. &.. &.. &.. &.. &. &. &.$\cdot$ &.. &.. & .. \\
\hline PNUD & 5,7 & 14,6 & 18,4 & 18,0 & 16,4 & 4,1 & 3,4 & 0,5 & 0,5 & 0,3 & 1,0 & 0,2 & 0,3 & 2,4 \\
\hline $\begin{array}{l}\text { Autres donateurs } \\
\text { multilatéraux }\end{array}$ & 0,5 & 3,5 & 27,4 & 101,1 & 31,0 & 57,8 & 24,8 &.. & 0,0 & 1,5 & 1,0 & 0,3 & 0,2 & 0,2 \\
\hline Sous-total & 3955,1 & 4381,0 & 6370,4 & 7407,6 & 8944,9 & 8407,2 & 10900,3 & 1,4 & 5,1 & 15,6 & 21,5 & 61,4 & 38,5 & 38,0 \\
\hline $\begin{array}{l}\text { AIDE POUR LE COMMERCE } \\
\text { TOTALE }\end{array}$ & 6247,2 & 8814,5 & 12165,4 & 13907,3 & 17984,4 & 14627,8 & 18786,8 & 45,6 & 23,9 & 98,2 & 72,7 & 115,6 & 54,9 & 83,9 \\
\hline
\end{tabular}


Millions d'USD (constants de 2017)

Tableau A.16. Aide pour le commerce par donateur et par groupe de revenu, engagements (page 3 of 6 )

PAYS À REVENU INTERMÉDIAIRE DE LA TRANCHE INFÉRIEURE

\begin{tabular}{l|l|l|l|l|l|} 
Moyenne & Moyenne & Moyenne & Moyenne & 2015 & 2016
\end{tabular} 2002-2005 2006-2008 2009-2011 2012-2014

PAYS À REVENU INTERMÉDIAIRE DE LA TRANCHE SUPÉRIEURE

\begin{tabular}{|c|c|c|c|c|c|c|c|c|c|c|c|c|c|c|}
\hline & $\begin{array}{c}\text { Moyenne } \\
\text { 2002-2005 }\end{array}$ & $\begin{array}{c}\text { Moyenne } \\
2006-2008\end{array}$ & $\begin{array}{c}\text { Moyenne } \\
2009-2011\end{array}$ & $\begin{array}{c}\text { Moyenne } \\
\text { 2012-2014 }\end{array}$ & 2015 & 2016 & 2017 & $\begin{array}{c}\text { Moyenne } \\
2002-2005\end{array}$ & $\begin{array}{c}\text { Moyenne } \\
2006-2008\end{array}$ & $\begin{array}{c}\text { Moyenne } \\
2009-2011\end{array}$ & $\begin{array}{c}\text { Moyenne } \\
2012-2014\end{array}$ & 2015 & 2016 & 2017 \\
\hline \multicolumn{15}{|l|}{ Pays CAD } \\
\hline Allemagne & 560,8 & 645,6 & 1086,6 & 2066,2 & 2155,8 & 2300,2 & 2049,8 & 338,7 & 624,2 & 827,5 & 1190,2 & 1735,1 & 1356,0 & 1183,7 \\
\hline Australie & 117,3 & 183,4 & 257,7 & 164,3 & 209,0 & 177,2 & 207,2 & 31,7 & 34,4 & 23,8 & 25,4 & 18,0 & 21,1 & 35,0 \\
\hline Autriche & 17,9 & 10,8 & 16,8 & 22,7 & 23,4 & 16,2 & 17,8 & 7,8 & 11,4 & 10,6 & 2,9 & 0,5 & 4,9 & 0,8 \\
\hline Belgique & 55,6 & 54,5 & 81,9 & 29,0 & 25,1 & 36,2 & 29,3 & 46,0 & 45,4 & 25,7 & 10,1 & 10,0 & 13,3 & 12,1 \\
\hline Canada & 103,0 & 89,7 & 106,2 & 113,5 & 234,6 & 223,1 & 38,1 & 64,6 & 15,8 & 22,3 & 49,2 & 55,7 & 13,2 & 20,4 \\
\hline Corée &.. & 255,7 & 542,4 & 410,5 & 429,9 & 657,9 & 940,5 &.. & 35,1 & 41,9 & 27,6 & 26,4 & 69,7 & 22,3 \\
\hline Danemark & 142,1 & 69,9 & 111,6 & 42,8 & 58,9 & 40,4 & 64,9 & 23,8 & 13,6 & 16,4 & 9,6 & 1,2 & 22,2 & 12,4 \\
\hline Espagne & 96,8 & 267,0 & 217,7 & 24,3 & 14,2 & 13,0 & 22,5 & 205,1 & 302,9 & 125,1 & 24,3 & 13,0 & 11,5 & 57,4 \\
\hline États-Unis & 753,7 & 1746,7 & 1518,8 & 1104,4 & 963,0 & 1153,1 & 726,3 & 2597,1 & 1933,6 & 678,4 & 300,7 & 229,4 & 134,7 & 172,5 \\
\hline Finlande & 27,5 & 24,3 & 64,4 & 34,0 & 3,5 & 7,4 & 34,9 & 21,5 & 13,6 & 21,4 & 8,6 & 0,8 & 1,3 & 11,5 \\
\hline France & 274,9 & 821,6 & 666,5 & 1338,0 & 1708,8 & 970,0 & 1588,1 & 173,5 & 298,7 & 257,8 & 664,5 & 438,2 & 701,7 & 574,6 \\
\hline Grèce & 3,1 & 4,1 & 1,8 & 0,0 & 0,0 & 0,0 & 0,0 & 8,0 & 11,6 & 13,3 & 0,0 &.. &.. & .. \\
\hline Hongrie &. &.. &.. &.. & 0,0 & 0,1 & 0,1 &. &.. &.. &.. & 0,0 & 0,1 & 0,1 \\
\hline Irlande & 2,0 & 6,9 & 7,8 & 4,6 & 4,3 & 4,9 & 4,8 & 0,7 & 1,0 & 0,4 & 0,3 & 0,2 & 0,3 & 0,1 \\
\hline Islande &. & . & 0,3 & 0,3 & 0,1 & 0,0 &.. &.. &.. & 0,0 & 0,0 & .. & 0,1 & .. \\
\hline Italie & 51,0 & 76,0 & 33,6 & 41,6 & 78,3 & 25,7 & 43,5 & 89,1 & 81,8 & 79,3 & 17,5 & 19,4 & 12,2 & 128,7 \\
\hline Japon & 3022,4 & 3798,2 & 4006,3 & 5453,8 & 7427,8 & 6617,9 & 7354,7 & 1091,8 & 1125,5 & 874,6 & 766,8 & 1146,9 & 1878,6 & 818,2 \\
\hline Luxembourg & 6,2 & 9,8 & 7,3 & 8,4 & 7,7 & 4,1 & 8,0 & 4,3 & 4,9 & 2,9 & 1,6 & 0,6 & 1,0 & 1,0 \\
\hline Norvège & 32,8 & 62,0 & 55,9 & 31,7 & 24,1 & 9,7 & 29,4 & 31,0 & 26,9 & 44,0 & 21,9 & 12,6 & 5,8 & 3,5 \\
\hline Nouvelle-Zélande & 7,6 & 8,7 & 13,8 & 26,4 & 29,0 & 15,2 & 41,0 & 6,3 & 6,7 & 26,1 & 35,3 & 27,5 & 12,3 & 43,7 \\
\hline Pays-Bas & 103,4 & 65,8 & 46,3 & 35,6 & 16,2 & 39,4 & 79,4 & 33,8 & 30,2 & 7,2 & 2,2 & 0,9 & 13,9 & 3,8 \\
\hline Pologne &. &.. &. & 1,6 & 3,9 & 11,5 & 3,8 &.. &. &.. & 0,1 & 0,0 & 0,5 & 0,3 \\
\hline Portugal & 16,9 & 21,6 & 44,8 & 23,1 & 7,5 & 0,9 & 0,7 & 15,3 & 0,0 & 0,1 & 0,2 & 0,2 & 0,5 & 0,2 \\
\hline République slovaque &. &. &. & 0,3 & 0,8 & 0,6 & 0,5 & .. &.. &. & 0,1 & 0,0 & 0,1 & 0,0 \\
\hline République tchèque &. &. & 1,3 & 3,0 & 5,6 & 2,7 & 3,5 &.. &.. & 1,1 & 2,1 & 2,8 & 1,9 & 2,5 \\
\hline Royaume-Uni & 155,3 & 191,7 & 281,2 & 259,2 & 151,3 & 80,6 & 87,7 & 204,2 & 96,5 & 164,8 & 109,0 & 136,4 & 155,0 & 37,7 \\
\hline Slovénie &.. & & 0,1 & 0,2 & .. & 0,0 & 0,1 &.. &.. & 1,7 & 0,7 & 0,1 & 0,8 & 0,5 \\
\hline Suède & 45,3 & 51,6 & 41,2 & 47,1 & 33,2 & 16,7 & 65,2 & 29,0 & 20,9 & 22,0 & 9,7 & 13,6 & 13,2 & 5,6 \\
\hline Suisse & 92,1 & 66,7 & 69,8 & 81,8 & 72,4 & 57,6 & 164,1 & 40,1 & 37,4 & 27,9 & 36,6 & 31,6 & 53,5 & 62,0 \\
\hline Sous-total & 5687,6 & 8532,2 & 9282,0 & 11368,4 & 13688,6 & 12482,1 & 13605,7 & 5063,3 & 4772,2 & 3316,5 & 3317,2 & 3921,2 & 4499,6 & 3210,8 \\
\hline \multicolumn{15}{|c|}{ Autres donateurs bilatéraux } \\
\hline Arabie saoudite &. & .. &.. &.. & 255,1 & 741,2 & 180,0 &.. &.. &.. &.. & 121,5 &.. & 56,7 \\
\hline Azerbaïdjan & .. &.. &. &.. & .. & .. &.. &.. &. &. &.. & .. & .. & .. \\
\hline Croatie &. &.. & .. & .. &.. &.. &.. &. &.. &.. &.. &. & .. & 0,5 \\
\hline Émirats arabes unis &.. &.. & 73,0 & 749,2 & 392,5 & 40,7 & 311,0 &.. &.. & 16,5 & 35,7 & 84,7 & 30,5 & 74,0 \\
\hline Estonie &. &.. &. & 1,2 & 1,2 & 1,7 & 1,1 &.. &.. &.. & 0,1 & 0,0 & 0,1 & 0,0 \\
\hline Kazakhstan &. &.. &.. &.. & .. & .. &.. &.. &.. &.. &.. &.. & .. & .. \\
\hline Koweït &. & .. & 197,6 & 214,7 & 190,1 & 341,0 & 77,4 &. &. & 3,4 & 38,7 & 48,8 & 121,8 & 13,9 \\
\hline Lettonie &.. &.. &.. &.. &.. & 0,2 & 0,0 &.. &.. &.. &.. &.. &.. & .. \\
\hline Lituanie &.. & .. & .. & 0,0 & 0,4 & 0,3 & 0,4 &.. &.. &.. & 0,0 & 0,2 & 0,1 & 0,0 \\
\hline Roumanie &.. &.. &.. & 0,1 & 0,5 & 1,3 &.. &.. &.. &.. &. &.. &.. & .. \\
\hline Taipei chinois &.. &.. &.. &. &.. & .. &. &.. &. &.. &.. &. &.. & .. \\
\hline Thaïlande &.. &.. &. &.. &.. &.. &.. &.. &. &.. &.. &. &.. & .. \\
\hline Turquie &.. &.. & 0,4 &. & .. &.. &. &.. &.. & 1,0 &.. & .. &.. & .. \\
\hline Sous-total & .. & .. & 271,0 & 965,2 & 839,8 & 1126,5 & 569,9 & .. & .. & 21,0 & 74,5 & 255,2 & 152,6 & 145,0 \\
\hline
\end{tabular}


Millions d'USD (constants de 2017)

Tableau A.16. Aide pour le commerce par donateur et par groupe de revenu, engagements (page 4 of 6 )

PAYS À REVENU INTERMÉDIAIRE DE LA TRANCHE INFÉRIEURE

\begin{tabular}{l|l|l|l|l} 
Moyenne & Moyenne & Moyenne & Moyenne & 2015 \\
\end{tabular}

2002-2005 2006-2008 2009-2011 2012-2014
PAYS À REVENU INTERMÉDIAIRE

DE LA TRANCHE SUPÉRIEURE

\begin{tabular}{l|l|l|l|l|l|l} 
Moyenne & Moyenne & Moyenne & Moyenne & 2015 & 2016 & 2017
\end{tabular} 2002-2005 2006-2008 2009-2011 2012-2014

\begin{tabular}{|c|c|c|c|c|c|c|c|c|c|c|c|c|c|c|}
\hline \multicolumn{15}{|l|}{ Donateurs multilatéraux } \\
\hline BAfD & 30,9 & 119,6 & 208,8 & 427,7 & 393,3 & 176,3 & 151,2 & .. &.. & 0,5 & 2,4 & 4,8 & 3,4 & 4,0 \\
\hline $\begin{array}{l}\text { Banque de développement } \\
\text { des Caraïbes }\end{array}$ & .. &. & &.. &.. &.. & & &.. &.. &.. & 1,5 & 24,5 & 10,5 \\
\hline $\begin{array}{l}\text { Banque islamique } \\
\text { de développement }\end{array}$ & 33,5 & 61,2 & 63,6 & 39,0 & 157,0 & 51,4 & 27,2 & 13,5 & 16,0 & 9,1 & 6,1 & & 0,5 & 0,5 \\
\hline Banque mondiale & 1993,0 & 1870,1 & 2946,4 & 3555,1 & 3202,2 & 2521,2 & 3737,5 & 241,7 & 181,1 & 92,2 & 53,7 & 27,3 & 130,3 & 80,1 \\
\hline BAsD & 375,5 & 364,4 & 647,8 & 847,3 & 856,7 & 881,0 & 482,8 & 10,5 & 6,1 & 8,0 & 30,0 & 31,3 & 40,6 & 19,0 \\
\hline $\mathrm{BID}$ & 168,0 & 78,8 & 207,8 & 341,2 & 562,0 & 317,0 & 373,8 & 37,2 & 26,2 & 90,5 & 84,0 & 45,1 & 71,3 & 27,7 \\
\hline Cadre intégré renforcé (CIR) &.. &.. & 0,3 & 0,1 &.. & 0,3 & .. & .. &.. & 0,4 & 1,6 & 0,2 & 0,3 & 0,4 \\
\hline CEB &.. &.. &.. &.. & .. &.. & .. & .. &.. &.. & .. & 2,8 & .. & .. \\
\hline CEE-ONU &.. &.. &.. &.. & .. & 0,0 & 0,1 &.. &.. & 0,1 & 0,1 & 0,0 & 0,0 & .. \\
\hline CESAO &.. & 0,0 & .. & 0,0 & .. &.. & 0,0 &.. &.. &.. & 0,0 & .. & .. & 0,0 \\
\hline CESAP &.. &.. & 0,0 & 0,0 & 0,0 & .. & .. &.. &.. &.. & 0,0 & .. & .. & .. \\
\hline FAO &.. &.. &.. & .. &.. & .. & .. &.. &.. & .. &.. &.. &.. & .. \\
\hline FIDA & 96,4 & 138,3 & 222,4 & 186,7 & 315,1 & 175,5 & 483,7 & 26,3 & 53,7 & 20,8 & 43,1 &.. & 2,6 & 99,4 \\
\hline FMI &.. & 2,7 & 4,1 & 2,9 &.. &.. & .. & .. & 3,0 & 3,8 & 2,9 & .. & .. & .. \\
\hline FODI &.. &.. & 102,3 & 212,5 & 207,1 & 239,5 & 206,5 &.. &.. & 70,1 & 57,8 & 68,2 & 202,2 & 97,2 \\
\hline Fonds arabe (FADES) &.. & 129,5 & 636,5 & 497,9 & 1000,9 & 539,4 & 610,7 &.. &.. & 7,8 & 3,5 & 107,8 &.. &. \\
\hline $\begin{array}{l}\text { Fonds d'investissement pour } \\
\text { le climat }\end{array}$ &. &.. &.. & 403,3 & 183,4 & 478,9 & 238,9 & .. &.. & .. & 216,9 & 250,4 & 10,2 & 120,8 \\
\hline $\begin{array}{l}\text { Fonds pour l'environnement } \\
\text { mondial }\end{array}$ &. &.. & 20,9 & 68,0 & 30,6 & 58,3 & 89,0 &.. &.. & 42,9 & 113,9 & 37,6 & 15,8 & 181,0 \\
\hline Fonds vert pour le climat &.. &.. &.. &.. & .. & 62,6 & 86,3 &.. &.. &.. & .. & $"$ & 28,7 & 30,9 \\
\hline Institutions de l'UE & 561,2 & 634,4 & 899,5 & 2712,4 & 2202,4 & 2152,7 & 2530,1 & 451,8 & 560,5 & 1583,7 & 4008,0 & 3238,8 & 3322,9 & 3220,2 \\
\hline ITC &.. & .. &.. & .. & .. & .. & .. & .. & .. & .. & .. &.. &.. & .. \\
\hline OMC &.. & 2,2 & 1,3 & 0,3 & 0,2 & 0,3 & 0,2 &.. & 3,8 & 1,5 & 0,5 & 0,3 & 0,6 & 0,5 \\
\hline ONUDI &.. & 5,7 & 17,5 & 1,2 &.. & 24,6 & 1,2 &.. & 4,6 & 16,4 & 3,8 & & 24,7 & 2,5 \\
\hline $\begin{array}{l}\text { Organisation mondiale } \\
\text { du tourisme }\end{array}$ &. &.. &.. &.. &.. &.. &.. &.. &.. &.. &.. &.. & .. &. \\
\hline PNUD & 3,9 & 5,7 & 8,4 & 5,6 & 5,2 & 2,0 & 1,9 & 1,8 & 3,2 & 2,4 & 2,5 & 2,9 & 0,5 & 0,5 \\
\hline $\begin{array}{l}\text { Autres donateurs } \\
\text { multilatéraux }\end{array}$ & 0,4 & 0,0 & 11,6 & 18,4 & 14,9 & 17,8 & 6,9 & 0,1 & 0,0 & 0,2 & 9,8 & 14,5 & 4,6 & 21,4 \\
\hline Sous-total & 3262,9 & 3412,7 & 5999,3 & 9319,6 & 9130,9 & 7698,6 & 9028,1 & 782,8 & 858,2 & 1950,4 & 4640,6 & 3833,5 & 3883,8 & 3916,5 \\
\hline $\begin{array}{l}\text { AIDE POUR LE COMMERCE } \\
\text { TOTALE }\end{array}$ & 8950,5 & 11944,8 & 15552,3 & 21653,1 & 23659,3 & 21307,2 & 23203,7 & 5846,1 & 5630,5 & 5287,9 & 8032,3 & 8009,9 & 8535,9 & 7272,3 \\
\hline
\end{tabular}


Millions d'USD (constants de 2017)

\section{Tableau A.16. Aide pour le commerce par donateur et par groupe de revenu, engagements (page 5 sur 6 )}

NON SPÉCIFIQUE À UN PAYS

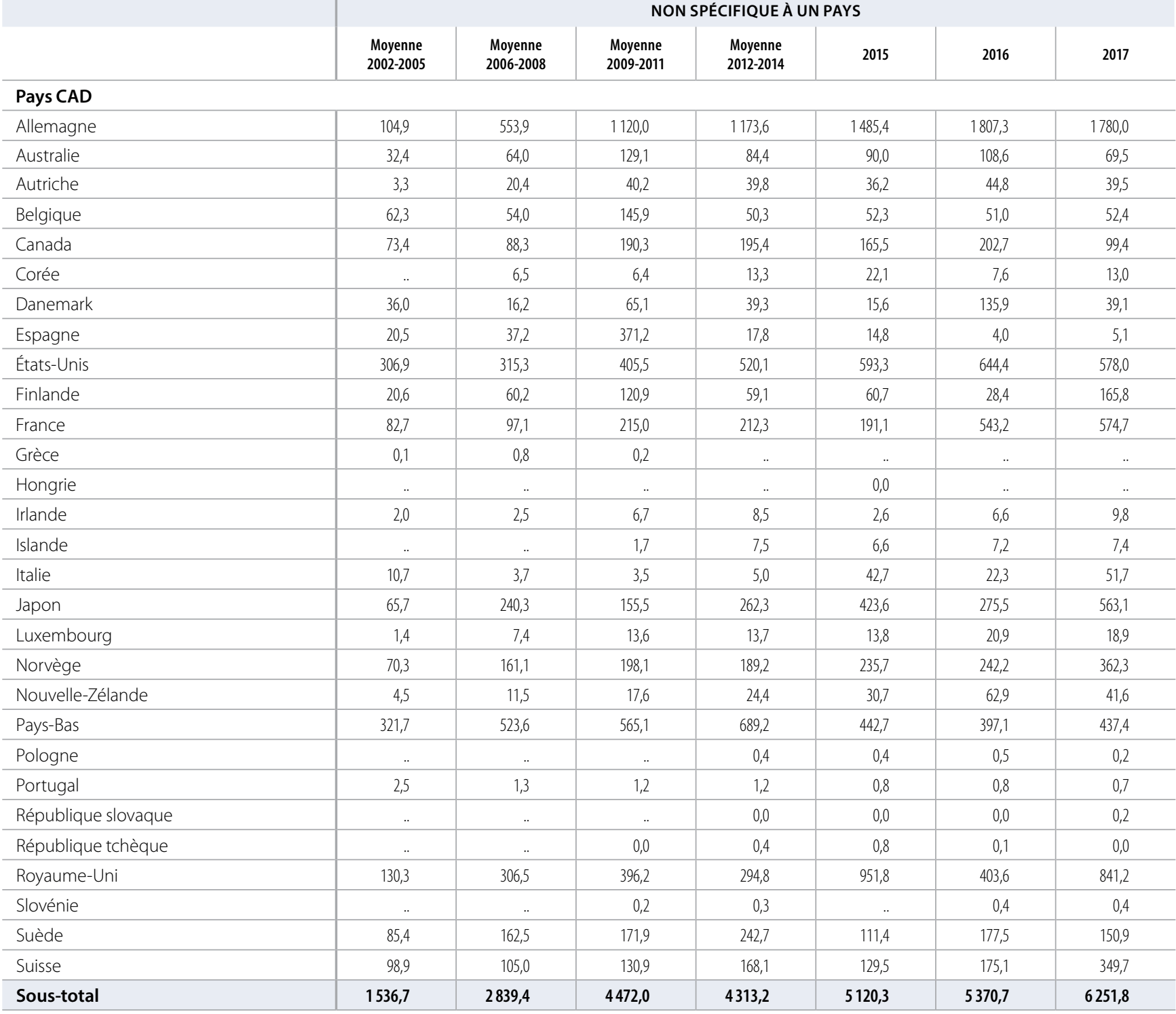

\section{Autres donateurs bilatéraux}

\begin{tabular}{|c|c|c|c|c|c|c|c|}
\hline Arabie saoudite & .. & .. &.. &. &. &.. & .. \\
\hline Azerbaïdjan & .. & .. &.. & .. &.. &.. & 2,3 \\
\hline Croatie & .. & .. &.. & .. &.. &.. & 0,0 \\
\hline Émirats arabes unis & .. & .. & 1,3 & 2,4 & 0,1 & .. & 40,8 \\
\hline Estonie & .. & .. &.. & 0,2 &. & 0,2 & 0,9 \\
\hline Kazakhstan & .. & .. &.. & .. &.. &. & .. \\
\hline Koweït & .. & .. & 0,0 &. & 1,0 &. & .. \\
\hline Lettonie & .. & .. & .. & .. &. & .. & 0,0 \\
\hline Lituanie & .. & .. &.. & 0,0 & 0,1 & 0,0 & 0,1 \\
\hline Roumanie & .. & .. &. &. & 0,0 & 0,0 & .. \\
\hline Taipei chinois & .. & .. & .. & .. &. & .. & .. \\
\hline Thaïlande & .. & .. & .. &. &. & .. & .. \\
\hline Turquie & .. & .. & 32,5 & .. & .. & .. &. \\
\hline Sous-total & .. & .. & 33,9 & 2,6 & 1,2 & 0,2 & 44,1 \\
\hline
\end{tabular}


Millions d'USD (constants de 2017)

\section{Tableau A.16. Aide pour le commerce par donateur et par groupe de revenu, engagements (page 6 sur 6 )}

NON SPÉCIFIQUE À UN PAYS

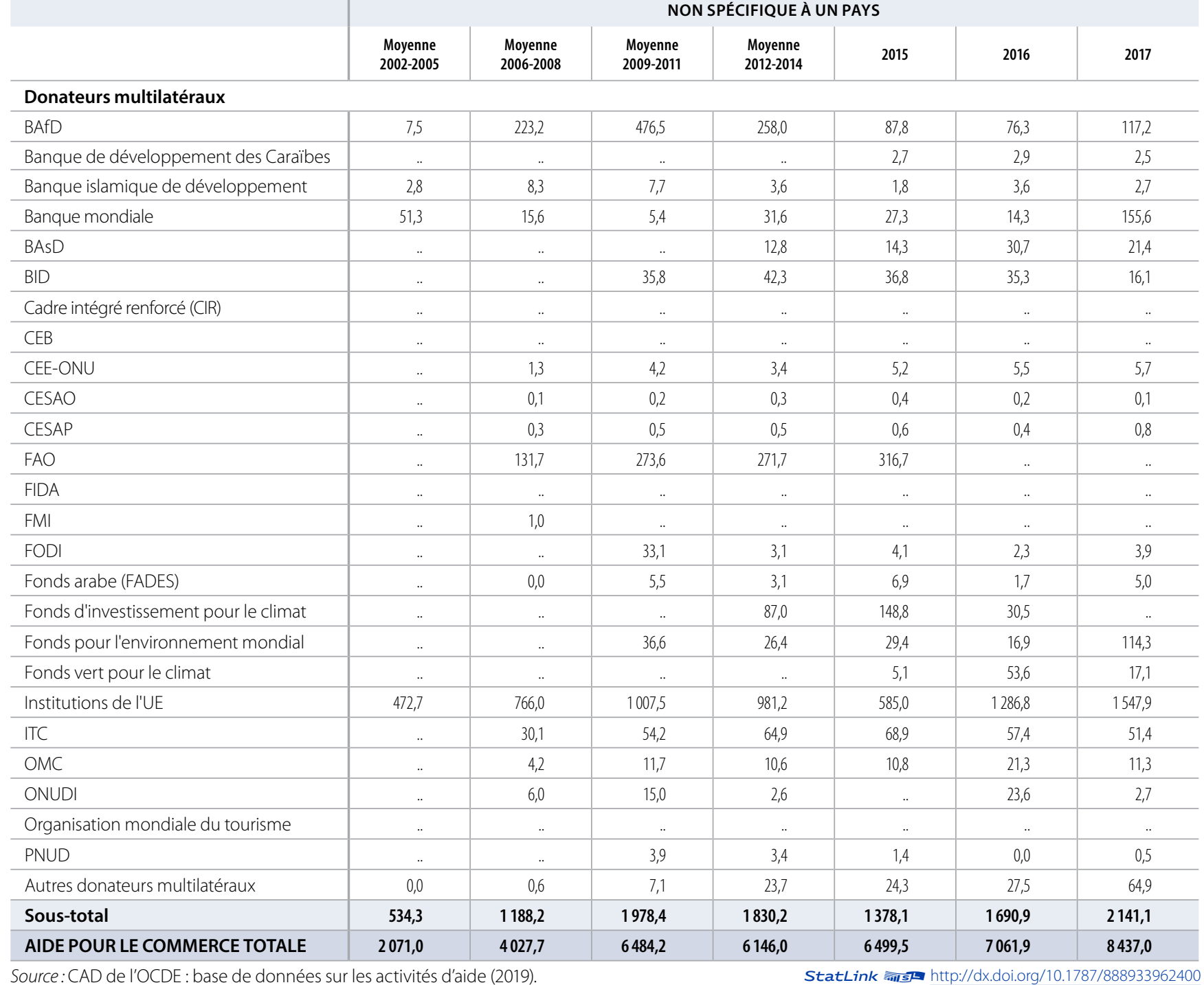


Millions d'USD (constants de 2017)

Tableau A.17. Aide pour le commerce par donateur et par groupe de revenu, décaissements (page 1 sur 6)

PAYS LES MOINS AVANCÉS

\begin{tabular}{c|c|c|c|c|} 
Moyenne & Moyenne & Moyenne & 2015 & 2016 \\
$2006-2008$ & $2009-2011$ & $2012-2014$ & &
\end{tabular}

2006-2008 $2009-2011 \quad 2012-2014$

\section{AUTRES PAYS À FAIBLE REVENU}

\begin{tabular}{l|l|l|l|l|l} 
Moyenne & Moyenne & Moyenne & 2015 & 2016 & 2017
\end{tabular} 2006-2008 $2009-2011 \quad 2012-2014$

\section{Pays CAD}

Allemagne

Australie

Autriche

Belgique

Canada

Corée

Danemark

Espagne

États-Unis

Finlande

France

Grèce

Hongrie

Irlande

Islande

Italie

Japon

Luxembourg

Norvège

Nouvelle-Zélande

Pays-Bas

Pologne

Portugal

République slovaque

République tchèque

Royaume-Uni

Slovénie

Suède

Suisse

Sous-total

\begin{tabular}{|c|c|c|c|c|c|}
\hline 209,8 & 218,7 & 261,0 & 327,0 & 305,6 & 367,1 \\
\hline 29,3 & 68,2 & 106,4 & 94,7 & 87,1 & 115,7 \\
\hline 9,3 & 8,5 & 10,3 & 11,8 & 8,6 & 13,1 \\
\hline 60,0 & 128,1 & 105,5 & 115,9 & 99,9 & 98,0 \\
\hline 103,4 & 245,3 & 121,3 & 130,1 & 146,4 & 128,5 \\
\hline 54,7 & 149,7 & 218,9 & 283,7 & 256,9 & 247,3 \\
\hline 128,3 & 170,0 & 171,5 & 126,1 & 124,8 & 111,8 \\
\hline 34,6 & 81,2 & 31,5 & 18,8 & 18,3 & 20,8 \\
\hline 1019,5 & 1989,6 & 1589,7 & 1280,9 & 1122,5 & 918,1 \\
\hline 8,7 & 28,8 & 41,1 & 43,0 & 49,0 & 23,9 \\
\hline 182,3 & 118,9 & 189,5 & 219,5 & 240,5 & 323,8 \\
\hline 0,1 & 0,2 &. &. &. & .. \\
\hline .. & .. & 0,1 & 0,4 & 3,8 & 2,2 \\
\hline 30,9 & 42,8 & 33,4 & 24,0 & 27,0 & 26,3 \\
\hline .. & 1,3 & 4,1 & 1,8 & 1,4 & 1,0 \\
\hline 107,0 & 40,9 & 36,3 & 56,1 & 27,2 & 60,4 \\
\hline 312,8 & 493,7 & 927,2 & 1355,8 & 1167,1 & 2075,5 \\
\hline 9,2 & 10,2 & 15,1 & 11,7 & 12,6 & 27,4 \\
\hline 120,8 & 160,4 & 187,5 & 169,4 & 137,5 & 119,9 \\
\hline 9,4 & 18,4 & 37,0 & 36,4 & 38,4 & 34,4 \\
\hline 60,2 & 61,6 & 106,0 & 76,8 & 84,1 & 108,8 \\
\hline. &. & 6,7 & 27,5 & 68,1 & 11,8 \\
\hline 5,2 & 5,0 & 3,2 & 14,9 & 3,2 & 2,2 \\
\hline. &. & 0,1 & 0,1 & 0,0 & 0,1 \\
\hline.. & 1,1 & 2,3 & 2,0 & 2,2 & 3,0 \\
\hline 134,2 & 290,8 & 280,2 & 476,5 & 317,0 & 424,9 \\
\hline.. & 0,1 & 0,0 &.. & 0,0 & .. \\
\hline 92,0 & 88,1 & 97,0 & 127,7 & 94,7 & 149,8 \\
\hline 48,4 & 40,7 & 62,5 & 87,2 & 77,4 & 88,6 \\
\hline 2770,1 & 4462,2 & 4645,3 & 5119,7 & 4521,2 & 5504,4 \\
\hline
\end{tabular}

\begin{tabular}{|c|c|c|c|c|c|}
\hline 1,7 & 5,6 & 3,7 & 2,3 & 2,9 & 4,8 \\
\hline 0,0 & 9,4 & 5,2 & 0,4 & 0,3 & 0,5 \\
\hline 0,3 & 0,0 & 0,0 & .. & 0,0 & 0,0 \\
\hline 0,1 & 0,1 & & .. & & .. \\
\hline 0,1 & 0,4 & 0,3 & 0,5 & 0,2 & 0,4 \\
\hline 0,1 & 1,3 & 0,6 & 0,5 & 0,7 & 0,4 \\
\hline .. & 10,3 & 12,4 & 10,2 & 5,2 & .. \\
\hline 0,1 & 0,2 & 0,0 & 0,2 & 0,2 & 0,0 \\
\hline 5,4 & 8,9 & 15,8 & 7,9 & 9,4 & 6,6 \\
\hline 0,1 & 0,2 & 0,2 & 0,1 & 0,2 & 0,2 \\
\hline 4,3 & 1,8 & 0,9 & 0,9 & 0,7 & 0,7 \\
\hline 0,1 &.. &. & .. & .. &. \\
\hline .. & .. & .. & .. & .. & .. \\
\hline 0,8 & 0,7 & 1,0 & 1,9 & 1,4 & 1,7 \\
\hline .. & .. & .. & .. & .. &. \\
\hline 0,0 & 0,1 & 0,3 & 0,4 &. & 0,2 \\
\hline 1,0 & 0,4 & 0,9 & 1,5 & 2,0 & 8,3 \\
\hline .. & .. & .. & .. & .. & .. \\
\hline 0,3 & 1,4 & 1,6 & 0,5 & 0,4 & 0,2 \\
\hline .. & .. & .. & .. &. &. \\
\hline 0,1 & 0,3 & 0,0 & .. &. &. \\
\hline .. & & 0,0 & 0,0 &. & 0,0 \\
\hline.. &.. & .. & .. & .. & .. \\
\hline .. & .. &.. & .. & .. &. \\
\hline .. &.. & 0,0 & 0,0 & 0,0 & .. \\
\hline 0,2 & 15,1 & 15,9 & 18,2 & 24,6 & 18,3 \\
\hline .. &.. & .. & .. & .. & .. \\
\hline 0,4 & 0,4 & 0,3 & 1,1 & 1,4 & 1,8 \\
\hline 2,2 & 1,8 & 0,5 & 0,7 & 1,8 & 1,8 \\
\hline 17,3 & 58,6 & 59,5 & 47,6 & 51,6 & 45,8 \\
\hline
\end{tabular}

Autres donateurs bilatéraux

\begin{tabular}{|c|c|c|c|c|c|c|c|c|c|c|c|c|}
\hline Arabie saoudite &. &.. &. & 5,9 & 0,3 & .. & .. & .. &. &.. &. & .. \\
\hline Azerbaïdjan & .. &.. &. & 0,0 &.. & .. & .. & .. & .. & .. & .. & .. \\
\hline Croatie &.. &. &.. & .. &. & .. & .. & .. & .. &. &. & .. \\
\hline Émirats arabes unis & & 37,9 & 53,6 & 395,7 & 134,0 & 72,3 & .. & .. &. &. &. &. \\
\hline Estonie &. & .. & 0,0 & 0,1 & 0,0 & 0,0 & .. & .. &. &. & .. & .. \\
\hline Kazakhstan &.. &.. &. & .. &.. & .. & .. & .. & .. &. & .. & .. \\
\hline Koweït & .. & 60,4 & 81,9 & 170,5 & 181,8 & 167,1 & .. & .. & 0,1 & 3,8 & 0,3 & 5,3 \\
\hline Lettonie & .. &. & .. & .. &.. & .. & .. & .. & .. & .. & .. & .. \\
\hline Lituanie & .. & .. & .. & .. &.. &. & .. & .. &. & .. &. & .. \\
\hline Roumanie & .. &.. & .. & .. &.. &. & .. & .. &. & .. &.. & .. \\
\hline Taipei chinois & .. &.. &. & .. & 8,7 &.. & .. & .. &.. &. &.. & .. \\
\hline Thaïlande & .. &. &. & .. & 18,4 & 18,7 & .. & .. &. &. &.. & .. \\
\hline Turquie & .. & 0,5 &. & .. &.. &. & .. & .. &. &.. & .. & .. \\
\hline Sous-total & .. & 98,8 & 135,6 & 572,2 & 343,3 & 258,1 & .. & .. & 0,1 & 3,8 & 0,3 & 5,3 \\
\hline
\end{tabular}


Millions d'USD (constants de 2017)

Tableau A.17. Aide pour le commerce par donateur et par groupe de revenu, décaissements (page 2 sur 6)

PAYS LES MOINS AVANCÉS

\begin{tabular}{|c|c|c|c|c|c|c|c|c|c|c|c|c|}
\hline & \multicolumn{6}{|c|}{ PAYS LES MOINS AVANCES } & \multicolumn{6}{|c|}{ AUTRES PAYS A FAIBLE REVENU } \\
\hline & $\begin{array}{c}\text { Moyenne } \\
2006-2008\end{array}$ & $\begin{array}{l}\text { Moyenne } \\
\text { 2009-2011 }\end{array}$ & $\begin{array}{l}\text { Moyenne } \\
\text { 2012-2014 }\end{array}$ & 2015 & 2016 & 2017 & $\begin{array}{l}\text { Moyenne } \\
2006-2008\end{array}$ & $\begin{array}{l}\text { Moyenne } \\
2009-2011\end{array}$ & $\begin{array}{l}\text { Moyenne } \\
\text { 2012-2014 }\end{array}$ & 2015 & 2016 & 2017 \\
\hline \multicolumn{13}{|l|}{ Donateurs multilatéraux } \\
\hline BAfD & 290,7 & 608,7 & 567,3 & 781,9 & 617,1 & 949,7 &.. & .. & .. & 0,3 & 3,3 & 1,1 \\
\hline $\begin{array}{l}\text { Banque de développement } \\
\text { des Caraïbes }\end{array}$ &. &. &. & .. & .. &. &. &. &. & .. & .. & .. \\
\hline Banque islamique de développement &.. &.. &.. & .. & .. & .. &.. &. & .. & .. & .. & .. \\
\hline Banque mondiale & 1735,0 & 1879,8 & 2369,3 & 2518,7 & 2424,9 & 3328,5 & .. & .. & .. & .. & .. & .. \\
\hline BAsD &.. & 247,1 & 532,0 & 438,6 & 542,6 & 657,3 & .. &.. &.. & .. & .. & .. \\
\hline BID &.. & 73,4 & 103,1 & 115,9 & 50,0 & 70,9 & .. &.. & .. & .. & .. & .. \\
\hline Cadre intégré renforcé (CIR) &.. & 9,7 & 15,4 & 7,6 & 21,6 & 13,8 & .. &. & .. & .. & .. & .. \\
\hline CEB &.. &.. & .. & .. & .. & .. & .. & .. & .. & .. & .. & .. \\
\hline CEE-ONU &.. &.. &. & .. & .. &. & .. &.. &.. &.. & .. & .. \\
\hline CESAO & 0,0 & .. & 0,0 & .. & .. & 0,0 & .. & .. & .. & .. & .. & .. \\
\hline CESAP & 0,0 &.. & 0,0 & 0,1 & .. &.. & .. &.. & .. & .. & .. & .. \\
\hline FAO &.. & .. & .. & .. & .. &.. &. &. &. &. &. & .. \\
\hline FIDA &.. & .. & .. & .. & .. &.. &.. & .. &.. & .. &.. & .. \\
\hline FMI &.. &.. & 0,1 & .. & .. &.. &.. &.. & 0,0 &.. & .. & .. \\
\hline FODI &.. & 67,9 & 81,3 & 111,9 & 166,5 & 126,9 &.. &.. & 0,0 & 0,1 &.. & 1,4 \\
\hline Fonds arabe (FADES) & 81,9 & 179,8 & 233,2 & 197,9 & 107,2 & 128,7 & .. &. & .. & .. & .. & .. \\
\hline Fonds d'investissement pour le climat &.. & .. & 2,7 & 2,2 & 5,8 & 57,3 & .. &.. & .. & .. & .. & .. \\
\hline Fonds pour l'environnement mondial & 17,4 & 28,7 & 26,0 & 33,2 & 27,3 & 10,0 & .. & .. & 0,0 & 0,0 & .. & .. \\
\hline Fonds vert pour le climat &.. &. &. &. & .. &. &.. &. &. & .. &. &. \\
\hline Institutions de l'UE & 926,1 & 836,8 & 790,9 & 783,6 & 1129,9 & 1035,7 & 1,8 & 12,8 & 18,4 & 12,3 & 11,2 & 6,2 \\
\hline ITC & .. & .. & .. & .. & .. & .. & .. &.. &. & .. & .. & .. \\
\hline OMC & 2,5 & 1,0 & 0,5 & 0,3 & 0,8 & 0,3 & 0,0 & 0,0 & 0,0 & 0,0 & 0,0 & 0,0 \\
\hline ONUDI & .. & .. & .. & .. & 11,0 & 10,1 & .. & .. & .. & .. & .. & .. \\
\hline Organisation mondiale du tourisme & .. & .. & .. & .. & 0,1 & .. & .. &. &. & .. & .. & .. \\
\hline PNUD & 14,1 & 18,4 & 18,0 & 16,4 & 4,1 & 3,4 & 0,5 & 0,3 & 1,0 & 0,2 & 0,3 & 2,4 \\
\hline Autres donateurs multilatéraux & 1,6 & 15,3 & 60,2 & 75,6 & 30,8 & 20,1 & .. & 0,0 & 0,1 & 0,3 & 0,2 & 0,2 \\
\hline Sous-total & 3069,3 & 3966,7 & 4800,1 & 5084,0 & 5139,7 & 6412,7 & 2,3 & 13,1 & 19,6 & 13,2 & 15,0 & 11,3 \\
\hline AIDE POUR LE COMMERCE TOTALE & 5839,4 & 8527,7 & 9581,0 & 10775,9 & 10004,3 & 12175,2 & 19,6 & 71,7 & 79,3 & 64,6 & 66,8 & 62,4 \\
\hline
\end{tabular}


Millions d'USD (constants de 2017)

Tableau A.17. Aide pour le commerce par donateur et par groupe de revenu, décaissements (page 3 sur 6 )

PAYS À REVENU INTERMÉDIAIRE

DE LA TRANCHE INFÉRIEURE

\begin{tabular}{l|l|l|l|l|} 
Moyenne & Moyenne & Moyenne & 2015 & 2016
\end{tabular}

2006-2008 2009-2011 2012-2014
PAYS À REVENU INTERMÉDIAIRE

DE LA TRANCHE SUPÉRIEURE

2017

\begin{tabular}{l|l|l|l} 
Moyenne & Moyenne & Moyenne & 2015
\end{tabular}

2006-2008 2009-2011 2012-2014
2017

\section{Pays CAD}

Allemagne

Australie

Autriche

Belgique

Canada

Corée

Danemark

Espagne

États-Unis

Finlande

France

Grèce

Hongrie

Irlande

Islande

Italie

Japon

Luxembourg

Norvège

Nouvelle-Zélande

Pays-Bas

Pologne

Portugal

République slovaque

République tchèque

Royaume-Uni

Slovénie

Suède

Suisse

Sous-total

Autres donateurs bilatéraux

\begin{tabular}{|c|c|c|c|c|c|c|c|c|c|c|c|c|}
\hline Arabie saoudite &.. &. &. & 0,9 & 0,1 &.. &.. &.. &.. &.. & 3,5 & .. \\
\hline Azerbaïdjan & .. & .. & .. & .. & .. &. & .. &. &. & 0,0 & 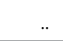 & .. \\
\hline Croatie &.. &. &. &.. &. &.. & .. &.. &.. &.. &.. & 0,5 \\
\hline Émirats arabes unis &.. & 44,2 & 615,7 & 469,4 & 287,0 & 475,1 & .. & 5,1 & 31,2 & 32,4 & 1,4 & 23,0 \\
\hline Estonie &.. & .. & 0,8 & 1,2 & 0,9 & 1,1 &.. &.. & 0,1 & 0,0 & 0,1 & 0,0 \\
\hline Kazakhstan &.. &. & .. & .. & .. & .. & .. &.. &. &.. & .. & .. \\
\hline Koweït & .. & 167,0 & 164,2 & 198,9 & 489,0 & 179,8 & .. & 23,8 & 23,4 & 35,5 & 21,9 & 21,0 \\
\hline Lettonie & .. & .. & .. & .. & 0,2 & 0,0 & .. & .. & .. & .. &.. & .. \\
\hline Lituanie & .. & .. & 0,0 & 0,4 & 0,3 & 0,4 & .. & .. & 0,0 & 0,1 & 0,1 & 0,0 \\
\hline Roumanie & .. & .. & 0,3 & 0,5 & 1,3 & .. & .. &.. &.. &.. &.. & .. \\
\hline Taipei chinois &.. & .. & .. & .. & .. &.. &.. &.. &.. & .. &.. & .. \\
\hline Thaïlande &.. & .. & .. &.. &.. &.. &.. &.. &.. &.. &.. & .. \\
\hline Turquie &.. & 0,4 & .. &.. &.. &.. & .. & 1,0 &.. &.. &.. & .. \\
\hline Sous-total & .. & 211,6 & 781,0 & 671,3 & 778,8 & 656,4 & .. & 29,9 & 54,6 & 68,1 & 27,0 & 44,6 \\
\hline
\end{tabular}


Millions d'USD (constants de 2017)

Tableau A.17. Aide pour le commerce par donateur et par groupe de revenu, décaissements (page 4 sur 6 )

PAYS À REVENU INTERMÉDIAIRE

\begin{tabular}{l|l|l|l} 
Moyenne Moyenne Moyenne $2015 \quad 2016$
\end{tabular}

\section{Donateurs multilatéraux}

BAfD

Banque de développement des Caraïbes

Banque islamique de développement

Banque mondiale

BAsD

BID

Cadre intégré renforcé (CIR)

CEB

CEE-ONU

CESAO

CESAP

$\mathrm{FAO}$

FIDA

FMI

FODI

Fonds arabe (FADES)

Fonds d'investissement pour le climat

Fonds pour l'environnement mondial

Fonds vert pour le climat

Institutions de I'UE

ITC

OMC

ONUDI

Organisation mondiale du tourisme

PNUD

Autres donateurs multilatéraux

Sous-total

AIDE POUR LE COMMERCE TOTALE
DE LA TRANCHE INFÉRIEURE

2008 2009-2011 2012-2014

2017

\begin{tabular}{|c|c|c|c|c|}
\hline & \multicolumn{4}{|c|}{ DE LA TRANCHE SUPÉRIEURE } \\
\hline Moy & Moyenne & Moyenne & 2015 & 2016 \\
\hline
\end{tabular}

2017

\begin{tabular}{|c|c|c|c|c|c|c|c|c|c|c|c|}
\hline 49,4 & 200,5 & 331,7 & 363,1 & 238,6 & 339,5 & .. & 0,1 & 1,3 & 1,7 & 1,8 & 4,5 \\
\hline.. & .. &.. &.. &.. & .. & .. &.. &.. &.. & .. & .. \\
\hline.. & .. & .. &.. &.. & .. & .. & .. &.. &.. & .. & .. \\
\hline 1473,0 & 1838,6 & 2321,6 & 3085,1 & 2186,2 & 2394,3 & 114,0 & 105,5 & 101,2 & 50,8 & 40,5 & 134,8 \\
\hline.. & 228,8 & 686,3 & 1086,7 & 879,4 & 649,1 & & 10,7 & 21,1 & 18,5 & 38,9 & 41,9 \\
\hline.. & 173,9 & 337,7 & 311,8 & 222,1 & 558,5 & .. & 80,2 & 87,4 & 53,4 & 62,1 & 78,8 \\
\hline.. & 0,1 & 0,1 &.. & 0,2 & 0,1 & .. & 0,4 & 0,5 &.. & 1,4 & 1,5 \\
\hline.. & .. &.. &.. &.. & .. & .. & 12,6 & 2,0 & 1,4 & 1,4 & .. \\
\hline .. & .. & .. &.. & 0,0 & 0,1 & .. & 0,1 & 0,1 & 0,0 & 0,0 & .. \\
\hline 0,0 & .. & 0,0 &.. &.. & 0,0 & .. & .. & 0,0 &.. & .. & 0,0 \\
\hline .. & 0,0 & 0,0 & 0,0 &.. &.. & .. & .. & 0,0 & .. & .. & .. \\
\hline
\end{tabular}


Millions d'USD (constants de 2017)

\section{Tableau A.17. Aide pour le commerce par donateur et par groupe de revenu, décaissements (page 5 sur 6 )} NON SPÉCIFIQUE À UN PAYS

Moyenne
2006-2008

\section{Pays CAD}

\begin{tabular}{|c|c|c|c|c|c|c|}
\hline Allemagne & 477,0 & 955,5 & 970,4 & 1407,1 & 1490,5 & 1226,3 \\
\hline Australie & 44,7 & 92,1 & 84,4 & 90,0 & 108,6 & 69,5 \\
\hline Autriche & 15,3 & 37,0 & 35,1 & 22,7 & 26,9 & 33,5 \\
\hline Belgique & 45,5 & 147,1 & 43,9 & 53,1 & 57,2 & 50,9 \\
\hline Canada & 60,2 & 183,9 & 186,7 & 82,6 & 79,2 & 186,6 \\
\hline Corée & 6,2 & 6,0 & 12,9 & 16,9 & 7,8 & 13,9 \\
\hline Danemark & 13,2 & 50,4 & 54,4 & 49,9 & 40,9 & 37,4 \\
\hline Espagne & 41,0 & 257,0 & 25,0 & 20,5 & 23,4 & 22,2 \\
\hline États-Unis & 262,6 & 372,2 & 426,1 & 499,5 & 614,5 & 721,6 \\
\hline Finlande & 31,1 & 69,6 & 70,5 & 65,7 & 52,3 & 113,7 \\
\hline France & 104,9 & 216,9 & 200,3 & 154,6 & 286,0 & 232,4 \\
\hline Grèce & 0,8 & 0,2 & .. & .. &. & .. \\
\hline Hongrie & .. & .. & 1,9 & 0,0 &.. & .. \\
\hline Irlande & 2,5 & 6,7 & 8,5 & 2,6 & 6,6 & 9,8 \\
\hline Islande & .. & 1,7 & 7,5 & 6,6 & 7,2 & 7,4 \\
\hline Italie & 4,3 & 2,3 & 5,5 & 48,0 & 28,8 & 43,8 \\
\hline Japon & 233,9 & 156,8 & 257,6 & 415,4 & 278,0 & 558,6 \\
\hline Luxembourg & 7,4 & 13,6 & 13,7 & 13,8 & 20,9 & 18,9 \\
\hline Norvège & 115,4 & 125,4 & 190,7 & 275,0 & 237,7 & 280,7 \\
\hline Nouvelle-Zélande & 7,5 & 10,5 & 18,2 & 25,8 & 29,5 & 25,6 \\
\hline Pays-Bas & 309,2 & 332,7 & 478,3 & 436,2 & 497,7 & 395,1 \\
\hline Pologne & .. & .. & 0,4 & 0,4 & 0,3 & 0,2 \\
\hline Portugal & 1,3 & 1,2 & 1,2 & 0,8 & 0,8 & 0,7 \\
\hline République slovaque &. & .. & 0,0 & 0,0 & 0,0 & 0,2 \\
\hline République tchèque & .. & 0,0 & 0,4 & 0,8 & 0,1 & 0,0 \\
\hline Royaume-Uni & 287,1 & 409,9 & 466,5 & 1074,6 & 1060,0 & 1095,3 \\
\hline Slovénie & .. & 0,2 & 0,3 & 0,1 & 0,4 & 0,4 \\
\hline Suède & 153,5 & 177,9 & 229,1 & 154,0 & 193,5 & 231,3 \\
\hline Suisse & 94,0 & 101,9 & 131,5 & 170,0 & 178,5 & 115,5 \\
\hline Sous-total & 2318,6 & 3728,8 & 3920,9 & 5086,9 & 5327,2 & 5491,5 \\
\hline
\end{tabular}

\section{Autres donateurs bilatéraux}

\begin{tabular}{|c|c|c|c|c|c|c|}
\hline Arabie saoudite & .. &. & .. &.. &. &.. \\
\hline Azerbaïdjan & .. & .. & 0,1 & 0,1 & 1,8 & 2,3 \\
\hline Croatie & .. & .. & .. &.. & .. & 0,0 \\
\hline Émirats arabes unis & .. & 1,3 & 3,4 & 0,1 & 6,8 & 13,9 \\
\hline Estonie & .. &. & 0,1 & 0,2 & 0,1 & 0,7 \\
\hline Kazakhstan & .. &. & 0,1 & 0,7 & 1,8 & 0,1 \\
\hline Koweït & .. & 0,0 & 0,0 & .. & .. & .. \\
\hline Lettonie & .. &. & .. &.. &. & 0,0 \\
\hline Lituanie & .. &. & 0,0 & 0,1 & 0,0 & 0,1 \\
\hline Roumanie & .. & .. & .. & 0,0 & 0,0 &. \\
\hline Taipei chinois & .. &. & .. &. & .. & .. \\
\hline Thaïlande & .. & .. & .. &.. & 0,1 & .. \\
\hline Turquie & & 32,5 & .. &.. & .. & .. \\
\hline Sous-total & .. & 33,9 & 3,7 & 1,1 & 10,7 & 17,2 \\
\hline
\end{tabular}


Millions d'USD (constants de 2017)

Tableau A.17. Aide pour le commerce par donateur et par groupe de revenu, décaissements (page 6 sur 6 )

NON SPÉCIFIQUE À UN PAYS

Moyenne
$2006-2008$

Moyenne

2009-2011

Moyenne

2012-2014

2015

2016

2017

Donateurs multilatéraux

\begin{tabular}{|c|c|c|c|c|c|c|}
\hline BAfD & 39,6 & 395,6 & 104,3 & 91,5 & 142,7 & 148,7 \\
\hline Banque de développement des Caraïbes &. &.. &.. &.. &. & .. \\
\hline Banque islamique de développement &.. & .. & .. & .. &.. & .. \\
\hline Banque mondiale & 2,0 & 30,8 & 16,5 & 27,6 & 21,7 & 30,3 \\
\hline BAsD & .. & 0,0 & 12,5 & 29,4 & 37,8 & 31,7 \\
\hline $\mathrm{BID}$ & .. & 27,4 & 35,3 & 40,1 & 39,7 & 29,6 \\
\hline Cadre intégré renforcé (CIR) & .. & .. & .. & .. & .. & .. \\
\hline CEB & .. & .. & .. & .. & .. & .. \\
\hline CEE-ONU & 1,3 & 4,2 & 3,4 & 5,2 & 5,5 & 5,7 \\
\hline CESAO & 0,1 & 0,2 & 0,3 & 0,3 & 0,2 & 0,1 \\
\hline CESAP & 0,2 & 0,5 & 0,5 & 0,6 & 0,4 & 0,8 \\
\hline FAO & 131,7 & 273,6 & 271,7 & 316,7 & .. &. \\
\hline FIDA &. & .. & .. & .. & .. & .. \\
\hline $\mathrm{FMl}$ &. & .. & 0,0 &. &. & .. \\
\hline FODI &. & 1,9 & 1,9 & 5,6 & 2,2 & 37,8 \\
\hline Fonds arabe (FADES) & 0,4 & 3,8 & 4,5 & 2,1 & 1,9 & 6,1 \\
\hline Fonds d'investissement pour le climat &. & .. & 0,3 & 0,6 & .. & 3,6 \\
\hline Fonds pour l'environnement mondial & 16,9 & 23,5 & 24,8 & 29,6 & 24,0 & 9,7 \\
\hline Fonds vert pour le climat & .. & .. &. & .. & .. & .. \\
\hline Institutions de l'UE & 404,6 & 700,2 & 696,7 & 588,6 & 898,1 & 709,7 \\
\hline ITC & 29,6 & 51,9 & 58,0 & 66,2 & 54,9 & 52,8 \\
\hline OMC & 4,2 & 11,7 & 10,6 & 10,8 & 21,3 & 11,3 \\
\hline ONUDI & .. & .. &.. & .. & 17,5 & 25,2 \\
\hline Organisation mondiale du tourisme &.. & .. &.. & .. & 13,2 & 12,7 \\
\hline PNUD & .. & 3,9 & 3,4 & 1,4 & 0,0 & 0,5 \\
\hline Autres donateurs multilatéraux & 0,6 & 3,0 & 25,1 & 23,1 & 29,1 & 36,4 \\
\hline Sous-total & 631,0 & 1532,3 & 1269,7 & 1239,4 & 1310,3 & 1152,6 \\
\hline AIDE POUR LE COMMERCE TOTALE & 2949,6 & 5295,0 & 5194,3 & 6327,4 & 6648,2 & 6661,2 \\
\hline
\end{tabular}

Source: CAD de l'OCDE : base de données sur les activités d'aide (2019). 
Millions d'USD (constants de 2017)

Tableau A.18. Autres apports du secteur public liés au commerce, par catégorie

ENGAGEMENTS

Moyenne Moyenne Moyenne Moyenne 2015 2002-2005 2006-2008 2009-2011 2012-2014
DÉCAISSEMENTS

\begin{tabular}{l|l|l|l|l|l} 
Moyenne & Moyenne & Moyenne & 2015 & 2016 & 2017
\end{tabular} 2006-2008 2009-2011 2012-2014

\section{Politique et réglementation commerciales}

\begin{tabular}{|c|c|c|c|c|c|c|c|c|c|c|c|c|c|}
\hline $\begin{array}{l}\text { Politique commerciale } \\
\text { et gestion administrative }\end{array}$ & 285,1 & 138,1 & 283,9 & 267,7 & 138,3 & 938,6 & 609,3 & 56,0 & 150,8 & 73,6 & 53,6 & 76,7 & 72,4 \\
\hline Facilitation des échanges & 82,5 & 28,6 & 215,1 & 413,7 & 501,8 & 960,2 & 662,2 & 16,3 & 157,7 & 418,6 & 451,9 & 180,8 & 735,6 \\
\hline Accords commerciaux régionaux & 67,0 & 0,0 & 13,7 & 0,0 & & 4,3 & 32,0 & 0,0 & 15,1 & .. &.. & 4,3 & 4,7 \\
\hline $\begin{array}{l}\text { Négociations commerciales } \\
\text { multilatérales }\end{array}$ & .. & 11,7 & 3,2 & &.. & .. & & 11,2 &.. & &.. &.. & \\
\hline $\begin{array}{l}\text { Éducation/ formation dans } \\
\text { le domaine du commerce }\end{array}$ & .. & .. & .. & 214,9 & 250,1 & 73,1 & 0,0 & .. &.. & 7,4 & 4,3 & 4,7 & 5,4 \\
\hline Sous-total & 434,5 & 178,4 & 515,9 & 896,3 & 890,2 & 1976,2 & 1303,5 & 83,5 & 323,6 & 499,6 & 509,9 & 266,5 & 818,2 \\
\hline \multicolumn{14}{|l|}{ Infrastructure économique } \\
\hline Transport et entreposage & 5659,5 & 8301,3 & 11813,2 & 11885,3 & 13795,4 & 11873,4 & 13735,0 & 2633,1 & 6968,0 & 7888,5 & 9391,7 & 9914,7 & 9269,3 \\
\hline Communications & 612,1 & 692,7 & 687,8 & 1245,5 & 1161,8 & 1514,1 & 955,1 & 343,0 & 705,9 & 861,7 & 615,0 & 1315,7 & 509,6 \\
\hline Production et distribution d'énergie & 2187,0 & 6075,5 & 12486,2 & 10414,8 & 13567,0 & 21940,7 & 15243,3 & 1216,3 & 6386,8 & 6038,8 & 11308,0 & 9943,7 & 10829,2 \\
\hline Sous-total & 8458,6 & 15069,4 & 24987,2 & 23545,6 & 28524,3 & 35328,3 & 29933,4 & 4192,4 & 14060,7 & 14789,0 & 21314,7 & 21174,1 & 20608,1 \\
\hline
\end{tabular}

Renforcement des capacités de production

\begin{tabular}{|c|c|c|c|c|c|c|c|c|c|c|c|c|c|}
\hline Entreprises et autres services & 579,4 & 1318,6 & 2043,6 & 690,2 & 1891,5 & 1134,2 & 1648,9 & 715,3 & 1375,5 & 653,8 & 1054,0 & 1075,3 & 821,3 \\
\hline Banque et services financiers & 2409,7 & 2592,2 & 8203,0 & 11328,9 & 15518,4 & 11303,4 & 9906,1 & 1688,8 & 7345,4 & 6187,7 & 9471,3 & 8292,1 & 8876,8 \\
\hline Agriculture & 1219,9 & 1128,7 & 2073,0 & 2337,6 & 2552,6 & 3164,2 & 4686,3 & 717,3 & 1107,6 & 1392,2 & 1382,0 & 1630,7 & 1955,5 \\
\hline Sylviculture & 84,9 & 68,1 & 323,2 & 303,5 & 128,1 & 296,3 & 144,6 & 52,1 & 174,0 & 197,3 & 149,8 & 180,3 & 178,4 \\
\hline Pêche & 7,7 & 1,5 & 46,9 & 206,3 & 119,9 & 81,7 & 84,5 & 1,6 & 21,3 & 31,5 & 100,1 & 112,3 & 100,6 \\
\hline Industrie & 1576,6 & 4210,8 & 4185,8 & 6433,1 & 8933,7 & 12186,4 & 7968,5 & 2041,8 & 4003,3 & 5041,1 & 8210,6 & 8871,3 & 5827,7 \\
\hline Industries extractives & 260,5 & 897,1 & 1932,8 & 1711,5 & 3295,4 & 1669,2 & 4573,8 & 657,1 & 1454,1 & 995,3 & 1660,7 & 2024,1 & 647,4 \\
\hline Tourisme & 114,3 & 80,6 & 241,6 & 243,9 & 208,1 & 250,6 & 192,6 & 53,8 & 94,9 & 105,7 & 121,4 & 139,5 & 217,0 \\
\hline Sous-total & 6253,0 & 10297,6 & 19049,9 & 23255,0 & 32647,6 & 30085,9 & 29205,4 & 5927,9 & 15576,1 & 14604,7 & 22149,8 & 22325,7 & 18624,7 \\
\hline $\begin{array}{l}\text { TOTAL DES AUTRES APPORTS } \\
\text { DU SECTEUR PUBLIC LIÉS } \\
\text { AU COMMERCE }\end{array}$ & 15146,2 & 25545,5 & 44553,0 & 47696,9 & 62062,1 & 67390,4 & 60442,3 & 10203,9 & 29960,4 & 29893,3 & 43974,4 & 43766,3 & 40051,1 \\
\hline
\end{tabular}

Part dans le total

\begin{tabular}{|c|c|c|c|c|c|c|c|c|c|c|c|c|c|}
\hline $\begin{array}{l}\text { Politique et réglementation } \\
\text { commerciales }\end{array}$ & $2,9 \%$ & $0,7 \%$ & $1,2 \%$ & $1,9 \%$ & $1,4 \%$ & $2,9 \%$ & $2,2 \%$ & $0,8 \%$ & $1,1 \%$ & $1,7 \%$ & $1,2 \%$ & $0,6 \%$ & $2,0 \%$ \\
\hline Infrastructure économique & $55,8 \%$ & $59,0 \%$ & $56,1 \%$ & $49,4 \%$ & $46,0 \%$ & $52,4 \%$ & $49,5 \%$ & $41,1 \%$ & $46,9 \%$ & $49,5 \%$ & $48,5 \%$ & $48,4 \%$ & $51,5 \%$ \\
\hline $\begin{array}{l}\text { Renforcement des capacités } \\
\text { de production }\end{array}$ & $41,3 \%$ & $40,3 \%$ & $42,8 \%$ & $48,8 \%$ & $52,6 \%$ & $44,6 \%$ & $48,3 \%$ & $58,1 \%$ & $52,0 \%$ & $48,9 \%$ & $50,4 \%$ & $51,0 \%$ & $46,5 \%$ \\
\hline $\begin{array}{l}\text { Part dans les autres apports } \\
\text { du secteur public ventilable } \\
\text { par secteur }\end{array}$ & $45,7 \%$ & $63,7 \%$ & $64,8 \%$ & $71,9 \%$ & $69,7 \%$ & $73,1 \%$ & $64,1 \%$ & $59,4 \%$ & $61,6 \%$ & $68,9 \%$ & $70,4 \%$ & $71,1 \%$ & $73,1 \%$ \\
\hline $\begin{array}{l}\text { Part dans le total des autres } \\
\text { apports du secteur public }\end{array}$ & $43,4 \%$ & $58,5 \%$ & $61,9 \%$ & $69,1 \%$ & $66,9 \%$ & $69,7 \%$ & $60,6 \%$ & $44,4 \%$ & $56,9 \%$ & $61,7 \%$ & $60,3 \%$ & $66,0 \%$ & $65,8 \%$ \\
\hline
\end{tabular}


Millions d'USD (constants de 2017)

Tableau A.19. Autres apports du secteur public liés au commerce, par fournisseur

ENGAGEMENTS

Moyenne Moyenne Moyenne Moyenne 2015

2002-2005 2006-2008 2009-2011 2012-2014
DÉCAISSEMENTS

\begin{tabular}{l|l|l|l|l|l} 
Moyenne & Moyenne & Moyenne & 2015 & 2016 & 2017
\end{tabular} 2006-2008 2009-2011 2012-2014

\begin{tabular}{|c|c|c|c|c|c|c|c|c|c|c|c|c|c|}
\hline \multicolumn{14}{|l|}{ Pays CAD } \\
\hline Allemagne &.. & 1036,1 & 1074,8 & 1041,7 & 888,6 & 748,2 & 920,4 & 850,4 & 1172,5 & 1067,9 & 956,8 & 773,1 & 945,5 \\
\hline Australie & .. & 0,9 & 13,6 & 28,9 & 11,9 & 14,9 & 9,0 & 2,7 & 13,6 & 28,9 & 11,9 & 14,9 & 9,0 \\
\hline Autriche & 1,4 & .. &.. & 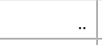 & .. & 95,4 & 61,3 &.. & .. &.. & .. & 182,1 & 86,8 \\
\hline Belgique &.. &.. & 0,0 & 49,9 & 90,8 & 5,7 & 186,7 &.. &.. & 93,4 & 90,8 & 162,8 & 143,7 \\
\hline Canada & .. &.. & 4,0 & 16,1 &.. & .. & & & 4,0 & 16,1 & & & .. \\
\hline Corée & .. & 1866,9 & 4382,9 & 6216,1 & 11896,1 & 8704,1 & 6642,5 & 1703,9 & 3793,2 & 5549,2 & 12742,9 & 9191,9 & 6046,0 \\
\hline Danemark & 7,2 &.. &.. &.. &.. & 97,4 & 70,6 &.. &.. & 13,2 & 32,2 & 49,8 & 46,3 \\
\hline Espagne & .. & 2,1 & & 4,4 & 0,0 & .. & 1,4 &.. &.. & 4,9 & 0,0 & .. & 1,4 \\
\hline États-Unis & 189,0 & 399,4 & 733,6 & 469,0 & 349,4 & 1203,3 & 353,5 & 126,7 & 362,6 & 261,3 & 296,9 & 424,5 & 675,9 \\
\hline Finlande & 16,0 & 30,0 & 41,0 & 31,7 & 42,4 & 77,4 & 162,5 & 29,8 & 40,0 & 26,3 & 46,0 & 66,2 & 90,6 \\
\hline France & 235,2 & 279,9 & 912,4 & 1240,7 & 892,7 & 894,0 & 1049,3 & 263,0 & 622,6 & 973,5 & 1116,3 & 956,3 & 833,7 \\
\hline Grèce & .. & 1,3 &.. &.. &.. &.. & .. & 1,3 &.. &.. &.. &.. & .. \\
\hline Italie & .. &.. & 0,4 & 1,6 &. &.. & .. &.. & 0,4 &.. &.. & 2,4 &.. \\
\hline Japon & 921,7 & 1380,7 &.. &.. &.. & 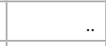 & .. & 25,1 & .. & .. &.. & .. &.. \\
\hline Norvège & .. &.. &.. & 109,5 & 578,8 & 584,2 & 460,6 &.. &.. & 125,6 & 779,2 & 179,8 & 136,1 \\
\hline Pays-Bas & 7,9 &.. &.. &.. &.. & .. & .. &.. &.. &.. &.. & .. & .. \\
\hline Pologne & .. &.. &.. &.. & .. &.. & 0,0 &.. & .. &.. & .. & .. & 0,0 \\
\hline Portugal & .. &.. & 0,4 & 2,8 & 2,3 & 1,1 & 2,3 &.. & 0,4 & 2,2 & 1,5 & 1,7 & 1,1 \\
\hline Royaume-Uni & 183,4 & 13,2 & 102,2 & 63,4 &.. & .. & .. &.. & 102,2 & 63,4 &.. & 869,1 & .. \\
\hline Suède & 1,6 & 0,0 &.. & 45,2 & 55,8 & 21,7 & 46,8 & 0,1 &.. & 32,7 & 37,4 & .. & 51,7 \\
\hline Suisse & .. &.. &.. & 6,6 &.. & .. & .. &.. &.. & 6,6 & 26,1 & 16,9 & 98,9 \\
\hline Sous-total & 1563,3 & 5010,5 & 7265,2 & 9327,7 & 14808,8 & 12447,6 & 9966,8 & 3002,9 & 6111,3 & 8265,2 & 16138,2 & 12891,4 & 9166,8 \\
\hline \multicolumn{14}{|l|}{ Autres donateurs bilatéraux } \\
\hline Arabie saoudite & .. &.. &.. &. &.. &.. & 30,0 &.. &.. &.. &.. & .. & .. \\
\hline Émirats arabes unis & .. &.. &.. &. &.. & .. & &.. & 12,7 & 21,1 & 33,8 & 0,8 & .. \\
\hline Estonie &.. &.. &.. &. &.. &.. & 0,1 &.. &. &.. &.. & .. & 0,1 \\
\hline Koweït &.. &.. &.. &. &.. &.. & &.. &.. &.. &.. & .. & 0,2 \\
\hline Sous-total & .. &.. &.. & & & .. & 30,1 & .. & 12,7 & 21,1 & 33,8 & 0,8 & 0,3 \\
\hline \multicolumn{14}{|l|}{ Donateurs multilatéraux } \\
\hline BAfD & 337,9 & 938,4 & 3519,2 & 1788,8 & 3261,7 & 4530,8 & 3729,6 & 487,2 & 2129,5 & 2108,4 & 1994,2 & 2674,2 & 3727,3 \\
\hline $\begin{array}{l}\text { Banque asiatique d'investissement } \\
\text { dans les infrastructures }\end{array}$ & .. &.. & $\cdot$ &.. &. & 1214,2 & 1618,0 &. &. & 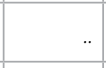 & 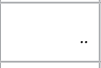 & 9,9 & 691,3 \\
\hline $\begin{array}{l}\text { Banque de développement } \\
\text { des Caraïbes }\end{array}$ & .. &. &.. &.. & 9,1 & 95,4 & 113,1 &. &.. & &. & .. & .. \\
\hline $\begin{array}{l}\text { Banque européenne pour la } \\
\text { reconstruction et le développement }\end{array}$ & & 0,0 & 3771,5 & 4107,1 & 7033,4 & 5694,8 & 5335,1 &. & 2657,9 & 3199,9 & 4698,5 & 5425,8 & 3318,3 \\
\hline $\begin{array}{l}\text { Banque islamique } \\
\text { de développement }\end{array}$ & 520,5 & 1218,0 & 2313,4 & 2581,5 & 3150,4 & 7476,3 & 7839,5 &. &. &. &. &. &. \\
\hline Banque mondiale & 5628,1 & 7124,9 & 14600,5 & 8887,2 & 11022,3 & 10143,6 & 8571,2 & 5280,7 & 9275,6 & 7331,1 & 9782,9 & 10123,6 & 8230,6 \\
\hline BAsD & 3350,6 & 3785,2 & 4451,9 & 6333,8 & 8595,8 & 6836,4 & 13357,6 &.. & 2175,5 & 3897,5 & 4999,4 & 7154,7 & 7247,9 \\
\hline BID & 1734,9 & 2687,9 & 5184,2 & 4997,6 & 4168,9 & 3706,4 & 4258,6 &.. & 4048,6 & 3468,3 & 5076,3 & 3196,7 & 3813,4 \\
\hline CEB & .. &.. & 150,5 & 206,3 & 132,6 & .. & 408,6 &.. & 133,5 & 205,3 & 234,8 & 216,5 & 129,1 \\
\hline FIDA & 22,4 & 35,1 & 64,3 & 88,5 & 268,2 & 168,8 & 74,2 &.. &.. &.. & 4 &.. & .. \\
\hline FODI & & 0,0 & 451,2 & 563,3 & 499,9 & 627,0 & 709,0 &.. & 368,6 & 487,1 & 524,8 & 358,6 & 522,8 \\
\hline $\begin{array}{l}\text { Fonds d'investissement } \\
\text { pour le climat }\end{array}$ & .. &.. &.. &.. &. & .. & .. &.. & .. & 38,5 & .. & 10,3 & .. \\
\hline Fonds vert pour le climat & & 0,0 & 0,0 & 0,0 & 20,3 & 555,8 & 628,0 &.. &. &.. &.. &.. & .. \\
\hline IDB Invest & & 0,0 & 0,0 & 0,0 & & 1910,9 & 2478,9 &.. &.. &.. &.. & .. & 1858,4 \\
\hline Institutions de l'UE & 1988,4 & 4745,4 & 2781,0 & 948,5 & 655,1 & 1575,4 & 1323,9 & 1438,0 & 3047,2 & 870,8 & 491,6 & 1704,0 & 1344,9 \\
\hline Société financière internationale & & 0,0 & 0,0 & 7866,6 & 8435,5 & 10406,8 & &. &. &.. &.. &. & .. \\
\hline Sous-total & 13582,9 & 20534,9 & 37287,8 & 38369,2 & 47253,3 & 54942,8 & 50445,3 & 7205,9 & 23836,4 & 21607,0 & 27802,4 & 30874,1 & 30884,0 \\
\hline $\begin{array}{l}\text { TOTAL DES AUTRES APPORTS } \\
\text { DU SECTEUR PUBLIC } \\
\text { LIÉS AU COMMERCE }\end{array}$ & 15146,2 & 25545,5 & 44553,0 & 47696,9 & 62062,1 & 67390,4 & 60442,3 & 10208,8 & 29960,4 & 29893,3 & 43974,4 & 43766,3 & 40051,1 \\
\hline
\end{tabular}


Tableau A.20. Autres apports du secteur public liés au commerce par pays bénéficiaire (page 1 sur 4)

\section{ENGAGEMENTS}

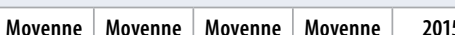

\begin{tabular}{l|l|l|l|l|}
$2002-2005$ & $2006-2008$ & $2009-2011$ & $2012-2014$
\end{tabular}

Afghanistan

Afrique du Sud

Albanie

Algérie

Angola

Antigua-et-Barbuda

Argentine

Arménie

Azerbaïdjan

Bangladesh

Bélarus

Belize

Bénin

Bhoutan

Bolivie

Bosnie-Herzégovine

Botswana

Brésil

Burkina Faso

Cabo Verde

Cambodge

Cameroun

Chili

Chine (République populaire de)

Cisjordanie et bande de Gaza

Colombie

Comores

Congo

Costa Rica

Côte d'Ivoire

Cuba

Dominique

Djibouti

Égypte

El Salvador

Équateur

Eswatini

Éthiopie

Fidji

Gabon

Gambie

Géorgie

8,0

\begin{tabular}{|r|r|r|r|r|r|r|r|}
\hline 8,9 & 26,0 & 22,8 & 24,8 & 3,2 & 3,5 &.. \\
\hline 143,4 & 178,0 & 2698,5 & 306,6 & 260,4 & 853,6 & 81,7 \\
\hline 11,5 & 41,7 & 173,1 & 248,6 & 92,4 & 285,9 & 195,2 & \\
\hline 112,7 & 0,0 & 202,8 & 95,0 & 473,9 & 0,0 & $\ldots$ \\
\hline
\end{tabular}

DÉCAISSEMENTS

\begin{tabular}{|c|c|c|c|c|c|}
\hline Moyenne & Moyenne & Moyenne & 2015 & 2016 & 2017 \\
\hline
\end{tabular}

2006-2008 2009-2011 2012-2014

\begin{tabular}{|r|r|r|r|r|r|}
\hline 14,4 & 19,2 & 5,5 & 3,1 & 0,5 & $\cdots$ \\
\hline 22,3 & 980,4 & 1167,1 & 587,9 & 645,2 & 812,3 \\
\hline
\end{tabular}

\begin{tabular}{|r|r|r|r|r|r|r|r|r|r|r|r|r|r|}
\hline.. & 6,3 & 28,1 & 326,1 & 4,6 & 148,4 & 370,4 & 3,0 & 29,2 & 190,7 & 0,1 & 439,6 & 149,7 \\
\hline
\end{tabular}

\begin{tabular}{|r|r|r|r|r|r|r|r|r|r|r|r|r|}
\hline.. &.. &. &.. &.. & 6,1 & 48,3 &.. &.. &.. &.. &.. &.. \\
\hline 525,5 & 1357,1 & 829,1 & 511,1 & 397,2 & 1422,7 & 1547,2 & 165,5 & 971,6 & 728,0 & 662,5 & 611,4 & 953,1 \\
\hline.. & 14,8 & 231,1 & 224,7 & 476,1 & 288,3 & 198,6 & 15,5 & 145,3 & 112,6 & 203,1 & 267,0 & 207,5 \\
\hline
\end{tabular}

\begin{tabular}{|l|l|l|l|l|l|l|l|l|l|l|l|l|}
\hline 23,9 & 483,9 & 476,1 & 646,5 & 801,4 & 1264,4 & 1405,0 & 30,9 & 252,0 & 469,6 & 504,4 & 935,2 & 1144,9 \\
\hline
\end{tabular}

\begin{tabular}{|r|r|r|r|r|r|r|r|r|r|r|r|r|}
\hline 113,1 & 253,0 & 461,7 & 727,4 & 1193,6 & 1556,7 & 2461,3 & 13,3 & 107,9 & 310,3 & 377,8 & 498,3 & 550,9 \\
\hline.. & 23,8 & 192,7 & 318,4 & 89,4 & 91,5 & 173,4 & 10,7 & 68,4 & 281,0 & 77,7 & 128,3 & 233,4 \\
\hline
\end{tabular}

\begin{tabular}{|r|r|r|r|r|r|r|r|r|r|r|r|r|r|r|}
\hline 2,4 & 0,9 & 7,4 & 15,1 & 15,2 & 19,3 &.. & 0,0 & 3,3 & 5,7 & 3,9 & 3,2 & 6,4 \\
\hline 8,0 &.. & 6,8 & 67,5 & 118,9 & 17,0 & 117,6 &.. &.. & 5,3 & 0,2 & 17,0 & .. \\
\hline
\end{tabular}

\begin{tabular}{|r|r|r|r|r|r|r|}
\hline.. &.. & 16,4 & 8,9 & 80,5 &.. &.. \\
\hline 13,4 & 10,9 & 39,0 & 14,2 & 261,3 & 30,2 & 310,5 \\
\hline 50,6 & 182,4 & 191,2 & 224,1 & 164,4 & 356,7 & 202,2 \\
\hline 13,1 & 2,1 & 694,1 & 0,6 & 23,0 &.. & 134,0 \\
\hline 1701,0 & 1397,9 & 2704,8 & 2588,6 & 1297,5 & 2587,6 & 1916,3 \\
\hline
\end{tabular}

\begin{tabular}{|r|r|r|r|r|}
\hline 11,2 & 2,1 & 0,0 & 11,1 & 4,2 \\
\hline 3,1 & 6,6 & 53,8 & 27,0 & 18,1 \\
\hline
\end{tabular}

\begin{tabular}{|l|l|l|l|l|l|}
\hline 56,7 & 224,4 & 222,4 & 209,3 & 117,3 & 70,6 \\
\hline
\end{tabular}

\begin{tabular}{|l|l|l|l|l|l|}
\hline 2,1 & 333,1 & 23,7 & 11,8 & 31,5 & 4,5 \\
\hline
\end{tabular}

\begin{tabular}{|r|r|r|r|r|r|r|r|r|r|r|r|r|}
\hline 1701,0 & 1397,9 & 2704,8 & 2588,6 & 1297,5 & 2587,6 & 1916,3 & 520,5 & 2201,4 & 1276,8 & 2181,9 & 1874,8 & 2713,9 \\
\hline 2,4 & 5,0 & 10,3 & 77,6 & 207,5 & 338,6 & 479,7 &.. & 1,4 &.. & 14,1 & 49,0 & 83,6 \\
\hline.. & 19,4 & 32,8 & 40,3 &.. &.. &.. &.. & 38,1 & 14,4 & 14,2 & 6,5 & 10,3 \\
\hline
\end{tabular}

\begin{tabular}{|l|r|r|r|r|r|r|r|r|r|r|r|r|}
\hline 5,2 & 1,4 & 21,2 & 128,2 & 144,3 & 365,9 & 117,0 & 4,6 & 17,6 & 63,3 & 105,6 & 95,2 & 171,1 \\
\hline
\end{tabular}

\begin{tabular}{|r|r|r|r|r|r|r|r|r|r|r|r|r|}
\hline 4,4 & 10,1 & 46,5 & 106,0 & 794,3 & 881,7 & 496,3 & 17,0 & 41,7 & 33,9 & 62,1 & 33,1 & 115,4 \\
\hline 58,3 & 260,6 & 139,5 & 463,5 & 319,9 & 555,0 & 336,6 & 64,3 & 177,1 & 183,0 & 318,0 & 107,6 & 271,6 \\
\hline 2159,9 & 3023,2 & 3560,6 & 4396,0 & 5822,1 & 5173,4 & 4862,1 & 1578,6 & 2814,5 & 3453,2 & 5204,5 & 4438,2 & 4876,2 \\
\hline
\end{tabular}

\begin{tabular}{|r|r|r|r|r|r|r|r|r|r|r|r|r|}
\hline 2159,9 & 3023,2 & 3560,6 & 4396,0 & 5822,1 & 5173,4 & 4862,1 & 1578,6 & 2814,5 & 3453,2 & 5204,5 & 4438,2 & 4876,2 \\
\hline.. & 124,0 & 11,2 & 16,3 & 0,3 & 53,5 & 13,6 &.. &.. & 9,8 & 9,0 & 10,2 & 8,3 \\
\hline
\end{tabular}

\begin{tabular}{|r|r|r|r|r|r|r|r|r|r|r|r|r|}
\hline.. & 124,0 & 11,2 & 16,3 & 0,3 & 53,5 & 13,6 &.. &.. & 9,8 & 9,0 & 10,2 & 8,3 \\
\hline 367,3 & 459,3 & 717,8 & 704,3 & 1427,7 & 1848,5 & 1394,4 & 312,4 & 452,3 & 444,4 & 880,9 & 1876,8 & 910,5 \\
\hline.. &.. & 1,6 &.. &.. & 20,4 & 22,0 &.. & 0,8 &.. &.. &.. &.. \\
\hline
\end{tabular}

\begin{tabular}{|r|r|r|r|r|r|r|r|r|r|r|r|r|}
\hline.. &.. & 1,6 &.. &.. & 20,4 & 22,0 &.. & 0,8 &.. &.. &.. &.. \\
\hline.. & 0,6 &.. & 6,9 & 134,9 & 84,6 &.. &.. &.. & 0,0 & 0,1 & 0,1 & 28,5 \\
\hline 54,0 & 32,0 & 110,7 & 387,0 & 397,8 & 204,1 & 102,6 & 21,8 & 165,9 & 245,4 & 280,8 & 129,4 & 304,8 \\
\hline
\end{tabular}


Millions d'USD (constants de 2017)

Tableau A.20. Autres apports du secteur public liés au commerce par pays bénéficiaire (page 2 sur 4)

ENGAGEMENTS

\begin{tabular}{c|c|c|c|c} 
Moyenne & Moyenne & Moyenne & Moyenne & 2015 \\
\hline $2002-2005$ & $2006-2008$ & $2009-2011$ & $2012-2014$ &
\end{tabular}

Ghana

Grenade

Guatemala

Guinée

Guinée-Bissau

Guinée équatoriale

Guyana

Haïti

Honduras

Inde

Indonésie

Iran

Iraq

Jamaïque

Jordanie

îles Cook

îles Marshall

îles Salomon

Kazakhstan

Kenya

Kirghizistan

Kiribati

Kosovo

Lesotho

Liban

Libéria

Libye

Macédoine du Nord

Madagascar

Malaisie

Malawi

Maldives

Mali

Maroc

Maurice

Mauritanie

Mexique

Micronésie

Moldova

Mongolie

Monténégro

Mozambique

Myanmar

\begin{tabular}{|c|c|}
\hline .. & .. \\
\hline .. & 5,9 \\
\hline
\end{tabular}

15,4

\begin{tabular}{|r|r|r|r|r|r|r|r|r|r|r|r|r|r|}
\hline 3,9 & 96,1 & 80,7 & 170,1 & 105,6 & 546,8 & 147,7 & 33,7 & 54,7 & 85,1 & 79,2 & 37,4 & 114,3 \\
\hline 0,5 &.. & 4,2 &.. & 12,7 &.. & 5,5 & 0,0 & 1,8 & 1,4 & 6,1 & 1,5 & 6,3 \\
\hline 189,4 & 55,1 & 98,4 & 83,4 & 80,2 & 403,3 & 192,4 & 74,2 & 117,6 & 76,0 & 89,4 & 22,1 & 175,1 \\
\hline 6,8 &.. & 3,3 & 56,0 & 138,7 & 357,9 & 39,6 &.. &.. & 0,1 & 0,7 &.. & 2,8 \\
\hline 0,5 &.. &.. &.. &.. &.. &.. &.. &.. &.. &.. &.. &.. \\
\hline
\end{tabular}

\section{DÉCAISSEMENTS}

\begin{tabular}{|l|l|l|l|l|l|}
\hline Moyenne & Moyenne & Moyenne & 2015 & 2016 & 2017 \\
\hline
\end{tabular} \begin{tabular}{c|c|c|c|c} 
Moyenne & Moyenne & Moyenne \\
$2006-2008$ & $2009-2011$ & $2012-2014$
\end{tabular}

\begin{tabular}{|r|r|r|r|r|r|r|r|r|r|r|r|r|}
\hline.. & 0,2 & 3,7 & 33,9 & 6,0 & 0,7 & 0,5 &.. & 2,5 & 5,4 & 4,2 & 0,2 & 0,2 \\
\hline 3,1 & 68,9 & 27,9 & 101,6 & 233,2 & 110,5 & 48,6 & 4,2 & 20,3 & 50,7 & 159,3 & 167,8 & 74,9 \\
\hline 2307,7 & 2217,5 & 4343,4 & 3672,3 & 4236,9 & 4561,7 & 6139,0 & 1116,2 & 2631,2 & 2070,6 & 2659,6 & 4047,6 & 3402,0 \\
\hline
\end{tabular}

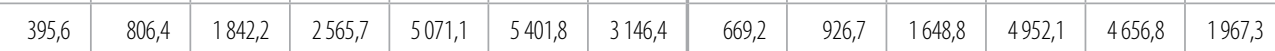

\begin{tabular}{|r|r|r|r|r|r|r|r|r|r|r|r|r|}
\hline 193,9 & 131,8 & 298,9 & 93,9 &.. & 105,5 & 13,3 & 34,0 & 16,0 & 4,5 &.. & 0,0 & 13,3 \\
\hline 14,2 & 249,1 & 110,6 & 349,6 & 954,1 & 494,3 & 168,0 & 18,9 & 58,3 & 114,1 & 827,8 & 182,2 & 151,5 \\
\hline
\end{tabular}

\begin{tabular}{|r|r|r|r|r|r|r|r|r|r|r|r|r|}
\hline 14,2 & 249,1 & 110,6 & 349,6 & 954,1 & 494,3 & 168,0 & 18,9 & 58,3 & 114,1 & 827,8 & 182,2 & 151,5 \\
\hline 29,7 & 31,6 & 207,2 & 107,9 & 248,5 & 162,4 & 88,2 & 0,9 & 133,4 & 89,7 & 107,0 & 152,2 & 101,0 \\
\hline
\end{tabular}

\begin{tabular}{|r|r|r|r|r|r|r|}
\hline 29,7 & 31,6 & 207,2 & 107,9 & 248,5 & 162,4 & 88,2 \\
\hline 21,3 & 118,0 & 250,4 & 271,7 & 401,8 & 904,6 & 384,5 \\
\hline
\end{tabular}


Tableau A.20. Autres apports du secteur public liés au commerce par pays bénéficiaire (page 3 sur 4)

ENGAGEMENTS

\begin{tabular}{|c|c|c|c|c|c|c|c|c|c|c|c|c|c|}
\hline & $\begin{array}{l}\text { Moyenne } \\
2002-2005\end{array}$ & $\begin{array}{l}\text { Moyenne } \\
2006-2008\end{array}$ & $\begin{array}{c}\text { Moyenne } \\
2009-2011\end{array}$ & $\begin{array}{l}\text { Moyenne } \\
2012-2014\end{array}$ & 2015 & 2016 & 2017 & $\begin{array}{l}\text { Moyenne } \\
2006-2008\end{array}$ & $\begin{array}{l}\text { Moyenne } \\
\text { 2009-2011 }\end{array}$ & \begin{tabular}{c|} 
Moyenne \\
$2012-2014$
\end{tabular} & 2015 & 2016 & 2017 \\
\hline Namibie & 20,4 & 15,6 & 33,4 & 92,1 & 101,8 & 357,7 & 255,8 & 20,9 & 33,8 & 24,2 & 94,7 & 205,5 & 379,2 \\
\hline Nauru &. &. &.. &.. &. & 0,0 & .. &. &.. &.. &.. & 0,0 &. \\
\hline Népal &. &. &.. & 21,7 & 3,1 &.. & .. &. &.. &.. & 0,0 &.. & .. \\
\hline Nicaragua & 2,8 & 35,2 & 43,7 & 86,1 & 12,4 & 86,5 & 93,4 & 14,0 & 17,0 & 47,1 & 32,2 & 26,2 & 61,9 \\
\hline Niger & 2,4 & 6,2 & 7,4 & 28,1 & 31,8 & 146,2 & 34,5 &. & 6,0 & 5,6 & 0,0 & 23,9 & 7,7 \\
\hline Nigéria & 52,1 & 127,4 & 211,7 & 931,7 & 896,2 & 843,1 & 523,2 & 25,7 & 150,6 & 322,5 & 559,8 & 398,7 & 692,5 \\
\hline Ouganda & 2,9 & 96,7 & 24,0 & 195,4 & 531,0 & 143,8 & 50,4 & 29,2 & 63,2 & 50,4 & 37,3 & 29,2 & 31,8 \\
\hline Ouzbékistan & 123,7 & 93,8 & 368,8 & 1113,7 & 792,4 & 386,2 & 526,4 & 29,9 & 61,3 & 406,2 & 729,3 & 394,0 & 272,7 \\
\hline Pakistan & 687,2 & 851,2 & 657,2 & 1041,3 & 1074,4 & 2993,8 & 3439,0 & 138,2 & 300,2 & 420,7 & 452,1 & 808,2 & 1158,7 \\
\hline Palaos &. &. &. &.. & 0,3 & 17,2 & 0,2 &. &. &.. & 0,3 & 6,3 & 6,2 \\
\hline Panama & 33,4 & 255,4 & 512,7 & 309,7 & 694,2 & 1049,7 & 400,3 & 18,0 & 238,6 & 495,0 & 612,3 & 497,3 & 677,5 \\
\hline Papouasie-Nouvelle-Guinée & 16,4 & 31,0 & 32,4 & 119,7 & 56,8 & 102,2 & 540,9 & 10,3 & 9,6 & 54,1 & 76,3 & 100,0 & 84,1 \\
\hline Paraguay & 9,7 & 164,9 & 118,8 & 273,7 & 367,8 & 258,1 & 325,4 & 18,9 & 118,9 & 143,7 & 190,4 & 135,3 & 186,4 \\
\hline Pérou & 258,1 & 410,0 & 564,3 & 653,2 & 419,0 & 1062,6 & 357,6 & 159,8 & 572,4 & 211,8 & 681,5 & 198,8 & 187,4 \\
\hline Philippines & 109,3 & 1119,1 & 201,1 & 702,1 & 1488,5 & 272,6 & 552,2 & 143,0 & 174,1 & 299,3 & 1097,1 & 711,6 & 183,7 \\
\hline République arabe syrienne & 203,5 & 84,8 & 72,4 &.. & .. &.. & .. &. & 47,3 &. &.. &. & .. \\
\hline République démocratique du Congo &. &.. &.. & 67,9 & 76,6 &.. & 7,8 &. & 2,2 & 10,1 & 53,3 & 34,0 & .. \\
\hline $\begin{array}{l}\text { République démocratique populaire } \\
\text { de Corée }\end{array}$ &. &. & 0,2 & 1,1 & .. &. &. &. & 0,2 & 1,1 &. & .. & .. \\
\hline $\begin{array}{l}\text { République démocratique populaire } \\
\text { lao }\end{array}$ & 24,8 & 9,5 & 7,4 & 85,8 & 145,7 & 28,2 & 63,8 & 11,5 & 10,0 & 31,5 & 6,5 & 14,1 & 52,7 \\
\hline République dominicaine & 126,7 & 34,6 & 356,4 & 213,0 & 232,0 & 182,4 & 127,8 & 46,2 & 202,3 & 70,6 & 344,2 & 38,7 & 45,9 \\
\hline Rwanda & 3,4 & 2,9 & 28,1 & 39,4 & 40,8 & 33,0 & 33,8 & 0,3 & 7,5 & 21,9 & 5,5 & 19,1 & 17,3 \\
\hline Sainte-Lucie & 0,9 & 0,1 & 0,5 &. &. & 10,8 &. & 0,1 & 0,5 & 0,0 &. & ." &. \\
\hline Saint-Vincent-et-les Grenadines & 1,4 &. &. &. &. &. &. & 0,9 & 0,0 & 0,0 &.. &.. & .. \\
\hline Samoa & &.. &. &. & 0,1 & 0,1 & 2,0 &.. &.. &. & 0,1 & 0,1 & 2,7 \\
\hline Sao Tomé-et-Principe & .. &.. &.. &.. &. &. & .. &.. &.. & 0,6 &.. & 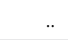 & .. \\
\hline Sénégal & 15,4 & 18,6 & 158,9 & 97,8 & 410,6 & 1014,7 & 461,4 & 7,0 & 23,9 & 55,7 & 106,5 & 89,2 & 153,0 \\
\hline Serbie & 23,4 & 200,4 & 924,8 & 583,2 & 711,7 & 212,0 & 541,1 & 12,8 & 603,8 & 412,2 & 575,8 & 561,4 & 370,6 \\
\hline Seychelles &. &.. & 12,0 & 2,5 & 11,4 & 5,1 & 5,0 &. & 5,1 & 4,7 & 2,5 & 16,4 & 6,7 \\
\hline Sierra Leone &. &.. & 7,6 & 8,4 &. & 45,7 & 129,5 &. &. & 17,2 &. & 18,3 & 0,3 \\
\hline Somalie &. &.. &.. &.. & & 0,4 &. &. &.. &.. &. & 0,2 & \\
\hline Soudan & 18,3 & 45,5 & 65,5 & 56,5 &.. & 12,4 &. & 2,4 & 23,8 & 7,0 &. &. & .. \\
\hline Soudan du Sud &. &.. &.. & 1,1 &. & 2,2 &. &. &.. & 0,3 & 2,4 & .. & 1,0 \\
\hline Sri Lanka & 125,3 & 236,7 & 159,0 & 179,7 & 488,9 & 636,8 & 488,2 & 9,1 & 122,1 & 190,6 & 210,2 & 302,2 & 250,4 \\
\hline Suriname & 5,6 & 1,4 & 13,8 & 59,3 &.. & 130,5 & 49,3 &. & 23,6 & 43,2 & 30,7 & 78,4 & 6,6 \\
\hline Tadjikistan &. &. & 18,2 & 51,2 & 176,3 & 74,1 & 94,8 &. & 16,8 & 12,1 & 71,5 & 23,0 & 22,9 \\
\hline Tanzanie & 6,1 & 18,1 & 8,2 & 99,6 & 563,9 & 181,3 & 47,9 & 15,0 & 10,0 & 27,7 & 31,3 & 44,4 & 122,2 \\
\hline Tchad & 8,3 & 21,2 & 52,4 & 67,8 & 153,1 &.. & 5,4 & 4,5 &.. & 0,4 &. &. & \\
\hline Thaïlande & 25,7 & 58,0 & 218,4 & 267,8 & 182,2 & 111,6 & 118,6 & 21,1 & 60,8 & 178,5 & 157,1 & 150,5 & 120,6 \\
\hline Timor-Leste &.. &.. &.. & 26,5 & 11,9 & 55,1 & 0,1 &.. &.. & 4,2 & 11,8 & 15,7 & 10,4 \\
\hline Togo & 0,0 & 55,8 & 24,1 & 22,4 & 215,7 & 122,5 & 76,0 &. & 53,4 & 36,5 & 23,5 & 1,9 & 8,0 \\
\hline Tonga &. &. &.. &. & 2,2 & 2,4 & 0,9 &. &. &.. & 2,2 & 2,4 & 0,9 \\
\hline Tunisie & 317,3 & 507,8 & 846,1 & 345,1 & 1203,5 & 648,1 & 1121,9 & 203,1 & 608,7 & 289,3 & 690,9 & 482,8 & 818,7 \\
\hline
\end{tabular}


Millions d'USD (constants de 2017)

Tableau A.20. Autres apports du secteur public liés au commerce par pays bénéficiaire (page 4 sur 4) ENGAGEMENTS

\begin{tabular}{|c|c|c|c|c|c|c|c|c|c|c|c|c|c|}
\hline & \multicolumn{7}{|c|}{ ENGAGEIMEINIS } & \multicolumn{6}{|c|}{ DECAISSEMIENIS } \\
\hline & $\begin{array}{c}\text { Moyenne } \\
2002-2005\end{array}$ & \begin{tabular}{|c|} 
Moyenne \\
$2006-2008$
\end{tabular} & $\begin{array}{l}\text { Moyenne } \\
\text { 2009-2011 }\end{array}$ & $\begin{array}{l}\text { Moyenne } \\
\text { 2012-2014 }\end{array}$ & 2015 & 2016 & 2017 & $\begin{array}{c}\text { Moyenne } \\
2006-2008\end{array}$ & $\begin{array}{l}\text { Moyenne } \\
\text { 2009-2011 }\end{array}$ & $\begin{array}{l}\text { Moyenne } \\
\text { 2012-2014 }\end{array}$ & 2015 & 2016 & 2017 \\
\hline Turquie & 1168,2 & 3398,6 & 3279,5 & 3319,8 & 3678,1 & 5214,3 & 3396,5 & 1710,9 & 3219,8 & 2399,7 & 2736,3 & 3134,3 & 2556,6 \\
\hline Turkménistan &. &. & 267,8 & 13,8 & 12,8 & 726,1 & 305,3 &. & 11,6 & 39,4 & 19,7 & 31,1 & 28,9 \\
\hline Tuvalu &. &.. &. &.. & 0,2 & 0,2 & 0,1 &.. &.. &.. & 0,2 & 0,2 & 0,1 \\
\hline Ukraine & 58,6 & 421,0 & 1438,0 & 1616,0 & 2385,0 & 553,0 & 713,8 & 197,3 & 1140,4 & 1239,5 & 1310,9 & 1065,4 & 441,4 \\
\hline Uruguay & 234,3 & 136,2 & 216,9 & 615,3 & 782,5 & 170,8 & 409,0 & 63,7 & 186,9 & 191,7 & 186,1 & 101,4 & 314,1 \\
\hline Vanuatu & 0,1 & .. & 1,8 & 1,1 & 0,8 & 0,5 & 0,3 &.. & 1,8 &.. & 0,8 & 0,5 & 0,3 \\
\hline Venezuela & 13,1 & 265,3 & 545,0 & 2,2 & 0,9 & 0,0 &.. & 0,0 & 365,8 & 26,0 & 25,8 & 34,4 & 5,9 \\
\hline Viet Nam & 27,9 & 736,5 & 1592,1 & 1635,3 & 1455,3 & 1431,3 & 1531,6 & 215,8 & 779,1 & 1493,9 & 1920,3 & 1293,3 & 1641,6 \\
\hline Wallis-et-Futuna & 0,0 &. &. &. &. & 14,8 &. &. &. &. & .. & 7,4 & 2,1 \\
\hline Yémen &. & 164,2 & 11,1 & 15,4 & .. & .. &.. & 180,1 & 32,8 & 0,4 &. &.. & .. \\
\hline Zambie & 16,8 & 30,9 & 21,4 & 53,4 & 151,5 & 289,9 & 121,6 & 30,6 & 9,4 & 8,9 & 79,4 & 150,9 & 21,8 \\
\hline Zimbabwe &.. &. &.. & 17,7 & 4,0 & 27,5 & &.. &. & 8,7 & 0,0 & 3,7 & 1,6 \\
\hline Total pays bénéficiaires & 15012,3 & 25162,2 & 42809,1 & 43775,8 & 59264,1 & 63389,7 & 56849,8 & 9932,9 & 28766,4 & 28037,0 & 42375,0 & 42016,0 & 38094,9 \\
\hline Non spécifique à un pays & 133,9 & 383,3 & 1743,9 & 3921,1 & 2798,0 & 4000,7 & 3592,5 & 270,9 & 1194,0 & 1856,3 & 1599,3 & 1750,3 & 1956,1 \\
\hline $\begin{array}{l}\text { TOTAL DES AUTRES APPORTS } \\
\text { DU SECTEUR PUBLIC } \\
\text { LIÉS AU COMMERCE }\end{array}$ & 15146,2 & 25545,5 & 44553,0 & 47696,9 & 62062,1 & 67390,4 & 60442,3 & 10203,9 & 29960,4 & 29893,3 & 43974,4 & 43766,3 & 40051,1 \\
\hline
\end{tabular}

Source: CAD de l'OCDE : base de données sur les activités d'aide (2019).

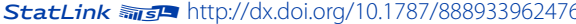




\section{ANNEXE B}

\section{LISTE DES BÉNÉFICIAIRES DE L'APD ÉTABLIE PAR LE CAD, PAR GROUPE DE REVENU}

\section{PAYS LES MOINS AVANCÉS}

$\begin{array}{llll}\text { Afghanistan } & \text { Guinée } & \text { Mozambique } & \text { Soudan } \\ \text { Angola } & \text { Guinée-Bissau } & \text { Myanmar } & \text { Soudan du Sud } \\ \text { Bangladesh } & \text { Haïti } & \text { Népal } & \text { Tanzanie } \\ \text { Bénin } & \text { Tles Salomon } & \text { Niger } & \text { Tchad } \\ \text { Bhoutan } & \text { Kiribati } & \text { Ouganda } & \text { Timor-Leste } \\ \text { Burkina Faso } & \text { République démocratique } & \text { République centrafricaine } & \text { Togo } \\ \text { Burundi } & \text { populaire lao } & \text { République démocratique } & \text { Tuvalu } \\ \text { Cambodge } & \text { Lesotho } & \text { du Congo } & \text { Vanuatu } \\ \text { Comores } & \text { Libéria } & \text { Rwanda } & \text { Yémen } \\ \text { Djibouti } & \text { Madagascar } & \text { Sao Tomé-et-Principe } & \text { Zambie } \\ \text { Érythrée } & \text { Malawi } & \text { Sénégal } & \\ \text { Éthiopie } & \text { Mali } & \text { Sierra Leone } & \\ \text { Gambie } & \text { Mauritanie } & \text { Somalie } & \end{array}$

AUTRES PAYS À FAIBLE REVENU

(RNB par habitant $<=1005$ \$ en 2016)

République démocratique Zimbabwe

populaire de Corée

\section{PAYS À REVENU INTERMÉDIAIRE DE LA TRANCHE INFÉRIEURE (RNB par habitant $<=1006 \$-3955$ en 2016))}

$\begin{array}{lll}\text { Arménie } & \text { Ghana } & \text { Micronésie } \\ \text { Bolivie } & \text { Guatemala } & \text { Moldova } \\ \text { Cabo Verde } & \text { Honduras } & \text { Mongolie } \\ \text { Cameroun } & \text { Inde } & \text { Nicaragua } \\ \text { Congo } & \text { Indonésie } & \text { Nigéria } \\ \text { Côte d'Ivoire } & \text { Jordanie } & \text { Ouzbékistan } \\ \text { Égypte } & \text { Kenya } & \text { Pakistan } \\ \text { Eswatini } & \text { Kosovo1 } & \text { Papouasie-Nouvelle-Guinée } \\ \text { El Salvador } & \text { Kirghizistan } & \text { Philippines } \\ \text { Géorgie } & \text { Maroc } & \text { République arabe syrienne }\end{array}$

Sri Lanka

Tadjikistan

Tokélaou*

Tunisie

Ukraine

Viet Nam 
PAYS À REVENU INTERMÉDIAIRE DE LA TRANCHE SUPÉRIEURE (RNB par habitant <= 3956 \$-12 235 \$ en 2016)

$\begin{array}{ll}\text { Afrique du Sud } & \text { Équateur } \\ \text { Albanie } & \text { Guinée équatoriale } \\ \text { Algérie } & \text { Fidji } \\ \text { Antigua-et-Barbuda } & \text { ex-République yougoslave } \\ \text { Argentine } & \text { de Macédoine } \\ \text { Azerbaïdjan } & \text { Gabon } \\ \text { Bélarus } & \text { Grenade } \\ \text { Belize } & \text { Guyana } \\ \text { Bosnie-Herzégovine } & \text { Îles Cook } \\ \text { Botswana } & \text { Iran } \\ \text { Brésil } & \text { Iraq } \\ \text { Colombie } & \text { Jamaïque } \\ \text { Costa Rica } & \text { Kazakhstan } \\ \text { Cuba } & \text { Liban } \\ \text { Dominique } & \text { Libye } \\ & \\ \text { Notes: } & \\ \text { *Territoire. } & \\ \text { 1. Cela est sans préjudice du statut du Kosovo en droit international. }\end{array}$

Malaisie
Maldives
Îles Marshall
Maurice
Mexique
Monténégro
Montserrat*
Namibie
Nauru
Nioué
Palaos
Panama
Paraguay
Pérou
République dominicaine

République populaire de Chine

Saint Vincentet-les Grenadines Sainte-Hélène* Sainte-Lucie Samoa Serbie Suriname Thaillande Tonga Turquie Turkménistan Venezuela Wallis-et-Futuna*

* Territoire 


\section{ANNEXE C LISTE DES BÉNÉFICIAIRES DE L'APD ÉTABLIE PAR LE CAD, PAR RÉGION}

AFRIQUE

$\begin{array}{ll}\text { Nord du Sahara } & \text { Sud du Sahara } \\ \text { Algérie } & \text { Afrique du Sud } \\ \text { Égypte } & \text { Angola } \\ \text { Libye } & \text { Bénin } \\ \text { Maroc } & \text { Botswana } \\ \text { Tunisie } & \text { Burkina Faso } \\ & \text { Burundi } \\ & \text { Cabo Verde } \\ & \text { Cameroun } \\ & \text { Comores } \\ & \text { Congo } \\ & \text { Côte d'lvoire } \\ & \text { Djibouti } \\ & \text { Érythrée } \\ & \text { Eswatini } \\ & \text { Éthiopie } \\ & \text { Gabon }\end{array}$

Gambie

Ghana

Guinée

Guinée-Bissau

Guinée équatoriale

Kenya

Lesotho

Libéria

Madagascar

Malawi

Mali

Maurice

Mauritanie

Mozambique

Namibie

Niger

Nigéria
Ouganda

Rwanda

Sainte-Hélène

République centrafricaine

République démocratique du Congo

Sao Tomé-et-Principe

Sénégal

Sierra Leone

Somalie

Soudan

Soudan du Sud

Tanzanie

Tchad

Togo

Zambie

Zimbabwe

\section{AMÉRIQUE}

\section{Amérique du Nord}

\section{et Amérique centrale}

Antigua-et-Barbuda

Antilles (région)

Belize

Costa Rica

Cuba

Dominique

El Salvador

Grenade

Guatemala

Haïti

\section{Amérique du Sud}

Honduras

Jamaïque

Mexique

Montserrat

Nicaragua

Panama

République dominicaine

Saint-Vincent-et-

les Grenadines

Sainte-Lucie
Argentine

Bolivie

Brésil

Colombie

Équateur
Guyana

Paraguay

Pérou

Suriname

Venezuela 
ASIE

Afghanistan

Arménie

Azerbaïdjan

Bangladesh

Bhoutan

Géorgie

Inde

Kazakhstan

Kirghizistan
Maldives

Myanmar

Népal

Ouzbékistan

Pakistan

Sri Lanka

Tadjikistan

Turkménistan

\section{Moyen-Orient}

Cisjordanie

et bande de Gaza

Iran

Iraq

Jordanie

Liban

République arabe syrienne

Yémen

\section{Extrême-Orient}

Cambodge

Chine (République populaire de)

Indonésie

Malaisie

Mongolie

Philippines

République démocratique populaire de Corée

République démocratique populaire lao

Thaillande

Timor-Leste

Viet Nam

Monténégro

Ukraine

Kosovo

Macédoine du Nord

Serbie

Turkey

Moldova

Turquie

Ukraine

\section{OCÉANIE}

Fidji

îles Cook

Îles Marshall

Kiribati
Îles Salomon

Micronésie

Nauru

Nioué
Palaos

Papouasie-Nouvelle-Guinée

Samoa

Tokelau
Tonga

Tuvalu

Vanuatu

Wallis-et-Futuna 


\section{ANNEXE D}

\section{AIDE POUR LE COMMERCE : SECTEURS ET DÉFINITIONS}

\section{CODE OBJET DU SNPC DÉSIGNATION}

Politique et réglementation commerciales et ajustement lié au commerce 


\section{Infrastructure économique}

TRANSPORT ET ENTREPOSAGE Note : La construction de matériel de transport devrait figurer sous le code 32172.

\begin{tabular}{|c|c|c|}
\hline 21010 & $\begin{array}{l}\text { Politique des transports et } \\
\text { gestion administrative }\end{array}$ & $\begin{array}{l}\text { Politique des transports, planification et programmes; aide aux } \\
\text { ministères des transports; renforcement des capacités institutionnelles } \\
\text { et conseils; transports non spécifiés; activités qui recouvrent le transport } \\
\text { routier, le transport ferroviaire, le transport par voies d'eau et/ou le } \\
\text { transport aérien. }\end{array}$ \\
\hline 21020 & Transport routier & $\begin{array}{l}\text { Infrastructure routière, véhicules; transport routier de voyageurs, voitures } \\
\text { particulières. }\end{array}$ \\
\hline 21030 & Transport ferroviaire & $\begin{array}{l}\text { Infrastructure ferroviaire, matériel ferroviaire, locomotives, autre matériel } \\
\text { roulant; y compris les tramways et les métropolitains. }\end{array}$ \\
\hline 21040 & Transport par voies d'eau & $\begin{array}{l}\text { Ports et docks, systèmes de guidage, navires et bateaux; transport sur } \\
\text { voies navigables intérieures, bateaux de voies d'eau intérieures. }\end{array}$ \\
\hline 21050 & Transport aérien & $\begin{array}{l}\text { Aéroports, systèmes de guidage, avions, équipement d'entretien des } \\
\text { avions. }\end{array}$ \\
\hline 21061 & Stockage & Associé ou non au transport. \\
\hline 21081 & $\begin{array}{l}\text { Éducation/formation dans les } \\
\text { transports et le stockage }\end{array}$ & \\
\hline COMMUNICATIONS & \multicolumn{2}{|l|}{ COMMUNICATIONS } \\
\hline 22010 & $\begin{array}{l}\text { Politique des communications et } \\
\text { gestion administrative }\end{array}$ & $\begin{array}{l}\text { Politique des communications, planification et programmes; } \\
\text { renforcement des capacités institutionnelles et conseils; y compris } \\
\text { développement des services postaux; activités de communications non } \\
\text { spécifiées. }\end{array}$ \\
\hline 22020 & Télécommunications & Réseaux de téléphones, satellites, stations terrestres. \\
\hline 22030 & Radio, télévision, presse écrite & Liaisons et équipement; journaux; imprimerie et édition. \\
\hline 22040 & $\begin{array}{l}\text { Technologies de l'information et } \\
\text { de la communication (TIC) }\end{array}$ & $\begin{array}{l}\text { Matériel informatique et logiciels; accès Internet; formations aux TI. } \\
\text { Lorsque le secteur ne peut pas être spécifié. }\end{array}$ \\
\hline \multicolumn{3}{|c|}{ ÉNERGIE : PRODUCTION, DISTRIBUTION } \\
\hline 23110 & $\begin{array}{l}\text { Politique de l'énergie et gestion } \\
\text { administrative }\end{array}$ & $\begin{array}{l}\text { Politique et planification du secteur de l'énergie; aide aux ministères } \\
\text { de l'énergie; renforcement des capacités institutionnelles et conseils; } \\
\text { activités non spécifiées dans le domaine de l'énergie. }\end{array}$ \\
\hline 23111 & $\begin{array}{l}\text { Politiques, planification et } \\
\text { administration du secteur de } \\
\text { l'énergie }\end{array}$ & \\
\hline 23112 & Réglementation de l'énergie & $\begin{array}{l}\text { Réglementation du secteur de l'énergie, y compris l'approvisionnement } \\
\text { en électricité en gros et au détail. }\end{array}$ \\
\hline 23181 & $\begin{array}{l}\text { Éducation/formation dans le } \\
\text { domaine de l'énergie }\end{array}$ & Tous les niveaux de formation ne figurant pas sous un autre code. \\
\hline 23182 & $\begin{array}{l}\text { Recherche dans le domaine de } \\
\text { l'énergie }\end{array}$ & Y compris inventaires et études. \\
\hline 23183 & $\begin{array}{l}\text { Économies d'énergie et efficacité } \\
\text { du côté de la demande }\end{array}$ & $\begin{array}{l}\text { Tous les projets visant à la réduction de la demande d'énergie, par } \\
\text { exemple: modernisation des bâtiments et des industries, réseaux } \\
\text { intelligents, compteurs et tarifs. Comprend également les cuisinières } \\
\text { efficaces et les projets de biogaz. }\end{array}$ \\
\hline
\end{tabular}




\begin{tabular}{|c|c|c|}
\hline 23210 & $\begin{array}{l}\text { Production d'énergie, sources } \\
\text { renouvelables - multiples } \\
\text { technologies }\end{array}$ & $\begin{array}{l}\text { Programmes de production d'énergie d'origine renouvelable qui ne } \\
\text { peuvent être attribués à une seule technologie (codes } 23220 \text { à } 23280 \\
\text { ci-après). La production de bois de chauffage/charbon de bois devrait } \\
\text { figurer sous la rubrique sylviculture } 31261 \text {. }\end{array}$ \\
\hline 23220 & Centrales hydrauliques & Dont centrales flottantes. \\
\hline 23230 & Énergie solaire & Solaire photovoltaïque, thermodynamique et chauffage solaire. \\
\hline 23240 & Énergie éolienne & Éoliennes de pompage et production d'électricité. \\
\hline 23250 & Énergie marine & $\begin{array}{l}\text { Conversion de l'énergie thermique des mers, énergie marémotrice et } \\
\text { houlomotrice. }\end{array}$ \\
\hline 23260 & Énergie géothermique & $\begin{array}{l}\text { Application de l'énergie géothermique pour produire de l'électricité ou } \\
\text { production de chaleur à usage agricole, etc. }\end{array}$ \\
\hline 23270 & Centrales à biocombustibles & $\begin{array}{l}\text { Utilisation de matières solides et liquides issues de la biomasse pour } \\
\text { la production directe d'électricité. Comprend également les biogaz } \\
\text { produits par fermentation anaérobie (par exemple : gaz de décharge, } \\
\text { gaz issus des boues d'épuration, fermentation de végétaux des cultures } \\
\text { énergétiques et de déjections animales) et par traitements thermiques } \\
\text { (également connus sous l'appellation de gaz de synthèse); centrales } \\
\text { brûlant des déchets municipaux biodégradables (déchets ménagers et } \\
\text { déchets du tertiaire assimilables à des déchets ménagers, collectés dans } \\
\text { des installations spécifiquement conçues pour leur élimination et leur } \\
\text { récupération sous forme de liquides ou de gaz combustibles ou } \\
\text { de chaleur). Voir code } 23360 \text { pour la production d'électricité, déchets } \\
\text { non renouvelables. }\end{array}$ \\
\hline 23310 & $\begin{array}{l}\text { Production d'énergie, sources } \\
\text { non renouvelables - non spécifié }\end{array}$ & $\begin{array}{l}\text { Centrales thermiques dont la source d'énergie est indéterminée; } \\
\text { centrales mixtes gaz - charbon. }\end{array}$ \\
\hline 23320 & Centrales au charbon & Centrales thermiques brûlant au charbon. \\
\hline 23330 & Centrales au fioul & Centrales thermiques brûlant du fioul ou du gazole. \\
\hline 23340 & Centrales au gaz naturel & Centrales thermiques brûlant du gaz naturel. \\
\hline 23350 & $\begin{array}{l}\text { Centrales thermiques classiques } \\
\text { avec captage et stockage du } \\
\text { carbone (CSC) }\end{array}$ & $\begin{array}{l}\text { Centrales thermiques classiques exploitant une technologie de captage } \\
\text { et de stockage des émissions de carbone (CSC). Les techniques de CSC } \\
\text { non associées à la production d'électricité devraient figurer sous la } \\
\text { rubrique 41020. Les activités de CSC ne sont pas éligibles à I'APD. }\end{array}$ \\
\hline 23360 & $\begin{array}{l}\text { Production d'électricité, déchets } \\
\text { non renouvelables }\end{array}$ & $\begin{array}{l}\text { Centrales brûlant des déchets industriels et municipaux non } \\
\text { biodégradables. }\end{array}$ \\
\hline 23410 & Centrales hybrides & $\begin{array}{l}\text { Centrales fonctionnant avec des énergies renouvelables et non } \\
\text { renouvelables. }\end{array}$ \\
\hline 23510 & Centrales nucléaires & Dont sûreté nucléaire. \\
\hline 23610 & Production de chaleur seule & Installations produisant uniquement de la chaleur. \\
\hline 23620 & $\begin{array}{l}\text { Réseaux urbains de chaleur et } \\
\text { de froid }\end{array}$ & $\begin{array}{l}\text { Distribution de chaleur produite dans une chaufferie unique, ou d'eau } \\
\text { froide, à des fins de climatisation des locaux dans les secteurs résidentiel } \\
\text { et tertiaire. }\end{array}$ \\
\hline 23630 & $\begin{array}{l}\text { Transport et distribution } \\
\text { d'électricité }\end{array}$ & $\begin{array}{l}\text { Distribution d'électricité par le réseau, de la source au consommateur } \\
\text { final; lignes de transport. Inclut également le stockage de l'énergie pour } \\
\text { la production d'électricité (par exemple : stations de pompage, batteries) } \\
\text { et l'extension de l'accès au réseau, souvent dans des zones rurales. }\end{array}$ \\
\hline 23640 & Distribution du gaz & Acheminement du gaz jusqu'au consommateur final. \\
\hline
\end{tabular}


Renforcement de la capacité de production (les codes suivants concernent le marqueur du développement du commerce)

\section{BANQUES ET SERVICES FINANCIERS}

\begin{tabular}{|c|c|c|}
\hline 24010 & $\begin{array}{l}\text { Politique des finances et gestion } \\
\text { administrative }\end{array}$ & $\begin{array}{l}\text { Politique des finances, planification et programmes; renforcement des } \\
\text { capacités institutionnelles et conseils; marchés et systèmes financiers. }\end{array}$ \\
\hline 24020 & Institutions monétaires & Banques centrales. \\
\hline 24030 & Intermédiaires financiers officiels & $\begin{array}{l}\text { Tous les intermédiaires financiers dans le secteur formel; lignes de crédit; } \\
\text { assurance, crédit-bail, capital-risque, etc. (sauf ceux spécialisés dans un } \\
\text { seul secteur). }\end{array}$ \\
\hline 24040 & $\begin{array}{l}\text { Intermédiaires financiers du } \\
\text { secteur informel et semi-formel }\end{array}$ & Microcrédits, coopératives d'épargne et de crédit, etc. \\
\hline 24050 & $\begin{array}{l}\text { Facilitation, promotion et } \\
\text { optimisation des transferts de } \\
\text { fonds des migrants }\end{array}$ & \\
\hline 24081 & $\begin{array}{l}\text { Éducation/formation bancaire et } \\
\text { dans les services financiers }\end{array}$ & \\
\hline
\end{tabular}

\section{ENTREPRISES ET AUTRES SERVICES}

\begin{tabular}{|c|c|c|}
\hline 25010 & $\begin{array}{l}\text { Services et institutions de soutien } \\
\text { commerciaux }\end{array}$ & $\begin{array}{l}\text { Soutien aux associations de commerce et d'entreprises, chambres } \\
\text { de commerce; réformes juridiques et réglementaires afin d'améliorer } \\
\text { les activités liées à l'entreprise; renforcement des capacités } \\
\text { institutionnelles du secteur privé et conseils; information commerciale; } \\
\text { réseaux de liaison entre les secteurs public et privé y compris les foires } \\
\text { commerciales; commerce électronique. Quand le secteur ne peut pas } \\
\text { être spécifié : soutien général aux entreprises du secteur privé. } \\
\text { En particulier, pour les entreprises du secteur industriel, c'est le code } \\
32130 \text { qui doit être utilisé. }\end{array}$ \\
\hline 25020 & Privatisation & $\begin{array}{l}\text { Lorsque le secteur ne peut pas être spécifié. Y compris programmes } \\
\text { de restructuration d'entreprises publiques et de démonopolisation; } \\
\text { planification, programmation, conseils. }\end{array}$ \\
\hline 25030 & $\begin{array}{l}\text { Services de développement des } \\
\text { entreprises }\end{array}$ & $\begin{array}{l}\text { Fourniture publique et privée de services de développement } \\
\text { des entreprises, par exemple les incubateurs, les stratégies } \\
\text { commerciales, les programmes de relations commerciales et les } \\
\text { services d'appariement. Y compris le soutien aux organisations privées } \\
\text { représentant des entreprises, par exemple les associations d'entreprises; } \\
\text { les chambres de commerce; les associations de producteurs; } \\
\text { les fournisseurs de savoir-faire et autres services de développement } \\
\text { des entreprises. Pour les services financiers, les codes SNPC } 24030 \text { ou } \\
24040 \text { doivent être utilisés. Pour le développement des PME et pour } \\
\text { le soutien aux entreprises du secteur industriel, les codes } 32130 \text { à } 32172 \\
\text { doivent être utilisés. Pour le soutien aux entreprises du secteur agricole, } \\
\text { le code } 31120 \text { doit être utilisé. }\end{array}$ \\
\hline
\end{tabular}




\begin{tabular}{|c|c|c|}
\hline 25040 & Code de conduite responsable & $\begin{array}{l}\text { Soutien à la réforme des politiques, mise en œuvre et application des } \\
\text { principes et normes du code de conduite responsable, et facilitation } \\
\text { des pratiques responsables par les entreprises. Y compris l'établissement } \\
\text { et l'application d'un cadre juridique et réglementaire pour protéger } \\
\text { les droits des parties prenantes et l'environnement et récompenser } \\
\text { l'efficacité; mise en avant du code de conduite responsable dans les } \\
\text { activités économiques des pouvoirs publics, telles que les opérations } \\
\text { des entreprises publiques ou la passation des marchés publics; soutien } \\
\text { à la mise en œuvre des principes directeurs de l'OCDE à l'intention des } \\
\text { entreprises multinationales, y compris la divulgation, les droits humains, } \\
\text { l'emploi et les relations industrielles, l'environnement, la lutte contre } \\
\text { la corruption passive, les intérêts des consommateurs, la science et la } \\
\text { technologie, la concurrence et la fiscalité. }\end{array}$ \\
\hline \multicolumn{3}{|c|}{ AGRICULTURE } \\
\hline 31110 & $\begin{array}{l}\text { Politique agricole et gestion } \\
\text { administrative }\end{array}$ & $\begin{array}{l}\text { Politique agricole, planification et programmes; aide aux ministères de } \\
\text { l'agriculture; renforcement des capacités institutionnelles et conseils; } \\
\text { activités d'agriculture non spécifiées. }\end{array}$ \\
\hline 31120 & Développement agricole & Projets intégrés; développement d'exploitations agricoles \\
\hline 31130 & Ressources en terres cultivables & $\begin{array}{l}\text { Y compris la lutte contre la dégradation des sols; amélioration des sols; } \\
\text { drainage des zones inondées; dessalage des sols; études des terrains } \\
\text { agricoles; remise en état des sols; lutte contre l'érosion, lutte contre } \\
\text { la désertification. }\end{array}$ \\
\hline 31140 & $\begin{array}{l}\text { Ressources en eau à usage } \\
\text { agricole }\end{array}$ & $\begin{array}{l}\text { Irrigation, réservoirs, structures hydrauliques, exploitation de nappes } \\
\text { phréatiques. }\end{array}$ \\
\hline 31150 & Produits à usage agricole & Approvisionnement en semences, engrais, matériel et outillage agricoles. \\
\hline 31161 & Production agricole & $\begin{array}{l}\text { Y compris céréales (froment, riz, orge, maïs, seigle, avoine, millet, sorgho); } \\
\text { horticulture; légumes; fruits et baies; autres cultures annuelles et } \\
\text { pluriannuelles. [Utiliser le code } 32161 \text { pour les agro-industries.] }\end{array}$ \\
\hline 31162 & $\begin{array}{l}\text { Production industrielle de } \\
\text { récoltes/récoltes destinées à } \\
\text { l'exportation }\end{array}$ & $\begin{array}{l}\text { Y compris sucre; café, cacao, thé; oléagineux, graines, noix, amandes; fibres; } \\
\text { tabac; caoutchouc. [Utiliser le code } 32161 \text { pour les agro-industries.] }\end{array}$ \\
\hline 31163 & Bétail & Toutes formes d'élevage; aliments pour animaux. \\
\hline 31164 & Réforme agraire & Y compris ajustement structurel dans le secteur agricole. \\
\hline 31165 & $\begin{array}{l}\text { Développement agricole } \\
\text { alternatif }\end{array}$ & $\begin{array}{l}\text { Projets afin de réduire les cultures illicites (drogue) à travers d'autres } \\
\text { opportunités de marketing et production agricoles (voir code } 43050 \\
\text { pour développement alternatif non agricole). }\end{array}$ \\
\hline 31166 & Vulgarisation agricole & Formation agricole non formelle. \\
\hline 31181 & $\begin{array}{l}\text { Éducation et formation dans le } \\
\text { domaine agricole }\end{array}$ & \\
\hline 31182 & Recherche agronomique & $\begin{array}{l}\text { Étude des espèces végétales, physiologie, ressources génétiques, } \\
\text { écologie, taxonomie, lutte contre les maladies, biotechnologie agricole; } \\
\text { y compris recherche vétérinaire (dans les domaines génétiques et } \\
\text { sanitaires, nutrition, physiologie). }\end{array}$ \\
\hline 31191 & Services agricoles & $\begin{array}{l}\text { Organisation et politiques des marchés; transport et stockage; } \\
\text { établissements de réserves stratégiques. }\end{array}$ \\
\hline 31192 & $\begin{array}{l}\text { Protection des plantes et des } \\
\text { récoltes, lutte antiacridienne }\end{array}$ & $\begin{array}{l}\text { Y compris la protection intégrée des plantes, les activités de protection } \\
\text { biologique des plantes, la fourniture et la gestion de substances } \\
\text { agrochimiques, l'approvisionnement en pesticides; politique et } \\
\text { législation de la protection des plantes. }\end{array}$ \\
\hline
\end{tabular}




\begin{tabular}{|c|c|c|}
\hline 31193 & Services financiers agricoles & $\begin{array}{l}\text { Intermédiaires financiers du secteur agricole, y compris les plans } \\
\text { de crédit; assurance récoltes. }\end{array}$ \\
\hline 31194 & Coopératives agricoles & Y compris les organisations d'agriculteurs \\
\hline 31195 & Services vétérinaires (bétail) & Santé des animaux, ressources génétiques et nutritives. \\
\hline \multicolumn{3}{|c|}{ SYLVICULTURE } \\
\hline 31210 & $\begin{array}{l}\text { Politique de la sylviculture et } \\
\text { gestion administrative }\end{array}$ & $\begin{array}{l}\text { Politique de la sylviculture, planification et programmes; renforcement } \\
\text { des capacités institutionnelles et conseils; études des forêts activités } \\
\text { sylvicoles et agricoles liées à la sylviculture non spécifiées. }\end{array}$ \\
\hline 31220 & Développement sylvicole & $\begin{array}{l}\text { Boisement pour consommation rurale et industrielle; exploitation et } \\
\text { utilisation; lutte contre l'érosion, lutte contre la désertification; projets } \\
\text { intégrés. }\end{array}$ \\
\hline 31261 & $\begin{array}{l}\text { Reboisement (bois de chauffage } \\
\text { et charbon de bois) }\end{array}$ & $\begin{array}{l}\text { Développement sylvicole visant à la production de bois de chauffage } \\
\text { et de charbon de bois. }\end{array}$ \\
\hline 31281 & $\begin{array}{l}\text { Éducation/formation en } \\
\text { sylviculture }\end{array}$ & \\
\hline 31282 & Recherche en sylviculture & $\begin{array}{l}\text { Y compris reproduction artificielle et amélioration des espèces, } \\
\text { méthodes de production, engrais, coupe et ramassage du bois. }\end{array}$ \\
\hline 31291 & Services sylvicoles & \\
\hline \multicolumn{3}{|c|}{ PÊCHE } \\
\hline 31310 & $\begin{array}{l}\text { Politique de la pêche et gestion } \\
\text { administrative }\end{array}$ & $\begin{array}{l}\text { Politique de la pêche, planification et programmes; renforcement } \\
\text { des capacités institutionnelles et conseils; pêche hauturière et côtière; } \\
\text { évaluation, études et prospection du poisson en milieu marin et fluvial; } \\
\text { bateaux et équipements de pêche; activités de pêche non spécifiées. }\end{array}$ \\
\hline 31320 & Développement de la pêche & $\begin{array}{l}\text { Exploitation et utilisation des pêcheries; sauvegarde des bancs } \\
\text { de poisson; aquaculture; projets intégrés. }\end{array}$ \\
\hline 31381 & $\begin{array}{l}\text { Éducation/formation dans le } \\
\text { domaine de la pêche }\end{array}$ & \\
\hline 31382 & $\begin{array}{l}\text { Recherche dans le domaine de } \\
\text { la pêche }\end{array}$ & Pisciculture pilote; recherche biologique aquatique. \\
\hline 31391 & $\begin{array}{l}\text { Services dans le domaine de la } \\
\text { pêche }\end{array}$ & $\begin{array}{l}\text { Ports de pêche; vente de produits de la pêche; transport et entreposage } \\
\text { frigorifique du poisson. }\end{array}$ \\
\hline \multicolumn{3}{|c|}{ INDUSTRIE } \\
\hline 32110 & $\begin{array}{l}\text { Politique de l'industrie et gestion } \\
\text { administrative }\end{array}$ & $\begin{array}{l}\text { Politique de l'industrie, planification et programmes; renforcement } \\
\text { des capacités institutionnelles et conseils; activités industrielles non } \\
\text { spécifiées; industries manufacturières non spécifiées ci-dessous. }\end{array}$ \\
\hline 32120 & Développement industriel & \\
\hline 32130 & $\begin{array}{l}\text { Développement des petites et } \\
\text { moyennes entreprises (PME) }\end{array}$ & $\begin{array}{l}\text { Soutien direct au développement des petites et moyennes entreprises } \\
\text { dans le secteur industriel, y compris la comptabilité, l'audit et les services } \\
\text { de conseil. }\end{array}$ \\
\hline 32140 & Artisanat & \\
\hline 32161 & Agro-industries & $\begin{array}{l}\text { Industries alimentaires de base, abattoirs et équipements nécessaires, } \\
\text { industrie laitière et conserves de viande et de poisson, industries } \\
\text { des corps gras, sucreries, production de boissons, tabac, production } \\
\text { d'aliments pour animaux. }\end{array}$ \\
\hline
\end{tabular}




\begin{tabular}{|c|c|c|}
\hline 32162 & Industries forestières & Industrie et travail du bois, production de papier et de pâte à papier. \\
\hline 32163 & $\begin{array}{l}\text { Industrie textile, cuirs et produits } \\
\text { similaires }\end{array}$ & Y compris bonneterie. \\
\hline 32164 & Produits chimiques & $\begin{array}{l}\text { Production industrielle et non industrielle; y compris fabrication } \\
\text { des pesticides. }\end{array}$ \\
\hline 32165 & Production d'engrais chimiques & \\
\hline 32166 & Ciment, chaux et plâtre & \\
\hline 32167 & Fabrication d'énergie & Y compris liquéfaction du gaz; raffineries de pétrole. \\
\hline 32168 & Produits pharmaceutiques & $\begin{array}{l}\text { Matériel médical et fournitures médicales; médicaments et vaccins; } \\
\text { produits d'hygiène corporelle. }\end{array}$ \\
\hline 32169 & Industrie métallurgique de base & Sidérurgie, éléments de construction métallique. \\
\hline 32170 & $\begin{array}{l}\text { Industries des métaux non } \\
\text { ferreux }\end{array}$ & \\
\hline 32171 & $\begin{array}{l}\text { Construction mécanique et } \\
\text { électrique }\end{array}$ & $\begin{array}{l}\text { Fabrication de machines électriques et non électriques, moteurs } \\
\text { et turbines. }\end{array}$ \\
\hline 32172 & Matériel de transport & $\begin{array}{l}\text { Construction de navires, construction de bateaux de pêche; construction } \\
\text { de matériel ferroviaire; véhicules automobiles et voitures particulières; } \\
\text { construction aéronautique; systèmes de navigation et de guidage. }\end{array}$ \\
\hline 32182 & $\begin{array}{l}\text { Recherche et développement } \\
\text { technologiques }\end{array}$ & $\begin{array}{l}\text { Y compris les standards industriels; gestion et contrôle de la qualité; } \\
\text { métrologie; essais; accréditation; certification. }\end{array}$ \\
\hline \multicolumn{3}{|c|}{ INDUSTRIES EXTRACTIVES } \\
\hline 32210 & $\begin{array}{l}\text { Politique de l'industrie extractive } \\
\text { et gestion administrative }\end{array}$ & $\begin{array}{l}\text { Politique du secteur des industries extractives, planification et } \\
\text { programmes; législation et cadastre, recensement des richesses } \\
\text { minérales, systèmes d'information; renforcement des capacités } \\
\text { institutionnelles et conseils; exploitation des ressources minérales } \\
\text { non spécifiées. }\end{array}$ \\
\hline 32220 & $\begin{array}{l}\text { Prospection et exploration des } \\
\text { minerais }\end{array}$ & $\begin{array}{l}\text { Géologie, géophysique et géochimie; à l'exclusion de hydrogéologie } \\
\text { (14010) et géologie de l'environnement (41010), production et } \\
\text { extraction minérales, infrastructure, technologie, économie, sécurité } \\
\text { et gestion de l'environnement. }\end{array}$ \\
\hline 32261 & Charbon & Y compris lignite et la tourbe. \\
\hline 32262 & Pétrole et gaz & $\begin{array}{l}\text { Pétrole, gaz naturel, condensés, GPL (gaz de pétrole liquéfié), GNL } \\
\text { (gaz naturel liquéfié); y compris derricks et plates-formes de forage. }\end{array}$ \\
\hline 32263 & Métaux ferreux & Fer et alliages. \\
\hline 32264 & Métaux non ferreux & Aluminium, cuivre, plomb, nickel, étain et zinc. \\
\hline 32265 & Métaux et minerais précieux & Or, argent, platine, diamant et pierres précieuses. \\
\hline 32266 & Minerais industriels & Baryte, chaux, feldspath, kaolin, sable, gypse, gravier, pierres d'ornement. \\
\hline 32267 & Engrais minéraux & Phosphates, potasse. \\
\hline \multirow[t]{2}{*}{32268} & Ressources des fonds marins & Nodules métalliques, phosphorites, sédiments marins. \\
\hline & TOURISM & \\
\hline 33210 & $\begin{array}{l}\text { Tourism policy and administrative } \\
\text { management }\end{array}$ & \\
\hline
\end{tabular}




\section{CADRE INTÉGRÉ RENFORCÉ}

Le CIR est un partenariat mondial qui a vocation à aider les pays les moins avancés (PMA) à utiliser le commerce comme un instrument de croissance économique et de lutte contre la pauvreté en créant des emplois et des sources de revenus. Le CIR donne aux PMA des outils pour déterminer dans quels domaines et de quelle manière le commerce peut faire partie intégrante de leurs stratégies nationales de développement et les aide à utiliser l'Aide pour le commerce pour atteindre cet objectif.

Le CIR apporte un soutien personnalisé, adapté à chaque pays, qui couvre l'éventail complet des besoins en matière de renforcement des capacités. En œuvrant au renforcement des capacités commerciales, les partenaires travaillent ensemble pour soutenir l'action des PMA eux-mêmes visant à :

- identifier et surmonter les principaux obstacles au commerce;

- veiller à ce que le commerce soutienne directement le programme national de développement;

- mettre en place des mécanismes institutionnels et de coordination pour l'assistance technique liée au commerce; et

- entreprendre des réformes et mobiliser des ressources financières et techniques supplémentaires pour répondre aux besoins commerciaux prioritaires.

\section{INTERNATIONAL TRADE CENTRE}

L'TC est un organisme multilatéral qui se consacre entièrement au développement de la compétitivité internationale des PME. En tant qu'organisme conjoint de I'OMC et de I'ONU, I'ITC concentre son action sur la réussite des petites entreprises à l'exportation. Il intervient en particulier dans les pays les moins avancés, les pays en développement sans littoral, les États fragiles ou qui sortent d'une période de conflit, les petits États insulaires en développement et l'Afrique subsaharienne. II aide à créer des secteurs d'exportation dynamiques et durables qui offrent des possibilités entrepreneuriales, en particulier pour les femmes, les jeunes et les communautés pauvres.

Les principaux domaines d'action en faveur de la compétitivité des PME sont les suivants:

- Développement de l'information commerciale et de l'information sur les marchés

- Création d'un environnement favorable aux affaires

- Renforcement des institutions d'appui au commerce et à l'investissement

- Intégration dans les chaînes de valeur

- Soutien à l'intégration régionale et à la coopération Sud-Sud

- Intégration d'un commerce inclusif et respectueux de l'environnement

\section{UNITED NATIONS CONFERENCE ON TRADE AND DEVELOPMENT}

Régie par ses 194 États membres, la CNUCED est l'organe des Nations Unies chargé des questions de développement, en particulier du commerce international qui en est le principal moteur. Son action peut se résumer en trois mots : réfléchir, dialoguer, réaliser. La réflexion sur le développement est au cœur du travail de la CNUCED. Elle donne lieu à des analyses qui permettent d'adresser des recommandations aux responsables des politiques. La CNUCED c'est aussi un forum où les représentants de tous les pays peuvent dialoguer librement et débattre des voies et moyens d'instaurer un meilleur équilibre économique mondial. En outre, la CNUCED fournit une assistance technique directe aux pays en développement et en transition pour les aider à renforcer les capacités dont ils ont besoin pour s'intégrer équitablement dans l'économie mondiale et améliorer le bien-être de leurs populations.

La CNUCED se réunit tous les quatre ans au niveau ministériel pour débattre des grands enjeux économiques mondiaux et définir son programme de travail. Tous les deux ans, elle organise le Forum mondial de l'investissement, qui réunit les principaux acteurs de la communauté internationale de l'investissement afin de débattre des défis et des opportunités, ainsi que de promouvoir des politiques d'investissement et des partenariats au service du développement durable et d'une croissance équitable. 


\section{ORGANISATION DES NATIONS UNIES POUR LE DÉVELOPPEMENT INDUSTRIEL}

L'Organisation des Nations Unies pour le développement industriel (ONUDI) est l'institution spécialisée des Nations Unies dont la mission est de promouvoir le développement industriel (y compris la mondialisation et la durabilité environnementale) au service de la réduction de la pauvreté. Au 1er avril 2019, I'ONUDI comptait 170 États membres qui discutent et décident à intervalles réguliers des orientations et politiques de l'Organisation lors des séances des organes de décision. Le mandat de l'Organisation des Nations Unies pour le développement industriel, tel que décrit dans la Déclaration de Lima adoptée à la 15ème session de la Conférence générale de I'ONUDI en 2013, est de promouvoir et d'accélérer le développement industriel inclusif et durable dans les États membres.

L'orientation pragmatique de l'ONUDI est axée sur quatre priorités stratégiques :

- création d'une prospérité partagée

- renforcement de la compétitivité économique

- protection de l'environnement;

renforcement des connaissances et des institutions.

\section{GROUPE DE LA BANQUE MONDIALE}

Le Groupe de la Banque mondiale a fixé deux objectifs à atteindre d'ici à 2030 : éliminer l'extrême pauvreté en ramenant à 3\% au maximum la proportion de personnes vivant avec moins de 1,25 dollar par jour; et promouvoir une prospérité partagée en favorisant la croissance des revenus des $40 \%$ les plus pauvres dans chaque pays. Dans le domaine du commerce et de la compétitivité, le Groupe de la Banque mondiale aide les pays à atteindre ces deux objectifs grâce à une croissance économique rapide et diversifiée, reposant sur la contribution importante du secteur privé. À cette fin, il fournit aux pays une aide pour accroître le volume et la valeur des échanges, améliorer le climat de l'investissement, renforcer la compétitivité des différents secteurs et encourager l'innovation et l'entrepreneuriat.

\section{ORGANISATION MONDIALE DU COMMERCE}

L'Organisation mondiale du commerce $(\mathrm{OMC})$ est la seule organisation internationale qui s'occupe des règles régissant le commerce entre les pays. Au cœur de l'Organisation, il y a les Accords de I'OMC, négociés et signés par la plupart des nations commerçantes et ratifiés par leurs parlements. Le but est d'aider les producteurs de marchandises et de services, les exportateurs et les importateurs à mener leurs activités.

Les principales activités de l'OMC sont les suivantes:

- négocier la réduction ou l'élimination des obstacles au commerce (droits de douane à l'importation, autres obstacles au commerce) et convenir de règles régissant le commerce international (par exemple mesures antidumping, subventions, normes relatives aux produits, etc.);

- administrer et suivre l'application des règles convenues régissant le commerce des marchandises, le commerce des services et les aspects des droits de propriété intellectuelle qui touchent au commerce;

- suivre et examiner les politiques commerciales des Membres et assurer la transparence des accords commerciaux régionaux et bilatéraux;

- régler les différends entre les Membres concernant l'interprétation et l'application des accords;

- renforcer la capacité des fonctionnaires gouvernementaux des pays en développement chargés des questions commerciales internationales;

- faciliter le processus d'accession de quelque 30 pays qui ne sont pas encore Membres de l'Organisation;

- mener des recherches économiques et recueillir et diffuser des données sur le commerce pour soutenir les autres activités principales de l'OMC;

- apprendre et expliquer au public en quoi consiste I'OMC, quelle est sa mission et quelles sont ses activités.

L'OMC compte actuellement 164 Membres dont plus des deux tiers sont des pays en développement ou des territoires douaniers distincts. 


\section{ORGANISATION DE COOPÉRATION ET DE DÉVELOPPEMENT ÉCONOMIQUES}

L'OCDE est un forum unique en son genre, où les gouvernements œuvrent ensemble pour relever les défis économiques, sociaux et environnementaux que pose la mondialisation. L'OCDE est aussi à l'avant-garde des efforts entrepris pour comprendre les évolutions du monde actuel et les préoccupations qu'elles font naître. Elle aide les gouvernements à faire face à des situations nouvelles en examinant des thèmes tels que le gouvernement d'entreprise, l'économie de l'information et les défis posés par le vieillissement de la population. L'Organisation offre aux gouvernements un cadre leur permettant de comparer leurs expériences en matière de politiques, de chercher des réponses à des problèmes communs, d'identifier les meilleures pratiques et de travailler à la coordination des politiques nationales et internationales.

Les pays membres de l'OCDE sont : I'Allemagne, I'Australie, I'Autriche, la Belgique, le Canada, le Chili, la Corée, le Danemark, l'Espagne, I'Estonie, les États-Unis, la Finlande, la France, la Grèce, la Hongrie, I'Irlande, I'Islande, Israël, I'Italie, le Japon, la Lettonie, le Luxembourg, le Mexique, la Norvège, la Nouvelle-Zélande, les Pays-Bas, la Pologne, le Portugal, la République slovaque, la République tchèque, le Royaume-Uni, la Slovénie, la Suède, la Suisse et la Turquie. L'Union européenne participe aux travaux de I'OCDE. Les Éditions OCDE assurent une large diffusion aux travaux de l'Organisation. Ces derniers comprennent les résultats de l'activité de collecte de statistiques, les travaux de recherche menés sur des questions économiques, sociales et environnementales, ainsi que les conventions, les principes directeurs et les modèles développés par les pays membres. 


\section{A.}

AIDE POUR LE COMMERCE

Examen globat

3-5 juillet 2019

\section{PANORAMA DE L'AIDE POUR LE COMMERCE 2019 DIVERSIFICATION ET AUTONOMISATION ÉCONOMIQUES}

Panorama de l'aide pour le commerce 2019 analyse la manière dont le commerce peut contribuer à la diversification et à l'autonomisation économiques, en mettant l'accent sur l'élimination de l'extrême pauvreté, en particulier par la participation active des femmes et des jeunes; et sur la manière dont le commerce peut contribuer à la réalisation de ces objectifs en remédiant aux contraintes qui pèsent sur l'offre et l'infrastructure commerciale, y compris pour les micro, petites et moyennes entreprises, en particulier dans les zones rurales.

L'analyse est basée sur les vues des 133 participants - dont 88 pays en développement, 35 donateurs, 5 fournisseurs d'assistance Sud Sud liée au commerce et 5 organisations régionales - à l'exercice 2019 de suivi et d'évaluation de l'Aide pour le commerce. Tous sont d'avis que la diversification économique ouvre la voie à l'autonomisation économique, mais aussi que l'autonomisation est essentielle à la diversification économique, notamment en ce qu'elle permet aux jeunes, aux femmes et aux micro, petites et moyennes entreprises de participer au commerce international.

Aperçu

Auteur

Chapitre 1 Contexte

OMC

Chapitre 2 Aide pour le commerce, diversification et autonomisation économiques

OCDE

Chapitre 3 Promouvoir la diversification économique et la transformation

ONUDI structurelle par l'industrialisation

Chapitre 4 L'aide pour le commerce dans les contextes difficiles

PNUD et CIR

Chapitre 5 Diversification économique: enseignements tirés de la pratique

Groupe de la Banque mondiale

Chapitre 6 Le rôle essentiel de la facilitation des échanges dans la promotion Banque mondiale, OCDE, de la diversification économique et des réformes structurelles

CNUCED

Chapitre 7 La diversification des exportations à l'heure de la "Mondialisation lente" CNUCED

Chapitre 8 Autonomiser les jeunes pour un commerce durable

ITC

Chapitre 9 Enseignements à tirer de l'aide pour le commerce en faveur de

OCDE l'autonomisation économique des femmes 